Universidade do Estado de Santa Catarina Série ANAIS

\title{
I FÓRUM INTERNACIONAL DE GESTÃO DO TRABALHO E EDUCAÇÃO PERMANENTE EM SAÚDE
}


UNIVERSIDADE DO ESTADO

DE SANTA CATARINA I UDESC

Dilmar Baretta

Reitor

Luiz Antonio Ferreira Coelho

Vice-Reitor

Marilha dos Santos

Pró-Reitor de Administração

Márcio Metzener

Pró-Reitor de Planejamento

Nerio Amboni

Pró-Reitor de Ensino

Mayco Morais Nunes

Pró-Reitor de Extensão, Cultura e Comunidade

Letícia Sequinatto

Pró-Reitor de Pesquisa e Pós-Graduação

\section{EDITORA UDESC}

Marcia Silveira Kroeff

Coordenadora

\section{CONSELHO EDITORIAL}

Marcia Silveira Kroeff| Presidente

Samira Kauchakje | CESFI

Gilmar Moraes Santos |CEFID

Giovanni Lemos de Mello | CERES

Avanilde Kemczinski | CCT

Sandra Regina Rech | CEART

Delcio Pereira | CEPLAN

Fabiano Maury Raupp | ESAG

Marilei Kroetz | CEAVI

William Campo Meschial|CEO

Jordan Paulesky Juliani | CEAD

Fernando Coelho | FAED

Roseli Lopes da Costa Bortoluzzi | CAV

\section{EDITORA UDESC}

Fone: (48) 3664-8100

E-mail: editora@udesc.br

http://www.udesc.br/editorauniversitaria 
Dra. Carine Vendruscolo

Dra. Letícia de Lima Trindade

Dra. Rosana Amora Ascari

\section{COMISSÃO ORGANIZADORA DO EVENTO}

Dra. Rosana Amora Ascari | Coordenadora

Dda. Fernanda Karla Metelski

Dra. Carine Vendruscolo

Dra. Clarissa Bohrer da Silva

Dra. Denise Antunes de Azambuja Zocche

Dra. Leila Zanatta

Dra. Letícia de Lima Trindade

COMISSÃO CIENTÍFICA

Dda. Fernanda Karla Metelski

Dr. Willian Campo Meschial

Dra. Carine Vendruscolo

Dra. Carla Argenta

Dra. Clarissa Bohrer da Silva

Dra. Claudio Claudino S. Filho

Dra. Daniela Savi Geremia

Dra. Denise Antunes de Azambuja Zocche

Dra. Edlamar Kátia Adamy

Dra. Jouhanna do Carmo Menegaz

Dra. Leila Zanatta

Dra. Letícia de Lima Trindade

Dra. Rosana Amora Ascari | Coordenadora

Dra. Silvana dos Santos Zanotelli

Me. Adriane Karal

Me. Ana Paula Lopes da Rosa

Me. Andreia Cristina Dall'agnol

Me. Carise Fernanda Schneider

Me. Cheila Siega

Me. Juliana Campos

Me. Mônica Ludwig Weber

Me. Suellen Fincatto

Me. Tavana Lorenzon

Me. Vanesa Nalin

Me. Vanessa Moraes

Mda. Alana Camila Schneider

Mda. Aline Lemes de Souza

Mda. Ana Maira Teló

Mda. Camila Soligo Bernardi

Mda. Carlise Krein

Mda. Cristiane Baretta

Mda. Débora Vicente

Mda. Diana A. Tres

Mda. Fernanda Norbak

Mda. Francieli Cecconello

Mda. Jamine Bernieri

Mda. Jane Tavares Gomes
Mda. Karina Schopf

Mda. Maiara Daís Schoeninger

Mda. Maristela Izcak Baldissera

Mda. Mirian Giacomel

Mda. Raquel Cristinai Sulzbach

Mda. Suzanne Cristina Abido

Mda. Taiza Dal Pian

Mda. Wanderson Luís Teixeira

Mdo. Reges Antônio Deon

COMISSÃO AVALIADORA DOS

TRABALHOS CIENTÍFICOS

Acad. Enf. Bruna Pedroso Oliveira

Acad. Enf. Karine Regina Reinehr

Acad. Enf. Laura Milena Motter

Acad. Enf. Lucas Lasta Angonese

Acad. Enf. Marina Klein Heinz

COMISSÃO DE APOIO

Willian Xavier de Almeida | Coordenação Ariel Gustavo Zuquello | Colaborador

SUPORTE DE TI

Rosana Amora Ascari

COMPILAÇÃO E ORGANIZAÇÃO DOS

TRABALHOS CIENTÍFICOS/BANNER'S

Os resumos seguiram padrões

individuais de revisão e apresentação sem alteração de conteúdo, prevalecendo a vontade de seus autores.

REVISÃO

João Vitor Antunes Lins dos Santos CAPA/ARTE FIGEPS 


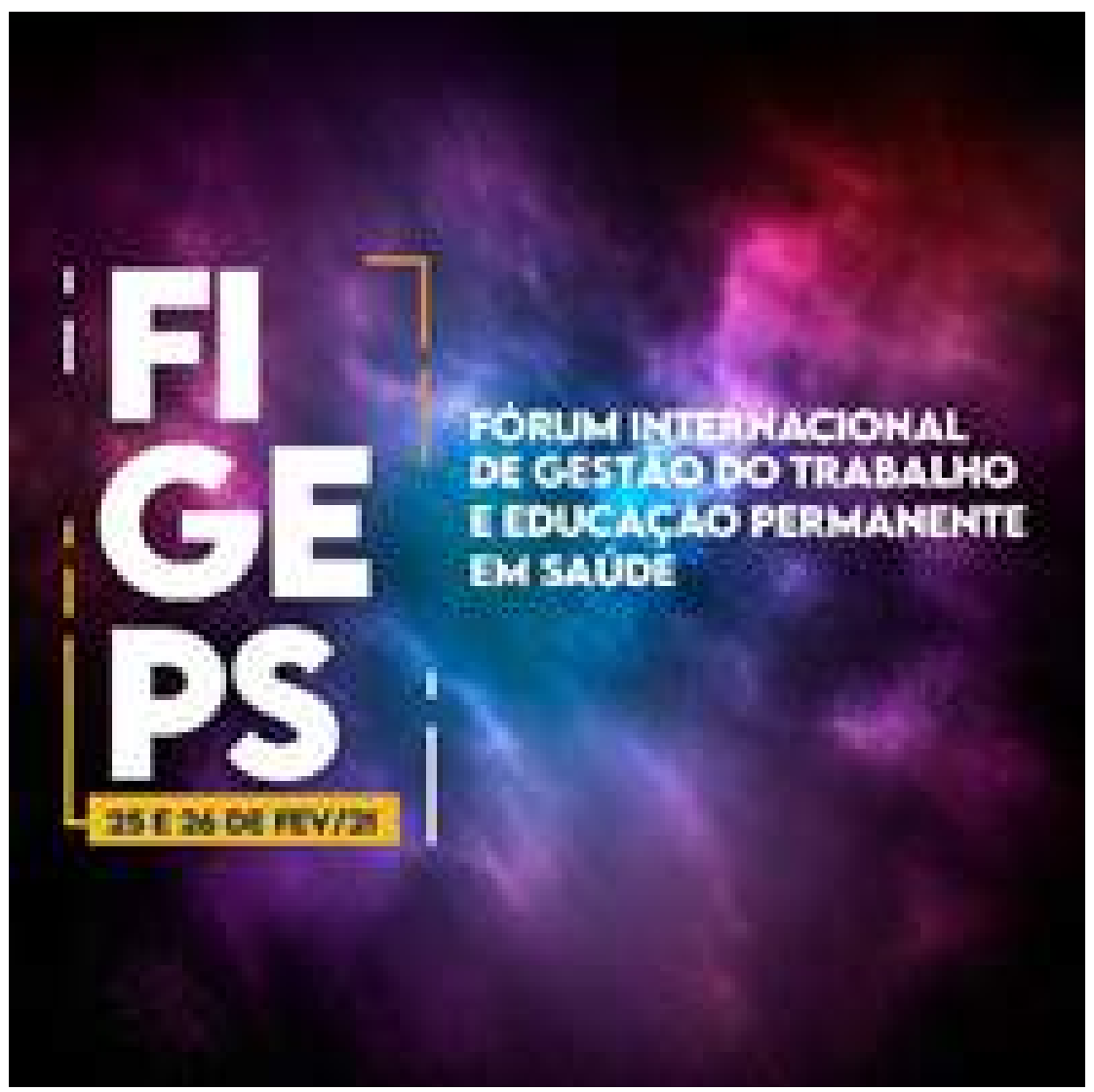

Apoiadores

(C) UDESC PPGENF

hacenaur oc pas canouncte
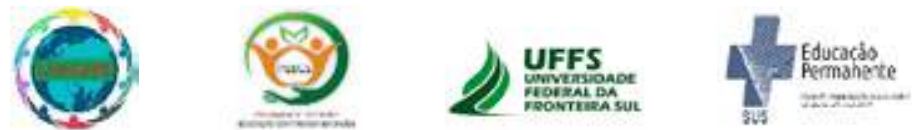


\section{FÓRUM INTERNACIONAL DE GESTÃO DO TRABALHO E EDUCAÇÃO PERMANENTE EM SAÚDE}


PRODUÇÃO EDITORIAL

Editora Udesc

PROJETO GRÁFICO

Bruna Costa

CONSULTORIA E

EDITORAÇÃO ELETRÔNICA

Chris Dalla Costa

\section{CAPA}

Mauro Tortato

\section{IMAGENS INTERNAS}

Domínio Público by Pixabay

F745 Fórum Internacional de Gestão do Trabalho e Educação Permanente em Saúde FIGEPS (1. : 2020 : Chapecó, SC) / Comissão do FIGEPS: Rosana Amora Ascari et al.

Anais [recurso eletrônico] / 1. Fórum Internacional de Gestão do Trabalho e Educação Permanente em Saúde; 25 e 26 de fev. de 2020, Chapecó, SC. Florianópolis: Ed. UDESC, 2021 (Série ANAIS).

526 p.: il. $29 \mathrm{~cm}$.

ISBN-e: 978-65-88565-29-2

1. Saúde pública - Pesquisa. 2. Política de saúde - Brasil. 3. Pessoal de saúde pública - Brasil. 4. COVID-19 (Doença) - Brasil. I. Ascari, Rosana Amora. II. Universidade do Estado de Santa Catarina.

CDD: 614.072 - 20. ed.

DOI: 10.5965/978-65-88565-29-2.

Ficha catalográfica elaborada pela Bibliotecária Alice de A. Borges Vazquez CRB 14/865 Biblioteca Central da UDESC 
APRESENTAÇÃO $\mid$ o9

PROGRAMAÇÃO DO I FIGEPS | $\mathbf{1 1}$

LISTA DE TRABALHOS CIENTÍFICOS • MODALIDADE BANNER

ELETRÔNICO $\mid \mathbf{1 3}$

LISTA SE TRABALHOS CIENTÍFICOS

• MODALIDADE APRESENTAÇÃO ORAL | 24

LISTA SE TRABALHOS CIENTÍFICOS

• MENÇÃO HONROSA I FIGEPS 2O21 | $\mathbf{2 6}$

RESUMOS • MODALIDADE BANNER ELETRÔNICO

RESUMOS DO EIXO TEMÁTICO 1

Gestão do trabalho nos sistemas de saúde públicos $\mid \mathbf{2 7}$

RESUMOS DO EIXO TEMÁTICO 2

Movimentos de educação permanente em saúde | $15^{0}$

RESUMOS DO EIXO TEMÁTICO 3

Práticas/produtos inovadores na atenção à saúde $\mid 308$

RESUMOS • MODALIDADE APRESENTÇÃO ORAL | $\mathbf{3} \mathbf{7 7}$

\section{LANÇAMENTO DE LIVROS | $\mathbf{4 5 0}$}

Prevenção Quaternária: proposições para a educação e prática interprofissional na Atenção Primária à Saúde | 451

Cargas de Trabalho: um referencial para entender a relação entre trabalho e saúde $\mid \mathbf{4 5 2}$

Produções do Mestrado Profissional em Enfermagem na Atenção Primária a 
Saúde: contributos para a gestão e o cuidado $\mid 454$

Práticas de Ensino em Enfermagem | 455

Grupos de Desenvolvimento Humano: uma estratégia para trabalho com grupos nas políticas Públicas $\mid \mathbf{4 5 6}$

BANNER'S ELETRÔNICOS | 457

Banner's Eletrônicos divulgados durante o I FIGEPS | 458

MENSAGEM FINAL $\mid \mathbf{5 2 6}$ 


\section{APRESENTAÇÃO}

Frente a atual situação mundial decorrente da pandemia pelo novo Coronavírus (COVID-19), o distanciamento social exige a compreensão de que a participação em eventos científicos na modalidade presencial não é viável neste momento. Assim, o Mestrado Profissional em Enfermagem na Atenção Primária à Saúde da Universidade do Estado de Santa Catarina (MPEAPS/UDESC) assumiu o compromisso social no desenvolvimento deste evento no formato totalmente on-line.

A enfermagem, assim como demais profissões da área de saúde têm sido resiliente, atributo necessário em todas as suas dimensões, em especial no que se refere à gestão do trabalho e aos movimentos de educação permanente que perpassam o cotidiano laboral, sobretudo na Atenção Primária e neste incomparável momento de crise na saúde coletiva. Este evento caracteriza-se como uma estratégia para a difusão científica, no cenário nacional e internacional, na perspectiva de melhoria da prática investigativa, da formação e do trabalho em saúde e enfermagem.

Entre as vantagens em participar deste evento destaca-se: maior segurança, benefícios econômicos e ambientais pois não há necessidade de se deslocar; certificação correspondente à modalidade de participação; interação com colegas de diferentes localidades geográficas e realidades profissionais; publicação dos resumos aprovados nos anais do evento e os melhores trabalhos serão convidados a compor o livro do I Fórum de Gestão do Trabalho e Educação Permanente em Saúde e Enfermagem.

Para a realização do evento online utilizaram-se diferentes mídias virtuais: página do evento no site da UDESC Oeste (https:// www.udesc.br/ceo/figeps), Facebook e Instagram, oferecendo aos profissionais de saúde e comunidade, informações sobre o evento: I Fórum Internacional de Gestão do Trabalho e Educação Permanente em Saúde. A programação proporcionou troca de conhecimentos e experiências advindas dos saberes e fazeres da Enfermagem e demais profissões da área de saúde. O I FIGEPS no formato digital, oportunizou a divulgação via web da Universidade, no Canal do YouTu$b e$, postagem de atividades relacionadas à gestão do trabalho nos sistemas de saúde públicos, movimentos de educação permanente em saúde e práticas e produtos inovadores na atenção à saúde. Ainda, ocorreram cinco paineis (Webinar): Desafios da Gestão do Trabalho em Saúde e o papel do Enfermeiro; Experiências de Educação Permanente em Saúde para Enfermagem no enfrentamento da pandemia do Coronavírus; Desafios no uso de novas ações pedagógica para a formação em Saúde e Enfermagem; A Centralidade do Enfermeiro 
na Gestão do Trabalho e; Protagonismo da Enfermagem na Gestão do Trabalho e Educação Interprofissional no Trabalho em Saúde, os quais estão acessíveis ao público pelo canal da UDESC Oeste no YouTube (https://www.youtube.com/channel/UCxI7jYa-HXvOnWt205BYo8A/ playlists).

Ainda, ocorreram quatro sessões de comunicações livres contemplando as Melhores Práticas na Gestão do Trabalho em Enfermagem e as Melhores Práticas na Educação Permanente em Saúde e Enfermagem, além de sessão para lançamento de livros e Reunião Estudantil com ênfase nas atividades protagonistas na gestão e educação permanente em saúde.

Foram aprovados no evento 139 trabalhos científicos, nas modalidades de resumo expandido advindos de diversas regiões do Brasil e de outros países. O evento contou com o apoio das instituições parceiras: Universidade Federal da Fronteira Sul (UFFS), Grupo de Estudos sobre Saúde e Trabalho (GESTRA), Laboratório de Inovação e Tecnologia para Gestão do Cuidado e Educação Permanente em Saúde (LABIGEPS), Programa de Extensão Educação Continuada em Saúde (PEECS), Comissão de Integração Ensino-Serviço (CIES). Participaram profissionais de Enfermagem, docentes, residentes e estudantes de graduação e pós-graduação. Agradecemos a participação de todos no I FIGEPS da UDESC Oeste.

Este evento visou a partilha de experiências exitosas, nacionais e internacionais, alinhadas ao desenvolvimento da gestão do trabalho e da educação permanente em saúde, que fomentam cenários promotores de saúde em diferentes espaços laborais.

Abraços fraternos,

\section{Rosana Amora Ascari, Letícia de Lima Trindade e Carine Vendruscolo}

Comissão Organizadora do I FIGEPS 


\section{PROGRAMAÇÃO DO I FIGEPS}

\section{Dia 25/02/2021}

\begin{tabular}{|c|c|c|c|}
\hline ATIVIDADE & PLATAFORMA & HORÁRIO & LINK \\
\hline Abertura do Evento & YouTube & 14 hoo & $\frac{\text { https://www.youtube.com/ }}{\text { watch?v=2c6kXlMeq8k }}$ \\
\hline $\begin{array}{l}\text { Painel: Desafios da Gestão do Trabalho } \\
\text { em Saúde e o papel do Enfermeiro }\end{array}$ & YouTube & $14 \mathrm{~h}_{40}$ & $\frac{\underline{h t t p s: / / w w w . y o u t u b e . c o m / ~}}{\text { watch?v=2c6kX1Meqsk }}$ \\
\hline $\begin{array}{l}\text { Comunicações livre | Sala A: } \\
\text { Melhores Práticas na Gestão do } \\
\text { Trabalho em Enfermagem } \\
\text { (*Experiências exitosas) }\end{array}$ & YouTube & 17 hoo & $\frac{\text { https://www.youtube.com/ }}{\underline{\text { watch?v=tgwzkcqMZ5U }}}$ \\
\hline $\begin{array}{c}\text { Comunicações livre | Sala B: } \\
\text { Melhores Práticas na Educação } \\
\text { Permanente em Saúde e Enfermagem } \\
\text { (*Experiências exitosas) }\end{array}$ & YouTube & 17hoo & $\frac{\underline{\text { https://www.youtube.com/ }}}{\underline{\text { watch?v=BGT6-xbXp_I }}}$ \\
\hline $\begin{array}{l}\text { Painel: Experiências de Educação } \\
\text { Permanente em Saúde para } \\
\text { Enfermagem no enfrentamento da } \\
\text { pandemia do Coronavírus }\end{array}$ & YouTube & $19 h 30$ & $\frac{\underline{\text { https://www.youtube.com/ }}}{\text { watch?v=ZSovY-oz73k }}$ \\
\hline
\end{tabular}


Dia 26/02/2021

\begin{tabular}{|c|c|c|c|}
\hline ATIVIDADE & PLATAFORMA & HORÁRIO & LINK \\
\hline $\begin{array}{l}\text { Painel: Desafios no uso de novas } \\
\text { ações pedagógica para a formação } \\
\text { em Saúde e Enfermagem }\end{array}$ & YouTube & o8:00 & $\frac{\text { https://www.youtube.com/ }}{\text { watch?v=uZUYYYIgG1E }}$ \\
\hline $\begin{array}{l}\text { Comunicações livre | Sala A: } \\
\text { Melhores Práticas na Gestão do } \\
\text { Trabalho em Enfermagem }\end{array}$ & YouTube & 10:OO & $\frac{\text { https://www.youtube.com/ }}{\text { watch?v=fkbohiXLgdo }}$ \\
\hline $\begin{array}{c}\text { Comunicações livre | Sala B: } \\
\text { Melhores Práticas na Educação } \\
\text { Permanente em Saúde e Enfermagem }\end{array}$ & YouTube & $10: 00$ & $\frac{\text { https://www.youtube.com// }}{\underline{\text { watch?v=6IoYsXtcizo }}}$ \\
\hline $\begin{array}{l}\text { Painel: A Centralidade do } \\
\text { Enfermeiro na Gestão do Trabalho }\end{array}$ & YouTube & 14:OO & $\begin{array}{l}\text { https://www.youtube.com/ } \\
\text { watch?v=dHkWSyisZHU }\end{array}$ \\
\hline $\begin{array}{l}\text { Lançamento de Livros e } \\
\text { reunião estudantes }\end{array}$ & YouTube & $16: 30$ & $\frac{\text { https://www.youtube.com/ }}{\text { watch?v=KmwKZ } 3 \text { DliKE }}$ \\
\hline $\begin{array}{l}\text { Reunião Estudantil: Atividades } \\
\text { protagonistas na Gestão e } \\
\text { Educação Permanente em Saúde }\end{array}$ & $\begin{array}{l}\text { Plataforma } \\
\text { Teams }\end{array}$ & $17: 30$ & \\
\hline $\begin{array}{c}\text { Painel: Protagonismo da } \\
\text { Enfermagem na Gestão do Trabalho } \\
\text { e Educação Interprofissional } \\
\text { no Trabalho em Saúde }\end{array}$ & YouTube & 19:00 & $\frac{\text { https://www.youtube.com/ }}{\underline{\text { watch?v=Bo80_7z6Ytw }}}$ \\
\hline $\begin{array}{l}\text { Encerramento: Divulgação dos } \\
\text { melhores trabalhos (Eixo GT e Eixo } \\
\text { EPS) e discurso de fechamento }\end{array}$ & YouTube & 20:00 & $\frac{\text { https://www.youtube.com/ }}{\text { watch?v=Bo80_7z6Ytw }}$ \\
\hline
\end{tabular}

Programação Disponível em: https://www.udesc.br/arquivos/ceo/id_cpmenu/3256/Programa_o_FIGEPS_16039903484068_3256.pdf 


\section{LISTA DE TRABALHOS}

\section{MODALIDADE BANNER ELETRÔNICO}

\begin{tabular}{|c|c|c|}
\hline Eixo & Título & Autores \\
\hline 01 & $\begin{array}{l}\text { Aplicabilidade da política de atenção } \\
\text { hospitalar: uma reflexão crítica }\end{array}$ & $\begin{array}{l}\text { Fernanda Norbak Dalla Cort, } \\
\text { Patrícia Poltronieri, Débora Rafaelly } \\
\text { da Silva Vicente, Letícia de Lima } \\
\text { Trindade e Carine Vendruscolo }\end{array}$ \\
\hline 01 & $\begin{array}{l}\text { Grupos etários e internações por doença diarreica } \\
\text { aguda na região oeste de Santa Catarina }\end{array}$ & $\begin{array}{l}\text { Carlise Krein, Lucimare } \\
\text { Ferraz e Arnildo Korb }\end{array}$ \\
\hline 01 & $\begin{array}{l}\text { Métodos de trabalho dos enfermeiros no } \\
\text { contexto hospitalar: scoping review }\end{array}$ & $\begin{array}{l}\text { João Miguel Almeida Ventura- } \\
\text { Silva, Maria Manuela Ferreira } \\
\text { Pereira da Silva Martins, Letícia } \\
\text { de Lima Trindade, Olga Maria } \\
\text { Pimenta Lopes Ribeiro e Maria } \\
\text { Filomena Passos Teixeira Cardoso }\end{array}$ \\
\hline 01 & Políticas de saúde prisional: avanços e desafios & $\begin{array}{l}\text { Reges Antonio Deon, Suzanne } \\
\text { Cristina Abido, Jane Tavares Gomes } \\
\text { e Letícia de Lima Trindade }\end{array}$ \\
\hline 01 & $\begin{array}{l}\text { Processo de trabalho dos agentes comunitários } \\
\text { de saúde em tempos de pandemia por covid-19 }\end{array}$ & $\begin{array}{l}\text { Suellen Fincatto, Danielle } \\
\text { Bezerra Cabral e Arnildo Korb }\end{array}$ \\
\hline 01 & $\begin{array}{c}\text { Estratégia saúde da família como cenário de melhores } \\
\text { práticas de enfermagem em tempos de covid-19 }\end{array}$ & $\begin{array}{l}\text { Mônica Ludwig Weber, Carine } \\
\text { Vendruscolo, Edlamar Kátia } \\
\text { Adamy, Maristela Izcak } \\
\text { Baldissera e Adriane Karal }\end{array}$ \\
\hline 01 & $\begin{array}{l}\text { A comunicação como ferramenta de gestão } \\
\text { frente à COVID-19 na região sul de São Paulo }\end{array}$ & $\begin{array}{l}\text { Paulo Fernando Capucci, } \\
\text { Felipe Gargantini Cardarelli } \\
\text { e Débora A. Mozar }\end{array}$ \\
\hline 01 & $\begin{array}{l}\text { A importância da gestão para um cuidado } \\
\text { qualificado em saúde mental na atenção primária }\end{array}$ & Jamine Bernieri e Leila Zanatta \\
\hline 01 & $\begin{array}{l}\text { Política nacional de atenção integral à } \\
\text { saúde da criança frente ao crescimento } \\
\text { e desenvolvimento infantil }\end{array}$ & $\begin{array}{l}\text { Alana Camila Schneider, Ana Maira } \\
\text { Teló, Mirian Giacomel, Wanderson } \\
\text { Luiz Teixeira, Carine Vendruscolo } \\
\text { e Letícia de Lima Trindade }\end{array}$ \\
\hline 01 & $\begin{array}{l}\text { Implementação do monitoramento COVID-19: } \\
\text { repercussões na formação acadêmica }\end{array}$ & $\begin{array}{l}\text { Demile Regina Carraro, Gabriela } \\
\text { Moresco, Yasminne Rita Marolli, } \\
\text { Clarissa Bohrer da Silva, Letícia } \\
\text { de Lima Trindade e Marta Kolhs }\end{array}$ \\
\hline
\end{tabular}




\begin{tabular}{|c|c|c|}
\hline 01 & $\begin{array}{l}\text { Transição entre os serviços e continuidade do } \\
\text { cuidado de crianças com condições crônicas }\end{array}$ & $\begin{array}{l}\text { Vitória Carolini Gomes, Caroline } \\
\text { Cechinel-Peiter, Gabriela } \\
\text { Marcellino de Melo Lanzoni }\end{array}$ \\
\hline 01 & $\begin{array}{l}\text { Impacto das úlceras venosas no cotidiano de } \\
\text { homens e mulheres: um olhar necessário }\end{array}$ & $\begin{array}{l}\text { Joana Trombetta, Ana Maria Cisotto } \\
\text { Weihermann e Rosana Amora Ascari }\end{array}$ \\
\hline 01 & $\begin{array}{l}\text { O Lean Healthcare como filosofia } \\
\text { para a gestão em saúde }\end{array}$ & $\begin{array}{l}\text { Heloisa Schatz Kwiatkowiski, } \\
\text { Júlia Valéria de Oliveira Vargas } \\
\text { Bitencourt e Maiara Bordignon }\end{array}$ \\
\hline 01 & $\begin{array}{l}\text { Eventos adversos na atenção primária à saúde: } \\
\text { um estudo envolvendo a enfermagem brasileira }\end{array}$ & $\begin{array}{l}\text { Bruna Carine Heinrichs, Ana } \\
\text { Maria Cisotto Weihermann } \\
\text { e Rosana Amora Ascari }\end{array}$ \\
\hline 01 & $\begin{array}{l}\text { Processo de trabalho de enfermeiros na Estratégia } \\
\text { Saúde da Família: entre o cuidar e o administrar }\end{array}$ & $\begin{array}{l}\text { Mariana Mendes, Leticia de } \\
\text { Lima Trindade, Denise Elvira } \\
\text { Pires de Pires, Elaine Cristina } \\
\text { Novatzki Forte, Lara Vandresen } \\
\text { e Priscila Rodrigues da Cunha }\end{array}$ \\
\hline 01 & $\begin{array}{l}\text { Gestão do serviço de enfermagem na } \\
\text { atenção primária à saúde no enfrentamento } \\
\text { da pandemia pelo novo Coronavírus }\end{array}$ & $\begin{array}{l}\text { Rui Carlos Sacramento e } \\
\text { Rosana Amora Ascari }\end{array}$ \\
\hline 01 & $\begin{array}{l}\text { Impactos das atividades gerenciais no } \\
\text { prazer e sofrimento de docentes da } \\
\text { pós-graduação stricto sensu }\end{array}$ & $\begin{array}{c}\text { Chancarlyne Vivian e Letícia } \\
\text { de Lima Trindade }\end{array}$ \\
\hline 01 & $\begin{array}{l}\text { Caracterização da atenção domiciliar no } \\
\text { atendimento às crianças com necessidades } \\
\text { especiais em Santa Catarina }\end{array}$ & $\begin{array}{l}\text { Diana Augusta Tres, Elisangela } \\
\text { Argenta Zanatta e Beatriz Rosana } \\
\text { Gonçalves de Oliveira Toso }\end{array}$ \\
\hline 01 & $\begin{array}{l}\text { Impactos da oferta de práticas integrativas } \\
\text { e complementares na gestão do trabalho } \\
\text { de profissionais da saúde }\end{array}$ & $\begin{array}{l}\text { Carine dos Santos Spindola, Ana } \\
\text { Beatriz da Costa Franceschini, } \\
\text { Larissa de Oliveira Derussi Gil, } \\
\text { Letícia de Camargo Pereira, } \\
\text { Fabiana Zucchi Beneli e } \\
\text { Leandra Andréia de Sousa }\end{array}$ \\
\hline 01 & $\begin{array}{l}\text { Organização do fluxo de trabalho biderecional para } \\
\text { atendimento na atenção primária na pandemia }\end{array}$ & $\begin{array}{c}\text { Fabíola Moreira Casimiro de } \\
\text { Oliveira, Ailma de Souza Barbosa, } \\
\text { Carolina Carvalho Nogueira, Joyce } \\
\text { Lane Braz Virgolino da Silva e } \\
\text { Veronica Ebrhaim Queiroga }\end{array}$ \\
\hline 01 & $\begin{array}{l}\text { Proposta de implantação de contrarreferência online } \\
\text { entre um hospital pediátrico e a atenção domiciliar }\end{array}$ & $\begin{array}{l}\text { Diana Augusta Tres, Francieli } \\
\text { Cecconello, Denise Antunes } \\
\text { de Azambuja Zocche e } \\
\text { Elisangela Argenta Zanatta }\end{array}$ \\
\hline
\end{tabular}




\begin{tabular}{|c|c|c|}
\hline 01 & $\begin{array}{c}\text { A pratica de notificações de incidentes } \\
\text { pela equipe de enfermagem }\end{array}$ & $\begin{array}{l}\text { Aline Cristina Andrade Furini, } \\
\text { Cibele Cirino de Sousa e Maria } \\
\text { Eulália Lessa do Vale Dallora }\end{array}$ \\
\hline 01 & $\begin{array}{l}\text { O acolhimento com classificação de risco na } \\
\text { atenção básica: a experiência de uma capital da } \\
\text { amazônia legal, Porto Velho, Rondônia, Brasil }\end{array}$ & $\begin{array}{l}\text { Eldenilson Gomes de Sousa, } \\
\text { Marcuce Antonio Miranda dos } \\
\text { Santos e Jane Carvalho Cardoso }\end{array}$ \\
\hline 01 & $\begin{array}{l}\text { Gestão e intervenções adotadas diante agressão verbal } \\
\text { laboral na atenção primária e terciária em saúde }\end{array}$ & $\begin{array}{l}\text { Marina Klein Heinz, Karine Regina } \\
\text { Reinehr e Letícia de Lima Trindade }\end{array}$ \\
\hline 01 & $\begin{array}{l}\text { Instrumentos gerenciais na enfermagem: } \\
\text { um relato da prática assistencial }\end{array}$ & $\begin{array}{l}\text { Liliane Bergamin, Laura } \\
\text { Cocco, Adriana Hillesheim e } \\
\text { Letícia de Lima Trindade }\end{array}$ \\
\hline 01 & $\begin{array}{l}\text { A violência naturalizada no trabalho da } \\
\text { enfermagem na atenção primária à saúde }\end{array}$ & $\begin{array}{l}\text { Grasiele Fatima Busnello, } \\
\text { Maiara Daís Schoeninger, } \\
\text { Kaciane Boff Bauermann e } \\
\text { Letícia de Lima Trindade }\end{array}$ \\
\hline 01 & $\begin{array}{l}\text { Análise do número de contatos dos casos } \\
\text { confirmados de COVID-19 com os serviços de saúde }\end{array}$ & $\begin{array}{l}\text { Karine Regina Reinehr, Marina } \\
\text { Klein Heinz, Mateus Dall' Agnol, } \\
\text { Clarissa Bohrer da Silva, Letícia } \\
\text { de Lima Trindade e Marta Kolhs }\end{array}$ \\
\hline 01 & $\begin{array}{l}\text { Reestruturação do serviço da Comissão Hospitalar de } \\
\text { Transplante (CHT) de um hospital público no oeste }\end{array}$ & $\begin{array}{l}\text { Jussara de Lima, Elisandra Cleonice } \\
\text { Pritsch e Olvani Martins da Silva }\end{array}$ \\
\hline 01 & $\begin{array}{c}\text { Gerência de investigação, prevenção e controle } \\
\text { de infecção da corrente sanguínea }\end{array}$ & $\begin{array}{l}\text { Maria Lucivane de Oliveira e } \\
\text { Suely Lopes de Azevedo }\end{array}$ \\
\hline 01 & $\begin{array}{l}\text { Perspectivas da atuação da enfermagem no } \\
\text { mundo pós-pandemia: uma reflexão teórica }\end{array}$ & $\begin{array}{l}\text { Lucas Soares dos Santos, } \\
\text { Aline Maffissoni, Manoela } \\
\text { Brum, Angela Maria Alvarez e } \\
\text { Rosane Gonçalves Nitschke }\end{array}$ \\
\hline 01 & $\begin{array}{l}\text { Vacinação contra o Coronavírus em uma unidade } \\
\text { de pronto atendimento: relato de experiência }\end{array}$ & $\begin{array}{l}\text { Daiane Freitas de Oliveira, } \\
\text { Nicole Hertzog Rodrigues e } \\
\text { Adriana Aparecida Paz }\end{array}$ \\
\hline 01 & $\begin{array}{l}\text { Organização da gestão do trabalho na } \\
\text { Estratégia Saúde da Família }\end{array}$ & $\begin{array}{l}\text { Daniela Savi Geremia e } \\
\text { Jiennifer Souza de Oliveira }\end{array}$ \\
\hline 01 & $\begin{array}{l}\text { Caracterização da atenção domiciliar no } \\
\text { atendimento às crianças com necessidades } \\
\text { especiais em Santa Catarina }\end{array}$ & $\begin{array}{l}\text { Diana Augusta Tres, Elisangela } \\
\text { Argenta Zanatta e Beatriz Rosana } \\
\text { Gonçalves de Oliveira Toso }\end{array}$ \\
\hline
\end{tabular}




\begin{tabular}{|c|c|c|}
\hline 01 & $\begin{array}{l}\text { Rotatividade médica e seus desafios na atenção } \\
\text { básica: análise em um município do sul catarinense }\end{array}$ & $\begin{array}{l}\text { Daniela Pizoni e Janaina } \\
\text { Niero Mazon }\end{array}$ \\
\hline 01 & $\begin{array}{l}\text { Tecnologia da informação: ferramenta para o } \\
\text { processo de tomada de decisões na enfermagem }\end{array}$ & $\begin{array}{l}\text { André Luiz de Souza Braga, } \\
\text { Rosangela Cunha Machado } \\
\text { Tavares, Suely Lopes de Azevedo, } \\
\text { Maritza Consuelo Ortiz Sanchez, } \\
\text { Pedro Ruiz Barboza Nassar e } \\
\text { Maria Lucia Costa de Moura }\end{array}$ \\
\hline 01 & $\begin{array}{l}\text { Metodologias utilizadas na avaliação de custo- } \\
\text { efetividade: tendência da produção científica }\end{array}$ & $\begin{array}{c}\text { Graziele Gorete Portella da Fonseca } \\
\text { e Márcio Kist Parcianello }\end{array}$ \\
\hline 01 & $\begin{array}{l}\text { Processo de trabalho e gerenciamento do } \\
\text { cuidado: reflexões sobre o papel do enfermeiro }\end{array}$ & $\begin{array}{c}\text { Graziele Gorete Portella da Fonseca } \\
\text { e Márcio Kist Parcianello }\end{array}$ \\
\hline 01 & $\begin{array}{c}\text { Avaliação da capacidade para o trabalho } \\
\text { dos profissionais da atenção primária } \\
\text { à saúde: estudo transversal }\end{array}$ & $\begin{array}{c}\text { Cassia Gonçalves Santos da Silveira, } \\
\text { Barbara Pompeu Christovam, } \\
\text { Josélia Braz dos Santos Ferreira, } \\
\text { Selma Petra Chaves Sá e Ana } \\
\text { Maria Fernandes Pitta }\end{array}$ \\
\hline 01 & $\begin{array}{l}\text { Transtorno mental comum em profissionais da } \\
\text { atenção primária em tempo de COVID-19 }\end{array}$ & $\begin{array}{l}\text { Raquel Tatielli Daneluz Rintzel, } \\
\text { Endria Mendes Fabrizzio, Lisiane } \\
\text { da Rosa, Crhis Netto de Brum, Júlia } \\
\text { Grasel e Samuel Spiegelberg Zuge }\end{array}$ \\
\hline 01 & $\begin{array}{l}\text { Orientações do Ministério da Saúde } \\
\text { para a atuação e gestão de enfermagem } \\
\text { na saúde da mulher no puerpério }\end{array}$ & $\begin{array}{c}\text { Mirian Giacomel, Silvana } \\
\text { dos Santos Zanotelli e Denise } \\
\text { Antunes de Azambuja Zocche }\end{array}$ \\
\hline 01 & $\begin{array}{l}\text { Educação permanente como estratégia } \\
\text { para consolidação da meta de prevenção } \\
\text { de quedas em hospital pediátrico }\end{array}$ & $\begin{array}{l}\text { Fernanda de Ávila Carvalho } \\
\text { Neves, Priscila Coelho Amaral, } \\
\text { Stephanie Greiner e Victória } \\
\text { Tiyoko Moraes Sakamoto }\end{array}$ \\
\hline 02 & $\begin{array}{l}\text { Desafios e potencialidades da educação } \\
\text { permanente em saúde a partir da vivência } \\
\text { de gestores e trabalhadores da atenção } \\
\text { básica na zona sul de São Paulo }\end{array}$ & $\begin{array}{l}\text { Israel Victor de Oliveira e } \\
\text { Rogério Nogueira de Oliveira }\end{array}$ \\
\hline 02 & $\begin{array}{c}\text { Educação permanente em saúde e o } \\
\text { programa nacional de melhoria do acesso } \\
\text { e qualidade da atenção básica }\end{array}$ & $\begin{array}{l}\text { Israel Victor de Oliveira e } \\
\text { Rogério Nogueira de Oliveira }\end{array}$ \\
\hline 02 & $\begin{array}{l}\text { Cartas para Freire: reflexões de profissionais sobre } \\
\text { educação permanente na Estratégia Saúde da Família }\end{array}$ & $\begin{array}{l}\text { Priscila Rodrigues da Cunha, } \\
\text { Mariana Mendes, Maria } \\
\text { Elisabeth Kleba e Vanessa } \\
\text { Denardi Antoniassi Baldissera }\end{array}$ \\
\hline
\end{tabular}




\begin{tabular}{|c|c|c|}
\hline 02 & $\begin{array}{c}\text { Educação permanente em saúde: possibilidade } \\
\text { de aprimoramento da prevenção quaternária } \\
\text { na atenção primária à saúde }\end{array}$ & $\begin{array}{l}\text { Karina Schopf, Aline Lemos de } \\
\text { Souza e Carine Vendruscolo }\end{array}$ \\
\hline 02 & $\begin{array}{l}\text { Educação permanente: uma abordagem } \\
\text { necessária para minimizar os impactos das } \\
\text { náuseas e vômitos no pós-operatório }\end{array}$ & $\begin{array}{l}\text { Mateus Dall Agnol, Robson } \\
\text { Lovison, Bruna Fontana, Cristiane } \\
\text { Baretta e Rosana Amora Ascari }\end{array}$ \\
\hline 02 & $\begin{array}{l}\text { Autocuidado e autoestima do idoso: uma } \\
\text { atividade de educação em saúde }\end{array}$ & $\begin{array}{l}\text { Camila Soligo Bernardi } \\
\text { e Carla Argenta }\end{array}$ \\
\hline 02 & $\begin{array}{l}\text { Prevenção ao COVID-19: uma estratégia de educação } \\
\text { em saúde para agentes comunitários de saúde }\end{array}$ & $\begin{array}{l}\text { Raquel Cristina Sulzbach, Lucimare } \\
\text { Ferraz e Sueli Regina Sulzbach }\end{array}$ \\
\hline 02 & $\begin{array}{l}\text { Educação permanente: transformando o } \\
\text { cotidiano da segurança do paciente }\end{array}$ & $\begin{array}{l}\text { Andressa Reginatto Percisi, } \\
\text { Angélica Zanettini, Jonatan } \\
\text { Pellenz e Aline Massaroli }\end{array}$ \\
\hline 02 & $\begin{array}{l}\text { Política nacional de educação permanente } \\
\text { em saúde e suas estruturas elementares }\end{array}$ & $\begin{array}{l}\text { Cristiane Baretta, Maristela Izcak } \\
\text { Baldissera, Rafaela Bedin, Taiza } \\
\text { Dal Pian, Carine Vendruscolo } \\
\text { e Letícia de Lima Trindade }\end{array}$ \\
\hline 02 & $\begin{array}{l}\text { Sede no pós-operatório: uma característica definidora } \\
\text { que merece atenção e ações de educação permanente }\end{array}$ & $\begin{array}{l}\text { Mateus Dall Agnol, Robson } \\
\text { Lovison, Cristiane Baretta } \\
\text { e Rosana Amora Ascari }\end{array}$ \\
\hline 02 & $\begin{array}{l}\text { Educação permanente em saúde: a percepção e } \\
\text { práticas relatadas por atores que a constroem }\end{array}$ & $\begin{array}{l}\text { Daiane Mayara Alves e } \\
\text { Simone Rennó Junqueira }\end{array}$ \\
\hline 02 & $\begin{array}{l}\text { Ciclo de oficinas com profissionais de uma equipe } \\
\text { de ESF: (re)significando as reuniões de equipe }\end{array}$ & Daiane Mayara Alves e Flávia Carotta \\
\hline 02 & $\begin{array}{l}\text { Capacitação de enfermeiros para o cuidado } \\
\text { do paciente estomizado na atenção primária: } \\
\text { cenário de educação permanente em saúde }\end{array}$ & $\begin{array}{l}\text { Caroline Cunha Machado, Letícia } \\
\text { Calcagno Gomes, Jéssica da Cruz } \\
\text { Telles, Aline Silveira Lopes, } \\
\text { Fernanda Jennifer Ribeiro Pereira } \\
\text { e Edaiane Joana Lima Barros }\end{array}$ \\
\hline 02 & $\begin{array}{l}\text { O que dizem os trabalhadores hospitalares } \\
\text { acerca da cultura de segurança? }\end{array}$ & $\begin{array}{c}\text { Carolyne Diehl Stuani, Rosana } \\
\text { Amora Ascari, Gloriana } \\
\text { Frizon, Paulo Cesar da Silva } \\
\text { e Olvani Martins da Silva }\end{array}$ \\
\hline 02 & $\begin{array}{l}\text { Dilemas éticos de enfermagem mediados } \\
\text { por discussões na incubadora de } \\
\text { aprendizagem: relato de experiência }\end{array}$ & $\begin{array}{l}\text { Tanise Pereira Santini, Taís Leal } \\
\text { Machado, Gabriella Córdova } \\
\text { Dalla Corte, Luiza Fortes } \\
\text { Lamberty, Cristina de Freitas } \\
\text { Rodrigues e Dirce Stein Backes }\end{array}$ \\
\hline
\end{tabular}




\begin{tabular}{|c|c|c|}
\hline 02 & $\begin{array}{l}\text { Estratégias utilizadas no ensino em } \\
\text { saúde sobre segurança no uso dos } \\
\text { medicamentos: revisão integrativa }\end{array}$ & $\begin{array}{l}\text { Juliane Cabral, Domênica } \\
\text { Bossardi Ramos, Camila Borba } \\
\text { Ferreira, Rita Catalina de Aquino } \\
\text { Caregnato e Carine Raquel Blatt }\end{array}$ \\
\hline 02 & $\begin{array}{l}\text { Movimentos de educação permanente } \\
\text { para saúde renal no contexto da atenção } \\
\text { primária: relato de experiência }\end{array}$ & $\begin{array}{l}\text { Morgana Cristina Nardi, Bruna } \\
\text { Chiossi Presoto, Gabrieli Bieger, } \\
\text { Gabriele Cristine Metzger, Francielli } \\
\text { Girardi e Olvani Martins da Silva }\end{array}$ \\
\hline 02 & $\begin{array}{l}\text { Produção de um curso para qualificação } \\
\text { de profissionais de saúde sobre } \\
\text { vacinação: relato de experiência }\end{array}$ & $\begin{array}{l}\text { Franciele dos Santos Moreira, } \\
\text { Karina Vieira Pinheiro, Michelle } \\
\text { Jaime, Taiane Saraiva Freitas, } \\
\text { Alessandra Luiza Tolentino } \\
\text { Silva e Marilene Lopes Vieira }\end{array}$ \\
\hline 02 & $\begin{array}{l}\text { Contribuições da equipe de enfermagem na atenção } \\
\text { básica nas orientações e prevenção de diarreias agudas }\end{array}$ & $\begin{array}{l}\text { Milena Lorenzini, Diora Dorigon } \\
\text { Faita, Carlise Krein e Arnildo Korb }\end{array}$ \\
\hline 02 & $\begin{array}{l}\text { A educação permanente: estratégia para } \\
\text { um cuidado qualificado em saúde }\end{array}$ & $\begin{array}{l}\text { Maria Lucia Costa de Moura, Suely } \\
\text { Lopes de Azevedo, Aline Silva } \\
\text { da Fonte Santa Rosa de Oliveira } \\
\text { e André Luiz de Souza Braga }\end{array}$ \\
\hline 02 & $\begin{array}{l}\text { Ações de educação em saúde para uma assistência } \\
\text { segura em uma Unidade Básica de Saúde }\end{array}$ & $\begin{array}{l}\text { Thiemmy de Souza Almeida } \\
\text { Guedes e Andrezza do Rêgo Leal }\end{array}$ \\
\hline 02 & $\begin{array}{l}\text { Roda de conversa: planejando o suporte } \\
\text { básico de vida em pediatria no domicílio }\end{array}$ & $\begin{array}{c}\text { Diana Augusta Tres, Elisangel } \\
\text { Argenta Zanatta, Carine } \\
\text { Vendruscolo e Edlamar Katia Adamy }\end{array}$ \\
\hline 02 & Educação permanente em saúde na formação & $\begin{array}{l}\text { Tatiana Almeida Couto e } \\
\text { Josiane Moreira Germano }\end{array}$ \\
\hline 02 & $\begin{array}{l}\text { Gestão da segurança e o registro de } \\
\text { enfermagem acerca das lesões por pressão }\end{array}$ & $\begin{array}{c}\text { Cristiane Baretta e Rosana } \\
\text { Amora Ascari }\end{array}$ \\
\hline 02 & $\begin{array}{l}\text { Participação de discentes nas ações de } \\
\text { educação permanente acerca da implantação e } \\
\text { implementação do processo de enfermagem }\end{array}$ & $\begin{array}{l}\text { Débora Althaus Bonet, } \\
\text { Laura Cocco, Carla Argenta } \\
\text { e Edlamar Kátia Adamy }\end{array}$ \\
\hline 02 & $\begin{array}{c}\text { Processo de educação permanente em } \\
\text { saúde hospitalar no oeste catarinense: } \\
\text { um relato de experiência }\end{array}$ & $\begin{array}{l}\text { Daniel Jesse Junior Ferreira } \\
\text { Cassemiro, Jussara dos Santos } \\
\text { Valentini, Jacira Batista de } \\
\text { Oliveira, Gleica Pressi, Vânia Maria } \\
\text { Lovera e Rosana Amora Ascari }\end{array}$ \\
\hline
\end{tabular}




\begin{tabular}{|c|c|c|}
\hline 02 & $\begin{array}{l}\text { Relato de experiência da articulação da } \\
\text { Comissão de Integração Ensino-Serviço } \\
\text { da região oeste/SC de 2016-2020 }\end{array}$ & $\begin{array}{l}\text { Otilia Cristina Coelho Rodrigues, } \\
\text { Adriana Aparecida Polmann, Ediane } \\
\text { Bergamin e Letícia de Lima Trindade }\end{array}$ \\
\hline 02 & $\begin{array}{l}\text { Construção de um curso de cateter venoso central } \\
\text { em crianças no domicílio: relato de experiência }\end{array}$ & $\begin{array}{c}\text { Gabriela Beatriz Leonhardt, Simone } \\
\text { Boettcher, Elisângela de Fraga Vidal, } \\
\text { Marcelo Machado dos Santos, Milena } \\
\text { Mallon e Adriana Aparecida Paz }\end{array}$ \\
\hline 02 & $\begin{array}{l}\text { O manejo da dor oncológica em cuidados } \\
\text { paliativos, na práxis laboral da enfermagem }\end{array}$ & $\begin{array}{l}\text { Robson Lovison, Érica Catarina } \\
\text { Dalabona, Débora Marchetti, Tania } \\
\text { Maria Ascari e Sandra Maria Vanini }\end{array}$ \\
\hline 02 & $\begin{array}{l}\text { Educação permanente em saúde: } \\
\text { capacitação de enfermeiros para execução } \\
\text { de eletrocardiograma de repouso }\end{array}$ & $\begin{array}{l}\text { Nicole Hertzog Rodrigues, } \\
\text { Daiane Freitas de Oliveira e } \\
\text { Adriana Aparecida Paz }\end{array}$ \\
\hline 02 & $\begin{array}{l}\text { Saúde única: uma nova abordagem para } \\
\text { enfrentamento da resistência a antimicrobianos }\end{array}$ & $\begin{array}{l}\text { Ana Júlia Mânica Machado, Bruna } \\
\text { Cristina Ozelaime, Keli Cristina } \\
\text { Calza e Marinez Amabile Antoniolli }\end{array}$ \\
\hline 02 & $\begin{array}{c}\text { A utilização das ferramentas tecnológicas } \\
\text { na prática pedagógica de monitoria digital } \\
\text { no ensino remoto emergencial }\end{array}$ & $\begin{array}{l}\text { Kimberly de Mattos, Ketlin } \\
\text { Simões da Luz e Carmen } \\
\text { Elizabeth Kalinowski }\end{array}$ \\
\hline 02 & $\begin{array}{l}\text { Educação permanente: uma prática aplicável na } \\
\text { prevenção e controle de infecção hospitalar }\end{array}$ & $\begin{array}{l}\text { Patricia Daiane Zanini e } \\
\text { Bruna Valmorbida Biavatti }\end{array}$ \\
\hline 02 & $\begin{array}{l}\text { Educação em tempos de pandemia: } \\
\text { relato de experiência }\end{array}$ & $\begin{array}{c}\text { Ana Beatriz Mattozo Amorim, } \\
\text { Ingrid Manoella Borges, Sarah Dany } \\
\text { Zeidan Yassine, Thais Marafon, } \\
\text { Victoria Vieira Hertz e Marta Kolhs }\end{array}$ \\
\hline 02 & $\begin{array}{l}\text { Apoio institucional e educação } \\
\text { permanente em saúde como práticas para } \\
\text { o enfermeiro: possibilidades e desafios }\end{array}$ & $\begin{array}{l}\text { Cinira Magali Fortuna, Priscila } \\
\text { Norié de Araujo, Maristel Kasper, } \\
\text { Adriana Barbieri Feliciano e } \\
\text { Monica Vilchez da Silva }\end{array}$ \\
\hline 02 & $\begin{array}{l}\text { Bundles e educação permanente como } \\
\text { estratégias para prevenção de pneumonia } \\
\text { associada à ventilação mecânica }\end{array}$ & $\begin{array}{l}\text { Raquel de Oliveira Laudiosa da } \\
\text { Motta, Suely Lopes de Azevedo }\end{array}$ \\
\hline 02 & $\begin{array}{l}\text { Aplicação da metodologia on the job como estratégia } \\
\text { de educação permanente no contexto hospitalar }\end{array}$ & $\begin{array}{l}\text { Lucas Corrêa Preis, Giuliana } \\
\text { Cosentino Freitas Santos, } \\
\text { Jaqueline Caetano, Marli Rafael } \\
\text { Joaquim e Marion Hoelz Ioras }\end{array}$ \\
\hline
\end{tabular}




\begin{tabular}{|c|c|c|}
\hline 02 & $\begin{array}{l}\text { Educação permanente on line na rede a atenção a } \\
\text { saúde do município de Chapecó: relato de experiência }\end{array}$ & $\begin{array}{l}\text { Jaqueline Imlau, Nauri } \\
\text { Fernando Desordi, Saionara } \\
\text { Vitória Barimacker, Lígia } \\
\text { Schacth, Olvani Martins da } \\
\text { Silva e Sandra Mara Marin }\end{array}$ \\
\hline 02 & $\begin{array}{l}\text { Portal educativo para um programa de educação } \\
\text { permanente hospitalar no sul do país }\end{array}$ & $\begin{array}{l}\text { Rosane Mortari Ciconet, Eva } \\
\text { Joseane Fontana, Denise Antunes } \\
\text { de Azambuja Zocche e Vania } \\
\text { Celina Dezoti Micheletti }\end{array}$ \\
\hline 02 & $\begin{array}{l}\text { A teoria de Paulo Freire e suas interfaces com a } \\
\text { professoralidade: uma reflexão teórico-epistemológica }\end{array}$ & $\begin{array}{l}\text { Bianca Joana Mattia e Carla } \\
\text { Rosane Paz Arruda Teo }\end{array}$ \\
\hline 02 & $\begin{array}{c}\text { Ações de sensibilização sobre infecções } \\
\text { sexualmente transmissíveis em uma unidade } \\
\text { prisional: um relato de experiência }\end{array}$ & $\begin{array}{l}\text { Patrícia Porto Almeida, Laís Mara } \\
\text { Caetano da Silva, Luiza Silveira de } \\
\text { Oliveira, Pedro Fredemir Palha, } \\
\text { Márcia Gabriela Rodrigues de } \\
\text { Lima e Júlia Zancan Bresolin }\end{array}$ \\
\hline 02 & $\begin{array}{l}\text { Educação permanente no serviço de atendimento } \\
\text { móvel de urgência: a representação do tempo resposta }\end{array}$ & $\begin{array}{c}\text { Rosane Mortari Ciconet, Vania } \\
\text { Celina Dezoti Micheletti, } \\
\text { Denise Antunes de Azambuja } \\
\text { Zocche, Caroline Vargas } \\
\text { Attademo, Cristina Orlandi } \\
\text { Costa e Dinorá Claudia Cenci }\end{array}$ \\
\hline 02 & $\begin{array}{l}\text { O enfermeiro prevenindo acidentes de trabalho } \\
\text { em tempos de pandemia: relato de experiência }\end{array}$ & $\begin{array}{l}\text { Márcio Kist Parcianello e Graziele } \\
\text { Gorete Portella da Fonseca }\end{array}$ \\
\hline 02 & $\begin{array}{l}\text { Momentos de educação permanente em saúde para } \\
\text { um projeto de intervenção: um relato de experiência }\end{array}$ & $\begin{array}{l}\text { Luciano Fiorentin, Karina } \\
\text { Schopf, Carine Vendruscolo } \\
\text { e Vilma Beltrame }\end{array}$ \\
\hline 02 & $\begin{array}{c}\text { Procedimento Operacional Padrão (POP): } \\
\text { Relato de Experiência de Qualificação } \\
\text { na Rede de Atenção à Saúde }\end{array}$ & $\begin{array}{l}\text { Adriana Aparecida Polmann, Bianca } \\
\text { Lima da Cunha, Letícia Sandrin e } \\
\text { Otilia Cristina Coelho Rodrigues }\end{array}$ \\
\hline 02 & $\begin{array}{l}\text { Concepções de educação permanente em planos } \\
\text { estaduais de educação permanente em saúde }\end{array}$ & $\begin{array}{l}\text { Mariana Costa Matos, Silvana } \\
\text { Lima Vieira e Liliana Santos }\end{array}$ \\
\hline 02 & $\begin{array}{l}\text { Educação permanente para profissionais de } \\
\text { enfermagem sobre cuidados com hipodermóclise }\end{array}$ & $\begin{array}{c}\text { Cândida Caniçali Primo, Walckiria } \\
\text { Garcia Romero Sipolatti, Catrine } \\
\text { Storch Moitinho, Ramon Araújo } \\
\text { dos Santos e Alessandra Monteiro } \\
\text { Guimarães Carvalho Barbosa }\end{array}$ \\
\hline 02 & $\begin{array}{l}\text { Educação permanente na pandemia da } \\
\text { COVID-19: relato de experiência }\end{array}$ & $\begin{array}{c}\text { Eliete Aparecida Teodoro Amaral, } \\
\text { Eliane Ramos Pereira, Janaína } \\
\text { Mengal Gomes Fabri e Raquel } \\
\text { Dias dos Santos Dantas }\end{array}$ \\
\hline
\end{tabular}




\begin{tabular}{|c|c|c|}
\hline 02 & $\begin{array}{l}\text { Primeiros socorros na graduação de ciências } \\
\text { biológicas: uma discussão necessária }\end{array}$ & $\begin{array}{l}\text { Karen Cristiane Pereira de } \\
\text { Morais e Aline Gomes Ilha }\end{array}$ \\
\hline 02 & $\begin{array}{l}\text { A importância da educação permanente para a } \\
\text { equipe de enfermagem na pandemia da COVID-19 }\end{array}$ & $\begin{array}{l}\text { Aline Silva da Fonte Santa } \\
\text { Rosa de Oliveira, Suely Lopes } \\
\text { de Azevedo, Thais de Rezende } \\
\text { Bessa Guerra, Rosane Burla de } \\
\text { Aguiar, Herica Félix de Oliveira } \\
\text { e Natalia Anisia Costa Marques }\end{array}$ \\
\hline 02 & $\begin{array}{l}\text { Educação permanente como estratégia } \\
\text { para consolidação da meta de prevenção } \\
\text { de quedas em hospital pediátrico }\end{array}$ & $\begin{array}{l}\text { Fernanda de Ávila Carvalho } \\
\text { Neves, Priscila Coelho Amaral, } \\
\text { Stephanie Greiner e Victória } \\
\text { Tiyoko Moraes Sakamoto }\end{array}$ \\
\hline 02 & $\begin{array}{l}\text { Principais erros no gerenciamento de medicamentos } \\
\text { pela equipe de enfermagem e seus fatores relacionados }\end{array}$ & $\begin{array}{l}\text { Helena Fornari Basso, Luana Reis, } \\
\text { Angélica Zanettini e Julia Valeria } \\
\text { de Oliveira Vargas Bitencourt }\end{array}$ \\
\hline 03 & Mulheres: prostituição e cuidados & $\begin{array}{l}\text { Carlos Botazzo e Thainá } \\
\text { Buono Paulino dos Santos }\end{array}$ \\
\hline 03 & $\begin{array}{l}\text { Uso de tecnologias pelo enfermeiro auditor em } \\
\text { contas hospitalares: revisão integrativa de literatura }\end{array}$ & $\begin{array}{l}\text { Jaqueline Ana Foschera, Jane } \\
\text { Tavares Gomes, Odila Migliorini } \\
\text { Rosa, Letícia de Lima Trindade } \\
\text { e Angélica Zanettini }\end{array}$ \\
\hline 03 & $\begin{array}{l}\text { Processo de certificação em boas práticas na atenção } \\
\text { primária à saúde suplementar: relato de experiência }\end{array}$ & $\begin{array}{l}\text { Fabiele Farina, Maykler Cristiane } \\
\text { Vanzin e Kátia Jamile da Silva }\end{array}$ \\
\hline 03 & $\begin{array}{l}\text { Estratégias para a preceptoria } \\
\text { interprofissional: uma revisão de escopo }\end{array}$ & $\begin{array}{l}\text { Camila Mendes da Silva, } \\
\text { Nathalia Romeu de Mazzi, } \\
\text { Thalita Cristine Ramirez Duarte } \\
\text { e Valéria Marli Leonello }\end{array}$ \\
\hline 03 & $\begin{array}{c}\text { Contribuições das práticas integrativas } \\
\text { e complementares a gestão do trabalho: } \\
\text { desafios e possibilidades }\end{array}$ & $\begin{array}{l}\text { Gabriela Trevisan, Lúcia Esteves } \\
\text { Duarte, Monica Vilchez da Silva, } \\
\text { Maria Teresa Luz Eid da Silva, } \\
\text { Leandra Andréia de Sousa e } \\
\text { Adriana Barbieri Feliciano }\end{array}$ \\
\hline 03 & $\begin{array}{l}\text { Adaptação da formação em serviço dos enfermeiros } \\
\text { na unidade cardiológica de um hospital de Portugal }\end{array}$ & $\begin{array}{l}\text { Tânia Dionísia Oliveira, Suéli Regina } \\
\text { Sulzbach, Anabela Abreu Azevedo, } \\
\text { Denise Antunes de Azambuja Zocche } \\
\text { e Esperança do Gago Alves Pereira }\end{array}$ \\
\hline 03 & $\begin{array}{l}\text { Elaboração do guia de orientações para os novos } \\
\text { colaboradores da enfermagem: relato de experiência }\end{array}$ & $\begin{array}{l}\text { Julyhe Nunes Paulin, Nathália } \\
\text { Dias Oliveira, Caroline Barbosa } \\
\text { da Silva, Cíntia Eliane Costa } \\
\text { Corrêa, Ana Amélia Antunes } \\
\text { Lima e Adriana Aparecida Paz }\end{array}$ \\
\hline
\end{tabular}




\begin{tabular}{|c|c|c|}
\hline 03 & $\begin{array}{l}\text { A formação em saúde repensando a gestão de } \\
\text { trabalho em unidade de saúde da família }\end{array}$ & $\begin{array}{l}\text { Tatiana Almeida Couto, } \\
\text { Josiane Moreira Germano }\end{array}$ \\
\hline 03 & $\begin{array}{l}\text { Implantação da sistematização da } \\
\text { assistência de enfermagem em uma unidade } \\
\text { de terapia intensiva pediátrica }\end{array}$ & $\begin{array}{c}\text { Natália Hoefle, Vivian Rahmeier } \\
\text { Fietz, Shanna Machado de } \\
\text { Sousa e Talyne Francisca } \\
\text { Ferraz Nogueira Moraes }\end{array}$ \\
\hline 03 & $\begin{array}{l}\text { Plantas medicinais e suas interações no } \\
\text { tratamento oncológico: uma revisão narrativa }\end{array}$ & $\begin{array}{l}\text { Maísa Schneider Lazarotto, } \\
\text { Kelly Cristina Meller Sangoi }\end{array}$ \\
\hline 03 & $\begin{array}{l}\text { Processo de validação de instrumento } \\
\text { de pesquisa: uma } \\
\text { abordagem conceitual }\end{array}$ & $\begin{array}{l}\text { Wanderson Luís Teixeira, Fernanda } \\
\text { Norbak Dalla Cort, Cristiane } \\
\text { Barreta, Jane Tavares Gomes e Denise } \\
\text { Antunes de Azambuja Zocche }\end{array}$ \\
\hline 03 & $\begin{array}{l}\text { O papel do enfermeiro na prevenção de lesões por } \\
\text { pressão, na pronação do paciente com COVID-19 na } \\
\text { unidade de terapia intensiva: relato de experiência }\end{array}$ & $\begin{array}{l}\text { Cibele Cirino de Sousa, Aline } \\
\text { Cristina Andrade Furini, } \\
\text { Adriana de Fatima Manoel e } \\
\text { Eliseu da Costa Campos }\end{array}$ \\
\hline 03 & $\begin{array}{l}\text { Confecção de folder acerca da profilaxia pré- } \\
\text { exposição de risco à infecção pelo HIV }\end{array}$ & $\begin{array}{l}\text { Luiza Silveira de Oliveira, Laís Mara } \\
\text { Caetano da Silva, Maria Denise } \\
\text { Schmith, Patrícia Porto Almeida, } \\
\text { Márcia Gabriela Rodrigues de } \\
\text { Lima e Júlia Zancan Bresolin }\end{array}$ \\
\hline 03 & $\begin{array}{l}\text { Notificações de flebite e construção } \\
\text { do método PDSA }\end{array}$ & $\begin{array}{l}\text { Carla Moreira Lorentz Higa, } \\
\text { Patrícia Trindade Benites, Flávia } \\
\text { Rosana Rodrigues Siqueira }\end{array}$ \\
\hline 03 & $\begin{array}{l}\text { Agendamento da vacina influenza como } \\
\text { estratégia para aumentar cobertura vacinal }\end{array}$ & $\begin{array}{l}\text { Joice Rodrigues Machado Hahn, } \\
\text { Melanie Schröder, Vanisa Cavallini } \\
\text { da Silva, Rosa Ladi Lisbôa, } \\
\text { Angelica de Lima Izaguirres } \\
\text { e Adriana Aparecida Paz }\end{array}$ \\
\hline 03 & $\begin{array}{l}\text { Impacto e relevância: interface no processo de } \\
\text { avaliação dos programas de pós-graduação }\end{array}$ & $\begin{array}{l}\text { Alana Camila Schneider, Patrícia } \\
\text { Poltronieri e Denise Antunes } \\
\text { de Azambuja Zocche }\end{array}$ \\
\hline 03 & $\begin{array}{l}\text { Evidências na aplicação do processo de enfermagem } \\
\text { no cuidado a pacientes em tratamento radioterápico }\end{array}$ & $\begin{array}{l}\text { Gabriele Capeletti e } \\
\text { Maiara Bordignon }\end{array}$ \\
\hline 03 & $\begin{array}{l}\text { Estágio curricular supervisionado em atenção } \\
\text { hospitalar: experiências na pandemia COVID-19 }\end{array}$ & $\begin{array}{l}\text { Denise Antunes de Azambuja } \\
\text { Zocche e Fabiane Pertille }\end{array}$ \\
\hline
\end{tabular}




\begin{tabular}{|c|c|c|}
\hline 03 & $\begin{array}{l}\text { Atuação da enfermagem na relação } \\
\text { entre câncer e sexualidade }\end{array}$ & $\begin{array}{l}\text { Robson Lovison, Tania Maria } \\
\text { Ascari, Sandra Maria Vanini }\end{array}$ \\
\hline 03 & $\begin{array}{l}\text { Elaboração de uma tecnologia educacional pela } \\
\text { enfermagem: serious game sobre cirurgia segura }\end{array}$ & $\begin{array}{c}\text { Camila Zanesco, Ana } \\
\text { Paula Magalhães de Abreu de } \\
\text { Giacomo, Jossandro Rodrigues da } \\
\text { Cruz e Luciana Schleder Gonçalves }\end{array}$ \\
\hline 03 & $\begin{array}{l}\text { Relato de experiência: roda de conversa } \\
\text { em uma unidade prisional durante } \\
\text { a campanha novembro azul }\end{array}$ & $\begin{array}{l}\text { Patrícia Porto Almeida, Laís Mara } \\
\text { Caetano da Silva, Luiza Silveira de } \\
\text { Oliveira, Maria Denise Schimith, } \\
\text { Marcia Gabriela Rodrigues de } \\
\text { Lima e Julia Zancan Bresolin }\end{array}$ \\
\hline 03 & $\begin{array}{l}\text { Desenvolvimento de dispositivo de comunicação } \\
\text { aumentativa, produzido a baixo custo, para } \\
\text { pacientes com disfunções motoras }\end{array}$ & $\begin{array}{l}\text { Sidclei Benevides da Conceição, Fábio } \\
\text { César Bonfim de Moraes, Camila } \\
\text { Rocha da Silva e Edson Palhares Leite }\end{array}$ \\
\hline 03 & $\begin{array}{l}\text { Teoria de Nola Pender, uso no trabalho em home } \\
\text { office, durante a pandemia de COVID-19 }\end{array}$ & $\begin{array}{c}\text { Izaiane Paes Ribeiro de Sousa, } \\
\text { Francisco Antônio Borges de } \\
\text { Oliveira Júnior, Isaura Danielli } \\
\text { Borges de Sousa e Márcia } \\
\text { Teles de Oliveira Gouveia }\end{array}$ \\
\hline 03 & $\begin{array}{l}\text { Tecnologia educacional: um caminho para } \\
\text { educação em saúde na hemodinâmica }\end{array}$ & $\begin{array}{l}\text { Rosana Moreira de Sant'Anna, } \\
\text { Cristina Lavoyer Escudeiro, } \\
\text { Alessandra Conceição Leite Funchal } \\
\text { Camacho, Vitória Meireles Felipe } \\
\text { de Souza, Marcos Aurélio Pinto da } \\
\text { Silva e Harlon França de Menezes }\end{array}$ \\
\hline 03 & $\begin{array}{l}\text { Utilização do Short Form Health Survey para avaliar } \\
\text { a qualidade de vida de pessoas desempregadas }\end{array}$ & $\begin{array}{c}\text { Francisco Antonio Borges de Oliveira } \\
\text { Júnior, Izaiane Paes Ribeiro de Sousa, } \\
\text { Isaura Danielli Borges de Sousa e } \\
\text { Márcia Teles de Oliveira Gouveia }\end{array}$ \\
\hline 03 & $\begin{array}{c}\text { Efeitos terapêuticos dos Grupos de Desenvolvimento } \\
\text { Humano na Atenção à Saúde Mental }\end{array}$ & $\begin{array}{l}\text { Bruno Huffel de Lima, Márcia } \\
\text { Luíza Pit Dal Magro, Elizangela } \\
\text { Felipi e Marta Neckel Menezes }\end{array}$ \\
\hline
\end{tabular}




\section{LISTA DE TRABALHOS}

\section{MODALIDADE APRESENTAÇÃO ORAL}

\begin{tabular}{|c|c|c|}
\hline Eixo & Título & Autores \\
\hline $\mathrm{O} 1$ & $\begin{array}{l}\text { Acolhimento multiprofissional no sistema } \\
\text { prisional como instrumento de ressocialização }\end{array}$ & $\begin{array}{l}\text { Reges Antonio Deon, Camila } \\
\text { Lorenzoni Cortina, Rosi Maria } \\
\text { De Carli, Nathieli Aparecida } \\
\text { da Silva e Arnildo Korb }\end{array}$ \\
\hline 01 & $\begin{array}{l}\text { Felicidade no trabalho: um estudo com } \\
\text { enfermeiros portugueses em contexto insular }\end{array}$ & $\begin{array}{l}\text { Sofia Azevedo Feitor e Elisabete } \\
\text { Maria das Neves Borges }\end{array}$ \\
\hline O1 & $\begin{array}{l}\text { Campanha de prevenção e enfrentamento } \\
\text { do assédio moral nos serviços de saúde }\end{array}$ & $\begin{array}{c}\text { Maiara Daís Schoeninger, Kaciane } \\
\text { Boff Bauermann, Grasiele Fatima } \\
\text { Busnello, Rosana Amora Ascari, } \\
\text { Elisabete Maria das Neves Borges } \\
\text { e Letícia de Lima Trindade }\end{array}$ \\
\hline $\mathrm{O} 1$ & $\begin{array}{l}\text { Perfil dos pacientes infectados pelo } \\
\text { coronavírus no estado de SC }\end{array}$ & $\begin{array}{c}\text { Fernanda Norbak Dalla Cort, Reges } \\
\text { Antonio Deon, Leila Zanatta, Arnildo } \\
\text { Korb e Samuel da Silva Feitosa }\end{array}$ \\
\hline $\mathrm{O} 1$ & $\begin{array}{l}\text { Fatores que contribuem para a } \\
\text { satisfação profissional na APS }\end{array}$ & $\begin{array}{c}\text { Júlia Grasel, Samuel Spiegelberg } \\
\text { Zuge, Letícia de Lima } \\
\text { Trindade e Jacks Soratto }\end{array}$ \\
\hline $\mathrm{O} 1$ & $\begin{array}{l}\text { Contribuições das PICS a gestão do } \\
\text { trabalho: desafios e possibilidades }\end{array}$ & $\begin{array}{l}\text { Gabriela Trevisan, Lúcia Esteves } \\
\text { Duarte, Monica Vilchez da Silva, } \\
\text { Maria Teresa Luz Eid da Silva, } \\
\text { Leandra Andréia de Sousa e } \\
\text { Adriana Barbieri Feliciano }\end{array}$ \\
\hline 01 & $\begin{array}{l}\text { Qualidade de vida de profissionais de enfermagem } \\
\text { atuantes na AP em tempos de COVID }\end{array}$ & $\begin{array}{l}\text { Endria Mendes Fabrizzio, Raquel } \\
\text { Tatielli Daneluz Rintzel, Lisiane da } \\
\text { Rosa, Crhis Netto de Brum, Júlia } \\
\text { Grasel e Samuel Spiegelberg Zuge }\end{array}$ \\
\hline $\mathrm{O} 1$ & $\begin{array}{l}\text { Gestão do cuidado na atenção a polifarmácia } \\
\text { em pacientes com Insuficiência Cardíaca }\end{array}$ & $\begin{array}{c}\text { Julia Gonçalves Escossia Campos, } \\
\text { Michelle Alves dos Santos, Liana } \\
\text { Amorim Corrêa Trotte e Marluci } \\
\text { Andrade Conceição Stipp }\end{array}$ \\
\hline o1 & Polifarmácia em pacientes com diabetes tipo 2 & $\begin{array}{l}\text { Daniela Paula Marion Santin, } \\
\text { Luciano Fiorentin e Vilma Beltrame }\end{array}$ \\
\hline
\end{tabular}




\begin{tabular}{|c|c|c|}
\hline O1 & $\begin{array}{l}\text { Gerenciando o cuidado e a segurança } \\
\text { do paciente com o Safety Huddle }\end{array}$ & $\begin{array}{l}\text { Lucas Corrêa Preis, Giuliana } \\
\text { Cosentino Freitas Santos, } \\
\text { Jaqueline Caetano, Leonan } \\
\text { José Raimundo, Marli Rafael } \\
\text { Joaquim e Marion Hoelz Ioras }\end{array}$ \\
\hline $\mathrm{O} 2$ & $\begin{array}{l}\text { Fragilidades identificadas na prática } \\
\text { hemoterápica: contribuições para EP_EE }\end{array}$ & $\begin{array}{l}\text { Renata Gobetti Borges, Samara } \\
\text { Lunardi, Bianca Gabriela Pasa } \\
\text { Begnini e Rosana Amora Ascari }\end{array}$ \\
\hline $\mathrm{O} 2$ & $\begin{array}{l}\text { Experiência de matriciamento na saúde do } \\
\text { trabalhador vítima de acidente de trabalho }\end{array}$ & $\begin{array}{l}\text { Marta Neckel Menezes, Márcia Luíza } \\
\text { Pit Dal Magro, Bruno Huffel de } \\
\text { Lima e Nalu Aparecida Oro Paludo }\end{array}$ \\
\hline $\mathrm{O} 2$ & $\begin{array}{l}\text { O ensino da administração em } \\
\text { enfermagem no estado do Paraná }\end{array}$ & $\begin{array}{l}\text { Carmen Elizabeth Kalinowski e } \\
\text { Isabel Cristina Kowal Olm Cunha }\end{array}$ \\
\hline $\mathrm{O} 2$ & $\begin{array}{l}\text { Reações transfusionais na pratica hemoterápica } \\
\text { de enfermagem: um estudo de revisão. }\end{array}$ & $\begin{array}{c}\text { Rosana Amora Ascari, Cauana } \\
\text { Gasparetto, Natallya Carla } \\
\text { Rodrigues, Renata Gobetti } \\
\text { Borges, Samara Lunardi e Bianca } \\
\text { Gabriela Pasa Begnini }\end{array}$ \\
\hline $\mathrm{O} 2$ & $\begin{array}{l}\text { Monitoramento e avaliação das ações de } \\
\text { EPS nos planos dos estados brasileiros }\end{array}$ & $\begin{array}{c}\text { Suelen Guedes Souza, Camila Fonseca } \\
\text { Figueiredo, Vitória Valéria Cristo } \\
\text { Santos e Silvana Lima Vieira }\end{array}$ \\
\hline $\mathrm{O} 2$ & $\begin{array}{l}\text { O que pode uma pesquisa cartografia como } \\
\text { dispositivo de educação permanente na atenção básica }\end{array}$ & $\begin{array}{l}\text { Josiane Moreira Germano, } \\
\text { Tatiana Almeida Couto e Alba } \\
\text { Benemérita Alves Vilela }\end{array}$ \\
\hline $\mathrm{O} 2$ & $\begin{array}{l}\text { Educação Permanente no processo de trabalho das } \\
\text { equipes de saúde/atenção básica: usos e sentidos }\end{array}$ & $\begin{array}{l}\text { Josiane Moreira Germano, } \\
\text { Tatiana Almeida Couto e Alba } \\
\text { Benemérita Alves Vilela }\end{array}$ \\
\hline $\mathrm{O} 2$ & $\begin{array}{c}\text { Análise das ações de EP contidas } \\
\text { nos Planos estaduais de EPS }\end{array}$ & $\begin{array}{l}\text { Camila Fonseca Figueiredo, Suelen } \\
\text { Guedes Souza, Vitória Valéria Cristo } \\
\text { Santos e Silvana Lima Vieira }\end{array}$ \\
\hline $\mathrm{O} 2$ & $\begin{array}{l}\text { Gestão do programa de residência } \\
\text { médica do HRO_AEPS }\end{array}$ & $\begin{array}{c}\text { Gleica Pressi, Jacira Batista de } \\
\text { Oliveira, João Batista Baroncello, } \\
\text { Jussara dos Santos Valentini, } \\
\text { Rosana Amora Ascari e Daniel } \\
\text { Jesse Junior Ferreira Cassemiro }\end{array}$ \\
\hline $\mathrm{O} 2$ & $\begin{array}{l}\text { A EPS no enfrentamento das situações } \\
\text { problema no cuidado ao paciente }\end{array}$ & $\begin{array}{l}\text { Valentina Barbosa da Silva, Sandra } \\
\text { Cristina de Souza Borges Silva e } \\
\text { Marluci Andrade Conceição Stipp }\end{array}$ \\
\hline
\end{tabular}




\section{LISTA DE TRABALHOS}

MENÇÃO HONROSA I FIGEPS 2021

\begin{tabular}{|c|c|c|}
\hline EIXO & TÍTULO & AUTORES \\
\hline O1 & $\begin{array}{c}\text { Contribuições das práticas integrativas } \\
\text { e complementares à gestão do trabalho: } \\
\text { desafios e possibilidades }\end{array}$ & $\begin{array}{l}\text { Gabriela Trevisan, Lúcia Esteves } \\
\text { Duarte, Monica Vilchez da Silva, } \\
\text { Maria Teresa Luz Eid da Silva, } \\
\text { Leandra Andréia de Sousa e } \\
\text { Adriana Barbieri Feliciano }\end{array}$ \\
\hline 01 & $\begin{array}{l}\text { Campanha de prevenção e enfrentamento } \\
\text { do assédio moral nos serviços de saúde }\end{array}$ & $\begin{array}{c}\text { Maiara Daís Schoeninger, Kaciane } \\
\text { Boff Bauermann, Grasiele Fatima } \\
\text { Busnello, Rosana Amora Ascari, } \\
\text { Elisabete Maria das Neves Borges } \\
\text { e Letícia de Lima Trindade }\end{array}$ \\
\hline $\mathrm{O} 2$ & $\begin{array}{l}\text { O que pode uma pesquisa? Cartografia como dispositivo } \\
\text { de educação permanente na atenção básica }\end{array}$ & $\begin{array}{l}\text { Josiane Moreira Germano, } \\
\text { Tatiana Almeida Couto e Alba } \\
\text { Benemérita Alves Vilela }\end{array}$ \\
\hline $\mathrm{O} 2$ & $\begin{array}{l}\text { Monitoramento e avaliação das ações de educação } \\
\text { permanente em saúde nos planos dos estados brasileiros }\end{array}$ & $\begin{array}{l}\text { Suelen Guedes Souza, Camila } \\
\text { Fonseca Figueiredo, Vitória } \\
\text { Valéria Cristo Santos e } \\
\text { Silvana Lima Vieira }\end{array}$ \\
\hline 03 & $\begin{array}{c}\text { Efeitos terapêuticos dos Grupos de Desenvolvimento } \\
\text { Humano na atenção à saúde mental }\end{array}$ & $\begin{array}{l}\text { Bruno Huffel de Lima, Márcia } \\
\text { Luíza Pit Dal Magro, Elizangela } \\
\text { Felipi e Marta Neckel Menezes }\end{array}$ \\
\hline $\mathrm{O} 3$ & $\begin{array}{l}\text { Desenvolvimento de dispositivo de comunicação } \\
\text { aumentativa, produzido a baixo custo, para } \\
\text { pacientes com disfunções motoras }\end{array}$ & $\begin{array}{l}\text { Sidclei Benevides da Conceição, } \\
\text { Fábio César Bonfım de } \\
\text { Moraes, Camila Rocha da } \\
\text { Silva e Edson Palhares Leite }\end{array}$ \\
\hline
\end{tabular}


Eixo temático I

\section{GESTÃO DO TRABALHO NOS SISTEMAS DE SAÚDE PÚBLICOS}




\section{APLICABILIDADE DA POLÍTICA DE ATENÇÃO HOSPITALAR: UMA REFLEXÃO CRÍTICA}

\section{Fernanda Norbak Dalla Cort Patrícia Poltronieri Débora Rafaelly da Silva Vicente \\ Letícia de Lima Trindade Carine Vendruscolo}

\section{Introdução}

O hospital é uma instituição secular na história da humanidade, o qual passou por profundas alterações vinculadas aos contextos políticos, sociais, econômicos e culturais, além das múltiplas descobertas científicas e o avanço tecnológico na área da saúde ${ }^{1}$. Considerando que a regulamentação da atenção hospitalar no Sistema Único de Saúde (SƯS) iniciou-se a partir da Constituição Federal Brasileira de 1988, no período até 2013, foram instituídos documentos legais oriundos do Poder Executivo Federal que formularam processualmente as bases regulamentadoras à atenção hospitalar no SUS. Diante disto, institui-se a Política Nacional de Atenção Hospitalar (PNHOSP), a qual tem como objetivo estabelecer diretrizes para a organização do componente hospitalar da Rede de Atenção à Saúde (RAS), baseada na Política Nacional de Humanização (PNH), na Política Nacional de Regulação (PNR) e na Comissão Nacional de Incorporação de Tecnologias (CONITEC)2. Também estabelece orientações sobre a prestação de assistência de qualidade ao paciente, de forma a garantir segurança e continuidade atenção à saude nesse nível assistencial. Nesse contexto, a atenção hospitalar é objeto de importante análise e discussão de políticas públicas de saúde, esta desperta permanente inquietação por parte dos gestores, e das instituições, tendo em vista a complexidade e os desafios existentes neste âmbito. Segundo a PNHOSP, o hospital é 
conceituado como uma organização complexa, responsável pela assistência à saúde, atuando como espaço de educação e pesquisa, formação de pessoas, promovendo tecnologias em saúde, desempenhando funções dentro do âmbito da RAS. A PNHOSP possui seis eixos, a saber: assistência hospitalar; gestão hospitalar; formação, desenvolvimento e gestão da força de trabalho; financiamento; contratualizaçã̃o; e responsabilidades das esferas governamentais de gestão, caracterizando dentro do contexto das políticas públicas². É evidenciado a precariedade nas pesquisas sobre políticas de saúde, bem como, especificamente sobre as lacunas em relação à atenção hospitalar e sua importância para a saúde coletiva'. Outrora evidencia-se pouca produção científica, relacionado à reflexão crítica da aplicabilidade da PNHOSP, em relação aos Planos Nacionais de Saúde (PNS) e às Conferências Nacionais de Saúde (CNS)3. Neste sentido, algumas questões são levantadas na aplicabilidade e execução desta Política, visto que se deve ter um alinhamento entre os problemas priorizados pelos hospitais e os eixos estruturantes da PNHOSP, a qual por vezes dá-se ênfase excessiva em problemas administrativos e em tecnologias de informação, subestimando problemas relacionados ao modelo de atenção e à gestão da clínica ${ }^{1}$.

\section{Objetivo}

Refletir sobre a Política Nacional de Atenção Hospitalar e sua aplicabilidade na atenção à saúde.

\section{Metodologia}

Trata-se de uma reflexão crítica baseada na exploração estrutural e analítica da Política Nacional de Atenção Hospitalar e sua aplicabilidade na gestão em saúde, desafio apresentado na disciplina de Políticas Públicas de Saúde, do Mestrado Profissional em Enfermagem na Atenção Primária à Saúde da Universidade do Estado de Santa Catarina. Para o processo de análise do conteúdo utilizou-se a análise de conteúdo ${ }^{4}$, compreendendo as fases propostas, para organização da análise, desmembrada em pré-análise, apoiando-se na leitura flutuante e escolha dos documentos, tais como portarias e artigos, e dissertações relacionadas ao tema, cumprindo as regras de exaustividade, homogeneidade e de pertinência. Após seguidas regras, houve a preparação do material de acordo com objetivo do estudo para codificar e categorizar, de acordo com relevância e pertinência do tema, os recortes, formando assim o arcabouço qualificado de materiais para a escrita $^{4}$. A reflexão foi baseada na metodologia de problematização do Arco de Maguerez, com foco na quinta etapa, que diz sobre a aplicação da realidade. Sobretudo, essa fase se materializa pela capacidade de analisar a problemática e implementar estratégias viáveis que gerem soluções eficientes ${ }^{3}$, com a finalidade de atingir o objetivo em questão.

\section{Resultados e discussões}

Como marcos normativos da atenção hospitalar, destaca-se a continuidade do processo de implantação do SUS, com a descentralização da gestão por esferas de governo, por meio das Normas Operacionais Básicas e de Assistência de Saúde. Observa-se através da formalização, a regulação sobre a rede hospitalar pública e privada ficou sob nível estadual da gestão do SUS. Uma vez formalizada por meio do modelo contratual, como se dariam os repasses de fundos de forma tripartite e a administração pública, as mesmas ficaram estabelecidas como obrigatória para atenção hospitalar. Portanto, iniciou-se um movimento necessário para fortalecer as políticas intrínsecas à PNHOSP, tais como a de PNH e a PNR do SUS. Como diretrizes, a PNHOSP é orientada pelos princípios da universalidade, equidade, integralidade, controle social, regionalização da atenção e continuidade da atenção por meio da articulação regulada com os outros serviços. O modelo de atenção deve ser centrado no cuidado humanizado e interdisciplinar. O financiamento é tripartite, conforme pactuação, e o monitoramento, avaliação, transparência deve ser acompanhada não só pelo governo como pela população, para observar a eficiência na aplicação dos recursos 5 . Alguns eixos estruturantes da política merecem destaque: a gestão hospitalar refere-se à qualidade da assistência, cumprimento de metas contratualizadas, eficiência e transparência, planejamento participativo, a adoção de ferramentas de gestão, investimentos e integração com os demais pontos da RAS. O financiamento tripartite e os instrumentos formais de contratualização regularizam a relação entre o gestor e os hospitais públicos e privados. Isso se dá por meio de critérios regionais, orçamentários, de monitoramento e cumprimento das metas, aprimoramento assistencial, efetivação do controle social e transparência. Administrativamente, a Política reforça a importância sobre a racionalização dos custos, também em relação a contratualização. Na prática, as ações de condução da atenção hospitalar são capazes de manejar o percurso da gestão e da gerência. 
Algumas estratégias que são abordadas na Política, que refletem na atividade da rede de atenção hospitalar, no dia a dia do trabalhador e na qualidade do atendimento prestado ao paciente, são identificadas nas ações de valorização dos trabalhadores com incentivo à avaliação de desempenho e educação permanente. Também, é estabelecido dentro do hospital, os Núcleo de Acesso e Qualidade Hospitalar (NAQH) e Núcleo Interno de Regulação (NIR) para realizar a regulação de leitos, avaliar indicadores e estimular boas práticas em saúde. Preconiza também, a prática de visitação aberta com o intuito e manter o suporte da rede de apoio individual. Entre tantas outras recomendacões da Política, entende-se que para que sua aplicação seja efetiva e se fortaleça, é necessário um envolvimento por parte de todos os seus atores sociais, em especial os gestores e gerentes, para que haja uma sincronicidade entre objetivos e pactuações. Apesar de todos os avanços decorrentes da formulação da PNHOSP, seu processo de implementação enfrenta obstáculos e problemas que reduziram bastante o escopo de sua real implementação no Brasil, tais como a ausência de planejamento, o alto custo dos serviços hospitalares, o financiamento insuficiente, a incorporação tecnológica acrítica, a sobreposição de tecnologias, o baixo investimento em qualificação profissional, a insuficiência de parâmetros técnicos e epidemiológicos existentes e a baixa regulação da oferta assistencial hospitalar ${ }^{5}$. Nota-se ainda uma priorização de temas e problemas relacionados à racionalização da vida hospitalar, em detrimento da gestão do trabalho em saúde, com importante desvalorização dos espaços coletivos e evidente distanciamento da direção dos hospitais em relação aos trabalhadores, usuários e gestores do SUS.

\section{Considerações finais}

A PNHOSP se destaca em apoiar a tomada de decisões e nortear as atividades diárias de gestão hospitalar de forma explicitada nas suas disposições. Portanto, é necessário incorporar o conhecimento, a divulgação e o debate sobre a Política entre os trabalhadores da área de saúde, através da educação continuada e permanente, com a finalidade de habilitar e melhorar a prestação de serviços de qualidade à comunidade. Para além disto, é importante a população apoderar-se de seus direitos para exercer seu dever de fiscalização, ou seja, o controle social, auxiliando no monitoramento e na avaliação do serviço prestado nesse nível da RAS. Novos estudos são necessários para avaliar o impacto da Política no atual modelo de atenção hospitalar, vislumbrar a aplicabilidade da mesma e promover reflexão crítica entre os trabalhadores da saúde.

Descritores: Gestão Hospitalar; Políticas Públicas de Saúde; Sistema Único de Saúde; Legislação Hospitalar.

Financiamento: Fundação de Amparo à Pesquisa e Inovação do Estado de Santa Catarina (FAPESC) segundo o Edital MCTIC/ CNPq/FNDCT/MS/SCTIE/Decit № o7/2020 e acordo CAPES/COFEN.

\section{Referências}

1. Santos TBS, Souza JS, Martins JS, Rosado LB, Pinto ICM. Gestão indireta na atenção hospitalar: análise da contratualização por publicização para rede própria do SUŞ. Saúde em Debate. 2018. 42(esp2):247-261.

2. Ministério da Saúde (BR). Diário Oficial da União. Portaria no 3.39o, de zo de dezembro de 2013. Institui a Política Nacional de Atenção Hospitalar (PNHOSP) no âmbito do Sistema Único de Saúde (SUS), estabelecendo se as diretrizes para a organização do componente hospitalar da Rede de Atenção à Saúde. Brasília: Munistédio da Saúde; 2015.

3. Santos TB, Pintos ICM. Política Nacional de Atenção Hospitalar: con(di)vergências entre normas, Conferências e estratégias do Executivo Federal. Revista Saúde Debate. 2017. 41 (esp 3): 99-113.

4. Urquiza MA, Marques, DB. Análise de conteúdo em termos de Bardin aplicada à comunicação corporativa sob o signo de uma abordagem teorico-empírica. Entre textos. 2016.16(1): 115-144. 5. Solla J, Chioro dos Reis AA. Atenção Ambulatorial Especializada. In: Giovanella L. et al. organizadores. Políticas e Sistema de Saúde no Brasil. 2. ed. Rio de Janeiro: Fiocruz; 2012. p. 547-576. 
Pesquisa Original

GRUPOS ETÁRIOS E

INTERNAÇÕES POR DOENÇA

DIARREICA AGUDA NA REGIÃO

OESTE DE SANTA CATARINA

\section{Carlise Krein \\ Lucimare Ferraz}

Arnildo Korb

\section{Introdução}

A morbidade por Doença Diarreica Aguda (DDA) é mais prevalente em países de baixa renda, e é associada à vários fatores, sobretudo aos determinantes sociais em saúde ${ }^{1}$. Frente aos diversos fatores de risco da doença, o perfil da população acometida pode divergir entre os diferentes territórios. A DDA em adultos e idosos é influenciada pela baixa cobertura de saneamento básico, ineficiente organização do serviço de atenção em saúde do local, baixa escolaridade e renda ${ }^{2}$. Ademais, a ocorrência da doença na infância é associada principalmente à introdução precoce de alimentos na dieta, baixa escolaridade da mãe, e insuficiente cobertura de vacinação contra rotavírus². Além dos fatores de risco supracitados, fatores como pluviosidade e temperatura ambiental também influenciam na infecção, dependendo das características do agente etiológico envolvido. Os estudos sobre a doença se concentram em desvelar fatores associados a diarreia infantil, que foi por muitas décadas, hegemonicamente, o grupo etário mais acometido pela doença e suas complicações, gerando inclusive, altos indicadores de letalidade ${ }^{2}$. Todavia, estudos recentes demonstram que o perfil de morbidade pela DDA modificou no país, e houve expressiva diminuição da hospitalização de crianças em decorrência da doençàa. A região Oeste de Santa Catarina apresentou a maior frequência relativa de hospitalizações por DDA entre os anos de 2014 e 2018, em comparação às demais regiões do mesmo Estado. Nesse 
contexto, torna-se relevante conhecer o perfil de morbidade da população pela doença no Oeste de Santa Catarina, e identificar as faixas etárias de maior prevalência, para posterior direcionamento de medidas de prevenção primária efetivas, que abranjam as lacunas assistenciais existentes no local.

\section{Objetivo}

Identificar os grupos etários com maior frequência relativa de hospitalizações por DDA entre os anos de 2014 e 2018 na Região Oeste de Santa Catarina, e comparar com indicadores do Estado de Santa Catarina e Brasil, do mesmo período.

\section{Método}

Trata-se de um estudo transversal de abordagem quantitativa, com coleta de informações na base de dados sobre hospitalizações por DDA na plataforma digital DATASUS. Os dados foram coletados por local de residência, com seleção de dados dos 25 municípios pertencentes à região de saúde Oeste, do Estado de Santa Catarina, e de todo território nacional, entre os anos de 2014 e 2018. Foram selecionados os registros cuja causa atribuída foi "Diarreia e gastroenterite de origem infecciosa presumível". Na seleção de dados, foi demarcada a opção "Faixa Etária 1" (menores que 1, 1-4, 5-9, 10-14, 15-19, 20-29, 30-39, 40-49, 50-59, 60-69, 70-79, 80 + anos). Os dados obtidos foram processados com a utilização da ferramenta IBM SPSS, versão 20.0/2011. Para a descrição, análise e representação dos dados, foi utilizada a estatística descritiva, com a apresentação da frequência relativa de ocorrência por faixa etária, e desvio padrão populacional da comparação entre os indicadores de hospitalizações pela doença, em cada local. O valor do desvio padrão expressa o grau de dispersão do grupo de dados da média. Ou seja, no presente estudo, o dado irá mensurar e retratar a diferença entre as frequências relativas de hospitalização nos diferentes grupos etários. A apresentação da frequência relativa de hospitalização pela faixa etária, será efetuada com a descriçã̃o dos três maiores indicadores de cada local, em ordem decrescente. A mesma metodologia será utilizada para exposição do desvio padrão do indicador de cada local.

\section{Resultados e Discussão}

$\mathrm{Na}$ região Oeste, prevaleceram as hospitalizações na faixa etária de 1 a 4 anos $(12,03 \%)$, seguida de 60 a 69 anos $(11,29 \%)$ e 20 a 29 anos $(10,56 \%)$. No Estado de Santa Catarina, as maio- res proporções de hospitalização foram identificadas no grupo etário de 1 a 4 anos $(16,63 \%)$, 20 a 29 anos $(9,73 \%)$, e 5 o a 59 anos $(8,85 \%)$. Da mesma forma, no Brasil, predominaram hospitalizações na faixa etária de 1 a 4 anos $(28,04 \%)$, procedido de crianças de 5 a 9 anos $(11,31 \%)$, e de adultos jovens de 20 a 29 anos $(6,77 \%)$. O cálculo de desvio padrão demonstrou que na região Oeste, a morbidade hospitalar apresentou menores dispersões entre os diferentes grupos etários ( $\mathrm{d} p=2,41$ anos) seguido do Estado $(\mathrm{d} p=2,90$ anos) e Brasil ( $\mathrm{dp}=6,59$ anos). O elevado indicador obtido no cálculo de dispersão de dados no país, demonstra a grande concentração de hospitalizações entre crianças. A ocorrência da doença é exacerbada em grupos mais vulneráveis, como de idosos e crianças ${ }^{4}$. A maior suscetibilidade nesses grupos etários ocorre em decorrência de imunossupressão, presença de doenças crônicas, alteracão da motilidade intestinal, e maior suscetibilidade à intolerâncias por alimentos e medicamentos ${ }^{1}$. Além do risco aumentado de complicações da doença, os indivíduos das faixas etárias supracitadas, em geral, também requerem períodos maiores de hospitalização, assim como geram níveis de absenteísmo no trabalho para familiares, que necessitarão prestar cuidados à crianças e idosos ${ }^{5}$. Alguns dados apresentados corroboram com resultado de estudo ${ }^{2}$ desenvolvido com dados de todo território brasileiro entre 2000 e 2015, que demonstrou elevações de hospitalizações pela doenças nos extremos de idade. O grupo etário entre 1 e 4 anos ain$\mathrm{da}$ apresenta os maiores indicadores de morbidade hospitalar por DDA, em todos os locais analisados no presente estudo. Esse dado demonstra a necessidade de, além de diminuir as vulnerabilidades sociais em saúde da população, organização do serviço de saúde para otimizar o manejo da doença, a estimulação do aleitamento materno, da vacinação contra rotavírus, e promoção da auto-efiććcia materna na prevenção da DDA. Por outro lado, autores sugerem que o modelo econômico vigente, e a falta de políticas públicas específicas para a população idosa propiciam o adoecimento desse grupo etário por condições que poderiam ser evitadas, como a DDA'. Algumas medicações também podem causar interações medicamentosas e alterações da flora intestinal, que podem suscitar ou agravar sintomatologia $\mathrm{da}$ DDA. Essa situação é frequente em nonagenários, em virtude da polimedicação, determinada pelo grande número de indivíduos nessa faixa etária com múltiplas doenças associadas, ou pela automedicação. Também, surpreende a elevada frequência relativa de hospitalizações 
na faixa etária entre 20 e 29 anos, identificada em todos os locais analisados. Frente a tal assertiva, ressalta-se a necessidade de estudos mais aprofundados para elucidar agentes etiológicos e determinantes sociais, ou fatores individuais envolvidos na alta morbidade hospitalar por DDA nessa faixa etária. As DDAs são consideradas condições sensíveis à atenção primária em saúde, visto que em geral, são doenças de fácil manejo, e não exigem tecnologias de elevado custo para o tratamento ${ }^{2}$. Dessa forma, o diagnóstico situacional local do perfil de morbidade e o planejamento de intervenções que contemplem as fragilidades identificadas, podem promover gestão mais eficiente do trabalho, e dos recursos financeiros dos serviços de saúde na prevenção e manejo da doença.

\section{Conclusão}

As faixas etárias que compreendem a infância detiveram a maior frequência relativa de hospitalizações por DDA. Assim, é a população mais vulnerável as complicações da doença. Sob esse prisma, o presente estudo apresenta subsídios para a gestão do trabalho dos serviços de saúde da região Oeste de Santa Catarina em relação à DDA. Do mesmo modo, visto a concentração de estudos referentes à doença na infância, e a mudança no perfil de morbidade, aponta-se também, a importância de discussões sobre a morbidade hospitalar pela doença em adultos e idosos. Visto que a doença pode debilitar o organismo do indivíduo acometido, e considerando a vigência de pandemia da COVID-19, são necessárias medidas de prevenção da DDA, principalmente, direcionadas aos grupos etários mais suscetíveis à doença.

Descritores: Diarreia; Hospitalização; Grupos etários.

Financiamento: Fundação de Amparo à Pesquisa e Inovação do Estado de Santa Catarina (FAPESC)

\section{Referências}

1. Wischneski AG, Ahmadpour B, Iacono LBP, Scopel D, Dias-Scopel RP. Aspectos socioambientais da Terra Indígena Kwatá e morbimortalidade por doenças diarreicas em idosos Munduruku no estado do Amazonas, Brasil. In: Anais do $13^{\circ}$ Congresso Internacional $\mathrm{da}$ Rede Unida; 2018; 4(1). Disponível em: http:// conferencia2018.redeunida.org.br/ocs2/index.

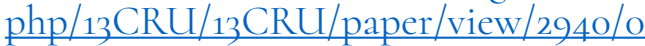

2. Kuiava VA, Perin AT, Chielle EO. Hospitalização e taxas de mortalidade por diarreia no Brasil: 2000-2015. Revista Ciência e Saúde. 2019 abr/jun. [acesso em 17 de novembro de 2020]; 12(2):e30022. Disponivel em: http://revistaseletronicas.pucrs. br/ojs/index.php/faenfi/article/view/32022

3. Krein C, Korb A, Zanatta L. Hospitalizações por doença diarreica aguda em Santa Catarina e tecnologias educativas para intervenção. In: Anais do 3. Congresso Sul Brasileiro de Sistematização da Assistência de Enfermagem e 2. Mostra Internacional de Cuidado de Enfermagem no Ciclo da Vida; 2019 nov. 19 - 21. Chapecó, Santa Catarina. Florianópolis: Editora UDESC; 2019.

4. Meneguessi GM, Mossri RM, Segatto TCV, Reis PO. Morbimortalidade por doenças diarreicas agudas em crianças menores de 10 anos no Distrito Federal, Brasil, 2003 a 2012. Epidemiol. Serv. Saúde. 2015 out/dez. [acesso em 19 de novembro de 2020]; 24 (4):721-730. Disponível em: https://doi.org/10.5123/S167949742015000400014

5. Papadopoulos T et al. The health and economic impact of acute gastroenteritis in Belgium, 2010-2014. Epidemiology and Infection, 2019; 147(146):1-7. Disponível em: https:// www-cambridge.ez74.periodicos.capes.gov.br/ core/journals/epidemiology-and-infection/ article/health-and-economic-impact-of-acute-gastroenteritis-in-belgium-20102014/DoDD$\mathrm{o}_{6} \mathrm{C}_{57} 8 \mathrm{~A}_{43} \mathrm{H}_{2} \mathrm{FBE}_{21} \mathrm{CA}_{4} \mathrm{EA}_{4} 8 \mathrm{~A}_{797} \mathrm{~F}$ 
Estudo de REVISÃo

\section{MÉTODOS DE TRABALHO DOS ENFERMEIROS NO CONTEXTO HOSPITALAR: SCOPING REVIEW}

\author{
João Miguel Almeida \\ Ventura-Silva \\ Maria Manuela Ferreira \\ Pereira da Silva Martins \\ Letícia de Lima Trindade \\ Olga Maria Pimenta \\ Lopes Ribeiro \\ Maria Filomena Passos \\ Teixeira Cardoso
}

\section{Introdução}

Numa sociedade cada vez mais exigente, na qual se verifica um elevado desenvolvimento tecnológico e dinâmicas de trabalho complexas, as questões da qualidade em saúde têm sido uma preocupação na gestão das organizações $^{1}$. Os profissionais de saúde devem centrar-se na excelência da assistência prestada, promovendo a satisfação do cliente, figura central do sistema de saúde, assegurando uma prestação de cuidados seguros. Aos enfermeiros é exigido que apliquem as competências que adquiriram ao longo do seu processo formativo, com método e rigor, e de forma a dar resposta a todas as necessidades e problemas manifestados pelas pessoas ${ }^{2}$. O modo os cuidados são concebidos, organizados e implementados pelos enfermeiros, traduz a forma como estes profissionais se direcionam para atender às reais necessidades cuidados. Já Florence Nightingale, precursora da enfermagem moderna, alertava para uma conceção de cuidados centrados na pessoa, como também para a necessidade da organização dos cuidados de enfermagem, através da existência de um método de trabalho dos enfermeiros3. Efetivamente, e de acordo com a literatura, nos vários contextos de cuidados, e especificamente na área hospitalar, é possível identificar diferentes métodos de trabalho adotados pelos enfermeiros ${ }^{2}$. Face ao apresentado e à relevância desta temática para a enfermagem, pretendemos mapear a produção de conheci- 
mento, relativamente aos métodos de trabatho adotados pelos enfermeiros portugueses no contexto hospitalar.

\section{Método}

Revisão do tipo scoping, baseada nos princípios do "Joanna Briggs Institute". O processo de pesquisa foi orientado de forma independente por dois investigadores, no mês de dezembro de 2020, nos Repositórios Científicos de Acesso Aberto de Portugal, em que estão indexados todos os conteúdos científicos em acesso aberto existentes nos repositórios institucionais das entidades nacionais de ensino superior e outras organizações de investigação e desenvolvimento, e no Google Academico. Recorreu-se aos descritores "Método", "Trabalho", "Gestão em Saúde", "Enfermagem", "Enfermeiro" e "Hospitais", tendo sido os achados extraídos, segundo critérios de inclusão e exclusão. Incluíram-se referências nacionais da autoria e coautoria de enfermeiros portugueses, sem limites temporais. Excluíram-se os documentos, que não se direcionassem para o contexto hospitalar e que não tivessem como autores profissionais de enfermagem. Para além dos critérios anteriormente definidos, a identificação dos achados a incluir nesta revisão seguiu um processo de seleção rigoroso e sistematizado, a partir da recomendação de Prisma ${ }^{\circledR}$ (Preferred Reporting Items for Systematic Review and MetaAnalyses).

\section{Resultados e Discussão}

Dos 187 documentos encontrados pela pesquisa científica elaborada, após as diferentes etapas percorridas da recomendação Prisma ${ }^{\circledR}$, incluíram-se três estudos para análise. Salienta-se que os achados encontrados remetem-se para os anos de 1998, 2004 e 2017. Foi possível agrupá-los em duas áreas temáticas: caracterização dos métodos de trabalho dos enfermeiros e método de trabalho adotado pelos enfermeiros promotor da qualidade e segurança. No que concerne à caracterização dos métodos de trabalho dos enfermeiros, é possivel identificar seis métodos, divididos em duas tipologias: uma centrada na tarefa e as restantes direcionadas para o cliente. Relativamente ao método de trabalho centrado na tarefa, salienta-se o método funcional, em que os cuidados de enfermagem têm como base as teorias de Taylor, Fayol e de Weber, marcadas pela fragmentação do trabalho, pela separação da conceção e execução, pela hierarquia, e racionalização das estruturas administrati- vas, dando realce aos procedimentos e às rotinas. A compreensão da pessoa como um todo não existe. Apesar de este método ser o mais rápido na realização das tarefas, compromete a qualidade dos cuidados e a segurança da pessoa e dos cuidados. Já o método individual, o método por equipa, o método por enfermeiro responsável, o método por posto de trabalho e o método de gestão de caso direcionam-se para o cliente. Relativamente ao método individual, privilegia-se um cuidado global, durante um turno, a um conjunto de clientes, por um enfermeiro, com a responsabilidade da conceção e execução de cuidados de forma integral. Pela sua lơgica, julga-se ser um dos métodos mais utilizados nos contextos hospitalares. No caso do método por equipa, requer a concertação das capacidades individuais, tendo a orientação de um coordenador de equipa. Trata-se de um trabalho em colaboração e em função das competências dos enfermeiros da equipa, pelo que é fundamental que o enfermeiro gestor conheça as potencialidades e fragilidades de todos os elementos da equipa. O método por enfermeiro responsável decorre de uma parceria de cuidados entre o cliente e a família, que estão envolvidos ao longo de todo o processo de cuidados. É considerado o método que melhor responde à satisfação das necessidades dos clientes, durante a execução de cuidados, devido à relação terapêutica estabelecida entre o enfermeiro e o cliente, proporcionando autonomia na tomada de decisão. O método por posto de trabalho refere-se a uma distribuiçã̃o de cuidados por posto de trabalho, estando presente quando um enfermeiro é o responsável por um local ou posto de traba1ho. A respeito do método de gestão de caso, direciona-se para os momentos de diagnóstico, planeamento, facilitação, implementação, coordenação, monitorização e avaliação de opções, com participações técnicas individualizadas, respondendo às necessidades de clientes mais vulneráveis e com necessidades complexas/ crónicas de saúde 4 . Neste sentido, independentemente do método de trabalho adotado pelos enfermeiros, todos devem direcionar-se para a promoção da satisfação do cliente e a garantia da qualidade e segurança dos cuidados e das pessoas. Acerca do método de trabalho adotado pelos enfermeiros promotor da qualidade e segurança, esta é uma das premissas fundamental no exercício profissional dos enfermeiros. A Ordem dos Enfermeiros de Portugal, em 2001, através dos Padrões de Qualidade dos Cuidados de Enfermagem, alertou para a necessidade $d a$ 
utilização de métodos de trabalho capazes de serem um subsídio fundamental para a garantia da qualidade do exercício profissional ${ }^{2}$. No entanto, poderão existir fatores capazes de comprometer a adoção de um método de trabalho e, como tal, influenciar a qualidade e segurança da assistência em enfermagem. Existem varias dinâmicas e condições inerentes ao exercício profissional do enfermeiro, a exemplo, a carga de trabalho, a dotação de enfermeiros, por vezes, condicionam o método de trabalho adotado. Neste sentido, poder-se-á incorrer numa assistência de enfermagem centrada nas tarefas, com práticas fragmentadas e automatizadas, direcionadas para uma lógica dos serviços, compromentendo a satisfação das reais necessidades dos clientes. Desta forma, entendemos que um método de trabalho que garanta uma prestação de cuidados individualizados, personalizados e de qualidade é essencial. Assumimos como limitações a escassa produção científica desta temática, apesar de sua relevância. Contudo, os dados encontrados permitiram refletir sobre as implicações dos métodos de trabalho na qualidade e segurança dos cuidados e das pessoas, a necessidade nos hospitais da promoção de uma reflexão sobre a organização dos cuidados de enfermagem. A promoção de discussões, relativamente às dinâmicas organizacionais são fundamentais, no sentido de perceber as condições promotoras da adoção de um método de trabatho capaz de responder às exigências das pessoas e das instituições.

\section{Conclusão}

Atendendo à relevância da temática, o facto de apenas terem sido identificadas três referências, evidencia uma fragilidade na evidência dos métodos de trabalho adotados pelos enfermeiros portugueses no contexto hospitalar. Neste sentido, urge a necessidade de se repensar na forma como o enfermeiro mostra o seu método de trabalho à sociedade, o que pressupõe um conjunto de atividades intencionais e fundamentadas cientificamente, e que permitem a tomada de decisão face aos problemas das pessoas internadas no hospital. Neste sentido, reconhece-se a importância de estimular os enfermeiros a aumentar a produção de conhecimento científico neste domínio, de forma a reforçar as evidências de uma atuação congruente com os padrões de qualidade dos cuidados de enfermagem.

Descritores: Método; Trabalho; Gestão em Saúde; Enfermagem; Enfermeiros; Hospitais.

\section{Referências}

1. Feiten A, Coelho TR. Quality management in service organizations: barriers and sucess factors. R. Adm FACES Journal Belo Horizonte. [Internet]. 2019 July/Sept; 18(3):56-71. DOI: 10.21714/1984-975 FACES2019V18N3ART6619

2. Ordem dos Enfermeiros. Padrões de Qualidade dos Cuidados de Enfermagem: Enquadramento Conceptual e Enunciados Descritivos. Lisboa: Ordem dos Enfermeiros; 2001.

3. Shin B. Whole person and people-centred care. In: International Council of Nurses, editor. Nurses: A Voice to Lead Nursing the World to Health - International Nurses Day 2020 Resources and Evidence [Internet]. Genebra: International Council of Nurses; 202O; 7-8. Available from: https://2020.icnvoicetolead.com/wp-content/uploads/2020/03/IND_ Toolkit_120320.pdf

4. Nunes L. Desafios da tomada de decisão autónoma em enfermagem. In II Workshop Urgência geral e Cuidados intensivos [Internet]. Lisboa: Centro Hospitalar de Lisboa Central; 2016; 1-14. Available from: https://comum. rcaap.pt/bitstream/10400.26/18072/1/Desafios\%2oda\%2otomada\%2ode\%2odecisao\%2oautonoma\%2oem\%2oEnfermagem.pdf

5. Ribeiro OMPL, Martins MMFPS, Tronchin DMR, Silva JMAV, Forte ECN. Professional practice models used by nurses in Portuguese hospitals. Rev Bras Enferm. [Internet]. 2019; 72(Suppl 1):24-31. DOI: 10.1590/0034-7167-2017-0670 
POLÍTICAS DE SAÚDE PRISIONAL: AVANÇOS E DESAFIOS

\section{Reges Antonio Deon Suzanne Cristina Abido Jane Tavares Gomes Letícia de Lima Trindade}

\section{Introdução}

As políticas públicas são ações, programas ou determinações desenvolvidas pelos governos, nos diferentes níveis, em resposta a um problema público em diversas áreas. Afetam a todos os cidadãos, de todas as escolaridades, independente de sexo, raça, religião ou nível social. Com a expansão da democracia há uma diversificação das responsabilidades dos representantes populares, por esse motivo é comum dizer que a função principal das políticas é a promoção do bem-estar da sociedade. $\mathrm{Na}$ área da saúde, atuam em resposta a uma demanda da população; implementando e executando entre outros aspectos, ações e serviços. A concepção do sistema de saúde, descentralizado e administrado democraticamente e com a participação da sociedade organizada, estabelece mudanças nas relações de poder político e na distribuição de responsabilidades entre o Estado e a sociedade, e entre os distintos níveis de governo cabendo aos gestores o papel fundamental na concretização dos princípios e diretrizes das políticas públicas. Neste sentido, a Política Nacional de Atenção Integral à Saúde das Pessoas Privadas de Liberdade no Sistema Prisional (PNAISP), instituída pelo Ministério da Saúde (MS) em 2014, tem como objetivo aproximar a população penitenciária ao Sistema Único de Saúde (SUS). Um dos princípios da política é a integralidade, o qual reforça o direito universal à saúde, ao reconhecer as 
situações de iniquidades e os determinantes sociais da saúde, que afetam as pessoas privadas de liberdade (PPL) ${ }^{2}$

\section{Objetivo}

Apresentar e refletir sobre os principais marcos da PNAISP e sua operacionalização como instrumento de direito social.

\section{Método}

Trata-se de estudo analítico-descritivo, elaborado a partir da análise de instrumentos legais que asseguram o direito à saúde das PPL.

\section{Resultados e Discussão}

De acordo com o Conselho Nacional de Justiça, há um aumento populacional nos cárceres nos últimos dez anos, as questões de desigualdade social vêm potencializando as tensões sobre os responsáveis na elaboração de políticas sociais que visem melhorar as condições de vida das PPL. No contexto de saúde, existem três marcos fundamentais das políticas sociais de saúde voltadas à população prisional: a Lei de Execução Penal de 1984, o Plano Nacional de Saúde no Sistema Penitenciário (PNSSP) de 2003 e PNAISP ${ }^{3}$. A PNAISP apresenta a conformação das equipes, o financiamento destas e a organização dos serviços. Classifica as equipes em três faixas a partir do número de apenados, correlacionando a cada faixa a carga horária e a composição da equipe. As equipes de Atencão Primária Prisional (eAPP) têm a função de realizar ações de saúde nas instituições prisionais e fazem parte da atenção básíca, com a obrigatoriedade de utilizar os sistemas de informação, de acesso à educação permanente e acesso regulado à Rede de Átenção. Assim, torna cada unidade prisional uma porta de entrada e um ponto de atenção da rede e coloca a gestão técnica plenamente no âmbito do SUS no território ${ }^{4}$. Sob a análise da política de saúde em questão, a gestão prisional no país é carente de conceitos que amparem a sua especificidade, prevalecendo ainda o empréstimo de saberes de outras áreas, sobretudo do conhecimento importado da atividade policial. Há uma fragmentação e distanciamento que historicamente marca a gestão das políticas prisionais em relação às demais pofíticas públicas e sociais, tendendo-se a compreender e operacionalizar a gestão prisional exclusivamente a partir dos princípios legais e criminológicos que marcam o campo. A operacionalização da Política, tem por desafio conceber e implantar modos estratégicos que privilegiem o desenvolvimento das PPL, buscando, em um conjunto mais amplo de ações, romper com o processo crescente de encarceramento e com os ciclos individuais e coletivos de prisão - soltura - reaprisionamento. Compreende-se que o enfrentamento ao hiperencarceramento no Brasil não pode obnubilar outros processos que contribuem para o acirramento das condições insalubres e desumanas que compõem o cenário prisional. Compreende-se também que o desenvolvimento de estratégias para uma boa gestão das políticas penitenciárias, como base num modelo que privilegie a promoção de direitos aos sujeitos em privação de liberdade, é tarefa urgente para uma nação que busca o desenvolvimento pleno de sua população. Neste sentido, há necessidade de efetivar a intersetorialidade, envolvendo os cenários de desenvolvimento social, educação, trabalho, justiça e segurança pública, efetivando assim o papel social de ressocialização dos indivíduos e, consequentemente fortalecendo um processo capaz de romper ciclos de desigualdade, exclusão e miséria intra e extra muros. Ainda sob o ponto de vista operacional da PNAISP, o cotidiano prisional deve privilegiar uma abordagem multidimensional das rotinas, fluxos e procedimentos, com vistas a garantir às pessoas em privação de liberdade a efetivação dos direitos fundamentais, o acesso a um conjunto de políticas públicas e sociais, o direito à vida e à dignidade. Esta gestão deve, ain$\mathrm{da}$, assegurar que os aspectos de vigilância e contenção estejam articulados à garantia dos direitos, potencialmente à saúde, produzindo ambientes seguros para todos os sujeitosPPL, visitantes e servidores - que interagem no interior dos estabelecimentos prisionais. Outra questão, refere-se há necessidade de formação e capacitação de trabalhadores e profissionais capazes de compreender as particularidades da população e do ambiente de trabalho para efetivação da Política.

\section{Considerações finais}

A garantia de direitos e serviços, a esta população, ocorre por meio de políticas intersetoriais. O Brasil tem avançado significativamente na normatização destas e de programas voltados à garantia de direitos para as PPL e neste rol, a PNAISP vem mostrando que é possível estabelecer parâmetros para a abertura dos sistemas prisionais às políticas públicas e sociais, diversificando os atores 
que interagem com estes sistemas e ampliando a oferta de serviços. A nível local, o conhecimento desta Política sob seus aspectos organizacionais e operacionais, é ferramenta para que gestores e trabalhadores possam estabelecer fluxos e rotinas, a fim de melhor operacionalizar, principalmente, o acesso aos demais níveis de atenção, quando necessário. As particularidades dessa assistência ainda precisam ser melhores pactuadas entre os setores que a compõem, e isso exige diálogo e construção continua. É constante e necessária esta comunicação com o gestor municipal com o intuito de adequar ainda mais a gestão da política. Esta não tem sido apenas uma ação individual, mas de todos os profissionais de saúde e demais atores que trabalham diretamente com pessoas privadas de liberdade.

Descritores: Políticas Públicas de Saúde; Prisões; População privada de liberdade; Atenção Primária à Saúde.

\section{Referências}

1. Secchi L. Análise de políticas públicas: diagnóstico de problemas, recomendação de soluções. São Paulo, Cengage Learning, $2^{\underline{a}}$ ed., 2017.

2. Miranda AE, Rangel C, Costa-Moura R. Questões sobre a população prisional no Brasil: saúde, justiça e direitos humanos. Universidade Federal do Espírito Santo, Pró-reitoria de extensão, Vitória, 1 ed., 2018; 3. Disponível em: https://proex.ufes.br/sites/proex.ufes.br/files/ field/anexo/questoes_3_completo.pdf

3. Lermen HS et al. Saúde no cárcere: análise das políticas sociais de saúde voltadas à população prisional brasileira. Physis: Revista de Saúde Coletiva, 2015; 25(3):905-24. Disponível em: https://www.scielo.br/scielo. php?pid $=$ So10 $3=73312015000300905-\&$ script sci_abstract\&tlng=pt

4. Brasil. Ministério da Saúde. Portaria Interministerial n. 1, de 2 de janeiro de 2014. Institui a Política Nacional de Atenção Integral à Saúde das Pessoas Privadas de Liberdade no Sistema Prisional (PNAISP) no âmbito do Sistema Único de Saúde (SUS). Diário Oficial da União, Brasília, DF, 3 de jan. 2014. Disponível em: http://bvsms.saude.gov.br/bvs/saudelegis/ $\mathrm{gm} / 2014 /$ prt0482_01_04_2014.html 
RELATO DE EXPERIÊNCIA

PROCESSO DE TRABALHO DOS AGENTES COMUNITÁRIOS DE SAÚDE EM TEMPOS DE PANDEMIA POR COVID-19

\section{Suellen Fincatto}

Danielle Bezerra Cabral

Arnildo Korb

\section{Introdução}

O Programa de Agentes Comunitários de Saúde (PACS) e o Programa de Saúde da Família, atualmente chamado de Estratégia Saúde da Família (ESF), foram desenvolvidos tendo como base os princípios que regem o Sistema Único de Saude (SUS): a universalidade, a integralidade, a equidade, a descentralização, a regionalização e a participação social. O PACS teve objetivo apoiar ações integrais e resolutivas na Atenção Primária à Saúde (APS), vinculadas à comunidade ${ }^{1}$. Deste modo, passou-se a enfocar as estratégias não somente no indivíduo, mas em seu âmbito familiar e social, proporcionando uma compreensão ampliada do processo saúde/doença ${ }^{2}$. Dentro deste contexto, o Agente Comunitário de Saúde (ACS), desempenha um papel fundamental na equipe de atenção primária, no que se refere à relação de trocas de experiências estabelecidas, especialmente entre os saberes populares de saúde e os conhecimentos técnicos científicos, o que torna o ACS o elo entre a comunidade e os serviços de saúde, proporcionando com isso o fortalecimento do vínculo com a família, a aproximação das ações de saúde ao contexto domiciliar, a orientação comunitária, o cadastro de todas as pessoas de sua área, mantendo os dados atualizados no sistema de informação vigente, a utilização de instrumentos para a coleta de informações que apoiem no diagnóstico demográfico e sociocultural 
da comunidade, o auxílio para informar os usuários sobre as datas e horários de consultas e exames agendados, entre outras atribuições dispostas através do Política Nacional da Atenção Básica, portaria 2.436 de $2017^{3}$. Diante da pandemia pelo novo Coronavírus (SARS-CoV-2), as equipes de saúde da APS, principalmente os ACS tiveram que adequar o processo de trabalho, em consequência das restrições logísticas e espaço-temporais, afim de evitar a propagação da doença. Tais mudanças provocam o comprometimento das ações nos diferentes territórios de abrangência das equipes da ESF, o vínculo presencial com os usuários/comunidade, especialmente, no contexto das visitas domiciliares, assim como exigiu mudanças nos fluxos assistenciais e na interrelação entre os membros da equipe, dificultando, inclusive, a realização de reuniões presenciais para o planejamento das atividades da equipe 4 . Diante do exposto o presente estudo busca descrever a reconfiguração acerca das estratégias adotadas pela gestão, para adequar o processo de trabalho desenvolvido pelos ACS, em tempos de enfrentamento da pandemia da COVID-19.

\section{Método}

Trata-se de um estudo descritivo, do tipo relato de experiência, que compreendeu, como cenário de pesquisa, a Unidade Básica de Saúde do município de Riqueza SC. O município é composto por duas ESF, equipe multiprofissional composta por quatro médicos, três enfermeiras, três técnicas de enfermagem, dois dentistas, dois técnicos em saúde bucal e 13 ACS. A descrição das atividades desenvolvidas pelos ACS compreendeu de março a dezembro de dezembro de $20 z \mathrm{O}$.

\section{Resultados e Discussão}

Com o advento da pandemia por Coronavírus, toda equipe multiprofissional que compõem a APS, teve que readequar sua organização de trabalho, afım de garantir a promoção, proteção e recuperação de saúde da população de maneira integral e continuada. O ACS tem papel fundamental, neste cenário, devido sua competência cultural e orientação comunitária, que não podem ser excluídos do cotidiano dos serviços, pois a partir deles é possível reconhecer a demandas da população, e auxiliar na educação em saúde 4 . Na ESF do município de Riqueza, ao repensar a gestão do processo de trabalho, com os eventos de emergência em saúde pú- blica, foram desenvolvidas novas estratégias e metodologias de trabalho, para a atuação dos ACS. Inicialmente foi realizado um treinamento pela enfermeira sobre a infecção pelo Coronavírus, explicando a doença, modo de transmissão, sinais e sintomas, medidas de prevenção. Nesta oportunidade também foi ofertando os ACS equipamentos de proteção individual (máscaras, álcool em gel 70\%) e orientado a maneira correta de se proteger e educar a população para o mesmo. Destaca-se a importância em garantir condições dignas de trabalho, capacitação e educação permanente ao ACS, para o aperfeiçoamento do trabalho ${ }^{4}$. As visitas domiciliares passaram por adequações, conforme a nota técnica $003 / 2020^{5}$ da Secretaria de Saúde de Santa Catarina (SC), com isso, os ACS priorizaram as visitas domiciliares em situações de maior risco de vulnerabilidade clínica e social, não realizando as atividades dentro domicílio, deixando a visita domiciliar limitada apenas na área peridomiciliar (frente, lados e fundo do quintal ou terreno), mantendo o distanciamento de dois metros do paciente, utilizando máscara e fazendo higiene das mãos com álcool em gel. Como cada ACS conhece seu território, e tem o cadastramento de suas famílias, optou-se por estratégias de comunicação remota ou virtual, para auxiliar na divulgação de informações, e acompanhamento das pessoas. Com a tecnologia virtual, através da utilização do aplicativo whatsApp, cada ACS pode se comunicar com suas famílias, tirando dúvidas, auxiliando a equipe na busca ativa e no monitoramento de casos suspeitos e confirmados, divulgando os dados da situação atual, além de pode enviar informações de saúde. Os ACS também participaram das confecções de máscaras de tecido, auxiliando a comunidade, sendo que posteriormente, cada ACS entregou uma máscara para cada munícipe, orientando como utiliza-la, fazer sua lavagem e troca. O grande desafio tem sido garantir que os cuidados contínuos aos usuários não sejam interrompidos e que os pacientes do território não sejam desassistidos principalmente os pacientes com comorbidades e grupos de risco (idosos, hipertensos, diabéticos, gestantes, crianças, pacientes oncológicos, entre outros).

\section{Conclusão}

Percebe-se que a pandemia por Coronavírus, demandou reestruturação dos sistemas de saúde e reorganização do processo de trabalho e dos fluxos assistenciais, porém essa 
reorganização da APS não pode acontecer, sem dar continuidade para os demais cuidados já existentes no território. Diante do treinamento realizado para orientar os ACS, bem como a busca de novas estratégias, ferramentas e tecnologias para garantir que o trabalho pudesse ser desenvolvido, proporcionou a continuidade da assistência prestada mantendo contato com as famílias. Além disso foi possivel identificar síndrome gripal, para um manejo mais rápido, bem como sanar dúvidas em menor tempo, garantindo o monitoramento dos ACS, maior confiança e adesão das famílias ao isolamento social, e a uma menor taxa de internação por agravamento desta doença. Espera-se que, a longo prazo, essa nova reorganização do processo de trabalho, bem como com a utilização de tecnologias em saúde, proporcionem uma melhora na eficiência e a efetividade do trabalho do ACS e favoreça a longitudinalidade e a acessibilidade aos cuidados prestados pela APS.

Descritores: Agentes Comunitários de Saúde; Fluxo de Trabalho; Gestão em Saúde; Infecções por Coronavírus; Pandemia.

\section{Referências}

1. Simas PRP, Pinto ICM. Trabalho em saúde: retrato dos agentes comunitários de saúde da região Nordeste do Brasil. Ciênc. saúde coletiva. 2017; 22 (6):1865-1876. Disponível em: https://www.scielo.br/pdf/ csc/v22n 6/1413-8123-csc-22-06-1865.pdf

2. Alonso CMC,Béguin PD, Duarte FJCM. Trabalho dos agentes comunitários de saúde na Estratégia Saúde da Família: metassíntese. Rev. Saúde Pública [Internet]. 2018; 52: 14. Disponível em: https://www.scielo.br/pdf/rsp/v52/pt o034-8910-rsp-S1518-87872018052000395.pdf

3.Brasil. Ministério da Saúde. Portaria 2.436 de 21 de setembro de 2017. Aprova a Política Nacional de Atenção Básica, estabelecendo a revisão de diretrizes para a organização da Atenção Básica, no âmbito do Sistema Único de Saúde (SUS). Disponível em: http://www.saude.df.gov.br/wp-conteudo/uploads/2018/04/Portaria-n\%C2\%BA-2436-2017-Minist\%C3\%Agrio-da-Sa\%C3\%BAde-Aprova-a-Pol\%C3\%ADtica-Nacional-de-Aten ${ }_{2} \mathrm{C}_{3} \% \mathrm{~A}_{7} \% \mathrm{C}_{3} \% \mathrm{~A}_{30}-\mathrm{B} \% \mathrm{C}_{3} \% \mathrm{~A}_{1}$ sica..pdf

4. Maciel FBM, Santos HLPC, Carneiro RAS, Souza EA, Prado NMBL, Teixeira CFS.
Agente comunitário de saúde: reflexões sobre o processo de trabalho em saúde em tempos de pandemia de Covid-19. Ciênc. saúde coletiva [Internet]. 2020; 25 (Suppl 2):41854195. Disponível em: https://www.scielo.br/ $\mathrm{pdf} / \mathrm{csc} / \mathrm{v2} 5 \mathrm{~s} 2 / 1413-8123-\mathrm{csc}-25-\mathrm{s} 2-4185 \cdot \mathrm{pdf}$

5. Brasil. Estado de Santa Catarina, Secretaria de Estado da Saúde. Superitendência de Planejamento em Saúde. Diretoria de Atenção primária à Saúde. Nota Técnica no 003/2020 - DAPS/SPS/SES/SC. Recomendações sobre o trabalho dos agentes comunitários de saúde (ACS) na atenção primária à saúde para o enfrentamento da pandemia de COVID-19. Disponível em: https://www. saude.sc.gov.br/coronavirus/arquivos/Nota-Tecnica-003-2020-DAPS-SPS-SES-SC.pdf 
RELATO DE EXPERIÊNCIA

\section{ESTRATÉGIA SAÚDE DA FAMÍLIA COMO CENÁRIO DE MELHORES PRÁTICAS DE ENFERMAGEM EM TEMPOS DE COVID-19}

\section{Mônica Ludwig Weber Carine Vendruscolo \\ Edlamar Kátia Adamy \\ Maristela Izcak Baldissera \\ Adriane Karal}

\section{Introdução}

A Estratégia Saúde da Família (ESF), prioritária para a expansão, consolidação e qualificação da Atenção Básica $(\mathrm{AB})$ no ẩmbito do Sistema Único de Saúde (SUS), fortalece a reorientação do processo de trabalho com potencial de ampliação e resolutividade, tendo em vista que prioriza as ações de prevenção, promoção e recuperação da saúde do indivíduo e da coletividade ${ }^{1}$. Dentre seus atributos, destaca-se o acesso de primeiro contato, a longitudinalidade e a coordenação do cuidado. A operacionalização da ESF ocorre pelas equipes de Saúde da Família (eSF), compostas por um médico, um enfermeiro, um auxiliar ou técnico de enfermagem e pelo menos quatro agentes comunitários de saude, além de profissionais de saúde bucal ${ }^{2}$. Nesse contexto, o enfermeiro assume papel estratégico como articulador e coordenador da equipe, atuando nas dimensões do cuidado, da gestão e da educação, para enfrentar os desafios do cotidiano profissional. Para isso, pode apoiar-se em uma atuação baseada nas Melhores Práticas de Enfermagem, conceito que envolve: os melhores resultados de pesquisas científicas, a perícia clínica do profissional e o reconhecimento das necessidades de cada indivíduo. Nessa perspectiva, uma boa prática visa melhorias na assistência prestada, nos diferentes cenários, sendo que, para tal, o enfermeiro deve pautar sua conduta nas melhores evidências disponíveis para o manejo clínico3. Em tempos de Coronavírus Disease 
2019 (COVID-19), a atuação dos profissionais de enfermagem ganha destaque, pois operam nos diferentes servicos da rede assistencial, na prestação de cuidados contínuos às vítimas e, historicamente buscam a prevenção, em meio a situações semelhantes. As lacunas estruturais e de pessoal para atender os casos suspeitos e confirmados de COVID-19 em todo país são muitas, sobretudo, dificuldades em garantir a segurança dos profissionais para a prestação de assistência adequada, seja pela sobrecarga de trabalho ou pela insuficiência de Equipamentos de Proteção Individual (EPI).

\section{Objetivo}

Descrever a vivência como enfermeira de uma eSF, na perspectiva das melhores práticas em tempos da COVID-19.

\section{Método}

Estudo qualitativo, descritivo, do tipo relato de experiência, realizado em uma Unidade Básica de Saúde (UBS) do município de Águas de Chapecó/SC. Após longa experiência na assistência em nível hospitalar, as atividades como enfermeira na $A B$ tiveram início no mês de outubro de 2020. A UBS localizada no interior, com população de 541 famílias, conta com uma eSF composta pelos seguintes profissionais: uma médica, uma enfermeira, um técnico em enfermagem, uma dentista, uma auxiliar de consultório odontológico, duas auxiliares de serviços gerais, uma farmacêutica e cinco Agentes Comunitários de Saúde (ACS). Atualmente, por conta da pandemia causada pela COVID-19, as atividades realizadas pela equipe encontram-se restritas ao atendimento de demanda espontânea e Visita Domiciliar (VD) $1 \mathrm{x} /$ semana, não sendo realizadas atividades coletivas. As ações serão discutidas à luz do conceito de melhores práticas em enfermagem.

\section{Resultados e Discussão}

Estudo $^{2}$ demonstra que a consolidação da ESF tem sido associada à melhoria da qualidade de vida da população, que se evidencia pela redução dos coeficientes de mortalidade infantil e de mortalidade materna, diminuição das taxas de doenças imunopreveníveis e de internações por condições evitáveis, uma vez que o aumento da cobertura da ESF também tem potencial de inferir nos determinantes sociais da saúde, tais como aspectos socioeconômicos, culturais, ambientais e comportamentais, que influenciam a ocorrência de problemas de saú- de $^{2}$. Em tempos de pandemia, a eSF precisou adaptar suas atividades, suspendendo a realização de grupos como hipertensos, diabéticos, gestantes e atividades educativas na escola, e restringir o atendimento individual para situações de urgência e emergência. No mês de setembro, aos poucos, foi retomando o atendimento em livre demanda, bem como as VD. Ainda, com assistência restrita, o acolhimento e a escuta qualificada se potencializaram, tendo em vista que as queixas de ordem psicológica tiveram um aumento significativo, e a comunicação e discussão de casos na equipe, enquanto tecnologia leve, cresceu. Em meio à esse cenário pandếmico, a enfermagem teve a oportunidade de demonstrar sua importância, como agente produtor de saúde, sobretudo na AB. A atuação dos profissionais na linha de frente, sem uma estratégia de enfrentamento sólida, defendida uniformemente pelas autoridades do país, aliada a pouca disponibilidade de EPI e de políticas de proteção dos trabalhadores da área da saúde, chamou a atenção de entidades de classe e mesmo de outras profissões. Entre as principais medidas de prevenção da COVID-19 e que também se caracterizam como desafios para o trabalho dos profissionais está a conscientização sobre a higienização e lavagem de mãos, uso correto de máscaras e as recomendações de distanciamento social, principalmente, a orientação para que as pessoas permaneçam em casa, na medida do possível. Para orientar tais condutas, a enfermagem pauta-se em práticas que, embora reconhecidas na profissão desde as primeiras epidemias por ela enfrentadas, na atualidade, são ancoradas em evidências científicas e na experiência das enfermeiras 3 . O conceito de melhores práticas em enfermagem, no Brasil, tem sido foco de muitos espaços de discussão da profissão, pois são aquelas reconhecidas por ancorarem-se em um método, possível pela experiência e investigação, que conta com total confiabilidade para conduzir a um determinado resultado, sem a utilização desmedida de recursos para atingir os resultados desejados e que pode ser adaptada a problemas de saúde semelhantes em outros contextos 5 . $\mathrm{Na} A B$, uma das prioridades é avaliar o indivíduo em sua integralidade, atentando ao cenário no qual o mesmo encontra-se inserido e acompanhando seu percurso pela Rede de Atenção à Saúde. No contexto discutido neste texto, uma das práticas de trabalho da equipe, são os encontros mensais com ACS, momentos nos quais trazem demandas das famílias e/ou do território e é nas quais ocorre troca de informações e aprendizado coletivo entre a equipe. Nesses 
encontros, são planejadas as VD do mês, atualizado o mapa do território, sendo o feedback positivo dos profissionais e da população acerca dessa ação. A enfermeira da eSF desempenha papel fundamental nessa atividade, pois reconhece o perfil da população atendida e fundamenta suas condutas nesse reconhecimento, o que durante a pandemia se intensificou. A escuta, o acolhimento e a educação em saúde individualizada se destacaram. Cumpre destacar que para a ocorrência dessas atividades é necessário empenho e dedicação dos integrantes da equipe, perfil e formação profissional para atuar na $\mathrm{AB}$, apoio do gestor e conscientização da população sobre a importância de se trabalhar com prevenção e promoção da saúde. A interação entre gestores, profissionais da saúde e usuários nos processos assistenciais, orienta as ações, melhorando a prática. Observa-se dificuldade da própria equipe em realizar o trabalho de modo coletivo, pois isso requer colaboração, diálogo e tempo, prerrogativas fundamentais no trabalho interprofissional. Outro empecilho é o frequente rodízio de profissionais, que dificulta o entrosamento e a adaptação, bem como prejudica a criação do vínculo usuário-equipe. Nessa direção, a Educação Permanente em Saúde (EPS) constitui-se em ferramenta potencializadora das melhores práticas, trazendo para a equipe os conteúdos técnicos necessários, ajudando a desenvolver também as competências dialógicas, éticas, de comunicação, de escuta, de planejamento e de avaliaçã̃o ${ }^{4}$. Desenvolver tais competências fomenta e promove mudanças positivas na prática profissional.

\section{Conclusão}

A enfermagem brasileira desenvolveu sobremaneira suas competências e habilidades nas últimas décadas, em especial com o advento da pandemia, pois houve um importante movimento e esforço das instâncias relacionadas à profissão para garantir a valorização da profissão e acima de tudo, reforçar o potencial de sua contribuição para o fortalecimento da $\mathrm{AB}$ e do SUS. A atuação dos profissionais na $A B$ exige cada vez mais preparo e formação específica devido à complexidade do contexto e o caráter ordenador da RAS. Além do conhecimento técnico-científico, o domínio de instrumentos de cuidado, informação e gestão; a atualização e participação em movimentos de educação permanente constituem requisitos primordiais para o desenvolvimento de um cuidado de enfermagem de qualidade e fundamentado nas melhores práticas.
Descritores: Enfermagem; Estratégia Saúde da Família; Atenção Primária à Saúde; Atitudes e Práticas em Saúde.

\section{Referências}

1. Brasil. Ministério da Saúde. Portaria no 2.436, de 21 de setembro de 2017. Aprova a Política Nacional de Atenção Básica, estabelecendo a revisão de diretrizes parara a organização da Atenção Básica, no âmbito do Sistema Único de Saúde (SUS). Diário Oficial [da] República Federativa do Brasil, Brasília, DF, 22 set. 2017.

2. Malta DC, Santos MAS, Stopa SR, Vieira JEB, Melo EA, Reis AAC. A Cobertura da Estratégia de Saúde da Família (ESF) no Brasil, segundo a Pesquisa Nacional de Saúde, 2013. Cien Saude Colet 2016; 21(2):327-338.

3. Toso BRGO, Padilha MI, Breda KL. The euphemism of good practice or advanced nursing practice. Esc Anna Nery 2019; 23(3):e20180385.

4. Dolny LL, Derda Lace JT, Nilson LG, Calvo MCM, Natal S, Maeyama MA. Educação permanente em saúde (EPS) no processo de trabalho de equipes de saúde da família (ESF). Brazilian Journal of Health Review, 2020; 3(1):15-38.

5. University Of Iowa. College of Nursing [internet]. Iowa. University of Iowa. Csomay Center - Beste Practices for healthcare e profissionals: 2014 . 
RELATO DE EXPERIÊNCIA

\section{A COMUNICAÇÃO COMO FERRAMENTA DE GESTÃO FRENTE À COVID-19 NA REGIÃO SUL DE SÃO PAULO}

\author{
Paulo Fernando Capucci \\ Felipe Gargantini Cardarelli \\ Débora A. Mozar
}

\section{Introdução}

A OSS Associação Saúde da Família (ASF), responsável por cinco contratos de gestão no município de São Paulo, dentre eles os de Capela do Socorro e Parelheiros que, desde o primeiro caso de COVID-19 no Brasil, passou a organizar a equipe de gestão regional para chegada dos primeiros casos nessas periferias. Com o contexto de significativa disparidade social, grande extensão territorial e alta porcentagem de usuários SUS dependentes, os Contratos de Gestão oo1 (Capela do Socorro) e 002 (Parelheiros) tem 4.245 funcionários distribuídos em 68 serviços de saúde de diferentes complexidades. São os distritos de maior extensão territorial de São Paulo. Concomitantemente foram distribuídos 174 smartphones à cada equipe de atenção básica e 1167 tablets distribuídos para os Agentes Comunitários de Saúde (ACS) com chips e acesso à internet. Tendo em vista os portes da rede de serviços e do desafio imposto pela pandemia construímos o Plano de Comunicação Estratégica e Educação Permanente (EP). Comunicação Estratégica é uma forma de ação social que se caracteriza por se produzir em uma situação estratégica na qual os envolvidos fazem uso da interação simbólica para resolver problemas e maximizar oportunidades. A Política Nacional de Educação Permanente em Saúde estabelece a Educação Permanente deve se configurar como aprendizagem no trabalho, onde o aprender e o ensinar se 
incorporam ao cotidiano das organizações e ao trabalho. Segundo Cateells, no âmbito da Sociedade em Rede, o papel da comunicação na gestão organizacional já vinha ganhando importância. O Objetivo deste estudo é explorar a execução do Plano de Comunicação Estratégica e Educação Permanente frente a pandemia através de seus objetivos, estrutura, produtos, principais ações e resultados.

\section{Método}

Trata-se de um relato de experiência, utilizando os dados disponíveis nas plataformas de compartilhamento de vídeos e de áudio e dados epidemiológicos para inferir resultados do Plano de Comunicação Estratégica e Educação Permanente da Ảssociação Saúde da Família Sul.

\section{Resultados e Discussão}

Com o distanciamento social a ênfase nas ferramentas tecnológicas associadas à comunicação em rede tornou-se indispensável. A gestão utilizou o momento oportuno mobilizando as melhores formas de se comunicar para qualificar processos de trabalho. Entretanto, Bourdieu postula que toda comunicação acontece em um meio, estrutura ou ainda campo social carregado de diferentes culturas, narrativas e saberes que tecem linhas de forças em constante disputa. Portanto, qualquer projeto de comunicação na Saúde deve desenvolver estratégias de negociação, tendo claro seus objetivos: Criar maior sinergia entre a Gestão da ASF Sul e seus profissionais das Redes de Atenção à Saúde (RAS) Capela do Socorro e Parelheiros ao estruturar canais e produzir conteúdo de comunicação; Favorecer o engajamento dos profissionais das RAS nos processos de gestão em curso no território e nos princípios e valores institucionais, ao afetar positivamente trabalhadores através da produção de conteúdo com abordagem acessível, oportuna e convidativa; Dar visibilidade às práticas, demandas, inovações e desafios das RAS sempre com a perspectiva do acesso, cuidado e território; e Potencializar processos de EP de modo a promover as melhores práticas em saúde. Buscando formas de comunicação mais interativas, desenvolveu-se conteúdos audiovisuais voltados para a qualificação profissional, tendo como protagonista os próprios trabalhadores. Estes foram convidados, de acordo com o domínio que têm sobre o tema a ser abordado, a compartilhar seus conhecimentos com os demais. Outros conteúdos são produzidos pela pelos próprios funcionários, que buscam compartilhar suas práticas, e enviados à sede da ASF Sul para edição ou somente para divulgação. Imbuídos desses objetivos, com a base desta metodologia e cientes da necessidade de atualizações diárias que precisavam chegar ao conhecimento de todos os profissionais desta rede extensa de serviços, utilizamos os celulares institucionais e tablets para a comunicação, que se baseou na seguinte estruturação: Boletim informativo: Foi montado grupo online de comunicação específica da pandemia intitulado "Plano Coronavírus" composto pela equipe de gestão, gerentes, enfermeiro e médico responsável técnico de cada unidade que recebiam conteúdos diariamente. O Boletim, disparado neste grupo, pode ser descrito como uma imagem interativa com os tópicos de maior relevância do dia e links de acesso para maiores detalhes do conteúdo em questão, que poderia seriam ser novos protocolos, pactos de fluxo da rede, vídeos de humanização de enfrentamento à pandemia e ações de EP; Transmissão ao Vivo: Para costura de informações e manter aquecida a rede de saúde também instituímos a realização de Transmissões ao vivo pautada pela equipe de gestão e apresentada pelo Coordenador ASF Sul. A interação com os profissionais da rede foi possível por meio de dispositivo de trocas de mensagem; Plataforma \#coronavírusrede: plataforma virtual que possibilita que diferentes aplicativos possam ser usados ao mesmo tempo por internautas, desde que façam login com e-mail institucional, que passou a centralizar de forma organizada e facilitada os conteúdos produzidos, como os documentos revisados pela Mesa Técnica; Mesa Técnica: formada por médicos e enfermeiros disponíveis para atender à rede por telefone e e-mail com a proposta de prover suporte clínico. Também responsáveis pela validação dos documentos técnicos ofertados à rede e identificar necessidades que desdobravam ações de EP; e Sala de Situação: formada por assessores técnicos que monitoram indicadores de saúde, ofertam análises à rede de serviços e acionam diferentes setores frente a isso. Todas estas estratégias foram integradas por construções de EP, cunhada na ideia de que qualificação profissional não se trata de uma lista de treinamentos e capacitações. Trata-se de construir, a partir das necessidades territoriais de qualificação, pautadas por indicadores de qualidade e de produção, bem como análise de necessidades identificadas pelas equipes de saúde. Na pandemia, mudamos a modelagem mas seguimos na mesma lógica conceitual. Investimos e disponibiliza- 
mos mais vídeo aulas, tutoriais e debates em áudio (podcast), com os profissionais da rede de serviços como protagonistas. As acões mais relevantes desenvolvidas foram: habilitar profissionais da $\mathrm{AB}$ com manejos de urgência em parceria com a Universidade Santo Amaro; Capacitação dos profissionais para realização de teste rápido por vídeo transmissão; Vídeo aula sobre coleta de PCR SWAB (https:// youtu.be/mAUlg8vPh1Rk); Visibilidade às melhores práticas da rede (https://youtu.be/ 7Vf_LNSIEsE); Trabalho da unidade indígena de acolhimento (https://youtu.be/nCwWHZHTABI); Vídeo aula sobre teleatendimento (https://youtu.be/_izP 4 ye1dZc); Ações virtuais de educação em saúde (direcionadas aos usuários da rede de serviço), abordando assuntos como o uso de máscaras, higiene (https:// youtu.be/oza-r8nFlNI) e orientações para pacientes que tiveram alta de internação por COVID-19 (https://youtu.be/95kzsHCGmyU, https://youtu.be/StKsgw8uO5g, https://youtu.be/86ywg-kXdL4). Com o formato adaptado e o fato das temáticas serem diretamente relacionadas com a prática cotidiana vivida, os treinamentos atingiram outra escala: de maior impacto e proveito das equipes envolvidas. Investir em ferramentas informatizadas de comunicação, como estratégia de alinhamento e potencialização do trabalho dos serviços de saúde foi decisivo. Da perspectiva da EP que compartilha dos processos de gestão, as trocas e metodologias de comunicação utilizadas vieram para ficar e trouxeram aprendizados já incorporados pela equipe de gestão regional. No primeiro treinamento tivemos $90 \%$ de presença dos profissionais e devolutiva positiva sobre aumento da segurança técnica para manejo de urgência. Não tivemos registro de mortes em casos de agravos do quadro na Atenção Básica. Já no segundo treinamento, tivemos $100 \%$ de presença, avaliação de que o formato foi mais focado e gerencialmente o relato de que foi possível se aproximar o manejo técnico do enfermeiro para realizar a coleta do teste rápido e menor taxa de dúvidas referente ao procedimento de realização do teste rápido para COVID-19. Já sobre os demais conteúdos, as informações eram processadas, compatibilizadas e organizadas, enviadas em Boletins de acordo com a necessidade. Processo incorporado à rotina de trabalho, segue presente e relevante para alinhamento das meIhores práticas em saúde. Durante a fase crítica da pandemia, foram: 37 transmissões ao vivo, com 18.493 espectadores; 103 vídeos com 24.036 visualizações; 77 podcasts com 4.048 ouvintes; 103 edições do boletim; 27 Documentos
Técnicos elaborados; 14 mil usuários suspeitos de terem contraído COVID-19. Acreditamos que toda construção descrita nos fez alcançar o resultado mais relevante: o de menor mortalidade nas áreas de maior contaminação da cidade, segundo o Observatório das Metrópoles.

\section{Conclusão}

Os principais resultados deste processo indicaram que investir na comunicação também como ferramenta de Educação Permanente, favoreceu o alinhamento de orientações, protocolos, manejo clínico, esclarecimento de dúvidas, proporcionando à rede potências e possibilidades de qualificar o cuidado das pessoas. Concluímos que a importância da forma de se comunicar é tão importante quanto o conteúdo que se comunica.

Descritores: Gestão da Tecnologia de Informação e Comunicação; Ferramentas e Metodologias baseadas em Tecnologias Inovadoras de Informação e Comunicação; Comunicação Educativa; Gestão de Serviços de Saúde; Educação Permanente.

\section{Referências}

1. Brasil. Ministério da Saúde. Secretaria de Gestão do Trabalho e da Educação na Saúde. Departamento de Gestão da Educação na Saúde. Política Nacional de Educação Permanente em Saúde (PNEPS). 2018. Disponível em: https://bvsms.saude.gov.br/bvs/publicacoes/ politica_nacional_educacao_permanente_saude_fortalecimento.pdf

2. Bourdieu P. Teoria do Poder Simbólico. Editora Bertrand. Rio de Janeiro, 1997.

3. Castells M. A sociedade em rede: do conhecimento à ação política. In: Castells M.; Cardoso G. (Org.). A sociedade em rede. Lisboa: Casa da Moeda, Imprensa Nacional, 2005.

4. Observatório das Metrópoles. Mortalidade por COVID-19 em São Paulo: ainda rumo à periferia do município. Disponível em: https:// www.observatoriodasmetropoles.net.br/mortalidade-por-covid-19-em-sao-paulo-ainda-rumo-a-periferia-do-municipio/ Acesso em: o8 de dezembro de 2020.

5. Pérez RA. Estrategias de comunicación (4. ed.). Barcelona: Editorial Ariel, 2008. 


\section{A IMPORTÂNCIA DA GESTÃO PARA UM CUIDADO QUALIFICADO EM SAÚDE MENTAL NA ATENÇÃO PRIMÁRIA}

\section{Jamine Bernieri \\ Leila Zanatta}

\section{Introdução}

O cuidado adequado em Saúde Mental (SM) é um tema que vem sendo discutido no Brasil desde o início da Reforma Psiquiátrica. A priorização por uma assistência integral com enfoque não apenas aos indivíduos em sofrimento mental, mas também às suas famílias, associada ao aumento dos transtornos mentais comuns na população, tem implicado em um aumento desta demanda na Atenção Primária à Saúde (APS)․․ Diante deste cenário, profissionais e gestores encontram desafios para assegurar um cuidado de qualidade a estas pessoas. Neste sentido, compreende-se que o enfermeiro desenvolve papel essencial nas equipes da APS, podendo contribuir para a consolidação de uma assistência adequada em SM neste nível de atenção, pois através do uso de suas habilidades e conhecimento científico, este profissional tem condições de acolher e apoiar os usuários em sofrimento mental, bem como seus familiares. Porém, atualmente o cenário que se observa na maioria das Unidades Básicas de Saúde (UBS), é de um cuidado fragmentado, curativo e com enfoque medicamentoso às demandas de SM, ocasionando uma assistência pouco resolutiva. Pode-se atribuir tal situação à presença de inúmeras barreiras, como a escassez de recursos humanos, pouca sensibilidade das equipes, despreparo dos profissionais e falta de apoio da gestão ${ }^{2}$. Tais situações fazem com que as questões de SM, representem uma das mais complexas dificul- 
dades de alocação de recursos para os gestores de saúde, devido às altas taxas de utilização dos serviços, piores resultados de tratamento e inúmeras rehospitalizações, fatores que elevam os custos do cuidado. . Frente ao exposto, justifica-se a importância de uma investigação, para compreender o processo saúde-doença mental e sua assistência na APS.

\section{Objetivo}

Relatar a experiência de uma mestranda sobre a realização de um estudo referente às percepções dos profissionais de saúde sobre o manejo dos usuários em sofrimento mental na APS.

\section{Método}

Trata-se de um estudo do tipo relato de experiência, sobre uma pesquisa de campo, de caráter descritivo e exploratório, realizado em uma UBS, através da interface de alguns profissionais da equipe multiprofissional, de um município ao norte do Rio Grande do Sul. Os critérios de inclusão dos participantes foram: Ser maior de 18 anos, médicos, enfermeiros, técnicos de enfermagem e psicóloga da APS, estarem atuando no mínimo há seis meses na APS. Os critérios de exclusão aplicados foram: Estar afastado de suas atividades laborais por motivo de doença ou ser demitido de suas funções. A coleta de dados foi realizada no mês de novembro de 2020 , por meio de entrevista individual presencial, respeitando-se os protocolos de segurança de prevenção à COVID-19, sendo norteadas por um roteiro semiestruturado, que continha na primeira parte questões fechadas, visando à caracterização dos dados dos participantes. A segunda parte possuía perguntas abertas que visaram facilitar o diálogo para a obtenção das percepções dos profissionais acerca do manejo dos usuários em sofrimento mental na APS. Todas as entrevistas foram gravadas e após transcritas. Participaram da pesquisa três médicos, duas enfermeiras, uma psicóloga e dois técnicos de enfermagem. Justifica-se a ausência de dois profissionais, pois um estava afastado por motivo de doença e outro havia sido demitido. Os dados pessoais dos participantes foram apresentados em números absolutos e porcentagens. A última parte do roteiro de coleta de dados foi analisada por meio da análise de conteúdo de Bardin, que contou com três fases: pré-análise, exploração do material e tratamento dos resultados ${ }^{3}$. Á pesquisa atendeu à Resolução no 466/2012 do Conselho Nacional de Saúde para pesquisas realizadas em seres humanos, foi submetida ao Comitê de Ética em Pesquisa da Universidade do Estado de Santa Catarina e aprovada sob o parecer $n^{\circ}$ 4.407.279 em 20 de outubro de 2020.

\section{Resultados e Discussão}

A maioria dos participantes era do sexo feminino $(\mathrm{n}=7,87,5 \%)$, com média de idade de 39 anos e média de tempo de atuação profissional de 10,5 anos. Após análise das informações obtidas, foi possivel identificar as potencialidades e fragilidades do manejo dos usuários em sofrimento mental na APS, bem como a importância da gestão do serviço para uma assistência de qualidade e resolutiva. Identificou-se como pontos positivos a partir das entrevistas: $O$ fácil acesso ao serviço, o atendimento a todas pessoas que buscam a UBS, as consultas com neurologista, os atendimentos prestados pela psicóloga, o fornecimento de medicamentos pela farmácia, o trabalho em equipe e a facilidade para encaminhamento dos usuários para consultas com psiquiatra e internações. Denota-se que os profissionais consideraram o cuidado focado no modelo biomédico e medicalizador como positivo, indo contra ao que é preconizado pela Reforma Psiquiátrica e pelo próprio propósito das equipes de Estratégia de Saúde da Família (ESF)4. Já as fragilidades identificadas foram: O despreparo emocional e/ou a falta de base teórica suficiente, para atender e dar sustentação as ações que os usuários em sofrimento mental requerem no âmbito da APS, a falta de acompanhamento a longo prazo dos usuários, a não realização $d a$ busca ativa para atendimento das pessoas em sofrimento mental, o déficit de recursos humanos, a elevada demanda de serviço, a ausência de práticas de cuidado baseadas em tecnologias leves na UBS, a não adesão por parte dos usuários de tratamentos não medicamentosos e a elevada medicalização. Nota-se que tais fatores são impeditivos para a realização de uma assistência adequada, ocasionando o agravamento dos quadros, o aumento do consumo de psicotrópicos, acarretando ainda, em um cuidado pouco resolutivo. Observa-se que a maioria das fragilidades, depende direta ou indiretamente do gestor para serem solucionadas. Cabe destacar ainda, que o novo modelo de cuidado em SM, coloca em evidência as inter-relações entre subjetividade, processo de trabalho e gestão. Sendo que, esta última merece uma posição de destaque, pois as formas de gestão dos serviços de saúde podem contribuir de maneira şignificativa para práticas de cuidado alinhadas as premissas $\mathrm{da}$ 
Reforma Psiquiátrica5. Entende-se que a formação profissional baseada em um modelo biologisista, e também a ausência de educação permanente em serviço sobre a temática, possam ser uma das causas dessa assistência fragmentada ${ }^{4}$. Diante deste contexto, considera-se que o investimento por parte dos gestores em educação permanente é imprescindível para a transformacão do processo de trabalho, no sentido da efetivação das práticas de SM na APS ${ }^{1}$. Com relação a ausência de tratamentos não medicamentosos na UBS atualmente para o cuidado desta demanda, as mesmas foram atribuídas às medidas de prevenção adotadas pelo gestor, em decorrência da pandemia por Coronavírus. Porém, compreende-se que o sofrimento mental aumentou na população, devido às medidas de isolamento e distanciamento social, impostas pela pandemia. Deste modo, considera-se que as ações de cuidado com enfoque no apoio emocional e na subjetividade, deveriam ser fortalecidas e não interrompidas no serviço. Referente a problemática da não adesão dos usuários aos tratamentos não medicamentosos, esta pode estar relacionada a uma construção cultural de que a "cura" das doenças só ocorre mediante o uso de fármacos. Entende-se neste sentido, que cabe a equipe multiprofissional a sensibilização das pessoas sobre a importância dos demais aparatos de cuidado para a solução dos problemas apresentados. Quanto à medicalização, pensa-se que somente através da ampliação do conhecimento dos profissionais e do apoio da gestão, haverá uma mudança deste cenário. Ademais, evidenciou-se que os próprios entrevistados reconhecem a importância de novas estratégias para qualificar o atendimento em SM na APS. Pois emergiu nas entrevistas diversas sugestões, como a disponibilização e uso de tecnologias leves no cuidado, melhores avaliações antes da prescrição de psicotrópicos e implantação de um processo de educação permanente sobre a temática. Observa-se que a maioria das estratégias sugeridas vão ao encontro do que o Sistema Único de Saúde (SUS) preconiza para o cuidado em SM na APS, que é adoção de tecnologias leves, como acolhimento, acompanhamento horizontal e longitudinal dos usuários, fortalecimento da autonomia, enfoque na subjetividade, bem como o incentivo à participação em atividades comunitárias e grupos de apoio ${ }^{4}$. Considera-se como limitações deste estudo a não abrangência dos demais membros da equipe e do gestor da APS. Este estudo tem relevância, pois oferece uma perspectiva da dinâmica do processo saúde-doença mental, bem como da assistência em SM na APS.
Com relação à enfermagem, espera-se ter contribuído para um processo crítico-reflexivo por parte destes profissionais sobre a relevância de sua atuação nesta área.

\section{Conclusão}

A experiência vivenciada na realização deste estudo possibilitou o conhecimento sobre a percepção dos profissionais de saúde acerca do manejo dos usuários em sofrimento mental na APS, além da identificação dos desafios que gestores e equipes de saúde precisam vencer, para que de fato haja uma assistência qualificada e resolutiva neste nível de atenção. Espera-se com esta pesquisa, contribuir para o avanço do conhecimento científico sobre a temática, além de promover uma sensibilização de profissionais e gestores, para uma modificação na assistência em SM.

Descritores: Gestão; Atenção Primária à Saúde; Saúde Mental.

\section{Referências}

1. Barros S, Nóbrega SSPM, Santos CJ, Fonseca ML, Floriano, MSL. Saúde Mental na Atenção Primária: Processo saúde-doença segundo profissionais de saúde. Rev. Bras. De Enfermagem, 2019 [acesso em 10 de dezembro de 2020]; 72 (6). Disponível em: http://www.scielo.br/pdf/reben/v72n6/pt_0034-7167-reben-72-06-1609.pdf

2. Souza J, Almeida YL, Luis VAM, Nievas FA, Veloso CMT, Barbosa BS, et al. Mental health in the Family Health Strategy as perceived by health professionals. Rev Bras Enferm. 2017; 70(5):935-41. Disponível em: https://doi. org/10.1590/0034-7167-2016-0492

3. Bardin L. Análise de conteúdo. Tradução: Luis Antero Reto, Augusto Pinheiro. 7o. ed. São Paulo: 2011.

4. Brasil. Ministério da Saúde. Cadernos de Atenção Básica. Saúde Mental. Ministério da Saúde. Brasília (DF) 2013; (34). Disponível em: http://bvsms.saude.gov.br/bvs/publicacoes/cadernos_atencao_basica_34_saude_mental.pdf

5. Pessoa VLK, Jorge BSM, Lourinho AL, Catrib AMF. Gestão do cuidado e interdisciplinaridade: desafios do cotidiano da atenção psicossocial. Revista de Salud Pública [revista em internet]. 2018; 20(6), dez. Disponível em: https://doi.org/10.15446/rsap.Vzon6.64641 


\section{POLÍTICA NACIONAL DE ATENÇÃO INTEGRAL À SAÚDE DA CRIANÇA FRENTE AO CRESCIMENTO E DESENVOLVIMENTO INFANTIL}

\author{
Alana Camila Schneider \\ Ana Maira Teló \\ Mirian Giacomel \\ Wanderson Luiz Teixeira \\ Carine Vendruscolo \\ Letícia de Lima Trindade
}

\section{Introdução}

A construção de uma política pública de saúde ocorre pela determinação social do processo de saúde e doença, considerando aspectos afetivos e emocionais, assim como ambientes facilitadores à vida. Nessa direção, a política pública propõe-se a enfrentar as desigualdades através da recomendação de linhas de cuidado‥ A Política Nacional de Atenção Integral a Saúde da Criança (PNAISC) foi criada com o objetivo de cuidar integralmente da saúde das crianças, desde a gestação até os nove anos de vida, voltada especialmente às crianças na faixa etária que compreende a primeira infância, atuando diretamente para a redução da morbidade e mortalidade infantil e promovendo o crescimento e desenvolvimento em ambiente facilitador e com condições dignas ${ }^{1}$. A Política foi instituída através da Portaria $\mathrm{n}^{\mathrm{o}} 1.13 \mathrm{O}$, de 05 de agosto de 2015 e, até este marco, um longo caminho foi percorrido e diversas estratégias e programas haviam sido criados anteriormente, com a finalidade de cuidar integralmente da saúde da criança. A PNAISC agrega princípios, diretrizes e eixos estratégicos para compor a atenção integral à saúde da criança e se utiliza das Redes de Atenção à Saúde (RAS) e da intersetorialidade para descrever as responsabilidades de cada nível de atenção, bem como da gestão. Um dos eixos estratégicos que se destaca, tanto na atuação profissional do enfermeiro da Atenção Primária à Saúde (APS), quanto na atenção especializada, é o 
terceiro eixo. Este compreende a Promoção e Acompanhamento do Crescimento e do Desenvolvimento Integral ${ }^{1}$.

\section{Objetivo}

Discutir sobre o papel do enfermeiro no acompanhamento do crescimento e desenvolvimento integral da criança, conforme o terceiro eixo estratégico da Política Nacional de Atenção Integral à Saúde da Criança.

\section{Método}

Trata-se de um estudo reflexivo, ancorado em uma revisão narrativa de literatura, com abordagem qualitativa. Utilizou-se dos seguintes passos metodológicos: procura literária; busca dos descritores; critérios de seleção (inclusão e exclusão dos estudos); avaliação crítica dos estudos; redação das conclusões, discussão e análise dos resultados².

\section{Resultados e Discussão}

A PNAISC, estruturada em sete eixos estratégicos, traz no seu terceiro eixo a "Promoção e Acompanhamento do Crescimento e do Desenvolvimento Integral". Além disso, a política tem como proposição que, para um desenvolvimento pleno da criança durante a primeira infância, que compreende o período do nascimento até os cinco anos de idade, não se deve pensar apenas em sobrevivência e no crescimento, mas também, é necessário primar pela vigilância e promoção da saúde ${ }^{1}$. O crescimento infantil está definido na PNAISC como resultado da associação de fatores genéticos, biológicos, psíquicos e sociais, envolvendo características intrínsecas e extrínsecas. Também esclarece que o desenvolvimento infantil não é composto apenas pelo amadurecimento neurocerebral, mas inclui também fatores biológicos, de relação, afetivos, sociais, simbólicos, ambientais e contextuais ${ }^{1}$. O desenvolvimento, especialmente na primeira infância, é considerado uma importante etapa com grandes promessas, assim como, grandes ameaças na área de saúde, pois esse processo é marcado por influências decorrentes de experiências vivenciadas, sejam elas positivas ou negativas, que afetam futuramente a aprendizagem, comportamentos e a própria saúde da criança. $\mathrm{O}$ enfermeiro que está inserido nos serviços de Atenção Primária à Saúde tem estabẻlecido como rotina o acompanhamento do desenvolvimento e do crescimento infantil por meio de consultas de puericultura, intercaladas com outros profissionais, que abrangem açoes de promoção, prevenção, tratamento, reabilitação e recuperação da saúde, promovendo o cuidado centrado na pessoa e em seus aspectos biopsicossociais ${ }^{3,4}$. É importante ressaltar que o acompanhamento do crescimento e desenvolvimento infantil ocorre majoritariamente na APS, porém não é atividade exclusiva desse cenário e, se necessário, outros pontos das RAS devem ser integrados nesse cuidado, incluindo a maternidade, local que inicia este acompanhamento ${ }^{1}$. As consultas de enfermagem em puericultura são estratégias eficazes, de baixa complexidade de implantação e baixo custo, em que é possível avaliar o crescimento e desenvolvimento da criança, reconhecer vulnerabilidades, estabelecer prioridades e propor intervenções em tempo oportuno, tendo em vista que o enfermeiro possui autonomia na tomada de decisões e implementação de condutas necessárias ${ }^{3.5}$. A consulta de enfermagem em puericultura é uma das estratégias que preconiza a vigilância do Desenvolvimento da Primeira Infância (DPI) e é orientada pela Caderneta de Saúde da Criança (CSC). A CSC pode ser considerada como um prontuário da criança, que além de ser um instrumento de cuidado efetivo por conter dados significativos de saúde, é uma forma de comunicação entre os profissionais e familiares. Os dados de saúde contidos na CSC são fundamentais para a vigilância, proteção e promoção da saúde, bem como, para o fornecimento do cuidado integral, efetivo e resolutivo, pois o crescimento e desenvolvimento são avaliados através de marcos que analisam e classificam a situação da criança, com estes é possível fornecer informações adequadas e, desta forma empoderar a família no cuidado da criança ${ }^{1,3}$. Somado a CSC, o acompanhamento do crescimento e desenvolvimento infantil realizado pelo profissional enfermeiro acontece através da Sistematização da Assistência de Enfermagem (SAE), utilizando-se do Processo de Enfermagem (PE), constituído por cinco etapas: anamnese e exame físico, diagnósticos de enfermagem, planejamento, implementação das intervenções e avaliação dos resultados. $5^{3}$. O papel do enfermeiro no acompanhamento do crescimento e desenvolvimento de crianças, exercido por meio de ações de vigilância à saúde, objetiva envolver o fortalecimento de vínculos entre profissional e família, fortalece as boas práticas parentais, a relação afetiva com os filhos, redução de estresse e prevenção de agravos à saúde das crianças, o que evita danos ao desenvolvimento infantil ${ }^{4}$. Salienta-se que quando há identificação de vulnerabilidades que podem gerar danos ao desenvolvimento 
da criança, além das intervenções já planejadas durante a consulta de enfermagem, também é recomendado utilizar como estratégia visitas domiciliares com intuito de dar suporte às famílias, fortalecendo vínculos com criança, família e comunidade, para promoção de ambientes que favorecem e estimulem o desenvolvimento infantil, visto que tanto o crescimento quanto o desenvolvimento são também influenciados por fatores extrínsecos ${ }^{1}$.

\section{Conclusão}

A Política Nacional de Atenção Integral à Saúde da Criança vem para assegurar os direitos da criança, estando estruturada em eixos estratégicos para garantir integralidade do cuidado. Com relaçã̃o ao terceiro eixo aqui discutido, que discorre sobre o acompanhamento do crescimento e desenvolvimento infantil, percebe-se que o profissional enfermeiro possui importante papel nesse cuidado, por possuir amplo conhecimento no que cerne a saúde da criança. O acompanhamento do crescimento e desenvolvimento infantil realizado pelo enfermeiro contribui para a redução de vulnerabilidades, envolvendo a família e comunidade no cuidado prestado à criança, fortalecendo vínculos, possibilitando a identificação de fragilidades e intervenções precoces para a resolução destas, propiciando assim evoluções nos indicadores de saúde infantil.

Descritores: Saúde da Criança; Políticas Públicas de Saúde; Promoção da Saúde; Enfermagem Pediátrica; Cuidado da Criança.

\section{Referências}

1. Brasil. Política Nacional de Atenção Integral à Saúde da Criança: orientações para implementação. Brasília: Ministério da Saúde, 2018.

2. Ferrari R. Writing narrative style literature reviews. Medical Writing. 2015; 24(4):230-235. Disponível em: https://doi.org/10.1179/204748 0615Z.000000000329

3. Vieira DS, Dias TKC, Pedrosa RKB, Vaz EMC, Collet N, Reichert APS. Processo de trabalho de enfermeiros na vigilância do desenvolvimento infantil. REME - Rev Min Enferm. 2019; 23:e1242. Disponível em: https://cdn.publisher.gn1. link/reme.org.br/pdf/e12.42.pdf

4. Yakuwa MS, Neill S, Mello DF. Estratégias de enfermeiros para a vigilância à saúde da criança. Rev. Latino-Am. Enfermagem. 2018; 26:e3007. Disponível em: https://www.scielo.br/ pdf/rlae/v26/pt_0104-1169-rlae-26-e3007.pdf

5. Hanzen IP, Zanotelli SS, Zanatta EA. Diagnósticos, intervenções e resultados de enfermagem para subsidiar a consulta de enfermagem à criança. Enferm. Foco. 2019; 10(7):16-21. Disponível em: http://revista.cofen.gov.br/index.php/ enfermagem/article/view/2683. DOI: https:// doi.org/10.21675/2357-707X.2019.v10.n7.2683 
RELATO DE EXPERIÊNCIA

IMPLEMENTAÇÃO DO MONITORAMENTO
COVID-19: REPERCUSSÕES NA
FORMAÇÃO ACADÊMICA

\author{
Demile Regina Carraro \\ Gabriela Moresco \\ Yasminne Rita Marolli \\ Clarissa Bohrer da Silva \\ Letícia de Lima Trindade \\ Marta Kolhs
}

\section{Introdução}

A COVID-19 é uma doença infectocontagiosa que surgiu na China, em dezembro de 2019 e que tem como patógeno o Coronavírus, denominado SARS-CoV-2. Desde o seu aparecimento a humanidade tem enfrentado uma crise sanitária global. Os casos aumentaram aceleradamente em diversos continentes, o que fez a Organização Mundial da Saúde (OMS) estabelecer como pandemia no dia 11 de março de $202 \mathrm{O}^{1}$. Este cenário complexo estabelece dificuldades à vigilância epidemiológica, às relações internacionais e à programação de políticas públicas, especialmente por meio de medidas que amenizem as desigualdades de acesso aos sistemas de saúde e a condições estruturais para o autocuidado. Nesse sentido, contemplar o monitoramento da pandemia nas diferentes regiões torna-se imprescindível para a atualização e regulação de métodos de enfrentamento à nível local e para gestão do trabalho nos sistemas de saúde. ${ }^{2}$ No município de Chapecó, localizado no oeste de Santa Catarina, com aproximadamente 200 mil habitantes, até o dia 13 de dezembro de 2020 registrava 12.472 casos confirmados, sendo 11.303 recuperados. ${ }^{3} \mathrm{O}$ monitoramento dos casos suspeitos e confirmados de COVID-19 faz parte do Protocolo de Manejo Clínico da COVID-19 na Atenção Primária à Saúde desenvolvido pelo Ministério da Saúde, e tem como objetivo orientar a Rede de Serviços de Atenção à Saúde para atuação na identifica- 
ção, na notifícação e no manejo oportuno de casos de infecção, de modo a mitigar a transmissão sustentada no território nacional. ${ }^{4}$

\section{Objetivo}

Relatar as repercussões na formação acadêmica na implementação do monitoramento dos casos suspeitos e confirmados de COVID-19 em Chapecó.

\section{Método}

Trata-se de um relato de experiência, descritivo, vivenciado por acadêmicos da décima fase durante o Estágio Curricular Supervisionado II (ECS II) no curso de Enfermagem da Universidade do Estado de Santa Catarina (UDESC). Diante de um acordo de cooperação entre a UDESC e a Secretaria Municipal de Saúde de Chapecó, foi elaborado um plano de trabalho para a ampliação do monitoramento de casos suspeitos e confirmados de COVID-19 que foi assumido pela $10^{\mathrm{a}}$ fase do curso, composta por 14 acadêmicos e três docentes. Foi pactuada a realização inicial do monitoramento de casos pertencentes a três Centros de Saúde da Familia (CSF) do município. O monitoramento, realizado de 15 de junho a 28 de agosto de 2020 , ocorreu numa sala ampla da própria Universidade, atentando à todas as medidas sanitárias exigidas no período (higienização dos sapatos, das mãos e objetos, uso de máscara e distanciamento social). Foram disponibilizados seis celulares da UDESC para realizar o contato telefônico e/ ou via WhatsApp com os usuários que precisavam ser monitorados a cada $48 \mathrm{~h}$ ou $24 \mathrm{~h}$ (os grupos de risco). Para acompanhamento dos casos de COVID-19 foi compartilhada uma planilha do Microsoft Excel com os CSF, os quais inseriam os casos pertencentes ao seu território adscrito. Os acadêmicos foram divididos em três grupos (de acordo com a unidade de saúde) e escalados em 6 pessoas diariamente para monitorar os casos de segunda à sexta-feira, no turno vespertino, das 13 às 18 horas, totalizando cinco horas diárias. O registro do monitoramento era realizado na planilha da unidade de saúde e no prontuário eletrônico do paciente acessado via sistema web nos computadores disponibilizados. Com uma média de 100 casos diários, o monitoramento era supervisionado diretamente pelas docentes enfermeiras da fase e compartilhado com as enfermeiras coordenadoras dos CSF.

\section{Resultados e Discussão}

Durante a realização do monitoramento de casos suspeitos e confirmados de COVID-19, foi possivel executar de forma satisfatória ações que competem ao enfermeiro no âmbito da assistência, gestão, educação e investigação, mesmo que de forma remota, mas com o enfoque integral aos pacientes, o que repercute na formação diferencial dos acadêmicos envolvidos. As tecnologias de informação tornaram possível que os acadêmicos realizassem telemonitoramento e, muitas vezes, teleconsultas de enfermagem respaldadas pela Resolução No 634/2020 do Conselho Federal de Enfermagem, 5 mantendo o distanciamento social. Em relação à dimensão assistencial, desenvolveram-se as competências clínicas dos acadêmicos, na observação de respiração, fala e alterações de quadro clínico dos pacientes, além de identificação de ansiedade, medo e solidão, denotando uma interface contínua com a saúde mental. Para um cuidado qualificado, os acadêmicos realizaram escuta ativa pautada em roteiro pré-elaborado de forma a identificar as demandas em saúde e realizar as orientações aos usuários, com base em evidências científicas, de forma ética e responsável, realizando os encaminhamentos necessários diante das particularidades, e registrando no sistema de informações em saúde municipal. Esse atendimento também possibilitou o desenvolvimento da educação em saúde dos usuários (dimensão educativa) sobre a COVID-19, testagem, fisiopatogenia e medicamentos, de modo a esclarecer dúvidas, compartilhar informativos via WhatsApp, evitando informações equivocadas a fim de contribuir com a saúde comunitária, impedir a procura desnecessária aos serviços, e permitir a assistência à saúde de forma remota. ${ }^{4}$ Além disso, o monitoramento realizado pelos acadêmicos de enfermagem possibilitou a dimensão gerencial, com o aprendizado da sistemática de priorização dos pacientes com maior risco de agravamento dos sintomas e ativação da rede de atenção à saúde, organização do plano de trabalho por meio das planilhas e quantidade de pacientes a cada dia, indicadores de monitorização, estabelecimentos de metas e gerenciamento do sistema de informação. Destaca-se que essa atividade também contribuiu para auxiliar os profissionais das unidades de saúde que se encontram sobrecarregados com outras demandas de atendimentos presenciais e remotas. Em relação à dimensão de pesquisa, a repercussão do monitoramento foi na construção de habilidades investigativas em 
relação ao quadro clínico dos pacientes, prática baseada em evidências, que na situação da COVID-19 está em constante atualização em vistas do reconhecimento da patologia, além de participação na análise dos relatórios advindos dos pacientes monitorados.

\section{Conclusão}

A realização do monitoramento de casos de COVID-19 oportunizou repercussões na formação acadêmica dos graduandos no que se refere à dimensões assistencial, gerencial, educativa e investigativa do processo de trabalho do enfermeiro, incluindo novos desafios quanto a adaptação ao contexto de distanciamento e ao teleatendimento, assim como no desenvolvimento de pensamento crítico-reflexivo frente aos pacientes e situações vivenciadas. Dessa maneira, os acadêmicos tiveram a oportunidade de estar desenvolvendo as competências necessárias para as atribuições do enfermeiro juntamente com a equipe de saúde da APS em um contexto atípico. Atuar no monitoramento é aprender a observar e analisar o contexto de saude do paciente por meio da abordagem clínica e escuta ativa, realizando um cuidado integral, de forma a empoderar o usuário mesmo sem estar presencialmente com ele, denotando a essencialidade das competências do Enfermeiro nesse atendimento e acompanhamento dos casos de COVID-19. O telemonitoramento tem contribuído com a organização do enfrentamento à pandemia de COVID-19, possibilitando o aprendizado dos acadêmicos e o desenvolvimento de uma efetiva resposta à sociedade, considerando a responsabilidade social das instituições envolvidas e a gestão do trabalho nos sistemas de saúde.

Descritores: Enfermagem; Infecções por Coronavírus; Telemonitoramento; Atenção Primária à Saúde; Gestão em saúde.

\section{Referências}

1. Aquino EML, Silveira IH, Pescarini JM, Aquino R, Filho JAS, Rocha AS, et al. Medidas de distanciamento social no controle da pandemia de COVID-19: potenciais impactos e desafios no Brasil. Ciênc. Saúde Colet. 2020; 25(1):2423-46.

2. Rafael RMR, Neto M, Carvalho MMB, David HMSL, Acioli S, Faria MGA. Epidemiologia, políticas públicas e pandemia de COVID-19: o que esperar no Brasil? Rev Enferm UERJ. 2020; 28:e49570.

3. Prefeitura Municipal de Chapecó. Boletim Informativo Coronavírus. [Internet]. 2020. Disponível em: https://www.chapeco.sc.gov. br/coronavirus. Acesso em: 13 dez. 2020.

4. Brasil. Ministério da Saúde. Protocolo de Manejo Clínico da Covid-19 na Atenção Especializada. Brasília: Ministério da Saúde, 2020. 41 p.

5. Conselho Federal de Enfermagem. Resolução COFEN N ${ }^{\circ}$ 634/2020. Autoriza e normatiza, "ad referendum" do Plenário do Cofen, a teleconsultas de enfermagem como forma de combate à pandemia provocada pelo novo Coronavírus (SARS-CoV-2) [...]. Brasília: COFEN. 2020. Disponível em: http://www.cofen.gov.br/ resolucao-cofen-no-0634-2020_78344.html 
TRANSIÇÃO ENTRE OS SERVIÇOS

E CONTINUIDADE DO CUIDADO DE CRIANÇAS COM CONDIÇÕES CRÔNICAS

\author{
Vitória Carolini Gomes \\ Caroline Cechinel-Peiter \\ Gabriela Marcellino \\ de Melo Lanzoni
}

\section{Introdução}

A continuidade do cuidado vem sendo cada vez mais demandada no Brasil, considerando sua relevância para a integralidade da atenção na organização da assistência nos diversos níveis de densidade tecnológica na Rede de Atenção à Saúde (RAS). A continuidade do cuidado é conceituada como um acompanhamento do paciente entre os serviços de saúde por meio de referência e contrarreferência para promoção da saúde e prevenção de agravos e exacerbações, sendo especialmente importante no cuidado longitudinal de pacientes com condições crônicas. ${ }^{1}$ Nestes casos, a ausência de continuidade do cuidado impacta na desqualificação da atenção à saúde e no retorno constante e desnecessário de pacientes aos serviços de saúde nos casos de agudização, resultando em baixa qualidade do cuidado e gastos desnecessários ao sistema de saúde. ${ }^{2}$ Especialmente, o cuidado de crianças com condições crônicas requerem especial atenção, tanto pelo potencial de vulnerabilidade intrínseca à infância, quanto às consequências que podem influenciar na saúde do indivíduo em sua via adulta, e ao impacta destas condições na vida de toda a família. Além disso, o momento de transição entre os serviços de saúde representa vulnerabilidade para a continuidade do cuidado, e as ações de transição do cuidado requerem estratégias para a manutenção desta continuidade no decorrer do tempo. Nesse sentido, destaca-se a importância da transição do cuidado de 
criança com condições crônicas entre os serviços de saúde e fluxos de referência e contrarreferência estruturados na RAS, resultando na continuidade do cuidado ao longo do tempo. ${ }^{1}$

\section{Objetivo}

Analisar a continuidade do cuidado de crianças com condições crônicas durante a transição entre os serviços após a alta hospitalar.

\section{Método}

Este estudo foi realizado em dois hospitais da região Sul do país, no período de fevereiro a setembro de 2019. Foi realizada uma pesquisa de métodos mistos. Para a fase quantitativa utilizou-se o instrumento Care Transitions Measure (CTM-15 Brasil), que foi desenvolvido nos Estados Unidos em 2002 e posteriormente traduzido e validado para uso no Brasil. O CTM-15 Brasil tem como objetivo mensurar a qualidade da transição do cuidado do hospital para o domicílio pela perspectiva dos pacientes e familiares. Outro instrumento foi utilizado para coletar as características sócio-demográficas dos pacientes. Duas etapas foram realizadas na fase quantitativa da pesquisa. No primeiro momento houve a abordagem dos pacientes e acompanhantes no âmbito hospitalar, onde ocorreu o convite formal à pesquisa e aplicação do instrumento de caracterização. Na segunda etapa, ao paciente que recebia alta, era realizada uma ligação telefônica de sete a trinta dias após a alta hospitalar para aplicação do CTM-15 Brasil. Foram incluídos no estudo os pacientes internados nos hospitais analisados que possuíssem alguma condição crônica de saúde. Os critérios de exclusão envolveram responsáveis com idade inferior a 18 anos, participantes que não receberam alta ou vieram a óbito no período de coleta e aqueles que não atenderam a ligação da segunda etapa. No total, 201 participantes foram incluidos na etapa quantitativa do estudo. Aos resultados obtidos foram aplicados o teste t-Student e análise de variância (ANOVA). A fase qualitativa utilizou a Teoria Fundamentada nos Dados (TFD), vertente construtivista, ${ }^{3}$ onde foram entrevistados 35 participantes, entre enfermeiros (10), médicos (5), familiares (5), psicólogos (4), nutricionista (4), fisioterapeutas (3), assistentes sociais (2), fonoaudiólogos (1), e gestor hospitalar (1). Os participantes foram divididos em três grupos amostrais, obedecendo a técnica de amostragem teórica. Os dados coletados foram analisados por meio de codificação inicial e focalizada, resultando em oito categorias, das quais duas foram combinadas com os dados quantitativos por integração e serão apresentadas neste estudo.

\section{Resultados e Discussão}

A primeira categoria, "Buscando promover a continuidade do cuidado da criança com condições crônicas na Rede de Atençã̃o à Saúde", evidencia as práticas adotadas pelos profissionais da saúde em assegurar os pacientes ao longo da RAS, enquanto a segunda categoria, "Desconhecendo a trajetória do paciente após a alta hospitalar e sua integração com a Atenção Primária", apresenta as dificuldades dos profissionais em garantir a continuidade do cuidado a partir da transição do hospital para o domicílio. A média encontrada do CTM-15 Brasil foi de $89,5(\mathrm{dp}=12,5)$ em uma escala de zero a 100 pontos. Apesar do instrumento não possuir um ponto de corte indicado pelos autores, a média encontrada sugere uma qualidade satisfatória na transição do cuidado quando comparada a outros estudos brasileiros que aplicaram o instrumento com participantes adultos. ${ }^{4}$ Pode-se inferir que, apesar de não haver mecanismos institucionais que subsidiem uma transição do cuidado de alta qualidade, práticas diferenciadas e individuais realizadas pelos profissionais da equipe hospitalar na atenção à as' pude da criança, impactam na qualidade de transição do cuidado destes pacientes. Não foi encontrada, neste estudo, diferença estatisticamente significante entre a qualidade da transição do cuidado em relação ao gênero, instituição hospitalar, tipo de vínculo com a criança, número de internações nos últimos 12 meses, capítulo CID-10 da doença crônica, idade da criança e dias de internação. Quando comparada ao município de residência da criança, foi verificada diferença na qualidade da transição do cuidado, sendo maior naqueles pacientes que residiam em municípios pertencentes a regiões de saúde diferentes da dos hospitais. Este resultado indica que os profissionais reconhecem a importância da referência e contrarreferência na RAS, que tem por objetivo a transição dos pacientes, garantindo o recebimento dos cuidados necessários de forma plena e com qualidade, especialmente de pacientes que consideram em maior risco de fragmentação do cuidado.O engajamento dos profissionais nas ações de transição do cuidado na alta hospitalar, identificando as necessidades do paciente e família, facilita a promoção da continuidade do cuidado no contexto do domicílio. ${ }^{5}$ 


\section{Conclusão}

Este estudo buscou analisar a continuidade do cuidado de crianças com condições crônicas no momento de transição dos cuidados entre os serviços após a alta para o domicílio. Foram evidenciadas estrategias adotadas pelos profissionais para driblar os empecilhos encontrados durante a transição entre os serviços de crianças com condições crônicas e assegurar a continuidade do cuidado por meio de ações de transição do cuidado. Apesar da ausểncia de estratégias institucionais para a transição do cuidado, foram identificadas iniciativas individuais dos profissionais que assistem as crianças com condições crônicas no contexto hospitalar, o que pode ter impacto na qualidade da transição do cuidado percebida pelos familiares.

Descritores: Enfermagem; Gestão em saúde; Integralidade; Saúde da criança; Continuidade da assistência ao paciente.

\section{Referências}

1. Nóbrega VMD, Silva MEA, Fernandes LTB, Viera CS, Reichert APDS, Collet N. Chronic disease in childhood and adolescence: continuity of care in the Health Care Network. Rev Esc Enferm USP. 2017;51(1):e03226. Doi:10.159o/S1980-220X2016042503226.

2. Uchimura LYT, Silva ATC, Viana ALD. Integration between Primary Health Care and Emergency Services in Brazil: Barriers and Facilitators. Int J Integr Care. 2018;18(4):1-10. Doi:10.5334/ijic.4066.

3. Charmaz K. A construção da Teoria Fundamentada: guia prático para análise qualitativa. 2. ed. Porto Alegre: Artmed, 2009.

4. Acosta AM, Lima MADS, Pinto IC, Weber LAF. Care transition of patients with chronic diseases from the discharge of the emergency service to their homes. Rev. Gaúcha Enferm. 2020;41(1):e20190155. Doi: 10.1590/19831447.2020.20190155.

5. Weber LAF, Lima MADS, Acosta AM, Marques GQ. Care transition from hospital to home: integrative review. Cogitare Enferm. 2017;22(3):e47615. Doi: 10.5380/ce.v22i3.47615. 
Pesquisa Original

\section{IMPACTO DAS ÚLCERAS VENOSAS NO COTIDIANO DE HOMENS E MULHERES: UM OLHAR NECESSÁRIO}

\section{Joana Trombetta \\ Ana Maria Cisotto Weihermann \\ Rosana Amora Ascari}

\section{Introdução}

A úlcera venosa (UV) é uma condição causada, principalmente, pela insuficiência venosa crônica (IVC) e caracterizada por edema em pé e tornozelo, alterações na pigmentação da pele e dor intensa. ${ }^{1}$ Cerca de $0,164 \%$ da população apresenta algum tipo de lesão crônica e, destas, $50 \%$ são de etiologia venosa. ${ }^{2}$ Além de sinais e sintomas físicos, as UV trazem prejuízos emocionais, sociais e psicológicos, que variam de acordo com o contexto em que o indivíduo está inserido. ${ }^{3}$ Indivíduos portadores de feridas crônicas podem sofrer preconceito devido à ferida ser vista como algo depreciativo e contagioso, motivo pelo qual os pacientes normalmente tentam esconder a lesão com roupas compridas. Além dos gastos necessários ao tratamento da lesão, há o afastamento temporário do trabalho que por vezes culmina com aposentadoria por invalidez. Assim, questiona-se: qual o impacto de úlcera venosa no cotidiano de homens e mulheres? Este estudo tem por objetivo conhecer o impacto provocado pelas úlceras venosas no cotidiano de homens e mulheres de um município catarinense.

\section{Método}

Estudo transversal de abordagem qualitativa, desenvolvido com 18 indivíduos portadores de ulceras venosas, adscritos às Estratégias Saúde da Família (ESF) num município catarinense. Considerou-se critérios de inclu- 
são: possuir pelo menos uma úlcera com duração de seis semanas ou mais, em atividade, decorrente de alteração da circulação venosa em membros inferiores; ser adscrito a uma ESF do município investigado, ter idade maior ou igual a 18 anos. Como critério de exclusão considerou-se: pacientes não localizados por ligação telefônica ou visita após três tentativas durante o período de coleta de dados. Os dados foram coletados durante o mês de setembro de 2020 por meio de uma entrevista semiestruturada, aplicada na residência de cada um dos participantes e pré-testada com dois indivíduos. Todas as entrevistas foram precedidas de leitura, explicação e assinatura do Termo de Consentimento Livre e Esclarecido (TCLE), as quais foram audiogravadas para garantir maior fidedignidade das respostas. A partir do deferimento da pesquisa por parte do Secretário Municipal de Saúde, os enfermeiros disponibilizaram uma lista com nome e telefone dos usuários elegíveis que possuíam úlceras venosas. Os pesquisadores realizaram contato, via telefone, com todos os possíveis participantes, para explanar sobre a pesquisa e, com os que aceitaram participar, foram agendados dia e horário para a entrevista. Ao todo, 32 indivíduos elegíveis foram informados pelo município, sendo que o contato via telefone foi efetivado com 24 deles e 20 aceitaram participar da pesquisa. Para as entrevistas foram adotadas medidas de prevenção e controle do novo Coronavírus (SAR$\mathrm{S}-\mathrm{CoV}-2$ ) em todos os momentos, conforme orientações sanitárias no país. As entrevistas foram transcritas em Word, salvas em Portable Document Format (PDF) e importadas pelo software NVivo. Os dados coletados foram analisados pelo método de análise de conteúdo. A pesquisa foi aprovada pelo Comitê de Ética em Pesquisa Envolvendo Seres Humanos (CEPSH) da Universidade do Contestado (UnC), sob o parecer consubstanciado número $4.217 .703 \mathrm{em} 17$ de agosto de 2020 , respeitou as determinações das Resoluções 466/2012, 510/2016 e 580/2018 do Conselho Nacional de Saúde, que dispõem sobre a pesquisa envolvendo seres humanos e o Código de Ética dos Profissionais de Enfermagem.

\section{Resultados e Discussão}

O estudo contou com a participação de 20 homens e mulheres portadores de úlceras venosas, adscritos a oito ESF do município catarinense. Todas as ESF do município foram contatadas, porém somente oito disponibilizaram o número de pacientes com UV. Das 20 entrevistas realizadas, duas tiveram a finalidade de testar o instrumento de coleta de dados, o qual foi ajustado e 18 foram utilizadas para a análise. Dos participantes, nove eram mulheres e nove eram homens, com idade entre 50 e 84 anos. Quanto ao estado civil, cinco eram casados, sete viúvos, três divorciados e três estavam em uma união estável, sendo que dois residiam sozinhos, 15 com familiares e um com uma cuidadora. Com relação a escolaridade, três eram analfabetos, nove não completaram o ensino fundamental, quatro completaram o ensino fundamental e dois concluiram o ensino médio. Ainda, observou-se que um dos participantes possuía emprego, três estavam desempregados, recebendo auxílio doença e 14 eram aposentados, a maior parte pela idade avançada e não pela condição de doença. No que diz respeito ao tempo de existência da UV, sete participantes tinham entre $1-5$ anos, quatro entre 6-10 anos, quatro entre 11-20 anos, dois há mais de 20 anos e um não soube responder. Na caracterização das lesões, verificou-se que nove participantes tiveram o início da lesão de forma espontânea e nove de forma traumática, 14 tinham apenas uma úlcera, três indivíduos apresentavam duas e um tinha três úlceras venosas. Todas as lesões apresentadas pelos participantes estavam localizadas no terço distal dos membros inferiores, sendo uma no pé direito, cinco no pé esquerdo, cinco na região maleolar direita, cinco na região maleolar esquerda, duas na perna direita e duas na perna esquerda. Entre os prejuízos causados pelas UV, o financeiro foi o que emergiu nas falas dos participantes, decorrente de gastos com o tratamento ou da perda do emprego em si. Por outro lado, nem todos referiram ter tido prejuízos, considerando que mantiveram seus empregos ou já eram aposentados quando a úlcera se desenvolveu. A literatura evidencia que as úlceras venosas exercem influência sobre a vida laboral, uma vez que os gastos com o tratamento podem gerar dificuldades financeiras, principalmente entre os indivíduos que tiveram afastamento do trabalho, e pode haver casos em que é necessário manter a atividade laboral, mesmo com as limitações causadas por esta condição. Dessa forma, o agravamento da condição socioeconômica pode culminar em desequilíbrios emocionais. ${ }^{4}$ Além do afastamento do emprego, os participantes também relataram dificuldades para caminhar e para a realização de atividades diárias e tarefas domésticas como consequências da lesão. O surgimento de uma úlcera venosa promove inúmeras mudanças no estilo e na qualidade de vida de seus portadores, a rotina muda e 
algumas das atividades simples do cotidiano que eram realizadas antes, ficam limitadas. ${ }^{3}$ No aspecto social, a maioria dos participantes afirmou nunca ter sido discriminado por conta da úlcera ou se mostrou indiferente aos comentários e olhares alheios, contrastando com outros estudos, que mostram que o preconceito costuma ser uma grande dificuldade a ser enfrentada por portadores de úlceras nas pernas.3.5 Quando questionados sobre o sentimento de vergonha de possuir a úlcera, alguns relataram que a condição não foi uma escolha, então não teriam motivo para se envergonhar, enquanto outros lamentam por não poderem usar roupas que deixem a úlcera à mostra. $\mathrm{O}$ constrangimento, enfatizado em outro estudo, se apresenta na vergonha da própria aparência, no fato de o indivíduo acreditar incomodar os outros com a sua condição e por não se sentir confortável fora de casa. ${ }^{5}$ Os principais incômodos provenientes da úlcera que foram citados pelos participantes foram o odor, a sensibilidade da pele, o prurido, a dificuldade para dormir, a impossibilidade de usar certos tipos de calçados e a dor, como sendo a mais presente nas respostas obtidas. A dor é um dos sintomas mais presentes em uma úlcera venosa e pode ser intensa a ponto de prejudicar as atividades do dia a dia, a locomoção e a qualidade do sono. ${ }^{2,3}$ Percebe-se que o presente estudo foi limitado, pois foi desenvolvido em uma realidade específica, com um número baixo de participantes, não possibilitando, dessa forma, a generalização dos resultados, motivo pelo qual sugere-se a investigação dessa temática em outras localidades.

\section{Conclusão}

Ao investigar o impacto provocado no cotidiano de homens e mulheres portadores de úlceras venosas num município do interior do estado catarinense, percebe-se que indivíduos convivem durante anos com as lesões, as quais causaram prejuízos financeiros, limitação para o trabalho e de realização de atividades de vida diária. Tais lesões são motivos de discriminação e constrangimento social. Ainda, dor, sensibilidade local, prurido, odor, limitação para determinados tipos de calçados e para dormir foram considerados fatores de incômodo pelos participantes. Os portadores de úlcera venosa evitam sair de casa, o que aumenta a tendência para o isolamento social que, a longo prazo, pode causar implicações na saúde mental. Nesse contexto, enfatiza-se a necessidade da reinserção do indivíduo com úlcera venosa nas práticas coletivas, tanto para manter a interação social, quanto para melhorar sua autoestima, o que requer um olhar atento dos profissionais da atenção primária à saúde. A úlcera venosa é um problema de saúde que pode levar a desdobramentos desfavoráveis e repercutir negativamente na saúde de seus portadores, o que demanda conhecimento técnico para condução de tratamento adequado pelos profissionais de saúde, visando evitar a evolução da lesão e agravos sistêmicos. Propõe-se a realização de novos estudos para ampliar as evidências relacionadas aos sentimentos e ao impacto das úlceras venosas no cotidiano dos indivíduos, assim como à novas técnicas e métodos para tratamento, minimizando os prejuízos financeiros e sociais com vistas ao desenvolvimento de um cuidado seguro e de qualidade.

Descritores: Insuficiência Venosa; Úlcera Varicosa; Qualidade de Vida; Atenção Primária à Saúde; Enfermagem.

Financiamento: Fundo de Apoio à Manutenção e ao Desenvolvimento da Educação Superior - FUMDES.

\section{Referências}

1. Hinkle JL, Cheever KH. Brunner \& Suddarth: tratado de enfermagem médico-cirúrgica. $14^{\underline{a}} \mathrm{ed}$. Rio de Janeiro: Guanabara Koogan; 2020.

2. Borges EL, Filho HMN, Júnior JFP. Prevalência de lesões crônicas de município da zona da mata mineira (Brasil). REME Rev Min Enferm. 2018; 22:e1143, 2018. DOI: 10.5935/14152762.20180074 .

3. Moraes CD, Diogo NS, Moreira TR, Mendonça ET, Caetano VR, Amaro MF. As ações de enfermagem refletindo na qualidade de vida de indivíduos com úlcera de perna. Rev Enferm UFPE On Line. 2017; 11(Supl. 5):2168-2176. DOI: 10.5205/reuol.9302-81402-1-RV.1105sup201723.

4. Castro RG. O sofrimento na perspectiva de pacientes com úlceras venosas [dissertação]. Belo Horizonte: Universidade Federal de Minas Gerais; 2017.

5. Aguiar ACSA, Sadigursky D, Martins LA, Menezes TMO, Santos ALS, Reis LA. Repercussões sociais vivenciadas pela pessoa idosa com úlcera venosa. Rev Gaúcha Enferm. 2016; $37(3)$ :e55302. DOI: http://dx.doi. org/10.1590/1983-1447.2016.03.55302. 


\section{O LEAN HEALTHCARE COMO FILOSOFIA PARA A GESTÃO EM SAÚDE}

\section{Heloisa Schatz Kwiatkowiski Júlia Valéria de Oliveira Vargas Bitencourt Maiara Bordignon}

\section{Introdução}

Espera-se cada vez mais que os sistemas de saúde sejam eficientes, eficazes, que prestem cuidados centrados nos pacientes e seguros ${ }^{1}$. Para tanto, dentre diversos aspectos, é necessário que os gestores dos recursos e a organização dos serviços estejam alinhados à cultura de melhoria contínua da qualidade da assistência e aumento da eficiência dos processos, com redução de cus$\operatorname{tos}^{1-2}$. Diante disso, estratégias que buscam sanar essas lacunas foram criadas ou adaptadas para a área da saúde, visando promover a qualidade $\mathrm{da}$ assistência em meio a um cenário de desafios relacionados ao aumento da demanda e dos custos em saúde ${ }^{1}$. Assim, destaca-se o Lean Healthcare, que possui origem no Sistema Toyota de Produção, chamado de Lean Thinking. Este processo de trabalho sofreu adaptações e atualmente tem sido aplicado na área da saúde com o propósito de reduzir desperdícios, atender as necessidades de saúde dos usuários dos serviços no tempo e da maneira desejada e promover a satisfação dos profissionais com a melhoria dos processos de trabalho ${ }^{1-2}$. Embora o Lean Healthcare tenha sido aplicado internacionalmente em várias experiências, no Brasil a temática ainda é pouco explorada, assim como na área da Enfermagem³.

\section{Objetivo}

Refletir acerca do Lean Healthcare enquanto recurso para a melhoria da qualidade da gestão em saúde. 


\section{Método}

Estudo de reflexão que apresenta sobre a proposta da filosofia do Lean Healthcare para a gestão em saúde, suas potencialidades e fragilidades, fundamentando-se em resultados de estudos individuais e em revisões da literatura acerca desta temática.

\section{Resultados e Discussão}

O pensamento Lean na área da saúde pode ser definido como uma filosofia que busca identificar e eliminar desperdícios no processo de trabalho em saúde, podendo ser implementado em diferentes contextos, como: setores de emergência, oncologia, radiologia, farmácia, ambulatórios, serviços de saúde mental, de cardiologia e ortopedia, unidades de terapia intensiva, entre outros ${ }^{1,3}$. Seguindo as experiências do sistema de produção da Toyota, são descritos na literatura sete desperdícios aplicados à área da saúde, para cada qual cita-se um exemplo': i - superprodução: a preparação pode ser excessiva na medida em que seu aproveitamento não é otimizado diante de eventuais sobras, ou quando os medicamentos são preparados e posteriormente descartados por não terem sido utilizados em tempo hábil; ii - estoque: existência de produtos ou materiais em desacordo com as demandas da instituição, havendo a possibilidade de vencimento dos mesmos e descarte; iii - movimentação: deslocamento dos pacientes para realização dos seus tratamentos e dos profissionais para execução das atividades laborais; iv - transporte: movimentação excessiva de recursos materiais, prontuários ou outros que caberiam estar nos seus locais de utilização e que estão sujeitos a desgastes, extravios ou outras problemáticas advindas de movimentações desnecessárias; v - superprocessamento: repetição de atividades, sem que isso adicione contribuições para a qualidade e segurança do paciente; vi - espera: diz respeito ao tempo, isto é, o quanto a espera propriamente dita é equilibrada com o tempo que se justifica racionalmente, sendo um exemplo as filas nas quais o usuário aguarda pelo atendimento; vii - defeito: representam erros nas etapas do processo de trabalho que exigem correções ou retrabalhos, a exemplo de formulários preenchidos incorretamente ou de maneira incompleta que implicam em idas e vindas dos pacientes aos serviços de saúde. Ainda, como oitavo desperdício, destaca-se a não utilização dos talentos dos profissionais, que pode impactar diretamente na qualidade da assistência, no sentido de que utilizar-se desses talentos pode beneficiar o trabalho em saúde em questões de segurança e eficiência pela expertise e habilidades dos profissionais ${ }^{1}$. Portanto, estes aspectos são a base para o Lean Healthcare, sendo que a partir deles analisa-se os processos e elabora-se estratégias para melhoria dos serviços ${ }^{1}$. Estudos demonstram a utilização do Lean Healthcare e os resultados obtidos, ainda que a maioria dos dados seja proveniente de estudos internacionais, mas com expansão para o Brasil ${ }^{3-4}$. Estudo de revisão integrativa da literatura, realizado com o objetivo de demonstrar o conhecimento científico acerca do Lean, seu impacto e contribuições para o cuidado e Enfermagem, menciona que esta filosofia aplicada ao contexto da saúde transforma tanto aspectos organizacionais como assistenciais dos serviços, implicando positivamente na qualidade e segurança dos cuidados por meio da redução no tempo de espera do paciente, aumento da satisfação do paciente e dos profissionais, melhoria no desempenho e eficiência da equipe, colaborando com o trabalho em equipe, além de padronização de processos, redução do tempo de internação e diminuição de custos? ${ }^{3}$ Estudo brasileiro conduzido com o objetivo de analisar o processo de implementação do Lean Healthcare em hospitais evidenciou benefícios a partir da redução do tempo de espera, do estoque, do prazo para exames e da capacidade de atendimento ${ }^{2}$. Entretanto, o fato dos estudos acerca da implantação do Lean Healthcare serem ainda incipientes no Brasil sinaliza para a necessidade de pesquisas nesta área e caracteriza uma lacuna de conhecimento que pode implicar na implementação desta filosofia nos serviços'3. Bem como, a literatura aponta para a importância de novos estudos que analisem a participação da Enfermagem na liderança e transformações na organização do trabalho com base na filosofia Lean, e que auxiliem na compreensão acerca dos fatores de sucesso e as barreiras para a implementação e seu impacto a longo prazo $0^{3-5}$. Por estar continuamente nos serviços de saúde, os profissionais de enfermagem assumem papel fundamental na condução e efetivação de mudanças almejadas pela instituição, com base nos princípios Lean'. Há, ainda, poucas informações nas investigações a respeito do processo de implementação do Lean Healthcare e que poderiam orientar e facilitar o planejamento e aplicação de novas experiências, em outros contextos de saúde 4 . Neste ínterim inclui-se a necessidade de registros sobre os fatores motivacionais para a implementação, os períodos e profissionais envolvidos no projeto, problemas enfrentados, ferramentas utilizadas, barreiras 
ou fatores críticos para o sucesso, aspectos de sustentabilidade (continuidade do projeto) e resultados obtidos ${ }^{4}$.

\section{Conclusão}

Entende-se que a filosofia Lean Healthcare pode ser válida para melhorar processos de trabalho nos servicos de saúde, por meio do uso de diferentes ferramentas e de análise organizacional direcionada e ampliada no âmbito da instituição. No entanto, a sua implementação requer conhecimento sobre a filosofia e o fortalecimento de uma cultura de melhoria contínua nos serviços.

Descritores: Administração de Serviços de Saúde; Gestão da qualidade total; Gestão em saúde; Sistema Único de Saúde.

\section{Referências}

1. Min LL, Sarantopoulos A, Spagnol G, Calado RD. O que é esse tal de Lean Healthcare? 2 ed. rev. ampl. Campinas: ADCiência Divulgação Científica; 2019.

2. Régis TKO, Gohr CF, Santos LC. Lean Healthcare implementation: experiences and lessons learned from brazilian hospitals. Rev. adm. empres. 2018;58(1):30-43.

3. Magalhães ALP, Erdmann AL, da Silva EL, dos Santos JLG. Pensamento Lean na saúde e enfermagem: revisão integrativa da literatura. Rev. Latino-Am. Enfermagem. 2016; 24:e2734.

4. Costa LBM, Godinho Filho M. Lean healthcare: review, classification and analysis of literature. Production Planning \& Control. 2016; $27(10): 823-836$.

5. Fernandes HMLG, Jesus MVN, Silva D, Guirardello EB. Lean Healthcare in the institutional, professional, and patient perspective: an integrative review. Rev. Gaúcha Enferm. 2020;41:e20190340. 
EVENTOS ADVERSOS NA ATENÇÃO PRIMÁRIA À SAÚDE: UM ESTUDO ENVOLVENDO A ENFERMAGEM BRASILEIRA

\section{Bruna Carine Heinrichs \\ Ana Maria Cisotto Weihermann}

Rosana Amora Ascari

\section{Introdução}

Eventos Adversos (EA) são incidentes não relacionados à evolução natural da doença de base de um paciente, contudo são incidentes que resultam em danos não intencionais. A segurança do paciente tem sido considerada um dos pilares que sustentam os níveis da qualidade dos serviços de saúde, sendo identificada como de grande impacto nas discussões envolvendo a qualidade da assistência. Os riscos de EA existem em diferentes cenários assistenciais, com maior ênfase na literatura cientifica para a área hospitalar, ${ }^{1-3}$ provavelmente em decurso do risco da ocorrência de EA estar associado ao nível de complexidade do serviço de saúde. ${ }^{4}$ Portanto, as ações e atitudes frente aos EA devem propiciar a atenuação dos danos e riscos inerentes ao paciente, visto que o aumento da resiliência no âmbito organizacional garante um processo de cuidar mais seguro ao paciente. 5 Os profissionais de enfermagem juntamente com o gestor da unidade têm entendimento da real necessidade de treinamentos, capacitações, educação permanente e reuniões em equipe com objetivo de garantir a prevenção de agravos e qualificar a assistência a saúde. ${ }^{4}$ Mediante o exposto, considerando a importância do reconhecimento dos EA e seus fatores contribuintes, bem como as estratégias de gestão na atenção primária à saúde para mitigar a ocorrências de EA, questiona-se: $\mathrm{O}$ que a produção científica brasileira aborda sobre EA relacionados à prática de enfermagem na atenção primária à saúde? 


\section{Objetivo}

Mapear o que a produção científica aborda sobre eventos adversos relacionados à prática profissional da enfermagem brasileira na atenção primária à saúde.

\section{Método}

Trata-se de um estudo de revisão integrativa da literatura na Biblioteca Virtual em Saúde, através dos descritores "Eventos adversos", "Segurança do paciente", "Enfermagem" e "Atenção Primária à Saúde", de janeiro de 2011 à setembro de 2020 (últimos 10 anos). O protocolo de revisão integrativa foi validado por dois pesquisadores externos à pesquisa. A busca dos estudos primários ocorreu nos dias 24 à 26 de outubro de 2020 diretamente na base de dados da Biblioteca Virtual em Saúde. Das 675 publicações elegíveis analisadas, dez foram incluídas por atender ao objetivo. Foram percorridas as seguintes etapas: (1) definição do tema de pesquisa com elaboração da questão norteadora; (2) definição dos critérios de inclusão e exclusão de estudos; (3) definição informações a serem extraídas dos estudos selecionados; (4) análise dos estudos com decodificação e categorização dos achados; (5) análise e interpretação dos resultados; (6) apresentação do relatório de pesquisa. A análise dos estudos inclusos na revisão foi realizada com preenchimento de formulário específico para a interpretação dos dados e a análise de conteúdo deu origem a quatro categorias temáticas, sendo elas: Tipos de EA; Fatores causais relacionados aos EA; Notificação de EA; Estratégias de gestão frente aos EA.

\section{Resultados e Discussão}

Da análise dos artigos emergiram quatro categorias, a saber: Tipos de EA: Observa-se que 90\% dos estudos abordaram algum tipo de EA, dentre estes foram mencionados EA relacionados a medicação, diagnóstico ou diagnóstico incorreto que causaram EA, EA devido a complicações decorrentes de quedas, e chamou a atençã̃o que metade dos estudos (50\%) dessa revisão estão relacionados à vacinas revelando as manifestações locais e sistêmicas da vacinação. Constatou-se que um artigo abordou EA mais específicos da área hospitalar, porém elencou alguns que estão presentes na Atenção Primária a Saúde sendo: EA devido a complicações decorrentes de quedas e EA a medicações. Fatores relacionados aos EA: Mencionou-se as falhas na comunicação com o paciente, comunicação interprofissional e comunicação na rede de atenção como os fatores mais comuns para ocorrência de EA, além das falhas na gestão, sobrecarga de trabalho associada à defasagem salarial do profissional de enfermagem e o ambiente físico inapropriado para o exercício profissional, e, os fatores relacionados a vacinação estão associados na sua maioria à vacina aos vacinados, a forma de administração, ou devido à prescrição ou indicação de um imunobiológico. Notifícação de EA: Os fatores relacionados à notificação e subnotificação de EA estiveram presentes em mais da metade dos estudos da revisão integrativa (70\%). Dentre os fatores relacionados à notificação dos EA, pode-se notar a baixa adesão a esta prática devido a diferentes barreiras, tais como: falta de confiança, medo de exposição por má prática, medo de perda da reputação, o excesso de trabalho e o pouco tempo disponível para fazer a notificação, além da escassez de conhecimento de alguns profissionais a respeito da notificação de incidentes. Embora a literatura tenha abordado que a notificação de evento adverso pós vacinação (EAPV) é muito importante para a vacinação segura, ainda existem casos de subnotificaçã̃o. Estratégias de gestão frente aos EA: Grande parte dos estudos analisados apresentaram estratégias de gestão frente à ocorrência de EA, sendo elas: fortalecimento da cultura de segurança e do trabalho em equipe entre os profissionais e o envolvimento do paciente na educação profissional, além da mitigação da cultura punitiva, a implementação de protocolos, programas de capacitação profissional e avaliação periódica sobre temáticas específicas, realizar campanhas de vacinação para qualificar a vigilância epidemiológica de EAPV, e a formação de recursos humanos, com implementação da educação continuada nos serviços de saúde. Os serviços de saúde vem buscando considerar indicadores que possam interferir nesta qualidade, sendo os EA o indicador mais relevante, pois embora indesejáveis, são frequentemente observados na prática assistencial. No que diz respeito aos eventos adversos envolvendo medicação, estes poderiam ser evitados com implementação de cuidados específicos envolvendo a prescrição, armazenamento, dispensação e administração dos medicamentos. Nesse sentido, percebe-se a elevada ocorrência de EA relacionada a vacinação, gerando preocupação entre gestores, além do fato repercutir negativamente na população em geral, colocando em dúvida a segurança gerada pelas vacinas. Há que se destacar o fato da grande semelhança e tamanho reduzido dos rótulos entre a maioria dos imunobiológi- 
co, o que pode condicionar os profissionais ao erro. Ainda, o conhecimento insuficiente de profissionais sobre o sistema de notificação, o excesso de trabalho, a pressão e a ausência de feedback, são algumas das limitações sentidas frente a ocorrência de EA. Ainda, o excesso de trabalho, os déficits na estrutura física e a insatisfação com salários e jornada de trabalho excessiva, podem repercutir de maneira positiva e negativa na qualidade dos cuidados prestados, e, quando associadas à condições de trabalho e gestão inapropriadas, dificulttam a efetividade do serviço da APS. Promover a segurança do paciente no contexto da APS evidencia a qualidade da assistência prestada, sendo o gestor responsável por incentivar e capacitar os profissionais para a prevenção, notificação e o correto manejo dos possíveis riscos durante a realização da assistência. ${ }^{5}$ Ações educativas como capacitações de equipes, implementacão de um sistema de notificação de EA; trabalhar a comunicação interprofissional; melhorar a gestão dos recursos; motivar profissionais a compartilhar dúvidas e acontecimentos como forma de aprendizagem, são formas de auxiliar na prevenção da ocorrência de EA. ${ }^{4}$

\section{Conclusão}

Os dados evidenciam predomínio de eventos adversos envolvendo medicações e imunizações, tendo como fatores causais a falta de comunicação, falhas na infraestrutura, no dimensionamento de pessoal e na execução da assistência, os quais contribuem para a ocorrência de subnotificações. Aos gestores cabe disponibilizar recursos e ferramentas adequadas, incentivando a equipe na incorporação de boas práticas ao cuidado prestado na APS. A notificação de eventos adversos pelos profissionais é permeada por medo, fruto de uma cultura punitiva que pode ser amenizada pela implantação de protocolos clínicos, diálogo entre profissionais e pacientes, educação permanente em saúde e qualificação profissional, tornando possivel o reconhecimento e prevenção de EA em ambiente favorável à melhor segurança do paciente.

Descritores: Eventos Adversos; Atenção Primária à Saúde; Segurança do Paciente; Enfermagem.

Financiamento: Programa de bolsas Universitárias do Estado de Santa Catarina UNIEDU.

\section{Referências}

1. Duarte SCM, Stipp MAC, Silva MM, Oliveira FT. Eventos adversos e segurança na assistência de enfermagem. Rev. Bras. Enferm [Internet]. 2015 Feb [acesso em 23 Out. 2020]; 68(1):144-54. Disponível em: http://www. scielo.br/scielo.php?script=sci_arttext\&pi$\mathrm{d}=$ So034-71672015000100144\&lng=en. DOI: https://doi.org/10.159o/o034-7167.201568012op.

2. Figueiredo ML, Oliveira e Silva CS, Brito MFSF, D'Innocenzo M. Analysis of incidents notified in a general hospital. Rev Bras Enferm [Internet]. 2018 [acesso em 23 Out. 2020]; 71(1):111-9. Disponível em: https://www.scielo.br/pdf/reben/v71n1/pt o034-7167-reben-71-01-0111.pdf. DOI: https:// doi.org/10.1590/0034-7167-2016-0574.

3. Lanzoni GMM, Goularte AF, Koerich C, Reisdorfer E, Miotello M, Meirelles BHS. Eventos adversos e incidentes sem dano em unidades de internação de um hospital especializado em cardiologia. Rev Min Enferm [internet]. 2019 [acesso em 23 Out. 2020]; 23:e-1184. Disponível em: https://cdn.publisher.gn1.link/reme.org.br/ pdf/e1184.pdf. DOI: 10.5935/1415-2762.20190032.

4. Santos PVM, Mendes PM, Abreu IM, Sá AGS, Ramos JV, Avelino FVSD. Conhecimento de enfermeiras sobre evento adverso na atenção primária à saúde. Revista enfermagem atual [internet]. 2019 [acesso em 05 Nov. 2020]; 89(27):01-07. Disponivel em: https://revistaenfermagematual. com.br/index.php/revista/article/view/459/475.

5. Oliveira RM, Bandeira ES, Silva CR, Soares AML, Fonteles DB, Barboza FBM. Tomada de decisão de enfermeiros frente a incidentes relacionados à segurança do paciente. Cogitare Enfermagem [internet]. $2016 \mathrm{Jul} / \mathrm{set}$ [acesso em Nov. 2020]; 21(3):01-10. Disponível em: https://revistas. ufpr.br/cogitare/article/view/45683/pdf. 
Pesquisa Original

\begin{abstract}
PROCESSO DE TRABALHO DE ENFERMEIROS
NA ESTRATÉGIA SAÚDE DA FAMÍLIA:

ENTRE O CUIDAR E O ADMINISTRAR
\end{abstract}

\author{
Mariana Mendes \\ Leticia de Lima Trindade \\ Denise Elvira Pires de Pires \\ Elaine Cristina Novatzki Forte \\ Lara Vandresen \\ Priscila Rodrigues da Cunha
}

\section{Introdução}

A enfermagem tem contribuído substancialmente para o acesso universal à saúde no Brasil e está presente em todas as estruturas organizacionais do sistema de saúde brasileiro, especialmente, na Atenção Primária à Saúde (APS), por meio da Estratégia Saúde da Família (ESF), considerada a porta de entrada para o Sistema Único de Saúde (SUS), o qual prevê o acesso universal e gratuito para todos cidadãos e é responsável pelo atendimento de $75 \%$ da população brasileira'. O processo de trabalho de enfermagem no Brasil é desenvolvido por três categorias profissionais: enfermeiro, tecnico e auxiliar de enfermagem e se divide em quatro dimensões, a saber: Cuidado; Administrativo-gerencial; Educativa e Investigativa ${ }^{2}$. O processo de trabalho da enfermagem é amplamente reconhecido por envolver o cuidado aos indivíduos, sendo que as atividades de cunho administrativo-gerencial, têm sido consideradas indispensáveis para a realização do cuidado com as pessoas ${ }^{2}$. Nessa perspectiva, o objetivo deste estudo é analisar o processo de trabalho dos enfermeiros na ESF no que concerne a dimensão administrativa do trabalho profissional dos enfermeiros.

\section{Método}

Participaram 79 profissionais de enfermagem (45 enfermeiros, 30 técnicos de enfermagem, quatro auxiliares de enfermagem) 
que atuavam na ESF há pelo menos um ano. O cenário foi composto intencionalmente por sete municípios distribuídos nas cinco Regiões do país e selecionadas zo Unidades Básicas de Saúde (UBS) que atuavam exclusivamente com o modelo assistencial da ESF. Para coleta de dados utilizou-se entrevistas, observação e estudo documental. As entrevistas foram realizadas mediante questionário, gravadas e transcritas na íntegra. A observação não participante e estudo documental ocorreram em média durante dois turnos de trabalho (oito horas) e foram registrados em diário de campo. Os dados foram coletados no período de 2015 a 2017 e para análise utilizou-se o software ATLAS.ti 8.o, seguindo as etapas da Análise Temática: pré-análise, exploração do material e tratamento dos resultados obtidos, inferência e interpretação ${ }^{3}$. A pesquisa foi aprovada pelo Comitê de Ética em Pesquisa da Universidade do Estado de Santa Catarina (Parecer n. 366.844/2010 e emenda Parecer n. 1.933.348/2017). Os participantes assinaram o Termo de Consentimento Livre e Esclarecido e foram identificados com as letras iniciais de cada categoria; a Região de atuação; e o número sequencial (por exemplo: EN1, EN2, TES $\left.1, \mathrm{TES}_{2}, \ldots\right)$. Os dados provenientes do estudo documental (ED) ou observação (OBS) foram descritos por sua abreviatura seguido da Região.

\section{Resultados e Discussão}

Nas práticas gerenciais realizadas pelos enfermeiros na ESF predominam a supervisão de técnicos, auxiliares e Agentes Comunitários de Saúde (ACS), coordenação de programas, realização de reuniões de equipe, definição de agendas, organização do processo de trabatho da equipe de enfermagem e, por vezes, de outros profissionais. Estas atividades ocupam boa parte do tempo de trabalho dos enfermeiros, pois muitos deles desenvolvem práticas assistenciais e de gestão das UBS, incluindo a coordenação do trabalho desenvolvido pelas equipes de Saúde da Família (eSF): "Então todos os relatórios, o agente comunitário, a supervisão do técnico, não é só a assistência ao usuário. Por trás disso tem ' $N$ ' situações que ficam muito na referência do enfermeiro. [...] todo o funcionamento burocrático da equipe acaba ficando na mão do enfermeiro. Desde o gerenciamento dos relatórios, as pautas de reunião diária. Então eu acho que é uma outra situação que sobrecarrega (ES6)". "O enfermeiro trabalha muito as duas coisas porque a gente como gerência tem de organizar o trabalho tanto na parte da assistência e cuidar das pessoas, da equipe, e eu acho bem cansativo, lidar com con- flitos de funcionários, tudo cai para o enfermeiro e sempre a enfermeira vai ter de resolver. Aconteceu alguma coisa na secretária para quem eles ligam? Para o enfermeiro, mesmo que o problema não seja diretamente ligado a enfermagem, se o problema for com o médico eles ligam para nós para que a gente fale com o médico (ES1o)". A PNAB, reeditada em 2017, criou o cargo de gerente e reconhece a necessidade de um profissional que não componha a equipe mínima para gerenciar as UBS por conta da sobrecarga de trabalho, permitindo ao enfermeiro da equipe priorizar as demandas de cunho assistencial. Nessa perspectiva, o gerente deve cumprir carga horária de 40 horas semanais, gerenciar as eSF e insumos, acompanhar e analisar indicadores, dentre outras atividades ${ }^{4}$. Contudo, a dimensão administrativa dos enfermeiros na ESF ultrapassou a gerência da equipe e o processo de trabalho da enfermagem, de modo que estes profissionais acabam desenvolvendo atividades de gerência das eSF simultaneamente às assistenciais, gerando sobrecarga de trabalho, reduzindo a resolutividade das acões em virtude da realização de diversas atividades ao mesmo tempo e causando insatisfação ao profissional devido à constante sensação de "não dar conta": "Tenho todo um trabalho administrativo para fazer e mais a parte assistencial, isso eu acho que pesa sim, o administrativo eu posso me organizar para fazer, mas muitas vezes, tem coisas que saem da minha organização. E o assistencial está marcado e eu não tenho como não atender, não posso dizer que não atendo porque preciso fazer um relatório. Vou ter que atender e vou ter que fazer o relatório $\left(E C \mathrm{O}_{1}\right)$ )" "A minha autoavaliação é que eu não dou conta. Eu não dou conta de fazer o atendimento, preencher o meu e-SUS, digitar o meu e-SUS, dar conta das demandas que o enfermeiro tem de responder ao distrito, de fazer a planilha das ações educativas, então existe uma tristeza, por não dar conta do tanto de coisas que há para a gente dar conta, no tempo que a gente tem que dar conta (ENE7)". $\mathrm{O}$ acúmulo das atividades assistenciais/gerencias no âmbito do processo de trabalho da enfermagem com a coordenação e/ou gerenciamento das UBS transformam as práticas dos enfermeiros, tendo em vista que o tempo destinado à assistência passa a ter de comportar as atividades que deveriam ser desenvolvidas por outros profissionais. Estudo recente evidencia que a sobreposição das atividades de assistir e gerenciar são considerados enormes desafios para os enfermeiros, interferindo no exercício da liderança e na qualidade das práticas desenvolvidas no contexto da ESF5, contrapondo o prescrito pela $\mathrm{PNAB}$ em relação à presença de um profissional para realizar, especificamente, 
as atividades de gestão das equipes ${ }^{4}$. A melhoria das condições de trabalho e reorganização do processo de trabalho em saúde, somadas à aprovação de suas reinvindicações imprescindíveis para realização de um trabalho digno, são emergentes para a Enfermagem, devendo ser alvo de constantes esforços para tornar visível o potencial da categoria que representa o maior quantitativo da força de trabalho em saúde no mundo'. Nesse cenário desafiador, de assistir e administrar, entre outras tarefas, vivenciado pelos enfermeiros na ESF, o apoio dos técnicos e auxiliares de enfermagem, bem como da equipe multidisciplinar, assume grande importância para que, na prática, o processo de trabalho provisionado pelo enfermeiro possa ser executado e qualificado.

\section{Conclusão}

A ausência de um profissional que atue exclusivamente no apoio administrativo e na gestão das eSF torna o trabalho dos enfermeiros desafiador e desgastante, em especial, devido ao enfermeiro absorver as demandas administrativas e burocráticas que envolvem o processo de trabalho, não apenas da enfermagem, reduzindo o tempo de dedicação à assistência e influenciando no processo assistencial, com potencial detrimento do administrativo-gerencial, e ainda menor possibilidade de investir nas demais dimensões.

Descritores: Enfermagem de atenção primária. Estratégia saúde da família. Administração de serviços de saúde.

Financiamento: Este estudo compõe uma macropesquisa financiada pelo CNPq.

\section{Referências}

1. Silva MCN, Machado MH. Sistema de Saúde e Trabalho: desafios para a Enfermagem no Brasil. Ciência \& Saúde Coletiva [Internet]. 2020; 25(1):07-13. Doi:10.1590/1413-81232020251.27572019.

2. Bertocini J, Pires D, Ramos F. Dimensões do trabalho da enfermagem em múltiplos cenários institucionais. Revista tempus actas saude coletiva [Internet]. 2011;5(1):123-33. Doi: 10.18569/ tempus.v5i1.922.

3. Bardin L. Análise de conteúdo. 3. ed. rev. e ampl. São Paulo: Edições 70; 2016.

4. Ministério da Saúde (BR). Política Nacional de Atenção Básica [Internet]. Brasília: MS; 2017. [Acessado em 2021 jan 07]. Disponível em: http:// pesquisa.in.gov.br/imprensa/isp/visualiza/index.jsp?jornal $=1 \&$ pagina $=68 \&$ dat $a=22 / 09 / 2017$.

5. Oliveira C, Santos LC, Andrade J, Domingos TS, Spiri WC. A liderança na perspectiva de enfermeiros da Estratégia Saúde da Família. Rev. Gaúcha Enferm. [Internet]. 2020; 41:e20190106. Doi: 10.1590/1983-1447.2020.20190106. 
RELATO DE EXPERIÊNCIA

GESTÃO DO SERVIÇO DE ENFERMAGEM NA ATENÇÃO PRIMÁRIA À SAÚDE NO ENFRENTAMENTO DA PANDEMIA PELO NOVO CORONAVÍRUS

\author{
Rui Carlos Sacramento \\ Rosana Amora Ascari
}

\section{Introdução}

A inserção política do enfermeiro no cenário da saúde do Brasil foi se consolidando a partir da estruturação do Sistema Único de Saúde (SUS), quando se passou a compreender a enfermagem como parte de uma estrutura social, com participação nas mudanças das políticas de saúde que se traduzem em ações voltadas para a cidadania e promoção da saúde. Portanto, no processo de formação do enfermeiro, espera-se que se delineie um saber sustentado pela criticidade e capacidade reflexiva profissional no que tange aos elementos basais de uma sociedade nas perspectivas política, social, econômica e cultural. Desse modo, há demanda de alterações curriculares, ao se buscar o ajustamento às exigências do perfil profissional do enfermeiro no Brasil, discutindo-se, assim, os novos rumos para a valorização da enfermagem no interior das equipes de saúde. ${ }^{1}$ Face ao exposto, em decorrência da pandemia causada pelo novo Coronavírus (SARS-CoV-2), ${ }^{2}$ também chamada COVID-19, é possível evidenciar a importante atuação do enfermeiro no contexto de crise. A pandemia da COVID-19 tem-se mostrado, em termos de gravidade, como uma das mais avassaladoras dos últimos tempos. Contribui para esse fato a facilidade de transmissão do novo Coronavírus, que ocorre de pessoa para pessoa, por meio da autoinoculação nas mucosas ou de vírus presentes em fômites (objetos inanimados contaminados). ${ }^{2}$ Desse modo, 
as adequações de estratégias adotadas nos serviços de saúde foram importantes medidas de proteção humana, buscando impedir a contaminação dos trabalhadores e pacientes. O processo de trabalho da gestão em enfermagem, mais especificamente na atenção básica, obteve inúmeros ajustes durante a pandemia da COVID-19, dentre eles pode-se citar o aumento exagerado dos equipamentos de segurança e ao mesmo tempo, a dificuldade na aquisição dos mesmos, exigindo rápida atuação da gestão local dos serviços.

\section{Objetivo}

Relatar os principais entraves enfrentados pela gestão da atenção primária à saúde para manter o funcionamento dos serviços de saúde e os indicadores de saúde estabelecidos pelas esferas estaduais e federais, num município do interior de Santa Catarina.

\section{Método}

Trata-se de um relato de experiência acerca da vivência enquanto enfermeiro atuante na coordenação de atenção básica de um município do meio oeste catarinense. Frente aos momentos vivenciados pelo mesmo, buscou-se a conectividade com estudos científicos para tal embasamento, visando contribuir no processo de gestão em saúde e enfermagem, delineado pela pandemia.

\section{Resultados e Discussão}

O enfermeiro na gestão encontra-se como protagonista no processo de ajustes de condutas na práxis, sobretudo, resguardando a segurança da equipe de colaboradores e usuários do sistema público de saúde. O maior desafio enquanto gestão está em conseguir manter o fluxo de trabalho seguro, tanto no que diz respeito aos recursos humanos, quanto para o quantitativo de equipamentos de proteção individual (EPI) e estrutura física, de forma diferenciada e ao mesmo tempo adequada às demandas do momento crítico o qual estamos vivenciando. Vale lembrar, que a atenção primária à saúde segue os princípios doutrinários do SUS (universalidade, equidade e integralidade nos serviços e ações de saúde) garantido mediante políticas sociais e econômicas o acesso universal e igualitário às ações e serviços para a promoção, proteção e recuperação da saúde. Nesse sentido, algumas ações foram prejudicadas frente o novo modo de agir para combater a pandemia. Após a análise e expla- nação das alterações de fluxo de trabalho necessárias ao enfrentamento da pandemia no cenário local e implementá-los, pode-se observar que o processo de gestão de enfermagem durante a pandemia foi embasado através de vários estudos científicos e orientações sanitárias nacionais e internacionais, contemplando adequações nos fluxos interno dos serviços de saúde, bem como ao atendimento da população adstrita e a segurança dos profissionais quanto às medidas de prevenção do novo Coronavírus. Ao considerar o atual cenário de pandemia e a efetiva atuação dos profissionais e serviços de saúde, as políticas assistenciais devem levar em conta ações de saúde voltadas para os grupos com maior vulnerabilidade. Com a estruturação interna e maior demanda de atendimentos relacionados à pandemia, os profissionais precisaram intensificar ações para não prejudicar ainda mais os indicadores de saúde municipais, visto os demais agravos continuam a ocorrer. $\mathrm{E}$, nesse ínterim, os trabalhadores da saúde têm um papel relevante na dinâmica de disseminação do novo Coronavírus, motivo que pelo qual foi necessário gerenciar o processo e as condiçoes de trabalho para minimizar o potencial de disseminação do agente infeccioso (SAR$\mathrm{S}-\mathrm{CoV}-2)$ entre os trabalhadores da saúde. A não observância desse aspecto implica sua invisibilidade e pouca valorização nas políticas públicas voltadas à proteção, levando ao adoecimento e óbito de trabalhadores. A literatu$\mathrm{ra}^{3}$ destaca que a análise da situação da força de trabalho em saúde no Brasil tem sido feita em vários estudos, que apontam os principais problemas, tanto o que diz respeito a disponibilidade e distribuição das diversas categorias profissionais para atender às necessidades de funcionamento adequado dos serviços, nos diversos níveis de atenção, quanto os problemas relacionados à gestão do trabalho, isto é, os mecanismos de contratação, qualificação e valorização da força de trabalho no setor. Ainda, os problemas decorrentes do subfinanciamento do SUS, do congelamento dos gastos no setor, da deterioração dos serviços e da precarização da força de trabalho, ${ }^{4}$ denunciam seus efeitos negativos na prestação de serviços de atenção, particularmente na atenção primária à saúde, seriamente afetada pelas mudanças na lógica do financiamento ocorridas nos ưltimos anos. Configura-se, de fato, uma crise permanente do sistema de saúde, fortemente afetada pela reorientação das políticas de saúde adotadas a partir da crise econômica e do "golpe do capital" na saúde, marcadas pela financeirização da saúde, pelo ajuste fiscal demarcado pela emenda Constitucional n. 95 de 2016, restauração do 
neoliberalismo, privatização "por dentro" do sistema público e desmonte do Sistema Único de Saúde (SUS), tal como foi proposto e legitimado na Constituição Federal de 1988. Assim, a luta pela manutenção de um sistema público, gratuito, de qualidade e resolutivo é uma constante tanto para a população, como para os gestores e é na micropolítica que as pequenas mudanças fazem a diferença.

\section{Conclusão}

De acordo com a vivência profissional mencionada, pode-se observar que o processo de gestão em saúde e enfermagem na atenção primária à saúde durante a pandemia, é um fator comum aos gestores de diferentes esferas administrativas no setor público, com ênfase para as esferas municipais, as quais são a porta de entrada dos usuários aos serviços de saúde, relaciona-se diretamente com a população adstrita, viabiliza acesso e responsabiliza-se pela implementação de ajustes conforme as necessidades locaîs da população e recursos disponíveis. Esse estudo contribui para a reflexão acerca das práticas de gestão do SUS. A atenção primária a saúde, como porta de entrada principal do SUS está precisando de ajustes cada vez mais rápidos e eficazes, evitando assim a sobrecarga do serviço de saúde básico e consequentemente dos serviços de média e alta complexidade. Sabe-se que o planejamento/gerenciamento não acabou, afinal, é a atenção primária à saúde que precisa monitorar e acompanhar os efeitos decorrentes da COVID-19 na população e muitos serviços precisam ser incrementados com recursos humanos e materiais nos próximos meses com monitoramento assíduo de dados epidemiológicos no processo de disseminação do novo Coronavírus, evitando ainda mais sobrecargas aos serviços de saúde, e consequentemente, o temido colapso desse sistema.

Descritores: Gestão da Informação em Saúde; Atenção Primária à Saúde, Infecções por Coronavírus; Gestão da Segurança; Enfermagem.

\section{Referências}

1. Edwards CH, Tomba GS, de Blasio BF. Influenza in workplaces: transmission, workers' adherence to sick leave advice and European sick leave recommendations. Eur J Public Health [Internet]. 2016;26(3):478-85. Disponível em: https://doi.org/10.1093/eurpub/ckwo31

2. Adamy EK, Korb A, Zanatta L, Menegaz JC, Ascari RA. Instruções de controle e prevenção da COVID-19 na UDESC. Série Material Instrucional. 2. Ed. Florianópolis: Editora Udesc, 2020, 28 p.

3. Machado MH, Ximenes Neto FR. Gestão da Educação e do Trabalho em Saúde no SUS: trinta anos de avanços e desafios. Cien Saude Colet 2018; 23(6):1971-1979.

4. Teixeira CF, Paim JS. A crise mundial de 2008 e o golpe do capital na política de saúde no Brasil. Saúde Debate 2018; 42(n. esp. 2):11-21. 
Pesquisa Original

\begin{abstract}
IMPACTOS DAS ATIVIDADES GERENCIAIS NO PRAZER E SOFRIMENTO DE DOCENTES DA PÓS-GRADUAÇÃO STRICTO SENSU
\end{abstract}

\section{Chancarlyne Vivian Letícia de Lima Trindade}

\section{Introdução}

Para a Psicodinâmica do Trabalho ${ }^{1-2}$, o sofrimento sempre estará presente na prática laboral, visto que o fato de trabalhar é sempre operar no sentido de modificar o real, sendo o sofrimento o resultado na contraposição entre o trabalho prescrito e o real do trabalho. ${ }^{1}$ Esse aspecto não é diferente no contexto laboral dos docentes do ensino superior, e dentre estes aqueles que atuam na pós-graduação Stricto Sensu. Estudos ${ }^{3-4}$ mostram a intensificação e potencial desgaste destes profissionais, tendo em vista as muitas demandas do seu trabalho, que envolvem a exigência por alta produção científica, conseguir boa performance diante do que se é exigido burocraticamente pela instituição, preparação, elaboração e organização das aulas, busca constante por inovação dos métodos, sobrecargas de trabalho que muitas vezes chegam aos profissionais em seus dias/horários de descanso por meio das Tecnologias de Informação e Comunicação (TIC). Além disso, agrega-se às atividades de ensino, pesquisa e extensão, diversas exigências gerenciais e administrativas, que revelam que as novas estratégias de gestão oriundas do mundo corporativo distanciam o trabalho real do trabalho prescrito no contexto de ensino. Nesse sentido, esse recorte dos achados de uma dissertação busca apresentar os impactos que estas atividades têm no prazer e sofrimento docente, sob a ótica da Psicodinâmica do Trabalho. 


\section{Objetivo}

Compreender o papel que as atividades gerenciais exercem no prazer e sofrimento de docentes da pós-graduação Stricto Sensu.

\section{Método}

trata-se de recortes dos achados de um estudo de caráter descritivo, que adotou a abordagem quali-quantitativa, a fim de compreender na totalidade e com profundidade o contexto investigado. A pesquisa teve como cenário uma universidade do oeste do estado de Santa Catarina e como participantes da primeira etapa quantitativa 47 docentes que atuavam em sete cursos de pós-graduação Stricto Sensu, das áreas: Engenharia, Ciências Sociais e Aplicadas, Ciências da Saúde, Ciências Humanas, Ciências Biológicas, Ciências Agrárias e Ciências Exatas e da Terra. Como critérios de inclusão dos docentes no estudo, utilizou-se: ser docente permanente nos cursos de Pós-Graduação Stricto Sensu e estar atuando por um período mínimo de um ano completo na atividade. Foram excluidos os docentes que estavam afastados das atividades no período da coleta de dados. Todos os docentes que se encaixavam nos critérios de inclusão do estudo, foram convidados via e-mail a participar da investigação. A participação na primeira etapa do estudo consistiu em responder a um Questionário de Dados Sociolaborais e de Condições de Saúde e ao Inventário sobre Trabalho e Riscos de Adoecimento (ITRA). Na segunda etapa, foram sorteados aleatoriamente, 14 docentes para responder uma entrevista semiestruturada. A análise dos dados quantitativos, coletados no Questionário e no ITRA, foram tabulados e posteriormente analisados com auxílio do programa Statistical Package for the Social Sciences, versão 21.0. Já para a análise dos dados qualitativos foi utilizada a Análise Temática. ${ }^{5} \mathrm{~A}$ pesquisa cumpriu integralmente as Resoluções no 466/2012 e no 510/2016, do Conselho Nacional de Saúde e foi aprovada pelo Comitê de Ética em Pesquisa com Seres Humanos (parecer de $\mathrm{n}^{\mathrm{o}}$ 2.799.056/2018). O período de coleta de dados ocorreu entre os meses de outubro de 2018 e março de 2019.

\section{Resultados e Discussão}

Os docentes que participaram da pesquisa, eram, na maioria, homens $(61,7 \%)$, com companheiros $(n=42 / 89,4)$, com filhos $(n=$ $34 / 72,3)$, com em média 46,5 anos de idade (desvio padrão de 10,1), formados em média há 17 anos, atuavam em média 15 anos na docência, mas somente quatro anos em média, na pós-graduação. Os achados quantitativos ilustraram que quanto maior é o tempo de formação profissional, mais negativa é a avaliação que os docentes têm do domínio da Organização do Trabalho $(\mathrm{p}=\mathrm{O}, \mathrm{Oz2})$ e maior é a percepcão de danos físicos ocasionados pelo trabalho $(p=0,011)$. Ainda, identificou-se associação significativa entre apresentar sintoma que sugere alteração de saude física ou emocional e o domínio de Organização do Trabalho $(\mathrm{p}=\mathrm{O}, \mathrm{OO} 1)$. Para tanto, para superar as condições adversas no trabalho, 29,8\% ( $p$ $=0,004)$ dos docentes fazem uso de medicamentos, especialmente analgésicos e ansiolíticos. Além disso, as pressões sofridas pelas exigências institucionais, de órgãos que fiscalizam e avaliam a pós-graduação também são fatores que atravessam o cotidiano docente. A desvalorização do profissional pela instituição, a banalização pela sociedade e o não reconhecimento também apareceram como dimensões que impactos significativamente a vida destes profissionais. Ademais, encontrou-se danos a saúde do professor, entre eles o cansaço físico, o aumento de peso, resultados metabólicos, dores de cabeça e alteração da pressão arterial, os quais foram ilustrados pelos docentes como consequência de processos de trabalho exaustivos. Além disso, respostas somáticas como alteração de sono, preocupação, ansiedade e cansaço foram elencados como respostas advindas do desajustamento da organização do trabalho. Em face do exposto, a multicausalidade das fontes de prazer e sofrimento na docência permitem compreender que tanto um quanto outro são experienciados de maneira singular pelos profissionais docentes. O prazer sublimatório e o sofrimento criativo suscitado pelos pares no trabalho só são possibilitados quando há solidariedade, cooperação e reconhecimento entre os colegas de trabalho e a gestão. Em razão disso, prazer e sofrimento não podem ser compreendidos de forma simplista, mas devem ser interpretados a partir de um somatório de vieses, pois tanto um quanto outro são resultado da combinação da história da pessoa com a organização do trabalho. ${ }^{1}$

\section{Conclusão}

Os achados sinalizam que as atividades gerenciais tem agregado mais sofrimento ao trabalho docente no pós-graduação, e para a necessidade de compreender os profissionais da pós-graduação integralmente, visto que 
suas respostas sintomáticas derivam de incompreensões, imposições e movimentos psicoafetivos gerados pela evolução dos seus conflitos inter e intrasubjetivos, sendo importante que ocorra a sensibilização dos pares e da gestão, com o intuito de proporcionar a estes profissionais processos de escuta e recuperação de diálogo, com a finalidade de fortalecer as situações geradoras de prazer e a minimizacão daquelas que provocam sofrimento. Dessa forma, a organização e os processos de trabalho poderão ser ressignificados com o intuito de reavaliar os desastrosos efeitos dos atuais métodos de avaliação do trabalho sobre a saúde dos trabalhadores, é preciso afrouxar a pressão exercida pela gestão e ampliar o suporte a estes docentes singulares no contexto da Ciência.

Descritores: Trabalho; Docentes; Saúde Ocupacional; Universidades.

Financiamento: Estudo com bolsa de estudo pela Universidade Comunitária da Região de Chapecó.

\section{Referências}

1. Dejours C, Deranty JP, Renault E, Smith N. The Return of Work in Critical Theory: self, society, politics. New York: Columbia Unniversity Press; 2018.

2. Dejours C. Psicodinâmica do Trabalho: Casos Clínicos. Porto Alegre: Dublinense; 2017.

3. Silva AV, Piolli E. A Centralidade na Psicodinâmica de Christophe Dejours, O Campo Educacional e o Trabalho Docente: Aproximações Possíveis. Devir Educação. 2017; 1(1): 50-65.

4. Hoffmann C, Marchi J, Comoretto E, Moura GL. Relações entre autoconceito profissional e produtivismo na pós-graduação. Psicologia \& Sociedade, Belo Horizonte. 2018; 30(167961): 1-10.

5. Bardin L. Análise de conteúdo. Edição Revista e Ampliada. São Paulo: Edições 7o; 2016. 
CARACTERIZAÇÃO DA ATENÇÃO DOMICILIAR NO ATENDIMENTO ÀS CRIANÇAS COM NECESSIDADES ESPECIAIS EM SANTA CATARINA

\author{
Diana Augusta Tres \\ Elisangela Argenta Zanatta \\ Beatriz Rosana Gonçalves \\ de Oliveira Toso
}

\section{Introdução}

A Atenção Domiciliar (AD) no Brasil foi regulamentada em 2011, pela portaria $\mathrm{n}^{\mathrm{o}}$ 2.029. Em 2016 ocorreu a última redefinição e atualização por meio da portaria no 825 , que definiu a ẢD como uma modalidade de atenção à saúde que se caracteriza pela realização de ações de prevenção e tratamento de doenças, reabilitação, paliação e promoção à saúde, ações estas que devem ser prestadas no domicílio do usuário com a finalidade de garantir a continuidade dos cuidados. ${ }^{1}$ A AD está dividida em três modalidades: $\mathrm{AD}_{1}, \mathrm{AD}_{2}$ e $\mathrm{AD}_{3}$. Os usuários que se encaixam às modalidades $\mathrm{AD}_{2} \mathrm{e}$ $\mathrm{AD}_{3}$, são usuários elegíveis para o Serviço de Atenção Domiciliar (SAD) e se caracterizam por apresentarem doenças agudas, crônico agudizadas, crônico-degenerativas e necessidade de cuidados paliativos semanais. Da mesma forma, necessitam de cuidados intensificados, uso de equipamento e procedimentos de maior complexidade. ${ }^{1}$ Assim, o SAD pode ser definido como um serviço complementar aos cuidados realizados na Atenção Primária à Saúde (APS) e em serviços de urgência, substitutivo ou complementar à internação hospitalar, realizado pelas Equipes Multiprofissionais de Atenção Domiciliar (EMAD) e Equipes Multiprofissionais de Apoio (EMAP). ${ }^{1}$ Nesse contexto, a $\mathrm{AD}$ é indicada para pessoas de qualquer faixa etária, clinicamente estáveis, mas que necessitam de uma atenção especial à saúde. ${ }^{1}$ Dessa forma, devido aos critérios de elegibi- 
lidade das modalidades $\mathrm{AD}_{2}$ e $\mathrm{AD}_{3}$, a $\mathrm{AD}$ precisa ser inclusa na assistência de Crianças com Necessidades Especial de Saúde (CRIANES), ou seja, aquelas que se caracterizam por apresentarem uma condição crônica de saúde, normalmente necessitando de cuidados contínuos ou temporários e, muitas vezes, permanentes, com um número maior de atendimentos do que uma criança que não apresente qualquer condição crônica de saúde. Do mesmo modo, demandam cuidados técnicos especializados e podem necessitar de internações frequentes e prolongadas. ${ }^{2}$

\section{Objetivos}

Caracterizar os Serviços de Atenção Domiciliar em Santa Catarina (SC) e conhecer as demandas de cuidados e as necessidades de atenção especial a saúde de crianças atendidas pelos SADs de SC.

\section{Método}

Pesquisa descritiva, exploratória, de abordagem quantitativa, vinculada a macro pesquisa "Produção do cuidado e validação de protocolo de fluxo para serviços de atenção domiciliar a crianças com necessidades especiais de saúde". O estudo foi realizado com os SADs do Estado de SC. Inicialmente foi enviado um convite via e-mail aos 11 municípios do Estado que possuem o serviço implantado e em pleno funcionamento (Áraranguá, Biguaçu, Blumenau, Brusque, Capivari de Baixo, Chapecó, Gaspar, Jaraguá do Sul, Joinville, Lages e Maravilha). Dos 11 serviços, sete aceitaram participar, dois não responderam e dois não realizam atendimento a crianças. A coleta de dados foi realizada de abril a julho de 2020, sendo o link do questionário enviado por correio eletrônico para os sete SADs que aceitaram participar da pesquisa. O questionário foi respondido pelo coordenador de cada SAD ou por um outro membro da equipe indicado por ele. Os dados foram exportados para o programa Excel organizados em frequências relativa e absoluta, sendo construída uma matriz para a análise dos dados descritivos. O estudo foi aprovado pelo comitê de ética em pesquisa com seres humanos, sob parecer número 3.477.776.

\section{Resultados e Discussão}

Dos profissionais que responderam o questionário $4(57,1 \%)$ eram enfermeiros. A maioria dos serviços possuí somente uma $\operatorname{EMAD}(57,1 \%)$, sendo que $4(57,1 \%)$ serviços contam com uma EMAP. Dos serviços que possuem EMAP, todos têm psicólogo e nutricionista, três deles contam com fonoaudiólogo, dois tem fisioterapeuta e assistente social e um deles conta com farmacêutico. O profissional enfermeiro realiza a coordenação de $6(85,7 \%)$ serviços, $4(57,1 \%)$ possuem a sede localizada anexa à secretaria de saúde e, os outros $5(71,4 \%)$, realizam o atendimento dos usuários somente no domicílio. Todos os serviços possuem atendimento de segunda a sexta e $5(71,4 \%)$ atendem, também, aos finais de semana. Da mesma forma, os sete SADs recebem encaminhamentos de pacientes $\mathrm{da}$ APS, $6(85,7 \%)$ recebem de hospitais públi$\cos$ e $3(42,9 \%)$ de UPAs e hospitais oncológicos. Assim, de acordo com a portaria que regulamenta o SAD, todos profissionais que compõem as EMAP's são de nível superior e as ocupações foram escolhidas de acordo com o que é regulamentado, possibilitando um trabalho em equipe multiprofissioal. ${ }^{1}$ Apesar da recomendação de que o serviço deve funcionar em dias úteis e nos finais de semana e feriados, de forma a assegurar a continuidade da atenção em saúde, dois municípios não realizam o atendimento no final de semana. Referente as solicitações de atendimento, observou-se que a maioria dos SADs recebe pacientes da APS e de hospitais, contribuindo então para a desospitalização de usuários e favorecendo a articulação do serviço com a Rede de Atenção à Saúde (RAS). ${ }^{1}$ Em estudo realizado no Esstado do Paraná, o enfermeiro também realiza a coordenação da maioria dos serviços, desenvolvendo assim um papel fundamental na $\mathrm{AD}$, que além de envolver a função de coordenar a equipe e o plano de cuidado dos usuários, também é quem reali$\mathrm{za}$, na maioria das vezes, as orientações aos usuários, cuidadores e familiares. ${ }^{3}$ Todos os serviços que participaram do estudo realizam $o$ atendimento às CRIANES, sendo um total de 18 crianças, destas, 15 (83,3\%) possuem até seis anos incompletos. Em relação ao atendimento $6(85,7 \%)$ SADs realizam visita domiciliar semanal a elas. Das 18 crianças, $10(55,5 \%)$ estão na modalidade $\mathrm{AD}_{2}$ e $8(44,4 \%)$ na $\mathrm{AD}$. Todas as CRIANES do estudo necessitam de reabilitação psicomotora e social, consequentemente, são dependentes de algum tipo de dispositivo e/ou cuidado especial. A maioria faz uso de gastrostomia $12(66,6 \%)$, traqueostomia $10(55,5 \%)$ e metade é dependente de ventilação mecânica 9 (50\%). Observou-se um número elevado de crianças dependentes de complementos alimentares $14(77,7 \%)$, fárma$\cos 13(72,2 \%)$, cuidados especiais $13(72,2 \%)$ e 
em número menor, as que fazem uso de sonda nasoenteral $7(38,8 \%)$, cateter totalmente implantado $1(5,5 \%)$ e ostomias $1(5,5 \%)$. Dentre os diagnósticos principais, destacam-se as alterações neurologicas ou neuromusculares 11 $(61,1 \%)$, prematuridade $3(16,6 \%)$, malformação congênita $3(16,6 \%)$ e cardiovasculares 1 $(5,5 \%)$. A pesquisa revelou que, a maioria das crianças, faz uso de dispositivos tecnológicos e apresentam uma condição crônica, assim corroborando que os avanços tecnológicos na área da saúde tềm provocado mudanças importantes na atenção à saúde da criança, especialmente, levando ao aumento da sobrevivência de crianças, que antes morriam precocemente devido a doenças graves, tais como: prematuridade, malformações congênitas e condições crônicas. ${ }^{4}$ Essa evolução tem permitido a transferência do cuidado de crianças do ambiente hospitalar para o domiciliar, mas para que isso aconteça, a família precisa ser assistida por uma equipe multiprofissional de saúde para que se sintam seguras e amparadas no processo de cuidar de um filho dependente de dispositivos tecnológicos no domicílio. ${ }^{4}$

\section{Conclusão}

O cuidado às CRIANES apresenta diversas complexidades devido as condições crônicas e o uso de dispositivos para manutenção da vida. O SAD, pelas suas características e por contar com equipes multiprofissionais de saúde, configura-se como um componente fundamental na RAS para o atendimento de crianças que necessitam de cuidados complexos em domicílio. Assim, as equipes de AD, além de participarem do processo desospitalização desenvolvem um papel importante na reabilitação, adaptação da criança ao uso de dispositivos e na orientação e capacitação de pais/cuidadores para a continuidade dos cuidados com a criança no domicílio.

Descritores: Saúde da Criança; Assistência Domiciliar; Serviços de Assistếncia Domiciliar; Doença Crônica; Enfermagem.

Financiamento: Edital CHAMADA UNIVERSAL - MCTI/CNPq $\mathrm{N} \cong$ 28/2018

\section{Referências}

1. Brasil. Ministério da Saúde. Portaria $n^{-}$ 825, de 25 de abril de 2016. Redefine a Atenção Domiciliar no âmbito do Sistema Único de Saúde (SUS) e atualiza as equipes habilitadas. Brasília: Ministério da Saúde, 2016. [acesso 05 de agosto de 20zo] disponível em: http:// bvsms.saude.gov.br/bvs/saudelegis/gm/2016/ prto825_25_04_2016.html

2. Neves ET. et al. Rede de cuidados de crianças com necessidades especiais de saúde. Texto Contexto Enfermagem [revista em internet] Florianópolis, 2015. [acesso o5 de agosto de 2020]; 24 (2). Disponível em: http://www. scielo.br/pdf/tce/v24n2/pt_0104-0707-tce-24-02-00399.pdf

3. Rosseto V, Toso BRGO, Rodrigues RM, Viera CS, Neves ET. Cuidado desenvolvido às crianças com necessidades especiais de saúde nos serviços de atenção domiciliar no Paraná - Brasil. Escola Anna Nery [revista em internet] Rio de Janeiro, 2019. [Acesso 05 de agosto de 2020]; 23 (1). Disponivel em: http://www.scielo.br/pdf/ ean/v23n1/pt_1414-8145-ean-23-01-e20180o67.pdf

4. Carvalho MSN, Menezes AL, Filho da Cruz AD, Maciel CMP. Desospitalização de crianças com condições crônicas complexas: perspectivas e desafios. Eldorado [livro de internet]. Rio de Janeiro, 2019. 
IMPACTOS DA OFERTA DE PRÁTICAS INTEGRATIVAS E COMPLEMENTARES NA GESTÃO DO TRABALHO DE PROFISSIONAIS DA SAÚDE

Carine dos Santos Spindola

Ana Beatriz da Costa Franceschini

Larissa de Oliveira Derussi Gil

Letícia de Camargo Pereira

Fabiana Zucchi Beneli

Leandra Andréia de Sousa

\section{Introdução}

O Sistema Único de Saúde (SUS) é considerado mundialmente como um dos maiores e mais complexos sistemas de saúde pública do mundo. Nele, destaca-se a Atenção Primária à Saúde (APS) enquanto reordenadora do sistema e principal porta de entrada do usuário ao Sistema e, a Estratégia Saúde da Família (ESF), prioridade nacional para fortalecer a APS e organizar o acesso ao SUS. Ressalta-se também os Núcleos Ampliados de Saúde da Família e Atenção Básica (NASF AB), compostos por equipes multiprofissionais que atuam de forma compartilhada e integrada com as equipes da ESF, para ampliar a abrangência, escopo e resolubilidade das ações da APS. Nesse contexto, se inserem as Práticas Integrativas e Complementares (PIC) que, além de serem recomendadas e apoiadas pela Organização Mundial de Saúde ${ }^{[1]}$, são ofertadas no SUS por meio da Política $\mathrm{Na}$ cional de Práticas Integrativas e Complementares (PNPIC) $)^{[2]}$. Atualmente a PNPIC reúne 29 práticas terapêuticas. As PIC favorecem o protagonismo do usuário, valorizam a promoção da saúde, ressignificam positivamente o trabalho em saúde e a relação entre profissionais de saúde e usuários e predispõem o cuidado ampliado na direção de um modelo integral de atenção no SUS. A interface entre NASF e PIC é profícua e assinala potência de fortalecimento mútuo na direção do fortalecimento do SUS, pois favorece a produção da gestão do trabalho e, consequentemente, do cuidado na APS. 


\section{Objetivos}

Identificar facilidades e dificuldades da oferta de PIC nos serviços da APS, na percepção de profissionais do NASF e mapear as PIC ofertadas por profissionais do NASF, em um Departamento Regional de Saúde do Estado de São Paulo.

\section{Método}

Trata-se de um estudo de natureza descritiva com abordagem quanti-qualitativa. $\mathrm{O}$ presente trabalho se desenvolve no contexto das equipes NASF e faz parte de uma pesquisa abrangente acerca da implantação das PIC nos serviços de APS dos 24 municípios integrantes de um DRS/SP, o qual se divide em quatro regiões: A, B, C e D. Participaram deste estudo profissionais da equipe de oito NASFs, sendo três da região $\mathrm{A}$, três da $\mathrm{C}$ e dois da região $\mathrm{B}$, totalizando oito participantes, os quais atenderam aos critérios de inclusão: trabalhar no NASF do município integrante do DRS, cujo SUS local oferte ou não uma ou mais PIC previstas na PNPIC; dispor de aparelho digital, como computador, notebook ou celular e acesso à internet e aceitar participar da pesquisa. A inclusão do recurso digital foi incluída em virtude da pandemia de COVID-19. Os dados foram coletados por meio de questionário, diário de campo dos encontros virtuais e entrevista semiestruturada. A partir da análise temática de conteúdo, três núcleos de sentido emergiram: Apoio da gestão, Profissionais e equipe de saúde; e Conselho Municipal de Saúde e instrumentos de gestão, os quais foram interpretados à luz dos referenciais do campo da temática. Procedimentos éticos: projeto aprovado sob parecer número: 3.382.7654.

\section{Resultados}

Segundo as equipes de profissionais NASF as PIC ofertadas são: Acupuntura/ Auriculoterapia, Arteterapia, Constelação Familiar, Dança Circular, Terapia de Florais, Homeopatia, Lian Gong, Meditação, Ozonioterapia, Reiki, Shantala, Terapia Comunitária, Ventosa e Yoga. A seguir são apresentados os núcleos de sentidos. Apoio da gestão: foram apontadas como facilidades: apoio, suporte e compreensão sobre a eficácia e, como dificuldades: desconhecimento. Profissionais e equipe de saúde: facilidades: interesse, comprometimento, autonomia e como dificuldade: falta de conhecimento e formação. Esses núcleos de sentidos podem ser ilustrados a partir de trechos das falas: O fator que facilita é "o apoio e suporte da gestão!" NASF/A; "A principal dificuldade é a falta de conhecimento das PIC pelos gestores municipais (...). Há também deficiência na formação dos profissionais nas PIC. (...) O que facilita é a disponibilidade dos profissionais para a formação nas PIC, muitas vezes arcando com recursos próprios." NASF/B; "Fatores que dificultam: falta de formação dos profissionais e fatores que facilitam: profissionais interessados em se qualificar e apoio da gestão" NASF/C1. Fatores que dificultam: gestão (prefeito, coordenadores)... profissionais, (...) por talvez não conhecerem...equipe não adere... não comprometida. Facilita: compreensão da gestora sobre a eficácia. Alguns membros da equipe comprometidos." NASF/C2. Conselho Municipal de Saúde (CMS) e instrumentos de gestão: esse núcleo se revela como dificuldade, conforme o extrato da fala: "as PICS não foram institucionalizadas, não foram contempladas em nenhum instrumento de planejamento municipal, nem foram discutidas no Conselho Municipal de Saúde". NASF/B.

\section{Discussão}

O apoio da Gestão de saúde é citado como fator potencializador da implantação e/ou implementação das PIC nos municípios pela equipe de profissionais NASF, além da compreensão da eficácia e relevância terapêutica das Práticas. Nesse sentido, o desapoio dos gestores de saúde e desconhecimento acerca das PIC e da PNPIC pode se estabelecer como barreira para manutenção da oferta das Práticas pelas equipes NASF. Na equipe de profissionais em questão, a maior parte dos municípios reconhecem apoio por parte dos gestores de saúde e contam com uma variedade de Práticas ofertadas na região. Indicativo de que a apropriação por parte da Gestão de saúde do trabalho feito pelos profissionais e dos mecanismos da PNPIC viabiliza a implantação e implementação das PIC ${ }^{|3|}$. A expansão do conhecimento e formação em PIC por parte dos profissionais de saúde é importante para o enraizamento das Práticas nos municípios e para aumentar a oferta e cobertura. A gestão de saúde a níveis municipal, estadual e federal têm o poder de promover a formação em PIC ${ }^{|4|}$. A dificuldade apontada pela ausência das PIC nos instrumentos de gestão e nas pautas dos conselhos municipais de saúde corrobora a necessidade da gestão no nível municipal em assumir o compromisso político com a institucionalização das PIC no SUS ${ }^{[5]}$. 


\section{Conclusão}

A falta de apoio, o desconhecimento, a ausência das PIC nos instrumentos de gestão e na pauta dos CMS se configuram em dificuldades da oferta das PIC na APS, cuja superação requer vontade política e participação popular. Por outro lado, a oferta de uma diversidade de PIC no NASF da região estudada ratifica a pluralidade terapêtutica e o protagonismo profissional, trazendo para o cotidiano dos serviços de saúde a produção de integralidade e acesso no SUS. Destaca-se o apoio da gestão, reconhecido pela equipe como fundamental para oferta dessas práticas na APS e a resiliência das equipes NASF, que mesmo com a extinção do incentivo financeiro e não credenciamento das equipes, segue não só desenvolvendo seu trabalho junto às equipes, como o enriquecendo pela oferta das PIC, ressignificando o trabalho em equipe e qualificando o cuidado ofertado à população.

Descritores: Sistema Único de Saúde (SUS), Atenção Primária Saúde (APS), terapias complementares.

Financiamento: Pesquisa financiada pelo Programa Institucional de Bolsas de Iniciação Científica- PIBIC

\section{Referências}

1. World Health Organization. The WHO Traditional Medicine Strategy. Geneva: WHO 2014-2023.

2. Brasil. Ministério da Saúde. Portaria no 971, de 4 de maio de 2006. Dispõe sobre a Política Nacional de Práticas Integrativas e Complementares (PNPIC) no Sistema Único de Saúde. Diário Oficial da União. 5 Maio 2006.

3. Barbosa FES, Guimarães MBL, Santos CR, Bezerra AFB, Tesser CD, et al. Oferta de Práticas Integrativas e Complementares em Saúde na Estratégia Saúde da Família no Brasil. Cad. Saúde Pública [Internet]. 2020 [acesso em 2021Jan 17]; 36(1): eoozo8818. Disponível em: https://doi.org/10.159o/0102-311xo0208818.

4. Tesser CD, Sousa IMC, Nascimento MC. Práticas Integrativas e Complementares na Atenção Primária à Saúde brasileira. Saúde debate Internet]. 2018 [acesso em 2021 Jan 17]; 42(spe1):174-188. Disponível em: https://doi.org/10.1590/0103-11042018s112.

5. Sousa LA, Barros NF, Pigari JO, et al. Acupuntura no Sistema Único de Saúde - uma análise nos diferentes instrumentos de gestão. Ciênc. saúde coletiva [Internet]. 2017 lacesso em 2021 Jan 17]; 22(1):301-310. Disponível em: https://doi.org/10.1590/1413-81232017221.10342015. 
RELATO DE EXPERIÊNCIA

\section{ORGANIZAÇÃO DO FLUXO DE TRABALHO BIDERECIONAL PARA ATENDIMENTO NA ATENÇÃO PRIMÁRIA NA PANDEMIA}

\section{Fabíola Moreira Casimiro de Oliveira \\ Ailma de Souza Barbosa \\ Carolina Carvalho Nogueira \\ Joyce Lane Braz \\ Virgolino da Silva \\ Veronica Ebrhaim Queiroga}

\section{Introdução}

A Atenção Primária à Saúde é a porta de entrada prioritária na rede de saúde e, durante surtos e epidemias, tem papel fundamental na resposta global à doença em questão, pois oferece atendimento resolutivo, além de manter a longitudinalidade e a coordenação do cuidado em todos os níveis de atenção à saúde, com grande potencial de identificação precoce de casos graves que devem ser manejados para serviços especializados (BRASIL, 2020). A reorganização dos serviços de Atenção Primária à Saúde para, simultaneamente, enfrentar a epidemia e manter a oferta regular de suas ações é imperativa, e seu necessário protagonismo e readequação vêm sendo destacados em documentos e relatórios produzidos no país (ENGSTROM et al., 202o). Dessa forma, a pandemia do novo coronavírus possibilitou a reorganização da gestão do trabatho dentro dos serviços de saude para o fluxo de atendimentos dos sintomáticos gripais e não sintomáticos nas unidades de saúde $\mathrm{da}$ família da Atenção Primária à Saúde e assim, minimizar o risco de transmissão para infecção pelo novo coronavírus em cumprimento às normas sanitárias vigentes, tambèm é uma premissa de acesso ao usuário.

\section{Objetivo}

Apresentar o fluxo bidirecional nas unidades de saúde da família. 


\section{Método}

Trata-se de um relato de experiência implantado em duas unidades de saúde da família, Bessa e Timbó I, pertencentes ao Distrito Sanitário V, a partir de março de zozo no município de João Pessoa, Paraíba.

\section{Resultados e Discussão}

A construção do fluxo bidirecional de atendimento aos usuários sintomáticos gripais e não sintomáticos direcionando o translado dentro da estrutura física a partir de sinalização horizontal, setas indicativas, marcação de lugares, oferta da máscara cirúrgica ao sintomatico gripal e uso do álcool gel. Permitiu a organização do processo de trabalho da equipe com definição dos papéis dos trabalhadores em cada espaço, uso racional de equipamentos de proteção individual e orientação da limpeza de superfícies e equipamentos, além de proporcionar maior segurança para os usuários não sintomáticos, bem como aos profissionais de saúde. A triagem da Enfermagem baseada em protocolos e critérios clínicos considera a classificação de risco fundamental para redução de contágio por infecção cruzada de fluxo dentro do serviço. Os grupos operativos foram suspensos temporariamente para evitar aglomerações e, na tentativa de manter o vínculo com as famílias, favorecer o acesso as informações e orientações antes realizadas de forma presencial durante as consultas, grupos e rodas de conversas, foi criado grupos de gestantes, puérperas e mães da puericultura no aplicativo de mensagens e usado às redes sociais já existentes na comunidade. Participaram como colaboradores discentes e docentes da Universidade Federal da Paraíba (UFPB), como atividades da disciplina de educação em saúde do curso de Enfermagem, Pet-Saúde e projeto de extensão Saúde em comunidades (Probex) que tiveram que adequar o conteúdo curricular ao novo momento das tecnologias de informação e comunicação (TICs). Juntamente com os membros da equipe foi elaborado e postado diariamente informações para evitar a propagação do coronavírus, orientações sobre o distanciamento social, sinais e sintomas da COVID19, formas de contágio, os perigos da automedicação. Assim como, ajudar as crianças a entenderem a pandemia, como cuidar da saúde mental, como fazer exercícios mesmo dentro de casa, a importância da vacinação, aleitamento materno, introdução de alimentos no desmame, direitos das gestantes, puerpério, sífilis, bem como o novo fluxo de atendimento e agenda- mentos afim de evitar aglomeração nas unidades de saúde e outros assuntos solicitados pelos participantes dos grupos que a todo momento traziam suas dúvidas, angústias e dificuldades para se adaptar ao novo normal. Apesar deste trabalho colaborativo, logo no início da Pandemia, foram muitos desafios enfrentados pelos trabalhadores de saúde. Os profissionais ao mesmo tempo que cuidavam das pessoas também foram acometidos pelo adoecimento e tiveram que se afastar ficando uma equipe mínima, sobrecarga de trabalho. Os trabalhadores deste modelo de atenção à saúde estão expostos à realidade dos conflitos sociais das comunidades e ao estresse decorrente da violência nestas áreas. Além disso, convivem diretamente com o sofrimento do próximo, com a escassez de recursos e a imensa demanda de responsabilidades, que afetam a resolutividade das ações, contribuem para o desenvolvimento de doenças ligadas ao trabalho e influenciam no processo de viver humano (SIQUEIRA et al., 2013). Apesar disso, nesse processo de recriar os modos de cuidar, utilizou-se das TIC's como meio de aproximação e divulgação das informações, porém emergiu outro problema que foi a falta de acesso de parte da população a internet, principalmente os idosos com baixo desenvolvimento cognitivo. Apesar disso, essas tecnologias contribuíram na produção do cuidado, a partir da compreensão do usuário quanto à sua singularidade; no estabelecimento de vínculos solidários e de participação coletiva no processo de gestão; no mapeamento e interação com as demandas sociais, coletivas e subjetivas de saúde; na valorização dos diferentes sujeitos implicados no processo de produção de saúde: usuários, trabalhadores e gestores; no fomento da autonomia e do protagonismo desses sujeitos; e no aumento do grau de corresponsabilidade na produção de saúde (CECCON, 2020). A organização do fluxograma de atendimentos foi uma estratégia utilizada na atenção primária à saúde (APS) relevante para manter o cuidado no momento da avaliação de um caso suspeito de COVID-19. A APS ẻ uma das portas de entrada do Sistema único de Saúde (SUS) e deve reorganizar o fluxo dos usuários, assumindo o protagonismo dos serviços de saúde. Os profissionais da equipe tiveram que usar a criatividade para reorganizar o espaço de cuidado, mantendo o vínculo com os pacientes. Mesmo a distância as equipes da APS continuaram os atendimentos de demanda livre, agendamento e teleatendimento das demandas livres e atendimentos preconizados pelo ministério da saúde como vacinas, puericultura, pré-natal, atendimentos de diabéti- 
cos e hipertensos. Reorientação do fluxo das portas de entrada diferenciando a entrada do atendimento de sintomáticos gripais. Atendimentos covid e não covid nos três horários de funcionamento da unidade manhã, tarde e noite. A atuação das equipes foi em conjunto com a residência médica e multiprofissional em saúde da família e comunidade onde todos os profissionais de saúde demonstraram a capacidade de reagirem à pandemia, oferecendo respostas adequadas seguindo o protocolo do manejo da COVID 19 pela APS. Foram ofertados atendimentos presencias agendados e de demanda livre, assim como teleatendimentos e monitoramento dos casos sintomáticos. Destacaram no cenário de crise sanitária a produção de vídeos explicativos de fluxo, orientação de cuidados, importância do isolamento domiciliar assim como práticas de educação permanente das equipes da APS, ações de educação em saúde e facilitação para comunicação entre serviços, comunidades e conselho local de saúde. As atividades contaram com a necessidade de ações de estímulo à participação da comunidade como corresponsáveis da sua saúde e controle social. Toda a equipe contribuiu utilizando recursos simples como vídeos, lives e grupos com aplicativos de mensagens, distinguindo os fakenews das reais orientações de saude. Foi priorizado informações para a população mais vulnerável da comunidade e fortalecido a parceria com o conselho local de saúde como potente instrumento de aproximação entre os serviços de saúde e a comunidade. Para dar respostas adequada ao enfrentamento da pandemia, o SUS precisou estruturar um fluxograma, contar com infraestrutura adequada das unidades de saúde, insumos adequados, Equipamentos de Proteção Individuais (EPI), organização da força de trabalho, comunicação unificada, clara e efetiva com a população e toda a rede de atenção à saúde, apoio da telemedicina e regulação mais ágil para direcionar a demanda às vagas adequadas.

\section{Conclusão}

Os servicos de saúde devem se adaptar as normas de distanciamento social e higienização de forma a garantir o acesso ao cuidado ao usuário não sintomático gripal em seguimento ao pré-natal, puericultura, controle de doenças crônicas, planejamento familiar, prevenção ao câncer de colo de útero, mamas e próstata, vacinação, dentre outros, além de assistir cuidadosamente o usuário sintomático gripal para notificação, monitoramento, testagem e vigilância à saúde. Neste contexto, torna-se oportuno ressaltar a relevância da interprofissionalidade e a interdisciplinaridade mediante práticas colaborativas vivenciadas pelos profissionais e que foi uma estratégia para fortalecer a atuação da equipe de saúde e melhorar a qualidade de cuidados diante de quadros leves e graves da doença, interação e cooperação para potencializar a dinâmica e a qualidade dos cuidados ofertados. A reestruturação das ações de saúde mostrou-se desafiadora, exigindo interconexão entre gestão do cuidado e da saúde, organização de recursos humanos, de insumos e tecnologias, utilização de indicadores epidemiológicos, fluxogramas e ações interprofissionais.

Descritores: Atenção Primária à Saúde; fluxo de trabalho; pandemia.

\section{Referências}

1. Brasil. Protocolo de manejo clínico do coronavírus (COVID19) na atenção primária à Saúde. Brasília - DF, Março de 2020.

2. Engstrom E, Giovanella L, Melo E, Mendes A, Grabois V, Mendonça MHM. Recomendações para a organização dả atenção primária à saúde no SUS no enfrentamento da COVID-19. 2020.

3. Siqueira GF, Barrêto AJR, Menezes MS, Alves SRP, Freitas FFQ et al. Trabalho do enfermeiro na atenção primária em saúde: conhecimento dos fatores estressores. Rev Ciênc Saúde Nova Esperança 2013;11(2):72-85. Disponível em: http://www.facene.com.br/wp-content/ uploads/2010/11/Trabalho-do-enfermeiro-na-aten $\% \mathrm{C}_{3} \% \mathrm{~A}_{7} \% \mathrm{C}_{3} \% \mathrm{~A}_{3} 0$-prim\% $\mathrm{C}_{3} \% \mathrm{~A}$ 1ria-em-sa\%C3\%BAde.pdf. Acesso em o9/o1/2021.

4. Ceccon RF, Schneider IJC. Tecnologias leves e educação em saúde no enfrentamento à pandemia da COVID-19. SciELO Public Health; 2020. 
RELATO DE EXPERIÊNCIA

PROPOSTA DE IMPLANTAÇÃO DE CONTRARREFERÊNCIA ONLINE ENTRE UM HOSPITAL PEDIÁTRICO E A ATENÇÃO DOMICILIAR

Diana Augusta Tres
Francieli Cecconello
Denise Antunes de
Azambuja Zocche

Elisangela Argenta Zanatta

\section{Introdução}

O Serviço de Atenção Domiciliar (SAD) é definido como um serviço complementar aos cuidados realizados na Átenção Básica (AB) e em Serviços de Urgência, substitutivo ou complementar à internação hospitalar, com a finalidade de desenvolver ações de prevenção, tratamento de doenças, reabilitação, paliação e promoção à saúde, prestadas em domicílio na modalidade de Atenção Domiciliar (AD). Dentre os objetivos do SAD destaca-se: redução das internações hospitalares, redução da permanência de usuários internados, humanização no atendimento ao usuário, autonomia do usuário no autocuidado, desinstitucionalização, otimização dos recursos financeiros e estruturais das Redes de Atenção à Saúde (RAS) ${ }^{1}$. As RAS são organizações de serviços de saúde com missões e objetivos comuns, realizando ações por meio de uma atenção à saúde continua e integral, organizada pela atenção primária à saúde (APS) de forma humanizada e com equidade. Assim, preconiza que os diferentes pontos de atenção devem colaborar entre si, pois todos são importantes no processo do cuidado que deve ser contínuo entre os níveis primário, secundário e terciário. $\mathrm{O}$ atendimento em saúde da criança necessita, em muitos casos, de um grau de especialização avançado, que não pode ser atingido na APS e, por esse motivo, surge a necessidade de critérios de encaminhamento para a atenção secundária e terciária ${ }^{2}$. Ainda, condições crôni- 
cas na infância duram ou têm potencial para se manterem pelo menos por um ano e produzem uma ou mais das seguintes consequências: limitações de função, atividade ou papel social; dependência de medicamentos, alimentação especial, uso de dispositivo tecnológico para os cuidados e necessidade de assistência em serviços de saúde ou educacionais acima do usual para a idade da criança. A alteração do perfil de morbidade da infância demanda uma reorganização dos serviços de saúde, referente às necessidades das crianças de acordo com a sua condição de saúde, buscando a continuidade do cuidado, de forma a garantir sua qualidade de vida. ${ }^{3}$. Assim após a alta hospitalar a criança precisa ser referenciada para os outros pontos da RAS, incluindo as equipes de Atenção Domiciliar, que necessitam estar envolvidas em todo o processo de alta hospitalar'. Amparar o processo da alta hospitalar corresponde a uma das dimensões da assistência do enfermeiro, seja do nível hospitalar ou da atenção básica, assim, há necessidade de integração entre estes dois níveis de atenção. Contudo, na realidade vivenciada, observa-se ineficiência no sistema de referência e contrarreferência, que dificulta o processo de articulação entre a unidade hospitalar e $\mathrm{AB}$, bem como a integralidade do cuidado. A falta de informação e as limitações organizacionais do processo de trabalho favorecem uma ruptura na assistência prestada ${ }^{4}$. Sendo assim, como por exemplo, o hospital contribuiria para a integralidade da assistência quando fosse referência em determinadas situações e, após realizar o atendimento, deveria fazer uma adequada contrarreferência para a $\mathrm{AD}$, considerando a alta hospitalar o momento adequado para se trabalhar a integralidade. Ressaltamos que uma das principais finalidades da AD é a desospitalização de pacientes clinicamente estáveis, proporcionado agilidade no processo de alta hospitalar e garantindo que esse cuidado seja realizado no domicílio pelas equipes do SAD, com o objetivo de minimizar intercorrências clínicas e diminuir os riscos de infecções hospitalares por longo tempo de hospitalizações. Assim, para que isso ocorra de uma forma organizada, o SAD deverá articular-se com os outros serviços da RAS, principalmente hospitais, serviços de urgência e $A B$, para construir instrumentos que organizem um eficiente sistema de referência e contrarreferências.

\section{Objetivo}

Apresentar uma proposta de implantação de um fluxograma para realização de contrarreferência online entre um Hospital Pediátrico e um Serviço de Atenção Domiciliar, em um município da Macrorregião Oeste de Santa Catarina.

\section{Método}

Trata-se de um relato de experiência sobre a uma proposta de implantação de um fluxograma para realização da contrarreferência online com o uso do Google Drive. Com a apresentação da proposta, pretende-se que o hospital pediátrico e o SAD compartilhem documentos, usando tecnologias na gestão dos serviços de Saúde. A proposta foi apresentada na disciplina de Tecnologias e técnicas inovadoras como instrumentos para a gestão em redes do Mestrado Profissional em Enfermagem na Atenção Primária à Saúde.

\section{Resultados e Discussão}

Atualmente o fluxograma de contrarreferência utilizado pelos serviços descreve que o médico ou enfermeiro da unidade de internação pediátrica preencha uma ficha de solicitação de avaliação, após o preenchimento a ficha deve ser entregue para um responsável pela criança e ele deverá entregá-la na sede do SAD. Considerando o avanço da tecnologia, pensando em reduzir impressões, o uso de fotha de papel e a necessidade de deslocamento do familiar até o SAD, as mestrandas sugeriam a elaboração de um fluxograma para realização da contrarreferência online do hospital pediátrico para o SAD. Dessa forma, iniciou-se a elaboração do fluxograma, que se caracteriza por ser uma ferramenta que representa com racionalidade, clareza e síntese as rotinas e procedimentos5. Foi descrito que a ferramenta para o compartilhamento do fluxograma e demais documentos/informações entre os dois serviços seria o Google drive, por meio da criação de uma pasta e compartilhamento dos seguintes documentos: o fluxograma de encaminhamento de usuários do hospital pediátrico para o $\mathrm{SAD}$, critérios de inclusão para elegibilidade de usuários no SAD e ficha de encaminhamento de usuários para o SAD. Pretende-se compartilhar a pasta entre os e-mails do hospital pediátrico e o SAD, assim, todos os profissionais dos dois serviços terão acesso aos documentos utilizados no fluxo de encaminhamento. O fluxograma descreve ainda que para a contrarreferência se concretizar, o profissional do hospital deve preencher a ficha de encaminhamento com os dados da criança e a mesma deve ser enviada no e-mail 
ao SAD. Levando-se em conta que a contrarreferência é o retorno do usuário da média e alta complexidade para o nível primário ${ }^{4}$.

\section{Conclusão}

A construção do fluxograma possibilitou o pensamento e articulação em rede, uma vez que, para realizar um cuidado integral à criança, é preciso uma assistência que possa romper os limites entre a instituição hospitalar e às equipes de APS. Assim, torna-se fundamental a elaboração de estratégias que contribuam com o fortalecimento da referência e contrarreferência entre os serviços. Acredita-se que com o compartilhamento online e o fluxo estabelecido, os serviços terão acesso as informações de uma forma fácil e rápida. Salienta-se ainda, que os profissionais do hospital pediátrico poderão realizar a contrarreferência com segurança e garantia, sabendo que o SAD terá acesso rápido a solicitação de acompanhamento domiciliar da criança, contribuindo para que a desospitalização ocorra de uma forma segura e eficaz e que a criança possa ser assistida por uma equipe multiprofissional, logo após a alta hospitalar, no seu domicílio.

Descritores: Tecnologia em Saúde; Fluxograma, Gestão dos Serviços de Saúde, Hospital Pediátrico, Assistência Domiciliar

\section{Referências}

1. BRASIL. Portaria n⿳0 825, de 25 de abril de 2016. Redefine a Atenção Domiciliar no âmbito do Sistema Único de Saúde (SUS) e atualiza as equipes habilitadas. Brasília: Ministério da Saúde, 2016. Disponível em: http://bvsms.saude.gov.br/ bvs/saudelegis/gm/2016/prto825_25_04_2016. html. Acesso em: 10 jan. 2021.

2. MENDES, E. V. As redes de atenção à saúde. 2.ed. Brasília: Organização Pan-Ảmericana da Saúde, 2011. Disponível em: < http://bvsms. saude.gov.br/bvs/publicacoes/redes_de atencao_saude.pdf $>$ Acesso em: 04 dez 2019.

3. DUARTE, E. D. et al; Cuidado à criança em condição crônica na atenção primária: desafios do modelo de atenção à saúde. Texto Contexto Enfermagem, Florianópolis, v. 24, n.4, p. 1009-1017. 2015. Disponível em: <http:// www.scielo.br/pdf/tce/v24n4/pt_0104-0707-tce-24-04-01009.pdf.> Acesso em: 09 jan. 2021.

4. CARvalho, M. S. N. ET AL. Desospitalização de crianças com condições crônicas complexas: perspectivas e / [orgs. Lívia Almeida de Menezes... ET al.]. on-line. Rio de Janeiro: Eldorado, 2019.

5. FARIA, R.M. O território e as redes de atenção à saúde: intercambiamentos necessários para a integração das ações do sistema único de saúde (SUŞ) no Brasil. Bol. geogr., Maringá, v. 32, n. 2, p. 173-191, mai.-ago., 2014. Disponível em: https://www.researchgate.net/ publication/286171964_O_TERRITORIO_E_ AS_REDES_DE_ATENCAO_A_SAUDE_INTERCAMBIAMENTOS_NECESSARIOS PARA_A_INTEGRACAO_DAS_ACOES DO_SISTEMA_UNICO_DE_SAUDE_SUS NO_BRASIL. Acesso em: o9 jan. 2021. 
Pesquisa Original

\section{A PRÁTICA DE NOTIFICAÇÕES DE INCIDENTES PELA EQUIPE DE ENFERMAGEM}

\section{Aline Cristina Andrade Furini Cibele Cirino de Sousa \\ Maria Eulália Lessa do Vale Dallora}

\section{Introdução}

O maior desafio na segurança do paciente é buscar a redução dos eventos indesejáveis nas instituições de saúde. Em especial, a assimilação, por parte dos dirigentes, de que a causa dos erros e eventos adversos é multifatorial e que os profissionais de saúde estão suscetíveis a cometer erros quando os processos técnicos e organizacionais são complexos e não adequadamente planejados. Desde que a assistência seja prestada por seres humanos há a possibilidade de promoção de riscos e danos aos pacientes, embora o que seja de fato importante neste momento é que esta realidade não seja mais ignorada. A monitorização dos incidentes é importante para a garantia da segurança dos pacientes e depende de esforços para que a sua identificação seja feita antes de causarem danos. A importância em notificar os eventos explica-se pelo fato de proporcionar um meio de comunicação a respeito das ocorrências inesperadas, possibilitando o reconhecimento das falhas para a promoção de modificações necessárias e colaborando para o sucesso do desenvolvimento assistencial. Assim, a notificação reduz a ocorrências de erros semelhantes no futuro, promove aprendizagem, e por meio da investigação e análise dos incidentes, geram informações úteis para corrigir falhas ${ }^{1}$. A notificação de EAs depende amplamente de um trabalho de sensibilização da equipe de profissionais que atuam na assistência ao paciente. É imprescindível que 
sejam envolvidos e estejam habilitados para detectar incidentes relacionados à assistência à saúde, reconhecendo-os como um instrumento de melhoria contínua para segurança do paciente, e não como um mecanismo de punição. Para as ações de gestão de riscos serem efetivas, é necessária a sensibilização de todos os integrantes da instituição em seu papel de evitar riscos, estejam eles envolvidos na assistência direta ou não, pelo fato de cada um estar, de alguma forma, relacionado à segurança do paciente. A promoção de segurança e prevenção de danos deve ser a primeira consideração em todos os atos e tarefas, e é responsabilidade de todos os colaboradores, membros das equipes multidisciplinares, visitantes, familiares e pacientes. A notificação voluntária, que consiste na comunicação de eventos adversos e demais incidentes, encaminhada por profissionais de saúde ou pacientes, espontaneamente, é o método mais utilizado ao redor do mundo para coletar informações sobre incidentes, tornando-se mais eficiente com a participação ativa dos funcionários. O principal fator que leva a subnotificação de incidentes é o foco na culpabilidade do profissional envolvido, que ocorre por diversos fatores, entre eles o medo, a culpa, a vergonha, a autopunição, medo da crítica de outras pessoas. Diante disto, algumas estratégias como a garantia do anonimato e da confidencialidade podem ser utilizadas para aumentar a confiança e a adesão dos profissionais nos sistemas de notificação.

\section{Objetivo}

Demonstrar a importância da participação da atuação da equipe de enfermagem na notificação de incidentes e eventos adversos.

\section{Método}

Estudo descritivo, retrospectivo, transversal, de análise documental, com abordagem quantitativa, com base nos dados do sistema de notificação do Serviço de Gerenciamento de Risco de um complexo hospitalar público do interior de São Paulo, de agosto de 2015 a julho de 2016.

\section{Resultados e Discussão}

Foram analisadas 4.691 notificações registradas no Serviço de Gerenciamento de Riscos (SGR) do complexo hospitalar em estudo, destas $3.312(70,60 \%)$ foram realizadas por enfermeiros seguido dos médicos $(\mathrm{n}=373 ; 7,95 \%)$, oficial administrativo $(\mathrm{n}=223$; $4,73 \%)$, farmacêutico $(\mathrm{n}=204 ; 4,35 \%)$ e técnicos e auxiliares de enfermagem $(n=210 ; 4,48 \%)$. A equipe de enfermagem composta por enfermeiros, técnicos e auxiliares de enfermagem, representaram 75,08\% das notificações. Evidenciou-se a escassez de notificações por médicos, sendo apenas $8 \%$ dos incidentes registrados no período, valor este muito baixo diante do papel que exerce este profissional na terapêutica do paciente. No mesmo hospital referido nesta pesquisa, em estudo realizado em 2012, foi identificado que os enfermeiros também foram os profissionais que mais notificaram $(76,6 \%)$ na implantação do sistema de notificações informatizadas no ano de 2010, e os médicos que contribuíam com $16,6 \%$ das notificações por meio do sistema manuscrito, na implantação das notificações informatizadas contribuíram com apenas $2,5^{2}$. Corroborando com este estudo, ao analisarem os incidentes notificados em um hospital público do Distrito Federal, identificaram que os enfermeiros foram responsáveis pela maioria das notificações $(26,3 \%)$, seguido dos médi$\cos (5,7 \%)^{3}$. Todos os profissionais atuantes nos serviços de saúde precisam ser alcançados pelas estratégias de sensibilização sobre a importância de sua participação no processo de notificação de incidentes, favorecendo a redução da subnotificação, e o envolvimento dos diversos níveis hierárquicos e categorias profissionais no movimento em prol da segurança do paciente. Estes resultados expressam a necessidade de incluir outras categorias de profissionais da saúde em pesquisas sobre o tema, entre eles os médicos, farmacêuticos, que compõem uma importante parcela dos profissionais desta área. Outros estudos, tanto no Brasil quanto em outros países, identificaram que as notificações ficaram centradas na figura do enfermeiro e por consequência esses profissionais notificam mais incidentes que outras categorias. Do ponto de vista da equipe de enfermagem, a questão da segurança do paciente ou da notificação de incidentes, não pode ser atribuição restrita dos enfermeiros, mesmo este sendo responsável pela coordenação e gerenciamento da assistência prestada ${ }^{4}$. A enfermagem é a categoria profissional que está em constante proximidade dos pacientes, seja nos cuidados diretos, seja no gerenciamento dos serviços prestados, além de ser quantitativamente, a maior força de trabalho na assistência à saúde. Constitui-se uma fonte potencial de informações a respeito da ocorrência dos incidentes e possui treinamento acerca da importância de re- 
gistrar o processo de prestação de cuidados. Além disso, observa-se a relação direta da categoria com o tema segurança do paciente e suas estratégias para a prevenção de erros e redução de falhas nos cuidados de saúde.

\section{Conclusão}

Observou-se que as notificações ficaram centradas na figura do enfermeiro, que é imprescindível no processo de trabalho, pois se faz peça fundamental no auxílio ao diagnóstico de riscos e incidentes na assistência à saúde, além de gerenciar, planejar, organizar e executar ações de cuidados. Vale destacar que a notificação de incidentes não é de responsabilidade de uma única categoria profissional. A notificação dos incidentes indesejáveis deve ocorrer por profissionais da linha de frente, médicos, enfermeiros, técnicos e auxiliares de enfermagem. O presente estudo contribui para o conhecimento sobre cuidado a saúde e segurança do paciente, uma vez que fornece subsidios para se discutir a notificação dos erros e formular planos e estratégias para aumentar a adesão da equipe multidisciplinar para relatar os incidentes e fornecer informações sobre os processos vulneráveis $\mathrm{da}$ instituição, com o intuito de evitar danos aos pacientes e adotar intervenções de melhoria na estrutura e nos processos assistenciais.

Descritores: Enfermagem; Notificação; Incidentes; Segurança do Paciente.

\section{Referências}

1. Wachter RM. Compreendendo a segurança do paciente. 2. ed. Porto Alegre: Artmed; 2013.

2. Capucho HC. Sistemas manuscrito e informatizado de notificação voluntária de incidentes como base para a cultura de segurança do paciente. Ribeirão Preto: Universidade de São Paulo, 2012. Tese - Doutorado em Ciências. Escola de Enfermagem de Ribeirão Preto.

3. Göttems LBD, Santos MLG, Carvalho PA, Amorim FF. A study of cases reported as incidents in a public hospital from 2011 to 2014. Rev Esc Enferm USP. 2016;50(5):861-867. [Citado 2018 fev 18]. Disponível em: http://www. scielo.br/scielo.php?script=sci_arttext\&pi$\mathrm{d}=$ Soo8o=62342016000500861-\&lng=es\&nrmiso. Doi: http://dx.doi.org/10.159o/Soo8o623420160000600021

4. Ferezin TPM. Avaliação da notificação de eventos adversos em hospitais acreditados. Escola de Enfermagem de Ribeirão Preto. Ribeirão Preto: Escola de Enfermagem de Ribeirão Preto, Universidade de São Paulo, 2015. Tese mestrado. 
RELATO DE ExPERIÊNCIA

\section{O ACOLHIMENTO COM CLASSIFICAÇÃO DE RISCO NA ATENÇÃO BÁSICA: A EXPERIÊNCIA DE UMA CAPITAL DA AMAZÔNIA LEGAL, PORTO VELHO, RONDÔNIA, BRASIL}

\author{
Eldenilson Gomes de Sousa \\ Marcuce Antonio \\ Miranda dos Santos \\ Jane Carvalho Cardoso
}

\section{Introdução}

Sabe-se que de um modo geral, o trabatho em saúde é sempre relacional, ou seja, é na relação de um com o outro que se produz o cuidado. Esta relação se dá entre os trabalhadores, e entre estes e os usuários, pois o processo de trabalho acontece, sobretudo, nos encontros. O processo de trabalho em saúde é o modo como se organiza o trabalho e o acesso dos usuários a este, definindo-se pelas atividades cotidianas, seja na gestão ou na assistência à saúde, sendo estas duas dimensões inseparáveis (MERHY, 2003). Partindo dessa premissa, o presente artigo apresenta um relato de experiếncia, vivida no âmbito da gestão de saude municipal de Porto Velho, capital do Estado de Rondônia, acerca da implantação da estratégia de Acolhimento com Classificação de Risco (ACR) e Agenda por Bloco de Horas na Atenção Básica de Porto Velho, Rondônia.

\section{Objetivo}

Implantar a estratégia de Acolhimento com Classificação de Risco e Agenda por Bloco de Horas na Atenção Básica de Porto Velho.

\section{Metodologia}

Trata-se de uma pesquisa descritiva, do tipo relato de experiếncia, onde buscou-se pontuar o caminho percorrido do planejamento à execução da atividade, descrever o 
encontro sucedido, bem como a percepção dos profissionais de saúde que idealizaram o grupo de trabalho. A experiência se deu no período de março a novembro de 2018 , e foi realizada na cidade de Porto Velho, capital do Estado de Rondônia. O modelo conceitual que orientou o trabalho dos profissionais no grupo foi baseado nas concepções teóricas de Merhy e Franco (2003) e Mendes (2011), além dos Cadernos n. 28 do Ministério da Saúde - Acolhimento a Demanda Espontânea na Atenção Básica volumes 1 e 2 (Brasil, 2013).

\section{Resultados e Discussão}

Inicialmente foi formado um Grupo de Trabalho (GT), composto por técnicos do Departamento de Atenção Basica (DAB), da Assessoria Técnica do Gabinete (ASTEC); do Núcleo Gestor de Educação Permanente (NUGEP), do Departamento de Média e Alta Complexidade (DMAC), do Departamento de Assistência Farmacêutica (DAF), que atuaram como Facilitadores do processo de implantação da proposta, atendendo ao Plano Diretor de Reorganização da Atenção Básica de Porto Velho - PDRAB-PV, junto às 61 equipes de saúde da família de Porto Velho, existentes naquele momento. Através de um Workshop, reuniu-se cerca de 112 profissionais de saúde, entre enfermeiros, médicos e gerentes das 19 Unidades Básicas de Saúde (UBS) da cidade, para uma ampla discussão sobre a importância de implementar uma nova proposta de trabalho, que garantisse o acesso dos usuários que procuravam as UBS da cidade, bem como identificar os fatores potencializadores e dificultadores existentes nos serviços. Para apoiar a compreensão dos participantes, utilizou-se conteúdos e materiais científicos sobre o tema, além de experiências exitosas de outras capitais que conseguiram avançar na organização da $A B$, com a implantação da estratégia de classificação de risco e da agenda por bloco de horas, contendo depoimentos de profissionais, como forma de aproximar a experiência da realidade local. De forma prática, a metodologia envolveu a formação de grupos de trabalho, compostos pelos profissionais das equipes e o gerente da UBS, trabalhou-se as questões teóricas e práticas da estratégia de ACR e da Agenda por Bloco de Horas, como uma nova possibilidade de organização dos atendimentos nas UBS pelas equipes de saúde da família. Com o uso de uma matriz, os participantes construíram suas Agendas por bloco de horas, contendo as demandas programadas e as demandas espontâneas, adaptadas a cada realidade, com garantia de coordenação pelo profissional de nível superior da equipe, por meio do sistema e-SUS-AB. Essa construção substituiu a rotina existente nos serviços, onde as vagas de atendimento das equipes, ficavam sob a responsabilidade dos ACS, mesmo sem possuir o conhecimento técnico e científico para classificar os riscos dos usuários, além de uma compreensão ampliada de que o modelo instituído até aquele momento, desprivilegiava os usuários que procuravam os serviços, atendendo muito mais as necessidades internas das UBS. Cerca de 30 dias após o encontro do Workshop, o GT-AB desenvolveu o monitoramento das USB participantes, apoiada por técnicos das áreas estratégicas da Atenção Básica, Média, Média e Alta Complexidade, Vigilância em Saúde, Setor de Administrativo e Compras, dentre outros. Para o coordenar as visitas e apoiar nos levantamentos das demandas, utilizou-se um roteiro abordando alguns aspectos de avaliação da implantação da proposta, sendo: 1. Foi iniciado alguma medida de acolhimento? Se sim, como o acolhimento está organizado? 2. Como os usuários estão recebendo o processo de modificação do acolhimento e da agenda por bloco de horas? Se não, quais os motivos? 3. Foi modificada a agenda de atendimento por bloco de horas? Sim. Como está o processo? Se não, quais os motivos? 4. Quais as principais demandas oriundas dos atendimentos de demanda espontânea? 5. Como está distribuída a procura por atendimento de demanda espontânea? Quais Horários de pico? 6. De onde estão vindo as pessoas em busca de atendimento? (do próprio bairro? De outros bairros? Área descoberta?). Nestes encontros, surgiram depoimentos que demonstravam as dificuldades enfrentadas pelos profissionais relacionados à falta de infraestrutura, recursos humanos e materiais para pequenos procedimentos como curativos, atendimento de pequenas urgências e emergências, como pode ser percebido na fala a seguir: "Aqui nós não temos uma estrutura adequada para esse novo projeto de vocês. Nossa equipe está incompleta no período vespertino e a nossa médica atende sozinha com os alunos que ela acompanha. Além disso, temos dificuldade acentuada com o tumulto que isso está trazendo" (Médica da UBS 5). Observa-se que a inquietação com a proposta de reorganizar o processo de trabalho, está intimamente ligada a infraestrutura existente. Durante o percurso, foram sendo sanadas as dificuldades, adaptando as estruturas existentes, bem como redimensionamento de materiais, que em algumas UBS tinham em excesso e outras faltavam. Em outras realidades, alguns profissionais mostraram-se colabo- 
rativos com o novo processo, percebendo que o novo modelo a ser implantado, acarretaria uma nova identificação das necessidades do território: "Aqui na UBS ficamos sempre muito ociosos das 1oh as 12h. Os pacientes que chegam são sempre os mesmos com as mesmas necessidades. Isso dá um desânimo. As vezes eles são barrados no SAME mesmo. Não vejo o ACS agendar visitas, trazerem demandas diferentes, e olha que sempre cobro isso nas reuniões. Assim como vejo equipe que chegam atrasadas aqui. O DAB sempre soube...na minha visão, agente finge que atende e os usuários que vem aqui fingem que são atendidos". Todavia, a equipe de matriciamento percebeu, mediante as falas, que em sua essência, os profissionais de saúde desconheciam a integralidade da política da $\mathrm{AB}$ e as diretrizes da Saúde da Família instituídas pelo MS, e os processos de trabalhos estão fragmentados, não havendo uma interlocução entre os membros da equipe. A APS prima que todos os usuários do SUS devem ter sua demanda acolhida nas UBS, no intuito de serem coordenados dentro da RAS municipal, a fim de terem seus problemas resolvidos. O processo de acolhimento desenvolvido dentro da Agenda Programada, permite identificar, elaborar e negociar as necessidades do usuário, através da escuta qualifica, desenvolvida por um profissional de saúde, favorecendo o acesso e a coordenação dos cuidados do território. Isso nos levou a uma reflexão de como os processos de trabalho estavam de fato descoordenados. A figura do ACS no contexto da equipe, está intimamente ligada a criação de vínculo entre a comunidade e a equipe, por meio de ações de educação e promoção à saúde, identificando necessidades individuais e coletivas que devam ser acompanhadas pela equipe. O papel de "agendador de consultas", tornava o trabalho do ACS limitado, bem como descaracterizado da sua função.

\section{Considerações finais}

Sabe-se que um processo de mudança desta magnitude, traz consigo diversos desafios e necessita de constante monitoramento. Na lógica do trabalho em saúde, a microgestão deste processo pôde ser compreendida como exitosa e capaz de transformar o cenário proposto. Em relação a macrogestão dos processos, esse sim caracteriza-se em um grande desafio. A constante rotatividade de gestores, gerentes e profissionais, demandam esforços ainda maiores a serem superados. Além disso, a necessidade de manutenção das infraestruturas e dos insumos para as UBS, tendo em vista ao aumento da demanda de atendimentos e necessidades que adentram a $A B$, por naturalmente perceberem que neste espaço, tais necessidades poderão ser resolvidas. Outro importante desafio a ser superado, é a resistência humana às mudanças. Nos espaços de produção de cuidado, alguns profissionais ainda se veem adaptados em modelos de processos de trabalho, que privilegiam o dia "D", definido previamente e mostrando-se mais oportuno para os profissionais do que para os usuários dos serviços de saúde. Talvez, porque esse modelo de organização de agenda, se caracterize em uma oportunidade de "organização" pessoal, onde o profissional consegue prever sua agenda integral e preparar-se para um grupo previamente definido pelos ACS.

\section{Referências}

1. MENDES, E.V. As redes de atenção à saúde./ Eugênio Vilaça Mendes. Brasília: Organização Pan-Americana da Saúde, 2011. 549 p.: il.

2. MERHY, E.E \& FRANCO, T.B. Por uma Composição Técnica do Trabalho em saúde centrada no campo relacional e nas tecnologias leves. Apontando mudanças para os modelos tecno-assistenciais. Saúde em Debate, Rio de Janeiro, v. 27, n. 65, p. 316-323, set./dez. 2003

3. BRASIL. Ministério da Saúde. Secretaria de Atenção à Saúde. Departamento de Atenção Básica. Acolhimento à demanda espontânea / Ministério da Saúde. Secretaria de Atenção à Saúde. Departamento de Atenção Básica. - 1. ed.; 1. reimpr. - Brasília: Ministério da Saúde, 2013.

4. WebDoc Brasil Aqui tem SUS. Experiência de Porto Velho. Disponível em: https://www. youtube.com/watch?v=abSFu6WPypY. Acesso em 11 de jan de 2021.

5. STARFIELD B. Atenção primária: equilíbrio entre necessidades de saúde, serviços e tecnologia. Brasília: UNESCO, Ministério dả Saúde; 2002.

6. Conselho Nacional de Secretários de Saúde. Atenção Primária e Promoção da Saúde. Brasília: CONASS; 2011.

7. Oliveira MAC, Pereira IC.Atributosessenciais da Atenção Primária e a Estratégia Saúde da Família. Rev Bras Enferm.66(esp):158-64, 2013. 
Pesquisa Original

\section{GESTÃO E INTERVENÇÕES ADOTADAS DIANTE AGRESSÃO VERBAL LABORAL NA ATENÇÃO PRIMÁRIA E TERCIÁRIA EM SAÚDE}

\author{
Marina Klein Heinz \\ Karine Regina Reinehr \\ Letícia de Lima Trindade
}

\section{Introdução}

O fenômeno da violência no trabalho é definido pela Organização Mundial da Saúde (OMS) como o uso intencional da força física ou autoritária, em forma de ameaça ou praticada, contra uma outra pessoa ou grupo, em situações relacionadas com o trabalho que possa resultar em lesão física, morte, dano psicológico, privação e desenvolvimento deficiente. Tal agressão pode se manifestar de diversas formas, como na violência interpessoal, institucional, social, no trabalho, política, estrutural, cultural, criminal, de resistência, agressão física, abuso sexual, violência psicológica e/ou omissões. No ambiente de trabalho, a violência pode se expressar na forma física ou psíquica. $\mathrm{Na}$ agressão psicológica ocorrem comumente a agressão verbal, intimidação ou assédio moral, assédio sexual e discriminação racial ${ }^{(1)}$. $O$ trabalho em saúde ainda que se caracterize como uma necessidade ao desenvolvimento humano, tendo em vista suas intervenções voltadas ao cuidado dos indivíduos, aponta um alto potencial de danos à saúde dos profissionais da área. A exposição destes trabalhadores aos mais diversos riscos ocupacionais trata-se de um problema de dimensão global e não apenas de domínio da comunidade científica ${ }^{(2)}$. Essa situação, faz refletirmos sobre a necessidade que os profissionais de saúde disponham de atitudes para reconhecer e denunciar a violência em todas as instâncias cabíveis, para que essa problemática possa ter uma maior visibilidade e, 
assim, possibilitar que as esferas governamentais, os conselhos, seus sindicatos e os gestores das instituições, possam planejar e programar medidas de prevenção da violência e proteção.

\section{Objetivo}

Estimar as medidas adotadas diante agressão verbal e as interfaces do seu enfrentamento no local de trabalho, que afeta trabalhadores municipais dos serviços da atenção primária e terciária de saúde do Sistema Único de Saúde (SUS).

\section{Método}

Estudo de abordagem mista, desenvolvido em unidades de Atenção Primária à Saúde e em um hospital público referência em 23 municípios da região Oeste e Extremo Oeste do Estado de Santa Catarina, com uma população alvo de 647 profissionais. Para determinar o tamanho amostral considerou-se $95 \%$ de confiança e um erro amostral de 5\%. Desta forma, a amostra do estudo foi composta por 449 profissionais atuantes na APS e 198 profissionais atuantes na Atenção Hospitalar. Os participantes responderam ao Survey Questionnaire Workplace Violence in the Health Sector, aplicado por membros de um Grupo de Pesquisa, entre janeiro de 2016 e março de 2019. Os dados foram analisados com auxílio do software Statistical Package for the Social Sciences (SPSS), versão 21.0 e posteriormente transcritos. O projeto foi aprovado pelo Comitê de Ética em Pesquisa via Plataforma Brasil, pareceres $\mathrm{n}^{\mathrm{o}} 713.728 / 2015, \mathrm{n}^{\mathrm{o}}$ $2.835 .706 / 2018$ e $n^{-0} 3.414 .195 / 2019$ e respeitou os aspectos éticos recomendados pelas Resoluções $n^{\circ} 466 / 2012$ e $n^{0}$ 510/2016.

\section{Resultados e Discussão}

Dentre os 647 participantes, 90,1\% $(n=583)$ eram mulheres e 9,6\% $(n=62)$ homens, com idade média de 39,3 anos, a maioria da cor branca $86,2 \%(n=583)$ e com média de 14,2 anos de estudo. Dos participantes, $47,44 \%(n=307)$ relataram ter sofrido agressão verbal no último ano, com mediana de 4 agressões. Quando questionados sobre as reações que teve frente à ocorrência da agressão verbal no trabalho $59,6 \%(n=183)$ foi contar para um colega; $55,4 \%$ $(\mathrm{n}=170)$ relatar para um chefe; 30,3\% $(\mathrm{n}=93)$ contar para amigos e familiares; $28,0 \%(n=86)$ pedir para a pessoa parar e, $24,4 \%(n=75)$ dos profissionais não teve reação. Ainda, $24,8 \%$ $(\mathrm{n}=76)$ das vítimas fizeram o registro do evento, mas o instrumento não permite identificar onde e em qual documento o registro foi feito. Tratando-se das providências tomadas diante do evento, a maioria dos profissionais se sentiu desassistido, visto que em 69,3\% $(\mathrm{n}=210)$ dos casos nenhuma providência foi tomada $\mathrm{e}$ apenas $30,7 \%(\mathrm{n}=93)$ das ocorrências tiveram alguma conduta posterior. Confirmando as evidências de um suporte inadequado às vítimas, $62,4 \%(n=186)$ dos profissionais se sentiram totalmente insatisfeitos ou insatisfeitos em como o incidente foi tratado. Em relação às consequências geradas para o agressor, $80,1 \%$ $(n=246)$ dos profissionais relataram que na maioria dos casos o agressor não teve nenhuma consequência. Nos demais casos, $8,5 \% \quad(n=26)$ dos agressores foram advertidos verbalmente, $1,3 \%(\mathrm{n}=4)$ tiveram o tratamento interrompido ou foram transferidos de setor, $2,3 \%(n=7)$ passaram por registro na polícia e o restante não sabia informar ou foram adotadas outras medidas de intervenção. Vale destacar que em nenhum dos eventos o agressor passou por processo judicial. No que concerne as condutas formais e relatos da violência no local de trabalho, apenas $32,9 \%(\mathrm{n}=101)$ dos participantes que já sofreram algum tipo de agressão e 40,9\% $(n=138)$ do restante confirmaram que existem procedimentos legais para o relato da violência no local de trabalho. Além disso, 33,8\% $(\mathrm{n}=103)$ das vítimas e $32,1 \%(\mathrm{n}=108)$ dos que não sofreram agressões referiram estímulos para o registro e relato da violência no trabalho. Os dados demonstram que até então existe um grande déficit quanto às condutas que devem ser tomadas para evitar a recorrência desses eventos. Ainda diante do exposto, mesmo que o apoio às vítimas seja progressivo, se mostra inexpressivo na maioria dos casos. Na categoria das estratégias individuais utilizadas para proteção da violência no trabalho, um estudo verificou que tanto os enfermeiros, como os técnicos de enfermagem adotaram o silêncio como uma forma de se proteger da violência dos agressores e buscaram apoio e ajuda com outras pessoas, principalmente com a equipe de trabalho ${ }^{(3)}$. Outro estudo menciona como estratégia de cunho coletivo que o enfermeiro, enquanto líder da equipe de enfermagem, possui alguns papéis relevantes na articulação de um diálogo entre os envolvidos nas situações de violência, colaborando na elaboração de "diretrizes institucionais de prevenção, proteção e acompanhamento" que minimizem a perpetuação dos casos de violência no trabalho ${ }^{(4)}$. Nesse contexto, é notória a importância da criação e implementação de protocolos ou outros dispositivos para manejo da violência no trabalho, bem como políticas públicas específicas para 
os profissionais de saúde, que primam pela sua segurança e bem-estar no ambiente laboral ${ }^{(5)}$.

\section{Conclusão}

Conforme os dados apresentados, ainda existe a naturalização e até mesmo, banalização da agressão verbal no ambiente de trabaIho, que é negligenciada, não combatida, não questionada e não prevenida. São limitadas as ocorrências que são tratadas com procedimentos formais e o percentual de notificação dos episódios é baixo, tornando os eventos pouco visíveis, onde os trabalhadores optam pela fuga do problema. Acredita-se que uma política de desvalorização dos profissionais de saúde aliada a uma realidade social em que não há punição contra os atos de violência, acabam desmotivando a denúncia e a busca por providências cabíveis no âmbito da justiça. Com isso, ressalta-se que o tema deve ser trabalhado com os profissionais, destaque para o enfermeiro que tem papel à frente da gestão e gerência dos serviços, especialmente no que se refere a ausência de denúncias e condutas cabíveis, ressaltando a importância de criar estratégias que envolvam a sensibilização dos trabalhadores, usuários, familiares, gestores e lideranças políticas. Ainda, é possível refletir a partir dos achados a importância de políticas públicas específicas para os trabalhadores de saúde, os quais dedicam-se à assistência da população.

Descritores: Violência no trabalho; Agressão; Atencão Primária à Saúde; Atenção Terciária à Saúde; Trabalhadores da Saúde.

\section{Referências}

1. Organização Mundial da Saúde. Relatório de status global sobre prevenção da violência. Geneva: OMS [online]; 2014.

2. Pedro DRC, Silva GKT, Lopes APAT, Oliveira JLC, Tonini NS. Violência ocupacional na equipe de enfermagem: análise à luz do conhecimento produzido. Saúde debate [online]. 2017 abr; 41(113): 618-629 [acesso em 23 jan 2020]. Disponível em: https://doi.org/10.1590/0103-1104201711321.

3. Lima GHA, Sousa SMA. Violência psicológica no trabalho da enfermagem. Rev Bras Enfer [online]. 2015; 68(5) [acesso em 23 jan 2021]. Disponível em: http://dx.doi.org/10.1590/ o034-7167.2015680508i.

4. Cordenuzzi OCP, Lima SBS, Prestes FC, Beck CLC, Silva RM, Pai DD. Estratégias utilizadas pela enfermagem em situações de violência no trabalho em hemodiálise. Rev Gaúcha Enferm [online]. 2017; 38(2) [acesso em 23 jan 2021]. Disponível em: https://doi. org/10.1590/1983-1447.2017.02.58788.

5. Trindade LL, Ribeiro ST, Zanatta EA, Vendurscolo C, Dal Pai D. Agressão verbal no trabalho da enfermagem na área hospitalar. Rev. Eletr. Enferm. [online]. 2019; 21(54333) [acesso em 23 jan 2021]. Disponível em: https://doi. org/10.5216/ree.v21.54333. 
RELATO DE EXPERIÊNCIA

INSTRUMENTOS GERENCIAIS

NA ENFERMAGEM: UM RELATO

DA PRÁTICA ASSISTENCIAL

\section{Liliane Bergamin \\ Laura Cocco}

Adriana Hillesheim

Letícia de Lima Trindade

\section{Introdução}

A Enfermagem vem se destacando cada vez mais na área da saúde, e isso se deve ao fato de que os enfermeiros têm assumido cada vez mais papéis de liderança, coordenando equipes de saúde que planejam, executam, monitoram e avaliam os processos de trabalho, contribuindo, assim, para melhoria destes serviços, e garantindo melhoria da qualidade de vida da população ${ }^{1}$ e participando da promoção do acesso dos usuários. Para atuar na gestão dos serviços com eficiência é fundamental que o enfermeiro consiga identificar problema(s), reunir dados, realizar análise de causas e consequências, investigar soluções alternativas e seja capaz de implementar metas de avaliação das alternativas de solução mais adequadas, bem como de implementar ações que contribuam com a resolutividade das demandas ${ }^{1}$. Para a tomada de decisões é necessário perceber o que não está em conformidade e identificar os problemas no cotidiano, o que torna o trabalho do enfermeiro desafiador. Para auxiliar este processo, os instrumentos gerenciais devem ser utilizados no intuito de qualificar a assistência e a gestão dos serviços de saúde e de enfermagem. ${ }^{1}$ A utilização de instrumentos gerenciais, como forma de apoio para uma melhor tomada de decisão nas organizações, se caracteriza como uma relevante ferramenta estratégica e um diferencial apresentado. A gestão dos serviços deve ter transparência e bons processos operacionais, a fim 
de facilitar e otimizar o acompanhamento das ações necessárias. Aliado a isso, a tecnologia em saúde, também é de suma importância na busca de melhorias gerenciais. Os sistemas de gestão, aliados a outras ferramentas, auxiliam na organização e facilitam também a gestão do cuidado. Para isso, há alguns passos necessários e fundamentais para que a gestão em saúde funcione de fato, sendo eles: conhecer o perfil dos pacientes; melhorar continuamente o atendimento prestado; boa estrutura; capacitação dos profissionais; planejamento estratégico; comunicação efetiva e indicadores de desempenho. ${ }^{2}$ Dentre os instrumentos gerenciais mais conhecidos na prática profissional destaca-se os Procedimentos Operacionais Padrão (POP), o Fluxograma e as Escalas de Trabalho. Os POP são documentos organizacionais, que trazem instruções detalhadas e descritas para alcançar o objetivo do trabalho a ser executado. ${ }^{3}$ Os Fluxogramas são mapas visuais dos acontecimentos de um setor ou empresa, onde possibilita criar um conjunto de atividades, de forma padronizada, tornando-se mais fácil, funcional e eficaz a execução das atividades, gerando resultados vantajosos para a Instituição. ${ }^{4}$ As Escalas de Trabalho são utilizadas para a organização dos dias e horários de trabalho dos colaboradores da Instituição, onde o principal objetivo é garantir o atendimento ao público nos horários estabelecidos, estruturar os turnos de trabalho, além de garantir o descanso de seus colaboradores. ${ }^{5}$

\section{Objetivo}

Relatar a experiência vivenciada na Disciplina de Gestão e Gerência em Enfermagem acerca do levantamento dos instrumentos gerenciais utilizados pelos enfermeiros.

\section{Método}

Trata-se de um estudo do tipo relato de experiência, acerca de uma atividade de apresentação de seminário sobre Círculos de Cultura, da disciplina de Gestão e Gerência em Enfermagem, no sétimo período, em uma metodologia de fomento de discussões em grupo acerca de temas definidos, sendo eles: Liderança Transformacional, Planejamento Estratégico, Empreendedorismo e Marketing na enfermagem e Instrumentos gerenciais, sendo este último, o escolhido para este trabalho. Para isso utilizou-se a revisão da literatura do tema e o resgate em documentos normativos da profissão acerca dos instrumentos necessários para a gestão dos serviços de saúde.

\section{Resultados e Discussão}

A partir do estudo feito no contexto do componente curricular, observou-se que os instrumentos gerenciais utilizados pelas enfermeiras e enfermeiros possuem todas as informações necessárias e suficientes para que os colaboradores de uma instituição possam utilizá-lo como um guia. Os principais instrumentos gerenciais mapeados na literatura e de interesse na formação foram os fluxogramas, POP e escalas de trabalho. A utilização destes mostra a organização do serviço de enfermagem por meio de diretrizes detalhadas que apresentam o atendimento indicado para situações específicas, que resultarão na melhoria de seus processos e resultados. Deste modo, é possível afirmar que a racionalização, devido à padronização das rotinas, propicia maior segurança na realização dos procedimentos. ${ }^{1}$ Destacam-se entre os documentos o fluxograma, o qual consiste em um mapa visual dos acontecimentos de um setor que possibilita criar um conjunto de atividades, de forma padronizada, tornando mais fácil a execução das atividades. São divididos em fluxogramas simples, verticais, descritivos e multifuncionais. A escala de trabalho tem o objetivo de estruturar os turnos dos trabalhadores, atendendo o horário de funcionamento do setor. ${ }^{5}$ Os POP são instruções detalhadas, descritas para alcançar o planejamento do trabalho e a uniformidade em uma função específica, onde apresenta a sequências das operações e sua frequência de execução, apontando elementos fundamentais, como, o responsável pela execução e listagem dos equipamentos, a descrição dos procedimentos que devem ser executados, e o roteiro de inspeções periódicas dos equipamentos de produção. ${ }^{3}$ E importante que neste contenham todas as informações suficientes para a equipe detenha conhecimento do setor e interaja, podendo utilizar este como guia, assim como, em caso de dúvida, saibam onde buscar mais informações. ${ }^{3}$ Os múltiplos instrumentos gerenciais que permeiam o cotidiano da enfermagem deixam nítido que a profissão vai muito além do cuidado com o paciente, e que administrar e gerenciar são desafios constantes que requerem subsídios ainda na formação dos graduandos em Enfermagem. Para isso, a disciplina agrega ainda a experiência com os estágios na Coordenação Macrorregional de Saúde, no setor de Atenção Primaria à Saúde, que contribuem para a construção de uma práxis em Gestão e Gerência em Ẻnfermagem, amplia o olhar e prepara os acadêmicos para atender as demandas dos 
serviços de saúde, além de possibilitá-los observar a utilização dos instrumentos no trabalho cotidiano das equipes. Ao término das atividades os estudantes concluíram que estudar gestão e gerenciamento confere visibilidade e oportunidade a essa profissão, proporciona experiência, espaço de trabalho, independência e domínio das práticas.

\section{Conclusão}

Durante toda a graduação, os acadêmicos são incentivados e orientados a trabalhar como líderes e profissionais autônomos. É importante que, durante as atividades teóricas práticas e também durante os estágios, os estudantes possam exercitar o gerenciamento, a liderança, o domínio na utilização dos instrumentos gerenciais comuns nos serviços, e assim aprofundar seus conhecimentos na dimensão gerencial do trabalho das enfermeiras e enfermeiros. Esses requisitos fazem refletir criticamente acerca dos desafios e competências necessárias à profissão de enfermagem, e fomenta os estudantes a pensar sobre suas escolhas, contribuindo para a formação de profissionais críticos com capacidade de qualificar a assistência prestada pelas equipes de saúde.

Descritores: Enfermeiros; Atenção Primária à Saúde; Gestão em Saúde. Administração de Serviços de Saúde.

\section{Referências}

1. Almeida ML, Segui MLH, Maftum MA, Labronici LM, Peres AM. Instrumentos gerenciais utilizados na tomada de decisão do enfermeiro no contexto hospitalar. Texto Contexto Enfermagem, Florianópolis, 2011; 20 (Esp): 131-7. [Acesso em 25 jan. 2021] Disponível em: https:// www.scielo.br/pdf/tce/vzonspe/v2onspea17.pdf.

2. MV Hospitalar. Os 10 passos da gestão hospitalar de sucesso. [acesso em 25 jan. 2021] Disponível em: https://mv.com.br/pt/blog/os-10-passos-da-gestao-hospitalar-de-sucesso

3. Barbosa CM, Mauro MFZ, Cristóvão SAB, Mangione JA. A importância dos procedimentos operacionais padrão (POPs) para os centros de pesquisa clínica. Revista de Associação Médica Brasileira, 2011; 57(2):134-135. [acesso em 25 jan. 2021]. Disponivel em: https://www. scielo.br/scielo.php?script=sci_arttext\&pi$\mathrm{d}=$ S0104-42302011000200007

4. Blog, Flatbox. Fluxograma: O que é? Para que serve? E como criar um? Set, 2019. [acesso em 25 jan. 2021] Disponível em: https://flatbox. ag/fluxograma/

5. Berrytech. Como montar uma escala de trabalho de forma fácil. [acesso em 25 jan. 2021] Disponível em: https://berrytech.com.br/blog/ como-fazer-escala-de-trabalho 
Pesquisa Original

\section{A VIOLÊNCIA NATURALIZADA NO TRABALHO DA ENFERMAGEM NA ATENÇÃO PRIMÁRIA À SAÚDE}

\section{Grasiele Fatima Busnello Maiara Daís Schoeninger \\ Kaciane Boff Bauermann Letícia de Lima Trindade}

\section{Introdução}

A violência no trabalho tem sido determinada de maneira consistente em vários serviços de saúde distribuídos pelo mundo, se caracteriza como problema de saúde pública e um desafio mundial em relação à saúde e segurança dos trabalhadores que atuam nestes locais, devido a sua prevalência, naturalização, consequências psiquicas, físicas, laborais, sociais e financeiras. ${ }^{1,2}$ Os episódios de violência no trabalho têm sido observado principalmente contra as equipes de enfermagem, que possuem maior riso de sofrê-la comparando-se com outros trabalhadores da saúde.

\section{Objetivo}

Identificar os tipos de violência que acometem os trabalhadores de enfermagem, os perpetradores e as situações vivenciadas pelas vitimas.

\section{Método}

Trata-se de um estudo de métodos mistos, explanatório sequencial ${ }^{4} \mathrm{em}$ que foi conduzida uma etapa quantitativa seguida pela etapa qualitativa. Foi realizado em 53 ESF, distribuidas em 26 Centros de Saúde da Família de um município do Sul do Brasil. Para definição dos participantes da primeira etapa do estudo foi realizado cálculo amostral por categoria populacional elegível, considerando 95\% 
de confiança e erro de $5 \%$ da amostra. Os participantes foram 169 profissionais da categoria de Enfermagem (enfermeiros, técnicos de enfermagem e auxiliares de enfermagem). A coleta de dados ocorreu entre setembro de 2018 a março de 2019. Na etapa quantitativa foram utilizados um questionario e o Survey Questionnaire Workplace Violence in the Health Sector, proposto pela Organização Mundial da Saúde, Organização Internacional do Trabalho e de Serviços Públicos e Conselho Internacional de Enfermagem, ${ }^{5}$ o Survey mensurou a ocorrência dos tipos de violência física e psicológica, esta última subdividida em agressão verbal, assédio moral/intimidação, assédio sexual e discriminação racial, ocorridas nos últimos 12 meses. Foram incluídos trabalhadores de enfermagem que atuavam há mais de um ano na ESF e excluídos os que estavam afastados por qualquer motivo. Na etapa qualitativa foram convidados profissionais que participaram na etapa anterior, sendo selecionados por sorteio. Compuseram essa etapa 18 profissionais que participaram de uma entrevista. Os dados quantitativos foram codificados, tabulados e analisados por meio do software Statistical Package for the Social Sciences (SPSS), versão 21.o. As variáveis de natureza quantitativa foram descritas por meio de medidas de tendência central e dispersão: média, desvio padrão, mediana, valor mínimo e máximo observado e amplitude interquartílica, estimativa por intervalo de confiança para a média populacional com base no número de respostas válidas e nível de confiança de $95 \%$. Os dados qualitativos provenientes das transcrições das entrevistas foram submetidos à Análise Temática de Bardin. O estudo foi aprovado por um Comitê de Ética em Pesquisa, via Plataforma Brasil, sendo a aprovação sob parecer $2.835 .706 / 2018$. Todos os participantes assinaram o Termo de Consentimento Livre e Esclarecido. Para preservar o anonimato dos participantes no uso dos fragmentos das falas, estes foram codificados como: Enfermeiro (E), Técnico/auxiliar de Enfermagem (TAE), seguido do número de ordem dos instrumentos.

\section{Resultados e Discussão}

Dentre os trabalhadores participantes do estudo revelou-se que $93,5 \%$ da amostra eram mulheres, de cor branca (91,1\%), casadas (70,4\%), possuíam em média (1 a 2) filhos, com média de escolaridade de 15,4 anos, dormiam em média 7,1 horas de sono ao dia e $(50,3 \%)$ faziam uso de medicações. Os trabalhadores de Enfermagem que compuseram a amostra eram $(27,8 \%)$ enfermeiros, $(72,2 \%)$ auxiliares/técnicos de enfermagem. No que diz respeito aos atos violentos em seus locais de trabalho, $(83,4 \%)$ dos trabalhadores declararam ter sido expostos há algum tipo de violência nos últimos 12 meses. A respeito dos tipos de violência sofrida por estes trabalhadores, destaca-se maior prevalência da violência psicológica, distribuída em $(75,7 \%)$ agressões verbais, $(39,1 \%)$ intimidação/assédio moral, $(8,9 \%)$ assédio sexual e $(4,1 \%)$ discriminação racial. Ainda, $(3,0 \%)$ dos trabalhadores sofreram violência física. No estudo, 141 trabalhadores revelaram ter sofrido nos últimos 12 meses, 221 episódios de violência, dentre eles $76(45,0 \%)$ sofreram um tipo de violência, 50 (29,6\%) dois tipos de violência e $15(8,9 \%)$ três tipos de violência. A respeito dos perpetradores da violência constatou-se que o usuário foi o principal agressor. Na etapa qualitativa aspectos singulares do fenômeno foram desvelados, especialmente por permitir a escuta dos participantes que sofreram com episódios de violência. Os achados foram categorizados e demonstraram que os trabalhadores expostos às situações violentas têm impactos negativos em sua saúde, bem como consideram a naturalização do fenômeno devido a frequência com que ocorrem e a banalização nos serviços de saude da APS. Destaca-se a seguir a subcategoria "naturalização da violência" a qual demonstra por meio dos relatos dos trabalhadores como o fenômeno ocorre no ambiente laboral: "I...] violência a gente sofre todos os dias, é tanto xingamento, que já nem ligamos, isso é normal" (E13). Ah, tem vários acontecimentos [violência], mas isso é do dia a dia. É tão rotineiro que eu considero normal. (AE15)". "Quando o paciente vem me xingar, reclamar, insultar por algo que eu não posso solucionar, eu não levo como agressão [...], não é culpa minha e sim do sistema, então não me estresso mais, porque cansei de ficar doente ouvindo esse tipo de coisas" (TAE16). Eu penso que, se nós ficarmos considerando todas as gritarias, xingamentos, falta de respeito e grosseria dos pacientes como violência, vamos ficar loucos, então é melhor pensar que isso passa e considerar normal no dia a dia de trabalho" (TAE17). Diante dos achados que confirmam a frequência e naturalização da violência laboral, revela-se um importante agravante para a saúde dos trabalhadores, os quais necessitam de apoio da gestão e medidas de prevenção e controle da violência, bem como proteção à sua saúde, sob consequência destes se tornarem desmotivados, estressados, manifestarem sintomas como medo, ansiedade, frustações e necessitarem fazer uso de medicamentos para tratamento de distúrbios provocados pela violência. A pesquisa de métodos mistos permitiu a complemen- 
taridade dos dados no estudo e maior enfoque sobre o fenômeno investigado. Os achados demonstram as implicações dos diferentes tipos de violência nas práticas de Enfermagem no contexto da ESF e a importância dos estudos e medidas na temática.

\section{Conclusão}

A violência que ocorre no cenário da ESF contra os trabalhadores de Enfermagem, prejudica a saúde destes, refletindo diretamente no labor, bem como possui implicações nas práticas destes profissionais e consequentemente na assistência prestada aos usuarios. A frequência com que ocorre o fenômeno e sua naturalização tem se tornado um grave problema de saúde pública, o qual requer medidas institucionais para contenção do problema, assim como considera-se de extrema relevância instituir a Cultura de Paz como forma de conscientização dos trabalhadores e usuários dos serviços de saúde deste cenário.

Descritores: Violência no Trabalho; Enfermagem; Saúde do Trabalhador; Atenção Primária à Saúde.

Financiamento: Coordenação de aperfeiçoamento de pessoal de nível superior (Capes/ taxa; bolsa de doutorado) e Fundacão de Amparo à Pesquisa de Santa Catarina (FAPESC).

\section{Referências}

1. Bambi S, Guazzini A, Piredda M, Lucchini A, De Marinis MG, Rasero L. Negative interactions among nurses: an explorative study on lateral violence and bullying in nursing work settings. J Nurs Manag. 2019; 27(4):749-757.

2. Lanthier S, Bielecky A, Smith PM. Examining risk of workplace violence in Canada: a sex/gender-based analysis. Ann Work Expo Health. 2018; 62(8):1012-20.

3. Shafran-Tikva S, Zelker R, Stern Z, Chinitz D. Workplace violence in a tertiary care Israeli hospital - a systematic analysis of the types of violence, the perpetrators and hospital departments. Isr J Health Policy Res. 2017; 6(1):43.

4. Creswell JW, Clark VLP. Pesquisa de métodos mistos. 2 ed. Porto Alegre: Penso; 2013.

5. Di Martino V. Workplace violence in the health sector - country case studies: Brazil, Bulgarian, Lebanon, Portugal, South Africa, Thailand, plus an additional Australian study: synthesis report. Geneva: WHO; 2003. 
Pesquisa Original

\section{ANÁLISE DO NÚMERO DE CONTATOS DOS CASOS CONFIRMADOS DE COVID-19 COM OS SERVIÇOS DE SAÚDE}

\author{
Karine Regina Reinehr \\ Marina Klein Heinz \\ Mateus Dall Agnol \\ Clarissa Bohrer da Silva \\ Letícia de Lima Trindade \\ Marta Kolhs
}

\section{Introdução}

No final de 2019 foi identificada a doença denominada COVID-19 causada pelo SAR-

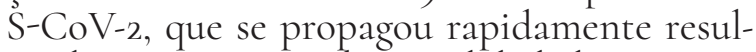
tando em uma pandemia global de espectro clínico variado. ${ }^{1}$ Esse vírus apresenta uma alta transmissibilidade e provoca uma síndrome respiratória aguda, que varia de casos assintomáticos e leves em aproximadamente $80 \%$ dos infectados, até casos mais graves que necessitam de atendimento hospitalar e suporte ventilatório, entre 5 a 10\% dos casos. Sua letalidade varia conforme a faixa etária e as condições clínicas associadas. ${ }^{1-2}$ A Atenção Primária à Saúde (APS) é a principal porta de entrada do Sistema Único de Saude (SUS) e, portanto, tem papel fundamental na resposta global frente a epidemias e pandemias. Nesse caso, a relevância da APS se dá principalmente, pela oferta de um atendimento resolutivo para maior parte dos casos, ${ }^{2}$ visto que, de acordo com estimativas, apenas $14 \%$ necessitarão de internação hospitalar e 5\% demandarão de leitos de Unidade de Terapia Intensiva (UTI). ${ }^{1}$ Ademais, a APS é o nível de atenção responsável por manter a longitudinalidade e a coordenação do cuidado em todos os níveis de atenção, sendo elemento essencial para organização da Rede de Atenção à Saúde (RAS), integrando os diversos pontos de atenção. ${ }^{1-2}$ Assim, cabe a esse nível assistencial a estratificação da gravidade dos casos e definição das condutas adequadas para cada situação clínica dos usuários, seja 
mantê-los sob cuidados e monitoramento ou encaminhá-los a serviços especializados nos casos mais graves. Para o manejo dos indivíduos com síndrome gripal, suspeitos ou confirmados com COVID-19 as equipes multiprofissionais da APS, utilizam-se de estratégias como o teleatendimento, seguindo o fluxo assistencial disponibilizado pelo Ministério da Saúde no Protocolo de Manejo Clínico do Coronavírus no nível primário de atendimento, que dentre as medidas descreve que o acompanhamento do usuário deve ser feito preferencialmente a cada 24 horas ou 48 horas dependendo dos riscos, até completar 14 dias do início dos sintomas. ${ }^{2}$ Considerando as especificidades desse contexto, pretende-se discutir a atuação dos serviços na RAS e a forma como cumprem com a sua função essencial de garantir atenção contínua e integral para os usuários do SUSS.

\section{Objetivo}

Analisar o número de contatos dos casos confirmados de COVID-19 com os serviços de saúde. Método: estudo epidemiológico, realizado a partir de banco de dados secundários dos casos confirmados de COVID-19 em um município do Sul do Brasil. A coleta foi realizada no prontuário eletrônico e nas planilhas de monitoramento dos casos, por meio de um instrumento que contemplava dados sociodemográficos e do perfil assistencial do caso nos serviços de saúde. O cálculo amostral, realizado com uma proporção de $50 \%$, considerando o intervalo de confiança de $95 \%$ e a margem de erro de $5 \%$, foi estimado em 366 casos. Foram incluídos no estudo 500 casos notificados no período de março a setembro de 2020 , selecionados aleatoriamente. Indivíduos não residentes no município foram excluídos. Realizou-se análise estatística descritiva. Estudo aprovado pelo Comitê de Ética em Pesquisa.

\section{Resultados e Discussão}

Dos 500 prontuários de casos confirmados de COVID-19, 50,8\% $(n=254)$ eram do sexo feminino, $86,6 \%(\mathrm{n}=433)$ cor branca, com média de idade de 40,72 anos $( \pm 14,70)$. Destes, $35,6 \%(\mathrm{n}=178)$ pertenciam a grupos considerados de risco a COVID-19. Houve um total de 3.263 contatos realizados com os 500 casos analisados. O número de contatos dos usuários com os serviços de saúde, seja presencialmente ou por telefone para monitoramento do caso, por sua iniciativa ou pelo próprio serviço, obteve-se uma média de 6,53 contatos com desvio padrão de 2,97. Considerando os serviços de saúde do município, a maior média de contatos foi com as Unidades Básica de Saúde (UBS) (média 1,91, desvio padrão 1,97), seguida do ambulatório de campanha (média 1,19, desvio padrão 1,10). O papel da APS nesse contexto demonstra a ampla capacidade na execução de ações comunitárias, o que amplia a possibilidade de resposta local não só para reduzir a disseminação do vírus, como também para amenizar os efeitos sociais e econômicos das medidas de distanciamento social. ${ }^{3} \mathrm{Na}$ atenção clínica individual, utilizando a modalidade de teleatendimentos e telemonitoramento do caso após o primeiro atendimento presencial, profissionais da APS, em especial enfermeiros, orientam os casos suspeitos quanto ao isolamento e reconhecimento dos sinais de alerta, monitoram e previnem casos leves e suspeitos quanto à evolução clínica, realizam teleconsultas e solicitam internação hospitalar ao identificar sinais de agravamento, além de seguir com o acompanhamento dos usuários hospitalizados. Todas essas ações resultam em redução da demanda nos demais níveis de atenção e permitem a concentração de seus recursos no atendimento aos casos mais graves. ${ }^{3}$ Destaca-se a articulação dos serviços de saúde, especialmente com a criação de polos de atenção à COVID-19, denominados ambulatórios de campanha, os quais são destinados ao primeiro atendimento presencial dos casos suspeitos e testagem diagnóstica, sendo possível realizar o manejo inicial, facilitar a estratificação de risco dos casos e encaminhar para internações necessárias. O ambulatório de campanha se mostra uma alternativa válida de gestão do trabalho a fim de adequar a RAS à realização do atendimento de forma segura, sem prejudicar os demais pacientes que buscam os serviços de saúde como a APS e unidades de pronto atendimento por outras causas. ${ }^{4}$ Em relação à distribuição dos contatos ao longo do período de acompanhamento do caso clínico confirmado de COVID-19 preconizado desde o início dos sintomas, perfazendo, no mínimo, 14 dias, dá-se destaque, como resultado do presente estudo, ao número de contatos na modalidade presencial entre o $4^{\underline{0}}$ e $5^{\underline{o}}$ dia de início dos sintomas (frequentemente, para o primeiro atendimento e avaliação) e ao contato na modalidade telefônica entre 14 e 21 dias de início dos sintomas, para a alta do monitoramento do caso de COVID-19. Apesar do bom desempenho do telemonitoramento desenvolvido pela APS, em 4O,4\% $(\mathrm{n}=2 \mathrm{O2})$ dos casos confirmados de COVID-19 analisados, em algum momento não foi conseguido contato com o usuário por telefone para monitoramento da situação 
de saúde, obtendo-se uma média de número de tentativas de contato sem sucesso de $0,7 \mathrm{e}$ desvio padrão de 1,10. Destaca-se ainda, que essas tentativas de contato registradas resultaram em um desfecho de $7 \%(\mathrm{n}=34)$ de usuários que foram colocados em busca ativa junto às unidades de APS, sem resolução registrada em prontuário até o momento da coleta de dados do estudo. Porém, apenas $1,65 \%(\mathrm{n}=8)$ dos casos não foram monitorados no município. A gestão do trabalho no combate à COVID-19, envolve o monitoramento, acompanhamento e tratamento da situação de saúde do caso, contemplando o itinerário percorrido pelo paciente na RAS. 5 Como limitaç̃o do estudo aponta-se a incompletude de informações nos prontuários de pacientes internados e daqueles acompanhados pelas instituições privadas, nos quais não foi possível o acesso ao registro de informações das mesmas. Quanto às implicações para o avanço científico para a área de saủde, evidencia-se a importância dos contatos com os serviços para fins de orientações sobre prevenção e cuidados frente à doença, evidenciando novas formas de atendimento com o avanço de tecnologias. Além disso, para a Enfermagem, essa forma de monitoramento expressou a relevância dos saberes no que se refere à valorização do cuidado baseado cientificamente, reforçando sua importância.

\section{Considerações finais}

Ao analisar o número de contatos dos casos confirmados de COVID-19 com os serviços de saúde evidencia-se que a pandemia impõe ao sistema de saúde a reorganização da RAS com redefinição de papéis e fluxos de atendimento e também, a criação de novos pontos de acesso ao sistema de saúde (com o ambulatório de campanha), inclusive por via remota (telemonitoramento desenvolvido pela APS). Assim, o aperfeiçoamento dos mecanismos de comunicação e da gestão do trabalho em saúde se constituiu como estratégia de avaliação e o monitoramento dos casos, prezando pela integralidade do cuidado, no qual a enfermagem protagonizou ao estar na atenção direta aos pacientes seja presencialmente ou remotamente.

Descritores: Atenção primária à saúde; Infecções por coronavírus; Telemonitoramento; Pandemias; Enfermagem.

\section{Referências}

1. Conselho Nacional de Secretarias Municipais de Saúde (BR). Covid-19: guia orientador para o enfrentamento da pandemia na rede de atenção à saúde. za ed. Brasília: Governo Federal; 2020. Disponível em: https://www.conass. org.br/wp-content/uploads/2020/o8/Instrumento-Orientador-Conass-Conasems-2-ed-com-anexos.pdf

2. Ministério da Saúde (BR). Protocolo de Manejo Clínico do Coronavírus (Covid-19) na Atenção Primária à Saúde. v. 9. Brasília: Secretaria de Atenção Primária à Saúde; 2020.

3. Daumas RP, Silva GA, Tasca R, Leite IC, Brasil P, Greco DB, et al. O papel da atenção primária na rede de atenção a saúde no Brasil: limites e possibilidades no enfrentamento $d a$ COVID-19. Cad. Saúde Pública. 2020; 36(6): e00104120.

4. World Health Organization. Operational considerations for case management of COVID-19 in health facility and community: interim guidance. Disponível em:

5. Sodré F. Epidemia de Covid-19: questões críticas para a gestão da saúde pública no Brasil. Trabalho, Educação e Saúde. 2020;18(3): eOO302134. 


\section{REESTRUTURAÇÃO DO SERVIÇO DA COMISSÃO HOSPITALAR DE TRANSPLANTE (CHT) DE UM HOSPITAL PÚBLICO NO OESTE}

\section{Jussara de Lima \\ Elisandra Cleonice Pritsch \\ Olvani Martins da Silva}

\section{Introdução}

O papel do enfermeiro frente a doação de órgãos a partir do protocolo de morte encefálica é de fundamental importância no momento delicado em que a família passa pela perda e que ao mesmo tempo existe a possibilidade de salvar vidas, cabe ao enfermeiro acompanhar, repassar informações aos familiares, organizar e junto com o médico realizar protocolo de morte encefálica. Onde após a confirmação do diagnóstico é necessário comunicar a família, prestar esclarecimentos e sanar todas as dúvidas para que se possa dar início ao processo de doação, caso seja desejo da família. A conduta neste momento é um fator determinante para que esta família opte ou não pela doação caso o paciente não tenha sinalizado sua vontade ${ }^{1}$. A empatia, o zelo do enfermeiro e da equipe para com o paciente e familiar, o cuidar não como um paciente em óbito, mas como um ser que necessita de cuidados é um dos fatores determinantes para que o processo de doação de órgãos seja possivel. A gestão e educação permanente da equipe multiprofissional sobre os aspectos de doação e transplante de órgãos são fundamentais, pois entende-se que quanto mais a equipe estiver preparada e esclarecida para sanar as dúvidas dos familiares, mais efetivo serão os resultados para o sucesso da doação. Cabe ao enfermeiro agir como mediador entre família e equipe profissional para que todo este processo atinja seu objetivo com êxito ${ }^{2}$. Objetivo: 
relatar as ações gerenciais de enfermagem desenvolvidas para remodelar o serviço da Comissão Hospitalar de Transplante (CHT) de um hospital público no oeste de santa Catarina, com vistas ao aumento da efetivação de captação de órgãos e tecidos humanos.

\section{Metodologia}

Relato de experiência que retrata a sequência de ações realizadas pela coordenação do serviço de captação e transplante de um hospital público do Oeste de Santa Catarina, com vistas ao aumento da efetivação de captação de órgãos e tecidos humanos. O período das atividades foi nos anos de 2019 e 20zo, quando ocorreu a implantação e implementação da remodelação das rotinas do setor no que se refere aos Processos administrativos, assistenciais e Educação permanente. A unidade composta por uma enfermeira coordenadora, um médico intensivista coordenador, cindo enfermeiros assistenciais, um técnico de enfermagem, a jornada de trabalho da coordenadora e do técnico é de oito horas diárias e sobreavisos nos demais horários e finais de semana.

\section{Resultados}

Ao acompanhar os índices dos últimos cinco anos do serviço da CHT, em 2015, o número de notificações de morte encefálica era de 28 , com 20 entrevistas, 9 doações e 10 recusas. Após a remodelação das rotinas do setor no inicio de 2019, houve um expressivo aumento, que refletiu ao final do mesmo ano em 7 notificações de morte encefálica, 33 entrevistas com familiares, 19 doações efetivadas e 6 recusas, neste mesmo ano, o transplante foi suspenso a partir do mês de março, devido a pandemia pela COVID-19, por consenso clinico ao considerar não haver paciente renal em condições lições limite de acesso ou em estado grave, assim, optaram por mantê-los em dialise, para evitar exposição ao procedimento cirúrgico durante a pandemiả. Para obtenção da melhoria dos resultados, a equipe da CHT, trabalhou em três frentes a saber: gerenciamento e reestruturação das ações; educação permanente e implementação da assistência. Gerenciamento e reestruturação das ações: A partir de fevereiro de 2019, houve mudança na coordenação da equipe da CHT na instituição. Com essa mudança, a coordenação optou em realizar uma nova seleção de enfermeiros para integrar a equipe. A partir daí, a escala de trabalho destes profissionais foi ajustada, as datas de sobre aviso foram respeitadas conforme a disposição e horário do colaborador, mantendo os sobreavisos em horários noturnos e finais de semana. A escala de funções no trabalho foi adaptada para envolver todos os enfermeiros a participarem das entrevistas e dos procedimentos cirúrgicos das captações. Um cronograma de reuniões mensais foi estabelecido, para compartilhar o balanço dos resultados do mês e pontuar os aspectos positivos e a serem melhorados. Assim, buscou-se estipular metas a serem alcançadas em relação as respostas positivas à doaçã̃o por parte das famílias. Também, foi implantado rotina para busca ativa três vezes ao dia, a qual passou a ser informada ao sistema de busca ativa na central de transplantes de Santa Catarina. Todo esse trabalho é auditado mensalmente por profissional da SC transplante, o que garantiu não ter perdas com nem um paciente em diagnóstico de morte encefálica em 20zo. Entretanto, ao longo desse processo houve algumas dificuldades, alguns profissionais enfermeiros do sobreaviso, não se adaptaram com o serviço e foram substituídos, pela compreensão de que todos precisam gostar e entender o processo do trabalho e sentir-se bem na função. Educação permanente: $\mathrm{O}$ início das reestruturações das rotinas do serviço, contou com o apoio e acompanhamento da central de transplante de Florianópolis no que se refere acompanhamento as famílias dos possíveis doadores. As capacitações com os colaboradores do serviço foram realizadas mensalmente, e para os recém admitidos na instituição, as capacitações ocorrem durante a integração dos funcionảrios. No mês de setembro, foi realizado campanha educativa sobre morte encefálica e doação de órgãos na Universidade Comunitária ďa Região de Chapecó, nessa ocasião a enfermeira coordenadora da Comissão Hospitalar de Transplante, palestrou no evento. Implementação da Assistência: Um dos principais focos da assistência de enfermagem foi direcionado ao acolhimento dos familiares. Esse acompanhamento muitas vezes se inicia no pronto socorro, na chegada do paciente em condições clínica grave, observada pela alteração pupilar, histórico do caso e observação dos exames de imagem que indicam comprometimento neurológico. A equipe da CHT já é acionada e inicia um acolhimento aos familiares, independentemente do desfecho do caso. Um bom acolhimento à família requer considerar vários aspectos, seja referente ao auxilio com transportes, proporcionar refeições caso o familiar necessite, organizar horários para visitas onde todos possam ter contato com seu familiar na Unidade de 
Terapia Intensiva (UTI) sempre acompanhados de um profissional da Comissão Hospitalar de Transplante, para informá-los de todos os procedimentos realizados com o paciente, utilizando linguagem compreensível para o entendimento da gravidade, embora o familiar receba informações do intensivista, se faz necessário que o enfermeiro da CHT acompanhe, e após dependendo o entendimento da família retome a informação sempre que necessário, pois a família é dependente de informações e acolhimento neste momento delicado da vida. Para efetivação deste acolhimento é necessário ouvir a família, e até contornar situações do grupo familiar. Em algumas ocasiões em que as famílias solicitam e autorizam receber informações via Whatzapp, essas são fornecidas por meio do dispositivo eletrônico. A questão da doação é possibilitada somente após ter concluído o protocolo de doação, e a família ter compreendido o que ocorreu com seu familiar, por isso a empatia do profissional faz a diferença para auxiliar a família a minimizar a dor do momento. Outra conduta implementada foi o informativo a todos os envolvidos com o protocolo de morte encefálica do paciente, ou seja, o resultado da positiva familiar, essa prática tem motivado a todos trabalharem em parceria, buscando o resultado da doação. O outro foco da assistência direcionada ao paciente em 2020, foi direcionada ao advento da COVID 19, que necessitou novos treinamentos e cuidados, com acréscimo da realização do teste para a covid modificando a logística dos exames, o qual é realizado no Lacen Florianópolis. Todos os pacientes ao iniciar o protocolo de morte encefálica realizam o teste para covid.

\section{Considerações}

Observou-se melhora significativa no número de doações efetivadas em consequência da reestruturação do gerenciamento das atividades, da educação permanente com os profissionais e do acolhimento dos familiares entre os anos de 2019 e 2020. Tais resultados refletiram no estado, e em novembro de $2019 \mathrm{em}$ evento comemorativo aos 20 anos da SC transplantes, a equipe da CHT, do HRO, recebeu homenagem de "melhores resultados do ano", assim como, a enfermeira coordenadora do serviço recebeu mérito de "enfermeira que mais implementou ações no ano, no estado de SC". Os resultados positivos, ocorreram pelo empenho e preparo dos profissionais, pelo trabalho com os familiares ao compreender que cada um tem seu tempo e entendimento. Os desafios seguem. Para o ano de 2021, espera-se que mesmo com a COVID 19, seja possivel manter o os índices de efetivação de doação de órgãos e transplantes, manter o acompanhamento aos familiares por meio da liberação para visitas seguindo as normas de segurança para controle da COVID 19. Acredita-se que permitir a visita do familiar ao potencial doador impacta na decisão da doação, o que é perceptível pelos agradecimentos à equipe por parte dos familiares quanto a forma de acolhimento.

Descritores: Doação de órgãos e tecidos; Morte encefálica; Gerência de serviços de saúde; Educação continuada em enfermagem

\section{Referências}

1. Alves MP et al. Processo de Morte encefálica: Significado para enfermeiros de uma unidade de terapia intensiva [internet]. Bahia: Revista Baiana de Enfermagem; 2019. 33 p. 33 v. [Acesso em: 15 dez. 2020]. Disponível em: https://periodicos.ufba.br/ index.php/enfermagem/article/view/28033.

2. COSTA IF; NETTO JM; BRITO MCC; GOYANNA NF; SANTOS TC; SANTOS, SS. Fragilidades na atenção ao potencial doador de órgãos: percepção de enfermeiros. Revista Bioética, [s.1.], v. 25, n. 1, p.130-137, abr. 2017. FapUINIFESP (SciELO). Acesso em 15 dez 2019. Disponível em: http://dx.doi.org/10.1590/1983-80422017251174.

3. Santa Catarina Transplantes. Estatísticas. Acesso em 20 jan. 2021. Disponível em: http://sctransplantes.saude.sc.gov.br/index.php/estatisticas 
Estudo de Revisão

\section{GERÊNCIA DE INVESTIGAÇÃO, PREVENÇÃO E CONTROLE DE INFECÇÃO DA CORRENTE SANGUÍNEA}

Maria Lucivane de Oliveira
Suely Lopes de Azevedo

\section{Introdução}

As infecções hospitalares consistem em um sério problema de saúde pública, sendo considerada como causa importante de morbidade e mortalidade. Caracteriza-se como Infecções Relacionadas à Assistência à Saúde (IRAS), definidas como uma condição local ou sistêmica resultante de uma reação adversa à presença de um agente infeccioso ou sua toxina e sem evidência de que a infecção estava presente ou incubada no momento da admissão do paciente em ambiente hospitalar ou ambulatorial. São diagnosticadas, em geral, a partir de 48 horas apó a internação'. Estudos apontam para o fato de que as principais IRAS são as infecções do trato respiratório, trato urinário, corrente sanguínea e sítio cirúrgico. Dentre as IRAS mais frequentes está a Infecção da Corrente Sanguínea (ICS) e constitui umas das complicações relacionadas ao uso do Cateter Venoso Central (CVC), que envolve cuidados diários e está associado com fatores complexos e multifatoriais relacionados desde a situação clínica do paciente, o tipo de cateter, sua composição, a técnica de inserção, a localização, a frequência de manipulação do sistema e a duração da cateterização ${ }^{2}$. Tal IRA uma vez instalada pode tornar-se altamente dispendiosa, potencialmente letal, associando-se à elevada morbidade, com prolongamento do tempo e de aumento dos custos de internação? 


\section{Objetivo}

Promover conhecimento acerca das medidas preventivas para o controle de infecção na corrente sanguínea.

\section{Método}

Estudo de revisão integrativa, a partir das fontes, indexadas às bases de dados da Literatura Latino-Americana e do Caribe em Ciências da Saúde (LILACS), Literatura Internacional em Ciências da Saúde (MEDLINE) e Scientific Electronic Library Online (Scielo), realizada no período de setembro a dezembro de 2020, por meio dos descritores: controle de infecções, infecção hospitalar; corrente sanguínea; prevenção e controle. Os critérios de inclusão foram: artigos disponíveis na integra; indexados nas bases supracitadas; publicados em português e inglês no período de 2015 a 2020.

\section{Resultados e Discussão}

A maioria das evidências aponta para o aumento dos índices de ICS relacionadas ao uso frequente do cateter venoso central. Nos estudos analisados aponta-se que o impacto da realização da Higienização das Mãos (HM) é expresso por meio das IRAS, tendo em vista que essa ação é reconhecida como a principal intervenção no controle de infecção. Enfatiza-se que, quando a prática da HM não acontece adequadamente, favorece a transmissão cruzada de micro-organismos, principalmente em pacientes críticos, que apresentam maior possibilidade de ser colonizados ou infectados ${ }^{3-4}$. Para tanto é necessária à prática das principais medidas de manutenção instituídas pelo Disease Control and Prevention (CDC) e pela ANVISA, a saber: higienização das mãos antes da manipulação do CVC; uso de luvas estéreis para o manuseio do cateter no momento da realização do curativo; o uso de clorexidina alcoólica a o,5\% para a limpeza durante o curativo; a avaliação da inserção do cateter diariamente para monitorizar sinais de infecção e a desinfecção do hub antes da administração de medicamentos 5 . Aponta-se também a utilização dos bundles como método auxiliar na redução de ICS. Desta maneira, o uso de uma abordagem adequada e eficiente para os bundles, que nada mais é que um conjunto de medidas preventivas realizadas em conjunto voltadas à prevenção de $\mathrm{ICS}^{6}$. Desse modo, é sabido que os riscos de infecção da corrente sanguínea também estão relacionados com o sítio ana- tômico de inserção do CVC, maiores para a inserção em vias baixas (femoral) e menores para vias altas (jugular e subclávia, sendo esta última o sítio preferencial), uma vez que o fator preponderante são a quantidade e a diversidade de micro-organismos encontrados em cada uma das regiões supracitadas? ${ }^{7}$. Portanto, para o procedimento de inserção do cateter, é indispensável a barreira máxima de precaução, que consiste na paramentação com luva estéril, gorro, máscara, capote e campo estéril, o que contribui para diminuir a contaminação pela microbiota do profissional e do ambiente para o paciente e o subsequente risco de infecção. O preparo da pele e essencial a fim de prevenir e uma das medidas importantes do pacote de prevenção, para isso é necessária à utilização de clorexidina alcoólica o, 5 \% previamente à punção, e recomenda-se deixar secar antes da inserir o CVC, promovendo desta forma um efeito residual, reduzindo a propagação de micro-organismos extraluminais no local do sítio de inserção $0^{7-8}$. Nos estudos verificou-se também que os curativos oclusivos devem ser substituídos conforme recomendado, pois a umidade da pele e a presença de sujidade e secreções promovem um ambiente propício ao crescimento microbiano. Deve-se trocar o curativo feito com gaze estéril em até 48 horas devido à dificuldade de visualizar o local de inserção e à possibilidade de este umedecer-se durante o banho. Acrescenta-se que o curativo transparente semipermeável de poliuretano permite a visualização do local de inserção e, por isso, requer trocas menos frequentes, podendo ficar até sete dias ou sempre que estiver sujo, solto ou úmido. Para isso uma boa fixação do curativo é fator determinante para a manutenção do curativo ocluído, o qual contribui para a redução da colonização da pele pericateter. Sabe-se que a desinfecção do hub antes da administração de medicamentos deve ser feita pela fricção alcóolica, por 15 a 30 segundos, a fim de se evitar/reduzir a propagação dos micro-organismos presentes no hub para o lúmen interno do cateter 9 . Além disso, a troca dos equipos, linhas venosas e conexões deverá ser realizada de acordo com protocolo da Comissão de Controle de Infecção Hospitalar (CCIH) da instituição ${ }^{3}$. Demostrou-se, portanto nos estudos analisados, a importância da adesão da equipe multiprofissional às medidas de prevenção e a implementação de bundles na redução das ICS são de extrema relevância na medida em que contribuem para a construção do conhecimento, o que vem ao encontro da prevenção de ICS relacionada ao CVC. 


\section{Conclusão}

As infeccões hospitalares consistem em um sério problema de saúde, cujo o desafio para prevenir danos e prejuízos estão associados aos cuidados decorrentes dos processos de trabalho ou das estruturas da assistência em saúde. Atualização de protocolos específicos, de critérios diagnósticos e medidas de prevenção para a redução das ICS deve ser preocupação dos gestores dos serviços de saúde. Para tanto, recomenda-se implantar e manter as estratégias para melhorar a adesão no que concerne a HM, tendo em vista que tal procedimento é reconhecido como a prática mais efetiva na prevenção das IRAS, no entanto, de acordo com alguns estudos, apesar da sua importância, a adesão a essa prática ainda permanece baixa nos serviços de saúde. Além de treinamentos pelos profissionais da CCIH, para auxiliar o gerenciamento de medidas no combate às infecções. $\mathrm{Na}$ análise dos estudos indicou que há necessidade de pesquisas adicionais com a finalidade de contribuir para seleção da melhor evidência disponível para a avaliação de opções e tomada de decisão na prevenção e controle das infecções na corrente sanguínea nas instituições hospitalares. Nesse contexto, revela-se a importância dos profissionais de saúde estarem preparados para o desenvolvimento de habilidades voltadas para práticas de inserção, manuseio e manutenção dos cateteres venosos centrais. Assim como a relevância da construção do conhecimento para a prática, no tocante às IRAS, na melhoria dos processos de trabalho e das práticas assistenciais fundamentadas em treinamentos, educação permanente e feedback às equipes envolvidas na assistência ao paciente.

Descritores: Controle de Infecções; Infecção Hospitalar; Corrente Sanguínea; Prevenção e Controle.

\section{Referências}

1. Brasil. Agência Nacional de Vigilância Sanitária. Medidas de Prevenção de Infecção Relacionada à Assistência a Saúde. Brasília, 2017.

2. Silva A G, Oliveira AC. Adesão às medidas para prevenção da Infecção da Corrente Sanguínea relacionada ao cateter venoso central. Enfermagem em Foco; 8 (2): 36-41, 2017.

3. Agência Nacional de Vigilância Sanitária (ANVISA). Programa Nacional de Prevenção e Controle de Infecções Relacionadas à Assistência à saúde (2016-2020). Brasília; 1:1-38, 2016.

4. Belela-Anacleto ASC, Peterlini MAS, Pedreira MLG. Hand hygiene as a caring practice: a reflection on professional responsibility. Revista Brasileira de Enfermagem; Mar/Apr; $70(2): 442-5,2017$. 
RefleXÃo TeÓRICA

PERSPECTIVAS DA ATUAÇÃO DA ENFERMAGEM NO MUNDO PÓSPANDEMIA: UMA REFLEXÃO TEÓRICA

\section{Lucas Soares dos Santos Aline Maffissoni \\ Manoela Brum Angela Maria Alvarez Rosane Gonçalves Nitschke}

\section{Introdução}

A COVID-19, doença causada pelo vírus SARS-CoV-2, têm modificado completamente os hábitos e costumes das mais diversas sociedades e culturas, uma vez que as restrições relacionadas ao distanciamento social causaram repercussões no cotidiano das pessoas e instituições. Quando se trata das instituições de saúde, as mudanças ocorreram rumo à reorganização da assistência, fluxos de atendimento, bem como a adaptação a novas recomendações e protocolos de cuidado ${ }^{1}$. Neste momento histórico, a enfermagem se caracteriza por possuir o maior quantitativo de profissionais atuantes no setor da saúde mundial, representando aproximadamente 59\% das forças de trabalho em saúde, e, portanto, é considerada pilar das equipes multiprofissionais de saúde ${ }^{2}$. No entanto, nas últimas décadas, a enfermagem tem se encaminhado para um crescente déficit da força de trabalho que vem se agravando cronicamente. Ainda antes da chegada da COVID-19, identificou-se que a enfermagem já atuava com altas cargas de trabalho, resultados de saúde deficitários, altos índices de síndrome de Burnout, além da falta de pessoal de enfermagem e limitação de recursos 3 . Neste contexto, buscou-se refletir sobre a situação global da enfermagem e suas tendências para o período pós-pandêmico. 


\section{Método}

Trata-se de um estudo de reflexão teórica sobre as perspectivas da atuação da enfermagem no mundo pós-pandemia utilizando dados do relatório lançado em 2020 sobre o estado da enfermagem no mundo da Organização Mundial da Saúde (OMS) ${ }^{2}$. Este estudo foi desenvolvido entre setembro e novembro de 2020, a partir da revisão narrativa da literatura sobre a temática e as reflexões exploradas na disciplina "Concepções teórico-filosóficas no Processo de Cuidar em Enfermagem e Saúde", ofertada pelo curso de Pós-Graduação em Enfermagem da Universidade Federal de Santa Catarina (UFSC).

\section{Resultados e Discussão}

Preocupada em conhecer o panorama da enfermagem no mundo atual, a OMS realizou um levantamento em 191 países, iniciado no ano de 2018 e publicado em 2020 intitulado: "Estado da enfermagem mundial: investindo em educação, trabalho e liderança". Neste relatório, o órgão denota sua preocupação com a enfermagem no contexto da atualidade, especialmente no que se refere às tendências da profissão para os próximos anos e a necessidade de estímulo à formação de lideranças na enfermagem para promover maior representatividade e visibilidade profissional, bem como maior investimento em educação e desenvolvimento profissional e melhoria das condições de trabalho da enfermagem ${ }^{2}$. Para compreender as novas perspectivas do trabalho em enfermagem nos próximos anos é necessário refletir sobre o panorama atual dos profissionais. A equipe de enfermagem no mundo é composta por 27,9 milhões de profissionais, sendo 19,3 milhões enfermeiros. Estimado em 6,6 milhões de profissionais da enfermagem em 2016, o déficit de profissionais reduziu nos últimos anos para 5,9 milhões em 2018, o que evidencia melhorias, mas ainda um longo caminho a avançar na formação de novos profissionais e retenç̃̃̃o daqueles já atuantes no setor da saúde. Alêm disso, o relatório da OMS aponta que um em cada oito profissionais exerce a profissão em um país diferente de onde estudou ou do seu nascimento. O órgão ainda aponta para a crescente mobilidade de enfermeiros e a necessidade de realizar uma gestão cautelosa da migração para evitar iniquidades de acesso aos serviços de saúde, visto que a migração ocorre principalmente para países desenvolvidos e de alta renda. Desde o início da pandemia, a equipe de enfermagem tem sido a linha de frente no combate à pandemia por COVID-19, atuando nos mais diversos cenários para fortalecer os sistemas de saúde e evitar o colapso impulsionado pelo aumento significativo das demandas de cuidado trazidas por esta emergência em saúde pública. Por esta razão, o fluxo de enfermeiros, local e internacional, tornou-se uma realidade para os profissionais de saúde, ou seja, inúmeros enfermeiros foram convocados para trabalhar em outras localidades e sair de suas cidades, estados ou países para prestar assistência em um outro ambiente com culturas diferentes ${ }^{4}$. A exemplo disso, pode-se destacar o fato de que inúmeros enfermeiros da américa latina migraram para países europeus e diversos países fortemente afetados pela pandemia passaram a facilitar e flexibilizar o processo de imigração de profissionais de saúde de modo a suprír as demandas de trabalho em saúde. O senado americano, por exemplo, lançou um projeto de lei para disponibilizar mais de 40.000 vistos de trabalho para médicos e enfermeiros se unirem às forças de trabalho do país no combate à pandemia. Até mesmo no Brasil ocorreu o deslocamento de profissionais de saúde de algumas regiões para outras, como o fluxo para o estado do Amazonas, e a chamada de profissionais para regiões interioranas. Outra característica que chama atenção no perfil da enfermagem é a tendência ao envelhecimento da classe. Embora uma parcela grande da enfermagem tenha idade relativamente jovem, a OMS aponta que há discrepâncias em determinados países europeus e americanos quanto a idade e que devem ser levadas em consideração para os próximos anos. Há 18 países que estão em risco de envelhecimento da força de trabalho e as estatísticas apontam que 1 em cada 6 enfermeiros no mundo se aposentem nos próximos 10 anos. Os dados do relatório também demonstram que o número de profissionais $\mathrm{da}$ equipe de enfermagem é desproporcional para alcançar a cobertura na saúde mundial e que $80 \%$ dos profissionais se encontram em países que somam metade da população mundial. Essas carências concentram-se em países com rendas mais baixas, como em países da África, Sudeste Asiático, Mediterrâneo Oriental e alguns países da América Latina. Diante desse cenário, vislumbramos a necessidade da divisão mais homogênea dos profissionais de enfermagem, viabilizando um atendimento integral para toda população mundial. Entretanto, o quantitativo de profissionais que estão com idade próxima da aposentadoria traz à tona a primordialidade da formação de novos profissionais para manutenção adequada da força de trabalho, estimando a necessidade do aumento 
de $8 \%$ ao ano no número total de graduados para preencher a escassez até $2030^{2}$. O engrandecimento da profissão por meio sensibilização ocasionada pela pandemia atrai o olhar das demais áreas e da população para a enfermagem, com o imaginário de profissionais "heróis", "anjos" e "salvadores". Todavia, não se pode desviar das problemáticas vivenciadas pela classe da enfermagem, tais como a precariedade do trabalho, salário, cargas horárias exaustivas e demandas psicológicas vivenciadas pelos profissionais que estão na linha de frente da saúde 5 . No Brasil, os auxiliares e técnicos de enfermagem se enquadram na maior parte dos profissionais que constituem a equipe na linha de frente das instituições no atendimento a casos suspeitos e confirmados de COVID-19. Oito em cada dez desses profissionais são mulheres que, por vezes, após a jornada de trabalho assumem os cuidados a pessoas próximas como crianças, idosos ou enfermos, ou iniciam nova jornada em outra instituição. Claramente, esses fatores nos instigam a pensar como estamos cuidando dos profissionais expostos ao contágio pelo COVID-19 na linha de frente da saúde, que majoritariamente dispõem de condições de trabalho inadequadas, falta de equipamentos e baixa retribuição salarial'. Com vistas à realidade previamente apresentada, é necessário refletir quanto às formas de melhorar as condições de trabalho e métodos de cuidar da equipe de saúde. Neste momento, é importante proporcionar maior qualidade de vida frente às circunstâncias existentes para que, no período pós-pandemia, os profissionais da saúde sofram impactos reduzidos em relação a saúde física, mental e emocional. No pós-pandemia, a atenção em saúde precisará ser repensada, adequando demandas antigas às novas, focadas no desempenho de ações assistenciais, gerenciais, educativas como também pesquisas científicas que contribuam com o progresso da profissão e a qualidade no cuidado. Espera-se que, apesar dos efeitos deletérios da pandemia, a enfermagem ganhe visibilidade e seja valorizada pela sua potencialidade, efetividade, qualidade e saber científico.

\section{Conclusão}

A pandemia de COVID-19 realça a relevância da enfermagem na redução da mortalidade, prevenção e controle de disseminação da doença. Tal classe que há décadas reivindica direitos e busca melhorias das condições de trabalho merece e necessita ser ouvida e atendida. Quando se trata das tendências da profissão para os anos subsequentes aos da pandemia, nota-se que a enfermagem tem adentrado diferen- tes culturas e atravessa fronteiras nacionais e internacionais para atuar em outras localidades e países. Observa-se que a equipe de enfermagem permanece e continuará sendo o pilar dos serviços de saúde, todavia necessita de atenção para com o desgaste físico e emocional advindo das condições de trabalho desfavoráveis e falta de suporte para melhorias laborais. Dessa forma, é necessário obter colaboração e fortalecimento das instituições governamentais para a formação de novos profissionais, de modo a suprir o déficit da força de trabalho, continuar contribuindo com as ações sanitárias e receber apoio para a formação de lideranças, assim ganhando mais representatividade social.

Descritores: Equipe de Enfermagem, Recursos Humanos de Enfermagem, Gestão em Saúde, Pandemias.

\section{Referências}

1. Machado MH, Pereira EJ, Ximenez Neto FRG, Wermelinger MCMW. Enfermagem em Tempos da COVID-19 no Brasil: um olhar da gestão do trabalho. Rev Enferm Foco [Internet]. 2020; 11(1):32-39. Disponível em: http:// revista.cofen.gov.br/index.php/enfermagem/ article/view/3994/8002

2. World Health Organization, International Counsil of Nurses, Nursing NOW. State of the World's nursing 2020: investing in education jobs and leadership [Internet]. Geneva, Switzerland, 2020; 116 p. ISBN: 978-92-4-000327-9. Disponível em: https://www.who.int/publications-detail-redirect/9789240003279

3. Lasater KB, et al. Chronic hospital nurse understaffing meets COVID-19: an observational study. BM] Qual Saf [Internet]. 2020; 0:1-9. DOI 10.1136/bmjqs-2020-011512. Disponível em: https://qualitysafety.bmj.com/content/ghc/ early/2020/08/13/bmjgs-2020-011512.full.pdf

4. Lacerda M. Governança na Pandemia: a ciência como regulação moral e os problemas da biopolítica. Rev. Simbiótica [Internet]. 2020;7. Disponível em: https://periodicos.ufes.br/simbiotica/article/view/30983/20724

5. Minayo MCS, Freire NP. Pandemia Exacerba Desigualdades na Saúde. Ciênc. saúde coletiva [Internet]. 20zo; 25(9):3555-56. Disponível em: http://www. scielo.br/scielo.php?script $=$ sci_arttext \&pi$\mathrm{d}=\mathrm{S} 1413-81232020000903555 \& \operatorname{lng}=\mathrm{en} \& \mathrm{nrm}=$ iso 
RELATO DE EXPERIÊNCIA

\begin{abstract}
VACINAÇÃO CONTRA O CORONAVÍRUS EM UMA UNIDDE DE PRONTO ATENDIMENTO: RELATO DE EXPERIÊNCIA
\end{abstract}

\author{
Daiane Freitas de Oliveira \\ Nicole Hertzog Rodrigues \\ Adriana Aparecida Paz
}

\section{Introdução}

O novo coronavírus SARS-CoV-2 (COVID-19) trata-se de ácido ribonucleico (RNA) vírus envelopados, habitualmente encontrados em humanos, outros mamíferos e aves, podendo ocasionar doenças respiratórias, entéricas, hepáticas e neurológicas. Os sintomas podem variar, a maioria dos casos ocorre com sintomatologia leve, como a de um resfriado. Os sintomas mais comuns são tosse, febre, coriza, dor de garganta e dispneia. Porém, casos mais graves evoluem para síndrome de desconforto respiratório e possuem necessidade de cuidados em unidades de terapia intensiva. Essa infecção viral apresentou os primeiros casos contaminados em dezembro de 2019, na cidade de Wuhan, na China ${ }^{1}$. No Brasil, o primeiro caso confirmado de coronavírus foi em fevereiro de 2020. Desde então, os números de contágio e mortes aumentaram de forma rápida. Em março de 2020 foram adotadas medidas de distanciamento social, com o objetivo de implementar ações para o enfrentamento e a minimização do aumento do número de casos buscando conscientizar a população e difundir medidas de prevenção ${ }^{2}$. Nessa conjuntura, a enfermagem se apresenta com a excelência de uma profissão de autêntico nível superior, atuando em diversas frentes no combate à pandemia. Assim, o enfermeiro se desponta de maneira semelhante a outros momentos históricos, em que epidemias e catástrofes acometeram a 
população, colocando-se em risco para realizar assistência à saúde mais uma vez. ${ }^{3}$ Diante do exposto, sem dúvida, um dos grandes desafios dessa pandemia é garantir a segurança e a proteção efetiva dos trabalhadores da saúde, de forma a prevenir, tratar e controlar a doença ${ }^{4}$. Desde o início da pandemia, a descoberta de um produto eficaz e seguro para prevenir infecções pelo novo coronavírus tem sido aguardada como uma esperança capaz de deter o avanço da doenças. Em dezembro de 2020, as primeiras vacinas para prevenção $d a$ COVID-19 foram autorizadas para uso emergencial, pelas principais agências regulatórias dos Estados Unidos e Brasil, trazendo assim, esperança para a população mundial.

\section{Objetivo}

Relatar a experiência de uma gestora enfermeira de uma Unidade de Pronto Atendimento (UPA) no processo de vacinação contra a COVID-19.

\section{Método}

Trata-se de um relato de experiência que descreve a vivência da coordenadora de enfermagem e sua equipe, frente a vacinação contra a COVID-19 em uma UPA na cidade de Porto Alegre, Rio Grande do Sul (RS), Brasil. Este relato engloba aspectos envoltos na organização do cronograma para vacinação, preparo, comunicação para equipe multiprofissional, recepção da equipe para aplicação da vacina nos profissionais da UPA e o dia da vacinação. As ações descritas no presente relato foram obtidas a partir da vivência profissional associada às discussões científicas das autoras.

\section{Resultados e Discussão}

A UPA integra a Rede de Urgência e Emergência (RUE) do município, com funcionamento 24 horas, sete dias por semana, ininterruptamente, com atendimento por demanda espontânea, executando atividades de assistência à saúde envolvendo atendimentos de urgência e emergência (adulto e pediátrico). A unidade conta com 12 leitos, sendo 6 leitos de observação adulto, 4 leitos de observação pediátrica e 2 leitos de estabilização. Realiza uma média de 15.000 atendimentos/ mês. Quando falamos de atendimento de pacientes COVID-19, contabilizamos de março de 2020 a janeiro de 2021, um total de 14.836 pacientes atendidos com síndrome gripal e suspeitos para COVID-19. A vacinaçã̃o para
COVID-19 foi o momento mais aguardado desde o início da pandemia. Na semana que antecedeu a vacinação foi um período de muitas dúvidas, angústias e incertezas, pois ocorreram muitas mudanças, e não se tinha certeza de quem realmente seria vacinado. $\mathrm{O}$ quantitativo de colaboradores a ser vacinado era de 194, destes 73 eram profissionais de enfermagem. A organização se deu da seguinte forma: planejamento em conjunto com o setor de Imunizações do Estado do RS, Gerência Distrital Municipal e Coordenação de Enfermagem da UPA. Foram elaboradas planilhas em Excel para controle de todos os colaboradores, divisão por categoria profissional e distribuição por horário (8:30 as 10:00 e 15:00 às 16:00). Os profissionais que estavam saindo do plantão noturno e os que estavam entrando no plantão da manhã, realizaram a vacina no primeiro horário. Os profissionais do plantão da tarde e do plantão da noite ficaram para o segundo horário. A campanha de vacinação para COVID-19 foi realizada na UPA no dia 25 de janeiro de 2021, com o intuito de imunizar todos os profissionais de saúde da linha de frente. A unidade contou com a equipe de apoio da Gerência Distrital - três técnicos de enfermagem e duas enfermeiras. As entrevistas com os profissionais de saúde, controle de temperatura ficaram a cargo das enfermeiras e a confecção da carteira de vacinação e aplicação da vacina, com as técnicas de enfermagem. A coordenação de enfermagem e administrativa da UPA organizou a logística interna. A primeira profissional a ser vacinada foi uma enfermeira do turno da noite, ela relatou, que seu coração bateu tão forte que não conseguiu segurar a emoção. O acompanhamento de perto de todo o processo de vacinação dos funcionários, foi possível observar a felicidade e alegria de cada um, porque também sabia que por trás daquelas faces sorridentes houveram muitos momentos difíceis, enfim, tratou-se de um momento emocionante para todos os funcionários deste serviço. Foram vacinados 156 (80\%) profissionais, sendo 68 deles profissionais de enfermagem, correspondendo à 93\% destes. A meta era vacinar a totalidade dos profissionais de enfermagem, porém dentre algumas das contra indicações da vacina era ter sido acometido pela COVID-19. Nesta condição, dois profissionais não se enquadravam no momento, sendo recomendada a administração da vacina após zo dias do início dos sintomas. Além disso, outros três profissionais por motivos pessoais não compareceram para receber o imunobiológico. 


\section{Conclusão}

A campanha de vacinação dos profissionais da UPA foi emocionante e bem organizada. Com muito sorriso no rosto, muitas fotos e esperança de dias melhores. Esta experiência foi extremamente relevante no que tange a gestão do cuidado e do processo de trabalho e organização de uma campanha de vacinação tão esperada, e especialmente, para a enfermagem que atua na linha de frente. Ter uma equipe alinhada e coesa, garantiu a harmonia e sucesso nas tomadas de decisões. Pode-se constatar que a gestão do trabalho se faz ainda mais importante nos tempos de crise, assim como ter uma comunicação efetiva e clara com as equipes de trabalho.

Descritores: Enfermagem; Infecções por Coronavírus; Programas de Imunização; Vacinas.

\section{Referências}

1. Organização Pan-Americana de Saúde (BR). OPAS [Internet]. 2021 [acesso em 28 Jan 2021] Disponível em: https://www.paho.org/pt/covid19

2. Ministério da Saúde (BR). Portaria № 356, de 11 de março de 2020: dispõe sobre a regulamentação e operacionalização do disposto na Lei $n^{\circ}$ 13.979, de 6 de fevereiro de 2020, que estabelece as medidas para enfrentamento da emergência de saúde pública de importância internacional decorrente do coronavirus (COVID-19) [Internet]. Brasília, DF(BR): Ministério da Saúde; 2020 [acesso em 28 Jan 2021]. Disponível em: https://www.in.gov.br/en/web/dou/-/portaria-n-356-de-11-de-marco-de-2020-247538346

3. Word Health Organization (SZ). Coronavirus disease (COVID-19) outbreak: rights, roles and responsibilities of health workers, including key considerations for occupational safety and health [internet]. 2020 [acesso em 28 Jan 2021]. Disponivel em: https://www.who.int/docs/default-source/coronaviruse/who-rights-roles-respon-hw-covid-19.pdf?sfvrsn=bcabd401_o

4. Ribeiro AP, Oliveira GL, Silva LS, Souza ER. Saúde e segurança de profissionais de saúde no atendimento a pacientes no contexto da pandemia de COVID-19: revisão de literatura. Rev Bras Saude Ocup. 2020;45:e25. Doi: http:// dx.doi.org/10.1590/2317-6369000013920

5. Stevanim LF. Uma vacina para a humanidade: da expectativa à realidade, os esforços para se chegar a uma vacina contra COVID-19 acessível à população. Fundação Oswaldo Cruz. Radis. 2020; 216. Disponível em: https://radis.ensp.fiocruz.br/index.php/todas-as-edicoes/216 
Pesquisa Original

\section{ORGANIZAÇÃO DA GESTÃO DO TRABALHO NA ESTRATÉGIA SAÚDE DA FAMÍLIA}

\section{Daniela Savi Geremia Jiennifer Souza de Oliveira}

\section{Introdução}

A Estratégia Saúde da Família (ESF) promove inovações e mudanças nos processos de trabalho, o que se deve em grande parte a atuação das equipes multi e interprofissionais de saúde. Essa organização de trabalho permite a atuação com base em determinantes sociais de saúde, possibilita a criação de vínculo com a população e fortalece o compromisso e corresponsabilidade dos usuários, atributos essenciais da Atenção Primária à Saúde (APS). As ESF são compostas por enfermeiros, médicos, técnicos e auxiliares de enfermagem, farmacêuticos, odontólogos, técnicos de saúde bucal e agentes comunitários de saúde que devem atuar de forma integrada e interprofissional para garantir a qualidade dos cuidados prestados. Não obstante, além da relação direta com os usuários, o trabalho em equipe envolve as relações interpessoais, como pode ser compreendido a partir do próprio conceito de equipe: se refere ao coletivo, múltiplos conceitos em formação, uma rede de conexões e, para que esse trabalho aconteça, fatores como comunicação, cooperação, interação e empatia tornam-se fundamentais ${ }^{1}$. Para dar suporte a equipe a atividade de organização do processo de trabalho, garantindo a qualidade e a resolutividade na ESF/APS, prescinde de uma atuação proativa da gestão nesses espaços, de modo que as práticas de atenção à saúde e as ações estratégicas desenvolvidas atendam às necessidades da população em relação ao cui- 
dado. Também, cabe ao coordenador da ESF motivar, sensibilizar e engajar sua equipe para o enfrentamento de adversidades cotidianas no local de trabalho'. Outrossim, o reconhecimento de que a equipe deve estar organizada de maneira que objetive continuamente a melhoria da qualidade assistencial faz parte do rol de funções do coordenador da equipe, a gestão não se dissocia da atenção, e ambas precisam ocorrer em sintonia. Em virtude de todo esse contexto de atuação profissional, os coordenadores responsáveis pela gestão dos Centros de Saúde da Família (CSF) enfrentam diferentes desafios na organização, planejamento e execução do seu processo trabalho na ESF, sendo importante conhecer quais são os fatores que estão implicados nesse processo.

\section{Objetivo}

Analisar as implicações do processo de gestão e organização do trabalho dos coordenadores da Estratégia Saúde da Família em um município polo da região oeste catarinense.

\section{Método}

Trata-se de um estudo qualitativo realizado por meio de grupo focal com vinte e dois coordenadores de CSF. O método de escolha foi intencional considerando a função profissional de coordenador do CSF. Foram delimitados os seguintes critérios de inclusão no estudo: 1) todos os coordenadores (as) que atuam na APS há pelo menos um ano. E como critérios de exclusão: os profissionais que estavam em férias, afastados ou em atestado médico. A entrevista de grupo focal com os coordenadores das CSF foi realizada em outubro de 2019, em auditório na secretaria municipal de saúde, sendo mediada por um facilitador da equipe da pesquisa que promoveu o debate sobre temas relacionados ao processo de trabalho na coordenação de um serviço de APS. Esta pesquisa foi aprovada pelo Comitê de Ética em Pesquisas com Seres Humanos da Universidade Federal da Fronteira Sul (UFFS) por meio do parecer n⿳⺈ 3.440.211. As questões abordadas versaram sobre a estrutura dos serviços frente à disponibilidade de equipamentos, medicamentos, materiais e suas interferências no atendimento; quando ao processo de trabalho foi questionado sobre a rotatividade, organização da agenda de atendimentos, condução das reuniões de equipe, identificação dos espaços de debates entre a equipe, relações interprofissionais e intersetoriais e avaliação dos coordenadores sobre os serviços ofertados; foram debatidos ainda, a percepção dos coordenadores sobre a resolutividade, longitudinalidade e integralidade da assistência a saúde. $O$ tempo de duração da entrevista de grupo focal foi de 90 minutos e as discussões foram gravadas e transcritas mediante a autorização dos participantes. As perguntas foram lançadas para o grupo e o debate foi mediado para oportunizar que todos pudessem se expressar. O método de análise foi o Discurso do Sujeito Coletivo, que originou três ideias centrais: I) Organização do processo de trabalho na coordenação da ESF; II) Apoio intersetorial e interprofissional na organização das práticas de cuidado e gestão; e, III) Sobrecarga e falta de motivação para os coordenadores e profissionais na ESF.

\section{Resultados e Discussão}

$\mathrm{Na}$ análise do processo de trabalho sob a ótica do enfermeiro gestor das unidades de ESF, percebe-se que: "Melhorou muito essa questão da rotatividade profissional em relação a equipe de enfermagem e ao setor administrativo, mas no momento a maior rotatividade é médica. Estou abrindo a agenda para sete médicos diferentes na unidade, porque vem em dois dias da semana uma determinada pessoa, dois turnos outra pessoa, e assim vai! É um momento de troca após o concurso público e aí tem muito servidor contratado, na minha unidade por exemplo, de três clínicos dois são contratados" (DSC 1). A rotatividade dos profissionais está associada a outros aspectos relacionados ao fazer típico da gestão da força de trabalho em saúde? Nessa perspectiva, e considerando a construção de vínculos com os usuários, o DSC 2 e DSC3 revelam importantes questões sobre a organização dos serviços e do processo de trabalho. "Hoje, na minha unidade de saúde fazem milagre no atendimento aos usuários. Como vamos fazer para criar vínculo numa ESF com até 3.500 usuários? Então não existe aquela palavra chamada vínculo, não se cria vínculo, não existe vínculo com a estratégia de saúde da família $e$ os profissionais. (DSC 2 ). Cabe destacar que cada território apresenta especificidades, e a definição do número de habitantes deveria se dar considerando o profundo conhecimento do perfil demográfico, epidemiológico, administrativo, tecnológico, político, social e cultural de cada região $0^{4}$. Outras implicações apresentadas na relação com a equipe e na sobrecarga: "Então, eu vejo uma dificuldade muito grande nessa questão de você ter que pedir para as pessoas fazerem o trabalho delas, porque afinal, está contratada para isso, mas não faz. (DSC 3 )". 
"Tu és o espelho e o termômetro, se tu um dia chega meio para baixo, você percebe que a equipe afunda também" (DSC 4 ). O gerenciamento de equipe requer um profissional que tenha afinidade com a gestão, preparado e com habilidades de comunicação, motivação, competência técnica e acima de tudo, empatia para tomar decisões em momentos oportunos. Os coordenadores precisam utilizar ferramentas ao seu alcance, como o reconhecimento do trabalho em equipe e habilidades para trabalhar as relações sociais e as particularidades de cada pessoa, tornando-se referência como facilitador das práticas5. E dada toda a situação apresentada a sobrecarga se torna inevitável: "A sobrecarga é grande, e ao mesmo tempo você vê a sua equipe adoecendo. Eu sou coordenadora e enfermeira assistencial, então né? não tem como não se sobrecarrega. A coordenação, além da gente fazer toda parte de gestão, a gente tem que fazer a parte clínica. A gente faz múltiplas funções" (DSC 5). Algumas estratégias que estimulem a cooperação e a divisão de atribuições e responsabilidades com autonomia entre a equipe da ESF podem contribuir favoravelmente para a melhoria das relações de trabalho, da organização das práticas e do serviço de saúde ${ }^{2,5}$. Entre os fatores que influenciam a organização do trabalho dos coordenadores estão a alta rotatividade dos membros da equipe, infraestrutura inadequada, falta de cooperação dos profissionais, déficit de apoio intersetorial e interprofissional e sobrecarga de trabalho. Esta pesquisa contribui com o diagnóstico local sobre as práticas de gestão na ESF e sinaliza o compromisso em avançar no campo do conhecimento científico e político em instrumentos que possibilitem qualificar o planejamento e a gestão na APS. Suas limitações estão na necessidade de expandir as análises para analisar a percepção dos profissionais que atuam na assistência.

\section{Conclusão}

Nesse contexto, o trabalho de coordenação e gestão dos CSF tem sido desafiante e impacta diretamente na capacidade técnica e operacional de desenvolvimento de práticas de atenção à saúde que preconizem os princípios e atributos essenciais da APS no Brasil. Esta pesquisa evidenciou a imprescindibilidade de ofertar melhores condições de estrutura e de trabalho para os coordenadores e equipes que atuam nas ESF. Considera-se relevante também a realização de capacitações para fortalecer o trabalho em equipe; sensibilização dos profissionais e a motivação para o desem- penho de suas funções, o respeito e a valorização profissional; reorganização e definição das atividades assistenciais e gerenciais, apoio interprofissional e intersetorial de forma ampliada visando um atendimento resolutivo e satisfatório em saúde.

Descritores: Enfermagem; Gestão em Saúde; Atenção Primária à Saúde

Financiamento: Universidade Federal da Fronteira Sul (UFFS).

\section{Referências}

1. Soder R, Oliveira IC, Silva LAA, et al. Desafios da gestão do cuidado na atenção básica: perspectiva da equipe de enfermagem. Enferm. Foco [Internet]. 2018 [acesso 2020 Jan 20]; 9(3):76-80. Disponível em: https://doi.org/10.21675/2357-707X.2018.v9.n3.1496.

2. Ferreira J, Celuppi IC, Baseggio L, et al. Planejamento regional dos serviços de saúde: o que dizem os gestores? Saúde e Sociedade [Internet]. 2018 [acesso 2020 Mai 11]; 27(1):6979. Disponível em: http://dx.doi.org/10.159o/ $\underline{\text { S0104-12902018170296. }}$

3. Pires, DEP et al . Gestão na atenção primária: implicações nas cargas de trabalho de gestores. Rev. Gaúcha Enferm., Porto Alegre, v. 40, e20180216, 2019. Disponível em: https:// doi.org/10.1590/1983-1447.2019.20180216.

4. Rocha TAH, Almeida DG, Amaral PV, et al. Proposal for a methodology to estimate the potential coverage of primary care teams. Rev Panam Salud Publica [Internet]. 2019 [acesso 2020 Abr 23]; 43:e47. Disponível em: https:// doi.org/10.26633/RPSP.2019.47

5. Fernandes JC, Cordeiro BC. The management of basic health units from the point of view of nursing managers. Rev enferm UFPE [Internet]. 2018 jan lacesso 2020 Mai 20]; 12(1):194-202. Disponível em: https://doi.org/10.5205/1981-8963-v12io1a23311p194-202-2018. 
CARACTERIZAÇÃO DA ATENÇÃO DOMICILIAR NO ATENDIMENTO ÀS CRIANÇAS COM NECESSIDADES ESPECIAIS EM SANTA CATARINA

\author{
Diana Augusta Tres \\ Elisangela Argenta Zanatta \\ Beatriz Rosana Gonçalves \\ de Oliveira Toso
}

\section{Introdução}

A Atenção Domiciliar (AD) no Brasil foi regulamentada em 2011, pela portaria $\mathrm{n}^{\circ}$ 2.029. Em 2016 ocorreu a última redefinição e atualização por meio da portaria $\mathrm{n}^{\mathrm{0}} 825$, que definiu a AD como uma modalidade de atenção à saúde que se caracteriza pela realização de ações de prevenção e tratamento de doenças, reabilitação, paliação e promoção à saúde, acões estas que devem ser prestadas no domicílio do usuário com a finalidade de garantir a continuidade dos cuidados. ${ }^{1} \mathrm{~A}$ AD está dividida em três modalidades: $\mathrm{AD}_{1}, \mathrm{AD}_{2}$ e $\mathrm{AD}_{3}$. Os usuários que se encaixam às modalidades $\mathrm{AD}_{2}$ e $\mathrm{AD}_{3}$, são usuários elegíveis para o Serviço de Atenção Domiciliar (SAD) e se caracterizam por apresentarem doenças agudas, crônico agudizadas, crônico-degenerativas e necessidade de cuidados paliativos semanais. Da mesma forma, necessitam de cuidados intensificados, uso de equipamento e procedimentos de maior complexidade. ${ }^{1}$ Assim, o SAD pode ser definido como um serviço complementar aos cuidados realizados na Atenção Primária à Saúde (APS) e em serviços de urgência, substitutivo ou complementar à internação hospitalar, realizado pelas Equipes Multiprofissionais de Atenção Domiciliar (EMAD) e Equipes Multiprofissionais de Apoio (EMAP). ${ }^{1}$ Nesse contexto, a AD é indicada para pessoas de qualquer faixa etária, clinicamente estáveis, mas que necessitam de uma atenção especial à saúde. ${ }^{1}$ Dessa forma, devido 
aos critérios de elegibilidade das modalidades $\mathrm{AD}_{2}$ e $A D_{3}$, a $\mathrm{AD}$ precisa ser inclusa na assistência de Crianças com Necessidades Especial de Saúde (CRIÁNES), ou seja, aquelas que se caracterizam por apresentarem uma condição crônica de saúde, normalmente necessitando de cuidados contínuos ou temporários e, muitas vezes, permanentes, com um número maior de atendimentos do que uma criança que não apresente qualquer condição crônica de saúde. Do mesmo modo, demandam cuidados técnicos especializados e podem necessitar de internações frequentes e prolongadas. ${ }^{2}$

\section{Objetivos}

Caracterizar os Serviços de Atenção Domiciliar em Santa Catarina (SC) e conhecer as demandas de cuidados e as necessidades de atenção especial a saúde de crianças atendidas pelos SADs de SC.

\section{Método}

Pesquisa descritiva, exploratória, de abordagem quantitativa, vinculada a macro pesquisa "Produção do cuidado e validação de protocolo de fluxo para serviços de atenção domiciliar a crianças com necessidades especiais de saúde". O estudo foi realizado com os SADs do Estado de SC. Inicialmente foi enviado um convite via e-mail aos 11 municípios do Estado que possuem o serviço implantado e em pleno funcionamento (Áraranguá, Biguaçu, Blumenau, Brusque, Capivari de Baixo, Chapecó, Gaspar, Jaraguá do Sul, Joinville, Lages e Maravilha). Dos 11 serviços, sete aceitaram participar, dois não responderam e dois não realizam atendimento a crianças. A coleta de dados foi realizada de abril a julho de 2020, sendo o link do questionário enviado por correio eletrônico para os sete SADs que aceitaram participar da pesquisa. O questionário foi respondido pelo coordenador de cada SAD ou por um outro membro da equipe indicado por ele. Os dados foram exportados para o programa Excel organizados em frequências relativa e absoluta, sendo construída uma matriz para a análise dos dados descritivos. O estudo foi aprovado pelo comitê de ética em pesquisa com seres humanos, sob parecer número 3.477.776.

\section{Resultados e Discussão}

Dos profissionais que responderam o questionário $4(57,1 \%)$ eram enfermeiros. A maioria dos serviços possuí somente uma EMAD $(57,1 \%)$, sendo que $4(57,1 \%)$ serviços contam com uma EMAP. Dos serviços que possuem EMAP, todos têm psicólogo e nutricionista, três deles contam com fonoaudiólogo, dois tem fisioterapeuta e assistente social e um conta com farmacêutico. O profissional enfermeiro realiza a coordenação de $6(85,7 \%)$ serviços, $4(57,1 \%)$ possuem a sede localizada anexa à secretaria de saúde e, os outros $5(71,4 \%)$, realizam o atendimento dos usuários somente no domicílio. Todos os serviços possuem atendimento de segunda a sexta e $5(71,4 \%)$ atendem, também, aos finais de semana. Da mesma forma, os sete SADs recebem encaminhamentos de pacientes da APS, $6(85,7 \%)$ recebem de hospitais públicos e 3 $(42,9 \%)$ de UPAs e hospitais oncológicos. Assim, de acordo com a portaria que regulamenta o SAD, todos profissionais que compõem as EMAP's são de nível superior e as ocupacões foram escolhidas de acordo com o que è regulamentado, possibilitando um trabalho em equipe multiprofissioal. ${ }^{1}$ Apesar da recomendação de que o serviço deve funcionar em dias úteis e nos finais de semana e feriados, de forma a assegurar a continuidade da atenção em saúde, dois municípios não realizam $\mathrm{o}$ atendimento no final de semana. Referente as solicitações de atendimento, observou-se que a maioria dos SADs recebe pacientes da APS e de hospitais, contribuindo então para a desospitalização de usuários e favorecendo a articulação do serviço com a Rede de Atenção à Saúde (RAS). ${ }^{1}$ Em estudo realizado no Estado do Paraná, o enfermeiro também realiza a coordenação da maioria dos serviços, desenvolvendo assim um papel fundamental na $\mathrm{AD}$, que além de envolver a função de coordenar a equipe e o plano de cuidado dos usuários, também é quem realiza, na maioria das vezes, as orientações aos usuários, cuidadores e familiares. 3 Todos os serviços que participaram do estudo realizam o atendimento às CRIANES , sendo um total de 18 crianças, destas, 15 $(83,3 \%)$ possuem até seis anos incompletos. Em relação ao atendimento $6(85,7 \%)$ SADs realizam visita domiciliar semanal a elas. Das 18 crianças, $10(55,5 \%)$ estão na modalidade $\mathrm{AD}_{2}$ e $8(44,4 \%)$ na $\mathrm{AD} 3$. Todas as CRIANES do estudo necessitam de reabilitação psicomotora e social, consequentemente, são dependentes de algum tipo de dispositivo e/ou cuidado especial. A maioria faz uso de gastrostomia 12 $(66,6 \%)$, traqueostomia $10(55,5 \%)$ e metade é dependente de ventilação mecânica 9 (50\%). Observou-se um número elevado de crianças dependentes de complementos alimentares 14 $(77,7 \%)$, fármacos $13(72,2 \%)$, cuidados especiais $13(72,2 \%)$ e em número menor, as que fazem uso 
de sonda nasoenteral $7(38,8 \%)$, cateter totalmente implantado $1(5,5 \%)$ e ostomias $1(5,5 \%)$. Dentre os diagnósticos principais, destacam-se as alterações neurológicas ou neuromusculares $11(61,1 \%)$, prematuridade $3(16,6 \%)$, malformação congênita $3(16,6 \%)$ e cardiovasculares 1 $(5,5 \%)$. A pesquisa revelou que, a maioria das crianças, faz uso de dispositivos tecnológicos e apresentam uma condição crônica, assim corroborando que os avanços tecnológicos na área da saúde tếm provocado mudanças importantes na atenção à saúde da criança, especialmente, levando ao aumento da sobrevivência de crianças, que antes morriam precocemente devido a doenças graves, tais como: prematuridade, malformações congênitas e condições crônicas. ${ }^{4}$ Essa evolução tem permitido a transferência do cuidado de crianças do ambiente hospitalar para o domiciliar, mas para que isso aconteça, a família precisa ser assistida por uma equipe multiprofissional de saúde para que se sintam seguras e amparadas no processo de cuidar de um filho dependente de dispositivos tecnológicos no domicílio. ${ }^{4}$

\section{Conclusão}

O cuidado às CRIANES apresenta diversas complexidades devido as condições crônicas e o uso de dispositivos para manutenção da vida. O SAD, pelas suas características e por contar com equipes multiprofissionais de saúde, configura-se como um componente fundamental na RAS para o atendimento de crianças que necessitam de cuidados complexos em domicílio. Assim, as equipes de AD, além de participarem do processo desospitalização desenvolvem um papel importante na reabilitação, adaptação da criança ao uso de dispositivos e na orientação e capacitação de pais/cuidadores para a continuidade dos cuidados com a criança no domicílio.

Descritores: Saúde da Criança; Assistência Domiciliar; Serviços de Assistểncia Domiciliar; Doença Crônica; Enfermagem.

Financiamento: Edital CHAMADA UNIVERSAL - MCTI/CNPq $N \cong 28 / 2018$

\section{Referências}

1. Brasil. Ministério da Saúde. Portaria $n^{-}$ 825, de 25 de abril de 2016. Redefine a Atenção Domiciliar no âmbito do Sistema Único de Saúde (SUS) e atualiza as equipes habilitadas. Brasília: Ministério da Saúde, 2016. [acesso 05 de agosto de 20zo] disponível em: http:// bvsms.saude.gov.br/bvs/saudelegis/gm/2016/ prto825_25_04_2016.html

2. Neves ET. et al. Rede de cuidados de crianças com necessidades especiais de saúde. Texto Contexto Enfermagem [revista em internet] Florianópolis, 2015. [acesso o5 de agosto de 2020]; 24 (2). Disponível em: http:// www.scielo.br/pdf/tce/v24n2/pt_0104-0707-tce-24-02-00399.pdf

3. Rosseto V, Toso BRGO, Rodrigues RM, Viera CS, Neves ET. Cuidado desenvolvido às crianças com necessidades especiais de saúde nos serviços de atenção domiciliar no Paraná - Brasil. Escola Anna Nery [revista em internet] Rio de Janeiro, 2019. [acesso o5 de agosto de 2020]; 23 (1). Disponivel em: http://www.scielo.br/pdf/ ean/v23n1/pt_1414-8145-ean-23-01-e20180o67.pdf

4. Carvalho MSN, Menezes AL, Filho da Cruz AD, Maciel CMP. Desospitalização de crianças com condições crônicas complexas: perspectivas e desafios. Eldorado [livro de internet]. Rio de Janeiro, 2019. 
Pesquisa Original

\section{ROTATIVIDADE MÉDICA E SEUS DESAFIOS NA ATENÇÃO BÁSICA: ANÁLISE EM UM MUNICÍPIO DO SUL CATARINENSE}

\author{
Daniela Pizoni \\ Janaina Niero Mazon
}

\section{Introdução}

No Brasil, o termo adotado para definir o primeiro nível de acesso da Rede de Atenção em Saúde (RAS) é Atenção Básica (AB) e sua principal estratégia de implementação é a Estratégia Saúde da Família (ESF) (BRASIL, 2017). A rotatividade de médicos na $A B$ é um dos maiores desafios dos gestores de saúde $\mathrm{e}$ influencia diretamente na consolidação do trabalho (MAGNAGO; PIERANTONI, 2014), sobretudo na ESF, onde o estabelecimento de vínculos com a comunidade é uma das mais importantes diretrizes de organização (BRASIL, 2017). Tendo em vista que os altos índices de rotatividade impedem a efetivação do trabalho na $\mathrm{AB}$, buscou-se responder, por meio desta pesquisa, por que há um grande indice de rotatividade de médicos na $A B$ e quais as implicações ocasionadas por este fenômeno.

\section{Objetivo}

Investigar as possíveis causas e quais os prejuízos da rotatividade dos médicos na $A B$, em um município do Sul Catarinense, por meio do levantamento da taxa de rotatividade de médicos da ESF do município analisado.

\section{Método}

Esta é uma pesquisa de finalidade básica, de abordagem mista, descritiva e exploratória quanto a seus objetivos. Os dados 
necessários para a realização dos objetivos deste estudo foram coletados por meio de pesquisa bibliográfica, documental e de campo. A pesquisa de campo foi realizada com 16 médicos que passaram pela $A B$ do município analisado, em um período de três anos e quatro meses, que foi escolhido por ser o período de atuação de uma mesma equipe na gestão de saúde do município. O nome dos médicos, bem como o período que permaneceram atuando no município, foi consultado no Cadastro Nacional de Estabelecimentos de Saúde (CNES). Dos 28 médicos cadastrados nas seis Unidades Básicas de Saúde (UBS) do município, na data de corte proposta pelo estudo, 26 foram contatados e receberam o convite para participar da pesquisa, recebendo o link de acesso a um questionário aplicado em ambiente virtual, na ferramenta Google For$m s$. Os médicos foram informados sobre os objetivos da pesquisa e assinalaram no questionário o Termo de Consentimento Livre e Esclarecido (TCLE). A Secretária Municipal de Saúde assinou o Termo de Concordância das Instituições Envolvidas, autorizando o estudo. A pesquisa foi aprovada pelo Comitê de Ética em Pesquisa do Centro Universitário Barriga Verde - UNIBAVE.

\section{Resultados e Discussão}

Caracterização da Amostra: o número total de respondentes, que assinalaram o TCLE e deram prosseguimento nas respostas foi de 16 médicos. Dentre eles, 63\% (n=10) são do sexo feminino e $37 \%(\mathrm{n}=6)$ são do sexo masculino. Entre os entrevistados, $75 \%(\mathrm{n}=12)$ têm entre 26 e 30 anos, $13 \%$ têm mais de 60 anos $(n=2), 6 \%(n=1)$ têm até 25 anos e $6 \%(n=1)$ com idade entre 51 e 55 anos. O vínculo empregatício mantido durante o período trabalhado no município era contrato temporário para $44 \%(n=7)$ dos entrevistados, processo seletivo para $31 \%(\mathrm{n}=5)$ e concurso público para $25 \%(n=4)$. O tempo de trabalho na ESF do município foi de dois a seis meses para cerca de $62 \%(\mathrm{n}=10)$ dos entrevistados e todos os profissionais afirmaram que o término de contrato de trabalho foi determinado a pedido deles. Índice de Rotatividade: Segundo dados do CNES, entre o período de janeiro de 2017 e abril de 2020, 28 médicos passaram pelas seis UBS existentes no município analisado. O valor médio da taxa de rotatividade anual de médicos no município fica acima dos $130 \%$. Esse valor está acima da taxa de rotatividade global no mercado de trabalho formal no Brasil, que era de 47,5\% em 2015 (DIEE-
$\mathrm{SE}, 2017)$. Isto significa que, em média, os médicos estão permanecendo menos de um ano nas equipes. Esses dados revelam um índice de rotatividade importante, que pode prejudicar o funcionamento da ESF e ocasionar em prejuízos para a administração pública. Motivações para o desligamento: as motivações para o desligamento foram apresentadas em lista e os participantes deveriam atribuir valor de zero a cinco, à importância que cada motivação teve em seu desligamento. Dentre as opções que mais obtiveram respostas entre 4 e 5 , teve destaque a opção referente às más condições da infraestrutura de saúde do município. Para cerca $56 \%(n=9)$ dos entrevistados, as más condições do local de trabalho tiveram importância moderada ou elevada em seus desligamentos da $\mathrm{AB}$. A discordância com o estilo de gestão foi muito importante ou teve importância moderada para o desligamento de cerca de $62 \%(n=10)$ dos profissionais. A alternativa que apresentou mais respostas entre 3 e 4 foi interesse pessoal em outra área de atuação, sendo considerado um fator de importẩncia moderada na motivação para o desligamento de $62,5 \%(n=10)$ dos entrevistados. A impossibilidade de crescimento na carreira teve importância moderada ou elevada para a maioria dos entrevistados (56\%). Analisando as respostas que obtiveram grau de importância e média ponderada entre o e 1, é possível observar que não foram fatores relevantes para o desligamento de cerca de 90\% dos entrevistados: dificuldade de relacionamento com a equipe, distância da família e local de residência e encerramento do contrato. A carga horária excessiva foi um fator pouco importante para $87,5 \%(\mathrm{n}=14)$ dos entrevistados. A questão salarial também não foi uma motivação relevante para o desligamento de $75 \%$ $(n=12)$ dos entrevistados. Condições para a permanência: quanto às condições ou mudanças que teriam feito com que os profissionais permanecessem na $A B$, mudança no estilo de gestão da saúde no município foi mencionado por $68,7 \%(n=11)$ dos entrevistados, seguido de melhorias na infraestrutura da rede de saúde no município para $56 \%(\mathrm{n}=9)$, existência de benefícios trabalhistas para $50 \%(n=8)$ e limitação do número de atendimentos para $43,7 \%$ $(n=7)$. Consequências da rotatividade: as consequências negativas geradas pela saída precoce dos médicos da $\mathrm{AB}$, que são percebidas pelos respondentes, estão relacionadas à perda de vínculo com a população atendida, impossibilidade de continuidade dos tratamentos, impossibilidade de efetivar a integralidade do cuidado e executar programas de prevenção 
e promoção de saúde, interrupção da relação entre a equipe e perda de continuidade do fluxo de trabalho, insegurança do profissional e prejuízo para o município. Diante da metodologia proposta por este estudo, percebe-se que a quantidade de médicos que responderam a entrevista foi influenciada por fatores geográficos e temporais, posto que não foi realizado contato com dois médicos que passaram pelo município, por não existência de meios conhecidos disponíveis. Alguns dos profissionais contatados não estão mais na região, outros retornaram a seu país de origem, como no caso dos médicos contratados pelo Programa Mais Médicos. Ainda há aqueles que deixaram a $A B$ do município há muito tempo e não se interessaram em responder a pesquisa. Deve-se considerar ainda que índices de rotatividade de médicos do município foram calculados a partir dos dados do CNES. Se a atualizacão de dados sobre os médicos das unidades foi feita de modo inconsistente com a realidade, as taxas podem variar de acordo com o ano analisado. Por fim, cabe considerar que estudos desta natureza podem contribuir com a compreensão global do problema de rotatividade médica a partir de realidades locais e, assim, desenvolver estratégias de gestão que possam fortalecer a $\mathrm{AB}$ nos municípios onde isso ocorre.

\section{Conclusão}

A pesquisa evidenciou que há um grande índice de rotatividade de médicos na $A B$ do município analisado, por motivos relacionados à satisfação dos medicos com as condições de trabalho oferecidas e com a própria carreira. Os resultados apontam que as dificuldades em aplicar os princípios da $A B$ no trabalho cotidiano, seja pelas faltas de materiais, de suporte da rede ou pelo estilo de liderança, fazem com que os profissionais se desliguem do trabalho. A preocupação com a impossibilidade de crescimento na carreira revela que a inexistência de benefícios trabalhistas é um fator relevante de não fixação dos profissionais. A não identificação com o trabalho na ESF é uma motivação subjetiva, que também está entre as causas de rotatividade, à medida que os profissionais se desligam para se especializarem em outras áreas. A saída precoce dos médicos causa prejuízos ao atendimento da população, que perde o vínculo com o profissional e não é atendida de forma integral e contínua de acordo com sua realidade, como preconizam os princípios e diretrizes da AB. Diante dos resultados desta pesquisa, sugere-se que mais estudos sejam realizados nos municípios onde a rotatividade é frequente, para que se possa compreender as motivações para desligamentos dos médicos de acordo com a realidade local e assim pautar estratégias de enfrentamento do problema junto aos gestores e à população.

Descritores: Atenção Primária à Saúde; Rotatividade de Pessoal; Gestão de Serviços de Saúde.

\section{Referências}

1. Brasil. Ministério da Saúde. Portaria $n^{\circ}$. 2.436 de 21 de setembro de 2017. Diário Oficial [da] República Federativa do Brasil, 2017 set. 22; Seção 1.p 68.

2. Magnago C. Pierantoni C.R. A percepção de gestores dos municípios de Duque de Caxias e Rio de Janeiro quanto à rotatividade de profissionais na Estratégia Saúde da Família. Revista Cereus. 2014; 06: 3-18.

3. Dieese. Movimentação no mercado de trabaIho: rotatividade, intermediação e proteção ao emprego. São Paulo, SP: DIEẺSE; 2017. 
RELATO DE EXPERIÊNCIA

TECNOLOGIA DA INFORMAÇÃO: FERRAMENTA PARA O PROCESSO DE TOMADA DE DECISÕES NA ENFERMAGEM

André Luiz de Souza Braga

Rosangela Cunha Machado Tavares

Suely Lopes de Azevedo

Maritza Consuelo Ortiz Sanchez

Pedro Ruiz Barboza Nassar

Maria Lucia Costa de Moura

\section{Introdução}

A tomada de decisão, no cotidiano do enfermeiro, é um instrumento essencial à sua prática. ${ }^{1}$ Os Sistemas de Informação em Saúde (SIS) configuram uma ferramenta tecnológica auxiliar neste processo. Em vista disso, existe a preocupação no que concerne à qualidade das informações que os alimentam². Com os avanços da Estratégia de Saúde Digital no Brasil, o Departamento de Informática do SUS (DATASUS) percebeu a necessidade de rever e atualizar a Política Nacional de Informação e Informática em Saúde (PNIIS) de 2015, criando a plataforma nacional de interoperabilidade de dados em saúde Rede Nacional de Dados em Saúde (RNDS), portaria GM/MS n. 1.434 , de 28 de maio de $202 \mathrm{O}^{4}$, como um projeto estruturante do Conecte SUS, programa do Governo Federal para a transformaçã̃o digital da saúde no Brasil com o objetivo de promover o uso inovador, criativo e transformador da tecnologia de informação nos processos de trabalho em saúde, definindo os princípios e as diretrizes para práticas observadas bem como entidades ligadas ao Ministério da Saúde, promover a troca de informações entre os pontos da Rede de Atenção à Saúde, permitindo a transição e continuidade do cuidado tanto nas entidades públicas de saúde do SUS como nos setores de saúde privado ${ }^{3,4}$. No que tende ao HIV/AIDS, ressalta-se que a Secretaria de Vigilância em Saúde, do Ministério da Saúde (DCCI/SVS/MS), apresenta infor- 
mações sobre os casos de HIV e de aids no Brasil, regiões, estados e capitais, de acordo com as informações obtidas pelos sistemas de informação utilizados para a sua elaboração. As fontes utilizadas para a obtenção dos dados são: 1) as notificações compulsórias dos casos de HIV e de aids no Sistema de Informação de Agravos de Notificação (SINAN), 2) os óbitos notificados com causa básica por HIV/aids (CID1o: B20 a B24) no Sistema de Informações sobre Mortalidade (SIM), 3) os registros do Sistema de Informação de Exames Laboratoriais (SISCEL) e 4 ) os registros do Sistema de Controle Logístico de Medicamentos (SICLOM). Inclui as ações como aprimorar o sistema de informação e maior acesso aos dados epidemiológicos e pesquisas atualizadas no combate a transmissão da doença e seu tratamento, foram incorporadas na estrutura do SUS, além do uso de inovações tecnológicas baseadas em evidências científicas para enfrentar as DST, o HIV/AIDS e as hepatites virais 5 . No entanto, na prática, após mais de quatro décadas do surgimento da doença, ainda existem diversos estigmas que dificultam seu controle epidêmico. Assim, destaca-se a importância os profissionais de saúde, enfermeiros, coordenadores de Programas de Saúde, gestores dos serviços em saúde, terem como subsídio os diferentes sistemas de informações para que suas ações e seu processo de decisão sejam melhor direcionadas.

\section{Objetivos}

Relatar a experiência vivenciada, enquanto bolsista de iniciação científica da Universidade Federal Fluminense - PIBIC/ UFF, na construção do corpus, para correlacionar as informações oriundas do Sistema de Informação de Agravos de Notificação, o gerenciamento da assistência de enfermagem e a tomada de decisão do enfermeiro nas ações relacionadas ao HIV/AIDS.

\section{Método}

Estudo do tipo relato de experiência elaborado a partir das atividades assistenciais e administrativas enquanto acadêmica de enfermagem, bolsista de iniciação à pesquisa (PIBIC) do Curso de Graduação da Universidade Federal Fluminense no ano de 20120 junto ao docente e enfermeiro responsável pelo serviço de vigilância em saúde da Policlínica Regional do Largo da Batalha, situada no município de Niterói, estado do Rio de Janeiro.

\section{Resultados e Discussão}

A pesquisa tem se mostrado espaço de grandes construções de saber científico e aplicabilidade de conhecimentos teóricos à prática. Na unidade, o bolsista tem a oportunidade de conhecer de perto o atendimento prestado aos usuários acometidos pelo HIV. Tendo como premissa a atenção individualiza do usuário, observa-se a atuação da equipe de enfermagem, o que leva a uma sobrecarga de suas atividades. Devido à pandemia da COVID-19, a coleta de dados para a pesquisa propriamente dita, encontra-se em fase inicial. Entretanto a ambientação com o tema e com a unidade de saúde ratificou a necessidade da mesma, que permitirá a interface entre o conhecimento teórico e prático e a qualificação do gerenciamento da assistência a partir de novas evidências. No período em que começou coleta dos dados, foi possível avaliar a completitude dos campos de preenchimento da ficha de notificação compulsória e de que maneira esta interfere na atuação dos profissionais da unidade de saúde, bem como nas medidas de prevenção e controle do HIV/ AIDS. Em alguns atendimentos, foi possível observar que nem todos os usuários fornecem todas as informações referentes aos campos disponíveis para o preenchimento das fichas. Dessa forma, os atendimentos podem ser prejudicados por conta da falta de informações necessárias, dificultando não só o atendimento, como também, a tomada de decisões do profissional que o está atendendo. Contudo, a falta de dados prejudica a alimentação do SINAN, levando-se em consideração que tais informações são de extrema importância para atuação efetiva do Município e do Estado por intermédio de medidas de controle e prevenção do agravo. De acordo com o Ministério da Saúde, as informações orientadas das fichas contribuem para um maior conhecimento sobre a situação epidemiológica do agravo, tais como, fontes de infecção, modo de transmissão e identificação dos grupos de risco, entre outros dados importantes para as ações de controle. A avaliação da qualidade de informações coletadas é de grande importância para a obtenção de dados confiáveis, a partir dos quais serão calculados os indicadores de saúde, que são úteis para o acompanhamento de surtos e epidemias. A experiência também tem permitido a discussão de possíveis implicações no processo de tomada de decisão sobre a vigilância epidemiológica do HIV/AIDS e as ações de saúde implementadas. Além das orientações durante o atendimento, também 
são intensificadas as atividades de educação em saúde na unidade, com a disseminação de informações com materiais impressos, por exemplo. É a partir destas medidas que as informações geradas, a partir do preenchimento adequado do SINAN, podem orientar intervenções pertinentes no serviço e reduzir a transmissão mediante a detecção dos agravos coletivos.

\section{Conclusão}

A tomada de decisão oportuna e com embasamento é primordial na transcendência das barreiras que interferem no gerenciamento de enfermagem no HIV/AIDS. A pesquisa tem trazido resultados benéficos no que diz respeito a vivenciar a rotina da unidade, conhecer os SIS - em especial, o SINAN - e as fichas de notificação compulsória, além de permitir o reconhecimento da importância das mesmas, para a qualidade da tomada de decisão. É, ainda, necessário que sejam analisados os dados que dizem respeito a completitude das fichas, para que sejam, então, formuladas novas hipóteses e teorias acerca da temática. $\mathrm{O}$ presente relato elucida a relevância da inserção do acadêmico na iniciação científica e no fortalecimento de sua formação, enquanto futuro profissional. Além disso, a pesquisa em curso, destaca o uso da tecnologia em favor de melhorias ao processo de gestão e assistência em saúde. A precisão das informações contidas no SINAN, permitem o desenvolvimento de ações, dentro e fora da unidade, promovendo o crescimento da qualidade de vida da comunidade como um todo e agindo de maneira específica com cada comorbidade nas regiões, respectivamente, mais afetadas por elas. Assim, contribuir-se-á para o estímulo ao uso da tecnologia da informação como ferramenta facilitadora à prática de enfermagem, tanto no âmbito gerencial quanto assistencial.

Descritores: Tecnologia da informação; Tomada de Decisões; Liderança; Enfermagem.

\section{Referências}

1. Marquis BL, Huston CJ. Administração e Liderança em Enfermagem. 6 $6^{\underline{a}}$ ed. Porto Alegre: Artmed, 2015.

2. Correia, LOS; Padilha, BM; Vasconcelos, SML. Métodos para avaliar a completitude dos dados dos sistemas de informação em saúde do Brasil: uma revisão sistemática. Ciênc. saúde coletiva [Internet]. 2014; 19(11):4467-78. Disponível em: http://www.scielo.br/pdf/csc/ v19n11/1413-8123-csc-19-11-4467.pdf

3. Brasil. Ministério da Saúde. Secretaria de Vigilância em Saúde. Guia de Vigilância em Saude. [Internet]. 2019. Disponivel em: https://portalarquivos2.saude.gov.br/images/

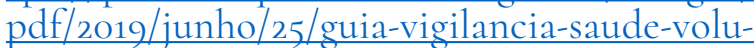
me-unico-zed.pdf

4. Brasil. Ministério da Saúde. Rede Nacional de Dados em Saúde (RNDS). Conecte SUS. Portaria $\mathrm{n}^{\mathrm{o}} 1.434$, de 28 de maio de 2020. Dispõe sobre o Programa Conecte SUS e altera a Portaria de Consolidação n⿳ำ 1/GM/MS, de 28 de setembro de 2017, para instituir a Rede Nacional de Dados em Saúde e dispor sobre a adoção de padrões de interoperabilidade em saúde. Diário Oficial da União. Brasília: Ministério da Saúde, em: 29/05/2020. Edição: 102, Seção: 1, p. 231. Disponivel em: https://www.in.gov.br/ en/web/dou/-/portaria-n-1.434-de-28-de-maio-de-2020-259143327

5. Brasil. Ministério da Saúde. FIOCRUZ. Instituto de Tecnologia em Imunobiológicos. A política brasileira de controle de DST/AIDS e Hepatites Virais [Internet]. 2015. Disponível em: https://www.bio.fiocruz.br/index.php/br/ noticias/896-a-politica-brasileira-de-controle-de-dst-aids-e-hepatites-virais. 
METODOLOGIAS UTILIZADAS NA AVALIAÇÃO DE CUSTO-EFETIVIDADE: TENDÊNCIA DA PRODUÇÃO CIENTÍFICA

\section{Graziele Gorete Portella da Fonseca}

\section{Márcio Kist Parcianello}

\section{Introdução}

A avaliação de tecnologias em saúde (ATS) consiste em um processo abrangente, no qual são avaliados os impactos clínicos, sociais e econômicos das tecnologias em saúde ${ }^{(1)}$. O termo tecnologia em saúde, abrange um conjunto de aparatos, como medicamentos, procedimentos, diagnósticos e dispositivos medicos, com o objetivo de promover a saúde, prevenir e tratar doenças, bem como reabilitar indivíduos $^{(2)}$. As avaliações econômicas em saúde fazem parte das ATS, de maneira que, tanto os custos como as consequências das tecnologias são avaliados. Já a avaliação de custo-efetividade de tecnologias em saúde, se refere à comparação dos custos (em unidade monetária) versus o resultado em unidade quantitativa não monetária, ou seja, refere-se aos impactos clínicos resultante da utilização de determinada tecnologia ${ }^{(2)}$. Desse modo, pode-se afirmar que estudos de avaliação econômica do tipo avaliação de custo-efetividade são relevantes, pois, avaliam, ao mesmo tempo, tanto os custos quanto a efetividade da tecnologia utilizada. Ainda, questões econômicas, como o custo-efetividade, carecem ser levadas em conta ao escolher alguma tecnologia, uma vez que isso contribui na definição da opção mais adequada tanto para o paciente no que se refere à tecnologia mais efetiva, tanto para a instituição ao designar a tecnologia mais custo-efetiva ${ }^{(3)}$. Além disso com o crescimento das tecnologias em saúde em diferentes cenários torna-se ne- 
cessária a avaliação do impacto de indicadores clínicos e econômicos, com isso os estudos de custo-efetividade são considerados os métodos mais adequados para análise de valores dos procedimentos em saúde. Frente ao exposto, elaborou-se a seguinte pergunta de pesquisa: quais as metodologias utilizadas para avaliar o custo-efetividade de tecnologias para a saúde nas produções brasileiras defendidas nos programas de pós-graduação na área da saúde?

\section{Objetivo}

Identificar as metodologias utilizadas na avaliação do custo-efetividade de tecnologias para a saúde nas produções brasileiras defendidas nos programas de pós-graduação na área da saúde. Método: Trata-se de um estudo bibliométrico. A busca das produções foi realizada em maio e junho de 202O, na Biblioteca digital de teses e dissertações (BDTD), na Literatura Latino-Americana e do Caribe em Ciências da Saúde (LILACS), e nos Catálagos de Dissertações e Teses do Centro de Estudos e Pesquisas em Enfermagem (CEPEn) da Associação Brasileira de Enfermagem (ABEn) e no banco de dados da Coordenação de Aperfeiçoamento de pessoal de nível Superior (CAPES). Foram utilizados os seguintes termos para as buscas: "custo-efetividade", "análise de custo efetividade", "avaliação de custo-efetividade", em conjunto com os operadores booleanos OR e AND, para todos os campos, área de concentração- enfermagem, medicina, farmácia, administração, gestão, ensino e avaliação em saúde, desenvolvidos no Brasil. No total, foram encontradas 330 produções, sendo a seleção das produções realizada de forma dupla independente. Foram incluídas todas as teses e dissertações produzidas em programas de pós-graduação no Brasil sobre a temática até o ano de 20zo. Para acessar os textos completos, foram utilizadas as ferramentas dos bancos de dados e buscas no Google. As produções que apareceram em mais de um banco foram analisadas somente uma vez. Foram excluídas 236 produções após leitura do título; 65 após leitura do resumo e 20 duplicados, totalizando 9 produções para compor o corpus da pesquisa. Para a descrição das produções selecionadas, foi utilizado um quadro sinóptico elaborado para este fim com os seguintes itens: ano de publicação, instituição de ensino, área do conhecimento, nível de formação acadêmica, delineamento do estudo, participantes e cenário da pesquisa e a metodologia utilizada para a avaliação de custo-efetividade. A análise dos dados foi realizada de maneira descritiva.

\section{Resultados e Discussão}

Das nove produções selecionadas seis foram realizadas na região Sudeste estando distribuídas entre a Universidade Federal Fluminense com uma, Universidade de São Paulo com duas e a Universidade Estadual do Rio de Janeiro com três produções. Quanto ao número de produção por ano, iniciou-se com uma produção no ano de 2007 , uma produção no ano de 2011 e uma produção em 2014, destacando-se os anos de 2009, 2010, 2012 com duas produções anuais. No que se refere à área do conhecimento, a maioria foi de programas de pós-graduação em epidemiologia com cinco, seguido da enfermagem com duas, odontologia e farmácia com uma. Das nove pesquisas selecionadas cinco foram em nível de mestrado. Quanto ao delineamento e abordagem dos estudos, quatro eram ensaios clínicos e cinco coortes, sendo que a maioria 6 utilizaram como método de análise de custo-efetividade o método de Markov, os quais prestam apoio aos problemas de decisão envolvendo incertezas em um período contínuo de tempo. Ainda, os modelos de Markov são considerados ferramentas analíticas utilizadas na área da saúde para avaliações de doenças por meio da perspectiva econômica, que podem ser utilizados em diferentes cenários. Este método é especialmente adequado para pesquisas de doenças com curso clínico de episódios constantes e prolongados, bem como estudos de delineamento do tipo coorte e ensaio clínico são os mais aconselhados para a utilização junto ao método de Markov na busca por análise de custo-efetividade ${ }^{(4,5)}$. Além disso, a avaliação de tecnologias em saúde por meio do método de Markov permiti uma incorporação e utilização mais racional dos recursos tecnológicos disponíveis em um sistema de saúde.

\section{Conclusão}

A partir desta revisão foi possível identificar as metodologias de avaliação de custo-efetividade na perspectiva das tecnologias em saúde, utilizadas na produção da pós-graduação brasileira na área da saúde. O pico de produção ocorreu de 2010 até 2012, tendo duas produções ao ano, sendo a maioria dos estudos realizados na região sudeste, distribuída entre a Universidade do Rio de Janeiro e a Universidade de São Paulo, predominantemente em nível de mestrado na área da medicina. No que se refere ao método de avaliação de custo- efetividade, a maioria dos estudos utilizou o método de Markov, evidenciando ser essa a 
tendência para a avaliação de custo-efetividade de tecnologias em saúde. Como fator de limitação do presente estudo, tem-se a dificuldade de análise dos dados de alguns trabalhos, devido à falta de clareza na apresentação da metodologia de avaliação de custo-efetividade utilizada. Sugere-se a realização de novos estudos acerca da temática avaliação do custo-efetividade com vistas a expandir o conhecimento científico na área da saúde especialmente quanto aos métodos, desenvolvimento e importância deste tipo de estudo no processo de tomada de decisão dos gestores públicos.

Descritores: Gestão em saúde, Avaliação de custo-efetividade, Tecnologia biomédica, Avaliação em saúde.

\section{Referências}

1. Brasil. Ministério da Saúde. Diretrizes metodológicas: elaboração de pareceres técnico científicos. 3. ed. Brasília, 2011.

2. Brasil. Ministério da Saúde. Diretrizes metodológicas: elaboração de estudos para avaliação de equipamentos médicos assistenciais. Brasília, 2013.

3. Andrade CCD, et al. Cost of topical treatment of pressure ulcer patients. Rev. Esc. Enferm. USP. 2016; 50(2): 295-298.

4. Soarez PC, Soares M O, Novaes HMD. Modelos de decisão para avaliações econômicas de tecnologias em saúde. Ciência \& Saúde Coletiva. 2014;19(10):4209-4222.

5. Moraz G, Garcez AS, Assis EM, Santos JP, Barcellos NT, Kroeff LR. Estudos de custoefetividade em saúde no Brasil: uma revisão sistemática. Ciência \& Saúde Coletiva. 2015; 20(10):3211-3229. 
RELATO DE EXPERIÊNCIA

PROCESSO DE TRABALHO E GERENCIAMENTO DO GUIDADO: REFLEXÕES SOBRE O PAPEL DO ENFERMEIRO

\section{Graziele Gorete Portella da Fonseca}

Márcio Kist Parcianello

\section{Introdução}

As Diretrizes Curriculares Nacionais do Curso de Graduação em Enfermagem (DCN/ENF) trouxeram avanços na formação do enfermeiro, incorporando um processo formativo mais amplo e próximo às necessidades de saúde da população, voltado ao interdisciplinar, com vistas a adequar a formação do enfermeiro à complexidade dos dias atuais $^{(1)}$. Quando se trata do processo de ensino-aprendizagem do gerenciamento em enfermagem, no entanto, as visões da administração clássica ainda continuam arraigadas, com termos como coordenação, organização e planejamento presentes no discurso de alguns docentes ao se referirem ao gerenciamento do cuidado $^{(2)}$. Dessa maneira, ainda há um longo caminho a ser percorrido para superar a visão dicotomizada: gerenciamento versus cuidado. Embora o gerenciamento do cuidado como articulação da prática assistencial e gerencial do enfermeiro deva ser um ideal perseguido pelo profissional, por promover um cuidado integral e propiciar maior visibilidade à sua prática, embora, esse termo seja incipiente no cotidiano do trabalho(3). Neste sentido, faz-se necessária uma ampla discussão ao longo da trajetória acadêmica do enfermeiro, bem como de formação continuada do mesmo, no sentido de uma prática menos dicotomizada do gerenciamento do cuidado ${ }^{(4)}$. Embora as Diretrizes Curriculares do Curso de Graduação em Enfermagem norteiam a formação 
pautada na busca por competências visando a formação integral, existe a necessidade $d a$ superação dos saberes fragmentados, de modo a exigir novos olhares voltados ao desenvolvimento de um pensamento apto a enfrentar o complexo desafio de perceber a totalidade do ser enfermeiro. Assim, considerando a necessidade de refletir a formação acadêmica principalmente em administração referente a concepção dos estudantes de graduação sobre o gerenciamento do cuidado.

\section{Objetivo}

Relatar a experiência de conduzir uma aula acerca do processo de trabalho do enfermeiro e o gerenciamento do cuidado, bem como a percepçã̃o dos acadêmicos sobre a temática.

\section{Método}

Trata-se de um estudo descritivo do tipo relato de experiência. Este relato foi elaborado a partir da experiência da autora no desenvolvimento de uma aula na disciplina do curso de Graduação em Enfermagem, ofertada no sétimo semestre em uma Universidade do sul do Brasil. A atividade desenvolvida abordou o tema processo de trabalho do enfermeiro e o gerenciamento do cuidado, por meio das metodologias ativas. A turma era composta por 22 discentes, sendo esta atividade desenvolvida em março de 2019 .

\section{Resultados e Discussão}

Por meio das atividades de docência, pode-se vivenciar o processo de ensino-aprendizagem acerca do processo de trabalho do enfermeiro e o gerenciamento do cuidado. A referida aula foi desenvolvida na disciplina "Enfermagem na administração dos serviços de saúde II". Essa aula foi executada em dois momentos. $1^{-}$momento: varal de trabalho e gerenciamento do cuidado: referente a concepção construída ao longo da graduação - $\mathrm{O}$ desafio do ensino da administração em enfermagem é desviar-se da separação entre o gerenciamento e o cuidar, ou seja, da prática que considera esses elementos como independentes entre si. Nesta perspectiva, o pensamento complexo pode ser visto como elemento que sustenta uma prática que busca mudança, que vai de encontro ao paradigma fragmentado. Dessa maneira, isso ocorre, a medida que percebe-se o processo de trabalho do enfermeiro como algo complexo, devido a gama de atividades inter-relacionadas que engloba o seu dia-dia ${ }^{(3)}$. No intuito de disparar uma discussão sobre a concepção do processo de trabatho e o gerenciamento do cuidado, formada ao longo da graduação, foi elaborado um varal com algumas palavras empregadas pelos próprios estudantes que representavam o papel do enfermeiro, como: responsabilidade, comunicação, trabalho em equipe, liderança, tomada de decisão, planejamento, proatividade, entre outas. Alem disso, para realizar a gestão do cuidado o enfermeiro carece utilizar algumas ferramentas como: planejamento, indicadores, processo de tomada de decisão, recursos humanos e materiais de modo articula$\mathrm{do}^{(3)}$. O gerenciamento em enfermagem carece ser entendido como parte do cuidado ao paciente, de modo que, necessita-se estimular o estudante a desenvolver um pensamento crítico e reflexivo, que reconheça que a atuação do enfermeiro não pode ser fragmentado, principalmente $\mathrm{O}$ ato de gerenciar e cuidar ${ }^{(5)}$. $\mathrm{O}$ cuidar e o gerenciar articulam-se de maneira dialética, de modo que influenciam-se mutuamente, ou seja, são ao mesmo tempo produto e produtores ${ }^{(3)}$. A reflexão proposta pela atividade demonstrou que a percepção da turma, é que o cuidar é a base do processo de trabalho do enfermeiro, além disso, gerenciar este cuidado é o verdadeiro papel deste profissional, e que isso ocorre quando este proporciona o cuidado direto e indiretamente ao paciente. Assim, o enfermeiro apresenta-se como articulador do cuidado prestado ao paciente ao gerenciar e direcionar as diversas atividades assistenciais $^{(4)}$. $2^{\mathrm{O}}$ momento: Gerenciamento do cuidado em diferentes cenários: leitura de artigos científicos - o gerenciamento do cuidado em diferentes contextos, como no serviço hospitalar de emergência, unidade de hemodinâmica, unidade básica de saúde, finalizou as atividades propostas, consolidando o conhecimento e gerando reflexões a respeito do tema e de como este é discutido na prática profissional científica, incentivando a aproximação e o convívio com a pesquisa, e com a prática baseada em evidências. As metodologias ativas utilizadas para o desenvolvimento das atividades propostas promoveram reflexões, criando mecanismos que articulam os saberes adquiridos ao longo da formação. Além disso, à medida que o estudante se torna sujeito de seu próprio conhecimento e processo de formação, reconhece que o cuidado integral está atrelado ao gerenciamento. Assim, a adoção de metodologias ativas no ensino da enfermagem tem sido considerado um avanço na formação do enfermeiro, por facilitar a articulação da teoria à prática ${ }^{(1)}$. 


\section{Conclusão}

Por meio deste relato, pode-se perceber que as reflexões propostas contribuíram com a construção do conhecimento, à medida que propiciou a percepção de que o trabalho do enfermeiro é complexo, culminando com o reconhecimento de que o gerenciamento do cuidado é a base do processo de trabalho do enfermeiro diariamente no exercício da sua profissão. Além disso, evidenciou-se que os estudantes estão se aproximando do conceito de gerenciamento do cuidado e distanciando-se da visão dicotômica do gerenciar versus cuidar. Percebeu-se também a importância de se utilizar metodologias que coloquem o estudante como um ser ativo em seu próprio aprendizado. De modo que as metodologias ativas auxiliam neste processo, pois, proporcionam o desenvolvimento de profissionais críticos e reflexivos capazes de distanciarem-se da prática na perspectiva do modelo biomédico.

Descritores: Enfermagem; Gestão em Saúde; Educação em Enfermagem; Integralidade em Saúde.

\section{Referências}

1. Vieira MA, Lima CA, Martins ACP, Domenico EBL. Diretrizes Curriculares Nacionais do Curso de Graduação em Enfermagem: implicações e desafios. Rev. Pesq cuid fundam online. 2020; 12: 1099-1104.

2. Lucca TRe, Vannuchi M TO, Garanhani ML, Carvalho BG, Pissinati PSC. O significado da gestão do cuidado para docentes de enfermagem na ótica do pensamento complexo. Rev. Gaúcha Enferm. 2016; 37 ( 3 ): 61097.

3. Siewert JS, Rodrigues DB, Malfussi LBH, Andrade SR, Erdemann AL. Gestão do cuidado integral em enfermagem: reflexões sob a perspectiva do pensamento complexo. REME. 2017; 21: e1047.

4. Senna MH, Drago LC, Kirchner ÂR, Santos JL G, Erdmann AL, Andrade SR. Significados da gerência do cuidado construídos ao longo da formação profissional do enfermeiro. Rev Rene. 2014; 15(2):196-205.

5. Ferreira VHS, Teixeira VM, Giacomini MA, Alves LR, Gleriano JS, Chaves LDP. Contribuições e desafios do gerenciamento de enfermagem hospitalar: evidências científicas. Rev. Gaucha Enferm. 2019; 40: e20180291. 
Pesquisa Original

\section{AVALIAÇÃO DA CAPACIDADE PARA O TRABALHO DOS PROFISSIONAIS DA ATENÇÃO PRIMÁRIA À SAÚDE: ESTUDO TRANSVERSAL}

\author{
Cassia Gonçalves \\ Santos da Silveira
}

Barbara Pompeu Christovam

Josélia Braz dos

Santos Ferreira

Selma Petra Chaves Sá

Ana Maria Fernandes Pitta

\section{Introdução}

A avaliação da saúde do trabalhador quanto à sua capacidade para o trabalho mostra-se relevante, pois o profissional necessita ser avaliado e acompanhado quanto à prevenção de doenças ocupacionais, que podem aparecer ao longo de sua função laboral, se acentuar com o processo de envelhecimento e com o aparecimento de doenças crônicas. A questão do envelhecimento e o potencial dos idosos constitui sólida base para o desenvolvimento futuro, permitindo a sociedade recorrer cada vez mais, à competência, experiência e sabedoria dos idosos, não só para tomar a iniciativa de sua própria melhoria, mas também, para participar ativamente de toda a sociedade. O processo de envelhecimento depende de muitos fatores intrínsecos e extrínsecos de cada indivíduo ${ }^{1}$. A prática dos profissionais enfermeiros na Atenção Primária à Saúde (APS) no Brasil mostra-se como ferramenta de transformações nas atuações e desempenhos no Sistema Ủnico de Saude (SUS), transmitindo propostas do atual modelo assistencial, orientado para a integralidade do cuidado, na intervenção diante dos fatores de risco, na prevenção de doenças e agravos, na promoção da saúde e da qualidade de vida, necessitando-se de um olhar diferenciado $^{2}$. A identificação precoce de situações e de fatores relacionados ao trabalho que possam afetar as condições de saúde dos trabalhadores que exercem suas atividades na Atenção Primária à Saúde, pode propiciar as definiç̧ões de 
ações e estratégias de implementação de medidas preventivas, assim como, a promoção, recuperação da saúde e da capacidade laboral por parte de gestores e profissionais. Considera-se que o acompanhamento da saúde dos trabalhadores que atuam na atenção básica pode estar aquém do ideal e que medidas preventivas poderão melhorar a capacidade para o trabalho desses profissionais. Assim, o desenvolvimento deste estudo torna-se relevante. Logo, estabeleceu-se a seguinte questão norteadora: Que fatores estão consideravelmente associados à capacidade funcional dos profissionais de saúde da Atenção Primária à Saúde?

\section{Objetivo}

Avaliar a capacidade funcional dos profissionais da Estratégia de Saúde da Família (ESF) por meio do Índice de Capacidade para o Trabalho (ICT).

\section{Método}

Trata-se de estudo transversal, exploratório, descritivo, de abordagem quantitativa. Sabe-se que o estudo transversal viabiliza a determinação simultânea entre o fator de interesse e o desfecho em uma investigação, realizada em uma população bem definida e em determinado momento específico. Pode-se dizer que, é uma fotografia de um dado momento com um grupo específico. Para coleta de dados o instrumento utilizado foi o ICT, que é um instrumento composto de perguntas abertas e fechadas distribuidas em duas partes: a primeira parte é um questionário de dados gerais dos profissionais de saúde da atenção básica; e a segunda parte é o ICT propriamente dito, em que o profissional se auto avalia na sua capacidade para o trabalho, no momento atual e em um futuro próximo. O ICT é um instrumento muito utilizado em análise da saúde do trabalhador, inicialmente utilizado em uma indústria na Finlândia na década do 80 , sendo útil até os dias atuais ${ }^{3}$. Realizado em nove Unidades de Atenção Primária à Saúde da ESF, Niterói, Rio de Janeiro, Brasil, de julho a novembro de 2018, com 88 profissionais. Utilizou-se estatística descritiva a todas as variáveis e cálculo de coeficiente de variação para as variáveis quantitativas.

\section{Resultados e Discussão}

A maioria dos participantes $(80,7 \%)$ do gênero feminino, com média de 43 anos, apenas um emprego $(85,2 \%)$; com 40 horas se- manais trabalhadas $(87,5 \%)$; com apenas um ano trabalhado (30,7\%). Os profissionais que se destacaram com maior quantitativo foram os agentes comunitários de saúde (ACS) com $33,0 \%$ dos participantes, técnicos de enfermagem com 21,6\% e enfermeiros e médicos, ambos com $19,3 \%$ cada. Sentiam-se exigidos no trabalho física e mentalmente (95,5\%). As comorbidades mais predominantes dentre estes profissionais de saúde foram: hipertensão arterial sistêmica (HAS) e as lesões nas costas, ambas com $26,1 \%$ dos participantes; a Lesão nas Pernas com 21,6\%; a Depressão Leve e a Obesidade com 20,5\%; Lesões nos Braços/ Mãos e Alergia-Eczema com 20,5\%. Destaca-se que $100 \%$ os participantes apresentaram ao menos um tipo de comorbidade. Informaram que não recebiam adicional de insalubridade ou periculosidade, mesmo atuando em atividades insalubres e periculosos, não possuíam vínculos empregatícios, carteira de trabalho assinada e seguridade social, caracterizando ao total descumprindo à Consolidação das leis do Trabalho (CLT). Apresentavam-se inseguros no campo de trabalho devido à violência urbana, além da insegurança no próprio emprego, gerando stress e desgaste no trabalho e na saúde pessoal de cada trabalhador. Dentre as várias comorbidades detectadas, mesmo com as frequências de doenças descritas, nenhum dos profissionais participantes da pesquisa declarou ter lesão/ doença como impedimento para realização do trabalho atual. Quando indagados sobre, quantos dias os profissionais estiveram fora das atividades laborais por problemas de saúde, consulta médica ou para fazer exames nos últimos 12 meses: 6o,2\% informaram que não estiveram fora do trabalho nenhum dia por causa de problemas de saúde; 30,7\% tiveram afastamento de até 9 dias do trabalho e; 9,1\% foram afastados das atividades laborais de 10 a 24 dias nos últimos 12 meses. Comparando as estatísticas, observa-se que o profissional de saúde que tem lesões nas costas apresenta Índice de Capacidade para o Trabalho significativamente menor que o profissional que não tem lesão nas costas ( $p$-valor $=0,013)$. O mesmo vale para a depressão leve: o profissional de saúde que tem depressão apresenta Índice de Capacidade para o Trabalho significativamente menor que o profissional que não tem depressão leve ( $p$-valor $=0,002)$. Então, pelos $\mathrm{p}$-valores e diferenças nas médias, observa-se que o impacto da depressão é maior e mais significativo ainda que o impacto da lesão nas costas. Sendo assim, respondendo à questão norteadora da pesquisa baseado no ICT, a de- 
pressão e lesões nas costas despontam como fatores que mais impactam na diminuição da capacidade funcional dos profissionais de saúde da APS. A depressão e o estresse são considerados problemas mentais emergentes na atual sociedade e são responsáveis por $18 \%$ das enfermidades e de absenteísmo relacionados ao contexto do trabalho. Segundo a OMS, a depressão é considerada o $5^{\mathrm{O}}$ maior problema de saúde pública do mundo 4 .

\section{Conclusão}

Diante dos resultados, doenças relacionadas com depressão e lesões nas costas influenciam diretamente na capacidade para o trabalho, repercutindo assim, em escore mais baixos, sendo que o impacto da depressão ainda é maior e mais significativo que o impacto das lesões nas costas. Em outras palavras, as lesões nas costas e a depressão emergiram como fatores que influenciam diretamente a capacidade para o trabalho, ou seja, profissionais que relataram possuir essas comorbidades tiveram seus Îndices de Capacidade para o Trabalho diminuídos em relação aos que não apresentavam as mesmas. Depressão é um tema da atualidade e não diferente, apresenta-se também nos profissionais que exercem suas atividades na Atenção Básica. Processos de trabalho associados ao estresse da vida cotidiana podem provocar adoecimento e distúrbios emocionais de leve intensidade ou até mesmo graves. Destaca-se como ponto grave e preocupante deste estudo, a falta de seriedade dos gestores públicos de saúde com os profissionais que exercem suas atividades no Programa Saúde da Família, principalmente no que se refere aos direitos constitucionais trabalhistas, que encontram-se cerceados, por não possuírem vínculos empregatícios, carteira de trabalho assinada, seguridade social, não fazerem jus ao adicional de insalubridade, auxílio transporte, auxílio alimentação, entre outros, além da insegurança do próprio emprego. As limitações no desenvolvimento deste estudo, deve-se a dificuldade de acesso a algumas das ESF, que por muitas vezes, o alerta "vermelho" estava acionado (alerta implantado pela própria equipe de saúde estabelecendo perigo real de ameaça física ao trabalhador e ao usuário), consequência imposta pela violência urbana, e impedindo o acesso aos serviços nestas unidades de saúde nos momentos de conflitos armados. Espera-se que esta pesquisa contribua para a área da saúde do trabalhador e políticas públicas, além de oferecer suporte teórico e prático no que tange à Política de Saúde do Trabalhador, pois aponta a importância da implementação e avaliação de ações sistemáticas de vigilância da saúde do trabalhador, bem como da necessidade de monitoramento da segurança no espaço-território de atuação da equipe de saúde, buscando contribuir junto aos gestores de saúde, conforme se propicia a reflexão e aponta para necessidade de valorizar o processo de trabalho dos trabalhadores da Atenção Primária à Saúde, com melhorias das políticas públicas. Há necessidade de se ter um olhar diferenciado voltado à equipe multiprofissional da ESF, com investimento em sua saúde e cuidados para que estes profissionais encontrem subsídios para desenvolverem suas funções propostas no campo da ESF com melhor propriedade, tendo seus direitos e necessidades trabalhistas atendidos no contexto da APS.

Descritores: Avaliação da Capacidade de Trabalho; Atenção Primária à Saúde; Saúde do Trabalhador; Política Pública; Envelhecimento.

\section{Referências}

1. Mari FR, Alves GG, Aerts DRGC, Câmara S. O processo de envelhecimento e a saúde: o que pensam as pessoas de meia-idade sobre o tema. Rev bras geriatr gerontol. 2016;19(1):35-44. https://doi.org/10.1590/1809-9823.2016.14122

2. Buss, Paulo Marchiori, Promoção da saúde e qualidade de vida. Ciênc. saúde coletiva [online]. 200o, vol.5, n.1, pp.163-177. ISSN 1678-4561. https://doi.org/10.1590/S1413$\underline{81232000000100014}$.

3. Tuomi K, Ilmarinen J, Klocarks M, Nygard CH, Seitsamo J, Huuhtanen P, Martikainen RL. Finish research project on aging workers in 1981-1992. Scand J Work Environ Health [Internet] 1997 [cited 2019 Jan 04]; 23 (Suppl 1): 7-11. Available from: https://www.sjweh.fi/ show_abstract.php?abstract_id=207

4. Demarchi ME, Casselli DDN, Figueira GM, Silva E de SM e, Souza JC. Inibidores seletivos de recaptação de serotonina no tratamento da depressão: síndrome de descontinuação e/ou de dependência? RSD [Internet]. $8^{\circ}$ de setembro de 2020 [citado $28^{\circ}$ de janeiro de 2021];9(9): e815998035. Disponível em: https://www.rsdjournal.org/index.php/rsd/article/view/8035 
Pesquisa Original

TRANSTORNO MENTAL COMUM

EM PROFISSIONAIS DA ATENÇÃO

PRIMÁRIA EM TEMPO DE COVID-19

\section{Raquel Tatielli Daneluz Rintzel \\ Endria Mendes Fabrizzio \\ Lisiane da Rosa \\ Crhis Netto de Brum \\ Júlia Grasel \\ Samuel Spiegelberg Zuge}

\section{Introdução}

A atividade profissional está associada à saúde física e mental dos indivíduos, podendo interferir no seu âmbito pessoal e social, refletindo na produtividade e qualidade dos serviços prestados, bem como na necessidade de assistência à saúde ao próprio trabalhador. Dentre os aspectos que podem interferir na saúde do trabalhador, destaca-se os Transtornos Mentais Comuns (TMC), que se caracterizam por transtornos não-psicóticos com manifestações emocionais e somáticas, mais prevalentes em indivíduos do sexo feminino e expostos a altos níveis de estresse e cobrança $^{1}$. Assim, o TMC é caracterizado por sinais e sintomas como modificações do humor, irritabilidade, insônia, fadiga, esquecimento, dificuldade de concentração, agressividade e queixas psicossomáticas, que muitas vezes são negligenciados. O trabalho exercido pelos profissionais da saúde, principalmente da categoria da enfermagem, tem como base em diversos cenários de trabalho por terem maior número e visibilidade nessa área. Considerando o crescimento da Atenção Primaria em Saúde (APS) e formação de profissionais de saúde, a força de trabalho em saúde é fundamental para a gestão do sistema, em especial pelo enfermeiro. Nesse âmbito assistencialista, o Brasil em sua grande totalidade possui o modelo de APS regida pelas políticas públicas e orientada pelos princípios e diretrizes do SUS, a partir dos quais assume funções e 
características específicas. Esse processo de trabalho associa-se ao desenvolvimento de TMC pela frequente exposição a elementos e fatores que favorecem o adoecimento, como longas jornadas de trabalho, alta demanda e condições próprias do serviço ${ }^{2}$. Associado a isso, percebe-se um aumento do TMC em decorrência do agravamento das condições de saúde a nível mundial ocasionado pelo vírus SARS-CoV-2, causador da Coronavirus Disease 2019 (COVID-19). Este fato trouxe um quadro de instabilidade e angústia devido ao aumento da procura pelos serviços de saúde pública e quadros reduzidos de profissionais. Ainda, muitos sofreram realocações em outros serviços e afastamento pelo adoecimento pela COVID-19, assim, aumentando os fatores desencadeantes e provavelmente o desenvolvimento/agravamento de $\mathrm{TMC}^{3}$. Dentre os profissionais da saúde os enfermeiros da Atenção Primária em Saúde (APS), por ser porta de entrada aos serviços de saúde pública, representam um dos grupos que sofreram impacto por conta da COVID-19.

\section{Objetivo}

Identificar a presença de transtorno mental comum em enfermeiros da atenção primária a saúde em tempos de COVID-19.

\section{Método}

Trata-se de um estudo transversal do tipo quantitativo, o qual passou de Comitê de Ética em Pesquisa da Unochapecó, sob o parecer número: 3.927.461/2020. A população do estudo contou com enfermeiros da Atenção Primária a Saúde de um município do oeste de Santa Catarina. A coleta de dados ocorreu no período outubro a dezembro de 2020 a partir de um questionário online disponibilizados aos enfermeiros por e-mail, contendo um questionário sociodemográfico, econômico e laboral e o Self-Reporting Questionnaire (SRQ-20). O SRQ-2o tornou-se um instrumento amplamente utilizado para o rastreamento diagnóstico dos transtornos mentais comuns. Esse instrumento conta com respostas do tipo sim/não, sendo que essas, quando afirmativas pontuam 1 ponto, passando a compor o escore final através do somatório destes valores. Os escores variam de zero (o) a vinte (20), sendo que valores próximos a zero indicam nenhuma probabilidade e valores próximos a 20 sinalizam extrema probabilidade de presença de transtornos não-psicóticos. O ponto de corte é oito (8), valores iguais ou superiores indicaram presença de TCM. Foram realizadas análises descritivas a partir do software Statistical Package for the Social Sciences (SPSS), version 20.0.

\section{Resultados e Discussão}

Participaram do estudo 25 enfermeiros, sendo $84 \%$ do sexo feminino, com idade média de 34,9 anos $\pm 6,9$. Dentre os enfermeiros, $24 \%$ relatam sentirem sintomas em relação a TMC e $28 \%$ utilizam algum medicamento para TMC. Em relação ao SRQ-2o, as questões que apresentaram o maior número de respostas afirmativas, nas quais indicam maior possibilidade de TMC foram: sente-se nervoso, preocupado ou tenso $(84 \%)$; tem-se sentido triste ultimamente $(72 \%)$; você se cansa com facilidade ( $72 \%)$; tem dificuldade para pensar com clareza (64\%); e encontra dificuldades para realizar com satisfação suas atividades diárias (64\%). Em relação a avaliação do TMC pelo SRQ-2O, identificou-se uma média de pontos de $9,2 \pm 5,8$ entre os enfermeiros, sendo considerada elevada esta média e indicando a presença de TMC na maioria dos enfermeiros. Ao categorizar a avaliação do TMC, foi possível identificar que $68 \%$ dos enfermeiros indicaram presença de TMC. Essa análise mostra uma presença significativa de TMC nos profissionais enfermeiros atuantes na atenção primária, principalmente quando comparada com a estimativa geral de que $10 \%$ dos adultos apresentam transtornos mentais e comportamentais ${ }^{1}$. Isso se deve em partes pela atual situação da saúde brasileira com as dificuldades encontradas frente ao elevado número de casos de COVID-19. Os enfermeiros da APS e o processo de trabalho que a envolve, trazem enfrentamentos dos trabalhadores, o medo de transitar em locais de risco e após estar em contato direto com familiares, condições pré-existentes que foram intensificadas com a chegada do novo coronavírus, além de toda a pressão e impacto emocional sofrida também pelo restante da população, o que eleva a incidência de TMC e consequentemente interfere de forma direta sua qualidade de vida ${ }^{4}$. Além disso, destaca-se que estudo de revisão sistemática ${ }^{5}$ apontou que a pandemia da Covid-19 está gerando adoecimento mental na população geral e nos profissionais de saúde, e dentre os mais acometidos estão os profissionais enfermeiros. O estudo evidencia o impacto que as condições profissionais enfrentadas durante a pandemia possuem sobre a qualidade de vida dos mesmos, o que pode gerar prejuízos a curto e longo prazo pela piora das condições de saúde desses e todo o ônus que isso gera aos 
próprios profissionais, suas famílias, comunidades e também ao sistema de saúde ${ }^{1}$.

\section{Conclusão}

O estudo evidenciou que mais da metade dos enfermeiros (68\%) apresentam indicativos de TMC e quase $25 \%$ relataram apresentar sintomas perceptíveis. A alta incidência mostra que as dificuldades enfrentadas pelos enfermeiros atuantes na Atenção Primária à Saúde afetam não apenas de forma física, como também os aspectos cognitivos e psicossociais. Assim, com o intuito de melhorar a condição de saúde do trabalhador da APS, torna-se necessário o desenvolvimento de ações que visem minimizar os danos sofridos por esses profissionais, para que estejam mais preparados e amparados em situações próprias do trabalho e principalmente em momentos de instabilidade e maiores dificuldades.

Descritores: Enfermagem; Saúde Mental; Pandemias, Estresse Psicológico.

Financiamento: Bolsa de Pesquisa - PIBIC/FAPE - 2019.,

\section{Referências}

1. Carvalho DB, Araujo TM, Bernardes KO. Transtornos mentais comuns em trabalhadores da Atenção Básica à Saúde. Rev bras saúde ocup. 2016; 41: e17. DOI: http://dx.doi. org/10.1590/2317-6369000115915.

2. Alves AP, Pedrosa LAK, Coimbra MAR, Miranzi MAS, Hass VJ. Prevalência de transtornos mentais comuns entre profissionais de saúde. Rev Enferm UERJ 2015;23(1):64-9. https:// doi.org $/ 10.12957 /$ reuerj.2015.8150

3. Ministério da Saúde (BR). Coronavírus e o novo coronavírus: o que é, causas, sintomas, tratamento e prevenção. 2020. Disponível em: https:// www.saude.gov.br/saude-de-a-z/coronavirus

4. Pereira MD, et al. Emotional distress of nurses in the hospital setting in the face of the COVID-19 pandemic. Research, society and development. 2020; 9(8):1-21.

5. Lopes JVR, Santos JX. Saúde mental dos profissionais de saúde diante da COVID-19: uma revisão sistemática. Revista Científica da Escola Estadual de Saúde Pública de Goiás. v. 6, n. 3, p. 1-7, 2020. 


\section{ORIENTAÇÕES DO MINISTÉRIO DA SAÚDE PARA A ATUAÇÃO E GESTÃO DE ENFERMAGEM NA SAÚDE DA MULHER NO PUERPÉRIO}

\section{Mirian Giacomel \\ Silvana dos Santos Zanotelli \\ Denise Antunes de Azambuja Zocche}

\section{Introdução}

As Políticas e Programas Públicos de atenção à saúde da mulher no pré-natal, parto e nascimento, no âmbito do Sistema Único de Saúde (SUS), são elaborados e implantados para garantir às mulheres e seus filhos os benefícios dos avanços científicos. Além disso, permite e estimula o exercício da cidadania feminina, resgatando a autonomia da mulher no processo do planejamento familiar, da gravidez e do parto, garantindo o fácil acesso a consultas e aos exames, a informação e, procedimentos comprovadamente benéficos ${ }^{1}$. A construção de políticas e programas públicos de saúde se dão pela determinação social de saúde, que considera os aspectos afetivos e emocionais, assim como ambientes facilitadores a vida, propõe enfrentar as desigualdades por meio de linhas de cuidado ${ }^{2}$. Os marcos legais sobre as políticas públicas de saúde no contexto de atuação do enfermeiro no puerpério na APS (Atenção Primária à Saúde) apresentam uma série histórica, marcada por quatro principais publicações: em 1984, paralelo ao Movimento Sanitário, o SUS, o Ministério da Saúde (MS) formula e elabora o Programa de Assistência Integral à Saúde da Mulher (PAISM), que incorpora como princípios e diretrizes as propostas de descentralização, hierarquização e regionalização dos serviços, bem como a integralidade e a equidade da atenção'; em 2000 o MS institui o Programa de Humanização no Pré-natal e Nascimento, no âmbito do Sistema Único de 
Saúde (Portaria n⿳o 569 , de $1^{-}$de junho de 200o) e estabelece como competência dos estados e do Distrito Federal para diminuir o número de partos cesáreos, método canguru para recém nascidos baixo peso e ações para redução de morte materna e infantil ${ }^{1}$; em 2004 o MS elabora a Política Nacional de Atenção Integral à Saúde da Mulher que tem por objetivo promover a melhoria das condições de vida e saúde das mulheres, garantia de direitos e ampliação do acesso aos meios e serviços de promoção, prevenção, assistência e recuperação da saúde. Além de contribuir para a redução da morbidade e mortalidade feminina brasileira, amplia e qualifica a atenção integral ${ }^{2}$. Em março de 2011, o MS lançou ả Rede Cegonha (RC), composta por um conjunto de medidas para garantir atendimento adequado, seguro e humanizado no pré-natal, parto, puerpério, até os dois primeiros anos de vida do bebể. Frente ao exposto, que diversas estratégias e programas foram criados com a finalidade de cuidar integralmente da saúde da mulher.

\section{Objetivo}

Descrever a atuação e gestão de enfermagem no puerpério na atenção primária à saúde a partir das publicações legais do Sistema Único de Saúde.

\section{Método}

Trata-se de uma revisão narrativa com os seguintes passos: procura literária; busca dos descritores; critérios de seleção; avaliação crítica dos estudos; redação das conclusões, discussão e análise dos resultados.

\section{Resultados e Discussão}

As políticas e programas da saúde da mulher tem como proposição o acompanhamento pleno da mulher durante sua gestão e puerpério, com definição mais precisa até $042^{\underline{0}}$ dia, que se deve pensar no acompanhamento, vigilância e promoção da saúde ${ }^{1}$. Desde 2011, a Rede Cegonha apresenta um processo lento de adesão ainda que preconize, porém garante ás mulheres gestantes e puérperas atenção e cuidado ampliados'. A RC conta com recursos aplicados na construcão de uma rede de cuidados primários à mulher e à criança, que envolve a APS e a atenção hospitalar, incluindo o transporte seguro, até o parto nos leitos maternos do SUS ${ }^{13}$ O enfermeiro que está inserido nos serviços de APS tem estabelecido como rotina o acompanhamento das gestantes meio de consultas de pré-natal, intercaladas com outros profissionais, que abrangem ações de promoção, prevenção, tratamento, reabilitação e recuperação da saúde, promovendo o cuidado centrado na pessoa e em seus aspectos biopsicossociais ${ }^{1,2,3}$. É importante ressaltar que o acompanhamento da mulher ocorre majoritariamente na APS, porém não é atividade exclusiva desse cenário e, se necessário, outros pontos das Redes de Atenção à Saúde (RAS) devem ser integrados nesse cuidado, incluindo a maternidade. As consultas de enfermagem (CE) são estratégias eficazes, de baixa complexidade de implantação e baixo custo, em que é possível reconhecer vulnerabilidades, estabelecer prioridades e propor intervenções em tempo oportuno, tendo em vista que o enfermeiro possui autonomia na tomada de decisões e implementação de condutas necessárias ${ }^{2,3,4}$. A CE em puerpério é uma das estratégias que preconiza a vigilância da saúde da mulher gestante e puérpera e é orientada pela Caderneta de Saúde da Gestante (CSG), que pode ser considerada como um prontuário além de ser um instrumento de cuidado efetivo por conter dados significativos de saúde, é uma forma de comunicação entre os profissionais e familiares. Os dados de saúde contidos na CSG são fundamentais para a vigilância, proteção e promoção da saúde, bem como, para o fornecimento do cuidado integral, efetivo e resolutivo, pois são avaliadas através de marcos que analisam e classificam a situação da criança, e com estes é possível fornecer informações adequadas ${ }^{1,2}$. Além da CSG, o acompanhamento da puérpera realizado pelo profissional enfermeiro, é realizado por meio do Processo de Enfermagem (PE), que este constitui-se de cinco etapas: anamnese e exame físico, diagnósticos de enfermagem, planejamento, implementação das intervenções e avaliação dos resultados 5 . O papel do enfermeiro no acompanhamento da puérpera, exercido por meio de ações de vigilância à saúde, objetiva envolver o fortalecimento de vínculos entre profissional, a mulher e a família, fortalece as boas práticas parentais, a relação afetiva com os filhos, redução de estresse e prevenção de agravos à saúde da mulher e do recém-nascido, o que evita danos ao desenvolvimento infantilt. Salienta-se que quando há identificação de vulnerabilidades que podem gerar danos a puérpera ou ao desenvolvimento da criança, além das intervenções já planejadas durante a consulta de enfermagem, também é recomendado utilizar como estratégia visitas domiciliares com intuito de dar suporte às famílias, fortalecendo vínculos, família e comunidade, para promoção de ambientes que favorecem e estimulem 
o desenvolvimento infantil, visto que tanto o crescimento quanto o desenvolvimento são também influenciados por fatores extrínsecos ${ }^{1}$.

\section{Conclusão}

Os marcos legais apresentados vêm para assegurar os direitos da mulher gestante, puérpera e ao recém-nascido, e garantir integralidade do cuidado. O acompanhamento da mulher realizado pelo enfermeiro contribui para a redução de vulnerabilidades, fortalece vínculos, e possibilita a identificação de fragilidades e intervenções precoces, propiciando assim evoluções nos indicadores de saúde materno infantil. Entretanto, acredita-se que o conjunto das medidas de humanização ao pré-natal e parto, tornar-se-á efetivo quando, as práticas profissionais de saúde, entre elas as $\mathrm{da}$ enfermagem tornarem-se mias resolutivas e eficazes. Para tanto, torna-se necessário uma (re) orientação do MS no sentido de atualizar seus programas e políticas, pois como revelado nessa revisão, a mais de uma década, não há ações efetivas que atendam a grande parte das necessidades de saúde das mulheres, reduzindo assim as vulnerabilidades sociais, além de melhorar os indicadores epidemiológicos como a taxa de mortalidade materno-infantil. Diante deste cenário, o MS tem a necessidade de reedição ou revisão da Política, assim como a Rede Cegonha, além de implantação de novos programas adequados a realidades atuais materno infantis do país.

Descritores: Saúde da Mulher; Políticas Públicas de Saúde; Período Pós-parto; Cuidado de Enfermagem; Atenção Primária à Saúde.

\section{Referências}

1. Santos HFL, Araujo MM. Políticas de humanização ao pré-natal e parto: uma revisão de literatura. Revista Científica FacMais, Volume. VI, Número 2. Ano 2016/1을 Semestre. ISSN 22388427. [citado em 22 Jan. 2021]; Disponível em: https://revistacientifica.facmais.com.br/wp-content/uploads/2016/o7/Artigo-6-POL\%C3\%8DTICAS-DE-HUMANIZA\%C3\%87\%C3\%83O-AO-PR\%C3\%89-NATAL-E-PARTO.pdf.

2. MINISTÉRIO DA SAÚDE. Secretaria de Atenção à Saúde. Política Nacional de Atenção Integral à Saúde da Mulher: princípios e diretrizes. Brasília (Brasil): Ministério da Saúde; Departamento de Ações Programáticas Estratégicas. Brasília 2004b. 82 p. ISBN 85-3340781-5 [citado em 22 Jan. 2021];

3. MINISTÉRIO DA SAÚDE. Portaria n⿳⺈ 2.351/ GM/MS de 5 de outubro de 2011. Altera a Portaria $\mathrm{n}^{\mathrm{o}} 1.459 / \mathrm{GM} / \mathrm{MS}$, de 24 de junho de 2011 , que institui, no âmbito do Sistema Único de Saúde (SUS), a Rede Cegonha. DOU. 2011 jul. 27.

4. MINISTÉRIO DA SAÚDE. Secretaria de Políticas de Saúde. Área técnica de saúde da mulher. Parto, aborto e puerpério: assistência humanizada a mulher: manual técnico. Brasília (Brasil): Ministério da Saúde; 2001. 199 p.: il.ISBN: 85-334-0355-0.

5. MINISTÉRIO DA SAÚdE. Secretaria de Políticas de Saúde. Área técnica de saúde da mulher. Humanização do parto: humanização no pré-natal e nascimento: manual Técnico. Brasília (Brasil): Ministério da Saúde; 2002. 
RELATO DE EXPERIÊNCIA

GESTÃO DA ATENÇÃO PRIMÁRIA À

SAÚDE: DESAFIOS E PERSPECTIVAS

PARA O CUIDADO INTEGRAL

Adriani Cristiani Stanga Joel Morschbacher

Marinez Amabile Antoniolli Julia Stanga Rech

Letícia de Lima Trindade

Samuel Spiegelberg Zuge

\section{Introdução}

A Atenção Primária à Saúde (APS) emerge a partir de um movimento global iniciada em meados da década de 7o, em resposta à acentuada medicalização da saúde e da necessidade de uma concepção não centrada na doença. Nesse sentido, entende-se que a APS foi originada a partir da Primeira Conferência Internacional sobre Cuidados Primários de Saúde proferida em Alma-Ata, no Cazaquistão em 1978, convocada pela Organização Mundial da Saúde (OMS) e tinha como propostas combater as desigualdades políticas, sociais e econômicas, de forma a contribuir para reorientação dos sistemas de saúde do mundo, principalmente dos países em desenvolvimento, estabelecendo como meta a projeção de "Saúde para todos no ano 200o". Esta Conferência representou um marco referencial para a criação do Sistema Único de Saúde (SUS) no Brasil, e trouxe significativas mudanças no modelo assistencial do país, antes pautado em práticas curativas e acrescentando ações de promoção da saúde e prevenção das doenças.

\section{Objetivo}

Refletir teoricamente sobre a gestão da APS e sua influência na consolidação da integralidade do cuidado em saúde. 


\section{Método}

Trata-se de uma reflexão teórica originada no componente curricular Planejamento e Gestão em Saúde, ofertado no segundo semestre de 2020, pelo Programa de Pos-graduação Stricto sensu em Ciências da Saúde, da Universidade Comunitária da Região de Chapecó (UNOCHAPECÓ). O objetivo principal do componente curricular foi compreender os princípios do planejamento e gestão em saúde, com ênfase nos sistemas de saúde no Brasil, bem como discutir as políticas públicas que favoreçam a formação e intervenção crítica em favor de práticas inovadoras de planejamento e gestão em saúde. Assim, a partir das discussões realizadas em sala de aula, juntamente com os materiais disponibilizados pelos professores e na construção de seminários com abordagem nos três níveis de assistência (primária, secundária e terciária), os estudantes, em três distintos grupos deveriam construir um texto, relacionando os conteúdos ministrados na disciplina ao seu tema delimitado a partir de um nivel de assistência.

\section{Resultados e Discussão}

A APS no Brasil constitui o primeiro ponto de atenção à saúde e a porta de entrada preferencial, que deve ordenar as ações e serviços de saúde e ser o centro de comunicação da Rede de Atenção à Saúde (RAS). É ofertada de forma integral e gratuita a todas as pessoas do território, conforme suas necessidades e demandas, considerando os determinantes e condicionantes de saúde local e regional ${ }^{(1)}$. Nessa conjuntura, convém destacar que, até 1994, não havia definição de um modelo de atenção na área de APS. A atenção era prestada por postos de saúde nos bairros periféricos, sem atender às diretrizes e princípios do SUS, disponibilizando à população apenas ações assistenciais-curativas. E em 1994 que surge a Estratégia de Saúde da Família (ESF), amparada pelos avanços nos resultados obtidos com o Programa de Agentes Comunitários de Saúde (PACS) estabelecido em 1991, que propunha a reestruturação da APS em substituição ao modelo assistencial-curativo vigente, consolidando a garantia à população ao acesso mais próximo e com qualidade de vida por via de um modelo amplo de saúde. É por meio da operacionalização exercida pela ESF que é possível abarcar ações preventivas, promocionais e de reabilitação, prestando cuidados fundamentados nos princípios do SUS, e que torna-se um pilar fundamental na estruturação de cuidados de saúde e a principal plataforma na garantia da cobertura universal no país. A expansão da ESF desde a década de 1990 vem trazendo (mesmo por vezes em baixa escala) resultados positivos de saúde e reduções nas desigualdades de saúde de grupos populacionais ${ }^{(2)}$. Do mesmo modo, a ESF que é orientada pela APS, possui características importantes que a diferencia dos modelos de APS de outros países, como a existência de equipes multiprofissionais, a exemplo da ESF e do Núcleo Ampliado de Saúde da Família (NASF) que atuam nos territórios e reconhecem os problemas da população; a presença dos ACS que atuam de forma singular e a presença da equipe de saúde bucal no sistema público de saúde (3). O trabalho desenvolvido na APS do Brasil é normatizado pela Política Nacional de Atenção Básica (PNAB). De acordo com essa portaria, a APS é equivalente ao termo Atenção Básica $(\mathrm{AB})^{(1)}$. Além da ESF, a PNAB reconhece outras estratégias de organização da APS, que devem seguir os principios da APS e do SUS, que considere a dinamicidade do território, constituindo um processo progressivo e singular, conforme as especificidades locais e regionais, e que existem populações específicas, itinerantes e dispersas, que também constitui responsabilidade da equipe de saúde que atua no território, em conformidade a política de promoção da equidade em saúde $^{(1)}$. No enfoque da ẢPS, o trabalho dos profissionais acontece por meio da utilização de tecnologias que incluem os equipamentos e o instrumental para o desenvolvimento do trabalho, tais como, os aparelhos, a estrutura física, os procedimentos técnicos, os folhetos educativos, os conhecimentos estruturados acerca da epidemiologia, o planejamento em saúde, dentre outros, quanto de tecnologias que envolvem as relações, as interações e as associações entre os usuários e as famílias, almejando-se, nesse ínterim, uma nova forma de organização do trabalho, pautada no vínculo, na humanização, no acolhimento e na parceria com outras instituições e outros setores, na tentativa de estar mais próximo do usuário e suas vulnerabilidades ${ }^{(4)}$. No que tange às atribuições de todos os profissionais da ESF, para operacionalização do trabalho, estes devem participar do processo de territorialização e diagnóstico de saúde da comunidade; desenvolver relações de vínculo e responsabilização entre as equipes e a população, identificando situações de risco e vulnerabilidade; realizar cadastros e manter atualizados os dados de indivíduos e famílias do território para planejamento em saúde; realizar o cuidado em saúde da população adscrita, considerando as 
necessidades da população; organizar o fluxo de usuários para os diversos pontos da RAS; participar do gerenciamento dos insumos necessários para o adequado funcionamento da unidade e, estimular o controle social ${ }^{(1)}$. A organização e gestão APS também é influenciada pelas dimensões "políticas, ideológicas, organizacionais, econômicas e culturais". Neste cenário destaca-se o papel do gestor das unidades locais, regionais e municipais e quais as opções que utilizará para enfrentar e gerenciar "conflitos político-ideológicos, socioeconômicos e administrativo-financeiros na busca de um agir que proporcione uma atenção à saúde em sentido ampliado" para a população adscrita ao seu território. Para tanto, torna-se de supra importância firmar posicionamento em defesa da garantia do direito ao acesso universal à saúde, organizando "sistemas de saúde que considerem aspectos socioculturais, organizacionais e econômicos, de modo a atender as necessidades das populações, fornecendo infraestrutura, recursos humanos e tecnologias de saúde adequadas e com custos financeiros suportáveis"(5). Entre os desafios ou dificuldades que afetam a efetividade da APS pode-se destacar o desconhecimento ou falta de formação dos gestores para a atividade de gestão, na tomada de decisões para o gerenciamento do território e coordenação dos serviços de saúde com vistas a oferecer uma atenção centrada nos usuários. Outro aspecto que interfere na gestão é a alta rotatividade dos profissionais de saúde, a qual dificulta o estabelecimento de vínculos entre profissionais, gestores e usuários. No entanto, neste cenário, a educação permanente surge como uma potencialidade para o enfrentamento das dificuldades da gestão da APS, pois é um recurso que permite qualificar gestores e suas equipes para tomar decisões que priorizem a implantação de ações e serviços que garantam o cuidado aos sujeitos, famílias e comunidade, bem como pode ser considerada uma estratégia para reorganização do funcionamento dos serviços e dos processos de trabalho(5).

\section{Conclusão}

Todavia, sabe-se que é um grande desafio trabalhar com as dimensões da APS para atender às necessidades das famílias, que por serem complexas, exigem o desempenho de novas práticas, sobretudo aquelas que enfatizam as ações de prevenção e de promoção da saúde, e as de gestão, que favoreçam maior participação tanto dos trabalhadores como dos usuários, bem como identificação precoce de possíveis vulnerabilidades ou riscos voltados à saúde. Nesse sentido, a partir desta reflexão compreende-se que, a investida na práxis dialógica na articulação entre trabalho, formação, organização e adequação ao modelo na ẢPS pode constituir-se enquanto alternativa necessária para a compreensão da complexidade do processo saúde-doença, uma vez que intrínseco a estas abordagens, o próprio entendimento do conceito ampliado de saúde que vigora nestas práticas se apresenta como possibilidade na garantia da efetivação e integralidade do cuidado em saúde.

Descritores: gestão em saúde; atenção primária à saúde; integralidade.

\section{Referências}

1. Brasil. Ministério da Saúde. Portaria n⿳⺈ 2.436, de 21 de setembro de 2017. Aprova a Política Nacional de Atenção Básica, estabelecendo a revisão de diretrizes para a organização da Atenção Básica, no âmbito do Sistema Único de Saúde (SUS). Brasília, 2017.

2. Hone, T. et al. Association between expansion of primary healthcare and racial inequalities in mortality amenable to primary care in Brazil: a national longitudinal analysis. Plos Medicine, v. 14, n.5, p.1-19, mai. 2017. Disponível em: https://journals.plos.org/plosmedicine/article?id=10.1371/journal.pmed.1002306

3. Sampaio, LFR; Mendonça, CS; Lermen Junior, N. Atenção Primária à Saúde no Brasil. In: GUSSO, G.; LOPES, J. M. C. (Orgs) Tratado de medicina de família e comunidade: princípios, formação e prática. Porto Alegre: Artmed, p. 29-43, 2012.

4. Falcón, GCS.; Erdmann, AL.; Backes, DS. Significados do cuidar na promoção da saúde. Rev. Latino-Americana de Enfermagem, Ribeirão Preto, v. 16, n. 3, pág. 419-424, jun. 2008. Disponível em: https://www.revistas.usp.br/ rlae/article/view/16972

5. Pires, DEP. et al. Gestão na atenção primária: implicações nas cargas de trabalho de gestores. Rev. Gaúcha de Enfermagem. v.40, Epub Oct o3, 2019. Disponível em: https://www.scielo.br/pdf/ rgenf/v40/1983-1447-rgenf-40-e2018o216.pdf 
Eixo temÁtico II

\section{MOVIMENTOS DE EDUCAÇÃO PERMANENTE EM SAÚDE}




\section{DESAFIOS E POTENCIALIDADES DA EDUCAÇÃO PERMANENTE EM SAÚDE A PARTIR DA VIVÊNCIA DE GESTORES E TRABALHADORES DA ATENÇÃO BÁSICA NA ZONA SUL DE SÃO PAULO}

\author{
Israel Victor de Oliveira \\ Rogério Nogueira de Oliveira
}

\section{Introdução}

A despeito da polissemia em torno do termo Educação Permanente em Saúde (EPS), tomamos como referência sua concepção mais atual, onde EPS é uma estratégia político-pedagógica que toma como objeto os problemas e necessidades emanadas do processo de trabalho em saúde, com o objetivo a qualificar e aperfeiçoá-lo em vários níveis organizacionais e gerenciais do sistema; orientando-se para a melhoria do acesso, qualidade e humanização na prestação de serviços e para o fortalecimento dos processos de gestão político-institucional do SUS no âmbito federal, estadual, municipal e local. Após quase duas décadas da criação da Política Nacional de Educação Permanente em Saúde (PNEPS), com a indução de diferentes ações de formação técnica, superior e qualificação da força de trabalho do Sistema Unico de Saúde no território nacional, muitos avanços ocorreram: dados oficiais coletados no $2^{\mathrm{O}}$ ciclo do Programa de Melhoria da Qualidade da Atenção Básica (PMAQ) (2013) revelaram no panorama nacional que 90\% ( $\mathrm{n}=9184)$ das Equipes de Saúde da Família (EqsF) afirmaram participar de alguma ação de EPS. Programas pioneiros de educação digital e à distância desenvolvidos por instituições parceiras da Universidade Aberta do SUS (UNA-SUS) permitiram o acesso a 506 ofertas educacionais entre cursos rápidos, autoinstrucionais e especializaccões, garantindo a matrícula de mais de 1 milhão de profis- 
sionais de saúde. Todavia, ao tomarmos como referencial crítico e analítico a micropolítica da gestão e do cuidado em saúde, notamos que a condução das políticas de educação em saude pouco tem privilegiado os diversos encontros e o trabalho vivo em saúde em uma proposta mais ampla de EPS: reflexiva e interrogativa do instituido, ou seja, a EPS tem sido fortemente caracterizada como educação continuada, restrita ao saber técnico-científico, à atualização e ao agir protocolado em saúde ${ }^{1}$. Assim, o desenvolvimento de ações pautadas na Política Nacional de Educaçã̃o Permanente em Saúde e a consequente participação dos diversos atores do Sistema Único de Saúde em atividades de educação permanente e continuada no microcosmo dos territórios é permeado pelas apostas da gestão local, disputas e tensões da micropolítica do trabalho em saúde e por diversos obstáculos, citamos: distorção ou desconhecimento sobre a EPS, formação e capacitações insuficientes, sobrecarga e desvalorização profissional e vulnerabilidade dos trabalhadores diante da precariedade de vínculos, sob forte influência do modelo gerencial.

\section{Objetivo}

Apresentar os resultados de um estudo sobre o cotidiano da EPS na realidade de trabalhadores e gestores de Unidades Básicas de Saúde da zona sul do município de São Paulo, tendo como referencial a Educação Permanente em Saúde e a micropolítica da gestão e do cuidado em saúde.

\section{Método}

Trata-se de um estudo qualitativo, analítico e descritivo que utilizou as técnicas de entrevista individual e de grupo focal com a finalidade de identificar concepções, atividades, fatores facilitadores e barreiras aos processos de educação permanente em saúde identificados por equipes de Saúde da Família (EqsF) e gestores em quatro Unidades Básicas de Saude da zona sul do município de São Paulo. A análise dos dados obtidos foi feita a partir do que a Minayo (2014) ${ }^{2}$ propõe, onde a abordagem qualitativa é entendida como aquela capaz de incorporar a questão do significado e da intencionalidade como inerentes aos atos, às relações, às estruturas sociais que tomadas no seu advento ou transformação denotam construções humanas significativas. A pesquisa foi aprovada pelo Comitê de Ética em Pesquisa, mediante o parecer consubstanciado no 2.943 .879 de 5 de outubro de 2018 , sendo obedecidos os procedimentos éticos estabelecidos pela resolução 466/12 do Consetho Nacional de Ética em Pesquisa (CONEP). Utilizamos os seguintes critérios de inclusão: profissionais das EqSF das Unidades Básicas de Saúde da parceria público privada Secretaria Municipal de Saúde e Instituto Israelita de Responsabilidade Social; aceitar participar da pesquisa mediante assinatura do Termo de Consentimento Livre e Esclarecido (TCLE); ser maior de 18 anos. Os instrumentos de coleta utilizados foram os roteiros semi-estruturados (com perguntas abertas) para entrevistas individuais com os gestores $(\mathrm{n}=05)$ e grupo focal com os profissionais das equipes de saúde da família $(n=25)$. A coleta de dados foi realizada entre os meses de fevereiro e abril de 2019, em quatro UBS selecionadas. As perguntas realizadas foram baseadas em aspectos relevantes da pesquisa, considerando as concepções de educação permanente dos gestores e trabalhadores das EqSF, atividades de EPS presentes no cotidiano e fatores considerados como facilitadores e dificultadores dos processos de EPS no cotidiano do serviço.

\section{Resultados e discussão}

Apresentamos os principais resultados obtidos, de maneira sintética, a partir das categorias a) concepções de EPS, b) ações de EPS, c) Dificultadores (ou barreiras) para a EPS e d) Facilitadores para a EPS. A pergunta disparadora inicial nos grupos focais e nas entrevistas foi: qual o significado de educação permanente em saúde para vocês? Os resultados obtidos revelaram que a maior parte das EqSF e dos gestores pesquisados compreendem as principais características e a concepção de EPS contida na PNEPS, porém há contradições e confusão sobre o termo, frequentemente associado à formação continuada, o que demonstra a necessidade de abordagem sobre a temática sob uma perspectiva mais ampla, crítica e reflexiva. Seguindo o roteiro do grupo focal e entrevista individual utilizamos uma tabela, que consta no Instrumento de avaliação externa para as Equipes de Atenção Básica do PMAQ-AB, a fim de facilitar a discussão, a partir da pergunta norteadora: quais ações ou atividades de EPS vocês veem no seu cotidiano? A maior frequência de respostas se deu em 1. Seminários, mostras, oficinas e grupos de discussão, seguidos de 2. Cursos presenciais e 3. Grupos de discussão, o que demonstrou o protagonismo dos trabalhadores em espaços de aprendizagem coletiva e colaborativa e de intercâmbio de saberes e experiência, além do desenvolvimento de cursos, 
capacitações e processos formativos por iniciativa da gestão. As dificuldades desveladas pelas EqSF e gestores para a concretização de atividades de formação, educação permanente e continuada advém de diversos fatores: falta de ferramentas para a operacionalização da política pelos gestores, necessidade de articulação entre os níveis de gestão, falta de profissionais qualificados e com adesão a atividades educacionais, falta de planejamento pelos gestores das UBS, rotatividade dos profissionais devido ao vínculo precário, baixa participação da população e enfoque no trabalho fragmentado por profissões. Em diálogo com o presente estudo, os resultados de uma pesquisa-ação realizada no município de Arvorezinha, no estado de Rio Grande do Sul com 33 profissionais da Atenção Básica mostraram que a sobrecarga de trabalho e a falta de infraestrutura e de participação dos profissionais se constituem como entraves nos processos de EPS. 3 No referido estudo, realizado por Pinheiro et al. (2018)3 , a manutenção de espaços para a promoção de atividades de EPS, planejamento prévio, utilização de metodologias ativas e integracão da equipe foram agentes facilitadores identificados no cotidiano dos serviços pelas equipes. No presente estudo, a garantia de um tempo protegido (e a periodicidade) de ações, a valorização do trabalhador e da lógica da EPS pelo gestor também foram considerados como facilitadores da EPS na prática. Da mesma forma, gestores sensibilizados e que compreendem o uso da Educação Permanente em Saúde como ferramenta de gestão no serviço podem apoiar e garantir a sustentabilidade da política de educação, de forma que seja mantido seu espaço institucional.

\section{Conclusão}

Neste estudo pudemos identificar algumas concepções para trabalhadores e gestores locais de saúde que mesmo alinhadas à política, são permeadas no cotidiano por várias dificuldades, citamos: a sobrecarga, supervalorização de metas e indicadores, entraves burocráticos, engessamento de processos de trabalho (agir protocolado) e escassez de recursos tecnológicos e infraestrutura para acesso a atividades de educação digital e à distância. Porém há vários facilitadores para os processos formativos e materialidade da política de EPS, que identificamos: a integração da equipe, a motivação dos trabalhadores, o planejamento prévio de atividades, a garantia de um tempo protegido para estudo, a valorização do trabalhador da saúde e da educação permanente pelos gestores das Unidades Básicas de Saúde. Quando tomada como um dispositivo para a gestão do cuidado, em alinhamento aos princípios e diretrizes do SUS, a EPS pode promover a reflexão e aprendizado a partir de diferentes contextos, dialogando com as singularidades locais, para a produção do trabalho vivo em ato nos territórios. Ao vivenciar a EPS no cotidiano do fazer em saúde, gestores e trabalhadores interrogam as suas práticas; se aproximam mais de sua concepção enquanto estratégia de gestão; inventam espaços formais e informais para a garantia dos encontros entre os mesmos; e, reconhecem o seu protagonismo e potência para a construção de conhecimento e de estrategias coletivas e compartilhadas que fazem diferença na produção do cuidado no SUS. Mesmo sob à égide das forças ao modelo biomédico, gerencialista e a ameaça neoliberal que interferem na produção do cuidado e produzem efeitos perversos no processo de trabalho das equipes, a EPS é uma estratégia fundamental que coloca os diversos atores da saúde em movimento na Atenção Básica, fazendo um contraponto ao instituído, apesar dos desafios cotidianos.

Descritores: Educação continuada. Sistema Único de Saúde. Atenção Primária à Saúde. Estratégia de Saúde da Família.

\section{Referências}

1. Merhy EE, Feuerwerker LCM, Santos MLM, Bertussi DC, Baduy RS. Rede Básica, campo de forças e micropolítica: implicações para a gestão e cuidado em saúde. Saúde debate [internet]. 2019 [acesso em 2021 jan 05]; 43 (spe) 7083. Doi: 10.1590/0103-11042019s606. Disponível em: https://www.scielo.br/pdf/sdeb/v43nspe6/ 0103-1104-sdeb-43-speo6-oo7o.pdf

2. Minayo MCS. O desafio do conhecimento: pesquisa qualitativa em saúde. São Paulo: Hucitec; 2014.

3. Pinheiro GEW, Azambuja MS, Bonamigo AW. Facilidades e dificuldades vivenciadas na Educação Permanente em Saúde, na Estratégia Saúde da Família. Saúde Debate [internet], dez 2018 [acesso em 2021 jan 05]; 42(4):187-97. Doi: 10.1590/0103-11042018s415. Disponivel em: https://www.scielo.br/pdf/sdeb/v42nspe4/ 0103-1104-sdeb-42-speo4-0187.pdf 
Pesquisa Original

EDUCAÇÃO PERMANENTE EM SAÚDE E O

PROGRAMA NAGIONAL DE MELHORIA DO

ACESSO E QUALIDADE DA ATENÇÃO BÁSICA

\section{Israel Victor de Oliveira Rogério Nogueira de Oliveira}

\section{Introdução}

A Educação Permanente em Saúde (EPS) é definida pela Organização Pan-Americana da Saúde (OPAS) como um processo dinâmico de ensino e aprendizagem, ativo e contínuo, com a finalidade de análise e melhoramento da capacitação de pessoas e grupos, frente à evolução tecnológica, às necessidades sociais e aos objetivos e metas institucionais ${ }^{1}$ A expansão do sistema de saúde brasileiro, iniciada na década de 1970 , e a consequente necessidade de desenvolvimento de recursos humanos para o setor levaram ao surgimento de diversos programas de formação, que buscaram construir modelos político-pedagógicos comprometidos com a promoção do diảlogo entre educação e formação de serviços de saúde. Nesse sentido, o Sistema Único de Saúde (SUS), em um contexto mais específico da Atenção Básica ( $\mathrm{AB}$ ), por seu tamanho e abrangência, está presente na arena dos processos formativos no setor saúde como um lugar privilegiado de ensino e aprendizagem, especialmente em locais onde a assistência à saúde é prestada. Educar 'pelo' e 'para' o trabalho compreendem a assunção da EPS: onde há produção do cuidado visando à integração, à responsabilidade compartilhada e à resolução de problemas existe simultaneamente o cenário da produção pedagógica, pois é ali que se concentram os encontros entre trabalhadores e usuários. O Programa Nacional de Melhoria do Acesso e da Qualidade da Atenção Bási- 
ca (PMAQ-AB) foi criado em 19 de julho de 2011, através da Portaria no 1.654 Gabinete do Ministro/Ministério da Saúde, como resultado de um processo de negociação e pactuação das três esferas do SUS, em debates que formularam soluções para a criação de um programa que permitisse a ampliação do acesso e da melhoria da qualidade da $\mathrm{AB}$ em todo o País. Diante dos inúmeros desafios colocados pela realidade, o PMAQ-AB propõe como modelo de avaliação de desempenho dos sistemas de saúde a indução de diversas iniciativas para a garantia de um padrão de qualidade em nível nacional, regional e local. O programa é permeado pela lógica da EPS em todas as suas fases, desde a adesão das equipes até a recontratualização. Há um espaço privilegiado de produção coletiva de iniciativas para o trabalho, e a possibilidade de desenvolvimento articulado dos diversos atores da $\mathrm{AB}$ com vistas à ampliação da resolutividade e do acesso no território. Além do exposto, os dados obtidos no censo de avaliação externa com as Equipes de Atenção Básica (eAB) na fase de certificação podem fornecer importantes subsídios para gestores, pesquisadores e formuladores de políticas públicas em nível local, regional e nacional.

\section{Objetivo}

Obter um painel brasileiro de participação, dispositivos e atendimento a demandas de Éducação Permanente em Saúde das Equipes de Saúde da Família na Atenção Básica, a partir da análise dos dados secundários do Ministério da Saúde, extraídos do censo de avaliação externa do PMAQ-AB no 2ํㅡㄹ Ciclo em 2013.

\section{Método}

Trata-se de um estudo transversal descritivo, com a análise de dados secundários obtidos no $2^{\text {o }}$ Ciclo do PMAQ- $\mathrm{AB}^{2}$. Foram avaliadas as respostas obtidas no censo de avaliação externa das Equipes de Saúde da Família (eSF), no $2^{\circ}$ Ciclo (2013), utilizando as variáveis do instrumento de avaliação externa relacionadas à EPS no módulo II - Entrevista com o profissional de saúde na Unidade de Saúde. As variáveis selecionadas foram coletadas por pesquisadores/professores das universidades/institutos de ensino e pesquisa na etapa de avaliação externa (módulo II - Entrevista com o profissional da eAB) no Ciclo 2 do PMAQ-AB. Utilizam-se os seguintes critérios de inclusão: eSF com adesão ao PMAQ$-A B$ e participação no censo de avaliação externa do MS (n=10.213/100\%). Foram excluídas
(364/3,44\%) equipes pelo fato de não terem recebido os censores do MS à época de avaliação. Os dados, de acesso livre e disponíveis em http://aps.saude.gov.br/ape/pmaq/cicloz/ foram tratados de acordo com a frequência simples e o percentual de distribuição das variáveis. Foram utilizados filtros e tabelas dinâmicas em Microsoft Excel ${ }^{\circledR}$, cruzando os dados obtidos a partir das variáveis selecionadas. A pesquisa foi aprovada pelo Comitê de Ética em Pesquisa, mediante o parecer consubstanciado $n^{\circ} 2.943 .879$, de 05 de outubro de 2018.

\section{Resultados e Discussão}

Nesse censo, 90\% das equipes $(n=9.184)$ entrevistadas responderam afirmativamente sobre a participação em atividades de EP. Cerca de $10 \%(n=991)$ responderam que não participavam de ações de EP e 38 (o,37\%) equipes não souberam ou não responderam. A segunda questão selecionada buscou identificar de quais ações de EP as eSF participaram. De acordo com os dados coletados, pode-se concluir que, no panorama brasileiro, a participação em ações de EP, das eSF, se materializou principalmente através de seminários, mostras, oficinas e grupos de discussão $(\mathrm{n}=8.243 / 80,71 \%)$, além de cursos presenciais $(\mathrm{n}=7808 / 76,45 \%)$. Das opções ofertadas pelo MS, a menos frequente foi a Rede Universitária de Telemedicina (RUTE) $(n=475 / 1,32 \%)$. Algumas equipes informaram não participar de nenhuma ação de EP $(n=577 / 1,61 \%)$. A terceira questão buscou investigar se as demandas e necessidades de EP das eSF eram contempladas, ou seja, se as ofertas de ações formativas oferecidas pela gestão consideravam a real necessidade dos trabalhadores $d a$ $\mathrm{AB}$, que de forma geral foram atendidas pela gestão. Os dados aqui descritos revelam um panorama nacional e por região das ofertas de EP, da participação das eSF nessas atividades e da opinião destas equipes sobre a contemplação de suas necessidades formativas. Uma avaliação desse $2^{\underline{0}}$ Ciclo revela que $90 \%$ das equipes afirmaram participar de alguma atividade de EP, o que demonstra uma ampliação, se comparada aos dados tratados por pesquisadores do MS em 2012. O PMAQ-AB procura também integrar as ofertas de atividades de EPS e apoiar os processos de qualificação intraequipes através das mudanças ocorridas no programa. O protagonismo dos trabalhadores da saúde nas ações formativas e educativas se evidencia através das tecnologias leves e leves-duras utilizadas no cotidiano do trabalho na $\mathrm{AB}$. As reuniões de equipe, a 
construção de projetos terapêuticos, grupos educativos, interconsultas, oficinas e o matriciamento, entre outros recursos, denotam a troca de saberes e a dinâmica de uma enorme riqueza para a produção de cuidado e conhecimento no âmbito do SUS. A oferta de cursos presenciais foi a segunda resposta mais frequente $(n=7.808 / 21,74 \%)$, demonstrando que a prática formativa hegemônica (da formação pontual, transmissiva e de caráter transitório) ainda não foi rompida e que, dada a sua complexidade, a EP necessita de um aprofundamento, assim como a compreensão do seu significado para gestores e trabalhadores de saúde. A terceira questão buscou investigar se as demandas e necessidades de EP das eSF foram contempladas, ou seja, se as ofertas de ações formativas oferecidas pela gestão consideraram a necessidade dos trabalhadores da AB. A participação ativa e o protagonismo dos trabalhadores da $\mathrm{AB}$ nos processos decisórios são pressupostas da EPS e os dados coletados mostraram que a maior parte das equipes $(n=8.949 / 87,62 \%)$ respondeu que teve suas necessidades atendidas pela gestão. Dada a posição privilegiada da EP, particularmente no SUS, recomendam-se maiores investimentos em pesquisas educacionais, que considerem outras variáveis não inclusas devido aos limites e à aplicabilidade do instrumento. ${ }^{3}$

\section{Conclusão}

Através das variáveis selecionadas do instrumento de avaliação externa, pôde-se identificar que o Programa investigou os processos formativos de forma macropolítica quando foram consideradas as grandes regiões geopolíticas brasileiras, e de forma micropolítica quando se debruçou sobre o lócus intraequipes nas Unidades Básicas de Saúde. De forma geral, obteve-se um painel da EPS, em que quase a totalidade das equipes aderentes ao PMAQ-AB afirmou participar de ações de EP, tendo suas necessidades formativas contempladas pela gestão. O instrumento apresenta robustez de dados e contempla diversos aspectos da gestão, incluindo elementos importantes de EPS que podem nortear a tomada de decisão e interferir em políticas e programas de EPS nos serviços.

Descritores: Educação continuada. Sistema Único de Saúde. Avaliação em saúde.

\section{Referências}

1. França T, Pierantoni C, Belisario AS, et al. A capilaridade da Política Nacional de Educação Permanente em Saúde no Brasil. Atas-Investig. Qualit. Saúde [internet]. 2016 [acesso em 2021 jan 04]; (2):66-75. Disponível em: https:// proceedings.ciaiq.org/index.php/ciaiq2016/article/view/738/725.

2. Brasil. Ministério da Saúde (Brasil). Programa Nacional de Melhoria do Acesso e da Qualidade da Atenção Básica (PMAQ): Manual Instru-

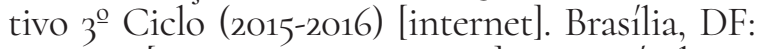
MS: 2015[acesso em 2021 jan 04]. Disponível em: http://189.28.128.100/dab/docs/portaldab/documentos/Manual_Instrutivo_3_Ciclo_PMAQ.pdf.

3. Oliveira IV, Santos JMM, Carrer FCSA, Oliveira RN. Educação Permanente em Saúde e o Programa Nacional de Melhoria do Acesso e Qualidade da Atenção Básica: um estudo transversal e descritivo. Saúde em Debate, 202O; 44(54):43. [acesso em 2021 jan 05]. Disponível em: https://www.scielo.br/scielo.php?script=sci_arttext\&pi-

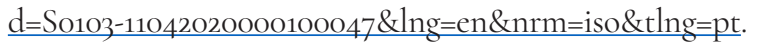


Pesquisa Original

CARTAS PARA FREIRE: REFLEXÕES DE PROFISSIONAIS SOBRE EDUCAÇÃO PERMANENTE NA ESTRATÉGIA SAÚDE DA FAMÍLIA

\author{
Priscila Rodrigues da Cunha \\ Mariana Mendes \\ Maria Elisabeth Kleba \\ Vanessa Denardi \\ Antoniassi Baldissera
}

\section{Introdução}

A educação é um processo que envolve ação-reflexão-ação e, quando libertadora, desenvolve a capacidade de as pessoas aprenderem a partir de ações concretas, no diálogo e interação com outros sujeitos, considerando contexto cultural, político e social. ${ }^{.}$Sabidamente, Freire ${ }^{1}$ compreendeu a educação problematizadora como, reflexiva, questionadora, política, que desperta os sujeitos para um novo agir, e promove sua capacidade para, ao reconhecer sua realidade, transformá-la. Por isso, seus conceitos têm sido amplamente utilizados como alicerce teórico-metodológico e prático no campo da saúde. Nesta perspectiva, a implementação da atenção integral à saúde, preconizada pela Política Nacional de Atenção Básica e operacionalizada pela Estratégia Saúde da Família (ESF), encontra na problematização um modo favorável ao desenvolvimento dos profissionais da saúde, visando a prestação de serviços de qualidade, resolutivos e com maior satisfação à todos os envolvidos. A problematização coloca o cotidiano do trabalho como foco da reflexão e lócus de aprendizagem. Para tanto, a Educação Permanente em Saùde (EPS) tem como proposta possibilitar reflexão crítica a partir das vivências, produzindo novos modos de fazer/agir e novas alternativas para o trabalho conjunto entre serviços e comunidade. Notadamente, o legado de Freire está presente na proposta da EPS que permeia o desenvolvimento dos profissionais da ESF no 
Brasil, o que nos leva aos seguintes questionamentos: $\mathrm{Na}$ atualidade, o que o profissional da ESF salientaria no diálogo com Freire? O que diria sobre a educação na e para a saúde? Como a EPS contribui para o desenvolvimento profissional em seu cotidiano de trabalho? Para tanto, o objetivo deste estudo é desvelar as inquietações dos profissionais expressadas em cartas endereçadas a Freire acerca da educação permanente no contexto da ESF.

\section{Método}

Trata-se de recorte de uma dissertação, na qual realizou-se uma Pesquisa Convergente Assistencial (PCA) ${ }^{2}$ permeada pelo referencial teórico de Paulo Freire. A pesquisa ocorreu em uma Unidade Básica de Saúde (UBS) no litoral de Santa Catarina, na qual, atuam profissionais da ESF, Núcleo Ampliado de Saúde da Família e Atenção Básica (Nasf-AB) e residentes de um Programa de Residência Multiprofissional. Participaram 13 profissionais, sendo: dentistas (3), médicos (3), enfermeiros (2), fisioterapeutas (2), educador físico (1), farmacêutico (1), terapeuta educacional (1). A coleta dos dados ocorreu por meio do Círculo de Cultura, inspirado em Paulo Freire ${ }^{1}$, em quatro etapas: investigação do universo vocabular e dos temas geradores, codificação, descodificação e desvelamento crítico. As cartas para Freire foram escritas pelos participantes na fase do desvelamento crítico como uma forma de avaliação dos encontros do Círculo de Cultura. A proposta era imaginar que essa carta chegaria a Paulo Freire, e desse modo, o profissional pudesse expressar a Ele reflexões sobre a educação permanente no contexto da ESF que emergiram ao longo dos encontros do Círculo de Cultura. Os participantes escolheram pseudônimos referentes a nomes de pedras preciosas, como: Diamante, Esmeralda, Rubi, dentre outros, sendo assim identificados neste manuscrito. Os dados foram coletados de julho a setembro 2018 e a pesquisa aprovada em Comitê de Ética de Pesquisa em Seres Humanos, respeitadas as Resoluções no 466/2012 e 510/2016.

\section{Resultados e Discussão}

As cartas para Freire demonstraram o inegável legado de Paulo Freire devido sua incansável luta para que as pessoas pudessem usar do conhecimento para transformar-se, e consequentemente, transformar o contexto em que vivem. ${ }^{3}$ A educação permanente proposta por Freire, amplamente utilizada no campo da saúde, permite reconhecer dinâmica e flexibilidade das práticas profissionais, bem como visualizar necessidade e viabilidade de promover transformações no contexto da prática. Para o autor, quando o ser humano age a partir da realidade, ele aumenta sua capacidade de conhecimento, à medida que este se dá como resultado dessa vivência, de modo que a educação é continuamente refeita pela práxis. ${ }^{3}$ A partir dos escritos para Freire produzidos pelos participantes da pesquisa, é possível perceber poucas iniciativas de os profissionais da saúde questionarem o processo de trabalho que executam e de refletir criticamente sobre dificuldades e potencialidades presentes na prática. Entretanto, quando o fazem, percebem que realizam muito pela população, mesmo em meio a tantos desafios: "Querido Paulo Freire, nossos encontros foram realmente especiais! Ter a oportunidade de parar e refletir sobre o nosso dia a dia, nosso trabalho, foi intenso, muitas vezes angustiante, mas acima de tudo [...] você me oportunizou olhar para o meu "EU", e para a equipe que estou inserida. Com todo esse processo, pude perceber o quanto realizamos e também o quanto ainda podemos contribuir para o SUS tão sonhado! Obrigada pela oportunidade" (Ágata). Neste excerto, o processo de reflexão oportunizado pelo Círculo de Cultura provoca o sentido de pertencimento ao grupo e favorece mudanças: "Querido Paulo, [...I por diversas vezes pensei em não estar fazendo muito, senti desânimo. Ler o que você escreveu e ouvir suas frases foi muito inspirador, além de me animar me pôs a pensar em quanto eu faço com os recursos que possuo e me fez perceber também que o mais valioso eu tenho, que são pessoas maravilhosas que caminham comigo, $e$ temos também a sua inspiração, de que podemos mais. [...] Por isso e por tudo o que você nos inspira, eu agradeço" (Ametista). Quando os profissionais destacam que a EPS ocorre o tempo todo, torna-se relevante mencionar a importância do sentido das ações realizadas por eles. Essas não devem ser somente ações pautadas em cumprir determinações, e sim como um trabalho que interage e reflete na população. ${ }^{4}$ Entretanto, foi na escuta entre si, que os participantes perceberam que as inquietudes eram sentimentos comuns entre eles. Dessa forma, as reflexões inspiradas em Freire durante os encontros do Círculo de Cultura proporcionaram aos profissionais inquietar-se, buscando fortalecer as relações de trabalho e o comprometimento de ser protagonista da própria história: "Paulo Freire, a sensação vivenciada por mim durante os encontros do círculo de cultura foi de: somos todos atores e protagonistas das ações. E quando isso ocorre na forma compartilhada de conhecimentos, os saberes 
aumentam e conhecemo-nos como peças fundamentais de todo o processo de aprender e ensinar ao mesmo tempo [...] Porém, o inédito é viável, se não fosse, não teria passado tanto tempo nos ensinando. Valeu!' (Jade). A educação permanente permeada pela amorosidade de Freire assegura que eles não estão sozinhos, e mais, que juntos podem obter resultados ainda melhores: "Paulo, agradeço por dar luz as minhas preocupações relacionadas ao trabalho, ao ler um pouco mais sobre o que escrevestes, pude ver que não são inquietações solitárias e tampouco infundadas. Agradeço pela inspiração, por fortalecer minha persistência e tolerância" (Pérola). Nesse sentido, a EPS se configura como suporte da ESF na consolidação da Atenção Básica, uma vez que a assistência continuada exige da equipe novos conhecimentos e habilidades baseados no pensamento crítico-reflexivo. ${ }^{4}$ Os participantes destacaram a importância do engajamento e do comprometimento em relaçã̃o as práticas realizadas na ESF, que, com apoio dos profissionais do Nasf-AB e residentes, fortalecem interação e promovem corresponsabilidade entre equipes e comunidade. Os resultados deste estudo demonstram a importância dos espaços de diálogos no cotidiano de trabalho, de modo a potencializar relações de cooperação entre equipes, bem como reforçar os aspectos indispensáveis prescritos pela $\mathrm{AB}$ no Brasil, como a integralidade e longitudinalidade do cuidado. Ainda, reforçam a importância de alicerces teóricos como o de Paulo Freire, permeado pela aprendizagem significativa e crença no potencial da educação para transformar a realidade. As limitações deste estudo estão relacionadas a escolha do cenário de investigação, podendo as angustias destes profissionais, não representar quem atua em outras equipes da ESF no Brasil.

\section{Conclusão}

As cartas para Freire demonstraram a importância do alicerce teórico deixado como legado por Ele e que tão bem se aplica ao contexto da ESF. No desvelamento crítico, os participantes reconheceram que as potencialidades sobressaíram as dificuldades, quando esses se colocaram como protagonistas, corresponsáveis diante da realidade que vivenciam e ainda, por contarem com uma relação profícua entre equipe da ESF, Nasf-AB e residentes. Para além, perceberam que os desafios são elementos fundamentais ao processo de evolução no aprendizado, aproximando-se do inédito viável refletido por Freire, o qual parte da ideia de que sonhos, utopias e esperança é que nos move para a transformação da realidade, da qual somos parte.
Descritores: Educação Permanente; Profissionais de Enfermagem; Estratégia Saúde da Família.

Financiamento: Agradeço a Fundação de Amparo à Pesquisa e Inovação de Santa Catarina (FAPESC) pela concessão de bolsa, a qual viabilizou minha pesquisa durante o mestrado.

\section{Referências}

1. Freire P. Pedagogia do oprimido. 1. ed. Rio de Janeiro: Paz e Terra; 2019. 256 p.

2. Trentini M, Paim L. Pesquisa Convergente Assistencial: um desenho que une o fazer e opensar na prática assistencial em Saúde-Enfermagem. 2. Ed. Florianópolis: Insular; 2004. 143 p.

3. Freire P. Conscientização: teoria e prática da libertação: uma introdução a pensamento de Paulo Freire. Mello e Silva K, tradutor. São Paulo: Cortez \& Moraes; 1979.

4. Dolny LL, Lace JT, Nilson LG, Calvo MC, Sônia Natal, Maeyama MA. Permanent health education in family health teams work process. Braz. J. Hea. Rev. [Internet]. 2020; 3(1):15-38. Available from: https://doi.org/10.34119/bjhrv3n1-OO2. 
Pesquisa Original

EDUCAÇÃO PERMANENTE EM SAÚDE: POSSIBILIDADE
DE APRIMORAMENTO DA PREVENÇÃO
QUATERNÁRIA NA ATENÇÃO PRIMÁRIA À SAÚDE

Karina Schopf

Aline Lemos de Souza

Carine Vendruscolo

\section{Introdução}

A Educação Permanente em Saúde (EPS) é considerada uma estratégia transformadora nas práticas dos profissionais de saúde, visa valorizar a experiência, o conhecimento e os desafios na realidade das equipes, sendo oportunizada no cotidiano de trabalho, mediante metodologias pedagógicas problematizadoras e participativas'. A Atenção Primária à Saúde (APS) representa cenários de práticas promissoras para a consolidação da EPS, pois a atuação dos profissionais demanda constante reflexão e implementação de ações que contribuam para mudanças no processo de trabalho, por meio da troca de saberes e do fortalecimento de práticas interdisciplinares. No âmbito da APS, a Prevenção Quaternária $\left(\mathrm{P}_{4}\right)$ torna-se tema de interesse e que demanda habilidades específicas para os profissionais das equipes, a fim de evitar riscos de ações preventivas excessivas aos usuários. Atualmente, as ações preventivas avançaram significativamente, principalmente, pela influência do avanço tecnológico e científico, com inserção de tratamentos preventivos na área da farmacologia. Com isso, estimulando a conversão de pessoas saudáveis em doentes². A $\mathrm{P}_{4}$ é um conceito relativamente recente, que consiste em ações que visam identificar pessoas em risco de tratamentos excessivos e/ou desnecessários, seja medicamentoso ou de intervenções clínicas como exames e procedimentos. A $\mathrm{P}_{4}$ não incide sobre o risco da doença, mas sobre 
o risco de adoecimento iatrogênico, protegendo pessoas saudáveis de práticas intervencionistas danosas. Nesse sentido, reafirma as boas práticas no agir profissional visando reduzir o excesso de intervenções e iatrogenias clínicas, sociais ou culturais ${ }^{2}$.

\section{Objetivo}

Relatar a percepção dos profissionais das equipes Saúde da Família (eSF) sobre a necessidade e a importância de momentos de EPS para fortalecer a Prevenção Quaternária.

\section{Método}

Trata-se de um recorte da macro pesquisa: Prevenção Quaternária na Atenção Primária: interfaces com as melhores práticas em saúde. Estudo de abordagem qualitativa, com utilização de metodologia participativa, voltado à investigação de concepções e práticas de $\mathrm{P}_{4}$, em dois municípios de pequeno porte, na região Oeste de Santa Catarina. A metodologia participativa fomenta a EPS e, nessa direção, contribui para a compreensão das percepções dos profissionais sobre este tema, além de propor movimentos pedagógicos para a transformação da práxis ${ }^{3}$. As informações foram produzidas entre junho e outubro de 2020, em encontros presenciais e on-line, mediante rodas de conversa com os profissionais de duas eSF (uma de cada município), representando $100 \%$ da APS, em ambos. Foi utilizado como critério de inclusão estar a mais de dois anos no serviço e como critério de exclusão estar afastado do trabalho por qualquer motivo. O estudo obedece aos critérios do Comitê de Ética da Universidade do Estado de Santa Catarina (UDESC) sob parecer n. 3.375.951/2019.

\section{Resultados e Discussão}

Os profissionais, de uma das localidades, reconheceram, inicialmente, um déficit de conhecimento sobre o conceito de $\mathrm{P}_{4}$, porém em ambas as localidades, percebe-se que há possibilidades de desenvolver e/ou melhorar as práticas de $\mathrm{P}_{4}$ já desenvolvidas. Em meio as discussões promovidas, foi possível abordar a temática e, com isso, houve a compreensão de que os profissionais desenvolvem algumas ações nessa direção, mesmo não associando à temática. As metodologias participativas utilizadas para a coleta, produção e registro dos dados da pesquisa se configuraram em momentos de EPS, oportunizando a reflexão e a aprendizagem no cotidiano das instituições de saúde. Foi reconhecido pelos participantes a possibilidade de fomentar redes de apoio e discussão no cotidiano laboral, como também se destacou a importância da participação da gestão para o fortalecimento das ações de EPS. Mais de uma década se passou desde a implantação da Política Nacional de Educação Permanente em Saúde (PNEPS) e ainda momentos de EPS são pouco praticados ou valorizados no cotidiano das equipes, apesar de seu potencial na transformação da realidade dos serviços. Por vezes, as ofertas educativas são verticalizadas e essa prática é compreendida como sendo possível apenas em momentos programados e sistemáticos voltados a formalidades e conhecimento técnico especializado, discernindo-a do seu papel transformador voltado a situações do cotidiano e realizado pelos próprios profissionais do serviço, mediante suas experiências, dificuldades e anseios ${ }^{4}$. Através desta pesquisa, quando questionados sobre os momentos de reuniões, que podem ser oportunidades pedagógicas para a equipe, os participantes sinalizam dificuldades relacionadas ao apoio institucional. Sabe-se que todos os sujeitos devem estar envolvidos para que a educação ocorra de maneira multiprofissional, colaborativa e coletiva, no intuito de realmente produzir conhecimento formal e não formal, capazes de contribuir para a transformação da prática profissional partir da realidade vivida no trabalho e, por conseguinte, melhorar a oferta de cuidados na assistência aos usuários ${ }^{1}$. Os participantes apontam para a importância do trabalho em equipe e da participação da gestão para efetivação de momentos de EPS, além do conhecimento dos serviços prestados e das políticas públicas, considerados aspectos cruciais para o seu desenvolvimento, prejudicados pela falta de tempo e excesso de demanda. Entende-se que há a necessidade de valorizar as estratégias de EPS, tanto como ferramenta de ensino-aprendizagem, como de remodelação da assistência à saúde ${ }^{4}$, bem como, de haver mais estudos voltados a sistematizacão de momentos de EPS, fortalecendo essa política no cotidiano de prática das equipes de saúde. Vale lembrar que em ações dessa natureza também é relevante a integração ensino-serviço, com o envolvimento de instituições de ensino, além das instâncias gestoras, como uma forma de criar espaços dialógicos que favorecem o enriquecimento intelectual de maneira horizontal e flexívels. 


\section{Conclusão}

Momentos de EPS são capazes de contribuir significativamente na troca de saberes e transformação da prática. A importância desses momentos foi reconhecida pelos participantes da pesquisa, que também apontam desafios que ainda necessitam ser superados para sua efetivação nos serviços de saude. Entretanto, para que a EPS aconteça é necessário apoio de todos os atores envolvidos para sua organização, instrumentalização e operacionalização na prática. Além do apoio institucional e multiprofissional, o envolvimento de instituições de ensino também corrobora para o fortalecimento do processo de ensino-aprendizagem no trabalho, criando espaços dialógicos, que consequentemente, repercutem na qualidade dos serviços ofertados. Em relação a $\mathrm{P}_{4}$, os participantes reconhecem suas limitações em relação ao conceito, mas evidenciou-se que através de ações de EPS, há possibilidades para a aplicabilidade da $\mathrm{P}_{4}$ com melhorias nas práticas já realizadas. Estas são importantes para diminuir riscos decorrentes de intervenções excessivas aos usuários, que, por vezes, podem ocasionar iatrogenias.

Descritores: Educação Permanente; Estratégia Saúde da Família; Prevenção Quaternária.

\section{Referências}

1. Campos KFC, Marques R de C, Silva KL. Educação permanente: discursos dos profissionais de uma unidade básica de saúde. Escola Anna Nery [Internet]. 2018; 22(4).

2. Tesser CD. Por que é importante a prevenção quaternária na prevenção? Rev Saude Publica. 2017; 51:116.

3. Weber ML, Vendruscolo C, Adamy EK et al. Itinerário de Educação Permanente para Melhores Práticas em Enfermagem na Rede de Atenção. In.: Zanatta EA et al (org.). Produção do mestrado profissional em enfermagem na atenção primária à saúde: contributos para a gestão e o cuidado. Florianópolis: UDESC, 2020.

4. Silva, CBG, Scherer, MDA. A implementação da Política Nacional de Educação Permanente em Saúde na visão de atores que a constroem. Interface (Botucatu). 2020; 24: e190840.

5. Vendruscolo C, Prado ML, Kleba ME et al. Instâncias intersetoriais de gestão: movimentos para a reorientação da formação na Saúde. Interface (Botucatu) [online], 2018; 22(1):1353-64. Disponível em: https://www.scielo.br/pdf/icse/ v22s1/1807-5762-icse-1807-576220170180.pdf 


\section{EDUCAÇÃO PERMANENTE: UMA ABORDAGEM NECESSÁRIA PARA MINIMIZAR OS IMPACTOS DAS NAÚSEAS E VÔMITOS NO PÓS-OPERATÓRIO}

\author{
Mateus Dall Agnol \\ Robson Lovison \\ Bruna Fontana \\ Cristiane Baretta \\ Rosana Amora Ascari
}

\section{Introdução}

Náuseas e vômitos são sintomas frequentes, associados a diversas causas, dentre elas, estão causas relacionadas ao paciente, a anestesia, a analgesia e ao procedimento cirúrgico a ser realizado, e que se manifestam também em várias situações clínicas, por exemplo, durante alguns tratamentos oncológicos. Náusea é a manifestação clínica caracterizada pela sensação subjetiva e desagradável na região do epigástrio e orofaringe, tendo intensidade variavel e produzindo o enjoo, podendo ou não ocorrer o vômito. $\mathrm{O}$ vômito é a expulsão, a saída forçada do bolo alimentar do estômago ou da porção inicial do intestino, envolvendo componentes voluntário ou não e sendo controlado por complexo neuromuscular. O ato de vomitar é controlado pelo centro do vômito que fica localizado na medula e desencadeado por receptores acetilcolínicos muscarínicos, dopaminérgicos, histamínicos, opióides, serotoninérgicos e neurocínicos. Esses receptores podem ser ativados por diversos estímulos, sendo eles: desidratação, alguns odores, dor, apreensão e medo. ${ }^{1}$ Esses desconfortos são situações esperadas que podem ocorrer no pós-operatório e para que isso seja amenizado, é necessário que a equipe de enfermagem esteja habilitada e com conhecimentos específicos para lidar com estas questões, principalmente a equipe da sala de recuperação pós-anestésica, que precisa estar atenta aos sinais e sintomas que 
o paciente apresentar, por tratar-se da unidade com maior risco de desenvolvimento de complicações no pós-operatório imediato, local que geralmente o paciente permanece nas primeiras horas após a intervenção cirúrgica. E para que os profissionais estejam atualizados e qualificados para atender essas demandas, a Educação Permanente em Saúde (EPS) com ações de trabalho-aprendizagem, vem para auxiliar nesse processo.

\section{Objetivo}

Descrever o que a literatura aborda sobre náuseas e vômitos no pós-operatório e sua interface com a assistência cirúrgica de enfermagem.

\section{Método}

Este trabalho é fruto das atividades desenvolvidas pelo Programa de Extensão Educação Continuada em Saúde (PEECS), vinculado à Universidade do Estado de Santa Catarina (UDESC) para um aprofundamento científico sobre náuseas e vômitos no pós-operatório (NVPO), uma temática que balizou a construção de um capítulo de livro e uma vídeo aula para o fortalecimento da cultura de segurança no paciente no ambiente hospitalar. Trata-se de um estudo de revisão narrativa, com busca de informações dos últimos cinco anos, na base de dados da Biblioteca Virtual em Saúde (BVS), utilizando os descritores "Náuseas" AND "Assistência Perioperatória", sem limite de período, nos idiomas português, inglês e espanhol, documento do tipo artigos completos disponível on line de forma gratuita que resultou em 77 artigos. Os resultados encontrados são apresentados de forma descritiva.

\section{Resultados/Discussão}

A náusea e vômito no pós-operatório são alguns dos efeitos colaterais mais desagradáveis e são definidas como aquelas com ocorrência até 24 horas após a realização de um procedimento cirúrgico, sendo precoces quando acontecem nas primeiras duas horas e tardios quando ocorrem entre duas e 24 ho$\mathrm{ras}^{2}$. As náuseas e vômitos estão entre as queixas e ocorrências mais comuns e incômodas no pós-operatório, presente em 30\% dos pacientes não tratados com antieméticos profiláticos, independentemente do tipo anestési$\mathrm{co}$, em $50 \%$ entre pacientes em geral e entre $70 \%$ e $80 \%$ nos pacientes de alto risco. Alguns estudos investigaram a incidência de náuseas e vômitos individualmente, apontando que as náuseas ficam entre $38 \%$ e $52 \%$ e os vômitos entre $21 \%$ e $33 \%$ de pacientes em geral 3 . As consequências das NVPO são diversas e importantes envolvendo complicações como pneumonia aspirativa, deiscência de sutura, laceração esofágica, desequilíbrio hidroeletrolítico e sangramento. Também podem provocar efeitos colaterais como desidratação e aumento da pressão intracraniana ${ }^{4}$. Os quatro fatores de risco definidos como os que mais influenciam nas NVPO são sexo feminino, histórico prévio de doença do movimento ou NVPO, não tabagismo e uso de opióides no pós-operatório ${ }^{1}$. Por muito tempo as diretrizes de profilaxia eram gerais, porém, desde 2003 as diretrizes orientam para a profilaxia das NVPO, baseado no risco individual, seguindo as seguintes diretrizes: para pacientes de baixo risco, não usar profilaxia; para pacientes de risco moderado, usar uma a duas estratégias profiláticas; para pacientes de risco elevado, usar, no mínimo, três estratégias profiláticas. Um estudo utilizou medidas profiláticas farmacológicas, a saber, Droperidol, Ondansetrona e dexametasona; e não-farmacológicas, tais como, música, raiz de gengibre, adesivo de nicotina para não-fumantes, oxigênio suplementar no intra-operatório e uma pequena dose de Midazolan ( $2 \mathrm{mg}$ ) logo após a cirurgias. Em pacientes que foi desenvolvida a profilaxia terapêutica, não-farmacológica, percebeu-se maior satisfação em pacientes com risco elevado de NVPỎ, assim como pacientes de baixo e médio risco. Algumas ações têm sido efetivadas e incluídas nos protocolos de prevenção e tratamento das NVPO, entre elas a profilaxia antiemética como anticolinérgicos, antihistaminicos, fenotiazinas, sedativos/ansiolíticos, butirofenonas, antagonistas da dopamina, antagonista do receptor de serotonina e corticosteróides em pacientes com risco justificável e já definidos em inúmeros modelos preditores publicados e bem testados e aprovados. As medicações indicadas para a profilaxia podem ser usadas de forma isolada ou combinadas. Além disso, em pacientes com risco de NVPO, medidas profiláticas não-farmacológicas se mostram eficientes, reduzem os custos de medicamentos e tem resultados satisfatórios, sem a presença de reações adversas que os fármacos causam ${ }^{5}$. A equipe de enfermagem tem papel fundamental na prevenção e no tratamento das NVPO, pois acompanha o paciente em todo o processo cirúrgico. No pré-operatório deve realizar o levantamento de problemas através do prontuário, do histórico, evolução clínica e de enfermagem, anotações da enfermagem 
e resultado dos exames. O diagnóstico de enfermagem é procedimento fundamental e se configura como a detecção das necessidades de cuidado, sendo que este precisa ser confirmado pelo paciente, ou seja, é a construção da definição das necessidades, desejos e associação com o diagnóstico médico. O diagnóstico de enfermagem é uma das etapas do processo de enfermagem (PE), o qual segue uma taxonomia padronizada. As etapas de anamnese e o exame físico completo auxiliam o enfermeiro à estabelecer diagnóstico prioritário e definindo os graus de risco de NVPO. A assistência de enfermagem durante o período pós-operatório imediato é muito importante e concentra-se em intervenções destinadas a prevenir ou tratar complicações. E pensando no contínuo processo de ensino/aprendizagem a EPS traz consigo a possibilidade de manter a equipe de enfermagem atualizada dentro das necessidades que são levantadas no ambiente de trabalho. Nesse interim, faz-se necessário o olhar atento da enfermagem na sala de recuperação pós-anestésica, assim como a implementação de ações de EPS para a sensibilização dos profissionais quanto às complicações pós-operatórias de modo geral, as quais tem-se a sensação de que náuseas e vômitos no pós-operatório, assim como outras complicações imediatas estão sendo naturalizadas entre os trabalhadores de enfermagem.

\section{Considerações finais}

A compreensão dos processos que influenciam na complicação de náuseas e vômitos no pós-operatório é complexa e exige a identificação dos fatores de risco individualmente, sendo, portanto, um processo que inicia no pré-operatório e pode ser melhor levantado pelo diagnóstico de enfermagem e pela atuação integrada da equipe de enfermagem e de medicina envolvidos no processo. O estudo de náuseas e vômitos no pós-operatório é de fundamental importância para a enfermagem e contribui, juntamente com o projeto de extensão, para o aprimoramento profissional, ao focar em uma das áreas mais complexas da enfermagem e balizar a assistência de enfermagem nas melhores práticas. É necessário que haja maior atenção da equipe de enfermagem para pacientes que possuem risco de náuseas e vômitos no pós-operatório, pois além de ser um sintoma importante na recuperação do paciente, também são determinantes para a prestação de cuidados pelos profissionais de enfermagem, evitando outros sintomas e agravos à saúde do paciente cirúrgico.
Descritores: Náuseas; Vômitos; Enfermagem Perioperatória; Segurança do Paciente; Educação Permanente.

\section{Referências}

1. Lages N; Fonseca C; Neves A; Landeiro N; Abelha FJ. Náuseas e vômitos no pós-operatório: uma revisão do "pequeno-grande" problema. Rev. Bras. Anestesiol. On line. 2005; 55(5): $575-585$.

2. Apfel CC. A simplified risk score for predicting postoperative nausea and vomiting: conclusions from cross-validations between two centers. Anesthesiology on line. 1999; 91(3):693-700.

3. Apfel CC; Roewer N; Korttila, K. How to study postoperative nausea and vomiting. Acta Anaesthesiol Scand on line. 2002; 46(8):921-8, 2002.

4. Dalila V; Pereira H; Moreno C; Martinho C; Santos C; Abelha FJ. Náusea y vómito en el postoperatorio: validación de la versión en portugués de la escala de intensidad de náuseas y vómitos postoperatorios. Rev. Bras. Anestesiol. On line. 2013; 63(4):340-346.

5. Gan TJ; Diemunsch P; Habib AS; Kovac A; Kranke P; Meyer TA et al. Consensus guidelines for the management of postoperative nausea and vomiting. Anesthesia \& Analgesia 2014; 118(1):85-113. 
RELATO DE EXPERIÊNCIA

\section{AUTOCUIDADO E AUTOESTIMA \\ DO IDOSO: UMA ATIVIDADE DE EDUCAÇÃO EM SAÚDE}

\section{Camila Soligo Bernardi Carla Argenta}

\section{Introdução}

A educação em saúde é fundamental para a Atenção Primária à Saúde (APS) e é reconhecida por meio de processos educativos de construção de conhecimentos que tem o objetivo de apropriar determinada população sobre alguma temática. Atualmente vivemos em meio a uma pandemia, na qual existem grupos de risco para a COVID-19, dentre eles, os idosos que precisaram cessar suas atividades e manter o isolamento social a fim de diminuir o risco de contágio pela doença ${ }^{2}$. Sendo assim, se percebe a necessidade da realização de atividades de Educação em Saúde para este público, tendo em vista a orientação para o autocuidado relacionado as questões de vida diária e também à prevenção e tratamento da COVID-19. Por meio de práticas de autocuidado, bem orientadas, se promove a saúde, o envelhecimento saudável e a qualidade de vida, assim como, o autocuidado que se caracteriza numa ferramenta importante para se evitar complicações decorrentes de doenças crônicas ${ }^{3}$. Proporcionar diálogos e estimular práticas de autocuidado e autoestima torna-se fundamental, no sentido de que o idoso venha a se manter com laços fortalecidos com si mesmo, com a família e com a comunidade, de modo a demonstrar a importância deles no contexto em que estão inseridos ${ }^{4}$. Com base no exposto, este resumo tem como objetivo relatar a experiência de uma atividade de educação em saúde realizada com idosos acerca dos s temas autocuidado e autoestima. 


\section{Método}

Trata-se de um estudo descritivo na modalidade relato de experiência a partir de uma atividade de educação em saúde, realizada de forma online, com 18 idosos, no município de Pinhalzinho/SC. A atividade aconteceu no dia 26 de junho de 2020, com duração de uma hora e trinta minutos, por meio de roda de conversa online, pelo aplicativo Google Meet. Os temas abordados foram autocuidado e autoestima em tempos de pandemia pela COVID-19. Os idosos foram convidados a participar da roda de conversa online através de grupos de WhatsApp, nos quais foi enviado o link com data e horario da atividade, sendo a participação voluntária.

\section{Resultados e Discussão}

Inicialmente foi realizada a recepção aos idosos que entraram na sala do Google Meet, dando as boas-vindas e agradecendo a presença. Após a recepção, a enfermeira realizou a apresentação pessoal e explicou como aconteceria a atividade de educação em saúde no formato online. Posteriormente foi realizada a problematização com a explanação do que é autocuidado e autoestima. Foram repassadas questões para que os participantes refletissem sobre os temas abordados e a relação entre eles. O autocuidado tem sido amplamente estudado devido a sua relação com o desenvolvimento de ações que promovem a saúde, além disso, estar relacionado com o envelhecimento saudável e como ferramenta na prevenção de complicações relacionadas com doenças crônicas. ${ }^{3} \mathrm{~A}$ autoestima é importante durante toda a vida, ela está relacionada com a satisfação da pessoa consigo mesma, tendo em vista a beleza, bem estar e saúde. Na velhice, devido à limitações e mudanças físicas, a autoestima pode estar em decadência ${ }^{4}$, por isso a importância de estimular ações que possam estimular a mesma. Na parte de Teorização foram conceituados o autocuidado e a autoestima, bem como explicado sobre o envelhecimento, entendendo-o como um processo natural, progressivo e irreversível, que ocorre a todos os seres, podendo sofrer influências psicológicas, políticas, sociais e econômicass. Durante este processo, o indivíduo pode ser acometido por alterações funcionais e estruturais, podendo ocasionar prejuízos ou dificuldades para a vida diária dos indivíduos 5 . Para o envelhecimento saudável é importante que o idoso busque cuidar de si, e para isso é preciso que autoconhecimento para adoção de medidas positivas, especialmente quando é preciso reagir com as adversidades, vivendo assim, com qualidade 3 . Para que o público participante, os 18 idosos entendessem sobre o assunto ocorreu a exemplificação das atividades que são realizadas para o autocuidado e como elas interferem na autoestima do idoso. Algumas atividades devem ser estimuladas pela enfermagem, sendo elas: lazer, gerenciamento emocional, o exercício da espiritualidade, ampliar o desenvolvimento para o uso de tecnologias, estimular participar de atividades online ${ }^{2}$. A enfermeira buscou envolver os idosos, que expuseram seus pontos de vista e suas rotinas para manter o autocuidado e autoestima, especialmente em meio a pandemia. Também foi discutido com o grupo sobre o autocuidado relacionado com a COVID-19 e a importância dele para diminuir os riscos de contágio pela doença e para evitar complicações. Os idosos fazem parte do grupo de risco da COVID-19 por, em grande parte dos casos, apresentar diminuição da força, resistência e função fisiológica, e com isso, se tornando mais vulneraveis ${ }^{2}$. Algumas orientações de enfermagem relacionadas ao autocuidado de idosos na prevenção da COVID-19 são fundamentais: lavagem das mãos, isolamento social, uso de álcool gel 70\%, o ambiente domiciliar bem ventilado, alimentação saudável e boa ingesta hidrica ${ }^{2}$. Estas orientações foram fornecidas aos idosos, além de tantas outras como uso correto de medicamentos, cuidados com quedas, alimentação saudável e prática de atividade física. Fảlou-se sobre as redes de apoio e a importância de manter a saúde física e mental. Os idosos citaram exemplos práticos do que estavam fazendo para cuidar de sua saúde. Para encerrar a atividade, a enfermeira agradeceu a presença de todos e transmitiu um vídeo motivacional. A avaliação da atividade ocorreu através dos feedbacks realizados pelos participantes $d a$ roda de conversa online. Estudos mostram que é importante estimular a autonomia e o autocuidado dos idosos com ações de educação em saúde, reconhecendo a importância dessas ações para o público idoso.

\section{Conclusão}

A educação em saúde é fundamental para o trabalho na APS. Ela pode ser realizada com atividades como a relatada, nas quais se pode, através de roda de conversa virtual ou presencial explanar sobre um assunto de interesse do público alvo, neste caso, os idosos. O público participante foi de idosos que realiza- 
vam muitas atividades antes da pandemia pela COVID-19 e de uma hora para outra se viram obrigados a ficar em suas casas, a fim de prevenir a contaminação pela doença. A atividade foi positiva, pois gerou ampla discussão e interação entre a enfermeira e os participantes, com momento para expor as dúvidas e angústias vivenciadas e como elas interferiram no autocuidado e autoestima. Ao final da atividade os idosos relaram que a mesma foi importante para reflexão sobre o tema abordado. Com isso pode-se perceber que mesmo de forma online consegue-se realizar atividades de educação em saúde que impactam na vida dos envolvidos.

Descritores: Educação em Saúde; Idoso; Autocuidado; Autoestima.

\section{Referências}

1. Seabra, CAM; Xavier, SPL; Sampaio, YPCC; Oliveira, MF; Quirino, GS; Machado, MFAS. Educação em saúde como estratégia para promoção da saúde dos idosos: Uma revisão integrativa. Rev. bras. geriatr. gerontol. 2019; vol.22 no.4 Rio de Janeiro. Disponivel em: https://doi.org/10.1590/1981-22562019022.190022

2. Marins, AMF; Domingos AM; Duarte, SCM; Gaspar; RB; Abreu, SF; Carvalho, LP. A saúde da pessoa idosa no contexto da pandemia do coronavírus: considerações para a enfermagem. Revista do Centro Oeste Mineiro, 2020; 10:e3789. Disponível em: http://seer.ufsj.edu. br/index.php/recom/article/view/3789/2439

3. Almeida, L; Bastos PEHO. Autocuidado do Idoso: revisão sistemática de literatura. Re. Espacios. 2017; vol $38 \mathrm{n}^{\mathrm{o}}$ 28. Disponível em: https://www.revistaespacios.com/a17v38n28/ a17v38n28po3.pdf

4. Roque, LP. "O Poder do batom vermelho e de uma barba bem-feita" Autoestima na terceira idade, um estudo bibliográfico sobre a relação entre convivência e autoestima em idosos que frequentem centros de convivência. Anais do $16^{\circ}$ Congresso Brasileiro de Assistentes Sociais. 2019. Disponivel em: https://broseguini.bonino.com. br/ojs/index.php/CBAS/article/view/400/392 
RELATO DE EXPERIÊNCIA

\section{PREVENÇÃO AO COVID-19: UMA ESTRATÉGIA DE EDUCAÇÃO EM SAÚDE PARA AGENTES COMUNITÁRIOS DE SAÚDE}

\author{
Raquel Cristina Sulzbach \\ Lucimare Ferraz \\ Sueli Regina Sulzbach
}

\section{Introdução}

A Educação Permanente em Saúde (EPS) é fundamental e primordial nos serviços de Atenção Primária à Saúde (APS) já que visa melhorar os processos de formação e reorganizar os serviços prestados à população. A EPS tem como ponto de partida problemáticas da realidade e com foco nas exigências e demandas, são pensadas em estratégias e métodos de relacionar o ensino e aprendizagem para promover a construção do conhecimento numa vinculação horizontal, interdisciplinar e inter-setorial ${ }^{1}$. Na APS, a Estratégia de Saúde da Família (ESF) está voltada para a promoção da saúde na comunidade, que visa garantir a todos o direito de acesso, integral e equânime, aos serviços de saúde, de acordo com os princípios do Sistema Único de Saúde (SUS). O profissional enfermeiro tem papel de grande destaque em uma equipe multiprofissional da Atenção Primária à Saúde (APS), já que possui a responsabilidade de realizar educação em saúde para o usuário, família e coletividade, além de orientar a equipe de trabalho. Os Agentes Comunitários de Saúde (ACS) são um grande alvo de educação em saúde, já que o trabalho deles é fundamental para o seguimento das ações de educação em saúde para a população. Com foco na atual problemática da pandemia de Covid-19, foi articulado um encontro virtual para orientações pertinentes ao período. 


\section{Objetivo}

Relatar a experiência de uma atividade de educação em saúde realizada de forma online para Agentes Comunitários de Saúde da Atenção Primária à Saúde abordando medidas protetivas não farmacológicas no período de pandemia causada pelo Covid-19, momento em que foi ensinado e enfatizado principalmente a importância da utilização correta da máscara o isolamento social quando possível e higienização das mãos.

\section{Método}

Estudo descritivo, tipo relato de experiência relacionado a uma atividade de educação em saúde realizada de forma online pelo profissional enfermeiro, com ACS que atuam na APS do município de Pinhalzinho/ SC. A ação aconteceu no dia o1 de julho de 2020 com duração de uma hora e trinta minutos, por meio de uma roda de conversa virtual. O convite foi realizado por meio do aplicativo WhatsApp, em que foi encaminhado um link com data e hora da atividade, sendo que a participação foi voluntaria conforme a disponibilidade dos ACS.

\section{Resultados e Discussão}

Inicialmente foi realizada a recepção dos ACS que entraram na sala da plataforma Zoom, dando as boas-vindas e agradecendo a presença. Após a recepção, foi realizada a apresentação pessoal e brevemente explicado como aconteceria à atividade. Posteriormente apresentada a problematização de que estamos vivendo em meio a uma pandemia causada pelo Covid-19, explanado sobre a importância da utilização da máscara, higienização das mãos, isolamento social e as demais medidas que evitam o aumento do número de casos de Covid-19. A forma de abordar o conteúdo foi através de uma apresentação em PowerPoint e um vídeo relacionado a temática, no decorrer da atividade desenvolvida teve uma satisfatória contribuição dos participantes. A teorização foi fundamentada a partir das informações disponibilizadas por sites da Organização Mundial da Saúde (OMS) e Ministério da Saúde (MS). A atividade realizada foi de grande importância em vista de que a utilização da máscara é uma das medidas que tem apresentado resultados positivos quando se fala em evitar a disseminação do virus do Covid-19. Nesse encontro virtual também foram abordadas ainda outras medidas não far- macológicas que visam a prevenção da infecção, dentre elas, enfatizado a importância da lavagem das mãos, do distanciamento social, da etiqueta respiratória e da prática de limpeza dos objetos e superfícies². Essas ações, quando adotadas no início de um período crítico como esse, ajudam a prevenir a transmissão, diminuem a velocidade de contaminação e, consequentemente, contribuem para achatar a curva epidêmica 3 . Assim, é possível diminuir a demanda instantânea por cuidados de saúde e atenuar as consequências da doença, incluindo a redução da mortalidade e a morbidade associada $^{4}$. Tais medidas são recomendadas pela OMS e o enfermeiro possui papel fundamental em abordar essas recomendações, e é através dos encontros em que são realizados educação em saúde, sejam eles presenciais ou online, uma ótima alternativa para capacitar a equipe de saúde e a população sobre as demandas, como no caso, para o enfrentamento da Covid-19. A educação em saúde visa a transformação dos processos de saúde e interfere na orientação da maneira de pensar e de fazer os processos educativos nos serviços de saúde, ela é tomada como um dispositivo para a problematização em relação ao processo de trabalho, partindo de uma situação já existente e a partir disso, transforma-la, muda-la e supera-las.

\section{Conclusão}

A realização de atividades de EPS são fundamentais para o trabalho na APS e é primordial para melhoria das práticas de saude, sejam elas assistencial ou de gestão, possibilitam a mudança do processo de trabalho em saúde e o enfermeiro é o principal mediador para a realização dessas ações, fortalecendo assim suas práticas no dia a dia e contribuindo para o avanço do conhecimento. Essa atividade de educação em saúde pode ser realizada como esta que foi relatada, nas quais se pode, através da roda de conversa, virtual ou presencial, explanar sobre um assunto de interesse. O público participante foi de ACS que num curto espaço de tempo tiveram que ser obrigadas a utilizarem a máscara, quando não for possível evitar o contato social e quando estiverem realizando as visitas domiciliares as famílias e também foram instruídas a realizar a higienização das mãos e materiais com uma maior frequência, adaptando a forma de trabalho para o momento. A ação de educação em saúde desenvolvida teve resultados positivos, gerou uma ampla discussão e interação entre os participantes, e também foi observado uma melhoria na qualidade da assistência prestada 
aos usuários/famílias em relação às acões de orientação em saúde, ao uso correto da máscara e as demais medidas protetivas não farmacológicas de prevenção ao Covid-19. Diante disso, conclui-se que o encontro realizado de forma online atendeu a expectativa e demanda estabelecida, demonstrando que é possível realizar atividades de educação em saúde que impactam na vida dos envolvidos, seja na equipe de saúde da APS como na vida dos usuários.

Descritores: Educação em Saúde; Agentes Comunitários de Saưde; Atenção Primária à Saúde.

\section{Referências}

1. Ferreira L, Barbosa JSA, Esposti CDD, Cruz MM. Educação Permanente em Saúde na atenção primária: uma revisão integrativa da literatura Saúde debate. Rio de Janeiro, Jan./Mar. 2019; 43(120). Disponível em: https://www.scielo.br/ $\mathrm{pdf} / \mathrm{sdeb} / \mathrm{v} 43 n 120 / 0103-1104-\mathrm{sdeb}-43-12 \mathrm{O}-0223 . \mathrm{pdf}$

2. Garcia LP, Duarte E. Intervenções não farmacológicas para o enfrentamento à epidemia da Covid-19 no Brasil. Epidemiol Serv Saúde,Brasília, 2020; 29(2):ezO2O222. Disponível em: $\quad$ https://www.scielo.br/pdf/ress/v29n2/ 2237-9622-ress-29-02-e2020222.pdf

3. Qualls N, Levitt A, Kanade N, Wrigh$\mathrm{t}$-Jegede N, Dopson S, Biggerstaff M, et al. Community Mitigation Guidelines to Prevent Pandemic Influenza - United States, 2017. MMWR Recomm Rep. 2017; 66(1);1-34. Disponível em: https://www.cdc.gov/mmwr/ volumes/66/rr/rr6601a1.htm

4. Anderson RM, Heesterbeek H, Klinkenberg D, Hollingsworth TD. How will country-based mitigation measures influence the course of the COVID-19 epidemic? Lancet. 2020; 395(10228):931-4. Disponível em: https://www.thelancet.com/action/show Pdf?pii $=$ So140-6736\%2820\%2930567-5

5. Silva KL, Matos JAV, França BD. A construção da Educação permanente no processo de trabalho em saúde no estado de Minas Gerais, Brasil. Esc Anna Nery 2017; 21(4):e2017006o. Disponível em: https://www.scielo.br/pdf/ean/v21n4/ pt_1414-8145-ean-2177-9465-EAN-2017-0060.pdf 
RELATO DE EXPERIÊNCIA

EDUCAÇÃO PERMANENTE:

TRANSFORMANDO O COTIDIANO

DA SEGURANÇA DO PACIENTE

\section{Andressa Reginatto Percisi \\ Angélica Zanettini \\ Jonatan Pellenz \\ Aline Massaroli}

\section{Introdução}

A segurança do paciente está se tornando um tema cada vez mais presente e debatido entre gestores e profissionais de instituições de diversos setores da área da saúde, visando institucionalizar melhores práticas nos ambientes prestadores de cuidado. Neste sentido, os investimentos em aperfeicoamento e aprimoramento para tal vem send̆o fomentado, tendo em vista a importância do assunto mundialmente ${ }^{1}$. No Brasil, a Enfermagem assume um papel de destaque nas discussões sobre a segurança do paciente, principalmente devido a permanência em tempo integral na assistência direta aos usuários e, por esse motivo, estar diretamente ligada à segurança dos cuidados. Para que os desfechos negativos não sejam recorrentes, se faz necessária a utilização de estratégias de ensino que contribuam com o aprendizado dos profissionais de saúde a partir das situações vivenciadas ${ }^{2}$. Para assegurar a atuação responsável e comprometida com a segurança do paciente, acredita-se que o tema deve estar presente na vida dos profissionais de saúde de modo contínuo e transversal durante todo o processo de formação acadêmica e profissional, pois contribui para que este desenvolva competências, possibilitando a identificação e manejo perante a ocorrência de erros, reconhecimento e aprendizado com suas falhas. Deste modo, uma alternativa que os serviços de saúde têm optado como forma de minimizar as falhas que ocorrem durante o 
processo assistencial, é a Educação Permanente em Saúde (EPS), que se caracteriza como uma proposta de aprendizagem no trabalho, onde o aprender e o ensinar se integram na rotina das instituições. Ainda, se fundamenta na possibilidade de transformar as práticas profissionais, englobando a discussão de temas que instigam a reflexão sobre o processo de trabalho, as transformações das práticas em serviço e o trabalho em equipe ${ }^{3}$. Neste contexto, é fundamental que as atividades de aprimoramento e aperfeiçoamento profissional sejam desenvolvidas com a integração entre as instituições de ensino superior com os serviços de saúde, pois faz com que os estudantes estabeleçam conhecimentos a partir das necessidades de saúde dos usuários e dos trabalhadores, contribuindo assim, para o desenvolvimento de competências necessárias em conformidade com as demandas reais das comunidades.

\section{Objetivo}

Descrever a experiência do uso da educação permanente em saúde como forma de transformar o cotidiano da segurança do paciente.

\section{Método}

Trata-se do relato sobre o desenvolvimento de um programa de extensão intitulado "Segurança do paciente: construindo caminhos para a cultura de segurança", desenvolvido entre uma universidade pública e um hospital do extremo Oeste Catarinense, no período de maio de 2018 a julho de 2019. As ações do programa de extensão foram desenvolvidas em conjunto com o Núcleo de Segurança do Paciente e foram baseadas nos princípios da EPS, por meio de recursos educativos direcionados aos profissionais de saúde da instituição, com enfoque no debate sobre segurança do paciente. A equipe de trabalho do projeto de extensão era constituída por discentes e docentes do Curso de Graduação em Enfermagem. Para o planejamento e organização das atividades educativas, os membros da equipe do projeto realizavam encontros semanais para aprofundar os conhecimentos sobre o tema. Nas ações realizadas participaram os profissionais das diversas categorias atuantes na instituição, como: enfermagem, nutrição, fisioterapia, limpeza, almoxarifado, suporte técnico, setor administrativo, copa, lavanderia, dentre outros. Para efetivação, as intervenções foram organizadas em ciclos de ações, cada um fundamentado nas metas de segurança do paciente, de acordo com as orientações d̀a Organização Mundial da Saúde (OMS). Cada ciclo foi composto por sete etapas, com duração de aproximadamente quatro meses cada uma. A saber: $1^{\underline{a}}$ etapa: reunião da equipe de trabalho do projeto com o Núcleo de Segurança do Paciente do hospital; $2^{2}$ etapa: definição do tema da ação que seria desenvolvida; $3^{\underline{a}}$ etapa: encontros semanais $d a$ equipe de trabalho para aprofundamento teórico, organização da atividade e produção dos materiais didáticos e informativos a serem utilizados; $4^{\underline{a}}$ etapa: validação e agendamento das atividades; $5^{\underline{a}}$ etapa: reprodução das atividades educativas dentro da equipe de trabalho do projeto como forma de teste e aperfeiçoamento; 6 etapa: realização das atividades com os profissionais de saúde do hospital em todos os turnos de trabalho; $7^{\underline{a}}$ etapa: avaliação da atividade desenvolvida por todos os envolvidos. Os temas elencados para os três ciclos desenvolvidos durante o vigor do programa de extensão foram: 1- sensibilização sobre a importância do movimento para segurança do paciente e identificação do paciente; 2 - comunicação segura e, 3 - higienização das mãos.

\section{Resultados e Discussão}

As ações foram realizadas nas dependências do hospital e in loco nas unidades de assistência, abrangendo os turnos matutino, vespertino e noturno, com duração de aproximadamente 15 minutos para cada intervenção, envolvendo a participação de 1000 pessoas entre profissionais de saúde, discentes, docentes e comunidade em geral. Para o primeiro ciclo, foram utilizados recursos educativos com duas dinâmicas: vídeos comparativos e pulseiras de identificação. $\mathrm{O}$ vídeo demonstrava duas cenas, uma com situação irregular, e outra, com a mesma situação seguindo as preconizações para a segurança do paciente conforme o Ministério da Saude (MS). As pulseiras tinham como objetivo mostrar quais dados são preconizados para realizar a identificação do paciente e demonstrar a importância de avaliar a qualidade do material utilizado para a confecção. No segundo ciclo, buscou-se apresentar estratégias de comunicação que podem ser utilizadas para com os pacientes, familiares e profissionais como forma de melhorar o entendimento/compreensão das informações. Para ilustrar as falhas na comunicação foi aplicada a dinâmica "telefone sem fio" e obteve-se como resultados a interpretação errônea ou a perda das informações referente às frases que foram utilizadas na dinâmica. No último ciclo, além de destacar a importância para o controle de infecções, utilizou-se como recurso educativo 
a "caixa preta" com produto fluorescente que possibilita a visualização das regiões das mãos que foram corretamente higienizadas. Os participantes realizavam os passos preconizados para a higienização de mãos com o produto e após, todos eram convidados a observar as mãos na caixa preta, observando-se que havia locais que não foram higienizados corretamente, o que requer atenção dos profissionais para tal prática. A EPS é uma estratégia que permite a aproximação entre a realidade de um local e novas práticas em saúde, contribuindo para o aprimoramento e desenvolvimento profissional ${ }^{4}$. A forma como o projeto buscou compreender a realidade do serviço, utilizando situações semelhantes às vivenciadas no dia a dia de trabalho, permitiu uma visão dos possiveis erros do cotidiano, gerando mudanças no comportamento individual e coletivo. Compreende-se a integração ensino-serviço como a construção de um trabalho coletivo, pactuado e integrado entre docentes, discentes, profissionais e gestores que constituem as equipes dos serviços de saúde, visando alcançar uma melhora na qualidade de atenção à saúde individual e coletiva, à qualidade da formação dos futuros profissionais e ao desenvolvimento e satisfação dos trabalhadores dos serviços 5 . Admitir falhas durante o processo de cuidado e realizar a notificação das mesmas, são passos importantes para melhorar a qualidade da assistência prestada. Promover a EPS de maneira transversal e multiprofissional é promover a cultura de segurança do paciente, uma vez que sensibiliza os profissionais para que estejam mais conscientes de suas responsabilidades ${ }^{2}$.

\section{Conclusão}

Através do desenvolvimento desse projeto pode-se afirmar que os profissionais de saúde se sensibilizaram durante os encontros, uma vez que o Núcleo de Segurança do Paciente do hospital afirmou que o projeto promoveu mudança positiva nas atividades diárias. Além disso, constata-se que houve a integração entre ensino e serviço. Percebe-se que, relações como estas facilitam o processo de formação de discentes da área da saúde, contribuem para o aperfeiçoamento e desempenho dos profissionais dentro dos ambientes prestadores de cuidado e proporcionam reflexões relacionadas à sua atuação no âmbito da segurança do paciente.

Descritores: Enfermagem; Segurança do Paciente; Educação Permanente em Saúde.

\section{Referências}

1. Garzin ACA, Melleiro MM. Segurança do paciente na formação dos profissionais de saúde. Cienc. Cuid. Saúde. 2019; 18(4):1-8. DOI: 10.4025/cienccuidsaude.v18i4.45780.

2. Wegner W, Silva SC, Kantorski KJC, Predebon CM, Sanches MO, Pedro ENR. Educação para cultura da segurança do paciente: implicações para a formação profissional. Esc. Anna Nery Rev. Enferm. 2016; 20(3):1-8. DOI: 10.5935/1414-8145.20160068.

3. Almeida PP. Metodologias ativas para a cultura de segurança. Vigil. Sanit. Debate. 2019; 7(4):96-103. DOI: 10.22239/2317-269x.01349.

4. Sade PMC, Peres AM, Zago DPL, Matsuda LM, Wolff LDG, Bernardino E. Avaliação dos efeitos da educação permanente para enfermagem em uma organização hospitalar. Acta Paul. Enferm. 2020; 33:1-8. DOI: 10.37689/acta-ape/2020a00023.

5. Khalaf DK, Reibnitz KS, Vendruscolo C, Lima MM, Oliveira VBCA, Correa AB. Integração ensino-serviço sob a percepção dos seus protagonistas. Rev. Enferm. UFSM. 2019; 9(9):1-20. DOI: $10.5902 / 21797692231464$. 
Estudo de REVISÃo

\section{POLÍTICA NACIONAL DE EDUCAÇÃO PERMANENTE EM SAÚDE E SUAS ESTRUTURAS ELEMENTARES}

\author{
Cristiane Baretta \\ Maristela Izcak Baldissera \\ Rafaela Bedin \\ Taiza Dal Pian \\ Carine Vendruscolo \\ Letícia de Lima Trindade
}

\section{Introdução}

A Educação Permanente em Saúde (EPS) é definida como o aprender e o ensinar incorporados no cotidiano do trabalho, com base nos nós críticos do dia a dia, a partir das necessidades específicas dos trabalhadores e apoiada no princípio pedagógico crítico, problematizador e reflexivo'. A Política Nacional de Educação Permanente em Saúde (EPS) foi inserida no Brasil a partir da cooperação interministerial entre o Ministério da Saúde com o Ministério da Educação (MEC), por meio das Portarias 198/o4 e 1996/o7, para contribuir com o desenvolvimento dos profissionais do Sistema Único de Saúde (SUS). Tem como principal objetivo nortear a formação e a qualificação dos profissionais inseridos nos serviços públicos de saúde ${ }^{2}$.

\section{Objetivo}

Identificar as estruturas elementares das Políticas Públicas: formal, substantiva, simbólica e material, presentes na Política Nacional de Educação Permanente em Saúde e refletir sobre o tema.

\section{Método}

Trata-se de uma reflexão crítica, apoiada em uma revisão da literatura sobre o tema. A busca de material foi realizada no Google acadêmico e na Biblioteca Virtual em Saú- 
de (BVS), sendo definido como critério de inclusão: artigos publicados de 2015 à 2020 e documentos interministeriais criados após a instituição da Política Nacional de Educação Permanente em Saúde (PNEPS). Para identificar os materiais relevantes para o desenvolvimento do estudo, utilizou-se o termo Política Nacional de Educação Permanente em Saúde para a busca. Os artigos foram selecionados de forma aleatória, de acordo com o interesse das pesquisadoras e o objetivo do presente estudo. A análise do material foi realizada com base nas configurações das estruturas elementares das Políticas Públicas, publicada por Di Giovanni ${ }^{3}$, que reforça que estas devem ser fundamentadas da seguinte maneira: a Estrutura Formal (composta por três elementos, teoria, práticas e resultados), a Estrutura Substantiva (composta pelos atores, interesses e regras), a Estrutura Material (composta pelos elementos: financiamento, suportes e custos) e a Estrutura Simbólica (composta pelos elementos: valores, saberes e linguagens).

\section{Resultados e Discussão}

Quanto a estrutura Formal da Política, é possivel analisar que com a Reforma Sanitária, identificou-se a necessidade de uma criação de uma Política para a Educação na Saúde. Em 2003, ocorreu uma reestruturação na organização do Ministério da Saúde (MS), sendo criada a Secretaria de Gestão do Trabalho e da Educação (SGTES), que articula a gestão do trabalho e a educação em saúde, tendo como objetivo implementar uma política de valorização do trabalho no SUS e dos trabalhadores de saúde em conformidade com os seus princípios e diretrizes ${ }^{4}$. A partir desta reestruturação o MS assumiu seu papel de gestor federal do SUS no que diz respeito à ordenação da formação de pessoal para o setor e à educação permanente do pessoal que nele trabalha'. A SGTES possibilitou a institucionalização de Políticas de educação em saúde e o estabelecimento de iniciativas relacionadas a reorientação da formação profissional, com ênfase na abordagem integral do processo saúde-doença, na valorização da Atenção Básica e na integração entre as Instituições de Ensino Superior (IES), serviços de saúde e comunidade, tendo como finalidade o fortalecimento do SUS ${ }^{1}$. Dessa forma, em fevereiro de 2004, institui-se pela Portaria GM/ MS no 198 a Política Nacional de Educacão Permanente em Saúde (PNEPS), considerada o marco para a formação e o trabalho em saúde no Brasil'. Posteriormente, identificando a necessidade de criar novas diretrizes, foi publica- da a Portaria GM/MS no $1.996 / 2007^{4}$. Com essa nova estrutura, os Colegiados de Gestão Regional (CGR), por meio da Comissões Permanente em Saúde (CIES), participam da formulação, execução, acompanhamento e avaliação das ações da EPS. Em 2017, após análise da ỉmplementação dessa Política nos estados e munícipios, aconteceu em Brasília uma reunião técnica visando a atualização da PNEPS. Foram realizadas oficinas regionais com o intuito de planejar e avaliar as ações de EPS desenvolvidas e assim traçar caminhos para o fortalecimento e institucionalização da PNEPS ${ }^{1}$. Entre as ações, a última PNEPS publicada em 2018, evidenciam-se algumas atividades para apoiar e fortalecer a Politica: Laboratório de Inovação em Educação na Saúde com foco na EPS, Educação Interprofissional em Saúde (EIP), Programa para o Fortalecimento das Práticas de Educação Permanente em Saúde no SUS (PRO EPS-SỦS) e Contratos Organizativos de Ação Pública Ensino-Saúde (COAPES) ${ }^{1}$. Ao avaliar a estrutura substantiva desta política, é possível observar claramente os atores que participam do processo, configurando um "quadrilátero de formação" - gestão, ensino, serviço e controle social. Para além de um quadrilátero, também é possível ilustrar essa formação por meio de um prisma, pois, considerando os quatro seguimentos envolvidos, pode-se refletir que ora faltam elementos para encaixar os vértices, ora percebe-se a intervenção de outros elementos em um mesmo seguimento. Assim, são muitos os pontos de vista envolvidos na formulação de ideias que compõem uma proposta de EPS, como sugere a Políticas. Para que as ações educativas sejam possíveis, a Portaria $\mathrm{n}^{-}$1996/2007 institui que o repasse dos recursos financeiros devem ser regular, na modalidade fundo a fundo, e que a gestão e a condução desses recursos ficam a cargo das CIES, com supervisão dos CGR ${ }^{1}$. Em relação à estrutura simbólica, a PNEPS tem seus valores pautados nos pressupostos da EPS, trazendo como marco conceitual a concepção de trabalho no SUS e na aprendizagem cotidiana de forma a transformar as práticas do trabalho em saúde ${ }^{1}$. A PNEPS propõe a aprendizagem significativa a partir da reflexão sobre as práticas, possibilitando olhares e saberes diversos, com vistas à reorientação entre sujeitos do ensino e do serviço5. No que tange os saberes para a implementação desta Política nos estados e municípios a DEGES realizou análises diagnósticas e avaliação de estudos realizados entre 2013 e 2015 que apontaram evidências importantes sobre os avanços e as dificuldades enfrentadas no processo'. Entre estas dificuldades cita-se a 
necessidade de se retomar a reflexão e o debate sobre a implementação da PNEPS e sobre o conceito de EPS visto que não há apropriação plena da concepção que fundamenta a política; pouca articulação entre gestores trabalhadores, controle social e IES; reduzida implantação das CIES regionais, participação incipiente dos gestores municipais; indefinição de parâmetros para construção dos projetos; ausência de avaliação acerca dos projetos desenvolvidos, no que se referem às mudanças nas práticas de formação, gestão e atenção na saúde; dificuldades na utilização dos recursos financeiros e ausência de indicadores que superem a mera quantificação dos cursos e outras atividades realizadas'.

\section{Conclusão}

O estudo demonstra que as estruturas elementares da PNEPS são importantes para a construção e implementação desta Política, que tem se concretizado como transformadora no que tange a educação permanente. Apesar das limitações por parte de profissionais e gestores no que se refere ao conceito de EPS e operacionalização da própria política, percebe-se uma mobilização da gestão federal na elaboração de medidas de fortalecimento junto às IES para efetivação da educação permanente no SUS.

Descritores: Educação Continuada, Política de Saúde, Sistema Único de Saúde, Gestão em Saúde, Educação Profissional em Saúde Pública.

\section{Referências}

1. Brasil. Ministério da Saúde. Secretaria de Gestão do Trabalho e da Educação na Saúde. Departamento de Gestão da Educação na Saúde. Política Nacional de Educação Permanente em Saúde: o que se tem produzido para o seu fortalecimento? 1. ed. rev. - Brasília: Ministério da Saúde, 2018. Disponível em: http://bvsms.saude. gov.br/bvs/publicacoes/politica_nacional_educacao_permanente_saude_fortalecimento.pdf

2. Ferreira L, Barbosa JSAB, Esposti CAD, Cruz MM. Educação Permanente em Saúde na atenção primária: uma revisão integrativa da literatura. Saúde debate. 2019;43, n(120):22339. Disponível em: http://www.scielo.br/ scielo.php?script $=$ sci_arttext \&pid=S0103$11042019000100223 \& \operatorname{lng}=e n \& n r m=i s 0$

3. Di Giovanni G. As Estruturas Elementares das Políticas Públicas. Universidade Estadual de Campinas-UNICAMP. Núcleo de estudos de Políticas Públicas-NESP. 2009.

4. Cardoso MLM, Costa PP, Costa DM, Xavier C, Souza RMP. A Política Nacional de Educação Permanente em Saúde nas Escolas de Saúde Pública: reflexões a partir da prática. Ciência \& Saúde Coletiva. 2017; 22(1):1489-500.

5. Vendruscolo C, Prado ML, Kleba ME. Reorientação do ensino no SUS: para além do quadrilátero, o prisma da educação. Revista Reflexão e Ação. 2016; 24(3):246-6o. Disponível em: https://online.unisc.br/seer/index.php/reflex/ article/view/5420 


\section{SEDE NO PÓS-OPERATÓRIO: UMA CARACTERÍSTICA DEFINIDORA QUE MERECE ATENÇÃO E AÇÕES DE EDUCAÇÃO PERMANENTE}

Mateus Dall Agnol

Robson Lovison

Cristiane Baretta

Rosana Amora Ascari

\section{Introdução}

Dentre as principais complicações decorrentes da intervenção anestésico-cirúrgica, destaca-se a sede, um sintoma reconhecido cientificamente como uma complicação prevalente no pós-operatório a qual pode contribuir com o desenvolvimento do estresse e ansiedade que permeia o período perioperatório. Além disso, o estresse da própria cirurgia, as náuseas e a hipoglicemia decorrentes do jejum prolongado são fatores que estimulam a liberação do Hormônio Antidiurético (ADH), desencadeando tal sintoma. A sede pode se sobressair aos demais sintomas, caracterizando-se por situação indesejável durante todo o processo cirúrgico, desde o início do período de jejum, que pode levar de oito a 12 horas, até a recuperação no pós-operatório. Frente ao exposto, há relatos de pacientes de que a falta de água durante esse processo gera a sede e causa desconforto intenso, interferindo na recuperação do paciente. Além disso, são escassos os estudos relacionados ao manejo, avaliação e mensuração da sede no pós-operatório com embasamento científico que padronize o cuidado do paciente com sede $e^{1}$. No entanto, a sede é uma característica definidora do diagnóstico de enfermagem "Volume de líquidos deficiente", que na práxis laboral é pouco considerada, mas interfere negativamente na recuperação clinica pós-operatória. Ao encontro dessas questões, vem a educação permanente em saúde (EPS) que apresenta interface com ensino e serviço 
na prática laboral em saúde, contribuindo para o desenvolvimento profissional, qualificação da assistência e minimização de eventos adversos. Nesse sentido, o serviço de educação permanente pode auxiliar a equipe de enfermagem nesse processo de qualificação, na identificação precoce dos achados clínicos que podem retardar a recuperação, bem como no planejamento de intervenção e registros adequados, com vistas a segurança do paciente. Destarte, diante do expostos, verificou-se a necessidade de ampliar o conhecimento científico sobre a complicação pós-operatória "sede" e identificar os possíveis diagnosticos de enfermagem sinalizados na literatura científica correlacionados com esta complicação do processo cirúrgico.

\section{Objetivo}

Descrever o que a literatura científica aborda sobre os diagnósticos de enfermagem frente à sede no pós-operatório e formas de mensuração.

\section{Metodologia}

Trata-se de uma revisão narrativa da literatura acerca da sede, diagnósticos de enfermagem e formas de mensuração no pós-operatório. Estudo qualitativo desenvolvido no primeiro semestre de 2019. A coleta de dados eletrônica foi realizada na Biblioteca Virtual em Saúde (BVS), juntamente com pesquisa em ambiente físico - biblioteca universitária da Universidade do Estado de Santa Catarina, entre janeiro e março de 2019. Inicialmente foi realizada a busca de estudos que abordaram a temática utilizando-se os descritores: "Sede" e "Assistência Perioperatória". Foram identificados sete artigos, dos quais nenhum abordou diagnósticos de enfermagem frente à sede.

\section{Resultados}

Embora a sede seja um sintoma importante e que possui impacto na recuperação do paciente, não existe Diagnósticos de Enfermagem (DE) específico para a mesma. Entretanto, alguns DE podem ser utilizados, tais como "Risco de boca seca", definido como a possibilidade de danos e desconforto na mucosa oral pela quantidade reduzida de saliva para hidratar a mucosa, comprometendo a saúde. Tem como fatores de risco relacionados ao período $\mathrm{PO}$ a desidratação, e por fim, condição associada aos agentes farmacêuticos e restrição hídrica devido ao processo cirúrgico. $\mathrm{O}$ diagnóstico de "Risco de Desequilíbrio eletrolítico" é a suscetibilidade de mudanças nos níveis de eletrólitos que podem comprometer a saúde, possui volume de líquidos deficiente como fator de risco e condição associada ao regime de tratamento. Outro DE é o "Volume de líquidos deficiente", que é definido pela diminuição do líquido no corpo do paciente referindo a desidratação e perda de água. As características que definem esse diagnóstico é a sede, relacionado à barreira de acesso a líquidos e ingestão de líquidos deficiente, com condições associadas ao agente farmacêutico, perda ativa de volume de líquidos, perda de líquidos por vias anormais e perda excessiva de líquidos por vias normais. O diagnóstico de "Risco de volume de líquidos deficiente" é definido pela suscetibilidade de diminuição de líquidos do corpo do indivíduo, tendo como fatores de risco e condições associadas as mesmas características do diagnóstico anterior. Ainda, o DE "Risco de recuperação cirúrgica retardada" definido pela suscetibilidade no aumento do número de dias no Pós-operatório necessário para desempenhar atividades que mantêm a vida, possui fator de risco, tal como o jejum pela espera da cirurgia e condições associadas ao agente farmacêutico e perda de água durante o procedimento cirúrgico ${ }^{2}$. No período perioperatório a sede pode se tornar mais intensa que a dor ou a fome e quando não tratada pode afetar a consciência, aumentando a fraqueza, irritabilidade e ansiedade. No Pós-operatório imediato (POI), quando o paciente ainda está em jejum, a sede é de alta intensidade, porém, é um sintoma pouco valorizado e os serviços de saúde muitas vezes não dispõem de protocolos de avaliação e registro. ${ }^{3}$ Ainda, a sede por ser um sintoma, muitas vezes subjetivo, o paciente em pós-operatório pode possuir dificuldades para a comunicação verbal, mostrando a importância do relato dos pais ou acompanhantes no processo de sede. Participantes de estudo científico relataram que sentiram de forma intensa os sintomas e alterações corporais decorrentes da sede, tais como: boca seca, lábios secos e rachados, saliva grossa, sensação de sufocamentos e fraqueza, relata-se também a dificuldade na fala e rouquidão durante o Pós-operatório 3 . Ademais, a sede também pode ser desencadeada por outros fatores, tais como os anestésicos utilizados durante o processo cirúrgico, opióides e anticolinérgicos que atuam na diminuição salivar, deixando a cavidade oral ressecada, provocando a sede. A perda de volume sanguíneo durante a cirurgia contribui para a hipovolemia e torna o paciente suscetivel ao sintoma ${ }^{4}$, variando de um indivíduo para outro. A sede pode ser diferente em idosos pois os mecanismos de controle fisio- 
lógicos apresentam-se alterados pela redução da sensibilidade dos receptores de volume no organismo, de disfunções cerebrais e alterações de liberação do hormônio antidiurético ${ }^{1}$. Já em crianças, a literatura sinaliza a carência de evidências científicas que abordem a correlação entre sede nessa população sob os aspectos fisiológicos, osmorregulatórios e manejo ${ }^{1}$. A ingestão de líquidos de duas a três horas antes da cirurgia não é prejudicial para a cirurgia e pode ser benéfica para o paciente, diminuindo todos os sintomas provenientes do jejum excessivo, incluindo a sede ${ }^{5}$. A sede é um sintoma ainda negligenciado dentro das instituições hospitalares e necessita de maior atenção da equipe de enfermagem. Ações de EPS, pautadas na literatura científica, e o fortalecimento da cultura de segurança do paciente podem contribuir para a intervenção precoce e minimizar as complicações da sede, bem como do correto registro dessa ocorrência no prontuário do paciente.

\section{Considerações finais}

Considerando a problemática apresentada, faz-se necessária a intervenção na equipe de enfermagem através de ações da EPS frente ao sintoma "Sede" em pacientes submetidos à processos cirúrgicos, uma vez que esta complicação pode gerar desconforto, irritabilidade, estresse e ansiedade e repercutir negativamente na recuperação do paciente. É possível diminuir do tempo de jejum pré cirurgico e implementar método de avaliação da sede para balizar o correto diagnóstico de enfermagem para cada caso. Nesse sentido, compete ao enfermeiro o diagnóstico preciso e em tempo hábil a fim de estabelecer métodos para o manejo adequado da sede no pós-operatório. Faz-se necessário atentar às queixas do paciente que podem direcionar à identificação precoce $\mathrm{da}$ sede no pós-operatório, tais como, boca seca, lábios ressecados, saliva grossa, garganta seca e vontade de beber água.

Descritores: Sede; Enfermagem; Cuidados de Enfermagem; Educação Continuada.

\section{Referências}

1. Conchon MF, Nascimento LA, Fonseca LF, Aroni P. Sede perioperatória: uma análise sob a perspectiv da teoría de manejo de Sintomas. Revista da Escola de Enfermagem da UsSP, 2015; 49(1):122-128. Disponível em: http://www. scielo.br/pdf/reeusp/v49n1/pt_oo80-6234reeusp-49-01-0122.pdf

2. Nanda Internacional. Diagnóstico de enfermagem da NANDA-I: definições e classificação 2018-2020. 11. Ed. Porto Alegre: Artmed, 2018.

3. Silva LCJR, Aroni P, Fonseca LF. Tenho sede! Vivência do paciente cirúrgico no período perioperatório. Revista Sobecc, [s.1.], 2016; 21(2):75-81. Zeppelini Editorial e Comunicação. Disponível em: https://revista.sobecc.org. $\underline{\mathrm{br} / \text { sobecc/article/view/21/pdf }}$

4. Garcia ACKA, Nascimento LA, Conchon MF, Garcia AKA, Fonseca LF. Perspectiva do anestesiologista em relação à sede no pós-operatório imediato. Ciência, Cuidado e Saúde, 2018; 16(3):1-7. Disponível em: http://www.periodicos.uem.br/ojs/index.php/CiencCuidSaude/article/view/37241/21583

5. Brady MC, Kinn S, Stuart P, Ness V. Preoperative fasting for adults to prevent perioperative complications. Cochrane Database of Systematic Reviews 2003, 4:CDoo4423. Disponível em: https://www.cochranelibrary.com/cdsr/ doi/10.1002/14651858.CDo04423/epdf/full 
Pesquisa Original

\section{EDUCAÇÃO PERMANENTE EM SAÚDE: A PERCEPÇÃO E PRÁTICAS RELATADAS POR ATORES QUE A CONSTROEM}

\author{
Daiane Mayara Alves \\ Simone Rennó Junqueira
}

\section{Introdução}

As mudanças no perfil demográfico e epidemiológico e as reformulações no processo de trabalho assistencial em saúde que vềm ocorrendo ao longo dos anos, exigem novas formas de prover a formação dos profissionais da saúde de modo que estejam aptos para lidar com os desafios dos sistemas de saúde, destacando-se a necessidade de uma constante capacitação dos trabalhadores atuantes nos serviços de saúde ${ }^{1}$. No contexto brasileiro, diversas iniciativas para fomentar processos de transformação da educação dos trabalhadores de saúde foram realizadas com o objetivo de organizar uma política de recursos humanos que articulasse saberes, práticas e valores condizentes com os princípios e diretrizes do Sistema Único de Saúde ${ }^{1}$, um exemplo, é a criação da Política Nacional de Educação Permanente em Saúde (PNEPS) ${ }^{2}$ regulamentada pela Portaria n. 198, de 13 de fevereiro de 2004, e pela Portaria n. 1.996, de 20 de agosto de 2007. A educação permanente em saúde (EPS) é considerada o aprendizado no trabalho, facilitando a participação dos profissionais, em que o aprender e o ensinar se articulam, e integram-se ao cotidiano. A EPS tem o objetivo de constituir relações sólidas, institucionais e pessoais entre os trabalhadores, gestores, usuários, professores e acadêmicos, que possibilitem a transformação das práticas profissionais e do ambiente de trabalho, a partir da articulação das necessidades dos serviços de saúde e dos profissionais atuantes². 


\section{Objetivo}

O objetivo deste artigo é relatar o processo de planejamento e organização da EPS em um município de médio porte do interior paulista, detectando as potencialidades e suas limitações.

\section{Metodologia}

O estudo foi realizado no município de Registro, localizado na região do Vale do Ribeira, interior do estado de São Paulo. O presente estudo seguiu as normas para pesquisas com seres humanos e foi iniciado após aprovação por Comitê de Ética em Pesquisa da Faculdade de Odontologia da Universidade de São Paulo, por meio do parecer $\mathrm{n}^{\mathrm{o}} 2.701 .759$ de o8 de junho de 2018. Este estudo de campo de base qualitativa alicerçou-se no referencial teórico metodológico de avaliação de programas e serviços elaborado por Deslandes', que segue cinco etapas essenciais: conhecimento aprofundado do objeto de análise; análise da correlação entre projeto institucional e políticas públicas vigentes; conhecimento empírico da atuação que se avalia; análise das representações sociais do público-alvo; e análise propriamente dita. Foi realizado um estudo, por meio de um levantamento sobre o material relacionado à EPS no município, complementado por entrevistas individuais semiestruturadas que objetivaram extrair a percepção de diferentes atores quanto ao tema. Participaram das entrevistas o responsável pela EPS; seis profissionais atuantes em uma unidade de Estratégia Saúde da Família (ESF) (dois médi$\cos$, dois cirurgiões-dentistas e dois enfermeiros), e dois profissionais atuantes no Núcleo de Apoio à Saúde da Família (NASF), independente da categoria. Três coordenadores de distritos de saúde, junto ao responsável pela EPS participaram de um grupo focal com o objetivo de exporem suas percepções acerca do tema. O período da coleta dos dados ocorreu entre junho a agosto de 2018.

\section{Resultado}

Compuseram o corpus para análise temática todo o material transcrito das entrevistas, os textos legislativos e dados municipais disponibilizados pela Secretaria Municipal de Saude (SMS). No ano de 2018, o município possuía o cargo de responsável pela EPS no organograma da SMS, assim, as atribuições de planejar, organizar e fornecer apoio às ações relativas à EPS dependia de uma pessoa que ocupasse o cargo, sem a existência de um setor próprio.
Isso corrobora com a realidade do Estado de São Paulo, pois, em um estudo realizado, dos 357 municípios avaliados, 43,1\% contavam com apenas uma pessoa responsável e não um setor. $\mathrm{O}$ estudo ainda revelou que quase um quarto dos municípios $(22,7 \%)$ não possuía qualquer estrutura organizada ou profissional específico para a EPS 4 . Conforme o relato do responsável pela EPS, o processo de elaboração das ações de EPS ocorre por meio dele e de colaboradores (coordenadores de distrito, coordenador de classe profissional, profissionais do NASF, enfermeiros, colaboradores da SMS, ou mesmo os profissionais das Unidades de Saúde), com o intuito de que as ações tenham significado a todos os envolvidos, com base na realidade enfrentada no dia a dia das equipes, bem como as experiências e dúvidas que essas tenham. O município de Registro não contava, até o momento da pesquisa, com uma Política Municipal de EPS, entretanto, o responsável relatou que algumas pactuações relativas à EPS eram definidas e elaboradas em conjunto com os trabalhadores da saúde e descritas no Plano Municipal de Saúde (PMS), na Programação Anual de Saúde e no Plano Plurianual. Situação semelhante a do estado de São Paulo, uma vez que quase a totalidade dos municípios paulistas (cerca de 90\%) incluem suas necessidades e propostas de EPS no PMS e na Programação Anual de Saúde 4 . O responsável pela EPS relata que embora presente no cotidiano do trabalho, a EPS ainda não é reconhecida pelos participantes, uma vez que muitos ainda confundem EPS com a educação continuada, e o entendimento que vigora entre os trabalhadores é que o aprendizado deve vir a partir de cursos, treinamentos e capacitações com profissionais especialistas e em ambiente fora do ambiente de trabalho. Profissionais que não se enxergam ou não participam deste processo, mantendo-se ligados ao modelo tradicional de ensino hierarquizado, relacionam a EPS com cursos e aulas expositivas, não conseguindo trazer esse conceito para o cotidiano de trabalho, deixando de perceber que eles mesmos, muitas vezes, realizam ações de EPS com sua equipe e/ ou comunidade. A falta de documentação formal das ações por meio de avaliações e monitoramento das atividades de EPS jả realizadas no município, assim como a ausência, nas unidades de saúde, de um documento específico sobre EPS foram apontados, pelo responsável, como fatores dificultadores para esse entendimento. Em relação à percepção dos profissionais acerca da EPS, no aspecto formal, apenas os coordenadores de distrito declararam ter ciência do teor da política, en- 
quanto os demais profissionais, afirmaram o desconhecimento. Entretanto, intuitivamente, os princípios que norteiam a política de EPS foram reconhecidos como importantes por todos. Considera-se relevante destacar que o conhecimento, por parte dos profissionais, sobre o conceito de EPS e suas práticas educativas pode ser considerado um facilitador para a institucionalidade da PNEPS, uma vez que pode motivar os profissionais a participar desses processos formativos e ainda irão auxiliar no planejamento e desenvolvimento das ações de EPS no município. Os coordenadores de distrito consideraram que a EPS é uma ferramenta que auxilia no processo de trabalho, propiciando momentos de discussão, através do estudo de caso, sobre as problemáticas surgidas dentro do próprio trabalho. Profissionais das ESF, relataram confundir os termos EPS e educação continuada e ainda destacaram que se devem trabalhar as singularidades, dificuldades e interesse das equipes durante a elaboração de ações de EPS no município; que as propostas sejam tangíveis e que depois as unidades tenham o suporte e governabilidade para colocá-las em prática. Os coordenadores de distrito e trabalhadores do NASF complementam que toda vez que a equipe se reúne e constrói algo em conjunto faz muito mais sentido para todos do que apresentar algo pronto, sob o risco de não ser seguido. Mesmo não sendo nomeada de tal forma, foi possível notar pelas entrevistas, com os profissionais da ESF, que ocorre um movimento de EPS nas unidades, ainda que pequeno realizado por eles, uma vez que esses elaboram ações dentro da sua área de formação, tanto para sua equipe, quanto para os pacientes e/ou comunidade dentro do seu território, de acordo com sua governabilidade. Eles mesmos consideraram que poderiam fazer mais, mas o grande empecilho era a falta de tempo. Quando indagados sobre a viabilidade em se realizar atividade de EPS, as respostas não foram homogêneas entre as categorias, principalmente quanto à liberação dos profissionais; alguns acreditavam que essa fosse uma questão política, na dependência da gestão vigente liberar ou não o profissional. É importante destacar que Registro está localizado em uma região de vários municípios de pequeno porte, não tendo muita estrutura de universidades, tendo os interessados, se deslocarem para os grandes centros, como Curitiba, no estado do Paraná ou São Paulo, capital, ambas a mais de $200 \mathrm{~km}$ de distância, o que dificulta que os profissionais se mantenham atualizados; assim, o fortalecimento da EPS no município pode ser um facilitador.

\section{Conclusão}

Os resultados mostram que, a EPS no município é recente e se apresenta em processo de implantação. Foi possível perceber, por parte do responsável pela EPS e alguns colaboradores, conhecimento e compatibilidade legislativa, embora ainda não cumprida em sua totalidade. Todavia, esse conhecimento ainda não era de domínio da maioria dos profissionais entrevistados, que carecem de mais discussões conceituais. Verificou-se que a EPS está presente no cotidiano dos trabalhadores e percebeu-se intencionalidade em exercê-la. Constatou-se que muito se alcançou, porém, muito ainda há o que ser feito com o objetivo de aproveitar melhor essa política, principalmente com relação à falta de um plano municipal e de mecanismos de avaliação e monitoramento das ações desenvolvidas, que auxiliariam na elaboração de ações futuras.

Descritores: Educação em Saúde, Sistema Único de Saúde, Avaliação em Saúde.

\section{Referências}

1. Brasil. Ministério da Saúde. Secretaria de Gestão do Trabalho e da Educação na Saúde. Departamento de Gestão da Educação na Saúde. Política Nacional de Educação Permanente em Saúde: o que se tem produzido para o seu fortalecimento? Ministério da Saúde, Secretaria de Gestão do Trabalho e da Educação na Saúde, Departamento de Gestão da Educação na Saúde - 1. ed. rev. - Brasília: Ministério da Saúde, 2018. 73 p.

2. Brasil. Ministério da Saúde. Secretaria de Gestão do Trabalho e da Educação na Saúde. Departamento de Gestão da Educação em Saúde. Política Nacional de Educação Permanente em Saúde. Ministério da Saúde, Secretaria de Gestão do Trabalho e da Educação na Saúde, Departamento de Gestão da Educação em Saúde. - Brasília: Ministério da Saúde, 2009. 64 p.

3. Deslandes SF. Concepções em pesquisa social: articulações com o campo da avaliação em serviços de saúde. Cadernos de Saúde Pública, jan.-mar. 1997; 13(1):103-107. DOI: http://dx.doi. org/10.1590/S0102-311X1997000100020

4. São Paulo (Estado). Secretaria da Saúde. Plano estadual de educação permanente em saúde de São Paulo 2020-2023. Secretaria da Saúde do Estado de São Paulo. São Paulo: SES/SP; 2019. 
RELATO DE EXPERIÊNCIA

\section{CICLO DE OFICINAS COM PROFISSIONAIS DE UMA EQUIPE DE ESF: (RE) SIGNIFICANDO AS REUNIÕES DE EQUIPE}

\section{Daiane Mayara Alves Flávia Carotta}

\section{Introdução}

O âmbito saúde, dada sua dinamicidade e complexidade, imprime adequações contínuas da estrutura de atenção a novas demandas sociais, demográficas, políticas, culturais, epidemiológicas e tecnológicas, sem perder de vista a defesa de um sistema de saúde democrático, gratuito e sustentável'. Para se atingir o ideal de profissional que se busca para o Sistema Único de Saúde, a educação permanente em saúde se coloca como uma importante política proposta pelo Ministério da Saúde, que pode auxiliar na transformação do processo de trabalho e das práticas profissionais, uma vez que, viabiliza a aprendizagem significativa, a reflexão crítica sobre a prática cotidiana dos trabalhadores da saúde, e a construção coletiva de conhecimentos no cotidiano por meio da interação da equipe, buscando uma formação integral e continua, a partir de temas que surgem das necessidades identificadas no próprio ambiente de trabalho². Para tanto, é importante o reconhecimento de espaços favoráveis à realização de ações de educação permanente em saúde nos diversos locais e momentos, e a reunião de equipe tem se mostrado um espaço com grande potencialidade. A realização de reuniões periódicas de equipe para discussão conjunta sobre o planejamento, gerenciamento, acompanhamento e avaliação das ações em saúde com todos os membros é uma atribuição dos profissionais das equipes de saúde da família, definida por normativas nacionais?. A 
proposta da educação permanente pode se fazer presente nesses momentos incluindo instrumentos que facilitam a didática, como por exemplo, oficinas em educação permanente, que é considerada um recurso oportuno para se construir conhecimento a partir da ação e da reflexão, articulando a teoria e a prăti$\mathrm{ca}$, tornando mais eficaz e dinâmico esses momentos. Os ciclos de oficinas são espaços coletivos que permitem a troca de saberes e o compartilhamento de informações ${ }^{1}$. Ainda podemos lançar mão de algumas metodologias, articulando-as e aproveitando o melhor de cada uma, assim, para a realização das oficinas, foram selecionadas três metodologias para serem trabalhadas: o arco de maguerez; a roda de conversa; e a árvore de problemas.

\section{Objetivo}

O objetivo deste artigo é relatar a experiência de ciclo de oficinas oferecidas a uma equipe de saúde da família, de um município do interior de São Paulo, durante o período de reunião de equipe.

\section{Método}

O estudo foi realizado no município de Registro, localizado na região do Vale do Ribeira, interior do estado de São Paulo. Para isso foi realizado um estudo descritivo, retrospectivo de análise de dados secundários por meio de atas das reuniões e diário de campo elaborado pelo pesquisador, que relata as experiências de quatro oficinas realizadas com uma equipe de multiprofissionais de uma unidade de estratégia saude da família, no período de janeiro a março de 2020. A equipe em questão era formada por um enfermeiro, um médico, dois auxiliares de enfermagem, um cirurgião-dentista, um técnico de saúde bucal, um auxiliar administrativo, um auxiliar de limpeza e onze agentes comunitários de saúde. Na programação das oficinas previu-se a participação de todos os trabalhadores da equipe. As oficinas ocorreram durante as reuniões semanais de equipe na própria unidade de saúde, utilizando o espaç da unidade, bem como os materiais disponíveis, como, por exemplo: flipchart, canetas, papel sulfite, entre outros. Para a elaboração desse material, seguiram-se os pressupostos metodológicos e pedagógicos das oficinas e foram selecionadas três metodologias para serem aplicadas: o arco de maguerez, que segue cinco etapas essenciais, observação da realidade, definição de pontos chaves, teorização, análise, aplicação à realidade, e que norteou as quatro oficinas; a roda de conversa; e a árvore de problemas. Por meio da combinação dessas metodologias, foi possível articular a teoria e a prática, obter o diagnóstico da situação, priorizar e selecionar os principais problemas, determinar os nós críticos e consequentemente planejar ações para superá-los.

\section{Resultados}

Foi possível realizar quatro oficinas, agendadas previamente com o enfermeiro da unidade (responsável técnico pela mesma). Cada oficina teve um tempo médio de 50 min, e foi iniciada com a apresentação dos objetivos da oficina no dia. É importante ressaltar aqui que uns dos objetivos das reuniões de equipe é a participação de todos, buscando a construção de um espaço coletivo de discussões, troca de experiências, reflexão crítica, problematização do processo de trabalho e a construção de conhecimentos de forma democrática buscando mesclar o processo de trabalho e a aprendizagem dos trabalhadores, entretanto, nem sempre todos os colaboradores participam da reunião e nem sempre esse espaço é utilizado realmente para discussões coletivas de assuntos pertinentes ao processo de trabalho e aprendizado, ficando assim subutilizado ou sendo utilizado para ações administrativas. Assim foi significativo trabalhar as oficinas com o intuito de fortalecer a prática da reunião de equipe na unidade. Um dos objetivos das oficinas foi que a equipe pudesse identificar, sistematizar e promover a análise do processo de trabalho e planejar coletivamente ações para o enfrentamento dos nós críticos e problemas identificados de acordo com as prioridades pactuadas, considerando sua governabilidade. Em algumas oficinas para facilitar e agilizar a comunicação entre os envolvidos, foi utilizado um aplicativo multiplataforma de mensagens instantâneas para envio prévio de perguntas norteadoras, para serem trabalhadas durante a reunião de equipe. Durante as oficinas buscou-se trabalhar o "ouvir opiniões", estimulando que todos expressassem suas dúvidas, necessidades, pontos de vista, medos, angústias, dificuldades e com o tempo foi possivel ter a participação de todos os membros da equipe, e o que antes era "medo de falar errado" acabou se tornando "motivação para contribuir para melhorias". Também foi criado um espaço para reflexão conjunta e compartilhamento de experiências através da metodologia pedagógica de roda de conversa, com o uso de técnicas que favoreceram o diálogo e a problematização, com o intuito de 
que a equipe trabalhasse em conjunto na identificação de problemas, nós críticos e na elaboração de ações para seu enfrentamento. É importante destacar que quando se problematiza e constrói em conjunto a resolução de uma determinada situação é muito mais enriquecedora do que quando se pensado individualmente, sendo importante conhecer a opinião de cada profissional, de acordo com o seu olhar crítico e suas experiências. Ao final de cada reunião, o próprio mediador, ou um relator, realizava um relatório padronizado contendo todo o conteúdo trabalhado durante a oficina, bem como a avaliação final do grupo sobre a experiência vivenciada no dia, registrando em um diário de campo. A equipe também registrava a síntese das ações e pactuações do grupo em ata. Esses documentos serviram de base para descrever as oficinas bem como avaliar e monitorar o desenvolvimento das ações com o grupo. Essa etapa é considerada de extrema importância, uma vez que proporciona uma visão geral dos processos já realizados e auxilia no planejamento de ações futuras para que sejam planejadas de forma mais eficiente. Durante as oficinas foi possível levantar pontos relevantes para serem trabalhados, entretanto, em março de 2020, começamos a enfrentar o problema da pandemia da covid-19 decretada pela Organização Mundial da Saúde, o que requereu toda atenção da equipe, desde então, na reorganização do atendimento, pensando em estratégias para enfrentar os novos problemas como, por exemplo, como administrar a falta de equipamentos de proteção individual, materiais e testes, criação de novos protocolos entre várias outras questões, deixando os demais problemas para um segundo plano. Desta forma as oficinas foram suspensas, no entanto, como já estava sendo realizada uma dinâmica de educação permanente, o exercício das oficinas pode ter feito a equipe trabalhar de forma mais coletiva na reorganização do serviço para enfrentar a pandemia, que foi essencial para o enfrentamento do problema durante a fase crítica.

\section{Conclusão}

Percorrida todas as cinco etapas sugeridas no arco de Maguerez, tendo a realidade como ponto de partida e como ponto de chegada, e analisando o ambiente de trabalho de uma maneira mais crítica, buscando conhecer a realidade, as suas necessidades e limitações, foi possível perceber que quando observamos nosso processo de trabalho, partimos de uma realidade que gostaríamos de mudar e chegamos a uma realidade que muitas vezes podemos transformar, sendo esse um dos objetivos das oficinas: melhorar as práticas profissionais e o ambiente de trabalho. Foi possivel, portanto, com base nos referenciais teóricos e a prática desenvolvida com a referida equipe, concluir que as oficinas realizadas de acordo com os fundamentos da educação permanente, bem como de outros instrumentos metodológicos que problematizam a prática de trabalho, obtiveram relevantes resultados aplicáveis no cotidiano do trabalho e ao se utilizar estratégias didáticas com base nos princípios de construção coletiva, cogestão e análise dos processos de trabalho pela equipe pode potencializar o processo de trabalho.

Descritores: Educação em Saúde, Estratégia Saúde da Família, Saúde Pública.

\section{Referências}

1. Brasil. Ministério da Saúde. Secretaria de Gestão do Trabalho e da Educação na Saúde. Departamento de Gestão da Educação na Saúde. Política Nacional de Educação Permanente em Saúde: o que se tem produzido para o seu fortalecimento? 1. ed. rev. - Brasília: Ministério da Saúde, 2018. 73 p.

2. Brasil. Ministério da Saúde. Secretaria de Gestão do Trabalho e da Educação na Saúde. Departamento de Gestão da Educação em Saúde. Política Nacional de Educação Permanente em Saúde. Brasília: Ministério da Saúde, 2009. 64 p.

3. Brasil. Ministério da Saúde. Portaria n.2.436, de 21 setembro de 2017. Aprova a Política Nacional de Atenção Básica, estabelecendo a revisão de diretrizes para a organização da Atenção Básica, no âmbito do Sistema Único de Saúde (SUS). Diário Oficial da União, Brasília (2017 set. 22); Sec.1:68. 


\section{CAPACITAÇÃO DE ENFERMEIROS PARA O CUIDADO DO PACIENTE ESTOMIZADO NA ATENÇÃO PRIMÁRIA: CENÁRIO DE EDUCAÇÃO PERMANENTE EM SAÚDE}

\author{
Caroline Cunha Machado \\ Letícia Calcagno Gomes \\ Jéssica da Cruz Telles \\ Aline Silveira Lopes \\ Fernanda Jennifer \\ Ribeiro Pereira
}

Edaiane Joana Lima Barros

\section{Introdução}

Estoma é a abertura da parede abdominal e exteriorização de parte do intestino ou ureter, realizados por meio de intervenção cirúrgica. Os pacientes estomizados necessitam de cuidados antes e depois da cirurgia, sendo de extrema importância para a adaptação à nova realidade. O enfermeiro da atençã̃o primária tem em sob sua responsabilidade a realização de cuidados à saúde dos usuários e suas famílias. Além disso, realiza a consulta de enfermagem e educação em saúde, pois mesmo que o paciente e seus familiares recebam orientações durante o período de internação, na alta pode restar inseguranças e não estar esclarecidos totalmente sobre a quem recorrer para dar continuidade ao cuidado e sanar suas dúvidas sobre os cuidados no domicilio. Para que isso ocorra de forma efetiva é necessário a capacitação dos enfermeiros da atenção primária, buscando o aperfeiçoamento destes profissionais, a fim de proporcionar aos pacientes estomizados uma maior qualidade de vida e aos profissionais uma ampliação de seus conhecimentos. Neste sentido, a educação permanente em saúde se torna uma ferramenta essencial de capacitação, atualização e aperfeiçoamento, trazendo a esses profissionais mais segurança na assistência aos estomizados e aos pacientes maior confiança. 


\section{Objetivo}

Identificar a partir da revisão de literatura subsídios para a construção de uma proposta de intervenção voltada à capacitação de enfermeiros da atenção primaria no cuidado de pacientes estomizados em uma cidade do interior do Rio Grande do Sul, região sul do país.

\section{Método}

Trata-se de uma revisão de literatura, realizada a partir de bases de periódicos nacionais, publicados nos últimos cinco anos, utilizou-se os descritores estomia, educação permanente e capacitação em serviço. Foram encontrados apenas quatro artigos nesse segmento publicados entre 2015 e 2020.

\section{Resultados e Discussão}

Os resultados apontaram como principal dificuldade a implementação da educação permanente pelos gestores e o despreparo dos profissionais para lidar com o paciente estomizado. Já no que se refere ao enfrentamento do problema foram citadas a implementação de educação permanente nas unidades, atualização profissional e capacitação a longo prazo. A educação permanente em saúde torna-se uma ferramenta de complementação do conhecimento, se bem aplicada, pode tornar a atenção básica um ponto de referência para os pacientes estomizados. É necessário que o enfermeiro tenha conhecimento científico para realizar o cuidado. Para isso é preciso implementar a educação permanente no ambiente de trabalho dos profissionais da área da saúde, pois esse é um excelente instrumento para preparar esses profissionais e auxiliar no desenvolvimento de uma postura crítica e reflexiva ${ }^{(1)}$. Para uma orientação correta o profissional não pode ter uma visão simplista e limitada do estoma, é preciso domínio do conhecimento fisiológico, patológico e fatores de risco. A falta do conhecimento do profissional sobre o cuidado ao paciente estomizado pode fazer com que o usuário entenda que esse não tenha capacidade e competência para atender as suas demandas, podendo haver assim uma ruptura da confiança do usuário em relação ao profissional, levando ao paciente a busca de outros serviços, causando uma distanciamento entre profissional e usuário ${ }^{(2)}$. Desse modo, atualizações através de educação permanente são necessários para a manutenção do conhecimento e oportunizar o cuidado mais especializado, aprimorando a capacidade prática para tratar estomas ${ }^{(1)},(2)$. No entanto, o processo de ensino deve assegurar o desenvolvimento de competências que correspondam a necessidade da comunidade, por meio da comunicação efetiva e do desenvolvimento de conhecimentos e atualizações, elevando o nível cientifico dos profissionais, ocasionando um impacto positivo em toda a comunidade ${ }^{(3)}$. A partir do exposto, recomenda-se aos profissionais de saude e gestores que reflitam sobre o processo de trabalho, com objetivo de responder às necessidades de cuidado do usuário, tendo em vista que a atenção primária/unidade básica de saúde deveria ser a porta de entrada e auxiliar acerca das questões da população citada. Nesse sentido, buscando a consolidação do cuidado integral ao paciente estomizado a atenção primária a saúde demanda ao serviço de estomaterapia especializado, geralmente situado na atenção secundária, ações de apoio, com o propósito de fornecer suporte técnico específico às equipes multiprofissionais, o que qualificará o cuidado prestado aos estomizados ${ }^{(4)}$. Portanto, o desenvolvimento de uma capacitação para atenção à pessoa com estomia favorece a construção do conhecimento, uma vez que vai ao encontro às demandas de cuidado (5). Assim, a capacitação dos profissionais através da educação permanente em saúde torna-se ferramenta de modificação e qualificação dos serviços prestados aos estomizados da atenção primária, tornando o processo de cuidado mais próximo, consofidando conhecimentos e ampliando a confiança do profissional no cuidado ao estoma.

\section{Conclusão}

Portanto, a partir dessa revisão percebeu-se que a educação permanente em saúde se executada através de capacitações tem o potencial de amplificar o conhecimento profissional e a articulação paciente estomizado/atenção primária/serviço de estomaterapia e tem a capacidade de aumentar o acesso ao atendimento pelo paciente estomizado e ampliar a atuação da atenção primária, tornando a unidade básica mais um local de auxílio a esses pacientes. Com isso, será possível implementar uma proposta de intervenção na qual será realizada uma capacitação dos enfermeiros da atenção primária em uma cidade do interior do Rio Grande do Sul, região sul do país.

Descritores: Estomia; Educação Permanente; Capacitação em Serviço. 


\section{Referências}

1. Oliveira LN, Lopes APAT, Decesaro MN. Cuidado integral à pessoa estomizada na atenção básica - conhecimento e atuação do enfermeiro. Rev Min Enferm; jan 2019; 23:e-1177. Disponível em: http://www.reme.org.br/exportar-pdf/1320/1177.pdf

2. Monteiro AKC, Mendes IAC, Pereira MCC, Gouveia MTO, Andrade JX, Andrade EMLR. Contribuição de educação permanente semipresencial no conhecimento de enfermeiros sobre estomias intestinais de eliminação. Rev Min Enferm. 2019; 23:e-1177. Disponível em: http://www. reme.org.br/exportar-pdf/1320/en_1177.pdf

3. Casamayor RDN, Gálvez JGP, Hernández RM. Pertinencia de la formación continua y el desarrollo de competencias profesionales en las ciencias médicas. Gac Méd Espirit [Internet]. 2020; 22(2):14-24. Disponível em: http:// $\underline{\text { scielo.sld.cu/scielo.php?script=sci_arttext\&pi- }}$ $\underline{\mathrm{d}=S 1608-89212020000200014 \& \operatorname{lng}=\mathrm{es}}$

4. Bandeira LR, Kolankiewicz ACB, Alievi MF, Trindade LF, Loro MM. Atenção integral fragmentada a pessoa estomizada na rede de atenção à saúde. Esc. Anna Nery. 20zo; 24(3):e20190297. Disponível em: http://www. scielo.br/scielo.php?script=sci_arttext \&pi$\underline{\mathrm{d}=S_{1414}-81452020000300210 \& \operatorname{lng}=\mathrm{pt}}$

5. Moraes JT, AE, Gontijo TL, Ribeiro RF, Faria RGS. Avaliação do impacto da capacitação no trabalho para o cuidado de pessoas com estomias. Enferm. Foco (Brasília); 2019; 10(3): 9398 Disponível em: http://revista.cofen.gov.br/ index.php/enfermagem/article/view/1810/575 
Pesquisa Original

O QUE DIZEM OS TRABALHADORES

HOSPITALARES ACERCA DA

CULTURA DE SEGURANÇA?

\section{Carolyne Diehl Stuani \\ Rosana Amora Ascari \\ Gloriana Frizon \\ Paulo Cesar da Silva \\ Olvani Martins da Silva}

\section{Introdução}

O cenário hospitalar se molda em uma dinâmica peculiar de assistência à saúde, onde se vivencia o desenvolvimento de práticas complexas envolvendo equipe multidisciplinar, por vezes em condições desfavoráveis à segurança devido a necessidade de agilidade e precisão, falta de recursos humanos e materiais compatíveis com a demanda local. Ao longo dos séculos a segurança esteve presente de várias formas. Para Hipócrates, a segurança partia da premissa de primeiro não ferir, ou seja, não causar dano, como afirmou "Primum non nocere". Já Florence Nightingale, precursora da enfermagem moderna, durante a guerra da Criméia no século XIX, deu prioridade para a segurança, como fator indispensável para a qualidade do cuidado prestado․ No que se refere à segurança do paciente, esta pode ser entendida como a redução, a um mínimo aceitável, do risco de dano desnecessário ao paciente associado ao cuidado de saúde. Por entender que a assistência à saúde é permeada por situações inseguras, a Organização Mundial da Saúde (OMS) define situações inseguras para o paciente, como: [...] evento ou circunstância evitável, decorrente do cuidado, não associado à doença de base e em 2004, lançou a aliança mundial para a segurança do paciente cujos elementos centrais são a formulação de desafios globais para a segurança do paciente. No Brasil, somente no ano de 2013, foi instituída através da Portaria MS/GM no 529, o Programa Nacional de Segurança do Paciente 
(PNSP) ${ }^{2}$, a qual impulsionou o desenvolvimento de estudos, estratégias e ações para fomentar a cultura de segurança do paciente nos serviços de saúde públicos e privados. O PNSP aborda a cultura de segurança como uma questão transversal e multiprofissional, contemplando quatro eixos: estímulo a uma prática assistencial segura; envolvimento do cidadão na sua segurança; inclusão do tema no ensino; e o incremento de pesquisa sobre o tema ${ }^{2}$. Alinhado ao PNSP, foi desenvolvido um estudo para avaliar a percepção de trabalhadores inseridos num hospital público no oeste catarinense acerca da cultura de segurança do paciente por meio do Hospital Survey on Patient Safety Culture3. Este estudo tem por objetivo apresentar os resultados da questão descritiva do instrumento Hospital Survey on Patient Safety Culture (HSOPSC) aplicado à trabalhadores de um hospital público no oeste catarinense.

\section{Método}

Trata de um estudo exploratório e descritivo, de abordagem qualitativa envolvendo a análise do ambiente hospitalar acerca da cultura de segurança do paciente em hospital de referência em oncologia, neurologia e traumato-ortopedia para mais de 1,5 milhão de habitantes no oeste catarinense. Para a coleta de dados foi utilizado um questionário contendo o Hospital Survey on Patient Safety Culture (HSOPSC), versão em português 3 . A coleta de dados ocorreu de dezembro de 2019 a agosto de 2020, tendo como critérios de inclusão os profissionais inseridos no quadro de funcionários do hospital, ambos os sexos, acima de 18 anos e os que aceitarem participar do estudo, como critério de exclusão, os trabalhadores terceirizados, residentes, profissionais de férias, atestado ou licença, em período de experiência (inferior à 90 dias), e profissionais atuantes nas áreas de atendimento à pacientes com novo Coronavírus (COVID-19). O presente estudo respeitou os aspectos éticos recomendados pelas Resoluções 466/2012, 510/2016 e 580/2018 do Conselho Nacional de Saúde e foi aprovada pelo Comitês de Ética em Pesquisa com Seres Humanos da Universidade Comunitária da Região de Chapecó - UNOCHAPECÓ sob parecer $\mathrm{n}^{\mathrm{0}} 3.720 .155 \mathrm{em} 22$ de novembro de 2019 . Os dados sofreram despersonalização através da identificação dos participantes com a letra "P" (participante", seguido de número arábico conforme a ordem de participação no estudo. Ainda, os dados qualitativos foram submetidos à análise de conteúdo por meio da criação e classificação de categorias ${ }^{4}$.

\section{Resultados e Discussão}

Participaram do estudo 485 funcionários da instituição, sendo a maioria do sexo feminino, com média de idade 35,4 anos. Houve predomínio de profissionais com ensino médio e com curso técnico de enfermagem, atuantes no hospital e na área de um a cinco anos. Os profissionais apontam que há falta de funcionários para dar conta da carga de trabalho, sobrecarregando os demais, assim como demonstram preocupação ao relatar um evento adverso pois o mesmo pode ser usado contra ele, devido ao fato que quando um evento adverso é relatado o foco recai sobre a pessoa e não sobre o evento. Entretanto os participantes afirmam uma boa interação com a chefia imediata. De maneira geral, os trabalhadores avaliaram como muito boa a segurança do paciente na instituição. A segurança do paciente é considerada satisfatória, com potencial para melhorias. Houveram $\mathrm{n}=76$ comentários a respeito da cultura de segurança, os quais foram analisados de forma qualitativa e agrupados em cinco categorias temáticas, à saber: a) Erros, b) Carga de trabalho elevada, c) Falta de Funcionários, d) Educação Permanente em Saúde (EPS) e, e) Outros. A categoria que apresentou maiores resultados está agrupada em "Outros", seguido por "Falta de funcionários", "Carga de trabalho", "Erros" e "EPS". Os participantes percebem a importância da segurança do paciente, como consta no relato: "Penso que se trata de um assunto relevante, da mais alta importância no atendimento ao paciente, o sucesso do trabalho prestado pela equipe está totalmente ligado a segurança que presta ao seu paciente. Equipe treinada e segura resulta no atendimento prestado" $(\mathrm{P}=91)$, assim como aclamam por um Núcleo de Segurança do Paciente (NSP) exclusivo, como aparece no comentário do $(\mathrm{P}=346)$ "Necessidade de um NSP exclusivo para os procedimentos de trabalho, segurança do paciente" e também sinalizam como fragilidade os gestores das unidades "O que mais priorizam é a segurança, mas é o que menos tem, é uma má coordenação da unidade, falta de ética profissional" $(\mathrm{P}=267)$, nesse sentido a enfermagem desempenha um papel fundamental na gestão dos serviços, dessa forma exercem funções de líderes, relacionado muitas vezes com o manejo de conflitos, que se torna inevitável nos espaços de trabalhos. No entanto, cabe ao gestor se posicionar e definir como proceder frente aos conflitos, sendo que estes ocorrem devido à quebra da ordem ocasionada por um erro ou falhas. O excesso de Carga de trabalho é sinalizado por diferentes participantes do 
estudo $(n=14)$, que enfatizam a sobrecarga de trabalho: "O nosso hospital quase sempre está sobrecarregado, somos referência na região, a demanda é alta, e nosso cliente na maioria das vezes não tem um atendimento como deveria ser, pela falta de funcionários e pela superlotação, mas sempre buscamos fazer o melhor para o cliente" $(\mathrm{P}=\mathrm{06})$. A Falta de funcionários fica evidente a partir dos relatos $(n=16)$, representado na afırmação: "Para haver real segurança do paciente é necessário dimensionamento real de colaboradores, profissionais melhores qualificadas independentes da profissão, condição de trabalho adequado com equipamentos suficientes incluindo a área física, haver planejamento de trabalho com equipe multiprofissional" $(\mathrm{P}=340)$. Quanto a Educação Permanente em Saude (EPS) os participantes $(n=9)$ sinalizaram fragilidades, com necessidades de orientações e treinamentos, conforme a descrição a seguir: "O usuário é nosso bem maior, devemos agir com zelo, com humanidade e ter empatia. Deve-se investir na segurança do paciente, aplicar treinamentos, orientações para que seja criada uma cultura de segurança em nossa instituição. Vemos diariamente as falhas e eventos adversos que ocorrem ao nosso redor. Precisa-se urgentemente a criação de um setor de profissionais exclusivos para trabalhar segurança do cliente, que consiga implementar ações para melhorias" $(\mathrm{P}=347)$. Assim, há necessidade de fortalecer a educação permanente no serviço em questão para fortalecer conhecimentos e processos acerca da segurança do paciente. Como limitação desse estudo pode-se afirmar a baixa adesão dos profissionais em participar e a limitação dos pesquisadores ao campo de investigação como consequência as medidas preventivas implementadas no serviço para conter a disseminação de infecção causada pelo novo Coronavírus. Além disso, houve muitas contratações para atuação em áreas de COVID-19, nas quais os profissionais se encaixavam nos critério de exclusão (período de experiência), não sendo possivel sua inclusão no presente estudo.

\section{Conclusão}

Sugere-se uma continuidade desse trabalho com ações futuras de sensibilização dos profissionais por meio do núcleo de segurança do paciente e setor de educação permanente institucional para incentivar a notificação de eventos adversos, implementar ações estratégicas, tais como o desenvolvimento de infográficos direcionados à público específico - gestores, profissionais da assistências e equipe de apoio fomentando a cultura de segurança do paciente.
Descritores: Cultura Organizacional; Gestão da Segurança; Segurança do paciente; Qualidade da Assistência à Saúde; Educação Permanente em Saúde.

\section{Referências}

1. Nascimento JC, Draganov PB. History of quality of patient safety. Hist enferm Rev eletronica [Internet]. 2015;6(2):299-309. Disponível em: http://biblioteca.cofen.gov.br/wp-content/ uploads/2016/10/Hist\%C3\%Bzria-da-qualidade-em-seguran $\% \mathrm{C}_{3} \% \mathrm{~A} 7 \mathrm{a}$-do-paciente.pdf

2. Brasil. Ministério da Saúde. Portaria MS/GM $\mathrm{n}^{\mathrm{o}}$ 529, de 1 de abril de 2013. Institui o Programa Nacional de Segurança do Paciente (PNSP). Disponível em: tp://bvsms.saude.gov.br/bvs/ saudelegis/gm/2013/prto-529_01_04_2013.html. Acesso em: 07/01/2021.

3. Reis CT, Laguardia J, Martins M. Adaptação transcultural da versão brasileira do Hospital Survey on Patient Safety Culture: etapa inicial. Cad Saúde Pública 2012; 28:2199-210. Disponível em: https://www.scielo.br/pdf/csp/v28n11/19.pdf

4. CARlOMAGNO, Márcio C.; ROCHA, Leonardo Caetano. Como criar e classificar categorias para fazer análise de conteúdo: uma questão metodológica. Rev Eletrônica de Ciência Política, v. 7, n. 1, p. 173-188, 2016. Disponível em: https://revistas.ufpr.br/politica/article/view/45771/28756. Acesso em: 16 de novembro de 2020.

5. Martins MM, Trindade LL, Vandresen L, Amestoy SC, Prata AP, Vilela C. Conflict management strategies used by Portuguese nurse managers. Rev Bras Enferm. 2020;73(Suppl 6):e20190336. doi: http://dx.doi. org/10.1590/0034-7167-2019-0336 
RELATO DE EXPERIÊNCIA

DILEMAS ÉTICOS DE ENFERMAGEM MEDIADOS POR DISCUSSÕES NA INCUBADORA DE APRENDIZAGEM: RELATO DE EXPERIÊNCIA

Tanise Pereira Santini

Taís Leal Machado

Gabriella Córdova Dalla Corte

Luiza Fortes Lamberty

Cristina de Freitas Rodrigues

Dirce Stein Backes

\section{Introdução}

Dilemas éticos, dilema com origem do grego 'díllemma,atos <, significa duas premissas. Ética origem do grego, 'ethos', que significa modo de ser, costume ou hábito. Dilemas éticos acontecem quando uma pessoa precisa tomar decisões do qual envolvem seus valores éticos e morais. Ela possui dois caminhos do qual necessita-se definir qual irá prosseguir. A moral são conceitos ditos 'certos' ou 'errados', onde esses são pregados no início de nossas vidas $^{(1)}$. A ética se detém em orientar no cotidiano dos trabalhadores estratégias reflexivas, onde desenvolve-se o senso crítico e possibilita a intervenção no campo do empoderamento, para realizar mudanças necessárias. Por isso, através do aporte teórico, é conferido auxiliar em escolhas, questionamentos e reflexões. Mas também, proporcionar aos profissionais, reflexões acerca da autonomia e eficiência no ramo profissional ${ }^{(2)}$. Da mesma forma aprofunda-se reflexões e questionamentos sobre a prática de enfermagem, a fim de enfrentar desafios, bem como as questões éticas que cotidianamente surgem em seu campo de atuação. Nesse sentido, é necessário que o profissional tome conhecimento de seus direitos e deveres, ampliando-se a segurança em atividades do ofício, evita-se o absenteísmo e os afastamentos prolongados ${ }^{(3)}$. Em vista disso, a utilização de ferramentas mais eficazes colabora nas condutas assistenciais, diminuindo fatores que possam retardar ou prejudicar a melhora do 
paciente. Tais ferramentas exigem responsabilidade e criatividade dos profissionais, para que as ações se fortaleçam na aplicação de um cuidado satisfatório. Salienta-se que quando ocorrer falhas técnicas, o comprometimento de comunicar ao paciente e os demais colegas são deveres do servidor, com o intuito de evitar situações graves e comprometedoras ${ }^{(3)}$.

\section{Objetivo}

relatar a vivências de estudantes de Iniciação Cientifica no que se refere à discussão de dilemas éticos de enfermagem, mediados pela Incubadora de Aprendizagem.

\section{Método}

Trata-se de um relato de experiência, construído a partir da vivência de alunos de Iniciação Científica no processo de reflexão acerca de Dilemas Éticos de Enfermagem, mediados pela Incubadora da Aprendizagem, situada no Hospital Casa de Saúde, localizado na cidade de Santa Maria, Rio Grande do Sul. O processo de intervenção, na prática, foi realizado nos meses de agosto e setembro, com um determinado número de profissionais, para tornar as discussões mais qualificadas. As intervenções foram efetuadas pelas bolsistas e contou com o apoio da Enfermeira responsável pela Gerência de Enfermagem e também, a Enfermeira do Centro de Controle de Infecção Hospitalar (CCIH). Foi efetuado na Incubadora de Aprendizagem, juntamente com as técnicas de enfermagem, em uma roda de conversa, foram alavancados assuntos pertinentes à prática profissional, e relatado um caso verídico a fim de sensibilizá-los. Os assuntos abordados foram: dilemas éticos, conflitos, condutas de enfermagem, retratado sobre penalidades e infraçôes, cuidados de enfermagem, e questões auto reflexivas. $\mathrm{O}$ projeto foi submetido e aprovado pelo Comitê de Ética em Pesquisa sob o número 2.766.732. Para o desenvolvimento deste estudo, foram respeitadas as recomendações da Resolução do Conselho Nacional de Saúde no 466/2012, que orienta a pesquisa com seres humanos ${ }^{(4)}$.

\section{Resultados e Discussão}

As intervenções ocorreram nos meses de agosto e setembro de 2019, no hospital Casa de Saúde, com base nas demandas previamente sugeridas por profissionais e gestores. A discussão durou em torno de uma hora e contou com a participação de profissionais de saúde prove- nientes dos turnos manhã e tarde. As bolsistas de iniciação científica, juntamente com a enfermeira da Gerência de Enfermagem e a enfermeira do Centro de Controle de Infecções, realizaram a intervenção para os profissionais de saúde do hospital a respeito do tema dilemas éticos. No cotidiano da prática de trabalho na enfermagem, são comuns momentos os quais apresentam impasses ou confrontos. Nessas ocasiões é necessária a presença de discernimento para boas escolhas baseadas em princípios éticos e legais. Por isso, as decisões devem ser tomadas de maneira consciente, para que não ocorra prejuízos a equipe e aos próprios pacientes. Um dos dilemas éticos encontrados de professores de uma universidade, foi da expansão do conhecimento e habilidades em relação a sua área de conhecimento. Assim, um segundo dilema, em relação a dificuldade na sua identidade docente, devido o precário entendimento de suas funções dentro da universidade. E, também o impulso econômico para atingir um aperfeiçoamento de sua prática ${ }^{(1)}$. No que tange código de ética profissional, observou-se que alguns profissionais de enfermagem compreendem seu significado de forma coerente, já outros a sua percepção é debilitada. Por isso, a preocupação por parte da Gerência de Enfermagem e os membros da Comissão de Ética do hospital, pois os mesmos estão sujeitos a desentendimentos sobre os dilemas éticos nas convicções, tomada de decisão ${ }^{(5)}$. No processo de construção e ampliação das perspectivas de saúde, a educação permanente se caracteriza como estratégia de formação ao longo da vida profissional. Para tanto, o ambiente de trabalho deve estimular relações horizontalizadas e dialógicas, bem como agregar novos conhecimentos. Realiza-se através da Incubadora de Aprendizagem e equipe de enfermagem, uma troca de informações, estimula-se a autorreflexão e a autocrítica, impulsiona-se para o pensamento de certas situações que devemos intervir no cotidiano. Ao debater sobre o tema houve muitos relatos, questionamentos e troca de ideias entre todos os profissionais presentes, despertando o conhecimento e favorecendo a reflexão das próprias ações realizadas no ambiente de trabalho. Assim, quando repensamos as nossas condutas, iniciamos um processo de ressignificação do ser profissional. A participação constante da equipe de enfermagem nos encontros realizados na incubadora de aprendizagem constrói métodos e avanços de reorganização das condutas do dia a dia da prática profissional, auxiliando na tomada de decisões e manejo de dificuldades no cotidiano de trabalho. 


\section{Conclusão}

Concluímos que as intervenções na Incubadora são de grande valia, pois possibilita e proporciona ao profissional de saúde, um ambiente calmo, acolhedor, que ele possa compartilhar seus conhecimentos, com a equipe do hospital. Desse modo, importante enfatizar a ética nos serviços de saúde, e trabalhar com ela diariamente. A intervenção foi muito importante, pois salientamos situações que estão presentes no seu cotidiano, fazendo com que os profissionais disponham de atenção nas suas práticas, e assim realizem um cuidado qualificado e humanizado. Assim, a troca de conhecimentos entre os profissionais e nos bolsistas, possibilita uma reflexão do cuidado de enfermagem. de saúde.

Descritores: Ética; Enfermagem; Pessoal

Financiamento: $\mathrm{O}$ projeto de pesquisa é financiado pela Fundação de Amparo à Pesquisa do Estado do Rio Grande do Sul FAPERGS.

\section{Referências}

1. Lovaton KYQ. Os valores que caracterizam a ética profissional dos professores da Universidade de Colima. Rev. colomb. educ., Bogotá, 2019; 1(76):265-284.

2. Bordignon SS, escobal APL, garcia B, Meincke SMK, Soares MC, Thofehrn MB. Produção científica acerca do ensino da ética na enfermagem. Journal of Nursing and Health, 2015; 5(1):55-67.

3. Shaefer R, zoboli ELCP, vieira M. Sofrimento moral em enfermeiros: descrição do risco para profissionais. Revista Scielo, 2018; 27(4):01-10.

4. BRASIL. Conselho Nacional de Saúde. Resolução $n^{-1}$ 466/2012. Dispõe sobre a realização de pesquisas com seres humanos[Internet].

5. Silva TN, Freire MEM, Vasconcelos MF, Silva Jr SV, Silva WJC, Araújo PS, et al. Deontological aspects of the nursing profession: understanding the code of ethics. Rev Bras Enferm [Internet]. 2018;71(1):3-10. 


\section{ESTRATÉGIAS UTILIZADAS NO ENSINO EM SAÚDE SOBRE SEGURANÇA NO USO DOS MEDICAMENTOS: REVISÃO INTEGRATIVA}

\section{Juliane Cabral \\ Domênica Bossardi Ramos \\ Camila Borba Ferreira \\ Rita Catalina de Aquino Caregnato \\ Carine Raquel Blatt}

\section{Introdução}

A falta de segurança do paciente no uso de medicamentos constitui um problema de saúde mundial aumentando a preocupação em torno de políticas que visam a melhoria da qualidade e segurança assistencial. Assim como, a sua inserção na formação do profissional, devendo ser de responsabilidade das organizações formadoras a educação e o desenvolvimentos de competências em relação à esta temática ${ }^{1}$. Em 2011, publicado pela OMS, O "Guia Curricular Multiprofissional de Segurança do Paciente", surge como apoio para as instituições de ensino da saúde a incluirem a segurança do paciente nos seus projetos pedagogicos, a fim de capacitar docentes e discentes $^{2}$. No Brasil, em 2013, o Ministério da Saúde (MS) implantou o Programa Nacional de Segurança do Paciente (PNSP), cujas ações articulam-se com os objetivos da Aliança Mundial e contemplam políticas de saúde a nível nacional, entre os protocolos publicados está incluído o de segurança na prescrição, uso e administração de medicamentos. O convívio entre diferentes profissionais e até mesmo entre discentes de diferentes cursos de graduação, permite interação, valorização, conhecimento e empatia, e refletirá em experiências futuras, propiciando melhoria no cuidado assistencial. 


\section{Objetivo}

Conhecer as metodologias utilizadas para o ensino na graduação em saúde sobre a segurança no uso dos medicamentos.

\section{Método}

A metodologia utilizada foi uma revisão integrativa, desenvolvida em seis etapas ${ }^{3}$ : 1) identificação do tema e elaboração da questão norteadora da pesquisa; 2) definição dos critérios de inclusão e exclusão dos estudos e seleção das bases de dados para a busca; 3 ) definição das informações a serem extraídas dos estudos selecionados e categorização dos mesmos; 4) avaliação dos estudos selecionados; 5) discussão dos resultados; e 6) proposta de análise, síntese dos dados e apresentação do conhecimento produzido. A questão norteadora da pesquisa foi: "quais as metodologias utilizadas para o ensino na graduação em saúde sobre a segurança no uso dos medicamentos?", nas seguintes bases de dados eletrônicas da área da saude: Medical Literature Analysis and Retrieval System Online (MEDLINE/PubMed), SCOPUS e Biblioteca Virtual em Saúde (BVS). Foram incluídos artigos publicados entre janeiro/2014 e junho/2019 que apresentaram metodologias de ensino para a graduação em saúde sobre a segurança no uso de medicamentos. As combinações dos descritores com os operadores booleanos utilizados foram: "Medication Therapy Management" OR "Medication Systems, Hospital" OR "Medication Errors" AND "Students, Health Occupations" OR "Health Occupations/education" OR "Educational Measurement".

\section{Resultados}

A partir da estratégia de busca foram identificados 354 artigos, sendo 35 selecionados para a revisão, escritos em inglês $(n=34)$ e português $(n=1)$. Os estudos foram desenvolvidos nos Estados Unidos $(\mathrm{n}=11)$, Austrália $(\mathrm{n}=09)$, Reino Unido $(\mathrm{n}=5)$, Brasil $(\mathrm{n}=1)$, Canadá $(\mathrm{n}=1)$, Dinamarca $(\mathrm{n}=1)$, Egito $(\mathrm{n}=1)$, Itália $(\mathrm{n}=1)$, Japão $(\mathrm{n}=1)$, Suécia $(\mathrm{n}=1)$, Tanzânia $(\mathrm{n}=1)$ e Turquia $(\mathrm{n}=1)$. Quanto ao público-alvo, destaca-se os alunos de graduação em enfermagem $(n=23)$, medicina $(n=5)$, farmácia $(n=4)$ e estudos com mais de um curso $(n=3)$. O tema de administração de medicamentos $(n=11)$ e cálculo de dose de medicamentos $(n=6)$ são os mais abordados e especificamente para os graduandos de enfermagem. O tema de prescrição de medicamentos $(\mathrm{n}=4)$ é abordado para os acadêmicos de medicina. A segurança da medicação foi abordada em 4 estudos. Os temas uso racional de medicamentos, segurança da medicação e erros de medicamentos foram abordados para grupos multiprofissionais. Em relação às metodologias, podemos identificar a simulação realística $(n=14)$, aprendizagem baseadas em problemas $(n=4)$, multimídias $(n=4)$ e outras metodologias ou metodologias mistas $(\mathrm{n}=13)$. Quanto ao nível de evidência, os artigos foram classificados em NE7 $(n=1)$, NE6 $(n=13)$, $\mathrm{NE}_{4}(\mathrm{n}=5), \mathrm{NE}_{3}(\mathrm{n}=15)$ e NE2 $(\mathrm{n}=1)$.

\section{Discussão}

O conteúdo de segurança do uso de medicamento deve ser obrigatório na formação dos diferentes cursos em saúde, a fim de promover maior segurança ao paciente, atenção aos possíveis eventos adversos e monitoramento das condições dos pacientes durante e após o uso de medicamentos ${ }^{4}$. Evidente que cada profissional de saúde tenha uma formação específica em relação às especificidades de sua area de atuação como a prescrição para os estudantes de medicina e administração de medicamentos para a enfermagem, contudo o uso racional de medicamentos onde está intrínseca a segurança do uso do medicamento perpassa todos os profissionais de saúde. Apesar dos esforços nacionais e mundiais para o incentivo a ensino, pesquisa sobre o tema, ainda há uma lacuna nos cursos de graduação. $\mathrm{O}$ assunto é complexo e possui muitas etapas para o aprendizado, devendo ser abordado por diferentes métodos de ensino ${ }^{4}$. A simulação realística foi utilizada para ensino de administração de medicamentos, cálculos de dose de medicamentos, segurança do uso do medicamento, transição do cuidado, reconciliação medicamentosa, prescrição e erros de medicação. A aprendizagem baseada em problemas, foi utilizada para ensino de administração de medicamentos, cálculos de dose de medicamentos, segurança do uso de medicamentos, prescrição e erros de medicação, sendo descrita como de excelência para o aprendizado, pois com o modelo de contextualização do problema, o conteúdo acaba sendo abrangente, permitindo visão e aprendizado amplo, levando à reflexão de qual seria a conduta do discente na prática. O uso de multimídias está cada vez mais frequente no ensino, pois se torna atrativa ao aluno, desde que esteja alinhada com o cenário e o público-alvo ao qual está sendo aplicada. As competências digitais são influenciadas pela tecnologia, sendo consideradas dinâmicas e evolutivas e necessitando de atualizações frequentes, para que atinjam seus objetivos. Outras metodologias 
foram utilizadas para o ensino sobre a segurança no uso de medicamentos nos cursos de graduação em saúde, como a sala de aula invertida, o método de quebra-cabeça consiste em aprendizagem cooperativa, filmagem do cenário clínico e métodos mistos.

\section{Conclusão}

A maioria dos artigos selecionados, foram aplicados para o ensino na graduação de enfermagem e relacionados a administração e cálculo de dose de medicamentos. A principal metodologia utilizada para ensino sobre a segurança no uso dos medicamentos na graduação em saúde é a simulação realística, e como método complementar, identificou-se o uso frequente de questionário pré e pós para avaliação da intervenção realizada. A metodologia a ser aplicada no ensino do uso seguro de medicamentos depende do contexto do discente e dos serviços de saúde, bem como dos objetivos de aprendizado. O raciocínio clínico e o pensamento crítico referente ao uso seguro de medicamentos devem ser praticados durante o ensino da graduação dos cursos de saúde, para que desenvolvam decisões coerentes e seguras no exercício da sua prática profissional.

Descritores: Segurança do paciente; Efeitos colaterais e reações adversas relacionados a medicamentos; Ensino.

\section{Referências}

1. Institute of Medicine (IOM). To Err is Human: building a safer health system. Washington, DC: National Academy Press; 1999.

2. World Health Organization. Patient safety curriculum guide: multi-professional edition. Geneva: WHO; 2011. Disponível em: http://apps.who.int/iris/bitstream/ handle/10665/44641/9789241501958_eng.pdf;jsessionid $=4$ D678ED 42006DFE18915FFD5EB86 $8 \mathrm{EA} 6$ ? sequence $=1$

3. Galvão CM, Mendes KDS, Silveira RCCP. Revisão integrativa: método de pesquisa para a incorporação de evidências na saúde e na enfermagem. Texto Contexto Enferm. 20o8; $17(4)$ : 758-644. Disponível em: https://www. scielo.br/scielo.php? script=sci_arttext\&pi$\mathrm{d}=$ S0104-07072008000400018

4. Adhikari, R., Tocher, J., Smith, P., Corcoran, J., \& MacArthur, J. A multi-disciplinary approach to medication safety and the implication for nursing education and practice. Nurse education today. 2014; 34(2), 185-190. Disponível em: https://doi.org/10.1016/j.nedt.2013.10.008 
RELATO DE EXPERIÊNCIA

MOVIMENTOS DE EDUCAÇÃO PERMANENTE PARA SAÚDE RENAL NO CONTEXTO DA ATENÇÃO PRIMÁRIA: RELATO DE EXPERIÊNCIA

\author{
Morgana Cristina Nardi \\ Bruna Chiossi Presoto \\ Gabrieli Bieger \\ Gabriele Cristine Metzger \\ Francielli Girardi \\ Olvani Martins da Silva
}

\section{Introdução}

A educação Permanente em saúde tem como contributo primordial o aprimoramento das práticas de saúde e a transformação do processo de trabalho com foco em uma maior resolutividade de problemas ${ }^{1}$. Tem como alicerce a aprendizagem significativa que possibilita transformar as práticas profissionais a partir das indagações do cotidiano do trabalho e os conhecimentos prévios, bem como base para as modificações da realidade local ${ }^{2}$. Assim, quando parte-se do pressuposto que os espaços de saúde possuem uma diversidade de informações e que quando essas são compartilhadas coletivamente, é possível transformar o cenário de saúde da população, o grupo de extensão "Enfrentamento da Doença Renal Crônica- ENDORC", buscou desenvolver atividades de educação permanente na atenção primária dos municípios da regional de saúde de Chapecó.

\section{Objetivo}

Relatar a experiência do grupo de extensionistas nas atividades de educação permanente junto as equipes de enfermagem dos municípios da regional de saúde de Chapecó.

\section{Método}

Relato de experiência de atividades de educação permanente realizadas para enfermeiros, técnicos de enfermagem e agentes 
comunitários de saúde dos 26 municípios da Regional de saúde de Chapecó. As ações de educação estão vinculadas ao programa de extensão ENDORC, vinculado ao curso de enfermagem da Universidade do Estado de Santa Catarina, e prevê a realização de capacitação dos profissionais da atenção primária e secundária da Macrorregional de Saúde de Chapecó para o enfrentamento da Doença Renal Crônica. Promover atualização sobre a doação de órgãos e transplante renal. Capacitar e sensibilizar os profissionais em relação aos Cuidado Paliativos, para esta última ação tem como parceira a Universidade Federal da Fronteira Sul- UFFS. A equipe ENDORC, conta com a participação de três professoras da UDESC, três bolsistas e quatro acadêmicos voluntários, um professor da UFFS, e duas enfermeiras do serviço, que são responsáveis por realizar o contato com as secretarias de saúde dos municípios e organizar a logística da liberação e transporte dos profissionais para participar dos encontros. As atividades são estruturadas por oficinas temáticas que abordam assuntos para sensibilização de prevenção e cuidado da doença renal crốnica, fatores de risco, prevenção e manejo da hipertensão arterial sistêmica e diabetes, o conviver com a doença renal crônica, doação de órgãos e transplante. Como metodologia para o desenvolvimento das oficinas, tem-se utilizado a aprendizagem baseado em problema que parte do cotidiano para uma reflexão da prática ${ }^{2}$, aliada a metodologia participativa baseada em técnicas lúdicas, vivências e dinâmicas de grupo. Cada oficina com duração de quatro horas, é direcionada de acordo com a categoria profissional, sendo esses grupos subdivididos posteriormente conforme as dinâmicas propostas pela temática abordada. O cronograma das oficinas possui uma periodicidade e agendamento semestral, entretanto, no ano de 2020, em virtude da pandemia pelo COVID-19, foram realizados três encontros presenciais, sendo necessário uma remodelação das atividades que estão sendo formatadas para a modalidade on line.

\section{Resultados e Discussão}

A primeira rodada de oficinas problematizou os aspectos da doença renal crônica, chamando a atenção para o contexto dos municípios da região, e sobre o cuidado paliativo aos pacientes renais. A equipe ENDORC, elaborou livretos que compartilhou com os profissionais, para a construção do conhecimento gerado por cada participante, afim de instigar o protagonismo individual e coletivo. A me- todologia trabalhada levou em consideração a categoria profissional. Quando realizada com os ACS, a oficina ocorreu simultaneamente em dois auditórios para contemplar a todos. Nessa oficina, foi realizado a sensibilização sobre a problemática da doença renal crốnica; apresentado vídeo sobre os fatores de risco da doença; na sequência o grande grupo foi dividido em subgrupos para integração entre os diferentes municipios e discussão de qual o papel do ACS na promoção da saúde e prevenção da DRC. A oficina direcionada aos técnicos de enfermagem, foi desenvolvida em três momentos: o primeiro e segundo momentos abordou as temáticas já citadas, e no terceiro momento contou com a participação e relato de um paciente transplantado, representante da Associação dos Pacientes Renais Crônicos de Chapecô, que explanou sobre o viver com a doença e o tratamento, também esteve presente nesse diálogo a Assistente social da Clínica Renal do Oeste. A oficina direcionada aos enfermeiros e as atividades de educação permanente em saúde, tiveram como objetivo rever os aspectos da Doença Renal Crônica, seus fatores de risco e impactos na vida do paciente. A estratégia de condução da atividade foi permeada por um estudo de caso onde cada subgrupo após discussão apresentou seu panorama de acordo com a realidade local de cada município. Por meio dessa proposta, foi possível identificar a percepção dos profissionais, suas inquietações e os caminhos percorridos pelos pacientes na busca da assistência na rede de saude e os serviços de atendimento ofertado. Para enriquecer a reflexão, foi convidado uma enfermeira da Clínica Renal do Oeste que explanou sobre a recepção, acolhida, anseios e dificuldades no atendimento dos pacientes renais na alta complexidade. As atividades de extensão aqui apresentadas, possuem caráter de educação permanente em saúde, cujo principal propósito é conduzir os profissionais a refletir sobre a produção do cuidado perante a problemática da doença renal crônica e a relação com o cotidiano do serviço de saúde de cada município. $\mathrm{O}$ aspecto principal $\mathrm{da}$ sensibilização dos profissionais quanto ao problema de saude, que embora crescente, ainda é naturalizado de forma incipiente nas agendas prioritárias das práticas de saúde, levou ao grupo tecer harmonicamente as discussão que buscaram embasar-se em instrumentos Legais para construção do conhecimento, tais como as Diretrizes Clínicas para o Cuidado ao Paciente com Doença Renal Crônica no Sistema Único de Saúde, critérios para a organização da Linha de cuidado da Pessoa com Doença Renal Crônica 
(DRC) e Incentivo financeiro de custeio destinado ao cuidado ambulatorial pré-dialítico e o Plano Operativo para Organização da linha de Cuidado da pessoa com Doença Renal Crônica em Santa Catarina. Esse foi o fio condutor que analogicamente desafiou os profissionais a refletir sobre o binômio: problema de saúde $\mathrm{x}$ protagonismo do cuidado em um ambiente pluralista ancorados pela valorização dos saberes que exterioriza o quadrilátero de saúde.

\section{Conclusão}

Por meio da educação permanente em saúde, o programa de extensão tem buscado discutir, refletir e sensibilizar os profissionais de saúde da atenção primária a vislumbrar os potenciais impactos na saúde da população em decorrência a doença renal crônica. É nesta direção que aponta-se possibilidades de traçar um plano operativo para prevenção e controle da doença renal crônica nos municípios da regional de saúde de Chapecó.

Descritores: Doença Renal Crônica; Atenção Primaria a Saúde; Educação Permante.

\section{Referências}

1. Padilha WS, Rojas FLL. Educação permanente em saúde: formas de imaginar as tecnologias leves em saúde a partir do aprendizado por associação. Revista Ciência e Estudos Acadêmicos de Medicina. 2017; 8; 52-64.

2. Oliveira FD. A influência dos movimentos de educação permanente em saúde na prática do agente comunitário de saúde. Revista Ciência Plural. 2018;4(2); 6-20.

3. Souza SC, Dourado L. Aprendizagem baseada em problemas (ABP): um método de aprendizagem inovador para o ensino educativo. HOLOS. 2015; 5; 182-200. 
RELATO DE EXPERIÊNCIA

\section{PRODUÇÃO DE UM CURSO PARA QUALIFICAÇÃO DE PROFISSIONAIS DE SAÚDE SOBRE VACINAÇÃO: RELATO DE EXPERIÊNCIA}

\section{Franciele dos Santos Moreira Karina Vieira Pinheiro Michelle Jaime Taiane Saraiva Freitas Alessandra Luiza Tolentino Silva Marilene Lopes Vieira}

\section{Introdução}

A rotina das salas de vacinação é influenciada por diversos aspectos como a estrutura, a organização e a operacionalização das atividades de imunização, incluindo o apoio técnico, ou pela escassez de informações a serem repassadas pelo município. Existem ain$\mathrm{da}$ aspectos inerentes ao profissional que atua na vacinação, que envolve suas atitudes, suas práticas quotidianas e seus conhecimentos. ${ }^{1}$ A pandemia da COVID-19 tem gerado um alerta sobre diversas situações para as quais o mundo não estava preparado. Entre elas a Organização Mundial da Saúde (OMS) e o Fundo das Nações Unidas para a Infância (UNICEF) enfatizam sobre a baixa adesão a vacinação em todo o mundo relacionado tanto a um declínio de entrega das vacinas nas unidades de saúde quanto ao medo da população de se imunizar, sendo que essa estagnação na adesão à vacinação retrocede anos de conquistas e esforços das campanhas realizadas por profissionais da saú$\mathrm{de}^{2}$. Por isso, nesse cenário de pandemia, outras estratégias educativas têm sido utilizadas para melhorarem as taxas de vacinação, precisando estarem ancoradas em propostas pedagógicas libertadoras, que sejam construídas a partir de um maior conhecimento do contorno geográfico, social, político, cultural, familiar e comunitário do indivíduo 3 . Esse pensamento recorre aos ideais freirianos, da necessidade de conhecer a realidade do outro - sujeito das práticas de saúde, e de autores que também defendem 
a aprendizagem pela experiência, como John Dewey (1859-1952) e Celèstin Freinet (1896$1966)^{2}$. Desta forma, deve-se conhecer o outro e valorizar seus saberes, procurar meios que não sejam apenas reflexo de práticas reducionistas, impositivas e pontuais? ${ }^{3}$. A vacinação é a principal e mais confiável fonte de informação para a população, estratégias de capacitação não são suficientes quando se trata de vacinação ${ }^{4}$. Cabe ressaltar, que é preciso que os profissionais atuantes nas unidades de saúde reflitam criticamente sobre a temática em seu processo de trabalho, uma vez que esta ação interfere diretamente com a assistência prestada à população usuária de seus serviços ${ }^{4}$. A ocorrência de oportunidades perdidas de vacinação aponta para a necessidade de sensibilização de todos os profissionais da saúde, para que se envolvam na atividade de vacinação contribuindo para o aumento das coberturas vacinais, além de garantir a proteção e promoção da saúde da população, não apenas em doenças imunopreveníveis, mas também em outras intervenções preventivas ${ }^{4}$. Mesmo sendo precários os estudos sobre a educação permanente em saúde quanto às atividades de vacinação, é de consenso na literatura que a atualização e o fornecimento de informação, principalmente, aos profissionais de saúde é o que irá melhorar e dar segurança para a população4. Deste modo, compreendeu-se que as imunizações possuem uma estreita relação com o enfrentamento das principais doenças transmissíveis da sua relevância para a saúde populacional. $\mathrm{O}$ aprimoramento e a atualização dos conhecimentos prévios sobre vacinas relacionadas às doenças poderão agregar novos saberes aos profissionais e estudantes da área da saúde.

\section{Objetivo}

Relatar a produção de um curso para o aprimoramento do processo de trabalho em saúde sobre o calendário vacinal relacionado às doenças imunopreveníveis em todas as fases do ciclo de vida.

\section{Método}

Trata-se de um relato de experiência para a produção de curso por estudantes de enfermagem da disciplina de Gerenciamento em Enfermagem I da Universidade Federal de Ciências da Saúde de Porto Alegre (UFCSPA). O curso teve validação por duas consultoras técnicas enfermeiras, sendo uma atuante na gerência distrital e assessora em todas as sala de vacinas do território na atenção primária à saúde (APS); e a outra uma professora doutora da UFCSPA. O público alvo do curso foram profissionais e estudantes $\mathrm{da}$ área da saúde que atuam ou desenvolvem práticas para a formação acadêmica na atenção primária à saúde (ẢPS). Utilizou-se de diversas ferramentas tecnológicas para a oferta do curso pela extensão na modalidade tutorado na Educação à Distância (EaD), promovendo a interatividade e a dinamicidade.

\section{Resultados e Discussão}

O curso teve um desenho pedagógico com carga horária de 8 horas, contendo nove tópicos que foram organizados para direcionar o participante para uma sequência que foi proposta na tela inicial, sendo possível a integralização em nove semanas. Entretanto, o participante pode acessar os conteúdos na ordem de sua preferência, dando autonomia e subjetividade na construção do seu conhecimento. A elaboração ocorreu na Plataforma PREZI que reuniu telas interativas, incorporação de vídeos (PoowTon e CANVA), personagens e atividades avaliativas, na modalidade da EaD. O planejamento do curso iniciou pelo desenvolvimento de um plano de ação pedagógica (PAP) que foi validado quanto ao conteudo pelas consultoras técnicas. Os conteúdos abordados nos tópicos foram: Orientações gerais; Contexto histórico da vacinação; Tipos de vacinas; Movimento anti-vacinas; Calendário vacinal; Doenças imunopreveníveis; Crianças: principais informações sobre as vacinas; Adolescentes: principais informações sobre as vacinas; Adultos: principais informações sobre as vacinas; Educação Sexual; Idosos: principais informações sobre as vacinas; Gestantes: principais informações sobre as vacinas; Conclusões e referências. Nas orientações gerais foi disponibilizado ao participante o suporte pedagógico e técnico do curso. Em cada tópico do curso houve uma interação dialógica na modalidade de fórum para discussão assíncrona da aplicação prática do conteúdo e para o esclarecimento de dúvidas dos participantes pelos ministrantes. Entende-se que essa interação amplia o desenvolvimento do conhecimento, permitindo a contextualização da realidade vivenciada pelos participantes. As atividades avaliativas foram elaboradas a partir de cinco casos clínicos, sendo um por ciclo vital com o uso do Google Forms ${ }^{\circledR}$ contendo de três a quatro perguntas, e acrescido de uma atividade avaliativa final de preenchimento do calendário vacinal. As assertivas utilizadas foram de escolha simples, sendo gerado a pontuação e 
feedback com respostas aos participantes imediatamente após a conclusão. O desempenho obtido em cada atividade foi registrado em planilhas do Google Sheets ${ }^{\circledR}$, sendo considerado aprovado o participante que atingiu no somatorio das seis atividades avaliativas a média mínima igual a 7,o. A certificação foi condicionada à realização das atividades avaliativas do curso e da obtenção do desempenho de no mínimo igual a 7,o, em conformidade com o Regimento Geral da UFCSPA. Com a conclusão do curso, os participantes, independentemente de sua aprovação, receberão um "guia de bolso", em Portable Document Format (PDF) para consulta rápida, contendo os principais conteúdos abordados. O acesso ao curso foi concedido aos participantes com inscrição confirmada até a data de início do curso, os quais receberão uma mensagem pelo correio eletrônico cadastrado no Sistema de Extensão da UFCSPA (SiEx). Este curso oportunizou ao participante a flexibilização e gerenciamento do seu tempo para o estudo com a finalidade de construir o conhecimento, alcançar o desempenho esperado e para o aprimoramento da prática no serviço da APS. O curso foi divulgado nas mídias sociais do Curso de Enfermagem, da UFCSPA e da Secretaria Municipal de Saúde de Porto Alegre. A inscrição do público externo ocorreu pelo sistema SiEx, e a partir da lista foi pela Comissão Organizadora. Conclusão: $O$ curso ofertado aos profissionais e estudantes da área da saúde apresentou o Calendário Nacional de Vacinação para a promoção e controle de doenças imunopreveníveis. Esste curso permitiu um diálogo ampliado da importância das vacinas e das doenças imunopreveníveis para a comunidade, pois foi capaz de contextualizar fatos que comprovem os benefícios da vacinação e da interatividade pelo uso de fóruns. Embora, a abrangência da oferta tenha ocorrido nacionalmente, houve uma expressiva participação local, o que possibilitou o fortalecimento da integração ensino-serviço pela disciplina de Gerenciamento em Enfermagem I da UFCSPA; assim como o desenvolvimento de competências na área da educação permanente para as estudantes, tornando-as como agentes de transformação social para a sociedade.

Descritores: Vacinas; Educação Permanente; Promoção em saúde; Atençã̃o Primária à Saúde; Enfermagem.

\section{Referências}

1. Assad SGB, Corvino MPF, Santos SPC, Cortez, EA, Souza FL. O quotidiano na sala de vacinação: vivências de profissionais de enfermagem. Rev enferm UFPE on line., Recife, 2017, 11(1):410-21. Doi: 10.5205/reuol.7995-699314-SM.1101sup201721

2.UNICEF global [página na internet]. Para cada criança. OMS e UNICEF alertam para um declínio na vacinação durante a pandemia de COVID-19. 2020 [citado 2021 jan 29]. Disponível em: https://www.unicef.org/brazil/ comunicados-de-imprensa/oms-e-unicef-alertam-para-um-declinio-na-vacinacao-durante-pandemia-de-covid-19

3. Palácio MAV, Takenami I. Em tempos de pandemia pela COVID-19: o desafio para a educação em saúde. Vigil. Sanit. Debate 2020; 8(2):10-15. Doi: 10.22239/2317-269x.01530

4. Martins JRT, Viegas SMF, Oliveira VC, Lanza FM. Educação permanente em saúde e atividades de vacinação: revisão integrativa. Av Enferm. 2019; 37(2):198-207. Doi: 10.15446/ av.enferm.v37n2.73784 
Pesquisa Original

\section{CONTRIBUIÇÕES DA EQUIPE DE ENFERMAGEM NA ATENÇÃO BÁSICA NAS ORIENTAÇÔES E PREVENÇÃO DE DIARREIAS AGUDAS}

\author{
Milena Lorenzini \\ Diora Dorigon Faita \\ Carlise Krein \\ Arnildo Korb
}

\section{Introdução}

A prática profissional da enfermagem na atenção primária em saúde envolve diversas ações como prevenção de doenças, promoção e proteção da saúde, e a reabilititação. As ações com maior investimento são as de promoção da saúde visando a aquisição de boas práticas de saúde da população para a diminuição de ocorrência de doenças. As Doenças Diarreicas Agudas (DDA) são caracterizadas pelo aumento das evacuações e/ ou diminuição da consistência das fezes, e que são geralmente provocadas por bactérias, vírus e parasitas 1 . Durante a atenção ao paciente com DDA, o enfermeiro deve saber realizar o manejo para cada situação. $O$ manejo adequado da doença pelo profissional depende $d a$ anamnese e exame físico detalhado. A anamnese completa é essencial para identificação da causa presumível da doença, o que direcionará as atividades preventivas que serão necessárias. Essa medida também é relevante para prevenção de complicações da desidratação e evolução para o óbito. As orientações dos profissionais de saúde aos usuários com DDA sobre hábitos que podem auxiliar na prevenção da doença, diminui a transmissão da doença entre contactantes, e diminui a recorrência de casos no mesmo indivíduo. Os Agentes Comunitários de Saúde (ACS) também são importantes replicadores de informações relacionadas a promoção de saúde e prevenção de doenças no território. O muni- 
cípio de Palmitos apresenta um dos maiores indices de DDA da região Oeste Catarinense. Dessa forma, o tratamento e prevenção da doença necessitam da atenção especial dos gestores e profissionais de saúde do local.

\section{Objetivo}

Frente ao exposto, o objetivo desse estudo é discutir a relevância das atividades de educação em saúde para prevenção da DDA.

\section{Método}

Tratou-se de uma pesquisa transversal de método misto, quantitativo e qualitativo. A amostra do estudo envolveu usuários do SUS, que no período de setembro de 2019 a fevereiro de 2020 procuraram as unidades de saúde do município de Palmitos com sintomas de diarreia, e que assinaram o Termo Consentimento Livre e Esclarecido (TCLE). O referido município está localizado no Oeste Catarinense, e possui população estimada para o ano de 2019 de 16.169 habitantes. Os participantes foram selecionados por conveniência, de acordo com os usuários disponíveis e concordantes. Foram entrevistados 35 pacientes, e as entrevistas ocorreram na residência dos mesmos com horário previamente definido, e em acordo entre ambas as partes, com o auxílio de um questionário estruturado que abordou questões socioculturais, econômicas, demográficas e de conhecimento sobre a doença. Este manuscrito apresenta apenas um recorte dos resultados da referida pesquisa. A análise ocorreu com auxílio do programa Microsoft Excel para análise descritiva, e para análise estatística foi usado o programa Statistical Package social Science (SPSS) versão 20.0 Durante o estudo, foram atendidas todas as disposições da Resolução № 466, de 12 de dezembro de 2012, do Conselho Nacional de Saúde. A pesquisa está envolvida em um projeto de pesquisa e extensão, aprovado pelo Comitê de Ética em Pesquisa com Seres Humanos da Universidade do Estado de Santa Catarina (CEPSH/UDESC) sob o número 3.589 .820 , em 20 de setembro de 2019.

\section{Resultados e Discussão}

Em estudo realizado na região de saúde Oeste de Santa Catarina sobre a morbidade hospitalar por DDAs entre os anos de 2014 e 2018, o município de Palmitos apresentou o terceiro maior indicador no período, em comparação aos demais 24 municípios da mesma região ${ }^{3}$. O elevado número de internações pode ocorrer em decorrência de fatores econômicos, culturais, sanitários, ou baixa resolução do sistema primário em saúde. Corroborando com isso, um fator importante para a prevenção das DDAs são as orientações em saúde, já que a base da atenção primária são orientações para guiar os usuários a boas práticas de saúde para alcançar as medidas consideradas saudáveis e evitar as doenças". Assim, a orientação para evitar diarreias envolve o hábito de boas práticas de higiene, e sobre agentes causadores para tentar evitar a contaminação. Do total de 35 usuários entrevistados, $100 \%$ relataram não ter recebido alguma orientação na Unidade Básica de Saúde (UBS) referente à métodos de se evitar a ocorrência de diarreias, e somente $2(5,7 \%)$ usuários relataram ter recebido algum tipo de orientação/ recomendação do ACS. Os ACSs, juntamente com os demais componentes da equipe de saúde são essenciais para a transmissão de informações de saúde, pois são eles que conhecem e adentram na residência das pessoas e conhecem a realidade de cada família. A equipe de saúde em uma unidade básica tem como principal objetivo a promoção da saúde para que assim se evitem doenças, ou otimizar a reabilitação. Dessa forma, a orientação em saúde atua como um fator indispensável em um cenário como a UBS, e é vista como o fator mais importante na Atenção Primária já que auxilia na capacidade de monitorar e identificar problemas no seu local de abrangência ${ }^{5}$. O fator apresentado pode estar interligado com o problema exposto: falta de orientações em saúde, já que nenhum paciente relatou ter recebido, o que implica muito com a gestão do município e de como ocorre o fluxo dos atendimentos. Todavia, no presente estudo realizou-se a entrevista apenas com usuários, o que possibilita viés de memória, visto que a orientação pode ser efetuada pelo profissional de saúde, porém não ser assimilada pelo usuário. Sobretudo, são necessárias orientações para utilização de linguagem adequada ao nível de compreensão do usuário, e certificar-se de que o mesmo compreendeu a informação. A educação permanente dos profissionais de saúde que atuam na atenção dos pacientes com DDA, e dos trabalhadores em saúde como os ACSs, sobre o tema, pode trazer importantes reduções na morbidade pela doença no local, diminuição dos custos do sistema de saúde e aumento na qualidade de vida da população. O estudo demonstrou, que apesar da elevada carga que a doença apresenta no município de Palmitos, as atividades 
de prevenção são insuficientes ou ineficazes. Nesse contexto, são necessárias medidas de intervenção no local para mudança de panorama. O enfermeiro, por ocupar papel de gestor das equipes em grande parte dos locais, pode ser um agente ativo dessa mudança.

\section{Conclusão}

Frente ao supracitado, concluímos que uma orientação de qualidade permite o conhecimento do indivíduo dos possíveis causadores da doença diarreica e maneiras de se evitar a contaminação, sendo essencial que o enfermeiro e sua equipe sejam capacitados e mantenham a rotina de orientações.

Descritores: Enfermagem; Controle de Infecções; Diarreia.

\section{Referências}

1. Santa Catarina. Diretoria de Vigilância Epidemiológica. Secretaria de Estado da Saúde. Manual de diagnóstico e tratamento de doenças diarreicas agudas. 2007. Disponível em: $<$ http://www.dive.sc.gov.br/conteudos/imunizacao/publicacoes/Manual\%2ode\%2oDiagnostico\%20e\%20 Tratamento\%2odas\%2oDDA.pdf>.

2. Ministério da Saúde (BR). DATASUS. 2020. Disponível em: < http://datasus.saude.gov.br/ informacoes-de-saude/tabnet/demograficas-e-socioeconomicas $>$.

3. Krein C, Korb A, Zanatta L. Hospitalizações por doença diarreica aguda em Santa Catarina e tecnologias educativas para intervenção. In: Anais do 3. Congresso Sul Brasileiro de Sistematização da Assistência de Enfermagem e 2. Mostra Internacional de Cuidado de Enfermagem no Ciclo da Vida; 2019 nov. 19 - 21. Chapecó, Santa Catarina. Florianópolis: Editora UDESC; 2019.

4. Brasil. Conselho Regional de Enfermagem do Rio de Janeiro / Prefeitura da Cidade do Rio de Janeiro. Protocolos de enfermagem na atenção primaria a saúde. 2012.

5. Paula WKAS, Samico IC, Caminha MFC, Batista FM, Figueirôa JN. Orientação comunitária e foco familiar: avaliação de usuários e profissionais da estratégia de saúde da família. Cad Saúde colet. 2017;25(2):242-48. 
Estudo de REVISÃo

\section{A EDUCAÇÃO PERMANENTE: ESTRATÉGIA PARA UM CUIDADO QUALIFICADO EM SAÚDE}

\section{Maria Lucia Costa de Moura Suely Lopes de Azevedo} Aline Silva da Fonte
Santa Rosa de Oliveira André Luiz de Souza Braga

\section{Introdução}

A Educação Permanente em Saúde (EPS), inserida pelo Ministério da Saúde como uma política de saúde no Brasil, por meio das Portarias $n^{\mathrm{o}}$ 198/2004 e $\mathrm{n}^{\mathrm{o}}$ 1.996/2007, têm como objetivo nortear a formação e a qualificação dos profissionais inseridos nos serviços públicos de saúde, com a finalidade de transformar as práticas profissionais e a própria organização do trabalho com base nas necessidades e dificuldades do sistema ${ }^{1}$. Possibilita a institucionalização da política de educação na saúde e o estabelecimento de iniciativas relacionadas à reorientação da formação profissional, com ênfase na abordagem integral do processo saúde-doença, na valorização da Atenção Básica e na integração entre as Instituições de Ensino Superior (IES), serviços de saúde e comunidade, propiciando o fortalecimento do Sistema Único de Saúde (SUS)². É necessário evidenciar a Educação Permanente em Saúde como uma estratégia que induz a reflexão das práticas do trabalho, fazendo os profissionais repensarem suas condutas, buscando a melhora no atendimento, proporcionando maior interação entre a equipe ${ }^{2}$ Para o Ministério da Saúde a EPS tem como marco conceitual a concepção de trabalho no SUS como aprendizagem cotidiana, reconhecendo o cotidiano como lugar de invenções, acolhimento de desafios e substituição criativa de modelos por práticas cooperativas, colaborativas, integradas e corajosas na arte de escutar a diversidade e a pluralidade do País3. A Política Nacional de Educação Perma- 
nente em Saúde (PNEPS) compreende que a transformação nos serviços, no ensino e na condução do sistema de saúde não pode ser considerada questão simplesmente tecnica. Envolve mudança nas relações, nos processos, nos atos de saúde e, principalmente, nas pessoas. Como estratégia, deve contribuir para a necessária transformação dos processos formativos, das práticas pedagơgicas e das práticas de condução do sistema e dos serviços de saúde, abarcando também a organização de modelos, processos colegiados e de assessoramento. Constitui-se em um trabalho articulado entre o SUS, em suas esferas de gestão e as instituições formadoras, com vistas à construção de uma saúde que diga respeito aos seus usuários e valorize os atores sociais do trabalho4. Não obstante, cabe a Política Nacional de Educação Permanente em Saúde (PNEP) promover transformações na práxis do trabalho, agregando o conhecimento teórico com a prática assistencial, por meio da união entre o aprender e o ensinar no cotidiano dos serviços. Sendo assim, esses profissionais necessitam de conhecimento técnico-cientifico, para fornecer cuidados seguros, eficientes, eficazes, oportunos, centrados no paciente e que sejam equitativos. Portanto, para que esse cuidado aconteça com eficiência, eficácia e efetividade, a atualização de teorias e evidencias, torna-se imprescindivel, já que atualmente o melhor conhecimento adquirido, poderá tornar-se inadequado amanhã, até porque existe uma perspectiva da melhoria na qualidade da assistência, que consolide as políticas do SUS. Partindo dessa ideia, em 28 de março de 2018, o MS, elaborou um manual do Programa para Fortalecimento das Práticas de Educação Permanente em Saúde, que oferece apoio e incentivos financeiros para a qualificação dos profissionais e trabalhadores nos serviços públicos de saúde, especialmente, na Atenção Básica 5 . Diante do exposto, o estudo em tela destaca a importância que EPS representam para a gestão, serviços de saúde, formação dos profissionais da saúde, tendo como resultado maior qualidade no processo do cuidado, através do contínuo desenvolvimento e aperfeiçoamento dos trabalhadores, o que pode garantir uma assistência digna e qualificada para os usuários dos serviços de saude, além da valorização dos trabalhadores, gestores, docentes e discentes, ou seja, todos os sujeitos envolvidos no processo do cuidado.

\section{Objetivo}

Refletir sobre a importância da prática da educação permanente para melhoria da qualidade da assistência em saúde nos diferentes contextos assistências.

\section{Método}

Estudo tipo bibliográfico, crítico reflexivo baseado nas evidências sobre os programas de educação permanente voltados para as instituições de saude em diferentes cenários do SUS. Para a contextualização foi realizada, no mês de janeiro de 2021, a busca por evidencias no portal da Biblioteca Virtual em Saúde (BVS) nas bases de dados Literatura Latino-Americana e do Caribe em Ciências da Saúde (LILACS) e Medical Literature Analysis and Retrieval System Online (MEDLINE), nos anos de 2015 até 2020. Utilizou-se os seguintes descritores: Educação Permanente. Enfermagem. Gestão em saúde, Saúde pública, de forma isolada e combinada com o uso do bolando AND. Após leitura dos títulos e resumos foram selecionados publicações e artigos que atendiam ao objetivo do estudo. Os critérios de seleção utilizados foram estudos disponíveis na integra, idioma português, acesso livre online e presença de dois ou mais descritores.

\section{Resultados e Discussão}

Após seleção de cinco artigos, as autoras identificaram que os profissionais de saúde carecem de programas de educação permanente nos serviços de saúde, o que interfere claramente para implementação de cuidados qualificados e atualizas, e que servem como ponte para a interlocução entre saber científico e o processo de cuidado, onde o conhecimento gerado pela pesquisa científica, políticas e práticas em saúde contribuem para uma assistência em saúde eficaz. A população está cansada de olhares velados sobre as suas necessidades. É necessário evidenciar que a Educação Permanente em Saúde é uma estratégia que induz a reflexão das práticas do trabalho, fazendo os profissionais repensarem suas condutas, buscando a melhora no atendimento, proporcionando uma maior interação entre a equipe. Sendo assim, esses profissionais necessitam de conhecimento técnico cientifico, para fornecer cuidados seguros, eficientes, eficazes, oportunos, centrados no paciente e que sejam equitativos. Portanto, para que esse cuidado aconteça com eficiência, eficácia e efetividade, a atualização de teorias e evidencias, torna-se imprescindível, já que atualmente o melhor conhecimento adquirido, poderá tornar-se inadequado amanhã, até porque existe uma perspectiva da melhoria na qualidade da assistência, que consolide as políticas do SUS. A importância desse raciocínio deixa claro que, o SUS, no Brasil, é fruto de uma luta popular pela democracia e pelo direito à saúde, com apenas 32 anos de existência. É uma política democrática e generosa, que venceu enormes desafios para 
cumprir seus princípios e diretrizes, cobrindo uma população em torno de 211,8 milhões de habitantes, e além disso o seu objetivo é a universidade e integralidade, indo de encontro aos contrastes evidenciado pelas desigualdades sociais. Assim, tanto o setor público quanto o privado, deverão preencher as lacunas existentes entre o atendimento atual e o atendimento ideal, já que a educação permanente é uma forma de manter as equipes de saúde a par das pesquisas atuais nas áreas em que atuam. Sabe-se que vários estágios de aprendizagem, incluem treinamento, educação e desenvolvimento profissional. Pensando dessa forma, esses termos são usados de forma intercambiável, mas devem ser feitas distinções claras devido à habilidades variadas para promover e limitar o aprendizado. O treinamento geralmente se refere à padronização de um processo para produzir resultados semelhantes. Educação refere-se ao processo pelo qual as pessoas aprendem a aplicar soluções para seus problemas e se adaptar a novas situações. O desenvolvimento profissional transcende ambos os conceitos e inclui áreas como aprendizagem autodirigida, mudanças de sistemas e melhoria da qualidade, existindo ainda, a necessidade de pesquisas conceituais e metodológicas para validar a cultura organizacional. Outro aspecto abordado nos estudos está no reconhecido do enfermeiro como elemento fundamental na rede de interações em qualquer ambiente organizacional, sendo que a formação de enfermeiros-líderes e desenvolvimento de atividades que garantam ao enfermeiro as habilidades necessárias para exercer essa função é limitada durante a graduação. A educação permanente torna-se uma estratégia de desenvolvimento desta competência durante o exercício da profissão.

\section{Conclusão}

Estudos apontaram para o fato que tendo em vista a vontade política, falta de recursos e investimentos para a Educação e a Saúde, o impacto a curto e médio prazo, afeta a qualificação profissional dos trabalhadores, reduzindo os espaços ofertados para as atividades de educação permanente e os treinamentos em serviço. O que resulta numa assistência desqualificada, profissionais desmotivados, sobrecarregados, desatualizados, contribuindo para prestação de serviço de baixa qualidade, o que interfere nos padrões esperados para o atendimento de excelência. Quando se propõe uma educação permanente, aguarda-se modificações nos métodos, no exercício profissional, na formação, na gestão e na participação de todos os membros das equipes de saúde, sejam eles os trabalhadores ou associados, espera-se adoção de programas de gestão em saúde com maior qualidade e resolutividade. Nesse contexto, acredita-se que haja uma carência de cursos sobre gestão de educação permanente nos serviços de saúde durante a formação profissional, o que poderia contribuir para maior seguranca ao profissional, contribuindo para maior qualidade do atendimento voltado para o paciente/cliente nos serviços de saúde.

Descritores: Educação Permanente. Enfermagem. Gestão em saúde, Saúde pública.

\section{Referências}

1. Brasil. Ministério da Saúde. Secretaria de Gestão do Trabalho e da Educação na Saúde. Departamento de Gestão da Educação na Saúde. Política Nacional de Educação Permanente em Saúde: o que se tem produzido para o seu fortalecimento? / Ministério da Saúde, Secretaria de Gestão do Trabalho e da Educação na Saúde, Departamento de Gestão da Educação na Saúde - 1. ed. rev. Brasília: Ministério da Saúde, 2018. 73 p. il.

2. Ferreira Lorena, Barbosa Júlia Saraiva de Almeida, Esposti Carolina Dutra Degli, Cruz Marly Marques da. Educação Permanente em Saúde na atenção primária: uma revisão integrativa da literatura. Saúde debate [Internet]. 2019 Mar [cited 2021, Jan 20]; 43 (120 ): 223-239.

3. Brasil. Ministério da Saúde. Secretaria de Gestão do Trabalho e da Educação na Saúde (SGTES). Educação Permanente em Saúde Reconhecer a produção local de cotidianos de saúde e ativar práticas colaborativas de aprendizagem e de entrelaçamento de saberes. Brasília, 2014. (Internet). Disponível em: http://bvsms.saude.gov.br/bvs/ folder/educacao_permanente_saude.pdf

4. Brasil. Ministério da Saúde. Secretaria de Gestão do Trabalho e da Educação na Saúde (SGTES). Ministério disponibiliza manual do Programa para o Fortalecimento das Práticas de Educação Permanente em Saúde no SUS. Distrito Federal. [Internet]. 2018 Mar [cited 2021, Jan 3o] Disponível em: <https://www.gov.br/saude/pt-br/assuntos/noticias/ ministerio-disponibiliza-manual-do-programa-para-o-fortalecimento-das-praticas-de-educacao-permanente-em-saude-no-sus>

5. Keillor M. Students with limited or interrupted formal education (slife). The Narrative of Slife Women in Minnesota and Their Future. Disponível em: https://ir.stthomas.edu/cgi/ viewcontent.cgi? article $=1115 \&$ context $=\mathrm{caps}_{\text {_ }}$ ed_lead_docdiss, Minnesota, 2018. 
RELATO DE EXPERIÊNCIA

\section{AÇÕES DE EDUCAÇÃO EM SAÚDE PARA UMA ASSISTÊNCIA SEGURA EM UMA UNIDADE BÁSICA DE SAÚDE}

\section{Thiemmy de Souza Almeida Guedes}

Andrezza do Rêgo Leal

\section{Introdução}

O processo de educação em saúde inicia-se não só na identificação das dificuldades, como também no reconhecimento e resolutividade dos problemas encontrados durante a assistência a partir da troca de saberes entre usuários e outros profissionais; encontrando assim, maneiras de uma assistência humanizada de acordo com as particularidades da comunidade e do local de trabalho. Algo que ocorre com maior frequência na Atenção Básica, devido intervenções individuais e coletivas que visam, dentre outras ações, a proteção e promoção da saúde por meio de atividades práticas proativas que intencionam o trabalho em equipe a desenvolver atividades educativas que impactem positivamente no processo saúde-doença da comunidade assistida, fortalecendo estratégias que visem o fortalecimento do controle social e da administração local ${ }^{1}$. A relevância da Atenção Primária à Saúde (APS) na ampliação do acesso à Estratégia Saúde da Família reduz as desigualdades socioeconômicas e regionais e aprimora os indicadores de saúde, estabelecendo uma valorização a nível nacional e internacional. $\mathrm{O}$ modelo brasileiro da APS é baseado no conhecimento territorial e comunitário, de modo que as equipes interdisciplinares possam trabalhar superando obstáculos e dificuldades². O Coronavírus (COVID-19) foi detectado pela primeira vez em dezembro de 2019 na cidade de Wuhan, China. É uma doença infecciosa que atinge as 
vias respiratórias e pode causar, dentre outros sintomas, febre, cansaço, dor de cabeça, tosse seca, diarreia, perda de paladar e olfato. A transmissão dá-se por goticulas respiratórias que podem contaminar de forma direta ou indireta, podendo ficar suspensas no ar por longos períodos. A partir da declaração de estado de pandemia causado pelo novo Coronavírus em março de 2020 pela Organização Mundial de Saúde (OMS), a assistência na Atenção Básica teve uma nova ressignificação: desde ações de segurança preconizadas pela OMS, como o uso de máscaras e lavagem das mãos, por exemplo, até o auxílio das redes sociais em aproximar os usuários da Unidade Básica de Saúde (UBS), que é uma das portas de entradas do Sistema Único de Saúde (SUS) 3 .

\section{Objetivo}

Relatar os impactos que o distanciamento social trouxe na continuidade da assistência na Atenção Básica aos usuários de uma Unidade Básica de Saúde, localizada no município de Queimadas, na Paraíba.

\section{Método}

Trata-se de uma pesquisa descritiva e de fundo exploratório pela particularidade das situações e seus sujeitos na construção de hipóteses, como também, do tipo estudo de caso pelo caráter observacional ${ }^{4}$, elaborado a partir das vivências de integrantes da equipe multidisciplinar da UBS, localizada na área rural do município de Queimadas-PB desde o início da pandemia e que foram estendidas até os dias atuais. A UBS assiste à 535 famílias, das quais pode-se fazer uma observação comportamental dos usuários que necessitavam de atendimento e que, de alguma forma, procuraram a UBS de forma aleatória, de modo a apresentar uma amostra das assistências em Unidades Básicas de Saúde no município. As questões bioéticas foram respeitadas e garantidas conforme Resolução $n^{0} 196$ de 10 de outubro de 1996, do Conselho Nacional de Saúdes.

\section{Resultados e Discussão}

Com a atenção voltada a assistência hospitalar e a ampliação dos números de leitos, muitos acabam esquecendo do impacto e da relevância que a Atenção Primária à Saúde tem. Por ser uma porta de entrada do SUS a UBS é, muitas vezes, o primeiro local de procura de muitos cidadãos brasileiros, que são assistidos de forma a garantir medidas de prevenção e promoção em saúde; podendo identificar, de forma precoce, casos graves e surtos, a UBS irá fazer o encaminhamento necessário ao serviço especializado de forma rápida e resolutiva ${ }^{2}$. Por outro lado, a equipe multidisciplinar fortaleceu as bases de conhecimento, capacitando-se e preparando-se para enfrentar um vírus, que até o então, pouco se sabia. Tendo o apoio das diretrizes de biossegurança preconizadas pela OMS, foi possível fazer a correta orientação quantos aos sinais e sintomas de uma possivel contaminação pelo Coronavírus aos pacientes através das Redes Sociais, encaminhando-os aos centros de referência para diagnóstico e tratamento no município. As reuniões semanais com a equipe multidisciplinar foram essenciais na criação de um fluxograma para que a assistência tivesse continuidade de forma segura; pacientes que apresentavam comorbidades, doenças autoimunes, gestantes, puérperas e idosos eram orientados a manter o isolamento social e utilizar os meios de comunicação, como as redes sociais, para entrar em contato com a equipe multidisciplinar. Quanto aos serviços ofertados, houve continuidade da assistência de forma presencial para aqueles que seguissem as medidas que visam a biossegurança, de forma a prevenir contaminações; evitar aglomerações com o agendamento de consultas, medidas como delimitação de espaço e distanciamento social, controle no fluxo de usuários, uso de máscaras, disponibilidade de álcool na forma de gel à $70 \%$, a relevância quanto a higienização das mãos, agendamento para imunização do Programa Nacional de Imunização, panfletos informativos, palestras, informes compartilhados nas Redes Sociais, distribuição de máscara e álcool em gel pelo município, dentre outros, foram relevantes para garantir a segurança da equipe multidisciplinar e dos usuários da unidade. Tendo como base um meio de retomar a centralidade do SUS à nível nacional de saúde, o apoio dos brasileiros aos serviços de saúde ofertados possibilitaria o fortalecimento dos princípios doutrinários do SUS: Universalidade, integralidade e equidade não só durante a pandemia, mas de forma continuada ${ }^{2}$. Sem contar, outros princípios que também que são importantes: a participação popular e preservação da autonomia, de modo a garantir direitos e assegurar a integralidade física e mental dos usuários.

\section{Conclusão}

Mesmo a distância é possível manter o processo de educação de saúde de forma a garantir uma assistência resolutiva e huma- 
nizada com os padrões de segurança preconizados pela OMS. Com o apoio das redes sociais facilitando o contato, pode-se assistir, mesmo a distância, o usuário de maneira efetiva; de modo a resolver questionamentos e sanar dúvidas em um momento desafiador como este, no qual a ciência precisa atuar de forma ativa o mais precocemente possível. Ainda assim, conta-se com ações locais e faz-se necessário o apoio dos conselhos e das esferas de governo no processo continuado em educação para os profissionais de saúde, tornando o atendimento da equipe multidisciplinar completo e randomizado, além de criar um elo com a comunidade adscrita.

Descritores: Educação em saúde; Coronavírus; Atenção Básica; Sistema Único de Saúde.

\section{Referências}

1. Política Nacional de Atenção Básica. 4. ed. Brasília, DF: Departamento de Atenção Básica, Ministério da Saúde, 2007.

2. ABRASCO-Associação Brasileira de Saúde Coletiva. Fortalecer a Estratégia Saúde da Família no enfrentamento da Covid-19 - Posicionamento da Rede APS. Brasil: 20zo. Disponível em: https://www.abrasco.org.br/site/noticias/ especial-coronavirus/fortalecer-a-estrategia-saude-da-familia-no-enfrentamento-da-covid-19/47785/ Acesso em: 22 de jan. de 2021.

3. Organização Mundial da Saúde (OMS), Organização Pan-americana da saúde (OPAS). Folha informativa - COVID-19 (doença causada pelo novo coronavírus). Disponível em https:// www.paho.org $/$ bra/index.php?option=com content\&view=article\&id=6101:covid 19\&Ite$\underline{\text { mid}=875}$ Acesso em 21 de jan. de 2021.

4. GIL, A C. Como elaborar projetos de pesquisa. 5. ed. São Paulo: Atlas, 2010.

5. Brasil. Resolução $n^{0}$ 196, de 10 de outubro de 1996. Dispõe sobre as diretrizes e normas regulamentadoras de pesquisa envolvendo seres humanos. Brasília (DF): Conselho Nacional de Saúde; 1996. 
RELATO DE EXPERIÊNCIA

\section{RODA DE CONVERSA: PLANEJANDO O SUPORTE BÁSICO DE VIDA EM PEDIATRIA NO DOMICÍLIO}

\section{Diana Augusta Tres Elisangela Argenta Zanatta Carine Vendruscolo Edlamar Katia Adamy}

\section{Introdução}

De acordo com a última atualização das diretrizes da American Heart Association, o Suporte Básico de Vida (SBV) corresponde ao atendimento a Parada Cardiorrespiratória (PCR), por meio da execução de manobras e ações realizadas pelo socorrista, sem a utilização de tecnologias avançadas como drogas vasoativas ou tratamentos ${ }^{1}$. Na criança, a PCR é tipicamente o resultado da deterioração progressiva das funções respiratória e/ou circulatória, sendo a assistolia e a atividade elétrica sem pulso os ritmos mais frequentemente observados. Observa-se também casos de PCR em pacientes pediátricos na ocorrência de bradicardia com hipoperfusão, ou seja, pulso central palpável em uma Frequência Cardíaca (FC) abaixo de 6o bpm, com inconsciência e apneia ou respiração agônica ${ }^{2}$. Assim, para um prognóstico favorável em uma vítima de PCR, os profissionais de saúde/socorristas precisam estar treinados para a rápida identificação do evento e início imediato das manobras de ressuscitação, com o objetivo de diminuir a isquemia e, consequentemente, garantir o fluxo mínimo de oxigênio para o cérebro ${ }^{1}$. Dentre os diferentes cenários de atuação das equipes de saúde em situações de PCR, tem-se o domicílio, nesse ambiente os usuários elegíveis para o atendimento das equipes de Atenção Domiciliar (AD) se caracterizam por apresentarem doenças agudas, crônico agudizadas, crônico-degenerativas, e necessidade de cuidados paliativos semanais. 
Da mesma forma, necessitam de cuidados intensificados, uso de equipamento e procedimentos de maior complexidade 3 . Assim, considerando que as crianças acompanhadas pelas equipes de $\mathrm{AD}$ apresentam condições crônicas de saúde e fazem uso de algum dispositivo ou equipamento tecnológico, as Equipes Multiprofissionais de Atenção Domiciliar (EMAD), por serem compostas por profissionais de diferentes áreas, necessitam de atualizações contínuas sobre situações de urgência e emergência que podem ocorrem no domicílio, incluindo o atendimento de SBV. Nesse contexto, a roda de conversa se configura como uma excelente estratégia para conduzir atividades de Educação Permanente em Saúde (EPS), uma vez que propicia discussões, auxilia na elaboração de fluxos de atendimentos, bem como, mantém o conhecimento da equipe atualizado conforme as diretrizes e recomendações preconizadas. Dessa forma, o uso da roda de conversa possibilita aprofundar o diálogo com a participação democrática, a partir das vivências e conhecimentos de cada pessoa, permitindo que os participantes expressem suas opiniões sobre o tema que está em discussão ${ }^{4}$.

\section{Objetivo}

Relatar uma atividade de Educação Permanente em Saúde realizada com a equipe de AD para planejar o SBV em pediatria no domicílio.

\section{Método}

Trata-se de um relato de experiência sobre o desenvolvimento de uma atividade de EPS, utilizando a estratégia de rodas de conversa, elaborada na disciplina de Formação e Educação em Saúde do Mestrado Profissional em Enfermagem na Atenção Primária a Saúde. As rodas de conversa foram realizadas com três equipes de um Serviço de Atenção Domiciliar (SAD) do oeste de Santa Catarina, no mês de junho de 2020, para discussão e planejamento do SBV em pediatria no domicílio. O Serviço onde foi realizada a atividade realiza atendimentos de crianças com necessidades especiais de saúde desde 2014, conta com duas EMAD e uma Equipe Multiprofissional de Apoio (EMAP). Os profissionais que participaram das rodas de conversa foram: dois enfermeiros, dois médicos, um técnico de enfermagem, três auxiliares de enfermagem, quatro fisioterapeutas, uma nutricionista e uma psicóloga. Inicialmente foi enviada uma pergunta disparadora no grupo de WhatsApp do SAD sendo ela: como realizar o suporte básico de vida em pediatria no domicílio? Após, foi enviado o capítulo 14 do caderno de complexidade do cuidado na $\mathrm{AD}$, subtítulo 5: Abordagem das vítimas de PCR no Suporte Básico de Vida $(S B V)^{1}$ e o Protocolo do SAMU: BPed 7 - PCR e RCP no bebê e na criança e BPed6 - Parada respiratória no paciente pediátrico5. Foi solicitado que os profissionais refletissem sobre a pergunta e realizassem a leitura dos materiais, sendo estipulado um prazo de uma semana para a leitura do material e na semana seguinte foram agendadas as rodas de conversas. Devido a impossibilidade de reunir as três equipes em um unico momento, respeitando as normas de distanciamento social em decorrência da pandemia da COVID-19, foram realizados dois encontros, um no período matutino e outro no período vespertino, com duração de uma hora e 30 minutos cada encontro, sendo mediados pela mestranda que elaborou a atividade.

\section{Resultados e Discussão}

Inicialmente, alguns profissionais expressaram sua insegurança e falta de conhecimento sobre a PCR em pediatria, outros informaram que estavam desatualizados sobre as diretrizes atuais e relataram a importância em debater o assunto e a necessidade de construção de um instrumento para orientar a equipe em uma situação de PCR no domicílio. Atualmente, a equipe realiza o atendimento de crianças que apresentam condições crônicas de saúde e fazem uso de dispositivos e equipamentos tecnológicos como traqueostomia e ventiladores mecânicos. Os principais temas dialogados nos encontros foram: diferencas na ressuscitação cardiopulmonar (RCP) de bebês e crianças; materiais necessários para a realização dos procedimentos de SBV em pediatria; atribuições dos profissionais da equipe multiprofissional $\mathrm{e}$ as singularidades do ambiente domiciliar. Segundo a última atualização da diretriz de ressuscitação cardiopulmonar da Sociedade Brasileira de Cardiologia (SBC), considera-se crianças na idade de um ano até a puberdade e bebês os menores de um ano, excluindo-se recém-nascido ${ }^{2}$. Com relação as diferenças da RCP, no bebê a responsividade deve ser avaliada por meio do estímulo plantar, verificação de pulso braquial e o esterno deve ser comprimido com dois dedos posicionados abaixo da linha intermamilar, deprimindo cerca de quatro centímetros do tórax. Na criança para avaliar a responsividade deve-se tocar os ombros e chamar a criança em voz alta, verificar o pulso carotídeo ou femoral e realizar 
compressões com uma ou duas mãos posicionadas na metade inferior do esterno, deprimindo cerca de cinco centímetros do tórax ${ }^{5}$. A relação compressão/ventilação deve ser 30:2 se realizada por um socorrista e 15:2 se realizada por dois socorristas ${ }^{2}$. Diante dessas recomendações e contemplando as discussões sobre as atribuições dos profissionais, ficou acordado que o SBV em domicílio sempre deverá ser realizado por, no mínimo dois profissionais, assim, ficou definido que o socorrista um $\left(S_{1}\right)$ seria o enfermeiro, o médico ou um técnico/ auxiliar de enfermagem que ficaria responsável por conduzir a RCP. O socorrista dois $\left(\mathrm{S}_{2}\right)$ seria um fisioterapeuta, nutricionista ou psicólogo que teria a função de chamar ajuda, providenciar os materiais e auxiliar o S1. Na RCP pediátrica convencional intra e extra-hospitalar, recomenda-se a realização de ventilações e compressões torácicas². Dessa forma, no que se refere aos materiais necessários para o SBV, ficou definido que a equipe sempre deverá dispor de um ressuscitador manual pediátrico na mochila de transporte de insumos e equipamentos. O ambiente domiciliar também foi tema de discussão, os profissionais trouxeram exemplos de residências distantes, falta sinal de telefonia móvel e locais de difícil acesso. Por fim, após as discussões e contribuições sobre o tema, as equipes realizaram a construção de um fluxograma de SBV em pediatria, o fluxograma foi construído na plataforma Lucidchart, e após apresentado a gerência da secretaria de saúde do município para aprovação.

\section{Conclusão}

A realização da roda de conversa proporcionou aos profissionais a discussão sobre um tema que constantemente precisa ser revisado e atualizado. As equipes de saúde precisam de momentos de EPS para que se sintam preparadas no que se refere aos conhecimentos e práticas do local de trabalho onde estão inseridas. Ouvir e discutir com uma equipe multiprofissional tornou o debate enriquecedor pois proporcionou visões diferentes sobre o mesmo tema. A construção do fluxograma possibilitou a organização do processo de trabalho permitindo a definição de atribuições, gerando a demanda de uma capacitação prática por meio de estudos de casos para que os profissionais possam executar o fluxograma na prática $e$ treinar o SBV em pediatria.

Descritores: Reanimação Cardiopulmonar; Criança; Atenção Domiciliar; Equipe de Assistência ao Paciente.

\section{Referências}

1. Ferreira AM, Gonçalves CR, Rodrigues DLG, Verdi DS, Machado DO, Hahne FS, et al. Complexidade do Cuidado na Atenção Domiciliar. Hospital Alemão Oswaldo Cruz - Sustentabilidade Social Projeto Complexidade do Cuidado na Atenção Domiciliar. São Paulo, 2017. [acesso 11 de janeiro de 2021]. Disponível em: https:// portalarquivosz.saude.gov.br/images/pdf/2018/ fevereiro/2o/Apostila-CCADinterativo.pdf

2. Bernoche C, Timerman S, Polastri TF, Giannetti NS, Siqueira AWS, Piscopo A et al. Atualização da Diretriz de Ressuscitação Cardiopulmonar e Cuidados de Emergência da Sociedade Brasileira de Cardiologia. Arq Bras Cardiol. São Paulo, 2019. [acesso 11 de janeiro de 2021]. Disponível em: publicacoes.cardiol.br/portal/abc/ portugues/2019/v11303/pdf/11303025.pdf

3. Brasil. Ministério da Saúde. Portaria no 825 , de 25 de abril de 2016. Redefine a Atenção Domiciliar no âmbito do Sistema Único de Saúde (SUS) e atualiza as equipes habilitadas. Brasília: Ministério da Saude, 2016. [acesso 11 de janeiro de 2021]. Disponível em: http:// bvsms.saude.gov.br/bvs/saudelegis/gm/2016/ prto825_25_04_2016.html

4. Dias ESM, Rodrigues ILA, Miranda HR, Corrêa JA. Roda de conversa como estratégia de educação em saúde para a enfermagem. Rev Fund Care Online. 2018. [acesso 11 de janeiro de 2021]; 10 (2). Disponível em: http://www. seer.unirio.br/index.php/cuidadofundamen$\mathrm{tal} /$ article/view/6053

5. Brasil. Ministério da Saúde. Protocolos de Intervenção para o SAMU 192 - Serviço de Atendimento Móvel de Urgência. Brasília: Ministério da Saúde, 2016. [acesso 11 de janeiro de 2021]. Disponível em: livro-avancado-2016.pdf (saude.gov.br). 
EDUCAÇÃO

PERMANENTE EM SAÚDE NA FORMAÇÃO

\section{Tatiana Almeida Couto Josiane Moreira Germano}

\section{Introdução}

O Sistema Único de Saúde (SUS), pela dimensão e amplitude que tem, aparece na arena dos processos educacionais de saúde como um lugar potente para o processo ensino-aprendizagem, especialmente sobre as práticas em saúde, dos movimentos realizados no território, as múltiplas demandas as quais os serviços são responsáveis. Desta maneira, educar "no" e "para o" trabalho, como pressuposto da proposta de educação permanente em saúde (EPS), é mister para deflagar mudanças que podem ser iniciadas na graduação. Os lugares de produção de cuidado, visando a integralidade, corresponsabilidade e resolutividade são, ao mesmo tempo, cenários de produção pedagógica, pois concentram, o encontro criativo entre trabalhadores e usuários ${ }^{1}$. Para a compreensão da EPS como recurso para a desconstrução dos processos de trabalho, gestão e cuidado é percebida a necessidade de abordagem desde a formação, para o fortalecimento de futuros profissionais da saúde que sejam críticos e reflexivos sobre sua atuação e auxilie na melhoria da atuação da equipe, considerando que consequentemente a assistência ao usuário será oferecida com pontos mais positivos. Portanto, na área da saúde, a formação não apenas gera profissionais que possam ser absorvidos pelos postos de trabalho do setor. O trabalho em saude é um trabalho que deve ser permeado por tecnologias relacionais que possam ampliar o cuidado. As incorporações dessas tecnologias são ininterruptas 
onde novos processos decisórios repercutem na concretização da responsabilidade assistencial, social e ética do cuidado, do tratamento ou do acompanhamento em saúde. Nesse sentido, a educação permanente, quando incorporada ao cotidiano dos serviços de saúde, imprime ao SUS, um interlocutor privilegiado como instituição formadora, na formulação e implementação dos projetos político-pedagógicos de formação profissional, e não mero campo de estágio ou aprendizagem prática².

\section{Objetivo}

Descrever a experiência na supervisão de discentes de Curso de graduação de medicina na construção sobre EPS em UUSF.

\section{Método}

Trata-se de um relato de experiência do segundo semestre de 2019, com dois grupos de 10 discentes do Curso de Graduação em medicina de uma Universidade Federal do interior da Bahia. Durante a apresentação do plano de ensino do componente curricular, os discentes compreendem que as atividades são realizadas no âmbito das discussões teóricas em sala de aula e no campo prático, com permanência de um período semanal na USF.

\section{Resultados e Discussão}

Com o intuito de produzir mudanças na formação em saúde, desde a graduação, a EPS é potente por apostar na integração dos processos educativos desde a graduação com os profissionais da saúde, compartilhando as experiências cotidianas dos serviços. Assim, se faz necessária uma mudança das estratégias pedagógicas ao tomar as práticas da graduação (em seus múltiplos territórios) assim, depois, no trabalho, como fonte de conhecimento, compreendendo a concepção de trabalhadores da saúde como agentes críticos e reflexivos capazes de construir o conhecimento e desenvolver ações alternativas para solucionar problemas, e o trabalho em equipe como modalidade de organização do trabalho3. Portanto, torna-se válido pensar sobre o nosso papel enquanto docentes e discentes que estão inseridos por um determinando período no cenário na USF, mas os membros da equipe estão ali inseridos a anos e portanto, conhecem com ainda mais propriedade as demandas do serviço, as necessidades de saúde da população. Dessa forma, não nos cabe apenas levantar problemas ou fazermos críticas, mas precisamos ter pertencimento a esse espaço e apresentarmos empatia com as pessoas envolvidas e resolutividade. Os sujeitos envolvidos precisam se ver como resolução, no sentido de co-responsáveis por tais demandas. No sentido de que somos partes integrantes da equipe e para a equipe a compreensão de que o cenário da USF também nos pertence, no sentido de ser dada a autonomia para expressar as sugestões e a realização de atividades. Os discentes desde o primeiro dia de aula são estimulados ao levantamento dos problemas existentes, fazendo o diagnóstico situacional e a partir de tal levantamento, são implementadas as atividades. No sentido de envolver-se enquanto discentes em formação, com a equipe que já conhece os problemas da USF e do território. Buscando embasamento também na educação popular em saúde, conforme Paulo Freire, com a metodologia do círculo de cultura em que são sugeridas as etapas de problematização, discussões a partir de temas geradores; fundamentação teoria (no sentido de conhecimento científico sobre o assunto apreendido); construção coletiva de saberes; síntese da experiência de ensino também com o uso da caixa de afetações e por fim, a avaliação e autoavaliação do processo de transformação do conhecimento. Fazendo vizinhança com a perspectiva pedagógica transformadora e emancipatória de Paulo Freire, a EPS vem sendo construída com base nas noções de aprendizagem significativa e de problematização apresentadas e discutidas pelo autor, constituindo-se, assim, em processos educativos cuja finalidade é promover a transformação das práticas de saúde e educação nos serviços de saúde ${ }^{4}$. Em reunião de equipe, por exemplo, espaço onde acontece "tempestades de ideias" com estratégias pedagógicas condizentes com o tempo e o espaço disponível. Entendendo que esse feedback na formação acontece desde o relato dos discentes com os membros da equipe referem a melhoria do relacionamento interpessoal, a atualização de temáticas pertinentes a partir das atividades realizadas (como as atribuições dos membros da equipe, conhecimento da rede de saúde, o uso de instrumentos de gestão, autocuidado, saúde laboral, acolhimento, registros adequados das consultas e visitas domiciliares), assim como os usuários também são impactados positivamente pelas ações de EPS. E a nível da formação dos discentes ocorre a formação no sentido de características de conhecimento, atitude e habilidades. Durante o período vivenciado foi muito produtivo a percepção dos discentes da potência vivenciada seja na USF, no território durante a cartografia e em visitas domiciliares, sobre o levantamento de temáti- 
cas que imergem desses espaços, desde que o sujeito seja sensível a escuta e disponível para a melhoria e transformação no cenário no qual atua. Assim, a Atenção Básica (AB) é tida como um espaço potente para o desenvolvimento da EPS. Capilar aos territórios, a AB reúne ações de promoção, prevenção, tratamento, reabilitação e acolhimento, assim como, trabalha com a lógica da intersetorialidade (apesar das dificuldades) de acordo com as necessidades de saúde da comunidade. Sendo, portanto, necessária a presença de discentes para compreenderem a busca pela integralidade, a gestão, o cuidado e os processos de trabalho5.

\section{Conclusão}

Conclui-se que apesar de na formação médica os discentes inicialmente apresentarem a compreensão equivocada sobre a educação permanente em saúde pensando ser um sinônimo entre educação em saúde e educação continuada, durante os diálogos são possíveis as desconstruções e os mesmos colocam-se como defensores de tais práticas durante a formação e que sejam mantidas durante a atuação profissional.

Descritores: Atenção Primária à Saúde; Educação Superior; Ensino; Equipes de Assistência à Saúde; Trabalho.

\section{Referências}

1. Franco TB. Produção do cuidado e produção pedagógica: integração de cenários do sistema de saude no Brasil. Interface Comun Saude Educ. 2007;11(23):427-38.

2. Ceccim RB, Feuerwerker LCM. O quadrilátero da formação para a área da saúde: ensino, gestão, atenção e controle social. Physis: Revista de Saúde Coletiva. 2004; 14(1), 41-65.

3. Figueredo FC. Desafios e perspectivas na educação permanente em saúde desenvolvida na atenção primária: uma revisão bibliográfica. Revista Científica do ITPAC. 2014; 7(4).

4. Miccas FL, Batista SHSS. Educação permanente em saúde: metassíntese. Revista de Saúde Pública. 2014; 48(1):170-185.

5. González AD, Almeida MJ. Movimentos de mudança na formação em saúde: da medicina comunitária às diretrizes curriculares. Physis 2010; $20(2): 55^{1-70 .}$ 
Estudo de Revisão

\section{GESTÃO DA SEGURANÇA E O REGISTRO DE ENFERMAGEM ACERCA DAS LESÕES POR PRESSÃO}

\section{Cristiane Baretta \\ Rosana Amora Ascari}

\section{Introdução}

As lesões por pressão (LP) constituem um desafio para os serviços de saúde, pois sua ocorrência é considerada um indicador de qualidade da assistência prestada aos pacientes em serviços de saúde de todo o mundo. O reconhecimento das lesões por pressão está relacionado ao conhecimento e capacidade de discriminação visual e o julgamento clínico para distinguir os diferentes aspectos que envolvem as LP, e mesmo dessa maneira existe uma certa dificuldade, pois as lesões são classificada em vários estágios que indicam danos teciduais diferentes entre eles. Tais agravos são definidos pelo $\mathrm{Na}$ tional Pressure Ulcer Advisory Panel (NPUAP) e pelo European Pressure Ulcer Advisory Panel (EPUAP) como um dano que se localiza na pele e/ou tecido subjacente, resultante de pressão intensa e/ou prolongada ou de pressão em combinação com cisalhamento. Portanto, uma compreensão minuciosa dos diferentes estágios da LP, habilidades de tomada de decisão clínica e capacidade de discriminação visual são particularmente importantes no cuidado dos pacientes que internam ou desenvolvem LP nos serviços de saúde, é essencial para a prática baseada em evidências e atividades eficazes de enfermagem. A presença de LP repercute negativamente na qualidade de vida dos pacientes e familiares causando dor, sofrimento, risco de infecção e complicações no estado de saúde. Além disso, gera um impacto significativo nos serviços de saúde, em virtude do aumento 
da carga de trabalho dos profissionais, além do aumento do uso de recursos materiais e dilatação do período da internação (FRANÇA et al., 2019). Nesse interim, observa-se a importância da educação permanente com o conhecimento a respeito da ocorrência de lesões por pressão em paciente institucionalizado, na atuação do enfermeiro com vistas à melhoria da qualidade do cuidado de enfermagem e dos registros de enfermagem acerca das LP. Assim, considerando a importância dos registros de enfermagem sobre LP para a continuidade do cuidado ao paciente institucionalizado como essencial para a adequada e segura prática profissional, buscou-se responder a seguinte questão norteadora do estudo: O que a literatura científica aborda sobre o registro de enfermagem de lesões por pressão em pacientes institucionalizados? $\mathrm{O}$ presente resumo sintetiza o que a literatura científica apresenta sobre o registro de enfermagem sobre lesões por pressão.

\section{Objetivo}

Mapear o que a literatura científica aborda sobre os registros de enfermagem de lesões por pressão em pacientes institucionalizados.

\section{Método}

Trata-se de uma revisão integrativa da literatura, realizada na Biblioteca Virtual em Saúde (BVS) referente ao período de janeiro de 2016 à dezembro de 2020, nos idiomas inglês, português e espanhol, a qual analisou artigos originais, em texto completo, gratuitos e disponíveis eletronicamente. Como estratégias de busca utilizou-se os descritores "Lesão por Pressão" e "Registros de Enfermagem", com o operador booleano AND. A busca resultou em nove (og) artigos, os quais foram importados para o Programa Academical para análise e classificação em pastas identificadas conforme critérios de inclusão e exclusão previamente definidos. $\mathrm{Na}$ Etapa I procedeu-se a leitura dos títulos e resumos $(\mathrm{n}=09)$. Os artigos incluídos compuseram a Etapa II (n=09) com leitura do texto completo. $\mathrm{Na}$ busca pelo artigo na íntegra, um foi excluído por duplicidade $(\mathrm{n}=\mathrm{O1})$ e dois estavam indisponíveis de forma gratuita. Assim, foram inclusos nesta revisão seis artigos $(n=06)$.

\section{Resultados e Discussão}

Dos seis artigos inclusos, quatro $(\mathrm{n}=\mathrm{O} 4)$ estavam disponíveis em espanhol e dois $(\mathrm{n}=\mathrm{O} 2)$ em português. Os artigos foram publicados nos periódicos Gerokomos, Revista de Enfermagem da UFPE online, Investigación y Educación em Enfermería, Revista da Escola de Enfermagme da USP, Enfermería Intensiva e Revista Gaúcha de Enfermagem. Os anos de publicação foram: $2020(n=02), 2018 \quad(n=02), 2017(n=01)$ e 2016 $(\mathrm{n}=\mathrm{O1})$. Na literatura, evidencia-se que o registro de enfermagem acerca das LP em pacientes institucionalizados ainda é incipiente e denota fragilidades que requerem atenção da gestão tanto na questão assistencial quanto no registro da assistência prestada. Os registros de enfermagem, em muitos casos, não refletem a situação real, pois existe um problema importante de subnotificação, uma vez que apenas 30,31\% dos pacientes que possuíam LP apresentavam o registro correspondente, ainda, os registros de enfermagem referente as lesões relacionadas a dependência (LRD) devem ser aprimorados, tanto no momento da admissão para determinar lesões adquiridas no hospital, quanto durante o processo de atendimento para registrar as lesões existentes e seu tratamento. ${ }^{1}$ Há discrepância ao comparar o registro de problemas de saúde que são documentados pelas enfermeiras e os relatados no hospital. ${ }^{2}$ Além disso, identificou-se que a educação permanente melhora a precisão diagnóstica e a integridade na comunicação sobre os eventos adversos (EA). ${ }^{2}$ Estudos descrevem que a forma mais utilizada para abordar as LP nos registros foi através da utilização da Escala de Braden, sendo este o principal instrumento utilizado pelos enfermeiros na prevenção do risco de desenvolvimento de LP. 3 Em contrapartida, outro estudo aborda que os registros fotográficos são uma ferramenta que permite o reconhecimento dos tipos de feridas igual que a visualização dos diferentes tipos de pele lesionadas. ${ }^{4}$ Ao avaliar a concordância entre os registros de enfermagem de LP e a valorização fotográfica dos três avaliadores especialistas das mesmas áreas, se observou uma boa concordância para determinar a presença de LP e moderada para a concordância dos graus de LP. ${ }^{4}$ A literatura revela a falta de qualidade / abrangência na documentação de enfermagem nas lesões por pressão e demonstra que os enfermeiros da equipe costumam ter um desempenho ruim na documentação referente ao estadiamento e tratamento das lesões por pressão. ${ }^{5}$ Nesse sentido, o registro de enfermagem das LP não fornece um quadro completo das necessidades de cuidados dos pacientes que as intervenções de enfermagem requerem. Faz-se necessário ampliar a discussão sobre o registro das lesões por pressão, bem como fomentar a cultura de segurança do paciente por meio de estratégias de gestã̃o e educação permanente no que tange ao conhecimento e habilidades 
para operacionalizar diretrizes clínicas e registros condizentes com a realidade local. Por fim, um programa padronizado de treinamento sobre LP para enfermeiros pode melhorar significativamente o julgamento clínico, qualificar a assistência e consequentemente melhorar os registros de enfermagem acerca da lesões por pressão em pacientes institucionalizados.

\section{Conclusão}

É necessário uma ferramenta precisa que além de contribuir para a identificação do risco de lesão por pressão, auxilie o enfermeiro no julgamento clínico dessas lesões. Acredita-se que se os enfermeiros souberem identificar, avaliar e tratar adequadamente as LP, enriquecerão os registros de enfermagem com informações pertinentes à continuidade da assistência. Assim, ações de educação permanente sobre a temática em questão podem ser implementadas nas diferentes unidades hospitalares, com vistas ao aperfeiçoamento de julgamento clínico pelos enfermagem e desenvolvimento de competências específicas na identificação e registro das lesões por pressão. É através de ações pontuais nos serviços de saúde que, coletivamente, pode-se alcançar as metas de segurança do paciente proposto pela Organização Mundial de Saúde.

Descritores: Lesão por Pressão; Registros de Enfermagem; Gerenciamento da Informação em Saúde; Gestão da Segurança; Educação Continuada.

\section{Referências}

1. Real López Luis, Diez Esteban M. a Eugenia, Serrano Hernantes Marta, Blasco Romero Irene, Capa Santamaría Sheila, Santamaría González Milagros et al. Prevalencia hospitalaria de lesiones relacionadas con la dependencia en la provincia de Burgos. Estudio multicéntrico. Gerokomos, 2020; 31(2):98-106. Disponible en: http:// scielo.isciii.es/scielo.php?script $=$ sci_arttext\&pid=S1134=928-2020000200008X\&lnges. Epub 05-Oct-2020.

2. González-Samartino Maribel, Delgado-Hito Pilar, Adamuz-Tomás Jordi, Cano Maria Fe Viso, Creus Mònica Castellà, Juvé-Udina María-Eulàlia. Precisão e integridade do registro de eventos adversos usando a terminologia de interface. Rev Esc Enferm USP [Internet]. 2018; 52: e03306. DOI: http://dx.doi. org/10.1590/S1980-220X2017011203306

3. Ponseti EJ, Millán AV, Chinchilla DO. Análisis dde las complicaciones del decúbito prono em el síndrome de distrés respiratório agudo: estándar de cualidad, incidência y factores relacionados. Enfermería Intensiva, 2017; 28(3):125-34. DOI: http://dx.doi.org/10.1016/j.enf1.2016.12.003

4. Cortes OL, Alvarado PA, Rojas YA, Salazar LD, Acuña X, Esparza M. Digital photography: a tool for nursing on the assessment of pressure lesions. Invest. Educ. Enferm. 2018; $36(2)$ :e07. DOI: http://doi.org/10.17533/udea.iee.v36nzeo7.

5. Li D. The relationship among pressure ulcer risk factors, incidence and nursing documentation in hospital-acquired pressure ulcer patients in intensive care units. J Clin Nurs. 2016 Aug;25(15-16):2336-47. DOI: 10.1111/jocn.13363. Disponivel em: https://pubmed.ncbi.nlm.nih. gov/27302084/. Acesso em 16 de Jan. 2020. 
RELATO DE EXPERIÊNCIA

PARTICIPAÇÃO DE DISCENTES NAS AÇÕES DE EDUCAÇÃO PERMANENTE ACERCA DA IMPLANTAÇÃO

E IMPLEMENTAÇÃO DO PROCESSO DE ENFERMAGEM

\author{
Débora Althaus Bonet \\ Laura Cocco \\ Carla Argenta \\ Edlamar Kátia Adamy
}

\section{Introdução}

O Processo de Enfermagem (PE) é um instrumento metodológico que auxilia o cuidado profissional de enfermagem, bem como a documentação e toda operacionalização da prática profissional. Isso evidencia a contribuição da enfermagem na atenção à saúde da população, aumentando a visibilidade e o reconhecimento profissional ${ }^{1}$. O PE permite organizar a gestão do cuidado, dando autonomia ao profissional de enfermagem, além de trazer especificidade e cientificidade à profissão, sendo um método dinâmico e sistemático, o que se traduz em uma melhora direta na assistência prestada ao cliente ${ }^{2}$. Este deve ser implantado e implementado nos ambientes onde ocorre o cuidado de Enfermagem de forma deliberada, sendo organizado em cinco etapas interdependentes e inter-relacionadas e recorrentes, sendo estas: Coleta de Dados, Diagnóstico de Enfermagem, Planejamento de Enfermagem, Implementação e Avaliação de enfermagem. Para que o PE seja efetivamente utilizado se torna imprescindível que o serviço de educação permanente atue a fim de interagir conteúdos teóricos, com conteúdo que se concretizem em situações reais nas quais os profissionais necessitam alcançar soluções efetivas, com base em respaldo teórico-prático ${ }^{3}$, já que estas, interagem e se complementam. A educação permanente tem sido considerada um instrumento para mudanças e transformações em uma sociedade. Ela é compreendida como a constan- 
te busca pelo aprender, como uma das ações que possibilita o desenvolvimento do processo de mudança e que visa à qualificação profissional da enfermagem e consequentemente à realização da prática profissional competente, consciente e responsável ${ }^{4}$.

\section{Objetivo}

Relatar a experiência de discentes na participação de ações de educação permanente acerca da implantação e implementação do Processo de Enfermagem.

\section{Método}

Trata-se de um relato de experiência elaborado a partir das vivências de discentes mediante ações de educação permanente relacionada a implantação e implementação do Processo de Enfermagem, em um hospital escola de alta complexidade na Região Oeste de Santa Catarina. As ações aconteceram no mês de março de 2020, por meio de dois encontros realizados quinzenalmente, em forma de roda conversa com a participação de enfermeiros, docentes e discentes.

\section{Resultados e Discussão}

Nestes encontros foram elaboradas matrizes assistenciais a partir dos sistemas de linguagens padronizadas, utilizando como referencial as seguintes taxonomias: Nanda Internacional ((NANDA-I), Classificação das Intervenções de Enfermagem (NIC), Classificação dos Resultados de Enfermagem (NOC), além de abordar estudos de caso, tendo como intuito o desafio de estimular o desenvolvimento dos profissionais sobre um contexto de responsabilidades e necessidades de atualização, uma vez que, a educação permanente é um processo de reflexão e crescimento com ciclos de mudanças e transformações, considerando para isso o serviço, o trabalho, o cuidado, a educação e a qualidade da assistência ${ }^{3}$. A Educação permanente permeia todas as atividades de implantação e implementação do PE, ou seja, da construção das matrizes assistenciais até as discussões acerca de estudos de casos levantados, em que todos os participantes, inclusive discentes, contribuem no processo. São analisadas minuciosamente cada etapa do PE, identificando potencialidades e fragilidades encontradas pela equipe. Os estudos de caso tem como objetivo elencar diagnósticos assertivos que vão de encontro com os achados clínicos obtidos através do exame físico e da anamnese, priorizando o planejamento de enfermagem para atender não só as necessidades do paciente, mas também de toda a equipe envolvida, o que resulta na melhoria do gerenciamento em enfermagem. Sendo assim, há um resultado favorável frente às intervenções resolutivas que se traduzem numa melhoria direta na assistência prestada, avaliando constantemente e revisando devidamente todo o processo, refletindo em como as ações de enfermagem impactam na saúde e na vida do paciente que está submetido ao tratamento, contribuindo assim, não somente para um maior crescimento profissional dos enfermeiros já formados, mas também dos discentes ali presentes, uma vez que permite o desenvolvimento de competências gerenciais como liderança, gestão de tempo, uso de linguagem padronizada, entre outras, e assistenciais como uso adequado das técnicas de procedimentos, contato com protocolos da instituição hospitalar, aperfeiçoamento técnico das habilidades utilizados no exame físico, comunicação com o paciente e familiares, gerando assim uma análise crítica de diferentes pontos de vista, o que contribui para o trabalho em equipe, melhorando a comunicação, exercitando o pensamento crítico e reflexivo, auxiliando na tomada de decisão, farmacologia utilizada, patologias apresentadas pelos pacientes em análise, bem como, a revisão de conteúdos referentes à fisiologia e anatomia humana. Desenvolver pessoas não é apenas dar informação para que aprendam novos conhecimentos, habilidades e atitudes para se tornarem mais eficientes naquilo que fazem. É também, auxiliar no desenvolvimento pessoal e social, na capacidade reflexiva dos trabalhadores em serviço e, sobretudo, proporcionar a formação básica para que aprendam novas atitudes, soluções, ideias, conceitos, modifiquem hábitos e comportamentos e se tornem mais eficazes naquilo que fazem 5 .

\section{Conclusão}

Nota-se a importância da contribuição da educação permanente na prática profissional evidenciada por meio das atitudes que o profissional assume enquanto cuida, dentre as quais está o compromisso firmado consigo mesmo, mediante a motivação pela busca do autoconhecimento, do aperfeiçoamento e da atualização, e prevendo melhorar o cuidado prestado ao cliente e à comunidade. Evidencia-se a importância do aperfeiçoamento, da atualização e da atitude crítica e reflexiva das situações vivenciadas na área da promoção, prevenção e reabilitação da saúde, contextua- 
lizada pelas políticas públicas no âmbito da saúde e da educação. Conclui-se, portanto, a notoriedade da participação dos discentes no processo de Educação permanente durante a implantação e implementação do PE num hospital escola, uma vez que permite aliar a teoria aprendida em sala de aula com a prática no ambiente hospitalar, vivenciando as dificuldades da futura profissão, tendo a oportunidade de mesmo antes da formação ter uma noção de suas futuras responsabilidades como profissionais de Enfermagem, sendo que, são responsáveis não só por pacientes, mas por toda uma equipe, que demanda fortemente de sua liderança. Isso tudo contribui para a construção de novas habilidades, como por exemplo: pensamento crítico, raciocínio clínico, tomada de decisão, comunicação assertiva, gestão do tempo, trabalho em equipe, liderança, organização, empatia, busca por aprimoramento técnico e científico. A geração de tais habilidades possibilitará o fortalecimento das ações de enfermagem tornando assim um cuidado em saúde seguro, resolutivo, eficaz, ao mesmo que diminui custo com a redução da permanência do paciente no ambiente hospitalar, beneficiando não somente a população que será atendida, bem como os novos profissionais da área da enfermagem.

Descritores: Educação permanente; Processo de Enfermagem; Cuidados de Enfermagem.

\section{Referências}

1. Conselho Federal de Enfermagem. Resolução COFEN-358/2009. Dispõe sobre Sistematização da Assistência de Enfermagem e a implementação do Processo de Enfermagem em ambientes, públicos ou privados, em que ocorre o cuidado profissional de Enfermagem, e dá outras providências. Brasília (DF): COFEN, 2009. Disponível em: http://www.cofen.gov.br/resoluo-cofen-3582009_4384.html. [Acesso em 21 jan. 2021].

2. Silva EGC, Oliveira VC, Neves GBC, Guimarães TMR. O conhecimento do enfermeiro sobre a Sistematização da Assistência de Enfermagem: da teoria à prática. Revista da Escola de Enfermagem USP 2011; 45(6):138o-6. Disponível em: https://www.scielo.br/pdf/reeusp/ v45n6/v45n6a15.pdf. [Acesso em 21 jan. 2021].

3. Paschoal AS, Mantovani MF, Lacerda MR. A educação permanente em enfermagem: subsídios para a prática profissional. Revista Gaúcha de Enfermagem, Porto Alegre (RS) 2006 set;27(3):336-43. Disponível em: https://seer. ufrgs.br/RevistaGauchadeEnfermagem/article/view/4621/2633. [Acesso em 27 jan. 2021].

4. Jesus MCP, Figueiredo MAG, Santos SMR, Amaral AMM, Rocha LO, Thiollent MJM. Educação permanente em enfermagem em um hospital universitário. Revista da Escola de Enfermagem USP 2011; 45(5):1229-36. Disponível em: https://www.scielo.br/pdf/reeusp/v45n5/ v45n5a28.pdf. [Acesso em 27 jan. 2021]. 
RELATO DE EXPERIÊNCIA

PROCESSO DE EDUCAÇÃO PERMANENTE

EM SAÚDE HOSPITALAR NO OESTE CATARINENSE: UM RELATO DE EXPERIÊNCIA

Daniel Jesse Junior Ferreira Cassemiro

Jussara dos Santos Valentini Jacira Batista de Oliveira

Gleica Pressi

Vânia Maria Lovera

Rosana Amora Ascari

\section{Introdução}

O Hospital Regional do Oeste (HRO), mantido pela Associação Hospitalar Lenoir Vargas Ferreira (ALVF) é um hospital público de referência em oncologia, neurologia/neurocirurgia, terapia nutricional, gestação de alto risco e traumato-ortopedia, sendo referência regional para o oeste de Santa Catarina, norte do Rio Grande do Sul e Paraná, pertence a $4^{\underline{a}}$ Regional da Saúde Catarinense e presta serviços aos usuários do Sistema Único de Saúde (SUSS), particulares e da saúde suplementar, atendendo a uma população de mais de 1,5 milhão de habitantes, caracterizado como centro de referência para média e alta complexidade (HRO, 2021). Atualmente o referido hospital conta com quadro funcional de 1.236 profissionais, contemplando o administrativo $(\mathrm{n}=249)$, enfermagem $(\mathrm{n}=623)$, áreas de apoio, tais como, higiene, lavanderia, cozinha e manutenção $(n=230)$ e diagnóstico e tratamento $(\mathrm{n}=134) .{ }^{1}$ No Cadastro $\mathrm{Na}$ cional de Estabelecimentos de Saúde (CNES), possui 339 leitos cadastrados, distribuídos nas unidades de Oncologia I e II, Privativo, Clínica Médica, Maternidade, Berçário, Unidade de Terapia Intensiva (UTI) Adulto, Pediátrica e Neonatal, Centro Cirúrgico (CC), Sala de Recuperação Pós-Anestésica (SRPA), Centro Obstétrico (CO), Clínica Cirúrgica Geral, Clínica Cirúrgica Traumato-Ortopédica, Pronto Socorro (PS) e Neurologia, além dos serviços auxiliares de diagnóstico e terapia, abrangendo 25 especialidades médicas, além de servir de 
campo prático para diferentes cursos da área de à nível técnico, graduação e residência, contemplando instituições públicas e privadas. ${ }^{1}$ Os processos de educação permanente institucional são disparados pela identificação de problemas e desafios encontrados no cotidiano laboral dos profissionais, orientado pela Política Nacional de Educação Permanente (PNEP) e pelas evidências científicas, as quais balizam ações de educação permanente em serviço. Portanto, as capacidades de gestão, orientadas por uma racionalidade estratégica, possibilitam a identificação da natureza dos problemas enfrentados, a priorização desses, construção de planejamento, avaliação e a comunicação dos resultados alcançados. ${ }^{2}$ A Educação Permanente em Saúde do HRO, constitui-se estratégia fundamental às transformações do trabalho com olhar crítico e reflexivo. Destaca-se a necessidade de adoção de novos modelos pedagógicos no intuito de (re)construir o conhecimento na busca de novos modos de ensinar, aprender, assistir e cuidar. ${ }^{3}$ Desta forma, aponta-se a capacitação dos profissionais de saúde e contribuição contínua da EPS para a melhoria dos processos educativos e transformação efetiva das práticas, sobretudo, dos "nós críticos" identificados e enfrentados pela gestão dos serviços na assistência em saúde na atenção hospitalar. O Centro de Estudos do Hospital Regional do Oeste (HRO), foi criado no ano de 2004, de forma discreta, na ocasião incluiu uma biblioteca física e um ponto para acesso virtual, os livros e manequins adquiridos foram por meio de venda de material reciclável provenientes da separação dos resíduos na própria instituição. Concomitante com este processo foi criado a Comissão de Educação Permanente composta por coordenadores dos diferentes unidades hospitalares, sendo estes disparadores dos processos de capacitações na instituição.

\section{Objetivo}

Relatar a experiência dos processos de educação em saúde em um hospital público do oeste de Santa Catarina.

\section{Resultados e Discussão}

No decorrer dos anos foi observado a necessidade de manter trabalhadores da saúde atualizados sobre suas práticas assistenciais e gerenciais, com vistas a qualificação profissional para redução de eventos adversos e fortalecimento da cultura de segurança do paciente, além de atender as recomendações legais que rege os serviços de saúde no país. Assim, no ano de 2012, o HRO disponibilizou um profissional enfermeiro para realizar atividades de educação continuada de enfermagem, profissional que realizava capacitações e acompanhamento de colaborados que estavam iniciando na instituição, conforme a necessidade. Em 2013, com o serviço e atividades já mais estruturadas, foi alocado um segundo enfermeiro para atuar junto ao setor Educação Permanente, com foco nas estratégias de gestão e educação em saúde em busca de novas oportunidades para qualificação dos trabalhadores, com oferta de capacitações, cursos internos e externos, bem como para secretariar os programas de residências médica, os quais foram planejados e impulsionados concomitantemente à reestruturação da educação permanente. Entre os anos de 2013 à 2015, foram realizados vários movimentos para transformar o hospital em Hospital de Ensino, para tanto, outras adequações foram iniciadas, como a criação de novas comissões que contemplasse a legislação vigente e sendo um dos critérios o credenciamento de programas de Residências Multiprofissional e Uniprofissional. Em 2018, foi criado um grupo de trabalho envolvendo profissionais do serviço e docentes de três universidades parceiras, a saber: Universidade do Estado de Santa Catarina (UDESC), Universidade Comunitária da Região de Chapecó (Unochapecó) e Universidade Federal Fronteira Sul (UFFS), e iniciado os primeiros movimentos, sendo em 2019 lançamento do primeiro edital dos Programas de Residências Multiprofissional em Atenção em Oncologia, nas áreas de psicologia, enfermagem, nutrição e farmácia, e; Uniprofissional em Enfermagem em Urgência e Emergência, ambos financiados pelo Ministério da Saúde - Sigresidências. Muitas destas conquistas vem sendo possível graças as parcerias fortalecidas ao longo dos anos com as Instituições de Ensino Superior (IES). Outras parcerias também foram firmadas com grande êxito, como: Associação Brasileira de Linfoma e Leucemia (ABRALE), a qual disponibiliza uma plataforma educacional gratuita por meio de capacitações e atualizações para profissionais da saúde envolvidos no atendimento oncológico. Destacamos ainda a parceria com Centro de Treinamento e Simulação de Emergências Médicas (CTSEM), com oferta de algumas vagas gratuitas nos cursos: Suporte Avançado de Vida (ACLS), Suporte Básico de Vida (BLS) e Suporte Avançado de Vida em Pediatria (PALS), estas vagas são destinadas a profissionais da enfermagem levando em consideração a necessidade do serviço, comprometimento e a disponibilidade do profissional em contribuir como multiplicador de conhecimentos por meio de capacitações à outros profissionais da instituição, além de 
colaborar na elaboração e ou revisão de Procedimento Operacional Padrão (POP's) e Protocolos institucionais. Cabe ressaltar ainda que entre as diferentes atividades desenvolvidas pelo setor de Educação Permanente do HRO, destaca-se as estratégias orientadoras para promover aos colaboradores, capacitações embasadas nos POP's e Protocolos, bem como o desenvolvimento de autonomia profissional, em especial da enfermagem, por ser a maior força de trabalho na instituição, tendo a devida participação registrada em lista de presença por atividade. No cenário hospitalar em questão, há constantes inovações técnico-científicas, o que requer atualização e qualificação permanente dos trabalhadores, gestores e colaboradores das instituições parceiras e formadoras. Esses movimentos são intensos para todos os envolvidos, proporcionando transformações e reorganizações institucional, ${ }^{4}$ propiciando aproximação com a comunidade científica através da inserção de projetos de pesquisa e extensão, com foco na qualidade da assistência prestada. Nesse contexto, a educação permanente em saúde, "no" e "para" o serviço, é compreendida como um processo dinâmico e contínuo, tendo como resultado a construção do conhecimento e um espaço para que os profissionais tenham, ao longo do tempo, sua inserção nos serviços de saúde, com oportunidade de refletir criticamente sobre o cotidiano laboral, práticas assistenciais, gerenciais entre outras. ${ }^{5}$ As demandas para educação em serviço não se definem somente valendo-se de uma lista de necessidades individuais de atualização, mas, majoritariamente, com base nos problemas da organização do trabalho. ${ }^{5}$ Observa-se na práxis que, processos educacionais partem do pressuposto da problematização voltada para construção de conhecimento, especialmente focada na resolução de dificuldades do dia a dia, favorecendo o desenvolvimento da aprendizagem colaborativa, apesar da rotatividade e carência de profissionais nos diferentes setores. Essa construção ocorre por meio do desenvolvimento da consciência crítico/reflexiva e do pensamento livre, que leva ao compromisso pessoal e profissional, de forma a refletir na transformação do contexto vivenciado. ${ }^{3}$ As demandas para educação em serviço estão permeadas por aspectos que vão além de habilidades técnicas e do conhecimento aprendido durante a formação profissional, passando pela subjetividade e por relações estruturadas entre os sujeitos envolvidos nos processos de atenção à saúde, contemplando o proposto na Política Nacional de Educação Permanente em Saúde (PNEPS), a valorização do trabalho, dos trabalhadores e da integralidade da atenção em saúde.

\section{Considerações finais}

Almeja-se que todos os profissionais engajados com a educação permanente em saúde hospitalar possam, de certa forma, evoluir pessoal e profissionalmente. O setor de educação permanente em saúde do Hospital Regional do Oeste, incorporado ao cotidiano da gestão assistencial e gerencial das unidades hospitalares, formula a implementação dos projetos político-pedagógicos, estratégias e ações voltadas às necessidades do serviço, se propõe à construir e organizar uma educação responsável por meio de processos interativos na realidade hospitalar para operar mudancas, negociar e pactuar processos, convocar profissionais ao protagonismo ativo e detectar precocemente interações e movimentos profícuos nesse cenário dinâmico, fortalecendo os processos de gestão e valorização das potências locais.

Descritores: Educação Permanente em Saúde; Qualidade da Assistência à Saúde; Gestão da Segurança; Segurança do Paciente, Administração Hospitalar.

\section{Referências}

1. HRO - Hospital Regional do Oeste. Portal da Transparência. Disponível em: http://www. relatecc.com.br/hro/. Acesso em: 12/01/2021.

2. Ribeiro OCE, Lima VV. Gestão de iniciativas educacionais: a educação permanente $\mathrm{em}$ questão. In: Série Processos Educacionais na Saúde. Volume I - Reflexões e Inovações na Educação de Profissionais de Saúde / Valéria Vernaschi Lima, Roberto de Queiroz Padilha 1. ed. - Rio de Janeiro: Atheneu, 2018

3. Guimarães EMP, Martins SH, Rabelo FCP. Educação permanente em saúde: reflexões e desafios. Ciencia y Enfermeria XVI (2): 25-33, 2010. Disponível em: https://scielo.conicyt.cl/ pdf/cienf/v16n2/art_o4.pdf

4. Adamy EK, Zocche DAA, Vendruscolo C, Metelski Fk, Argenta C, Valentini JS. Tecendo a educação permanente em saúde no contexto hospitalar: relato de experiência. Revista de Enfermagem do Centro-Oeste Mineiro. Revista de Enfermagem do CentroOeste Mineiro. 2017; 7:e1615. DOI: https://doi. org/10.19175/recom.v7io.1924

5. Domingues TAM, Chaves EC. O conhecimento científico como valor no agir do enfermeiro. Rev Esc Enferm USP. 2005; 39(esp):580-8. Disponível em: https://www. scielo.br/pdf/reeusp/vzgnspe/v39nspea10.pdf] 
RELATO DE EXPERIÊNCIA

\begin{abstract}
RELATO DE EXPERIÊNCIA DA ARTICULAÇÃO DA COMISSÃO DE INTEGRAÇÃO ENSINOSERVIÇO DA REGIÃO OESTE/SC DE 2016-2O2O
\end{abstract}

\section{Otilia Cristina Coelho Rodrigues}

Adriana Aparecida Polmann

Ediane Bergamin

Letícia de Lima Trindade

\section{Introdução}

A Comissão de Integração Ensino-Serviço (CIES) existe para apoiar os gestores do Colegiado de Gestão Regional (CGR) na discussão sobre Educação Permanente em Saúde (EPS), assumindo o papel de indutora de mudanças e promotora do trabalho articulado entre as várias esferas de gestão e as instituições formadoras, a fim de superar a tradição de se organizar um menu de capacitações/treinamentos pontuais. A partir desta prerrogativa, a CIES, anualmente, elabora o Plano de Ação Regional de Educação Permanente em Saúde (PAREPS), o qual deve ser executado, monitorado e avaliado em seus respectivos projetos. ${ }^{1}$ Em 2017, houve a instituição do Programa para o Fortalecimento das Práticas de Educação Permanente em Saúde no Sistema Único de Saúde (PRO EPS-SUS), modificando a forma de repasse dos recursos e, com isso, necessitando de um novo processo de trabalho para administrá-los. ${ }^{2}$ Deste modo, com os recursos sendo enviados diretamente aos municípios, houve um impasse sobre a forma como a CIES poderia apoiar a realização de eventos em conformidade com o PAREPS; assim como, de que forma o município poderia garantir formação ao maior número possível de servidores a uma variedade de formações/atualizações. Surgiu a possibilidade de uma articulação regional, para garantir a administração dos recursos. A proposta foi apresentada para a direção do Consórcio Intermunicipal de Saúde do Oeste de 
Santa Catarina (CIS-AMOSC) e após meses de análise por parte da equipe jurídica, garantido lisura ao processo a instituição aderiu ao convênio. Apresentamos a proposta a CIR Oeste que deliberou favorável a proposta, pactuando a CIS-AMOSC como instituição responsável pela administração e execução financeira dos recursos do PRO EPS-SUS.

\section{Objetivo}

Relatar a experiência da articulação da Comissão de Integração Ensino-Serviço (CIES) da Região de Saúde Oeste de Santa Catarina, nos anos de 2016-2020.

\section{Método}

Para a coleta de dados utilizou-se as atas das reuniões da CIES, os Planos de Ação Regional de Educação Permanente em Saude dos anos de 2016-2017 e 2018-2020, bem como o relato de experiência dos profissionais articuladores do mesmo período. A revisão das legislações e documentos vigentes também contribuíram para a elaboração deste relato. Os achados passaram pela análise temática e apresentam achados de domínio público.

\section{Resultados e Discussão}

No período entre 2016 à 2018 houve reunião da Comissão Intergestores Regional (CIR), mediante registro em ata, registrou-se as demandas dos 27 municípios que a compõem, e os quais pactuaram que iriam contratualizar com o CISAMOSC para a execução financeira dos recursos de EPS recebidos via PRO EPS-SUS. O acordo seria materializado em um contrato que os municípios fariam com o CISAMOSC repassando os recursos que seriam utilizados em ações do PAREPS 2018-2020 aos municípios que aderissem. Os temas definidos como prioritários foram POP - Protocolos Assistenciais, Referências e Contrareferencias, Desenvolvimento Humano e trabalho em equipe, PICS - Práticas Integrativas Complementares à Saúde, Inclusão dos portadores de deficiências e seu diagnóstico precoce através das análise comportamentais, Saúde Psicossocial com a instrumentalização da equipe para diagnóstico, tratamento e acompanhamento usuarios com transtornos mentais, uso de álcool e outras drogas, Urgência e Emergência com a instrumentalização para o manejo de usuários com alterações cardiovasculares, neurológicas, oncológicas, politraumas, distúrbios psiquiátricos, acidentes com animais peçonhentos,
Saúde da Mulher com a instrumentalização de equipe multiprofissional para a qualificação do pré-natal na Atenção Primária, com foco na prevenção de agravos, tratamentos com práticas integrativas e complementares, preparação para o parto e acompanhamento puerperal e do recém-nascido em conformidade com as normativas da rede cegonha, além de momentos de qualificação para as equipes dos hospitais de pequeno porte, na lógica de qualificar a atenção ao parto e puerpério imediato, Qualificação para a utilização dos Sistemas de Informação, Orientação para a utilização dos Instrumentos de Gestão e por fim ações para integração da Atenção Primária em Saúde e da Vigilância em Saúde. A princípio, com exceção do município de Chapecó, que tem setor próprio para executar ações de EPS, os demais se comprometeram em aderir, porém os municípios levaram mais de um ano para efetivar os contratos com o CISAMOSC, totalizando 14 municípios que aderiram ao contrato coletivo. Em janeiro de 2019 a CIES Oeste se reuniu para definir quais as ações do PAREPS 2018 seriam realizadas com os recursos dos municípios do PRO EPS SUS e as datas de realização, porém em março com a situação da Pandemia, todas as ações foram paralisadas. A partir de junho que foram retomadas as reuniões, porém foi necessário aguardar que o Ministério da Saúde definisse se a prestação de contas dos recursos que estava previsto para setembro, fosse adiada. A resposta do Ministério da Saúde veio em outubro e a partir daí se conseguiu organizar os cursos observando quais deles seriam possiveis de serem convertidos para a versão on-line. Frente ao panorama pandêmico e a urgência de iniciar as atividades em consonância com a Política Nacional de Educação Permanente em Saúde, foi realizada a atualização em Procedimentos Operacionais Padrão, na modalidade on line. Atualmente está sendo organizado um grupo de estudo em parceria com as principais faculdades da região para tratar da saúde mental com os profissionais de saúde que trabalham em CAPS, Unidade de Acolhimento e hospitais com leitos psiquiátricos; será realizado cursos para as PICS - Práticas Integrativas Complementares em Saúde; Instrumentos de Gestão, bem como os Sistemas de Informação. Para a efetivação das ações em andamento evidenciam-se as potencialidades dos projetos de extensão elaborados pelas universidades membros da CIES, as quais contribuem para a viabilidade e fortalecimento das ações de EPS. Contudo, os desafios são diversos, como a condução dos demais cursos prioritários, a ampliaçã̃o dos recursos e adesão dos 
municípios, bem como as formas de avaliacão e acompanhamento das ações desenvolvidas. Com a contratualização com o CISAMOSC a partir de 2019 criou-se um cronograma e as instituições de ensino e as empresas que tivessem interesse poderiam enviar projetos para serem avaliados. Em 2020 com a situação da Pandemia foi necessário aguardar um período para iniciar as atividades na modalidade on-line, uma vez que os encontros presenciais não estavam autorizados, devido aos riscos.

\section{Conclusão}

Ao relatar as ações da CIES da Região de Saúde Oeste de Santa Catarina, nos anos de 2016-2020, observa-se o processo de mudança das políticas públicas voltadas à EPS no Brasil, que enfrenta novos desafios para seu desenvolvimento, agravados pelo contexto introduzido pela pandemia, o que demonstra a necessidade de apoio às CIES para que possam efetivamente contribuir com a qualificação do pessoal de saúde no contexto de integração ensino-serviço e assim contribuir com a qualificação das práticas em saúde ofertadas no SUS.

Descritores: Educação continuada; Desenvolvimento de pessoal; Atenção Primária à Saúde; Política pública de Saúde; Sistema Único de Saúde.

\section{Referências}

1. Ministério da Saúde (BR). Política Nacional de Educação Permanente em Saúde. Brasília: Ministério da Saúde; 2009.

2. Ministério da Saúde (BR). Portaria n ${ }^{0}$ 3.194, de 28 de novembro de 2017. Dispõe sobre o Programa para o Fortalecimento das Práticas de Educação Permanente em Saúde no Sistema Único de Saúde - PRO EPS-SUS. Brasília: Ministério da Saúde; 2017. Available from: http:// bvsms.saude.gov.br/bvs/saudelegis/gm/2017/ prt3194_30_11_2017.html

3. Ministério da Saúde (BR). Manual Técnico 2018 - Programa para o Fortalecimento das Práticas de Educação Permanente em Saúde no SUS - PRO EPS-SUS. Brasília: Ministério da Saúde, 2018. Available from: https://portalarquivos2.saude.gov.br/images/pdf/2018/ marco/28/Manual-Tecnico-PRO-EPS-SUS-MINUTA17-10.pdf

4. Ministério da Saúde (BR). Política Nacional de Educação Permanente em Saúde: o que se tem produzido para o seu fortalecimento? -1 . ed. rev. - Brasília: Ministério da Saúde; 2018. Available from: http://bvsms.saude.gov.br/ bvs/publicacoes/politica_nacional_educacao_ permanente_saude_fortalecimento.pdf 
RELATO DE EXPERIÊNCIA

\section{CONSTRUÇÃO DE UM CURSO DE CATETER VENOSO CENTRAL EM CRIANÇAS NO DOMICÍLIO: RELATO DE EXPERIÊNCIA}

\author{
Gabriela Beatriz Leonhardt \\ Simone Boettcher \\ Elisângela de Fraga Vidal \\ Marcelo Machado dos Santos \\ Milena Mallon \\ Adriana Aparecida Paz
}

\section{Introdução}

Os cateteres venosos centrais (CVC) são acessos vasculares utilizados para infusão de diversas soluções endovenosas e para monitorização hemodinâmica invasiva'. A continuação da terapia intravenosa no domicílio é uma alternativa para os pacientes com tratamento prolongado $^{2}$. Diante das necessidades em aperfeiçoar o conhecimento em manutenção de CVC e prevenção de infecção no domicílio, buscou-se contribuir para a ampliação de competências por meio do desenvolvimento de um curso de formação profissional autoinstrucional para a educação à distância $(\mathrm{EaD})$ e permanente. Ademais, obteve-se a elaboração de produtos que são essenciais para apresentação do curso, os quais podem ser utilizados e reutilizados, de maneira independente em outras propostas pedagógicas e que estejam de acordo com a licença Creative Commons Atribuição 4.o Internacional. Este projeto foi vinculado ă linha de pesquisa "Redes de atenção à saúde e gestão do cuidado de enfermagem" do Programa de Pós-Graduação em Enfermagem - Mestrado Profissional da Universidade Federal de Ciências da Saúde de Porto Alegre (UFCSPA) e a linha "Educação de profissionais, estudantes e usuários na saúde e enfermagem" do Grupo de Pesquisa em Tecnologia, Gestão, Educação e Segurança no Trabalho (TeGEST), da mesma instituição.

\section{Objetivo}

Relatar a experiência na construção de 
um curso de formação profissional para enfermeiros com o foco na assistência às crianças em uso de CVC no domicílio.

\section{Método}

Trata-se de um relato de experiência para a construção de curso, alicerçado na produção tecnológica aliado às diretrizes do Instructional System Design, definindo-se, entre os diversos modelos do ISD, pelo uso do modelo ADDIE (acrônimo de Análise, Desenho, Desenvolvimento, Implementação e Avaliação). A abordagem sistêmica do modelo compreende a realização de ações estratégicas diante da complexidade dos problemas reais, destacando a interacão significativa dos envolvidos no projeto. O público alvo para oferta do curso foram enfermeiros que atuam na atenção primária à saúde (APS), os quais poderão atender crianças desospitalizadas com CVC. Logo, este profissional precisa receber ações educativas que promovam o conhecimento e habilidade técnica no manuseio e manutenção do CVC. Devido à complexidade deste cuidado que se apresenta ao enfermeiro no cenário da APS desenvolveu-se um curso autoinstrucional para a EaD.

\section{Resultados e Discussão}

O curso foi nominado de "Cuidados de cateteres venosos centrais no domicílio de crianças: curso de formação profissional", com carga horária de 40 horas. Na época de construção deste curso participaram três bolsistas de iniciação científica voluntários, uma enfermeira de Unidade de Tratamento Intensivo Pediátrica (UTIP), uma estudante mestranda responsável pela capacitação dos familiares e enfermeiros da APS sobre manutenção do CVC domiciliar em crianças e dois professores doutores. A elaboração deste curso foi uma atividade complexa e desafiadora, ao passo que exigiu um conhecimento abrangente de diversos recursos tecnológicos e teóricos sobre o tema proposto para que o recurso educativo fosse dinâmico, interativo, atualizado e construtivo aos profissionais enfermeiros. Para a construção deste curso, a equipe de trabalho realizou reuniões semanais e presenciais, com duração máxima de duas horas, no período agosto de 2019 a fevereiro de 2020. Em decorrência da pandemia causada pelo SARS-COV-2, por período indeterminado, as reuniões passaram a ser realizadas de maneira remota utilizando a plataforma Google Meet ${ }^{\circledR}$ e pela troca de mensagens para troca de ideias, agendamentos e agilidade no esclarecimento de dúvidas peloWhats $A p p^{\circledR}$. Este projeto de construção e desenvolvimento resultou em 26 produtos, considerados como recursos educativos que podem ser utilizados e reutilizados de maneira conjunta ou partes dos conteúdos, os quais sejam interessantes para as futuras propostas pedagógicas. $\mathrm{Na}$ fase inicial do modelo ADDIE elaborou-se um instrumento com 34 questões que foi publicizado pela mídia social do TeGEST para a abrangência nacional com a intencionalidade na abordagem de enfermeiros com experiência assistencial relacionada ao manejo do CVC em pediatria no domicílio ou hospital, enfermeiros da APS, por um período de trinta dias. Este instrumento auxiliou na caracterização e avaliação dos conhecimentos prévios, potencialidades e necessidades acerca do tema. Com o encerramento da coleta de dados da demanda, a equipe se organizou para analisar os itens descritivos relacionados as potencialidades e fragilidades, estratificando e agrupando os significados. Esses discursos dos enfermeiros possibilitaram refletir em como atender as necessidades e incluir na proposta pedagógica do curso. $\mathrm{Na}$ segunda fase foi desenvolvido o desenho pedagógico do curso, dando origem à quatro produtos denominados "Plano de Ação Pedagógica (PAP) do Curso de Formação Profissional". Nessa etapa, os membros da equipe se reuniram em ambientes compartilhados da UFCSPA, como as salas de aula e laboratórios de informática, para compartilhar ideias e desenvolver o desenho do curso de formação profissional, estima-se em torno de 120 horas na de elaboração dos PAPs e discussão do número de módulos, conteúdos, recursos a serem utilizados para alcançar a dinamicidade e interatividade, atividades formativas e avaliativas. A terceira fase contemplou a construção dos recursos educativos e didáticos do curso, sendo: seis storyboards, nove recursos educativos em multimídia e seis Sharable Content Object Reference Model (SCORM), que, posteriormente, foram implementados no Ambiente Virtual de Aprendizagem (AVA)-Moodle ${ }^{\circledR}$. Essa fase foi a que mais exigiu reflexão e discussão quanto ao conteúdo, personagens, vetores e características audiovisuais, de tipografia e colorimetria e tamanho da fonte. Esses materiais foram organizados e estruturados em storyboards na plataforma Canva ${ }^{\circledR}$, que foi escolhida por permitir a edição simultânea de um mesmo documento por diversas pessoas, e, posteriormente, foram migrados para o Power Point ${ }^{\circledR}$ para a finalização no formato de apresentação de slides (*.pptx). Os vídeos educativos foram gravados pela equipe no Centro de Simulação Realística da Santa Casa de Misericórdia de Porto Alegre (SCMPA) e UFCSPA e editados nos softwares DaVinci Resolve e Vídeo Maker ${ }^{\oplus}$, e outros utilizaram ilustrações que foram elaborados no Canva ${ }^{\circledR}$ e PowToon ${ }^{\circledR}$. Ao término da produção dos storyboards, eles foram 
enviados para validação pelo Comitê de Especialistas, através de um instrumento de validação de conteúdo educativo em saúde (IVCES). A coleta desses dados foi concluída em 39 dias, sendo estabelecido o Comitê de Especialistas com oito enfermeiros, que foram selecionados através do método SnowBall. Os storyboards alcançaram a validação mínima aceitável de $80 \%$. Com esta etapa de validação concluída e ajustes realizados nos storyboards seguiu-se para a quarta fase, a migração do conteudo pedagógico e teórico para o Articulate Storyline ${ }^{\circledR}$, que para a conclusão foram necessários 50 dias, tendo como produto final seis SCORMs. Neste software foi possível tornar o curso mais interativo e dinâmico; tanto na parte de conteúdo, quanto na resolução de atividades formativas. Para a implementação do curso no AVA-Moodle da UFCSPA, exigiu solicitação da instituição para abertura de sala virtual, a qual foi customizada, requerendo o empenho da equipe na organização e disposição dos elementos que orientam e informam o participante no decorrer de um curso autoinstrucional, e transferiu-se os seis objetos de aprendizagem para a sala virtual que foram testados e checados quanto a interatividade, a transição de telas e a geração de pontuação nas diferentes atividades formativas e avaliativas. A proposta do curso foi submetida no Sistema de Extensão ( $\mathrm{SiEx}$ ) para aprovação da Pró-Reitoria de Extensão, do Núcleo de Tecnologia e Informação (NTI) e do Núcleo de Educação à Distância (NEAD) da UFCSPA. Após a aprovação, o curso foi divulgado nas mídias sociais e sítios eletrônicos, com o apoio do Conselho Federal e Conselhos Regionais de Enfermagem. As inscrições via SiEx foram disponibilizadas por um período de 20 dias, sendo ofertado 300 vagas efetivas e 100 para a lista de espera. Posteriormente, em um período de seis dias, a equipe executou o gerenciamento de inscrições e realizou o contato por correio eletrônico com todos os participantes para confirmar o interesse na realização do curso para a inclusão na sala virtual. Os participantes do curso tiveram nove semanas para realizar os seis módulos, totalizando uma carga horária de 40 horas. Para a obtenção da certificação, a proposta pedagógica do curso considerou a atividade avaliativa do "módulo 6 - Avaliação da aprendizagem de cateteres venosos centrais" desde que o desempenho mínimo seja de 70\%, preconizado pelo Regimento Geral da UFCSPA quanto aos critérios para aprovação3. A quinta fase do método ADDIE-ISD preconiza a avaliação do curso para que seja possivel identificar as necessidades de adequação ou atualização do produto. A oferta do curso está em fase de andamento, até o momento 35 participantes já concluíram o curso com o desempenho superior ou igual a 70\%. Essa fase exige da equipe constante acompanhamento dos participantes do curso no AVA-Moodle.

\section{Conclusão}

A construção do curso autoinstrucional para a EaD possibilitou a produção de conhecimento e a atualização profissional de enfermeiros e estudantes de enfermagem acerca do cuidado às crianças em uso de cateter venoso central no domicílio. O desenvolvimento de novas ferramentas que auxiliam a formação baseada na evidência científica e inovação favorecem a segurança do paciente, e reduzem as reinternações hospitalares, eventos adversos e mortalidade. Ademais, este curso proporcionou à equipe a aquisição de conhecimentos acerca do tema do curso, no uso de diferentes softwares e na gestão do curso pela oferta e do acompanhamento no AVA-Moodle, sendo enriquecedor para a prática acadêmica e profissional dos envolvidos na equipe.

Descritores: Cateterismo Venoso Central, Educação Continuada, Assistência Domiciliar, Enfermagem, Educação em Enfermagem.

Financiamento: Bolsa de Iniciação Científica pelo Programa de Iniciação Científica (PIC) da Universidade Federal de Ciências da Saúde (UFCSPA). Bolsa de Iniciação à Docência pelo Programa de Iniciação à Docência (PID) da UFCSPA.

\section{Referências}

1. Rosado V, Romanelli RMC, Camargos PAM. Fatores de risco e medidas preventivas das infecções associadas a cateteres venosos centrais. J. Pediatr. [Internet]. 2011 [acesso em: 2021 Jan 29]; 87(6):469-477. Doi: https://doi.org/10.159o/ So021-75572011000600003

2. Merritt RJ, Cohran V, Raphael BP, Sentongo T, Volpert D, Warner BW, et al. Intestinal rehabilitation programs in the management of pediatric intestinal failure and short bowel syndrome. J. Pediatr. Gastroenterol. Nutr. [Internet]. 2017 [acesso em: 2021 Jan 29]; 65(5):588596. Doi: 10.1097/MPG.oooooooooooo1722

3. Universidade Federal de Ciências da Saúde de Porto Alegre. Conselho Universitário. Regimento Geral da Fundação Universidade Federal de Ciências da Saúde de Porto Alegre [acesso em: 2021 Jan 29]. Porto Alegre: Universidade Federal de Ciências da Saúde de Porto Alegre, 2018. Disponível em: https:/www.ufcspa.edu.br/ufcspa/ normasedocs/docs/regimento-rev-o6-12-18.pdf 
O MANEJO DA DOR ONCOLÓGICA EM CUIDADOS PALIATIVOS, NA PRÁXIS LABORAL DA ENFERMAGEM

\section{Robson Lovison \\ Érica Catarina Dalabona \\ Débora Marchetti \\ Tania Maria Ascari \\ Sandra Maria Vanini}

\section{Introdução}

O cuidado com a dor, é um dos elementos significativos para a qualidade de vida de pessoas com doenças neoplásicas que ameaçam a continuidade da vida'. Estima-se que a dor atinge cerca de $80 \%$ dos pacientes neoplásicos em fase avançada e ao menos 30\% dos pacientes diagnosticados². Assim, o termo dor total tem sido usado quando se trata de pacientes sem possibilidade de cura, pois, as fragilidades e limitações não se restringem aos aspectos físicos $^{1}$. A dor é uma experiência subjetiva, complexa e individual que afeta, em grau severo ou moderada, a maioria dos pacientes, ao menos transitoriamente ${ }^{3}$. É classificada como o quinto sinal vital e por essa razão, é preciso atenção dinâmica e constante das equipes de saúde². O diagnóstico é realizado clinicamente pela observação e relato do paciente, assim como, através de escalas de mensuração, que devem ser adequadamente classificadas 4 . A dor do paciente vai além do que se denomina nocicepção (dor ligada aos receptores neurais que são ativados por estímulos mecânicos, térmicos ou químicos), alcança as emoções, os sentidos e sentimentos ${ }^{1}$. A queixa de dor não pode apenas ser ouvida pelos profissionais da enfermagem como um incomodo em uma ou várias partes do corpo físico, pois, a dor referida pelo paciente pode se tratar de um sentir abstrato. Ao buscar meios para aliviar o sofrimento do paciente, em todas as suas dimensões, respeitando sua individualidade, o profissional está 
garantindo que o paciente receba o tratamento adequado. Estes elementos são a base para as práticas de Cuidados Paliativos e de conhecimento essencial aos profissionais de enfermagem que atuam na área ${ }^{2 ; 3 ; 4}$.

\section{Objetivo}

Aavaliar, através dos estudos publicados, o manejo da dor oncológica no contexto de Cuidados Paliativos, na práxis laboral da Enfermagem.

\section{Método}

Realizado revisão integrativa nos estudos publicados nas bases de dados, ScientificElectronic Library Online(SCIELO) e na Biblioteca Virtual de Saúde (BVS), utilizando-se como Descritores em Ciências da Saúde (DECS):"cuidados paliativos" AND "dor", AND "oncologia" OR "câncer" OR "neoplasia"AND "enfermagem"; seguindo as seguintes etapas metodológicas: seleção da hipotese, seleção da amostra (estudos), definição das características e análise dos estudos incluídos na revisão, interpretação dos resultados e síntese do conhecimento. Como critérios de inclusão foram definidos: artigos completos, em português, publicados entre 2015 e 2020 e como critérios de exclusão: artigos que não contemplam a práxis laboral e o desenvolvimento do conhecimento na enfermagem; teses, dissertações e editoriais.

\section{Resultados e Discussão}

A pré-seleção resultou em 43 estudos e, após aplicados os critérios de exclusão, 11 publicações foram selecionadas e fizeram parte deste trabalho. A maioria dos estudos foi publicada nos últimos três anos, sendo que estas não se referem especificamente acerca da dor e do trabalho da enfermagem, bem como, poucas são as pesquisas quantitativas que trazem a realidade do cotidiano laboral da enfermagem e, ainda, a discussão qualitativa e fenomenológica acerca do conhecimento da enfermagem a respeito da dor oncológica é incipiente. Apenas um dos 11 estudos analisados trata de escalas de mensuração da dor oncológica e de sua importância nos Cuidados Paliativos5. Há indicativos 3 , de que o NANDA-I é o sistema de classificação mais empregado para a formulação do diagnóstico de enfermagem, mas ainda são poucas as equipes que empregam diagnósticos de enfermagem como um dos instrumentos de mensuração da dor oncológica. Aqueles que a utilizam citam a dor como o diagnóstico mais prevalente ${ }^{1 ; 3} \mathrm{e}$ ainda há, na práxis laboral da enfermagem, pouca associação entre diagnósticos dos sintomas físicos e os comprometimentos psíquicos, emocionais e espirituais. Persiste a prevalência de mensuração dos sintomas físicos em detrimento aos demais, ou seja, há aplicação prevalente de escalas unidimensionais ${ }^{1 ; 4}$ o que pode comprometer a abordagem das práticas em Cuidados Paliativos ${ }^{3}$ Os estudos revelam a complexidade da paliação, assim como, do diagnóstico e abordagem da dor oncológica, exigem conhecimento científico, habilidade técnica e interpessoal para avaliar e promover alívio adequado da dor. Além disso, indicam sua essencialidade na práxis laboral da enfermagem e, portanto, da necessidade de ampliar os processos de construção do conhecimento na área, tanto na formação, como na educação permanente ${ }^{1}$. Os estudos ainda indicam que o enfermeiro tem consciência de que é protagonista nessa ação, pois é quem tem mais contato com o paciente durante as triagens e períodos de internações, em diversas instituições, sendo o cuidador mais atuante na paliaçã̃o ${ }^{2 ; 5}$. Entretanto, o enfermeiro tem dificuldade em encontrar o equilíbrio entre suas próprias emoções e sofrimento diante da possibilidade da finitude do outro e de harmonizar as técnicas e instrumentos de mensuração e diagnóstico, com as percepções e observações que podem ser colhidas espontaneamente durante o cuidado com o paciente ${ }^{1 ; 2}$.

\section{Conclusão}

Os estudos mostram que a maioria dos pacientes oncológicos diante de uma doença ameaçadora de vida, relata ou é diagnosticado com dor, o que afeta diretamente o desenvolvimento dos Cuidados Paliativos, onde o objetivo é promover o melhor bem-estar possível aos pacientes. Não se observa pelos estudos, entretanto, a mesma importância dada para a construção do conhecimento relativo a dor oncológica na enfermagem, seja em sua formação ou na educação continuada ou permanente. A dor física é mais fácil de ser identificada e consequentemente tratada, porém, as dores psicossociais e espirituais exigem do profissional maior atenção. Por vezes, se faz necessário sair dos protocolos técnicos e criar vínculo com paciente e seus familiares, para assim ouvir as falas de quem sente as dores e compreendê-las. Em Cuidados Paliativos é básico que a assistência do profissional de saúde seja voltada à dor total, tornando dessa forma, o processo de diagnóstico e de cuidado humanizado, individualizado, associado a 
medicamentos e técnicas. Por ser um tratamento complexo é fundamental valorizar o paliativismo no processo educativo de forma que o cuidado integral e multidimensional seja efetivamente aprendido e sentido pelos profissionais de saude. Cuidados Paliativos possibilita no exercício da profissão enquanto enfermeiro um caminho mais íntegro e humano de suas atividades, deixando da exclusividade mecanicista. Entre as possibilidades está a de realizar uma abordagem mais fenomenológica nos processos de construção do conhecimento, promovendo a reflexão em torno de todos os processos do ato de cuidar e do tratar em saúde, diante da vida, das possibilidades de cura e da finitude. Aprender a compreender a terminalidade é um dos elementos essenciais para se permitir olhar o paciente integralmente, priorizando seu bem-estar, proporcionando qualidade de vida e respeitando o seu tempo.

Descritores: Dor, Cuidados Paliativos, Oncologia, Enfermagem.

\section{Referências}

1. Mello BS, Almeida MA, Pruinelli L, Lucena AF. Resultados de enfermagem para avaliação da dor de pacientes em cuidado paliativo. Rev. Bras. Enferm. Fev 2019; 72(1):64-72. Disponível em: http://www. scielo.br/scielo.php?script=sci_arttext\&pi$\mathrm{d}=$ So034-71672019000100064\&lng=pt. http:// dx.doi.org/10.1590/0034-7167-2018-0307.

2. Castro CC de, Bastos BR, Pereira AKS. Implementação da avaliação da dor como o quinto sinal vital. Rev. Enferm. UFPE on line, Rev enferm UFPE on line., Recife, nov., 2018 12(11):3009-14.

3. Morais SM, Pereira SA, Oliveira LC, et al. Diagnósticos de Enfermagem para Pacientes em Cuidados Paliativos: Revisão Integrativa da Literatura. Rev Fun Care Online. jan./ dez. 2020; 12:1233-1240. DOI: http:// dx.doi. org/10.9789/2175-5361.rpcfo.v12.9612

4. Rolim DS, Arboit EL, Kaefer CT, Marisco NS, Ely GZ, Arboit, J. Produção científica de enfermeiros brasileiros sobre enfermagem e oncologia: revisão narrativa da literatura. Arq. Cienc. Saúde UNIPAR, Umuarama, v. 23, n. 1, p. 41-47, jan./set. 2019.

5. Oliveira DSS, Roque VA, Maia LFS. A dor do paciente oncológico: as principais escalas de mensuração. São Paulo: Revista Recien. 2019; 9(26):40-59. 
EDUCAÇÃO PERMANENTE EM SAÚDE: CAPACITAÇÃO DE ENFERMEIROS PARA EXECUÇÃO DE ELETROCARDIOGRAMA DE REPOUSO

\author{
Nicole Hertzog Rodrigues \\ Daiane Freitas de Oliveira \\ Adriana Aparecida Paz
}

\section{Introdução}

O eletrocardiograma (ECG) é a reprodução gráfica da atividade elétrica do coração durante o seu funcionamento, registrada a partir da superfície do corpo. O traçado eletrocardiográfico é formado por ondas, complexos, intervalos e segmentos, em que é possível identificar patologias através da captação dos impulsos elétricos do músculo cardíaco. O ECG é um exame investigativo mais comumente realizado em serviços de emergência para diagnóstico e vigilância nas doenças cardíacas. Deste modo, trata-se de uma ferramenta extremamente útil que orienta o diagnóstico, o prognóstico e o tratamento. Este exame é considerado seguro, não invasivo, de baixo custo, rápido e de simples realização. Geralmente, os enfermeiros são os primeiros profissionais de saúde que realizam a avaliação dos pacientes e que quando indicado executam o ECG ${ }^{1}$. A avaliação do ECG com exatidão depende do posicionamento preciso dos eletrodos, no entanto, estes costumam ser colocados de maneira imprecisa ${ }^{2}$. A execução de um ECG com o adequado posicionamento das derivações precordiais e periféricas é essencial para a interpretação precisa do diagnóstico do paciente. Logo, o conhecimento teórico e prático sobre o ECG, precisa ser continuamente abordado, o que pode melhorar com formação e o grau acadêmico. Nesse sentido, ao implementar a educação permanente possibilita aos profissionais melhorar e ampliar a qualidade do atendimen- 
to, realizando de forma correta o procedimento e obtendo o melhor diagnóstico3. A prática de educacão permanente em serviço sobre a eletrocardiografia contribui para o aprimoramento da realização e interpretação do procedimento. Recomenda-se aos profissionais de enfermagem recém-formados que busquem a especialização e a realização de cursos de aperfeiçoamento, para que possam atuar de forma segura visando promover uma melhor assistência e minimizar agravos aos pacientes ${ }^{4}$. Na prática profissional, para prestar atendimento ao paciente cardiológico, o enfermeiro necessita possuir competência considerando o conhecimento técnico, científico, domínio e habilidade técnica na realização de procedimentos, com a finalidade de executar as ações de forma ordenada e sistematizada, especialmente, para avaliar o estado de saúde do paciente e suas complicações. Prontamente, este profissional ao realizar um ECG deve avaliar as condições do aparelho para manuseio correto, propiciar um ambiente adequado, posicionar os eletrodos corretamente e identificar as derivações. Diante do exposto, observa-se a necessidade da educação permanente com o propósito de contribuir na formação dos enfermeiros, tendo em vista a necessidade do conhecimento teórico-prático para execução do ECG.

\section{Objetivo}

Descrever a experiência da prática de educação permanente para a execução de ECG de repouso.

\section{Metodologia}

Relato de experiência sobre a prática de educação permanente realizada em um hospital da região metropolitana de Porto Alegre, Rio Grande do Sul. O público alvo das práticas educativas foram enfermeiros de diversos setores da instituição. As atividades ocorreram durante a jornada de trabalho, em que foram agendados os encontros de acordo com a gerência de enfermagem do serviço, o que permitiu construir um espaço educativo com os enfermeiros. A educadora foi uma enfermeira que recebeu previamente as orientações educativas do chefe da cardiologia da instituição hospitalar para qualificar o conteúdo a ser abordado e o treinamento prático da realização do ECG.

\section{Resultados e Discussão}

A prática educativa foi aplicada em dois momentos distintos com os enfermeiros da instituição hospitalar. Em um primeiro momento, com o apoio dos gestores de cada área de enfermagem, foi ofertado um curso de formação profissional na plataforma de ensino e aprendizagem do hospital, tratando-se de um módulo teórico. O curso continha vídeos ilustrativos que orientavam sobre a anatomia do tórax, preparo da pele, posicionamento das derivações precordiais e periféricas, orientações a serem fornecidas ao paciente e sobre como proceder para a execução do ECG de repouso. $\mathrm{Na}$ plataforma de ensino foi realizado um pré teste para avaliação do conhecimento prévio dos enfermeiros quanto aos conteúdos a serem tratados no curso. Posteriormente, foram agendados com os enfermeiros encontros em um espaço educativo destinado para a realização da prática do curso, sendo oferecido em diversos dias e turnos. Os grupos para cada prática educativa foram de aproximadamente cinco enfermeiros, sendo estes ministrados por uma enfermeira. Nos encontros foram retomados os conteúdos abordados durante o curso teórico e foi proporcionado aos enfermeiros a utilização de simulação realística. Dessa forma, os profissionais puderam aplicar o conhecimento adquirido teoricamente, assim como esclarecer as dúvidas relacionadas à execução do procedimento. Durante a atividade presencial, muitos dos enfermeiros relataram que não possuíam conhecimento prévio para a realização do ECG e que aprendiam como executar o procedimento na prática clínica com colegas de profissão. Alguns mencionaram ainda que não realizavam o posicionamento correto dos eletrodos, assim como o cuidado com o preparo da pele. Ressalta-se que em um estudo com 47 enfermeiras de Unidade de Terapia Intensiva e Cardiologias foi observado que nenhuma das enfermeiras respondeu corretamente o questionário sobre a técnica de localização e posicionamento dos eletrodos precordiais. Dessa forma, evidencia-se a necessidade de uma prática educativa contínua e permanente em serviço com a finalidade de prestar um atendimento eficaz e seguro, assim como reforçar o protagonismo dos profissionais de enfermagem na realização do ECG. Portanto, torna-se essencial que as instituições de saúde realizem investigações periódicas para conhecer as dificuldades e limitações dos profissionais de enfermagem para a realização do ECG.

\section{Conclusão}

A prática educativa foi muito satisfatória pelos relatos dos enfermeiros que puderam perceber um ganho no conhecimento teórico-prá- 
tico. Além disso, esta abordagem trouxe melhorias na execução do procedimento conforme a avaliação e monitoramento da qualidade dos ECG pelo chefe da equipe de cardiologia. A educação dos enfermeiros, portanto, propiciou resultados positivos na qualidade do exame executado, assim como melhoria no conhecimento e domínio da técnica adequada para a realização do mesmo pelos profissionais. A partir deste relato de experiência foi possível desvelar a importância da educação permanente no serviço, tendo a finalidade de qualificar a assistência em enfermagem e saúde. Indiscutivelmente, esta ação contribuiu na formação dos profissionais de enfermagem, tendo em vista a ampliação do conhecimento teórico-prático para a realização de exames, especialmente, o ECG. A competência do enfermeiro requerida para realização deste exame é indispensável, pois é necessário para reconhecer as necessidades dos pacientes cardíacos para o alcance da qualidade assistencial. Cabe às supervisões e gerentes de enfermagem das instituições de saúde, propor espaços educativos aos profissionais envolvidos na realização de procedimentos e da aplicação de protocolos de acordo com as características de rotinas internas do serviço.

Descritores: Eletrocardiografia, Educação Continuada, Educação em Enfermagem, Educação em Saúde, Qualidade da Assistência à Saúde.

\section{Referências}

1. McGrath A, Sampson M. Electrocardiograms: a guide to rhythm recognition for emergency nurses. Enfermeira Emerg. 2018; 26(1):2129. Doi: 10.7748/en.2018.e1767

2. DiLibero J, DeSanto-Madyea S, O'Dongohue S. Improving accuracy of cardiac electrode placement: outcomes of clinical nurse specialist practice. Enfermeira ClínicaSpec. 2016;30(1):4550. Doi: 10.1097/NUR.ooooooooooooo172

3. Alcantar CES, Esparza CM, Cardona JPG. Competencia clínica y conocimiento teórico-prático del personal de enfermeira sobre electrocardiografia em pacientes adultos. Revista Enferm Instituto Mexicano Seguro Social. 2018; 26(1):29-33.

4. Silva ASS, Guimarães KSL, Narciso AC, Cruz RAO. Conhecimento de enfermeiros sobre a execução e interpretação do ECG: uma revisão integrativa. Revista Interscientia. 2019; 7(2):98108. Doi: 10.26843/interscientia.v7i2.1015

5. Fernandes LS, Lira MCLS, França VV, Valois AA, Valença MP. Conhecimento teórico-prático de enfermeiras sobre o eletrocardiograma. Revista Baiana de Enfermagem. 2015; $29(2)$ :98105. Doi: 10.18471/rbe.v29i2.12654 
Estudo DE REVISÃo

\section{SAÚDE ÚNICA: UMA NOVA ABORDAGEM PARA ENFRENTAMENTO DA RESISTÊNCIA A ANTIMICROBIANOS}

\author{
MACHADO, Ana Júlia Mânica \\ OZELAME, Bruna Cristina \\ CALZA, Keli Cristina \\ ANTONIOLLI, \\ Marinez Amabile
}

\section{Introdução}

O termo "Saúde Única", também conhecido como "One Health", é conceituado como uma tríade em saúde, interligando a saúde humana, a saúde animal, o meio ambiente e, dessa forma, reforcando o conceito ampliado de saúde ${ }^{1}$. A vigilẩncia em saúde pública, desenvolveu-se a partir da evolução da microbiologia e ampliação dos conhecimentos relacionados à transmissão de doenças e resistência aos antimicrobianos. Entretanto, só no decorrer dos anos cinquenta, a partir da consolidação e análise dos dados de morbidade, mortalidade e demais registros relevantes para a saúde pública, o conceito de vigilância foi ampliado. Nos anos seguintes, a vigilância tornou-se uma peça fundamental na saúde pública, abrangendo também a divulgação de informações epidemiológicas e medidas de controle de doenças. A incorporação de novas atribuições à ações de vigilância, ocasionou uma divisão de funções, sendo cada uma delas responsável por um setor. Esses setores foram caracterizados como: vigilância epidemiológica, responsável pela promoção e prevenção da saúde frente à doenças transmissíveis; a vigilância sanitária, responsável pela organização e fiscalização do cumprimento das normativas envolvendo todas as esferas de saúde; a vigilância ambiental, responsável pela detecção de fatores de risco ambientais, enquanto a vigilância da saúde do trabalhador investiga e realiza intervencões no que diz respeito às relações entre trabalho e saúde ${ }^{2}$. 


\section{Objetivo}

Este ensaio tem por objetivo discutir possibilidades de integração entre a vigilância em saúde em ações intersetoriais voltadas para a promoção do uso racional de medicamentos e prevenção da resistência bacteriana aos antimicrobianos.

\section{Método}

Este estudo foi desenvolvido a partir de revisões de literatura, no período de novembro de 2020 a janeiro de 2021. Os descritores e suas combinações usadas para construir as estratégias foram: Saúde Única, Resistência Microbiana a Medicamentos, Vigilância em Saúde Pública, Educação em Saúde, Educação Permanente. Junto aos descritores, foram utilizados termos booleanos: AND, OR e NOT, a fim de qualificar as buscas. As buscas foram realizadas nas seguintes bases de dados: Google Acadêmico e Scientific Library Online (SCIELO).

\section{Resultados e Discussão}

Estudar a Saúde Única interligada a resistência antimicrobiana assume grande importância para saúde pública e para o meio ambiente. A Organização Mundial da Saúde (OMS), em conjunto com Organização das Nações Unidas para Agricultura e Alimentação (FAO) e a Organizaçã̃o Mundial da Saúde Annimal (OIE), definiram que o desenvolvimento sustentável se baseia em uma ação mútua entre saúde e bem-estar dos seres humanos, animais e dos ecossistema ${ }^{3}$. Atualmente, a Saúde Única contribui para as discussões sobre questões mundiais importantes para o desenvolvimento de um ambiente íntegro destinado às futuras gerações, como por exemplo, o estudo do surgimento de novas zoonoses e a associação de micro-organismos resistentes à antibióticos ". $\mathrm{O}$ uso inadequado de antimicrobianos, tanto na medicina humana quanto na medicina veterinária, possibilita que os patógenos sofram mutações e produzam novos fatores de virulência, os quais são responsáveis pelo aumento do potencial de invasão, difusão, produção de toxinas e a resistência aos fármacos. Esses novos mecanismos contribuem para a disseminação de doenças infecciosas e, como consequência, afetam a integridade do complexo de saude. As discussões sobre as causas e consequências do surgimento de micro-organismos multirresistentes, devem ter uma atenção constante das autoridades dos setores das áreas de saúde e ambiental ${ }^{4}$. A resistência bacteriana aos an- tibióticos é atualmente o problema de saúde pública reconhecido como um problema global emergente, que afeta a saúde humana e animal e impõe encargos sociais, econômicos e prejuízos ambientais. Em países com sistema de saúde precário, o impacto econômico da resistência bacteriana a antimicrobianos tornou-se maior, já que parte da mortalidade infantil está relacionada a doenças infecciosas, geralmente causada por ineficácia dos medicamentos antimicrobianos, pois muitas bactérias que costumavam ser sensiveis aos antibióticos não respondem mais aos mesmos 5 . Entre os fatores que levam ao surgimento de bactérias multirresistentes está o uso indiscriminado de agentes antibacterianos na prática médica, veterinária e agrícola. Desta forma, a transmissão das bactérias entre vários hospedeiros e reservatórios ambientais desempenham um papel importante na disseminação da resistência aos antibióticos. Em humanos, os agentes indutores do uso incorreto de antibióticos, incluem a automedicação, prescrição irracional, comercialização isenta de prescrição médica e baixa adesão ao antibiótico prescrito, promovendo crescente desenvolvimento de resistência antimicrobiana. Outro fator que contribui para a exposição do ambiente e dos animais aos antibióticos, é a produção em grande escala de suínos, aves e bovinos destinados ao consumo humano, que utiliza de forma excessiva e indiscriminada antimicrobianos com objetivo profilático, curativo ou como promotores de crescimento. E, os seres humanos entram em contato com resíduos de antibióticos e com bactérias resistentes a antimicrobianos oriundas de animais, através do consumo de alimentos contaminados com antimicrobianos e/ou o contato indireto com os medicamentos através do meio ambiente, como por exemplos águas, que muitas vezes são destinadas ao consumo 4. Em 2014, a Organização Mundial de Saúde (OMS) com colaboração dos Estados membros publicou o documento "Resistência antimicrobiana: relatório global sobre vigilância”, o qual teve por objetivo divulgar a magnitude desse problema em nível global, visto que, a situação não é restrita a poucas localidades. Observou-se a inexistência de ações e respostas articuladas mundialmente para o enfrentamento da resistência aos antimicrobianos, demonstrando a fragilidade dos sistemas de vigilância. No ano seguinte, a OMS publicou o "Plano de Ação de Global para o Enfrentamento à Resistência aos Antimicrobianos", propondo ações que promovessem respostas efetivas às doenças infectocontagiosas, embasadas em uma abordagem de acordo com os princípios da 
Saúde Única. As principais consequências da resistência antimicrobiana para os serviços de saúde, estão no aumento da morbidade e mortalidade em doenças que, normalmente, seriam tratadas com os antimicrobianos disponíveis no mercado, além da reemergência de doenças infectocontagiosas, ocasionando de maneira geral um aumento no tempo de internação hospitalar e um impacto financeiro significativo com gastos em saúde 5 . Diante dessa realidade do aumento da resistência de micro-organismos aos antimicrobianos, a maioria dos autores, consultados para organização deste ensaio, mencionam a importância de ações da vigilância em saúde associadas ao conceito de Saúde Única, buscando integrar as ações de vigilância em saúde a partir de atividảdes multiprofissionais e intersetoriais, como auxílio da educação em saúde e de educação permanente, envolvendo profissionais e gestores das áreas de meio ambiente, agricultura, saúde humana e saúde animal, buscando promover o uso racional de medicamentos e reduzir a resistência aos antimicrobianos ${ }^{1}$.

\section{Conclusão}

O Conceito de Saúde Única surge como proposta para integrar as vigilâncias ambiental, sanitária, epidemiológica e saúde do trabalhador em ações intersetoriais no intuito de promover o uso racional de medicamentos e redução da resistência a antimicrobianos 1. O enfrentamento do problema da resistência antimicrobiana requer a mobilização de conhecimentos multidisciplinares, ações de equipes multiprofissionais e articulação intersetorial, envolvendo esforços de diversas áreas, com participação de profissionais de saúde, especialmente: médicos, farmacêuticos, odontólogos, enfermeiros, médicos veterinários e biólogos, além de autoridades sanitárias, companhias farmacêuticas, produtores de alimentos e operadores das cadeias produtivas do agronegócio. É necessário estimular o desenvolvimento de estudos sobre resistência a antimicrobianos que considerem a interação da tríade de saúde - seres humanos, animais e meio ambiente - uma vez que, os genes de resistência são móveis e circulam com facilidade em diferentes ecossistemas ${ }^{4}$. Atividades de educação em saúde e de educação permanente, por sua vez, poderão contribuir para o aprendizado e atualização dos profissionais de saúde, para a conscientização dos indivíduos, das famílias e das empresas a respeito das consequências da prescrição irracional, do uso indiscriminado e incorreto de antibióticos, assim como das consequências do descarte incorreto de tais medicamentos que provocam a contaminação do solo e da agua, que juntos resultam no desenvolvimento de micro-organismos multirresistentes às opções terapêuticas disponíveis para tratamento das infecções bacterianas, resultando em impactos negativos sobre as condições de saúde da população ${ }^{1,4}$.

Descritores: Saúde Única, Resistência Microbiana a Medicamentos, Vigilância em Saúde Pública, Educação em Saúde, Educação Permanente.

Financiamento: $\mathrm{O}$ presente trabalho foi realizado com apoio financeiro do Programa de Bolsas Universitárias de Santa Catarina (Programa UNIEDU), com recursos do Art. 170 da Constituição Estadual de Santa Catarina e da Universidade Comunitária da Região de Chapecó (UNOCHAPECÓ).

\section{Referências}

1. Lima NT da S, Araújo LRT de, Araújo BVS de, Batista VHT, Veloso LS, Leite AI. A Saúde Única na perspectiva da educação popular em saúde. RSD [Internet]. 24 de outubro de 2020 [citado 29 de janeiro de 2021];9(10):e8839109314e8839109314. Disponível em: https://rsdjournal.org/index.php/rsd/article/view/9314.

2. Arreaza ALV, Moraes JC de. Vigilância da saúde: fundamentos, interfaces e tendências. Ciênc. saúde coletiva [Internet]. julho de 2010 [citado 29 de janeiro de 2021];15:2215-28. Disponível em: https://www.scielosp.org/article/ csc/2010.v15n $4 / 2215-2228 / p t /$.

3. Folder - Saúde Única [Internet]. CFMV. 2020 [citado g de fevereiro de 2021]. Disponível em: https://www.cfmv.gov.br/folder-saude-unica/comunicacao/publicacoes/2020/08/03/.

4. Arias MVB, Carrilho CMD de M. Resistência antimicrobiana nos animais e no ser humano. Há motivo para preocupação. Sem Ci Agr [Internet]. 15 de maio de 2012 [citado 29 de janeiro de 2021];33(2):775-90. Disponível em: https:// www.redalyc.org/pdf/4457/445744112039.pdf.

5. Estrela T S. Resistência antimicrobiana: enfoque multilateral e resposta brasileira. Saúde e Política Externa: os 20 anos da Assessoria de Assuntos Internacionais de Saúde (1998 -2018). Disponível em: https://antigo.saude.gov.br/images/ pdf/2018/outubro/22/18_Tatiana_Estrela.pdf. 
RELATO DE EXPERIÊNCIA

\section{A UTILIZAÇÃO DAS FERRAMENTAS TECNOLÓGICAS NA PRÁTICA PEDAGÓGICA DE MONITORIA DIGITAL NO ENSINO REMOTO EMERGENCIAL}

\author{
Kimberly de Mattos \\ Ketlin Simões da Luz
}

Carmen Elizabeth Kalinowski

\section{Introdução}

A pandemia da COVID-19 provocou e exigiu adaptação nas atividades de trabalho, educação e da vida diária que possibilitassem a continuidade das mesmas. Para manter o ensino da graduação, o Conselho de Ensino, Pesquisa e Extensão da Universidade Federal do Paraná (UFPR) regulamentou o período especial de aulas denominado Ensino Remoto Emergencial (ERE), por meio da Resolução № 65/2020-CEPE ${ }^{1}$, bem como propôs o Programa de Monitoria Digital (PMD), promulgado pela Resolução № $55 / 2020-\mathrm{CEPE}^{2}$, frente a necessidade de apoio aos docentes e alunos com foco no acesso as plataformas virtuais de que a universidade detém, bem como o manejo das ferramentas e recursos tecnológicos e de comunicação que poderiam potencializar as práticas pedagógicas. Segundo Fernandes ${ }^{3}$ et al. (2020), a monitoria é conceituada como uma forma de ensino-aprendizagem contribuinte para o processo de formação dos alunos de graduação, mediante as necessidades encontradas na formação acadêmica. Os programas de monitoria contribuem na formação do aluno para a docência e pesquisa dos cursos de graduação, e é considerada um instrumento para a melhoria do ensino com a finalidade de promover a cooperação entre discente e docente. Ao passo que a monitoria digital também foi um grande desafio, porque alem de apoiar os docentes no processo de ensino-aprendizagem, os monitores precisaram potencializar o desenvolvimento em habili- 
dades no uso de ferramentas digitais, bem como gerar aproximação entre alunos de diferentes turmas, trocas de experiências e auxiliá-los nas dificuldades com o ensino remoto.

\section{Objetivo}

Relatar os resultados conquistados com a prática de monitoria digital em meio a pandemia da COVID-19, no PMD do curso de graduação em Enfermagem da UFPR.

\section{Método}

Relatar a experiência no PMD de duas discentes e uma docente na disciplina "Organização do Trabalho do Enfermeiro e Sua Função Social" com carga horária de 6o horas, com uma ementa que abrange conhecimentos da organização do trabalho da Enfermagem, apresentar os processos de trabalho do profissional no cuidado, na gerência, no ensino e na pesquisa nos âmbitos privado e público, além de discutir sobre contribuições sociais, ética e os avanços sociais da profissão. A monitoria digital iniciou em novembro de 2020 e encontra-se em andamento devido ao ERE que se encerra em março de 2021. A opção escolhida para execução da disciplina foi a Plataforma UFPR Virtual, que disponibiliza para o ensino diferentes recursos e ferramentas tecnológicas, e amplia possibilidades de contato de alunos e professores, assim como o grupo da disciplina na mídia social Whatsapp, um recurso para solucionar dúvidas e orientações. Ocorreram encontros semanais entre as monitoras e a docente responsável de forma online para adequação, alinhamento e elaboração de estratégias para as aulas, bem como discussão de planejamento das aulas, desenvolvimento, dúvidas e dificuldades que os alunos possam ter encontrado, para promover um ensino mais acessível e de qualidade mesmo diante do cenário de fragilidades educacionais decorrente do distanciamento social imposto para controle da pandemia. O PMD ofereceu suporte técnico para todos os monitores com duas aulas online para repasse de instruções básicas do uso da plataforma e das possibilidades de acesso às aulas, postagens de materiais, notas e outras informações referentes a disciplina e ao ambiente virtual UFPR Virtual.

\section{Resultados e Discussão}

Em relação as atribuições do monitor como acompanhar o docente nas atividades pedagógicas e/ou promover subsídios para o aprendizado dos discentes em relação aos conteúdos da disciplina, e/ou despertar o interesse dos alunos nos temas debatidos, pode-se indicar como resultados a formulação de orientações para atividades mobilizadoras de conhecimentos prévios para pesquisar, refletir, planejar, avaliar e reestruturar situações contribuindo para as novas condições de processos de ensino e aprendizagem. Pode-se indicar ainda que ao ampliar os conhecimentos sobre as temáticas abordadas a partir de análise prévia de interesse das monitoras, conseguiram desenvolver atividades motivacionais aos alunos matriculados na disciplina. Como a monitoria digital é realizada integralmente, de forma remota com apoio de tecnologia de informação, requereu dos monitores domínio de recursos e ferramentas, apoio da equipe técnica do PMD e expertise própria para pesquisar fontes de orientação de uso dos mesmos. No entanto, mesmo com as monitoras familiarizadas com o uso do computador, algumas dificuldades no manejo destes exigiram atualizações para aumentar, tanto habilidades como as possibilidades disponíveis, assim ampliando estratégias didáticas que valorizassem os conteúdos. Portanto, participar do PMD favoreceu não só o desenvolvimento de habilidades para o uso de diferentes tecnologias educativas, bem como reconhecer outros espaços que viabilizam diferentes conhecimentos. $\mathrm{O}$ ensino remoto apresenta desafios e intercorrências, como a inviabilidade dos alunos acompanharem as aulas síncronas, por motivos socioeconômicos, tais como necessidade de trabalhar, atender familiares, seja por estarem também em atividades remotas nos lares ou cuidarem de pessoas com alguma intercorrência no seu processo de saúde-doença; assim, na intenção de superá-las, as aulas são gravadas facilitando o acesso em horários adequados ao aluno. Há o chat de dúvidas disponibilizado continuamente, que permite interação assíncrona entre todos os participantes. Pode-se apontar que além dos motivos técnicos como falha de internet, indisponibilidade do aparelho digital ou com defeitos, ou por compartilharem estes com as pessoas que convivem, outras dificuldades foram evidenciadas ao passo que muitos alunos do curso utilizavam estes recursos nos laboratórios de informática da universidade, bem como discentes não souberam ou tiveram dificuldades em receber apoio e recursos que os possibilitassem participar das atividades de ensino remoto. Sendo estes os motivos alegados por muitos para não darem continuidade na disciplina. Do mesmo modo, a docente e as monitoras também enfrentaram dificuldades 
técnicas com a plataforma de transmissão Jit$s i$, que permite encontros em tempo real para atividades, sendo preciso utilizar outra plataforma como Google Meet. Outra, foi o manejo do Fórum ou Chat, proposta para as atividades assíncronas o que flexibilizou datas de participação e de entregas de atividades. Apesar das dificuldades encontradas, o uso das tecnologias de informação e comunicação proporcionaram às monitoras um melhor acompanhamento das dificuldades vivenciadas pelos alunos no processo de ensino-aprendizagem de forma online, facilitando uma maior aproximação e diálogo entre discentes e monitoras, principalmente pelo uso dos aplicativos de mensagens como Whatsapp, permitindo intervenções individuais nas dificuldades de cada um. Ỏutro benefício da monitoria digital é a facilidade e agilidade para disponibilizar artigos científicos, artigos de notícias, vídeos, entre outros recursos didáticos, seja por meio da UFPR Virtual ou do próprio grupo do Whatsapp. Percebeu-se que o uso de recursos tecnológicos na educação permite aos alunos sentirem-se mais à vontade para colocarem questões ou dúvidas aos monitores e a docente, deste modo, foi possível estabelecer vínculos, escuta ativa e solucionar algumas adversidades. Assim, os monitores puderam aprender a programar e, por exemplo, fazer a postagem de conteúdos didáticos em auxílio aos professores, ademais de obterem acesso a outras ferramentas digitais, de que a universidade possui licença, com a finalidade de tornar mais interessante, dinâmico e acessível os conteúdos das disciplinas aos alunos, monitores e professores.

\section{Conclusão}

A monitoria tem papel fundamental na formação do mesmo modo que a experiência de contato do monitor com a docência amplifica o processo de aprendizagem do próprio monitor. Outrossim, o PMD permite o acompanhamento do planejamento pedagógico junto ao docente responsável pela disciplina despertando a vocação de ser professor, além de incentivar à criação de novas metodologias pedagógicas, assim como seria no modelo presencial. A experiência de ter contato direto com o processo ensino-aprendizagem e poder observar esse processo com perspectiva de docência, permitiu incorporar as tecnologias como instrumentos pedagógicos facilitadores do processo de ensino-aprendizagem. Deste modo, ser monitora neste cenário no mundo digital contribuiu para aumentar o interesse de desvendar os desafios que a nova geração tecnológica propõe para os futuros profissionais da educação, e faz com que nos tornemos eternos aprendizes, pois sempre estaremos em constante mudança e evolução tecnológica.

Descritores: Educação/ensino a Distância; Educação em Enfermagem; Instituições de Ensino Superior.

\section{Referências}

1. Conselho de Ensino, Pesquisa e Extensão. Resolução no 65/2020-CEPE. Regulamenta, em caráter excepcional, novo período especial para o desenvolvimento de atividades de ensino nos cursos de educação superior, profissional e tecnológica da UFPR, no contexto das medidas de enfrentamento da pandemia de COVID-19 no País. [Internet]. Curitiba: CEPE; 2020. Disponível em: http://www.soc.ufpr.br/portal/wp-content/uploads/2020/10/RESOLU\%C3\%87\%$\mathrm{C}_{3} \% 83 \mathrm{O}-\mathrm{N} \% \mathrm{C}_{2} \% \mathrm{BA}-65-2020-\mathrm{CEPE} . \mathrm{pdf}$

2. Conselho de Ensino, Pesquisa e Extensão. Resolução no 55/2020-CEPE. Institui, em caráter excepcional, o Programa Emergencial de Monitoria Digital, mediante a adequação do Programa Institucional de Monitoria, enquanto vigorar as restrições para o desenvolvimento de aulas presenciais, em função da pandemia do Coronavírus. [Internet]. Curitiba: CEPE; 2020. Disponível em: http://www.soc.ufpr.br/portal/wp-content/uploads/2020/05/RESOLU\%C3\%87\%C3\%83O-N\%C2\%BA-55-2020-CEPE.pdf

3. Fernandes DCA, Fernandes HMA, Barbosa ES, et al. Contribuições da monitoria acadêmica na formação do aluno-monitor do curso de Enfermagem: relato de experiência. Debates em Educação, Maceió, 2020; 12(27):316-29. Disponível em: https://www.seer.ufal.br/index. $\mathrm{php} /$ debateseducacao/article/view/9134 
RELATO DE EXPERIÊNCIA

EDUCAÇÃO PERMANENTE: UMA PRÁTICA APLICAVEL NA PREVENÇÃO E CONTROLE DE INFECÇÃO HOSPITALAR

\section{Patricia Daiane Zanini Bruna Valmorbida Biavatti}

\section{Introdução}

Infecções relacionadas a assistência à saúde (IRAS) são considerados um grave problema em hospitais, pois leva ao aumento do uso de diversas classes de antimicrobianos, os quais levam a geração de resistência microbiana, tornando-se um problema de saúde pública grave. ${ }^{1}$ A higiene e limpeza do ambiente hospitalar tem uma forte ligação com a prevenção e controle de IRAS. As IRAS são infecções que não estavam presentes no momento de admissão do paciente, podem surgir durante o período de hospitalização, após quarenta e oito horas de admissão ou após a alta do paciente, especialmente em pacientes que são submetidos a procedimentos invasivos ou cirúrgicos. ${ }^{2}$ Diversos estudos demonstram que superfícies contaminadas, de quartos de pacientes colonizados ou infectados por germes multirresistentes (GMR) sobrevivem por longos períodos no ambiente, sendo que, potenciais falhas na limpeza do ambiente levam a disseminação do GMR no ambiente hospitalar. ${ }^{3}$ A educação permanente em saúde (EPS) tem como objetivo a construção do conhecimento, sobre problemas construídos na vivência do cotidiano do nosso ambiente de trabalho, buscando ensino e ações de melhoria nos serviços, sendo possível formular processos educativos capazes de transformar as práticas em saúde. ${ }^{4}$ Objetivo: Orientar a equipe de higiene e limpeza de um hospital privado do oeste de Santa Catarina, de modo 
lúdico e simplificado, sobre boas práticas e controle e prevenção de infecção hospitalar.

\section{Método}

Esse relato de experiencia é derivado de uma experiência que ocorreu no mês de fevereiro de 2020, em um hospital privado do Oeste de Santa Catarina, no qual uma atualização e treinamento foram elaborados para a equipe de higiene e limpeza, sendo que metade desta equipe tinha contrato ativo com a instituição e a outra metade era proveniente de uma empresa terceirizada. Um jogo de tabuleiro foi criado e adaptado, o qual era voltado para as boas práticas na prevenção e controle de infecção hospitalar. Naquele momento a equipe de higiene e limpeza foi dividida em duas turmas por turno, sendo eles: matutino, vespertino e noturno. Um dado, de jogos de tabuleiro, de tamanho grande foi confeccionado com caixas de papelão para participação no jogo, assim este dado foi disponibilizado para a equipe e cada participante jogava o mesmo, conforme o número que caia no lançamento do dado, eles andavam a mesma quantia de casas no tabuleiro, sendo que em determinadas casas havia questões relacionadas ao controle de infecção hospitalar, sendo elas: Qual modo de colocação e retirada das luvas no ambiente hospitalar? (neste momento um par de luvas de borracha era disponibilizado ao participante e ele deveria demonstrar como colocar e retirar essa luva). Uso de unhas de acrílico, gel, postiças, unhas compridas (unhas que transcendem a ponta do dedo), com glitter, esmalte não integro, adesivos e pedras, são permitidas? (nesta oportunidade uma inspeção na unha do participante era realizada, para ver se estava adequada ao tamanho, integridade do esmalte e entre outras). Qual o sentido correto para a realização da limpeza e higiene do ambiente do paciente? Quais as oportunidades de higiene de mãos eu tenho em meu dia a dia? Qual é a técnica para a higiene de mãos? (Neste momento o participante demonstrava como ele faz sua higiene de mãos), então a pessoa era questionada sobre essa questão na sua respectiva casa e o Serviço Controle de Infecção Hospitalar (SCIRAS̊), auxiliava na resposta, explicava e elucidava o fato que lhe foi questionado. Se a participante não soubesse ou não tentasse dar uma resposta, era necessário voltar algumas casas. Bem como, determinadas casas levavam o participante ao início do jogo novamente, sendo necessário passar mais uma vez por todas as questões. O participante que conseguisse che- gar ao final do jogo de tabuleiro como vencedor, por responder as questões certas, era recebido com aplausos e ganhava um chocolate, como forma de reforço positivo por ter chegado até o final do jogo, sem desistir.

\section{Resultados e Discussão}

A atividade durou cerca de duas horas por equipe que participava. Muitos colaboradores na questão das unhas trouxeram que não sabiam sobre a questão do comprimento, nem que o uso de glitter e adereços levava poderiam ser abrigo para microrganismos patogênicos. Levantamentos pertinentes sobre a higiene de mãos em vários momentos do dia a dia dos participantes foram trazidos até o jogo, principalmente fora do ambiente hospitalar, foram relatados os momentos de higiene de mãos: ao pegar a condução para suas casas, ao chegar e sair do trabalho, antes das refeições e ao utilizar o sanitário. A rotatividade das equipes de higiene e limpeza é grande, especialmente entre os funcionários da empresa terceirizada, por ofertarem vários locais para realização de serviço de higiene e a preferência dos mesmos ser supermercado, pois conforme relatos colhidos, é mais fácil atuar do que em hospitais. Deste modo, muitas contratações são realizadas, sendo que os treinamentos e atualizações precisam ser constantes, principalmente por não se tratar de profissionais técnicos voltados para a área da saúde. Conforme preconiza a Anvisa $a^{5}$ profissionais independentes de ser equipe técnica, coordenadores, enfermeiros ou equipes terceirizados devem ser treinados com uma periodicidade anual. Ao final da atividade questionamentos pertinentes foram levantados e dúvidas esclarecidas, obtendo um feedback positivo por parte das equipes, as quais reforçaram a importância do Serviço de Controle de Infecção Hospitalar estar envolvido e realizar esse molde de treinamento, pois fica de fácil entendimento, além de ser divertido e descontraído.

\section{Conclusão}

O setor de higiene e limpeza de um hospital é considerado um dos pilares principais no auxílio da prevenção de controle de infecção hospitalar. Desta forma tem demonstrado importante a prática de educação permanente no ambiente hospitalar, principalmente quando se trata de um serviço com alta demanda de rotatividade e por ser uma equipe com um menor nível de escolaridade, o que muitas vezes dificulta no entendimento $d a$ 
gravidade do que é uma infecção hospitalar e os danos que isso posso gerar ao paciente. Os supervisores destes setores também são orientados a observar e abordar as profissionais quando apresentam não conformidades, bem como elaborar treinamentos, principalmente pela alta rotatividade do setor, auxiliando o serviço do Serviço de Controle de Infecção nesse processo de educação permanente.

Descritores: Educação Permanente; Serviços de Controle de Infecção Hospitalar; Infecção Hospitalar.

\section{Referências}

1. Mourão, M F R; Chagas, D R. Ações de prevenção e controle de infecção em hospitais. Brazilian Journal of Development [Internet]. 2020 Junho [cited 2021 Jan 31]; 6(20):3840638417. DOI 10.34117/bjdv6n6-401. Available from: https://www.brazilianjournals.com/index.php/BRJD/article/view/11804/9868

2. Hespanhol, L A B, et al. Infección relacionada con la Asistencia a la Salud en Unidad de Cuidados Intensivos Adulto. Enfermería Global [Internet]. 2018 Janeiro [cited 2020 Dec 20]; 18(1):215-254. DOI https://doi.org/10.6018/eglobal.18.1.296481. Available from: https://revistas. um.es/eglobal/article/view/eglobal.18.1.296481

3. Governo do Estado de São Paulo. Melhores Práticas para higiene e limpeza em ambiente hospitalar [Internet]. São Paulo: Governo do estado de São Paulo; 2019 [cited 2021 Jan 1]. 102 p. Available from: https://proqualis.net/sites/proqualis.net/ files/Melhores\%2opr\%C3\%A1ticas\%2opara\%2ohigiene\%20e\%2olimpeza\%2ohospitalar.pdf

4. BRASIL. PORTARIA № 198/GM Em 13 de fevereiro de 2004 [Internet]. [place unknown]; 2021 Jan 31. Portaria; [cited 2020 Dec 22]; Available from: https://www.nescon.medicina. ufmg.br/biblioteca/imagem/1832.pdf

5. ANVISA. Segurança do paciente em serviços de saúde: limpeza e desinfecção de superfícies [Internet]. Brasília: [publisher unknown]; 2012 [cited 2020 Dec 14]. 118 p. ISBN: 1. Vigilância Sanitária. 2. Saúde Pública. I. Título. Available from: https://www2o.anvisa.gov.br/segurancadopaciente/index.php/publicacoes/item/seguranca-do-paciente-em-servicos-de-saude-limpeza-e-desinfeccao-de-superficies 
RELATO DE EXPERIÊNCIA

\section{EDUCAÇÃO EM TEMPOS \\ DE PANDEMIA: RELATO \\ DE EXPERIÊNCIA}

\section{Ana Beatriz Mattozo Amorim Ingrid Manoella Borges Sarah Dany Zeidan Yassine Thais Marafon Victoria Vieira Hertz Marta Kolhs}

\section{Introdução}

$\mathrm{O}$ ano de 2020 foi marcado pela pandemia do novo Coronavírus, que se espalhou rapidamente pelo mundo todo, levando a população ao isolamento social, a fim de conter sua propagação. Em consequência disso, as redes de ensino suspenderam temporariamente as aulas. ${ }^{1}$ Assim, aulas regulares passaram a ser feitas de forma remota e alunos, familiares e professores tiveram de se adaptar ao novo método, utilizando das mais diversas ferramentas disponíveis. Essa nova realidade trouxe um novo modo de ver e viver o ensino/educação, descobrindo assim novos métodos de ensinar e aprender. ${ }^{2}$ Junto a isso, a pandemia também mostrou a importância dos hábitos de higiene e práticas de lazer alternativas, que se tornaram cada vez mais presentes. Nesse contexto de reinventar-se, os componentes do Programa de Extensão em Saúde Mental da Universidade do Estado de Santa Catarina (UDESC), se desafiaram a desenvolver atividades educativas para os alunos do Ensino Fundamental da escola de Educação Básica Municipal.

\section{Objetivo}

Promover educação em saúde para crianças e pré-adolescentes de escolas públicas do município de Chapecó-SC. 


\section{Método}

A atividade foi realizada no segundo semestre de 2020 na modalidade online, através da plataforma do Google Meet com os alunos de 7 a 10 anos da Escola Básica Municipal na cidade de Chapecó-SC. A diretora da escola solicitou dois temas que julgou como sendo de extrema necessidade em época de pandemia, boas práticas em higiene e atividades de lazer. Nas boas práticas de higiene, foram separados dois temas de maior relevância: higiene corporal e prevenção da Covid-19. Para melhor engajar o conteúdo e de maneira lúdica, foram desenvolvidos pelos membros do Programa de Extensão em Saúde Mental, dois vídeos com teatros de fantoches, na qual abordou a Covid-19 e as boas práticas de higiene, um vídeo com orientação quanto a lavagem correta das mãos e uma apresentação em forma de slide para orientá-las quanto às atividades de lazer que poderiam estar realizando em época de pandemia. Após a apresentação dos materiais elaborados aqui citados, os alunos foram convidados a participar de um Quiz de perguntas de verdadeiro e falso com o intuito de reforçar os conteúdos aplicados.

\section{Resultados e Discussão}

A atividade contou com setenta participantes na sala online, sendo duas professoras do ensino fundamental e uma da graduação que esteve presente durante todas as atividades auxiliando as seis acadêmicas mediadoras, o restante eram alunos do ensino fundamental. Após uma breve apresentação das integrantes do grupo de extensão e uma pequena conversa relacionada às atividades que as crianças gostavam de realizar em suas horas de lazer, foi projetado uma apresentação em PowerPoint, abordando a importância do brincar, de se movimentar e não ficar somente conectados com as tecnologias, de tirar o tempo para brincar com seus familiares e não esquecendo de ajudar nas tarefas de casa. Toda criança tem a necessidade de praticar atividades de lazer como correr, pular, dançar, jogar e geralmente essas atividades eram desenvolvidas com seus colegas e amigos, o que foi impossibilitado com a prevalência da COVID-19. Assim, essas atividades tiveram que ser reajustadas e realizadas com seus familiares, levando em consideração que o espaço físico para realização delas se tornou menor, pois a fim de evitar aglomeração cada família desenvolve as atividades em suas residências. Pensando nisso, foram propostas ati- vidades que podem ser realizadas dentro de casa e que não demandam muito espaço para serem desenvolvidas, dentre elas podemos destacar as brincadeiras com a massinha de modelar e como fazê-la com ingredientes caseiros; Adivinhar qual é o desenho; Carrinho de mão; Morto ou vivo; Objeto oculto; Caça palavras; Percursos com obstáculos e Jogos de mímicas. A infância é marcada pelo brincar, que faz parte de práticas culturais típicas, o que permite à criança vivenciar o lúdico e descobrir-se a si mesma, além de apreender a realidade, tornando-se capaz de desenvolver seu potencial criativo. ${ }^{3}$ Em seguida foi apresentado o vídeo a respeito do teatro de fantoches sobre higiene corporal que contava a história de uma menina chamada Melissa, conhecida como a princesa da preguiça. Melissa mentia que tomava banho e ficava escondida mexendo no celular, os dias passaram e a princesa não tomou banho. Saindo para passear, Melissa reparou que os cidadãos do reino corriam e se escondiam de sua presença e decidiu chamar uma senhora para questionar sobre o ocorrido. A senhora desmaia diante do mau odor da princesa e ao despertar se revela a Tereza, a bruxa da limpeza. Tereza irritada com o cheiro da princesa lança um feitiço e a transforma em uma porquinha. Para quebrar o feitiço, Melissa corre até a floresta e chama Marlene a fada da higiene para aprender a ter bons hábitos de limpeza. Marlene ensina a tomar banho, escovar os dentes e se vestir através de músicas interativas. Após aprender hábitos de higiene, Melissa se transforma em princesa novamente e nunca mais deixa de se cuidar. $\mathrm{Na}$ temática da prevenção da Covid-19, foi elaborado um vídeo que iniciou com uma história contada pela Chapéuzinho vermelho. A personagem conta que em um belo dia estava indo visitar a sua avó para levar alguns produtos de higiene como sabão e máscaras descartáveis, para que ela se protegesse da Covid-19, no caminho encontrou o "lobo mau" que com o seu jeito desajeitado a assustou e perguntando: Aonde você está indo com essa cesta? Chapéuzinho com medo do "lobo" logo respondeu: estou indo a casa da vovó para levar alguns produtos, e explicou que com o surgimento do vírus sua avó não podia sair de casa, pois era perigoso por ser do grupo de risco. O "lobo" com tom de ironia e sarcasmo disse que ninguém precisava se prevenir, pois todos eram saudáveis e jamais iriam contrair a Covid-19. Quando chegou na casa da sua vovó, Chapéuzinho relatou que cumpriu com todas as recomendações para se proteger do vírus e que achou a postura do 
lobo mau muito feia. Na volta para casa, encontrou novamente o "lobo", mas desta vez estava deitado no chão da floresta, com tosse e febre. Vendo a situação, Chapéuzinho correu para a cidade para pedir ajuda, lá encontrou uma enfermeira que ajudou o "lobo" em sua recuperação. Ao final do vídeo, Chapéuzinho e o "lobo mau" explicam para os alunos/crianças o que é o Coronavírus, como proteger a si mesma e a sua família, bem como a importância de realizar as medidas de prevenção.Também foi apresentado um vídeo o qual tratava da lavagem das mãos de forma correta para diminuir a propagação da Covid-19 e eliminar os demais germes existentes. A simulação foi demonstrada por meio de tinta guache preta e uma luva de procedimento, onde mostrava o passo a passo de como deve ser a lavagem de mãos correta, também foi comentado para que as crianças imaginassem que a tinta guache era o sabão a fim de que elas percebessem que realizando o procedimento correto o sabão atinge toda a região das mãos, protegendo-a na sua totalidade.

\section{Conclusão}

No decorrer das atividades os membros do programa de extensão e os professores da referida escola perceberam o quão relevante foi a participaçã̃o e a interação das crianças. Durante toda a atividade, dentre todos os participantes a grande maioria interagia, retirando dúvidas, contando algum fato e colocando comentários no chat. A interação entre as crianças e acadêmicas do programa facilitou o desenvolvimento das atividades, possibilitou maior envolvimento com as criancas e mostrou que a educação em saúde pode ser feita de várias formas, sendo a remota também uma boa opção, sem perder a qualidade. Todo o material de educação em saúde produzido foi disponibilizado para as demais escolas públicas de Chapecó. Este momento proporcionou também o olhar para dentro da essência da extensão "estar na comunidade".

Descritores: Educação; Educação a distância; Pandemia

\section{Referências}

1. CORDEIRO, Karolina Maria de Araújo. O impacto da pandemia na educação: a utilização da tecnologia como ferramenta de ensino. Faculdades IDAAM. 2020, 2-3.

2. QGUEIROZ, Norma Lucia Neris et al. Brincadeira e desenvolvimento infantil: um olhar sociocultural construtivista. Paidéia, 2006, 16(34), 169-179.

3. AlmeidA, Alan Henrique da Guia e Silva, et al. Gamificação na educação física escolar: os professores iniciantes estão prontos para esta nova realidade? ResearchGate, Belém-PA, 2020. 
Pesquisa Original

APOIO INSTITUCIONAL E EDUCAÇÃO PERMANENTE EM SAÚDE COMO PRÁTICAS PARA O ENFERMEIRO: POSSIBILIDADES E DESAFIOS

\author{
Cinira Magali Fortuna \\ Priscila Norié de Araujo \\ Maristel Kasper
}

Adriana Barbieri Feliciano

Monica Vilchez da Silva

\section{Introdução}

O apoio institucional no Sistema Único de Saude (SUS) teve sua origem oficial em 2003, a partir do documento base da Política Nacional de Humanização (PNH)'. Trata-se de uma função gerencial que tem como propósito criar novos modos de fazer gestão em saúde². A Política Nacional de Educação Permanente em Saúde (PNEPS) é uma estratégia para a formação e desenvolvimento dos trabalhadores de saúde do SUS, no intuito de fortalecer a reflexão crítica sobre o trabalho em saúde para qualificar o cuidado promovendo a promoção da saúde individual e coletiva ${ }^{3}$. Pretende transformar, qualificar e romper com a lógica de sistema verticalizado para utilizar a ideia de rede 3 . A função de apoiador pode ser exercida por profissionais de saúde de diferentes formações. Os enfermeiros bem como os demais profissionais que exercem o apoio apontam uma série de desafios no exercício da função, dentre elas, da democratização das relações no trabalho e no avançar das práticas educativas ${ }^{4}$, uma vez que a institucionalização dessas profissões se faz apoiada em hierarquias, na divisão técnica e social do trabalho e em práticas educativas baseada na transmissão de informações. Na região do presente estudo criou-se uma distinção no nome das funções: o apoiador institucional é profissional que atua com a PNH e o articulador é o profissional que desenvolve ações em EPS. Em alguns municipios o mesmo profissional exerce as duas funções de forma concomi- 
tante. Já em outros, as funções de apoiador e articulador fazem parte da estrutura organizacional e os profissionais atuam exclusivamente nessas funções, sem desempenhar trabalho assistencial junto aos usuários. Neste texto iremos apresentar resultados oriundos de dois projetos de pesquisa, em que enfermeiros exerceram essa função e apresentar as contribuições da enfermagem para práticas de Educação Permanente em Saúde (EPS) no SUS.

\section{Objetivo}

analisar as aprendizagens e desafios de enfermeiras na função de apoiadores institucionais e articuladores de EPS, em uma região de saúde do interior do Estado de São Paulo.

\section{Método}

Trata-se de dados produzidos em duas pesquisas qualitativas, uma pesquisa-intervenção intitulada "Apoio institucional e Educação Permanente em Saúde em uma região de saúde no interior de São Paulo: uma pesquisa-intervenção" (FAPESP/PPSUS n ${ }^{\circ}$ 2016/15199-5) e uma pesquisa-ação-intervenção intitulada "Contribuições da pesquisa-ação para o desenvolvimento de práticas profissionais em Educação Permanente em Saúde e Apoio Institucional: pesquisa intervenção" (FAPESP/PPSUS $\mathrm{n}^{\mathrm{o}}$ 2019/03848-7), realizadas em 24 municípios pertencentes a um Departamento Regional de Saúde (DRS), tendo como referencial teórico-metodológico a análise institucional, vertente socioclínica². O período de coleta de dados dos projetos ocorreu entre 2017-2019 e 2020-atual. A população do estudo foi constituída de 13 enfermeiras, no primeiro projeto, no segundo projeto dos 39 apoiadores e articulares 12 são enfermeiros. Os dados foram produzidos por meio de encontros coletivos presenciais, virtuais (via plataforma google meet) e em entrevistas individuais. Os dados foram analisados a partir dos 8 princípios da Socioclínica Institucionals: 1- análise da encomenda e das demandas, 2- participação dos sujeitos no dispositivo, 3- trabalho dos analisadores, 4- análise das transformações que ocorrem à medida que o trabalho avança, 5- aplicação das modalidades de restituição, 6análise das implicações primárias e secundárias, 7- intenção da produção de conhecimentos, 8- atençã̃o ao contexto e as interferências institucionais. Os projetos foram aprovados pelo Comitê de Ética da Escola de Enfermagem de Ribeirão Preto da Universidade de São Paulo (EERP/USP) CAAE no 68438217.8.0000.5393 e $\mathrm{CAAE} \mathrm{n}^{-} 33638720.6 .0000 .5393$.

\section{Resultados e Discussão}

A maior parte das enfermeiras acumulam a função de apoiadoras de humanização e/ ou articuladoras de EPS nos seus municípios com a função de enfermeira assistencial, exigindo a reacomodação da agenda assistencial com a agenda de apoio às equipes da Atenção Primária à Saúde (APS). O início na função apoiadora e articulação é relatado, por algumas delas, como geradora de ansiedades pelo desconhecimento das atribuições a serem desempenhadas. Elas recorrem aos conhecimentos adquiridos na formação inicial em enfermagem como baliza para o desenvolvimento da função. As reuniões de equipe são um dos instrumentos mais utilizados no apoio às equipes da APS. Na agenda semanal, elas distribuem suas atividades assistenciais e as atividades de apoio e articulacão. Elas enumeram várias situações que configuram o trabalho de apoio e artículação, como no planejamento de atividades educativas em saúde, no redirecionamento do trabalho das equipes e nas situações em que são acionadas em razão de conflitos e queixas vividas pelas equipes. Um aspecto interessante é que a função apoio tem por missão auxiliar as equipes a interrogarem seus modos instituídos de produção de saúde, ou seja, de provocar análises e reflexões. No entanto, o enfermeiro apoiador e articulador é comumente acionado para resolver conflitos e por vezes, não problematiza esse aspecto com a equipe. Um dos desafios identificados foi a dificuldade de manter o trabalho de apoio e articulação nos momentos de redução de membros da equipe por licenças e /ou afastamentos, sendo priorizadas as atividades assistenciais da enfermeira. Outro desafio levantado para o desenvolvimento na função está na forma diretiva e/ou autoritária com que a enfermagem por vezes conduz os processos de gestão com as equipes, com pouco espaço para o diálogo e a construção compartilhada. Na região estudada, a enfermagem foi a profissão mais indicada pelos gestores de saúde para assumirem a função de apoiadoras e/ ou articuladoras, o que demonstra o reconhecimento de determinadas competências, como saber intermediar, remediar. Os resultados demonstram o reconhecimento por parte dos gestores, de competências adquiridas durante a formação do enfermeiro e que podem contribuir para o trabalho nas equipes de saúde. No tocante às equipes, o enfermeiro passa a ser visto como um representante da gestão que tem como papel acompanhar seu trabalho. Se esse aspecto é reforçado pelo enfermeiro que exerce a função apoio e articulação, a relação com 
equipes pode encontrar dificuldades, e assim assumir aquilo que justamente precisaria ajudar a desconstruir. A assunção à função apoio e articulação traz visibilidade ao profissional e uma diferença na relação com as equipes, mas necessita ser problematizada e acompanhada.

\section{Conclusão}

Os estudos revelaram que o enfermeiro tem sido indicado para ocupar esta função como apoiador e/ou articulador, para além das práticas convencionais como enfermeiros. A formação do enfermeiro facilita a sua atuação, no entanto, ao mesmo tempo, uma formação tradicional em gerenciamento com base nas teorias da administração científica também o impelem para o estabelecimento de relações mais verticalizadas e autoritárias na relação com as equipes apoiadas. Destacamos a importância do fortalecimento de experiências relacionadas ao trabalho em equipe, o apoio institucional e a educação permanente em saúde durante o processo de formação e do trabalho do enfermeiro. Princípios teóricos do movimento institucionalista, como os citados acima, também oferecem aporte para o desempenho destas funções, além de momentos de reflexão coletiva.

Descritores: Humanização da Assistência; Educação Permanente em Saúde; Política de Saúde; Şistema Único de Saúde.

Financiamento: PPSUS FAPESP: processos no 2016/15199-5 e n ${ }^{-0}$ 2019/03848-7

\section{Referências}

1. Ministério da Saúde (BR). Secretaria de Atenção à Saúde. Núcleo Técnico da Política Nacional de Humanização. HumanizaSUS: Documento base para gestores e trabalhadores do SUS/ Ministério da Saúde, Secretaria de Atenção à Saúde, Núcleo Técnico da Política Nacional de Humanização. 4 ed. 4 reimpressão. Brasília: Editora do Ministério da Saúde; 2010. [Internet]. [cited Oct 28,2017]; Disponível em: http:// bvsms.saude.gov.br/bvs/publicacoes/humanizasus_documento_gestores_trabalhadores_sus.pdf

2. Campos GWS. Um método para análise e cogestão de coletivos: A constituição do sujeito, a produção de valor de uso e a democracia em instituições - O método da roda. São Paulo: Hucitec; 2007.

3. Ministério da Saúde (BR). Portaria n. 198/GM/ MS de 13 de fevereiro de 2004 (BR). Institui a Política Nacional de Educação Permanente em Saúde como estratégia do Sistema Único de Saúde para a formação e o desenvolvimento de trabalhadores para o setor e dá outras providências. 2004. [cited Nov 01, 2017]; Disponível em: http:// www.saude.pb.gov.br/site/geab/portaria198.pdf

4. Fortuna CM, Franceschini TRC, Mishima SM, Matumoto S, Pereira MJB. Movements of Permanent Health Education Triggered by the Training of Facilitators. Rev. Latino-Am. Enfermagem [Internet]. 2011 Mar-Apr [cited Sep 25, 2017]; 19(2):[10 telas]. Available from: http:// www.scielo.br/pdf/rlae/v19n2/pt_25

5. Monceau, G. A socioclínica institucional para pesquisas em educação e em saúde. In: L'Abbate, S., Mourão, L. C., \& Pezzato, L. M. (Orgs.) Análise institucional \& saúde coletiva. São Paulo: Editora Hucitec, p. 91-103; 2013. 
Estudo de REVISÃo

\section{BUNDLES E EDUCAÇÃO PERMANENTE COMO ESTRATÉGIAS PARA PREVENÇÃO DE PNEUMONIA ASSOCIADA À VENTILAÇÃO MECÂNICA}

\author{
Raquel de Oliveira \\ Laudiosa da Motta
}

Suely Lopes de Azevedo

\section{Introdução}

As Infecções Relacionadas à Assistência em Saúde (IRẢS) são eventos adversos graves que acometem pacientes hospitalizados, principalmente aqueles na condição de gravidade internados em Unidade de Terapia Intensiva (UTI). Dentre as IRAS presentes neste cenário destaca-se a Pneumonia Associada à Ventilação Mecânica (PAVM), definida pela Agência Nacional de Vigilância Sanitária (ANVISA) como a pneumonia evidenciada após 48 horas do início da Ventilação Mecânica (VM), que não estava incubada no período da admissão do paciente, e 72 horas após a extubação. Segundo a Sociedade Paulista de Infectologia, podem ser classificadas de acordo com tempo após internação hospitalar em que ocorrem, podendo ser precoce, a qual ocorre até o quarto dia após intubação, e tardia, ocorrendo após o quarto dia de intubação. Tudo associado aos critérios clínicos observados na análise dos resultados de exames radiológicos e laboratoriais'. A PAVM é a infecção mais frequente em pacientes internados na UTI, podendo apresentar incidência entre 10 e 30\%. Está associada à hospitalização prolongada, aumento dos custos com cuidados de saúde e uma mortalidade de $8,1 \%$ a $31,9 \%$. Ocupa a segunda infecção nosocomial em termos gerais, o que representa um grande desafio terapêutico ${ }^{2}$. Diante desse contexto, as organizações internacionais e a ANVISA tem recomendado a adoção de bundles para a prevenção de PAVM, visto seu impacto na assistência e 
na redução das taxas de infecções, pressupondo que a escolha dessas intervenções considere custo, facilidade de implantaçã̃o e adesão $0^{2-3}$. Um bundle fundamenta-se na adoção de um conjunto de medidas baseadas em evidências científicas combinadas e integradas para a redução de infecções. Tais medidas são descritas pelo Center for Disease Control and Prevention (CDC) e têm sido incluídas, na prática clínica na forma de um pacote de intervenções estruturado, no intuito de melhorar os processos de trabalho e os resultados dos cuidados para o paciente, ou seja, um conjunto pequeno e simples de práticas (em geral de 3 a 5 ), que quando executadas coletivamente e de forma confiável, promove a melhoria nos resultados ${ }^{3}$. De maneira geral, o sucesso depende do envolvimento de toda equipe assistencial e serviços que colaboram direta ou indiretamente, de acordo com as necessidades de cada unidade.

\section{Objetivo}

Identificar na literatura científica as intervenções utilizadas na prática clínica pela equipe de enfermagem para prevencão e controle de Pneumonia Associada à Ventilação Mecânica.

\section{Método}

Trata-se de um estudo de revisão integrativa, realizado por meio das fontes indexadas às bases de dados Scientific Electronic Library Online (SCIELO), Literatura Internacional em Ciências da Saúde (MEDLINE), e Literatura Latino-Americana e do Caribe em Ciências da Saúde (LILACS). Os critérios de inclusão foram: artigos sobre a temática disponibilizados na íntegra, nos idiomas português e inglês, tendo em vista o recorte temporal de produções científicas publicadas nos últimos 5 anos.

\section{Resultados e Discussão}

Dos estudos selecionados na literatura sobre o assunto em tela, foi possivel definir que a identificação dos principais fatores de risco para PAVM são considerados como modificáveis e não modificáveis. Vários fatores estão associados, como: idade avançada, nível de consciência rebaixado, intubação e reintubação traqueal, condições imunitárias, uso de drogas imunodepressoras, entre outros. Alguns desses fatores estão relacionados com a assistência em saúde, dando início aos processos infecciosos, como o aumento da colonização da orofaringe e do estômago por bactérias patogênicas, utilização de sondas gástricas e en- terais, posição supina com a permanência da cabeceira da cama inferior a $30^{\circ}$, imobilidade pelo estado de coma, trauma ou cirurgias, uso prolongado da VM e as mãos contaminadas dos profissionais de saúde ${ }^{4}$. Os fatores modificáveis referem-se às intervenções e ações da equipe envolvida na assistêncía ao indivíduo sob VM, como vigilância microbiológica periódica, instituição de protocolos de prevenção, redução de prescrições inadequadas de antimicrobianos, entre outros ${ }^{4}$. A PAVM contribui para piorar o prognóstico do paciente, uma vez que aumentam as chances de complicações, o tempo de permanência nas UTI e, consequentemente, o de internação hospitalar, os custos dispendidos para o tratamento, além de apresentar um grande impacto nos índices de morbimortalidade. Adita-se também o fato que, uma vez instalada, caracteriza-se como uma assistência deficitária, bem como um baixo indicador de qualidade da assistência. Nesse contexto, estudos mostram que para a sua prevenção e controle é de extrema importância a adoçã̃o das principais medidas preventivas em conjunto, sob a forma de um bundle, tais como: 1) avaliação diária da sedação e sua redução sempre que possível, no entanto, apesar dos benefícios, esta medida pode apresentar alguns riscos, como extubação acidental, aumento do nível da dor e ansiedade, assincronia paciente-ventilador e gerar períodos de dessaturação, por isso a interrupção da sedação e o desmame ventilatório devem ser guiados por protocolos bem fundamentados e seguidos fielmente por toda equipe multidisciplinar, a fim de evitar extubações equivocadas e necessidade de reintubações, o que aumenta a chance de PAVM; 2) manter a cabeceira elevada de $30^{\circ}$ a $45^{\circ}$, é uma das principais recomendações para reduzir a broncoaspiração, além de aumentar o volume corrente inspirado, reduzir o esforço muscular e os índices de atelectasia, é essencial em pacientes em uso de nutrição enteral, é considerada uma medida simples e que não demanda custos adicionais; 3 ) higiene oral três vezes ao dia, estudos recomendam a utilização do antisséptico gluconato de clorexidina o,12\%, devido ao seu potencial antibactericida contra organismos gram-positivos e gram-negativos, incluindo os resistentes; 4) mensuração diária a cada 4 horas do cuff do tubo orotraqueal (que deve ser mantido entre 20 e $30 \mathrm{~cm} \mathrm{H} \mathrm{H}_{2} \mathrm{O}$ ), a manutenção da pressão adequada deve assegurar a vedaçã̃o da traqueia para impedir microaspirações de secreções subglóticas para o trato respiratório inferior, as quais são potencialmente causadoras de PAVM, e ao mesmo tempo não deve ser elevada, a fim de evitar o comprome- 
timento da perfusão traqueal, pois a hiperinsuflação pode ocasionar isquemia local, que pode evoluir com estenose, fístulas e traqueomalácia. Acrescenta-se também aos cuidados supracitados a checagem diária do posicionamento da sonda enteral; profilaxia da trombose venosa profunda e da úlcera gástrica'. E associada a todas essas medidas, e não menos importante, o reconhecimento pela equipe de saúde sobre o fato de ser imprescindível a Higienização das Mãos (HM). Tal procedimento e a medida individual mais simples e menos dispendiosa para prevenir a propagação das IRAS, uma vez que constituem a principal via de transmissão de micro-organismos durante a assistência prestada aos pacientes. A adequada HM por parte dos profissionais que atuam nos serviços de saúde é considerada como a principal medida de prevenção e controle das IRAS. Além de ser um método simples e barato, que deve ocorrer antes e após a assistência prestada, independente do uso de luvas $s^{4-5}$. Portanto, a adoção de pacotes de intervenções ou de um conjunto de boas práticas, denominados bundles, é de extrema relevância, pois de acordo com a literatura estudada, é sabido que a aplicação de intervenções em conjunto é comprovadamente mais eficaz, do que a aplicação de medidas isoladas.

\section{Conclusão}

A PAVM é considerada como um agravo de alta letalidade nas UTI, e por isso deve ser prevenida, por meio de intervenções e cuidados realizados não somente pela equipe de enfermagem, uma vez que requer o envolvimento de toda equipe multidisciplinar inserida no cuidado. Como estratégia para prevenção e controle da PAVM, os bundles têm sido recomendados para substituir as medidas isoladas de prevenção, visto que a utilização de protocolos melhora a segurança e a qualidade da assistência, mas requer adesão e treinamento periódico da equipe multidisciplinar, para que possam ser considerados indicadores de qualidade. Desse modo, a segurança do paciente emerge da interacão dos componentes, conhecimento, habilidades, atitudes e responsabilidade no cuidar, onde todos que compõem a equipe devem ter como prioridade uma assistência prestada de forma conjunta, simultânea, livre de danos e voltada para a pronta recuperação do paciente. Diante do exposto, conclui-se também que, além do processo educativo e da qualidade assistencial, é de extrema importância a supervisão dos processos de trabalho e gerenciamento das unidades, para que tais normas sejam instituídas e incorporadas. Ademais, ressalta-se a importân- cia de realização de capacitações de forma continuada, treinamentos e educação permanente nas instituições, tendo como propósito não somente capacitar, mas também promover a sensibilização da equipe multidisciplinar envolvida, com vistas à adesão dessas boas práticas.

Descritores: Pneumonia Associada à Ventilação Mecânica; Educação Permanente; Controle de Infecções; Segurança do Paciente.

\section{Referências}

1. Brasil. Agência Nacional de Vigilância Sanitária. Medidas de Prevenção de Infecção Relacionada à Assistência à Saúde. Brasília: Gerência Geral de Tecnologia em Serviços de Saúde, 2017.

2. Rodrigues, A. N. et al. Impactos e fatores determinantes no bundle de pneumonia associada à ventilação mecânica. Revista Brasileira de Enfermagem; Nov-dez; 69 (6):1108-14, 2016.

3. Alecrim, R. X. et al. Estratégias para prevenção de pneumonia associada à ventilação mecânica. Revista Brasileira de Enfermagem; 72 (2): 545-55, 2019 a.

4. Alecrim, R. X. et al. Boas práticas na prevenção de pneumonia associada à ventilação mecânica. Acta Paulista de Enfermagem; 32 (1): 11-7, $2019 \mathrm{~b}$.

5. Branco, A. et al. Educação para prevenção da pneumonia associada à ventilação mecânica em unidade de terapia intensiva. Revista Brasileira de Enfermagem;73(6), 2020. 
RELATO DE EXPERIÊNCIA

\section{APLICAÇÃO DA METODOLOGIA ON THE $J O B$ COMO ESTRATÉGIA DE EDUCAÇÃO PERMANENTE NO CONTEXTO HOSPITALAR}

\author{
Lucas Corrêa Preis \\ Giuliana Cosentino \\ Freitas Santos \\ Jaqueline Caetano \\ Marli Rafael Joaquim \\ Marion Hoelz Ioras
}

\section{Introdução}

Sabe- se que a educação não está sujeita apenas ao âmbito escolar. No contexto hospitalar enfrentamos dificuldades que requerem de todos os profissionais da enfermagem um processo contínuo de reflexão de suas práticas. As ações de educação permanente em saúde possuem objetivos que perpassam as atividades profissionais, promovendo o desenvolvimento pessoal, otimizado pelas atividades educativas que aumentam os espaços de comunicação e propiciam a capacitação técnica, obtenção de novas habilidades, conceitos e comportamentos ${ }^{1}$. Várias lacunas estão envolvidas na prestação de cuidados em serviços de saúde e a educação permanente fundamenta-se na promoção de estratégias e de novas maneiras para o enfrentamento da complexidade envolvida no processo assistencial. Além disso, as constantes inovações técnico-científicas acompanham as atividades dos profissionais no cenário hospitalar, o que consequentemente, exige atualização e qualificação permanente dos trabalhadores².

\section{Objetivo}

Relatar a experiência de uma instituição hospitalar de grande porte localizada na região sul com a utilização da metodologia on the job para a capacitação de profissionais de enfermagem. 


\section{Método}

Trata-se de um estudo do tipo relato de experiência que visa apresentar as estratégias de capacitação da equipe de enfermagem de um hospital de grande porte com a utilização da metodologia on the job. A instituição hospitalar está localizada na região sul do Estado de Santa Catarina e conta com aproximadamente 900 colaboradores de enfermagem, divididos em mais de 20 áreas assistenciais, apoio e administrativas. Todas as atividades de educação permanente voltadas aos profissionais de enfermagem da instituição são organizadas e executadas pelo setor de Educação Continuada, composto por três profissionais enfermeiros, sendo dois mestres em enfermagem e um especialista.

\section{Resultados e Discussão}

Os treinamentos realizados por meio $\mathrm{da}$ metodologia on the job são compreendidos como aqueles realizados diretamente no local de trabalho juntamente com a equipe. No contexto hospitalar, os treinamentos on the job significam aqueles realizados no setor/ unidade assistencial onde cada colaborador/ profissional está alocado para as suas atividades laborais. A complexidade do trabalho em saúde em ambiente hospitalar aponta para a necessidade da definição de estratégias mais efetivas para a manutenção constante de um programa de atualização da equipe de enfermagem. A equipe de enfermagem costumeiramente é considerada a maior força de trabalho no ambiente hospitalar e demais serviços de atenção primária. Mesmo sendo a maior força de trabalho, as instituições encontram dificuldades para o estabelecimento de um programa de educação permanente, uma vez que, não é possível suspender suas atividades para a realização rotineira de treinamentos com a equipe, haja vista que os pacientes não podem ser mantidos desassistidos. Dentre as estratégias para a minimização destas dificuldades, a metodologia on the job mostra-se eficiente, haja vista que ela acontece diretamente no local de trabalho de cada profissional. Todos os treinamentos on the job da instituição são realizados pelos profissionais atuantes no serviço de educação continuada e costumeiramente possuem duração média de 30 minutos. Os treinamentos são realizados em horário previamente agendados ou no horário em que as demandas assistenciais do setor/unidade já estejam em sua maioria atendidas. Os profissionais da educação continuada com o apoio do enfermeiro responsável pelo setor/unidade reune a equipe de enfermagem em um espaço com capacidade para a participação de todos, normalmente em círculo para que todos possam possuir uma visão ampla de todos e iniciam as discussões acerca do tema do treinamento. Após as discussões teóricas do conteúdo dos treinamentos, sempre se disponibiliza um espaço para troca de ideias e realização de questionamentos acerca dos temas apresentados. Os materiais utilizados durante os treinamentos são construídos pelos profissionais da educação continuada ou outras equipes especializadas da instituição, podendo incluir cartazes, flyers institucionais, flipp chart, entre outras. Os temas dos treinamentos fazem parte de um cronograma construído anualmente na instituição através de um brainstorming realizado com toda da equipe de enfermagem, bem como, em temáticas emergentes identificadas ao longo das atividades assistenciais por parte da equipe, coordenação de enfermagem ou gerência de enfermagem da instituição. Entre as facilidades na utilização desta metodologia na instituição destaca-se a possibilidade de alcançar um maior número de profissionais na realização dos treinamentos, possibilidade de interromper as atividades assistenciais sem que gere impacto na qualidade dos serviços prestados ou que pacientes fiquem desassistidos. Ao longo das discussões dos treinamentos on the job, um profissional da equipe é selecionado, normalmente o enfermeiro do setor/unidade, para permanecer a disposição dos pacientes caso haja solicitação de atendimento ao longo do treinamento. Além disso, por se tratar de treinamento realizado diretamente no local de trabalho dos profissionais, há diversos temas em que a teoria pode ser discutida diretamente na prática, favorecendo o ensino-aprendizagem dos profissionais de forma completa e através da associação teórico-prática. Entre as dificuldades que podem estar atreladas a utilização da metodologia on the job no ambiente hospitalar, destaca-se a demanda assistencial que pode ser requerida pelos pacientes nos setores/unidades, dificultando a execução das discussões e dos treinamentos. As atividades de educação continuada/permanente em saúde têm por objetivo o enfrentamento das dificuldades que emergem diariamente e visam unir o cuidado, educação e qualidade na assistência ${ }^{2}$. A discussão desta temática tem evoluído em seu conceito e no contexto dos sistemas de saúde. Deve ser considerado um processo permanente visando promover o desenvolvimento integral dos profissionais, empregando os acontecimentos do trabalho, o ambiente normal das atividades em saúde e os estudos 
dos problemas reais e do cotidiano e situações mais apropriadas para atingir uma aprendizagem significativa ${ }^{3}$. A educação dos trabalhadores da saúde é uma área que requer empenho para aprimoramento de métodos educativos que atinjam com eficácia as equipes de saúde. Para que as equipes de saúde possam desenvolver o processo de trabalho associado as atividades de educação permanente, inovar e criar estratégias de educação mais efetivas e práticas geram menos impacto às suas atividades assistenciais e mantem a possibilidade de capacitar os profissionais ${ }^{1}$.

\section{Conclusão}

A enfermagem é uma profissão com papel primordial no atendimento ao paciente, seja ele sob cuidados de baixa, média ou de alta complexidade. Possuir habilidades e uma capacidade ampla de conhecimentos, exige dedicação e atualização constante. Neste interim, estabelecer estratégias como a metodologia on the job para a atualização dos profissionais de enfermagem mostra-se positivamente frente aos desafios enfrentados diariamente durante as atividades laborais.

Descritores: Capacitação de Recursos Humanos em Saúde, Educação Continuada, Assistência Hospitalar, Enfermagem.

\section{Referências}

1. EK, Zocche DAA, Vendruscolo C, Metelski FK, Argenta C, Valentini JS. Tecendo a educação permanente em saúde no contexto hospitalar: relato de experiência. Revista de Enfermagem do Centro-Oeste Mineiro [Internet] 2018 [citado 20 jan 2021];8:e1924.

2. Flores GE, Oliveira DLL, Zocche DAA. Educação permanente no contexto hospitalar: a experiência que ressignifica o cuidado em enfermagem. Trab. Educ. Saúde [Internet] 2016 [citado 20 jan 2021];14(2):487-504.

3. França T, Medeiros KR, Belisario SA, Garcia AC, Pinto ICM, Castro JL, et al. Política de Educação Permanente em Saúde no Brasil: a contribuição das Comissões Permanentes de Integração Ensino-Serviço. Ciência \& Saúde Coletiva [Internet] 2017 [citado 21 jan 2021];22(6):1817-1828. 
RELATO DE EXPERIÊNCIA

\section{EDUCAÇÃO PERMANENTE ON LINE NA REDE A ATENÇÃO A SAÚDE DO MUNICÍPIO DE CHAPECÓ: RELATO DE EXPERIÊNCIA}

Jaqueline Imlau

Nauri Fernando Desordi

Saionara Vitória Barimacker

Lígia Schacth

Olvani Martins da Silva

Sandra Mara Marin

\section{Introdução}

A Rede de Atenção à Saúde (RAS) do município de Chapecó recebe um número expressivo de usuários diariamente, os quais trazem em suas demandas para o serviço de saúde uma diversidade de situações que exigem domínio técnico dos servidores da saúde. E na busca pelo cuidado integral e objetivando a resolução das demandas apresentadas pelos usuários, faz-se necessária a qualificação constante dos servidores. E em virtude da pandemia da COVID-19, a RAS de Chapecó precisou adaptar os serviços de saúde, alterando fluxos de trabalho, criando novos serviços e equipando as unidades já instaladas com equipamentos que permitam a assistência integral do usuário com sintomas respiratórios. Assim, houve a necessidade de desenvolver um projeto com atividades de educação permanente vinculada às situações de urgência e emergência, com as quais os servidores possam repensar as ações acerca dos processos de trabalho como uma necessidade de aprendizagem contínua, pois a qualificação deve ocorrer de maneira permanente, operacionado pelas sugestões e necessidades dos profissionais que atuam nestes serviços.

\section{Objetivos}

Relatar a experiência de ações de educação permanente via plataformas digitais, para qualificar o processo de trabalho em saúde na 
Rede de Atenção a Saúde com foco nas ações de urgência e emergência a partir das necessidades da equipe de saúde.

\section{Metodologia}

Relato de experiência das ações de educação permanente em plataformas digitais, realizadas via programa de extensão "Capacitação em urgência e emergência nas redes de atenção em saúde", do curso de Enfermagem da UDESC em conjunto com a Secretaria municipal de Saúde de Chapecó. Atividade que foi planejada para suprir a necessidade do serviço durante o período de pandemia do COVID-19 e será executada em fluxo contínuo, de acordo com a necessidade do serviço, mediante a prioridade das temáticas. O programa de extensão se fundamenta na Política Nacional de Atenção às Urgências, pautado no conceito andragógico que considera que, a experiência dos profissionais adultos pode ser um rico recurso para promover a aprendizagem. ${ }^{1}$ Estão previstas três ações a saber: ação 1: qualificar os profissionais para o atendimento as urgência e emergência por meio das plataformas digitais disponíveis gratuitamente, com atividades síncronas e assincronas. Ação 2: Produção de vídeos e matéria didático: no serviço pelos profissionais- nas unidades de pronto atendimento do município e no laboratório de enfermagem da Universidade do Estado de Santa Catarina - UDESC. Também serão confeccionados material didáticos como cartilhas informativas, folders, e apostilhas. Ação 3- Simulação realística, essa ação será desenvolvida posteriormente, após controle do estado da pandemia pelo COVID-19. Fazem parte da equipe duas professoras do curso de enfermagem da UDESC, quatro acadêmicos voluntário e três enfermeiras da secretaria de saúde de Chapecó, as quais são responsáveis pela organização das agendas dos profissionais para participação das atividades em horário de trabalho, controle da presença, elaboração de certificados e organização de vídeos quando no serviço. As oficinas são ministradas pelas professoras da UDESC, com duração de uma hora e os vídeos produzidos no laboratório de práticas de enfermagem na UDESC e nos serviços de saúde.

\section{Resultados e Discussão}

O projeto foi elaborado sob uma demanda da secretaria de saúde, e construído em conjunto com a equipe extensionista. Após definição das primeiras temáticas e tramitação do projeto na plataforma de extensão, iniciou-se a confecção das oficinas no formato on line, via plataforma Google meet. Para atender a demanda dos profissionais, as atividades foram realizadas nos turnos da manhã, tarde e noite. Ao todo até o momento forma realizadas 36 encontros on line com as seguintes temáticas: Parada Cardiorrespiratória, Insuficiência Respiratória Aguda, Crise Convulsiva, Crise Hipertensiva, e manuseio de equipamentos. A primeira temática trabalhado foi parada cardiorrespiratória e insuficiência respiratória, em virtude do contexto da COVID-19. Para essas oficinas, foram produzidos como complemento dois vídeos com duração de oito e dez minutos respectivamente, ambos no laboratório de práticas de enfermagem da UDESC, sob liberação da coordenação e seguindo o protocolo de cuidados para prevenção da COVID-19. Participaram das gravações dois acadêmicos e duas professoras. Os acadêmicos simularam um atendimento a parada cardiorrespiratória, explicando todas suas etapas sob supervisão e orientação das professoras. Posteriormente foi realizado o vídeo com demonstração dos dispositivos para administração de oxigênio e manobras de resgate das via aéreas em caso de insuficiência respiratória. A segunda temática foi sobre crise convulsiva e crise hipertensiva, com duração de 30 minutos cada temática, com utilização de recursos de vídeos educativos via yotube. Para a temática sobre manuseio de equipamentos, os vídeos foram realizados em duas unidades de pronto atendimento, pelos profissionais do serviço, com demonstração do manuseio do ventilador mecânico, bomba de infusão, aspirador de secreções, monitor cardíaco e eletrocardiograma. Após abordagem teórica sobre estes equipamentos, os vídeos eram expostos aos participantes. Para as demais oficinas utilizou-se formato expositivo dialogado, intercalando o tempo entre as professoras, afim de prender a atenção dos participantes.

\section{Discussão}

A educação permanente na Atenção Primaria a Saúde com abordagem no atendimento em Urgência e Emergência, possibilitou oferecer aos profissionais da saúde constante transformação e aprendizagem no trabalho fortalecendo seus conhecimentos e traz em comum um saber transformador e significativo. Além da atualização dos conceitos abordados, a incorporação da discussão e apresentação dos equipamentos utilizados pelo serviço, foi fundamental para aprimorar a prática do cotidiano, uma vez que alguns destes equipamentos começaram a fazer parte do serviço após a situação 
da pandemia. É indispensável à qualificação do profissional que atuam em serviços que tem como foco a prevenção, mas atento a todas as situações de urgência e emergência prestando uma assistência segura e com qualidade.

\section{Conclusão}

A atividade foi desafiante pelo formato on line, uma vez que as questões de urgência e emergência requerem o desenvolvimento de técnicas, demonstração, visualização, que foram supridas pelos vídeos. Por outro lado, reforça a necessidade da educação permanente, a preocupação do serviço e o esforço dos extensionistas para mesmo em tempos de pandemia, manter as equipes atualizadas e estimuladas a aprender. Acredita-se que através destas ações a educação permanente servirá como estratégia fundamental para as modificações no ambiente de trabalho fortalecendo a prática profissional no que tange o atendimento as urgência e emergências na Atenção Primária a Saúde.

Descritores: Educação permanente, Emergência, Enfermagem, Atenção Primária de Saúde.

\section{Referências}

1. BARROS, Rosanna. Revisitando Knowles e Freire: Andragogia versus pedagogia, ou O dialógico como essência da mediação sociopedagógica. Educ. Pesqui., São Paulo; 2018, 44:e173244. Available from. Accesso em o7 Sept. 2020.

2. BRASIL. MINISTÉRIO DA SAÚDE. Portaria $n{ }^{\circ} 1601$ de 07 de julho de 2011.Estabelece diretrizes para a implantação do componente Unidades de Pronto Atendimento (UPA 24h) e o conjunto de serviços de urgência 24 horas da Rede de Atenção às Urgências, em conformidade com a Política Nacional de Atenção às Urgências. Brasília, DF, zo11b.

3. BRASIL. MINISTÉRIO DA SAÚDE. Política Nacional de Educação Permanente em Saúde: $\mathrm{O}$ que se tem produzido para o seu fortalecimento? 1ำ edição revisada: Brasília 2018. 
Pesquisa Original

\section{PORTAL EDUCATIVO PARA UM PROGRAMA DE EDUCAÇÃO PERMANENTE HOSPITALAR NO SUL DO PAÍS}

\author{
Rosane Mortari Ciconet \\ Eva Joseane Fontana \\ Denise Antunes de \\ Azambuja Zocche
}

Vania Celina Dezoti Micheletti

\section{Introdução}

A educação permanente em saúde tem sido considerada como instrumento para produzir mudanças e transformações na atuação profissional e nos contextos de trabalho, envolvendo as tecnologias da informação e comunicação (TIC) como mediadoras neste processo. Além de serem facilitadoras e multiplicadoras no ensino, as tecnologias da informação (TICs) proporcionam autonomia e responsabilidade pela aquisição do próprio conhecimento, contribuindo e transformando de maneira positiva os processos do SUS. Essa sustentabilidade técnica e científica para o exercício da profissão do enfermeiro vem sendo estrategicamente trabalhada pela Educação Permanente em Saúde (EPS) ${ }^{1}$. Além da influência nos processos de trabalho em saúde ocasionado pelos avanços tecnológicos, também ocasionam mudanças nos vários contextos profissionais, incluindo a área da enfermagem. No âmbito das ciências da saúde, as tecnologias digitais de informação e comunicação têm proporcionado avanços na educação e na informatica em saúde, bem como a necessidade de repensar os sistemas de informação com relação à interoperabilidade entre os diversos sistemas desenvolvidos. Elas também contribuem tanto para a melhoria da qualidade no atendimento nas ações de cuidado de um paciente, quanto na gestão das organizações de saúde ${ }^{2}$. Nesse contexto, o programa de educação permanente tornou-se uma estratégia nos processos de educação em serviço. 
Com o objetivo de fornecer cada vez mais o atendimento resolutivo e qualificado o Hospital Restinga e Extremo Sul (HRES) implantou o programa de educação permanente, em outubro de 2018. Esse hospital enfrentou mudanças em sua estrutura organizacional e passou por uma transição onde mais de $90 \%$ do quadro de pessoal foi modificado, com ingresso de colaboradores com pouca experiência na área hospitalar. Tendo em vista a complexidade do ambiente do trabalho, houve a necessidade em dinamizar e abranger maior número de profissionais, em processos mais dinâmicos, considerando a alta rotatividade, entre outros fatores. Desse modo, aliando à necessidade do hospital, a enfermeira responsável pelo setor de ensino da instituição, escolhe como seu tema de pesquisa no Mestrado Profissional em Enfermagem desenvolver uma ferramenta para aprimoramento dos processos de ensino e aprendizagem³ ${ }^{3}$ Desse modo, foi desenvolvido um portal educativo com vistas a disseminar as informações, cursos, saberes e experiências bem como fomentar a participação dos colaboradores no Programa de Educação Permanente (PEP) do HRES.

\section{Objetivo}

Desenvolver um portal educativo para o programa de educação permanente do HRES.

\section{Método}

Estudo metodológico ${ }^{4}$ realizado no Mestrado Profissional em Enfermagem da UNISINOS, tendo sido aprovado pelo Comitê de Ética em Pesquisa (CEP) da Universidade do Vale dos Sinos (UNISINOS), sob o número 2419119.0.00o0.5344. Foi realizado em três etapas: pesquisa documental, construção e validação do portal educativo. A pesquisa documental baseou-se no modelo adaptado conforme Cellard'. A construcão do portal educativo utilizou o método de DADI e os processos de validação seguiram as recomendações da norma ISO/IEC 25010 e o processo de avaliação definido na norma 14598-64. Para avaliação de conteúdo utilizou-se o Instrumento de validação de conteúdo educativo em saúde (IVCES ), com três grupos específicos: avaliadores da equipe de TI (PTI), especialistas compostos pelas lideranças de enfermagem (ESPE) e lideranças médicas (ESPM) e a equipe assistencial composta por enfermeiros (ENF) e técnicos em enfermagem (TEC). Para a validação de conteúdo do "Fique por Dentro" participaram os enfermeiros e técnicos em enfermagem das áreas assistenciais.

\section{Resultados}

A pesquisa documental revelou as estratégias utilizadas para a implementação do PEP e a escolha das melhores ações de integração e ensino em serviço que poderiam servir de exemplo/modelo como experiências exitosas a serem desenvolvidos na instituição. Além disso possibilitou identificar as necessidades para a construção e validação do portal educativo. O processo de avaliação e validação do portal educativo envolveu três grupos: equipe de TI, especialistas representados pelas lideranças das áreas de enfermagem e médica e por enfermeiros assistenciais e técnicos em enfermagem. A avaliação realizada pela equipe da TI, mostrou 100\% de aprovação dos critérios avaliados: ef1ciência, funcionalidade, usabilidade e compatibilidade. A manutenibilidade apresentou 62,5\% de concordância. $\mathrm{Na}$ avaliação dos especialistas o portal educativo obteve $100 \%$ de aprovação nos critérios: eficiência, usabilidade e funcionalidade. A equipe assistencial composta pelos enfermeiros e técnicos em enfermagem validaram o conteúdo, obtendo $82 \%$ de concordância nos itens relacionados aos objetivos, $80 \%$ na concordância e $84 \%$ na avaliação da estrutura/ apresentação. Outras características que alcançaram $100 \%$ de aprovação foram a usabilidade e a compatibilidade, mostrando que o Portal Educativo, além de ser fácil de operar, controlar e executar as funções, permite adaptar e instalar com outros ambientes. O design gráfico e a cor do Portal foram considerados agradáveis pelos avaliadores. Neste quesito foi considerada a sugestão do profissional da TI em relação ao cuidado com a resolução das imagens anexadas. O menu principal do Portal foi dividido em seis categorias: apresentação do Programa Educa HRES, os eixos educativos, estágios, cursos de ensino a distância (EAD), fique por dentro e fale conosco. Os eixos educativos do Programa de Educação Permanente são compostos pelo Acolhe HRES, Apoia HRES, Empodera HRES e Fortalece HRES. O Acolhe é composto de: apresentação, cronograma, materiais didáticos, onde o colaborador também poderá acessar os materiais didáticos, as apresentações das capacitações e o guia do colaborador (composto de informações institucionais, postura e ética). O segundo eixo: "Apoia HRES" é composta pela apresentação, materiais didáticos, imagens e vídeos produzidos pelos grupos de estudo. O terceiro eixo: Empodera HRES, contém a apresentação, check-list de acompanhamento dos enfermeiros, imagens e vídeos. O quarto eixo educativo chama-se "Fortalece HRES", cuja página é composta de apresenta- 
ção, materiais didáticos, Práticas Integrativas e Complementares em Saúde (PICS), agenda de eventos, certificados, imagens e vídeos. $\mathrm{Na}$ aba estágios estão contidas informações e produções dos estagiários que atuam no hospital. $\mathrm{Na}$ aba cursos em EAD está um Menu direcionado aos cursos de ensino a distância abertos ou em andamento. $\mathrm{Na}$ aba fique por dentro estão contidos anexo de materiais contendo temas atuais na atenção hospitalar.

\section{Conclusão}

O portal educativo, além de ser uma ferramenta de comunicação, foi visto pelos avaliadores como uma importante estratégia para a educação, contendo informações eficientes e melhorando os processos de trabalho do HRES. A acessibilidade e a praticidade em usar o software foi um fator relevante apontado na pesquisa. Este resultado mostra que o portal educativo é uma ferramenta agregadora para a EPS.

Descritores: Educação permanente. Enfermagem. Hospital, desenvolvimento de recursos humanos.

\section{Referências}

1. Brasil. Portaria $n^{0} 3.390$, de 30 de dezembro de 2013. Institui a política Nacional de Atenção Hospitalar (PNHOSP) no âmbito do Sistema Único de Saúde (SUS). Diário Oficial da União 2013; $30 \mathrm{dez}$.

2. Sales O; Bentes VP. (2019). Tecnologias digitais de informação para a saúde: revisando os padrões de metadados com foco na interoperabilidade. Revista Eletrônica de Comunicação, Informação e Inovação em Saúde. 13. 10.29397/ reciis.v13i1.1469. Acesso em: 30 jan. 2021.

3. Fontana EJ. Desenvolvimento de um portal educativo para o programa de educação permanente de um hospital público no sul do país. 20zo. 115 f. Dissertação (mestrado) - Universidade do Vale do Rio dos Sinos, Programa de Pós-Graduação em Enfermagem, Porto Alegre, RS, 2020. [cited 2021 Jan 29] Available from: http://www.repositorio.jesuita.org.br/handle/UNISINOS/9370

4. Polit DF, Beck CT. Fundamentos de pesquisa em enfermagem: avaliação de evidências para a prática da enfermagem. 9. ed. Porto Alegre: Artmed, 2019. $670 \mathrm{p}$

5. Cellard A. Análise documental. In: Poupart, Jean., et al (Ed.). A pesquisa qualitativa: enfoques epistemológicos e metodológicos; 2008 Petrópolis/RJ: Vozes, 2008. p.316. ISBN 97885-326-3681-2. 
Estudo de REVISÃo

\section{A TEORIA DE PAULO FREIRE E SUAS INTERFACES COM A PROFESSORALIDADE: UMA REFLEXÃO TEÓRICO-EPISTEMOLÓGICA}

Bianca Joana Mattia

Carla Rosane Paz Arruda Teo

\section{Introdução}

Pensar a formação em saúde nos remete à quem forma o profissional de saúde, ou seja, o docente. Nesse contexto é importante refletir: como um profissional de saúde se torna professor? Quais são os aspectos envolvidos nesse processo? Mobilizadas por essas problematizações, considera-se que, a formação pedagógica dos docentes da área da saúde ocorre durante suas trajetórias profissionais. Nesse sentido, essa formação possui a influência das trajetórias de vida, pessoais, acadêmicas e profissionais. Assim, na busca por um conceito que relacione a formação docente com esses processos, surge a professoralidade. Formação e desenvolvimento profissional se complementam em um processo no qual a professoralidade vai se construindo. A partir disso, o professor pode ser considerado sujeito de sua própria vida e do processo educativo em que é participante ${ }^{1}$. Nesse sentido, buscou-se desvelar os processos que constituem a professoralidade na área da saúde, a partir da teoria de Paulo Freire, entendendo que ela possa contribuir para a formação de professores na área $\mathrm{da}$ saúde. Para isso, sentimos a necessidade, de ir além do conhecimento de sua teoria e conhecer também seus fundamentos epistemológicos. Com o propósito de buscar embasamento teórico para ampliar a compreensão dos conceitos que nortearam a teoria desse autor, a partir do estudo da epistemologia da teoria de Paulo Freire, nos propomos responder a 
seguinte pergunta: quais as contribuições do pensamento de Hegel, enquanto epistemologia da teoria de Paulo Freire, para a professoralidade na área da saúde?

\section{Objetivo}

Refletir teoricamente sobre as contribuições do pensamento de Hegel, enquanto epistemologia da teoria de Paulo Freire, para a professoralidade na área da saúde.

\section{Método}

Este ensaio consiste em uma reflexão teórica originada dos componentes curriculares: Seminarios e Epistemologia e Interdisciplinaridade do curso de doutorado do Programa de Pós-graduação em Ciências da Saude, da Universidade Comunitária da Região de Chapecó - Unochapecó. Faz parte de um programa de estudos maior, que consiste em estudar a epistemologia do pensamento Freireano, sendo assim, necessitou-se fazer um recorte sobre a temática, aqui abordaremos especificamente, as influências do pensamento de Hegel na teoria de Paulo Freire.

\section{Resultados e Discussão}

Nossas discussões partem da dialética senhor-escravo presente no livro Fenomenologia do Espírito, de Hegel. O pensamento Freireano é alimentado pela dialética Hegeliana, e enfatiza que o homem é consciência de si e consciência do outro. Ser consciente de si implica desejo, sendo que o homem, essencialmente, deseja o que é desejado por outros homens. Na dialética do senhor e do escravo, Hegel opera com duas consciências: a consciência do senhor, que representa a identidade de si, e a consciência do escravo. Na busca por satisfazerem seus desejos, senhor e escravo confrontam-se por meio de um processo que ocorre pela negação (recíproca) da consciência do outro ${ }^{2}$. A relação entre senhor e escravo é dialética, se encontra e permanece em movimento de contradição? Assim, dialética é um processo que implica identidade e diferença, negação e afirmação, "superar guardando". A contradição é o meio pelo qual a dialética acontece. As consciências necessitam sair de si, se negarem para se reconhecer. A superação vai ocorrer na medida em que houver negação, sendo que, negação não significa destruição, mas superação ${ }^{4}$. Nesse movimento dialético, primeiramente o pensamento assume determinada posição apresentando-se como tese; posteriormente, desperta críticas e será contraditória a sua posição que se apresenta como antítese; em conflito as duas concepções buscam reconciliação, apresentando-se como síntese. A síntese tem como característica absorver os momentos anteriores e conservar, a esse processo Hegel chama de "superar guardando"?. Para Paulo Freire assim como para Hegel, os homens são conduzidos pelos desejos. Ó desejo dos homens é a busca pelo ser mais, considerando que o homem possui consciência de seu inacabamento e por isso busca ser mais. Paulo Freire em sua proposta de educação libertadora diz que os oprimidos em seu desejo e busca de ser mais não podem desejar tornarem-se opressores. Sua real missão é a busca por libertação enquanto oprimidos e também libertação dos opressores, nisso consiste para Freire, a verdadeira dialética. Nesse ponto da teoria de Paulo Freire é possível observar fortemente as influências da dialética senhor-escravo de Hegel, servindo como base para a superação da condição opressor-oprimido para homens transformados e livres. Por isso, na proposta de educação libertadora de Paulo Freire, o autor baseia-se na problematização/libertação, reforçando que os homens são seres historicamente construídos, que se educam na práxis com o processo de ação-reflexão-ação, transformando o mundo por meio desse processo, criando cultura e historia. Nesse modelo de educação, a superação que ocorre por meio da dialética é a superação da contradição entre os educadores e educandos. O educador, nesse processo, é educado em diálogo com o educando. Ambos, se tornam sujeitos do processo e crescem juntos, sendo que quem forma, se (trans)forma, nesse processo dialético. Não há docência sem, discência, as duas se explicam e seus sujeitos, apesar das diferenças, não se reduzem à condição de objetos 5 . Ambos, ao final, tornam-se diferentes do início, em um processo, chamado por Hegel, de superar-guardando, ou seja, conservam consigo o que eram antes e, agregam o que viveram por meio do encontro das duas consciências (docente e discente) e são agora, pessoas diferentes. É nesse processo, em movimento dialético, no qual o professor, em contato com discentes, outros professores e outros elementos que constituem sua trajetória, se formam e se transformam e constituem um processo permanente de construção da professoralidade.

\section{Conclusão}

Pode-se concluir, afirmando que a principal contribuição do pensamento de Hegel, enquanto epistemologia da teoria de Paulo 
Freire para a professoralidade na área da saúde, é a dialética da atividade docente. Nesse processo, educador e educando encontram-se, transformam-se, e crescem juntos, por meio da dialética, em que ambos são sujeitos do processo ensino-aprendizagem e saem transformados. Assim, a professoralidade pode ser considerada um movimento de vir a ser professor, em permanente processo de construção e transformação, por meio da práxis. Ademais, compreende-se que nesse trabalho, a abordagem sobre a formação docente para a área da saude, é sobre o permanente processo de construção da professoralidade durante o percurso profissional. Porém, é importante ressaltar que, esse processo, não substitui a necessidade de pensar a formação docente nessa área, durante a formação inicial nos cursos de graduação.

Descritores: Saúde; Educação; Educação Superior.

Financiamento: Fundação de Amparo à Pesquisa e Inovação do Estado de Santa Catarina (FAPESC) e Universidade Comunitária da Região de Chapecó (Unochapecó).

\section{Referências}

1. CUNHA, MI; ISAIA, SMA. Professor da educação superior. IN: MOROSINI, Marilia Costa et al. Enciclopédia de pedagogia universitária: glossário vol. 2. Brasília: INEP/MEC; 2006.

2. KOJEVE, A. Introdução à leitura de Hegel. Rio de Janeiro: Contraponto; 2002.

3. BRUTSCHER, VJ. Educação e conhecimento em Paulo Freire. Passo Fundo: IFIBE e IPF; 2005.

4. CENCI, AV. Reconhecimento e intersubjetividade: elementos para uma antropologia filosófica a partir de Hegel. In: DALBOSCO, Cláudio Almir (Org.). Filosofia prática e pedagogia. Passo Fundo/RS: UPF Editora; 2003, p. 122-136.

5. FREIRE, P. Pedagogia da autonomia. 53 ed. Rio de Janeiro: Paz e Terra; 2016. 
RELATO DE EXPERIÊNCIA

\section{AÇÕES DE SENSIBILIZAÇÃO SOBRE INFECÇÕES SEXUALMENTE TRANSMISSÍVEIS EM UMA UNIDADE PRISIONAL: UM RELATO DE EXPERIÊNCIA}

\author{
Patrícia Porto Almeida \\ Laís Mara Caetano da Silva \\ Luiza Silveira de Oliveira \\ Pedro Fredemir Palha \\ Márcia Gabriela \\ Rodrigues de Lima \\ Júlia Zancan Bresolin
}

\section{Introdução}

O presente estudo tem como objetivo relatar as experiências das Acadêmicas de Enfermagem, nas ações preventivas sobre Infecções Sexualmente Transmissiveis (IST) com as Pessoas privadas de liberdade (PPL) na Penitenciária Estadual de Santa Maria (PESM), realizada através do projeto de extensão da Universidade Federal de Santa Maria (UFSM): "Ações de Sensibilização sobre doenças transmissiveis em Santa Maria/RS por meio da educação popular em saúde". Este projeto tem apoio do Servico de Atenção Especializada (SAE) / Centro de Testagem e Aconselhamento (CTA) Casa da Treze de Maio e da Política Municipal de HIV/ aids, Sífilis e Hepatites Virais. A PESM é uma unidade prisional masculina que fica localizado na cidade de Santa Maria região central do Rio Grande do Sul, segundo os dados do Conselho Nacional de Justiça (CNJ) a unidade prisional tem capacidade para comportar 766 presos do sexo masculino, porém segundo o relatório de og de dezembro de 2019 possui 931 detentos. ${ }^{1}$ A Constituição Federal de 1988 traz que a saúde da população é um dever do Estado, isso significa que todos tem direito a saúde, independentemente da situação social que apresenta, por meio do Plano Nacional de Saúde no Sistema Penitenciário (PNSSP), as PPL têm seus direitos à cidadania e a saúde garantidos pelo Sistema Único de Saúde (SUS), são populações que estão em situações de vulnerabilidades, desde da insalubridade nas celas 
ao risco de contrair ou desenvolver uma doença, referente a isso o ambiente carcerário é propício para os riscos de contrair uma IST, pois as práticas sexuais sem uso do preservativo e o compartilhamento de instrumentos de uso pessoal favorece que a transmissão ocorra. ${ }^{2} \mathrm{Si}$ tuações como superlotação, ambientes precários, úmidos, insalubres, escuros, propensos ao sedentarismo, falta de higiene, desenvolvimento de patologias, são alguns exemplos que evidenciam como fatores de vulnerabilidades das PPL no Sistema Prisional. As IST são consideradas infecções causadas por vírus, bactérias ou outros microrganismos, transmitidas principalmente, através do contato sexual desprotegido com uma pessoa infectada, independente se for contato oral, vaginal, anal, ocorre também por via sanguínea em compartilhamentos de instrumentos perfuro cortantes e ainda da mãe para o filho durante a gestação, parto ou amamentação. As principais IST são: herpes genital, sífilis, gonorreia, infecção pelo HIV, infecção pelo Papilomavírus Humano (HPV) e hepatites virais B e C. ${ }^{3}$ Vale ressaltar que ". As PPL são classificadas como populações-chave como estratégia de Prevenção combinada para o HIV, são populações que estão em vulnerabilidades por fatores comportamentais e estruturais da sociedade, apresentam um aumento desproporcional de infecção pelo HIV, quando comparadas à população geral. Essas vulnerabilidades estão relacionadas aos aspectos individuais e coletivos sobre indivíduos que correm riscos de adoecimento ou agravo, e que de forma desproporcional, tem menos acesso a recursos que favoreçam a sua proteção. ${ }^{4} \mathrm{~A}$ promoção da saúde e a prevenção de doenças são dois pilares que direcionam para um bem-estar individual ou coletivo do usuário do sistema de saúde, para isso é necessário ter clareza e uma comunicação efetiva. No sistema prisional torna evidente a necessidade de ações educativas que sensibilize o participante a compreender sobre o que são as IST, quais os riscos de transmissão, qual o primeiro passo se casos de contrair uma infecção, o processo do diagnóstico precoce e quais os tratamentos. 5 .

\section{Método}

Trata-se de um estudo do tipo relato de experiência. Os testes rápidos foram realizados de acordo com a demanda e a organização da unidade prisional, e somente com que precisava de atendimento médico no dia. Como ação educativa realizou-se os testes rápidos para HIV, Sífilis e Hepatites B e C, foram realizadas perguntas norteadoras afim de des- cobrir os conhecimentos prévios que tinham sobre as infecções. As principais perguntas foram: Conhece os testes rápidos? Se sim, quando foi a última que fez? Se não, já ouviu falar ou sabe como funciona? O que entende de Infecções Sexualmente transmissíveis? Se não, explicar as principais IST. Se sim, reforçar a importâncias e as formas de transmissão. Faz compartilhamentos de materiais de uso pessoal? (Tais como: lâminas de barbear, alicate de unha, tesoura de unha, material para confecções de tatuagens). Quando ocorreu a última relação sexual sem camisinha? Sabe o que é janela imunológica? E reforçar a importância da realização dos testes rápidos.

\section{Resultados e Discussão}

Durante o período de agosto a setembro de 2020 foram realizados 57 testes rápidos, apresentando como resultados para: Hepatite C um reagente, dois sem tratamento e um em tratamento; para Sífilis um reagente, e para HIV dois em tratamento. Segundo os relatos das PPL os compartilhamentos de materiais de uso pessoal eram muito frequentes nas celas, como a lâmina de barbear, cortador e tesoura de unha, as confecções de tatuagens ocorriam dentro das próprias celas, sem informações se havia troca das agulhas e das tintas utilizadas, são estes os fatores determinantes para os riscos de contrair a Hepatite C. Em relação aos testes rápidos contatou que a maioria nunca tinha feito ou tinham poucas informações sobre o procedimento. Por ser um ambiente "sistemático", algumas PPL interagiram pouco e demonstraram receio em desenvolver o assunto, mesmo assim foi possível para eles sanarem as principais dúvidas e desmitificar o preconceito existente acerca das IST. Oportunizou-se enfatizar a importância de fazer os testes rápidos, o uso do preservativo em todas as relações sexuais, sobre o diagnóstico precoce, as formas de transmissão, o tratamento, o desenvolvimento das patologias e sobre as parcerias sexuais, pois seria interessante que também fizessem o teste rápido.

\section{Conclusão}

O ambiente do sistema prisional torna-se propício para a exposição às doenças transmissiveis. Em relação às IST, a superlotação e a falta de informação são fatores determinantes para a transmissão e o agravamento das doenças. A promoção da saúde é instrumento fundamental para atuar nas unidades prisionais, uma vez que as informações ficam 
cada vez mais limitadas diante das realidades carcerárias, a prevenção as IST emergem frente aos riscos de transmissão e agravos das doenças, além disso contribui para evitar que novas contaminações possam surgir, como por exemplo as doenças oportunistas. A partir dessa experiência foi possível ampliar novos olhares para esta área, desde da valorização dos serviços de saúde à construção do conhecimento no processo de aprendizagem.

Descritores: Doenças sexualmente transmissíveis, Pessoas Privadas de liberdade, Educação em saúde.

Financiamento: Resumo financiado pelo Fundo de Incentivo de Extensão (FIEX - Pró-Reitoria de Extensão) - Universidade Federal de Santa Maria.

\section{Referências}

1. Conselho Nacional de Justiça. Dados das Inspeções nos Estabelecimentos Penais. [Internet] 2019. Acesso em 2021 jan. 25. Disponível em: https://www.cnj.jus.br/inspecao_penal/mapa.php.

2. Carvalho FF, Takeda E, Chagas EFB, Pinheiro OL. Conhecimento da população privada de liberdade sobre infecções sexualmente transmissíveis. Revista Gaúcha de Enfermagem. 2020, 41:e20190268.

3. BRASIL. Ministério da Saúde. Protocolo clínico e diretrizes terapêuticas para Profilaxia Pós-Exposição (PEP) de risco à infecção pelo HIV, IST e Hepatites Virais. Brasília: Ministério da Saúde, 2017.

4. Secretaria de Estado da Saúde de São Paulo. Diretrizes para Implementação da Rede de Cuidados em IST/HIV/AIDS. São Paulo, 2017.

5. Terra AAA, Silva GA. Representando as ações preventivas das IST/Aids realizadas por enfermeiros na atenção básica. Enfermagem Brasil. 2017, 16(5):276-83. 
RELATO DE EXPERIÊNCIA

\section{EDUCAÇÃO PERMANENTE NO SERVIÇO DE ATENDIMENTO MÓVEL DE URGÊNCIA: A REPRESENTAÇÃO DO TEMPO RESPOSTA}

\section{Rosane Mortari Ciconet Vania Celina Dezoti Micheletti \\ Denise Antunes de Azambuja Zocche \\ Caroline Vargas Attademo. \\ Cristina Orlandi Costa \\ Dinorá Claudia Cenci}

\section{Introdução}

O tempo resposta é um indicador usado para avaliação da qualidade do atendimento pré hospitalar. Consiste no transcurso entre a expressão do pedido de socorro pelo usuário ou solicitante e a chegada da equipe no local da ocorrência ${ }^{(1)}$. No Brasil, a atenção pré-hospitalar é prestada, principalmente pelo Serviço de Atendimento Móvel de Urgência (SAMÜ), cujas equipes de suporte básico de vida (SBV) são formadas por técnicos ou auxiliares de enfermagem e condutores e são responsáveis pela maioria dos atendimentos prestados pelo $\mathrm{SAMU}^{(2)}$. O tempo resposta pode ser influenciado por diversos fatores, relacionados à organização, à distribuição de recursos e performance operacional ${ }^{(1)}$. O tempo resposta é resultado do somatório de várias etapas do atendimento, que vão do acolhimento do chamado pela telefonista auxiliar de regulação, a escuta do médico regulador de urgência para avaliação da necessidade do usuário e sua tomada de decisão sobre o envio de recursos, a comunicação do rádio operador com a equipe que será deslocada para o atendimento, o tempo em que a equipe se prepara para partir para o local e o percurso da equipe até a cena do evento. O tempo de mobilização da equipe para a partida é o que mais influencia no aumento do tempo resposta. Esse intervalo é medido do momento em que a equipe é acionada pela central de regulação, por algum dispositivo de comunicação, até o momento em 
que, efetivamente, a ambulância movimenta-se para a saída. Esse intervalo varia entre menos de um minuto a dez minutos para a partida. Tempos menores que 1 minuto foram cumpridos em 30,1\% dos atendimentos, enquanto que em 51,6\% deles, os tempos variaram de 3,01 a 10 minutos para as equipes partirem para a cena. Esse resultado foi encontrado em estudo em um SAMU da região sul do Brasil, identificando que o tempo pode ser melhorado por meio de ações de educação permanente (EP) em serviço ${ }^{(3)}$. No SAMÜ, a EP se constitui em uma das estratégias fundamentais para refletir criticamente sobre os processos de trabalho, de modo a produzir mudanças, tanto individuais quanto em equipes ${ }^{(4)}$. Processos de ensino-aprendizagem inovadores contribuem para reconhecer as necessidades de mudanças (5), o que corrobora com a qualificação do atendimento prestado.

\section{Objetivo}

Descrever a experiência de educação permanente desenvolvida com os profissionais do SAMU referente ao tempo resposta executado pelas equipes em seus atendimentos e refletir acerca das rotinas do serviço quanto às práticas e a organização para o trabalho.

\section{Método}

Trata-se de um relato de experiência sobre atividade de educação permanente desenvolvida com as equipes no SAMU em estudo, a fim de apresentar os resultados da pesquisa aprovada pelo Comitê de Ética e Pesquisa sob CAEE 32126114.9.3001.53385 da Universidade Federal do Rio Grande do Sul (UFRGS), realizada naquele serviço. A atividade foi organizada pela pesquisad̊ora, em conjunto com a enfermeira responsável pelo Núcleo de Educação Permanente do SAMU, que tinha um cronograma de capacitações organizadas mensalmente, nas quais os profissionais eram distribuídos em grupos, para que todos pudessem estar presentes nas atividades, que ocuparam um turno de trabalho, com carga horária de 4 horas. Inicialmente as equipes foram informadas sobre a realização de uma simulação em formato de jogo, que compreendia "fazer compras no mercado". As "compras" deveriam ser feitas em duplas, adquirindo o maior número possivel de itens que foram apontados em uma lista, distinta para cada dupla, que deveriam ser feitas em determinada fração de tempo (um minuto, 2 minutos e assim por diante, até completar os 10 minutos). As duplas, ao receberem sua lista, deveriam encontrar os itens nas prateleiras, dentro do tempo cronometrado. Ao final de cada intervalo de tempo, um apito determinava que as "compras" deveriam ser interrompidas. O mercado foi simulado nas dependências contíguas à sala de aula, com embalagens recicladas de produtos dispostos em bancadas imitando prateleiras, usados no cotidiano das pessoas, tais como alimentos, limpeza, higiene, entre outros. A constituição das duplas respeitou a composição de uma equipe de SBV e o tempo cronometrado para cada equipe era a representação dos intervalos de tempo resposta encontrados na pesquisa. Quando todas as equipes concluíram suas "compras" nos tempos previstos, o grupo reuniu-se na sala de aula, onde cada dupla mostrou o que havia comprado, relatando sobre dois aspectos: como se organizaram para reunir o maior número dos itens da lista e como lidaram com o cumprimento do tempo. Seguido das apresentações, as organizadoras informaram ao grupo que a cronometragem do jogo significava os resultados encontrados na pesquisa quanto ao tempo dispendido por cada equipe para partir para o atendimento.

\section{Resultados e discussão}

Todos participaram ativamente da atividade, manifestando curiosidade pelas razões do jogo, especialmente por desconhecerem o significado do controle do tempo para as "compras". Ao combinarem previamente as estratégias, algumas adquiriram mais itens em tempos menores, o que demonstrou que pactuações entre os membros corroboram para organizar as tarefas e melhores resultados. Outras equipes, concluíram o desafio da "compra" antes mesmo de encerrada a cronometragem, o que mostrou discrepância entre o tempo estipulado e o ato de escolher os itens. A informação de que os tempos usados por cada dupla representavam o tempo dispendido por cada equipe para partir provocou surpresa, ao comparar a simulação das compras com a partida das equipes. Houve manifestação de preocupação em relação aos tempos demasiados longos, suscitando debates e críticas aos motivos atribuídos à demora das equipes partirem. O jogo permitiu explorar aspectos $\mathrm{da}$ organização do trabalho em equipe e da sintonia entre as duplas. Favoreceu também realizar várias analogias com o tempo gasto pelas equipes ao partirem para o atendimento, provocando a reflexão sobre prontidão, destreza, atenção. Permitiu a reflexão crítica sobre a responsabilidade do coletivo em perseguir tempos resposta adequados, pois estes são 
fundamentais para o desfecho favorável das situações atendidas. Um ponto fortemente destacado pelo grupo referiu-se à forma que os resultados de uma pesquisa foram apresentados, permitindo clara compreensão e dando materialidade aos objetivos do estudo. Conclusões: A atividade de educação permanente proposta repercutiu positivamente para o trabalho no SAMU. Resultou em manifestações expressas pelos profissionais quanto à necessidade de mudanças de comportamento de vários profissionais do serviço, referente à mobilização para os chamados. Alguns meses depois, os relatórios de gestão desse SAMU apontavam tempos menores de mobilização das equipes, o que permite inferir que a EP resultou em novas formas de organização das equipes, atingindo tempos menores de resposta, qualificando, assim, o atendimento.

Descritores: Educação permanente; tempo de reação; serviços mêdicos de emergência; indicadores de serviços.

\section{Referências}

1. Colla M, Oliveira GA, Santos GD. Operations Management in Emergency Medical Services: Response Time in a Brazilian Mobile Emergency Care Service. Procedia Manufacturing 39 (2019) 932-941

2. Oliveira BSA, Chagas MYC, Guimarães LM, Oliveira VAS. Caracterização dos acidentes de trânsito atendidos pelo S̉erviço de Atendimento Móvel de Urgência (SAMU) Estadual no Piauí. Rev. Interd. v. 12, n. 4, p. 39-46, out. nov. dez. 2019 [cited 2021 Jan 29] Available from: revistainterdisciplinar.uninovafapi.edu. br/index.php/revinter/article/view/1694

3. Ciconet RM. Tempo resposta de um serviço de atendimento móvel de urgência. 2015. $122 \mathrm{f}$. Tese (Doutorado em Enfermagem) Escola de Enfermagem, Universidade Federal do Rio Grande do Sul, Porto Alegre, 2015. [cited 2021 Jan 29] Available from: https://lume.ufrgs.br/ handle/10183/129481

4. Andrielly BS, Gabriel ML, Kamila MPB, Mônica CSC. A Educação Permanente em Saúde no Serviço de Atendimento Móvel de Urgência. Revista Sustinere, Rio de Janeiro, v.6 (1), p. 63-83, 2018.

5. Nascimento JSG, Pereira IM, Regino DSG, Silva AR, Oliveira JLG, Dalri MCB. Técnica de debriefing videoassistida para simulação em enfermagem: como proceder? Rev Gaúcha Enferm. 2021;42:e20190361.doi: https://doi. org/10.1590/1983-1447.2021.20190361 
RELATO DE EXPERIÊNCIA

\section{O ENFERMEIRO PREVENINDO ACIDENTES DE TRABALHO EM TEMPOS DE PANDEMIA: RELATO DE EXPERIÊNCIA}

\author{
Márcio Kist Parcianello \\ Graziele Gorete Portella \\ da Fonseca
}

\section{Introdução}

A enfermagem é uma profissão comprometida com a saude do ser humano e da coletividade, pois atua na promoção, proteção, recuperação da saúde e reabilitação das pessoas, respeitando os preceitos éticos e legais. O profissional enfermeiro presta assistência à saúde visando à promoção do ser humano como um todo. Nesta perspectiva o enfermeiro possui papel relevante frente ao acidente de trabalho, pois este se constitui um problema de saúde pública e é considerado um agravo à saúde do trabalhador. $\mathrm{O}$ acidente de trabalho, segundo a lei de 8.213, de julho de 1991, é definido como aquele em que o indivíduo sofre lesões físicas ou perturbações funcionais no exercício de suas atividades laborais e é considerado uma das principais causas de afastamento do ambiente laboral ${ }^{1}$. Nesse contexto, torna-se relevante que o enfermeiro promova ações de treinamentos, capacitações, implementações de medidas preventivas e conscientização dos colaboradores na prevenção de situações que possam prejudicar sua saúde, estimulando a autopromoção da saúde, bem como o uso correto e adequado de equipamentos de proteção individual (EPIs) ${ }^{1}$. Considera-se que essas ações são ferramentas que impactam diretamente na saúde do trabalhador, contribuindo assim para a diminuição do índice de acidentes de trabalho frente a pandemia Covid-19, em que os trabalhadores de saúde apresentam altos riscos de exposição a infecções ${ }^{2}$. Sabe-se 
que no cotidiano de trabalho os profissionais de saúde estão constantemente em contato com casos suspeitos e confirmados do novo coronavírus, adicionados de jornadas exaustivas de trabalho, muitas vezes com falhas de protocolos, EPIs em falta ou em uso indevido, desgastes físicos e emocionais, aumentando assim os riscos de contágio pela Covid-19.

\section{Objetivo}

Relatar o planejamento e o desenvolvimento de um cronograma estratégico de ações educativas para prevenção de acidentes de trabalho em tempos de pandemia.

\section{Método}

Trata-se de um relato de experiência que se subsidiou da elaboração de um cronograma de treinamentos, aplicado em um Hospital Regional de médio porte da região central do estado do Rio Grande do Sul, no período de junho a dezembro de 2020. O hospital é composto por setores administrativos, duas unidades de internação, cada unidade com 21 leitos, três unidades de terapia intensiva (UTI), contendo 1o leitos em cada, ambulatório médico, serviço de nutrição e dietética, laboratório de análises clínicas, farmácia, serviço de controle de infecção hospitalar (SCIH) e Serviço de higiene e limpeza.

\section{Resultados e Discussão}

O cronograma de treinamentos foi planejado por um enfermeiro coordenador assistencial das UTIs, o qual se propôs a elaborar e executar, em conjunto com a equipe de trabalhadores de saúde da instituição. O cronograma foi elaborado de forma participativa, envolvendo a equipe assistencial de enfermagem (técnicos de enfermagem e enfermeiros assistenciais) e trabalhadores do serviço de higienização e limpeza. Considerou-se realizar o cronograma de treinamentos tendo como objetivo a proteção e preservação da saúde dos trabalhadores frente a pandemia do Covid-19) atendendo assim à necessidade interna da equipe, bem como também a responsabilização de todos os profissionais não apenas com o planejamento em si, mas com a elaboração e execução das atividades teórico práticas, acompanhamento das atividades e avaliação das mesmas. Optou-se primeiramente em realizar os treinamentos nas UTIs e depois nas unidades de internação do referido hospital, devido à gravidade dos pacientes e a maior exposição dos profissio- nais à procedimentos invasivos realizados na UTI. As primeiras atividades foram teóricas, abordando o uso correto e adequado de EPIs, paramentação e desparamentação, protocolos e fluxos institucionais, descarte correto de resíduos hospitalares, encaminhamento seguro e correto de roupas para a lavanderia e higiene e limpeza em ambiente hospitalar. Nas próximas fases das treinagens foi revisto a teoria em conjunto com a prática, no intuito de reforçar a importância dos colaboradores se conscientizarem da relevância da prevenção. Estrategicamente, como citado anteriormente, foram envolvidos na elaboração e execução das atividades todos os trabalhadores técnicos de enfermagem, enfermeiros assistenciais e aqueles do serviço de higiene e limpeza, buscando-se assim que com esta abordagem a participação fosse mais efetiva. Nesta perspectiva alguns autores corroboram afirmando que é imprescindivel o planejamento em equipe, repensando assim a dinâmica processual do trabalho, pois é tão-somente a partir da percepção de pertencimento, partilhamento de objetivos e estabelecimento de analogias positivas que se estabelecem movimentos sólidos na reinvenção de fazeres ${ }^{3}$. Também se acreditou que seria profícuo a realização de algumas dinâmicas envolvendo toda a equipe. Cabe ressaltar que foram mantidas as normas de biossegurança, formaram-se várias turmas para evitar aglomeração. Foi orientado que todos os colaboradores usassem máscara cirúrgica na realização das atividades educativas. Durante a realização dos treinamentos, tanto teórico, como teórico-práticos, evidenciou-se vários questionamentos como por exemplo: "Para intubar o paciente eu preciso estar todo paramentado, mesmo que seja de emergência?; "Em uma parada cardíaca eu posso iniciar a reanimação do paciente sem a devida paramentação?"; "Preciso usar luvas para trocar a caixa de perfuro cortante?"; "Como fazer a limpeza das bombas de infusão que estão em uso nos pacientes?"; "Preciso usar óculos de proteção além do protetor facial?" ; "Como faço para limpar meu protetor facial?" ; "Posso utilizar máscara cirúrgica em cima da máscara N95?", entre outros. Diante dos inúmeros questionamentos realizados, comprovou-se a relevância dos treinamentos e da estratégia de envolvimento de todos os colaboradores na realização das atividades. Atribuímos a esses fatores a participação ativa dos mesmos. Sempre que surgia um questionamento, este era valorizado pelo enfermeiro coordenador no intuito de ensino/ aprendizagem e neste momento era discutido no grupo os fluxos e protocolos já existentes e que abordavam essas questões. Nesse contexto, 
a prática de ambientes de discussão que acercam as dificuldades do cotidiano do trabalho pode ser revertida em demandas educativas com a participação dos profissionais de saúde 4 . Elencou-se ainda que é mais efetivo trabalhar de forma transdisciplinar frente à problemas como o acidente de trabalho, uma vez que nada se consegue sozinho e, na área da saúde, é preciso fortalecer as relações de trabalho. Assim, indo ao encontro do Ministério da saúde do Brasil, que em seu Plano Nacional de Saúde prevê o fortalecimento da gestão democrática, com participação dos trabalhadores de saúde na educação e gestão dos serviços, assegurando a valorização profissional, fortalecendo as relações de trabalho e promovendo a regularização das profissões, a fim de efetivar a atuação solidária, humanizada e de qualidades. Portanto, o enfermeiro e sua equipe, subsidiados pelo conhecimento e pela abordagem transdisciplinar, com visão voltada para os processos e relações, e não somente para as estruturas em si, objetivam processos produtivos, transformando assim o cenário de atuação em prol do desenvolvimento pessoal e profissional saudável $\mathrm{em}$ tempos de pandemia Covid-19.

\section{Conclusão}

Diante desta vivência relatada, contatou-se que há necessidade de ações educativas direcionadas à temática, uma vez que os trabalhadores de saúde estão expostos frequentemente à riscos inerentes à execução de suas atividades, principalmente agora neste momento pandêmico. Por meio deste e de outras vivências e experiências evidencia-se que o enfermeiro precisa usar processos de aprendizagem de forma colaborativa e participativa junto com a equipe de trabalho, suprindo assim lacunas existentes, sendo muitas vezes impostas por meio de comando e controle. Assim, considera-se ressaltar a importância do investimento em treinamentos participativos, envolvendo toda a equipe de saúde, evidenciando essa prática como uma ferramenta capaz de proporcionar dinamismo e aproximação do grupo de trabalho, resultando em um menor índice de acidentes de trabalho na equipe.

Descritores: Acidente de Trabalho; Educação em Saúde; Enfermagem; Saúde do Traballhador.

\section{Referências}

1. Freitas AG de, Rodrigues EVV, Batista U de L, Rocha BM da. Perfil dos profissionais de enfermagem que sofrem acidentes de trabalho: revisão integrativa. Revista Saúde (Santa Maria). Santa Maria, 2019; 45 (I):1-16.

2. Helioterio MC, Lopes FQR de S, Sousa CC de, Sousa F de O, Pinho P de S, Sousa FNF, Araújo TM de. Covid-19: Por que a proteção de trabalhadores e trabalhadoras da saúde é prioritária no combate à pandemia? Trab. Educ. Saúde. Rio de Janeiro, 2020:18 (3).

3. Mota A dos S, Silva ALA da, S AC de. Educação permanente: práticas e processos da enfermagem em saúde mental. Rev. Portuguesa de saúde mental. Porto, 2016;(spe4):9-16.

4. Santos JR dos. Conduta gerencial do enfermeiro na unidade de terapia intensiva. Revista Científica Multidisciplinar Núcleo do Conhecimento. 2017; 09 (01): 30-46.

5. Brasil. Ministério da saúde. Plano nacional de saúde: um pacto pela saúde no Brasil: síntese/Ministério da saúde-Brasília: Ministério da Saúde, 2005. 
RELATO DE EXPERIÊNCIA

\section{MOMENTOS DE EDUCAÇÃO PERMANENTE EM SAÚDE PARA UM PROJETO DE INTERVENÇÃO: UM RELATO DE EXPERIÊNCIA}

\author{
Luciano Fiorentin \\ Karina Schopf \\ Carine Vendruscolo \\ Vilma Beltrame
}

\section{Introdução}

Atenção Primária em Saúde (APS) é a principal porta de entrada do Sistema Único de Saúde (SUS). Considerada a ordenadora do sistema e coordenadora do cuidado, tem a promoção da saúde como uma de suas bases de ação. (1) Em municípios de pequeno porte, nos quais a APS é o único cenário para ações de saúde pública do território, é essencial que estas sejam realizadas mediante práticas eficazes, voltadas às necessidades de saúde locais, ampliando a responsabilidade dos profissionais com estratégias na gestão do cuidado. A Hipertensão Arterial Sistêmica (HAS) é um exemplo de problema predominante na saúde pública, devido a elevada prevalência de pessoas acometidas pela doença. Segundo a Organização Mundial da Saúde (OMS), a HAS é o principal fator de risco para doenças cardiovasculares. Com a associação entre sua origem multifatorial e as influếncias trazidas pelo meio sócio cultural em que o hipertenso se insere, estima-se que aproximadamente dois terços dos usuários hipertensos precisarão do uso de combinações medicamentosas e não medicamentosas para seu controle. (2) Além dos riscos de agravos que a hipertensão arterial representa, sua falta de controle reflete em filas para consultas e redução na qualidade e expectativa de vida das pessoas. É nessa perspectiva que a Educação Permanente em Saúde (EPS) ganha espaço e permite reorganizar os serviços prestados, através de ações estratégicas e estruturação do 
trabalho interdisciplinar (3) buscando alternativas para controle, redução da necessidade de terapia medicamentosa anti-hipertensiva e equilíbrio nos valores pressóricos. Com a EPS, as equipes apropriam-se dos arranjos político-sociais, identificam os nós críticos e as potencialidades do seu cotidiano laboral, o que permite a intervenção transformadora.

\section{Objetivo}

O objetivo desse relato de experiência é descrever momentos de EPS de uma equipe de profissionais de APS, para elaborar um plano de intervenção para controle de HAS.

\section{Método}

Trata-se de um relato de experiência sobre os momentos de EPS com a equipe para desenvolver um plano de intervenção. A natureza desse estudo se embasa no método pelo qual o pesquisador interpreta e expõe opiniões sobre os fenômenos o qual se observa (4)"ISBN":"978-85-8341-204-5","language":"pt","number-of-pages":"119","publisher":"UFSM, NTE","publisher-place":"Santa Maria | RS","title":"METODOLOGIA DA PESQUISA CIENTÍFICA","URL":"https://repositorio.ufsm.br/bitstream/handle/1/15824/ Lic_Computacao_Metodologia-Pesquisa-Cientifica.pdf? sequence=1\&isAllowed=y", "author":[\{“family":"Pereira","given":"Adriana Soares"\},\{“family":"Shitsuka","given":"Dorlivete Moreira"\}, “"family":"Parreira","given":"Fabio José"\},\{“family":"Shitsuka","given":"Ricardo"\}],"accessed":\{“date-parts":[[“2021”,1,24]]\},"issued”:\{“date-parts":[["2018"]]\}\}\}],"schema":"https:// github.com/citation-style-language/schema/ raw/master/csl-citation.json"\}. Por se tratar de um relato de experiência sobre momentos de EPS para o desenvolvimento de um projeto de intervenção, não houve necessidade de elaboração de termo de consentimento aos participantes da pesquisa. No entanto, foi respeitando o anonimato dos trabalhadores e também local onde houve o seu desenvolvimento, de acordo com o preconizado pela Resolução 466/1212 do Conselho Nacional de Ética em Pesquisa.

\section{Resultados e Discussão}

No processo de desenvolvimento do plano de intervenção, os trabalhadores da APS utilizaram a EPS para a gestão do seu trabalho com o propósito de intervir na realidade das pessoas hipertensas, em busca de soluções capazes de promover a melhoria dessa condição crônica. O plano de intervenção constituiu-se por dois momentos distintos e complementares. No primeiro momento a equipe interdisciplinar buscou conhecer a realidade a ser transformada, identificou e priorizou ações para cada situação apresentada, tornando a realidade dinâmica e em permanente mudança. No segundo momento, a intervenção ocorreu junto aos usuários com Hipertensão. Para cada situação ou "nós críticos" relacionados ao processo de cuidado da HAS identificados pela equipe, os profissionais estudaram estratégias, utilizando momentos de EPS, para posteriormente realizar a intervenção junto aos usuários. O método de intervenção sempre depende do problema a ser superado (orientações, oficinas, terapias de grupos específicos, uso de mídias sociais, dentre outros). Diante do fato da Hipertensão Arterial ser uma doença crônica e por conter, entre seus princípios de atuação, a longitudinalidade, esses momentos são constantes. Durante o primeiro encontro da equipe, foram discutidas estratégias para intervenção sobre a realidade dos hipertensos do município. Nesse encontro, foram elencadas algumas sugestões sobre a necessidade para conseguir intervir na realidade identificada e obter resultados satisfatórios. Considerou-se necessário: 1 - reestruturação e consolidação de espaços, 2 - periodicidade dos encontros de EPS, compostos por equipes multiprofissionais e com inserção da perspectiva interdisciplinar com escopo transformador, 3 - fomento da reflexão crítica sobre o cenário que precisa ser transformado. Para teorizar a ação, a equipe foi provocada à refletir sobre a importância da problematização da realidade, como método de replanejamento de ações, capaz de se aproximar dos constantes movimentos que a sociedade apresenta e aos quais os serviços de saúde devem se adaptar (3). Com isso, o coletivo consegue reagir de maneira equânime, ampliando o poder de resposta da realidade. A EPS permite que o cuidado na APS seja pensado pelo coletivo (5)recorreu-se a Técnica de Análise de Conteudo. Os resultados evidenciam um conflito entre a teoria e prática da Educação Permanente, em que se confluem conceitos e práticas que se aproximam da educação continuada e educação em saúde. Os pesquisados da atenção básica confundiram ou desconheciam o conceito e desenvolvimento da prática de Educação Permanente.","container-title"."Revista de Pesquisa: Cuidado é Fundamental Online","DOI":"10.9789/2175-5361.2017.v9i2. 526-535","ISSN":"2175-5361", "issue":"2","language":"pt","note":"number: 2","page":"526-535","source":"www.seer.unirio.br","title":"Educação 
permanente no cotidiano das equipes de saúde da família: utopia, intenção ou realidade? Permanent education in everyday of family health teams: utopia, intention or reality?","title-short":"Educação permanente no cotidiano das equipes de saúde da família","volume":"g","author":[\{“family":"Bomfim","given”:" Eliane dos Santos"\},\{“family":"Oliveira","given":"Bruno Gonçalves","dropping-particle":"de" $\},\{$ “family":"Rosa","given":"Randson Souza"\},\{“family":"Almeida","given":"Marlón Vinicius Gama"\}, “family":"Silva","given":"Simone Santana","dropping-particle":"da"\}, “family":"Araujo","given":"Igor Brasil","dropping-particle":"de"\}],"issued":\{“date-parts":[["2017",4,11]]\}\}\}],"schema":"https://github. $\mathrm{com} /$ citation-style-language/schema/raw/master/csl-citation.json"\} . Por ser um município de pequeno porte, fez a diferença a presença e envolvimento do gestor de saúde, fator que agrega potencial para ação. Até o atual momento, já se consolidaram dois processos de intervenção, diretamente com os usuários. $\mathrm{O}$ primeiro foi em decorrência da necessidade identificada de redução da quantidade de sódio usado para a alimentação diária, fator preditor de elevação da pressão arterial, mesmo em uso regular de terapia medicamentosa. Para essa intervenção foi criado oficinas com alternativas de temperos, capaz de conferir à comida sabor semelhantes ao sal de cozinha, e reducão significativa do sódio utilizado. Também foi desenvolvido oficinas com manipulação de chás, folhas e frutas para sucos, bem como o estímulo à hidratação através do aumento da ingestão de água. Ỏs participantes experimentaram os produtos manipulados e receberam panfletos explicativos sobre ambas as oficinas. O que se observa, é que esses momentos já despertaram na equipe, a vontade de sonhar com a transformação da realidade, e que as trocas de experiências até o momento já inspiram novos horizontes em busca de outras intervenções.

\section{Conclusão}

A estruturação de espaços coletivos, com base na EPS e em esforços focados no trabalho articulado interdisciplinarmente, além de sustentado pelo envolvimento do grupo, permite transformar o agir da equipe de saúde frente a realidade que se apresenta e que precisa ser transformada. O gerenciamento do trabalho, a organização e a articulação da equipe foram algumas das conquistas dos profissionais, conquistadas pela EPS. Tais mudanças facilitam a educação em saúde para os hipertensos, promovendo mudanças no seu estilo de vida e oportunizando o alcance na melhoria da qualidade da saúde.

Descritores: Educação Permanente, Atenção Primária à Saúde, Hipertensão Arterial Sistêmica.

\section{Referências}

1. Santa Catarina. Atenção Primária à Saúde [Internet]. 2018 [citado 19 de janeiro de 2021]. Disponível em: https://www.saude.sc.gov.br/ index.php/servicos/profissionais-de-saude/ 10224-atencao-basica-atencao-primaria-a-saude

2. Oliveira GMM de, Mendes M, Malachias MVB, Morais J, Moreira Filho O, Coelho AS, et al. 2017 Guidelines for Arterial Hypertension Management in Primary Health Care in Portuguese Language Countries. Arquivos Brasileiros de Cardiologia. novembro de 2017;109(5):389-96.

3. Ferreira L, Barbosa JS de A, Esposti CDD, Cruz MM da, Ferreira L, Barbosa JS de A, et al. Educação Permanente em Saúde na atenção primária: uma revisão integrativa da literatura. Saúde em Debate. março de 2019;43(120):223-39.

4. Pereira AS, Shitsuka DM, Parreira FJ, Shitsuka R. METODOLOGIA DA PESQUISA CIENTÍFICA [Internet]. $1^{\circ}$ ed. Santa Maria | RS: UFSM, NTE; 2018 [citado 24 de janeiro de 2021]. 119 p. (e-book). Disponível em: https:// repositorio.ufsm.br/bitstream/handle/1/15824/ Lic_Computacao_Metodologia-Pesquisa-Cientifica.pdf? sequence $=1$ \&isAllowed $=\mathrm{y}$

5. Bomfim E dos S, Oliveira BG de, Rosa RS, Almeida MVG, Silva SS da, Araujo IB de. Educação permanente no cotidiano das equipes de saude da família: utopia, intenção ou realidade? Revista de Pesquisa: Cuidado é Fundamental Online. 11 de abril de 2017;9(2):526-35. 
RELATO DE EXPERIÊNCIA

\section{PROCEDIMENTO OPERACIONAL PADRÃO (POP): RELATO DE EXPERIÊNCIA DE QUALIFICAÇÃO NA REDE DE ATENÇÃO À SAÚDE}

\author{
Adriana Aparecida Polmann \\ Bianca Lima da Cunha \\ Letícia Sandrin \\ Otilia Cristina Coelho \\ Rodrigues
}

\section{Introdução}

O estudo tem como objetivo relatar a experiência acerca de um curso de qualificação realizado sobre os Procedimentos Operacionais Padrão (POP's) nas Redes de Atenção à Saúde, aos municípios da região Oeste de Santa Catarina. Trata-se de tema de relevância pois, são necessárias ações de Educação Permanente nas entidades de saúde para que as práticas sejam atualizadas e adequadas de acordo com as necessidades dos usuários. De acordo com a Política Nacional de Educação Permanente em Saúde (MINISTÉRIO DA SAÚDE, 2018, p.11) a Educação Permanente possibilita "análise crítica e constituição de conhecimentos sobre a realidade local" e por isso que precisa ser pensada e adequada de acordo com cada nível de saúde. Diante desse aspecto, a educação permanente precisa ir além da sala de aula, atendendo às necessidades da população e incluindo diversos sujeitos e entidades no processo. Este curso de Qualificação estava previsto no Plano Regional de Educação Permanente (PAREPS) da Comissão de Integração de Ensino e Serviço (CIES) Oeste desde 2018, de maneira presencial, porém com a pandemia que está sendo vivenciado, ficou inviável a sua realização. A alternativa foi pensá-lo de maneira digital, sendo apresentado à CIES, com subsequente aprovação e realização. Havendo desta forma a efetivação do primeiro curso na modalidade on-line ofertada pela CIES na região Oeste do Estado de Santa Catarina. A formação 
foi realizada com profissionais de saúde que atuam nas Unidades Básicas de Saúde (UBS), nos Hospitais de pequeno porte e na Coordenação Macrorregional de Saúde de Chapecó, para vinte e sete (27) municípios de abrangência da CIES Oeste e os nove (og) hospitais da região. Outro aspecto a ser considerado para a elaboração desse estudo é a "Incorporação de estratégias que possam viabilizar as ações de Educação Permanente em Saúde na realidade dos serviços de saúde, como as tecnologias de informaçã̃o e comunicação e modalidades formativas que se utilizem dos pressupostos $\mathrm{da}$ educação e práticas interprofissionais em saúde" (Ministerio da Saúde, 2018, p. 15). Pensando nisso, as tecnologias de informação contribuem de sobremaneira neste contexto.

\section{Método}

Trata-se de um estudo descritivo, na forma de relato de experiência, realizado a partir da aplicação de um curso de qualificação sobre os Procedimentos Operacionais Padrão (POP 's) nas Redes de Atenção à Saúde, na modalidade remota por meio da plataforma Teams, da Microsoft Office ${ }^{(\mathrm{R})}$. A qualificação ocorreu nos meses de outubro a dezembro de 2020. Permitiu que os participantes ao finalizarem o curso, tivessem subsidios para atualizar e aplicar os POP's dentro das entidades de saúde que atuam. Foi realizada coleta de dados secundários, pela Faculdade Senac de Chapecó, por meio de um instrumento de avaliação da satisfação do curso, aplicado no último dia de aula. Ả qualificação contou com trinta e quatro (34) alunos matriculados, desses dezesseis (16) não concluíram por diversos motivos relatados dentre os principais não conseguir conciliar os horários de curso com o trabalho principalmente devido a pandemia Covid-19. Dezoito (18) alunos foram aprovados, cerca de $51 \%$ da turma, desses, doze (12) responderam a pesquisa de satisfação.

\section{Resultados e Discussão}

Considerando que o curso ocorreu, em meio a uma pandemia, de forma totalmente remota destaca-se como ponto positivo a possibilidade de contar com uma professora de outra região especialista na temática para ministrar a qualificação; a redução de custos uma vez que tanto a professora como os participantes não necessitaram de deslocamento e a otimização das formações de maneira on-line. Pode-se destacar também que devido a metodologia da capacitação, permitiu maior flexibilidade na escolha do local, bem como facilidade de acompanhar de diversos locais ao mesmo tempo com segurança e conforto mesmo em meio a uma pandemia. Como fragilidades encontradas durante o processo, foi verificado que ainda existe dificuldade por parte dos profissionais de se identificarem com o modelo de ensino remoto, pois, mesmo apresentado as vantagens já pontuadas, interfere no aspecto teorico-prático e vivencial, uma vez que os profissionais sentem o distanciamento físico e a falta de interação presencial com os professores e colegas, o que consequentemente torna-se como uma forma de barreira no aprendizado. Algumas das citações encontradas na pesquisa de satisfação trazem colocações como: "Gostaria de ter realizado o mesmo de forma presencial, pois é difícil conseguir exclusividade para realizar on-line dentro do local de trabalho" (SENAC, 2020). O fato do curso ter sido realizado com aulas síncronas, isto é, com aulas realizadas de forma remota e em tempo real, na qual professor e aluno podem interagir em tempo real e mesmo espaço virtual, foi também citado na pesquisa: "Parabenizo à organização pela iniciativa da qualificação, visto que se trata de um tema relevante, para o qual temos muita demanda na saúde pública. A professora é bastante cordial, trouxe exemplos práticos e mostrou-se aberta aos questionamentos. Bem como as auxiliares de classe, bastante solícitas" (SENAC, 2020). Na análise geral da pesquisa o curso obteve $99 \%$ de satisfação como Otima e Bom, e em uma escala geral de "Ótimo, Bom, Regular e Ruim", no que tange ao planejamento de aula, utilização de exemplos claros e objetivos, uso de atividades práticas, uso de recursos didáticos como quadros, vídeos, livros e revistas, estímulo à participação nas aulas, cumprimento dos horários e intervalos, bem como oferecimento de oportunidades variadas mesmo em meio às situações de dificuldade de aprendizagem. $\mathrm{Na}$ análise geral da pesquisa o curso obteve $99 \%$ de satisfaçã̃o como Ótima e Bom.

\section{Conclusão}

A qualificação atendeu ao objetivo proposto de qualificar para Procedimentos Operacionais Padrão (POP ss) profissionais que atuam nas Redes de Atenção a Saúde, da região oeste de Santa Catarina, com êxito ao ser realizada de forma remota e com aulas síncronas. A de se considerar que a modalidade "síncrona" pode ter comprometido o percentual de concluintes, de modo que a forma de realização das ações poderá ser mesclada nas próximas versões de atividades on-line a serem realiza- 
das, buscando um maior percentual de concluintes. No período da realização do curso, as aulas presenciais não estavam sendo possíveis e a modalidade on-line tornou-se opção viável para a concretização do curso. Desta forma, as práticas de educação permanente tornam-se relevantes e necessárias em todos os cenários, principalmente quando relacionadas a qualificação profissional e satisfação, caracterizando $67 \%$ da amostra estudada.

Descritores: Procedimentos Operacionais Padrão (POP's); Redes de Atenção à Saúde; Qualificação Profissional; Sistema Único de Saúde (SUS); Educação Síncrona; Profissionais de Saúde.

\section{Referências}

1. Ministério da Saúde (BR). Manual Técnico 2018 - Programa para o Fortalecimento das Práticas de Educação Permanente em Saúde no SUS - PRO EPS-SUIS. Brasília: Ministério da Saúde, 2018. Available from: https://portalarquivosz.saude.gov.br/images/pdf/2018/marco/28/Manual-Tecnico-PRO-EPS-SUS-MINUTA17-10.pdf

2. Ministério da Saúde (BR). Política Nacional de Educação Permanente em Saúde: o que se tem produzido para o seu fortalecimento? -1 . ed. rev. - Brasília: Ministério da Saúde; 2018. Available from: http://bvsms.saude.gov.br/ bvs/publicacoes/politica_nacional_educacao permanente_saude_fortalecimento.pdf

3. CIES Oeste - Comissão de Integração Ensino-Serviço. Plano de Ação Regional de Educação Permanente em Saúde - PAREPS, 2018/2020. Chapecó: Novembro/2018.

4. SENAC 2020. Pesquisa de Satisfação Avaliação Docente. Faculdade Senac de Chapecó. Documento institucional, 2020. 
RELATO DE EXPERIÊNCIA

CONCEPÇÕES DE EDUCAÇÃO PERMANENTE EM PLANOS ESTADUAIS DE EDUCAÇÃO PERMANENTE EM SAÚDE

\section{Mariana Costa Matos Silvana Lima Vieira \\ Liliana Santos}

\section{Introdução}

A formação dos trabalhadores em saúde é um dos pilares para a consolidação do Sistema Único de Saúde (SUS) no Brasil, em que é atribuído ao SUS a competência de ordenar a formação na área da Saúde. ${ }^{1}$ Um importante avanço para efetivação deste preceito legal foi a criação da Política Nacional de Educação Permanente em Saúde (PNEPS) como a estratégia do SUS para a formação e o desenvolvimento de trabalhadores para a saúde. ${ }^{2}$ Enquanto política pública brasileira, pode ser interpretada como uma estratégia que visa proporcionar aos profissionais o desenvolvimento contínuo de seu aprendizado, na tentativa de superação dos problemas relacionados à qualificação e formação de trabalhadores da saúde, sobretudo o descompasso existente entre a formação técnica dos trabalhadores e as necessidades de saúde dos usuários. ${ }^{3}$ Para a consolidação da PNEPS no âmbito estadual, é determinada a elaboração de Planos de Ação Regional de Educação Permanente em Saúde (PAREPS) e dos Planos Estaduais de Educação Permanente em Saúde (PEEPS), que contém ações a serem desenvolvidas, linhas prioritárias, público alvo além de outras informações que o Estado decida incluir. Tomando como base os PEEPS faz-se relevante a análise das concepções de EPS neles contidas, uma vez que o entendimento e definição deste conceito influencia diretamente nas práticas instituídas e, consequentemente, no modo como a política é conduzida nos territórios. 


\section{Objetivo}

Analisar as concepções de Educação Permanente contidas nos Planos Estaduais de Educação Permanente em Saúde e a partir disso, discutir as aproximações e/ou fragilidades destas concepções à luz da Política Nacional de Educação Permanente em Saúde.

\section{Método}

Estudo qualitativo, com base em análise documental. Com fonte de dados Planos Estaduais de Educação Permanente em Saúde dos 27 estados do Brasil, disponíveis na íntegra, em meio eletrônico no portal do Conselho Nacional de Secretários de Saúde, com a vigência a partir de $2018^{4}$. Para a análise do material selecionado, foram utilizados instrumentos de coleta e síntese dos dados no programa Microsoft Excel $^{\odot}$, com o propósito de extrair, organizar e sumarizar as informações e facilitar a formação do banco de dados. Os Planos Estaduais de EPS foram nomeados com a letra "P" seguida de numeral ordinal de 1 a 27 , de acordo com cada Estado das cinco regiões geográficas brasileiras. A coleta se deu no período de janeiro a agosto de 2018. O primeiro instrumento foi utilizado para a categorização dos Planos Estaduais de Educação Permanente em Saúde e nele foram distribuídos os seguintes elementos: Plano; Região; Estado; Vigência do Plano e o segundo instrumento foram elencadas e as concepções de Educação Permanente em Saúde identificadas nos Planos. As concepções de EPS extraídas dos planos foram sistematizadas a partir dos componentes Político-Gerencial, Processo Educativo e os Efeitos/ Resultados esperados originados do modelo lógico da PNEPS, indicando as aproximações destes componentes em relação aos conceitos trazidos nos planos. O Componente político-gerencial engloba aspectos das concepções de EPS relacionadas ao projeto de governo, institucionalização das práticas de EPS, capacidade de gestão, governabilidade e planejamento e avaliação; O Componente Processo Educativo envolve características relacionadas às perspectivas pedagógicas, integração ensino-serviço-comunidade e práticas interprofissionais e o Componente efeitos/resultados esperados traz aspectos relacionados à transformações do processo de trabalho e atenção à saúde dos indivíduos e coletividades. Os dados obtidos foram então analisados através de análise de conteúdo temático composta de três etapas: pré-análise, exploração do material e tratamento dos resultados.

\section{Resultados e discussão}

A partir da busca em meio eletrônico foram encontrados 27 PEEPS, com anos de vigência que variaram do início em 2018, 2019 e 2020 e com final em 2020, 2021, 2022 e 2023, tendo, a maioria, duração de quatro anos. Apenas nos planos dos Estados de Alagoas, Mato Grosso e Rio Grande do Sul não foi possível identificar um período de vigência. Após leitura flutuante e exaustiva dos PEEPS, verificou-se que as concepções de EPS estavam descritas em 25 planos e ausente em dois documentos da região Sul (Rio Grande do Sul e Santa Catarina), os mesmos não fizeram menção ao conceito, atendo-se à descrição do processo metodológico de construção do PEEPS e da conformação das redes de atenção à Saúde no Estado. Foram observados na análise do material a incorporação de concepções fundamentais que estruturam o conceito de EPS no que diz respeito ao componente Político Gerencial, tais como: o fortalecimento dos processos de gestão político-institucional do SUS, a articulação intersetorial e interinstitucional no desenvolvimento das ações e a reorganização da rede de serviços em bases territoriais. A concepção de EPS que se destaca nos Planos no que se refere ao componente Político - Gerencial é a adoção da EPS enquanto estratégia ética-política-pedagógica do campo da educação no SUS, que esteve presente de forma direta em 14 dos 27 Planos analisados. Os elementos conceituais da EPS que estão ligados ao componente Político - Gerencial foram mais predominantes nos Planos dos Estados da Região Nordeste e Sudeste. A perspectiva de uma EPS operacionalizada de forma descentralizada e democrática com foco no âmbito loco-regional foi identificada de forma mais consistente nos planos das regiões Sul e Sudeste, com ênfase aos Estados de São Paulo e Paraná. A necessidade da ampliação do diálogo, mediação das relações entre os diversos atores e a produção de pactos e acordos coletivos de trabalho foram colocados em alguns PEEPS analisados, como os do estado de Sergipe, Pernambuco, Rio Grande do Norte, Minas Gerais e São Paulo. Outra concepção de EPS abordada nos PEEPS, sobretudo nos estados do Nordeste, Sudeste e no Distrito Federal, foi a potencialidade desta ferramenta no ordenamento e gestão do trabalho e dos processos formativos, estando comprometida com o desenvolvimento e aperfeiçoamento institucional do SUS. Nessa perspectiva, dentre as medidas para a retomada da PNEPS no país, a SGTES lançou o Programa para o Fortalecimento das Práticas de EPS no SUS (PRO EPS-SUS), tendo como uma de suas finalidades prover as instâncias locais de apoio técnico institucional 
e financeiro para a elaboração de instrumentos de planejamento e programação. $\mathrm{O}$ componente Processo Educativo do conceito de EPS foi o que se apresentou de forma mais consistente nos documentos analisados. No que diz respeito a esta categoria pode-se destacar entre os dados levantados que o Processo Educativo na EPS é entendido como um rompimento com o paradigma da educacão tradicional, tem como eixo central o trabalho, compreende o trabalhador como sujeito ativo em seu processo de formação e está alicerçado nos conceitos de aprendizagem significativa e de problematização do processo de trabalho em saúde. As concepções de EPS predominantes nos Planos no que se refere ao componente Processo Educativo é o entendimento desta como uma prática de problematização do processo de trabalho em saúde, onde a reflexão e discussão sobre este trabalho são objetos centrais para o processo de ensino-aprendizagem. Esta concepção esteve presente de forma direta em 18 dos 27 Planos analisados, de forma mais consistente nos Planos de todas as Regiões, com destaque para o Norte e Nordeste. A maior parte dos PEEPS analisados traz como principal resultado esperado/efeitos da implementação das práticas de EPS a transformação das práticas profissionais e da própria organização do trabalho, este entendimento também é trazido pela PNEPS. Nesta perspectiva a EPS representa uma proposta de mudança, tanto para o processo de formação e desenvolvimento dos trabalhadores, como também para a reorganização dos serviços de saúde. Pode-se perceber que a 16 dos PEÉPS apontam como principal Efeito/Resultados esperados da implementação das práticas de EPS nos serviços de saúde, a transformação das práticas profissionais e da própria organização do trabalho.

\section{Conclusão}

O estudo evidenciou que as concepções de EPS trazidas pelos PEEPS guardam estreita relação com o conceito adotado pelo Ministério da Şaúde na PNEPS, sobretudo no que diz respeito às perspectivas pedagógicas e educacionais preconizadas pelo órgão federal. Assim como na PNEPS os elementos relacionados à abordagem política, gerencial e institucional do conceito de EPS são abordados de maneira incipiente nos PEEPS, sendo o componente Processo Educativo do conceito de àquele que se apresentou de forma mais consistente nos documentos analisados. Com relação ao componente de efeitos/ resultados esperados a maior parte dos PEEPS analisados traz como objetivo principal das práticas de EPS a transformação das práticas pro- fissionais e da própria organização do trabalho. Pode-se apontar como limitações do estudo o fato de nem todos os Estados terem apresentado em seus Planos concepções de EPS, particularmente os Estados de Rio Grande do Sul e de Santa Catarina, o que prejudicou a análise do entendimento da EPS na Região Sul como um todo. Os resultados apontam para a necessidade das pautas ligadas à PNEPS estarem presentes de forma transversal nas agendas dos gestores estaduais, uma vez que verificou-se que, mesmo com o incentivo do Ministério da Saúde por meio de apoio técnico e financeiro, isto não se traduziu na elaboração de planos consistentes, seguindo normatizações técnicas que possibilitasse ao gestor local utiliza-lo com mais propriedade como instrumento para a gestão e implementação da PNEPS em alguns Estados.

\section{Referências}

1. Brasil. Constituição (1988). Constituição da República Federativa do Brasil. Brasília, DF. Disponível em: http://www.planalto.gov.br/ ccivil_o3/constituicao/constituicaocompilado. htm. Acesso em: o7/03/2019.

2. Brasil. Ministério da Saúde. Portaria n. 198/ GM de 13 de fevereiro de 2004. Institui a Política Nacional de Educação Permanente em Saúde como estratégia do Sistema Único de Saúde para a formação e o desenvolvimento de trabalhadores para o setor e dá outras providências. Disponível em: https://www. nescon.medicina.ufmg.br/biblioteca/imagem/1832.pdf. Acesso em: 03/04/2019.

3. Castro FCAQ. Concepções de educação permanente em saúde difundidas por gestores. Dissertação (Mestrado em Saúde Coletiva) - Universidade Federal do Espírito Santo, Centro de Ciências da Saúde. - 2014. Disponível em: http://repositorio.ufes.br/bitstream/10/5530/1/tese_7504_Disserta\% $3 \% \mathrm{~A} 7 \% \mathrm{C} 3 \% \mathrm{~A} 30 \% 20$ concep $\% \mathrm{C}_{3} \% \mathrm{~A} 7 \%$ C3\%B5es\%2ode\%2oEPS\%2odifundidas\%2opor\%20 gestores.pdf. Acesso em: 30/04/2019.

4. Conselho Nacional de Secretários de Saúde - CONASS. Programa de Apoio às Secretarias Estaduais de Saúde. Brasília / DF: 2019. Disponível em: https://www.conass.org.br/programa-de-apoio-as-secretarias-estaduais-de-saude/. Acesso em:05/04/2019.

5. Brasil. Ministério da Saúde. Portaria n ${ }^{0}$ 3.194, de 28 de novembro de 2017. Dispõe sobre o Programa para o Fortalecimento das Práticas de Educação Permanente em Saúde no Sistema Único de Saúde - PRO EPS-SUS. Disponível em: http:// bvsms.saude.gov.br/bvs/saudelegis/gm/2017/ prt3194_30_11_2017.html. Acesso em: 05/04/2019. 
RELATO DE EXPERIÊNCIA

EDUCAÇÃO PERMANENTE PARA

PROFISSIONAIS DE ENFERMAGEM SOBRE

CUIDADOS COM HIPODERMÓCLISE

Gândida Caniçali Primo

Walckiria Garcia

Romero Sipolatti

Catrine Storch Moitinho

Ramon Araújo dos Santos

Alessandra Monteiro Guimarães Carvalho Barbosa

\section{Introdução}

A hipodermóclise consiste na administração de fluídos no espaço subcutâneo, de forma contínua ou intermitente, sendo indicada quando há dificuldade ou impossibilidades na administração de medicamentos por via oral e endovenosa. Atualmente é uma tecnologia alternativa para hidratação, nutrição e terapia medicamentosa em crianças, adultos e idosos, principalmente em cuidados paliativos ${ }^{1}$. Dentre as vantagens para a escolha desta via destacam-se: maior conforto ao paciente e comodidade para equipe de saúde; efetividade da técnica em ambiente hospitalares e domiciliar, redução dos índices de infecção; procedimento de baixo custo $^{1,2}$. Nas instituições de saúde, os profissionais de enfermagem desenvolvem atividades de vários graus de complexidades e estas exigem responsabilidade e competência, além das atribuições de gestão que também fazem parte da atuação do enfermeiro ${ }^{3}$. Por isto, a adesão a práticas educativas que visam à construção do saber em detrimento das demandas do serviço tornam-se essenciais para melhorar o desempenho profissional e consequentemente a qualidade dos serviços de saúde.

\section{Objetivo}

Descrever a experiência da Comissão de Sistematização da Assistência de Enfermagem na elaboraçã̃o e aplicação de instrução de trabalho e capacitação da equipe de enfermagem 
de um Hospital Universitário na técnica de punção para hipodermóclise.

\section{Método}

Estudo descritivo com abordagem qualitativa, do tipo relato de experiência realizado em um Hospital Universitário na região sudeste do Brasil, no período de novembro de 2020. As atividades foram organizadas em dois momentos: no primeiro foi elaborado o material para a capacitação: uma instrução de trabalho, um conjunto de slides e um vídeo instrucional. E um grupo de 15 instrutores foi treinado para desenvolver a ação de educação permanente. No segundo momento ocorreu a capacitação e todos os 800 membros da equipe de enfermagem da instituição foram convidados. A capacitação ocorreu nos três turnos de trabalho.

\section{Resultado e Discussão}

Após a notificação de um incidente com hipodermóclise que ocorreu no hospital no ano de 2020, se observou a necessidade de capacitar a equipe de enfermagem quanto a prática de punção e cuidados com a hipodermóclise. Assim, no primeiro momento foi construído uma instrução de trabalho, denominado procedimento operacional padrão (POP), por profissionais com expertise no assunto seguindo as etapas de elaboração definidas pelo setor de qualidade da instituição, a saber: construção, avaliação e publicação do conteúdo. Posteriormente à publicação, iniciou a elaboração de uma capacitação para toda a equipe de enfermagem do hospital universitário com o objetivo de disseminar a prática baseada em evidências científicas e uniformizar as informações dentro da instituição. Foi elaborado um conjunto de slides utilizando como referência o $\mathrm{POP}$, artigos científicos e manuais e o conteúdo contemplou: escolha do local de punção, cuidados na infusão de medicamentos e soluções, normativas e resoluções sobre a prática, cuidados especiais, exemplos de casos clínicos que usaram hipodermóclise e exercícios de fixação de conteúdo. Buscando utilizar recursos mais ilustrativos e reais, foi confeccionado um vídeo com a instrução da técnica de puncionar o tecido subcutâneo para uso de infusão de terapia medicamentosa, reposição de fluidos e hidratação e demais cuidados para a manutenção da via e orientação nas condutas em casos de incidentes indesejáveis ou complicações. A confecção do vídeo ocorreu em quatro etapas: a primeira foi a revisão de literatura em bases de dados científicas, que incluiu artigos, livros, protocolos, normativas, manuais, além da busca e visualização de vídeos já produzidos sobre este conteúdo. A segunda foi a definição do roteiro e conteúdo do vídeo. A terceira etapa foi a confecção do vídeo, a gravação teve a participação de uma acadêmica de enfermagem do $8^{\circ}$ período, que autorizou ser puncionada em algumas regiões para demonstração da técnica. Por último, a quarta etapa foi a edição do vídeo e o mesmo foi incluído na apresentação em formato para microsoft power point. Antes da capacitação de toda a equipe, foi feito um treinamento para os enfermeiros instrutores com o objetivo de equalizar as informações e proporcionar troca de aprendizagem entre eles e avaliação final do conteúdo. No segundo momento, ocorreu a capacitação de 257 pessoas, dentre eles enfermeiros, acadêmicos, técnicos e auxiliares de enfermagem, de forma presencial no mês de novembro, com exposição oral e apresentação do vídeo instrucional. Foram ofertadas 20 turmas nos períodos matutino, vespertino e noturno distribuídas em quatro dias seguidos. Além disto, utilizou-se a ferramenta de exercícios de fixação com casos clínicos em grupo para potencializar a aprendizagem dos profissionais envolvidos. A educação permanente em saúde pode proporcionar uma nova visão, estimular a reflexão por parte dos profissionais e promover o desenvolvimento de suas competências, habilidades e atitudes 3 . Nesse sentido, destaca-se o aprimoramento das metodologias de ensino aprendizado como estratégia fundamental nas capacitações, com vistas a não tornar as intervenções e propostas nos serviços ultrapassados. Com isso, um programa de educação voltado aos profissionais requer planejamento dinâmico, participativo, interdisciplinar com objetivos definidos, que atenda tanto a instituição envolvida quanto seus profissionais ${ }^{4}$. Desta forma, as capacitações devem ser valorizadas e realizadas de forma contínua e sempre baseadas nas necessidades do serviço e dos profissionais envolvidos, pois as transformações organizacionais geradas pelo conhecimento adquirido são essenciais. Ademais é fundamental a compreensão dos gestores de que é preciso investir tempo, recurso e, em algumas situações, modificações no ambiente de trabalho para a obtençã̃o de resultados ${ }^{3,4}$.

\section{Conclusão}

Este estudo permitiu reconhecer que a educação permanente em saúde é muito importante para os profissionais atuantes nas organizações hospitalares, uma vez que a busca 
por conhecimento e capacitação para a prática assistência é um dos primeiros passos no processo de mudança e melhoria da qualidade dos serviços de saúde. Durante a elaboração da instrução de trabalho e capacitação, percebemos que o uso desta tecnologia demanda construção de protocolos assistenciais para a equipe de enfermagem e multiprofissional, que norteiem os cuidados na administração para as categorias dos fármacos e possibilitem uma melhor divulgação da técnica para ampliação do uso desta via na prática hospitalar considerando os seus benefícios. Além disto, oportunizou ouvir experiências sobre o tema e despertou a necessidade de qualificação e a responsabilidade profissional durante a sua atuação na prática e importância de executar as atividades laborais com base em evidências científicas. Após a capacitação, emergiu também a necessidade de aplicar outras ferramentas de aprendizagem como briefing e debriefing e como um desafio a inserção da avaliação do processo desde o conteúdo até a dinâmica desta atividade de educação permanente em saúde.

Descritores: Capacitação em Serviço; Hipodermóclise; Enfermagem.

\section{Referências}

1. SAGANSKI, G F et al. Hipodermóclise para tratamentos não convencionais em pediatria: revisão integrativa. Cogitare Enfermagem, [S.1.], v. 24, oct. 2019. ISSN 2176-9133. Disponível em: <https://revistas.ufpr.br/cogitare/ article/view/61546>. Acesso em: 27 jan. 2021. doi:http://dx.doi.org/10.538o/ce.v24io.61546.

2. Bruno Vanessa Galuppo. Hipodermóclise: revisão de literatura para auxiliar a prática clínica. Einstein (São Paulo) [Internet]. Março de 2015. 13 (1): 122-128. Acesso em 28 de jan de 2021; Disponível em: http://www. scielo.br/scielo.php?script=sci_arttext\&pi-

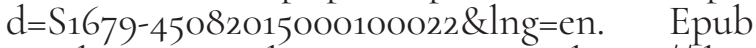
24 de março de 2015. DOI: <https://doi. org/10.1590/S1679-45082015RW2572>.

3. SILVA LFM, ALMEIDA MR, NETO PML, et al. Educação continuada em um hospital municipal: relato de experiência. Revista de Enfermagem do Centro Oeste Mineiro. 2020;10:e2713. Acesso em 27 de jan 2021; Disponível em: <http://seer.ufsj.edu.br/index.php/ recom/article/view/2713/2428>. DOI:<http:// doi.org/10.19175/recom.v10io.2713>.

4. COSTA DB, GARCIA SD, VANNUCHIMTO et al. Impacto do treinamento de equipe no processo de trabalho em saúde: revisão integrativa. Rev enferm UFPE on line, Recife, 9(4):7439-47, abr., 2015.Acesso em 28 jan 2021. Disponível em: $<$ https://periodicos.ufpe.br/revistas/revistaenfermagem/article/viewFile/13603/16430>. DOI: 10.5205/reuol.7275-62744-1-SM.0904201532. 
RELATO DE EXPERIÊNCIA

EDUCAÇÃO PERMANENTE NA PANDEMIA DA COVID-19 RELATO DE EXPERIÊNCIA

Eliete Aparecida Teodoro Amaral

Eliane Ramos Pereira Janaína Mengal Gomes Fabri

Raquel Dias dos Santos Dantas

\section{Introdução}

A declaração de pandemia pelo novo coronavírus, conceito definido por uma enfermidade epidêmica amplamente disseminada, em Março de 2020 pela Organização Mundial de Saúde (OMS), iniciou de uma série de mudanças organizacionais frente à ameaça representada pelo vírus. Segue-se então, o aumento exponencial de transmissão do vírus entre toda a população e uma lamentável estatística de mortes relacionadas à doença e complicações produzidas por ele ${ }^{1}$. Em meio às estratégias governamentais diárias para proteção dos mais vulneráveis e contenção da disseminação $d a$ Covid-19, as instituições de saúde assumem papeis fundamentais na assistência aos pacientes acometidos por essa doença. As instituições hospitalares, responsáveis diretamente pelo tratamento da Covid-19 em suas complicações mais graves, adaptaram fluxos e processos de trabalho de acordo com as diretrizes da OMS, de modo a prevenir a contaminação dos profissionais de saúde e a contaminação cruzada. Em âmbito nacional, o Ministério da Saúde (MS) ampliou aos canais de comunicação com a população em geral, objetivando o acesso a informações básicas de prevenção do novo coronavírus. Viabilizou, também, novos protocolos de manejo clínico do paciente portador da Covid-19 e suas complicações mais graves ${ }^{1}$. Os protocolos de manejo clínico da Covid-19, englobando a prevenção de contaminação antes, durante e após todos os processos as- 
sistenciais multidisciplinares, requereram treinamento contínuo e comunicação efetiva para uma distribuição homogênea de toda informação pertinentes à assistência'. Ante a necessidade de capacitar os colaboradores e seguindo as recomendações sanitárias, ações de educação permanente se tornaram necessárias para a implementação das novas rotinas adequadas ao novo perfil de atendimento. A Política Nacional de Educação Permanente ${ }^{2}$ (EPS) tem em suas premissas estratégias educativas que intercalam o aprendizado teórico e prático que preconiza, focando na aplicabilidade da teoria sobre resolução de problemas no contexto do qual eles emergem. O objetivo do estudo é relatar a experiência da atuação da educação permanente na capacitação profissionais de saúde e demais profissionais para o manejo clínico da Covid-19, na perspectiva da equipe de enfermagem.

\section{Método}

Trata-se de um relato de experiência sobre o papel da educação permanente diante da Pandemia da Covid-19, na perspectiva dos plantonistas uma unidade de terapia intensiva. O cenário do estudo foi o setor de terapia intensiva de um Hospital Universitário da cidade de Niterói. O hospital de grande porte passou a integrar a retaguarda de atendimento a casos suspeitos e confirmados para o Sars-Cov-2 em meados de Março de 20zo. A partir daí, as ações de educação permanente foram voltadas para treinamentos e capacitações sobre o manejo clínico da Covid-19. Os treinamentos e capacitações englobavam as ações assistenciais diretas e indiretas com o paciente suspeito ou que tenha testado positivo para o novo coronavírus, cuidados com pertences, superfícies e objetos contaminados e cuidados pós-morte. O público alvo foi toda a equipe de saúde que viria a ter contato direto ou indireto com o paciente com Covi19, isto é: médicos, fisioterapeutas, enfermeiros, técnicos de enfermagem, técnicos em radiologia, técnicos em laboratório, auxiliares de serviços gerais, maqueiros, dentre outros profissionais. O roteiro dos treinamentos seguiu as diretrizes do manejo clínico que foram sendo publicados pelo Ministério da Saúde ao longo do ano de 20zo. As equipes que eram formadas majoritariamente por enfermeiros utilizavam recursos audiovisuais e exposição in loco, mesclando ensino teórico e prático. Os encontros ocorreram em um auditório do Hospital e também nas áreas comuns do setor de terapia intensiva.

\section{Resultados e Discussão}

Os protocolos seguiram as diretrizes do Ministério da Saúde iniciando pelo conhecimento do agente etiológico, principal modo de transmissão (até então conhecido), grupos de risco, primeiras diretrizes terapêuticas, procedimentos intra-hospitalares, dentre outros. Os ciclos dos treinamentos abordaram: paramentação e desparamentação, manejo do corpo pós-morte, desinfecção de superfícies, cuidados com pertences pessoais e material contaminado, protocolo de intubação, protocolo de pronação e administração de medicamentos. A relação entre as diretrizes técnicas publicadas pelo Ministério da Saúde e a pauta das capacitações requereu sincronia e rapidez, visto que durante os primeiros meses da doença em território nacional houve atualizações frequentes dos protocolos de manejo clínico e terapêutico. Em estudo acerca do estado da arte da educação permanente no Brasil', salienta-se que quanto mais as atividades de educação permanente estiverem aliadas à prática profissional, as probabilidades de se obter motivação e comprometimento por parte dos educandos se eleva. A prática de enfermagem baseada em evidências é beneficiada pela atuação da educação permanente ${ }^{4}$, a medida que a concepção homogênea de conhecimento pode gerar desfechos positivos na assistência, como foco no cuidado seguro e de qualidade. A carência de treinamentos e capacitações sobre o manejo clínico da Covid-19 foram apontados como desafios por profissionais de enfermagem $^{5}$, correlacionados à falta de conhecimento técnico e científico frente ao avanço rápido da doença. As atividades de educação permanente também estiveram presentes na capacitação de profissionais recém-admitidos em instituições de saúde. Um estudo 5 apontou que tais atividades se mostraram efetivas na capacitação de funcionários novos no contexto da pandemia. É importante ressaltar que contratações emergenciais de profissionais da saúde foram realizadas afim de munir os estabelecimentos de recursos humanos para o enfrentamento da Covid-19. A partir daí, um número grande de funcionários novos foram sendo recebidos nessas instituições e, somando-se os afastamentos de servidores por contaminação com o vírus ou por comporem o grupo de risco para a doença, a alta rotatividade dos profissionais da saúde demandaram ainda mais esforços dos treinamentos e capacitações. A limitação do estudo se configura na perspectiva particular dos autores da percepção da atuação da educação permanente na pandemia da Covid-19, não 
sendo possível inferir dados acerca das percepções dos demais profissionais. O relato ressalta a importância de tais ações e pretende contribuir para novas pesquisas acerca da aplicabilidade destas ações no panorama pandêmico.

\section{Conclusão}

Durante os meses iniciais da assistência à Covid-19, a atuação da educação permanente foi cruscial para comunicar, informar e formar os profissionais diante $\mathrm{da}$ doença até então desconhecida, que transformaria a rotina de toda a sociedade. As circunstâncias advindas com o contexto pandêmico: rotatividade de profissionais, contratações emergenciais, necessidade iminente de capacitação de todo o pessoal com potencial risco de contaminação e/ou propagação do vírus criaram um cenário propício ao protagonismo da educação permanente em saúde.

Descritores: Educação em Enfermagem. Educação Continuada. Infecções por Coronavírus.

\section{Referências}

1. Ministério da Saúde (BR) Manejo Clínico e Tratamento da Covid-19. [Homepage da Internet] Acesso em Jul 2020. Disponivel em: https://coronavirus.saude.gov.br/manejo-clinico-e-tratamento.

2. Oliveira JA, Spagnol CA, Camargos AT, Matos SS de, Silva SF da, Oliveira JM de. Educação permanente em enfermagem no centro de tratamento intensivo. Rev enferm UFPE on line. 2020;14:e244644 DOI: https://doi. org/10.5205/1981-8963.2020.244644

3. Lemos, FM. Silva GGA. Educação Permanente em Saúde: o estado da arte. Revista Interdisciplinar de Promoção da Saúde, Santa Cruz do Sul, v. 1, n. 3, set. 2018. ISSN 25953664. Acesso em: 20 Jan 2020. doi:https://doi. org/10.17058/rips. v1i3.12867

4. Silva DO. Cruz I. Prática de enfermagem baseada em evidência sobre a resposta a ventilação mecânica: Adulto em UTI -- Revisão Sistematizada da Literatura. Journal of Specialized Nursing Care [Internet]. Acesso em 15 Jan 2020. Disponível em: http://web.a.ebscohost.com/ehost/detail/detail?vid=0\&sid=1d94d4bf-c298-40ec-a67b-7b821e7a6502\%4 osessionmgr40o6\&bdata $=$ ImxhbmcgcHQtYnImczloZT1laGgzdCisaXZl\#AN=142753735\&db=aph

5. Góes FGB, Silva ACSS, Santos AST, Pereira-Ávila FMV, Silva LJ, Silva LF, Goulart MCL. Challenges faced by pediatric nursing workers in the face of the COVID-19 pandemic. Rev. Latino-Am. Enfermagem. 2020;28:e3367. [Acesso 15 Jan 2021] Disponivel em: https://www.scielo.br/ pdf/rlae/v28/pt_0104-1169-rlae-28-e3367.pdfDOI: http://dx.doi.org/10.1590/1518-8345.4550.3367. 
Relato de Caso

\section{PRIMEIROS SOCORROS NA GRADUAÇÃO DE CIÊNCIAS BIOLÓGICAS: UMA DISCUSSÃO NECESSÁRIA}

\author{
Karen Cristiane \\ Pereira de Morais \\ Aline Gomes Ilha
}

\section{Introdução}

Primeiros socorros são ações iniciais à vítima, realizadas no local onde ocorre a situação de emergência, tendo como finalidade a manutenção da vida, sem provocar mais lesões ou agravar as já existentes, ao se trabalhar em uma escola principalmente com crianças podem ocorrer diversas situações que resultam em acidentes. ${ }^{1}$ Desta forma, é importante que os professores tenham conhecimento sobre primeiros socorros e neste contexto, o enfermeiro desempenha o papel de educador em saúde. Nesta perspectiva, realizar este ensinamento durante a formação dos professores auxilia no atendimento imediato preparando-os para atuar em situações de emergência. $\mathrm{O}$ ambiente escolar ganha espaço, principalmente pelos momentos de interação, podendo ocasionar acidentes, os quais desencadeiam ansiedade $\mathrm{e}$ inquietação dos professores, que são os responsáveis por esse espaço, portanto é fundamental para o professor uma preparação sobre primeiros socorros. Com isso, objetivando capacitar e proteger os profissionais da educação infantil no atendimento aos educandos que sofrem incidentes, entrou em vigor, em outubro de 2018, a Lei $\mathrm{n}^{\mathrm{O}} 13.722$, também denominada Lei Lucas, a qual recomenda que estabelecimentos de ensino devem capacitar os profissionais da educação para situações de emergência para que possam realizar um pré-atendimento seguro, evitando agravos e contribuindo para a preservação da integridade da vítima ${ }^{2} \mathrm{Vi}$ - 
sando esse atendimento, formulou-se uma oficina de noções básicas de primeiros socorros para acadêmicos do curso de ciências biológicas. Devido a situação sanitária atual, a oficina foi planejada de maneira online, a pandemia de Covid-19 reformulou o cotidiano tanto pessoal quanto laboral/acadêmico reorganizando as atividades presenciais para remota. Portanto, objetiva-se relatar a experiência de enfermeiras ao ministrar conteúdo de primeiros socorros a graduandos do curso de ciências biológicas.

\section{Método}

A oficina intitulada "Primeiros Socorros, o que fazer?" foi ministrada na disciplina "Temáticas Contemporâneas" do curso de Ciências Biológicas da Universidade Federal de Santa Maria, campus Palmeira das Missões, e foi realizado de maneira virtual com metodologia expositiva dialogada com apresentação de imagens e vídeos para ilustrar as falas das enfermeiras. A oficina foi realizada no mês de dezembro de 2020, teve duração de duas horas, com momentos para esclarecer dúvidas e no final foi sugerido que os participantes avaliassem de forma oral o conteúdo ministrado e realizassem sugestões. Os conteúdos abordados foram de acordo com a faixa etária dos alunos que os participantes irão atuar em seus estágios e vida profissional, por se tratarem de acadêmicos do curso de ciências biológicas entende-se que estes trabalharam com crianças maiores de 10 anos, sendo assim buscou-se no tempo estipulado abordar temas que contemplasse essa faixa etária, entre os assuntos abordados na oficina têm-se: conceitos de primeiros socorros e Lei Lucas, desmaio, convulsão, desobstrução de vias aéreas e ressuscitação cardiopulmonar. Cada assunto abordado era ilustrado com imagens e/ou vídeos, assim os participantes compreenderiam melhor as técnicas de atendimento, visto que estávamos em um ambiente virtual, optou-se por realizar a oficina desta maneira por ter mais interação com quem participa, podendo esclarecer em tempo real as dúvidas e perceber as dificuldades e melhorar a abordagem em futuras atividades.

\section{Resultados e Discussão}

Destaca-se que durante o período de isolamento social, o ensino superior teve que se readaptar e realizar as atividades de maneira remota, desta forma a Universidade Federal de Santa Maria organizou o Regime de Exercícios Domiciliares Especiais (REDE), portanto pensando no atual contexto, foi organizada uma atividade com foco na Lei Lucas e noções básicas de primeiros socorros para acadểmicos. Utilizou-se materiais teóricos, imagens e vídeos para explanação, no intuito de facilitar o entendimento dos participantes acerca das técnicas de cada conteúdo, por não ser possível realizar atividade prática, utilizou-se vídeos explicativos sobre desobstrução de vias aéreas e ressuscitação cardiopulmonar, sendo pausados em alguns momentos para explicações. Após a explanação teórica e explicação dos vídeos, foi disponibilizado um momento para interação dos participantes para esclarecimento de dúvidas, neste foi mencionado a importância da discussão da temática e de como foi significativo, mesmo que em tempos de distanciamento social, haver a disponibilidade de se discutir primeiros socorros. Em um estudo que investigou o conhecimento sobre primeiros socorros de estudantes da área de ciências biológicas em relação à participação dos acadêmicos em treinamentos ou cursos práticos internos ou externos à instituição envolvendo o assunto em questão, $67(46 \%)$ afirmaram participação, $58(40 \%)$ relataram nunca ter participado e 20 $(14 \%)$ não responderam a essa questão ${ }^{3}$. A inclusão da temática de primeiros socorros constitui-se como demanda iminente no campo da educação em âmbito mundial, considerando os diversos níveis de ensino, bem como a disponibilização de recursos nos mais diversos ambientes, não há necessidade de espera dos acadêmicos para realizar este treinamento posterior a formatura, a Lei Lucas garante aos alunos de educação básica um atendimento imediato e quando os acadêmicos possuem essa capacitação há mais chances de vidas serem salvas e o conhecimento de primeiros socorros não deve se restringir aos cursos da área da saúde. No que diz a respeito dos professores, estes não prestam assistência por não sentirem-se preparados, uma vez que possuem pouco ou nenhum conhecimento na área ${ }^{4}$.

\section{Considerações finais}

A oficina possibilitou abrangência de conhecimento dos acadêmicos e esclarecimento de dúvidas. Os graduandos avaliaram de maneira positiva os conteúdos ministrados e pertinentes para sua formação acadêmica, pois eles irão realizar estágios em escolas e se sentirão mais preparados para atuar em situações de emergência. Além disso, foi proporcionado aos acadêmicos um momento para sugerirem novas temáticas sobre o assunto e até mesmo sobre outros assuntos, como Infecções Sexualmente Transmissíveis. Entende-se que é de 
suma importância e relevância debater sobre este tema na academia, pois é uma forma de preencher uma lacuna no conhecimento. A pandemia causada pelo Coronavírus impôs novas rotinas e maneiras de se capacitar e estudar, fazendo da internet uma importante ferramenta de acesso às informações. Ministrar esta oficina de maneira online foi um desafio inicial para as autoras e cada oficina ministrada é adaptada conforme os participantes e evento, apesar disso, as autoras avaliam positivamente a realização de oficina neste formato, pois o objetivo principal é de que os participantes conheçam a Lei Lucas e consigam identificar e agir corretamente em situações emergência.

Descritores: Primeiros Socorros; Educação; Enfermagem.

\section{Referências}

1. Costa Ribeiro Geiciara, Lima Hilderlânia de Freitas, Rodrigues Rafaela Martins, et al. Avaliando o Nivel de Conhecimento em Primeiros Socorros dos Acadêmicos De Enfermagem em um Centro Universitário do Sertão Central. Mostra Interdisciplinar do curso de Enfermagem. 2016 Dec 01;2(2):921-926.

2. BRASIL. Presidência da República. Casa Civil. Subchefia para Assuntos Jurídicos. Lei no 13.722, de 4 de outubro de 2018. Torna obrigatória a capacitação em noções básicas de primeiros socorros de professores e funcionários de estabelecimentos de ensino públicos e privados de educação básica e de estabelecimentos de recreação infantil.

3. Zanesco Camila, Galvan Jéssica, Galvão Nathalia, Bordin Daniele, Berger-Fadel Cristina. Conhecimento e segurança de universitários da área de ciências biológicas e da saúde sobre primeiros socorros. Revista de Pesquisa: Cuidado é Fundamental Online. 2020 Jul 2; 12(o): 155-161.

4. Leite Hellen Samara Nunes, Bonfim Célio da Rocha, Formiga Henrique José Bandeira, et al. Primeiros socorros na escola: conhecimento da equipe que compõe a gestão educacional. Temas em Saude. 2018;290-332. 


\section{A IMPORTÂNCIA DA EDUCAÇÃO PERMANENTE PARA A EQUIPE DE} ENFERMAGEM NA PANDEMIA DA COVID-19

\author{
Aline Silva da Fonte \\ Santa Rosa de Oliveira \\ Suely Lopes de Azevedo \\ Thais de Rezende \\ Bessa Guerra \\ Rosane Burla de Aguiar \\ Herica Félix de Oliveira \\ Natalia Anisia Costa Marques
}

\section{Introdução}

A pandemia da covid-19, causada pelo vírus SARS-CoV-2 gerou repercussões negativas não apenas de ordem biomédica e epidemiológica, mas em toda a sociedade mundial devido a sua alta taxa de contágio e mortalidade. Dentre os grupos mais atingidos pela covid-19 estão os profissionais de saúde, sendo que os profissionais de enfermagem representam o maior número de mortes. Ademais, os profissionais de saúde têm maior capacidade de contaminação do que a população em geral, especialmente aqueles que estão na linha de frente prestando o cuidado à população, pela alta exposição a que estão submetidos nos diferentes contextos do cuidado nos serviços de saúde. A escassez de EPIs, a falta de profissionais capacitados e a precariedade das condições estruturais e organizacionais das instituições de saúde são fatores que estão dificultando o combate da pandemia. Soma-se a isso, maior criticidade e incidência em função da inexistência de uma política de enfrentamento adequada, por parte da gestão dos serviços de saúde. Diante desse cenário uma das principais causas de mortes de profissionais de enfermagem está relacionada com o fornecimento de epis, quantidade e qualidade, assim como ausência de programa de educação permanente nas instituições de saúde, retratada pela dificuldade dos profissionais em atender as normas específicas de biossegurança. Observa-se como consequência a incidência da doença nos profissionais de 
enfermagem, a categoria profissional que atua prestando assistência 24 horas ao paciente. Nesse bojo, a alta incidência pode ser causada ainda pela falta de treinamento para paramentação e desparamentação das equipes com ênfase nas práticas corretas e preventivas voltadas para as ações de biossegurança adequadas. Sendo assim, a Educação Permanente em Saúde (EPS), inserida pelo Ministério da Saúde como uma política de saúde no Brasil por meio das Portarias $n^{\circ}$ 198/2004 e n⿳o 1.996/2007 têm como objetivo nortear a formação e a qualificação dos profissionais inseridos nos serviços públicos de saúde, com a finalidade de transformar as práticas profissionais e a própria organização do trabalho com base nas necessidades e dificuldades do sistema. Não obstante, a estratégia da Política Nacional de Educação Permanente em Saúde é promover transformações na práxis do trabalho, agregando o conhecimento teórico com a prática assistencial, por meio da união entre o aprender e o ensinar no cotidiano dos serviços. Diante da nova demanda assistencial proveniente dos pacientes com a covid - 19 é imprescindível que ensino e aprendizagem permanente da equipe de enfermagem sejam requisito no enfrentamento adequado e eficiente.

\section{Objetivo}

Refletir sobre a importância da educação permanente para controlar os agravos causados nos profissionais de enfermagem que estão atuando na linha de frente da covid -19 .

\section{Método}

Pesquisa bibliográfica, descritiva, com abordagem qualitativa, que busca nas evidências destacar a educação permanente em saúde como fator que contribui para a diminuição do número de óbitos dos profissionais da equipe de Enfermagem que atuam na linha de frente em meio à pandemia da covid - 19 no Brasil. Para melhor compreensão da situação de saúde dos profissionais de enfermagem que estão sendo acometidos pela pandemia no âmbito nacional, iniciou-se um levantamento atualizado sobre os percentuais estatísticos dos casos de contaminação e óbitos registrados que são disponibilizados diariamente no portal oficial do Ministério da Saúde e no portal eletrônico do Conselho Federal de Enfermagem. Seguido da leitura crítica de todo o material selecionado, para então iniciar a escrita da parte introdutória do estudo. A próxima etapa foi à busca dos artigos relacionados com o objetivo do estudo através do Portal BVS (Biblioteca Virtual em
Saúde do Ministério da Saúde), e nas seguintes bases de dados: LILACS (Literatura Latino Americana e do Caribe em Ciências Sociais e da Saúde), BDENF e MEDLINE. Para realizar a coleta utilizou-se o operador boleano "AND" com cruzamento dos descritores: "enfermagem" and "educação permanente" and "covid - 19". Como critérios de inclusão foram selecionados artigos com texto completo, em português, no periodo de janeiro de 2020 á janeiro de 2021. Como critérios de exclusão: indisponibilidade integral dos textos no formato online, artigos em outro idioma que não fosse português. Foram encontrados 15 artigos, após a leitura dos mesmos foram selecionados o5 artigos que tiveram aderência com o objetivo do estudo.

\section{Resultados e Discussão}

A pandemia da covid -19 desafiou os serviços de saúde, requerendo assistência de alta complexidade, assim com novos modelos de trabalho e processos de Educação Permanente dos profissionais da saúde. É preciso destacar que nesse novo contexto emergencial do cuidar, os profissionais da enfermagem estão expostos ao maior risco de contaminação frente a exposição prolongada e frequente a pacientes potencialmente contaminados, agrega-se à intensificação da jornada e a complexidade das tarefas de trabalho. Após o levantamento, identificamos que até o dia 19 de Janeiro de 2021, o total de profissionais da enfermagem que foram acometidos pela covid -19 foi de 46 , 916, com a taxa de letalidade $1,94 \%$. A taxa de mortalidade destes profissionais é extremamente alta, com o número de 519 profissionais que foram a óbito no Brasil. Ao analisar os meses de abril a novembro de 2020 foi possível averiguar que no mês de setembro houve o maior percentual no número de óbitos, com 61 óbitos na equipe de enfermagem. De acordo com os estudos encontrados, um dos principais motivos da alta taxa de contaminação e mortalidade dos profissionais de enfermagem se dá pelas más condições de trabalho aliado à falta de equipamentos de proteção individual disponíveis para uso dos mesmos. Diante deste cenário, a Educação Permanente garante uma equipe preparada para lidar com a pandemia e executar adequadamente os protocolos, a mesma, contribui para reafirmar o papel de cada profissional integrante das equipes de saúde e cuidar dos aspectos relacionados à saúde física e mental desses profissionais. O reflexo que a pandemia da covid -19 gerou na equipe de enfermagem de todo o Pais demonstra a importância de pro- 
mover condições eficientes e responsáveis na administração de recursos materiais e humanos pelos gestores da saúde nos ambientes de trabalho, assim como melhores condições de trabalho. Dessa forma, a Educação Permanente promove ações de fácil implementação que contribuem no enfrentamento da covid-19 e acima de tudo amenizam diversos fatores estressores inerentes ao cuidado deste paciente.

\section{Conclusão}

Nesse clima de tensão causado pela pandemia no Brasil e no mundo, acredita-se que ainda é possível estabelecer um ambiente de trabalho harmonioso e seguro para que os profissionais de enfermagem possam manter as suas atividades profissionais de forma a garantir a segurança e qualidade da assistência ao paciente. No entanto, não podem esquecer que precisam preservar a sua própria vida e a de seus familiares. Assim os programas de Educação Permanente das instituições de saúde precisam encontrar estratégias que possam fazer com que seus profissionais sejam estimulados a atuarem de forma precisa, segura e consciente, o que visa alcançar a ressignificação das relações e dos processos de trabalho. E importante salientar que as ações realizadas pela Educação Permanente durante a pandemia contribuíram para melhorar a prática assistencial dos profissionais de enfermagem que estão diretamente na linha de frente da covid - 19, fortalecendo o vínculo multiprofissional. Diante disso, a Educação permanente configura-se como uma estratégia de ensino teórico-prático assegurando maior segurança, eficiência e qualidade para a assistência aos pacientes com execução das técnicas e procedimentos complexos e peculiares, voltados para a segurança de todos os profissionais que estão na linha de frente do combate a essa nova e devastadora patologia.

Descritores: Enfermagem; Educação permanente; Covid-19.

\section{Referências}

1- Ferreira Lorena, Barbosa Júlia Saraiva de Almeida, Esposti Carolina Dutra Degli, Cruz Marly Marques da. Educação Permanente em Saúde na atenção primária: uma revisão integrativa da literatura. Saúde debate [Internet]. 2019 Mar [cited 2021 Jan 20]; 43 ( 120 ): 223-239.

2- Rios, Amora Ferreira Menezes; Lira, Laís Santana Santos Pereira; Reis, Ilana Menezes; Silva, Gabriela Andrade. Atenção primária á saúde frente á covid-19 em um centro de saúde: Relato de experiêcia. Enferm. Foco [internet]. 2020 Ago [cited 2021 Jan 19]: Especial (art 39): 246-251.

3- Tavares, Claudia Mara Melo, Souza, Odilon Adolfo Branco de. Análise do processo de implantação do serviço de atenção ao paciente com COVID-19. Braz. j. Nurs. (Online); 19 set. 2020 [cited 2021 Jan 19].

4- Teixeira Carmen Fontes de Souza, Soares Catharina Matos, Souza Ednir Assis, Lisboa Erick Soares, Pinto Isabela Cardoso de Matos, Andrade Laíse Rezende de et al. A saúde dos profissionais de saúde no enfrentamento da pandemia de Covid-19. Ciênc. saúde coletiva [Internet]. 2020 Sep [cited 2021 Jan 20]; 25(9): 3465-3474.

5- Treccossi Sara Priscila Carvalho; Ferreira, Joabe Candido; Oliveira, Rafael Muniz de; Santos, Reginaldo Passoni dos; Carvalho, Ariana Rodrigues da Silva. Protagonismo da enfermagem na organização de uma unidade para assistência à pacientes com Coronavírus: Relato de experiência. J. nurs. health; 10(4): 20104039, abr.2020.V. 10, N. 4. 
RELATO DE EXPERIÊNCIA

\section{EDUCAÇÃO PERMANENTE COMO ESTRATÉGIA PARA CONSOLIDAÇÃO DA META DE PREVENÇÃO DE QUEDAS EM HOSPITAL PEDIÁTRICO}

\author{
Fernanda de Ávila \\ Carvalho Neves \\ Priscila Coelho Amaral \\ Stephanie Greiner \\ Victória Tiyoko \\ Moraes Sakamoto
}

\section{Introdução}

Sabe-se que a educação permanente em saúde foi instituída a partir da Portaria GM/MS n⿳o 198/2004 pelo Ministério da Saúde (MS) e recebeu alteração em 2007. Essa política visa o trabalho, a qualificação e, principalmente, a transformação das práticas de saúde e foi desenvolvida estrategicamente para fortalecer o Sistema Único de Saúde (SUS) ${ }^{(1)}$. Na prática, a educação permanente inicia na identificação de problemáticas que emergem no contexto do cuidado diário, evidenciando a necessidade de capacitações. Buscam-se melhorias através de um plano de ações voltado a um público-alvo que possui necessidades específicas e constantes, tanto de formação quanto de capacitação. Acredita-se que as estratégias educacionais que podem ser aplicadas pela educação permanente são capazes de auxiliar no processo de implementação, avaliação e monitoramento das ações de capacitação voltadas para o cuidado seguro, qualificando-o e aumentando a adesão das equipes à cultura de segurança. A segurança do paciente foi instituída no Brasil em 2013, pelo Programa Nacional de Segurança do Paciente que visa à implementação de medidas tanto assistenciais quanto educativas direcionadas à segurança do paciente em todos os níveis de atenção, organização e gestão ${ }^{(2)}$. E é nesse contexto que a gestão de risco assistencial foi implementada nos serviços de saúde. Um dos pilares que norteia suas ações está diretamente relacionado às seis metas internacionais de segurança, consideradas prioritárias nos serviços de saúde 
por maior risco de ocorrência. Dentre elas, destaca-se a prevenção de quedas no ambiente hospitalar, pois representa a segunda principal causa de morte acidental ou não intencional no cenário mundial. Na pediatria, muitas vezes o risco de quedas é aumentado, considerando o período de desenvolvimento, comportamentos desafiadores e a curiosidade inata da faixa etária. Sendo assim, é essencial que os profissionais compreendam o conceito de quedas, desmistificando o seu entendimento sobre a temática. A queda é conceituada como um deslocamento do corpo de forma não intencional para um nível inferior ao da posição que estava ocupando, provocado por múltiplas causas possíveis, podendo ou não resultar em dano ${ }^{(3)}$. Considerando a necessidade de desenvolver estratégias para consolidação das ações de educação permanente com a equipe, definiuiu-se como questão norteadora: "como o serviço de gestão de risco assistencial de um hospital pediátrico de referência organizou suas ações de educação permanente para a consolidação da promoção da cultura de segurança do paciente envolvendo a meta de prevenção de quedas na unidade piloto?"

\section{Objetivo}

Relatar a experiência da equipe da gestão de risco assistencial acerca das ações de educação permanente realizadas com equipe de unidade piloto como estratégia para qualificação dos processos de trabalho e consolidação das medidas preventivas relacionadas à meta internacional de segurança de prevenção de quedas em um hospital pediátrico referência pelo atendimento 100\% SUS.

\section{Método}

Trata-se de um relato de experiência, a partir das vivências da equipe da gestão de risco assistencial do hospital acerca das ações de educação permanente executadas com enfoque na meta de prevenção de quedas. A proposta de estudo surgiu a partir da necessidade de documentar as experiências exitosas da prática aliada às abordagens teórico-metodológicas das ações de educação permanente com a equipe. $\mathrm{O}$ cenário foi um hospital pediátrico que elegeu uma enfermaria clínica para ser sua unidade piloto para prevenção de quedas, dentro da proposta do Projeto Paciente Seguro. O Hospital Criança Conceição ingressou no Projeto em maio de 2019. A unidade piloto foi estrategicamente selecionada, de acordo com o perfil de pacientes atendidos (crianças entre 6 meses e 2 anos de idade) que, de acordo com a faixa etária, possuem um alto risco de queda. A partir disso, foram desenvolvidos indicadores de qualidade assistencial relacionados à incidência e prevalência de quedas na unidade e adesão às medidas preventivas. Para a obtenção dos indicadores, foram realizadas coletas quinzenais a partir de informações como: se pacientes apresentaram quedas durante a hospitalização; se foi realizada avaliação do risco de queda nas primeiras 24 horas após admissão na unidade e aplicação da escala de avaliação diariamente; se a criança está acompanhada, se possui calçado seguro, se o acesso está livre de obstáculos e iluminado; se a cama está travada e com grades elevadas; se a acomodação/cama está adequada ao tamanho da criança; se familiar recebeu orientações quanto à prevenção de quedas, a influência do diagnóstico e uso de medicamentos que influenciam no risco de quedas; e se houve algum transporte intra-hospitalar, foi realizado adequadamente conforme idade da criança. A gestão de risco assistencial é composta por uma enfermeira, uma acadêmica de enfermagem, uma farmacêutica e uma médica pediatra-hebiatra e atua ativamente com a equipe da unidade piloto promovendo treinamentos e formações a partir de problemáticas levantadas pelos próprios profissionais a partir de pensamento crítico direcionado ao cuidado seguro dos pacientes. Questionamentos como: "a unidade é um local seguro?"; "eu presto uma assistência segura aos meus pacientes"; "o transporte é seguro para os pacientes?", dentre outros serviram de inspiração para o processo de mudança a partir dos princípios da ciência da melhoria. A fim de verificar a consolidação das ações de educação permanente realizadas pela gestão de risco assistencial, utiliza-se uma ficha de coleta de indicadores relacionados ao processo de trabalho, principalmente da enfermagem, relacionado às ações voltadas à prevenção de quedas na unidade. Após as coletas, a equipe da gestão de riscos organiza os dados e avalia estatisticamente utilizando frequências, médias e medianas, conforme o indicador. Essa avaliação dos pontos permite verificar se houve consolidação das ações de educação permanente (melhoria) ou não (pioria).

\section{Resultados e Discussão}

A equipe assistencial da unidade piloto da meta de prevenção de quedas se mostrou bastante receptiva com os objetivos e planejamento de ações para a qualidade e segurança do cuidado prestado. Inicialmente, a equipe foi sensibilizada quanto ao tema de segurança do paciente e prevenção de quedas e, a partir disso, criou-se um time de referência para a meta, composto pelos membros da própria equipe, 
para que se tornassem multiplicadores das ações de educação permanente. Após a formação do time, a gestão de riscos iniciou com a coleta dos indicadores e montou uma linha de base previamente às intervenções educativas. Diversas capacitações e treinamentos foram realizados baseados no diagrama direcionador do Projeto do Paciente Seguro, porém, muitas temáticas foram levantadas pela equipe assistencial a partir de situações de seu cotidiano. Tais situações foram problematizadas e discutidas em busca pela compreensão e identificação de lacunas e, consequentemente, busca por melhorias nos processos de trabalho. As discussões direcionaram grande parte das horas de formação da equipe que apresentou resultados melhores quando refletiam e associavam a formação recebida à prática profissional. Por isso, inumeras melhorias foram identificadas na unidade, dentre elas o transporte mais seguro em meios adequados, orientações fornecidas aos responsáveis da criança na ad̆missão com folder informativo e termo de ciência quanto ao risco de queda na hospitalização, a utilização de escala de avaliação de risco de quedas e adequação da prescrição de enfermagem. Ao coletar os indicadores, percebeu-se que a maior causa das quedas foi por supervisão inadequada do responsável legal, convergindo com a literatura que aborda que a supervisão inadequada do adulto corresponde ao fator de risco mais citado dentre estudos realizados ${ }^{(4)}$. Observou-se o indicador dias entre quedas e foi possível destacar um dos principais resultados da equipe assistencial: o recorde de 308 dias sem nenhuma queda na unidade. Como a gestão de riscos faz parte da estrutura organizacional da instituição, emerge a necessidade de desenvolver uma estratégia para promover melhorias nos processos de trabalho que reflitam na qualificação assistencial e, consequentemente, redução de eventos adversos. A educação permanente também é uma estratégia de gestão, pois desvela a complexidade da problemática relacionada ao processo de trabalho, atuando pontualmente ou amplamente com as equipes em busca por melhorias. Embora a temática de educação permanente em saúde no âmbito do SUS seja desafiadora, é essencial olhar para os profissionais, contribuindo em seus processos de formação e desenvolvimento, transformando-os. Sob essa ótica, será possível revalorizar o processo de trabalho, colocando-o como centro de aprendizagem ao buscar por lacunas de conhecimento e nós críticos identificados no cotidiano da instituição. Apesar da limitação da equipe de não permanecer com ações em uma única unidade, considerando o andamento de todas as metas internacionais de segurança em diferentes unidades piloto, nota-se a consolidação efetiva das ações de educação permanente com a equipe de enfermagem.

\section{Conclusão}

As ações realizadas pela gestão de risco assistencial na unidade piloto de prevenção de quedas visavam não apenas qualificar os processos de trabalho, mas também proporcionar um aprendizado significativo para a equipe assistencial, para que refletissem sobre o processo e suas práticas profissionais. Além disso, os profissionais vivenciaram o problema identificado, ressignificando-o e se tornaram mais dispostos e engajados em buscar alternativas para melhorar os processos de trabalho, principalmente aqueles relacionados à meta de prevenção de quedas. Portanto, considera-se a educação permanente em saúde como uma estratégia essencial dentro da esfera de desenvolvimento e formação dos profissionais para que os processos de trabalho possam ser qualificados na instituição.

Descritores: Educação em Saúde; Segurança do Paciente; Gestão de Riscos; Estratégias; Indicadores de Qualidade em Assistência à Saúde.

\section{Referências}

1. Brasil. Ministério da Saúde. Portaria no 198 , de 20 de agosto de 2007, que institui a Política Nacional de Educação Permanente em Saúde como estratégia do Sistema Único de Saúde para a formação e o desenvolvimento de trabalhadores para o setor e dá outras providências. Disponível em lhttp://bvsms.saude.gov.br/bvs/ publicacoes/politica_nacional_educacao_permanente_sau de.pdf. Acessado em 28/o1/2021. 2. Brasil. Ministério da Saúde. Documento de referência para o Programa Nacional de Segurança do Paciente/Ministério da Saúde; Fundação Oswaldo Cruz; Agência Nacional de Vigilância Sanitária. Brasília: Ministério da Saúde; 2013. Disponível em: http://bvsms.saude.gov.br/bvs/publicacoes/documento_referencia_programa_nacional_seguranca.pdf. Acessado em 29/01/2021.

3. Brasil. Ministério da saúde. Protocolo de prevenção de quedas. Fundação Oswaldo Cruz; Agểncia Nacional de Vigilẩncia Sanitária. Brasília: Ministério da Saúde; 2013. Disponível em file://C:/Users/usuario/Downloads/protoc_ prevencaoQuedas.pdf. Acessado em 29/01/2021. 4. World Health Organization. Global reporto n falls prevention in older age [internet]; 2018. Disponivel em: https://www.who.int/news-room/ fact-sheets/detail/falls. Acessado 29/01/2021. 
REVisão de Literatura

PRINCIPAIS ERROS NO GERENCIAMENTO DE MEDICAMENTOS PELA EQUIPE DE ENFERMAGEM E SEUS FATORES RELACIONADOS

Helena Fornari Basso

Luana Reis Angélica Zanettini

Julia Valeria de Oliveira Vargas Bitencourt

\section{Introdução}

O tema segurança do paciente, marcado pela amplitude da ocorrência de eventos adversos, ou seja de lesão ou danos ao paciente em consequência do cuidado de saúde, tornou-se notório quando o Instituto de Medicina (IOM) publicou na década de go um relatório sobre "To err is human: building a safer health system" traduzindo, "Errar é humano: construindo um sistema de saúde mais seguro", onde foram relatados em um ano a morte de 44.000 a 98.000 americanos resultantes de incidentes onde boa parte eram evitáveis, diante disso, os níveis de conhecimento e conscientização sobre o tema eventos adversos aumentou consideravelmente, acelerando as iniciativas governamentais para a prevenção do tema ${ }^{1}$. A partir dos anos 2000, a segurança do paciente passou a ser reconhecida como uma dimensão fundamental na qualidade do serviço de saúde prestado ao paciente, sendo definida pela Organização Mundial de Saúde (OMS) como a diminuição do risco de danos desnecessários a um mínimo aceitável. Em 2004 a OMS estabeleceu a Aliança Mundial para a Segurança do Paciente, o qual tinha o objetivo de definir e identificar quais aspectos eram prioridades na área de segurança do paciente em diversos países ${ }^{2}$. No Brasil foi instituído o Programa Nacional de Segurança do Paciente (PNSP), por meio da Portaria $\mathrm{n}^{\mathrm{o}} 529$, de abril de 2013 , que tinha como objetivo implementar ações e metas voltadas a qualificação da segurança 
do paciente no âmbito dos serviços de saúde, fundamentado nas áreas prioritárias, foi definido seis protocolos básicos: identificacão do paciente, cirurgia segura; prevenção de ủlceras por pressão; higienização das mãos; segurança na prescrição, uso e administração de medicamentos; e prevenção de quedas ${ }^{3}$. Dentre os eventos adversos mais frequentes estão os erros de medicação, e em sua maioria os mesmos poderiam ser evitados, baseado no levantamento dos fatores envolvidos nesse processo, pode-se fazer a prevenção destes erros, diminuindo os riscos à saúde dos pacientes. $\mathrm{O}$ processo de medicação envolve muitos caminhos até sua administração no paciente, como a prescrição, dispensação, e por fim a administração, na qual envolve os processos de checagem, diluição, preparação e administração, dessa forma a equipe de enfermagem possui um papel crucial em todos os processos, pois suas ações e cuidados podem evitar possiveis erros.

\section{Objetivo}

Identificar os principais erros no processo de administração de medicamentos e os fatores que influenciam na ocorrência desses erros pela equipe de enfermagem.

\section{Método}

Trata-se de uma revisão de literatura. A pesquisa foi realizada nas bases de dados eletrônicos PubMed Central (National Library of Medicine) e SCIELO (Scientific Eletronic Library Online), utilizando artigos sobre o tema publicados entre os anos de 2015 e 2020, em idiomas inglês e português e que apresentaram texto online disponivel.

\section{Resultados e discussões}

A administração de medicamentos é um processo multidisciplinar, pois envolve a equipe médica, equipe de enfermagem, e equipe farmacêutica, diante disso, diversos erros podem acontecer no caminho percorrido deste a prescrição dos medicamentos até a administração do mesmo no paciente. Sendo assim, é necessário a atenção redobrada da equipe de enfermagem devido seu contato direto com a preparação e administração dos medicamentos. Fundamentado em diversos estudos os principais erros de medicações estão ligados com a execução incorreta dos 9 certos - dentre eles o paciente certo, medicamento certo, dose certa, via certa, horário certo, registro certo, ação certa, forma farmacêutica certa e moni- toramento certo -, além desses erros podem ser listados a realização incorreta dos cálculos de medicação, erros de produção/rótulos dos medicamentos, velocidade de infusão, frequência de administração errada e ausência de notificações em caso de erros ${ }^{4,5}$. Diante disso, os principais fatores correlacionados com a ocorrência destes erros de medicamentos pela equipe de enfermagem são a sobrecarga de trabalho (cansaço e estresse), displicência ou falta de experiência dos profissionais, desconhecimento da terapêutica medicamentosa, negligência ou imprudência, dificuldade na compreensão da prescrição, erros de dispensação, que é definido como o desvio de uma prescrição médica, falta de planejamento, distração com celular, conversas e televisão, falha na comunicação entre a equipe de saúde, e por vezes a estrutura inadequada dos serviços de saúde ${ }^{4}$. Além disso, os erros ocorridos durante o dia (manhã e tarde) podem ser relacionados à dinâmica do serviço, visto que são admitidos um maior número de pacientes no turno diurno, e como consequência há o aumento das medicações a serem preparadas e administradas pela equipe. Por vezes os erros de medicamentos não estão ligados apenas a desatenção, mas sim em razão de prescrições médicas, devido a abreviaturas que não existem, letra ilegível, ausência da dosagem dos medicamentos, ausência da via de administração, e dados incompletos sobre o paciente, dessa forma são necessários adotar medidas que possam prevenir ou diminuir a ocorrência dos erros, para que se possa ofertar uma assistência de qualidade e sem intercorrências ${ }^{4,5}$. A partir do exposto, pode-se elencar métodos que auxiliem a equipe de enfermagem na diminuição dos incidentes devido a erros de medicamentos, como seguir os nove certos antes de administrar todos os medicamentos, usar procedimentos de dupla conferência dos medicamentos potencialmente perigosos, fazer uso de prescrição eletrônica e sem abreviaturas, devendo assim recusar prescrições que sejam ilegíveis ou que contenham abreviaturas, siglas, símbolos, expressões de dose, não executar prescrições rasuradas, nunca realizar prescrição quand̉o tiver dúvida, as mesmas devem ser retiradas com o médico, enfermeiro ou farmacêutico e implementar a cultura de segurança do paciente dentro do serviço de saude por meio de educação permanente, bem como sensibilizar a equipe sobre o assunto.

\section{Considerações finais}

Assim sendo, a prevenção de erros relacionados a medicações e a disseminação da 
cultura de segurança do paciente atualmente são de extrema relevância, porém não existe sistema de saúde livre de erros, mas a diminuição e prevenção da ocorrência dos erros são uma obrigação de todos os profissionais envolvidos na assistência prestada ao paciente, desde os médicos, enfermeiros, técnicos de enfermagem e farmacêuticos, pois é um trabalho coletivo e as responsabilidades devem ser partilhadas, dessa forma todos serão responsáveis pelo desfecho clínico do paciente. Além disso, estratégias para atualização dos conhecimentos dos profissionais, como a educação permanente, definição de protocolos e a reorganização do processo de trabalho são métodos que podem intervir em erros recorrentes.

Descritores: Erros de Medicação; Equipe de Enfermagem; Segurança do Paciente.

\section{Referências}

1. Silva AT, Alves MG, Sanches RS, Terra F de S, Resck ZMR. Assistência de enfermagem e o enfoque da segurança do paciente no cenário brasileiro. Saúde em Debate. 2016;40(111):292-301.

2. Maia CS, Freitas DRC de, Gallo LG, Araújo WN de. Notificações de eventos adversos relacionados com a assistência à saúde que levaram a óbitos no Brasil, 2014-2016. Epidemiol e Serv saude Rev do Sist Unico Saude do Bras. 2018;27(2):e2017320.

3. Gomes AT de L, Salvador PTC de O, Rodrigues CCFM, Silva M da F, Ferreira L de L, Santos VEP. A segurança do paciente nos caminhos percorridos pela enfermagem brasileira. Rev Bras Enferm. 2017;70(1):146-54.

4. Mieiro DB, Oliveira ÉBC de, Fonseca REP da, Mininel VA, Zem-Mascarenhas SH, Machado RC. Strategies to minimize medication errors in emergency units: an integrative review. Rev Bras Enferm. 2019;72(Suppl 1):307-14.

5. Forte ECN, Machado FL, Pires DEP de. A Relação Da Enfermagem Com Os Erros De Medicação: Uma Revisão Integrativa. Cogitare Enferm. 2016;21(5):1-10. 
Eixo temático III

\section{PRÁTICAS/PRODUTOS INOVADORES NA ATENÇÃO À SAÚDE}


Pesquisa Original

MULHERES:

PROSTITUIÇÃO

E CUIDADOS

Carlos Botazzo

Thainá Buono Paulino

dos Santos

\section{Introdução}

Este estudo teve como tema a saúde sexual da mulher. O motivo da escolha desse tema adveio de uma experiência profissional em Obstetrícia que a autora vivenciou. Durante o atendimento no pré-parto, a autora pôde observar que a infecção sexualmente transmissível era um fator recorrente no dia a dia desse hospital. Com isso, observou-se que havia a necessidade de se investir na saúde da mulher. No entanto, ela também pôde perceber a questão de gênero presente, considerando que culturalmente há uma certa resistência ao uso do preservativo e até mesmo do ato de cuidar-se por parte do público masculino. O cuidado com o corpo, e com o outro, envolvem questões relativas à educação; reflexão que advém, principalmente, do meio sócio familiar e do Estado, também. Pareceu-lhe interessante lidar com prostitutas em seu estudo, porque refletiu que podia analisá-las, além de suas profissões, vê-las como mulheres que, assim como outras mulheres estão vulneráveis a qualquer infecção transmissível sexualmente, dependem de políticas públicas e estão mais expostas do que outras mulheres a sofrerem qualquer intempérie.

\section{Objetivos}

Saber o que é e como se dá o cuidado para as prostitutas a fim de enxergá-las, principalmente como mulheres, independentemente de sua profissão levando em conside- 
ração, a revolução sexual, visto que esta fez com que cada mulher pudesse exercer sua sexualidade com mais liberdade. Com isso, quis saber se há diferença no tratamento dado a elas em suas consultas ginecológicas, se elas recebem mais orientações quanto aos métodos preventivos de ISTs do que outras mulheres que não são prostitutas. Além disso, quis conhecer o meio social e as histórias de vida desse público e contribuir com as Políticas Públicas de saúde para a mulher.

\section{Método}

Foi realizada pesquisa qualitativa, com a utilização de entrevistas face a face e roteiro semiestruturado. Além disso foram formuladas duas questões norteadoras. As entrevistas foram gravadas, duraram entre 5 a 30 minutos, posteriormente foram transcritas e os depoimentos foram analisados de acordo com a análise temática. As participantes também autorizavam o uso de sua voz. O Termo de Consentimento Livre e Esclarecido para realizar a entrevista foi fornecido em duas vias, um ficou com a participante da pesquisa e o outro com a pesquisadora e foram rubricados por ambas em todas as páginas e igualmente foram assinados e datados por ambas na última página. Houve a utilização de observação na forma de diários de campo e análise hermenêutica dialética das entrevistas. Os benefícios dessa pesquisa são o de poder refletir sobre o cuidado em saúde sexual da mulher, e pode refletir, também sobre o cuidado em saúde sexual com o outro.

\section{Resultados e Discussão}

Nesse estudo houve a colaboração de 11 mulheres que são prostitutas do baixo meretrício na região central da cidade de Santos/SP, com idade entre 19 a 59 anos. Os resultados foram agrupados em seis categorias temáticas, à saber: a) História de vida- Infância traumática e falta de uma estrutura familiar, b) O cuidado para elas, c) $\mathrm{O}$ não uso do preservativo na primeira relação sexual, d) A homossexualidade e profissão, e) Reincidência na profissão e o desejo de mudança e f) Preconceitos. O cuidado para a maioria das entrevistadas está atrelado ao uso do preservativo masculino em todas as relações sexuais, quando estão trabalhando. Muitas alegam o uso do preservativo masculino pelo medo do vírus da imunodeficiência humana. Somente duas, das onze mulheres entrevistadas relataram terem usado preservativo feminino. A cidade de Santos/SP produz um serviço valoroso de prevenção a doenças se- xualmente transmissíveis, o qual é indicação internacional ${ }^{1}$. Em relação aos cuidados de saúde relatados por elas, apesar de terem citado a ida ao centro de saúde e à realização de exames, uma entrevistada de nome social Viviane disse que na cidade onde ela mora (Cubatão/SP) é muito difícil o acesso aos serviços de saúde, apesar de ela querer se consultar. Isso me faz questionar se a Equipe Consultório na Rua poderia abranger seu atendimento a esse público que trabalha na rua. A ausência das prostitutas nos serviços de saúde se dá, de modo geral, pela dificuldade de acesso a estes ${ }^{2}$. Os serviços de saúde devem adequar seus horários, estrutura e qualificar seus profissionais a fim de satisfazer as demandas apresentadas por essa população². A maioria das mulheres declarou falar de sua profissão para os profissionais de saúde, uma delas falou que dizer sua profissão aos profissionais de saúde é uma forma de se orientar mais sobre saúde e se caso, precisar de algum tratamento disse que é mais fácil para realizá-lo. O cuidado foi relatado não somente pelo uso da camisinha, mas também, algumas entrevistadas relataram fazer exames para ISTs/aids, exame preventivo e tomar anticoncepcional. Não foi relatado por elas, a orientação de dicas personalizadas-levando em conta sua profissão- a elas pelos serviços de saúde. O manual realizado pelo Ministério da Saúde ${ }^{3}$ discorre sobre a questão dos fatores afetivo-sexuais das vidas das trabalhadoras do sexo que as vulnerabilizam igualmente àquelas que não realizam essa atividade. Esta questão é constatada pelo fato de existirem infimas ações de prevenção direcionadas às parcerias fixas delas. Quando os profissionais de saúde observam que a mulher é homossexual, não lidam abertamente sobre esse assunto. De acordo com os dados desse estudo, a utilização do preservativo nas relações homossexuais não é usual, especialmente quando há parceiros fixos. Sobre essa situação podemos recorrer ao caso da participante Silvana, a qual relata que nunca utilizou preservativo com sua esposa.

\section{Conclusão}

Esses dados são fortes indicativos de escassa realização de direitos e que se trata de população vulnerável. Percebemos que faltam os serviços de saúde olharem para a diversidade sexual, precisa-se falar mais sobre os benefícios do preservativo feminino, não só às prostitutas, mas também a toda população (homens e mulheres). O manual chamado "Dicas para mulheres profissionais do sexo" deveria ser acessível a todas as mulheres, indepen- 
dentemente de suas profissões e poderíamos pensar na inserção da Equipe Consultório na Rua no atendimento às demandas emergentes e necessárias às prostitutas.

Descritores: Cuidado; Mulher; Prostituição; Saúde sexual.

\section{Referências}

1. Oliveira SF. Cortina de fumaça. Praia Grande: Don Muñoz; 2009.

2. Cruz NL, Ferreira CL, Martins E, Souza M. O cuidado com a saúde das mulheres profissionais do sexo: uma revisão narrativa. Disciplinarum Scientia. 2016;17(3):339-52.

3. Brasil. Ministério da Saúde. Secretaria de Políticas de Saúde. Coordenação nacional de DST e AIDS. Brasília, DF: Ministério da Saúde; 2002. 
Estudo DE REVISÃo

\section{USO DE TECNOLOGIAS PELO ENFERMEIRO AUDITOR EM CONTAS HOSPITALARES: REVISÃO INTEGRATIVA DE LITERATURA}

\author{
Jaqueline Ana Foschera \\ Jane Tavares Gomes \\ Odila Migliorini Rosa \\ Letícia de Lima Trindade \\ Angélica Zanettini
}

\section{Introdução}

A auditoria em enfermagem avalia constantemente a qualidade da assistência de enfermagem ofertada ao cliente, desde sua internação até a alta, analisando toda documentação e anotações da equipe multiprofissional registradas no prontuário do paciente, como esse atendimento foi prestado, por meio de visitas in loco, assegurando desta maneira, primeiramente a segurança do paciente e consequentemente que o pagamento hospitalar seja feito de maneira justa e transparente. O profissional auditor em enfermagem, possui em sua formação atividades de gestão que o influenciam a um olhar mais abrangente para as necessidades dos usuários, da equipe de saúde e gestores, focando na qualidade da assistência. Portanto, o enfermeiro auditor necessita constante aperfeiçoamento técnico-científico para que exerça seu papel de gestor, educador, líder e quiçá, um potencial inovador ${ }^{1}$. O Conselho Federal de Enfermagem (COFEN), em sua resolução 266/2001 aponta que o enfermeiro é o profissional capacitado para realizar auditoria, cabendo-lhe privativamente organizar, dirigir, coordenar, avaliar, prestar consultoria e auditoria e emitir parecer sobre os serviços de auditoria de enfermagem, cabendo somente ao enfermeiro realizar auditoria em enfermagem ${ }^{1}$. O uso das tecnologias em saúde proporciona melhores registros, armazenamento de dados e de informações, melhorando a qualidade da assistência prestada, assim 
sendo, o uso das Tecnologias da Informação e Comunicação (TIC's) traz vantagens ao ensino, administração e processo de enfermagem. Essas tecnologias vêm sendo utilizadas na auditoria em saude para facilitar, agilizar e otimizar processos ${ }^{1}$. Uma das novas tecnologias em auditoria é a "Machine Learning" (Tradução livre: Aprendizado de Máquina) que diz respeito ao funcionamento de sistemas computacionais, que, por meio de algoritmos, são capazes de aprender e modificar seu comportamento em resposta a estímulos externos ou através de experiências acumuladas, como por exemplo, uma busca no Google que armazena o que foi pesquisado para ser usado posteriormente em um anúncio. Constitui-se ainda, em examinar e experimentar estratégias eficazes para a construção de programas que aprendem a partir da experiência, adquirindo conhecimento de forma automática'.

\section{Objetivo}

Analisar produções científicas relacionadas ao uso de tecnologias em auditoria de enfermagem, no período de fevereiro de 2010 a fevereiro de 2020 .

\section{Metodologia}

Trata-se de um estudo de revisão integrativa de literatura, que foi desenvolvido após etapas pré-determinadas. Para iniciar a pesquisa, foram definidos previamente o tema, os objetivos, os descritores e a pergunta da pesquisa, ambos relacionados com o uso de tecnologias em auditoria de contas hospitalares. A pergunta norteadora da pesquisa foi: quais tecnologias o enfermeiro auditor utiliza ou tem disponivel em sua rotina de trabalho? As buscas foram realizadas no mês de novembro de 2020, nas bases de dados LILACS, BDENF e SciELO, através da combinação dos descritores, os critérios de inclusão foram: artigos nacionais; publicações que englobam a temática do estudo; publicações que contenham os descritores listados no protocolo, preferencialmente no resumo ou no título; publicações disponíveis online na íntegra e publicadas no período de fevereiro de 2010 a fevereiro de 20zo. Como critérios de exclusão: estudos que englobam pessoas menores de 18 anos; publicações que demandem pagamento para acesso; publicações referentes à atenção básica; publicações fora do ano de seleção; teses; editoriais; cartas; protocolos e livros. Foram encontrados 135 artigos no total, 17 na BDENF, 115 LILACS e três na SciELO e, após serem utilizados os critérios de seleção, restaram cinco artigos. As buscas e a análise dos artigos foram realizadas pelos autores. Primeiramente iniciou-se com uma pré-seleção com análise dos títulos e resumos, após, foi realizada a leitura e análise completa dos artigos pré-selecionados, com a aplicação dos critérios de inclusão e exclusão. Os artigos que restaram desta última seleção foram os selecionados para a construção deste resumo expandido.

\section{Resultados e Discussão}

Os artigos utilizados foram publicados na Revista Journal of Health Informatics (Tecnologia da informação e comunicação na auditoria em enfermagem, GROSSI, L.M.; PISA, I.T.; MARIN, H.F. e Sistema inteligente para apoio em auditoria de contas médicas. ARAYA, A.M.P. et al.) Revista Acta Paulista de Enfermagem (Oncoaudit: desenvolvimento e avaliação de aplicativo para enfermeiros auditores. GROSSI, L.M.; PISA, I.T.; MARIN, H.F.), Revista de Gestão em Sistemas de Saúde (Um levantamento sobre o uso de algoritmos de aprendizado de máquina em auditorias de planos de saúde. RADUENZ, J.C.; FERNANDES, A.M.R.) e no Sistema de Bibliotecas da Fundação Getúlio Vargas (Impacto da inteligência artificial na atividade de auditoria: equacionando gargalos nos repasses da União para entes subnacionais. CARVALHO, S.T.N.). Sendo publicados nos anos 2014, 2015, 2016 e 2020. Na literatura, evidencia-se que a utilização das tecnologias ajuda o profissional a desempenhar seu trabalho de forma melhorada, na tomada de decisão e otimização do processo de cuidado e avaliação, tendo condições de desempenhar seu trabalho com mais efícácia. Além disso, o uso de tecnologias em saúde proporciona a otimização de processos, redução do tempo, rentabilidade aumentada e a melhoria da qualidade da assistência prestada. Possibilita ainda, prever antecipadamente custos futuros e riscos, contribuindo para a sustentabilidade econômica do setor saúde. Os prestadores de serviços hospitalares e ambulatoriais produzem diariamente grande quantidade de dados, sendo esse mais um dos fatores que encorajam o uso de tecnologias, pois formas mais eficientes de desempenho melhoram seu aproveitamento ${ }^{4}$. As vantagens do uso de tecnologias na administração e no processo de enfermagem são senso comum. Na auditoria em saúde, o enfermeiro utiliza a informática para auxiliar na codificação dos honorários médicos, medicamentos e materiais e na análise dos 
prontuários eletrônicos ${ }^{1}$. O uso das tecnologias na auditoria deve ser estimulado, visto que o auditor aprende a lidar com técnicas de mineração de dados, inteligência artificial, entre outras. O uso dessas tecnologias diminui custos e agiliza os processos 5 . Ainda, possibilitam ao enfermeiro, a oportunidade de conduzir seu destino profissional, pois pode adaptar recursos tecnológicos em sua rotina, observando tendências emergentes na área da saúde como oportunidades e desafios para evolução em sua carreira, pois esta é uma área em ascensão, há um vasto número de oportunidades em hospitais, clínicas, consultorias e áreas jurídicas em saúde, para aquele que decidir incluir as tecnologias em sua prática diária $^{3}$. Por fim, o uso de tecnologias traz apenas benefícios ao enfermeiro auditor, pois é uma ferramenta que facilita, agiliza e otimiza processos da auditoria. Há ainda muito que se trabalhar e divulgar a respeito deste assunto, sendo necessário mais profissionais enfermeiros auditores especialistas em informática em saúde, mais incentivo de gestores e pesquisas na área, para que ocorra o desenvolvimento de softwares e/ou aplicativos customizados que possam facilitar o trabalho do auditor ${ }^{1}$.

\section{Considerações finais}

O enfermeiro auditor conhece tanto a área da assistência de enfermagem quanto à negociação e cobrança de contas hospitalares e auditoria de enfermagem, sendo o profissional mas indicado para auxiliar a equipe técnica de informática a desenvolver projetos e protótipos de aplicativos ou outras tecnologias que venham auxiliar o serviço de auditoria de contas hospitalares. Este profissional também reconhece que o uso das tecnologias em saúde vem de encontro com os princípios da usabilidade e funcionalidade, padrões de segurança da informação, confidencialidade, privacidade, entre outros. Além disso, potencializa a construção de novos conhecimentos, otimiza e melhora a qualidade dos processos organizacionais que refletem na qualidade da assistência prestada ao paciente e saúde financeira institucional.

Descritores: Auditoria de Enfermagem; Tecnologia em Saúde; Administração Hospitalar; Informática em Enfermagem.

\section{Referências}

1. Grossi LM, Pisa IT, MARIN HF. Tecnologia da informação e comunicação na auditoria em enfermagem. J. Health Inform, São Paulo, 2015; 7(1):30-4. Disponível em: http://www. jhi-sbis.saude.ws/ojs-jhi/index.php/jhi-sbis/ article/view/314

2. Raduenz JC, Fernandes AMR. Um levantamento sobre o uso de algoritmos de aprendizado de máquina em auditorias de planos de saúde. Rev. Gest. Sist. Saúde, São Paulo, 20zo; 9(1):119-31. Disponível em: https://periodicos. uninove.br/revistargss/article/view/15296/8239

3. Grossi LM, Pisa IT, MARIN HF. Oncoaudit: desenvolvimento e avaliação de aplicativo para enfermeiros auditores. Acta Paul. Enferm., São Paulo, 2014; $27(2): 179-85$. Disponível em: https://www.scielo.br/scielo. php?pid $=S_{010}=21002014000200015-\&$ script sci_arttext\&tlng=pt

4. Araya AMP, Chupel JS, Carvalho DR, Dallagassa MR, Ioshii SO. Sistema inteligente para apoio em auditoria de contas médicas. J. Health Inform, São Paulo, 2016; 8(2):49-56. Disponível em: http://www.jhi-sbis.saude.ws/ ojs-jhi/index.php/jhi-sbis/article/view/394

5. Carvalho STN. Impacto da inteligência artificial na atividade de auditoria: equacionando gargalos nos repasses da União para entes subnacionais. Dissertação, Mestrado Profissional em Administração Pública. Fundação Getúlio Vargas. Escola Brasileira de Administração Pública e de Empresas. Rio de Janeiro, 2020. Disponível em: https://repositorio.cgu.gov.br/ handle/1/46670 
PROCESSO DE CERTIFICAÇÃO EM BOAS PRÁTICAS NA ATENÇÃO PRIMÁRIA À SAÚDE SUPLEMENTAR: RELATO DE EXPERIÊNCIA

\section{Fabiele Farina \\ Maykler Cristiane Vanzin \\ Kátia Jamile da Silva}

\section{Introdução}

A Atenção Primária à Saúde (APS) é a principal porta de entrada do serviço de saúde, e tem como foco o cuidado individualizado centrado na pessoa e nos determinantes biopsicossociais de saúde e doença, coordenando e integrando toda a rede de atenção à saúde. ${ }^{1}$ Dessa forma, além de maior resolutividade, a APS possibilita redução significativa dos custos em saúde, sendo considerada, portanto, um modelo eficiente tanto assistencial, quanto economicamente. ${ }^{2}$ Nesse sentido, cabe salientar que o atual modelo de atenção, praticado pelo serviço de saúde suplementar que se refere este estudo, tem como premissa a melhoria na qualidade $d a$ assistência prestada aos usuários, criando um elo de confiança e segurança, e também com vistas à sustentabilidade da operadora, seguindo referenciais técnicos que norteiam o serviço dentro da rede de atenção. Neste contexto, surgiu a necessidade da operadora de saúde seguir a Resolucão Normativa (RN) 440 de 13 de dezembro de 2018, através da iniciativa do Programa de Certificação de Boas Práticas em Atenção à Saúde de Ỏperadoras de Planos Privados de Assistência à Saúde, o qual visa certificar empresas, por meio de entidades Acreditadoras em Saude reconhecidas pela ANS, que ofereçam os serviços recomendados na Resolução, ${ }^{3}$ com objetivo de padronização e aumento da qualidade dos serviços. 


\section{Objetivo}

Relatar o processo de implementação da Certificação em Boas Práticas em uma Atenção Primăria à Saúde suplementar.

\section{Método}

Trata-se de um estudo qualitativo de caráter descritivo, que consiste em um relato de experiência sobre o processo de Certificação em Boas Práticas na APS, realizado por duas enfermeiras em um serviço de APS suplementar, durante o período de quatro meses, as quais realizaram a estruturação dos itens para a organização da prática, com dedicação exclusiva durante esse período. O nível de certificação a que a operadora buscou foi a de Nível III, o qual compete assegurar uma cobertura mínima de acordo com o número total de beneficiários da sua carteira, considerando uma equipe multiprofissional de APS para no máximo 2,5 mil beneficiários, atuando de forma interdisciplinar, e composta por, no mínimo: médico de família e comunidade, prioritariamente, ou médico especialista em Clínica Médica com capacitação em APS ou experiência mínima de dois anos em APS; Enfermeiro especialista em Saúde da Família ou generalista; e outro profissional de saúde de nível superior, o qual foi inserido mais duas categorias profissionais, psicólogo e farmacêutico. Para a adequação e implementação dos itens foram seguidas as normas vigentes, direcionando e orientando o serviço para atender as demandas em saúde de maneira ordenada e efetiva, norteada pela $\mathrm{RN}$ $\mathrm{n}^{\mathrm{o}} 44 \mathrm{O}$ de 13 de dezembro de 2018. ${ }^{3}$ Composto por requisitos classificados como essenciais, complementares e de excelência, o processo de construção contemplou sete dimensões, sendo elas: 1)_Planejamento e Estruturação Técnica - com 13 itens -; 2) Ampliação e qualidade do acesso - com 8 itens -; 3 ) Qualidade e Continuidade do Cuidado - com 14 itens -; 4) Interações centradas no paciente - com 10 itens -; 5) Monitoramento e avaliação da qualidade - com 11 itens -; 6) Educaçã̃o Permanente - com 3 itens -; 7) Modelo de Remuneração Baseado em valor - com quatro itens, totalizando com a estruturação e adequação, os 63 itens contidos na norma. Durante o processo de construção, a APS teve o suporte do Núcleo de Segurança e Qualidade da Assistência da instituição. Através dessa RN o serviço precisou ser reestruturado, com novos objetivos, política e diretrizes, os quais utilizaram como fundamentação o Manual de
Certificação de Boas Práticas em APS de Operadoras de Planos Privados de Assistência à Saúde da Agência Nacional de Saúde (ANS) e as melhores evidências científicas nacionais e internacionais sobre este nível de atenção. Para a adequação dos itens propostos, foram construídos fluxogramas, protocolos, manuais, formulários e o plano estruturado, os quais nortearam a prática laboral, organizacional e assistencial e todos os demais fatores que envolvem a melhoria do serviço referido, além de novo espaço físico e contratação de profissionais com base no nível da certifícação.

\section{Resultados e Discussão}

Dessa forma, foi possível reestruturar a APS com base legal e científica em todos os âmbitos desse serviço. Aderir ao processo de certificação trouxe o desenvolvimento da maturidade da APS suplementar, pois cumprir os requisitos da norma proporcionou melhor organização e funcionalidade do sistema e ainda oportunizou auditorias periódicas, contribuindo para a qualificação da equipe de saúde no serviço e a obtenção de resultados no aprimoramento da assistência e na qualidade de vida da população de abrangência. Todas as ações voltadas para o atendimento dos itens recomendados pela Agência Nacional de Saúde, contribuíram para a estruturação de estratégias de prevenção de doenças e agravos e de promoção da saúde, que levam à redução dos riscos em saúde e a diminuição das Doenças Crônicas não Transmissíveis (DCNT) e suas complicações. O que se mostra como o maior desafio nesse processo, é a inserção da cultura de autopercepção de saúde e de autocuidado, e do entendimento do usuário frente a este modelo de atenção, o qual envolve um trabalho multidisciplinar pautado nas bases teóricas da vigilância em saúde, com gerenciamento de pacientes crônicos e crônicos complexos, busca ativa, consultas médicas, e consultas de enfermagem, seguindo os princípios da APS, realizando todas as dimensões da assistência à saúde: prevenção, promoção, tratamento e reabilitação. Considerada um modelo eficiente, tanto assistencial, quanto economicamente, a APS possibilita resultados em curto, médio e longo prazo, além da redução significativa dos custos em saúde, tendo como impacto a rentabilidade e sustentabilidade da instituição que assume o papel de provedora de saúde, ${ }^{2}$ o que foi observado ao reestruturar o serviço de saúde com base no modelo da APS através da RN que norteou o processo. 


\section{Conclusão}

A estruturação e implementação da Certificação em Boas Práticas na APS suplementar permitiu que os usuários percebessem o serviço como a porta de entrada para suas necessidades em saúde, a medida que promove o entendimento, a autonomia e a responsabilidade frente ao seu estado de saúde e qualidade de vida, criando vínculo com a equipe de referência ao promover um cuidado integral, coordenado e longitudinal dentro da rede de serviços, gerando segurança e satisfação ao usuário, além de ser uma estratégia conveniente, produtiva e sustentável para a operadora. Dessa forma, foi notória a importância do processo de certificação para oportunizar um modelo de atuação direcionado nos princípios da APS por toda equipe, haja vista que foi embasada nas melhores evidências científicas sobre esse nível de atenção, bem como, na legislação vigente para serviços de saúde suplementares.

Descritores: Certificação, Enfermeiras e Enfermeiros, Saúde Suplementar, Atenção Primária à Saúde.

\section{Referências}

1. Starfield B. Atenção Primária: equilíbrio entre necessidades de saúde, serviços e tecnologia. Brasília: UNESCO, Ministério da Saúde, 2002. $726 \mathrm{p}$.

2. Brasil. Ministério da Saúde. Portaria n⿳ํㅡ 2.436, de 21 de setembro de 2017. Aprova a Política Nacional de Atenção Básica, estabelecendo a revisão de diretrizes para a organização da Atenção Básica, no âmbito do Sistema Único de Saúde (SUS). Diário oficial da União, Brasília, DF, 22 de setembro de 2017.

3. Brasil. Agência Nacional de Saúde - ANS. Resolução Normativa - RN no 440 , de 13 de dezembro de 2018. Institui o Programa de Certificação de Boas Práticas em Atenção à Saúde de Operadoras de Planos Privados de Assistência a Saúde. Ministério da Saúde. 13 de dezembro 2018. 
Estudo de REVISÃo

ESTRATÉGIAS PARA A PRECEPTORIA INTERPROFISSIONAL: UMA REVISÃO DE ESCOPO

\section{Camila Mendes da Silva Nathalia Romeu de Mazzi \\ Thalita Cristine Ramirez Duarte} Valéria Marli Leonello

\section{Introdução}

A Educação Interprofissional em Saúde (EIP) é considerada uma abordagem estratégica para reorientação da formação dos profissionais da saúde, para promover a prática colaborativa (PIC) e melhorar a qualidade do cuidado e atenção à saúde. A EIP surge em resposta à necessidade de ultrapassar a atenção fragmentada e o modelo biomédico centrado na doença, sendo definida como ocasiões em que alunos/profissionais de pelo menos duas profissões aprendem com os outros, sobre os outros e entre si, com o propósito explícito de melhorar a colaboração e a qualidade do cuidado em saúde. No Brasil, a EIP compartilha diversos pressupostos do Sistema Único de Saúde (SUS), como o da integralidade do cuidado e o trabalho em equipe. Entre os marcos teórico-conceituais da EIP destaca-se a articulação ensino-serviço, considerada chave para o desenvolvimento de competências colaborativas entre alunos de diferentes profissões da saúde, a partir do trabalho em saúde nos cenários de prática. Nesse contexto, os preceptores são os responsáveis por mediar o aprendizado dos alunos nos serviços, promover a aprendizagem significativa, estimular o pensamento crítico-reflexivo sobre/no cotidiano do trabalho em equipe, principalmente, a partir de estratégias do trabalho em saúde já desenvolvidas nos serviços. Não há orientações ou diretrizes que norteiam a atuação da preceptoria interprofissional, e a literatura evidencia que os preceptores sentem dificuldades para implementação da 
EIP, sendo uma das razões o desconhecimento sobre possíveis estratégias que podem ser utilizados por eles para promoção da $\mathrm{EIP}^{1-3}$. Com isso, para auxiliar os preceptores no desenvolvimento de competências colaborativas por meio da EIP, foi realizada a presente revisão.

\section{Objetivo}

Mapear na literatura cientifica quais estratégias utilizadas pelos preceptores para o desenvolvimento da EIP com alunos de graduação e pós-graduação.

\section{Método}

Revisão de escopo delineada segundo as orientações do Instituto Joanna Briggs ${ }^{4}$ e PRISMA-ScR5. A questão de pesquisa foi elaborada considerando o acrônimo PCC (população conceito - contexto), resultando em: quais estratégias são utilizadas por preceptores para o desenvolvimento da EIP? Os estudos foram levantados nas bases de dados BDENF, CINAHL, IBECS, Lilacs, EMBASE, ERIC, MedLine e Scopus, com a combinação de descritores, palavras-chave e operadores booleanos individuais à cada uma das bases de dados. Foram incluídos artigos originais, nos idiomas português, inglês e/ou espanhol e que tratavam da preceptoria em qualquer cenário de EIP. Excluíram-se os artigos indexados repetidamente e que não atendiam ao objetivo proposto. Foi feita revisão por pares independente por duas autoras, com disponibilidade de uma terceira para discussão de divergências. Os dados extraídos foram colocados em formulário que foi anteriormente testado, discutido e alterado (formulário piloto). Os dados foram listados e sintetizados para apresentação no presente trabalho. Por se tratar de um estudo que não envolve seres humanos, não foi necessária a submissão do trabalho no comitê de ética em pesquisa.

\section{Resultados e Discussão}

Houve um total de 669 estudos e, ao aplicar os critérios de inclusão e exclusão, 351 restaram para a leitura do título e resumo e 61 para a leitura do texto completo, resultando em uma amostra de 28 estudos. Um total de 69 estratégias foram identificadas, sendo que diversas ou são repetidas ou possuem pequenas variações metodológicas. A estratégia mais citada foi o "Projeto Terapêutico Singular" (PTS), estando presente em quatro estudos nacionais e três internacionais com as variações terminológicas "Plano de Gerenciamento Interprofissional" e
"Planejamento de Cuidados". O PTS é considerado uma estratégia de organização da gestão do cuidado inovadora para o SUS, que compõe a Clínica Ampliada preconizada pela Estratégia Saúde da Família (ESF), sendo ressaltada por promover a PIC e possuir os pressupostos da integralidade da atenção. O PTS permite a definição clara dos papéis de cada núcleo profissional por meio de discussões de casos, planejamento do cuidado sistematizado com ações programáticas e a reavaliação conjunta terapêutica. Portanto, o preceptor pode estimular a participação de alunos de graduação e pós-graduação nas reuniões do PTS e, caso o cenário de prática não disponha desse momento de integração com a equipe, nos estudos internacionais os preceptores pediram aos alunos para realizarem o planejamento de cuidados de forma conjunta e centrada nas necessidades dos usuários para, posteriormente, ser apresentado para a equipe e os preceptores das diferentes profissões da saúde. A próxima estratégia envolveu as discussões de casos em distintas conformações: "Rounds Multiprofissionais", "Rondas Interprofissionais Diárias", "Rodadas Interprofissionais", "Estudos de caso", "Discussão de Casos", "Conferências de Casos Multidisciplinares" e "Relatórios Matinais/Apresentações de Casos". As discussões de caso interprofissional são caracterizadas como encontros em que os alunos apresentam os casos dos seus usuários para os preceptores e toda a equipe. As reuniões de equipe são momentos oportunos em que a EIP pode ser desenvolvida. Além da apresentação de casos, os alunos podem interagir com a equipe multiprofissional, observando e reconhecendo trocas e articulação entre os saberes profissionais, bem como identificando conflitos e possíveis barreiras para o trabalho em equipe. Outra opção para as reuniões de equipe, seria realizar uma reunião com os alunos para apresentação e reconhecimento dos papéis e atribuições de cada profissional que compõe a equipe multiprofissional. Estratégias que integram alunos, preceptores e comunidade também foram ressaltados: "territorialização", "salas de espera" e "visitas interprofissionais às instituições da comunidade". O reconhecimento do território deve ser realizado de forma compartilhada e sua potência está no encontro e dialogo, por meio da troca de experiências e saberes entre alunos e preceptores. A "Consulta Interprofissional", também chamada de "Interconsulta" ou "Consulta Multiprofissional", é facilitadora para a interprofissionalidade entre as equipes de saúde e desenvolvimento da EIP. Inserida na lógica da Clínica Ampliada no Brasil, a interconsulta ocorre quando o atendimento ao usuário é compartilhado entre diferentes 
profissionais da saúde de uma mesma equipe, com uma comunicação transversal entre esses membros, e entre equipes. Ela pode ser realizada em qualquer serviço de saúde da rede de atenção, com os diferentes núcleos profissionais, e envolver também alunos de graduação e pós-graduação. A fim de promover ações conjuntas entre residentes e preceptores de diferentes programas de residência (ênfases) de um mesmo cenário, preceptores promovem as "ações interênfases" ou "ações intercampos" como uma proposta de formação. Por exemplo, residentes dos programas de saúde mental, adulto crítico, saúde da criança e controle de infecção são integrados para apresentação de seminário, troca de experiências e saberes, estimulando novas interações no trabalho, cooperação e solidariedade. Na "Tenda Invertida", estratégia levantada envolvendo residentes, os preceptores vão até o cenário de prática dos alunos ao invés do contrário, ou seja, o educador vai até o cotidiano de trabalho do aluno, se inteira dos desafios para efetivar o ensino, aprendizagem e reflexão. Essa é uma potente estratégia para a interprofissionalidade quando aliada à concepcão do preceptor campo, que tem o papel específico de mediar as relações das equipes entre si, entre os alunos e entre os usuários, com enfoque na facilitação interprofissional. Por fim, outras estratégias ressaltadas foram: "Preceptoria de campo e núcleo", "Campeão da EIP", "Aprendizagem entre Pares", "Estudos em grupos multiprofissionais", "Mapa Cognitivo" e "Quadro de Jornada do Usuário". As metodologias ativas de ensino-aprendizagem também são muito destacadas, e elas fundamentam a mediação pedagógica dos preceptores e a aprendizagem interprofissional. De modo geral, as estratégias promovem a aprendizagem significativa por se basearem na reflexão da realidade a partir do cotidiano do trabalho com todas as suas potências e desafios. As estratégias oriundas do cenário brasileiro se destacam das demais, pois há um contexto histórico nacional que desde a década de 1980 estimula uma atenção à saúde integral, com ênfase no trabalho em equipe e integração ensino-serviço-comunidade. Como limitacỗes desta revisão, destaca-se a inclusão apenas de artigos originais no levantamento dos estudos, e a pluralidade de termos relacionados à preceptoria no âmbito nacional e internacional, o que pode ter influenciado na seleção dos descritores, mesmo com a análise dos tesauros para a seleção das melhores estratégias de busca. Apesar de tais limitações, acredita-se que a presente revisão contribui com o avanço nas pesquisas relacionadas à EIP no país, com o reconhecimento do papel dos preceptores sobre a sua atuação nesse âmbito, com o planejamento de futuras iniciativas de EIP a partir da identificação de estratégias que já acontecem no cotidiano do trabalho em saúde.

\section{Conclusão}

A revisão de escopo permitiu o levantamento de estratégias que podem ser utilizadas pelos preceptores no desenvolvimento da EIP durante o seu cotidiano de trabalho, para proporcionar aos alunos de graduação e pós-graduação um ensino que promova o aprendizado interprofissional. Os preceptores desempenham um papel crucial na EIP, e a identificação de estrategias no cenário de práticas é uma etapa fundamental para o avanço da EIP, dando visibilidade às práticas já realizadas e fortalecendo o trabalho dos preceptores.

Descritores: Sistema Único de Saúde, Educação Interprofissional, Preceptoria, Prática Profissional.

\section{Referências}

1. Fusco NM, Ohtake PJ. Training the trainers: A preceptor development program targeting interprofessional collaboration competencies. Currents in pharmacy teaching and learning [Internet]. 2019 [cited 2021 Jan 22];11(11):1138-43. Available from: https://doi. org/10.1016/j.cptl.2019.07.007.

2. Grice GR, Thomason AR, Meny LM, Pinelli NR, Martello JL, Zorek JA. Intentional Interprofessional Experiential Education. Am. j. pharma. Educ [Internet]. 2018 [cited 2021 Jan 22];82(3): 204-8. Available from: https://doi. org/10.5688/ajpe6502.

3. Zeitoun A, Sacre H, Hallit S, Zeenny RM, Sili G, Salameh P. Clinical preceptor competencies for a better pharmacy education: a suggested framework for Lebanon. J. Pharm. Policy Pract. 2020 [cited 2021 Jan 22];13(21):1-4. Available from: https://doi.org/10.1186/s40545-020-00217-3.

4. Aromataris E, Munn Z (Editors). JBI Manual for Evidence Synthesis. JBI; 2020. doi: https:// doi.org/10.46658/JBIMES-2O-01.

5. Tricco AC, Lillie E, Zarin W, O'Brien KK, Colquhoun H, Levac D, et al. PRISMA extension for scoping reviews (PRISMA-ScR): Checklist and explanation. Ann. Intern. Med. [Internet]. 2018 [cited 2021 Jan 22];169(7):467-73. Available from: https://doi.org/10.7326/M18-0850. 
REFLEXÕES NA PÓS-GRADUAÇÃO: APROXIMANDO A ACADEMIA AOS CENÁRIOS EXITOSOS EM ATENÇÃO SECUNDÁRIA À SAÚDE

\section{Vanessa Aparecida Gasparin Eduardo Simões Da Matta Francis Maira Schabat Letícia de Lima Trindade Samuel Spiegelberg Zuge}

\section{Introdução}

O Sistema Único de Saúde (SUS) foi instituído pela Constituição da República Federativa do Brasil, de 1988 , em seu artigo 196, e regulado pela Lei no . 8.08o/1990, buscando assegurar a garantia da universalidade, da integralidade, da equidade, descentralização e participação social ao acesso à saúde como dever do Estado e um direito de todo cidadão. ${ }^{1} \mathrm{O}$ SUS, é um dos maiores sistemas públicos de saúde do mundo. Contudo, a situação atual do SUS concerne em vários desafios, destacando-se as dificuldades de acesso a medicamentos, encaminhamentos desnecessários a consultas e procedimentos especializados pelos profissionais médicos aos setores de regulação, resultando em grande demanda de solicitações; morosidade na realização de procedimentos especializados, com potencial agravamento das morbidades e a busca dos usuários por alternativas do serviço privado ou restrição de acesso à Atenção Secundária à Saúde (ASS) ${ }^{1,2}$ A ASS é caracterizada como um nível de média complexidade, oferecendo suporte à Atenção Primária à Saúde, com densidade tecnológica entre a atenção primária e terciária. Compreende os serviços especializados encontrados em ambulatórios e hospitais, apoio diagnóstico e terapêutico, e atendimento de urgếncia e emergência. Nessa premissa, o Centro de Integração de Educação em Saúde (CIES Global), uma organização sem fins lucrativos, oferece atendimento de saúde móvel 
com a finalidade de reduzir as filas de espera por consultas, exames e cirurgias no SUS, por meio de parcerias com o poder público.

\section{Objetivo}

Relatar uma experiência exitosa na ASS para mestrandos e doutorandos em Ciências da Saúde.

\section{Método}

Trata-se de um relato de experiência oriundo da disciplina de Planejamento e Gestão em Saúde do Programa de Pós-Graduação Stricto sensu em Ciências da Saúde, da Ủniversidade Comunitária da Região de Chapecó (Unochapecó) ocorrido no semestre $2020 / 2$. Uma das atividades avaliativas do componente englobou a divisão da turma por grupos de trabalho para a explanação de uma experiência exitosa nos níveis de atenção em saude, sendo que o presente grupo abordou a ASS. Os grupos possuíam livre escolha na melhor forma de abordar a temática e explanar a experiência de acordo com o nível de atenção correspondente, bem como autonomia para busca da experiência considerada exitosa no contexto do SUS.

\section{Resultados e Discussão}

A organização CIES Global foi escolhida para atender a proposta, por ser reconhecida pelo emprego de unidades móveis e modulares, como carretas e contêineres adaptadas para esse serviço, garantindo agilidade em consultas, exames e cirurgias no SUS, indo ao encontro das demandas, dificuldades e desafios enfrentados nas gestões públicas. A partir de sua instauração, em 2008 , e através da primeira carreta da saúde, a fundação realizou atendimentos pontuais, oferecendo exames de média complexidade às populações carentes. Em 2012, a organização firmou seu primeiro contrato para atendimento de longo prazo, com a Prefeitura do Município de São José dos Campos (SP). No ano seguinte, através de contrato com a Prefeitura do Município de São Paulo, implementou-se o programa Hora Certa Móvel, com atendimento em unidades móveis (Carreta, Box e Van da Saúde). Em 2015, a Rede Hora Certa Móvel tornou-se política pública na cidade de São Paulo, com a Lei de $\mathrm{n}^{\mathrm{o}} 16.133 / 2015$. Para melhor abordar seu funcionamento e de que forma a organização foi criada, foi realizada uma entrevista com um dos colaboradores do projeto, de forma virtual com o auxílio da ferramenta Google Meet. A entrevista teve duração de 60 minutos e foi gravada mediante autorização para ser reproduzida posteriormente em sala. Aspectos como idealização e criação, expansão, progressão para política pública e surgimento de novas demandas, foram abordados no material audiovisual. Para, além disso, também se tratou de uma das especialidades abordada pelo CIES, a resolução da Insuficiência Venosa Crônica (IVC). Ỏ material gravado, aliado a uma breve apresentação introdutória ao tema, possibilitou a discussão e reflexão no grande grupo. A agilidade e resolutividade da assistência são essenciais, uma vez que evita o agravamento das morbidades, proporciona a satisfação do usuário, melhoria da gestão e aperfeiçoamento dos serviços de saúde. ${ }^{2}$ No que tange a IVC, um dos agravos que resulta em mais demandas pelo CIES, é considerada uma das condições médicas de maior prevalência no mundo, com limitação importante da qualidade de vida e com um impacto econômico significativo, representando 1-2\% dos gastos em saúde nos países ocidentais. ${ }^{3,4}$ A importância do CIES frente ao diagnóstico e tratamento desta afecção tem sido singular e exitosa uma vez que esta iniciativa, através de uma gestão profissional, comprometida e séria, vem diminuindo a fila do SUS por meio de equipes criteriosamente selecionadas, altamente especializadas, materiais de diagnóstico e tratamento de qualidade, além de condutas que seguem as principais referências nacionais e internacionais no assunto, tudo isso em unidades modulares móveis. Nesse sentido, modelos assistenciais itinerantes emergem como estratégia no enfrentamento crônico no tempo de espera por consultas, exames e até cirurgias de baixa e média complexidade, melhorando as condições de assistência e acesso à saúde pública e proporcionando a aproximação das comunidades envolvidas. Torna-se uma alternativa que considera a atenção voltada para as necessidades de forma singular e equânime, podendo favorecer as lacunas nas diversas áreas assistenciais, principalmente tendo em vista o montante de usuários que dependem exclusivamente do SUS. ${ }^{1}$ Nesse cenário, a qualidade da atenção em saúde é medida pela satisfação do usuário, a qual relaciona-se intimamente com a resolutividade da assistência, e torna-se a base para a reorganização, agilidade e aperfeiçoamento dos serviços de saude. ${ }^{2}$ Contudo vale salientar, que apesar desse arranjo organizacional apresentar alta resolutividade em algumas especialidades, acaba por gerar novas demandas 
de saúde, que muitas vezes não são passíveis de resolução neste nível de atenção. Nesse contexto, destaca-se o trabalho articulado na perspectiva de Redes de Atenção à Saúde, o qual proporciona a continuidade, integralidade e efetividade da assistência prestada. ${ }^{5}$

\section{Conclusão}

A experiência exitosa relatada, com olhar na ASS, possibilitou a ampliação dos horizontes e compartilhar ações que favorecem o acesso e promovem a resolutividade das demandas em saúde. O debate frente às potencialidades e desafios dos níveis de atenção em saúde apresenta-se como um momento muito enriquecedor e reflexivo, principalmente quando tem-se a possibilidade de envolver a academia e a prática em um mesmo cenário. Ademais, incentiva a introdução de novas estratégias por discentes gestores que apropriaram-se de tal conhecimento.

Descritores: Saúde; Sistema único de saúde (SUS); População; Pacientes.

\section{Referências}

1. Silva, LS,Viegas, SMDF, Nascimento, LCD,Menezes, C ,Martins, JRT, Potrich, T. Universalidade do acesso e acessibilidade no quotidiano da Atenção Primária: Vivências de usuários do SUS. RECOM - Revista de Enfermagem do Centro Oeste Mineiro. 2020; 10 (3575): 1-9. DOI: https://doi.org/10.19175/recom.v10io.357

2. Bastos, LB.R, Bastos, DADS, Vasconcelos, LGP, Costa, ABD, Fonseca, EFR, Wanzeler, KM. Agravamento de morbidades na Atenção primária à saúde. Pesquisa em Saúde e Enfermagem: Inovação à Ciência. 2020; 1 (1): 1-8. DOI: https://doi.org/10.47879/ed.ep.2020137p145.

3. Mutlak, O, Aslam, M, Standfield, NJ. Chronic venous insufficiency: a new concept to understand pathophysiology at microvascular level - a pilot study. Perfusion. 2019; 34 (1): 84-89.

4. Davies, AH. The seriousness of chronic venous disease: a review of real-world evidence. Adv Ther. 2019, 36, (suppl 1): 5-12.

5. Maffissoni, AL, Vendrusculo, C, Trindade, LDL, Zocche, DADA. Redes de atenção à saúde na formação em enfermagem: interpretações a partir da atenção primária à saúde. Revista Cuidarte. 2018; 9 (3): 1-13. DOI: http:// dx.doi.org/10.15649/cuidarte.v9i3.549. 
RELATO DE EXPERIÊNCIA

\begin{abstract}
ADAPTAÇÃO DA FORMAÇÃO EM SERVIÇO DOS ENFERMEIROS NA UNIDADE CARDIOLOGICA DE UM HOSPITAL DE PORTUGAL
\end{abstract}

\section{Tânia Dionísia Oliveira \\ Suéli Regina Sulzbach \\ Anabela Abreu Azevedo \\ Denise Antunes de Azambuja Zocche}

Esperança do Gago Alves Pereira

\section{Introdução}

O processo de formação possui grande importância no itinerário dos individuos, proporcionando conhecimento e crescimento pessoal e profissional. A classe dos enfermeiros portugueses tem seu percurso marcado por processos formativos de educação contínua, a formação em serviço e a própria autoformação'. Atualmente, frente ao contexto pandêmico provocado pela COVID-19, o setor saúde, no que diz respeito aos processos de formação em serviço, precisou realizar adaptações e inovar a fim de atender as demandas da saúde no cotidiano ao mesmo tempo que continuou recebendo novo profissionais e estudantes, para atuarem nos serviços de saúde, que cada vez necessitam de mais pessoal. Logo, educar para inovar e reorganizar os processos de trabalho no serviço são objetivos permanentes, presentes nos processos formativos dos enfermeiros, constituindo-se também como estratégia para desenvolver competências e habilidades nos profissionais de enfermagem ${ }^{1}$. Em Portugal, o termo Formação em Serviço é comumente empregado, e a enfermagem portuguesa é considerada referência e pioneira nesse quesito, pois em 1967, a Escola de Ensino e Administração em Enfermagem deu início ao programa "Educação em Serviço", e seguiram estimulando as instituições de saúde a realizarem atualizações acerca das demandas do serviço como forma de capacitar os profissionais de enfermagem². O objetivo da educação e formação em serviço consiste no desenvolvi- 
mento profissional e tornando os mesmos mais capacitados e habilitados para exercerem suas funções. Deste modo, esse conceito é fruto de ações educativas realizadas com foco no ambiente de trabalho'. Os processos de formação buscam melhorias na qualidade dos cuidados, dentre as quais estão descritas no documento da Ordem dos Enfermeiros de Portugal, denominado Padrões de Qualidade dos Cuidados de Enfermagem, que também destaca que o desenvolvimento profissional e a qualidade devem ser promovidos por meio de uma política de formação contínua dos enfermeiros no serviço onde atuam 3 . Logo, frentes as demandas crescentes impostas pela pandemia, a enfermagem precisou se adaptar e desenvolver metodologias de ensino frente às necessidades de mesclar ensino em serviço com ensino remoto.

\section{Objetivo}

Relatar e caracterizar o processo de adaptação da formação dos profissionais de enfermagem do serviço de cardiologia em época de pandemia por Covid-19, bem como as vantagens e limitações encontradas no percurso.

\section{Método}

Relato de experiência, sobre o processo de formação dos profissionais enfermeiros do serviço de Cardiologia do Hospital da Senhora da Oliveira de Guimarães, Portugal, que migrou da modalidade presencial para o formato digital.

\section{Resultados e Discussão}

No serviço de Cardiologia, no ano de 2018, os enfermeiros foram organizados em vários grupos com o intuito de distribuir as responsabilidades da prática de enfermagem. Atualmente, são seis grupos, nomeadamente, Melhoria da qualidade e segurança do doente; Gestão em segurança das instalações; Prevenção e controle de infecção; cuidados prestados ao doente; Comunicaçã̃o e imagem; e Formação e qualificação profissional, sendo que o último será o tema do presente estudo. Logo, contextualizando, a formação em serviço acontece mediante a elaboração de um plano anual de formação em serviço, perante ao qual o responsável do grupo dẻlineia com o enfermeiro principal do serviço as formações para então, em seguida, junto dos grupos, elaborar e executar as ações. Todos os grupos são envolvidos nesse processo, consoante ao tema. Ainda, conforme a temática e necessidades da capacitação realizarem-se, por vezes, profissionais externos são convidados para participar das atividades. Juntamente com a pandemia por Covid-19, mudanças vieram e tona e as formações em serviço também foram atingidas, considerando que os encontros se realizavam através de metodologia presencial com atividades interativas de grupos. Com isso, a estratégia utilizada para reduzir as aglomerações foi organizar as formações de modo que elas pudessem ser repassadas no formato digital e assim, as formações presenciais foram substituídas por remotas. Esse período fomentou a colaboração entre os grupos, onde destaca-se o acréscimo da parceria entre o grupo da Formação com o grupo da Comunicação, os quais juntos se adaptaram e vem inovando as ações de formação em serviço. Como método de adaptação e organização do grupo de Formação, foi criado um e-mail de grupo, uma pasta no Drive (disco virtual), e um grupo no WhatsApp, para a comunicação dos membros. Quanto ao material, foram construídas videoaulas, apresentações e exposição de informações cientificas de enfermagem, as quais foram encaminhadas via e-mail institucional aos profissionais e disponibilizadas nos meios de comunicação do serviço. A criação do plano anual é elaborada de acordo com os enunciados descritivos dos padrões de qualidade dos cuidados de enfermagem e servem como instrumento de avaliação do impacto, e das necessidades formativas dos enfermeiros. São elas: a satisfação do cliente, promoção da saúde, prevenção de complicações, o bem-estar e o autocuidado, a readaptação funcional e a organização dos cuidados de enfermagem, todos com foco na excelência no exercício profissional. Com a incorporação da modalidade digital, foram disponibilizados aos profissionais questionários online, para identificar as necessidades formativas na área da enfermagem. Tais dados, são utilizados para nortear o planejamento das ações anuais. Dentre as vantagens, destaca-se o aumento considerável da adesão dos participantes refletido pelo número de formandos que usufruíram das atividades, em função da flexibilidade de horário e da possibilidade de realizar as capacitações de casa, ou seja, no modo remoto. Além disso, foi percebido também a diminuição do uso de papel, já que os testes de avaliação, passaram a ser realizados pelo Google Forms, ferramenta que também facilita a criação de estatísticas, permitindo a produção de dados para avaliação e criação de materiais para posterior divulgação. Entretanto, também existem algumas limitações que ocorreram com essa adaptação, como a alteração do plano anual de formação em serviço, sendo necessário diminuir o nú- 
mero de ações realizadas, considerando que o tempo gasto para a criação e produção do conteúdo é maior e com complexidades diferentes. Outra dificuldade é o défice de estratégias para promover a interação durante o processo formativo, já que o digital acaba, de certa forma, por inibir a comunicação entre alguns os participantes, quando realizadas ações síncronas, bem como não permitem a interação dos participantes em tempo real em atividades assíncronas, como é no caso dos vídeos.

\section{Conclusão}

Contudo, a formação em serviço dos enfermeiros na modalidade digital pode ser considerada uma prática inovadora da gestão dos enfermeiros líderes. Os resultados positivos dessa metodologia de ensino permitem pensar em novas estratégias para melhorias das formações em serviço de 2021 com a utilização de instrumentos didáticos para complementar as ações de formação serão utilizados, dentre os quais: QR Code, Mentimeter, Word Cloud, Audio Note, além da promoção de reuniões por meio de salas colaborativas utilizando o Zoom e Microsoft Teams. Ainda, a colaboração com outros hospitais para melhoria de estratégias da formação em serviço de forma remota, com o intuito de qualificar as ações desenvolvidas em ambos os locais, vem sendo cogitadas. Essas ações têm como foco que os profissionais se adaptem às transformações impostas pela pandemia. O grupo da área de formação em serviço busca promover entre os enfermeiros atualização e motivação a fim de que suas ações resultem em oportunidades de inovar. Tal experiência comprovou sua eficácia uma vez que houve maior adesão e um aumento de resultados avaliativos, que repercutirá em futuras produções científicas, bem como na qualificação das formações em serviço.

Descritores: Educação em enfermagem; Capacitação profissional; Educação a distância.

\section{Referências}

1. Salum Nádia Chiodelli, Prado Marta Lenise. Continuing education in the development of competences in nurses. Texto contexto enferm. 2014; 23 (2): 301-308. Acesso em 30 de janeiro de 2021. Disponível em:<http://www. scielo.br/scielo.php?script=sci_arttext\&pi$\mathrm{d}=$ So104-07072014000200301\&lng=en. https:// doi.org/10.1590/0104-070720140021600011>

2. Carneiro, Maria G. N. Formação permanente em enfermagem: contribuição para a sua história. Dossier. Lisboa. 1988; ISSN o871-0775. Ano IV, no 2/3, p 31- 36 apud Tojal, A. M. A. F. Percepção dos enfermeiros sobre a formação em serviço. Escola Superior de Enfermagem de Coimbra, 2011; tese de mestrado do curso em enfermagem médico-cirúrgica.

3. Ordem dos Enfermeiros. Padrões de qualidade dos cuidados de enfermagem: enquadramento conceptual e enunciados descritivos. Lisboa; 2001. 
RELATO DE EXPERIÊNCIA

ELABORAÇÃO DO GUIA DE ORIENTAÇÕES PARA OS NOVOS COLABORADORES DA ENFERMAGEM: RELATO DE EXPERIÊNCIA

Julyhe Nunes Paulin Nathália Dias Oliveira Caroline Barbosa da Silva Cíntia Eliane Costa Corrêa Ana Amélia Antunes Lima Adriana Aparecida Paz

\section{Introdução}

Atualmente, para prestarem um atendimento de excelência, as instituições de saúde precisam, constantemente, manter serviços qualificados e seguros, sendo os profissionais o cerne das ações para o aprimoramento das competências. Esses profissionais precisam de suporte e apoio para aplicar na prática o conhecimento técnico e científico, de modo a aprimorar, ou, adquirir as competências que sejam alinhadas às demandas exigidas do novo cenário laboral. Assim, evidencia-se a importância de pensar ações que tenham consonância com a proposta da Política de Educação Permanente em Saúde (PNEPS). Esta política tem o objetivo de promover a formação e o desenvolvimento dos trabalhadores de saúde, por meio da educação permanente em saúde (EPS) no ambiente laboral'. Para desenvolver ações educativas na perspectiva da EPS, deve ser considerada a cultura institucional para traçar estratégias que fortaleçam o compromisso com o desenvolvimento contínuo dos profissionais, alinhando os conhecimentos do profissional aos problemas enfrentados no cotidiano, construindo a reflexão crítica do fazer em busca de melhorias e mudanças. Em se tratando do processo de formação técnica e acadêmica, uma parcela considerável de profissionais da saúde inicia sua trajetória profissional no mercado de trabalho, com nenhuma experiência laboral, cabendo-lhes apenas as vivências de ensino-aprendizagem em práticas assistidas ou 
supervisionadas nas instituições de saúde. A potencialidade e fragilidade dessas vivências, depende dos projetos pedagógicos, componentes curriculares, carga horaria, quadro docente e número de alunos por vivência, definidos por cada instituição de ensino. Essa definição se respalda nas diretrizes curriculares nacionais de cursos somente para profissões de nível superior, enquanto no nível técnico, ainda se encontram em discussão normas orientadoras de formação técnica. As instituições de ensino assumem a responsabilidade na formação dos profissionais da saúde para que desenvolvam o pensamento crítico e raciocínio clínico, para atuar de acordo com a realidade dos serviços e da população atendida ${ }^{2}$. Ao deparar com essas insuficiências dos profissionais ao ingressarem no ambiente de trabalho, entendeu-se o quanto a instituição hospitalar precisa se preocupar e priorizar o aprimoramento dos colaboradores de enfermagem, sendo essencial estimular e desenvolver ações educativas. Logo, as ações precisam atender às características e demandas da área assistencial do profissional, ou seja, que de fato reflitam as reais necessidades, contribuindo para o desenvolvimento e, consequentemente, a oferta do cuidado seguro e qualificado ao paciente e ao próprio colaborador.

\section{Objetivo}

Elaborar um guia de orientações para o período de adaptação do novo colaborador de enfermagem na instituição hospitalar.

\section{Método}

Trata-se de um relato de experiência de elaboração de um guia de orientações para novos colaboradores da enfermagem, admitidos em uma instituição hospitalar, acompanhados pelo Programa de Inserção de Novos Colaboradores no período de adaptação (probatório) por três meses. O guia utilizou recursos tecnológicos para diagramação e um personagem para estabelecer a linguagem clara, coesa e direta das etapas para informar o novo colaborador. Este produto foi gerado no Programa de Pós-Graduação em Enfermagem (PPGEnf) - Mestrado Profissional, da Universidade Federal de Ciências da Saúde de Porto Alegre (UFCSPA).

\section{Resultados e Discussão}

O guia de orientações para novos colaboradores inclui como público alvo enfermeiros e técnicos de enfermagem e foi elaborado no período de maio a junho de 20zo, após a conclusão do fluxograma para acompanhamento do novo colaborador e da adaptação do instrumento de registro para o acompanhamento. Participaram na elaboração do guia três bolsistas de iniciação científica e três enfermeiras, sendo uma Mestre do PPGEnf e duas professoras doutoras da UFCSPA. A intencionalidade do uso do guia foi para facilitar a compreensão do novo colaborador da enfermagem quanto aos aspectos de acolhimento, acompanhamento e avaliação por competências. Entendeu-se, que quando o colaborador conhece a expectativa institucional em relação à função que exerce, tem mais chances de se desenvolver profissionalmente. Definiu-se o uso do CAN$V A^{\circledR}$ o qual permitiu a organização dos conteúdos textuais, visuais e ilustrações como o uso de imagens para a personalização do guia. Configurou o profissional enfermeiro como interlocutor dos itens necessários e específicos do programa. Buscou-se desenvolver uma fluência verbal e visual, visando uma comunicacão clara do período de adaptação do novo collaborador que será acolhido, acompanhado e avaliado. O guia contém 21 páginas e informa sobre todas as atividades e ações que serão realizadas durante a inserção do colaborador na instituição. O tempo de construção, revisões e alterações deste guia pelos envolvidos foi de aproximadamente 40 horas. Este produto será entregue no formato digital no segundo dia da atividade presencial, denominada de Integração em Enfermagem, ao novo colaborador no Laboratório de Prática da instituição e está disponível no endereço eletrônico hittps://bit. ly/34 $\mathrm{L}_{4} \mathrm{Ytn}$, apenas para leitura e download. O guia foi validado internamente pela equipe deste estudo. As melhorias nos processos institucionais são alcançadas quando instalada a participação ativa e colaborativa associada ao entendimento do quanto são corresponsáveis pelo próprio desenvolvimento das competências laborais, enquanto individuais e coletivas. A participação ativa dos profissionais é fundamental para os que estão na linha de frente, sendo isto evidenciado pela relevância do profissional envolvido na prática assistencial e gerencial, ao estruturar as ações educativas com foco nas necessidades identificadas?. Neste sentido, esta estratégia da proatividade alinhada com a prática colaborativa tornou importante a construção de uma aprendizagem significativa, na medida em que escutou as equipes quanto aos conteúdos necessários para o desenvolvimento profissional, promovendo de maneira sinérgica o protagonismo no processo educativo ${ }^{4}$. 


\section{Conclusão}

Com a implementação do programa, no primeiro dia de inserçã̃o no serviço hospitalar, o colaborador recebe as orientações e o guia para auxiliar no processo de acompanhamento e avaliação do seu desempenho para a efetivação no quadro de colaboradores permanentes. Este guia complementa os demais produtos do estudo e tem a capacidade de ampliar e melhorar o entendimento desse processo, pois cada etapa foi desenhada e alinhada de acordo com as reais necessidades de todos os participantes envolvidos na EPS da instituição. A percepção como bolsistas iniciação científica em participar deste estudo que gerou inúmeros produtos, sendo este um deles relatado, possibilitou desvelar o desenvolvimento de competências relevantes para a área da EPS, que como futuras enfermeiras, evidencia-se a responsabilidade com a educação profissional, instituições de saúde e a sociedade.

Descritores: Profissionais de enfermagem; Educação continuada; Educação em enfermagem; Serviço hospitalar de educação; Gestão em saúde.

Financiamento: Bolsa de Iniciação Científica do Programa Institucional de Bolsas de Iniciação Científica do Conselho Nacional de Desenvolvimento Científico e Tecnológico (PIBIC-CNPq). Bolsa de Iniciação Cientifica do Programa de Iniciação Científica da Universidade Federal de Ciểncias da Saúde de Porto Alegre (PIC-UFCSPA).

\section{Referências}

1. Brasil, M., 2009. Política Nacional de Educação Permanente em Saúde.. 1st ed. [PDF] Brasília: Secretaria de Gestão do Trabalho e da Educação na Saúde. Departamento de Gestão da Educação em Saúde., p.64. Disponível em: <http://Secretaria de Gestão do Trabalho e da Educação na Saúde. Departamento de Gestão da Educação em Saúde.> [Acesso Abril 2019].

2. Kleba, M., Hoefle, N., Oliveira, G. and Rodrigues, O., 2021. Fortalecendo o protagonismo da Comissão de Integração Ensino-Serviço para a educação permanente em saúde. Revista Gaúcha de Enfermagem. Disponível em: <http://dx. doi.org/10.1590/1983-1447.2017.04.2016-0008.> [Acesso Abril 2019].

3. Passos, L. P.; Pinho, L. Profissionais de saúde na promoção ao aleitamento materno: revisão integrativa. Revista de Enfermagem UFPE On Line, Recife, v. 10, n. 3, p. 1507-1516, 2016. Disponível em: <DOI: 10.5205/reuol.7057-60979-3-SM-1. 1003sup201619.> [Acesso Abril 2019].

4. Silva, L. A. A. Programa de aprimoramento e revitalização do conhecimento na enfermagem e saúde. Interface - Comunicação, Saúde, Educação, Botucatu, v. 22, n. 65, p.517-26, 2018. Disponivel em: <DOI: https://doi.org/10.1590/180757622016.0629.> [Acesso Abril 2019]. 
RELATO DE EXPERIÊNCIA

\section{A FORMAÇÃO EM SAÚDE REPENSANDO A GESTÃO DE TRABALHO EM UNIDADE DE SAÚDE DA FAMÍLIA}

\author{
Tatiana Almeida Couto \\ Josiane Moreira Germano
}

\section{Introdução}

As mudanças nas Diretrizes Curriculares Nacionais para os cursos da área da saúde invocam a inserção dos princípios do Sistema Único de Saúde (SUS) nas suas práticas. Com o objetivo de se investir na potência humana da reinvenção, inerente aos processos criativos, constitui-se um dos maiores desafios, para a formação de profissionais de saúde, ferramentas que potencializem a criticidade e reflexão, portanto, torna-se premente produzir os diferentes modos de facilitar os processos de aprendizagens e a comunicação em saúde, tornando-os menos disciplinares, sendo importante a recriação de sujeitos pensantes, vivos, sensíveis e atuantes na construção de uma sociedade mais igualitária ${ }^{1}$. $\mathrm{Na}$ atenção à saúde diante da diversidade de demandas é necessário entre as tecnologias, o desenvolvimento da comunicação, seja na versão escrita, falada ou por imagem para a melhoria do cotidiano do trabalho. Assim como existem os aspectos negativos nas atualizações constantes da comunicação e suas vias, sendo necessário o aprimoramento de discentes, docentes, equipes de saúde e gestores para discussão e incorporação de novas práticas². Emergindo de cada história de vida e o sentido que cada encontro com o outro propicia, a caixa de afetação pode ser considerada como um recurso que permite o aprimoramento $d a$ comunicação, o trabalho com a gestão e tem uma potência para a incorporação de práticas 
também de assistência. Vale ressaltar que tal instrumento pode ser de construção individual, como para a possibilidade de despertar para o trabalho coletivo.

\section{Objetivo}

Descrever as vivências da atuação docente com a proposta da caixa de afetações para repensar a gestão de trabalho em USF.

\section{Método}

Trata-se de um relato de experiência do segundo semestre de 2019, com dois grupos de 10 discentes do Curso de Graduação em medicina de uma Universidade Federal do interior da Bahia. A caixa de afetações trata-se de um produto do componente curricular, com os objetivos de permitir ao discente refletir sobre os momentos vividos nesse cenário da USF no qual está inserido; reconhecer os afetos e desafetos na construção da clínica; reconhecer a transferência e contratransferência no vínculo com os usuários e com os membros da equipe e trabalhar a empatia. Para direcionar a construção individual dessa caixa de afetações (que possui um formato livre, não sendo necessária a apresentação exclusivamente no formato de uma caixa, como em uma produção de mídia, uma versão impressa de texto, paródia, carta, desenho). Sendo as questões disparadoras: "O que vi? O que eu sinto do que eu vi? O que eu reflito e faço com isso?".

\section{Resultados e Discussão}

Historicamente, a formação na área $d a$ saúde tem sido baseada em métodos de ensino tradicionais, fundamentados numa formação conteudista e tecnicista, cujos currículos são altamente influenciados por Abrahan Flexner (que centralizou o foco do cuidado na doença). Por esta perspectiva, a área da saúde, no tocante ao cuidado e por consequência, o processo de ensino-aprendizagem se limitou, por bastante tempo, a um modelo fragmentado do saber-fazer no qual o docente assume o protagonismo, sendo transmissor do conhecimento, enquanto ao discente, cabe o papel passivo apenas retendo e reproduzindo aquilo que recebeu do docente'. Assim, compreende-se que ao ser oportunizado ao discente sobre a sua formação metodologias ativas e formas de expressar subjetivamente, no sentido de permitir o trabalho com as percepções dos sentimentos durante as consultas, atividades de educação em saúde, educação continuada e educação permanente em saúde, visita domiciliar. Pois diante da sugestão para o exercício de repensar a prática e refletir sobre o processo de trabalho percebido no cenário em que está inserido, esse instrumento é relevante não apenas para indivíduos em formação, como para os membros das equipes em saude. Pensando que para além da expressão da fala em reuniões de equipe e demais atividades produzidas nas USF, no território e em equipamentos sociais, a escrita tem a sua potência, como uma via na qual os sujeitos costumam também se expressar e demonstram também muita emoção, de forma que pode promover a resolutividade, a discussão de casos, o fortalecimento de vínculo e evitar o adoecimento desses sujeitos que constantemente tem acesso a muitas necessidades de saúde. Nas caixas de afetações compartilhadas individualmente pelos discentes os mesmos puderam expressar o quanto faz sentido tais atividades, pois criaram o hábito de registros das suas atividades realizadas na ida de um período semanal na USF e refletiam sobre a diversidade de dimensões contempladas. Sendo entre alguns pontos destacados: a estrutura física inadequada das USF, como um dos desafios para a realização de atividades coletivas; referindo à apropriação da realidade comunitária e socioeconômicas necessária aos membros da equipe e o empoderamento; a percepção crítica das atividades realizadas pela definição dos "meses coloridos" e as temáticas previamente definidas na agenda municipal, mas que não proporcionavam a continuidade do cuidado e a escuta efetiva das necessidades das equipes sobre os conteúdos e temas a serem abordados e trabalhos para a melhoria da gestão do trabalho e resoluções de conflitos interpessoais. Sobre os materiais utilizados em tais práticas, os discentes repensam sobre o uso de cartazes, materiais impressos que costumam ser acessados por uma minoria; a manutenção de práticas imperativas e que nem sempre a relevância do impacto de tais aprendizados compartilhados são sentidos. Sendo percebidas as temáticas e as demandas que emergem a serem trabalhadas como as atribuições dos membros da equipe, o que gera descontinuidade do cuidado e expectativas irreais na atuação do outro; questionam a atuação ainda na vertente biomédica, os registros inacessíveis, pela compreensão comprometida, diante da caligrafia. Dessa forma, a comunicação precisa ser vista como um recurso da gestão e a compreensão dos desafios, no sentido de ser trabalhado desde a formação, assim como em atividades individuais e coletivas ${ }^{1}$. 


\section{Conclusão}

No trabalho como docente é possível possibilitar aos discentes em formação a oportunidade do desenvolvimento de práticas inovadoras que venham a representar melhorias na assistência aos usuários, assim como para o melhor trabalho da equipe, no sentido de otimizar as demandas, promover melhor resolutividade e permitir um ambiente de trabalho mais saudável. Ne vivência descrita os discentes referem a oportunidade de através da caixa de afetações, como um produto de práticas de saúde, reconhecer a relevância da reflexão constante da atuação e se permitir a ressignificação e o estudo para as melhorias necessarias.

Descritores: Atenção Primária à Saúde; Equipes de Assistência à Saúde; Capacitação de Recursos Humanos em Saúde; Trabalho.

\section{Referências}

1. Sobral FR, Campos CJG. Utilização de metodologia ativa no ensino e na assistência de enfermagem na produção nacional: revisão integrativa. Rev Esc Enferm USP. 2012 Fev; 46 (1):208-18.

2. Paganini MC. A comunicação sob a ótica da gestão. In: PROENF Programa de Atualização em Enfermagem: Gestão: Ciclo 9. Porto Ảlegre: Artmed Panamericana, 2019. p.9-35.

3. Roman C et al. Metodologias ativas de ensino-aprendizagem no processo de ensino em saúde no Brasil: uma revisão narrativa. Clinical And Biomedical Research. 2017; 37 (4):349-357. 
RELATO DE EXPERIÊNCIA

IMPLANTAÇÃO DA SISTEMATIZAÇÃO DA ASSISTÊNCIA DE ENFERMAGEM EM UMA UNIDADE DE TERAPIA INTENSIVA PEDIÁTRICA

\author{
Natália Hoefle \\ Vivian Rahmeier Fietz \\ Shanna Machado de Sousa \\ Talyne Francisca Ferraz \\ Nogueira Moraes
}

\section{Introdução}

A Sistematização da Assistência de Enfermagem (SAE) é compreendida como toda ação que organize o trabalho profissional do enfermeiro, favorece a prática de enfermagem baseada no conhecimento científico e a tomada de decisão com base nos dados subjetivos e objetivos do indivíduo. Por meio da SAE e em seu cunho científico, é possível a operacionalização do Processo de Enfermagem (PE) ${ }^{(1-2)}$. A SAE é mais abrangente que o PE, visto que a assistência de enfermagem pode ser sistematizada de diversas formas, como por exemplo: em protocolos institucionais, escalas de funcionários, fluxos assistenciais e o PE propriamente dito. Este por vez, é organizado em fases - histórico de enfermagem; diagnóstico de enfermagem; planejamento de enfermagem; implementação; e avaliação de enfermagem - e tem como finalidade tornar a assistência de enfermagem sistemática e orientar o cuidado da equipe de enfermagem ${ }^{(3)}$. A resolução COFEN $\mathrm{n}^{\mathrm{o}} 358 / 2009$ apresenta o método científico para a SAE, que é o PE, esse deve ser pautado em referencial teórico que guie e organize as ações de enfermagem. A SAE além de ser um requerimento legal da profissão, é uma ferramenta que contribui para a demarcação do papel do enfermeiro e este, deve conduzir sua equipe para sua realização ${ }^{(2-3)}$. A prática assistencial de enfermagem de forma sistematizada melhora a qualidade da assistência, proporciona planejamento, execução e avaliação das condutas de 
enfermagem, cuidado individualizado ao paciente e contribui para a visibilidade das ações de enfermagem em qualquer nível de assistência à saúde ${ }^{(1)}$. Desse modo o objetivo deste trabalho será relatar a experiência de implantação da SAE e do PE em uma Unidade de Terapia Intensiva Pediátrica (UTIP).

\section{Metodologia}

Trata-se de um estudo descritivo, do tipo relato de experiência, realizado por enfermeiros de uma UTIP de um Hospital Público Federal da região centro oeste do Brasil acerca da implantação da SAE e do PE no setor. Esse hospital é caracterizado como referência na assistência à saúde de média e alta complexidade de toda macrorregião com uma cobertura 100\% Sistema Único de Saúde (SUS). É gerenciado pela Empresa Brasileira de Serviços Hospitalares (EBSERH), que é uma empresa pública, de direito privado, criado pela Lei Federal no 12.550 , de 15 de dezembro de 2011 e tem por objetivo a reestruturação e o gerenciamento dos hospitais universitários federais que aderirem a essa empresa (3). Uma das atribuições da EBSERH é a inovação tecnológica no serviço de saúde e a partir disso foi implantado na instituição o Aplicativo de Gestão para Hospitais Ủniversitários (AGHU), aplicativo criado pela EBSERH e adotado para todos os hospitais universitários federais filiados a empresa. Tem como objetivo ser um mecanismo de padronização das práticas assistenciais e administrativas dos hospitais e permitir a criação de indicadores nacionais no âmbito da Rede EBSERH. Esse hospital público federal iniciou a implantação do AGHU em 2015 e atualmente conta com oito módulos implantados. E um desses módulos que foram implantados é a prescrição de enfermagem. O módulo de "Prescrição de Enfermagem" foi criado com base no referencial teorico da Teoria das Necessidades Humanas Básicas, de Wanda de Aguiar Horta, e a Taxonomia da North American Nurse Diagnosis Association International (NANDA-I). Esse relato diz respeito a percepção de enfermeiros sobre a implantação da SAE e do PE a partir da funcionalidade "Prescrição de Enfermagem" do AGHU. A coleta de dados se deu através das percepções do cotidiano de trabalho, ao longo dos anos e sistematizado em dezembro de 2020. Este relato de experiência não necessitou de avaliação do Comitê de Ética em Pesquisa, segundo critérios da resolução ${ }^{\circ}$ 510/2016, pois provém de prática profissional e garante anonimato dos participantes.

\section{Resultados}

Antes da implantação do AGHU não era realizada SAE e o PE no setor. Devido a demanda de trabalho, era realizado pelos enfermeiros supervisores a admissão do paciente na UTIP, mas sem o acompanhamento sistematizado e registrado em prontuário cotidianamente. Em 2017 a UTIP passou por uma estruturação em seu quadro de colaboradores, incorporando nas equipes a assistência de enfermagem direta ao paciente crítico por enfermeiros. A partir dai, aumentou o número de enfermeiros no setor, e consequentemente, foi possível implantar a realização da SAE. Conforme ${ }^{(3)}$, o déficit de profissionais enfermeiros, juntamente com a sobrecarga de tarefas e rotinas exercidas por esses profissionais são fatores que influenciam para a não realização da SAE e na UTIP com a inserção de enfermeiros assistenciais no setor foi possivel implementar a SAE e o PE diariamente. Sendo cada turno de trabalho - manhã, tarde ou noite - responsável por um quantitativo de paciente. E essa estratégia tem dado certo, todas as crianças hospitalizadas são avaliadas diariamente por um enfermeiro. No início do processo de implantação, tiveram algumas dificuldades com a ferramenta, visto que conforme o diagnóstico de enfermagem selecionado, não condizia com o sinal de sintoma apresentado pela criança. A equipe de enfermagem a partir de então se debruçou em conhecer o AGHU e o item "Prescriçã̃o de Enfermagem" e foram aprendendo uns com os outros, partindo da percepção que era importante implantar a SAE e o PE no setor. De acordo com ${ }^{(3)}$, são desafios nos serviços de saúde quanto a implementação da SAE, por meio do PE, a descontinuidade entre os turnos, prescrição de cuidados realizados diariamente, falta de objetividade na prescrição, ausência de checagem dos cuidados prescritos; e falhas no registro de evolução ou de cuidados executados. Com a inserção da prescrição de enfermagem no AGHU, essas dificuldades foram superadas. Já que é possível nesse software elaborar o diagnóstico de enfermagem (com base em diagnósticos de enfermagem ou sinais e sintomas), a prescrição de Enfermagem por meio da seleção, orientar a realização do cuidado por meio do item "observação" e aprazamento de cuidados preestabelecidos em horários ou por turnos. A ferramenta permite incorporar blocos de cuidados, conforme as condições do paciente, o que facilita a busca pelos cuidados, prescrição e planejamento da assistência, como exemplo, é possivel citar os blocos de cuidados das medidas preventivas de lesão por pressão e 
da pneumonia associada a ventilação mecânica, o que torna após avaliação do enfermeiro, o processo de planejamento e prescrição mais ágil. O aplicativo AGHU permite aos enfermeiros da UTIP após a avaliação diária do paciente prescrever os cuidados de enfermagem de forma clara, quanto a maneira, hora de implementação, a peridiocidade e quem realizará os cuidados conforme orienta a literatura científica ${ }^{(3)}$. Atualmente, a equipe de enfermagem nos turnos é mista, sendo 4 enfermeiros e 3 técnicos de enfermagem, mas mesmo assim a SAE e o PE estão sendo realizados e os pacientes avaliados e evoluídos diariamente por um enfermeiro. E possível perceber a melhora ou a piora do paciente com base nos registros e acompanhamento diário da equipe de enfermagem e da avaliação diária do enfermeiro. $\mathrm{O}$ AGHU foi apontado como uma ferramenta que facilita e potencializa a realização da SAE no setor, visto que tornou o trabalho mais ágil, dinâmico e como os dados ficam salvos, permite acompanhar a evolução do paciente. Como o trabalho em saúde é dinâmico, e tem troca de colaboradores nas equipes de enfermagem, tem-se como desafio na UTIP a sensibilização das equipes de enfermagem (enfermeiros e técnicos de enfermagem) quanto a importância da SAE, no que diz respeito a planejar a assistência diária com base tanto na prescrição médica e na prescrição de enfermagem, promovendo o saber científico da profissão.

\section{Conclusão}

$\mathrm{O}$ incremento de tecnologias digitais no serviço de saúde facilita a operacionalização da SAE. Por meio do AGHU foi possível realizar o PE de forma clara e objetiva e o aumento de profissionais enfermeiros na UTIP potencializou o cuidado contínuo, sistematizado e diário do enfermeiro na assistência à criança hospitalizada.

Descritores: Software; Processo de enfermagem; Unidade de terapia intensiva pediátrica.

\section{Referências}

1. MOLA, R., et al. Conhecimento dos profissionais de enfermagem sobre a sistematização da assistência de enfermagem. J. res.: fundam. care. online $2019 \mathrm{jul} / \mathrm{set} 11(4)$ ): 887-893.

2. OLIVEIRA, M. R., et al. Sistematização da assistência de enfermagem: percepção e conhecimento da enfermagem Brasileira. Rev Bras Enferm. 2019;72(6):1625-31.

3. CAMPOS, E. C. Sistematização da assistência de enfermagem na rede EBSERH. In: Gestão e inovação em saúde: o que estamos fazendo na EBSERH / Organizado por Custódio Leopoldino de Brito Guerra Neto... [et al]. Natal: SEDIS-UFRN, 2018. 
RELATO DE EXPERIÊNCIA

\section{PLANTAS MEDICINAIS E SUAS INTERAÇÕES NO TRATAMENTO ONCOLÓGICO: UMA REVISÃO NARRATIVA}

\section{Maísa Schneider Lazarotto Kelly Cristina Meller Sangoi}

\section{Introdução}

O câncer é um problema de saúde pública, está entre as maiores causas de morte por doenças não transmissíveis. Por ser uma doença agressiva, seus sintomas é um desafio na hora do tratamento e acabam colaborando para o processo de reabilitação se tornar difícil, o que causa mais sofrimento para as pessoas acometidas por essa doença. Pesquisas realizadas em centros de referência no tratamento do câncer, é comum aparecerem manifestações clínicas nas escalas de sintomas, como dor, seguido de constipação e fadiga. ${ }^{1}$ Para o controle desses sintomas, além do tratamento farmacológico, utilizam-se de estratégias não farmacológicas. Nesse sentido, a procura por práticas complementares dá-se por dois motivos: a insatisfação com a medicina convencional e a busca de afinidades pela utilização de produtos naturais. O Brasil conta com uma Política Nacional de Práticas Integrativas e Complementares, no Sistema Único de Saúde (SUS), que usa a medicina tradicional para oferecer terapias complementares para auxiliar em tratamentos. Uma prática muito antiga utilizada e disseminada como crença popular, é o uso de plantas medicinais, que buscam tratar e aliviar sintomas das mais variadas enfermidades do corpo. No entanto, o uso dessas plantas pode gerar interações com os quimioterápicos utilizados no tratamento do cancer, o que traz a discussão da necessidade de maior conhecimento das plantas medicinais utilizadas por pacientes oncológicos durante seu tratamento. ${ }^{2}$ 


\section{Objetivo}

Conhecer a prevalência da utilização de plantas medicinais por pacientes em tratamento para neoplasias oncológicas.

\section{Método}

Caracteriza-se como uma revisão narrativa da literatura, de abordagem qualitativa. A pesquisa foi realizada nas Base de Dados de Enfermagem (BDENF), Literatura Larino-Americana e do Caribe em Ciências da Saúde (LILACS) e Literatura Internacional em Ciências da Saúde (MEDLINE), durante o mês de outubro de 2020, foram utilizados os descritores "plantas medicinais" AND "oncologia" e "plantas medicinais" AND "neoplasias". Dessa busca, encontrou-se um total de 5114 artigos; após usar os critérios de inclusão, que foram: texto completo, idioma português, entre 2010 a 2020, restaram 33 artigos. Após leitura minuciosa dos mesmos, percebeu-se a relação com à temática em apenas seis artigos.

\section{Resultados e Discussão}

O resultado da pesquisa demonstrou que há poucos trabalhos acerca da temática das plantas medicinais relacionadas ao tratamento oncológico. Um estudo realizado no sul do país, no ano de 2013 entrevistou 130 pacientes, onde foram citadas 316 plantas usadas de maneira geral para tratamento de saúde. Dos entrevistados, a maioria utiliza em busca de uma ação terapêutica, e especificamente $40 \%$ dos entrevistados para tratamento adjuvante do câncer.3 Tambem no sul do país, realizado em 2010, em um Serviço de Quimioterapia de um hospital de ensino, participaram seis pessoas, tendo resultados semelhantes ao estudo anterior. Alternativas citadas foram a fitoterapia e a homeopatia. Onde, percebe-se que os entrevistados se sentem bem após a utilização destas alternativas não-farmacológicas. Outro estudo citou o uso da babosa para o tratamento no câncer, onde $30 \%$ faziam uso desta planta como terapia complementar ao tratamento do câncer. Ainda sobre a utilização de plantas medicinais, foram citadas: babosa, erva-de-lagarto, noz-pecã, quebra-pedra, cocão, madressilva e carrapicho rasteiro como efetivas para o tratamento do câncer. ${ }^{4}$ Fortalecendo esta corrente, as plantas medicinais são utilizadas por $83 \%$ dos pacientes que frequentam o ambulatório de prevenção, diagnóstico e tratamento do câncer, alguns pacientes afirmam usar as plantas medicinais para controle dos efeitos colaterais do tratamento, como o uso do alecrim para alívio do mal-estar após as sessões de quimioterapia, o barbatimão na cicatrização de feridas (câncer de pele) e a camomila para aliviar as queimaduras provenientes da radioterapia. Já quando abordamos o manejo dos efeitos colaterais da quimioterapia, as plantas erva cidreira, camomila, capim santo e chá verde com limão foram as utilizadas. Ao analisarmos as interações medicamentosas, observamos que o uso da camomila com copidogrel e AAS, tem alto risco de sangramento, a erva cidreira e a morfina apresentam risco por intensificar a ação depressora do SNC e o chá verde com a valsartana, possivelmente pode aumentar a pressão arterial sistêmica. Evidenciamos a partir dos estudos que a maneira mais comum de acesso as plantas medicinais são através do quintal da própria casa, ou de familiares e amigos. As plantas usadas, em comum nos estudos, foram a babosa (Aloe vera) e o avelós (Euphorbia tirucalli), camomila (Matricaria recutita L.), graviola (Annona muricata), chá verde (Camellia sinensis). A babosa foi citada para a utilização na forma de "garrafada", onde a planta é incorporada ao mel e a uma bebida destilada, conservada dessa maneira para ingestão, utilizando uma colher de sopa três vezes ao dia. Destacando também, a graviola utilizada em cápsulas e/ou em infusão, e o ipê roxo em cápsula. A babosa não é indicada para ser ingerida via oral. Segundo o Informe Técnico $n^{\circ}$. 47, de 16 de novembro de 2011, a ANVISA informa a ausência de segurança comprovada para o uso de produtos à base de Aloe vera, como alimentos. O avelós, usado através de duas gotas do látex diluído em $200 \mathrm{ml}$ de água diariamente está proibido pela ANVISA, segundo Resolução no ${ }^{2}$ 2917, de 6 de julho de 2011, a sua comercialização e distribuição, no território nacional, por não ter sido submetido a testes de segurança e eficácia. ${ }^{3}$

\section{Conclusão}

Observou-se com essa pesquisa um número pequeno de estudos relacionados à temática proposta. Sabendo do amplo uso de plantas medicinais feito pela população, dentro da crença popular, ressalta-se a importância de pesquisas científicas com plantas medicinais, para poder identificar suas possíveis interações medicamentosas, seus benefícios e malefícios para a saúde das pessoas, e em especial pacientes oncológicos que buscam essas alternativas como cura para suas doenças e alívio de seus sintomas. Por conta disso, os profissionais da saúde devem capacitar-se mais sobre a temática, através de pesquisas, cursos e educação 
continuada para promover orientação sobre essas indicações e seus efeitos colaterais aos pacientes oncológicos, e, desta forma, oferecer um tratamento mais seguro e de qualidade a estes usuários. Dessa forma este estudo serve como alerta para a necessidade de ampliação de pesquisas nesta temática.

Descritores: Plantas Medicinais, Oncologia, Neoplasia.

\section{Referências}

1. SILVA, I. B. S.; et al. Avaliação da Qualidade de Vida de Pacientes Oncológicos em Cuidados Paliativos. Revista Brasileira de Cancerologia 2020; 66(3): e-121122. Acesso em: 29 out 2020 Disponível em: doi: https://doi. org/10.32635/2176-9745.RBC.2020v66n3.1122

2. ROLIM, D. S.; ARBOIT, E. L.; KAEFER, C. T.; MARISCO, N. da S.; ELY, G. Z.; ARBOIT, J. Produção científica de enfermeiros brasileiros sobre enfermagem e oncologia: revisão narrativa da literatura. Arquivos Ciências Saúde UNIPAR, Umuarama, v. 23, n. 1, p. 41-47, jan./set. 2019. Acesso em: 29 out 2020. Disponivel em: DOI: https://doi.org/10.25110/ arqsaude.v2311.2019.6261

3. DALMOLIM, AL MOLIN, G. T.; CAVINATTO, A. W.; COLET C. F. Utilização de plantas medicinais e fitoterápicos por pacientes submetidos à quimioterapia de um centro de oncologia de Ijuí/RS. O Mundo da Saúde, São Paulo - 2015;39(3):287-298. Acesso em: 29 out 2020. Disponivel em: http://bvsms.saude.gov.br/bvs/ periodicos/mundo_saude_artigos/Utilizacao_ plantas_medicinais_fitoterapicos.pdf

4. ANDRADE, F.P.; et al. Plantas medicinais utilizadas por sobreviventes do câncer no tratamento e prevenção desta doença. Revista Enfermagem UFPE on line. 2011 jun.;5(4):944-50. Acesso em: 31 out 2020. Disponível em: https://pesquisa. bvsalud.org/portal/resource/pt/biblio-1033215

5. ALVES, B.L.P.; et al. Polimedicação em Idosos Submetidos a Tratamento Oncológico. Revista Brasileira de Cancerologia 2019; 65(4): e-09379. Acesso em:31 out 2020. Disponível em: doi:https:// doi.org/10.32635/2176-9745.RBC.2019v65n4.379 


\section{PROCESSO DE VALIDAÇÃO DE INSTRUMENTO DE PESQUISA: UMA ABORDAGEM CONCEITUAL}

\section{Wanderson Luís Teixeira Fernanda Norbak Dalla Cort, Cristiane Barreta Jane Tavares Gomes Denise Antunes de Azambuja Zocche}

\section{Introdução}

Entre as diversas metodologias que são apresentadas no meio da pesquisa, escolher uma pode se tornar algo dificultoso. Porém, a que é capaz de dar conta do resultado estimado pelo objetivo do estudo é a que deve ser utilizada. Portanto, um processo vem sendo utilizado para qualificar e dispor de confrabilidade dos produtos construídos. Sendo assim, o processo de validação é configurado a partir de um instrumento construído pelos pesquisadores que se propõe a medir a representatividade e relevância dos elementos apresentados ${ }^{1}$. Para tanto, alguns critérios precisam ser acordados, entre eles validade, confiabilidade, praticabilidade, sensibilidade e responsividade. Para realizar essa mensuração, por exemplo em material educativo, deve-se pensar na aplicabilidade para o público-alvo, logo, focar na relevância da construção em relação ao que se propõe a avaliar, sendo analisado a partir de valores numéricos dado a conceitos abstratos ${ }^{2}$. Para elucidação das abordagens de validação na prática, utilizou-se uma dissertação do Mestrado Profissional da Universidade Federal do Espírito Santo, intitulada como: Tecnologia Educacional para Formação Profissional e Atualização sobre Rastreamento do Câncer do Colo do Útero. O trabalho, oportuniza visualizar de forma clara e objetiva o caminho para alcançar o objetivo da construção da tecnologia. 


\section{Objetivos}

Descrever fundamentação conceitual do processo de validação e apresentar como exemplo uma Dissertaçã̃o do Mestrado Profissional da Universidade do Estado do Espírito Santo.

\section{Metodologia}

Trata-se de uma explanação conceitual através da pesquisa bibliográfica sobre o processo de validação utilizando-se de um artigo pré escolhido pela qualidade de conteúdo e referencial potencial de Alexandre e Colucci (2011), e para complementar, artigos disponíveis no idioma português e inglês nas bases de dados Medline e Lilacs, periodo de 2016 a 2020, pesquisados em outubro de 2020, utilizando os descritores estudos de validação, métodos e enfermagem com operador booleano "AND". Selecionados primeiramente pelo título, após pelos resumos e na sequência lidos na integra. A escolha do trabalho exemplificador foi definida por conter o processo de validação estruturado, abordagem coerente e de uma Instituição referência para o Mestrado Profissional em Enfermagem.

\section{Resultados e Discussão}

A principal finalidade do desenvolvimento de validar é dispor de um instrumento confiável, preciso e útili. Instrumentos de questionário e escalas para instruir a validação vêm sendo construídos, adequados e aprimorados. Porém, é necessário direcionar o instrumento principalmente para estar de acordo com o objetivo do estudo, com o que pretende-se pontuar, que seja proveitoso e alcance o público alvo. Para isso, o processo de validação deve incorporar critérios e sobretudo, ter claro o referencial que será incorporado. Para a escolha de juízes, recomenda-se que seja baseada em critérios como: experiência na area de atuação, ser pesquisador e possuir publicações sobre a temática. A quantidade de juízes necessária para efetivar a validação também vai depender da referência a ser utilizada pelo pesquisador, e que pode ser de no mínimo 5 e no máximo 1o segundo Lynn, Lobiondo orienta que sejam utilizados números ímpares e outros autores entendem que a escolha ficaria entre 6 e 20 juízes². Porém, para essa quantificação, deve ser sustentada a partir das particularidades do instrumento, da disponibilidade e qualificação dos profissionais. O pesquisador deve encaminhar uma carta-convite explicando a escolha por aquele juiz, em seguida o questionário de avaliação, uma breve apresentação do estudo, e instruções para avaliação'. Primeiramente a avaliaçã̃o deve ser analisada em sua totalidade, verificando se os conceitos contemplaram os itens e dimensões proposta em sua abrangência. Posteriormente, será realizada a análise individualizada de questões de clareza e representatividade, sendo preciso incluir espaço para que os juízes possam comentar e sugerir. No início da construção do trabalho, o pesquisador pré define uma porcentagem mínima de aceitação dos juízes para quantificar o grau de concordância dos mesmos, podendo ser utilizado instrumentos de medida como o Índice de Validade de Conteúdo (IVC) ou Coeficiente Kappa $(\mathrm{k})^{2}$. A dissertação de Marcelo Davilla abordou a formação de uma Tecnologia Educacional para formação Profissional e Atualização sobre rastreamento do câncer do colo de útero. Tratou-se de um estudo metodológico, com três etapas: a) elaboração do conteudo teórico do curso online - revisão literatura e correção e adequação textual, b) validação do conteúdo teórico - análise de conteúdo e aparência pelos juízes através do questionário Google Formulários, compilado em planilhas Microsoft Excel e análise na Plataforma Delphi online, c) construção do objeto virtual de aprendizagem - através do método design centrado no usuário, contribuições da graduação de design da Universidade Federal do Espírito Santo e do Laboratório de Tecnologia em Saúde3. O questionário avaliativo utilizou de escala tipo Likert, que é estabelecida por critérios: adequado, parcialmente adequado e inadequado, foi subdividida em módulos e sequencialmente por telas do curso, com espaço para comentários e sugestões, que abrange o envoltório de orientações para a construção. Também, 21 juízes participaram da pesquisa, e o grupo foi formado por enfermeiros que atuam na atenção primária à saúde, professores e enfermeiros com experiência de, no mínimo, dois anos em uma das áreas de interesse: Saúde da Mulher, Enfermagem Obstétrica ou Ginecológica. A meta estabelecida de índice de concordância era de $\mathrm{o}, 8 \mathrm{o}$, que ao finalizar, superou-se. Alguns apontamentos identificados como pendente pela avaliação dos leitores, seria o retomar a discussão das sugestões e não concordância dos juízes em alguns critérios e como sugestão, a avaliação de impacto, que incorporou-se recentemente na pesquisa, sendo não obrigatória na dissertação. 


\section{Conclusão}

Para concluir a explanação, é importante enfatizar que o processo de validação é proveitoso para aprimorar e direcionar com qualidade o produto do trabalho, mas para isso é necessário que as abordagens do pesquisador sejam adequadas. Agregando assim, confiança e utilidade para a produção.

Descritores: Estudos de validação; Métodos; Enfermagem.

\section{Referências}

1. Alexandre NMC, Coluci MZO. Validade de conteúdo nos processos de construção e adaptação de instrumentos de medidas. Ciênc. saúde coletiva. 2011 [acesso em 27 de jan. 2021];16,(7),3061-3068. Disponível em: http:// dx.doi.org/10.1590/S1413-81232011000800006.

2. Sarah de Sá Leite et al. Construção e validação de Instrumento de Validação de Conteúdo Educativo em Saúde. Revista Brasileira de Enfermagem. 2018 [acesso 27 de jan. 2021]; 71, (4), 1732-1738. Disponível em: https://doi. org/10.1590/0034-7167-2017-0648

3. Polit DF, Beck CT. Fundamentos da pesquisa em enfermagem: avaliação de evidências para a prática de enfermagem. 7 a ed. Porto Alegre: ArtMed; 2017. 
RELATO DE EXPERIÊNCIA

O PAPEL DO ENFERMEIRO NA PREVENÇÃO

DE LESÕES POR PRESSÃO, NA PRONAÇÃO DO

PACIENTE COM COVID-19 NA UNIDADE DE TERAPIA

INTENSIVA: RELATO DE EXPERIÊNCIA

\section{Cibele Cirino de Sousa \\ Aline Cristina Andrade Furini, \\ Adriana de Fatima Manoel \\ Eliseu da Costa Campos}

\section{Introdução}

A Covid-19 é uma doença infectocontagiosa proveniente do novo vírus SARS-Covz, os quadros mais graves evoluem com dispneia, desconforto respiratório, cianose nos lábios ou face, saturação de oxigênio abaixo de 90\%, até hipoxemia severa, definida pelo Ministério da Saúde como Síndrome do Desconforto Respiratório Agudo (SDRA), e como medida terapêutica é necessário a suplementação de oxigênio por via aérea avançada e internação em Unidade de Terapia Intensiva (UTI). Com o surgimento dessa gravidade, e com o intuito de atender as especificidades destes pacientes, houve a necessidade do uso de estratégias pouco utilizadas até então. A técnica conhecida como pronagem, caracterizada pela colocação do paciente em posição ventral, passou a ser utilizada, permitindo uma melhora da mecânica pulmonar e das trocas gasosas que podem ser evidenciadas através de resultados de gasometria ${ }^{1}$. A posição pronada é indicada por períodos de duração mínima de 12 a 16 horas, e tem como fundamentos de indicação critérios específicos, tais como a relação $\mathrm{PaO}_{2} / \mathrm{FiO}_{2}$, a saturação de oxigênio e a frequência respiratória. Esste posicionamento melhora a oxigenação do paciente possibilita melhor drenagem de secreções das vias aéreas e redução do risco de infecção respiratória associada à ventilação mecânica, contudo também implica em várias complicações como instabilidade hemodinâmica transitória, abrasões de córnea, lesão ple- 
xo braquial, aumento do risco de edema facial, extubação acidental e o surgimento de Lesão Por Pressão (LPP) 2,3. O decúbito proposto exerce pressão sobre as regiões da testa, bochechas, nariz, queixo, clavícula, ombro, cotovelo, peito, genitália, ossos pélvicos anteriores (crista ilíaca, ísquio, sínfise púbica), joelhos, dorso dos pés, e dedos dos pés ${ }^{4,5}$. É necessário o correto posicionamento dos dispositivos médicos, diminuição da pressão nas prominências ósseas, inspeção diária, higiene, hidratação, manejo da umidade e da temperatura da pele. As LPP causam dores, infecções graves, sepse e aumento da mortalidade, prolongam o tempo de internação e impactam no aumento dos custos financeiros com os serviços de saúde ${ }^{2,3,4,5}$.

\section{Objetivo}

Relatar as principais medidas implantadas na prevenção de lesões por pressão, durante o posicionamento em prona do paciente com Covid-19, em unidade de terapia intensiva de um hospital particular do interior do estado de São Paulo.

\section{Métodos}

Trata-se de um relato de experiência do enfermeiro na prevenção da lesão por pressão na pronação de pacientes diagnosticados com Covid-19.

\section{Resultados e Discussão}

Com intuito de melhorar o padrão respiratório em pacientes com SDRA, o posicionamento em prona foi instituído precocemente, preferencialmente nas primeiras 24 horas ou em até 48 h pós intubação. A fim de garantir a segurança para a realização do procedimento foram disponibilizados treinamentos em formação continuada dos colaboradores da UTI. Para execução da manobra de posicionamento $\mathrm{em}$ prona foi sugerido a participação de três a cinco profissionais. Vários fatores de riscos foram evidenciados: como a compressão, a posição ventral mantida por muito tempo leva a um aumento da pressão sobre órgãos e tecidos, principalmente em regiões ósseas; a presença de dispositivos invasivos, causadores de constante atrito na pele provocam o rompimento da mesma; umidade da pele, causada pela sudorese excessiva e pela intensa salivação (provocada pela presença do tubo orotraqueal e pela falta de deglutição); a própria patologia, a Covid-19, causa uma elevação de citocinas, disfunção endotelial, queda na oxigenação e hipercoagulabilidade, levando a inflamação e isquemia tecidual; esse conjunto de fatores contribuem, consideravelmente, para o surgimento de lesões teciduais. Observou-se uma maior incidência de lesões na face (principalmente em olhos, nariz, bochechas e queixo), no tórax (na região das margens das costelas inferiores, ombros, região esternal e clavicular), na região pélvica, órgãos genitais e membros inferiores (região tibial e dorso do pé). A equipe de saúde, visando a recuperação tecidual e a prevenção dessas lesões, implantou algumas medidas que resultaram efetivamente na diminuição das ocorrências das lesões nestes pacientes. Foram estabelecidos treinamentos com a equipe multiprofissional, registro das ações realizadas em impresso próprio (com assinaturas de todos envolvidos), avaliação da pele previamente a pronagem e após a desprona, mudança de posicionamento da cabeça a cada 2 horas, colocação do paciente em posição de nadador, medidas de proteção da pele como aplicação de protetores de pele (placas de hidrocolóide e filme transparente em áreas de proeminência óssea e de maior incidência de lesões), passou-se a utilizar fixadores adequados, de tubo endotraqueal (fixação hollister) e de Sonda Nasoentérica, vigilância constante dos dispositivos que possam causar pressão em locais específicos, colocação dos eletrodos na região dorsal, uso de colchins em região torácica e pélvica, uso de colchões pneumáticos em 100\% dos paciente. Outra medida adotada pelo hospital, para o gerenciamento do risco de lesões, foi a realização de fiscalização das medidas instituídas, internas e externas à UTI, efetuada pelos enfermeiros de cada turno, por meio de um impresso em forma de check-list. As medidas foram devidamente realizadas e com isso podemos evidenciar a efetiva diminuição na ocorrência das lesões. Constatamos o envolvimento de toda a equipe assistencial, demostrado em anotações e comentários diários. Para o alcance de tal sucesso foi necessário um estímulo constante da gestão da unidade para com toda a equipe multiprofissional.

\section{Conclusão}

A posição prona é uma alternativa viável para auxiliar na melhoria da ventilação e perfusão de pacientes com Covid-19 apresentando quadros de hipoxemia, porém uma das principais complicações relacionadas a essa posição, são as LPP em face, ombros e outras proeminências ósseas. Isso ocorre devido a impossibilidade de mudança de decúbito, bem como a carência de protocolos institu- 
cionais relacionados ao manuseio da LPP nesses casos. Ressalta-se que essas lesões podem prolongar o tempo de internação tendo em vista o risco de complicações, o que impacta no aumento dos custos financeiros nos serviços de saúde. Desse modo é viável, realizar medidas preventivas para evitar esse agravo. Cabe à gestão e a cada profissional articular meios de garantir a implantação de rotinas adequadas para a realização do trabalho, utilizando-se de evidencias para a atuação prática das rotinas diárias. A equipe de enfermagem exerce papel fundamental na segurança do paciente, na diminuição da ocorrểncia de danos e na garantia da qualidade assistencial.

Descritores: Infecções por Coronavírus; Síndrome do Desconforto Respiratório do Adulto; Decúbito Ventral; Enfermagem; Terapia Intensiva.

\section{Referências}

1. Araújo MS, Santos MMP, Silva CJA, Menezes RMP, Feijão AR, Medeiros SM. Posição prona como ferramenta emergente na assistência ao paciente acometido por Covid-19: scoping review. Rev. Latino-Am. Enfermagem [Internet]. 2021 [cited 2021 Jan 15]. 29: e3397. Available from: http://www.scielo.br/scielo.php? script=sci arttext\&pid=So104=11692021000100600-\&lngen. Epub Jan o8, 2021. https://doi. org/10.1590/1518-8345.4732.3397.

2. Guirra, PSB, Gomes, JS, Biliu, KS, MedVed, IV, Almeida, VC (2020). Manejo do paciente com COVID-19 em pronação e prevenção de lesão por pressão. Health Residencies Journal, 1 (2).

3. Borges DL, Rapello GVG, De Andrade FM. Posição prona no tratamento da insuficiência respiratória aguda na Covid-19. ASSOBRAFIR, 2020:1-7. Disponível em: https://assobrafir.com. br/wp-content/uploads/2020/o3/ASSOBRAFIR_COVID-19_PRONA.v3- 1.pdf. doi: https:// doi.org/10.47066/2177-9333.AC20.covid19.011

4. Carmo GP, Nascimento JS, dos Santos TRM, Coelho PSO. Intervenções terapêutico-ocupacionais para pacientes com COVID-19 na UTI. Rev. Interinst. Bras. Ter. Ocup. Rio de Janeiro. 2020. suplemento, v.4(3):397-415. Doi: https:// doi.org/10.47222/2526-3544.rbto33997

5. Ramalho AO; Freitas PSS; Moraes JT; Nogueira PC. Reflexões sobre as recomendações para prevenção de lesões por pressão durante a pandemia de covid-19. ESTIMA, Braz. J. Enterostomal Ther. 2020, 18:e2520. Doi: https://doi. org/10.30886/estima.v18.940_PT 
RELATO DE EXPERIÊNCIA

\section{CONFECÇÃO DE FOLDER ACERCA DA PROFILAXIA PRÉ-EXPOSIÇÃO DE RISCO À INFECÇÃO PELO HIV}

\section{Luiza Silveira de Oliveira Laís Mara Caetano da Silva \\ Maria Denise Schmith \\ Patrícia Porto Almeida \\ Márcia Gabriela Rodrigues de Lima Júlia Zancan Bresolin}

\section{Introdução}

A prevenção combinada consiste na associação de diferentes abordagens preventivas, de acordo com as possibilidades e opções de cada indivíduo, sem a exclusão ou sobreposição de um método a outro. A Profilaxia Pré-Exposição ao Risco de Infecção pelo HIV (PrEP) configura-se como uma das estratégias e consiste no uso de antirretrovirais para reduzir o risco de adquirir a infecção, sobretudo junto a populações com risco aumentado de contrair a doença, chamada de populações-chave, como gays e outros homens que fazem sexo com homens (HSH), pessoas trans e profissionais do sexo ${ }^{1}$. Estudos globais contribuíram para gerar um relativo consenso sobre os benefícios da PrEP, assim como estabelecer parâmetros clínicos de uso seguro. Apesar dessa estratégia se mostrar eficaz e segura em pessoas com risco aumentado de adquirir a infecção, ainda existem indagações acerca dos seus efeitos compensatórios nas práticas sexuais, adesão e acesso amplo, seguro e efetivo, tais questões dificultam sua expansão ${ }^{2}$. Por essa razão, o folder contendo informações sobre a PrEP, uma estratégia de prevençã̃o ofertada pela cidade de Santa Maria/RS, tem o intuito de proporcionar melhor qualidade de vida aos usuários de saúde, oferecendo todas as estratégias incluídas na mandala da prevenção combinada. 


\section{Objetivo}

Disseminar informações acerca da Profilaxia Pré-Exposição de Risco de Infecção pelo HIV por meio de um folder informativo e explicativo para a comunidade da cidade de Santa Maria, Rio Grande do Sul, em parceria com a equipe da Política Municipal de HIV/Aids, Infecções Sexualmente Transmissíveis (ISTs) e Hepatites Virais e com ao Serviço de Atenção Especializada (SAE) Casa da Treze de Maio, visto que sua implementação é um acontecimento recente no município.

\section{Método}

Trata-se de um relato de experiência no que tange a elaboração de um folder informativo explicativo acerca da Profilaxia Pré-Exposição ao Risco da Infecção pelo HIV, feito por meio de site gratuito e online, por duas discentes do curso de enfermagem. Nesta ferramenta de divulgação, consta explicações sobre o que é a PrEP, como funciona, para as populações ela é indicada, como acessar o serviço de saúde para poder solicitá-la, onde é disponibilizada no município e contatos para maiores informações e dúvidas. Ainda, a fim de auxiliar na eláboração do informativo, foi ofertada uma capacitação online sobre a implementação da PrEP (ImPrEP) como uma política de saúde pública em Santa Maria/ RS aos profissionais e estudantes da área da saúde, no dia 24 de setembro de 2020, ministrada por um médico, investigador principal do estudo PrEP Brasil/Porto Alegre e ImPrep.

\section{Resultados e Discussão}

De acordo com o Boletim Epidemiológico HIV/AIDS de 2019, do Departamento de Doenças de Condições Crônicas e Infecções Sexualmente Transmissiveis, do Ministério da Saúde, de 1980 a junho de $2019^{3}$, foram identificados 966.058 casos de AIDS no Brasil. O país tem registrado, anualmente, uma média de 39 mil novos casos da doença nos últimos cinco anos. Por esse motivo, é substancial a oferta de estratégias de prevenção, como a PrEP, e o acolhimento na sua integralidade dos usuários, garantindo seus direitos à saúde de qualidade. No entanto, essa premissa encontra alguns desafios, haja vista que, além das populações-chave apresentarem maior risco de adquirir o Vírus da Imunodeficiência Humana, essas pessoas frequentemente estão sujeitas a situações de discriminação e preconceito decorrentes dos estigmas da doença, fazendo com que a suas vulnerabilidades aumentem. Para essas situações, a PrEP age como uma estratégia adicional de prevenção no Sistema Único de Saúde (SUS) de Santa Maria/RS, e a ferramenta de divulgação, o folder, contribuirá para o alcance das metas relacionadas à diminuição dos casos de HIV. O simples pertencimento a um dos grupos prioritários não é suficiente para caracterizar indivíduos com exposição frequente, para isso é necessário observar parcerias sexuais, práticas sexuais e os contextos específicos. Assim, deve-se considerar outros indicativos, tais como: repetição de práticas sexuais anais e/ou vaginais com penetração sem o uso de preservativo, frequência das relações sexuais com parcerias eventuais, quantidade e diversidade de parcerias sexuais, histórico de episódios de infecções sexualmente transmissiveis, busca repetida por Profilaxia Pós-Exposição (PEP), contextos de troca de sexo por dinheiro, objetos de valor, drogas, moradia, etc ${ }^{1}$. É importante ressaltar que o informativo elucida algumas questões acerca da profilaxia e explica os procedimentos, todavia a conversação e a escuta ativa são essenciais no processo de divulgação, visto que é importante que o indivíduo tenha sua autonomia para gerenciar os riscos, conforme suas práticas sexuais, experiências com outros métodos de prevenção e histórico de saúde, por exemplo. Nesse processo, deve-se explicar às pessoas que a PrEP é um método seguro e eficaz, com raros eventos adversos, os quais, quando ocorrem, são transitórios e passiveis de serem manejados clinicamente. Convém, também, reforçar que a efetividade dessa estratégia está diretamente relacionada ao grau de adesão ao tratamento ${ }^{1}$. Além disso, não previne as demais ISTs ou hepatites virais, sendo necessário orientar sobre o uso de preservativos. Com a perspectiva de auxiliar no alcance das metas relacionadas ao fim da epidemia do HIV, a disseminação de informações sobre a PrEP é substancial para alertar aos usuários sobre os serviços de prevenção e promoção de saúde que a cidade oferece. Dessa forma, espera-se que a ferramenta tenha um largo alcance entre a população, tendo em vista a facilidade com que é compartilhada, tanto por meio das mídias digitais, quanto impressa e distribuída nos serviços de saúde e em campanhas. Os dados presentes no folder são de fácil entendimento, uma vez que são uma síntese distribuída de forma dinâmica no texto, utilizando linguagem mais simples, com imagens e cores, destacando os pontos de maior relevância para as pessoas que não têm entendimento sobre o assunto ou sabem de forma superficial. 


\section{Conclusão}

Entende-se que o folder será um meio relevante para conhecer e ter informações sobre as políticas públicas de saúde à medida que proporciona ciếncia aos cidadãos sobre os seus direitos e disponibilidades de serviços, o que, consequentemente, pode aumentar a busca e o acesso a esses recursos no sistema de saúde. Além disso, fomenta discussões acerca das estratégias de prevenção e das ações que objetivam colaborar com a melhoria das condições de saúde da população, as quais são disponibilizadas no Sistema Único de Saúde. E válido ressaltar, também, que a política brasileira de enfrentamento ao HIV/Aids reconhece que nenhuma intervenção de prevenção isolada é suficiente para reduzir novas infecções ${ }^{3}$. Desse modo, a fim de garantir uma maior diversidade de opcões que orientem as decisões dos usuários, o folder opera como um agente de impacto para que as pessoas possam optar pelos melhores métodos para si, tendo, assim, uma melhor qualidade de vida.

Descritores: Enfermagem; Infecções Sexualmente Transmissíveis; Profilaxia; Saúde Sexual.

Financiamento: Resumo financiado pelo Fundo de Incentivo de Extensão (FIEX - Pró-Reitoria de Extensão) - Universidade Federal de Santa Maria.

\section{Referências}

1. Ministério da Saúde, Secretaria de Vigilância em Saúde, Departamento de Vigilância, Prevenção e Controle das Infecções Sexualmente Transmissíveis, do HIV/Aids e das Hepatites Virais. Protocolo Clínico e Diretrizes Terapêuticas para Profilaxia Pré-Exposição (PrEP) de Risco à Infecção pelo HIV. - Brasília : Ministério da Saúde, 2018.

2. Fonner VA, Dalglish SL, Kennedy CE, Baggaley R, O'Reilly KR, Koechlin FM, et al. Effectiveness and safety of oral HIV pre-exposure prophylaxis (PrEP) for all populations: a systematic review and meta-analysis. AIDS 2016; 30:1973-83.

3. Ministério da Saúde, Secretaria de Vigilância em Saúde. Boletim Epidemiológico. Brasília: Número Especial, Dez. 2019. 
RELATO DE ExPERIÊNCIA

NOTIFICAÇÕES DE FLEBITE E CONSTRUÇÃO DO MÉTODO PDSA

\section{Carla Moreira Lorentz Higa Patrícia Trindade Benites \\ Flávia Rosana Rodrigues Siqueira}

\section{Introdução}

A Organização Mundial de Saúde, em 2004 por meio da World Alliance for Patient Safety, identificou as prioridades na área da segurança do paciente e sugeriu medidas para reduzir os riscos e a ocorrência de eventos adversos (EA) ${ }^{1}$. Nas instituições hospitalares o cateter intravenoso periférico (CIP) é um dispositivo de uso constante na terapia medicamentosa. Sua utilização pode conduzir a diversas complicações que geram aumento do tempo de internação do paciente e de custos hospitalares². Dentre as complicações descritas, a flebite é a mais frequente. É identificada como um EA evitável que leva a uma inflamação das células endoteliais da parede venosa com sintomatologia em graus variáveis. Desta maneira, seu monitoramento demanda planejamento, vigilância e implementação de práticas de prevenção para garantir a segurança do paciente 3 . Com causas de cunho multifatorial, a prevenção de flebites demanda o rastreio de novos conhecimentos no campo científi$\mathrm{CO}^{2}$. No monitoramento dos eventos adversos notificados ao sistema interno de Vigilância Hospitalar (VIGIHOSP) observou-se uma elevada frequência de flebites num hospital, com um quantitativo acima de 150 notificações e com uma média anual de $9,1 \%$ no ano de 2019. Conforme dados da Nursinf Society of Intravenous Fluid, a taxa aceitável é de $5 \%$ ou menos ${ }^{2}$. A partir disso, o Núcleo de Segurança do Paciente (NSP) planejou ações de 
aprimoramento para a prevenção de flebites utilizando o método PDSA (Plan-Planejar/ Do-Executar/Study-Verificar/Act-Atuar). Esta ferramenta é de uso gerencial que utiliza uma sequência lógica para melhoria de processos ${ }^{4}$.

\section{Objetivo}

Relatar a experiência de construção e implementação do método PDSA, para prevenção de flebites associadas a CIP nas unidades de internação de um hospital público de ensino.

\section{Método}

O caminho metodológico ocorreu durante o ano de 20zo. O NSP elencou três unidades de internação para desenvolver as ações e dividir as experiências relacionadas a prevenção de flebites. Foi realizada a construção e aplicação do método PDSA. Realizou-se o levantamento e a análise estatística dos dados compilados em arquivo Excel, a partir das notificações no sistema VIGIHOSP referentes ao ano de 2019. No seguimento e para embasamento científico fez-se uma revisão de literatura nas bases de dados: SciELO e portal regional da BVS, com consecutiva construção e planejamento do método PDSA, nas quatro etapas. Finalmente, o NSP envolveu as unidades de internação definidas para o projeto piloto, para detalhamento, manifestação e refinamento das atividades a serem desenvolvidas.

\section{Resultados e Discussão}

$\mathrm{Na}$ primeira etapa do método PDSA "Plan", realizou-se o estudo dos casos notificados, no total de onze unidades de internação do hospital. Na revisão de literatura atentou-se aos tipos de flebite: mecânica (quando resultante de trauma), química (correlacionada ao uso medicamentos) e infecciosa (por contaminação). Esta afirmação coincide com os dados encontrados no hospital, que correlacionou como as possíveis causas da flebite diversas situações, como: ausência de salinização, infecção, trauma durante a punção, qualidade do material, fragilidade capilar, CIP utilizado acima de 72 horas, dentre outras. A maioria dos eventos ocorreu em pacientes do sexo masculino $(60,5 \%)$ e $40,8 \%$ das notificações se manifestaram na primeira semana de internação dos pacientes. Dentre os tipos de cateteres utilizados na terapia intravenosa, o CIP foi o mais frequente, quando comparado ao acesso venoso central, sendo este dispositivo relatado em $88,0 \%$ das notificações. Os medicamentos foram citados como causa dos eventos de flebi- te em $58,0 \%$ das notificações. Tais achados confirmam o encontrado na literatura, que descreve o evento adverso como causa multifatorials. Dentre as onze unidades que notificaram o evento, três tiveram os maiores índices $(37,5 \%$, $21,7 \%$ e $17,8 \%$ ) e foram eleitos pelo NSP como unidades piloto para seguimento do plano de ação. Estas unidades de internação representam 20,0\% dos leitos do hospital, cujos pacientes utilizam em sua maioria CIP em comparação aos acessos venosos centrais. No segundo passo do PDSA "Do", o método contemplou: identificação pela farmácia de orientações relacionadas ao uso de medicamentos irritantes e/ou vesicantes, pois o manual atual não disponibilizava essas informações, o que foi considerado como crítico para os profissionais médico e enfermeiro. Contemplou ainda: estímulo ao uso do curativo transparente estéril, adequado para fixação do CIP, que já era padronizado no hospital, mas seu uso era eventual ou prática de poucos profissionais; uso adequado do garrote, com realização da antissepsia correta orientada pelo Serviço de Controle de Infecção Hospitalar (SCIH) concomitante ao reforco ao uso individual para cada paciente, a fim de evitar riscos de contaminação no momento da punção venosa. Em consenso com as unidades piloto foram realizadas avaliações entre duas escalas de classificação de flebite validadas no Brasil: "Infusion Nurse Society (INS)" e "Maddox", para definição de qual seria utilizada, já que não havia padronização na instituição. Com 89,0\% das preferências, a INS foi a escolhida. Baseado nas captações realizadas junto as enfermeiras responsáveis técnicas das unidades piloto, surgiu a necessidade de padronizar as ações a serem realizadas na prevenção de flebites, de modo a compartilhar o conhecimento, descrever rotinas e facilitar a adesão às práticas seguras. Por isso, construiu-se o Protocolo de prevenção de flebite associada ao CIP. Este foi aprovado e publicado na intranet do hospital para amplo acesso. Como ação de sensibilização e atualização foi realizado treinamento in loco para a equipe assistencial e 44 profissionais das unidades piloto foram treinados. Cada treinamento durou em média de 60 a 90 minutos, consistiu na troca de experiências e receptividade dos treinadores para perceber e possibilitar o relato das dificuldades enfrentadas. Apesar da marcação prévia e convite a equipe multiprofissional, somente a enfermagem participou da ação. A falta de envolvimento na prevenção de flebite de outras categorias profissionais foi uma dificuldade relatada. Além disso, durante os treinamentos foi sugerido pelos profissionais a sensibilização 
junto às chefias para intervenção e possibilidade de indicação de acesso venoso central para administração de medicamentos vesicantes e/ ou irritantes concomitante as reflexões de risco-benefício para cada paciente. No intuito de divulgar o protocolo e atingir um maior número de profissionais, o NSP produziu um vídeo de treinamento e disponibilizou via Google Forms para todo o hospital. Em um mês de campanha, 140 profissionais realizaram o treinamento. No seguimento do método PDSA (passo "Study"), ao final do ano de 2020, um novo levantamento e análise estatística das notificações no sistema VIGIHOSP foi realizada. Observou-se que não houve alteração quanto a maior frequência do sexo masculino $(52,0 \%)$ em relação ao feminino (48,o\%). O CIP esteve presente em 94,0\% das notificações e os medicamentos estiveram relacionados aos eventos em 59,0\% dos incidentes. Houve melhoria na quantidade e qualidade das notificações com relação ao detalhamento dos incidentes. Foram acrescentados dados da possível relação de medicamentos e flebite, em que $37,7 \%$ das notificações relataram soluções eletrolíticas e 33,0\% antibióticos. Desta maneira será possível direcionar as ações ao uso específico destes medicamentos. As três unidades de internação serão monitoradas no decorrer do ano de 2021 e poderá ser possível verificar a incidência e identificar se houve alteração na frequência das notificações e consequente eficácia das ações realizadas. Como proposta para o último passo "Act", além do monitoramento da incidência e notificações, o NSP colocará em prática as solicitações das equipes, como: definição do local para anotação do score da escala INS no prontuário, formalização do envio mensal da incidência de flebite junto as unidades piloto e exposição aos chefes de unidade dos achados deste relato a fim de viabilizar embasamento para a possibilidade de uso de medicamentos em vias alternativas, quando possível. Como limitações destacamos a ausência do acompanhamento da incidência de flebite no ano de 2020, pois ocorreu somente o acompanhamento da frequência das notificações.

\section{Conclusão}

A experiência vivenciada na construção do método PDSA em conjunto com as ações necessárias para promover a prevenção de flebites associadas ao uso do CIP ocorreram de maneira exitosa. A utilização da ferramenta demonstrou que ao identificar os fatores predisponentes para flebite é possível elaborar ações de barreira para ocorrência de danos aos pacientes. Apesar de ser um desafio para a prática clínica, adotar rotinas e protocolos baseados na literatura científica contribui para evidenciar que medidas de rastreamento e planejamento podem proporcionar a reflexão no aprimoramento de ações para a segurança do paciente.

Descritores: Cuidados de enfermagem; Cateterismo periférico; Segurança do paciente; Gestão da segurança.

\section{Referências}

1. World Health Organization. World alliance for patient safety: WHO draft guidelines for adverse event reporting and learning systems: from information to action. World Health Organization. 2005. Available from: https://apps. who.int/iris/handle/10665/69797

2. Alves DA, Lucas TC, Martins DA, Cristianismo RS, Braga EVO, Guedes HM. Evaluation of peripheral intravenous cateter puncture and maintenance procedures. RECOM. 2019,9:e3005.

3. Salgueiro-Oliveira AS, Bastos ML, Braga LM, Arreguy-sena C, Melo MN, Parreira PMSD. Nursing Pratices in peripheral intravenous cannulation: phlebitis and patient safety. Texto Contexto Enferm. 2019,28:e20180109.

4. Silva CO, Agostino ÍRS, Souza SRO, Frota PC, Oliveira RD. A utilização do método PDCA para melhoria dos processos: um estudo de caso no carregamento de navios. Revista Espacios. 2017,38(27):9-22.

5. Enes SMS, Optiz SP, Faro ARMC, Pedreira MLG. Phlebitis associated with peripheral intravenous catheters in adults admitted to hospital in the Western Brazilian Amazon. Rev Esc Enferm USP. 2016,50(2):263-71. 
RELATO DE EXPERIÊNCIA

AGENDAMENTO DA VACINA INFLUENZA COMO ESTRATÉGIA PARA AUMENTAR COBERTURA VACINAL

\section{Joice Rodrigues Machado Hahn}

Melanie Schröder

Vanisa Cavallini da Silva

Rosa Ladi Lisbôa

Angelica de Lima Izaguirres

Adriana Aparecida Paz

\section{Introdução}

A influenza sazonal representa um importante problema de saúde pública afetando cerca de 5 a $10 \%$ dos adultos economicamente ativos. As complicações são responsáveis por um grande número de mortes e internações hospitalares, as quais causam doenças graves em 3 a 5 milhões de pessoas, podendo ocorrer em torno de 650.000 mortes em todo o mundo. Além disso, o vírus da Influenza pode ser o gatilho para o agravamento de problemas crônicos de saúde pré-existentes, como exacerbação de doenças respiratórias. No entanto, adultos saudáveis também podem contrair a Influenza e desencadear as consequências inoportunas para a saúde física, psíquica e laboral ${ }^{1}$. Por essas razões, a Organização Mundial de Saúde (OMS) recomenda a vacinação contra influenza sazonal para profissionais da saúde, além de pessoas consideradas de risco (crônicos, pessoas com mais de 65 anos, gestantes e crianças com idade de 6 meses a 5 anos) $)^{2}$. Atualmente no Brasil, o calendário de vacinação adulto é garantido pelo Ministério da Saưde em todo território nacional. Os informes técnicos são realizados pelo Programa Nacional de Imunização (PNI) para adultos com idade de 20 a 59 anos, sendo recomendadas diversas vacinas como: hepatite B, difteria e tétano, tríplice viral (sarampo, caxumba e rubéola), febre amarela e também a Influenza, além dessas, estão recomendadas pela Sociedade Brasileira de Imunizações (SBIm) a vacinação contra hepa- 
tite $\mathrm{A}$, varicela e doença meningocócica $\mathrm{B}^{2}$. A imunização é uma ferramenta extremamente efetiva para a prevenção de diversas doenças ao redor do mundo, diminuindo o risco de transmissão entre os grupos e a coletividade. Assim, o uso das vacinas é uma medida relevante e eficaz em saúde e, em se tratando do vírus Influenza, contribui para a diminuição de hospitalizações, casos graves e óbitos. Além disso, evitando os subsequentes danos socioeconômicos e laborais decorrentes dessa morbidade. Neste sentido, destaca-se a importância e a necessidade do gerenciamento da enfermagem nos serviços de saúde ocupacional e das unidades de saúde na atenção primária à saúde (APS) para realização de campanhas efetivas de vacinação. Por conta do constante contato com indivíduos assistidos por instituições e empresas de saúde, além da proteção individual e coletiva dos profissionais, a recomendação anual da vacina de influenza para trabalhadores de saúde como grupo prioritário, também visa reduzir indiretamente os óbitos e adoecimentos de suscetíveis na população3. No panorama mundial, observa-se uma baixa cobertura da vacina sazonal contra o vírus influenza para trabalhadores da saúde, fato que pode ser desencadeador de absenteísmo e gerar uma sobrecarga dos serviços de saúde ${ }^{4}$.

\section{Objetivo}

Relatar a experiência no gerenciamento de três diferentes campanhas de vacinação contra o vírus Influenza e o alcance da cobertura vacinal de acordo com duas estratégias utilizadas distintas.

\section{Metodologia}

Trata-se de um relato de experiência da atuação de um serviço de saúde ocupacional privado em Porto Alegre, Rio Grande do Sul - Brasil. Foram realizadas três campanhas de vacinação contra o vírus Influenza com diferentes estratégias de abordagem dos trabalhadores, no periodo de 2018 a 2020. O cenário tem aproximadamente 2000 trabalhadores em diversos setores administrativos, tecnológicos e assistenciais, cujo qual segue as recomendações da legislação vigente a Norma Regulamentora $32(\mathrm{NR}-32)^{5}$, referente à imunização.

\section{Resultados e discussão}

A legislação do exercício profissional do enfermeiro atribui a função de gerenciar, planejar e assistir com atividades e ações relacionadas ao cuidado com a saúde. Para que isso ocorra de forma segura e eficaz, a constante produção de ferramentas baseadas em evidências científicas é de extrema relevância para garantir a eficácia dos cuidados e das ações de promoção da saúde, não apenas no âmbito ocupacional, como para a população em geral. Em relação a vacinação, na primeira campanha de vacinação contra Influenza ocorreu em 2018, sendo utilizada a estratégia da abordagem dos trabalhadores no próprio setor de atuação dos trabalhadores em local privado e sem a necessidade de deslocamento até o serviço ocupacional. No ano de 2019, a equipe do serviço ocupacional manteve a mesma modalidade de abordagem dos trabalhadores do ano anterior. Em 2O2O, com a pandemia do vírus SARS-CoV-2, a equipe do serviço ocupacional assumiu as medidas preventivas como meio de reduzir o risco de exposição e da transmissibilidade desta morbidade aos trabalhadores nos diferentes setores do cenário, definiu como estratégia o agendamento. Esta estratégia para a vacinação ocorreu por meio de agendamento online pelo trabalhador no serviço ocupacional, sendo de sua escolha do dia e horário para aplicação do imunobiológico, incluindo os seus dependentes. O agendamento foi feito através do site da empresa, oferecendo ao trabalhador a possibilidade de escolher o dia e horário que se encaixasse com sua rotina e preferências. Constatou-se que em 2018 e 2019 em que a vacinação ocorreu nos diversos setores de atuação do trabalhador, a adesão foi maior ao comparar com o ano de 2020. O quantitativo de trabalhadores em 2018 e 2019 foi 1.400 e 1.500 vacinados, já em 2020 essa frequência foi de 1.100 colaboradores imunizados. O declínio no número de trabalhadores vacinados em resposta às diferentes estratégias evidenciou a necessidade de retomar a estratégia anterior. Por sua vez, o serviço ocupacional do cenário atende as diretrizes básicas para a implementação de medidas de proteção à segurança e à saúde dos trabalhadores dos serviços de saúde, bem como daqueles que exercem atividades de promoção e assistência à saúde em geral, infere que, existindo vacinas eficazes contra outros agentes biológicos a que os trabalhadores estão, ou poderão estar, expostos, o empregador deve fornecê-las gratuitamente em consonância com a NR-32. Assim sendo, ressalta-se a necessidade do comprometimento por parte das instituições em serem co-responsáveis ao mesmo tempo em que incentiva seu trabalhador para assumir o auto- 
cuidado com sua saúde evitando a hesitação vacinal para Influenza e contribuindo na elevação dos indicadores de cobertura vacinal para a proteção individual e coletiva.

\section{Considerações finais}

Face a estratégia adotada e implementada pela necessidade da pandemia em 2020, evidenciou-se que a estrategia de agendamento de vacina contra a Influenza utilizada resultou em um menor número de trabalhadores imunizados, podendo ser decorrente de diversos fatores como: hesitação vacinal; dificuldades tecnológicas para agendamento eletrônico; desconhecimento da vacinação anual; e/ou inexpressiva divulgação institucional da vacinação. Todavia, reconhece-se que a vacinação no setor de atuação dos colaboradores reforçou que a aplicação do imunobiológico alcançou resultados satisfatórios para a proteção individual, coletiva e dos indicadores de cobertura vacinal. Para obter melhores resultados, faz-se necessário ampliar estudos investigativos para conhecer os motivos para hesitação vacinal, bem como as características de gểnero, raça, condições socioeconômicas e função nos setores, de forma a criar novas estratégias coerentes com a realidade dos trabalhadores, ferramentas e/ou campanhas que tenham maior abrangência e, consequentemente, resultado mais satisfatório para a proteção à saúde coletiva.

Descritores: Cobertura Vacinal; Vigilância em Saúde do Trabalhador; Promoção da Saúde; Esquemas de Imunização; Vacinas contra Influenza.

\section{Referências}

1. Araújo TM, Souza FO, Pinho PS. Vacinação e fatores associados entre trabalhadores da saúde. Cad. Saúde Pública [Internet]. 2019 [citado 2021 Jan 25];35(4):e00169618. Doi: 10.1590/0102-311х00169618.

2. World Health Organization (SZ). Influenza (seasonal) [Internet]. 2018. [cited Jan 25]. Available from: http://www.who.int/mediacentre/ factsheets/fs211/en/

3. Center for Disease Control and Prevention (EUA). Influenza Vaccination Information for Health Care Workers [Internet]. 2015 [cited 2021 Jan 25]. Available from: http://www.cdc. gov/flu/healthcareworkers.htm

4. Maltezou HC, Maragos A, Katerelos P, et al. Influenza vaccination acceptance among health-care workers: a nationwide survey. Vaccine [Internet]. 2008 [cited 2021 Jan 25];26(11):14081410. Doi: 10.1016/j.vaccine.2008.01.049.

5. Ministério do Trabalho e Emprego (BR). Portaria $\mathrm{n}^{\mathrm{O}} 485$, de 11 de novembro de 2005 . Aprova a norma regulamentadora $n^{\circ} 3^{2}$ (Segurança e saúde no trabalho em estabelecimentos de saúde) [Internet]. Diário Oficial da República Federativa do Brasil, Brasília (DF); 2005 Nov 11 [citado 2021 Jan 25]. Disponível em: https:// www2o.anvisa.gov.br/segurancadopaciente/ index.php/legislacao/item/portaria-n-485-de-11-de-novembro-de-2005 
RELATO DE EXPERIÊNCIA

\section{IMPACTO E RELEVÂNCIA: INTERFACE NO PROCESSO DE AVALIAÇÃO DOS PROGRAMAS DE PÓS-GRADUAÇÃO}

\author{
Alana Camila Schneider \\ Patrícia Poltronieri \\ Denise Antunes de \\ Azambuja Zocche
}

\section{Introdução}

A pesquisa acadêmica busca gerar impacto através de inovações e produtos ou processos que apresentam variadas escalas de aplicação e repercussão na produção econômica e social. Neste sentido, reconhecendo os Programas de Pós-Graduação (PPG) como entidades que produzem pesquisas com resultados concretos, palpáveis e mensuráveis, faz-se necessário uma avaliação do impacto gerado pelo produto produzido durante a pós-graduação, diferenciada do habitual, como proposto no modelo de avaliação da Coordenação de Aperfeiçoamento de Pessoal de Nível Superior (CAPES $)^{1}$. A avaliação caracteriza-se por ser um sistema bastante denso e centrado na justificativa sustentada dos resultados da pós-graduação, na relevância econômica e social gerada pelo desempenho do programa e registro dos impactos gerados a partir dos produtos e/ou tecnologias desenvolvidos. A CAPES determina e coordena o processo de avaliação da qualidade dos programas de pós-graduação stricto sensu no Brasil, bem como a avalição de impacto e relevância econômica e social. No que tange o impacto, parte-se do pressuposto da avaliação dos efeitos de programas de desenvolvimento sobre o meio ambiente, todavia na produção científica pode-se envolver impactos de outras naturezas ${ }^{2}$. Para isso, o "impacto" caracteriza-se por tudo aquilo que pode trazer consequências e/ou benefícios à uma pessoa ou coletivo, a partir de uma ação desenvolvida. Assim, em um Progra- 
ma de Pós-Graduação, é necessário avaliar se o objetivo proposto foi atingido, sendo possível assim mensurar o impacto alcançado. Como impacto fundamental, há o chamado impacto científico, cujo qual busca gerar soluções futuras para problemas, sejam estes presentes e/ou futuros. Alguns tipos de impacto, como aqueles ocasionadores de renda, são chamados habitualmente de econômicos. Outrora tem-se o impacto social o qual depende de uma ampla gama de fatores, alguns relacionados à forma como o conhecimento científico é produzido, outros perante à forma como ele é disseminado para os atores situados além do sistema de produção de conhecimento, e ainda aqueles relacionados à forma como é recebido, aplicado, explorado e consumido?. Tanto o impacto científico quanto o social podem ser instrumentais, os quais resultam em ferramentas, ou podem ser conceituais, que geram uma transformação na construção de atividades despertando a sua reformulação, além disto poderiam ser caracterizados como amplos na mudança dos moldes científicos ou na mudança de padrões de vida e atenuação de desigualdades na esfera social. ${ }^{1}$ Ainda, podem ser caracterizados como amplos pela modificação de paradigmas que podem ocasionar.1. Para a avaliação de impactos, existem indicadores que são importantes para a análise, sendo eles: causalidade, tipo de impacto, duração prevista, classe do impacto, setor benefíciado, vínculo com o Plano de Desenvolvimento Institucional (PDI), tipo de aplicação, disponibilidade, setor beneficiado e a abrangência territorial. Vale ressaltar que há, tambèm, outros indicadores além dos supracitados. Além disso, os indicadores podem ser caracterizados em relevantes, observáveis: práticos e mensuráveis, compreensíveis: que faz sentido para os avaliadores e partes interessadas, específicos e válidos que fornecem dados precisos, imparciais, consistentes e os verificaveis ${ }^{2}$.Para que um impacto seja avaliado, há a necessidade de validação e auditoria dos dados gerados a partir da construção e utilização do produto desenvolvido, o que confere maior fidedignidade à avaliação, levando em consideração que dados que são passíveis de auditoria tem maior confiabilidade do que aqueles que não são auditados.

\section{Objetivos}

Conhecer e descrever o processo de avaliação de impacto e relevância econômica e social sobre os produtos e processos dos Programas de Pós-graduação, pelas proposições do Grupo de Trabalho CAPES.

\section{Metodologia}

Trata-se de um relato de experiência de uma atividade acadêmica desenvolvida na disciplina de Abordagens Metodológicas II do curso de Mestrado Profissional em Enfermagem na Atenção Primária à Saúde (MPEAPS) da Universidade do Estado de Santa Catarina (UDESC) sobre o aprimoramento do processo e elaboração de instrumentos relacionados a avaliação de produtos gerados na pós-graduações.

\section{Resultados e discussão}

O presente trabalho demonstra que para avaliar o produto desenvolvido, oriundo de uma pesquisa, é necessário avaliar o impacto gerado pelo mesmo por meio de seus resultados. Nesse sentido, embora as pesquisas atuais apresentem resultados importantes e que venham a gerar impactos expressivos na sociedade, há alguns pontos relevantes para serem analisados e considerações ao se caracterizar o impacto e a relevância econômica e social de um determinado produto. É importante ressaltar que para seleção dos indicadores de avaliação de impacto, assim como sua mensuração, é necessário considerar o tipo de produto gerado, bem como seu objetivo e aplicabilidade, para que assim a avaliação seja mais específica e autêntica. A relevẩncia também constitui um elemento fundamental na avalição, devido a sua importância, ou seja, é necessário caracterizar quem vai usufruir de um dado produto proveniente da pós-graduação, e qual a sua percepção da importância da utilização do mesmo e qual a repercussão caso não usufrua. É importante destacar que um produto derivado da pós-graduação para a solução de alguma carência e/ou problema só vai promover impacto quando alterações, mudanças e/ou transformações beneficiem e incorporem valor para a sociedade, e para isso é imprescindível que haja processos de validação e auditoria dos dados gerados, visando avaliar o impacto gerado. A avaliação é fundamentalmente um instrumento de gestão em que se orienta o desenvolvimento de uma iniciativa ou reformulação a partir de uma análise sobre os resultados obtidos em qualquer momento de um programa e finalmente verifica as mudanças ou impactos obtidos com a aplicação dos resultados.

\section{Conclusão}

Em síntese, os programas de pós-graduação não possuem a prática disseminada de 
realização de avaliação de impacto e relevância econômica e social dos seus projetos e produtos, existem muitas as variáveis que podem ser empregadas para prover uma qualificação do impacto, entretanto é de extrema importância e significativa contribuição a avaliação do impacto gerado dentro de uma escala temporal, a partir dos produtos desenvolvidos, pois alguns efeitos dos produtos pode ser perceptivel e continuar trazendo benefícios após muito tempo da aplicabilidade. Outrora para que um produto da pós-graduação gere impacto, este deve ser algo de importância, relevante, validado e auditado, com intuito de promover ou propor solução a um determinado problema anteriormente apresentado ou que possam surgir futuramente, bem como apresentar resultados convincentes e satisfazer a necessidade percebida.

Descritores: Impacto Agregado; Programas de Pós-Graduação em Saúde; Avaliação da Pesquisa em Saúde.

Financiamento: Acordo CAPES/COFEN.

\section{Referências}

1. Capes, Coordenação de Aperfeiçoamento de Pessoal de Nível Superior. GT Impacto e Relevância Econômica e Social. Brasília: Ministério da Educação, 2019. 75 p.

2. Sept, L.; Naylor, S.; Weston, R. Measuring the Impact of Social Programs:A Review of Best Practices.Stanford Global Supply Chain Management Forum. 2011.

3. Walker, R. et al. (2011) Literature Review. Disponível em: http://sisob.lcc.uma.es/repositorio/ deliverables/SISOBD2.1_Literature_Review.pdf 


\section{EVIDÊNCIAS NA APLICAÇÃO DO PROCESSO DE ENFERMAGEM NO CUIDADO A PACIENTES EM TRATAMENTO RADIOTERÁPICO}

\author{
Gabriele Capeletti \\ Maiara Bordignon
}

\section{Introdução}

As doenças crônicas não transmissíveis, incluindo o cầncer, estão entre os desafios atuais ${ }^{1}$ para a sociedade brasileira e ao sistema de saúde, implicando na organização dos serviços de saúde, na oferta de cuidados e nas políticas públicas. Além de integrar o conjunto de condições crônicas que assume destaque na carga de morbidade no Brasil, o câncer está entre as principais causas de mortalidade no país ${ }^{1-2}$. O Instituto Nacional do Câncer (INCA) estima que de 2020 a 2022 haverá 625 mil novos casos de câncer no Brasil, estando entre os tipos mais incidentes o câncer de pele não melanoma, de mama, próstata, cólon e reto, de pulmão e de estômago ${ }^{2}$. Desse modo, a atuação multiprofissional e intersetorial é fundamental para o enfrentamento da doença. Nesse sentido, é válido destacar que, em relação a câncer, o cuidado envolve a atuação de equipes multiprofissionais que estão vinculadas aos serviços de saúde nos diferentes níveis de atenção, tanto na Atenção Primária à Saúde (APS̉), quanto na atenção secundária e terciária. Os enfermeiros fazem parte destas equipes, participando de ações de prevenção às condições crônicas, do cuidado aos pacientes com cẩncer durante o tratamento, na reabilitação e/ou cuidados paliativos, e da gestão dos serviços de saúde. Uma importante ferramenta na atuação do enfermeiro é o Processo de Enfermagem (PE), que organiza o trabalho do enfermeiro e sistematiza o cui- 
dado prestado ao paciente, a fim de garantir melhores resultados na assistência ${ }^{3}$. Autores destacam sobre a importância de embasar o PE em Sistemas de Linguagens Padronizadas (SLP), tendo em vista que são nomenclaturas validadas e aplicadas internacionalmente ${ }^{4}$. Desse modo, o presente estudo tem como foco a busca de evidências com relação à aplicação do PE no cuidado à pacientes em tratamento radioterápico, que está entre as modalidades de tratamento para o câncer.

\section{Objetivo}

Mapear na literatura científica evidências e experiências com relação à utilização do Processo de Enfermagem, conforme Sistemas de Linguagens Padronizadas, no cuidado a pacientes em tratamento radioterápico.

\section{Método}

Estudo de Scoping Review conduzida em cinco etapas conforme recomendações de autores, sendo5: (i) identificação da questão de pesquisa; (ii) identificação de estudos relevantes; (iii) seleção dos estudos; (iv) mapeamento dos dados; e (v) síntese com relato dos resultados. A Scoping Review foi desenvolvida para responder a seguinte questão de pesquisa: Há evidências ou experiências com relação à utilização do Processo de Enfermagem no cuidado a pacientes em tratamento radioterápico considerando os Sistemas de Linguagens Padronizadas? Os estudos foram recuperados mediante acesso a cinco bases de dados: SciELO (Scientific Electronic Library Online), Medline (Medical Literature Analysis and Retrieval System Online; PubMed), LILACS (Literatura Latino-americana e do Caribe em Ciências da Saúde; Biblioteca Virtual em Saúde - BVS), BDENF (Base de dados em Enfermagem) e CINAHL (Cumulative Index to Nursing and Allied Health Literature). Nestas bases foram aplicadas estratégias de busca estruturadas a partir de operadores booleanos (or, and) e os termos: processo de enfermagem, cuidados de enfermagem, diagnóstico de enfermagem, radioterapia, braquiterapia, processos de enfermagem, nursing process, nursing diagnosis, brachytherapy, radiotherapy, nursing care. Os termos foram definidos com base nos vocabulários Descritores em Ciências da Saúde (DeCS)/Medical Subject Headings (MESH) e recorrência em publicações sobre o tema. Dois revisores estiveram envolvidos na seleção dos estudos e condução desta revisão. Os critérios de inclusão foram: artigo de pesquisa, artigo breve, relato de experiência, editorial ou trabalho de conclusão de curso que avaliou, descreveu ou discutiu a utilização do PE na assistência a pacientes em tratamento radioterápico segundo os Sistemas de Linguagem Padronizadas, publicados nos últimos 10 anos, em espanhol, inglês ou português. A revisão incluiu publicações ocorridas desde 2011 até a data de o8 de novembro de 2020, que compreende o momento que a coleta foi realizada nas bases de dados. Os critérios de exclusão foram: não estar disponível na íntegra, impedindo acesso dos pesquisadores ao relatório completo do estudo; ser uma publicação repetida ou com outra estrutura que não as mencionadas no item anterior (ex., revisões de literatura). Após a seleção dos estudos houve a extração de características das publicações e a apresentação final com a síntese dos resultados.

\section{Resultados e Discussão}

Oito estudos foram selecionados, e as publicações são dos últimos oito anos (2013, 2015, 2016, 2018, 2019). Em relação ao periódico de publicação destaca-se a Revista de Enfermagem UFPE online com dois estudos, e com um estudo cada a Revista Brasileira de Enfermagem, Revista Latino-americana de Enfermagem, Revista de Pesquisa: Cuidado é Fundamental Online, Revista Mineira de Enfermagem e Revista Brasileira de Cancerologia. Sete estudos em forma de artigo científico e uma tese de doutorado foi selecionada. Os estudos assumiram sobretudo abordagem quantitativa, com destaque para o desenho transversal, e incluíram análise da assistência com base no PE à pacientes com eventos adversos relacionados ao tratamento (1 estudo); avaliação de fatores relacionados aos diagnósticos de enfermagem (1); análise da ocorrếncia de diagnósticos de enfermagem e seus elementos (2); elaboração de diagnósticos e intervenções de enfermagem para eventos adversos ou complicações do tratamento radioterápico (2); além de estudos de acurácia (1) e de validação (1). Com relação aos SLP, identificou-se nos estudos a taxonomia da NANDA (North American Nursing Diagnosis Association International), NOC (Nursing Outcomes Classification) e NIC (Nursing Interventions Classification). Bem como, a $\mathrm{CIPE}^{\circledR}$ (Classificação Internacional para a Prática de Enfermagem) foi mencionada em três estudos. As publicações evidenciaram a importância do PE - construído a partir de terminologias padronizadas e com acurácia - para a assistência de enfermagem nas diferentes etapas do trata- 
mento, considerando as singularidades dos pacientes. Bem como destacam contribuições do PE para a organização do cuidado e consulta de enfermagem neste cenário que tem cada vez mais demandas devido ao aumento das condições crônicas de saúde, neste caso, o câncer ${ }^{1-2}$.

\section{Conclusão}

Esta revisão demonstra evidências e experiências de aplicação do $\mathrm{PE}$ de acordo com Sistemas de Linguagens Padronizadas na assistência a pacientes em tratamento radioterápico. Oito publicações foram selecionadas para compor a amostra, a maioria sob formato de artigo científico publicado em periódico. Os estudos assumiram objetivos variados, com destaque para análise da ocorrência de diagnósticos de enfermagem e elaboração de diagnósticos e intervenções de enfermagem para eventos adversos ou complicações do tratamento. O sistema NNN (NANDA, NOC, NIC) e a CIPE $^{\circledast}$ foram mencionados. Cabe mencionar que esta revisão, embora congregue várias bases de dados e termos, pode não ter incluído trabalhos que contribuíram com a proposta. Verifica-se a necessidade de novas pesquisas e publicações que compartilhem evidências e experiências exitosas com relação à aplicação do PE segundo SLP na assistência ao paciente que realiza radioterapia em diferentes espaços de atenção à saúde, assim como de pesquisas que demonstrem evidências quanto ao impacto da implantação do PE na assistência a pacientes em radioterapia e nos indicadores dos serviços de saúde.

Descritores: Radioterapia; Braquiterapia; Processo de Enfermagem; Cuidados de Enfermagem; Diagnóstico de Enfermagem.

\section{Referências}

1. Schmidt MI, Duncan BB, Silva GA, Menezes AM, Monteiro CA, Barreto SM et al. Doenças crônicas não transmissíveis no Brasil: carga e desafios atuais. The Lancet. 2011.

2. Brasil. Ministério da Saúde. Instituto Nacional de Câncer José Alencar Gomes da Silva. Estimativa 2020: incidência de câncer no Brasil. Rio de Janeiro: INCA; 2019.

3. Azevedo OA, Guedes ÉS, Araújo SAN, Maia MM, Cruz DALM. Documentation of the nursing process in public health institutions. Rev. esc. enferm. USP. 2019; 53: e03471.

4. Massaroli A, Vendruscolo C, Martini JG, Alvarez AM, Ferraz F, Percisi AR. O processo de enfermagem como melhor prática na interface com a segurança do paciente. In: Bitencourt JVOV, Adamy EK, Argenta C. Processo de enfermagem: história e teoria. Chapecó: Ed. UFFS; 2020.

5. Arksey H, O'Malley L. Scoping studies: towards a methodological framework. International Journal of Social Research Methodology. 2005;8(1):19-32. 
RELATO DE EXPERIÊNCIA

\section{ESTÁGIO CURRICULAR SUPERVISIONADO EM ATENÇÃO HOSPITALAR:} EXPERIÊNCIAS NA PANDEMIA COVID 19

\author{
Denise Antunes de \\ Azambuja Zocche \\ Fabiane Pertille
}

\section{Introdução}

A Enfermagem é uma profissão que vem construindo sua história ao longo do tempo e vive continuamente a necessidade de se (re) inventar, frente às mudanças demandadas naturalmente pelo viver. Com o começo da pandemia pelo Coronavírus (COVID-19), o mundo ficou exposto a situações imprevisíveis de risco principalmente na área da saúde. Entre as mudanças ocorridas, o setor educação sofreu grandes mudanças, exigindo assim estratégias de planejamento e gestão de conflitos frente às práticas de gestão e gerenciamento, entre serviços de saúde instituições de ensino, docentes e acadêmicos'. O processo formativo nos moldes tradicionais de ensino da enfermagem sofreu adaptações diversas desde que se instalou a pandemia pelo COVID 19. Estudantes e professores, no contexto da pandemia, vivenciam desafios no processo de ensino-aprendizagem, especialmente aqueles relacionados à relevância da presença do estudante no serviço de saúde, ao atendimento das necessidades sociais, com ênfase no SUS, à integralidade do cuidado, à avaliação baseada em conhecimentos, habilidades e atitudes e à gestão da qualidade na atenção à saúde e na segurança do pacien$t^{2}$. O estágio curricular supervisionado (ECS) pode ser compreendido como um momento da formação acadêmica permeado por anseios profissionais e aprimoramento das habilidades essenciais da enfermagem. O ECS apresenta-se como uma ferramenta de aproximação entre a 
academia e os serviços, pois pode possibilitar o emprego de conhecimentos, habilidades e atitudes profissionais apreendidos pelo estudante, que neste momento da formação fortalece suas competências inseridas nos processos de trabalho das instituições de saúde ${ }^{3}$.

\section{Objetivo}

Relatar as experiências de docentes de enfermagem durante o estágio curricular supervisionado na atenção hospitalar no cenário da pandemia pelo Coronavírus.

\section{Método}

Relato de experiência desenvolvido por docentes supervisores do curso de graduação em Enfermagem durante o estágio curricular supervisionado (ECS I) em serviços de atenção hospitalar, na região oeste de Santa Catarina. $\mathrm{O}$ estágio foi desenvolvido em dois hospitais de médio porte e compreendeu o período de março a dezembro de 2020 com 21 acadêmicos.

\section{Resultados e Discussão}

A realização das atividades do ECS I demanda do acadêmico a associação de distintas habilidades, atitudes e competências técnicas, e emocionais visando a integração do saber científico aplicáveis na prática profissional nos serviços de saúde. Desafios cotidianos permeiam a assistência e gestão do enfermeiro caracterizando-se como um cenário promissor para o desenvolvimento das habilidades essenciais deste profissional. Valorizado como um momento oportuno para o aprendizado prático do acadêmico, o ECS caracterizou-se em sua linha histórica como um momento profícuo de vivências, aprendizados e aprimoramento de competências profissionais. $\mathrm{O}$ acadêmico percebe-se como um ator inserido em um cenário de dilemas profissionais ao mesmo tempo que mantém seu caráter de aprendiz. Desafios de ordem assistencial, gerencial e até aspectos de autogestão apresentaram-se neste contexto pandêmico como elementos adicionais da vivência hospitalar e impeliram no acadêmico a necessidade de conviver com gestão de crise, instabilidade emocional e readaptações técnicas quase que diárias. Nesse contexto, o ECS I foi reconfigurado por meio de estratégias de ensino-aprendizagem que preservassem a saúde de seus docentes e discentes frente ao contágio expressivo pelo Sars- CoV2, com a suspensão inicial das atividades práticas. Questões de ordem burocrática e de saúde pública influenciaram esta decisão e subsidiaram a mesma por um determinado tempo, promovendo assim a segurança dos seus colaboradores, ao mesmo tempo que adicionava preocupações de ordem emocional. Em momento oportuno e respeitando os boletins epidemiológicos e demais prerrogativas legais, o retorno ao campo prático aconteceu de forma organizada, e com alguns acadêmicos realocados de seus campos originais, pré-pandemia. A satisfação pelo retorno em poder estar vivendo a experiência do ECS I, também esteve acompanhada de inúmeras (re) orientações de ordem técnica e assistencial para o manejo e atendimento de pacientes com foco em medidas de prevenção e proteção individual. Neste retorno às atividades, além das demandas específicas do fazer profissional do enfermeiro, os discentes apresentaram questões relacionadas a saúde mental, e questões socio-econômicas (medo, tristeza, desemprego e doenças na família), demonstrando a necessidade de intervenções pedagógicas por parte dos docentes supervisores a fim de apoiar e (re) direcionar as atividades, por vezes quase que diariamente. Além disso, houve muita preocupação por parte dos acadêmicos em não ter a sua performance comprometida frente ao cenário pandêmico, uma vez que estavam com medo e insegurança ao desenvolver suas atividades. Esse contexto exigiu uma abordagem contínua dos docentes supervisores, que buscaram fortalecer e valorizar determinadas atitudes e competências emocionais como resiliência e empatia e orientar os acadêmicos a atuarem estrategicamente a fim de se adaptarem ao contexto pandêmico, e à situação de crise complexa nunca antes enfrentada pelos profissionais de saúde de todo o mundo. Seguindo os informes epidemiológicos e respeitando as prerrogativas acadêmicas as atividades práticas foram suspensas novamente, o que exigiu uma pronta e complexa (re) organização das atividades previstas no portfólio do EC̉S para que tudo fosse mantido de forma remota. É de consenso acadêmico que as atividades presenciais são essenciais para o aprendizado do acadêmico e que as tecnologias de informação podem aproximar alguns objetivos. Neste sentido, atividades de cunho gerencial, educativo e organização de demandas que podem ser planejadas remotamente foram desenvolvidas e implementadas a turma, que expressou concordância com a realização das mesmas visto que tiveram contato direto com a assistência no período que estavam no campo prático. Todas as atividades remotas foram aprovadas pelo departamento de enfermagem e foram 
elaboradas visando as competências previstas no plano de ensino, sendo validadas com horas de supervisão docente e entrega das atividades, cumprindo assim a exigência da carga horária prevista para a disciplina. As atividades do ECS I são valorizadas pelo quadro docente pela sua singularidade e relevância formativa para o mundo do trabalho. Foi igualmente desafiador para os docentes experienciar o estágio em um ambiente pandêmico devido as questões inerentes de um ambiente de crise, transição de informações, medo da contaminação e gestão emocional dos discentes. As atividades desenvolvidas pelos acadêmicos em campo de prática revelaram os desafios que envolvem a gestão de crises decorrentes da mudança da rotina, alterações no processo de trabalho impostos por novos protocolos e instruções administrativas do setor saúde da gestão pública. No entanto, colaborou na formação da identidade profissional e possibilitou a oportunidade de superação e fortalecimento de habilidades e competências.

\section{Conclusão}

A realização do ECS I em ambiente hospitalar em meio a um cenário pandêmico certamente pode ser definida como um desafio para processos educativos, gerenciais e emocionais. Assegurar o aprendizado vivencial das competências do enfermeiro e estabilizar a ansiedade e demais aspectos emocionais dos acadêmicos e por vezes, dos docentes resultou em uma nova configuração de trabalho. Percebe-se ao final do mesmo, que a combinação de atividades práticas e atividades remotas permitiu o aprendizado do acadêmico, imprimindo a certeza de que a adaptação é necessária e de que o protagonismo do enfermeiro é um diferencial da categoria e do ambiente organizacional.

Descritores: docentes de enfermagem; educação em enfermagem; pandemias.

\section{Referências}

1. Spreeuwenberg P, Kroneman M, Paget J. Reassessing the Global Mortality Burden of the 1918 Influenza Pandemic. Am J Epidemiol [Internet]. 2018 [cited 2020 June 25];187(12):2561-7. Available from: https://doi.org/10.1093/aje/kwy191

2. LIRA, Ana Luisa Brandão de Carvalho et al. Educação em enfermagem: desafios e perspectivas em tempos da pandemia COVID-19. Rev. Bras. Enferm., Brasília, v. 73, supl. 2, e20200683, 2020 . Available from <http:// www.scielo.br/scielo.php?script=sci_arttext\&pi$\mathrm{d}=$ So034-71672020001400407\&lng=en\& $\mathrm{nrm}=\mathrm{i}-$ so $>$. access on 28 Jan. 2021. Epub Oct 26, 2020. https://doi.org/10.1590/0034-7167-2020-0683.

3. ESTEVES, Larissa Sapucaia Ferreira et al. O estágio curricular supervisionado na graduação em enfermagem: revisão integrativa. Rev. Bras. Enferm., Brasília, v. 71, supl. 4, p. 17401750, 2018. Available from <http://www. scielo.br/scielo.php?script=sci_arttext \&pi$\mathrm{d}=$ So034=71672018001001740-\&lng=en\&nrmiso $>$. access on 28 Jan. 2021. https://doi. org/10.1590/0034-7167-2017-0340. 
REVISÃo INTEGRATIVA

\section{ATUAÇÃO DA ENFERMAGEM NA RELAÇÃO ENTRE CÂNCER}

E SEXUALIDADE

\section{Robson Lovison \\ Tania Maria Ascari \\ Sandra Maria Vanini}

\section{Introdução}

O acometimento pelo câncer, em qualquer caso, é sempre complexo e doloroso e, quando o câncer está associado a sexualidade, os eventos estressores relacionados são intensificados. A disfunção sexual, definida como qualquer alteração relacionada a alguma das fases da sexualidade (desejo, excitação e orgasmo) afeta sobremaneira pessoas em tratamento oncológico1. Em torno de 59\% das mulheres e $79 \%$ dos homens em tratamento oncológico relatam diminuição ou ausência de frequência sexual e intimidade, associando aspectos físicos, psíquicos e sociais como causa $^{2}$. São dados que revelam a importância da abordagem acerca das questões que envolvem a sexualidade de pessoas em tratamento oncológico pelos profissionais da saúde ${ }^{1}$, sendo a enfermagem uma das profissões diretamente implicada, dada sua proximidade com os pacientes ${ }^{3}$. Entre os elementos destacados na atuação da enfermagem em relação a sexualidade, está a comunicação que tem sido aparentemente negligenciada nos processos educativos da enfermagem, seja na formação ou na educação permanente $e^{2 ; 3,4}$.

\section{Objetivo}

Discutir o atendimento e funções da enfermagem no contexto da sexualidade relacionada ao câncer. 


\section{Método}

Foi realizada revisão integrativa, com pesquisa nas bases de dados, Scientific Electronic Library Online (SCIELO) e na Biblioteca Virtual de Saúde (BVS), utilizando-se como Descritores em Ciências da Saúde (DECS): "enfermagem" AND "sexualidade", AND "oncologia" OR "câncer" OR "neoplasia", seguindo as seguintes etapas metodológicas: seleção da hipótese, seleção da amostra (estudos), definição das características e análise dos estudos incluídos na revisão, interpretação dos resultados, e síntese do conhecimento. Como critérios de inclusão foram definidos: artigos completos, em português, publicados entre 2016 e 2021 e como critérios de exclusão: artigos que não tratam do atendimento em enfermagem; teses, dissertações e editoriais.

\section{Resultados e Discussão}

Foram pré-selecionados 15 artigos nas duas bases de dados que, após lidos e analisados resultaram em nove publicações que atenderam a todos os critérios de inclusão e exclusão. Os estudos tratam tanto da sexualidade feminina, quanto masculina, sendo a maioria tendo como população alvo as mulheres com câncer de mama ou ginecológico. Não foram encontrados estudos envolvendo população LGBTQIA+. Os estudos enfatizam que é função importante da enfermagem, no atendimento integral, identificar possíveis disfunções sexuais, causas e comprometimentos e em conjunto com a equipe multidisciplinar, dado que o tema é multifatorial, traçar ações efeti$\operatorname{vas}^{1,2,3}$. Tanto os profissionais de saúde, especificamente a enfermagem, quanto os pacientes e mesmo familiares investigados, indicam a comunicação como o fator base para tratar da sexualidade e destacam a dificuldade em realizar esta comunicação $0^{2,3,4}$. Um estudo, investigou os principais fatores que dificultam a comunicação sobre a sexualidade pelos pacientes: desconforto, vergonha e constrangimento; ausência de vínculo com o profissional; consultas em focos de sinais e sintomas, sendo a sexualidade não prioritária; falta de tempo do profissional; incapacidade do profissional de abordar o tema, por falta de conhecimento e/ou experiência; diferença de idade e/ou de gênero entre paciente e profissional e falta de privacidade. Já os profissionais destacam: falta de conhecimento, habilidades e treinamento para discutir e abordar sobre sexualidade; falta de privacidade e tempo; sexualidade não é prioridade nas consultas; diferença de idade, gênero, religião, cultura; desconforto, vergonha; vínculo com o paciente. Ainda são destacados outros fatores menos pontuados, mas também importantes, já que abordados por alguns pacientes e profissionais de enfermagem: falta de serviços especializados; profissionais acreditam que o tema não é importante para o paciente; falta de apoio de colegas e gerentes; profissionais não veem como seu papel abordar o tema; interpretação social que paciente do sexo feminino faz da sexualidade, sendo associada a prazer, concebível apenas a mulheres saudáveis; sobrecarga de trabalho, devido rodízio de setores, burocracia institucional e organização institucional $^{2}$. Um dos estudos ${ }^{3}$ trata do modelo de comunicação PLISSIT que envolve quatro níveis de intervenção - Permissão, Informações Limitadas, Sugestões Específicas e Tratamento Intensivo. Este modelo comunicacional tem como foco as questões sexuais de pacientes com câncer que afeta a sexualidade, como o câncer de mama, especialmente no campo de cuidados de enfermagem na dimensão sexual. Os resultados da pesquisa apontam que modelos de comunicação organizados e adequados, podem ser muito eficazes no manejo e tratamento de disfunções sexuais decorrentes do câncer, pois promovem o atendimento individualizado e bem direcionado, podendo, portanto, ser incorporado à prática de cuidados baseado em evidências3. Estes instrumentos, entretanto, dependem da adequada preparação dos profissionais em enfermagem, tanto em termos comunicacionais como na compreensão da integralidade do sujeito, o que tem sido constantemente questionada e criticada $a^{1 / 3}$. De outra parte se destaca que a atuação da enfermagem na questão da sexualidade em relação ao câncer não se limita aos atendimentos especializados e nem no período específico pós-intervenção cirurgia ou tratamento que reconhecidamente afeta a sexualidade ${ }^{2,5}$. Esta abordagem é importante assim que se defina o diagnóstico e tratamento, através de informações coerentes e reais sobre as possiveis influências na sexualidade, tanto da doença em si, como das intervenções (cirurgia, quimioterapia, radioterapia) e ainda os aspectos emocionais, psíquicos e sociais $^{1,5}$. Momento essencial na questão da sexualidade é no pós-cirúrgico ou durante e após tratamentos quimioterápicos ou de radioterapia, em que o paciente já não está institucionalizado e tem atendimento na Unidades de Saúde. A Atenção Primária ou Atenção Básica são os locais de contato em que há maior proximidade da enfermagem com o paciente e a comunicação deve ser afinada para atender as necessidades individuais do paciente em 
relação a sexualidade, aspecto, entretanto que tem sido pouco trabalhado na formação profissional e tem sido revelada ineficiência ${ }^{5}$. A consulta de enfermagem, a comunicação sem ruídos a informação e educação são elementos bases das funções da enfermagem que carecem de maior atenção quanto o tema é sexualidade relacionada ao câncer no atendimento geral e especificamente na Atenção Básicaร.

\section{Conclusão}

É necessário ampliar a gama de estudos e público-alvo a respeito do trabalho da enfermagem em relação a sexualidade de pessoas afetadas pelo cầncer, promovendo assim, a intensificação da formação e conhecimento a respeito do tema. A comunicação se apresenta como fator primordial, sendo que, independente do instrumento técnico utilizado, como a consulta de enfermagem, ou outras ferramentas específicas, é através do diálogo controlado e ético que a enfermagem pode acessar as questões individuais que influenciam nas percepções e comportamentos sexuais relacionados ao câncer e que afetam diretamente na qualidade de vida do paciente. É importante papel da enfermagem promover a interação ampla com o paciente e ao reconhecer o sistema interpessoal, à enfermagem cabe estabelecer essa relação através da comunicação, seja ela verbal ou não, buscando as melhores estratégias para os objetivos da situação de promoção da saúde em questão. Isso exige o equilíbrio e transparência entre os papéis desempenhados por cada participante da relação que pode envolver além do paciente e o enfermeiro, a família e a equipe de enfermagem. Esse processo enseja, necessariamente, maior atenção dos programas e processos de educação e formação dos profissionais de enfermagem, já que os indicativos apresentados nos estudos revelam a pouca capacitação destes profissionais acerca do tema e as possibilidades de intervenção.

Descritores: Câncer, Sexualidade, Enfermagem, Comunicação.

\section{Referências}

1. Martins JOA, Holanda JBL, Santos AAP, Lima LKP, Trindade RFC. Sexualidade de mulheres submetidas à mastectomia: identificação das fases afetadas no ciclo da resposta sexual. Rev Fun Care Online. 2020 jan/dez; 12:67-72.

2. Vassão FV, Barbosa LR, Moraes GM, Domenico EBL. Abordagem da sexualidade no cuidado ao paciente oncológico: barreiras e estratégias. Acta paul. enferm. [Internet]. 2018; 31(5): 564-571.

3. Almeida NG, Britto DF, Figueiredo JV, Moreira TMM, Carvalho REFL, Fialho AVM. Modelo PLISSIT: aconselhamento sexual para sobreviventes de câncer de mama. Rev. Bras. Enferm. [Internet]. Agosto de 2019, 72 (4):1109-1113.

4. Varela AIS, da Rosa LM, Sebold N, laverde AG, Maçaneiro A, Erdmann AL. Comprometimento da sexualidade de mulheres com câncer de mama. 2017; 8 (67-71).

5. Dalla Barba P, Bittencourt VLL, Kolankiewicz ACB, Loro MM. Demandas De Cuidados De Pacientes Oncológicos Estomizados Assistidos Na Atenção Primária. Rev enferm UFPE on line., Recife, ago., 2017, 11(8):3122-9. 
Pesquisa Original

ELABORAÇÃO DE UMA TECNOLOGIA

EDUCACIONAL PELA ENFERMAGEM:

SERIOUS GAME SOBRE CIRURGIA SEGURA

Camila Zanesco

Ana Paula Magalhães de Abreu de Giacomo

Jossandro Rodrigues da Cruz

Luciana Schleder Gonçalves

\section{Introdução}

A segurança do paciente é um dos seis atributos da qualidade do cuidado que maximiza os benefícios da assistência em saúde e minimiza os riscos aos pacientes. Consiste na redução a um mínimo aceitável do risco de danos desnecessários, vinculados aos cuidados prestados nos serviços de saúde ${ }^{(1)}$. Atualmente, os incidentes associados ao cuidado de saúde, em particular os Eventos Adversos (EAs), que resultam em danos ao paciente, representam elevada morbidade e mortalidade nos sistemas de saúde. A Organização Mundial de Saúde (OMS), mostrando preocupação com a situação, criou, em 2004, a World Alliance for Patient Safety (Aliança mundial para a segurança do paciente), que tem como objetivos organizar os conceitos e as definições sobre segurança do paciente e propor medidas para reduzir os riscos e diminuir os $\mathrm{EAs}^{(2)}$. Considerando os espaços intra-hospitalares, o centro cirúrgico, constitui um ambiente hospitalar altamente propenso para a ocorrência de eventos adversos, em decorrência da complexidade dos procedimentos realizados, concentração de diversos profissionais e pressão constante para o trabalho. Nesse sentido, proporcionar uma assistência segura livre de danos é uma necessidade atual, que implica diretamente na qualidade do cuidado, além de, promover benefícios para os pacientes, profissionais e demais envolvidos. Para tanto, a utilização de tecnologias visando à redução dos agravos, custos, morbimortali- 
dade evitáveis provenientes das complicações cirúrgicas é o que fundamenta a institucionalização de estratégias relacionadas à educação permanente dos profissionais, para a qualificação do cuidado prestado à sociedade.

\section{Objetivo}

Planejar e desenvolver um serious game como recurso adicional para capacitação de profissionais de enfermagem de nível médio, voltado ao cuidado seguro do paciente cirúrgico, abrangendo a Meta 4 (Cirurgia Segura) da Aliança mundial para a segurança do paciente da OMS.

\section{Método}

Trata-se de uma pesquisa metodológica, aplicada, para desenvolvimento de jogo nomeado como: Nurses for Safety, que tem como tema a segurança do paciente cirúrgico, e abrange a meta quatro (cirurgia segura) da OMS para educação permanente de profissionais de enfermagem de nível médio. A pesquisa foi dividida em três etapas: concepção e planejamento; desenvolvimento do conteúdo e design instrucional; criação do material educacional ${ }^{(3)}$. A primeira fase, condiz com a concepção e planejamento: É a varredura, escolha da temática, definição dos objetivos educacionais do serious game e previsão dos recursos requeridos considerando o público-alvo ${ }^{(3)}$; A segunda fase, contempla o desenvolvimento do conteúdo e design instrucional: Neste momento, são realizados os levantamentos bibliográficos, e consequentemente a definição do referencial teórico, assim como, a seleção das mídias adequadas à temática e aos objetivos educacionais. Adicionalmente, ficam acondicionados nesta etapa, a escolha das formas de mensuração do aprendizado pelo público-alvo e as estratégias de motivação ${ }^{(3)}$; Por fim, a fase três consiste na criação do material educacional: Comporta a confecção do material instrucional, a elaboração da problemática e a criação das mídias e dos procedimentos didáticos ${ }^{(3)}$.

\section{Resultados e Discussão}

Cada etapa de produção de uma tecnologia educacional demanda esforço e agrega conhecimento para os envolvidos. A fase de concepção e planejamento de um jogo educativo, além de definir a temática, possibilita clareza sobre as delimitações do conteúdo, o que requer planejamento pedagógico, ou seja, a criação de um plano de jogo baseado nos objetivos educacionais e roteiro dos casos, baseados em evidências científicas. Neste estudo, o Manual da OMS - Cirurgias Seguras Salvam Vidas, foi o aporte teórico para a proposta, respeitando a recomendação do MS de que os protocolos a serem considerados nos programas de segurança do paciente considerem as distintas realidades ${ }^{2}$. Os protocolos clínicos são constantemente empregados na rotina dos serviços de saúde, com intuito de fomentar e disseminar informações que possam respaldar práticas baseadas em evidências científicas para problemas de saúde específi$\cos ^{(4)}$. Entretanto, dentre os principais desafios para o correto emprego dos protocolos na esfera profissional, encontram-se o desconhecimento sobre a importância e a carência na padronização dos processos ${ }^{(4)}$. Desse modo, é possível reconhecer a importância da educação permanente como estratégia para instruir a atuação prática dos profissionais de saúde. Por sua vez, para que os jogos educativos possam contribuir de forma significativa na educação permanente desses profissionais, alguns principios fundamentais devem ser seguidos durante a construção do produto: a liberdade para experienciar e fracassar, a possibilidade de seleção de novas identidades, e liberdade de interpretação e esforço ${ }^{(4)}$. A principal diferença entre um jogo educativo e um jogo para entretenimento é o enfoque nos objetivos pedagógicos, o que justifica uma maior atenção para a fase de planejamento. Deve ser dada ênfase à elaboração das perguntas que serão direcionadas ao jogador, sua relação direta com o conteúdo instrucional significativo, inserção desse conteúdo incorporando os objetivos educacionais nos diálogos entre os personagens que levarão o jogador a tomar decisões, atentar na elaboração de feedbacks concisos e de impacto e, consequentemente, propiciar o aprendizado ${ }^{(4)}$. A fase de desenvolvimento do conteúdo e design instrucional contemplou o levantamento bibliográfico nas bases de dados, a criação do conteúdo e design instrucional do serious game. Após definir o escopo do jogo (objetivos educacionais), foram elaborados os roteiros de três casos fictícios, porém fiéis à realidade do trabalho da enfermagem em um centro cirúrgico, e de acordo com o roteiro das demais fases do jogo educativo, e também foram criados novos personagens, figuras, imagens e cenários. No processo de desenvolvimento desta fase do jogo educativo, foi priorizada a apresentação do conteúdo do protocolo de maneira formal, por meio de uma linguagem dialógica usualmente utilizada pelo profissional ao desempenhar suas funções em seu espaço laboral, com 
foco no estilo da informação, sendo componente de preocupação a abordagem que seria utilizada com o público-alvo para que não fosse uma barreira para a aprendizagem. $\mathrm{Na}$ fase de criação do material educacional foi realizado um resumo dos elementos que compõem o módulo de Cirurgia Segura ${ }^{(2)}$. Ademais, destaca-se a preocupação em estabelecer os objetivos educacionais para serem incorporados ao roteiro do jogo, com foco nas atribuições dos técnicos e auxiliares de enfermagem como condutores da lista de verificação de segurança cirúrgica. A informação apresentada em um jogo educativo precisa ser qualificada e facilitar o acesso de quem joga, descomplicando a compreensão e respeitando o tempo de aprendizagem. Uma das principais características que deve ser contemplada em um design de jogo educativo é um sistema para avaliar a participação do jogador de acordo com os objetivos de aprendizagem. Acredita-se que os jogo educativo promovem uma autoavaliação, e consequentemente uma mudança de comportamento ao permitir ao jogador refletir sobre sua realidade profissional quando alinhada aos conceitos abordados no jogo. Toda a construção do jogo educativo priorizou aspectos relacionados a aparência das telas e a estruturação do conteúdo dentro de uma lógica que permitisse ligação com a prática profissional, valendo-se de ilustrações coerentes com a realidade. Ademais, para promover uma experiência agradável e aquisição de conhecimentos por parte dos jogadores, é necessário que se tenha ênfase no indivíduo e não na tecnologia, para tanto é necessário proporcionar conforto visual das ilustrações com a padronização de cores e descrição das imagens ${ }^{(5)}$. A inserção de um feedback com informações concisas e que levem ao aprendizado, demanda especial atenção para que os jogos educativos se tornem tão envolventes quanto os games de puro entretenimento ${ }^{(4)}$. É necessário um conjunto entre as partes, sendo assim, uma boa narrativa, que atraia o jogador, aumenta o seu envolvimento e favorece a retenção da informação em relação aos conteúdos pedagógicos ${ }^{(4)}$.

\section{Conclusão}

O planejamento, desenvolvimento e execução de uma tecnologia educacional é um processo de desafiador, e simultaneamente estimulante, visto que, objetiva proporcionar estratégias inovadoras que promovam a capacitação profissional refletindo diretamente na melhoria do processo de cuidado. Desse modo, espera-se que a disseminação da ferramenta elaborada possa impactar positivamente em distintas realidades e estimular a confecção de inúmeras outras, contribuindo, desse modo, para a qualidade das ações desempenhadas pela enfermagem nos diversos campos de atuação.

Descritores: Segurança do paciente, Educação em saúde, Informática em enfermagem, Tecnologia educacional, Educação continuada.

\section{Referências}

1. Brasil. Ministério da Saúde. Fundação Oswaldo Cruz. Agência Nacional de Vigilância Sanitária. Documento de referência para o Programa Nacional de Segurança do Paciente. Brasília/DF: Ministério da Saúde, 2014 [citado em 20 jan 2021]. Disponível em: http://bvsms. saude.gov.br/bvs/publicacoes/documento_referencia_programa_nacional_seguranca.pdf. Acesso em: 08 jun. 2017.

2. Organização Mundial da Saúde. Segundo desafio global para a segurança do paciente: Cirurgias seguras salvam vidas. Tradução de: Sanchez MN, Durán IA. Rio de Janeiro: Organização Pan-Americana da Saúde; Ministério da Saúde; Agência Nacional de Vigilância Sanitária, 2009 [citado em 20 jan 2021]. Disponível: http://bvsms.saude.gov.br/bvs/publicacoes/seguranca_paciente_cirurgia_salva_manual.pdf. Título original: The second global patient safety challenge: safe surgery saves lives.

3. Prado C, Vaz DR, Almeida DMde. Teoria da Aprendizagem Significativa: elaboração e validação de aula virtual na plataforma Moodle. Rev Bras Enferm [Internet]. 2011 [citado em 20 jan 2021]; 54 (6): 1114-21. Disponível em: http:// www.scielo.br/pdf/reben/v64n6/v64n6a19.pdf

4. Teixeira DJ, Cruz DM, Gonçalves BS. Uma proposta de roteiro para game educativo com base no design de narrativa digital interativa. Revista Metamorfose [Internet]. 2017 [citado em 20 jan 2021]; 2 (1): 252-275. Disponível em: https://portalseer.ufba.br/index.php/metamorfose/article/download/20883/14788

5. Silva VLdosS, Camelo SHH, Soares MI, Resck ZMR, Chaves LDP, Santos FC dos, et al. Práticas de liderança em enfermagem hospitalar: uma self de enfermeiros gestores. Rev. esc. enferm. USP [Internet]. 2017 [citado em 20 jan 2021]; 51: e03206. Available from: http://www. scielo.br/scielo.php?script=sci_arttext\&pi$\mathrm{d}=$ So080-62342017000100407\&lng=en 
RELATO DE EXPERIÊNCIA

RELATO DE EXPERIÊNCIA: RODA DE CONVERSA EM UMA UNIDADE PRISIONAL DURANTE A CAMPANHA NOVEMBRO AZUL

\author{
Patrícia Porto Almeida \\ Laís Mara Caetano da Silva \\ Luiza Silveira de Oliveira \\ Maria Denise Schimith \\ Marcia Gabriela \\ Rodrigues de Lima \\ Julia Zancan Bresolin
}

\section{Introdução}

A proposta deste trabalho é relatar a experiência de uma Roda de conversa sobre a saúde do homem, referente ao mês da Campanha Novembro Azul, realizada no dia 27 de novembro de 2020, com a população masculina do Presídio Regional de Santa Maria (PRSM). Vinculado ao Projeto de Extensão "Ações de sensibilização sobre doenças transmissiveis em Santa Maria/RS por meio da educação popular em saúde" da Universidade Federal de Santa Maria em parceria com a Política Municipal de HIV/Aids, ISTs e Hepatites Virais e Serviço de Atenção Especializada (SAE) / Centro de Testagem e Aconselhamento (CTA) Casa Treze de Maio. A Campanha Novembro Azul é uma inciativa que ocorre no mês de novembro, a proposta é que a população fique atento durante o ano todo, a campanha tem como objetivo reduzir a falta de adesão dos homens diante do Câncer de Próstata e outras doenças, faz-se necessário a realização da consulta médica periodicamente e prestar atenção aos principais sinais e sintomas. ${ }^{1}$ O PRSM fica localizado na cidade de Santa Maria região central do Rio Grande do Sul, a unidade prisional tem celas disponíveis para 172 pessoas privadas de liberdade (PPL) do sexo masculino e 100 para o sexo feminino. Atualmente conta com 151 presos do sexo masculino e 63 do sexo feminino. ${ }^{2}$ A Política Nacional de Atenção Integral à Saúde das Pessoas Privadas de Liberdade no Sistema Prisional (PNAISP) instituída pela 
Portaria Interministerial $\mathrm{n}^{\mathrm{o}} 1$, de 2 de janeiro de 2014 é uma política integrada ao Sistema Único de Saúde (SUS) em que defende os direitos à saúde das PPL. A PNAISP aparece com o objetivo de reduzir danos e agravos no ambiente carcerário. As situações das unidades prisionais brasileiras são precàrias desde da falta de estrutura, falta de fiscalização, assistência médica contínua, assistência jurídica precária, além da superlotação e a falta de informação que são fatores determinantes para a transmissão e o agravamento dos quadros clínicos dos detentos. Dessa forma, a educação em saúde e os testes rápidos contribuem com a prevenção das doenças transmissíveis no ambiente carcerário. ${ }^{3} \mathrm{~A}$ roda de conversa se caracteriza como uma dinâmica democrática e participativa, voltada para a ação de conversar, de ouvir, e praticar ações educativas no momento. Dessa forma estimula a autonomia do participante, tornando-o sujeito da ação. A roda de conversa tem como objetivo contribuir na construção do conhecimento dos envolvidos, para trocas de experiências em relatos e diálogos, estimula a formar opiniões, desenvolver temas/assuntos que sejam reflexivos e que faça sentido na vida dos participantes, segue os principais princípios do SUS a equidade, a descentralização, a integralidade, a universalidade e a participação popular. ${ }^{4}$ Quando se trabalha com pessoas na saude a estratégia de educação em saúde torna-se indispensável, desde da troca de aprendizagem até as orientações necessárias, Frente a atuação da Enfermagem, no Sistema Penitenciário, o (a) enfermeiro (a) tem como função atuar no processo de educação em saúde, mediante as suas atribuições concomitantes as disposições legais que regulamentam o exercício de cada profissão, referente às IST, destaca-se: "realizar consulta de porta de entrada utilizando um instrumento nos dez primeiros dias de aprisionamento oferecendo os exames de testagem rápida de HIV, Sífilis, Hepatite B e C, baciloscopia e exame de raio x para sintomáticos de tuberculose". A Educação em saúde ainda é a ferramenta mais importante em ações preventivas na Atenção Básica, a importẩncia de acolher o indivíduo para realizar essa interação e fazê-lo compreender sobre os riscos das infecções e das realizações do teste rápido, contribui para a identificação de casos suspeitos, para o diagnóstico precoce e encaminhamentos para tratamento imediato. ${ }^{5}$

\section{Método}

Trata-se de um estudo do tipo relato de experiência. A ação contou com uma equipe de duas assistentes sociais, uma enfermeira, uma psicóloga residente e duas acadêmicas de enfermagem para conduzir a conversa. Foi uma parceria da Assistentes sociais do PRSM e a Política Municipal de HIV/Aids, IST e Hepatites Virais. Os detentos foram convidados a participar de forma voluntária pelas assistentes sociais. Os temas abordados foram Câncer de Próstata, Hipertensão, Diabetes e IST. A roda de conversa foi realizada apenas com a população masculina, com a presença de 20 participantes separados em dois grupos de 10 PPL, no auditório do próprio presídio.

\section{Resultados e Discussão}

O primeiro grupo mostrou-se participativo, as principais dúvidas foram em relação a diferença do HIV e Aids, a cauterização da sifilis e HPV e sobre estratégias de adesão ao paciente com Câncer de Próstata, após o relato de um dos participantes sobre um familiar que não aceitou o diagnóstico. O segundo grupo interagiu menos que o primeiro, surgiram questionamentos relacionados a Hipertensão e a circulação sanguínea. Foi explicado também sobre a Profilaxia Pré-Exposição (PREP) e a Profilaxia-Pós Exposição (PEP), pois ainda acreditavam no uso dos "coquetéis" para tratamento do HIV. Apenas um participante tinha conhecimento sobre a sífilis, mostrando saber sobre os sinais e sintomas iniciais. Para ambos os grupos a IST que mais se destacou foi a Hepatite C, através de relatos e dúvidas. Observou-se que os compartilhamentos de materiais pessoais ocorriam com muita frequência, como: cortador e tesoura de unha, a equipe de saúde enfatizou a importância de não compartilhar os materiais de uso pessoal para prevenir os riscos de contrair a infecção. Além disso, surgiram dúvidas em relação a esterilização dos instrumentos compartilhados, alguns, estavam fazendo uso do álcool e água quente, o que não é recomendado, já que o vírus é multirresistente, poucos tinham conhecimento sobre as formas de transmissão da Hepatite C. O momento oportunizou que as PPL pudessem sanar as suas dúvidas sobre as formas de transmissão, os principais sinais e sintomas, a prevenção, os agravos e os tratamentos das infecções. Foi divulgado os locais que poderiam realizar os testes rápidos, e os serviços que são ofertados quando os mesmos respondessem em liberdade, sendo em Unidades Básicas de Saúde ou no SAE/CTA Casa Treze de Maio. No encerramento de cada grupo foram informados da realização dos testes rápidos para HIV, Hepatite $\mathrm{B}$, Hepatite C e 
Sífilis após as duas rodas de conversa, dos 20 participantes, oito foram testados e nenhum teste apresentou resultado reagente. Conclusão: A roda de conversa reforça a importância de uma educação em saúde com foco na prevenção de doenças nas unidades prisionais, as dúvidas e os relatos apresentaram como um desafio na busca de estratégias em proporcionar acesso à informação aos detentos, de forma clara e interativa, levando em consideração as suas reais necessidades de saúde.

Descritores: Doenças sexualmente transmissíveis, prisões, educação em saúde.

\section{Financiamento}

Resumo financiado pelo Fundo de Incentivo de Extensão (FIEX - Pró-Reitoria de Extensão) - Universidade Federal de Santa Maria.

\section{Referências}

1. Modesto AADA, Lima RLB, D'Angelis AC, Augusto DK. Um novembro não tão azul: debatendo rastreamento de câncer de próstata $e$ saúde do homem. Interfaces. 2017, $22(65: 251-62)$.

2. Conselho Nacional de Justiça. Dados das Inspeções nos Estabelecimentos Penais. [Internet] 2019. Acesso em 2021 jan. 25. Disponível em: https://www.cnj.jus.br/inspecao_penal/mapa.php.

3. Melgaço AM, Torres RH. Política Nacional de Atenção Integral à Saúde das Pessoas Privadas de Liberdade no Sistema Prisional (PNAISP): uma análise do seu processo de implementação no contexto atual do sistema prisional paranaense. Rev. Leg. Pr. 2020, (4): 133-150

4. Dias ESM, Rodrigues ILA, Miranda HR; Correa, A. Roda de conversa como estratégia de educação em saúde para a enfermagem. Res. Fundamen. Care online. 2018; 10(2): 379-384.

5. Terra AAA, Silva GA. Representando as ações preventivas das IST/Aids realizadas por enfermeiros na atenção básica. Enfermagem Brasil. 2017, 16(5):276-83. 
Pesquisa Original

DESENVOLVIMENTO DE DISPOSITIVO DE COMUNICAÇÃO AUMENTATIVA, PRODUZIDO A BAIXO CUSTO, PARA PACIENTES COM DISFUNÇÕES MOTORAS

\author{
Sidclei Benevides \\ da Conceição \\ Fábio César Bonfim de Moraes \\ Camila Rocha da Silva \\ Edson Palhares Leite
}

\title{
Introdução
}

A tecnologia assistiva em Comunicação Aumentativa Alternativa (CAA) é voltada para solucionar ou ampliar qualquer perda de habilidade comunicativa, a fim de proporcionar uma interação eficaz, promover a participação social e a melhora da qualidade de vida. Casos de pacientes hospitalizados mostram que até $38 \%$ das crianças em tratamento hospitalar apresentaram al̆guma dificuldade neste sentido, e que, $61 \%$ destes pacientes referiram dores durante a hospitalização. ${ }^{1}$ A literatura científica sugere que manter o cuidado direcionado, por equipe multidisciplinar, em cada indivíduo com necessidades de comunicação complexas, fazendo corresponder o seu perfil cognitivo-sensorial-motor poderá aumentar a aceitação e a qualidade de vida. São necessários sistemas de CAA para complementar a fala ou, em casos mais graves, para substituí-la completamente. A criação de dispositivos que proporcionem a implementação destes sistemas, torna-se um atrativo no sentido da humanização dos pacientes, e ainda, podendo ser um potencial produto no que diz respeito a sua inserção no mercado comercial, visto que não existe nenhum similar produzido e fornecido a baixo custo. Outro ponto importante a ser tocado no que se refere a ampliação da capacidade de comunicação é o desenvolvimento cognitivo do paciente. A possibilidade de comunicação, pode ser a porta de entrada para um processo complexo de desospitalização do paciente, 
ação de integração social e humanização que pode impactar significativamente na redução do custo com internações. ${ }^{2}$ E ainda, a ausência de comunicação pode induzir ao maior risco de erro médico e piores resultados devido à falta de um método sistemático para avaliação e monitoramento contínuo da equipe dentro do internamento. Este estudo aborda a construção do desenvolvimento, melhoria e sofisticaçã̃o de um método de CAA, no qual ocorre o diagnóstico de um problema, aqui descrito como interrupção da fala compreensível para comunicação efetiva em pacientes conscientes que não podem usar membros para apontar objetos. Neste sentido, o desenvolvimento deste projeto, realiza uma explanação sobre estratégias para manutenção de comunicação básica dos afetados, com a descrição e desenvolvimento de uma ferramenta tecnológica para viabilidade do acesso à comunicação aumentativa e alternativa em pacientes com cognição preservada, acometidos pela problemática do distúrbio da comunicação humana, e que precisam desfrutar do direito constitucional de se expressar e fazer escolhas sobre sua vida, diante de sua cognição que se mantém intacta.

\section{Objetivo}

Desenvolver dispositivo portátil de comunicação alternativa para pacientes com capacidade cognitiva reduzida, supressão de fala e perda de movimentos de membros, por meio de hardware com tecnologia do tipo Arduino e, desenvolver associado a este, software em código aberto, para solução da problemática da ausência de comunicação, com produção a baixo custo e posteriormente disponibilizar no setor público, com potencial para exportação.

\section{Método}

Em termos gerais, foram desenvolvidos hardware e software para aprimorar um equipamento já existente. O funcionamento do dispositivo atual é puramente mecânico, sem integração de software associado. O que se tem atualmente são óculos sem lentes, confeccionados em impressora $3 \mathrm{D}$, com adaptação em haste para acoplar um pequeno "laser" tipo caneta. O Laser emite um o sinal luminoso ao menor movimento de cabeça do paciente, este, por sua vez, transmite uma mensagem por meio da escolha de símbolos de comunicação com a representação de verbos, objetos, adjetivos, letras do alfabeto, símbolo e números. Por meio deste dispositivo mecânico buscou-se desenvolvimento e integração de software e hardware através tecnologia embarcada com câmera de vídeo integrada a fim de potencializar o entendimento dos movimentos realizados por cada paciente, bem como os principais comandos de Só coloca por extenso a primeira vez, depois cita apenas CAA comunicação desejados. A metodologia se baseia neste primeiro momento em um processo de prototipagem e desenvolvimento de produto, sendo testado a priori em seus desenvolvedores sob orientações de uma equipe multiprofissional composta por enfermeiros, fisioterapeutas e engenheiros. Utilizou-se uma EspCam e equipamento similar como meio de captação de imagem e processamento, e por meio de um sistema de HUB para realizar o controle de tráfego de informações. A linguagem de programação utilizada mesclou conceitos de Pyton e $\mathrm{C}_{++}$, utilizando de bibliotecas conhecidas de código aberto, como exemplo da OpenCV, a qual é responsável pelo reconhecimento de retina e processamento de imagem. O custo total empregado para produzir um dispositivo foi de $R$ \$ 199,oo, valor este, significativamente menor do que os produtos similares disponíveis no mercado, que se baseiam na leitura da retina do paciente para transformar este sinal físico em sinais eletrônicos que precisam ser obrigatoriamente interpretados por softwares específicos pagos.

\section{Resultados e Discussão}

O protótipo inicial foi desenvolvido e configurado inicialmente parar fazer o reconhecimento facial do indivíduo cadastrado como paciente, e posteriormente emitir sinais luminosos em dois LEDs a partir do movimento de abertura e fechamento das pálpebras do mesmo. O dispositivo desenvolvido utilizou uma biblioteca de código aberto, se mostrando um grande diferencial no que se refere as possibilidades de variedade nas adaptações e funcionalidades de configuração do produto. A programação em código aberto além de não incrementar custos ao projeto, possibilitou algumas diferentes maneires de funcionamento para o dispositivo. O produto, por se classificar como um dispositivo de uso hospitalar, contou em seu processo de montagem e escolha de componentes com rígidos critérios de segurança elétrica. Assim, foi exigido que o seu nível de qualidade fosse o mais alto possível, devendo atender também à normas específicas como a ISO13485, que se aplica a sistemas de gestão da qualidade para dispositivos médicos. Nesta etapa do desen- 
volvimento não se chegou a um design final para o protótipo, mas por se tratar de um equipamento novo, e estranho ao ver do paciente, acabou se mostrando minimamente invasivo, diminuindo assim as chances de riscos ou eventos adversos graves aos participantes.

\section{Conclusão}

Por fim, conclui-se que o dispositivo desenvolvido apresentou a proposição de uma estratégia eficaz para viabilizar a 'comunicação alternativa aumentativa a baixo custo e de fácil aplicabilidade, na tentativa de amenizar os danos causados pela ausência de comunicação verbal e básica entre pacientes que apresentem supressão da fala ou mesmo a fala ininteligível e não tenham controle sobre os movimentos. As próximas ações devem concentrar esforços no que se refere a ampliação das funções de comunicação, acabamento e design, para então, se buscar o parecer consubstanciado do comitê de ética iniciar o estudo da apresentação do dispositivo aos pacientes.

Descritores: Palavras-chave: Comunicação Alternativa Aumentativa; Inteligência Artificial; Transtornos de Comunicação.

\section{Referências}

1. Moraes, M. K. R. de, Santos, V. R. dos, Fávero, F. M., Oliveira, A. S. B., Rosseto, L. P., Tacon, K. C. B., Fernandes, V. L. S., \& Parreira, S. L. S. (2020). Utilization of alternative and augmentative communication resources by patients with amyotrophic lateral sclerosis. Manual Therapy, Posturology \& Rehabilitation Journal, 1-12. https://doi. org/10.17784/mtprehabjournal.2019.17.723.

2. Gonzales CH, Leroy G, Leo GD (2012): Augmentative and Alternative Communication Technologies. In: COULTER, C. Computer Engineering: concepts, methodologies, tools and applications.

3. Carniel, A., Berkenbrock, C. e Hounsell, M. 2017. Um mapeamento sistemático sobre o uso da comunicação aumentativa alternativa apoiada por recursos tecnológicos. Revista Brasileira de Computação Aplicada. 9, 2 (jul. 2017), 84-98. Doi: https://doi.org/10.5335/rbca.vgi2.6500 
TEORIA DE NOLA PENDER, USO NO TRABALHO EM HOME OFFICE, DURANTE A PANDEMIA DE COVID-19

\section{Izaiane Paes Ribeiro de Sousa Francisco Antônio Borges de Oliveira Júnior}

Isaura Danielli Borges de Sousa

Márcia Teles de Oliveira Gouveia

\section{Introdução}

No cenário atual, em meio a uma pandemia, em decorrência da alta capacidade de transmissão do coronavírus, o mundo teve que se adaptar rapidamente às novas regras de isolamento social, sendo essa a forma mais indicada pelas autoridades ligadas à saúde, para conter a disseminação desse vírus. ${ }^{1}$. MiIhões de trabalhadores tiveram suas atividades laborais impactadas e precisaram ajustar a forma de trabalhar. Nota-se que é crescente o exercício das atividades laborais de forma remota, em home office. Segundo o Instituto Brasileiro de Geografia e Estatística (IBGE), em maio de 2020, o Brasil possuía 8.7 milhões de trabalhadores desenvolvendo suas atividades em modalidade remota. A Teoria da Promoção da Saúde de Nola J. Pender, permite compreender os comportamentos humanos relacionados com a saúde. O modelo pretende integrar a enfermagem à ciência do comportamento, identificando os fatores que influenciam comportamentos saudáveis, além de ser um guia para explorar o complexo processo biopsicossocial que motiva indivíduos para engajarem em comportamentos produtores de saude $^{2}$. No Brasil, não encontramos referencias teóricas quanto ao uso do Modelo de Promoção da Saúde de Nola J. Pender. Sabe-se que estudos assim favorecem a melhoria da qualidade do cuidado, o que contribui claramente para a promoção da saúde, logo, esse trabalho busca mostrar a relevância da temática. 


\section{Objetivo}

Tendo em vista a disseminada adoção do home office para a continuidade das atividades laborais, este trabalho busca averiguar a realidade dessa modalidade laboral no cenário pandêmico mediante percepção de trabalhadores neste contexto. Pretende-se também verificar a possibilidade de sugerir o uso da teoria de Nola Pender no trabalho em home office.

\section{Método}

Foi realizada uma busca na literatura de artigos que investigaram os impactos do trabalho em home office na saúde dos trabalhadores e seu cotidiano. Foram selecionados quatro artigos publicados entre 2015 e 2020 em língua portuguesa.

\section{Resultados e Discussão}

Foi possivel observar entre os trabalhadores que antes se deslocavam para o trabalho e passaram a trabalhar em home office vêm aumentando sua familiaridade com tecnologias de comunicação e seu nível de autonomia, acima das demais modalidades de trabalho. Houve o impacto da rápida transição do trabalho presencial para o remoto entre os profissionais de diversos setores e segmentos da economia, com variadas funções. A principal vantagem desse sistema de trabalho é a flexibilidade de horários e, a desvantagem mais recorrente é a falta de socialização. Entre os problemas encontrados, cita-se os profissionais e pessoais, como implicações para a saúde e para a vida familiar dos trabalhadores, além de terem sido expostos contrapontos positivos para os mesmos âmbitos. Os resultados quanto as condições de trabalho chamaram atenção, em especial quanto ao aumento de horas diárias trabalhadas e de dias trabalhados semanalmente, durante a pandemia. Verificou-se um aumento de trabalhadores que executam atividades laborais por mais de oito horas diárias no trabalho remoto, bem como a quantidade de dias trabalhados durante a semana ${ }^{3}$. Identificou-se que os profissionais passaram a não possuir dias livres durante a semana e final de semana, desenvolvendo trabalho remoto em todos os dias, sem nenhum dia de descanso. Em relação ao ritmo de trabalho, ficou mais acelerado no trabalho remoto e a qualidade do trabalho no presencial parece ser melhor ou igual ao trabalho desenvolvido remotamente. As principais dificuldades no trabalho remoto é a falta de contato com os colegas de trabalho, as interrupções e a dificuldade em separar a vida familiar da vida profissional. Tem-se a necessidade da reflexão sobre o aprimoramento do regime de teletrabalho, de forma a conciliar em harmonia a produtividade e a saúde mental dos trabalhadores. Ressalta-se que essa atitude será útil mesmo após o fim do isolamento, uma vez que as práticas remotas vão continuar caracterizando relações de trabalho. Ficou claro que os estudos realizados com pessoas que estão desenvolvendo trabalho em home office demonstram que a atividade laboral está adoecendo o trabalhador, tanto fisicamente, como mentalmente e socialmente. Pode-se elencar como fatores positivos: estar mais próximo dos laços familiares, adequabilidade e flexibilidade de horários, além do aumento da quantidade de possibilidades de horários e dias de trabalho. Como fatores negativos, tem-se: as intercorrências do lar, interrupções familiares, a exaustão pelo trabalho prolongado, inexistência de folgas ao longo da semana, aumento de período na mesma posição, aumento do uso de computadores e outros dispositivos, dificuldade em preparar uma alimentação saudável, entre outros. Levando em consideração o Modelo de Promoção da Saúde de Nola Pender, esses indivíduos se encontram em situação de possibilidade de mudança de comportamento, visto estarem em faixa etária mediana da vida, portanto, entendem a importância de ter um estilo de vida saudável, serem pessoas que se comunicam e, possuírem uma renda para prover o sustento ${ }^{4}$. Com isso, observa-se que um plano de ação que envolva atividades físicas diárias, alimentação saudável, diminuição na jornada diária de trabalho, escolha estratégica de local e horário para desenvolver as atividades laborais e, frequentes meditações para relaxar, podem resultar numa melhora da qualidade de vida desses profissionais.

\section{Conclusão}

Em todos os artigos percebe-se a necessidade de igualar, ou aproximar, o investimento nas esferas pessoal e profissional, facilitando interação entre estas, a fim de diminuir os impactos negativos dos conflitos trabalho-trabalho e trabalho-família. A adaptação ao ambiente de trabalho, além de uma negociação com a família, em termos dos costumes e do espaço para realização da atividade, reforça o imperativo da formulação de rotinas que equilibrem a realidade do trabalho a partir de casa e partam da reali- 
dade do trabalhador 5 . Por estar em processo de inserção e consolidação no cenário brasileiro, o home office encontra entraves, como a falta de apoio, de reconhecimento e de incentivo à adaptação. Diante disso o uso da teoria de Nola Pender para melhora do trabalho em home office se mostra excelente uma vez que proporciona conhecer melhor cada contexto relacionado com a saúde dos trabalhadores de forma simples e eficaz, permitindo a adoção de estratégias de promoção da saúde. Esse modelo fornece ferramentas para a compreensão das questões biopsicossociais associadas à decisão dos indivíduos de adotar um comportamento saudável, devendo, portanto, ser utilizado mundialmente na perspectiva de melhoria da qualidade de vida dos profissionais em home office.

Descritores: Teoria de Enfermagem; Saúde do Trabalhador; Pandemias.

\section{Referências}

1. Losekann RGCB, Mourão HC. Desafios do teletrabalho na pandemia covid-19: Quando o home vira office. Caderno de Administração, 2020; Maringá, v.28, Ed.Esp.

2. Pender N, Murdaugh C, Parsons MA. Health Promotion in Nursing

Practice. New Jersey: Pearson, 2014.

3. Bridi MA, et al. Relatório técnico-científico da pesquisa: o trabalho remoto/home-office no contexto da pandemia Covid-19. Curitiba: UFPR, GETS, 2020; REMIR.

4. Mendes DC, Filho HNH, Tellechea JA. Realidade do trabalho home office na atipicidade pandêmica. Revista Valore, 20zo; Volta Redonda, 5 Ed.Esp.

5. Rafalski JC, De Andrade AL. Home-Office: Aspectos Exploratórios do Trabalho a partir de Casa. Trends in Psychology / Temas em Psicologia, 2015, Vol. 23, nำ 2, 431-441. 
Pesquisa Original

\section{TECNOLOGIA EDUCACIONAL UM CAMINHO PARA EDUCAÇÃO EM SAÚDE NA HEMODINÂMICA}

\section{Rosana Moreira de Sant'Anna Cristina Lavoyer Escudeiro Alessandra Conceição Leite Funchal Camacho \\ Vitória Meireles Felipe de Souza}

Marcos Aurélio Pinto da Silva Harlon França de Menezes

\section{Introdução}

Milhões de pessoas no mundo morrem anualmente em consequências das doenças cardiovasculares, elas se constituem em um problema de saúde pública com prevalência mundial nos grandes centros e atinge a população de idade mais avançada, contribuindo significativamente para uma das principais causas de permanência hospitalar prolongada e responsáveis pela principal alocação de recursos públicos em hospitalizações no Brasil, com aumento do ônus econômico nas últimas décadas. ${ }^{1} \mathrm{Na}$ atualidade vários recursos diagnósticos foram desenvolvidos para detectar os agravos que acometem o coração e entre eles destaca-se o cateterismo cardíaco, um exame que permite a visualização da rede vascular e a estrutura cardíaca. ${ }^{2}$ Entre os seus benefícios destaca-se a definição exata da condição cardíaca do paciente e a obtenção de informações de forma consistente para a escolha da melhor opção terapêutica. ${ }^{2} \mathrm{O}$ cateterismo cardíaco é um exame cardiológico invasivo que se constitui na introdução de finos cateteres nas artérias, através da punção ou dissecção de uma veia ou artéria periférica, seguida da administração de contraste radiológico. ${ }^{2}$ Com esse exame, se possibilita o diagnóstico através da medição da pressão e gradientes de pressão, mas também se faz o tratamento das estenoses das válvulas cardíacas, isquemias coronárias, por meio da desobstrução mecânica dos vasos ou da introdução de stents. ${ }^{2} \mathrm{O}$ exame ainda propicia o tratamento não cirúrgico de alguns aneurismas 
da aorta. ${ }^{2}$ A enfermagem inserida na equipe de saúde multiprofissional deverá estar atenta para a avaliação e o cuidado dos pacientes submetidos ao exame de cateterismo cardíaco, buscando conhecimentos e estratégias em saúde para que se possa contribuir com um olhar atento para as necessidades e dificuldades na assistência aos pacientes que buscam o serviço de hemodinâmica para a realização do cateterismo cardíaco. ${ }^{3}$

\section{Objetivo}

Construir tecnologia educativa com o intuito de possibilitar a educação em saúde aos pacientes portadores de doenças cardiovasculares atendidos no serviço de hemodinâmica.

\section{Método}

Para a realização deste estudo descritivo optou-se pela abordagem qualitativa, que procura explicar os meandros das relações sociais - consideradas essência e resultado da atividade humana criadora, afetiva e racional, e que podem ser apreendidas através do cotidiano, da vivência e da explicação do senso comum. O cenário do estudo foi o Serviço de Hemodinâmica do Hospital Universitário, vinculado à Universidade Federal Fluminense, no estado do Rio de Janeiro. Os participantes foram $20 \mathrm{pa}$ cientes que procuraram o serviço de hemodinâmica para agendamento e realização do exame e que aceitaram participar do estudo, realizado no período de mestrado do redator. A pesquisa foi aprovada pela Comissão de Ética em Pesquisa da Universidade Federal Fluminense, em consoante à Declaração de Helsinki revisada em 2000, World Medical Association e a Resolução 466/12 do Conselho Nacional de Saúde, o projeto foi submetido à apreciação do comitê e aprovado sob o parecer de $n^{\mathrm{O}} 429165$. Os critérios de inclusão adotados foram: pacientes de ambos os sexos, idade maior ou igual a 18 anos, atendidos ambulatoriamente e ou internados, e que estivessem sob cuidados médicos. Os critérios de exclusão: pacientes submetidos ao exame em caráter de urgência ou mentalmente comprometidos. A coleta de dados constituiu-se de questões de múltipla escolha e de perguntas abertas. Os dados foram analisados e interpretados a partir da triangulação dos achados, a luz da análise temática de conteúdo. $\mathrm{O}$ conteúdo das entrevistas foi agrupado em três categorias temáticas que emergiram a partir da leitura do material recolhido nas entrevistas relacionando-o à percepção e simbolismo dado pelo paciente ao exame e as necessidades de informação e orientação salientadas no estudo.

\section{Resultados e Discussão}

A amostra da presente pesquisa apresenta pacientes acima de 40 anos e avançando para idades mais elevadas. Observou-se que $25 \%(n=5)$ dos pacientes entrevistados encontram-se nas faixas etárias de 40 a 59 anos e $(75 \%(n=15)$ com 60 anos ou mais. Associa-se a isso as mudanças degenerativas do coração, ocasionadas pelo envelhecimento, passando esse grupo etário a ser o que precisa dessa opção diagnóstica ou terapêutica. No que concerne à escolaridade, predominantemente é incompleta, $\mathrm{n}=12$ (60\%), ambos os gêneros não conseguiram finalizar os estudos. É importante salientar que os pacientes que apresentam nível mais baixo de escolaridade podem apresentar dificuldades em lidar com informações abstratas, consequentemente poderão não assimilar as orientações/informações apresentadas. Torna-se necessário utilizar-se da seleção de vocabulário que atinja o paciente, promovendo acessibilidade à educação em saúde criando possibilidade da utilização de uma linguagem popular. Estudos demonstram que as orientações quando são aplicadas por profissionais detentores do conhecimento científico, utilizando-se estratégias e tecnologias disponíveis, bem como a criatividade, podem gerar nos pacientes melhor assimilação., ${ }^{2,4}$ Os profissionais de saúde seriam o meio pelo qual as informações deveriam ser repassadas para os pacientes, visto que detêm em si o conhecimento necessário para a realização do cateterismo cardíaco. ${ }^{2}$ É necessário salientar que a comunicação em enfermagem se dá através de orientações e fatos relevantes para a assistência direcionada ao paciente, que ajudem na resolução dos problemas, bem como orientações a ele e à família acerca do tratamento, condutas ou procedimentos, além de palavras que demonstrem calor humano e apoio. ${ }^{4}$ No contexto da Enfermagem as tecnologias estão sendo produzidas, validadas e avaliadas. ${ }^{4}$ Verificam-se estudos e estratégias voltadas para tecnologias educacionais reforçando que são fomentos úteis a democratização do saber, contribuindo para aproximar a prảtica $\mathrm{e}$ a teoria. ${ }^{4}$ Destaca-se a necessidade de formação do processo educativo, no qual se contemple uma educação progressista e compartilhada com a sociedade em processo democrático. ${ }^{4}$ Em relação aos depoimentos das entrevistas realizadas $e$ as respectivas análises o seu conteúdo foi agrupado em três categorias. Na categoria 1 - Finalidade do cateterismo cardíaco: diagnóstico ou tratamento - pode-se notar as dúvidas expressas pelos pacientes quanto ao exame diagnóstico ou tratamento a ser realizado. Tornam-se evidentes as dúvidas em relação ao uso de anestesia geral, à sala cirúrgica e ao próprio nome do exame. Os 
pacientes exprimem o sentimento de sofrer um procedimento invasivo de grande porte. Mesmo afirmando desconhecer o que seja propriamente o exame, eles apresentam alguma noção do que seja e expressam dúvidas. Na categoria 2 - Necessidade de informação sobre cateterismo - pode-se observar algumas das dúvidas que os pacientes apresentaram e que estão relacionadas aos cuidados pré e trans procedimento. As necessidades de orientações apontadas pelos clientes foram: quanto ao diagnóstico e ao prognóstico; quanto à possibilidade de cura e desobstrução das artérias; quanto à presença da dor, a duração do exame, riscos com a anestesia, com o contraste; quanto ao próprio exame, como é realizado o exame, se a equipe é preparada; se há possibilidade de vida normal apos o exame; e se o cigarro, a gordura e o açúcar têm relação com a sua patologia atual. $\mathrm{Na}$ categoria 3 - Cateterismo cardíaco: um risco sentido/percebido e a simbolização da morte A simbolização dos pacientes sobre o cateterismo cardíaco, tendo por base as suas respostas, mostra o teor das suas representações sobre o exame, com centralização na morte. Para eles, a morte não se resume só no processo do morrer propriamente dito, mas também em todas as mortes simbólicas que poderão advir com a confirmação diagnóstica como, por exemplo: do estilo de vida, com as questões relacionadas ao fumar e beber, vida noturna, comer ou não o que se gosta. A morte simbólica está relacionada também com a sua independência, sua autonomia e seu papel social. O estudo propiciou a construção de uma tecnologia educativa em forma de cartilha, onde se contemplou as necessidades de orientações relacionadas ao exame em si e as questões de saúde direcionadas aos pacientes portadores de doenças cardiovasculares. A possibilidade de uma intervenção mais efetiva aliado ao cuidado humanizado, perpassa pelo uso de tecnologias educativas nos cuidados prestados de acordo com o nível de complexidade que cada exame exige. 5 As tecnologias educativas pretendem contribuir com a proposta de ensino-aprendizagem em curso e/ou processo reflexivo sobre as tecnologias educacionais direcionando os estudantes, profissionais técnicos e docentes para o uso de uma linguagem globalizada de validação de tecnologias educativas a fim de propiciar a democratização do saber. ${ }^{4}$

\section{Conclusão}

O estudo mostrou o conhecimento limitado dos pacientes sobre o exame, que tendem a confundi-lo, atribuindo-lhe uma finalidade terapêutica. A tecnologia educativa elegida oferece um caminho em educação em saude com possibilidade de esclarecer dúvidas e minimi- zar os temores quanto a realização do exame. Com a construção da cartilha educativa pode-se programar intervenções direcionada ao cuidado dessa clientela. A assistência de saúde qualificada, realizada com base nas necessidades de informações, expressas pelo paciente e a criação de espaços que favoreçam o processo terapêutico do cuidar, dão ao enfermeiro, dentro de suas competências, possibilidades de orientar em saúde, contribuindo junto com estratégias educativas para a ampliação dos saberes. A oferta de orientações acerca das ações de promoção, prevenção e recuperação da saúde, consolidam-se com as políticas públicas do Sistema Único de Saúde referente à educação em saúde e humanização da assistência.

Descritores: Tecnologia Educacional; Educação em Saúde; Cateterismo Cardíaco; Cuidados de Enfermagem; Doenças cardiovasculares.

\section{Referências}

1. Précoma DB, Oliveira GMM, Simão AF, Dutra OP, Coelho OR, Izar COM et al. Atualização da Diretriz de Prevenção Cardiovascular da Sociedade Brasileira de Cardiologia - 2019. Arq. Bras. Cardiol. [Internet]. 2019 Oct [cited 2021 Jan 29]; $113(4): 787-891$. Available from: http://www.scielo.br/scielo.php?script=sci_arttext\&pid=So066-782X2019001000787\&lng=en. Epub Nov 04, 2019. https://doi.org/10.5935/ abc.20190204.

2. Barros Y, Tavares I, Oliveira A, Carvalho L. Conhecimento e significado do cateterismo cardíaco para pacientes cardiopatas. Rev Rene. 17 (1): 29-35, 2016. [Fecha de consulta: 3 de mayo de 2019]. Disponible en: https://www.redalyc. org/articulo.oa?id=.

3. Falkenberg, MB, Mendes TPL, Moraes EP, Souza EM. Educação em saúde e educação na saúde: conceitos e implicacões para a saúde coletiva. Ciência \& Saúde Coletiva [online]. 2014, v. 19, n. 03 [Acessado 29 janeiro 2021], pp. 847-852. Disponivel em: <https://doi.org/10.1590/141381232014193.01572013>. ISSN 1678-4561. https:// doi.org/10.1590/1413-81232014193.01572013.

4. da Silva Cavalcante C, do Amaral Diniz C, Teixeira E, Medeiros HP, dos Santos Ramos L, Batista RM, Saboia VM. Educação em saúde: Tecnologias educacionais em foco (Vol. 2). Difusão Editora. 2018.

5. Salci MA, Maceno P, Rozza SG, da Silva DMGV, Boehs AE, Heidemann ITSB. Educação em saúde e suas perspectivas teóricas: algumas reflexões. Texto \& Contexto Enfermagem, 22(1), 224-230. 2013.https://www.scielo.br/pdf/tce/v22n1/pt_27. 
Estudo de Revisão

\section{UTILIZAÇÃO DO SHORT FORM HEALTH SURVEY PARA AVALIAR A QUALIDADE DE VIDA DE PESSOAS DESEMPREGADAS}

\section{Francisco Antonio Borges de Oliveira Júnior}

Izaiane Paes Ribeiro de Sousa

Isaura Danielli Borges de Sousa

Márcia Teles de Oliveira Gouveia

\section{Introdução}

No cenário contemporâneo, o trabalho tem uma importância significativa na inserção social e na qualidade de vida do trabalhador. Contudo, o desemprego é divergente à boa qualidade de vida, pois compromete o bem-estar do indivíduo e pode ser relacionado com a baixa qualidade vida do prestador de serviço, uma vez que afeta o adoecimento físico e emocional, tanto quanto as condições precárias de serviço afetam. O Short Form Health Survey $(S F-36)$ é um questionário que possui 36 itens e pode ser utilizado para avaliar a qualidade de vida em 8 domínios: capacidade funcional; limitação por aspectos físicos; dor; estado geral de saúde; vitalidade; aspectos sociais; limitação por aspectos emocionais e saúde mental. A utilização desse instrumento no grupo de trabalhadores desempregados não é muito presente na literatura, com isso, esse trabalho busca mostrar a relevância da temática. ${ }^{1}$

\section{Objetivo}

Analisar a qualidade de vida entre os trabalhadores desempregados a partir da utilização do instrumento $S F-36$.

\section{Método}

Para o desenvolvimento deste estudo, foi realizada uma revisão bibliográfica, que se deu a partir de buscas na Biblioteca Virtual 
em Saúde (BVS), no Sistema Online de Busca e Análise de Literatura Médica (MEDLINE), via PubMed, e na Biblioteca Eletrônica Científica Online (SCIELO), utilizando os descritores "qualidade de vida", "desemprego" e "saúde do trabalhador", a partir dos quais foi possivel recuperar artigos que utilizaram o Short Form Health Survey para avaliar a qualidade de vida de pessoas desempregadas no mundo inteiro. Foram incluídos artigos nas línguas inglesa e portuguesa, sem período limite, além de não serem selecionados os filtros nas plataformas de busca de dados mencionadas.

\section{Resultados e Discussão}

Após utilização da estratégia de busca nas bases de dados escolhidas, os critérios foram aplicados e, a partir disso, foram selecionados quatro artigos, publicados entre 2016 e 2019, nas línguas inglesa e portuguesa. Em relação aos estudo selecionados, um se tratava de uma pesquisa realizada com 1825 cidadãos chineses desempregados; outro buscou diferenciar a qualidade de vida entre mulheres empregadas e desempregadas no pós-parto; outro fez uma comparação entre funcionários ativos e não ativos; e, por fim, o quarto estudo, relacionou o trabalho e a qualidade de vida de 682 mulheres brasileiras que emigraram para Portugal. Observou-se que indivíduos portadores de doenças crônicas tiveram a condição de vida agravada pelo desemprego, com os domínios físico e mental afetados pela perda de atividades laborais, principalmente no que diz respeito aos aspectos mentais. Em relação a população de mulheres que tiveram parto vaginal, quando empregadas, possuem qualidade de vida superior aquelas desempregadas, principalmente no que se refere as características da saúde mental. Entretanto, 12 semanas pós-parto as empregadas têm um declínio considerável na qualidade de vida. Em estudo que comparou a qualidade de vida entre emigrantes, foi observado que as desempregadas apresentavam qualidade de vida baixa nos domínios capacidade funcional, aspectos emocionais e saúde mental. Contudo, as emigrantes com carga horária excessiva de trabalho não apresentaram declínio na qualidade de vida. E uma ferramenta importante para avaliação da qualidade de vida, e a abrangência do seu uso em inquéritos populacionais e em estudos avaliativos de políticas públicas e do status de saúde de pacientes pode ser verificada pelo volume de referências disponíveis nas bases de dados bibliográficas e o número crescente de estudos de validação em diferentes países e contextos culturais. O propósito desse instrumento é detectar diferenças clínicas e socialmente relevantes no status de saúde tanto da população geral quanto de pessoas acometidas por alguma enfermidade, assim como as mudanças na saúde ao longo do tempo, por meio de um número reduzido de dimensões estatisticamente eficientes. De acordo com alguns autores, o desemprego é um fator condicionante de adoecimento da saúde mental, uma vez que pode desencadear ansiedade, estresse e baixa autoestima. Em todos os artigos, ficou demonstrado que o desemprego é um gatilho para a diminuição da qualidade de vida avaliada pelo Short Form Health Survey. Pode-se acrescentar que o único grupo de empregados que sofreu declínio da saude foi o de mulheres empregadas no pós-parto, visto que tiveram de acrescentar em sua jornada de trabalho os cuidados domésticos e infantis. Os cuidados da criança tornaram o trabalho mais desafiador, que compreende ao período que mulher voltou a trabalhar, assim, são necessárias novas oportunidades de emprego que sejam mais adequadas ao gênero delas, haja vista que carecem de uma licença-maternidade adaptada para suas necessidades. ${ }^{2,3,4}$ As características demográficas independeram da qualidade de vida e o enfrentamento da situação de forma mais positiva atenua a situação da população. Foi possível relacionar quad̀ros de depressão e suicídio devido a parte mental da qualidade de vida ter sido mais prejudicada. Notou-se que ter um emprego condiciona saúde às pessoas, uma vez que foi notável que a condição de desemprego gera adoecimento da saúde mental do trabalhador. Fatores como ansiedade, baixa autoestima e estresse podem ser desencadeados pela situação de "não-trabalho", considera-se, ainda, a depressão e o suicídio como agravantes da situação de saúde, pois, de acordo com o contexto, o desemprego pode ser considerado como um indicador de saúde e doença. É importante destacar que o desenvolvimento de habilidades de enfrentamento e aumento da autoeficácia em um contexto de desemprego pode condicionar saúde ao indivíduo, considerando que os domínios mentais são mais afetados. ${ }^{2,5}$

\section{Conclusão}

Conclui-se que ainda existe a necessidade de novos estudos que relacionem a qualidade de vida de pessoas desempregadas, quando comparado as empregadas. Observou-se a pouca quantidade de estudos brasi- 
leiros que buscam avaliar a qualidade de vida de trabalhadores desempregados. Ademais, o tempo de afastamento das atividades laborais é um fator estressante e interfere na sua qualidade de vida, além disso, ter um emprego condiciona saúde para a população, uma vez que todos os desempregados dos artigos analisados tiveram sua qualidade de vida comprometida. O Short Form Health Survey é um instrumento de pesquisa excelente para avaliar a qualidade de vida, tendo em vista que é utilizado por muitos países e permite avaliar a qualidade de vida de pessoas em qualquer situação de vida. Com isso, pode-se sugerir que é um instrumento interessante se fosse aplicado no atual contexto de pandemia para descobrir o quanto o desemprego afetou a qualidade de vida das pessoas.

Descritores: Qualidade de vida; Desemprego; Saúde do trabalhador.

\section{Rerefências}

1. Ciconelli R, Ferraz MB, Santos W, Meinão I, Quaresma MR. Tradução para a língua portuguesa e validação do questionário genérico de avaliação de qualidade de vida SF-36 (Brasil SF- 36). Rev. Bras Reumatol, 1999: Mai/Jun; 339): 143-50.

2. Chinweuba AU, Okoronkwo IL, Anarado AN, Agbapuonwu NE, Ogbonnaya NP, Ihudiebube-Splendor CN. Differentials in health-related quality of life of employed and unemployed women with normal vaginal delivery. Women's Health. 2018; 18:13.

3. Dutra FCMS, Costa LC, Sampaio RF. A influência do afastamento do trabalho na percepção de saúde e qualidade de vida de indivíduos adultos. Fisioter. Pesq. 2016 Mar; 23(1): 98-104.

4. Oliveira EN, Matias MMM, Félix TA, Cavalcante MMB, Lopes RE, Neto F. Mulheres brasileiras vivendo em Portugal: trabalho e qualidade de vida. Saúde Soc. 2019; 28(1): 182-192.

5. Yang X, Yao L, Wu H, Wang Y, Liu L, Wang J, Wang L. Quality of Life and Its Related Factors in Chinese Unemployed People: A Population-Based Cross-Sectional Study. International Journal of Environmental Research and Public Health. 2016 Aug 8; 13; 797. 
Pesquisa Original

\section{EFEITOS TERAPÊUTICOS DOS GRUPOS DE DESENVOLVIMENTO HUMANO NA ATENÇÃO À SAÚDE MENTAL}

\section{Bruno Huffel de Lima Márcia Luíza Pit Dal Magro Elizangela Felipi Marta Neckel Menezes}

\section{Introdução}

Com base na psicoterapia psicanalítica de grupo, no ano de 2012, constituiu-se em Chapecó-SC, uma proposta para atendimento em saúde mental, de forma grupal denominada Grupos de Desenvolvimento Humano (GDH). A proposta do GDH nasceu das dificuldades dos Centros de Saúde da Família (CSF) no atendimento às demandas de saúde mental, ganhando relevância especialmente na Atenção Básica (AB), com o envolvimento de diferentes profissionais dos Núcleos de Apoio à Saúde da Família na Atenção Básica (NASF-AB) e das Estratégias de Saúde da Família (ESF). Apesar do destaque para a $A B$, esta ação envolve diferentes serviços $d a$ Rede de Saúde como os Centros de Atenção Psicossocial (CAPS), e outras políticas públicas como Assistência Social e Educação. Esta proposta se inscreve no âmbito da Educação Permanente em Saúde, contando com um processo de formação que inclui estudos teóricos, técnicos e supervisões, bem como suporte emocional para os profissionais. Também se pauta no matriciamento em saúde, em que o profissional especialista em saúde mental presta suporte ao generalista. Estudos já realizados indicam que o GDH tem ampliado a capacidade de cuidado em saúde mental dos profissionais que participam da ação ${ }^{1}$. 


\section{Objetivo}

Compreender os efeitos terapêuticos dos Grupos de Desenvolvimento Humano a partir das mudanças na dinâmica psíquica dos participantes.

\section{Metodologia}

Este estudo utiliza o método clínico-qualitativo, o qual se caracteriza pela compreensão dos sentidos e significados de fenômenos acerca dos processos de saúde e doença, observados a partir de settings de saúde. $\mathrm{O}$ contexto deste estudo compreende Grupos de Desenvolvimento Humano que ocorreram nos Centros de Saúda da Família (CSF) do município de Chapecó/SC no período de aproximadamente quatro meses, com duração de agosto a dezembro de 2019. Participaram duas usuárias, sendo que os critérios de inclusão foram ter a idade mínima de 18 anos, não ter participado de outro grupo de GDH anteriormente, e ter participado durante todo o período de duração do grupo no serviço de saúde. Foram realizadas entrevistas semiestruturadas e aplicada a Baterial Fatorial de Personalidade (BFP) no início e final do grupo. As informações foram analisadas por meio da análise de conteúdo. Foram adotados os preceitos éticos previstos pelas Resoluções 466/2012 e 510/2016. O projeto foi aprovado pelo Comitê de Ética em Pesquisa da Unochapecó sob parecer consubstanciado número 2.841 .053 , e CAEE número 59798016.4.0000.0116.

\section{Resultados e Discussão}

As narrativas das usuárias indicam o papel do sintoma corporal que as conduz à busca pelo CSF, anunciando algo do psíquico, que só passa a ter sentido e ser nomeado, com a experiência do grupo. Ao mesmo tempo que se compreende o sintoma como uma manifestação do conflito psíquico que se faz presente no corpo, há necessidade de buscar formas de manejo do mesmo. Nessa interação, a sintomatologia que atinge o corpo, deve dar lugar à fala, à palavra. O modelo continente/contido proposto por Bion possui como função fundamental a digestão de elementos brutos, sensoriais e afetivos (elementos beta), que carecem ser contidos (acolhidos) por outra mente (as primeiras figuras de cuidado), continente, e fazer-se capazes de serem pensados (elementos alfa $)^{2}$. Dessa forma, a proposta do grupo é que atue como um continente de angústias e necessidades de seus participantes, onde cada par- ticipante aprende com o outro, o que emerge nas narrativas das usuárias. A análise um movimento de transição ocorrido com as usuárias do GDH pesquisadas, de uma postura passiva, de queixa e mecanismos primitivos e projetivos, à uma postura ativa, de pertencimento e responsabilização pelos seus desejos e dores. No entendimento de Almeida e Merhy se faz "necessário suportar e sustentar a própria dúvida. Dar espaço para esse não saber, questionar as respostas automáticas diante do que não se tinha uma solução simples". O efeito terapêutico positivo se dá na medida em que se amplia a capacidade de pensar das usuárias, por meio do trabalho psíquico, havendo uma espécie de luto das representações anteriores que às levavam à melancolia è às ideações suicidas e homicidas, por exemplo. Por meio do grupo, do sentido de pertencimento, do espelhamento, se consolida a capacidade de pensar, de transformar os elementos betas, desorganizados, em elementos alfas, mais organizados, movimento possível por meio das transferências cruzadas entre os integrantes do grupo, bem como do papel do coordenador ocupado pelo profissional de saúde. A capacidade de pensar bioniana depende de uma dose de frustração e demarca que o nascer, o crescer e o viver são experiências dolorosas, por essência, mesma característica do processo analítico, na medida em que nos coloca numa posição de consciência de nós mesmos. A noção de cura em Bion, percorre a representação de um desvelamento do inconsciente em direção à expansão mental, que seria possibilitado, neste caso, pela dinâmica do campo grupal de forma a compreender a relação indissociada e continuada existente entre o sujeito e o grupo, seja ele familiar, social, profissional ou cultural ${ }^{4}$. As usuárias manifestam ainda o desejo pela permanência no tratamento em grupo, apesar de apresentar suas limitações (relativas ao tempo e ao constrangimento de expor as intimidades no grupo, bem como o receio do julgamento do outro), assim como os registros de um desenvolvimento egóico e da capacidade de pensar, proposta por Bion, que contribui para reconhecer também os recursos disponíveis para lidar com suas queixas.

\section{Considerações finais}

As informações produzidas pela pesquisa indicam efeitos terapéuticos positivos promovidos pela ação terapêtica grupal do GDH. A experiência do processo grupal possibilitou que as usuárias apresentassem uma nova resposta aos eventos que provocavam sofrimento, substituindo posturas pautadas na mera repetição 
das experiências vivenciadas anteriormente. $\mathrm{O}$ GDH se constitui um espaço de trocas, de encontro e de produção de subjetividades, que se reconhece enquanto proposta de práticas e saberes em saúde mental no contexto do Sistema Único de Saúde. Nesse cenário, a psicanálise se configura um importante instrumento teórico-metodológico, por oferecer uma base para a formação dos profissionais e "uma maneira de organizar a escuta para que esta possa ser capaz de se desviar do evidente, do óbvio aparente, da literalidade para permitir a surpresa, o paradoxo e o insólito"s. O sujeito de que a psicanálise se ocupa é o sujeito do inconsciente, mas também o sujeito social, que é o sujeito imerso na cultura com sua singularidade, mas comprometidos com o seu processo e sua realidade, tornando-os autônomos e independentes. Por fim, o GDH se apresenta como uma nova oferta terapêutica no contexto estudado, para além das terapias medicamentosas, a fim de lidar com os sofrimentos psíquicos tão presentes na Atenção Primária à Saúde. Faz isso usando de uma abordagem teórica robusta que é a psicanálise, cujos efeitos terapêuticos são já amplamente demonstrados no campo da saúde mental, mas o faz de modo inovador no sentido de possibilitar sua implementação na política de saúde, valorizando intervenções grupais e com estreito diálogo com as políticas do SUS.

Descritores: Sistema Único de Saúde (SUS); Saúde Mental; Atenção Primária à Saúde; Psicoterapia de Grupo.

Financiamento: Bolsa de auxílio à pesquisa - Edital o13/REITORIA/2019 da Unochapecó. Trabalho financiado pela FAPESC e CNPQ por meio do Edital o6/2016.

\section{Referências}

1. Freitas, F. B. de; Felipi, E.; Dal Magro, M. L. P. (Orgs.). Grupos de Desenvolvimento Humano: uma estratégia para trabalho com grupos interativos nas políticas públicas. Chapecó: Argos, 2020.

2. Cassorla, R. M. S. Do baluarte ao enactment: o "não-sonho" no teatro da análise. Rev. Bras. Psicanál, São Paulo, v. 41, n. 3, pp. 51-68, 2007.

3. Almeida, S. A. De; Merhy, E. E. Micropolítica do trabalho vivo em saúde mental: composição por uma ética antimanicomial em ato. Rev. Psicologia Política. Vol. 20, n. 47, pp. 65-75, 2020.

4. Zimerman, D. Bion da teoria à prática: uma leitura didática. $2^{\underline{a}}$ ed. [Recurso eletrônico]. Porto Alegre: Artmed, 2008.

5. Bezerra Jr, B. Da verdade à solidariedade: a psicose e os psicóticos. In: BEZERRA JR, B.; AMARANTE, P. (Orgs.), Psiquiatria sem hospício: Contribuições ao estudo da reforma psiquiátrica. Rio de Janeiro: Relume-Dumará, 1994. 


\author{
Resumos
}

\title{
MODALIDADE APRESENTAÇÃO ORAL
}


RELATO DE EXPERIÊNCIA

ACOLHIMENTO MULTIPROFISSIONAL

NO SISTEMA PRISIONAL COMO

INSTRUMENTO DE RESSOCIALIZAÇÃO

\author{
Reges Antonio Deon \\ Camila Lorenzoni Cortina \\ Rosi Maria De Carli \\ Nathieli Aparecida da Silva \\ Arnildo Korb
}

\section{Introdução}

Um dos marcos de assistência à saúde prisional foi através da Lei de Execução Penal que estabelece as responsabilidades do Estado. Além disso, garante direitos assistenciais, como saúde, educação, trabalho, assistência jurídica, social e religiosa às Pessoas Privadas de Liberdade (PPL) durante o período de prisão. ${ }^{1}$ Após a regulamentação do Sistema Único de Saúde (SUS), e sob a ótica do direito universal à saúde, a população prisional também foi incluída nesta modalidade de assistência. O Plano Nacional de Saúde no Sistema Penitenciário, instituído em 2003, foi o marco efetivo desse direito. ${ }^{2}$ Visando melhor operacionalizar a assistência prestada as PPL no âmbito do SUS, foi instituída, em 2 de janeiro de 2014, a Política Nacional de Atenção Integral à Saúde das Pessoas Privadas de Liberdade no Sistema Prisional (PNAISP) com objetivo de promover o acesso das PPL à Rede de Atenção a Saúde, tendo em vista o cuidado integral. ${ }^{3} \mathrm{~A}$ equipe de Atenção Primária Prisional (eAPP) é multiprofissional composta por enfermeiro, médico, técnico ou auxiliar de enfermagem, cirurgião-dentista e técnico ou auxiliar de saúde bucal, psiquiatra, psicólogo e assistente social. Os profissionais cumprem carga horária entre 6 a 30 horas semanais, a depender do número de reeducandos custodiados. Além de proporcionar a atenção integral à saúde dos privados de liberdade, a equipe busca coletar informações das mais variadas do indivíduo 
a fim de subsidiar a tomada de decisão para elaboração do plano individualizador da pena. Este plano, conforme Art. $7^{\circ}$ da LEP (Lei de Execução Penal), deverá ser estabelecido pela Comissão Técnica de Classificação (CTC). A equipe "será presidida pelo diretor e composta, no mínimo, por 2 (dois) chefes de serviço, 1 (um) psiquiatra, 1 (um) psicólogo e 1 (um) assistente social, quando se tratar de condenado à pena privativa de liberdade".

\section{Objetivo}

O presente relato visa apresentar, como ocorrem as entrevistas de acolhimento inicial em uma instituição prisional de Santa Catarina e, como estas auxiliam na elaboração do plano individualizador previsto pela LEP bem como atender a proposta apresentada pela PNAISP no que se refere à atenção e promoção à saúde dos privados de liberdade.

\section{Método}

Trata-se de um relato de experiência elaborado a partir de entrevistas de acolhimento inicial realizada por uma equipe multiprofissional, composta por assistente social, enfermeiro e psicóloga, desenvolvidas em uma unidade prisional do Oeste de Santa Catarina. O instrumento utilizado para coleta de informações foi uma entrevista semiestruturada, adaptada do Manual de Atribuições da Equipe de Saúde no Sistema Prisional, ${ }^{3}$ composta por perguntas objetivas e subjetivas, que aborda acerca das condições de saúde (física e mental), experiência laboral, educacional, condições sociais e histórico prisional. As entrevistas são realizadas uma vez por semana, conforme cronograma definido pela equipe de saúde.

\section{Resultados e Discussão}

$\mathrm{Na}$ instituição prisional, desde a implementação do referido processo de trabalho em maio de 2018, até dezembro de 2019, foram realizadas cerca de 390 entrevistas iniciais. Deste contingente, foram realizados 340 encaminhamentos para estudo, 390 para o trabalho, 80 reeducandos foram encaminhados para consultas em diversas especialidades como oftalmologista, odontologia, psicologia, pneumologista, infectologista e clínica geral. Foram realizados 348 contatos familiares e encaminhados 98 reeducandos para confecção de documentação. No que se refere a consulta de enfermagem, foi oferecido testagem rápida para hepatites B e C, sífilis e HIV. Baciloscopia para os sintomáticos respiratórios; além de avaliação de doenças pré-existentes em tratamento ou não; situação vacinal e encaminhamentos, se necessário, ao clínico geral. A avaliação realizada pela psicologia no início do cumprimento da pena pressupõe análise de aspectos psicológicos do reeducando que antecedem a prisão. Esse estudo, busca conhecer sua constituição enquanto sujeito a partir da história de vida, familiar, social, laboral, educacional com vistas na identificação de habilidades e potencialidade, fragilidades e necessidades e com vistas aos encaminhamentos necessários. No que refere aos aspectos sociais e familiares, fica a critério técnico do assistente social identificar as necessidades e respectivos encaminhamentos que envolvem os aspectos citados. Dentre eles, o contato familiar para orientação das visitas ou reestabelecimento de vínculos. Encaminhamentos para confecção de documentos. Contato com a rede externa, a exemplo do Centro de Referência de Assistência Social (CRAS) e Centro de Referência Especializada de Assistência Social (CREAS), das principais demandas identificadas. A identificação das necessidades observadas nas entrevistas de acolhimento inicial, visam realização de encaminhamentos com vistas na resolutividade de situações que se constituem problemática na vida dos reeducandos. Neste sentido, o acolhimento multiprofissional, possibilita o olhar técnico de cada profissional e ao mesmo tempo, o diálogo entre as áreas de conhecimento para promover a atenção integral ao sujeito, e assim elaborar um plano individualizador da pena. O referido plano, pressupõe conhecer o sujeito, identificar suas necessidades, dificuldades, fragilidades e potencialidades concomitantemente com o que a instituição pode oferecer, a exemplo de: atividades educacionais e laborativas, promoção e prevenção em saúde (física e mental) e, assim acompanhar durante o processo de pena se este sujeito usufruiu das oportunidades disponibilizadas pela instituição, se não, por que motivos, bem como ir adequando o referido plano. A implementação deste processo de atenção e acompanhamento dos privados de liberdade é crucial para garantir a atenção à saúde (física e menta), manutenção de vínculos extra muros (familiares) em perspectiva futura de reinserção social, segundo os princípios constitucionais de garantia de direitos.

\section{Considerações finais}

Consideramos imprescindível a adoção de práticas que proporcionem mudanças significativas no ambiente prisional, que viabili- 
zem o processo de individualização da pena, a partir de medidas voltadas ao processo de ressocialização, a exemplo da pratica profissional exposta. Constata-se que a realização das entrevistas de acolhimento inicial torna-se imprescindíveis para vislumbrar a individualização da pena e o tratamento singular de cada indivíduo. $\mathrm{O}$ olhar individualizado multiprofissional possibilita redirecionar o indivíduo para um convívio social digno, possibilitando outras perspectivas de vida em sociedade. Ainda, o estabelecimento de uma proposta terapêutica individual atua em perspectiva preventiva, promotora de saúde e bem-estar físico e psicológico e social, assim como amplia a possibilidade de resolutividade dos casos necessários. Tratando-se, portanto, do acesso e garantia de direitos. Cabe ressaltar, que cada instituição prisional definirá a disposição e disponibilidade das equipes e a dinâmica das entrevistas de acolhimento inicial conforme sua realidade, mas se tratando de um dispositivo legalmente instituído, faz-se necessário a implementação deste processo de trabalho em todas as unidades prisionais.

Descritores: Acolhimento; Equipe multiprofissional; População privada de liberdade; Atenção Primária à Saúde.

\section{Referências}

1. Brasil. Casa Civil. Subchefia para Assuntos Jurídicos. Lei n. 7210 de 11 de julho de 1984. Institui a Lei de Execução Penal. Diário Oficial da União. Brasília - DF, 12 jul. 1984. Disponível em: http://www.planalto.gov.br/ccivil_oz/leis/l7210. htm\#: :text=L7210\&text=LEI\%20N\%C2\%BA\%20 7.210\%2C\%20DE\%2011\%20DE\%20JULHO\%20 DE\%201984.\&text=Institui\%20a\%2oLei\%20 de\%20Execu\% $\mathrm{C}_{3} \% \mathrm{~A} 7 \% \mathrm{C}_{3} \% \mathrm{~A}_{30} \% 20$ Penal.\&te$\mathrm{xt}=\mathrm{Art} . \% 201 \% \mathrm{C} 2 \% \mathrm{BA} \% 20 \mathrm{~A} \% 20 \mathrm{execu} \% \mathrm{C} 3 \% \mathrm{~A} 7 \%$ C3\%A30\%2openal,do\%20condenado\%20e\%20 do\%2ointernado Acesso em 26 nov. 2020.

2. Brasil. Ministério da Saúde. Ministério da Justiça. Portaria Interministerial no 1777 de 9 de setembro de 2003. Aprova o Plano Nacional de Saúde no Sistema Penitenciário. Diário Oficial da União da Brasília - DF, 11 ago. 2003. Disponível em http://bvsms.saude.gov.br/bvs/ saudelegis/gm/2003/pri1777_09_09_2003.html Acesso em 26 nov. 2020.

3. Brasil. Ministério da Saúde. Ministério da Justiça. Portaria Interministerial $n^{\circ} 1$ de 2 de janeiro de 2014. Institui a Política Nacional de Atenção Integral à Saúde das Pessoas Privadas de Liberdade no Sistema Prisional (PNAISP) no âmbito do Sistema Único de Saúde (SUS). Brasília - DF, o3 jan. 2014. Disponível em http://bvsms.saude.gov. br/bvs/saudelegis/gm/2014/prioo01_02_01_2014. html Acesso em 26 nov. 2020.

4. Governo do Estado de Santa Catarina. Secretaria de Estado da Saúde. Secretaria de Estado da Justiça e Cidadania. Atribuições da Equipe de Saúde no Sistema Prisional. Florianópolis - SC, 2016, 32. Disponível em https:// www.saude.sc.gov.br/index.php/documentos/ atencao-basica/sistema-prisional/1099o-atribuicoes-da-equipe-de-saude-no-sistema-prisional/file Acesso em 26 nov. 2020 
Pesquisa Original

FELICIDADE NO TRABALHO: UM ESTUDO COM ENFERMEIROS PORTUGUESES EM CONTEXTO INSULAR

\section{Sofia Azevedo Feitor \\ Elisabete Maria das \\ Neves Borges}

\section{Introdução}

O mundo laboral tem sofrido grandes mudanças ao longo das últimas décadas, principalmente devido à digitalização em massa, às novas exigências laborais, ao aumento da intensidade de trabalho, à precariedade, ao envelhecimento da população ativa e, consequentemente, à preocupação pela sustentabilidade dos sistemas econômicos. Todas estas mudanças contribuíram para que os riscos psicossociais no trabalho aumentassem, sendo que, na Europa, os trabalhadores da área da saúde e da educação têm sido os mais prejudicados. Assim, os paradigmas, teorias e práticas que orientavam empresas e sociedades desajustaram-se face às necessidades atuais de empregadores e empregados, surgindo novas práticas resultantes da investigação em diversas áreas. A psicologia positiva foi uma teoria emergente dessas necessidades, que procura estudar os aspetos positivos e a capacidade de resiliência de pessoas e comunidades. Derivado da mesma, os conceitos de bem-estar geral e felicidade tornaram-se temáticas de interesse crescente junto dos investigadores. $\mathrm{O}$ conceito de felicidade no trabalho pode ser definido como a ocorrência de experiências laborais positivas em maior número do que negativas ${ }^{(1)}$. Engloba as dimensões de engagement, satisfação com o trabalho e compromisso organizacional afetivo, abrangendo fatores individuais (como emoções e humo- 
res - aspectos transitórios - e atitudes - aspectos mais estáveis no tempo) e organizacionais ${ }^{(2)}$. Em enfermagem, os estudos sobre felicidade no trabalho são escassos a nível mundial, contudo, na última década tem-se assistido a um aumento de estudos publicados. Visto que, para os enfermeiros, ser feliz no trabalho passa por, em primeiro lugar, cuidar do outro de forma holística, torna-se importante que os gestores de enfermagem percebam como potenciar esta felicidade, de forma a que os profissionais sejam mais felizes, mais produtivos e que proporcionem cuidados seguros e de qualidade.

\section{Objetivo}

Identificar os níveis de felicidade no trabalho de enfermeiros açorianos e identificar a sua relação com variáveis sociodemográficas e profissionais.

\section{Método}

Foi desenvolvido um estudo quantitativo, descritivo, correlacional e transversal, com 113 enfermeiros de uma Unidade Hospitalar e de uma Unidade de Saúde de uma ilha dos Açores, selecionados através de uma técnica de amostragem não probabilística e amostra de conveniểncia. Os critérios de inclusão foram enfermeiros que exercessem funções na instituição há pelo menos seis meses e que estivessem no ativo durante a recolha de dados. Dos participantes, $89,4 \%$ eram do sexo feminino, $75,2 \%$ tinham idade inferior a 50 anos, $75,2 \%$ tinha parceiro, $68,1 \%$ tinha filho(s), $73,5 \%$ tinha bacharelado/licenciatura, 56,6\% tinha $\geq 16$ anos de experiência profissional, $63,7 \%$ tinha horário fixo e $97,3 \%$ vínculo definitivo com a instituição; $52,2 \%$ não tinha pessoas dependentes a cargo e 56,6\% realizavam atividades de lazer. Foi aplicado um questionário sociodemográfico e profissional e a Shorted Happiness at Work Scale (SHAW) ${ }^{(3,4)}$, no mês de setembro de zozo. A SHAW é composta por três dimensões (engagement, satisfação com o trabalho e compromisso organizacional afetivo), por nove itens e do tipo Likert, de sete pontos (1-7). A análise dos dados foi baseada em estatística descritiva e inferencial e realizada no SPSS versão 25.0.

\section{Resultados e Discussão}

Verificou-se que os enfermeiros apresentavam níveis moderados de felicidade no trabalho $(\mathrm{M}=4,25 ; \mathrm{DP}=1,05)$, com médias superiores na dimensão de engagement $(\mathrm{M}=4,77$;
$\mathrm{DP}=1,30)$ e médias inferiores na dimensão de satisfação com o trabalho $(\mathrm{M}=3,27 ; \mathrm{DP}=1,10)$. Enfermeiros do sexo masculino, com $61 \mathrm{ou}$ mais anos de idade, sem dependentes a cargo e que realizavam atividades de lazer apresentaram valores superiores na dimensão de satisfação com o trabalho da SHAW. Não existiram dados estaticamente significativos entre os níveis de felicidade no trabalho e as variáveis profissionais. Foram obtidos também níveis moderados de felicidade no trabalho, numa amostra heterogênea de trabalhadores, incluindo enfermeiros, utilizando a SHAW $(\mathrm{M}=3,6 ; \mathrm{DP}=1,7)^{(3)}$. De acordo com outro estudo sobre felicidade em enfermagem, utilizando outra escala, os níveis encontrados também foram moderados ${ }^{(5)}$. Os níveis moderados de felicidade no trabalho encontrados poderão ser justificados pelo fato dos enfermeiros estarem insatisfeitos com as suas condições de trabalho, mas motivados e emocionalmente ligados às suas instituições, utentes e famílias. As variadas tarefas e responsabilidades que a mulher assume dentro do núcleo familiar, em comparação com o parceiro; o fato de enfermeiros mais velhos terem mais experiência profissional, lidarem melhor com situações stressantes e possuírem um horário de trabalho mais flexivel e mais autonomia; o fato do profissional não ter que despender horas do seu tempo livre a cuidar de alguém dependente; e praticar atividades de auto-cuidado/lazer, promovendo assim o bem-estar mental; são algumas das justificações que podemos encontrar para as relações entre as variáveis sociodemográficas e os níveis de felicidade no trabalho encontradas. A avaliação da felicidade no trabalho dos enfermeiros trará benefícios para as organizações, sendo que a sensibilização das chefias para a importância de ambientes de trabalho saudáveis e felizes é imperativa. Os gestores de enfermagem necessitam aplicar estratégias de acordo com as necessidades levantadas, que promovam a saúde mental e física dos enfermeiros e que sejam passiveis de integrar harmoniosamente no contexto de trabalho. As limitações deste estudo prenderam-se com o fato do conceito de felicidade no trabalho ser recente e existirem poucos estudos a tratar esse tema em enfermagem, especialmente utilizando a SHAW; a pandemia COVID-19 que atrasou e impôs algumas condicionantes relativamente à recolha de dados; o fato de ser um estudo transversal, não permitindo comparações/evoluções temporais; e o fato de ser uma amostra de conveniência. Como sugestões para a prática e investigação em 
enfermagem, deverá continuar-se a investir em estudos focados na saúde ocupacional dos enfermeiros e criar ambientes de trabalho saudáveis para os mesmos, através da implementação de estratégias e projetos a nível organizacional e individual, no seio de uma equipe interna de saúde no trabalho.

\section{Conclusão}

Os níveis de felicidade no trabalho dos enfermeiros encontrados foram moderados, sendo que enfermeiros do sexo masculino, enfermeiros mais velhos, sem dependentes a cargo e que realizavam atividades de lazer fora do horário de trabalho apresentaram valores superiores para a dimensão de satisfação com o trabalho. Tendo em conta a falta de condições laborais dos enfermeiros e as cargas emocionais negativas que experienciam, torna-se necessário que os gestores de enfermagem conheçam as suas necessidades e apliquem estratégias que potenciem a felicidade no trabalho, baseadas numa cultura de promoção de saúde e postas em prática no seio de uma equipe multidisciplinar de saúde ocupacional.

Descritores: felicidade; enfermagem; saúde ocupacional.

\section{Referências}

1. Singh S, Aggarwal Y. Happiness at work scale: Construction and psychometric validation of a measure using mixed method approach. Journal of Happiness Studies. Springer Science and Business. 2018; 19(5): 1439-1463. Disponível em: https://doi.org/10.1007/s10902-017-9882-x

2. Fisher C. Happiness at work. International Journal of Management Reviews. 2010; 12 (4): 384-412. Disponível em: https://doi.org/10.1111/ j.1468-2370.2009.00270.x

3. Salas-Vallina A, Alegre J. Happiness at work: Developing a shorter measure. Journal of Management \& Organization. 2018; 1-21. Disponível em: https://doi.org/10.1017/jmo.2018.24

4. Queirós C, Faria S, Fonseca S, Oliveira S. Relatório interno: Hipertermia de corpo inteiro e seu impacto no stress, burnout e ansiedade (resultados outubro 2019 - junho 2020). Porto: LABP-FPCEUP; 2020.

5. Khosrojerdi Z, Tagharrobi Z, Sooki Z, Sharifi K. Predictors of happiness among Iranian nurses. International journal of nursing sciences. 2018; 5(3): 281-286. Disponível em: https:// doi.org/10.1016/j.ijnss.2018.06.008 
Pesquisa Original

CAMPANHA DE PREVENÇÃO E ENFRENTAMENTO DO ASSÉDIO MORAL NOS SERVIÇOS DE SAÚDE

\author{
Maiara Daís Schoeninger \\ Kaciane Boff Bauermann \\ Grasiele Fatima Busnello \\ Rosana Amora Ascari \\ Elisabete Maria das \\ Neves Borges \\ Letícia de Lima Trindade
}

\section{Introdução}

O assédio moral no trabalho não é um fenômeno novo, desde que existe o trabalho, ele se faz presente em suas mais variadas formas, sendo considerado um fenômeno comumente vivenciado pelos profissionais atuantes nos serviços de saúde ${ }^{1}$. Além de se tratar de uma forma de violência que afeta diretamente o indivíduo em sua integridade biológica e psíquica, o assédio moral viola de modo intencional os direitos do outro e afeta as relações de trabalho' ${ }^{2}$. Mesmo com a disseminação das leis trabalhistas e de direitos humanos, o fenômeno ainda ocorre de modo velado e naturalizado, enfatizando deste modo, a importância da discussão e reflexão sobre a temática no processo saúde-doença dos profissionais e trabalhadores dos serviços de saúde ${ }^{1}$. A tecnologia social, por meio da campanha publicitária, é uma ferramenta que amplia esse debate, podendo ser considerada um processo transformador que proporciona melhorias das condições de vida e de trabalho. Além de informar, orientar, empoderar e sensibilizar os atores sociais envolvidos, ela permite que os profissionais se apropriem de soluções, e repliquem-nas em seu contexto de trabalho ${ }^{3}$.

\section{Objetivo}

Desenvolver uma campanha publicitária para prevenção e enfrentamento do assédio moral nos serviços de saúde. 


\section{Método}

A campanha vem sendo desenvolvida como parte da pesquisa/intervenção da dissertação intitulada "Campanha de Prevenção e enfrentamento do assédio moral: uma tecnologia social voltada aos profissionais de saúde", do Mestrado Profissional em Enfermagem na Atenção Primária à Saúde (MPEAPS), da Universidade do Estado de Santa Catarina (UDESC). Este estudo faz parte do Grupo de Estudos Sobre Saúde e Trabalho (GESTRA) e está alinhado à macro pesquisa intitulada como: "Violência no processo de trabalho da enfermagem na Atenção Primária à Saúde". A pesquisa de métodos mistos forneceu os dados e subsídio para o desenvolvimento de um conjunto de recursos de mídia e impressos que compõem a campanha "A Atenção Primária à Saúde como um bom lugar para trabalhar". A necessidade do desenvolvimento dessa tecnologia surgiu após pesquisa de campo realizada no período de 2016 a 2019, com 647 trabalhadores e profissionais dos serviços de Atenção Primária e Terciária à saúde de 23 municípios da região Oeste e Extremo Oeste de Santa Catarina - Brasil. A Macropesquisa respeitou todos os aspectos éticos recomendados e foi aprovada em Comitês de Ética em Pesquisa com Seres Humanos (CEPSH), (pareceres $n^{0} 713.728 ; n^{0}$ 2.835.706; $\mathrm{n}^{\mathrm{o}}$ 3.414.195). Para o desenvolvimento de uma comunicação eficaz, utilizou-se referencial da área de publicidade e propaganda, composto por oito etapas: $1^{\underline{0}}$ identificar o público alvo; $2^{\underline{O}}$ determinar os objetivos; $3^{\underline{O}}$ planejar as comunicações; $4^{\underline{0}}$ selecionar os canais de comunicações; $5^{\underline{0}}$ determinar o orçamento; $6^{\underline{O}}$ escolher o mix de mídias; $7^{\underline{0}}$ mensurar os resultados; $8^{\circ}$ gerenciar o processo integrado de comunicaçã̃o e marketing. Os materiais da campanha foram subsidiados pelos achados das etapas quantitativa e qualitativa do estudo e o início dela se deu em dezembro de 2019, e se estenderá até dezembro de 2020 .

\section{Resultados e Discussão}

Atendendo aos quesitos de simplicidade, baixo custo, fácil aplicabilidade/replicabilidade e impacto social, originados da tecnologia social, até o presente momento, foram realizadas diversas ações e desenvolvimento de materiais instrucionais como: webpalestras; podcast; banner; flyer; boletim informativo; vídeos para televisor (TV) em salas de espera, vídeos para redes sociais direcionados aos profissionais de saúde, usuários e gestores, Live e Website. Considera-se que a sensibilização frente à problemática integra estratégias organizacionais, além de recursos audiovisuais que mostram a importância da utilização de ferramentas de comunicação. Transformar paradigmas culturais implica buscar alternativas criativas, sedutoras e alinhadas a parâmetros educacionais. Considera-se que a sensibilização frente a questões relacionadas à responsabilidade social exige novas tecnologias de informação e comunicação por parte das organizações, garantindo maior visibilidade e sensibilização referente ao tema proposto ${ }^{4}$. Os diversos materiais foram elaborados e estruturados pelos achados da pesquisa, incluindo elementos centrais como: conceitos da violência e do assédio moral, perfil dos perpetradores, associação entre a ocorrência dos diferentes tipos de violência e as características sociolaborais dos profissionais, formas de prevenção e enfrentamento, bem como promoção da Cultura de Paz. Até o momento, considera-se como mídias de interesses as gratuitas e de rápido acesso, com divulgação pelo período médio de uma semana cada recurso, e oferta dos mesmos, por tempo indeterminado em canal do YouTube e web página criada para a Campanha. Para divulgação e alcance dos profissionais, contou-se com a parceria da Agência de Desenvolvimento Regional de Saúde de referência das equipes participantes do estudo, além do contato com os respectivos gestores de cada um dos 23 municípios. Os materiais foram enviados de modo físico e digital. A divulgação contou ainda com o apoio do Telessaude de Santa Catarina e do Conselho Regional de Enfermagem do Estado. Além disso, a Campanha vem sendo divulgada nas redes sociais, em diversos congressos, mesas redondas, palestras nacionais e internacionais. Até o momento, como meio de avaliação, foi utilizado o Feedback dos profissionais coordenadores das equipes, por intermédio de uma pesquisa rápida via aplicativo do WhatsApp, bem como monitoramento dos acessos nos materiais digitais. Em uma análise prévia, os resultados foram positivos e repletos de incentivos para continuidade, o que reforça a importância de iniciativas dessa natureza. Ainda, dar "voz aos trabalhadores", ao inserir nos materiais as formas de enfrentamento utilizadas e sugeridas por eles, foi um ponto de destaque no retorno das apreciações. A construção coletiva do processo de trabalho, da promoção da educação e democratização da informação, gera um dinamismo colaborativo que pode prevenir situações de violência, promover a saúde do trabalhador e fomentar a cultura de paz' 


\section{Conclusão}

Ao desenvolver uma campanha publicitária com foco na prevenção do assédio moral nos serviços de saúde, observou-se a magnitude e singularidade da temática, identificando também, as lacunas existentes acerca da violência no trabalho. Os múltiplos recursos de mídia contribuíram para interagir com o público alvo e dar voz aos participantes. Acredita-se que os resultados desse trabalho possam oferecer subsídios para que o assédio moral nos serviços de saúde seja analisado, compreendido e enfrentado. A Campanha proporciona ainda, incentivo à produção e desenvolvimento de tecnologias que instrumentalizam e permitem manejar o fenômeno, garantindo o acesso à informação, autonomia e empoderamento dos profissionais, assim aproximando o problema vivenciado pela violência nos serviços de saúde, de possiveis soluções. Em virtude disso, os índices de registros e notificações acerca do tema poderão aumentar, bem como, poderá haver também, melhor condução para o seu desfecho. Além disso, ações como esta da campanha, tendem a fortalecer o Sistema Único de Saúde e proporcionar que a integralidade do cuidado também seja vivenciada por quem cuida do outro.

Descritores: Bullying; Violência no Trabalho; Pessoal de Saúde; Campanhas de Saúde; Gestão em Saúde.

Financiamento: Fundação de Amparo à Pesquisa e Inovação do Estado de Santa Catarina - FAPESC

\section{Referências}

1. Hagopian EM, Freitas GF. Moral harassment in the nurses' experiences: phenomenological perspective. Rev enferm. UFPE. 2019; 13:1-9. Doi: https://doi.org/10.5205/19818963.2019.239781.

2. Barreto M, Heloani R. Violence, health and labor: intolerance and bullying in labor relationships. Serv. Soc. Soc. 2015; 123:544-61. Doi: https://doi.org/10.1590/0101-6628.036.

3. Coordenação de Aperfeiçoamento de Pessoal de Nível Superior Produçã̃o Técnica. Ministério da Educação: Grupo de Trabalho, Brasília/ DF: Ministério da Saude; 2019. Disponível em: https://www.capes.gov.br/images/novo_portal/documentos/DAV/avaliacao/10062019_ Produ\%C3\%A7\%C3\%A30-T\%C3\%A9cnica.pdf. Acesso em: 17 de abril de 2020 .

4. Cabral R. Ecocine e Relações Públicas: estratégias integradas de sensibilização meio-ambiental para construção de uma cultura de paz. RIDH Bauru. 2015; 4:67-86. Disponível em: https://wwwz.faac.unesp.br/ridh/index.php/ ridh/article/view/263/121. Acesso em: 25 de novembro de 2019 .

5. Pereira LCB, Freitas CC. Educação na tecnologia social: análise de experiências. Rev. Tecnol. Soc. 2018; 14(30):105-120. Doi: 10.3895/rts. v14n30.5609. Acesso em: 20 de fevereiro de 2020. 
PERFIL DOS PACIENTES INFECTADOS PELO CORONAVÍRUS NO ESTADO DE SANTA CATARINA E OS PREJUÍZOS DO PREENCHIMENTO INADEQUADO DAS NOTIFICAÇÕES DE COVID 19

\section{Fernanda Norbak Dalla Cort Reges Antonio Deon \\ Leila Zanatta Arnildo Korb Samuel da Silva Feitosa}

\section{Introdução}

Desde os primeiros estudos publicados sobre a pandemia do novo coronavírus, houve a identificação de pessoas que apresentaram mais suscetibilidades às complicações causadas pelo vírus. O chamado grupo de risco portanto, incluem: pessoas com 60 anos ou mais, paciente cardiopatas, pessoas com problemas respiratórios graves, imunodeprimidos, doentes renais crônicos, diabéticos e gestantes de alto risco' ${ }^{1}$. Diante da proporção pandêmica, para realizar o controle dos casos que pudesse comportar a grande expansão territorial do Brasil, uma plataforma digital foi construida. Nesta deve ser realizada a notificação imediata dos casos suspeitos e/ ou confirmados no sistema da Vigilância Epidemiológica e-SUS (e-SUS VE). Para casos de internação ainda, é disponibilizado para preenchimento o formulário de Síndrome Respiratório Aguda Grave (SRAG) hospitalizado². Assim sendo, analisar o perfil dos pacientes, é imprescindível para relacionar questões longitudinais e epidemiológicas, para fundamentar ações de tomada de decisão, formulação de políticas e estratégias de saúde.

\section{Objetivo}

Apresentar o perfil sociodemográficos e condições de saúde de casos confirmados de COVID-19 no estado de Santa Catarina e explanar sobre as fragilidade do preenchimentos 
dos documentos de notificação e seus impactos para o registro assertivo das informações.

\section{Método}

Trata-se de estudo descritivo, com pesquisa documental e análise de dados secundários a partir do Portal de Dados Abertos de Santa Catarina, disponível no endereço eletrônico http://dados.sc.gov.br/dataset?tags=COVID-19. Este portal, dentre outros dados referente a COVID-19, apresenta um conjunto de dados em formato estruturado e de forma anonimizada, da relacão de casos confirmados de COVID-19 no âmbito do Estado de Santa Catarina, com informações da APS e hospitalar. O conjunto é formado por um dicionário de dados e por uma tabela de dados anonimizados em formato CSV. Esta ferramenta de divulgação dos dados foi criada em 14/05/2020 e a última atualização foi em 31/07/2020. Para este estudo utilizou-se a tabela CVS, disponível no link ftp://boavista:dados_abertos@ ftp2.ciasc.gov.br/boavista_covid_dados_abertos.csv. Na data de 16/10/2020 foi realizado o download da tabela, separando os primeiros 500 casos registrados. No Microsoft Excel, foi criado uma segunda planilha onde os dados originais foram codificados, para posterior análise no software IBM SPSS Statistics Base 22.o. Foram analisados dos 500 documentos, as seguintes variáveis: idade, sexo, raça, tipo de internação, sintomatologia, comorbidades, tipo de teste diagnóstico e óbito. Por se tratar de dados de acesso público, essa pesquisa dispensa aprovação em Comitê de ética.

\section{Resultados e Discussão}

$\mathrm{Na}$ ficha de notificação e-SUS, os dados apontados se referem: a dados pessoais sendo obrigatório o CPF, contato, endereço, raça (branca, preta, amarela, parda, indígena e ignorado), sintomas (dor de garganta, dispneia, febre, tosse, coriza, distúrbios olfativos, distúrbios gustativos, dor de cabeça, assintomático e outros), tempo de sintomas, fatores de risco (doenças respiratórias crônicas descompensadas, dỉabetes, imunossupressão, gestante, doenças cardíacas crônicas, gestante, puérpera, e outros), estado do teste (solicitado, coletado e concluído), tipo de teste (teste rápido anticorpo, teste rápido antígeno e RT-PCR), resultado do teste (positivo, negativo) ${ }^{2}$. Também, as notificações devem ser realizadas em Unidades públicas ou privadas sendo esses, em atenção primária, pronto atendimento, consultórios, clínicas, entre outros, pelo endereço https://notifica.saude. gov.br/login, cadastrando os dados do estabelecimento para o envio adequado das informações. $\mathrm{Na}$ análise dos dados, mais de $80 \%$ dos casos era do sexo masculino $(81,4 \%)$ e do sexo feminino cerca de $18 \%(18,6 \%)$. Em relação ao critério de raça, 93,4\% $(\mathrm{n}=467)$ das notificações não informaram este dado. A média de idade foi de 45 anos, entre as idades de o a 95 anos. Com relação a sintomatologia apresentada, os principais sintomas foram tosse, febre e dor de garganta. Referente às comorbidades, em 95,8\% dos casos não foi informada. Dentre os informados, predomina doença cardiovascular. Quanto ao diagnóstico, 98,8\% (494) foram por critério laboratorial. Deste, predomina o teste RT-PCR com 50,4\% (252) e teste rápido com $48,4 \%(242)$. Dos exames realizados, 79,8\% foram feitos no SUS via APS ou laboratório público de análises clínicas. Quando à origem das informações, $91,2 \%$ eram provenientes da APS via sistema E-SUS e apenas $6 \%$ a nível hospitalar. $2,4 \%$ foi o percentual de pacientes internados em UTI. A taxa de óbitos ficou em $3 \%$ (15) dentre os 500 casos notificados. Há significância estatística entre idade e o número de recuperados. Os recuperados correspondem a 94,4\% dos casos com maior percentual (23\%) na faixa etária de 30-39 anos, sendo que os não recuperados são os pacientes que estão em período de isolamento. Vale ressaltar que a pesquisa é um recorte dos dados disponiveis, portanto, não representa a totalidade dos dados. A pesquisa evidenciou uma porcentagem elevada de óbitos se comparado ao índice do dia cinco do mês de dezembro do Estado, de 1,01\%. Portanto, diante das fragilidades no preenchimento de dados, houveram limitações para a pesquisa. As informações no momento do preenchimento são importadas de outro sistema de registro do SUS após inserção do CPF do paciente. Inúmeras vezes essa informação de raça já fica preenchida como ignorada. Por isso é importante conferir as informações com os pacientes ao realizar a coleta, até mesmo os dados de endereço e de contato. Outro desleixo relevante, é que esse item de raça só foi acrescentado após mês de julho, onde notou-se a falta dessa informação por associações como a Associação Brasileira de Saúde Coletiva (Abrasco) e o Grupo de Trabalho Saúde Indígena Manaus, que reivindicaram ao Ministério da Saúde, o qual após medidas judiciais acatou que a informação passasse a ser obrigatória. Ou seja, além da inclusão tardia, ainda, não há o preenchimento correto do item. Aspecto relevante para reflexões sobre invisibilidade da temática, inclusi- 
ve em relação à dificuldade de mensurar pelo viés da equidade 3 . O artigo intitulado como: População Negra e COVID-19: reflexões sobre racismo e saúde, relata que foi a partir do relatório do governo americano de 580 hospitalizações em Nova York que se identificou taxas maiores de mortalidade em negros diante da SARS- $\mathrm{CoV}^{3}$. Porém, devido a inconclusividade dos números dos dados de Santa Catarina não é possível avançar em pesquisas evidenciando esse fator, fato que acarreta prejuízos para essa população e para toda a sociedade. A porcentagem de comorbidades não informadas, mais de $95 \%$, também é um reflexo de um preenchimento ineficiente no momento da notificação. A escassez dos dados não permite que haja uma discussão aprofundada sobre os fatores de risco dos dados pesquisados. Questões importantes, extremamente discutidas no cenário mundial com indícios de impacto no paciente COVID positivo. Dentre as comorbidades informadas, as doenças cardiovasculares foram as que atingiram o percentual mais relevante $(2,2 \%)$. Essas doenças atingem coração e/ou vasos sanguíneos e são a principal causa de morte no mundo. Incluem: doença coronariana, cerebrovascular, cardiopatia congênita, trombose venosa profunda, entre outros ${ }^{4}$. Diante da análise realizada, é evidente que não há o registro oportuno das informações nas notificações. Fato confirmado após o questionamento na Secretaria do Estado de Santa Catarina sobre essa fragilidade, com o intuito de descartar falhas de sistema informatizado.

\section{Conclusão}

Assim sendo, as informações preenchidas de maneira correta, são extremamente importantes pois são imprescindíveis para avaliar o panorama da situação, subsidiar o planejamento de políticas públicas, analisar fatores sociodemográficos e epidemiológicos. Os achados, provocam os pesquisadores a avaliar perspectivas de continuidade buscando um estratégia intervencionista para o a problematização da pesquisa.

Descritores: Infecção por coronavírus; Comorbidade; Fatores de risco; Gestão da informação em saúde; Educação em Saúde.

\section{Financiamento}

Fundação de Amparo à Pesquisa e Inovação do Estado de Santa Catarina (FAPESC)

\section{Referências}

1. Niquini RP, Lana RM, Pacheco AG, Cruz OG, Coelho FC, Carvalho LM, et al. IRAG por COVID-19 en Brasil: descripción y comparación de características demográficas y comorbilidades con el IRAG por influenza y con la población general. Cadernos de Saúde Pública [Internet]. 2020 [citado 15 de dezembro de 2020];36(7). Disponível em: http:// www.scielo.br/scielo.php?script=sci_abstract\&pi-

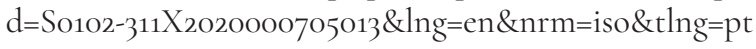

2. Guia de Vigilância Epidemiológica: COVID-19 [Internet]. [citado 15 de dezembro de 2020]. Disponível em: https://coronavirus.saude.gov.br/ guia-de-vigilancia-epidemiologica-covid-19

3. Santos MPAD, Nery JS, Goes EF, Silva AD, Santos ABSD, Batista LE, et al. População negra e Covid-19: reflexões sobre racismo e saúde. Estudos Avançados. 2020;34(99):225-44. DOI: 10.1590/s0103-4014.2020.3499.014 4. Organização Pan-Americana de Saude [homepage na internet] Folha Informativa COVID 19: Escritório da OPAS e da OMS no Brasil, [acesso em 14 dez 2020]. Disponível em: https://www. paho.org/pt/covid19

4. Folha informativa covid-19 - escritório da opas e da oms no brasil - opas/oms | organização pan-americana da saúde [Internet]. [citado 15 de dezembro de 2020]. Disponível em: https://www.paho.org/pt/covid19 
Pesquisa Original

FATORES QUE CONTRIBUEM PARA

A SATISFAÇÃO PROFISSIONAL NA ATENÇÃO PRIMÁRIA À SAÚDE

Júlia Grasel

Samuel Spiegelberg Zuge

Letícia De Lima Trindade

Jacks Soratto

\section{Introdução}

Atenção Primária à Saúde (APS) como componente estratégico do Sistema Único de Saúde (SUS), em especial por ser desenvolvida com alto grau de descentralização, é considerada a principal porta de entrada do usuário aos serviços de saúde, e apresenta papel de coordenar o cuidado à saúde da população de forma associada as Rede de Atenção à Saúde (RAS). Além disso, suas diretrizes estão pactuadas na integralidade do cuidado, atendendo às necessidades e demanda do território por meio das equipes de Saúde da Família $(\mathrm{eSF})^{1}$. Esse modelo de assistência à saúde e o processo de trabalho que a envolve, trazem enfrentamentos entre os profissionais da saúde. Neste sentido, o Ministério da Saúde (MS) aponta que o ambiente e as condições de trabalho influenciam diretamente no processo saúde-doença e na morbimortalidade do trabalhador'. Ỏ trabalho é considerado a identidade do indivíduo, e dependendo de sua condição, pode trazer consequências, não apenas físicas e financeiras, mas psicológicas, alem de repercutir na qualidade vida desse indivíduo². Assim, estas problemáticas ligada ao contexto da APS, podem repercutir diretamente na satisfação profissional. No que tange estes aspectos, existe uma relação entre a significação do trabalho por parte do profissional e, o valor dele para o indivíduo, sua capacidade de adaptação, às relações interpessoais, à qualidade da tarefa prestada, o bem-estar. A significação 
do profissional pode estar retratada a outras condições que influenciam a satisfação como, ao ambiente de trabalho, as condições econômicas, o estilo de vida, as condições e organização de trabalho e condições individuais ${ }^{2}$. Nesse cenário, é fundamental a incorporação do desenvolvimento pessoal e profissional $\mathrm{da}$ queles que trabalham no contexto da saúde, para o melhor funcionamento da instituição e, consequentemente do atendimento prestado. Assim, a satisfação no trabalho contribui para melhora na qualidade do serviço prestado, no ambiente de trabalho e na vida pessoal ${ }^{3}$.

\section{Objetivo}

Analisar os fatores que contribuem para a satisfação profissional na Atenção Primária à Saúde.

\section{Método}

Trata-se de um estudo multicêntrico de abordagem qualitativa, realizado na Atenção Primária à Saúde do estado de Santa Catarina, no Sul do Brasil. Os locais de estudo foram as cidades de Criciúma, Joinville, Blumenau, Lages e Chapecó, principal cidade de cada mesorregião de Santa Catarina. Foi excluído o município de Florianópolis representando a mesorregião Grande Florianópolis em decorrência da impossibilidade realizar a coleta os dados devido ao quadro de Pandemia. Deste modo foram sorteadas quatro equipes de Saúde da Família por município que possuem classificação acima da média e muito acima da média, segundo avaliação no último ciclo ( $3^{\circ}$ ) do Programa $\mathrm{Na}$ cional de Melhorias do Acesso e da Qualidade de APS (PMAQ-AB) realizado no ano de 2019. Participaram da pesquisa, profissionais de saúde atuantes nas equipes de saúde, porém foram excluídos os profissionais afastados por quaisquer motivos no período da coleta de dados. A amostra foi de 64 participantes, sendo adotado para o número de sujeitos os critérios de saturação dos dados. A coleta de dados aconteceu no período de março a dezembro de 2020, sendo utilizados duas técnicas de coletas: entrevista semiestruturada; e observação não participante. Os dados após transcritos foram inseridos no software para análise de dados qualitativos Atlas.ti 8.o, na qual foi realizado mediante análise de conteúdo temática $\mathrm{A}$ análise temática de conteúdo contempla três fases: 1) Pré-análise, que consiste na transcritas das entrevistas e as notas de observação em arquivo do Microsoft Word, na qual foi realizada uma criteriosa leitura desse material com correção ortográfica, ajustes linguísticos e gramaticais; 2) Exploração do material, na qual buscou-se alcançar o centro de compreensão da pesquisa. Nessa etapa, realizou-se a criação dos códigos (codes) nove e das categorias ou dos grupos de códigos. Os codes foram criados a partir da seleção de falas dos participantes (quotations) representados por uma palavra ou por um conjunto de palavras que classificam a fala dos entrevistados; 3) Tratamento dos resultados obtidos ou inferência e interpretação, na qual compreende a relação entre os códigos. Nessa etapa, foram realizadas associações utilizando as ferramentas de análises do software e o estabelecimento das relações entre quotations, codes e memos. Destaca-se que o projeto de pesquisa foi apreciado e aprovado pelo Comitê de Ética em Pesquisa de Universidade do Extremo Sul Catarinense, sendo cumprido todos os preceitos éticos exigidos pela Resolução 466/2012 do Conselho Nacional de Saúde, no qual recebeu o parecer nº 3.675.401/2019.

\section{Resultados e discussão}

Os resultados foram estruturados a partir da satisfação no trabalho das equipes de Saúde da Família composta por dezoito códigos, as quais agregaram 567 trechos de falas. Assim, mediante a análise dos fatores foi sintetizada três categorias: 1) Identificação com o trabalho com nove códigos e 272 trechos de falas; 2) Aspectos profissionais como satisfação dos profissionais da equipe de Saúde da Família contendo cinco códigos e 170 trechos de falas; e 3) Relação com os usuários representada por quatro códigos e 125 trechos de falas. $\mathrm{Na}$ categoria "Identificação com o trabalho" foi identificado o maior número de codes $(47,97 \%)$, das quais apontaram a satisfação como: Organização do trabalho / divisão das tarefas na equipe (64 falas), seguido de Identificação com a profissão / atividades ESF (6o falas); Trabalho em equipe ( 46 falas); Condições de trabalho: estrutura e materiais disponiveis para assistência (40 falas); Condições de trabalho/ carga horária e direitos trabalhistas (23 falas); composição da equipe (zo falas); Reconhecimento profissional por parte do usuário (11 falas); Reconhecimento profissional por parte da gestão e identificação com as atividades de gestão/coordenação (quatro falas em cada item). Na Categoria "Aspectos Profissionais" foi identificado $29,98 \%$ do número de codes e como fatores de satisfação: a boa relação profissional/ equipe contemplada (92 falas); a estabilidade no vínculo de trabalho ( 25 falas); remuneração (23 falas); resolutividade 
profissional (21 falas); e a comodidade/ localização da ESF ser próxima a residência (nove falas). A terceira categoria representada pela nomenclatura "Relação com os usuários" engloba 22,05\% dos codes, com os seguintes registros como satisfação profissional: boa relação com usuários ( 56 falas); Vínculo com usuários (33 falas); Longitudinalidade do cuidado (19 falas); e satisfacão do usuário com assistência prestada (17 falas). Ao analisar os fatores de satisfação profissional, que foram sintetizadas nas categorias acima apresentadas evidencia-se a satisfação como um fenômeno complexo com dimensão subjetiva, que tem forte relação com características processo de trabalho, condições e relações interpessoais. O trabalho em equipe possibilita troca de conhecimentos e estabelece relações profissionais operando a junção das intervenções técnicas por meio de responsabilidade mutuas ${ }^{4}$. Os profissionais necessitam de integração social na instituição para fortalecer uma maior integração entre os trabalhadores. A relação interpessoal entre os indivíduos da equipe, comunicação entre profissionais, boas condições de trabalho, organização da unidade de saúde, divisão do trabalho, direitos no trabalho, identificação com as atividades desenvolvidas, motivação e segurança são aspectos favoráveis a satisfação profissional ${ }^{4-5}$. A Construção do vínculo entre o usuário e profissional traz responsabilização e comprometimento com os amplos aspectos relacionados a vida do usuário, gerando resolutividade e longitudinalidade do cuidado4.

\section{Considerações finais}

Os achados do estudo revelam que os fatores que contribuem para satisfação no trabalho estão, majoritariamente, vinculados às relações que se estabelecem, às condições e organização no desenvolvimento do trabalho e o trabalho em equipe. A análise dos motivos que levam a satisfação ressalta a necessidade de investimentos no cuidado e na valorização do trabalhador para que a assistência em saúde consiga ser mais resolutiva repercutindo na melhoria do serviço prestado.

Descritores: Atenção Primária à Saúde; Estratégia de Saúde da Família; Satisfação no Trabalho; Saúde do Trabalhador.

\section{Referências}

1. Ministério da Saúde (Br). Portaria n. 2.436, de 21 de setembro de 2017. Aprova a Política Nacional de Atenção Básica, estabelecendo a revisão de diretrizes para a organização da Atenção Básica, no âmbito do Sistema Û́nico de Saúde (SUS). Diário Oficial da União; Brasília, DF, set. 2017.

2. Dejours C. A loucura do trabalho: estudo de psicopatologia do trabalho. 6. ed. São Paulo: Cortez; 2015.

3. Sturmer G, Pinto MEB, Oliveira MMC de, Dahmer A, Stein AT, Plentz RDM. Perfil dos Profissionais da Atenção Primária a Saúde, vinculados ao curso de especialização em saúde da família una-sus no rio grande do sul. Rev Conhecimento Online. 2020; 1:04-26. DOI: https://doi.org/10.25112/rco.v1io.1639

4. Soratto J, Pires DEP, Scherer MDA, Witt RR, Ceretta LB, Farias JM. Satisfação dos profissionais da estratégia saúde da família no Brasil: um estudo qualitativo. Texto Contexto Enferm. 2018;20(1):69-78. DOI: https://doi.or$\mathrm{g} / 10.1590 / 1980-265 \mathrm{X}-\mathrm{TCE}-2018-0104$

5. Farias MR, Maciel JAC, Teixeira AKM, Sampaio JJC. O Significado do Trabalho para os Profissionais de Saúde da Estratégia Saúde da Família. Revista Psicologia, Diversidade e Saúde. 2019; 8(2):167-78. Doi: 10.17267/23173394rpds.v8i2.2350. 
Pesquisa Original

CONTRIBUIÇÕES DAS PRÁTICAS INTEGRATIVAS

E COMPLEMENTARES A GESTÃO DO

TRABALHO: DESAFIOS E POSSIBILIDADES

Gabriela Trevisan

Lúcia Esteves Duarte

Monica Vilchez da Silva

Maria Teresa Luz Eid da Silva

Leandra Andréia de Sousa

Adriana Barbieri Feliciano

\section{Introdução}

Tendo em vista o atual cenário brasileiro e as reais necessidades de saúde da população quanto ao acesso e integralidade na atenção à saúde, ratifica-se a importância do Sistema Único de Saúde (SUS) e de uma Atenção Primária à Saúde (APS) estruturada e de qualidade ${ }^{[1]}$. No âmbito da APS, a Organização Mundial de Saúde (OMS) tem apoiado e recomendado a inserção das Práticas Integrativas e Complementares (PIC) nos sistemas públicos de saúde, com a publicação de diretrizes técnicas e políticas ${ }^{[2]}$. A Política Nacional de Práticas Integrativas e Complementares (PNPIC) e a oferta dessas abordagens terapêuticas no SUS traduzem uma inovação em saúde no âmbito do acesso, da integralidade e da promoção à saúde. Todo potencial dessas abordagens precisa ser cada vez mais explorado e incorporado tendo em vista a contribuição para a produção do cuidado integral ${ }^{[3]}$, e acrescentamos, para a produção da gestão do trabalho em saúde em uma perspectiva ampliada e compartilhada. Isso posto, destaca-se na produção de cuidado com as PIC, a imensa gama de dispositivos e arranjos organizacionais, entendendo-se arranjos como a reorganização do espaço coletivo da gestão que permite o acordo entre as necessidades e interesses dos usuários, trabalhadores e gestores; e dispositivos como um arranjo de elementos que podem ser concretos e/ou imateriais mediante o qual se faz funcionar, se catalisa ou se potencializa um processo, com a 
participação ativa de usuários, trabalhadores e gestores, para mudança nas linhas de poder já instituídas Os arranjos de cuidado e gestão devem estar voltados para ampliar a capacidade de criação, protagonismo e autonomia de profissionais de saúde na coordenação do cuidado na APS. Assim, o desenvolvimento e ampliação das PIC desvela a importante interface da gestão e do cuidado na produção de saúde o que requer um olhar que se volte também para a gestão municipal, instância responsável não exclusivamente, mas diretamente, pela tomada de decisão quanto ao desenvolvimento de ações e políticas públicas de saúde.

\section{Objetivo}

Identificar arranjos e dispositivos na gestão do trabalho no SUS, com ênfase na implantação e implementação das PIC, a partir de gestores e gestoras municipais de saúde, em um Departamento Regional de Saúde (DRS) do Estado de São Paulo (SP); identificar as PIC ofertadas em um DRS, a partir de gestores e gestoras municipais de saúde.

\section{Método}

Trata-se de um estudo de natureza descritiva com abordagem quanti-qualitativa, realizado junto a 24 municípios que abrangem uma regional de saúde do Estado de São Paulo. Participaram da pesquisa 24 gestores municipais de saúde que responderam questionário e entrevista semiestruturada. Os dados foram tratados por meio da análise de conteúdo modalidade temática e interpretados à luz do Método de Cogestão ${ }^{[4]}$. O estudo foi aprovado pelo Comitê de Ética da Universidade Federal de São Carlos - UFSCar, parecer número 3.382 .7654 .

\section{Resultados}

As PIC ofertadas nos municípios do DRS identificadas pela gestão são: Acupuntura, Fitoterapia, Arterapia, Dança circular, Meditação, Musicoterapia, Reike, Shantala, Yoga, Ảromoterapia, Imposição das mãos, Ozonioterapia e Terapia de florais. Os dados apontaram arranjos e dispositivos, dentre os quais destacam-se: o conselho de saúde como arranjo, e a educação permanente e o NASF como dispositivos, conforme ilustram os trechos das falas a seguir: "Quem vai priorizar é equipe técnica, conselho de saúde que vai se organizar com a gente, como que a gente tem aqui não será eu só isoladamente que vai to- mar decisão!" Gestão/Município A. Na equipe do NASF, as PICs vieram desse trabalho que estamos desenvolvendo, tentando desenvolver no município. Ela começa a pensar em propostas de cuidado diferenciadas (...) "Eu acho que o protagonismo é do NASF", Representante da Gestão/Município B. "Na EP (educação permanente) começou a falar bastante dessas práticas [...] eu sentei aqui com o gestor e falei assim "olha, você já ouviu falar de práticas integrativas? (...) vamos dar uma olhadinha no que é?" Porque o gestor, ele gosta muito de tudo o que oferta para a população". Representante da Gestão/Município C.

\section{Discussão}

Os gestores e gestoras referem que alguns dispositivos e arranjos organizacionais foram criados a partir da implantação e implementação das PIC e que outros já existentes, contribuíram para seu desenvolvimento. Dentre os existentes, o conselho de saúde desponta como espaço fundamental para a tomada de decisão de implementação de políticas de saúde, pactuada por gestores, trabalhadores e usuários. Quanto ao desenvolvimento das PIC, é quase uma unanimidade a importância das equipes multiprofissionais do NASF como as que mais disseminam essas práticas, inclusive junto às suas equipes, corroborando a qualidade na $\mathrm{APS}^{[1]}$, Nos municípios em que a implementação da educação permanente em saúde (EPS) criou espaços de gestão do trabalho, as discussões sobre as PIC estiveram presentes, ressaltando a necessidade de espaços como estes para o esclarecimento do que são as PIC e o reconhecimento das inovações produzidas no trabalho em saúde. A gestão revela, ainda, o desconhecimento acerca da PNPIC e a necessidade de informação quanto ao alcance das PIC na produção de saúde dos usuários, para a tomada de decisão. Isso reforça a importância da aproximação da gestão e do cuidado, da implementação da política de EPS que favorece a participação de diferentes atores sociais e institucionais para a consolidação e discussão dessas terapias complementares no âmbito da atenção básica ${ }^{[5]}$ e da presença de mecanismos legais, que reforcem sua sustentabilidade.

\section{Conclusão}

No presente estudo, o processo de implantação das PIC na APS favorece o compromisso e autonomia profissional na produção do cuidado, o que se dá também via EPS, com reconhecimento e apoio da gestão municipal. 
Nesse sentido, o estudo assinala que é imprescindível realizar uma articulação entre o conselho municipal de saúde, as equipes do NASF, demais profissionais da APS, usuários e outros atores sociais e institucionais para o desenvolvimento e ampliação das PIC. Essa articulação se mostra potente para a transformação e consolidação do SUS baseada em espaços coletivos, que provocam a desalienação dos trabalhadores e a ascensão de sua autonomia e governabilidade, acionadas pela contribuição das PIC que demonstraram o favorecimento na melhoria da qualidade na produção do cuidado integral e da gestão do trabalho em saúde.

Descritores: Gestão em saúde; Terapias complementares; Sistema Único de Saude; Atenção Primária à Saúde.

Financiamento: Pesquisa financiada pela Fundação de Amparo à Pesquisa do Estado de São Paulo (FAPESP)

\section{Referências}

1. Macinko J., Mendonça C. S. Estratégia Saúde da Família, um forte modelo de Atenção Primária à Saúde que traz resultados. Revista Saúde debate. 2018; 35, 18-37.

2. World Health Organization. The WHO Traditional Medicine Strategy. Geneva: WHO 2014-2023

3. Tesser Charles Dalcanale, Luz Madel Therezinha. Racionalidades médicas e integralidade. Ciênc. saúde coletiva [Internet]. 2008; Feb [cited 2021 Jan 16] ; 13(1):195-206. Available from:http:// www.scielo.br/scielo.php?script=sci_arttext\&pid=S1413-81232008000100024\&lng=en. https://doi.org/10.1590/S1413-81232008000100024.

4. Campos, Gastão Wagner de Sousa. Um Método para Análise e Co-gestão de Coletivos: a constituição do sujeito, a produção de valor de uso e a democracia em instituições: o método da roda - São Paulo; Hucitec; 4 ed; 2013. 240 p.

5. Santos MC, Tesser CD. Um método para a implantação e promoção de acesso às Práticas Integrativas e Complementares na Atenção Primária à Saúde. Cien Saude Colet 2012; 17(11):3011-3024. DOI: http://dx.doi. org/10.1590/S1413-81232012001100018. 
Pesquisa Original

\section{QUALIDADE DE VIDA DE PROFISSIONAIS DA ENFERMAGEM ATUANTES NA ATENÇÃO PRIMÁRIA EM TEMPOS DE COVID-19}

\author{
Endria Mendes Fabrizzio \\ Raquel Tatielli Daneluz Rintzel \\ Lisiane da Rosa \\ Crhis Netto de Brum \\ Júlia Grasel \\ Samuel Spiegelberg Zuge
}

\section{Introdução}

A Atenção Primária a Saúde (APS) é parte do modelo de assistência à saúde desenvolvido no Brasil, sendo a principal estratégia de coordenação do cuidado a saúde da população. No entanto, destaca-se que a saúde dos trabalhadores que atuam na APS tem sido uma preocupação frequente de pesquisadores, principalmente no que tange às condições de vida e trabalho. ${ }^{1}$ Uma vez que, existem situações que podem interferir diretamente na condição de saúde e qualidade de vida, que estão relacionadas principalmente a condições do trabalho, a exemplo, o nível de independência, tipo de vínculo empregatício, carga horária de trabalho, demanda excessivas de atividades, além de outras inerentes ao cotidiano pessoal do profissional, como a satisfação com o trabalho, condições biopsicossociais, seu desempenho, entre outras. Somado a estes enfrentamentos que incidem sobre sua condição de saúde e qualidade de vida, atualmente, vivencia-se um momento de intenso desafio para a saúde, a pandemia da Coronavirus Disease 2019 (COVID-19), que trouxe repercussões para indivíduos, famílias, comunidades, especialmente, para os profissionais da saúde, que em todo o mundo foram submetidos a pressões sem precedentes, mudanças no processo de trabalho, implicando no comportamento, nos aspectos psicossociais e em alterações fisiológicas, levando-os a adoecimento. ${ }^{2} \mathrm{~A}$ partir do exposto, questionou-se: 
a pandemia da COVID-19 tem impactado nos domínios (físico, psicológico, relações sociais, meio ambiente) da qualidade de vida dos profissionais enfermeiros da APS?

\section{Objetivo}

Avaliar os domínios da qualidade de vida de enfermeiros da APS em tempos de COVID-19.

\section{Método}

Estudo quantitativo, de corte transversal, realizado com 25 enfermeiros da APS de um município da região oeste de Santa Catarina, no período de outubro a dezembro de 2020. A coleta de dados ocorreu de forma remota, o qual foi encaminhado para os contatos eletrônicos dos enfermeiros um instrumento de pesquisa, para ser respondido pelo google forms, contendo um questionário sociodemográfico e laboral e o World Health Organization Quality of Life (WHOQOL-Bref). $\mathrm{O}$ WHOQOL-Bref trata-se de um instrumento cujo objetivo é avaliar a qualidade de vida, composto por 26 questões, duas de ordem geral, e as demais, dispostas em quatro domínios: físico, psicológico, relações sociais e meio ambiente. As respostas de todas as questões são obtidas através de uma escala tipo Likert de cinco pontos. Os escores bruto de cada domínio variam de quatro a 20 pontos, sendo que quanto maior for o escore melhor é o domínio. Foram realizadas análises descritivas e de correlação entre os domínios, a partir do software Statistical Package for the Social Sciences (SPSS), version 20.0. Para todas análises estatísticas foi adotado o nível de significância $p<0,05$. Este estudo atendeu os aspectos éticos de pesquisa em seres humanos, sendo aprovado pelo Comitê de Ética em Pesquisa da Unochapecó, recebendo o parecer numero: 3.927.461/2020.

\section{Resultados e Discussão}

Participaram do estudo 25 enfermeiros da APS, sendo predominantemente o sexo feminino $(84 \%)$. A faixa etária prevalente foi de 26 aos 35 anos $(60 \%)$. As questões que apresentaram maiores médias de repostas do WHOQOL-Bref foram: quão bem você é capaz de se locomover $(4,24 \pm 0,66)$; quão satisfeito está com as condições do local onde você mora $(3,88 \pm 0,67$; e quão satisfeito está com o seu meu de transporte $(3,88 \pm 0,83)$. Já, as questões que apresentaram as menores médias foram: quanto você aproveita a vida $(2,88 \pm 0,67)$; em que medidas tem oportunidade de fazer atividades de lazer $(2,88 \pm 0,67)$; e você tem energia suficiente para o dia-a-dia $(2,92 \pm 0,81)$. A partir da análise dos dados foi possível identificar que o domínio geral da qualidade de vida apresentou a melhor média $(13,84 \pm 2,44)$, seguido do meio ambiente $(13,66 \pm 2,04)$, domínio das relações pessoais $(13,39 \pm 2,76)$, domínio físico $(13,37 \pm 2,85)$ e o pior domínio da qualidade de vida dos profissionais foi o psicológico $(12,92 \pm 2,50)$. Ao correlacionar os domínios da qualidade de vida, foi possível identificar que os domínios têm uma correlação significativa entre si e de força moderada para alta, apontando que quanto maior for um domínio, terá uma melhora nos demais. Dentre os domínios correlacionados, a relação entre o domínio psicológico e físico foi a que apresentou maior força $(r=0,83 ; p=$ o,ooo) e a do domínio psicológico e das relações sociais $(r=0,78 ; p=0,000)$. Somente a relação entre os domínios geral da qualidade de vida e das relações sociais não apresentou correlação significativa. Observa-se que os domínios psicológicos e físicos apresentaram as piores médias entre os domínios da qualidade de vida e a de maior força de correlação. Assim, quanto maior for os niveis do domínio psicológico, maiores serão os níveis do domínio físico. A Organização Mundial da Saúde tem observado uma pressão sobre os profissionais de enfermagem neste período de pandemia, repercutindo em um severo aumento das condições psicossociais, com aumento dos níveis de ansiedade, acrescidos do risco de adoecer, provocando problemas de saúde mental e o acréscimo dos casos de Síndrome de Burnout. ${ }^{3}$ Além disso, observa-se que as demandas em decorrência da COVID-19 têm levado ao esgotamento dos profissionais de enfermagem, trazendo a público situações já conhecidas de desgaste físico e emocional ligadas ao processo de trabalho..$^{4-5}$ Os impactos psicológicos e físicos dos profissionais enfermeiros da APS em tempos de COVID-19 têm refletido nos demais aspectos da qualidade de vida e na condição de saúde.

\section{Conclusão}

Ao avaliar os domínios da qualidade de vida dos enfermeiros da APS em tempo de COVID-19 foi possível identificar, principalmente, a diminuição dos domínios físicos e psicológicos que apresentaram as menores médias entre os domínios da qualidade de vida e a maior força de correlação. Assim, en- 
tende-se que a pandemia evidenciou percalcos do processo de trabalho do profissional enfermeiro da APS, uma vez que intensificou desde a problemática salarial até as situações que envolvem, diretamente, a qualidade de vida destes profissionais. Assim, mesmo com as dificuldades e o aumento das demandas nos serviços de saúde, é necessário e premente haver uma preocupação com o processo de trabalho dos profissionais da saúde da APS, buscando intervir em aspectos que poderão promover a melhora da sua qualidade de vida e saúde.

Descritores: Qualidade de vida; Enfermagem; Atenção Primária a Saúde.

Financiamento: Bolsa de Pesquisa - PIBIC/FAPE - 2019.

\section{Referências}

1. Ferigollo JP, Fedosse E, Filha VA. Qualidade de vida de profissionais da saúde pública. Cad Ter Ocup UFSCar. 2016;24(3): 497-507.

2. Humerez DC de, Ohl RIB, Silva MCN da. Saúde mental dos profissionais de enfermagem do Brasil no contexto da pandemia Covid-19: ação do Conselho Federal de Enfermagem. Cogitare enferm. 2020; 25:1-10.

3. World Heatlth Organization (WHO). Actualización de la estrategia frente a la COVID-19. Geneva: WHO; 2020.

4. David HMSL, et al. Pandemia, conjunturas de crise e prática profissional: qual o papel da enfermagem diante da Covid-10. Rev Gaucha Enferm. 2021; 42:1-7.

5. Orsini $\mathrm{M}$, et al. Danos psíquicos durante pandemia por COVID-19 no Brasil. Enferm Brasil. 2020;19(3):196-201. 
Pesquisa Original

\section{GESTÃO DO CUIDADO NA ATENÇÃO A POLIFARMÁCIA EM PACIENTES COM INSUFICIÊNCIA CARDÍACA}

\section{Julia Gonçalves Escossia Campos}

Michelle Alves dos Santos

Liana Amorim Corrêa Trotte

Marluci Andrade

Conceição Stipp

\section{Introdução}

A Insuficiência Cardíaca é uma síndrome clínica que torna o coração impossibilitado de bombear de forma que atenda as necessidades metabólicas tissulares, ou apenas é capaz de fazê-lo com elevadas pressões de enchimento ${ }^{1}$. O crescimento do uso da polifarmácia relaciona-se a vários fatores, como: o aumento da expectativa de vida e o consequente aumento da multimorbidade, à maior disponibilidade de fármacos no mercado e de linhas-guia ${ }^{2}$.

\section{Objetivo}

Descrever o conhecimento dos pacientes com insuficiência cardíaca acerca das medicações utilizadas.

\section{Método}

Trata-se de um estudo transversal realizado em um ambulatório de insuficiência cardíaca de um hospital público universitário federal localizado no estado do Rio de Janeiro. Os participantes da pesquisa foram clientes $\mathrm{da}$ consulta de enfermagem integrantes do estudo intitulado "O gerenciamento do autocuidado de pacientes com insuficiência cardíaca" composta por pacientes atendidos no ambulatório de insuficiência cardíaca do hospital mencionado. Este serviço possui aproximadamente, um total de 130 (cento e trinta) pacientes atendidos, considerando que este número se atuali- 
za à medida que pacientes evoluem para óbito, e conforme o número de novas admissões. Deste total, go (noventa) pacientes foram cadastrados para o banco de dados, destes, 12 (doze) não aceitaram participar ou não responderam em tempo hábil para a tabulação dos dados ou porque não se manifestaram a favor da assinatura do Termo de Consentimento Livre e Esclarecido (TCLE). A amostra foi composta ao final por 78 pacientes. Os critérios de inclusão foram: pacientes que participaram da consulta de enfermagem, de ambos os sexos, maiores de 18 anos; em qualquer classe funcional da New York Heart Association. E os critérios de exclusão foram: pacientes que não responderam todas as perguntas necessárias para $\mathrm{o}$ estudo. A coleta de dados se deu no período de janeiro de 2019 a janeiro de 2020, sempre ao término da segunda consulta de enfermagem em diante. Utilizou-se como instrumento, um Guia de Consulta de Enfermagem que foi adaptado de uma versão previamente utilizado na Clínica de IC "Coração Valente" do Programa de Extensão da Universidade Federal Fluminense- UFF. A adequação foi necessária para atender ao perfil da clientela e do serviço. Após a coleta, os dados foram tabulados e armazenados em planilha do programa Excel for Windows 2013. Os resultados foram analisados pelo programa Statistical Package for the Social Science (SPSS), versão 22, por meio de estatística descritiva apresentada em frequências, com números absolutos e relativos. Este estudo foi aprovado pelo Comitê de ética em Pesquisa da EEAN/HESFA/UFRJ pelo parecer nº 307071227 CAAE: 02873918.0.0000.5238.

\section{Resultados e Discussão}

A amostra foi composta de $66,66 \%$ por idosos, 60,25\% do sexo masculino e $39,75 \%$ do sexo feminino. A autodeclaração de cor foi composta de: $37,18 \%$ pardos, $33,33 \%$ brancos, $24,35 \%$ pretos, $2,56 \%$ amarelos e $2,56 \%$ não responderam. Apenas $7,7 \%$ possuem o ensino médio completo, e $34,61 \%$ não completaram o ensino fundamental. $75,64 \%$ dos pacientes apresentaram conhecimento sobre quais medicações utilizaram, enquanto $43,6 \%$ dos pacientes desconheciam suas funções. Através deste estudo foi possível observar algumas características relevantes para a análise do uso de medicamentos dos pacientes entrevistados e como as orientações dadas pelos profissionais de saúde afetaram o conhecimento deles acerca de suas medicações. Com relação à faixa etária, foi possível observar que uma parcela considerável dos entrevistados é idosa, com 60 anos ou mais, sendo a maio- ria do sexo masculino. Um fator relevante a ser considerado são as Doenças Crônicas Não Transmissíveis, com destaque para a IC que é o foco de atendimento do ambulatório. Um dado estudo mostrou que $81,3 \%$ de sua amostra de 1391 idosos possuíam alguma DCNT33. Sobre o nivel de escolaridade da amostra em questão, observou-se um elevado índice de pacientes com um nível reduzido de escolaridade. Com relação à utilização de medicamentos pelos pacientes entrevistados, foi possível observar um elevado número de idosos estão em polifarmácia. Em outro estudo realizado, observou-se que $43 \%$ da amostra de pessoas com 60 anos e $89,4 \%$ com mais de 61 anos de idade estavam em polifarmácia ${ }^{4}$. Diante disso, é de grande importância o acompanhamento da enfermagem junto ao paciente que utiliza múltiplos medicamentos, a fim de minimizar agravos à saúde, interações medicamentosas e efeitos adversos. Outro fator que deve ser considerado é o baixo conhecimento dos pacientes acerca das funções dos medicamentos utilizados em seus respectivos tratamentos. Observou-se anteriormente a relação das DCNT e da polifarmácia com a baixa escolaridade e o avanço da idade, respectivamente. Um estudo mostra que a idade avançada e baixa escolaridade estão diretamente relacionadas com o menor nível de conhecimento dos pacientes sobre sua doença, gerando um déficit no gerenciamento do autocuidados. Portanto, é de extrema importância que a equipe de enfermagem oriente os pacientes com bastante clareza e sempre adaptando a forma de passar as informações de acordo com as características do indivíduo, para que haja maior compreensão e, consequentemente, melhora do autocuidado. Apesar dos medicamentos serem utilizados como forma de tratamento das doenças, muitas vezes seu uso excessivo pode acarretar riscos à saúde do paciente, como por exemplo, interacões medicamentosas e efeitos adversos. Diante disso, a enfermagem, como parte das equipes multidisciplinares e tendo o papel de educador em saúde, precisa incluir no seu processo de trabalho as ações educativas buscando a correta orientação desses indivíduos acerca de suas doenças, tratamento e terapêutica estabelecida, para que haja uma maior conscientização e melhor gerenciamento do autocuidado.

\section{Conclusão}

De acordo com os resultados obtidos durante a pesquisa, foi possível observar que a maioria dos pacientes entrevistados durante a consulta de enfermagem faz uso de polifarmácia, e um elevado número desconhece 
as funções dos medicamentos que utiliza para tratamento de suas doenças. $\mathrm{O}$ conhecimento destes dados contribui para a assistência a estes pacientes direcionando condutas e atentando para possíveis interações medicamentosas e efeitos adversos. Contribui ainda para uma melhor compreensão sobre autocuidado, tendo o enfermeiro como um profissional fundamental na prática clínica trazendo orientações aos pacientes e familiares sobre sua doença e sua terapêutica, a fim de estimular o gerenciamento do cuidado medicamentoso. Diante disso, torna-se evidente a necessidade do profissional de enfermagem estar focado no cuidado centrado ao paciente, na atenção aos cuidadores e familiares e todo o ambiente que o cerca.

Descritores: Polimedicação, Insuficiência cardíaca, Educação em saúde.

Financiamento: Este estudo conta com a participação de uma bolsista de Iniciação Científica PIBIC/UFRJ.

\section{Referências}

1. ROHDE, Luis Eduardo Paim et al. Diretriz Brasileira de Insuficiência Cardíaca Crônica e Aguda. Arq. Bras. Cardiol., São Paulo, v. 111, n. 3, p. 436-539, Sept. 2018. Available from <http://www. scielo.br/scielo.php?script=sci_arttext\&pi$\mathrm{d}=$ Soo66 $=782-2018001500436 \mathrm{X} \& \operatorname{lng}=\mathrm{en} \& \mathrm{nrm}-$ iso $>$. Access on 02 June 2020. https://doi. org/10.5935/abc.2018019o.

2. Cadogan CA, Ryan C, Hughes CM. Appropriate Polypharmacy and Medicine Safety: When Many is not Too Many. Drug Saf. 2016;39(2):109116. Doi:10.1007/s40264-015-0378-5.

3. SILVA, Amanda Ramalho et al. Doenças crônicas não transmissíveis e fatores sociodemográficos associados a sintomas de depressão em idosos. J. bras. psiquiatr., Rio de Janeiro, v. 66, n. 1, p. 45-51, Mar. 2017 . Available from <http://www.scielo.br/scielo.php?script=sci_arttext\&pid=So04720852017000100045\&ln$\mathrm{g}=\mathrm{en} \& \mathrm{nrm}=\mathrm{iso}>$. Access on o1 June 2020. https://doi.org/10.1590/0047-2085000000149.

4. Araújo LU, Santos DF, Bodevan EC, Cruz HL, Souza J, Silva-Barcellos NM. Patient safety in primary health care and polypharmacy: cross-sectional survey among patients with chronic diseases. Rev. Latino-Am. Enfermagem. 2019;27:e3217. [Access 01 June 2020]; Available in: https://www.scielo.br/pdf/rlae/v27/ pt_0104-1169-rlae-27-e3217.pdf. DOI: http://dx. doi.org/10.1590/1518-8345.3123.3217. 19

5. BORBA, Anna Karla de Oliveira Tito et al. Conhecimento sobre o diabetes e atitude para o autocuidado de idosos na atenção primária à saúde. Ciênc. saúde coletiva, Rio de Janeiro, v. 24 , n. 1, p. 125-136, Jan. 2019. Available from $<$ http://www.scielo.br/scielo.php?script=sci_arttext\&pid=S141381232019000100125\&ln$\mathrm{g}=\mathrm{en} \& \mathrm{nrm}=\mathrm{iso}>$. Access o9 June 2020. https:// doi.org/10.1590/1413-81232018241.35052016. 
Estudo ORIGINAL

POLIFARMÁCIA

EM PACIENTES

DIABÉTICOS TIPO 2

\section{Daniela Paula Marion Santin \\ Luciano Fiorentin Vilma Beltrame}

\section{Introdução}

O diabetes mellitus tipo 2, constitui umas das principais doenças crônicas não transmissíveis, comprometendo a qualidade de vida dos pacientes e quando associado a outras doenças, pode ocasionar danos a vários órgãos. $\mathrm{O}$ Brasil é o quarto país do mundo com o maior número de diabéticos, possui uma prevalência de $7,6 \%$, esse acréscimo ocorre devido à elevação da expectativa de vida, o crescimento populacional e ao sedentarismo (1). O aumento na prevalência das doenças crônicas não transmissiveis, associado ao aumento da longevidade, faz com que ocorra um aumento na demanda dos serviços de saúde, e o usuário acaba necessitando de um maior consumo de medicamentos. No caso dos diabéticos, crises hiperglicêmicas e complicações micro e macrovasculares somadas aos efeitos colaterais dos medicamentos utilizados para controle da doença, acrescentadas as interações medicamentosas tornam-se uma espécie de ciclo vicioso, elevando a necessidade do aumento do número de medicamentos prescritos para manter a doença estável. Outro agravante é o aparecimento das comorbidades, como a hipertensão arterial que no caso dos diabéticos é 2,4 vezes mais frequente (1), as hiperlipidemias, as doenças coronárias, que predispõe ao diabético a necessidade do uso da polifarmácia. Define-se polifarmácia o uso de 5 ou mais medicamentos, excluindo-se medicamentos injetáveis, de uso externo, antibióticos e quaisquer outros utilizados no tratamento de doenças 
não crônicas. A polifarmácia influencia diretamente a qualidade de vida do paciente diabético. Quando há o uso de vários medicamentos concomitantemente, aumentam as chances da ocorrência de interações medicamentosa resultando no aparecimento de efeitos colaterais (2). O desfecho desses resultados negativos na vida do diabético diminui o estímulo à adesão ao tratamento, resultando na piora do seu controle glicêmico e ou da patologia associada ao medicamento em questão (3). No caso de diabéticos idosos, com outras comorbidades associadas e alterações próprias do envelhecimento a questão fica ainda mais crítica, pois interações medicamentosas podem acontecer em 13\% para os idosos que utilizam dois medicamentos e em $58 \%$ para os que utilizam 5 tipos, podendo alcançar $82 \%$ nos pacientes que ultrapassam sete medicamentos (4). O uso associado de dois ou mais fármacos, pode em alguns casos melhorar a eficácia do tratamento, mas também pode causar toxicidade ao organismo ou ausência na ação do medicamento. A associação de vários fármacos, propicia erros na prescrição médica, aumento de confusões no seu uso, ocasionando consumo inapropriado agravando o controle do diabetes (5). A gestão do cuidado na terapia medicamentosa dos idosos em especial dos diabéticos e em uso de polifármacos, pode ser um diferencial na vida dessas pessoas. Além de uma prescrição bem planejada, a habilidade dos profissionais que executam a tarefa minuciosa na dispensação, seguida de orientações quanto ao uso desses medicamentos, e posologia, devem ser repassadas de forma clara e simples. Quando identificado que o usuário é o único responsável pelo gerenciamento de sua condição de saúde, faz-se necessário observar sua real capacidade para essa tarefa. Dessa forma, é importante que haja uma equipe multiprofissional e interdisciplinar para planejar e monitorar a saúde dessas pessoas que em muitas circunstâncias são idosas, de baixa escolaridade e vulnerável às consequências iatrogênicas das multimorbidades e uso de polifármacos. A gestão do cuidado, planejado de maneira singular, a partir da perspectiva da atenção integral à saúde e evitando nesses diabéticos e, em especial nos idosos, possíveis excessos terapêuticos, é a prerrogativa que requer a articulação dos profissionais e das equipes de saúde.

\section{Objetivo}

Verificar a quantidade de medicamentos prescritos, presença de polifarmácia e doenças associadas ao diabetes, com a intenção de instigar aos profissionais novas formas de pensar e agir frente a prescrição, dispensação e assistência ao paciente diabético.

\section{Método}

Trata-se de um estudo transversal quantitativo, que envolveu 100 pacientes com diagnóstico de diabetes mellitus tipo 2, em tratamento na Unidade Básica de Saúde do Município de Modelo-SC. Os dados foram coletados nos prontuários dos pacientes e através de questionário, preenchido pelos pesquisadores ao indagar o paciente oralmente, durante consultas de enfermagem na unidade de saúde ou em visitas domiciliares acompanhadas pelas agentes de saúde, nos meses de outubro a dezembro de 2020. O questionário continha dados sociodemográficos (sexo, idade, estado civil, anos de estudo), dados clínicos (tempo de diabetes, doenças associadas, complicações e medicamentos). Estudo aprovado pelo Comitê de Ética em Pesquisa da Unoesc, com parecer n⿳⺈ 4.250.730.

\section{Resultados e Discussão}

Participaram do estudo 100 pacientes diabéticos tipo 2, sendo 65 do sexo feminino e 35 do sexo masculino. A média de idade foi de 67,34 $( \pm 11,86)$ anos. Destes $79 \%$ eram idosos. Quanto ao estado civil: $74 \%$ eram casados/união estável, $5 \%$ divorciados/separados, $3 \%$ solteiros e $18 \%$ viúvos. No que dizia respeito a escolaridade, $70 \%$ dos participantes estudaram de o-4 anos, $18 \%$ de 5-8 anos, 7\% de $13-15$ anos, $4 \%$ de $9-12$ anos e $1 \%$ > 15 anos. O tempo médio de diagnóstico do diabetes tipo 2 nos participantes desse estudo é de 7,8 anos. As doenças associadas mais prevalentes foram: hipertensã̃o arterial $(76 \%)$, hiperlipidemias $(38 \%)$, doenças coronarianas $(27 \%)$, tabagismo (14\%), hipotireoidismo ( $9 \%)$, doença vascular prévia (7\%), retinopatia (2\%). A polifarmácia foi encontrada em $72 \%$ dos diabéticos, sendo que o consumo médio foi de 5,14 medicamentos por paciente e 13 medicamentos foi o número máximo encontrado. Isto é bastante preocupante, pois eleva o risco de interações medicamentosas e pode ocasionar graves efeitos adversos, tais como confusão mental e intoxicacões (4). As classes de medicamentos mais utilizadas foram: anti-hipertensivos (61\%), diuréticos (46\%), antidepressivos (40\%), hipolipemiantes (39\%), antiagregantes plaquetários $(35 \%)$, cardiotônicos $(27 \%)$.

\section{Conclusão}

Este estudo demonstrou maior prevalência de diabetes em mulheres, idosas. Dentre as doenças associadas, a mais prevalente foi a hi- 
pertensão arterial. Assim demonstra-se a necessidade do controle adequado da glicemia, pratica rotineira de atividade física e alimentação adequada. Acredita-se que são necessários ainda muitos estudos adicionais, com o interesse na diminuição da polifarmácia dos diabéticos, visando a melhora na qualidade de vida, controle da glicemia adequado, diminuição de complicações vasculares e redução de custos com medicações muitas vezes desnecessários. Para isso deve haver um trabalho multidisciplinar na unidade de saúde, reunindo nesta equipe nutricionista, médico, enfermeiro, farmacêutico e psicólogo, dentre outros. Planejando assim, um controle ideal da diabetes e de todas as doenças associadas sob a perspectiva da atenção integral à saúde, podendo resultar na retirada de medicamentos potencialmente inapropriados. Também há a necessidade do controle de fatores de risco associados ao diabetes, visando diminuir a ocorrência da doença e suas complicações crônicas, diminuindo riscos associados ao tratamento farmacológicos. É imprescindível uma qualificação aos profissionais da área da saúde, para que realizem uma seleção de medicamentos mais seguros e eficazes, bem como analisem o custo, para que se conquiste o uso racional dos medicamentos com ações multidisciplinares que instruam a prescrição, dispensação e o consumo dos medicamentos, alcançando assim o melhor tratamento possível ao paciente.

Descritores: uso de medicamentos; assistência a saúde; doenças crônicas.

\section{Referências}

1. Disponível em https://www.diabetes.org.br/ profissionais/images/DIRETRIZES-COMPLETA-2019-2020.pdf. SBD, Sociedade Brasileira de Diabetes. Tratamento farmacológico do diabetes mellitus tipo 2. In: Sociedade Brasileira de Diabetes. Diretrizes da Sociedade Brasileira de Diabetes 2019-2020.

2. Horii T, Momo K, Yasu T, Kabeya Y, Atsuda K. Determination of factors affecting medication adherence in type 2 diabetes mellitus patients using a nationwide claim-based database in Japan. PLOS ONE. 8 de outubro de 2019;14(10):e0223431.

3. Horii T, Iwasawa M, Kabeya Y, Atuda K. Polypharmacy and oral antidiabetic treatment for type 2 diabetes characterised by drug class and patient characteristics: A Japanese database analysis. Scientific Reports. 10 de setembro de 2019;9(1):12992.

4. da Silva Córralo V, Marconatto Binotto V, Bohnen LC, Gonzaga dos Santos GA, De-Sá CA, da Silva Córralo V, et al. Polifarmácia e fatores associados em idosos diabéticos. Revista de Salud Pública. junho de 2018;20(3):366-72.

5. Zanatta L, Cort FND, Mathias NS, Argenta C. Análise das interações medicamentosas e perfil epidemiológico de indivíduos com diabetes mellitus na atenção primária. Revista de Enfermagem da UFSM. 24 de junho de 2020;10(0):47. 
RELATO DE EXPERIÊNCIA

\section{GERENCIANDO O CUIDADO E A SEGURANÇA DO PACIENTE COM O SAFETY HUDDLE}

\section{Lucas Corrêa Preis \\ Giuliana Cosentino Freitas Santos \\ Jaqueline Caetano \\ Leonan José Raimundo \\ Marli Rafael Joaquim \\ Marion Hoelz Ioras}

\section{Introdução}

A área da gestão tem sido um campo de ação humana que visa à coordenação, articulaçã̃o e interação de recursos e trabalho humano para a obtenção dos objetivos. No contexto da saúde, a gestão está associada ao cuidado e à busca de assegurar o princípio da integralidade assistencial disponibilizada ao paciente. Assim, compreende-se que a gestão do cuidado em saúde, está relacionada ao provimento ou disponibilização das tecnologias de saúde, considerando as necessidades singulares de pessoas, nos distintos momentos de sua vida com vistas ao bem estar, segurança e autonomia. Além disso, o gerenciamento do cuidado também está pautado na organização e interação entre os profissionais de saúde, contribuindo para um enfoque ampliado da clínica e a qualificação dos cuidados em saúde $e^{1}$ Nos últimos anos, a melhoria do acesso a informação e as crescentes exigências requeridas pelos pacientes tem feito com que as práticas institucionais dos serviços de saúde, promovam um padrão assistencial cada vez mais qualitativo, eficiente e livre de danos ${ }^{2}$. Com base nisso, a metodologia Safety Huddle (SH) tem sido empregada no campo da segurança do paciente como uma estratégia que visa gerenciar riscos envolvidos no cuidado em saude e enfermagem. Trata-se de uma metodologia inspirada do esporte, onde um huddle ou conferência é representado pela união de uma equipe, geralmente em um círculo apertado visando for- 
mular estratégias, motivar a equipe ou comemorar uma vitória. Baseia-se em ser realizada sob o formato de uma reunião rápida, preferencialmente em até 15 minutos ou menos 3 .

\section{Objetivo}

Relatar a experiência de um hospital de grande porte com a implementação da metodologia SH.

\section{Método}

Trata-se de um estudo do tipo relato de experiência, abordando a utilização da metodologia SH como uma estratégia de gerenciamento do cuidado e da segurança do paciente em um hospital de grande porte localizado no sul do Estado de Santa Catarina. Desde a sua implementação na instituição, o SH ocorre diariamente envolvendo todos os setores assistenciais e de apoio no formato de reunião rápida, sempre no período matutino e com a participação da equipe multiprofissional atuante na instituição. Conta com o apoio da Direção Executiva e da Gerência de Enfermagem da instituição.

\section{Resultados e Discussão}

A implementação do SH na instituição hospitalar baseia-se em quatro princípios essenciais com foco no paciente: melhorar a gestão do cuidado, potencializar a segurança do paciente, maximizar a qualidade do cuidado prestado aos pacientes e qualificar as estratégias de comunicação entre as equipes multiprofissionais e dos diferentes setores do hospital. A execução diária do $\mathrm{SH}$ acontece sempre às o8h15min da manhã, em um auditório amplo com capacidade suficiente para a participação de todos. Todos os participantes ficam em formato de círculo, em pé e os encontros possuem duração de 15 minutos, comparecendo em média 20 profissionais de diferentes áreas $\mathrm{da}$ instituição. A liderança dos encontros é realizada por profissional responsável pela área de segurança do paciente seguindo um roteiro estruturado para servir como guia das discussões do grupo, contando com quatro itens de medições, sendo: segurança, qualidade, pessoas e produtividade. Entre os itens de medições encontram-se perguntas disparadoras como: "Há paciente grave na sua unidade? Ou algum paciente que está preocupando?; Houve óbitos inesperados na unidade?; $\mathrm{O}$ dimensionamento proposto atende a necessidade da unidade nas próximas 24 horas?", entre outras. Os encontros diários do $\mathrm{SH}$ favorecem uma maior integração das atividades profissionais entre os setores, bem como, torna-se um espaço para a construção e o compartilhamento de novos conhecimentos e experiências assistenciais. Estas trocas de conhecimentos tornam-se ainda em espaços para a solução de problemas simples e complexos de forma mais agil entre as equipes, uma vez que, ao longo das discussões diárias, os profissionais podem compartilhar situações-problema a serem solucionadas em seus setores naquele dia, os quais já haviam sido vivenciados e solucionados pelos demais participantes, transformando-se em um espaço de efetivo trabalho em equipe e melhorando a organização e a integração de todos na solução de problemas com foco no paciente. Considerando estes aspectos, há de se expressar que o $\mathrm{SH}$ também contribuiu para a melhoria da gestão do cuidado pelas equipes assistenciais, possibilitando a criação de mecanismos que auxiliem os profissionais na tomada de decisões para a garantia do cuidado integral aos pacientes. Faz com que os profissionais tomem decisões baseando-se em experiências qualitativas e assertivas anteriores, de forma participativa e descentralizada. No contexto da enfermagem, a gestão ou gerenciamento do cuidado é aplicado através da articulação entre dimensões gerenciais e assistenciais. As atividades gerenciais estão voltadas para organização do trabalho e de recursos humanos cujo propósito, é de viabilizar as condições adequadas tanto para a oferta do cuidado ao paciente como para a atuação da equipe de enfermagem ${ }^{4}$. A complexidade do cuidado envolvido no trabalho em saúde remete a necessidade de atividades interdisciplinares com o compartilhamento de saberes, responsabilidades e decisões. Essas ações permitem superar fronteiras disciplinares e se alcançar a integralidade do cuidado e a busca pela qualidade dos serviços prestados ${ }^{2}$. Dadas essas considerações, a utilização da metodologia SH mostra-se uma estratégia efetiva de gerenciar o trabalho e o cuidado no ambiente complexo de um hospital, permitindo que as atividades diárias de trabalho possam ser reorganizadas a partir de uma construção coletiva e a mobilização de maior força de trabalho nas áreas que apresentam maior déficit possam ser estabelecidas desde o início da jornada de trabalho na instituição. Essas ações consequentemente reforçam a cultura de segurança do paciente de forma institucional, uma vez que, a organização do trabalho e a tomada de decisões inapropriadas podem comprometer seriamente o processo de recuperação e tratamento dos pacientes, como também, segurança dos mesmos durante o processo assistencial. 


\section{Conclusão}

Baseado na proposta de ser uma reunião resolutiva, esta metodologia permite que a equipe seja rápida no desenvolvimento de planos de remediação de problemas, danos ou riscos para pacientes, familiares e trabalhadores. Está centrada no cuidado ao paciente e identifica-se com a formulação de uma cultura de segurança que auxilia no desenvolvimento eficaz e seguro das atividades assistenciais entre os setores, através do compartilhamento de preocupações e estabelecimento de compromissos coletivos. Dadas estas características, a aplicação diária da metodologia potencializa as ações de segurança do paciente continuamente, uma vez que, promove o engajamento efetivo da equipe nos processos de segurança, identificação de problemas, riscos e reclamações, gerencia a solução de compromissos e problemas de forma imediata e rápida, bem como, estabelece barreiras que maximizam a qualidade de nossas ações assistenciais.

Descritores: Gestão em Saúde, Gestão de Riscos, Segurança do Paciente, Enfermagem.

\section{Referências}

1. Fabrizzio GC, Júnior EG, Cunha KS, Kahl C, Santos JLG, Erdmann AL. Gestão do cuidado de um paciente com Doença de Devic na Atenção Primária à Saúde. Rev Esc Enferm USP [Internet]. 2018 [citado 15 jan 2021];52:e03345.

2. Mororó DDS, Enders BC, Lira ALBC, Silva CMB, Menezes RMP. Análise conceitual da gestão do cuidado em enfermagem no âmbito hospitalar. Acta Paul Enferm. [Internet] 2017 [citado 15 jan 2021];30(3):323-32.

3. Mello RLG, Christovam BP, Moreira APA, Moraes EB. Criação da metodologia Safety Huddle em um software para segurança do paciente: relato de experiência. Rev Bras Enferm. [Internet] 2020 [citado 16 jan 2021];73(Suppl 6):e20190788.

4. Ferreira VHS, Teixeira VM, Giacomini MA, Alves LR, Gleriano JS, Chaves LDP. Contribuições e desafios do gerenciamento de enfermagem hospitalar: evidências científicas. Rev Gaucha Enferm. [Internet] 2019 [citado 16 jan 2021];40:e20180291. 
FRAGILIDADES IDENTIFICADAS NA PRÁTICA HEMOTERÁPICA: CONTRIBUIÇÕES PARA EDUCAÇÃO PERMANENTE DA EQUIPE DE ENFERMAGEM

Renata Gobetti Borges

Samara Lunardi

Bianca Gabriela Pasa Begnini

Rosana Amora Ascari

\section{Introdução}

A terapia transfusional é um procedimento de suporte essencial para o cuidado do paciente clínico e cirúrgico que envolve riscos de reações transfusionais, mesmo sendo realizada por meio de indicação precisa e respeitando todas as normas técnicas preconizadas $^{1}$. A equipe de enfermagem ligada a assistência transfusional necessita ter apurado conhecimento cientifico e técnico do procedimento, já que são eles que passam a maior parte do tempo com o receptor, realizando os cuidados pré-transfusionais aos cuidados pós-transusionais ${ }^{2}$. Apesar dos avanços na medicina transfusional e todo o aparato legislativo e normativo desta prática, na realidade das instituições de saúde ainda há muitas inconsistências referentes a assistência de enfermagem nos cuidados transfusionais, bem como incertezas em como agir frente às reações transfusionais. Destaca-se aqui, a clara necessidade em reunir esforços e estratégias de gestão envolvendo profissionais assistenciais e de educação permanente, para identificação de inconsistências durante o processo transfusional e qualificar a equipe com vistas a garantir a segurança aos procedimentos transfusionais 3 .

\section{Objetivo}

Objetiva-se descrever as fragilidades presentes na prática hemoterápica em um hospital público de Santa Catarina. 


\section{Método}

Trata-se de um estudo transversal de abordagem qualitativa, derivado de um trabatho de conclusão de curso, vinculado à macro pesquisa: "Tecnologia educativa organizacional: melhores práticas para a gestão da segurança em procedimentos hemoterápicos". Como critérios de inclusão foram selecionados profissionais de enfermagem assistenciais de ambos os sexos, atuantes nos setores de Centro Cirúrgico, Sala de Recuperação, UTI Geral, UTI Neonatal, Oncologia, Clínica Médica, Centro Obstétrico e Neonatologia e como critérios de exclusão, os profissionais de férias ou em licença durante o período de coleta de dados. A coleta de dados foi realizada em fevereiro de 2020 em um hospital público de Santa Catarina, com 36 profissionais da área da enfermagem, representados por seis enfermeiros e 30 técnicos de enfermagem, selecionados por conveniência, nos três turnos de trabalho. O campo de estudo foi constituído pelas unidades consideradas maiores consumidoras de hemocomponentes, sendo em sua maioria setores fechados, onde os profissionais atuantes na agência transfusional (AT), não acompanham diretamente o ato transfusional em si. A coleta de dados deu-se por entrevistas audiogravadas, sem agendamento prévio, utilizando um roteiro semiestruturado. As gravações foram transcritas e a análise dos resultados ocorreu de acordo com o método de Análise de Conteúdo ${ }^{4}$, contemplando as três etapas: Pré análise; Exploracão do material e Tratamento dos resultados obtidos e interpretação. Para a análise dos dados utilizou-se Programa NVivo. A despersonalização dos participantes deu-se pela identificação numérica de acordo com a ordem de participação no estudo. O projeto foi aprovado pelo Comitê de Ética em Pesquisa da Universidade do Estado de Santa Catarina (UDESC), sob parecer número $3.675 .162 \mathrm{em}$ novembro/2019.

\section{Resultados e Discussão}

As transcrições das entrevistas foram convertidas para PDF e importadas para o Programa NVivo, os dados decodificados foram agrupados em quatro categorias, à saber: a) Prática assistencial de enfermagem pré-transfusional (Aquecimento do sangue, Identificação do receptor, Cuidados com acesso venoso e, Outros cuidados); b) Prática assistencial de enfermagem durante a transfusão (Gotejamento, Cuidados à beira leito,
Tempo máximo de infusão, Conduta caso ultrapasse o tempo máximo de infusão e, Outros Cuidados); c) Prática assistencial de enfermagem em caso de reações transfusionais (Possíveis manifestações clínicas, Conceito de reações imediatas e tardias, Conduta em casso de reação, Casos para interromper, Profissional comunicado, Profissional que acompanha, Registro das reações) e; d) Prática assistencial de enfermagem pós transfusão (Cuidados com o paciente, Cuidados com a bolsa, Cuidados com o registro transfusional). Nas quatro categorias apareceram inconsistências assim como boas práticas de hemotransfusão. Neste resumo em questão escolheu-se por deter-se apenas nas fragilidades identificadas, já que foi principalmente devido à presença destas que se identificou a necessidade intensificar ações de educação permanente da equipe de enfermagem. Na "Prática assistencial de enfermagem pré-transfusional", as principais inconsistências foram: o não reconhecimento da presença de um procedimento operacional padrão (POP) específico para hemotransfusão $(75 \%)$, o que pode propiciar o desenvolvimento de uma técnica incoerente ao preconizado; nenhum dos participantes já havia realizado o procedimento de aquecimento de sangue ou sabia descrever, como e/ou quando ocorria, apenas dois participantes $(6 \%)$ mencionaram o papel da agência transfusional neste cuidado; em relação ao acesso venoso ocorreu a menção de itens corretos, entretanto em pequena proporção como: acesso exclusivo $(47 \%)$ e calibre do acesso (33\%). Ainda se teve a menção de itens não preconizados pela literatura como a obrigatoriedade de: uma nova punção (14\%), punçã̃o pela AT (19\%) (setores fechados a punção ocorre pela equipe do setor) e via de transfusão periférica (25\%), podendo, no entanto, ocorrer em via central; em relação aos demais cuidados ocorreu também pouca menção aos seguintes itens essenciais: verificação de temperatura da bolsa (17\%), amostras pré-transfusionais (6\%) e equipo próprio de transfusão ( $3 \%$ ). Apenas um participante abordou uso de equipo próprio para transfusão, sem detalhar as caracteristicas específicas, o qual deve ser descartável, livre de pirógenos e que possuam filtro que retenha coágulos e agregados alternativamente ${ }^{5}$. Em relação a "Pratica assistencial de enfermagem durante a transfusão" o item gotejamento da infusão trouxe viesses ao demonstrar condutas diversas por não estar descrito em prontuário, a maioria (53\%) demonstrou guiar-se pelo período de infusão da bolsa para regular 
o fluxo de gotejo; minoria dos participantes (22\%) citaram a presença do profissional a beira leito do paciente nos 10 minutos iniciais da transfusão, cuidado este de suma importância já que as reações transfusionais mais graves tendem a ocorrer no momento inicial da transfusão; a conduta mencionada por alguns participantes no caso de ultrapassar o tempo máximo de infusão de avisar inicialmente a AT, é incorreta, já que a transfusão deve ser antes suspensa e o médico comunicado, independentemente de condutas estimuladas pela AT, como modificar o gotejo para infusão mais rápida; dentre os outros cuidados teve-se pouca menção a monitorização de reações transfusionaîs (33\%), verificar tempo máximo de infusão (11\%), postergar medicações (3\%) e orientar acompanhantes (3\%). Em relação à "Prática assistencial de enfermagem em caso de reações transfusionais", dentre a diversidade de manifestações clínicas de reações transfusionais possíveis, poucas foram citadas, bem como não há clareza no conceito de reação imediata e tardia, período correto dessas reações e manifestações clínicas para cada período; dos motivos para interromper uma transfusão, a reação transfusional foi a mais citada $(28 \%)$, embora por poucos profissionais. Citou-se também manifestações clínicas específicas. Alguns participantes citaram o termo amplo de reações transfusionais, enquanto outros citaram um, ou outro sintoma específico; para registro das reações transfusionais embora o serviço disponha de folha de notificação específica, esta foi pouco lembrada (31\%), prevalecendo o registro em prontuário. $\mathrm{Na}$ "Prática assistencial de enfermagem pós-transfusional", houve pouca menção ao monitoramento de reações transfusionais (17\%); assim como não houve consenso no cuidado com a bolsa de hemocomponente, sendo que alguns participantes desprezam-na (31\%), enquanto outros a mantém $(69 \%)$ por um determinado período no setor, situação que deve ser abordada e seguida em POP institucional para uma conduta padronizada; em relação aos registros da hemoterapia, a maioria cita a utilização do carimbo de sinais vitais no prontuário e as anotações/evolução de enfermagem, entretanto tem-se pouca menção a necessidade de anexar o rótulo da bolsa no prontuário (31\%). Algumas limitações ocorreram durante o percurso da pesquisa como a dificuldade dos profissionais de enfermagem em reservar um tempo adequado para participar da pesquisa, principalmente devido a correria de alguns setores, ou mesmo devido a recusa dos mes- mos. O turno matutino e vespertino foram os turnos de maior dificuldade de abordagem devido serem turnos de maior demanda assistencial. A partir deste diagnóstico situacional da prática assistencial de enfermagem na utilização de hemoterápicos, será possível propor estratégias para mitigar as fragilidades e potencializar as boas praticas no âmbito hospitalar, conferindo maior segurança transfusional ao receptor, qualificação do serviço, redução de custos e possíveis perdas humanas.

\section{Conclusão}

Por fim, foi possível traçar o diagnóstico situacional da prática hemoterápica de enfermagem na instituição investigada, sendo identificada inconsistências no que permeia a prática hemoterápica e a assistência frente às reações transfusionais. A partir dos resultados obtidos e entendendo a importância de um procedimento transfusional adequado, como forma de devolutiva à instituição e comunidade local, um curso de formaçãoo profissional de curta duração, o qual visa englobar todos os setores da instituição, bem como será disponibilizado ao público externo, estudantes de graduação e pós-graduação e demais interessados. O referido curso será disponibilizado em ambiente virtual de aprendizagem (AVA) via plataforma Moodle da UDESC, com atividades assíncronas, organizadas em três módulos, totalizando zo horas. Desta forma, a universidade cumpre seu papel social de atuação para melhoria dos cenários sociais, auxiliando a instituição hospitalar a mitigar as fragilidades e potencializar as boas práticas hemoterápicas, além de levar conhecimento à estudantes e trabalhadores de outras instituições, ampliando sua inserção social.

Descritores: Enfermagem; Prática transfusional; Reação transfusional; Segurança do paciente; Educação continuada. 


\section{Referências}

1. Hospital Universitário Lauro Wanderley da Universidade Federal da Paraíba. Protocolo de transfusão segura de hemocomponentes: agência transfusional HULW-UFPB. 2018. 36p. Disponível em: http://wwwz.ebserh.gov. br/documents/220250/3051126/Protocolo+de+Tranfus\%C3\%A30+Segura+HULW+2018.pdf/ a495501f-531d-4990-a6f7-202fioao8991

Acesso em: 08 dez. 2020.

2. Mattia DASR. Cuidados de enfermagem na transfusão de sangue: um instrumento para monitorização do paciente. Texto \& Contexto Enfermagem, Florianópolis, 2016; $25(2): 1-$ 8. Disponível em: https://www.scielo.br/pdf/ tce/v25n2/pt_0104-0707-tce-25-02-2600015. pdf Acesso em: o8 dez. 2020.

3. Amaral JHS et al. Hemoterapia: um desafio no cotidiano da equipe de enfermagem. Pernambuco: Rev Enferm. UFPE, 2016; 10(supl.6):48204827. Disponível em: https://periodicos.ufpe. br/revistas/revistaenfermagem/article/download/11261/12886 Acesso em: o8 dez. 2020.

4. Minayo MCS. O desafio do conhecimento: Pesquisa qualitativa em saúde. 14. ed., São Paulo: Hucitec, 2014.

5. Brasil. Portaria $n^{\circ} 158$, de 4 de fevereiro de 2016: redefine o regulamento técnico de procedimentos hemoterápicos. Ministério da Saúde, 2016. Disponível em: http://www.in.gov.br/ web/dou/-/portaria-n-158-de-4-de-fevereiro-de-2016-22301274 Acesso em: o8 dez. 2020. 
Pesquisa Original

EXPERIÊNCIA DE MATRICIAMENTO

NA SAÚDE DO TRABALHADOR VÍTIMA

DE ACIDENTE DE TRABALHO

Marta Neckel Menezes

Márcia Luíza Pit Dal Magro

Bruno Huffel de Lima

Nalu Aparecida Oro Paludo

\section{Introdução}

A saúde do trabalhador é um direito constitucional e um dever do Estado que se inscreve no âmbito do direito à saúde e está inserida na rede de serviços públicos, sendo corolário de avanços regulatórios que, a partir da criação do SUS (Sistema Único de Saúde), exigem a implementação de políticas públicas de proteção universal e integral à saúde do trabalhador. Com a definição da Política Nacional de Saúde do Trabalhador e da Trabalhadora (PNSTT), a Rede Nacional de Atenção Integral à Saúde do Trabalhador (RENAST) passou a estruturar essa área no SUS, sendo criados os Centros de Referência em Saúde do Trabalhador (CERESTs), que têm como função dar suporte técnico, de educação permanente, para toda a rede SUS, dar apoio matricial e ser um articulador e organizador das ações inter e intrassetoriais de saude do trabalhador no seu território de abrangência. Foi a partir deste viés que o CEREST de Chapecó, Santa Catarina, atentou para a realidade dos dados da acidentalidade da população trabalhadora, cujas estatísticas evidenciam um importante problema de saúde pública, e que, na região de sua abrangência, formada por 76 municípios, apresenta altos índices de acidentes de trabalho graves e fatais. ${ }^{1}$ Essa realidade comporta aproximadamente $50 \%$ dos trabalhadores acidentados que deixam de realizar suas atividades habituais e $19 \%$ que relatam sequelas decorrentes dos acidentes ${ }^{2}$, o que caracteriza uma demanda complexa e que exige acompanha- 
mento longitudinal, mediante articulações intra e intersetoriais que podem ser protagonizadas pelos profissionais de saúde. Dada essa realidade, o CEREST de Chapecó, no ano de 2016, deu início ao desenvolvimento de um projeto para o acompanhamento socioassistencial de trabalhadores vítimas de acidente de trabalho grave que passam por internação hospitalar, por meio da estratégia de matriciamento em saúde do trabalhador, tendo como objetivo estimular a articulação da rede de atenção à saúde para o atendimento das demandas decorrentes do acidente.

\section{Objetivo}

Analisar a experiência de apoio matricial desenvolvida pelo CEREST de Chapecó no projeto de acompanhamento socioassistencial de trabalhadores vítimas de acidentes de trabalho grave.

\section{Método}

A pesquisa, que teve início em maio de 2019, é caracterizada como mista e utilizou observação-participante, entrevista semiestruturada e pesquisa documental como instrumentos e técnicas. A observação-participante se deu durante o ano de 2019, mediante participação em ações e capacitações promovidas pela coordenaçã̃o e equipe técnica do CEREST de Chapecó, incluindo encontro de matriciamento, reuniões de técnicos do CEREST, reuniões e capacitações de profissionais da rede de saúde, acompanhamento de visitas domiciliares a trabalhadores acompanhados pelo projeto, fórum de debates e eventos municipais sobre a temática da pesquisa. Foi realizada entrevista de técnico do CEREST, de forma remota, por meio de plataforma google meet, em razão das recomendações sanitárias decorrentes da pandemia de covid-19. A pesquisa documental teve como objeto a computação e a análise dos dados de 201 (duzentas e uma) fichas de acompanhamento socioassistencial de trabalhadores vítimas de acidente de trabalho grave, que foram acompanhados pelo projeto no período de 2016 a 2019, no município de Chapecó. O acesso da pesquisadora às referidas fichas foi realizado nas instalações do CEREST de Chapecó, onde estão arquivadas, sendo feita a coleta dos dados e informações no período de junho a julho de 2020, mediante a criação de um banco de dados digital. As informações foram analisadas por meio de análise temática de conteúdo e estatística descritiva. Por envolver seres humanos, a pesquisa atende os preceitos éticos previstos nas Resoluções 466/2012 e 510/2016 do Conselho Nacional de Saúde, tendo o pro- jeto sido avaliado pela Comissão de Análise de Projetos de Pesquisa em Saúde da Secretaria de Saúde de Chapecó e submetido ao Comitê de Ética em Pesquisa envolvendo seres humanos da Universidade Comunitária da Região de Chapecó/CEP/Unochapecó, sendo aprovado por meio dos Pareceres 016/2020, de 13/04/2020, e 4.047.964, de 26/05/2020, respectivamente.

\section{Resultados e Discussão}

Os resultados da pesquisa documental permitiram levantar o perfil sociodemográfico dos trabalhadores acidentados, mostrando a predominância significativa de vítimas de acidentes de trabalho graves na população do sexo masculino, correspondente a 80,6\% dos 201 trabalhadores acompanhados, bem como a variação percentual conforme a faixa etária, o nível de escolaridade, a renda e a composição familiar, entre outros tantos apontamentos relativos ao acidente e à condição laboral, o que gerou elementos para maior compreensão acerca das repercussões do acidente de trabalho na vida do trabalhador e de sua família, especialmente em função das vulnerabilidades físicas, psíquicas e sociais por ele produzidas ou reforçadas. O CEREST de Chapecó deu início ao desenvolvimento do projeto de acompanhamento socioassistencial em 2016, na perspectiva de cumprir seu papel de dar suporte à promoção de ações de saude do trabalhador na Atenção Básica (AB), buscando favorecer à incorporação do cuidado integral à saúde do trabalhador nas suas rotinas de trabalho: trata-se de uma prática que tem sido chamada de apoio matricial ou matriciamento. ${ }^{3}$ A realização de visitas domiciliares contribuiu significativamente para qualificar o projeto, na medida em que permitiu ampliar a percepção e a compreensão quanto ao contexto individual, familiar e territorial que envolve o trabalhador acidentado. Também permitiu constatar que esse, após a alta hospitalar, acabava ficando, muitas vezes, desassistido e, por vezes, sequer possuía cadastro no SUS, sendo invisível para os serviços da $A B$. Inicialmente, as visitas domiciliares foram realizadas pelo assistente social do CEREST e, na medida em que o projeto foi sendo sistematizado, passaram a ser feitas pelos assistentes sociais do Núcleo Ampliado de Saúde da Família e Atenção Básica (NASF-AB). O projeto se processa a partir do mapeamento dos trabalhadores que sofreram acidente de trabalho grave e foram atendidos nos serviços de urgência e emergência do SUS e submetidos à internação hospitalar, seguido de acompanhamento do boletim epidemiológico e de monitoramento da alta hospitalar. Após a 
alta desses trabalhadores, o assistente social do CEREST comunica às equipes da $\mathrm{AB}$ para continuidade do atendimento de reabilitação e aos assistentes sociais dos NASF-AB para que realizem o acompanhamento socioassistencial no território de origem do trabalhador, mediante visita domiciliar, para a escuta qualificada e o acolhimento das necessidades do trabalhador e de sua família em relação ao acidente sofrido. A partir das demandas levantadas, o trabalhador recebe orientações sobre serviços de saúde, sobre direitos trabalhistas, previdenciários e assistenciais, sobre os fluxos dos atendimentos na rede de saúde e de assistência social, sendo feitas as articulações da rede e os encaminhamentos cabíveis ao caso. Em 2018, a sistematização do projeto foi formalizada, sendo elaborados projetos de capacitação e manual de instruções para os profissionais de saúde, bem como informativo destinado aos trabalhadores acompanhados pelo projeto. Aos profissionais de saúde que acompanham os trabalhadores acidentados, o CEREST oferece suporte técnico por meio de capacitações, orientações, atendimentos compartilhados, discussão de casos e temas específicos, passando por temáticas que vão desde a escuta qualificada até o complexo universo do trabalho e da rede de saúde, de modo a integrar saúde do trabalhador e atenção primária, possibilitando o reconhecimento dos usuários na sua condição de trabalhadores, a maior qualificação e resolutividade do cuidado e o avanço na produção do cuidado integral à saúde do trabalhador. A experiência do CEREST de Chapecó vai ao encontro do apoio matricial caracterizado como um arranjo organizacional e uma metodologia de compartilhamento de saberes que abre espaço para o suporte técnico-pedagógico, institucional, e de retaguarda especializada para os profissionais da rede de saúde pública4.

\section{Conclusão}

O apoio matricial promovido pelo CEREST de Chapecó por meio do projeto de acompanhamento socioassistencial dos trabalhadores vítimas de acidente de trabalho grave representa uma experiência potente para a qualificação da atenção à saúde do trabalhador, buscando garantir o acesso a direitos e serviços da rede de saúde, tão relevante para o enfrentamento das vulnerabilidades decorrentes do acidente de trabalho, ou por ele agravadas, o que vai ao encontro da universalidade e da integralidade propostas pelo SUS. As práticas de apoio matricial realizadas contribuem para dar visibilidade e maior resolutividade às demandas do usuário enquanto trabalhador e promovem articulação entre os pro- fissionais da rede de saúde. É possivel dizer que o projeto produz o reconhecimento do usuário como trabalhador na rede de saúde e fortalece a incorporação do papel do trabalho como determinante do processo saúde-doença. Entre os desafios que o projeto apresenta, destaca-se a importância da capacitação permanente, com o incremento da troca de saberes, da criação de espaços para o desenvolvimento e o aperféciçoamento conjunto de ações e, quando for o caso, para a criação de mecanismos de uniformização de práticas. Entende-se que o banco de dados digital produzido por esta pesquisa, acompanhado de suas análises, é uma ferramenta que pode contribuir para o enfrentamento desses desafios. No contexto atual de precarização das condições de trabalho, os achados da pesquisa levantam a perspectiva de que ela sirva como instrumento capaz de chamar a atenção quanto à premência de políticas públicas afirmativas da proteção aos direitos à saúde do trabalhador e quanto aos efeitos de reformas trabalhistas e previdenciárias e do subfinanciamento do SUS. Por fim, cabe destacar que a pesquisa poderá servir para qualificar a ação em questão, inclusive para sua replicação em outros contextos.

Descritores: Sistema Único de Saúde (SUS); saúde do trabalhador; acidente de trabalho.

\section{Financiamento}

Bolsa de auxílio à pesquisa - Edital o23/ REITORIA/2019 da Unochapecó - FUMDES/UNIEDU (art. $171 \mathrm{da}$ Constitucional Estadual). Trabalho financiado pela FAPESC e CNPQ Edital 06/2016.

\section{Referências}

1. Momoli R. Saúde do trabalhador na indústria da construção civil no oeste de Santa Catarina. [Dissertação]. Chapecó: Universidade Comunitária da Região de Chapecó - Unochapecó; 2017. 2. Malta DC, Stopa, SR, Silva, MMA et al. Acidentes de trabalho autorreferidos pela população adulta brasileira, segundo dados da Pesquisa Nacional de Saúde, 2013. Ciência e saúde coletiva. 2017 Jan-Ago; 22(1): 169-178.

3. Brasil. Ministério da Saúde. Secretaria de Atenção à Saúde. Secretaria de Vigilância em Saúde. Saúde do Trabalhador e da Trabalhadora. Brasília: Cadernos de Atenção Básica; 2019. 136 p.

4. Lazarino MAS, Lacerda e Silva T, Dias, EC. Apoio matricial como estratégia para o fortalecimento da saúde do trabalhador na atenção básica. Revista Brasileira de Saúde Ocupacional. 2019;44:e23. 


\section{O ENSINO DA ADMINISTRAÇÃO EM ENFERMAGEM NO ESTADO DO PARANÁ}

\section{Carmen Elizabeth Kalinowski Isabel Cristina Kowal Olm Cunha}

\section{Introdução}

A Organizações Mundial da Saúde (OMS) recomenda a presença do enfermeiro nas instâncias decisórias dos sistemas de saúde, reconhecendo que esta atuação estratégica colabora no fortalecimento de todos aos serviços ${ }^{1}$. No Brasil a Enfermagem encontra-se presente em todos os níveis organizacionais e assistenciais do Sistema Único de Saúde (SUS) representando a amplitude da ação da categoria ${ }^{2} \mathrm{e}$ ser reconhecida e valorizada também pela sociedade. Para tal, é importante compreender que o reconhecimento e a visibilidade do trabalho da Enfermagem acontecem pela consistência da sua ação profissional, amparada pelos processos de trabalho que caracterizam o seu ofício: assistir, gerenciar, ensinar, pesquisar e participar politicamente ${ }^{3}$. Processos de trabaIho interligados, mesmo com finalidades diferentes utilizam os recursos como negociação, motivação, liderança, tomada de decisão, entre outros, para realizar e finalizar a ação profissional ${ }^{3}$. Este estudo debruça-se sobre o ensinar do processo de trabalho participar politicamente, especialmente relacionados as disciplinas de administração e gerenciamento em enfermagem, por entender que é um dos cenários formativos possíveis para a formação das competências políticas dos profissionais. Para construir experiências formativas sobre o participar politicamente, o docente deve gerenciar o processo didático pedagógico a partir do projeto pedagógico do curso, articulando com a sua ex- 
pertise de conteúdos e práticas didáticas, bem como da visão ampliada do contexto da realidade. Destaca-se que as exigências do mercado de trabalho em saúde para profissionais com capacidade para resolver problemas, gerenciar conflitos, argumentar, dialogar, negociar, propor e alcançar mudanças, implementando estratégias que assegurem respostas efetivas nos serviços de saúde. Estas e outras são recomendações presentes nas Diretrizes Curriculares Nacionais para a Enfermagem (DCNENF), requerem projetos pedagógicos inovadores, articulados favorecendo a formação ampliada e generalista ${ }^{4}$. Destaca-se que a formação para participação política está em evidência, com um crescimento lento que necessita mais incentivo e mobilização não só dos docentes, mas dos pesquisadores em enfermagem.

\section{Objetivo}

Identificar conteúdos formativos para o processo de trabalho participar politicamente presentes nas ementas das disciplinas de administração em enfermagem.

\section{Método}

Estudo descritivo documental, com levantamento dos dados localizados no projeto pedagógico e ementas das disciplinas disponibilizados no site institucional e /ou pelos Coordenadores de doze Cursos de Enfermagem do Estado do Paraná, no período de agosto de 2017 a abril de 2018. Estruturados em cinco categorias que representam a similaridade dos assuntos pedagogicamente abordados.

\section{Resultados}

Em relação a categorização geral das disciplinas de administração, evidencia-se em média três a cinco por curso distribuídas em diferentes semestres, variando entre 40 a 160 horas. As disciplinas representam $4 \%$ do total das 4.000 horas nos cursos participantes deste estudo. Ressalta-se que 3 cursos apresentam disciplinas de estágio supervisionado específico para administração, nos demais localizado no projeto pedagógico que o estágio supervisionado deve envolver práticas de todos os processos de trabalho da Enfermagem. A análise das ementas possibilitou distribuir os temas em cinco categorias.A 1- A relação da Ciência da Administração em Enfermagem com outras Ciências e Políticas Públicas de Saúde, relacionado assuntos abrangentes, estruturantes e direcionadores para a administração em Enfermagem, destacando as teorias gerais da administração, a organização dos serviços de saúde e de enfermagem, o SUS e os modelos de atenção e de gestão em saúde. A 2- A administração dos serviços de saúde e de Enfermagem, englobando conteúdos formativos para a administração dos serviços de saúde e de Enfermagem, como protocolos, manuais, gerenciamento dos recursos físicos e materiais, de informação, de pessoal, destacando o dimensionamento da equipe de Enfermagem e as etapas de contratação e demissão de pessoal, bem como capacitação e qualificação e por último a de segurança do paciente. A categoria 3- A avaliação e controle de qualidade; envolvendo conceitos sobre a qualidade na saúde, os modelos de acreditação nacional e internacional, a auditoria, entre outros. A 4- Processo de trabalho em Enfermagem, destacando o gerencial e a sua articulação com o assistir, a pesquisa, a educação e o participar politicamente, nesta categoria foram agrupados temas que apoiam a formação política como: liderança, tomada de decisão, gerenciamento e negociação de conflitos e poder. Também inseridos explicitam a compreensão política em instituições, como a cultura organizacional, a motivação, a comunicação, o trabalho em equipe, interdisciplinar e multidisciplinar e a supervisão. A última categoria 5-Outras temáticas foram relacionadas assuntos como o empreendedorismo, a inovação e criatividade, entre outros.

\section{Discussão}

As ementas das disciplinas parecem estarem aliadas aos fundamentos teóricos e filosóficos das concepções de educação mais participativa, colaborativa, engajad̆a social e politicamente, delineados nos projetos pedagógicos dos cursos e no viés coerente com o contexto atual de saúde e sociedade. Bem como demonstram a quantidade e amplitude de temáticas que influenciam o trabalho do enfermeiro, especialmente o gerenciamento. Nas instituições de saúde as teorias e as concepções de administração e gerência são uma mescla entre o modelo clássico e aquelas com paradigma emergente. Considerando que o SUS é o maior empregador direto e indireto da Enfermagem é de se esperar que conteúdos que tratem deste sistema sejam explorados nas disciplinas de administração. O ensino de modelos de atenção e de gestão à saúde instituídos pelo Ministério da Saúde são fundamentais para o trabalho da Enfermagem, ressalta-se que o enfermeiro em muitos deles assume um papel de direção, liderando uma equipe de saúde e coordenando as redes de atenção. Entende-se que 
são espaços de poder e de ação política, que em muito visibilizam a atuação dos enfermeiros. A construção de protocolos ou manuais de procedimentos são significativos para a processo de participação política, porque requer dos profissionais a relação interdisciplinar e intersetorial, onde podem estabelecer processos de comunicação e de liderança. Este e outros projetos nos serviços de enfermagem e de saúde podem ser estratégias pedagógicas para que o aluno perceba a relevância de ter network, com profissionais, docentes, discentes e usuário, em que possa aplicar diferentes práticas profissionais apreendidas no seu processo formativo. $\mathrm{O}$ entendimento das condições culturais sociais, econômicas educacionais dos usuários e dos trabalhadores dos serviços de saúde é facilitador do ensino do processo de participação política, porque são estes atores estratégicos que conhecem e detém as condições e informações que interferem no processo saúde-doença e em determinadas situações dos serviços de saúde. Por serem aspectos estruturais e estratégicos devem ser significados e potencializados para o ensino da participação política. O trabalho da Enfermagem acontece em inúmeros espaços sociais, demonstrando visibilidade e abrangência da ação profissional. Esta ação acontece com a articulação de todas as dimensões do trabalho: assistir, gerenciar, ensinar, pesquisar e participação política, e que o ensino nas disciplinas de administração, não só, com os conhecimentos, mas possibilitando espaços pedagógicos em que os alunos exerçam os instrumentos gerenciais que apoiam a formação política, destaque para liderança, negociação, tomada de decisão, entre outros. Destarte salientar que o ensino do gerenciamento de recursos, são importantes para a organização do trabalho, mas são influenciadores na tomada de decisão seja para a implantação das ações em saúde ou as rotineiras nas instituições. Decisões que serão negociadas em instâncias colegiadas comissões, conselhos, conferências, espaços para o exercício formativo para recursos para a participação política. Como não foi analisado plano de ensino, não é possível neste momento inferir se processos pedagógicos e horas destinadas estão adequadas, reconhecendo como um grande limitante deste estudo.

\section{Conclusão}

A análise permitiu perceber a articulação dos docentes com as DCNEF e Projeto Pedagógico do curso como também inferir que são atuantes e participativos nos espaços em que a discussão sobre a educação em Enferma- gem está presente. Importante que o ensino do processo de participação política aconteça ao longo do curso e paulatinamente consolidando conteúdos e práticas que serão incorporados no arcabouço profissional, destacando que há no espaço universitários vários que devem ser estimulados, como as reuniões pedagógicas, as instâncias colegiadas e os centros acadểmicos, onde a horizontalidade de posições deve ser exercida, proporcionando a construção social de seus participantes. A Ciência da Administração em Enfermagem tem muito a contribuir na formação dos profissionais, mas principalmente de possíveis futuras lideranças, que muito precisamos.

Descritores: Enfermagem; Participação Política; Administração em Enfermagem; Ẻnsino Superior Enfermagem.

\section{Referências}

1. Organização Pan-Americana da Saúde. Diretriz estratégica para a Enfermagem na Região das Américas. Washington DC: OPAS, 2019.

2. Machado MH (coordenadora). Perfil da enfermagem no Brasil: relatório final: Brasil. Rio de Janeiro: NERHUS/ DAPS/ ENSP/Fiocruz; 2017.

3. Sanna MC. [Work processes in Nursing]. Rev. bras. enferm [Internet]. 2007 [cited 2019 Aug 09];60(2):221-224. Available from: http://dx.doi.org/10.1590/Soo3471672007000200018. Portuguese.

4. Ministério da Educação (BR). Conselho Nacional de Educação. Resolução CNE/CES no. 3 , de 7 de novembro de 2001. Institui Diretrizes Curriculares Nacionais do Curso de Graduação em Enfermagem. Brasília, Diário Oficial da União, 9 nov. 2001. Seção 1. p. 37

5. Kalinowski CE. A formação dos docentes de administração e gerência em Enfermagem para o ensino da participação política (Tese) São Paulo, Escola Paulista de Enfermagem da Universidade Federal de São Paulo. 2020. 


\section{REAÇÕES TRANSFUSIONAIS NA PRÁTICA HEMOTERÁPICA DE ENFERMAGEM: UM ESTUDO DE REVISÃO}

Rosana Amora Ascari

Cauana Gasparetto

Natallya Carla Rodrigues

Renata Gobetti Borges

Samara Lunardi

Bianca Gabriela Pasa Begnini

\section{Introdução}

A transfusão de hemocomponentes é um procedimento técnico muito utilizado como meio de repor componentes sanguíneos para salvar vidas. Entretanto, a mesma possui riscos em todas as etapas, desde a seleção do doador de sangue e derivados, até a transfusão sanguínea propriamente dita, dando ênfase para as reações transfusionais imediatas e tardias ${ }^{1}$. Assim, quando se trata de riscos relacionados ao receptor de transfusão, independente de ser transfusão autóloga onde o doador do hemocomponente e o receptor são a mesma pessoa, ou alogênica quando o doador e receptor são individuos diferentes, deve-se lembrar que as reações podem ser classificadas quanto ao tempo de aparecimento, ou seja, é considerada reação imediata quando ocorre durante ou até 24 horas após o início da transfusão, já a reação tardia relaciona-se quanto o seu aparecimento após as 24 horas do início do procedimento. Assim, a gravidade da reação transfusional, pode ser classificada em 4 graus, onde o grau 1 significa ausência de risco de vida e o grau 4 o mais grave representado pelo óbito do paciente, resultado do procedimento transfusional. Nesta mesma lógica pode-se classificá-las em relação a correlação, ou seja, se o evento adverso está ou não relacionado a transfusão. Portanto, a última classificação das reações transfusionais é quanto ao diagnóstico da mesma, onde os principais são: Reação Febril 
não hemolítica (RFNH) definida como presença de febre ou tremores durante a transfusão ou até quatro horas após a mesma; Reação Alérgica (ALG) descrita como aparecimento de hipersensibilidade durante ou até quatro horas após a transfusão; Reação Hemolítica Aguda Imunológica (RHAİ) caracterizada como rápida destruição dos eritrócitos durante a transfusão ou até 24 horas após a mesma; Reação Hipotensiva relacionada a transfusão (HIPO) definida como uma queda maior ou igual a $30 \mathrm{mmHg}$ e aferição menor ou igual a $80 \mathrm{mmHg}$ da pressão arterial sistólica em pessoas acima de 18 anos; Dispnéia Associada à Transfusão (DAT) caracterizada como desconforto respiratório dentro das primeiras 24 horas; Sobrecarga circulatória Associada à Transfusão (TACO) onde surge um edema pulmonar durante o procedimento hemoterápico ou até seis horas após; Reação Hemolítica não Imune (RHANI), neste caso ocorre hemólise durante ou até 24 horas após a transfusão do hemocomponente, podendo ser assintomático ou não². Dessa forma, frente a necessidade de garantir a segurança em relação ao ciclo do procedimento hemoterápico, que os profissionais da área da saúde se familiarizem com as orientações da Portaria № 158 , de 4 de fevereiro de 2016 que redefine o regulamento técnico de procedimentos hemoterápicos ${ }^{3}$, buscou-se responder a seguinte questão norteadora: $\mathrm{O}$ que a literatura científica aborda sobre as reações transfusionais relacionados à prática profissional de enfermagem em hemoterapia?

\section{Objetivo}

Sintetizar os achados científicos acerca das reações transfusionais na prática clínica de enfermagem em hemoterapia.

\section{Método}

Trata-se de uma revisão integrativa da literatura realizada na Biblioteca Virtual em Saúde (BVS) tendo critérios de inclusão, artigos publicados no período de janeiro de 2016 à dezembro de 2020, nos idiomas inglês, português e espanhol, artigos originais em texto completo, gratuitos e disponíveis eletronicamente. Utilizou-se como estratégias de busca, o cruzamento dos descritores em saúde com o operador booleano OR e AND em três idiomas, à saber: "Transfusão de Componentes Sanguíneos" OR "Reação Transfusional" AND "Enfermagem" OR "Cuidados de Enfermagem"; "Blood Component
Transfusion" OR "Trasfusion Reaction" AND "Nursing" OR "Nursing Care" e; "Transfusión de Componente Sanguineos" OR "Reacción a la Transfusión" AND "Enfermería" OR "Atención de Enfermería”. A busca resultou em 69 artigos, os quais foram importados para o Programa Academical para análise e classificação em pastas identificadas conforme critérios de inclusão (Reacões transfusionais na prática hemoterápica de enfermagem) e exclusão (Fuga do tema) previamente definidos. $\mathrm{Na}$ Etapa I procedeu-se a leitura dos títulos e resumos $(n=69)$. Os artigos incluídos nessa etapa $(n=25)$ compuseram a Etapa II, representada pela busca e leitura do texto completo. Assim, foram descartados dez artigos por serem pagos, um por duplicidade e três por fuga do tema, sendo incluídos nesta revisão $\mathrm{n}=11$ artigos. Aplicou-se a técnica de análise de conteudo ${ }^{4}$. Este estudo faz parte do Grupo de Estudos Sobre Saúde e Trabalho (GESTRA) e está alinhado à macro pesquisa intitulada: "Tecnologia educativa organizacional: melhores práticas para a gestão da segurança em procedimentos hemoterápicos".

\section{Resultados e Discussão}

Dos onze artigos inclusos, dez estavam disponíveis em inglês e um em português. Os artigos foram publicados nos periódicos: Revista de Enfermagem da UERJ; Hematology, Transfusion and Cell Therapy; Revista Brasileira de Enfermagem; Journal of Clinical Medicine; Current Oncology Reports; Transfuion Med Rev.; Transfusion Medicine; Vox Sang; Asian Journal Transfusion Science; Arch Pathol Lab Med. e; Transfusion Medicine Reviews. Os anos de publicação foram: $2020(\mathrm{n}=02), 2019(\mathrm{n}=03), 2018(\mathrm{n}=\mathrm{O} 2)$, $2017(n=03)$ e $2016(n=01)$. Evidencia-se que a identificação e notificação de reações transfusionais em pacientes institucionalizados ainda é incipiente e denota fragilidades que requerem atenção, especialmente da enfermagem que desenvolve assistência ininterrupta junto ao paciente hospitalizado. Foi possivel identificar fragilidades envolvendo a equipe de enfermagem durante a assistência hemoterápica, tais como, o desconhecimento de legislação específica, do tempo mínimo e máximo de infusão de hemocomponentes, dificuldade de identificação da reação transfusional, bem como sinais e sintomas característicos da mesmas. Mesmo os profissionais de enfermagem envolvidos diretamente na assistência não saberiam agir no caso de o paciente apresentar reações transfusionais, 
sendo que a maioria dos profissionais nunca participaram de treinamento sobre reações transfusionais e não conhecem o formulário para notificação de eventos adversos na instituição onde atuam. Há falta de compreensão do programa de hemovigilância e de cultura de notificação de eventos adversos pelos profissionais, medo de punição e carência de profissionais com expertise/experiência em hemovigilância. Nota-se que os eventos adversos relacionados a transfusão são bai$x{ }^{5}$, seja por sua baixa incidência, falta de reconhecimento clínico, notificação inconsistente, entre outros. A literatura sinaliza que as demandas de hemotransfusão são, majoritariamente decorrentes de anemia por doença neoplásica, hemorragias e fraturas, as reações são mais frequentes em paciente politransfundidos, e que, mais de dois terços das reações transfusionais não são relatadas/ notificadas. A baixa incidência de reações transfusionais, observada em diferentes estudos, pode ser decorrente da subnotificação das reações, seja por falta de diagnóstico ou baixa importância de sua notificação, falta de consciência e feedback inadequado aos profissionais, ou ainda, pelos profissionais temerem consequências pessoais negativas durante a transfusão de sangue. Quanto às reações propriamente ditas, às reações transfusionais febris não hemolítica (FNHTR) estão ligadas aos leucócitos e citocinas em unidades de sangue e, há correlação de polimorfismo do gene CTLA 4 (proteína 4 associada a linfócitos $\mathrm{T}$ citotóxicos) com reação transfusional, uma vez que foram encontrados alelos de quatro polimorfismo de núcleo único "simples" do CTLA 4 com risco aumentado para reação adversa relacionada a transfusão. As infecções transmitidas por transfusão podem ser graves e resultar em morte, as quais foram minimizadas por estratégias bem sucedidas de seleção estrita de doadores e implantação de teste de ácido nucleico universal, que reduziram o risco de transmissão de vírus da imunodeficiência adquirida (HIV), vírus da hepatite B (HBV) e vírus da hepatite C (HCV) por meio de transfusão de sangue. As reações mais frequentes observadas em pacientes de cuidados paliativos foram reacão transfusional febril não hemolítica, sobrecarga circulatória associada à transfusão, reações transfusionais alérgicas, hemolíticas e hipertensiva, não especificada e outros eventos adversos. Entre as reações transfusionais prevalentes estão as reações alérgicas, reação transfusional febril não hemoliticas. Estima-se que eventos adversos como hemó- lise aguda ou tardia, lesão pulmonar aguda relacionada à transfusão, sobrecarga circulatória associada à transfusão, infecção transmitida por transfusão, doença enxerto contra hospedeiro associada à transfusão e púrpura pós-transfusão, são raros. Ainda, contaminação bacteriana foi evidenciado em plasma por Staphylococcus epidermidis e Pseudomonas, não sendo identificado contaminação de hemácias. As transfusões confirmadas como não complicadas foram associadas apenas a mudanças marginais nos sinais vitais peri-transfusionaiss. Além do aumento esperado na temperatura e na taxa de pulso observada nas reações febris à transfusão, outros achados notáveis incluem a observação de que as anormalidades dos sinais vitais pré-transfusionais podem predizer mudanças nos sinais vitais temporariamente associadas à transfusão ou complicações transfusionais ${ }^{5}$. Apesar da baixa incidência de reações transfusionais, ocorreram reações graves a fatais, o que serve de alerta dos ríscos na terapia e da importância do uso consistente das diretrizes de transfusão para evitar transfusões inadequadas. Há ocorrência de transfusões que carecem de evidência nas indicações de eficácia para não expor os pacientes a riscos desnecessários. Estudos demonstram que estratégia mais restritiva de transfusão pode ser mais apropriada em detrimento de transfusões liberais, podendo implicar em maior taxa de sobrevida.

\section{Considerações finais}

Por fim, foi possivel constatar que a notificação de eventos adversos relacionados à hemoterapia requer colaboração entre agência transfusional e profissionais assistenciais, do conhecimento e identificação oportuna de eventos relacionados à transfusão de hemocomponentes e hemoderivados, do adequado manejo clínico e da efetiva busca ativa e investigações dos casos. Ademais, diferentes fragilidades foram identificadas no que tange as reações transfusionais que podem ser sanadas com ações de educação permanente em saúde.

Descritores: Enfermagem; Prática transfusional; Reação transfusional; Segurança do paciente; Educação continuada.

Financiamento: Programas de Bolsas de Iniciação Científica Voluntário PIVIC da Universidade do Estado de Santa Catarina (UDESC). 


\section{Referências}

1. Protocolo de transfusão segura de hemocomponentes: agência transfusional HULW-UFPB: Hospital Universitário Lauro Wanderley da Universidade Federal da Paraíba. 2018. 39p. Disponível em: http://www2.ebserh.gov. br/documents/220250/3051126/Protocolotde+Tranfus\%C $3 \% \mathrm{~A}_{30+\text { Segura+HULW }+2018 .}$. pdf/a495501f-531d-4990-a6f7-202f10ao8991Acesso em: 24 jan. 2021.

2. Marco Conceitual e Operacional de Hemovigilância: Guia para Hemovigilância no Brasil. Agência Nacional de Vigilẩncia Sanitária. 2015. 77p. Disponível em: https://www. hemocentro.unicamp.br/arquivos/2018/og/ Guia-Hemovigilancia-Marco-conceitual_Anvisa2015-1.pdf. Acesso em 21 jan. 2021.

3. Brasil. Portaria $\mathrm{n}^{\mathrm{o}} 158$, de 4 de fevereiro de 2016: redefine o regulamento técnico de procedimentos hemoterápicos. Ministério da Saúde, 2016. Disponível em: http://www.in.gov.br/ web/dou/-/portaria-n-158-de-4-de-fevereiro-de-2016-22301274 Acesso em: 24 jan. 2021.

4. Minayo MCS. O desafio do conhecimento: Pesquisa qualitativa em saúde. $14^{\underline{a}} \mathrm{ed}$. São Paulo: Hucitec, 2014.

5. Gehrie EA, Roubinian NH, Chowdhury D, Branbilla D, Murphy EL, Gottschall JL et al. A multi-centr study investigating vital sign changes occurring in complicated and uncomplicatd transfusions. Vox Sang, 2018 Feb; 113(2):160-9. Doi: 10.1111/vox.12621. 


\section{MONITORAMENTO E AVALIAÇÃO DAS AÇÕES DE EDUCAÇÃO PERMANENTE EM SAÚDE NOS PLANOS DOS ESTADOS BRASILEIROS}

\author{
Suelen Guedes Souza \\ Camila Fonseca Figueiredo \\ Vitória Valéria Cristo Santos \\ Silvana Lima Vieira
}

\section{Introdução}

Os Planos Estaduais de Educação Permanente em Saúde (PEEPS) são instrumentos de gestão da Política Nacional de Educação Permanente em Saúde (PNEPS) no âmbito estadual, municipal e no Distrito Federal. Por guiarem a formulação de propostas, organização e execução das ações de educação permanente do pessoal de saúde direta e indiretamente envolvidos na prestação de serviços de atenção básica, especializada e hospitalar, e com a gestão/gerência de serviços e programas de saúde'. A PNEPS expressa relação com os princípios e diretrizes do Sistema Único de Saúde (SUS), da Atenção Integral à Saúde e da Cadeia do Cuidado Progressivo à Saúde promovendo a ideia de rede dos serviços da atenção primária, secundária e terciária ${ }^{2}$. Além disso, a elaboração da PNEPS deve se constituir em um processo político participativo que incorpore distintos atores/sujeitos e organizações responsáveis pelas ações de Educação Permanente em Saúde (EPS) dos profissionais e trabalhadores do SUS'. Nesse sentido, os planos têm o objetivo de orientar um processo de programação geral de ações nesta área finalizando com sugestões para a elaboração de uma agenda governamental destacando prioridades, viabilidades e previsão orçamentária que balize a gestão do PEEPS no período de sua execução. Ademais, para a construção dos planos é indispensável a utilização de métodos, técnicas e instrumentos para recolher, processar e anali- 
sar distintas informações, como: demográfica, epidemiológica, socioeconômica, política, técnica e administrativa. Tal qual orienta a análise de problemas, identificação de necessidades e elaboração de propostas de ações de EPS. Neste instrumento, a avaliação e monitoramento das ações se constituem como uma importante ferramenta para a gestão na decisão temática das ações e dos seus impactos. E em uma perspectiva de cidadania, a avaliação pode vir a se constituir em um importante instrumento para controle social por parte da sociedade.

\section{Objetivo}

Analisar as estratégias de monitoramento e avaliação das ações de Educação Permanente em Saúde (EPS) contidas nos planos dos Estados Brasileiros.

\section{Método}

Trata-se de uma pesquisa qualitativa, com base na análise documental. Previamente foi realizada uma revisão sistemática de literatura com propósito de sistematizar a leitura e análise dos documentos, orientada pela seguinte questão norteadora: como se apresentam as estratégias de monitoramento e avaliação das ações de Educação Permanente em Saúde (EPS) contidas nos planos dos Estados Brasileiros? A fonte de informações foram os Planos Estaduais de Educação Permanente em Saúde dos 26 estados do Brasil e Distrito Federal, disponíveis em meio eletrônico no portal do Conselho Nacional de Secretários de Saúde (CONASS). O período da coleta foi de setembro de 2019 à janeiro de 2020. O recorte temporal adotado neste estudo considerou as publicações e vigências dos planos que representassem o período mais atual, finalizando em 2023. Foram incluídos no estudo os PEEPS disponíveis na íntegra em meio eletrônico. Os dados foram produzidos a partir da revisão de 27 PEEPS, os quais foram lidos na íntegra e nomeados com a letra (E), seguida de numeral ordinal de 1 à 27 . Utilizou-se a Análise de Conteúdo (AC) de Bardin (2016), tomando como categoria central o monitoramento e avaliação das ações de EPS. Para a AC são utilizados três polos cronológicos correlacionados, são eles: Pré-Análise; Análise do Material; Tratamento dos resultados, Inferência e Interpretação3. O instrumento de coleta de dados nos documentos consistiu em uma matriz contendo as seguintes variáveis: estado, período/vigência do plano, público-alvo, objetivos gerais e específicos, avaliação e monitoramento. A análise dos documentos foi subsidiada pelas seguintes categorias analíticas: monitoramento das ações de EPS e avaliação das ações de EPS. Tais categorias possibilitaram traçar um panorama de como a temática de monitoramento e avaliação é tratada e proposta como instrumentos de gestão para as ações de EPS em cada Estado. Todos os documentos são de domínio público e encontram-se disponíveis na página eletrônica do CONASS.

\section{Resultados e Discussão}

A elaboração dos Planos nos Estados foi impulsionada pelo Programa para o Fortalecimento das Práticas de Educação Permanente em Saúde no SUS (PRO EPS-SUS), que teve iniciativa da Secretaria de Gestão do Trabatho e da Educação. Uma das finalidades do PRO EPS-SUS é prover às instâncias locais de apoio técnico institucional e financeiro para a elaboração dos PEEPS 4 . Os planos estaduais revelam uma diversidade de formatos utilizados na sua construção, indicando que os documentos não seguem um padrão comum de organização e elaboração, amparados na análise das vigểncias dos planos, que variaram do início em 2018, 2019 e 2020 e com final em 2020, 2021, 2022 e 2023, tendo, a maioria, duração de quatro anos. Bem como nos objetivos gerais e específicos, que versam sobre algumas linhas de atuação como a vigilância a saúde, urgência e emergência, gestão em saúde, educação em saúde, atenção básica, entre outros. Contudo, dos 27 PEEPS encontrados, 13 planos não delimitam seus objetivos gerais e/ou específicos. Já o público-alvo delimitado no plano definiram ter como gestores e trabalhadores da saúde a partir do problema ou ação a ser realizada. Entretanto, dos PEEPS analisados, 10 não delimitam o público-alvo de suas ações. Quanto às estratégias de monitoramento e avaliação, os PEEPS foram organizados em níveis incipiente, moderado e avançado, de acordo com as estratégias de avaliação e monitoramento descritos nos planos, sendo utilizados os seguintes critérios: Nível Incipiente: composto pelos estados com pouca ou nenhuma referência ao monitoramento ou avaliação do plano; faz menção ou previsão de estratégias de monitoramento ou avaliação, porém não traz informações sobre a implementação. Nível Moderado: composto pelos estados com ações muito amplas, sem apresentar descrição detalhada do como monitorar; menciona as parcerias interinstitucionais; e indica o tempo para realização do monitoramento. Nível Avançado: estados que 
apresentam estratégias mais bem detalhadas, exemplificando a metodologia e indicadores a serem utilizados para avaliar e monitorar as ações do PEEPS, além disso, fazem menção a parcerias interinstitucionais e indicam o tempo em que será realizado o monitoramento das ações. Após a categorização da avaliação e monitoramento dos 27 PEEPS através dos níveis supracitados, temos como resultado que: A região Sul apresenta os três planos (100\%) em nivel avançado. A região Sudeste apresenta três planos $(75 \%)$ em nível avançado e um (25\%) no nível moderado. A região Centro-Oeste possui um plano (25\%) a nível avançado, dois planos no nível moderado (50\%) e um $(25 \%)$ a nível incipiente. Ao analisar a região Nordeste seis planos (66\%) estão a nível moderado e 3 planos (33\%) foram categorizados como incipiente. No que concerne a região Norte três planos $(42,86 \%)$ foram categorizados nível moderado e quatro planos $(57,14 \%)$ a nível incipiente. Os PEEPS da região Sul e Sudeste descrevem de forma mais detalhada as estratégias de monitoramento e avaliação, contemplando o nível avançado. A região Nordeste é a que mais se destaca quanto ao nível moderado, bem como a região Centro-Oeste. Com relação ao nível incipiente, a região Norte apresenta maior predominância de estados nessa categoria. Vale destacar que não é possível afirmar que os estados categorizados a nível incipiente não realizam o monitoramento e avaliação, mas sim que nos planos não está descrito, revelando, desse modo, a fragilidade do instrumento de gestão. Destaca-se que a temática de monitoramento e avaliação apresentada em alguns planos apresenta fragilidades em relação ao detalhamento do processo de análise das ações propostas. A análise em profundidade da composição de somente um quadriênio dos Planos Estaduais de Educação Permanente em Saúde consiste em uma limitação do estudo, por não permitir realizar comparações com a gestão e secretarias de saúde anteriormente vinculadas. Destaca-se também a não padronização dos planos, dificultando, dessa forma, a proposta de análise e correlação dos PEEPS.

\section{Conclusão}

O monitoramento e avaliação das ações de EPS apresentados nos PEEPS revelam-se como uma prática desafiadora, por isso pouco institucionalizada e implementada, apresentando-se como lacuna de conhecimento no âmbito acadêmico e da gestão, embora seja um importante instrumento para a gestão de tra- balhadores do SUS ao subsidiar tomadas de decisão e conhecimento de áreas prioritárias e de interesse para a melhoria do cuidado e gestão qualificada. Por esses aspectos, a implementação e institucionalização do monitoramento e avaliação das ações propostas na Política Estadual de Educação Permanente em Saúde constitui um desafio para gestores e trabalhadores do SUS, evidenciado pela lacuna e superficialidade do objeto verificado no estudo.

Descritores: Educação Permanente; Política Pública; Monitoramento; Avaliação de Programas e Projetos de Saúde; Sistema Único de Saúde.

Financiamento: Este estudo foi financiado pelo Programa de Iniciação Científica da Universidade do Estado da Bahia (PICIN-UNEB) no período de 2019/2020.

\section{Referências}

1. Ministério da Saúde (BR). Secretaria de Gestão do Trabalho e da Educacão na Saúde. Departamento de Gestão da Educação na Saúde. Planejamento das Ações de Educação Permanente em Saúde no Sistema Único de Saúde: Orientações. Brasília (DF); 2018.

2. Ministério da Saúde (BR). Secretaria da Gestão do Trabalho e da Educação na Saúde. Departamento de Educação em Gestão da Saúde. Política Nacional de Educação Permanente em Saúde. Brasília (DF); 2009.

3. Bardin, L. Análise de conteúdo. 1.ed. São Paulo: Edições 70; 2016.

4. Ministério da Saúde (BR). Secretaria da Gestão do Trabalho e da Educação na Saúde. Departamento de Educação em Gestão da Saude. Manual Técnico 2018: Programa para o Fortalecimento das Práticas de Educação Permanente em Saúde no SUS PRO EPS-SUS. Brasília (DF); 2018. 
Pesquisa Original

\section{O QUE PODE UMA PESQUISA? CARTOGRAFIA COMO DISPOSITIVO DE EDUCAÇÃO PERMANENTE NA ATENÇÃO BÁSICA}

\author{
Josiane Moreira Germano \\ Tatiana Almeida Couto
}

Alba Benemérita Alves Vilela

\section{Introdução}

O processo de trabalho em saúde tem ganhado bastante visibilidade nas pesquisas em Saúde Coletiva. Dada a complexidade do trabalho e do reconhecimento da atenção básica como dispositivo potente para o cuidado em saúde, compreende-se que os cotidianos abarcam grandes desafios para a gestão do trabalho e cuidado. Nas unidades de saúde, nota-se que cada trabalhador ocupa as cenas com suas intencionalidades disputando projetos de cuidados, de trabalho e de gestão, isso acontece, mediante as distintas experiências nas trajetórias acadêmicas e profissionais. Isso coloca o trabalho em saúde como um espaço de produção intensa de saberes-fazeres-viveres em ato, por meio dos encontros, que constituem os cotidianos das unidades de saúde. Desta maneira, assume-se que a organização dos serviços implica em grandes desafios metodológicos para os processos investigativos ${ }^{1}$.

\section{Objetivo}

Apresentar a proposta de uma pesquisa que serviu como dispositivo de Educação Permanente em Saúde no processo de trabalho do Núcleo Ampliado de Saúde da Família e Atenção Básica (NASF-AB). 


\section{Método}

Trata-se de um estudo proveniente de uma dissertação de mestrado na qual buscou analisar o processo de trabalho de uma equipe do NASF-AB. A pesquisa ocorreu de outubro de 2017 a outubro de 2018 em um município de pequeno porte na Costa do Cacau, no interior da Bahia. Participaram da pesquisa, os profissionais do NASF-AB e residentes multiprofissionais em Saúde da Família, além de dois pesquisadores colaboradores na relatoria. Apostamos na perspectiva micropolítica de análise e de produção do conhecimento que buscou dar visibilidades às permanentes disputas e campos de força em todos os planos, possibilitando experienciar diversas cenas do cotidiano. Sendo assim, imergimos no campo utilizando a cartografia proposta por Gilles Deleuze e Félix Guattari, ancorados pela obra "Mil Platôs: capitalismo e esquizofrenia", publicada no Brasil em 1995. Adotada por diversas áreas, a cartografia se faz potente por apostar na capilaridade, na multiplicidade, ampliando conceitos, como campo, território e pesquisa (inserindo os aspectos subjetivos e as produções de subjetividade que compõem esses territórios/espaços/campos, no nosso caso, as produções subjetivas que são produzidas acerca do trabalho, cuidado, gestão e até mesmo da própria atenção básica, que tem sido bastante atravessada por um conjunto de forças bastante hegemônicas). A cartografia também entra em cena, como um mapa aberto a ser cartografado, experienciado. Assim, o processo de trabalho em saúde é possível ser explorado por diversos planos/ composições, por múltiplas entradas. Utilizando o rizoma, conceito-chave da teoria de Deleuze e Guattari, nossa proposta foi experienciar distintos espaços nas quais os processos de trabalho eram produzidos, ou seja, unidades de saúde, escolas, igrejas, secretaria de saúde, praças, ruas, salões comunitários e domicílios. O território se fez como um espaço vivo, dinâmico em produção constante. Assim, a cartografia, como intercessor metodológico que pressupõe maior superfície de contato com o campo, não opera na dissolução entre pesquisadores com aquilo que se propõe analisar, mas sim, mediante ao que é experienciado, abre possibilidades, reflexões sobre aquilo que é vivido. A cartografia tem como elemento fundamental o encontro, o "pesquisar-com", pesquisar com o corpo, dando passagens aos afetos e ao campo do desejo (desejo na perspectiva dessa teoria é tido como potência para ação, como motim para a prática social nos territórios). Então, foi possível recolher pistas que emergiram no decorrer da pesquisa, as quais serviram como dispositivos para a construção de espaços reflexivos sobre o cotidiano do trabalho. Construídos com os trabalhadores do NASF-AB, este espaço foi denominado como Oficinaulas, proposta por Elisandro Rodrigues ${ }^{3}$ que apostou no arranjo de espaços coletivos embebidos por dinâmicas, pinturas, desenhos, colagens, murais, rodas de conversa, cirandas, produções intensas de conhecimento em um fluxo de linhas do desejo em ir além do habitual, do movimento dos corpos que proporcionam aberturas para debates, diálogos, denominada pelo autor como "nem oficina e nem aula, mas sim espaço de encontros". Dessa forma, foram produzidas quatro Oficinaulas (cada uma com média de 3 horas de duração): "conversando sobre o trabalho"; "de repente NASF-AB", "a Educação Permanente em Saúde em nosso cotidiano" e, "NASF-AB e as ferramentas para produção do cuidado: Educação Permanente em Saúde, Apoio Matricial e Clínica Ampliada". Ressalta-se que este projeto de pesquisa foi submetido e aprovado pelo Comitê de Ética em Pesquisa da UESB, sob CAAE 61486015.9.0000.0055.

\section{Resultados e Discussão}

Agenciados pela pergunta de Feuerwerker e Merhy "Como temos armado e efetivado nossos estudos, que fundamentalmente investigam políticas e práticas sociais de gestão e de saúde?", título de uma pesquisa sobre atenção domiciliar, tecemos algumas reflexões que fazem vizinhança com nossas apostas. Evidenciaremos três delas. A primeira, diz respeito à própria construção metodológica de estudos no campo da cartografia, que tem por objetivo a produção de sentidos neste processo de investigação para o pesquisador e o investigado. Sendo necessária a produção de um campo de implicação e a construção dos afetos no compartilhamento do conhecimento e da problematização (daí a importância da imersão nos territórios e o recolhimento dos efeitos desse cotidiano, das pistas que são deixadas nesses cenários), no refazimento de si e do outro nesse processo. O que, para nós, implica em processos de educação permanente em saúde (ou seja, auto análise daquilo que juntos, encontramos, e mediante isso, avaliamos e intervimos sempre em ato sobre os processos que eram vividos na atenção básica, por eles mesmos). Corroborando com Feuerwerker ${ }^{1}$; Figueiredo, Gouvêa e Silva', a pesquisa então, é capaz de funcionar como dispositivo de subjetivação sobre os corpos coletivos de ação no mundo do trabalho. 
Outra aposta de nosso estudo, a segunda, foi ampliar processos investigativos que vão além da demarcação de indicadores, mas sim, recolher efeitos das políticas de saúde no próprio cotidiano, onde o trabalho é produzido. Essa proposta se faz necessária, uma vez que apesar das regularidades exigidas pelas políticas de saúde, sabe-se que cada equipe produz seus próprios arranjos mediante a realidade local. Assim, a proposta cartográfica, também endereça os seus esforços para dar visibilidade às singularidades do que é "estar NASF-AB" em contextos nas quais esta equipe, alocada em um município de pequeno porte, amplia suas possibilidades para além do campo assistencial. Com isso, foi possivel participar de momentos, denominados como: Rodadas de Atenção Básica (que eram mensais), realizadas em concomitância com as reuniões de equipes e entre equipes nas unidades de saúde (estas, semanais e quinzenais). Esses espaços traziam consigo, a proposta de produzir discussões de casos, de reflexões sobre os processos de trabalho. Em que pese, ambos os espaços, bastante atravessados por um conjunto de forças biopolíticas, disciplinares e hegemônicas mas, que se fazia como um espaço potente para somar forças e constituir redes vivas de conexões com diversos serviços, disputando um outro sentido para as produções que seriam feitas entre aquelas equipes no município. Assim, essas duas apostas (produção de sentidos nos atos investigativos e a cartografia como intercessor metodológico) nos conduziram a nossa terceira, ou seja, que era ampliar a ideia de atenção básica e de como ela pode ser potente enquanto um território que está em processo e produção constantes e "indeterminados" apesar de vivenciarmos na época, as mudanças na política de atenção básica (por meio da Portaria $n^{-0} 2.436$ de 21 de setembro de 2017 , que aprovava a revisão de diretrizes para a organização do SUS). O sentido de "indeterminado" faz menção às diferentes experiências dos distintos atores que compõem a atenção básica, colocando este cenário em permanentes disputas de processos de trabalho, cuidado e de gestão, bem como o sentido de território para além da adscrição de clientela mas sim, considerando que é intersubjetivo, coletivo levando em considerações as mais diversas produções de existências (apesar da limitação imposta pelas metas, pelo gerencialismo, ao encontro). Portanto, desta pesquisa, identificamos que o processo de trabalho em saúde é complexo e diverso, é altamente disputado, imprimindo ao trabalho, a atenção básica, ao NASF-AB, ao SUS um território micropolítico de encon- tros em constante producão. Mediante isso, o trabalho das equipes produz algumas linhas de fuga, seus arranjos, driblando as dificuldades impostas pelas políticas governamentais e até mesmo os ruídos entre as equipes.

\section{Conclusão}

Assim, esta pesquisa, ao utilizar-se da cartografia permitiu que trouxéssemos para a cena dispositivos que dialogassem com as demandas daquelas equipes e que as Oficinaulas, também se constituiram como espaços de acolhimentos, de trocas, de produções de narrativas que ampliaram o sentido do trabalho para os trabalhadores e, para os pesquisadores, a possibilidade de articulação de equipes de saúde e academia, na produção de sentidos, de acolhimento, conhecimento pavimentados pelos afetos, experiências pelas cartografias, pelos espaços cenopoéticos que se renovaram em auto análise do cotidiano.

Descritores: Educação Continuada, Atenção Primária à Saúde, Cartografia, Equipes de Assistência à Saúde, Trabalho.

Financiamento: Fundação de Amparo à Pesquisa do Estado da Bahia/FAPESB.

\section{Referências}

1. Feuerwerker LCM. Pensando avaliação em Políticas e na Gestão em Saúde numa perspectiva cartográfica - construção compartilhada que favorece a mudança. In: Tanaka OY, Ribeiro EL, Almeida CAL. (Orgs.). Avaliação em saúde: contribuições para incorporação no cotidiano. 1ed. Rio de Janeiro: Editora Atheneu; 2017;1: 29-36.

2. Deleuze G, Guattari F. Mil Platôs: Capitalismo e Esquizofrenia 1. ed. Rio de Janeiro: 34, 1995;1.

3. Rodrigues E. Clínica de uma vida: estilhaços de Educação e[m] saúde. [dissertação]. Porto Alegre (RS): Universidade Federal do Rio Grande do Sul, Porto Alegre, 2015.

4. Feuerwerker LCM, Merhy E. Como temos armado e efetivado nossos estudos que fundamentalmente investigam políticas e práticas sociais de gestão e de saúde. In: Matos RA, Baptista TWF (Orgs.). Caminhos para a análise de política de saúde. Rio de Janeiro: Rede Unida; 2011: 290-305.

5. Figueiredo EBL, Gouvêa MV, Silva ALA. Educação Permanente em Saúde e Manoel de Barros: uma Aproximação Desformadora. Revista Brasileira de Educaçã̃o Médica. 2016; 40(3): 324-31. 
Pesquisa Original

\section{EDUCAÇÃO PERMANENTE NO PROCESSO DE TRABALHO DAS EQUIPES DE SAÚDE/ ATENÇÃO BÁSICA: USOS E SENTIDOS}

\author{
Josiane Moreira Germano \\ Tatiana Almeida Couto
}

Alba Benemérita Alves Vilela

\section{Introdução}

A educação permanente é utilizada e desenvolvida em diversos campos de saberes e práticas (como o campo da educação, pedagogia e também da área da saúde). Seus usos na saúde coletiva brasileira abarcam dimensões e sentidos amplos. Como todo conceito, a Educação Permanente em Saúde (EPS) apresenta uma ideia polissêmica que pode ser vista em diversas experiências, experimentações que ocorrem no cotidiano dos serviços de saúde nas mais distintas regiões do país, e nas produções de coletivos de pesquisadores da área'. Assim, observa-se que as interpretações para operar/produzir/fabricar/compreender a EPS nos serviços são plurais. O mesmo acontece com tantos outros conceitos como: território, atenção básica, atenção primária, acolhimento, educação em saúde e integralidade, por exemplo. Muitos, algumas vezes, são tomados por sinônimos, como temos visto no caso da atenção básica e atenção primária, assim como EPS e educação continuada/capacitação, apesar das bases teoricas, as apostas, o entendimento não os convergir para que sejam sinônimos mas sim, campos de tensão e disputas constantes que se juntam para pensar o trabalho, a gestão, a atenção e o cuidado em saúde. Considerando que estes conceitos (que podem e são tomados como conceito-ferramenta) também são constituídos a partir dos processos de subjetivação, uma vez que atravessam trabalhadores, gestores e usuários e, pode-se dizer que são bastante "provisórios", visto que seus usos e sentidos são revisitados/re- 
interpretados, sendo concorridos, o tempo todo, pelos diferentes atores que compõem as unidades de saúde, apesar das normativas/diretivas impostas pela própria política de EPS. Desta maneira, as estratégias de utilização da EPS no SUS também acontecem a seu modo, muito singular. Em alguns lugares, de forma mais participativa, é utilizada como dispositivo de gestão de coletivos e, em outros locais, nota-se a sua utilização no caráter de formação permanente, capacitação e ainda, como estratégia pedagógica².

\section{Objetivo}

Apresentar os usos e os sentidos da EPS no processo de trabalho de equipes de saúde da família e Núcleo Ampliado de Saúde da Família e Atenção Básica (NASF-AB).

\section{Método}

Este estudo integra as análises de uma dissertação de mestrado que se propôs a recolher os efeitos das políticas de saude no âmbito da atenção básica a partir da imersão no processo de trabalho de uma equipe do NASF-AB. A pesquisa ocorreu em um município de pequeno porte localizado no interior da Bahia no período de um ano (de outubro de 2017 a outubro de 2018). Como intercessor metodológico utilizou-se a cartografia proposta pelos filósofos franceses Gilles Deleuze e Félix Guattari, como proposta metodológica proveniente dos estudos da filosofia da diferença, como um novo paradigma ético-estético discutido pelos autores. No Brasil, a cartografia emerge em 1989 através de Suely Rolnik com o seu livro intitulado Cartografia Sentimental', que conceituou a cartografia como a conformação do desejo (como produção) no campo social. Esta proposta defende um pensar imanente que existe sempre em um dado objeto e é inseparável dele. Então, a cartografia produz um processo chamado de desterritorialização, ou seja, amplia a construção espacial de campo para inaugurar outros modos de produção de conhecimento, modos estes que envolvem produções artísticas, poéticas, de criação e imbricação/implicação daquele que se propõe a habitar (pesquisador/cartógrafo/investigados) estes espaços/territórios. Desta maneira, este estudo valeu-se de múltiplas ferramentas como: observação participante, diário de campo, rodas de conversa e informações diretas dos trabalhadores do NASF-AB e residentes em Saúde da Família, totalizando 15 participantes de diversas categorias profissionais, além de dois pesquisadores (doutorandos em Enfermagem e Saude), na relatoria. Outra ferramenta utilizada para problematizar/dialogar/discutir sobre as pistas encontradas na produção de nossas cartografias, para melhor explorar referente ao objeto de investigação, foi a construção de espaços de encontros, inspirados nas produções de Ẻlisando Rodrigues ${ }^{4}$ denominada de Ỏficinaula que, apostou no arranjo de espaços coletivos compostos por dinâmicas, pinturas, desenhos, colagens, murais, rodas de conversa, cirandas, produções intensas de conhecimento para além do habitual, mas, em fluxos do desejo como produção social, de movimento dos corpos que proporcionam aberturas para debates, diálogos nestes espaço. Foram produzidas quatro Oficinaulas (cada uma com média de 3 horas de duração): "conversando sobre o trabalho"; "de repente NASF-AB", "a Educação Permanente em Saúde em nosso cotidiano" e, "NASF-AB e as ferramentas para produção do cuidado: Educação Permanente em Saúde, Apoio Matricial e Clínica Ampliada". Além de participar de outros eventos que compõem o trabalho das equipes no contexto da atenção básica por todo o território. Este projeto de pesquisa foi submetido e aprovado pelo Comitê de Ética em Pesquisa da UESB, sob CAAE 61486015.9.0000.0055.

\section{Resultados e Discussão}

As experiências das cartografias produzidas no território existencial do processo de trabalho do NASF-AB permitiram que endereçássemos nossas análises, para este resumo, dando visibilidade a duas pistas. A primeira: trazendo os efeitos das políticas de saúde no cotidiano dos servicos (apresentando como era o processo de trabalho, como os profissionais entendiam as mudanças nas políticas de saúde) e, a segunda pista, como a EPS era fabricada/construida no processo de trabalho destas equipes (existiam espaços institucionais para que a EPS acontecesse ou como essas equipes compreendiam as produção para pensar o trabalho, o cuidado). Assim, mediante a primeira pista, denota-se que analisar os efeitos das políticas de saúde no cotidiano dessas equipes fez-se importante, uma vez que a aposta da EPS é colocar o trabalho em saúde em análise, já que o cotidiano sofre as influências das diretivas/normativas de tantas políticas de saúde (ressaltando as próprias políticas de $\mathrm{AB}$, de EPS e os modos de como a própria gestão também enxerga este processo). Desses atravessamentos, também se observou que o modo no qual os trabalhadores compreendem a sua realidade local, algumas prerrogativas/diretivas fazem mais ou menos sentido para os trabalhadores. Isto quer dizer que o trabalho em saúde é experimentado e experienciado de maneiras 
distintas pelas equipes da ESF/NASF. Deve-se levar em consideração suas trajetórias no SUS, como o SUS local é organizado, como são construídos os vínculos e como são as aproximações com os territórios. Assim, nota-se que o processo de trabalho desta equipe é altamente atravessado pelo modelo hegemônico estabelecendo os campos de disputas de projetos de cuidado e também de práticas. Porem, desses atravessamentos, observa-se que os trabalhadores fabricam linhas de fuga para driblar as limitações impostas pelas politicas de saúde, sobretudo pela diretiva da "meta", do protocolo, que acabam sendo dispositivos de captura do trabalho vivo. Mas, como escapar? Para Lemos ${ }^{1}$, a possibilidade de transformação do trabalho do SUS, a EPS, ancora-se a partir de três fundamentos centrais: a micropolitica do trabalho vivo, método da roda e problematização/aprendizagem significativa. A micropolítica do trabalho vivo reconhece o mundo do trabalho como espaço de criação de novas subjetividades essenciais para a mudança institucional. Micropolítica é um termo utilizado por Guattari, que tem influência de Deleuze. Assim, a micropolítica, diz respeito aos efeitos da subjetivação, conjunto de fenômenos e práticas capazes de ativar estados e alterar conceitos, percepções e afetos (modos de pensar-sentir- querer). Diante desse cenário, o campo foi se abrindo para que pensássemos na nossa segunda pista: infere-se que o NASF-AB dispara os processos reflexivos e dialógicos quando se encontram com as equipes, seja nas reuniões com as ESF, por meio do matriciamento e também da EPS. Sobre seus usos, nota-se que a EPS ocorre de maneira intrínseca ao trabalho, no cotidiano, nas reuniões de equipe do NASF, nas consultas integradas, nos grupos e no domicílio, no apoio mútuo entre os pares. Para alguns casos, observou-se que exploram o potencial pedagógico nesses espaços. Como proposta de qualificação do trabalho, EPS é uma proposta que o NẢS$\mathrm{F}-\mathrm{AB}$ tem em suas diretrizes, produzindo diferentes efeitos no contexto do trabalho. Assim, a EPS pode propiciar o fortalecimento da gestão do trabalho e do cuidado por meio de disputas de projetos, desterritorialização e construção de coletivos que desejam transformar o modo de produzir saúde e valorização dos trabalhadores no exercício de sua autonomia e desenhar novos processos no cotidiano ${ }^{2}$. Portanto, a EPS e o apoio matricial são tidos como dispositivos para produzir relações de proximidade entre profissionais de distintas áreas, projetos e campos de conhecimento 5 . Outro espaço cartografado foi um espaço institucionalizado de EPS que o município denomina como Rodadas de Atenção Básica, proporcionado pela gestão do Estado da
Bahia, com o apoio de Diretores e Técnicos das anteriormente intituladas de Diretorias Regionais de Saúde (DIRES), realizado mensalmente. Aqui, denota-se que os sentidos da EPS aparecem um pouco menos porosos ao que emerge do cotidiano, já que seu uso se aproxima do caráter continuado, com temática pré-determinada, mas que mesmo assim, ainda é capaz de produzir conversa já que é um encontro municipal.

\section{Conclusão}

Como visto, os serviços de saúde constituem-se como palco de muitas intencionalidades formadas por ações que disputam o sentido geral do trabalho. Nossas análises concluíram que a EPS pode ser uma prática que mobiliza desterritorializações nas equipes de trabalho em saúde, pois produz reflexão e autoanálise. Mas também pode ser captado por modelos instituídos e por olhares estritamente categorizados sobre o processo de trabalho, de gestão e de cuidado, levando a uma formação mais objetiva, positivista, com poucas flexibilidades e possibilidades de discussão das problemáticas do cotidiano.

Descritores: Educação Continuada; Atenção Primária à Saúde; Equipes de Assistência à Saúde; Trabalho.

Financiamento: Fundação de Amparo à Pesquisa do Estado da Bahia/FAPESB.

\section{Referências}

1. Lemos CLS. Educação Permanente em Saúde no Brasil: educação ou gerenciamento permanente? Ciênc. saúde coletiva, Rio de Janeiro, 2016; 21(3): 913-22

2. Feuerwerker LCM. Micropolítica e saúde: produção do cuidado, gestão e formação. Porto Alegre: Rede Unida, 2014.

3. Rolnik S. Cartografia Sentimental: transformações contemporâneas do desejo. $2^{\underline{a}}$ ed. Porto Alegre: Sulina, Editora da UFRGS, 2016.

4. Rodrigues E. Clínica de uma vida: estilhaços de Educação e[m] saúde. [Dissertação] Porto Alegre, Universidade Federal do Rio Grande do Sul, 2015.

5. Bertussi DC. O apoio matricial rizomático e a produção de coletivos na gestão municipal de saúde. 234 fls. Tese (Doutorado em Saúde Coletiva). - Faculdade de Medicina, Universidade Federal do Rio de Janeiro, Rio de Janeiro, 2010. 
Estudo de REVISÃo

\section{ANÁLISE DAS AÇÕES DE EDUCAÇÃO PERMANENTE CONTIDAS NOS PLANOS ESTADUAIS DE EDUCAÇÃO PERMANENTE EM SAÚDE}

\author{
Camila Fonseca Figueiredo \\ Suelen Guedes Souza \\ Vitória Valéria Cristo Santos \\ Silvana Lima Vieira
}

\section{Introdução}

Os avanços na área da educação na saúde, iniciaram a partir da implementação da Política Nacional de Educação Permanente em Saúde (PNEPS) que possui o objetivo de fortalecer a Educação Permanente em Saúde (EPS). A Educação Permanente é a aprendizagem no trabalho, onde o aprender e o ensinar se incorporam ao cotidiano das organizações e ao trabalho. Nesse sentido, a educação permanente se baseia na aprendizagem significativa e na possibilidade de transformar as práticas profissionais. ${ }^{1}$ As ações de EPS servem de incentivo para transformações no processo de trabalho das equipes, para uma melhor adequação dos atendimentos prestados ao modelo de atenção integral à saúde, como é proposto pelo Sistema Único de Saúde (SUS). ${ }^{2}$ A matriz avaliativa da PNEPS está estruturada em dimensões, sendo elas: a dimensão político-gerencial, do processo educativo e efeitos. A dimensão político-gerencial possui o objetivo de avaliar a implementação da política nas Secretarias Estaduais e sua formalização nos instrumentos legais e nas instâncias colegiadas do SUS. Podemos verificar essa dimensão nos planos a partir de indicadores de implementação e implantação além da institucionalização da política, aspectos do financiamento, participação intra e interinstitucional e se há processos sistematizados e contínuos de planejamento e avaliação das ações no âmbito da PNEPS. A dimensão Processo Educativo tem como objetivo avaliar a opera- 
cionalização e o desenvolvimento das ações de EPS no âmbito institucional das Secretarias de Saúde. Envolve aspectos das perspectivas pedagógicas, integração ensino-serviço e comunidade e práticas interprofissionais. Por fim, a dimensão Efeitos prevê avaliar os resultados obtidos e as inovações presentes no cotidiano de trabalho dos serviços advindas da implementação da PNEPS. Aborda o usuário da ação educativa, quer seja trabalhador, gestor, controle social, busca evidências da percepção dos usuários sobre a ação educativa, avaliação da aprendizagem e evidências de mudanças no processo de trabalho além do suporte institucional para a realização das mudanças. ${ }^{3}$

\section{Objetivo}

Analisar as ações de EPS que constam nos Planos Estaduais de Educação Permanente em Saúde (PEEPS), identificar as ações por linhas prioritárias e categorizar as ações segundo as dimensões político-gerencial, processos educativos e efeitos apresentadas nos planos estaduais.

\section{Método}

Trata-se de uma pesquisa avaliativa, com base na análise documental, tendo como fonte de coleta de informações os Planos Estaduais de Educação Permanente em Saúde dos 26 Estados Brasileiros e Distrito Federal, dos anos de 2018 a 2023, os quais foram encontrados no site de domínio público do Conselho Nacional dos Secretários de Saúde (CONASS). O período da coleta foi de setembro de 2019 à janeiro de 2020. O recorte temporal adotado neste estudo considerou as publicações e vigências dos planos que representassem o período mais atual. Foram incluídos no estudo os PEEPS disponíveis na íntegra em meio eletrônico. Os 27 PEEPS foram lidos na íntegra e nomeados com a inicial P (Plano) seguida do numeral arábico de 1 à 27. O instrumento de coleta de dados nos documentos consistiu de uma matriz construída no Excel contendo as seguintes variáveis: estado, ano de vigência do plano, objetivos gerais e específicos, público-alvo, metodologia de desenvolvimento das ações, linhas prioritárias e ações segundo as dimensões político-gerencial, processo educativo e efeitos apresentadas nos planos. Foi utilizada a Análise de Conteúdo de Bardin, tomando como ponto principal a ser abordado as ações de EPS contidas dos PEEPS. A análise de conteúdo desdobra-se em etapas, sendo elas: Pré-Análise; Análise do Material; Tratamento dos resultados, Inferência e Interpretação. ${ }^{4}$

\section{Resultados e Discussão}

Foi realizada uma análise das ações de EPS contidas nos planos, e assim foram identificadas 32 linhas prioritárias, que posteriormente foram divididas em 7 categorias, sendo elas: Redes de atenção à saúde; rede de apoio; rede cegonha; rede de urgência e emergência; componente sistema de apoio; educação e componentes da gestão. Sendo possível observar que as linhas prioritárias mais contempladas foram a Rede de Urgência e Emergência e os componentes da Gestão. As ações nos Planos estiveram mais voltadas à dimensão político-gerencial e do processo educativo, podendo notar a ausência da dimensão de efeitos dentro dos PEEPS. Essas dimensões foram evidenciadas devido a presença de elementos gerenciais, de acordo a proposta de institucionalizacão da política e elementos educativos que fomentam a prática da aprendizagem significativa, permitindo a integração ensino-serviço-comunidade e reflexão das práticas assistenciais. Quanto a análise das ações de Educação Permanente em Saúde nos estados brasileiros a partir dos PEEPS, verificamos que os objetivos gerais das ações dos PEEPS da região norte, menciona a necessidade de fortalecimento, implementação e institucionalização da EPS, chamando atenção o objetivo geral em quatro planos que reforçam a primordialidade desses aspectos. Em relação ao público-alvo, são instituídos na medida em que cada atividade é apresentada, com exceção de dois estados que não mencionam esta informação. No que se refere às metodologias para desenvolvimento das ações foram citados o uso de metodologias ativas como menciona um plano. Em dois planos são destacados a reflexão crítica, problematização e trabalho no território. A metodologia da problematização também é utilizada em um plano. Em dois planos não são mencionadas as metodologias utilizadas para desenvolvimentos das ações de EPS. Em relação aos planos da região nordeste, a apresentação dos objetivos das ações nos PEEPS são diversas. Cinco estados optaram pela apresentação em linhas de ação/eixos, um estado apresentou a objetivo geral de acordo com cada ação, mas não apresenta objetivo específico, um estado não menciona o objetivo geral, nem mesmo os específicos e dois estados do traçam o objetivo do plano como um todo. O público-alvo é delimitado somente em três planos de acordo com o problema ou ação a ser desenvolvida. Ao ser analisado as metodologias para desenvolvimentos das ações, dois planos abordam 
o uso de metodologias ativas para fundamentar a reflexão crítica, mas não descreve quais seriam as estratégias educacionais utilizadas. Um estado tambèm reforça a importância do uso de metodologias ativas, como aula expositiva e dialogada, estudo de texto, portfólio de aprendizagem, mapa conceitual, estudo dirigido, ensino em pequenos grupos, estudo de caso, atividades de educação a distância, painéis, palestras, discussões e debates, estudo do meio e ensino com pesquisa. Também elucida a necessidade de valorizar os elementos que incorporam o cotidiano vivenciado pelos atores sociais. Dois estados do nordeste não sinalizam quais metodologias serão utilizadas na execução das ações. Quanto à Região Centro-Oeste, em relação a apresentação dos objetivos gerais das ações, três estados estruturam-se em linhas de ação com objetivos próprios. Com relação às metodologias utilizadas para execução das ações, um estado apresenta-se conforme as linhas de ação, sendo utilizados métodos como seminários, rodas de conversa, cursos, especialização e treinamentos simulados e somente outro propõe a utilização de oficinas, cursos, capacitações e fóruns, com a proposta de atingir os objetivos estabelecidos em curto, médio e longo prazo. Em referência às estratégias educacionais, um estado sugere a utilização de metodologia da problematização com o Arco de Maguerez, aprendizagem baseada em equipe, método paidéia, aprendizagem baseada em projetos, apoio matricial, espiral construtivista, círculo de cultura, estudo de caso, brainstorming, painel integrado, grupos de estudo, ensino baseado em simulação, exposição dialogada, congressos, fóruns, conferências, seminarios, simpósios, workshops, relatórios, cursos e capacitações para promover situações de aprendizagem. A região sudeste apresenta nos seus planos os objetivos gerais em diversos formatos. Um estado não menciona os objetivos estabelecidos para a criação do plano, outro não apresenta as ações que serão desenvolvidas, afirmando que estas serão apresentadas posteriormente em outro documento. Somente dois planos apresentaram os objetivos gerais. Com relação ao público-alvo, dois estados não apresentam quais são os atores cujas ações são voltadas. Diante das metodologias propostas para desenvolvimento das ações estabelecidas, dois estados propõem o desenho anual dos projetos, permitindo conhecer fielmente as demandas e planejar conforme as necessidades. Na região sul, apenas um estado delimitou as ações, sendo estes apresentados em cada problema identificado no cenário ensino-servico-comunidade do estado. Dentre as metodologias utilizadas para execução das ações, um estado utiliza-se de cursos, seminários e oficinas e dois não apresentam os métodos para realização das ações.

\section{Conclusão}

Foi verificado que os PEEPS e as ações neles contidas são diversas, considerando a heterogeneidade do cenário nacional, e que a elaboração de alguns planos se apresenta frágil e incompleta, devido à ausência de um padrão a ser seguido pelos estados. Cada estado possui o plano organizado de acordo com suas particularidades, necessidades e objetivos, tendo em sua construção uma análise geral dos aspectos sociodemográficos. Por isso, a necessidade de que esse instrumento de planejamento da gestão e orientador de práticas contenham ações mais bem estruturadas e que tenham uma sistemática de monitoramento e avaliação.

Descritores: Educação Permanente; Política Pública; Sistema Único de Saúde.

Financiamento: Esse estudo contou com o financiamento do Programa de Iniciação Científica da Universidade do Estado da Bahia (PICIN-UNEB).

\section{Referências}

1. Ministério da Saúde (BR). Secretaria de Gestão do Trabalho e da Educação na Saúde. Departamento de Gestão da Educação na Saúde. Política Nacional de Educação Permanente em Saúde: o que se tem produzido para o seu fortalecimento? .1. ed. rev. - Brasília (DF); 2018.

2. Lima JVC de, Turini B, Carvalho BG, Nunes EFPA, Lepre RL, Mainardes P, Junior LC. A Educação Permanente em Saúde como estratégia pedagógica de transformação das práticas: possibilidades e limites. Trab. educ. saúde, 2010. 8(2), 207-227.

3. Instituto de Saúde Coletiva (ISC). Universidade Federal da Bahia. Caderno de Atividades. Oficinas Regionais de Monitoramento e Avaliação da Educação Permanente em Saúde. Salvador, 2019

4. Bardin L. Análise de conteúdo. 1.ed. São Paulo: Edições 7o; 2016. 
RELATO DE EXPERIÊNCIA

\section{GESTÃO DO PROGRAMA DE RESIDÊNCIA MÉDICA DO HOSPITAL REGIONAL DO OESTE: AÇÕES DE EDUCAÇÃO PERMANENTE EM SAÚDE}

\author{
Gleica Pressi \\ Jacira Batista de Oliveira \\ João Batista Baroncello \\ Jussara dos Santos Valentini \\ Rosana Amora Ascari \\ Daniel Jesse Junior \\ Ferreira Cassemiro
}

\section{Introdução}

O Hospital Regional do Oeste (HRO), mantido pela Associaçã̃o Hospitalar Lenoir Vargas Ferreira (ALVF) é um hospital público de referência em oncologia, neurologia/neurocirurgia, terapia nutricional, gestação de alto risco e traumato-ortopedia. Ainda, é referência regional atendendo o oeste de Santa Catarina, norte do Rio Grande do Sul e noroeste do Paraná, pertence a $4^{\underline{a}}$ Regional da Saúde do estado e presta serviços a todos os usuários do Sistema Único de Saúde (SUS), atendendo a uma população de mais de 1,5 milhões de habitantes, caracterizado como centro de referência para média e alta complexidade. ${ }^{1} \mathrm{O}$ referido hospital dispõe em seu quadro funcional 1.236 profissionais, sendo 249 de setores administrativos, 623 da enfermagem, 230 do apoio (higiene, lavanderia, cozinha e manutenção) e 134 do diagnóstico e tratamento (HRO, 2021). Conta com 339 leitos cadastrados no Cadastro Nacional de Estabelecimentos de Saúde (CNES) distribuídos nas unidades de Oncologia I e II, Privativo, Clínica Médica, Maternidade, Berçário, Unidade de Terapia Intensiva (UTI) Adulto, Pediátrica e Neonatal, Centro Cirúrgico (CC), Sala de Recuperação Pós-Anestésica (SRPA), Centro Obstétrico (CO), Clínica Cirúrgica Geral, Clínica Cirúrgica Traumato-Ortopedica, Pronto Socorro (PS) e Neurologia, além dos serviços auxiliares de diagnóstico e terapia. Dispõe de 25 especialidades médicas e serve de campo prático para diferentes cursos da área de saúde, ${ }^{1}$ contemplando instituições públicas e privadas, cursos técnicos, gradua- 
ção e pós-graduação. Ao longo dos anos, profissionais inseridos no serviço prestado à comunidade pela ALVF em conjunto com a Universidade Comunitária da Região de Chapecó (Unochapecó), idealizaram transformar o cenário hospitalar voltado para o processo de ensino-aprendizagem no campo de prática médica, por meio da oferta do Programa de Residência Médica (PRM). Assim, no ano de 2010, a cidade de Chapecó, no oeste do estado de Santa Catarina foi contemplada com o primeiro curso de Graduação de Medicina, sob a responsabilidade da Unochapecó, cursos que teve autorização de implementação por meio da Resolução $n^{-}$095/CONSU/2005 de 15 de setembro de 2005 e reconhecimento do Curso de Bacharelado em Medicina através do Decreto $n^{0} 711$ do Conselho Estadual de Educação em o7 de dezembro de 2011. ${ }^{2}$ Nesse interim, os médicos do corpo clínico, sentindo a necessidade locorregional em contribuir na qualificação e na presciếncia de profissionais médicos para atendimentos no Sistema Único de Saúde (SUS) da própria instituição e região, junto com a Unochapecó, iniciaram as primeiras tratativas para a construção do projeto com vistas à implantação do PRM do HRO, o qual teve início em 2010. Num primeiro momento a experiência desta implantação foi tecendo-se com considerações sobre dificuldades encontradas ao longo do processo, paralelamente, a experiência foi articulando elementos triviais e esperados como em todo e qualquer processo formativo. O Programa de Residência Médica foi aprovado em 2010, tendo seu primeiro edital divulgado no ano de $2011 \mathrm{com}$ a especialidade de Cirurgia Geral. Em 2013, com a publicação da Lei 12.871, de 22 de outubro de 2013 que instituiu alteração nas Leis $\mathrm{n}^{\circ} 8.745$, de 9 de dezembro de 1993 , e n⿳ำ 6.932, de 7 de julho de 1981 , em seu Art. $2^{-}$descreve " I - reordenação da oferta de cursos de Medicina e de vagas para residência médica, priorizando regiões de saúde com menor relação de vagas e médicos por habitante e com estrutura de serviços de saúde em condições de ofertar campo de prática suficiente e de qualidade para os alunos..." deu-se início ao credenciamento de novos PRM: Clínica Médica, Ginecologia/Obstetrícia e Ortopedia/ Tramatologia. ${ }^{3}$ No ano de 2015 houve a inserção da Universidade Federal Fronteira Sul (UFFS), como instituição parceira nos PRM, definindo-se as atribuições por um termo tripartite (Unochapecó, ALVF e UFFS). Atualmente, um dos principais atributos empregados, somados à desafiante tarefa de formação dos médicos residentes é a integração da Educação Permanente utilizada como estratégia fundamental na gestão das práticas assistenciais e na gestão dos residentes, a qual abarca o aprender e ensinar no contexto da realidade em que os profissionais em formação estão inseridos.
A Educação Permanente empregada nos PRM compõe uma estratégia que, fundamentalmente, gerou transformações na Instituição sede, moldando o ensino-trabalho médico com atuação crítica e reflexiva. Emergem dessas ações de educação coletivas ensino-serviço, aliadas à educação permanente em saúde institucionalizada, normatizações e técnicas que balizam a tomada de decisão dos residentes na prática profissional. Entende-se que a educação permanente aliada ao ensino formal, como é o caso da residência médica, configura-se como fundamental no desenvolvimento de atividades embasadas nas melhores práticas profissionais e abarcam médicos residentes, coordenadores e preceptores, além de trazer benefícios diretos à população adstrita.

\section{Objetivo}

Relatar a experiência de gestão dos Programas de Residência Médica do Hospital Regional do Oeste articulada às estratégias de Educação Permanente do hospital campo de prática para qualificação e provimento de médicos residentes em processo de formação no oeste catarinense.

\section{Método}

Trata-se de um relato de experiência de profissionais vinculados ao PRM, trabalhadores e colaboradores do setor de educação permanente do HRO/ALVF e de instituições de ensino superior parceiras da ALVF. O cenário em questão abrange um hospital público de Chapecó - SC, que atualmente conta com o6 especialidades no PRM, à saber: Anestesiologia, Cirurgia Geral, Cirurgia Geral R3, Clínica Médica, Obstetrícia/Ginecologia, Pediatria, Ortopedia/ Traumatologia. O PRM já formou 58 médicos especialistas e hoje possui 40 residentes ativos, sendo $18 \mathrm{R}_{1}$ (residentes do primeiro ano), $17 \mathrm{R}_{2}$ (residentes do segundo ano) e cinco $\mathrm{R}_{3}$ (corresponde ao terceiro ano de residência).

\section{Resultados e Discussão}

Quanto às instâncias decisórias dos PRM, cada especialidade conta com um médico especialista na coordenação, sendo que as questões de gestão do PRM que envolvem o serviço, são apreciadas pela coordenação da especialidade e encaminhadas à Coordenação do PRM, que habitualmente, ou resolve ou são encaminhadas à Comissão de Residência Médica (COREME), a qual possui representante das três Instituições parceiras, para apreciação, discussão e parecer final (definição da situaçã̃o em análise). Cotidianamente, são utilizadas iniciativas educacionais em capaci- 
tações programadas, de livre demanda e ações de gestão dos PRM por meio dos conceitos de Educação Permanente, em que o contexto pedagógico e metodológico potencializa o ensino-aprendizagem, reflexões críticas sobre o processo educativo nas práticas de serviço. A partir do resgate histórico acerca da Educação Permanente e vivência junto aos residentes de turmas anteriores, buscou-se identificar problemas que podem ter contribuído com insuficiências e dificuldades encontradas no decorrer do processo de formação, ocasionando, por vezes, vacância nas diferentes Especialidades médicas ofertadas. Esses fatores foram primordiais para um trabalho em conjunto entre a Coordenação atual e docentes de Instituições parceiras ao Programa, onde desenvolveram-se algumas atividades educacionais que fortaleceram o vínculo multiprofissional e interdisciplinar refletindo na qualidade da assistência. Ao ingressar no HRO, o profissional residente participa no primeiro dia letivo do PRM de uma atividade chamada de integração dos novos residentes, esse encontro reúne todos os R1 da Residência Médica e demais Residências em Saúde (Enfermagem, Farmácia, Nutrição, Psicologia) com duração de oito horas, distribuídas entre palestras ministradas por coordenadores de unidades hospitalares pelas quais os residentes irão desenvolver as atividades práticas no serviço, orientando-os sobre normas e condutas de rotina da Instituição hospitalar. De acordo com a Resolução da Comissão Nacional de Residência Médica (CNRM), nº O2 de 2006, de 17 de maio de 2006, a carga horária de 60 horas semanais dos residentes é distribuída entre atividades práticas e teóricas. ${ }^{4-5}$ Destaca-se algumas atividades teóricas e teórico-práticas, tais como, aulas, seminários, discussão de casos clínicos e rounds por especialidade que acontecem no auditório do Centro de Estudos do HRO semanalmente, com participação assídua de residentes, preceptores e coordenadores. No que tange o ensino das atividades práticas, os residentes participam de treinamentos em simuladores, como o de videoendoscopia, utilizado para a prática cirúrgica, atendimentos ambulatoriais e em clínicas de internação. Os rounds à beira leito tem a finalidade de discutir casos clínicos, valorizando o conhecimento prévio dos residentes e minimizando possiveis falhas e eventos adversos decorrentes da assistência. O processo de ensino-serviço evoluiu muito nos últimos anos e não foi diferente nos PRM. No entanto, os PRM do HRO/ALVF em parceria com instituições de ensino superior (IES), ainda apresenta limitadores, como por exemplo, o registro das atividades desenvolvidas ao longo da formação - um sistema de gestão acadêmica, integrado entre as IES e o Serviço para gerenciar atividades, frequências, carga horária, avaliações, entre outras. Um outro ponto observado são os aspectos de atuação multiprofissional que ao longo dos anos vem se estreitando, porém, faz-se necessário uma maior integração nas condutas interdisciplinar.

\section{Conclusão}

A organização das atividades e ações educacionais na assistência à saúde por meio de cada coordenador de especialidade, com o suporte do setor de Educação Permanente do $\mathrm{HRO}$, estimulam e favorecem o crescimento e desenvolvimento profissional dos residentes e demais colaboradores da Instituição, uma vez que o conhecimento é lançado, ele também é disseminado entre os demais integrantes do processo ensino-serviço, colaborando na superação de dificuldades e limitações.

Descritores: Gestão da Segurança; Segurança do Paciente; Qualidade da Assistência à Saúde; Educação Permanente em Saúde.

\section{Financiamento}

O Programa de Residência Médica do Hospital Regional do Oeste possui as suas bolsas mantidas pelo Ministério da Saúde e Ministério da Educação.

\section{Referências}

1. HRO - Hospital Regional do Oeste. Portal da Transparência. Disponível em: http://www. relatecc.com.br/hro/. Acesso em: 12/01/2021.

2. Unochapecó. Curso de Graduação em Medicina. Dados Legais. Autorização: Resolução $\mathrm{n}^{\mathrm{o}}$ 095/CONSUN/2005, publicado em 15 de setembro de 2005; Reconhecimento: Decreto $\mathrm{n}^{\mathrm{o}} 711$ - CEE, de o7 de dezembro de 2011. Disponivel em: https://www.unochapeco.edu.br/ medicina. Acesso em: 15/o1/2021.

3. Brasil. Lei Federal No 12.871 , de 22 de outubro de 2013. Institui o Programa Mais Médicos, altera as Leis $\mathrm{n}^{\circ} 8.745$, de 9 de dezembro de 1993 , e $n^{\circ} 6.932$, de 7 de julho de 1981 , e dá outras providências. Disponível em: http://www.planalto. gov.br/ccivil_03/_ato2011-2014/2013/lei/l12871. htm. Acesso em: 18/01/2021.

4. Brasil. Resolução CNRM № $02 / 2006$, de 17 de maio de 2006. Dispõe sobre requisitos mínimos dos Programas de Residência Médica e dá outras providências. Disponível em: http://portal.mec.gov.br/dmdocuments/resoluca002_2006.pdf. Acesso em: 18/01/2021.

5. CNRM - Comissão Nacional de Residência Médica. Ministério da Educação. Disponível em: http://portal.mec.gov.br/residencias-em-saude/ residencia-medica. Acesso em: 13/01/2021. 
Pesquisa Original

\begin{abstract}
A EDUCAÇÃO PERMANENTE EM SAÚDE NO ENFRENTAMENTO DAS SITUAÇÕES PROBLEMA NO CUIDADO AO PACIENTE
\end{abstract}

\section{Valentina Barbosa da Silva Sandra Cristina de Souza Borges Silva \\ Marluci Andrade Conceição Stipp}

\section{Introdução}

A Educação permanente em saúde (EPS) pode ser uma estratégia de fortalecimento das práticas cotidianas da enfermagem no ambiente destinado ao cuidado com o paciente hospitalizado'. Acontece por meio da relação dialógica e contínua entre os trabalhadores, que buscam o alcance da aprendizagem significativa. Esta aprendizagem se caracteriza pela interação cognitiva do conhecimento novo com os conhecimentos prévios dos trabalhadores, proporcionando o significado consciente do contexto no qual o educando, trabalhador de saúde, está inseri$\mathrm{do}^{2}$. Por isso acredita-se na contribuição das concepções de Paulo Freire, para compreensão da educação implementada nos serviços de saúde. $\mathrm{O}$ autor que caminhou na política e na educação, concebe numa perspectiva coletiva e libertadora a vivência dos homens no mundo do trabalho, considerando-os como sujeito de sua própria prática ${ }^{3}$. No trabalho da enfermagem percebe-se o desenvolvimento da EPS como atividade de cunho técnico-gerencial que viabiliza a continuidade e a organização do trabalho'. Questionamo-nos como a educação permanente em saúde se desenvolve no cotidiano do trabalho da enfermagem durante o cuidado ao paciente hospitalizado nos setores de internação, mas especificamente as clínicas médicas masculinas e femininas de um hospital de infectologia? 


\section{Objetivo}

Analisar as estratégias de educação permanente em saúde realizadas durante o cotidiano do trabalho da enfermagem em um hospital de referência em doenças infectocontagiosas.

\section{Metodologia}

Pesquisa qualitativa de natureza explicativa fundamentada na perspectiva Freiriana sobre a educacão. O estudo teve como cenário o Centro de Medicina Tropical - CEMETRON, unidade hospitalar escolhida para o estudo. Este hospital é caracterizado como Unidade de Assistência de Alta Complexidade, localizada no município de Porto Velho, capital do Estado de Rondônia, região Norte do Brasil. O manejo dos usuários exige um cuidado e tratamento diferenciado, por envolver complexidades advindas da particularidade de cada indivíduo e comunidade que necessitam do acesso deste serviço. No ano de 2020 tornou-se também referência para os casos de Infecção Humana pelo novo Coronavírus (COVID-19). Participaram deste estudo os técnicos de enfermagem e os enfermeiros que atuavam no setor de clínica médica masculina e feminina, bem como no Núcleo de Educação Permanente do CEMETRON. A coleta dos dados ocorreu no período de setembro de 2019 a junho de 2020, através da entrevista semi-estruturada. Para a organização, tratamento dos dados, utilizou-se O software IRAMUTEQ ${ }^{\circledR}$, por meio da classificação hierárquica descendente. Os dados apresentados são oriundos da tese de doutorado aprovada no Comitê de Ética em Pesquisa (CEP da EEAN/HESF/UFRJ), com CAAE 96065618.0.0000.5238.

\section{Resultados e Discussão}

No que tange a caracterização dos 32 participantes do estudo, identificou-se que a predominância do sexo feminino $(87,5 \%)$, na faixa etária entre zo a 49 anos $(81,24 \%)$. Quanto a categoria profissional, o quantitativo de técnicos de enfermagem $(37,50 \%)$ foi superior ao de enfermeiros $(62,50 \%)$, proporção relacionada a organização do processo de trabalho. Quanto a sua formação profissional, os participantes estão formados de 5 a 14 anos $(65,63 \%)$, trabalham no hospital, local da pesquisa, entre 5 a 9 anos $(59,39 \%)$ e possuem dois vínculos empregatícios $(62,5 \%)$. Para este estudo foram apresentados os resultados das entrevistas, relacionados às classes 3 e 4, que representaram $37,54 \%$ do total de Segmentos de Texto
(ST) do corpus textual. Estas foram intituladas respectivamente como "Situações problemas evidenciadas durante o cuidado ao paciente e "Desenvolvimento da educação permanente no cotidiano do trabalho da enfermagem". A classez obteve $13,34 \%$ de representatividade dentre todas as classes e 167 segmentos de textos de um total de 1.252 . A classe 4 possuiu $24,2 \%$ do total de ST, 303 de aproveitamento de segmentos de texto do total de 1.252 . As primeiras palavras que compuseram a classe 3 - medicação, paciente, administrar e cuidado - inicialmente direcionaram um olhar sobre a medicação administrada ao paciente e o cuidado. Na classe 4 também estiveram presentes as situações problema disparadoras da EPS e os temas que emergiram das conversas, contidas na classe 3. Acreditamos que a classe 4 complementa o sentido da classe 3 quando acrescenta a forma como a EPS foi realizada no cotidiano do trabalho. Além das situações problematizadoras e dos temas que pertencem a classe 4 , as falas dos profissionais revelaram como aconteceu os momentos de EPS, os principais locais onde aconteceram, o registro do cuidado prestado e a imersão nas situações problema do trabalho. Ao nos debruçamos nas recomendações metodológicas de Freire sobre as práticas de EPS no cotidiano do trabalho da enfermagem, coadunamos com a orientação da educação como prática pedagógica crítica, na qual o homem não é descontextualizado do mundo em que vive, mas interage com ele, problematizando e produzindo criticidade sobre estas relações e como elas se constroem para a prática analítica e transformadora da realidade Contrapõem-se ao modelo tradicional de educação, autoritário, pautado apenas na transmissão de conteúdo, que não considera os valores e a totalidade da dimensão humana ${ }^{4}$. Na necessidade de ressignificar o trabalho, a metodologia da problematização tem se difundido nos serviços de saúde, para o desenvolvimento intelectual, profissional e coletivo. A autora Berbel, têm discutido a implementação da problematização como metodologia pedagógica na área de saúde, que facilita tanto a compreensão dos problemas quanto a intervenção na realidades. Dentre os problemas encontrados nos conteúdos das falas dos participantes da pesquisa, foi observado que a medicação foi o que mais se destacou. Nesse sentido, acreditamos ser importante contextualizar a preocupação relacionada com as medicações no cenário da pesquisa, com suas peculiaridades, destacando dentre elas, as mais utilizadas pelos trabalhadores de enfermagem. Destacamos a importância deste problema no cuidado ao paciente hospita- 
lizado nas clínicas médicas do CEMETRON e os aspectos relacionados às internações decorrentes da patologia manifestada por cada paciente. Os pacientes que frequentemente necessitam de internação no CEMETRON são especialmente aqueles com: reações hansênicas; sequelas da turberculose; acidentes ofídicos; complicações do HIV e aids; hepatites B, C e D; malária, leishmaniose tegumentar americana e paracoccidioidomicose. Para o cuidado ao paciente acometido com esses agravos, é fundamental o conhecimento especifico sobre a doença, os sintomas, o tratamento e o manejo das medicações, a sua maneira correta de administração e as suas possíveis reações.

\section{Conclusão}

Os trabalhadores de enfermagem desenvolvem a educação permanente no durante o cotidiano do trabalho de diferentes formas. Através da análise compreende-se que as estratégias de EPS estão principalmente relacionadas ao cuidado ao usuário internado que necessita do uso de medicações, que neste ambiente hospitalar, está relatado como de alta complexidade, por existir riscos desde o preparo até os momentos após a administração destes fármacos. Entende-se que esta é a principal situação problema disparadora da EPS e tudo isto é problematizado, durante encontros considerados informais, por meio de conversas, nas visitas leito a leito, durante a pausa para o descanso, são realizadas anotações sobre as situações. Estes enfrentamentos acontecem no próprio ambiente de trabalho, utilizando-se da EPS, aprendendo e ensinando mutualmente.

Descritores: Educação Permanente; Prática Profissional; Trabalho; Enfermagem; Hospital.

Financiamento: $\mathrm{O}$ presente trabalho foi realizado com o apoio da Coordenação de Aperfeiçoamento de Pessoal de Nível Superior - Brasil (CAPES).

\section{Referências}

1. Silva LAA, Pinno C, Schmidt SMS, Sandra MSS, Helena CN, Iris EMG, Eduarda E. A educação permanente no processo de trabalho de enfermagem. R. Enferm. Cent. O. Min. [Internet] 2016 set/dez [citado 2020 mar 2]; 6(3):23492361. Disponível em http://www.seer.ufsj.edu. br/index.php/recom/article/view/1027

2. Freire P. Pedagogia do oprimido. 17a ed. Rio de Janeiro (RJ): Paz e Terra; 1987

3. Cassali, A. O Pensamento de Paulo Freire como matriz integradora de práticas educativas no meio popular: ciclo de seminários. Inácio da Silva, org. In: Paulo Freire e o pensamento complexo. São Paulo: Instituto Pólis, 2008. 67p.

4. -__P. Pedagogia da autonomia: saberes necessários à pratica educativa. São Paulo: Paz e Terra, 1996.

5. Berbel, N. N.: "Problematization" and Problem-Based Learning: different words or different way? Interface - Comunicação, Saúde, Educação, v.2, n.2, 1998. 
LANÇAMENTOS DE LIVROS 


\section{PREVENÇÃO QUATERNÁRIA: PROPOSIÇÕES PARA A EDUCAÇÃO E PRÁTICA INTERPROFISSIONAL NA ATENÇÃO PRIMÁRIA À SAÚDE}

\author{
ORganizadores \\ Carine Vendruscolo \\ Charles Dalcanale Tesser \\ Edlamar Kátia Adamy
}

\section{Introdução}

Trata sobre a prevenção quaternária $\left(\mathrm{P}_{4}\right)$, cujos 13 capítulos foram escritos por diferentes profissionais da área da saúde, que atuam na prática e na pesquisa no âmbito da APS, vão discutir essa temática que preocupa, pela excessiva demanda que tem gerado aos serviços de saúde. As pessoas procuram cada vez mais por medicalização, o que, por vezes, gera problemas, inclusive de ordem social e psicológica por torná-las dependentes de substâncias e com a ilusão de que todos os problemas da saúde apresentam um tratamento medicamentoso. Reduzir esse problema é o que chamamos de prevenção quaternária. O livro contribui sobretudo, ao trazer ao debate, profissionais de diferentes categorias, sobretudo da enfermagem.

Editora: Moriá 


\section{CARGAS DE TRABALHO: UM REFERENCIAL PARA ENTENDER A RELAÇÃO ENTRE TRABALHO E SAÚDE}

\section{ORGANIZADORES \\ Letícia de Lima Trindade Denise Elvira Pires de Pires}

\section{Introdução}

A Obra "Cargas de Trabalho: um referencial para entender a relação entre trabalho e saúde" apresentada no I FIGGEPS está divida em duas partes, a Parte I - Cargas de trabalho: reflexões e interfaces teórico conceituais e a Parte II - Cargas de trabalho em pesquisas na saúde, Brasil e Portugal, as quais reúnem 16 capítulo. No conjunto os manuscritos apresentam-se como um referencial profícuo para estudos acerca do trabalho humano, em especial a complexa interface entre trabalho e a saúde de quem o realiza, tomando-se o primeiro como ação transformadora para atender necessidades individuais ou sociais. Os pesquisadores trazem diferentes reflexões, estudos e relatos que trabalham as cargas de trabalho e suas implicações em diferentes aspectos. $\mathrm{O}$ referencial teórico-metodológico das cargas de trabalho ${ }^{1}$, com suporte na teoria do processo de trabalho' ${ }^{2}$, apresentado no livro, contribui para o entendimento do trabalho vivo, considerando o contexto histórico, micro e macro social da determinação do processo saúde-doença dos trabalhadores que realizam o trabalho. A Obra também traz importantes aspectos no trabalho em saúde, para além da natureza do trabalho e da intensidade das cargas, assume relevância a diversos aspectos da organização e das condições de trabalho no setor, com capítulos que problematizam a realidade brasileira e portuguesa. Assim, considera-se que o aporte teórico-metodológicos e resultados de pesquisa 
apresentados nesta Obra, constituem um instrumental a ser utilizado e criticado.

\section{Referências}

1. Laurell AC, Noriega M. Processo de produção e saúde: trabalho e desgaste operário. São Paulo: Hucitec; 1989.

2. Marx K. O capital: crítica da economia política. Livro I. São Paulo: Boitempo; 2013.

Grupos de Pesquisa envolvidos: PRÁXIS: Laboratório de Pesquisa sobre Trabalho, Ética, Saúde e Enfermagem da Universidade Federal de Santa Catarina e GESTRA: Grupo de Estudos sobre Saúde e Trabalho da Universidade do Estado de Santa Catarina

Financiamentos: Coordenação de Aperfeiçoamento de Pessoal de Nível Superior (CAPES), Fundação de Amparo à Pesquisa de Santa Catarina (FAPESC) e Conselho Nacional de Desenvolvimento Científico e Tecnológico (CNPq). 


\section{PRODUÇÕES DO MESTRADO PROFISSIONAL EM ENFERMAGEM NA ATENÇÃO PRIMÁRIA A SAÚDE: CONTRIBUTOS PARA A GESTÃO E O CUIDADO}

ORGANIZADORES

Elisangela Argenta Zanatta

Denise Antunes de Azambuja Zocche

Lucimare Ferraz

Rosana Amora Ascari

Arnildo Korb

\section{Introdução}

Trata-se do Volume 1 da Série Estudos e Inovações em Enfermagem, idealizada pelos docentes do Mestrado profissional em Enfermagem na Atenção Primária à Saúde (MPEAPS) cujo objetivo é divulgar os produtos científicos e tecnológicos produzidos no decorrer do Mestrado. sendo:

O volume 1 está dividido em três partes

- ESTUIDOS DESENVOLVIDOS COM RECURSOS DO EDITAL CAPES/COFEN n ${ }^{\circ}$ 27/2016 - Composta por três capítulos elaborados pelas mestrandas contempladas pelo edital e seus orientadores, em que são apresentados e discutidos parte dos resultados e produtos desenvolvidos no MPEAPS, visando a implementação do Processo de Enfermagem.

- ESUDOS ENVOLVENDO CUIDADO E TECNOLOGIAS EM SAÚDE - Também formada por três capítulos que discutem temas, cujo eixo central é o cuidado de enfermagem e o desenvolvimento de tecnologias que podem subsidiá-lo.

- ESTUDOS ENVOLVENDO A GESTÃO DO TRABALHO E EDUCAÇÃO EM SAÚDE, sessaõ em que são apresentados três capítulos cujo foco é o desenvolvimento de tecnologias, do tipo fluxograma, para a gestão de enfermagem, visando as melhores praticas em Enfermagem na Rede de Atenção à Saúde.

Editora: Editora UDESC 


\section{PRÁTICAS DE ENSINO EM}

\section{ENFERMAGEM}

ORganizadoRES Júlia Rossetto Marchetti Geisa Percio do Prado

\section{Introdução}

A obra "Práticas de Ensino em Enfermagem" conta com 14 capítulos e traz algumas experiências exitosas no campo da Educação em Enfermagem, práticas que podem enriquecer as atividades docentes, assim como de monitorias e preceptorias. Nesta coletânea de capítulos, trazemos diversos olhares sobre diferentes temas, sob ao ótica de profissionais $\mathrm{da}$ área da Saúde e Educação. A obra destina-se a profissionais da Educação e Saúde, alunos de graduação e preceptores de acadêmicos. Muitas das experiências já são aplicadas tanto em aulas práticas e teóricas como em monitorias, o que lhes confere aplicabilidade.

Editora: Appris Editora 


\section{GRUPOS DE DESENVOLVIMENTO HUMANO: UMA ESTRATÉGIA PARA TRABALHO COM GRUPOS NAS POLÍTICAS PÚBLICAS}

\section{ORGANIZADORES Flávio Braga de Freitas Márcia Pir Dal Magro Elizangela Felipi}

\section{Introdução}

Este livro tem como foco a ação denominada "Grupo de De- senvolvimento Humano" (GDH), a qual vem sendo desenvolvida na cidade de Chapecó, oeste do estado de Santa Catarina, desde 2012. Compreendemos que o GDH se caracteriza como uma tecnologia social, construída a partir da necessidade local de ajudar as pessoas a lidarem com situações que geram sofrimento psíquico.

Editora: Argos Editora 


\section{BANNER'S ELETRÔNICOS}




\section{ifl

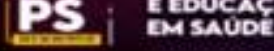

ACOLHISENTO MULTIPROFISSIONAL NO SISTEMA PRISIONAL COMO NSSTREMENTO DE RESSOCALIZACĂO

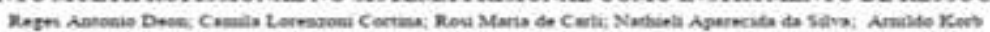

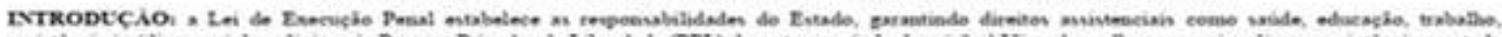

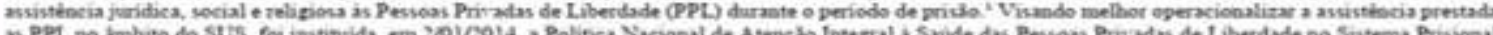

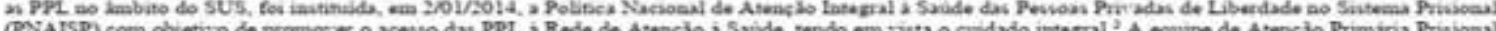
(o plpi)

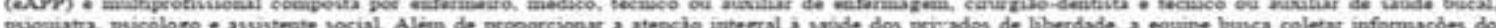

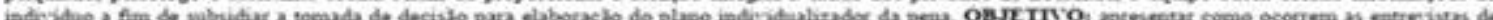

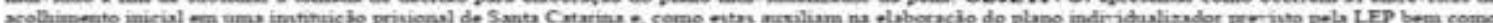

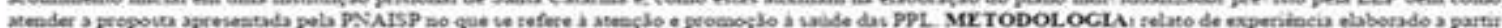

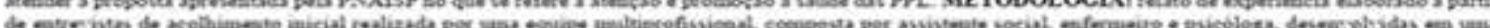

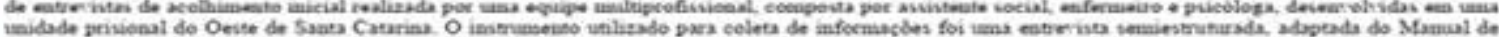

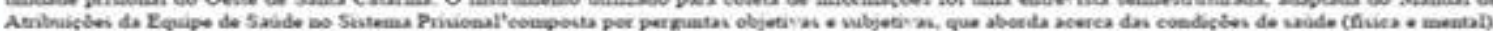

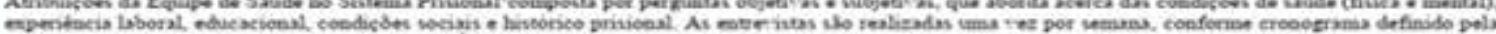

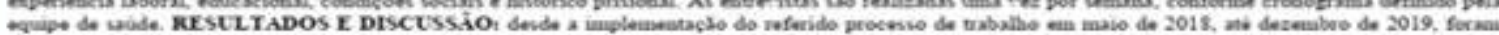

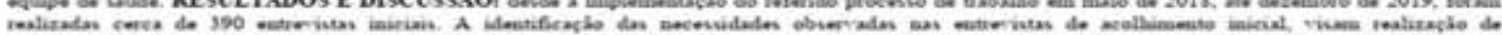

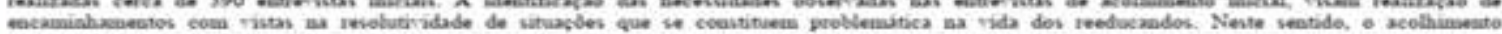

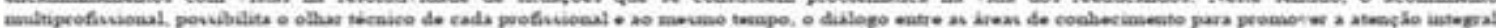

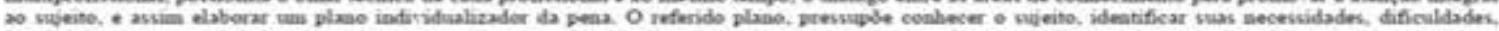

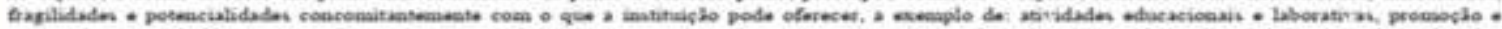

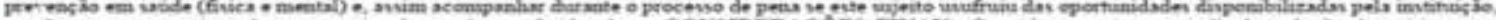

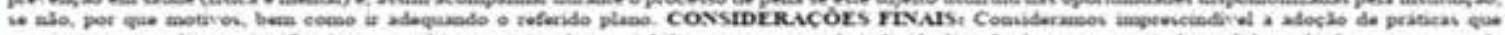

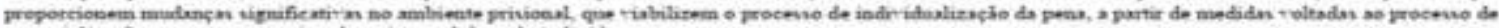

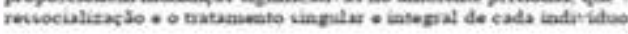

\section{REFERENCZS}

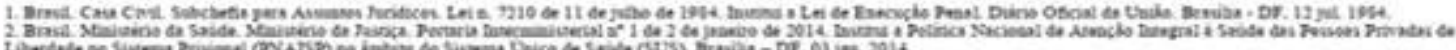

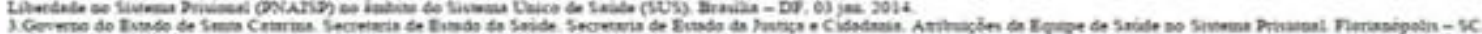

\section{I. BE E EDUCACA}

DESAFIOS E POTENCIAS DA EDUCACAO PERMANENTE EM SAÚDE A PARTIR DA VIVENCIA DE GESTORES ETRABALHADORES DA ATENCGAOO BLSICA NA ZONA SUL DE SAXO PAULO

Israel Victor de Oliveira, Rogetrio Nogueira de Oliveira

Objetivo: Apresentar um estudo sobre a realidade da Educaçåo Permanente em Saúde (EPS) no cotidiano de trabalhadores de Equipes de Saúde da Familia (EqSf) e gestores de Unidades Básicas de Saúde da zona sul de Sắo Paulo. Metrodos: Estudo descritivo e analitico com trabalhadores e gestores de Unidades Básicas de Saúde da zona sul de Sjo Paulo, tendo referéncia de anallise a concepçăo institucional da EPS e a micropolitica da gestlio e do cuidado em saúde. A coleta de dados foi realizada entre os meses de fevereiro e abril de 2019, com 25 trabalhadores de 05 gestores de Unidades Básicas de $5 a u d e ~(n=30)$ por meio de entrevistas e grupos focais. Os dados foram submetidos a analise de conteúdo tematica proposta por Minayo. Resultados e discussão: Problemas estruturais, sobrecarga, indisponibilidade de tempo e engessamento de processos foram as principais dificuldades apontadas, A integraçło e protagonismo das equipes e a valorizaçło dos trabalhadores de saúde foram apontados como facilitadores dos processos de EPS. Conclus3a: Apesar da influência do modeio gerencialista, a EPS tem a capacidade de movimentar os diversos atores da saúde da Atençăo Básica no sentido de promover açöes alinhadas com os principios e diretrizes do Sistema Único de Saúde para a produçăo do trabalho vivo nos territórios.

sentiming

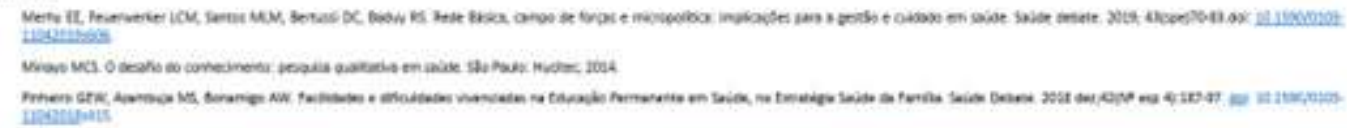


Introduçăo: A Eđucaçăo Permanente em Saúde, contemplada pelo Ministério da Saúde como política institucional, constitui um dos pilares de estratégico potencial de transformaçăo dos processos no Sistema Uniço de Saúde². Mátodos: Este estudo transwersal e descritivo obteve um painel brasileiro da Educaçåo Permanente em Saúde, a partír de dados secundários do Ministério da Saúde, extraídos do censo de avaliação externa do Programa Nacional de Melhoria do Acesso e da Qualidade da

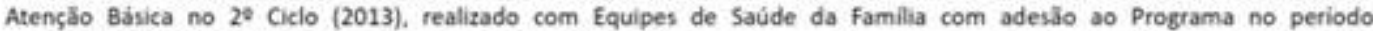
$(n=10.213 / 100 \%)^{2}$; Resultados e Discussăo: $90 \%(n=9.184)$ das equipes afirmaram participar de atividades de Educaçăo Permanente em Saúde, com maiores frequèncias das Regiâes Sudeste, Nordeste e Sul. As principais atividades de Educaçäo Permanente em Saúde relatadas foram seminários, mostras, oficinas e grupos de discussão (n=8.243/80,71\%), além de cursos presenciais $(n=7,808 / 76,45 \%)$. Das opçòes ofertadas pelo Ministério da Saúde, a menos frequente fol a Rede Universitária de Telemedicina ( $n=475 / 4,65 \%) ; 87,62 \%(8.948$ ) Equipes de Saúde da Familia tiveram suas demandas de Educaçăo Permanente em Saúde atendidas pela gestão. Conclusảo: $O$ instrumento apresenta robustez de dados e contempla diversos aspectos da gestăo, incluindo elementos importantes de Educaçăo Permanente em Saúde que podem nortear a tomada de decisão e interferir em politicas e programas próprios nos serviços. ${ }^{3}$

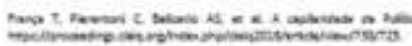

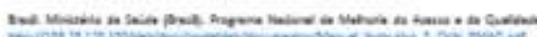

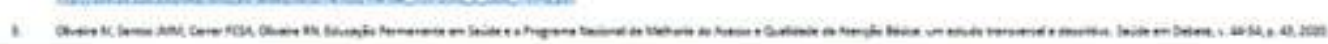

\section{CEl \\ P. EDUCACAO PERMANETIE \\ L- Ei EM SAUDE}

Felicidade no trabalho: Um estudo com enfermeiros portugueses em contexto insular

\section{INTRODUCXIO
mundo faboral tem sofrido grandes mudansas. Assim, os paradigmas,}

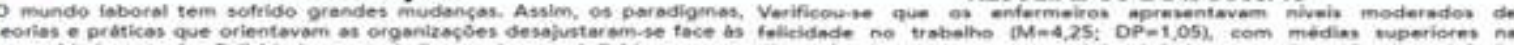

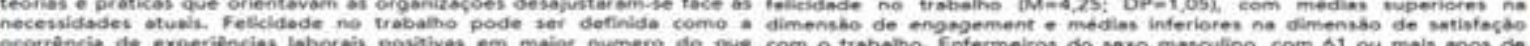

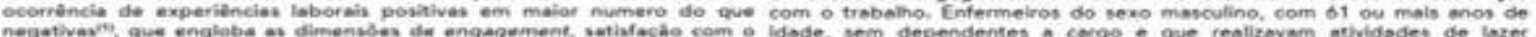

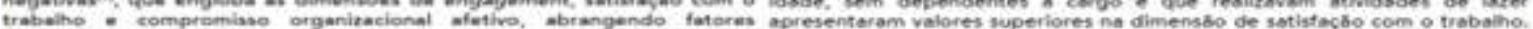

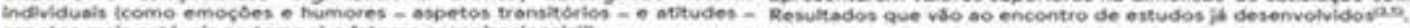
aspetos mais estaveis no tempol e fotores orpanizacionaising

\section{OBJETIVO}

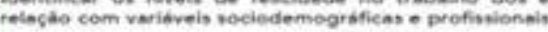

\section{MÉTODO}

Estudo quantitativa, descritivo, correlachonat of transversal, em 113 uma Unidoda Henpitalor e uma Unidsde de sajode de uma ithe dos Apores. Fol eplicedo in questionbilo soclodemogrbico e protiswionsi es shorted Happiness at Work scale ciraw

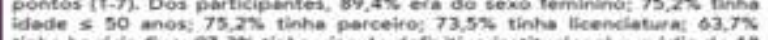

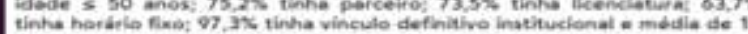

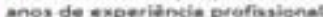

\section{CONCLUSAOO}

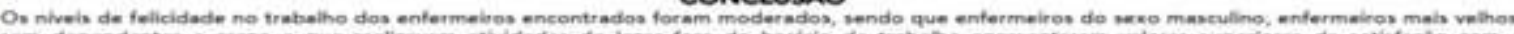

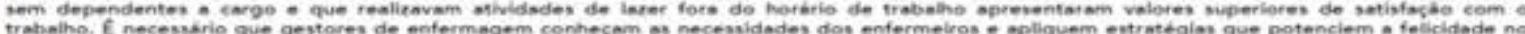

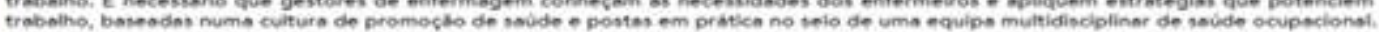

- 

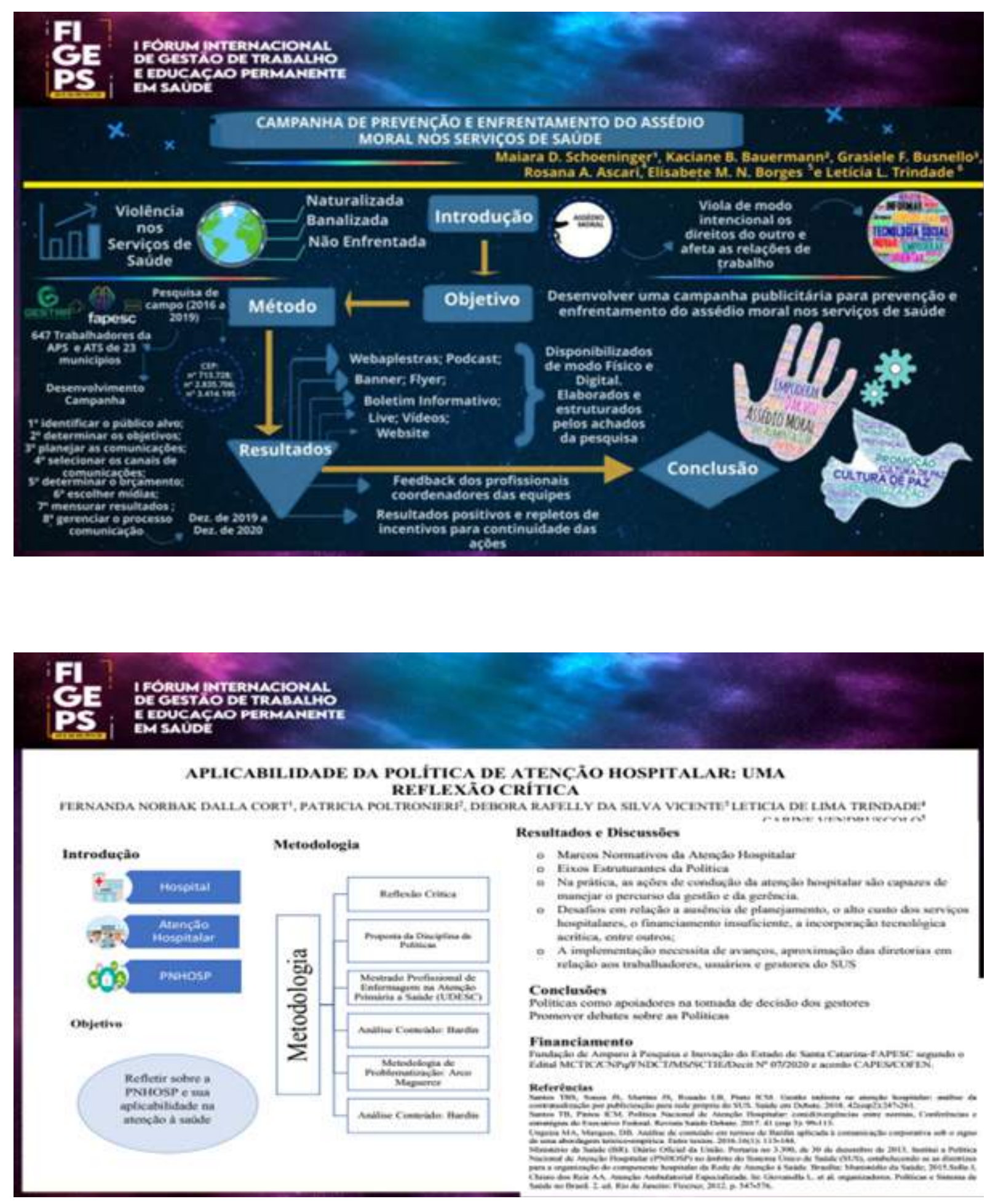

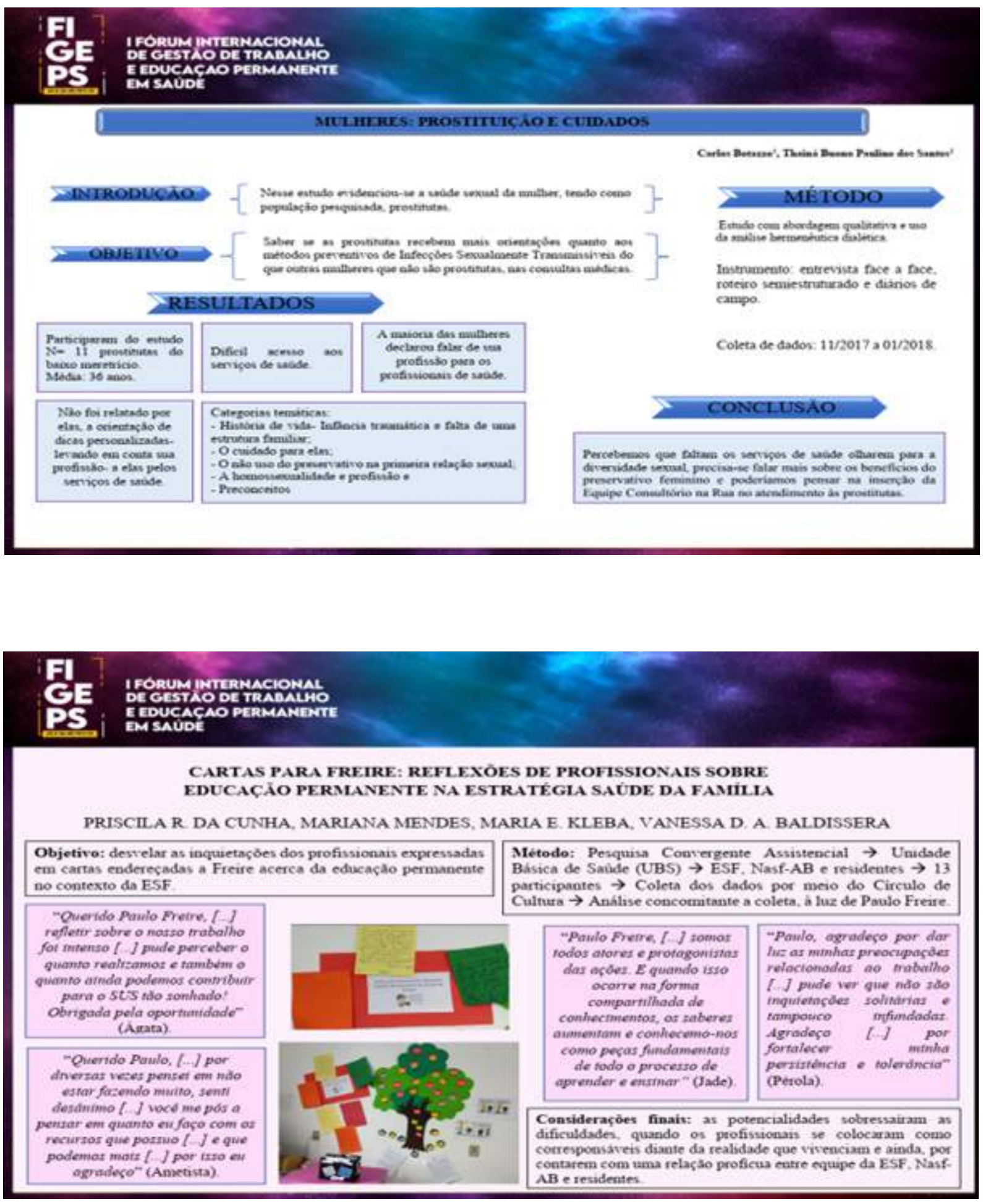

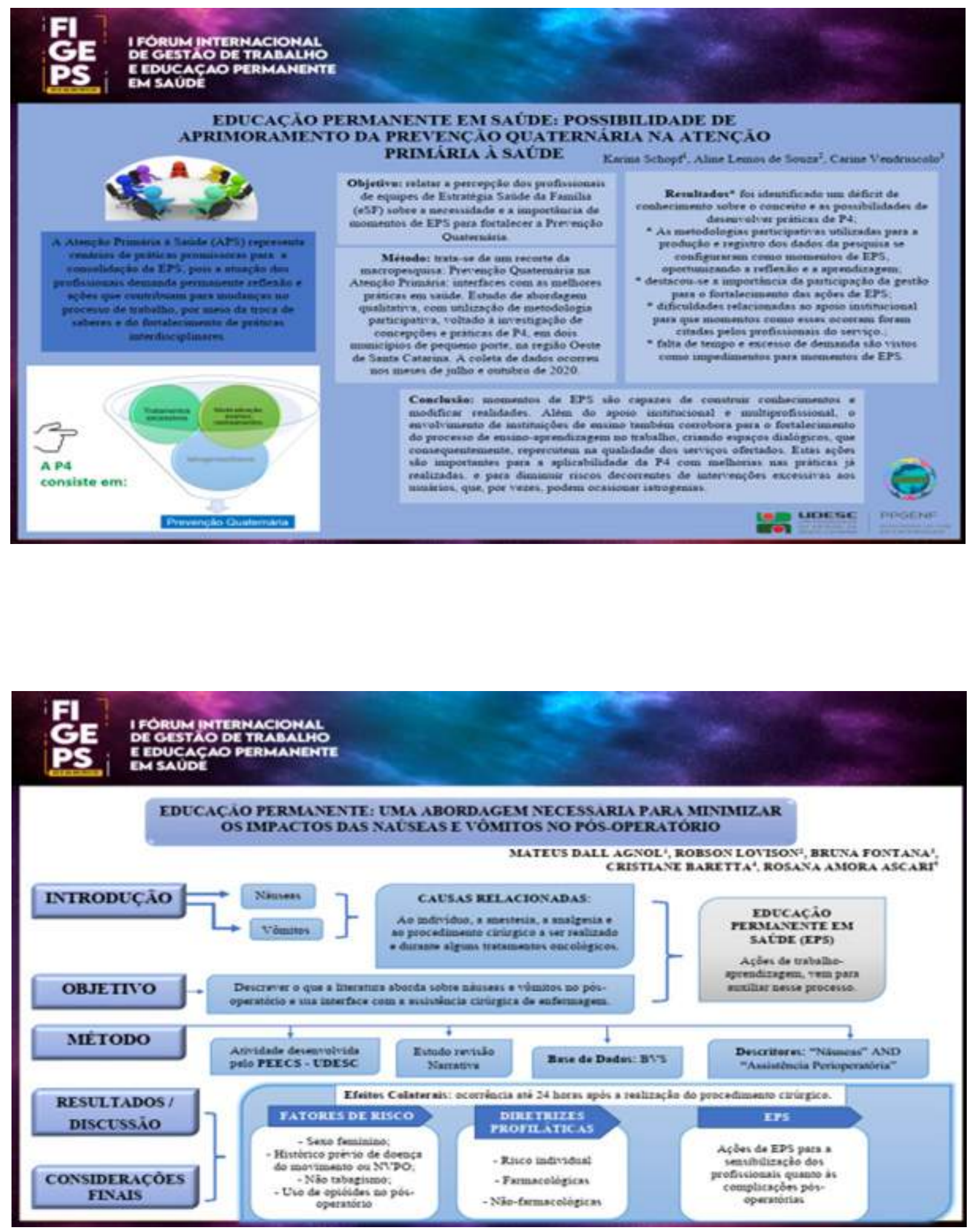

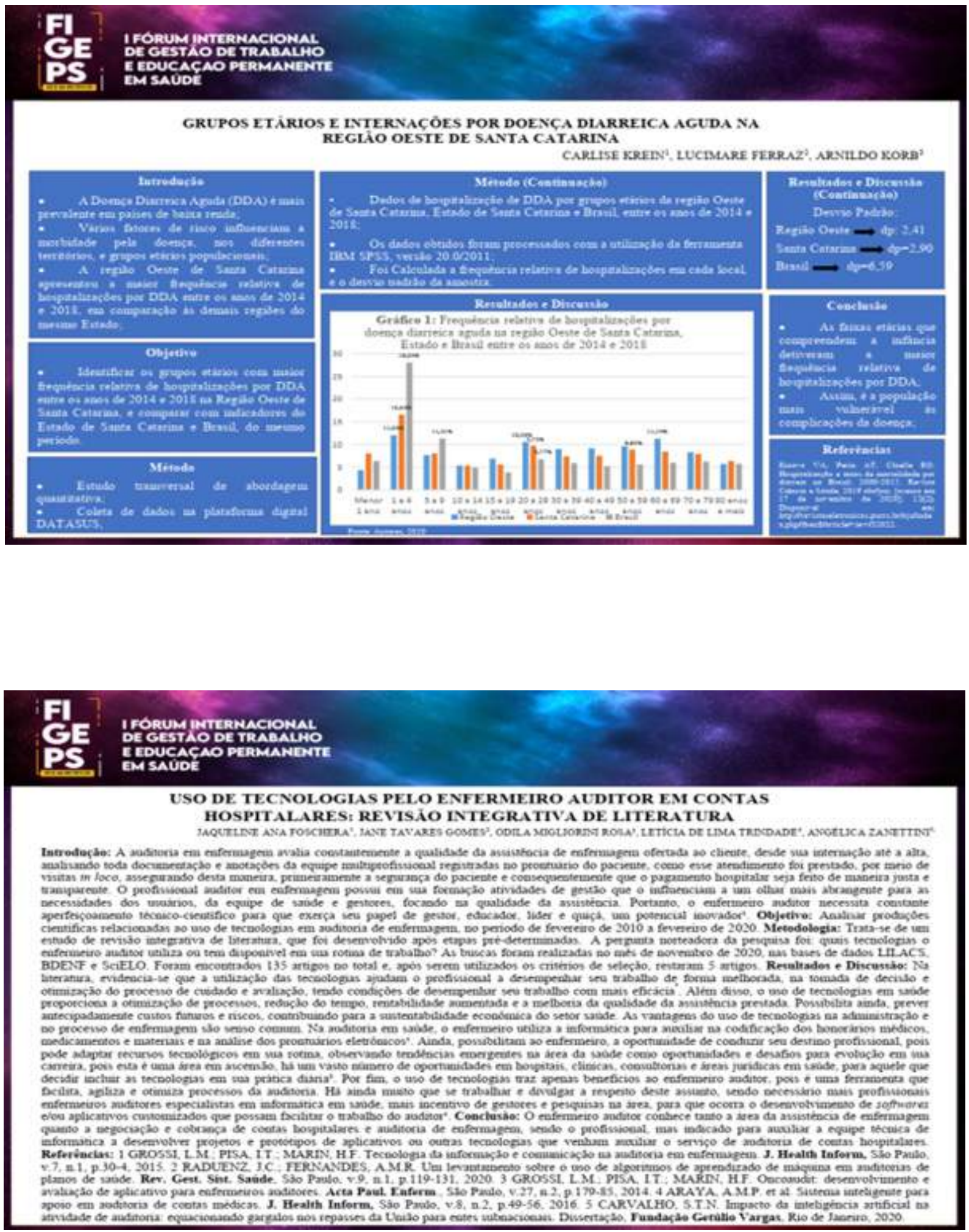

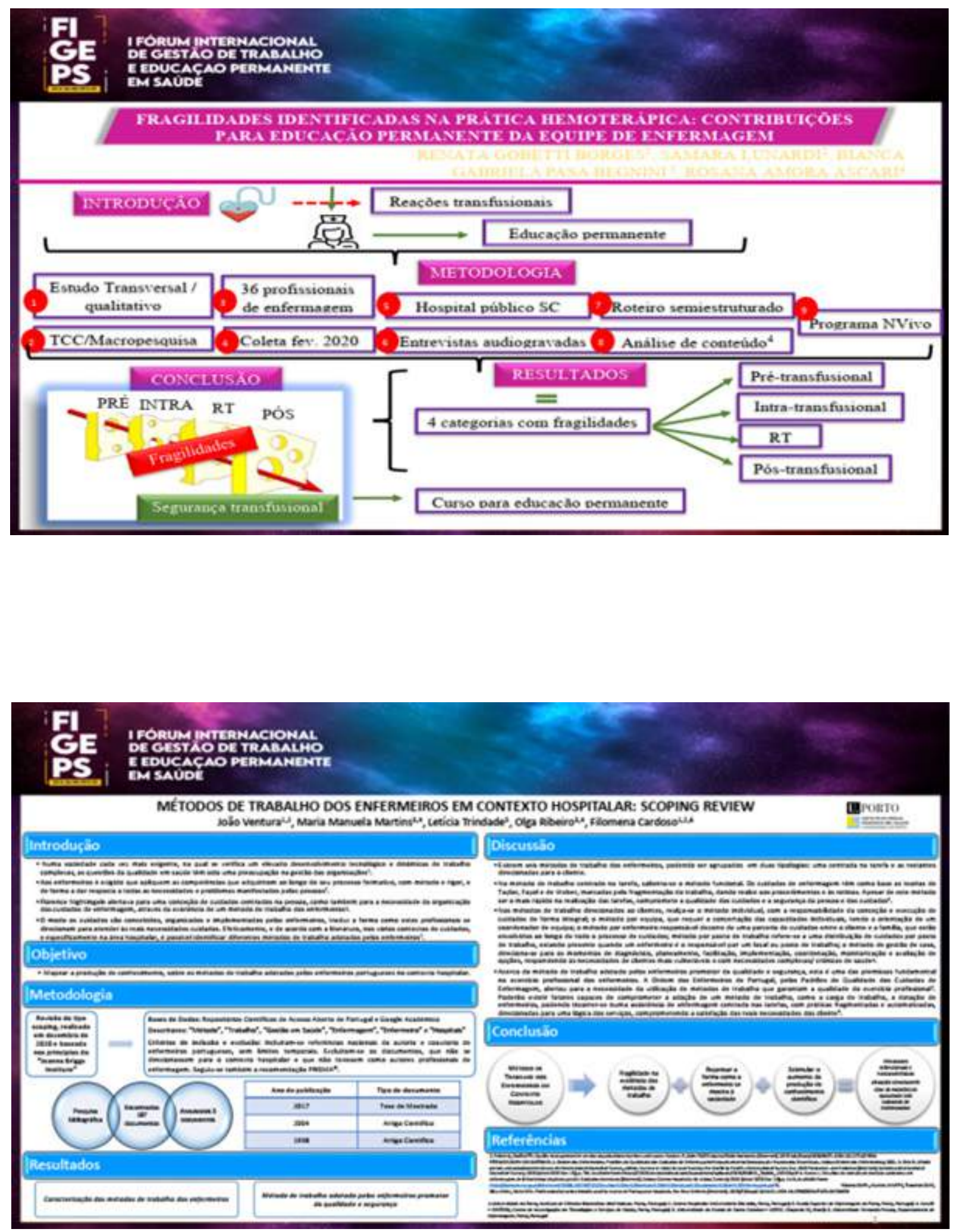


\section{I. LS; EMUCACAO PERTMARENTE}

PERFIL DOS PACIENTES INFECTADOS PELO CORONAVIRUS NO ESTADO DE SANTA CATARINAE OS PREJUIZOS DO PREENCHIMENTO INADEQUADO DAS NOTIFICACOES DE COVID 19

Iatredaçàe

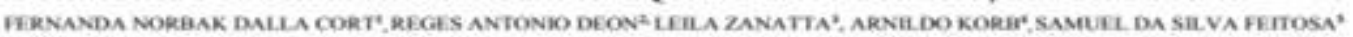

- Covis 19 - Evatus Pandindic

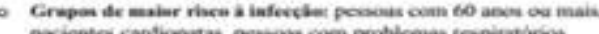

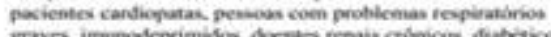

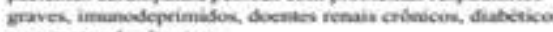
e gestantes de sho risce.

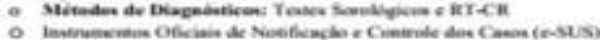
esrver ciesp:

Objetives

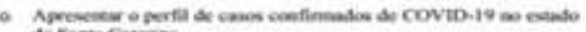

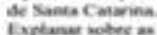

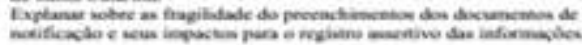

Metedelogia

Resultades e Discussầ

\begin{tabular}{|c|c|c|c|}
\hline 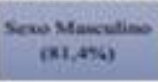 & $\begin{array}{l}\text { Sow Festining } \\
\text { (186) }\end{array}$ & $\begin{array}{l}\text { Rega - Nato } \\
\text { laformats } \\
(93.45)\end{array}$ & 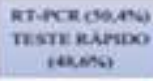 \\
\hline $\begin{array}{c}\text { M/dia de bitule } \\
\text { 45 abos }\end{array}$ & 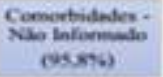 & $\begin{array}{c}\text { Taxu din Chato } \\
\text { ONe) }\end{array}$ & $\begin{array}{l}\text { Taxa de } \\
\text { Internestotr } \\
(2,+96)\end{array}$ \\
\hline
\end{tabular}

Conctusale

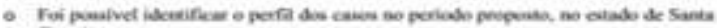

Curaine.

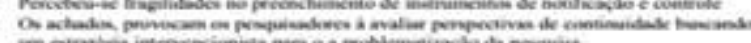

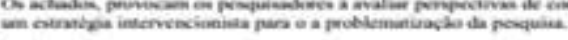

A gradecimente

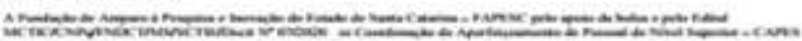
Beteriocian

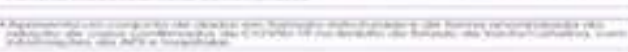

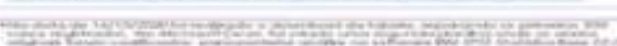

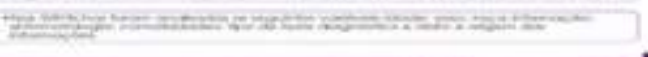

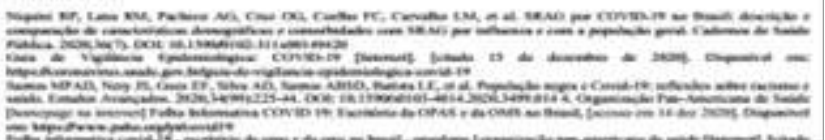

\section{Fi oe cest EM SAUDE

POLITICAS DE SACDE PRISIONAL - ATANCOS E DESAFIOS

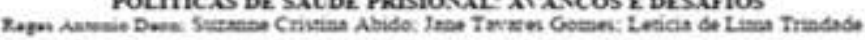

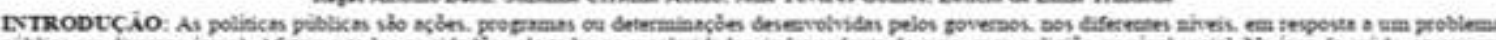

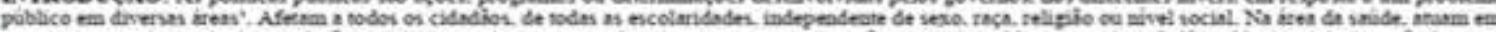

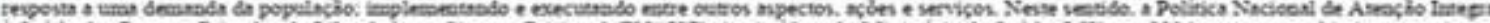

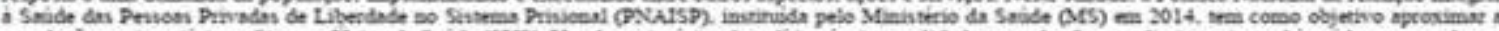

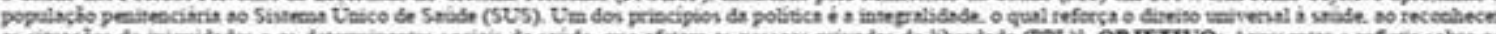

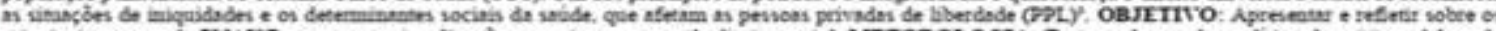

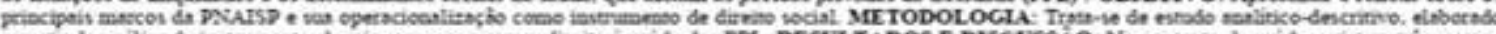

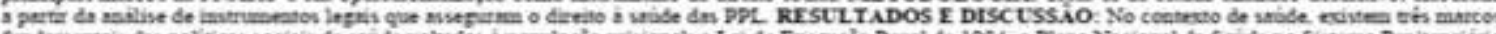

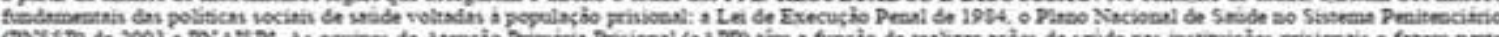

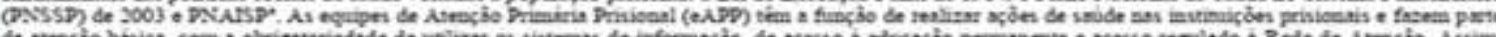

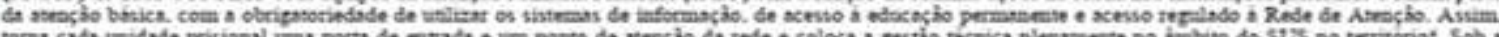

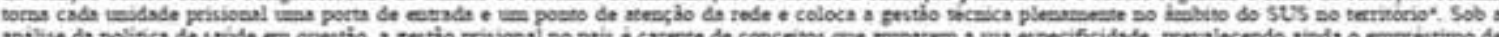

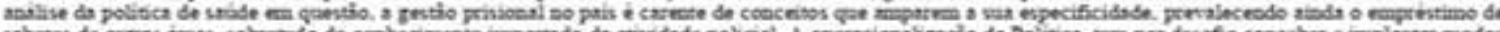

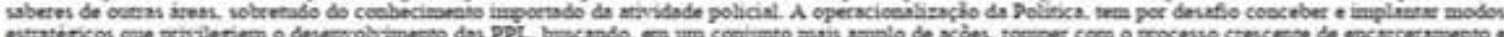

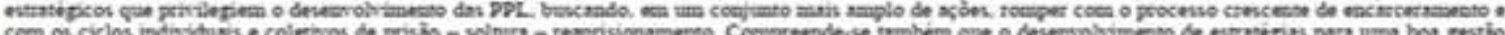

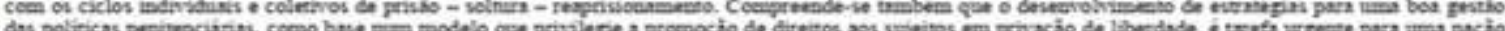

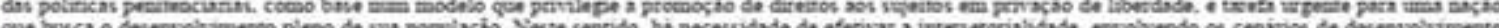

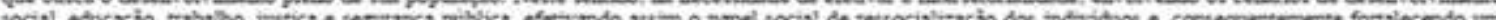

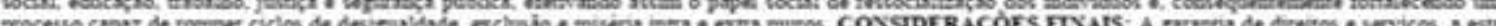

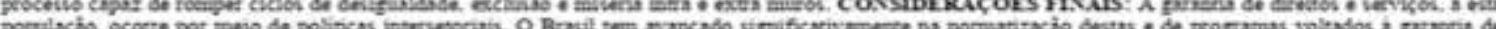

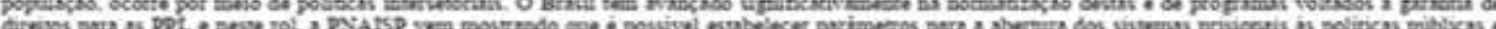

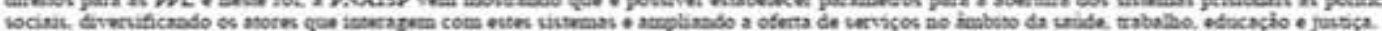

BerERfictas

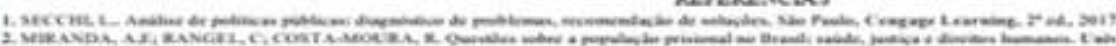

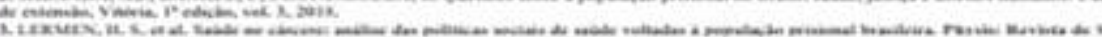

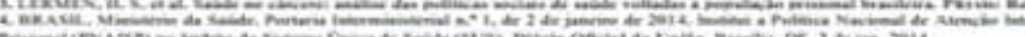


PROCESSO DE CERTIFICACÃO EM BOAS PRÁTICAS NA ATENCÃO

PRIMARIA İ SAÚDE SUPLEMENTAR: RELATO DE EXPERIÊNCLA

FABIELE FARINA ${ }^{3}$, MA YKLER CRISTLANE VANZIN ${ }^{2}$, KÁTLA IAMILE DA SILVA ${ }^{3}$

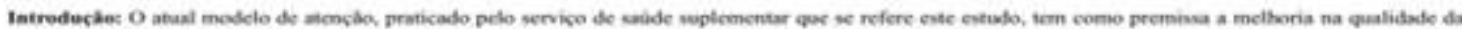

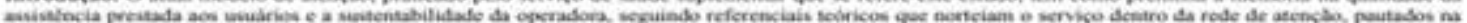

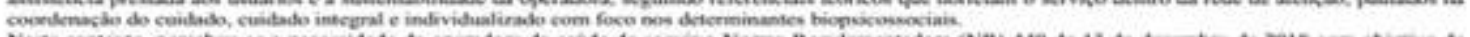

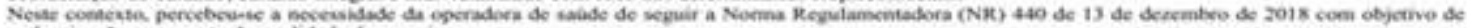

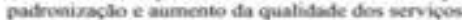

Objethe: Relatar o processe de implemsentacho da Certificacho em Boss Priticas em uma APS seplementar

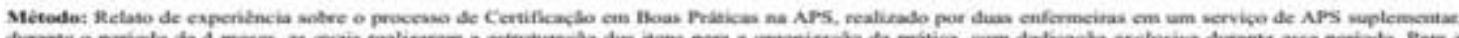

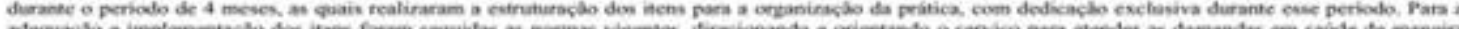

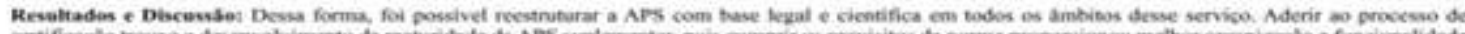

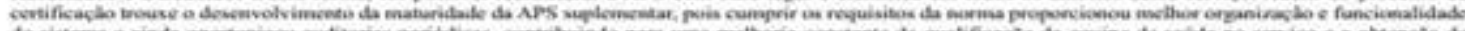

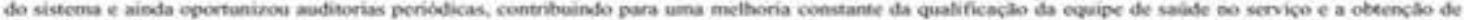

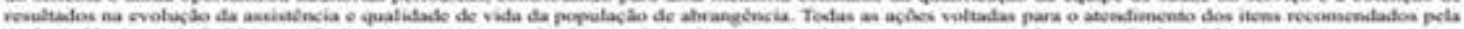

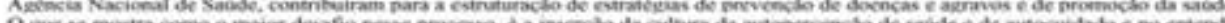

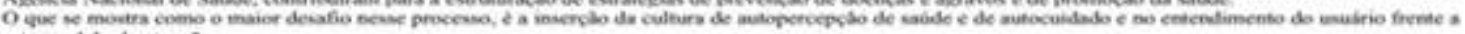
este modelo de atenglin

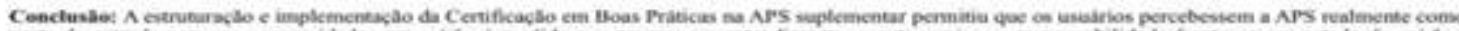

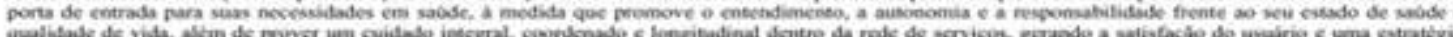

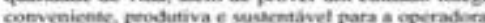

\section{[1] E PE}

\section{PROCESSO DE TRABALHO DOS AGENTES COMUNITARIOS DE SACDE EM TEMPOS DE PANDEMIIA POR COVID-19}

Suellen Fincatto ${ }^{1}$. Danielle Bezerra Cabral ${ }^{2}$. Arnildo Korb?

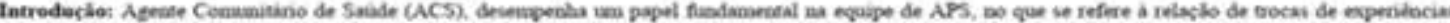
entabel

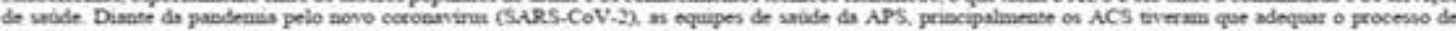

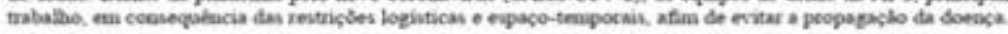

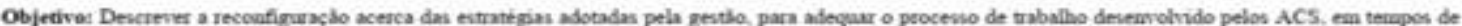
enfintentenento da pendemia da cOVID. 19

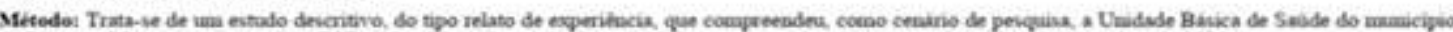

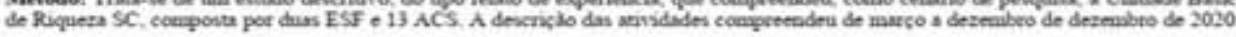

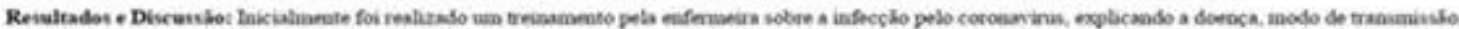

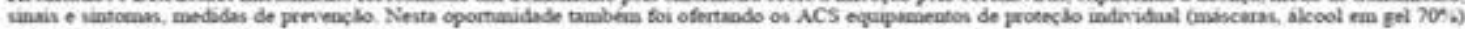

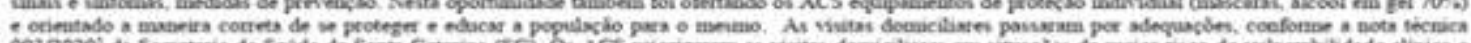

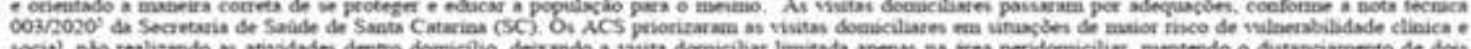

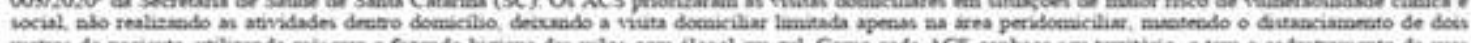

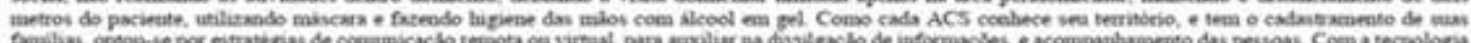

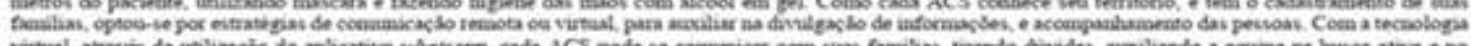

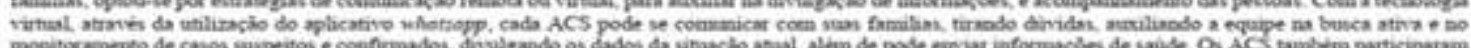

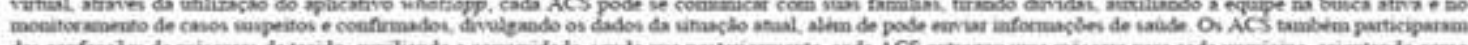

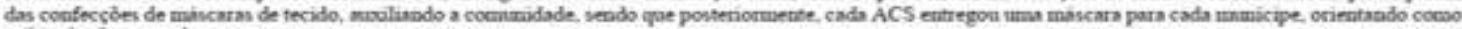

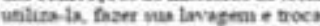

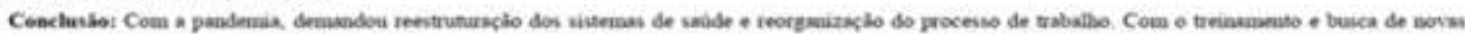

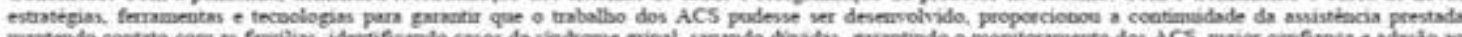

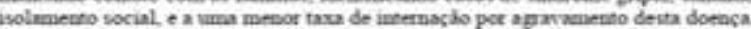




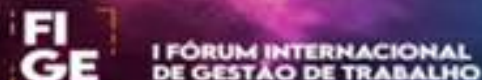 DEGESTO DE TRAMAHO \\ PSi Emsaút}

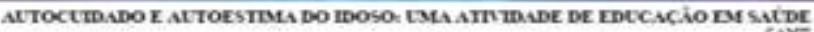

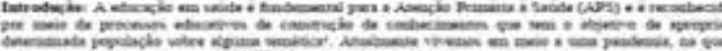

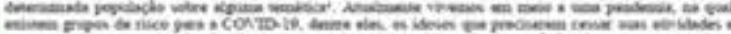

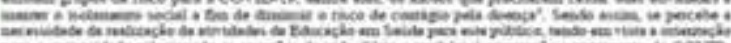

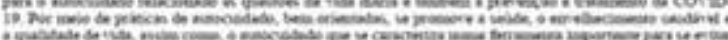

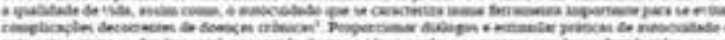
tho D

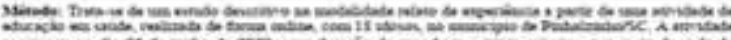

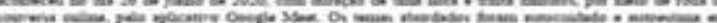

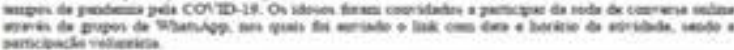

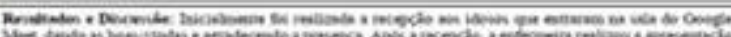

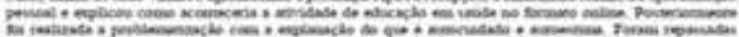

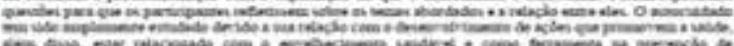

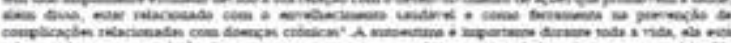

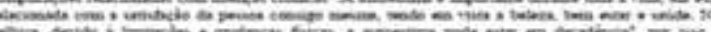

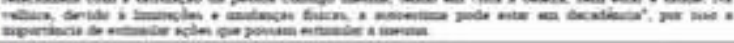

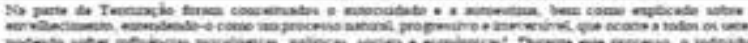

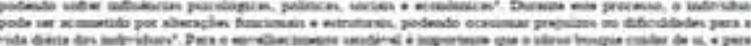

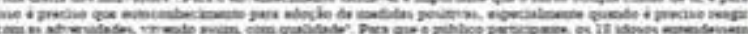

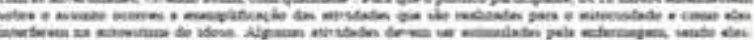

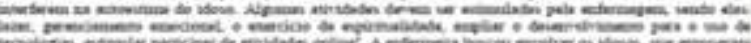

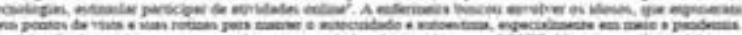

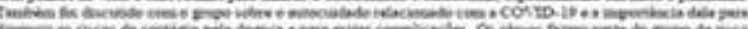

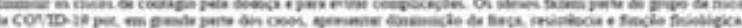

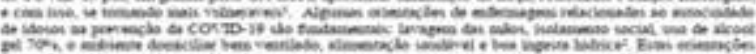

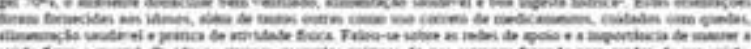
ch nive.

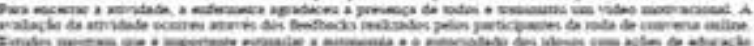

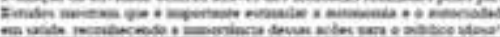

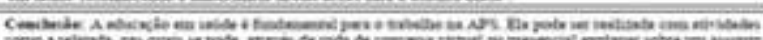

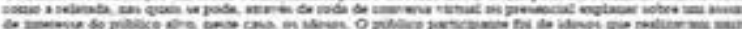

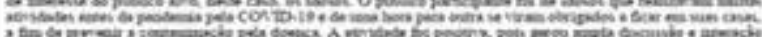

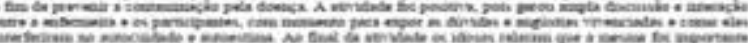

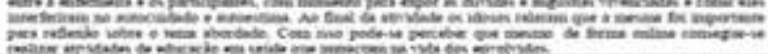

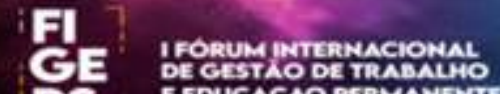 PS.

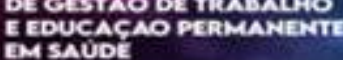

PREVENCÃO AO COVID-19: UMA ESTRATEGLA DE EDUCACÃO EM SAÚDE PARA

AGENTES COMUNTI ARIOS DE SACDE

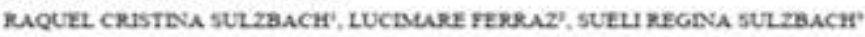

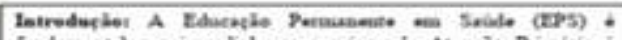

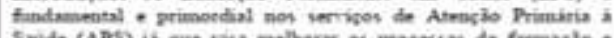

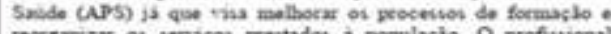

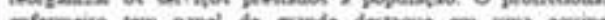

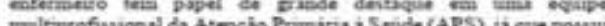

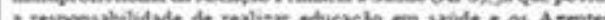

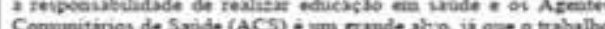

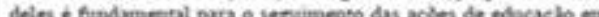
pura un popolacio.

Objetivet Relater a mpendacis de ima atividade de educacho em

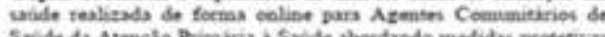

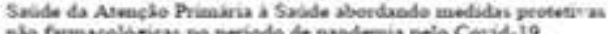

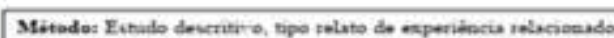

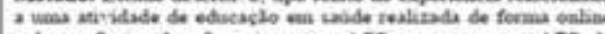
pelo peofivieasl edeforaseres, coen ACS que stusis ma APS do mamicipio de Pinhalitinlo $-\mathrm{SC}$.

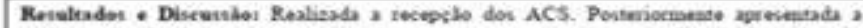

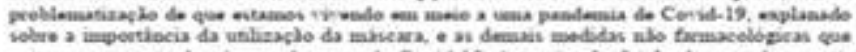

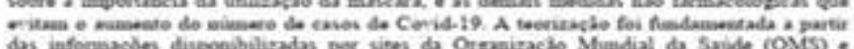

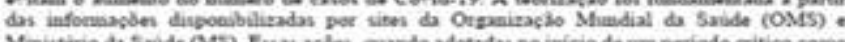

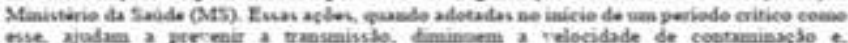

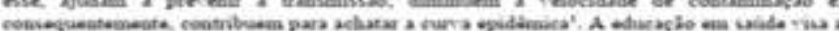

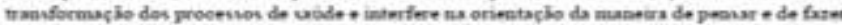

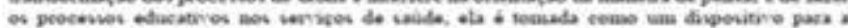

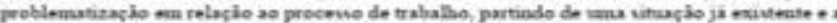

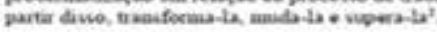

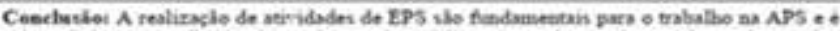

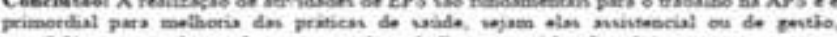

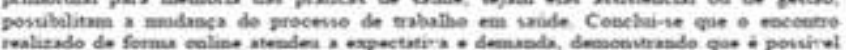

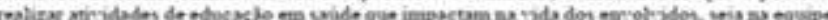
de wide da APS comeo as des umaino

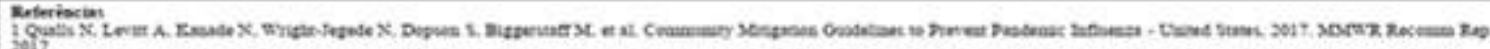

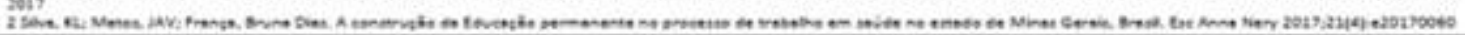




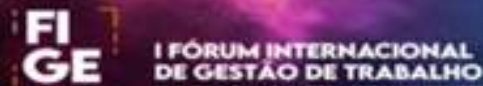 \\ PS. FEUCACAO PERMANEMTE \\ EMSAUDE}

EDUCAÇÃO PERMANENTE: TRANSFORMANDO O COTIDIANO DA SEGURANÇA DO PACTENTE

Introducho

A Segurança do Paciente (SP)està se tornundo mun tema cada vez mais presente e debatido entre gestores e profivisonass de instituacóes de diversos setores da irea da saude. Para que os desfechos negativos nìo sejam recorrentes, se faz necessaria a unilizacto de estrategias de ensino que contribiam com o prendizado dos profissionass de satide a purtir das stuacoes vivenciadas. Deste modo, mana alternativa utilizada pelos servicos de saude é a Educaçáo Permaneate em Saude (EDS)

Objetive

Descrever a experiència do uvo da Educaçăo Permanente em Saùde como forma de traniformar o cotidiano da seguranca do paciente

Metode

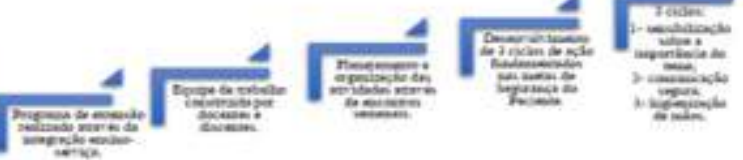

Resultados e discussào

As açes formm realyzadas nas dependerpcias do bospital e in loco nas unidades de assisténcia e eavolveram a partacipaça do de 1000 pessoas. Feram desenvolvides trós ciclos de atrvidades gae buscaram compreender a realidade do servico. unlizando stutuçcoes semelhantes is vivepciadas no dia a dia de traballho

portanto, compreende- fe que a integracto ensino-servico siag alcançar uma melhora na qualidade de atencto a saide individual e coletiva, ba qualidade da formaça dos futuros profissionais e no desenvolvimento e satisfaçito dos trabalhadores dos serviços.

Conclusào

Atraves do deveavolvimento desse projeto pode-se afirmar que os profissionais de satid se sersibulizaram durante os eacontros, uma vez que o Núcleo de Sepuranca do Pactente do houpital afimoou modancas positivas nas hoiptal afimmou
atrividades dianas.
SEOURANCA DOPACIENTE

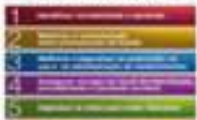

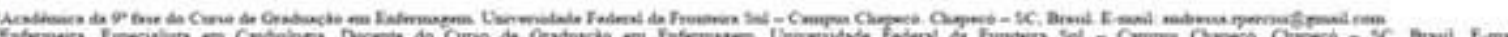

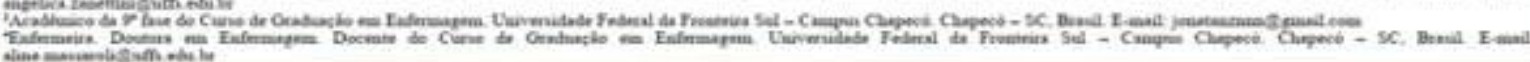

\section{[f] PS}

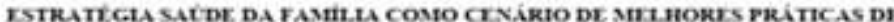
ENFERMAGEMEMTEMTOS DE COVTD-10

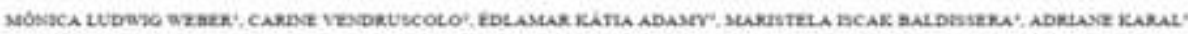

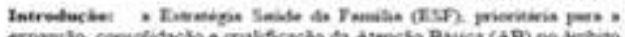

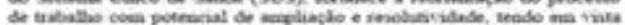

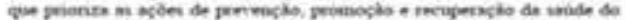

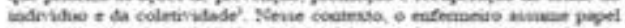

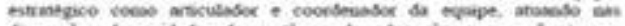

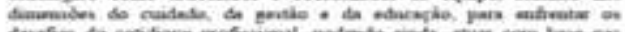

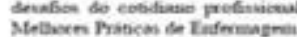

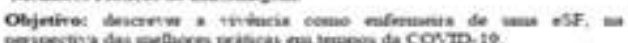

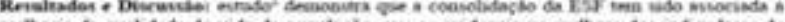

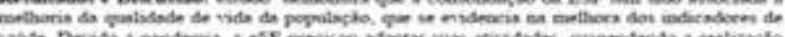

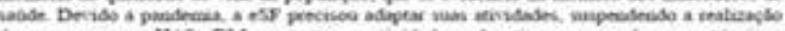

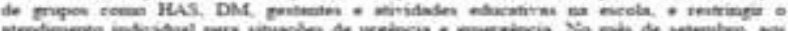

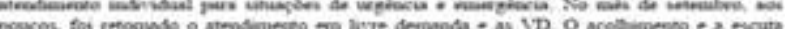

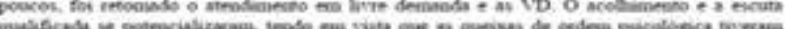

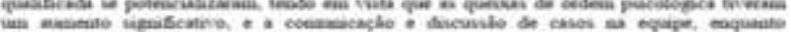

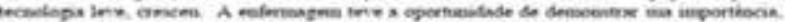

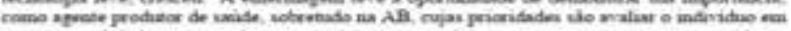

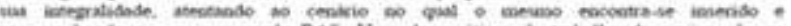

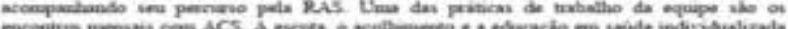

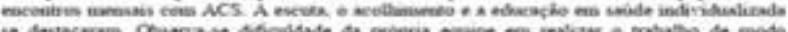

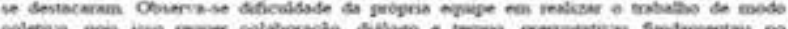

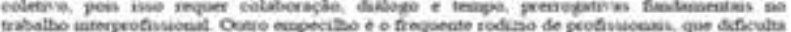

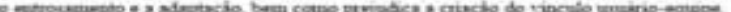

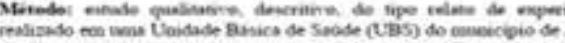

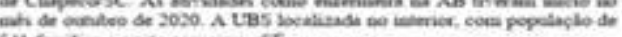

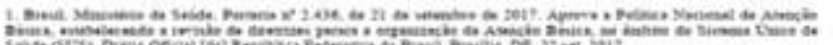

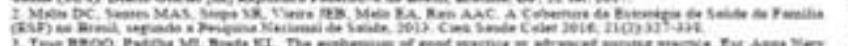

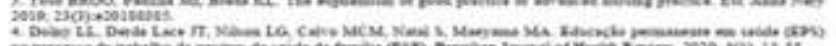

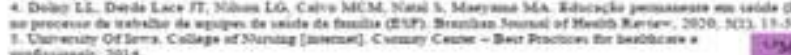

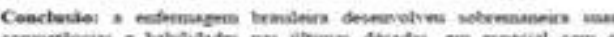

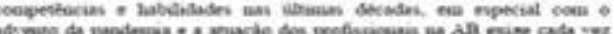

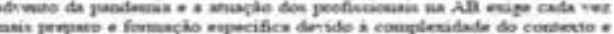

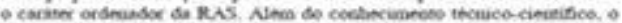

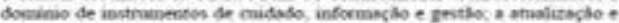

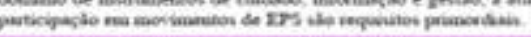


POLITICA NACIONAL DE EDECACAOO PERMANENTE EM SAUDE E SUAS ESTRUTURAS RE.EMNTARES

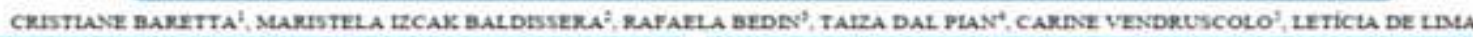

$$
\text { INTRODECATO }
$$

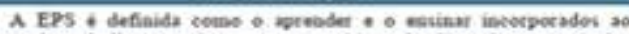

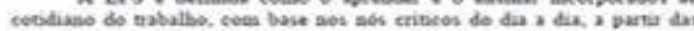

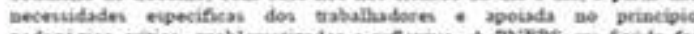

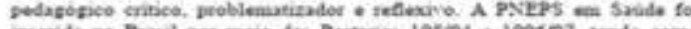

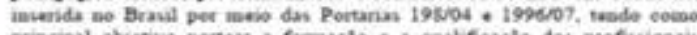

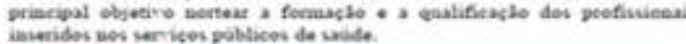

\begin{tabular}{|c|c|}
\hline Otpiethe & 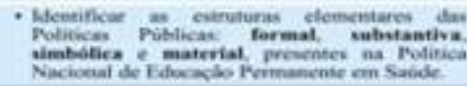 \\
\hline Meteale & 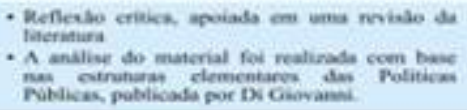 \\
\hline
\end{tabular}

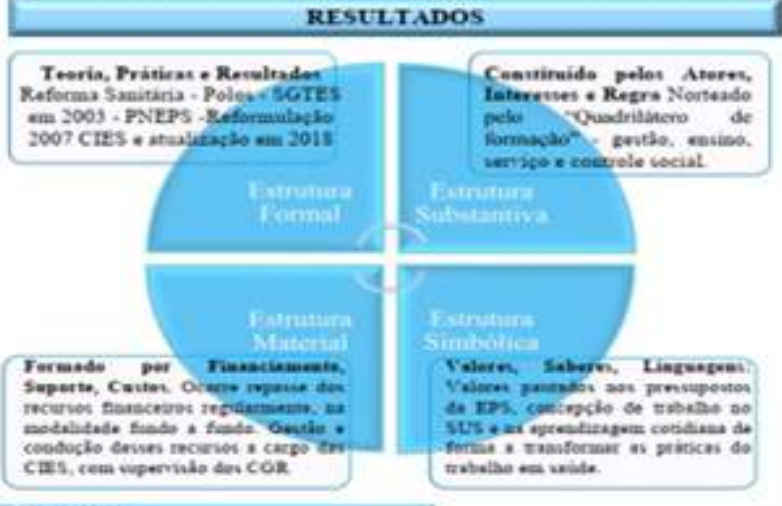
RESULTADOS

Covclusio

\section{[1] \\ PS. \\ EM EN SUDC}

\section{A COMUNICACĀo COMO FERRAMENTA DE GESTÃo FRENTE À COVID-19 NA REGLẢo SUL DE SẢo \\ PAULO}

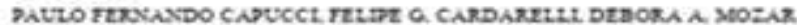

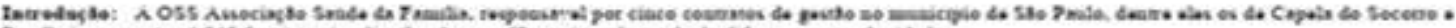

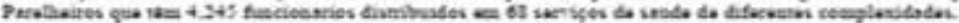

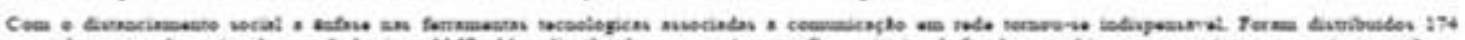

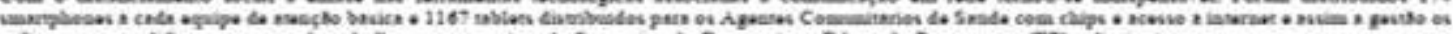

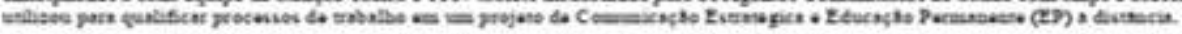

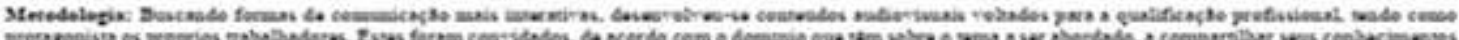

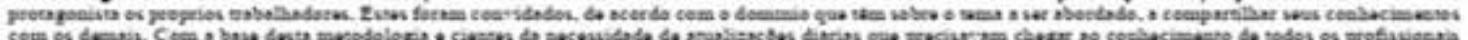

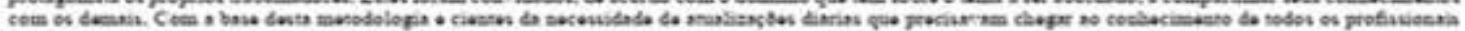

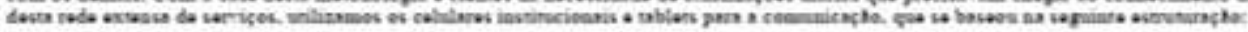

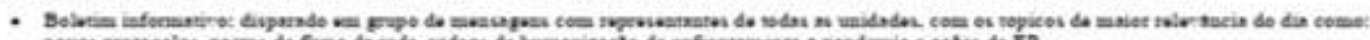

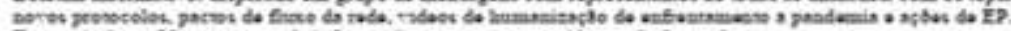

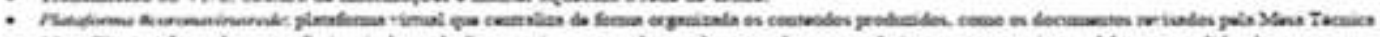

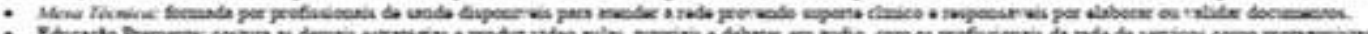

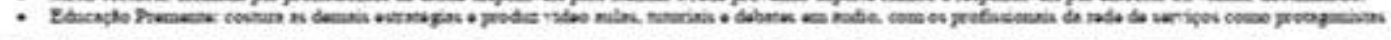

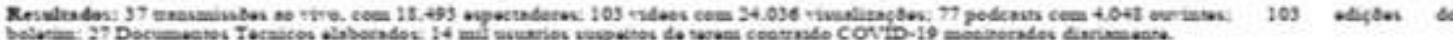

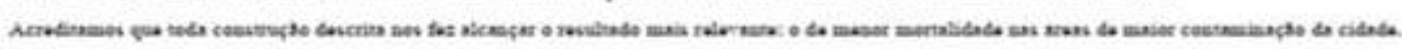

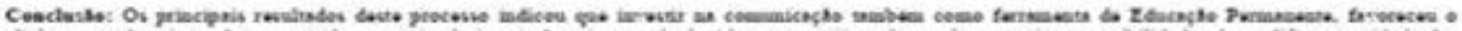

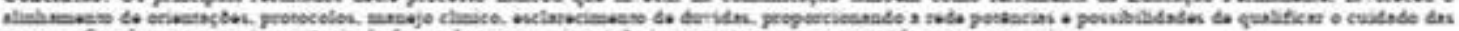

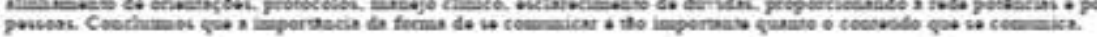




\section{A IMPORTANCLA DA GESTÃO PARA UM CUTDADO QUAIMICADO EM \\ SAÚDE MENTAL NA ATENCÃO PRIMÁRIA JAMIEE BERNER1' LEII ZAVATYA}

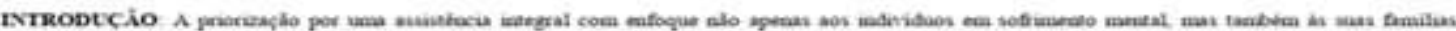

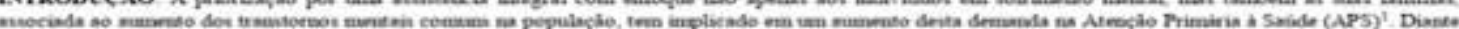

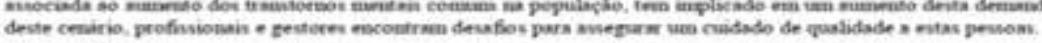

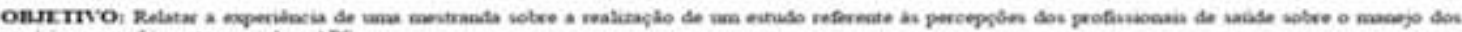
uevinios ena sofrimento mental na APS.

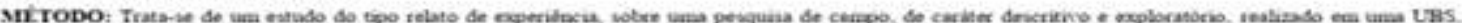

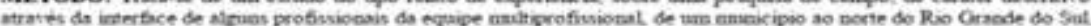

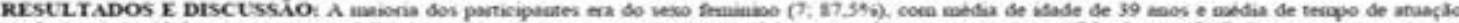

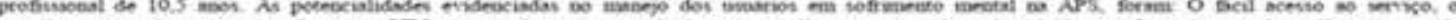

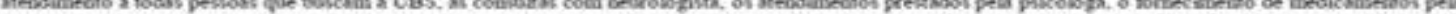

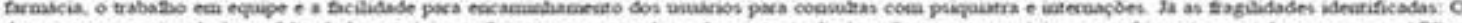

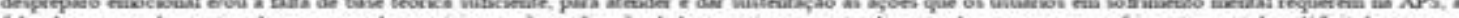

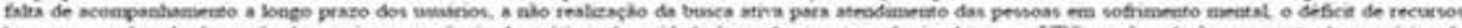

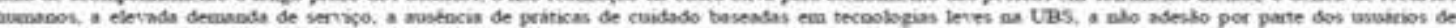

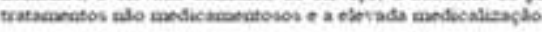

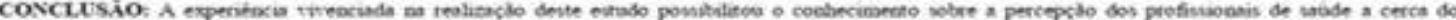

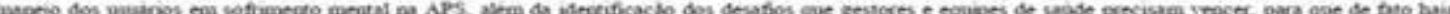

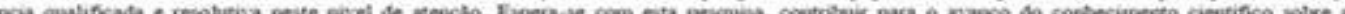

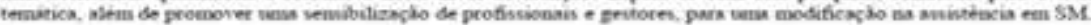

METER VCLS

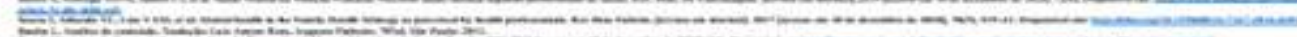

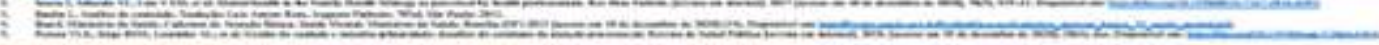

\section{[E] E

POLITICA NACIONAL DE ATENCÃO INTEGRAL A SACDE DA CRIANCA FRENTE AO CRESCIMENTO E DESENVOLVTMENO INFANTI

ALANA CAMII A SCHNEIDER', ANA MAIRA TELO'?, MIRIAN GLACOMEL'? WANDERSON TEIXEIRA ${ }^{4}$. CARINE VENDRUSCOLO', LETICIA DE LIMA TRINDADE

\section{Introducha

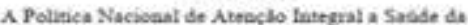 Crisass bo

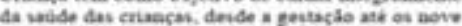

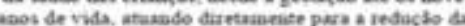 merbimertalidade imfainhl e promeveredo o

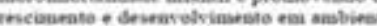 ferlitades e cons contigdes digmas}

Renultadet o discunio

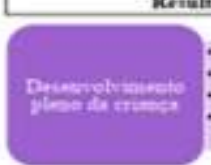

Cricialaente Sobvrisutacia Visiliecia - Promerto da nodade

Fiscalain Evantion oficases Procresure

Eventobin ofickes - Receniecer Fularrabaladadri - Proper iaterverdor

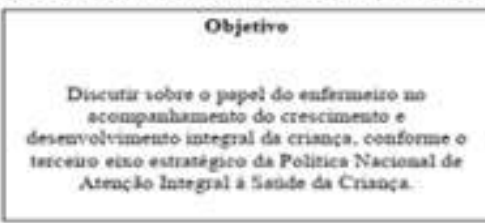

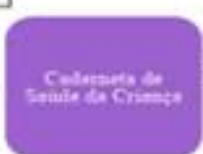

- Dasos tipuifcaterves - Informusces

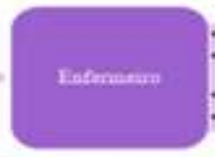

Vinciles - Beas juticas paiestas o mincon aterivas - Toenada de decisio - Pedacio de apme.

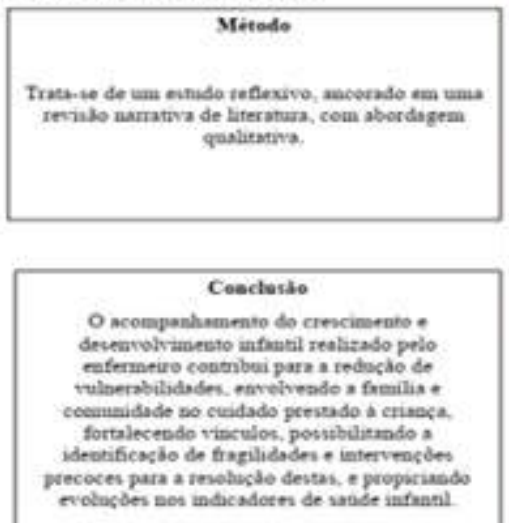




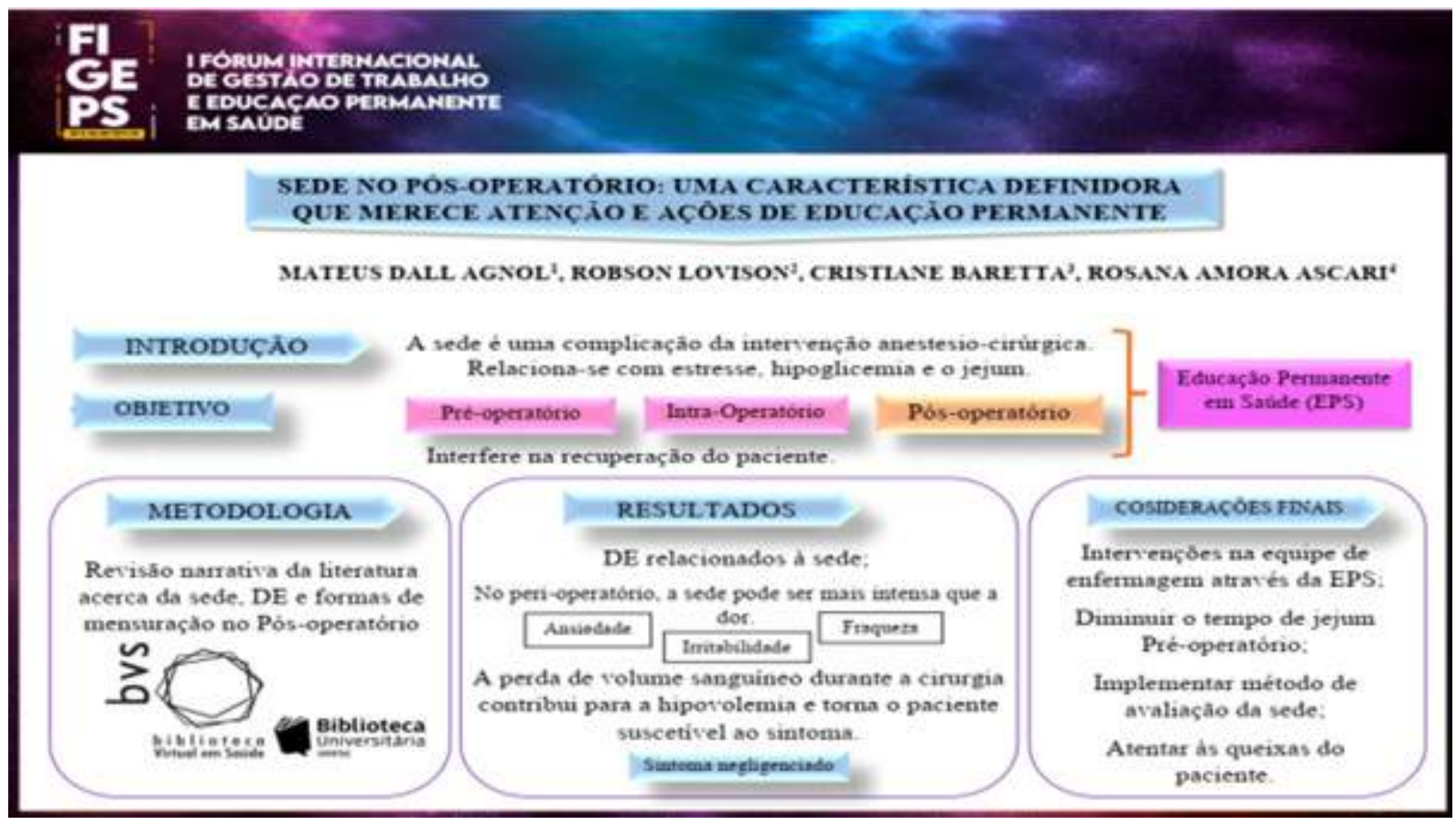

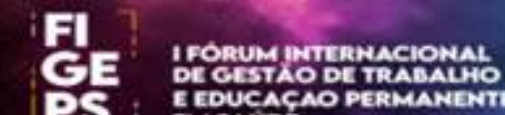 PSi EMSAUDE}

EDECACIO PERMANENTE EM SATDE:A PERCEPCIOE PRITICAS RELATADAS FOR ATORES OUE A CONSTROEM. Alves DM', Junqueira RS 2

Introdurter

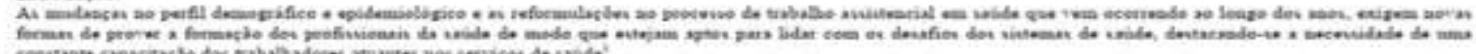

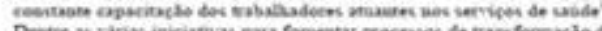

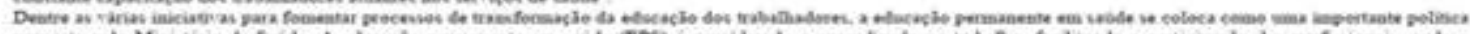

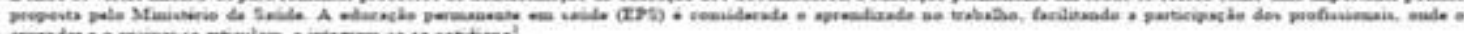

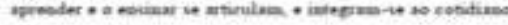

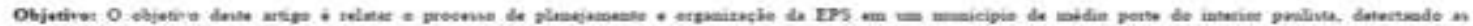

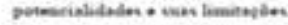

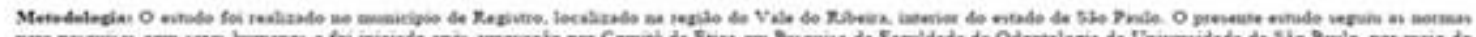

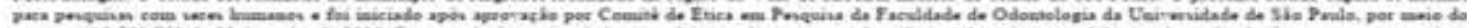

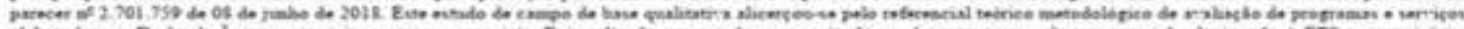

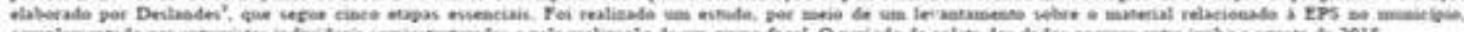

Reralindet

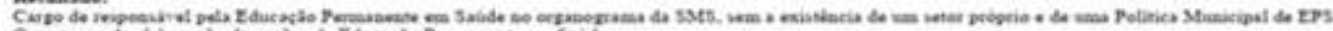

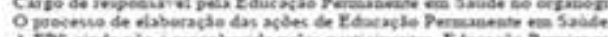

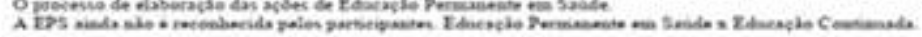

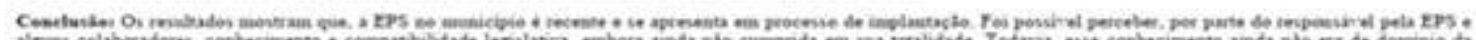

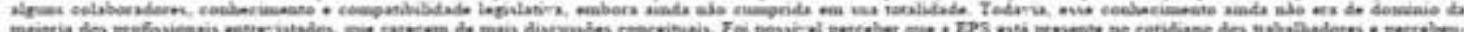

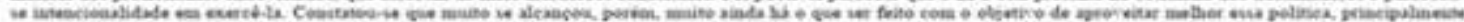

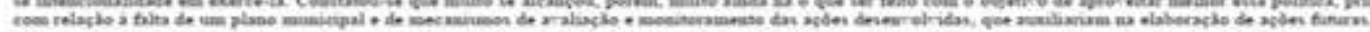




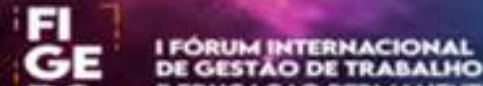 PS, EmUCACNO PERMANETIE}

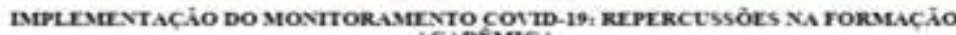

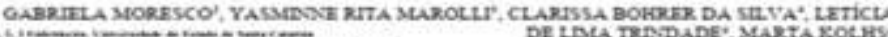

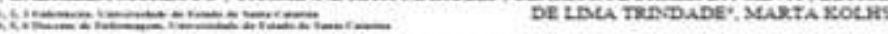

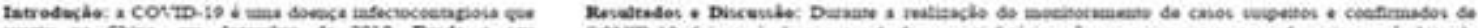

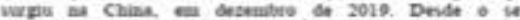

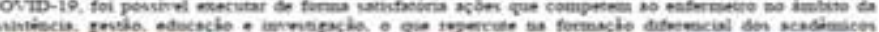
wobises.

zeotal:

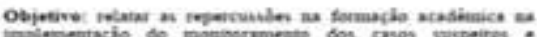

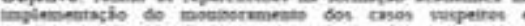

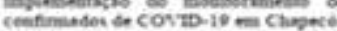

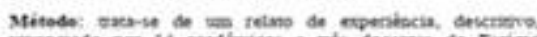

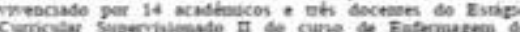

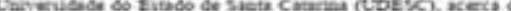

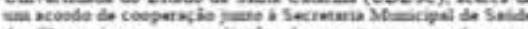

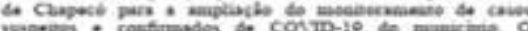

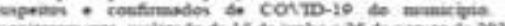

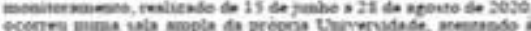

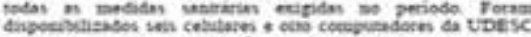

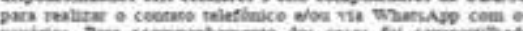

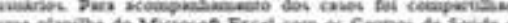

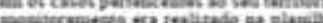

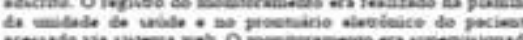

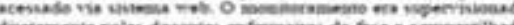

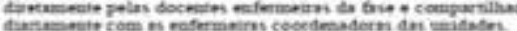
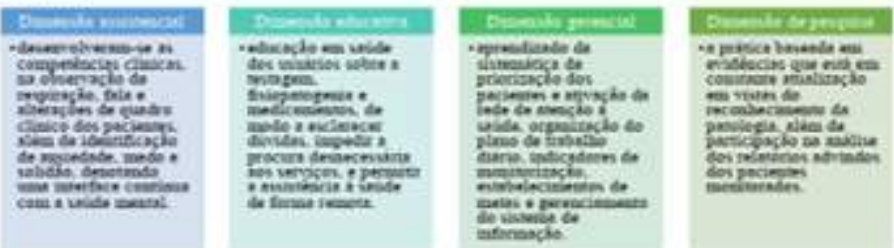

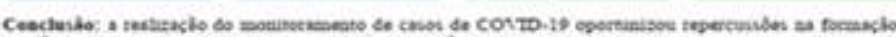

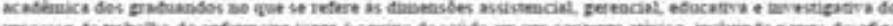

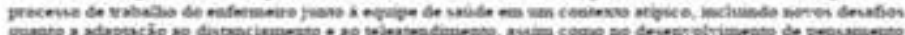

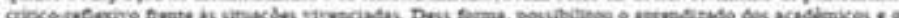

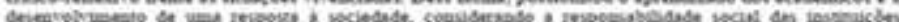

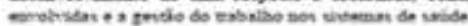

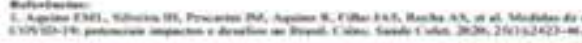

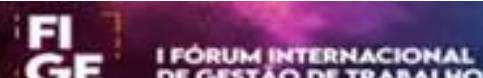 \\ C. ER EDUCACAO PERMANENT: \\ Hei Emsaube}

CICIO DE OFICINAS COM PROFISSIONAIS DE UMA EQUIPE DE ESF: (RE) SIGNHTCANDO AS REUNIOES DE EQUTPE.

Alves DM D $^{2}$, Carotta F

Intreduste:

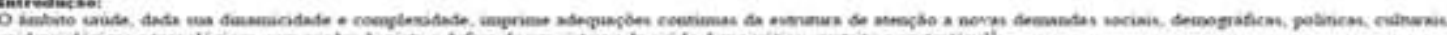

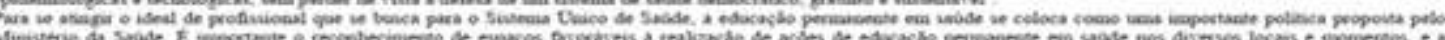

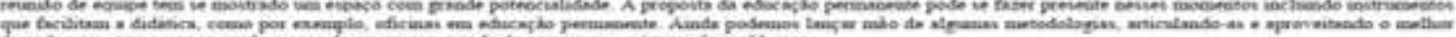

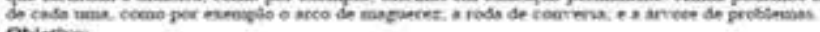

Otjetive:

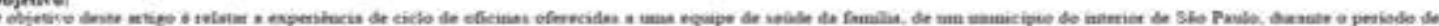

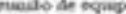

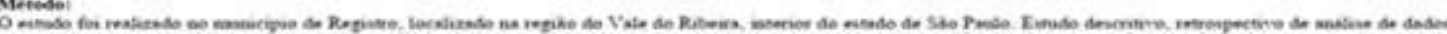

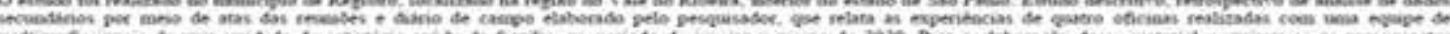

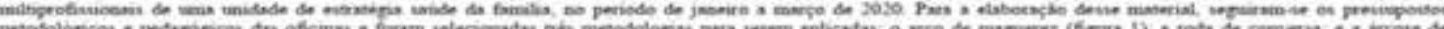
grotlemeir

Vigues 1: Aete de Maguenes

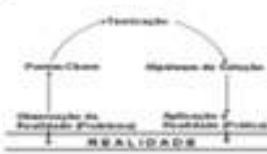

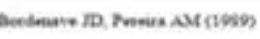

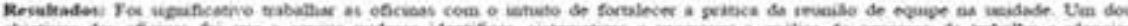

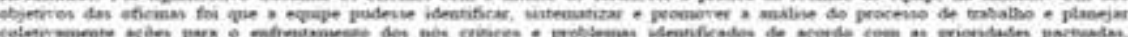

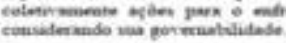

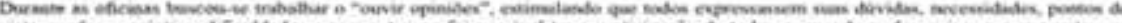

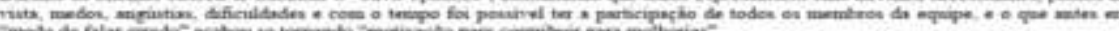

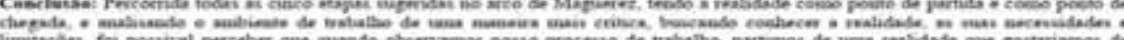

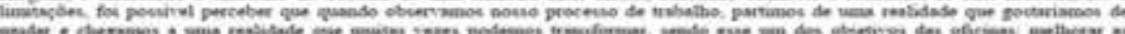

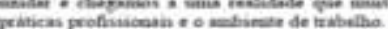


TRANSIÇÃO ENTRE OS SERVICCOS NA REDE DE ATENÇÃO À SAÚDE: SUBSÍDIOS PARA LIDERANCA DE ENFERMAGEM

Vadria Casolini Gones, Caroline Cochinel Peiker, Gabriels Maroellino de Melo Lansoei

Introducias

A contimuidade do cuidabo a refere a ver aceenunhamento do paciente entere on semicos do nabde por meio de reficríncia e contrumeficrtocia para o coetrole de wa sintornatologia es exacertaciles!

Devido a apresentaclo da sineoenueologia periedica das donnas crónicax, seu portabor mecessita of cuidudor coetinoor. Nese sentido, destaca-se : importincia de transiglo do cuidado entre of servipos e fueros de refartacia e conerarreforencia estrinurafos na R.AS, resultando ma continuidade do cuidado ao longe do tompot.

\section{Objetive}

Analisar a contimeifade de cieidede de criancas com condiçles cotnicas durante a transiçlo cotre os servicos apele a alta bospitalar.

\section{Mitede}

Pesquis de métodos minton

- Realizada en dois boepitais do sel do Brail, so periodo de feversino à sctemibro de 2019.

- Fase quantitativa ueilinou-se o inatrumento Can Thantinious Mearane (CTM-15 Brasil) para colkta de dados;

- Fase qualinativa utilusoo-se a Teoria Fuodimsentada cm Dados.

\section{Reseltader}

Duas catgorias foram criadas apos a malise dos dadon qualitatives: Buscando promener a sereinsidade do cuidude da crianca com confichles coninicas na Rede 4 .

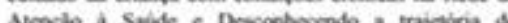
paciente apdis a alts hospialar e wa integraclo coen a Atenclo Primiria A media encontrab do CTM-15 Branal for de $80.5(\$ p=12.5)$
Nba for encootrata neste cotubla diferenca cutatinticamerne significanse entre a qualidade da transiclo do cuidado en relacklo an ginem, inatituicho hospitalar, tipo \&e vinculo coen a criacsa, mümero de intemapdes nos thimos 12 mesies, ietegrante do capinslo CID-10 conelacilo de idade e dia de internapho. Quande compurada os manikipio de revidtaxia da criansa, foi verifkada diferenca in qualiatade da tranichlo do cudaba, sendo maior napoeles pacienter que resilian en manicipios perencectacs a rogibes de caide deferentes da des bospitais.

\section{Cenclesia}

Foram evidesciades etratigias dotades pelos profivioesis para dnblar on empocilhon encontradon Murante a transicbo entre on semicos de criaryar com

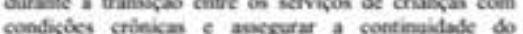
cusidato por melo de aciles de transixlo do cuidado, podendo ter impartado na equalidale da tranciclo do cuidedo perestida pelos familiares.

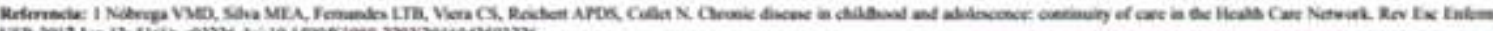

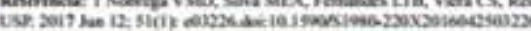

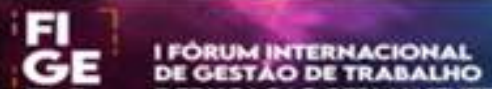 \\ i. E; E EUCACNO PERMANENTE
}

CAPACTIACXO DE ENFERTIROS PAR, O CUDADO DO PACIENTE ESTONIIZDO NA ATENCAO

PRTMLIRIA: CENARIO DE EDUCACÃO PERMLNENTE FM SAUDE

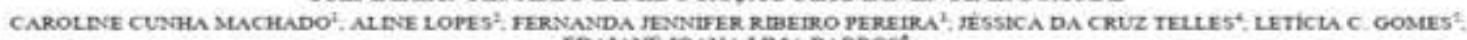
EDALANE 10 ANA LMA BulROS

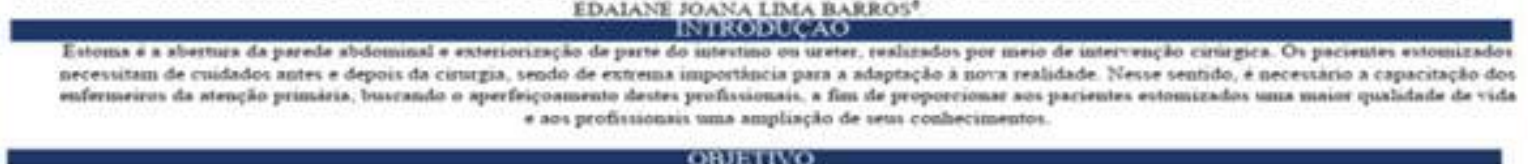

\begin{abstract}
comanco

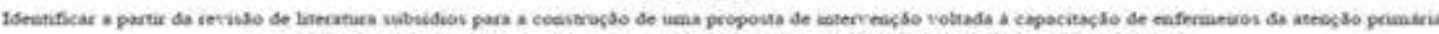

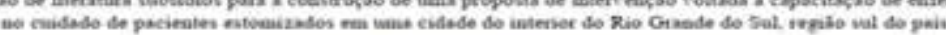

ए

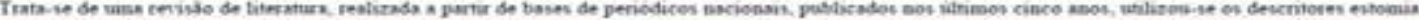

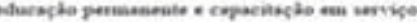

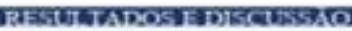

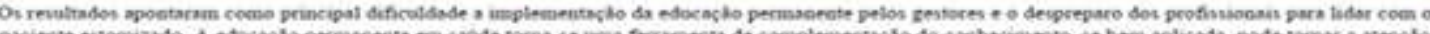

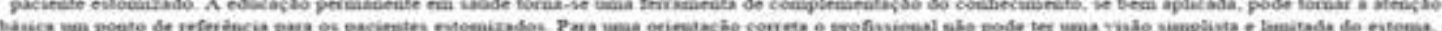

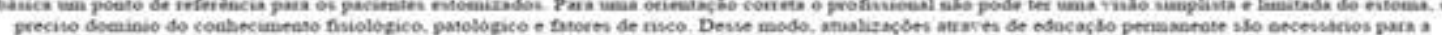

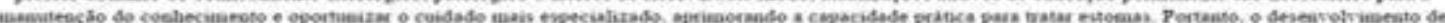

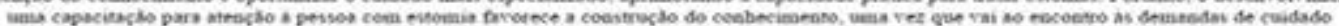

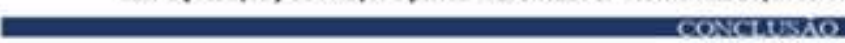

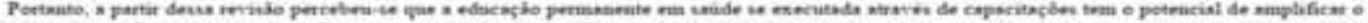

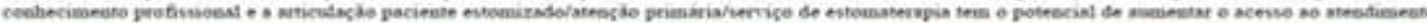
pelo paciente eitomitade 

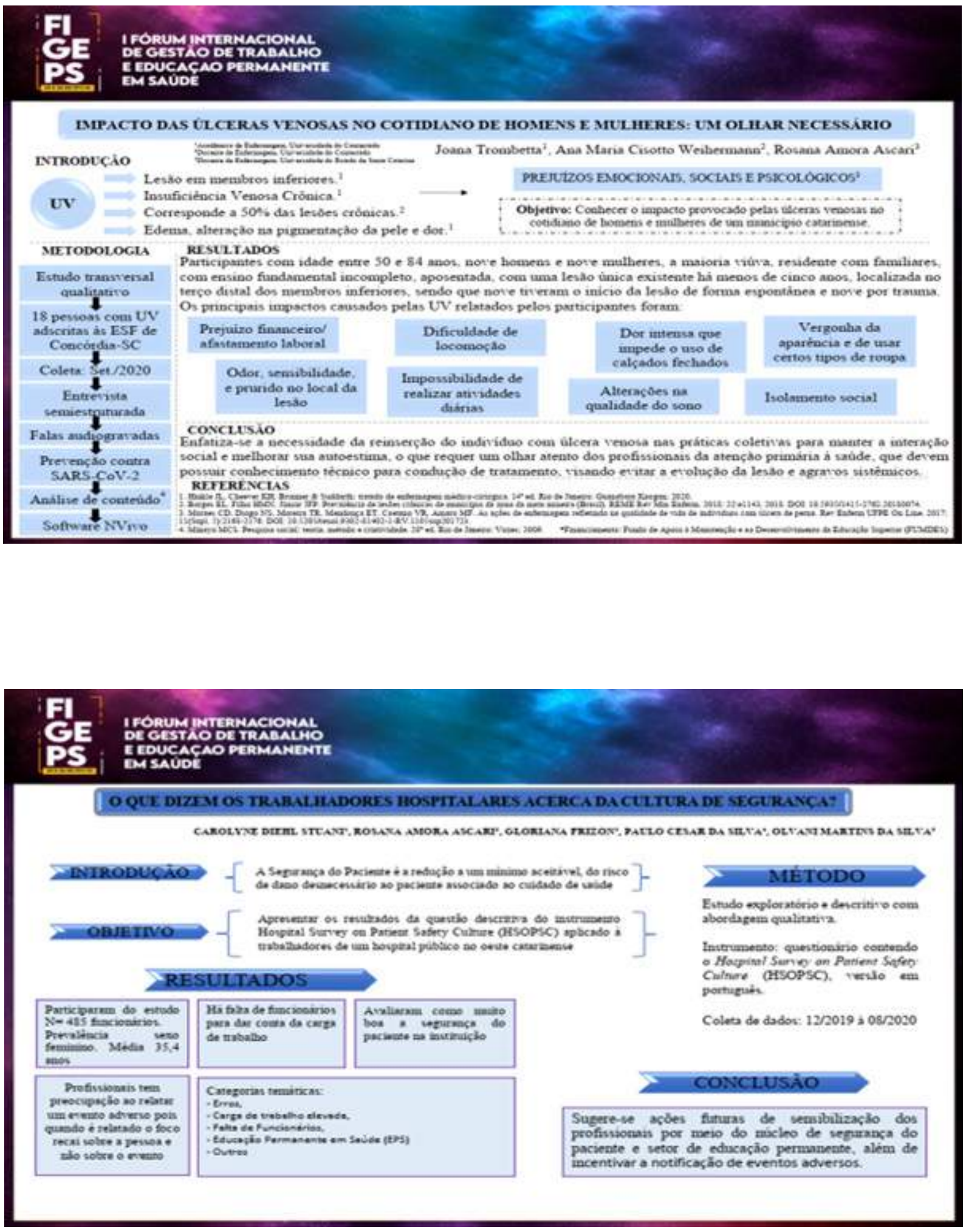


\section{O LEAN HEALTHCARE COMO FILOSOFIA PARA A GESTĀO EM SAÚDE}

KWLATKOWISKI. Heloisa Sehatz', BITENCOURT, Jülia Valéria de Oliveira Vargas², BORDIGNON, Maiara'

Introducto: Espera-se cada vez mais que os sistemas de saùde sejam eficientes, eficazes, que prestem cuidados centrados nos pacicntes e seguros. Diante disso, estratefear que buscam sanar essas tacunas foram criadas ou adaptadas para a jrea da saude. Assim. destaca-se o Lean Healtheare. que postui origem no Ststema Toyota de Prodtuçlo, chamado de Lean Thinking is

Objetive: Refletir acerca do Lean Healthcare enquanto tecurso para a melhoria da qualidade da gettilo em saide.

Método: Estudo de teflexdo que apresenta sobre a proposta da filosofa do Lean Henlthcare para a gentlo en saude, stus potenciabdades e fragibdades, fundameatando-se em resultrados de estudos mdividuais e em revisbes da literatura acerca desta temitica

Resultados e Discussaio: O pensamento Lean ma trea da saude pode ser definido como uma filosofia que busca adentificar e eliminar desperdicios no processo de trababo em saude. podendo ser implementado em diferentes contextos.
Sepaindo as experitacias do sistema de producto da Toyota s so descritos na lectahia sete desperdicios apbcados a atea da savide isuperproducto; in - eltoque; il - movimentacso, iv - transporte; v superprocessamento: vi - espera; vai - defeito; vin - vio utilazac to dos aleatos dos profissionsis

Eundos mencionam que eita fllosofa aplicada ao contexto 4 a saude transforma tanto aspectos oreanizacionats cormo assistenciass dos servisos, miplicando positivamente na qualidade e segurabsa dos cuidados

Conclusalo: Entendese gue o Lem Healthcare pode ser valido para methorar processos de trabatho nos servicos de saude. por meio do uso de difereates ferramentas e de ansise organizacional derecionada e ampliada no smbito da instituiçso. No entanto, a sua implementaça sequer conbecimento sobte a flosofa e o fortalecmento de uma cultura de melthoria continua nos serviços

nofisti:

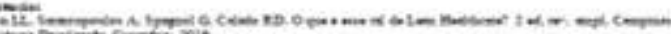

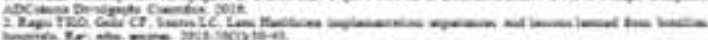

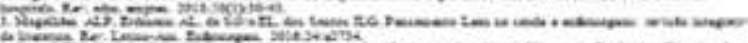

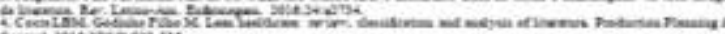

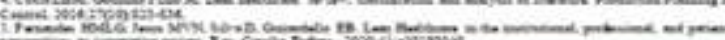

\section{II PS}
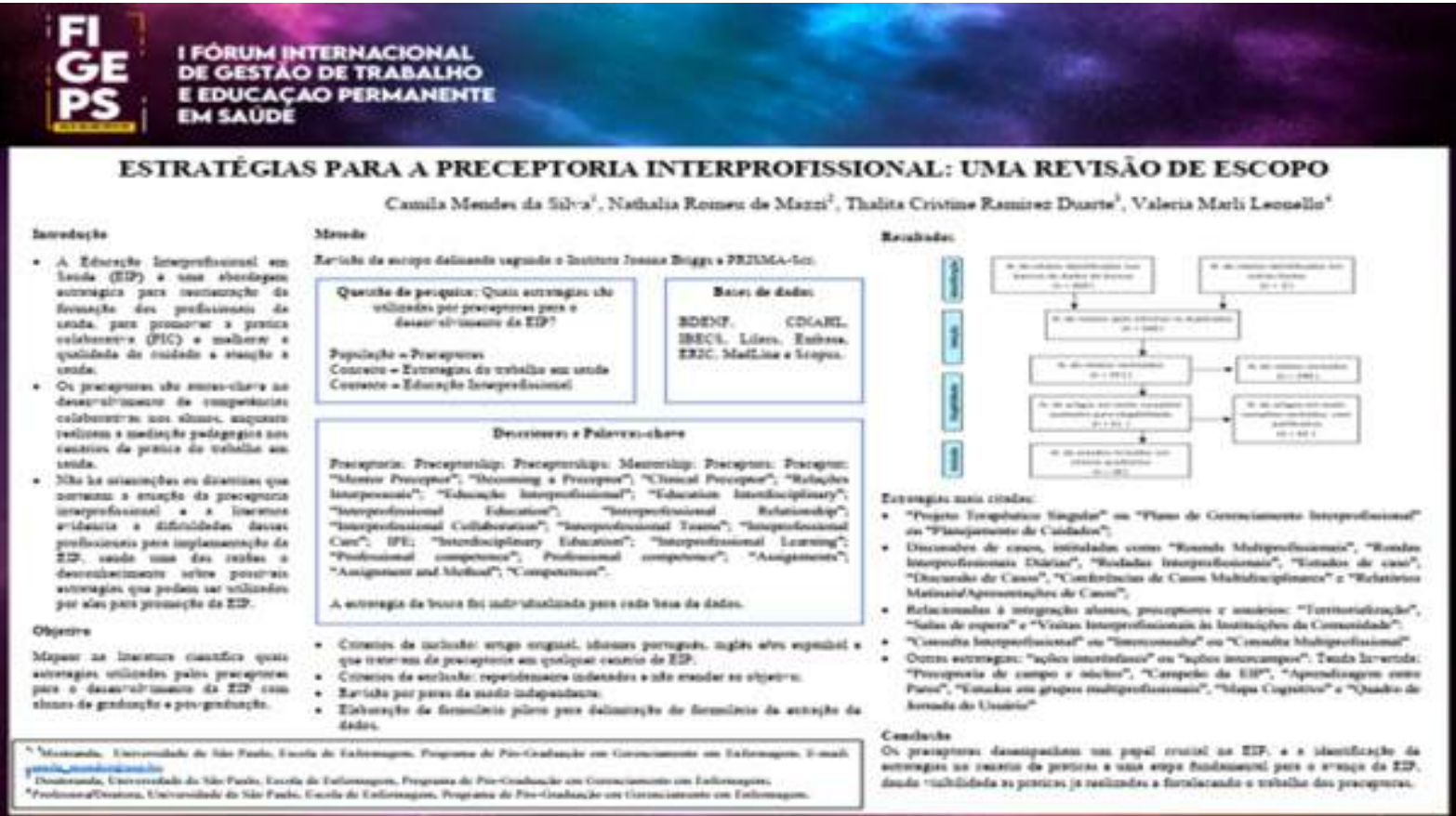

ESTRATÉGLAS PARA A PRECEPTORIA INTERPROFISSIONAL: UMLA REVTSÃO DE ESCOPO

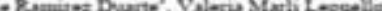

naciatust
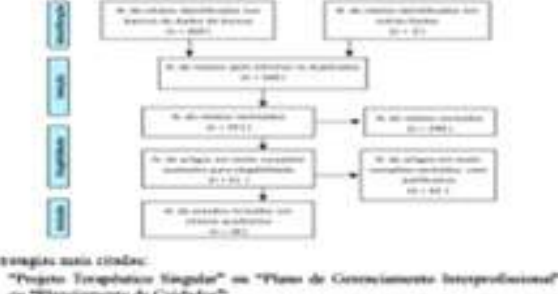

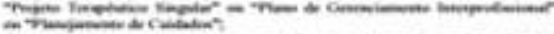

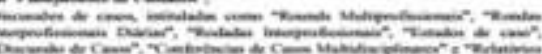

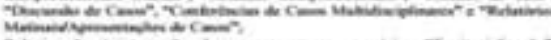

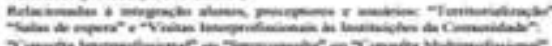

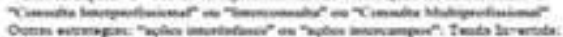

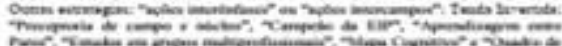
nision Setente O 

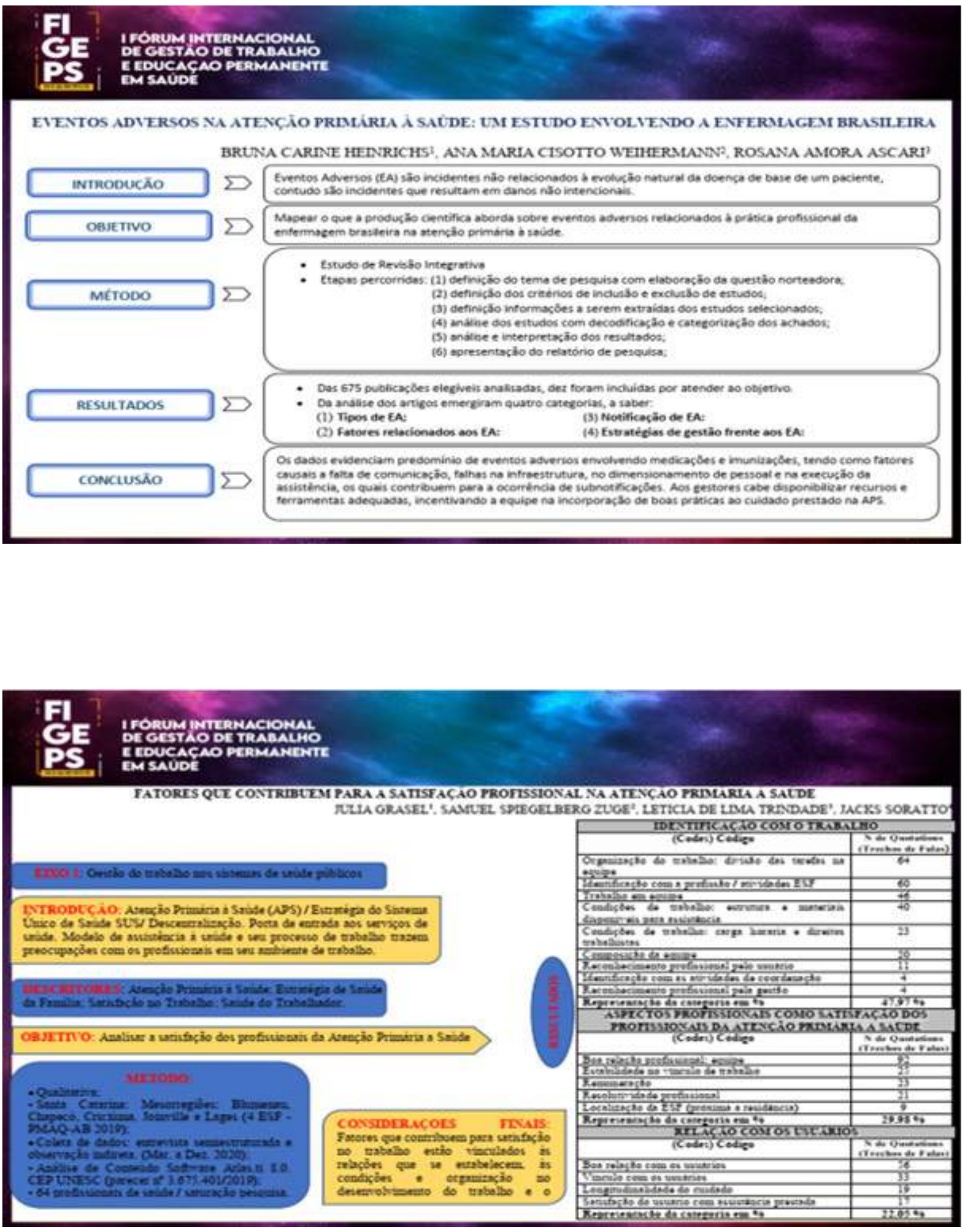
PROCESSO DE TRABALHO DE ENFERMEIROS NA ESTRATEGA SAÚDE DA FAMILLA: ENTRE O CUIDAR E O ADMINISTRAR

MARIANA MENDES, LETICLA DE LIMA TRINDADE, DENISE ELVIRA PIRES DE PIRES, ELAINE CRISTINA NOVATZKI FORTE, LARA VANDRESEN, PRISCILA RODRIGUES DA CUNHA

Objetive: analisar o processo de trabalho dos enfermeiros na ESF no que concerne a dimensio administratisa do traballo profisatonal enfermeiros

Resultados: nas praticas gerenciais prodominam a stupervalo de iécuscos, atuxiliares e Agentes Comumatimos de Sande (ACS), coordenaçlo de programas, realizaç̧o de reunicies de equape, definiça de agendas, otganizaço do processo de trabalho ds enfermagem e, por vezes, de outros profissionats

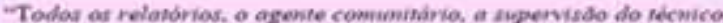

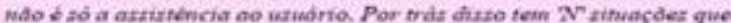

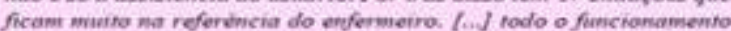
burocrínico da equipe acaba flicando na milo do enfermeina. Dvide o gerenciamento dos relotobrios, ax pounas de reumido didiria (LS6)"
Método: Pesquisa Qualitativa $\rightarrow 20$ Unidades Básicas de Saúde pas cinco Rlegióes do Brasal $\rightarrow$ ESF $\rightarrow 79$ participantes $\rightarrow$ Entrevista observaço e estudo documental $\rightarrow$ sofhvere ITZ.iS. $n$ i $8.0 \rightarrow$ Analise Tematica

Resultados: desenvolver atividades de gerểncia das eSF simultaneamente as assistenciais ocasiona sobrecarga de trabaltho e insatisfacto ao profissional devido a constante sensaça de "nilo dar conta"

"Eu milo dear comba de forer o atendimenno, prevencher diginar o men ests, dar conta das demiandas que o ayfarmeiro tem de responder eo diatrino, de faser a planilha

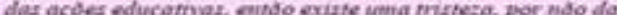
colagr f i no kempo gre a sente tem give dar conta (LNE7) -

Consideraçòes finais: o enfermeiro, ao absorver as demandas administrativas/oturocriticas que envolvem o processo de trabalho das eSF, reduz o tempo dedicado a dimenalo do cuidado, com potencial detrimento a dimensâo administrativo-gerencial, gerando sobrecarga e insatisfaçlo ao profissional que atua no contexto da ESF

\section{ifl IFORUM EMTERNCIONAL DE GESTAO DE TRADALHO E EDUCACAO PERMANENTE
EM SAUDE}

GESTÃO DO SERVIÇO DE ENFERMAGEM NA ATENÇÃO PRIMÁRIA Ȧ SAÛDE NO ENFRENTAMENTO DA PANDEMIA PELO NOVO CORONAVIRUS
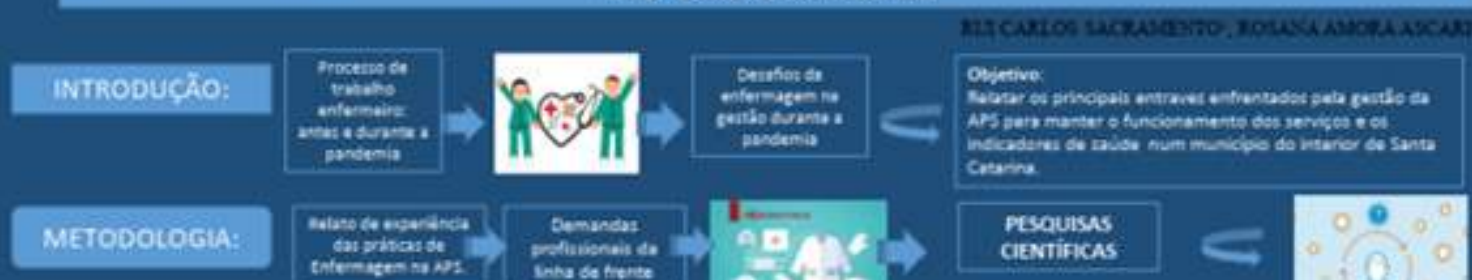

Matodotogta:
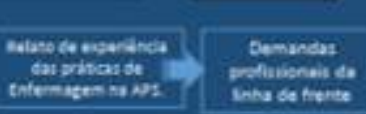

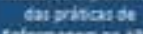

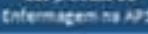

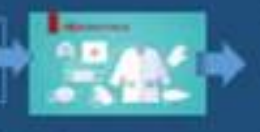
Crarne

RESULTADOS:
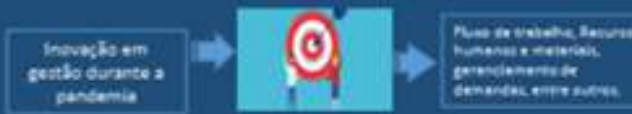
nombinger

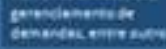

conctustio
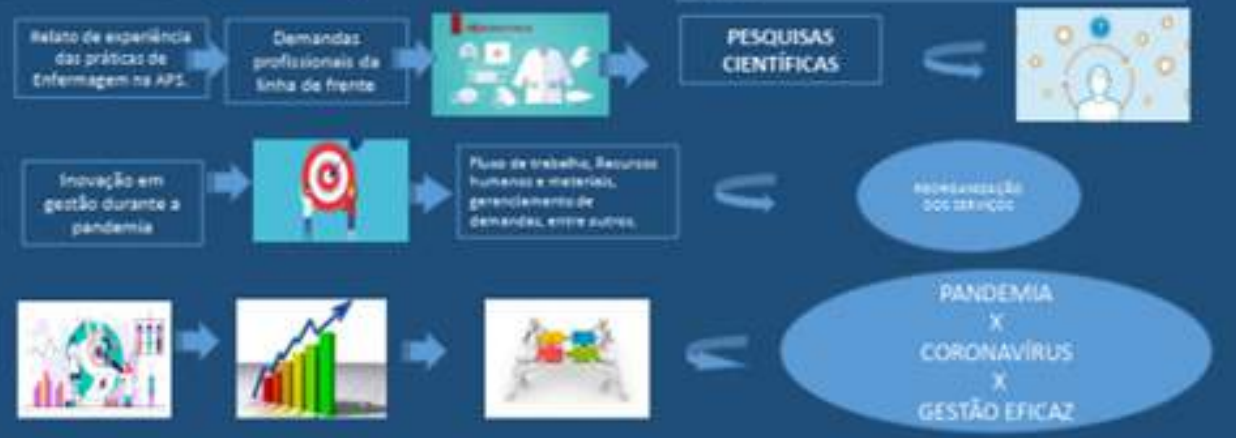

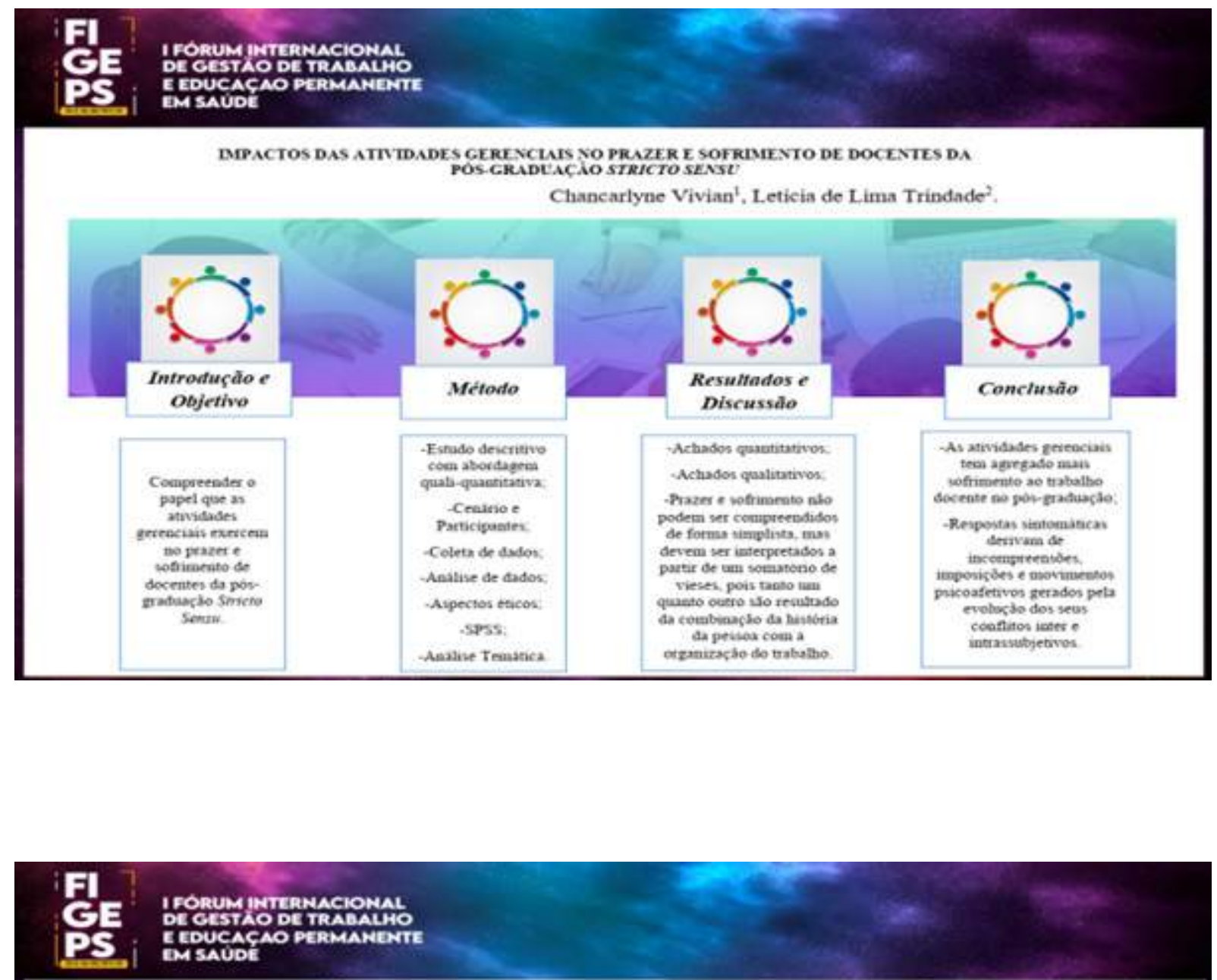

DHEMAS ÉTICOS DE ENFERMAGEM MEDIADOS POR DISCUSSÖES NA INCUBADORA DE APRENDIZAGEM: RELATO DE EXPERIÉNCLA

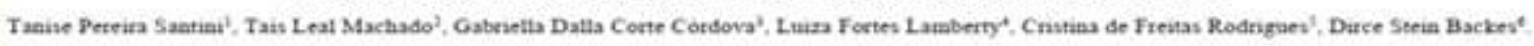

$$
\text { Introducalo }
$$

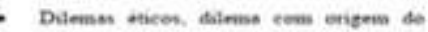

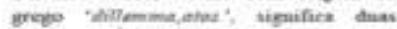

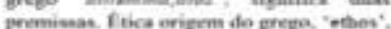
quat sigmifies medo de set, cortuma ou hibuts.

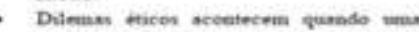
pensos greeris noemat decindes do guat

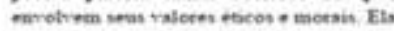

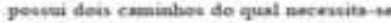
befinir caal irs previnguit

\section{Objetivo}

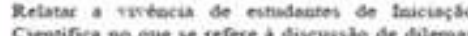

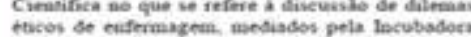
de Aprendiagna.

\section{Metedo}

Trastase to ten intate to expentacis.

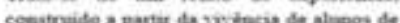
Tharias de Cipotiffere ne procense de rellosio acress de Dilemas Eticon de Enfermatre. mediades pelt larbobders at Apreadizagen

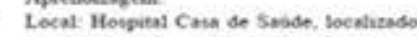
as cidode de Sants Maria, Rio Orande do Sul

Reslusade bes meses de whoute o setrative de 2019

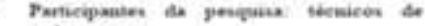
cotermatem

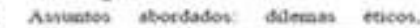
cenfines cestutes de mitrmeste.

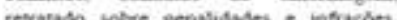

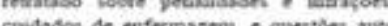
coudadon de

reterumint
Resultades e Discussae

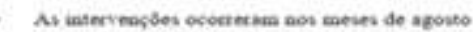
- sertemitro 4e 2019 , ne herpitsi Cans de Simide.

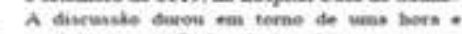
participarno profivionasin de wabde

- As Bolustas de vaciesslo cienatifica, juatamante

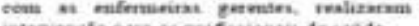

A participasso contante do equipe de

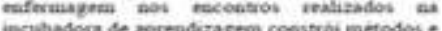

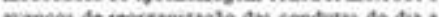

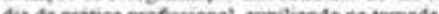

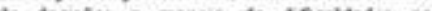

$$
\text { Conclusao }
$$

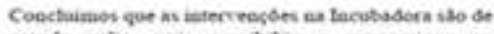

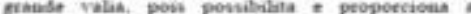

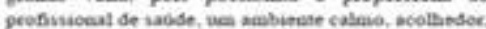

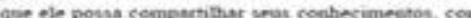
queque So betpital 


\section{'E] IFORUM NTIERACIONAL EOUCACAO PERMANAONT:

REFLEXOES NA PÓS-GRADUAÇÃO: aproximando a acađemia aos cenários exitosos em Atençào Secundária à Saùđe

Vanessa Aparecida Gasparin'1, Eduardo Simóes da Matta', Francis Maira Schabat', Leticia de Lima Trindade'. Samuel Spiegelberg Zuge'

\section{INTRODUCÃo}

A situagho afual do Sistema Unuico de Sande (SUS) concerne em vínios desafios:

- grande demanda de solicitagles;

- morosidade na realizaclo de procedimentos especializados:

- busca dos usuirios por altenuativas do servico privado

- restriça de acesso il Alençlo Secundiria à Saude (ASS).

\section{OBIETIVO}

Relatar uma experiênein exitoss na ASS para mestrandos e doutorandos em Ciéncias da Saude.

\section{METODOLOGI}

Trats-se de um relato de experiéncia oniundo de uma disciplina do Programa de Pós-Graduscilo em Cièncias da Saúde, ocorrido em $2020 / 2$. Uma das atividades do componente englobou a explanaçăo de uma experiéncia exitosa na ASS

\section{RESULTADOS}

A organizaclo CIES Olobal foi escothida para atender a jroposta, port uer reconhecida pelo emprego de unidades móveis e modulares, garantindo agilidade an coesultas, exumes e cirurgias no SUS

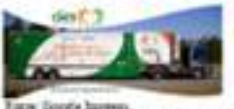

\section{$2008>2012>2015$}

Fintrevista - Google Meet -60 minutos

\section{CONCLusio}

O debate fiente is potencialidades e desafios dos niveis de atenefio en caude apresenta-se como un momento masito exriquecedor e reflexiro. principalmente quando tem-se a possbiblidade de envolver a aeademia e a pritich em um mesmo cenirio.

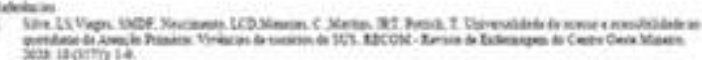

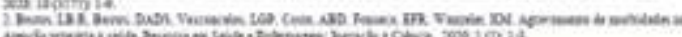

\section{E⿸广土 \\ PS}

CONTRIBUICOOES DAS PRÁTICAS INTEGRATTVAS E COMPLEMINTARES A GESTÃO DO TRABALHO: DESAFIOSE POSSIBI.IDADES

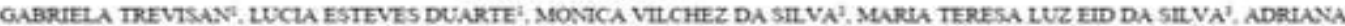
BARBIER FEUCLUNO' E LENDRA ANDREY DE SOUSA

Intrudarib

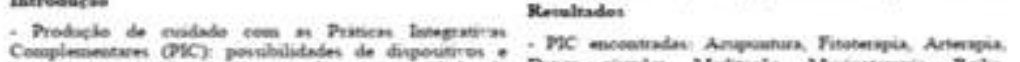

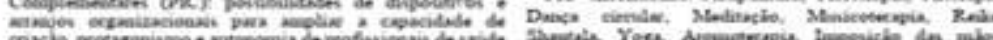

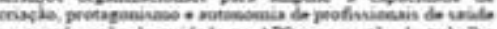

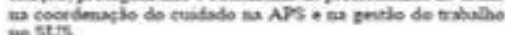
Otistiven

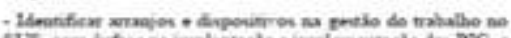

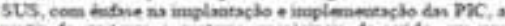

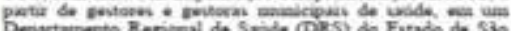
prele cish.

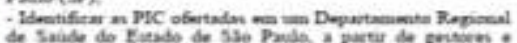

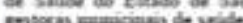

Mateodelecis

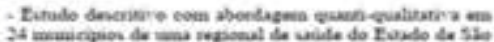
Pondo

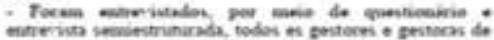

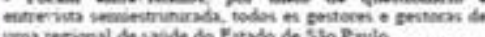

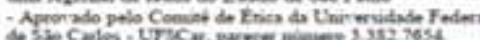

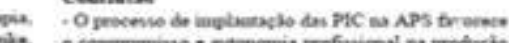
Youn Als

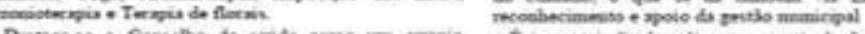

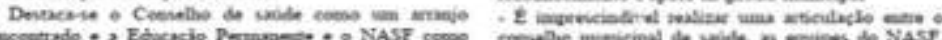
dophiri

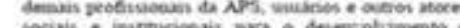

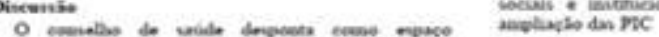

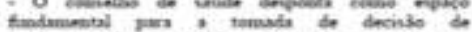

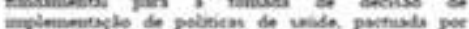

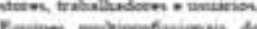

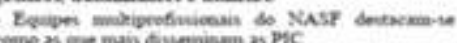
E

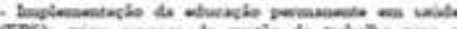

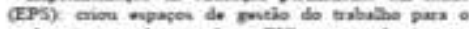

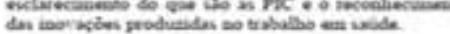

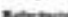

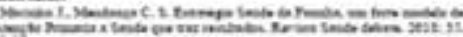

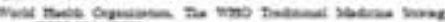

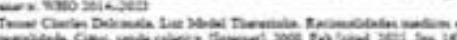

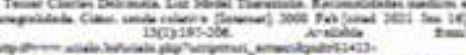

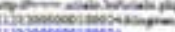

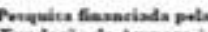
Fundorice de Anopare: Panle (TAPESP) 


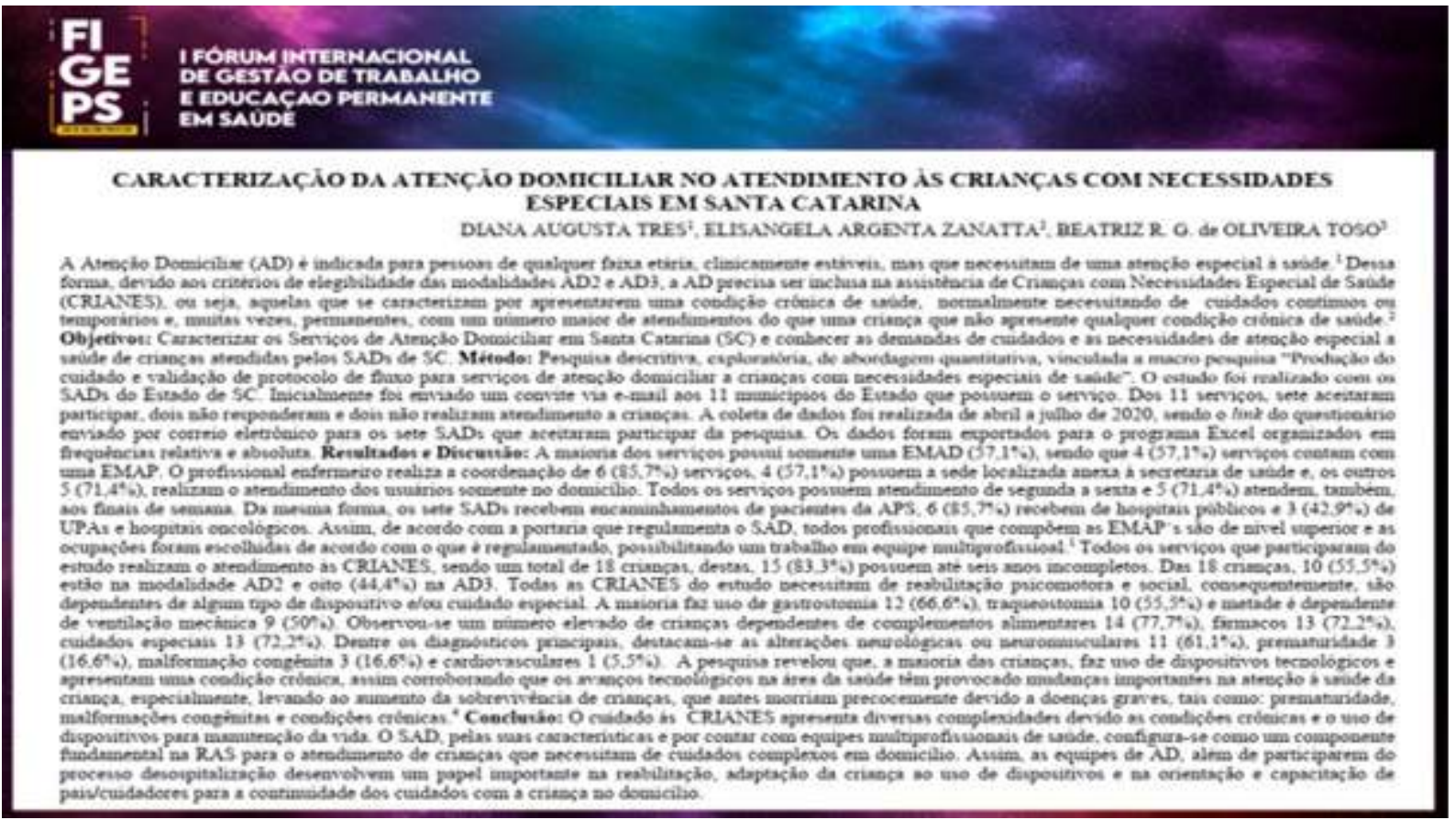

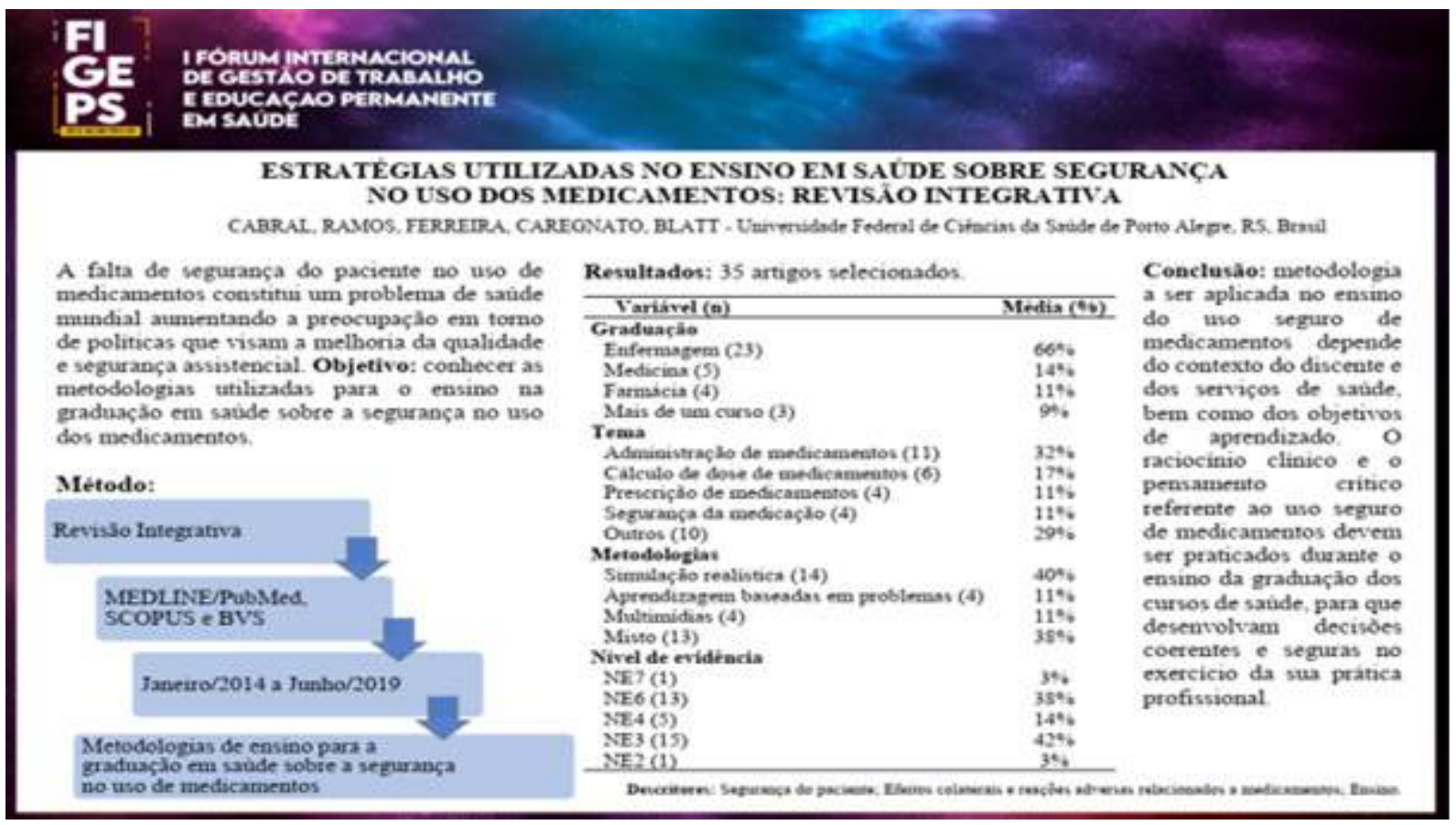


MOVTMENTOS DE EDUCACÃO PERMANENTE PARA SAÚDE RENAL

NO CONTEXTO DA ATENCĂO PRIMARIA: RELATO DE EXPERIÊNCLA

Introduça: : A educaç̧o Permanente em saude tem como contributo primordial o aprimoramento das praticas de saúde e a transformacto do processo de trabatho $\mathrm{com}$ foco $\mathrm{em}$ uma maior resolutividade de problemas ${ }^{2}$

Objetiva: Relatar a experiencia do grupo de extensionistas nas atividades de educaç3o permanente juato as equipes de enfermagem dos municipios da regional de saude de Chapeco.

Mtetodo: Relaro de experiencia de anvidades de educaçao permanente realizadas para enfermeiros. tecnicos de eafermagem e agentes comnutitatros de saude dos 26 municipios da Regional de saude de Chapecó
Resultades e Discussãe: A primeira rodada de oficinas problematizou os aspectos da dornça tenal crónica. chamando a atença para o contexto dos municipios da regilo. A oficina com os ACS foi realazado a sensibilizaç3o sobre a problematica da doensa renal erónica: apresentado sideo dos fatotes de risco da doença e discussto do papel do ACS na promoço da saude e prevenço da DRC. Com os tecnicos de Enfermagem. alem das tematicas it citadas costou com a participaço e relato de um paciente transplantado, representante da Associaça dos Pacientes Renats Crónicos de Chapece. A oficina com os Enfermeiros foi permead. por estudo de caso e discuss lo do panorama da realidade local de cada municipio. Para enriquecer a diseussalo esteve presente uma enfermeira da Clinica Renal do Oeste

Conclusào: Por meio da educaçło permanente em saude, o programa de extensto tem buscado discutir, refletir e sensibilizar os profivionais de saude da atençio primaria a vistumbrar os potenciais impactos na saude da populaçăo em decorrétacia a doença renal crónica. E nesta dirę̧o que aponta-se possibilidades de tracar um plano operativo para prevenc âo e controle da doenca renal crónica nos municipios da requonal de saùde de Chapecó

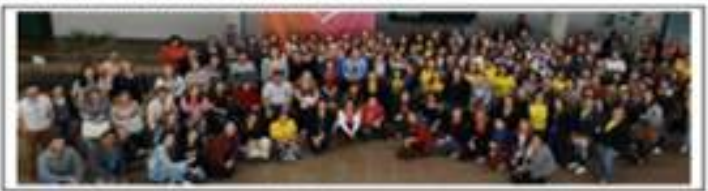

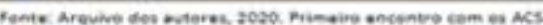

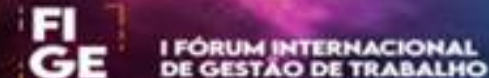 PS. EEUCACAO PERMANENTE EMSAUDE}

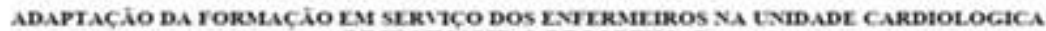
DE 13 HOSPITAL DE PORTEGAL

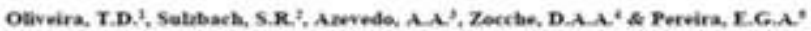

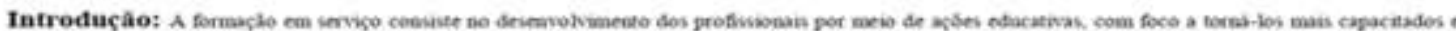

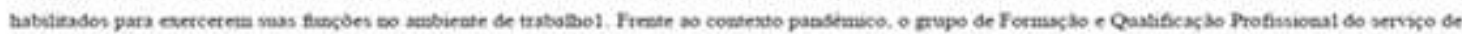
Cassiologa $₫$ HSOG, teve que madar as estrategis pasa capacitar os peoflusioeas so servico.

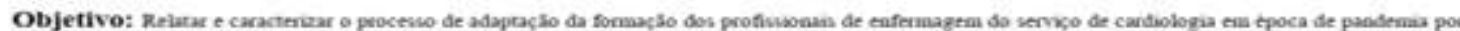

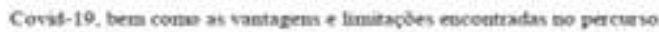

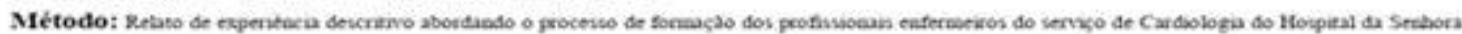

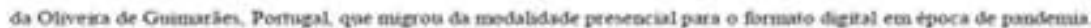

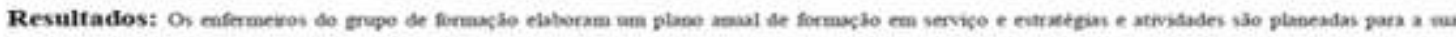

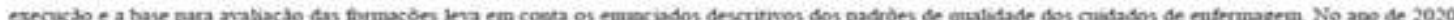

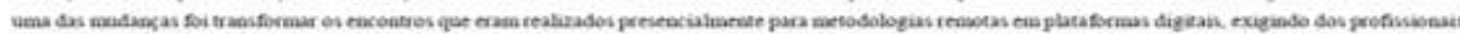

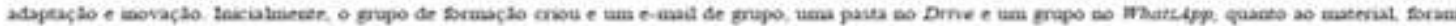

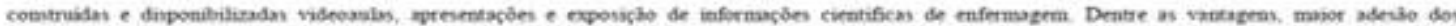

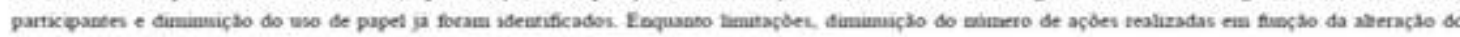

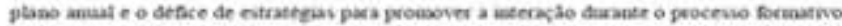

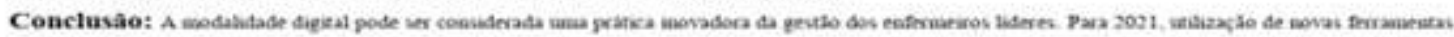

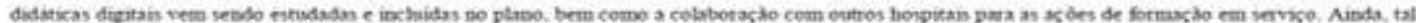

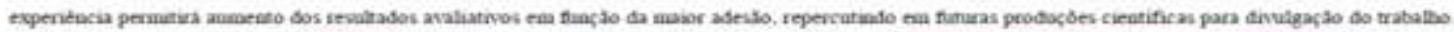




\section{II E EDUCACAO PERTMAMENTE

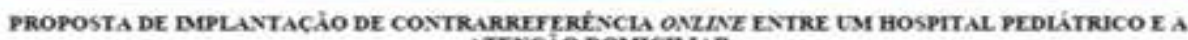
ATrcio DoMrtituR

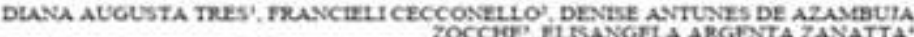

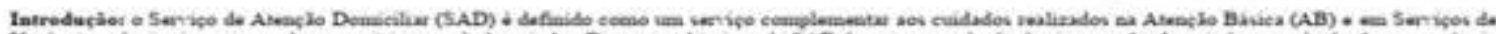

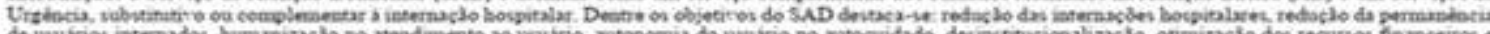

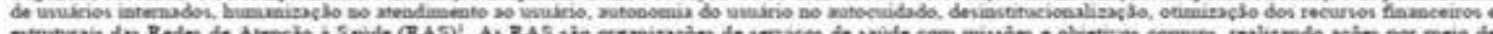

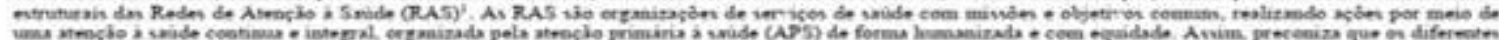

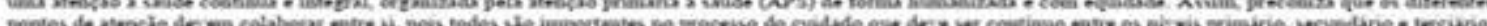

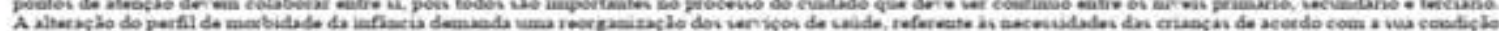

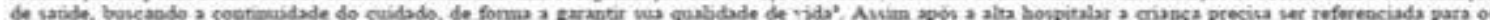

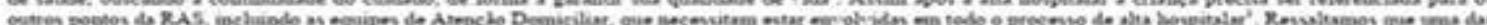

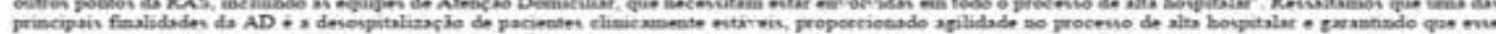

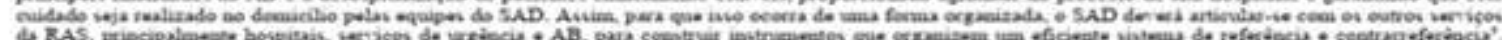

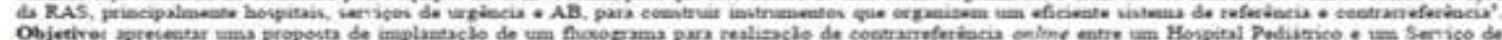

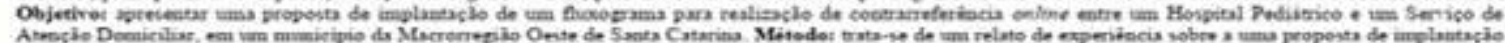

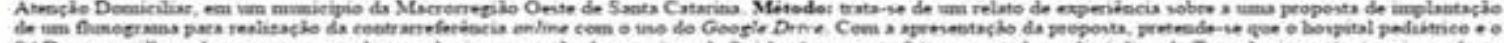

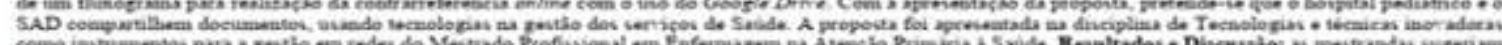

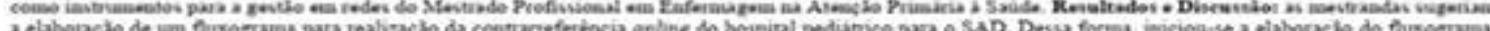

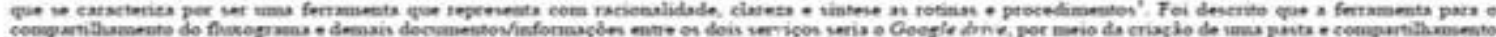

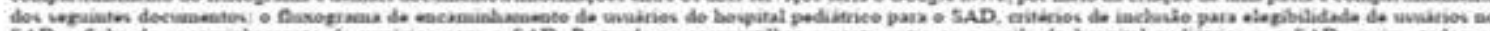

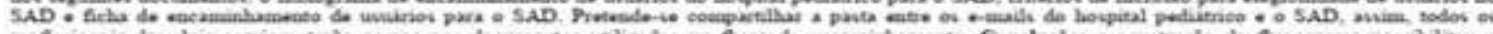

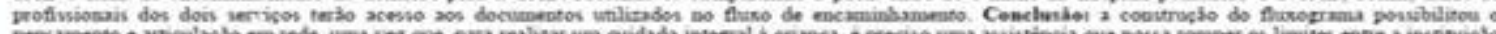

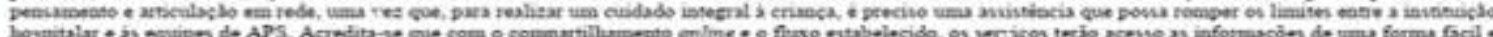

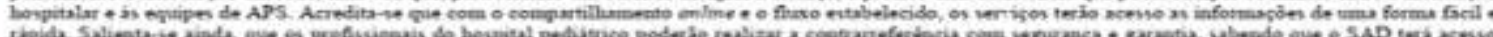

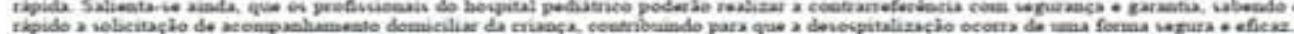

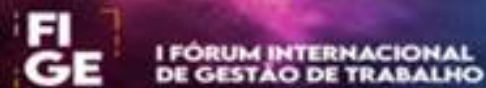 PS F EUCACAOPTRMANENTE}

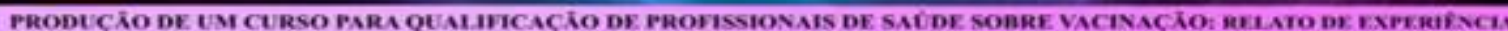

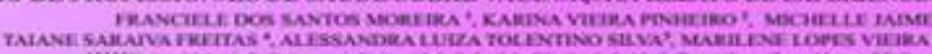

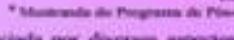

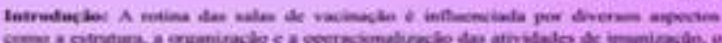

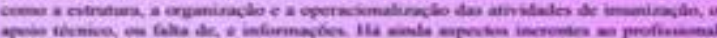

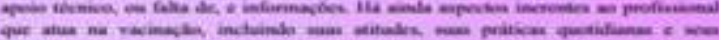

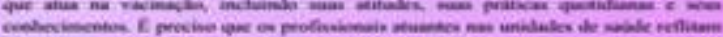

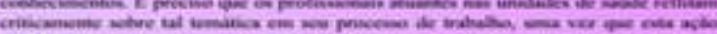

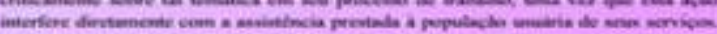

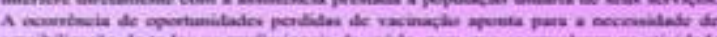

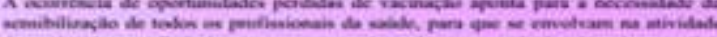

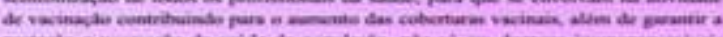

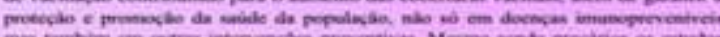

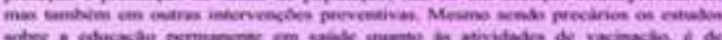

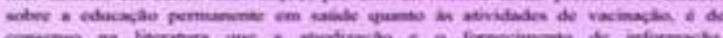

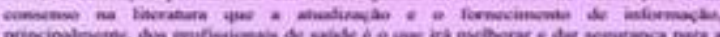
primaipot:

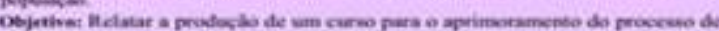

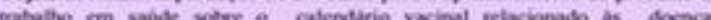

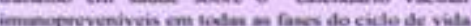

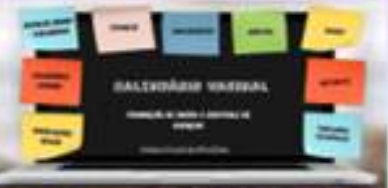

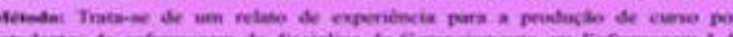

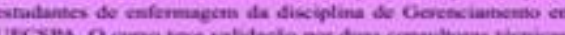

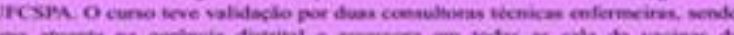

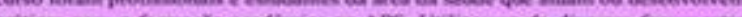

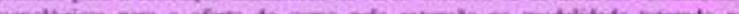

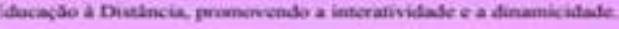

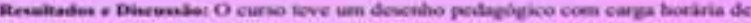

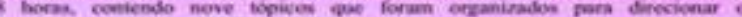

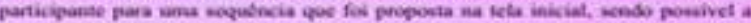

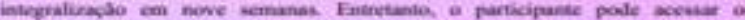

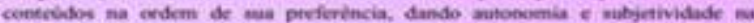

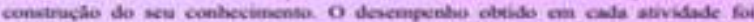

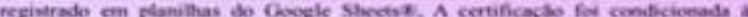

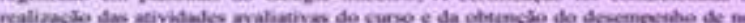

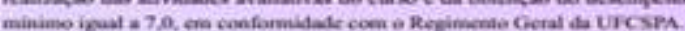

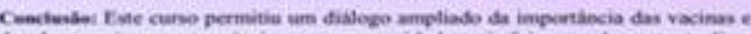

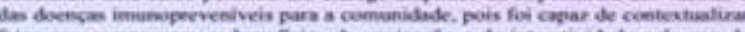

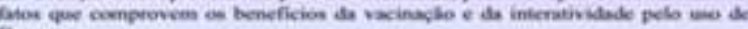

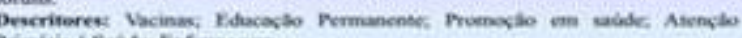
Vise- Movimentos de edocisclo penmanene em coble 


\section{EL.ABORACX̃O DO GUL DE ORIENTACOES PARA OS NOVOS COLABORADORES DA}

\section{ENFERMAGEM: REIATO DE EXPERIFNCIA}

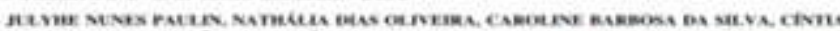

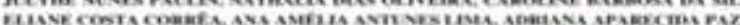

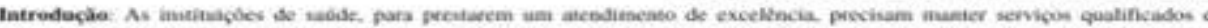

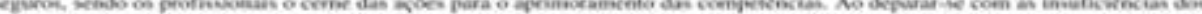

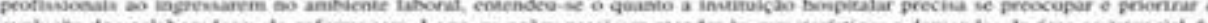

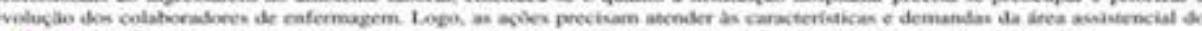

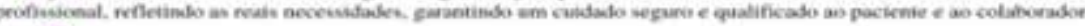

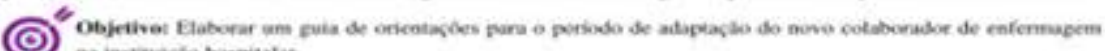

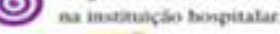

nasioeos, *

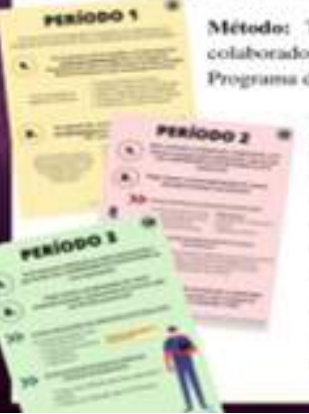

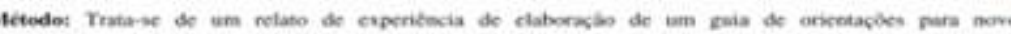

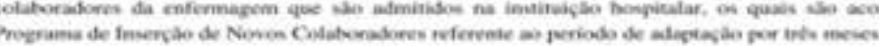

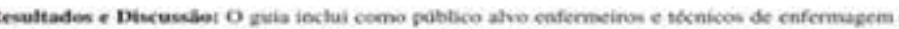

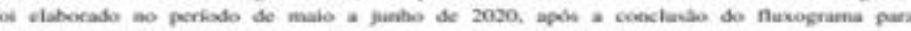

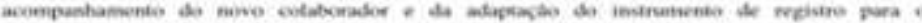

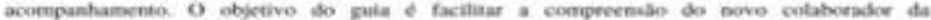

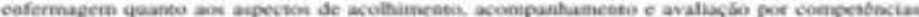

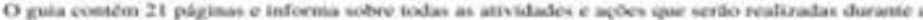

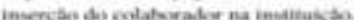

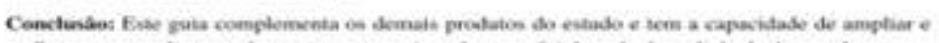

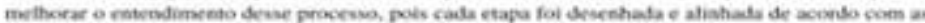

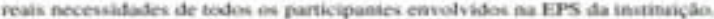

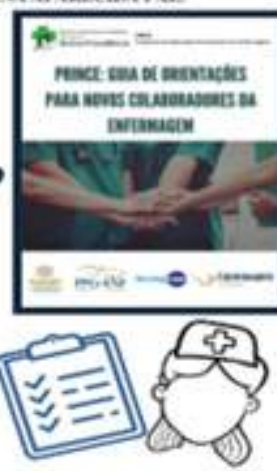

\section{[1] E \\ PS; E EDUCACAO PERMANGOTE}

CONTRIBEICOES DA FOUIPE DE ENEERUACEY NA ATENCAO BASICA NAS

ORIENTACOESE PREVENCAO DE DIARREIAS AGUDAS

MIILNA LORENZNT, DIORA FATTA?, CARLISE KRUEN ARNII DO KORB

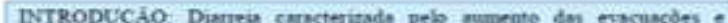

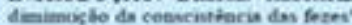

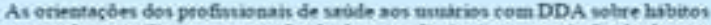

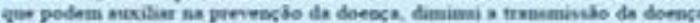

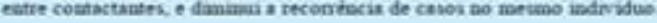

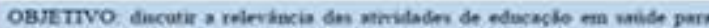
perrocio $\Rightarrow$ DDA

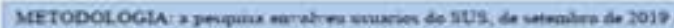

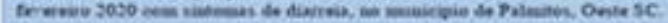

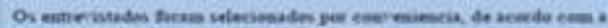

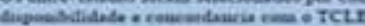

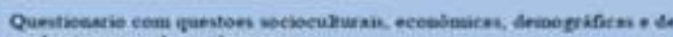
conbecimatate webre i derma

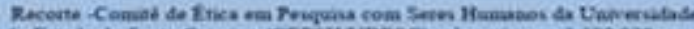

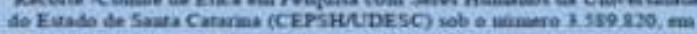
20 de setrubite de 2019

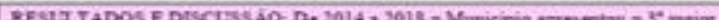

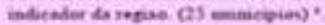

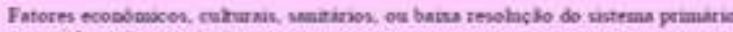

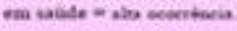

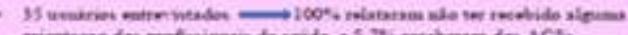

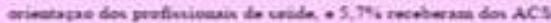

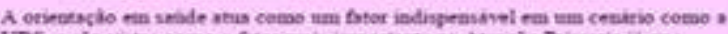

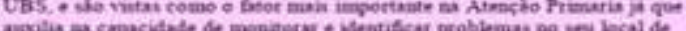
abranctocia"

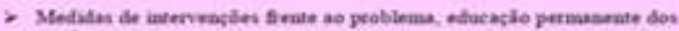
profonbonais

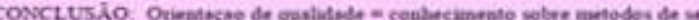
postar a doenca durreia

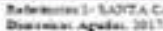

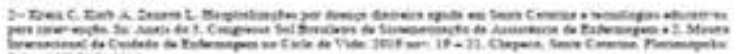

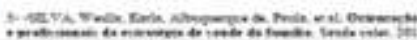




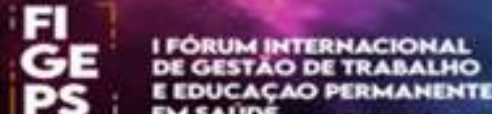

\section{EDUCACÃO PERMLNENTE: ESTRATEGLA PARA O CUIDADO QUALTHCADO EM}

SAOTDF

Suely Lopes de Azevedo, Maria Lucia da Costa Moura, Aline Silva F.S.R. Oliveira, Andrè Luiz de Souza Braga

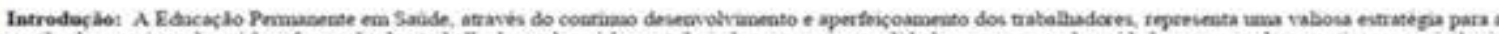

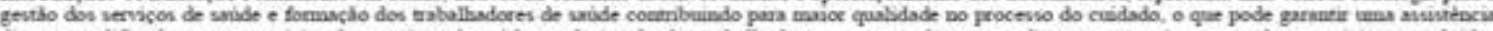

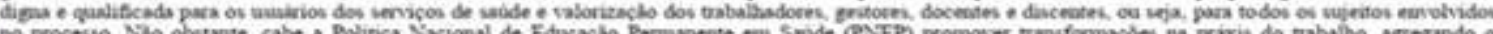

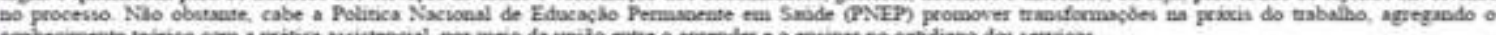

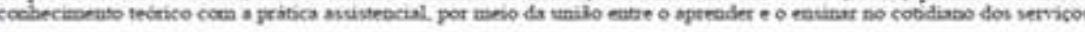

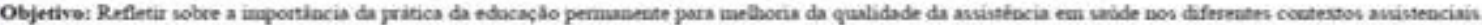

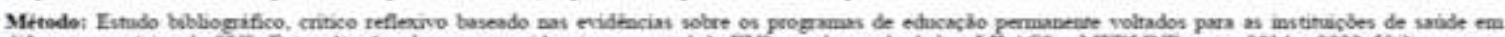

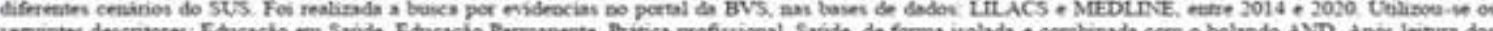

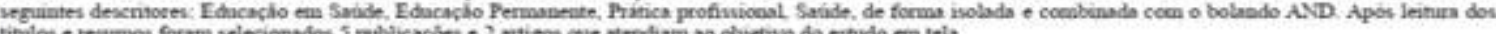

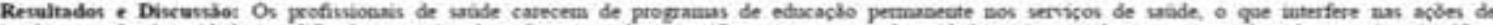

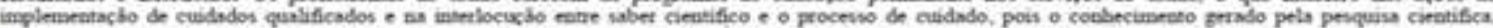

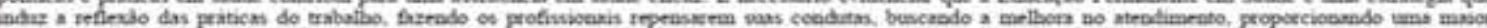

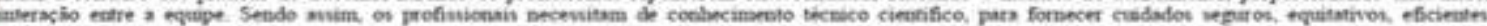

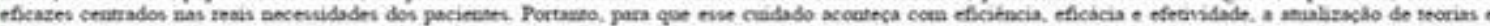

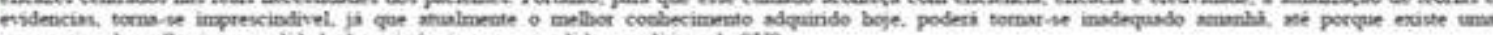

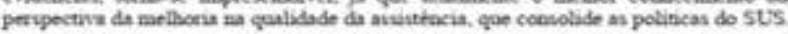

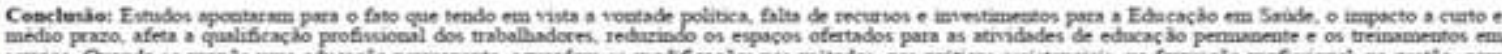

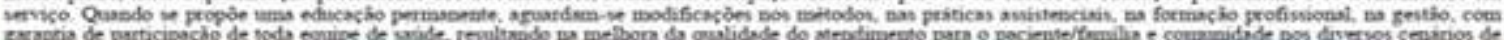
unde

\section{[E]

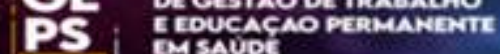

\begin{tabular}{|c|c|c|c|}
\hline \multicolumn{4}{|c|}{$\begin{array}{l}\text { A FORMACAO EM SACDE REPENSANDO A GESTAO DE TRABALFO EM } \\
\text { UNIDADE DE SACDE DA FAMIIIA }\end{array}$} \\
\hline 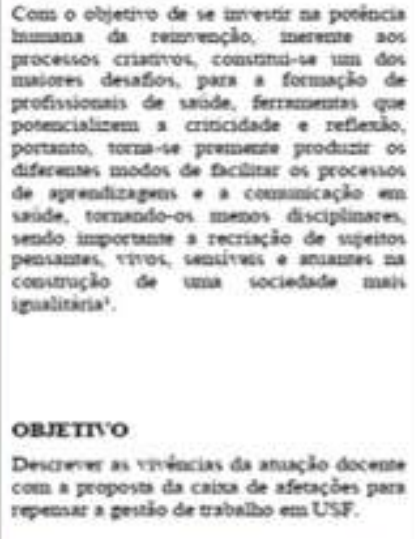 & 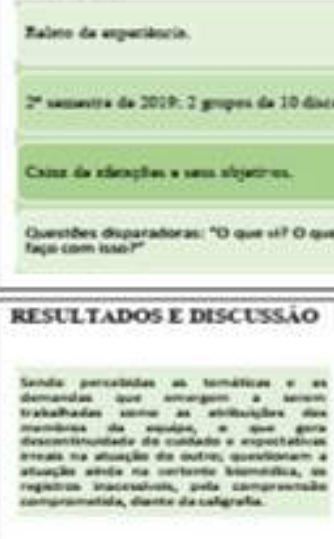 & 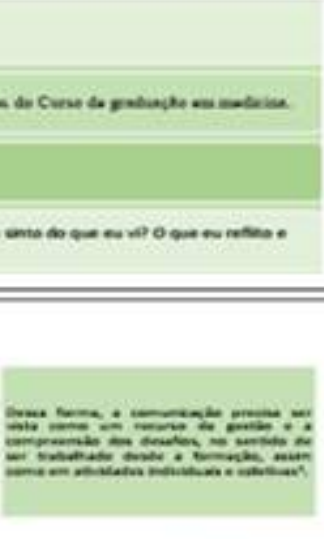 & 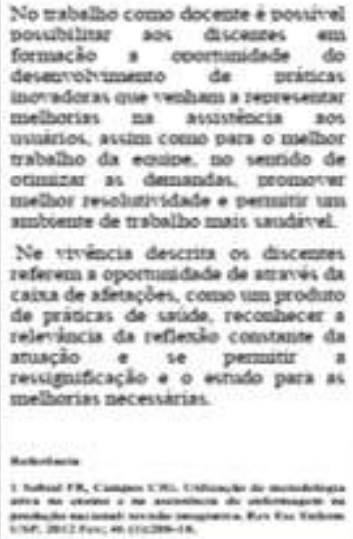 \\
\hline
\end{tabular}




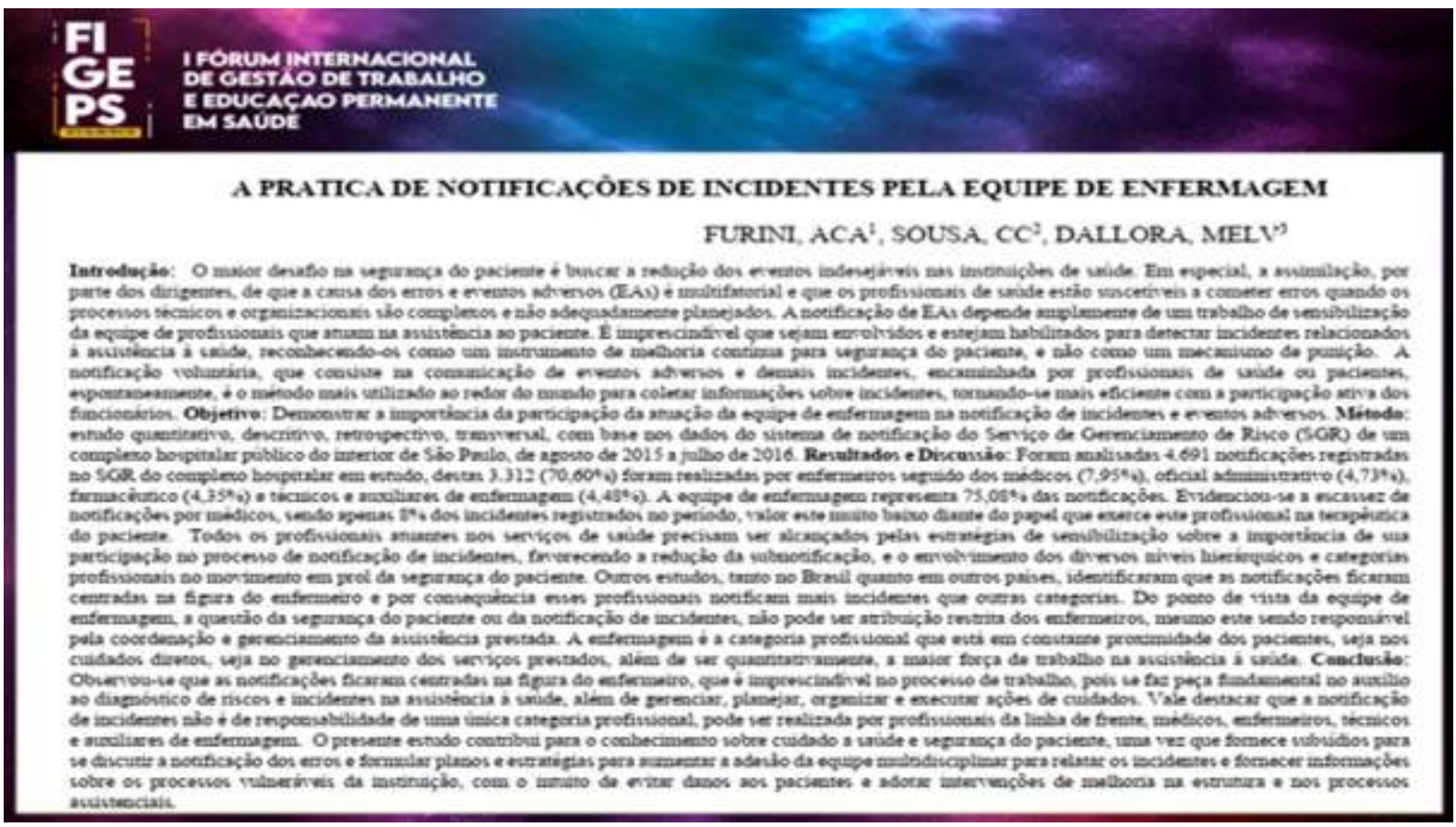

\section{'F] 'DORUM PS, ERSAUCE}

\section{ACŌES DE EDUCAĊ̃o EM SAÚDE PARA UMA ASSISTÉNCIA SEGURA}

EM UMA UNTDADE BASICA DE SAUDE

THIEMMY DE SOUZA AIMEIDA GUEDES: ANDREZZA DO REGO IEAL:
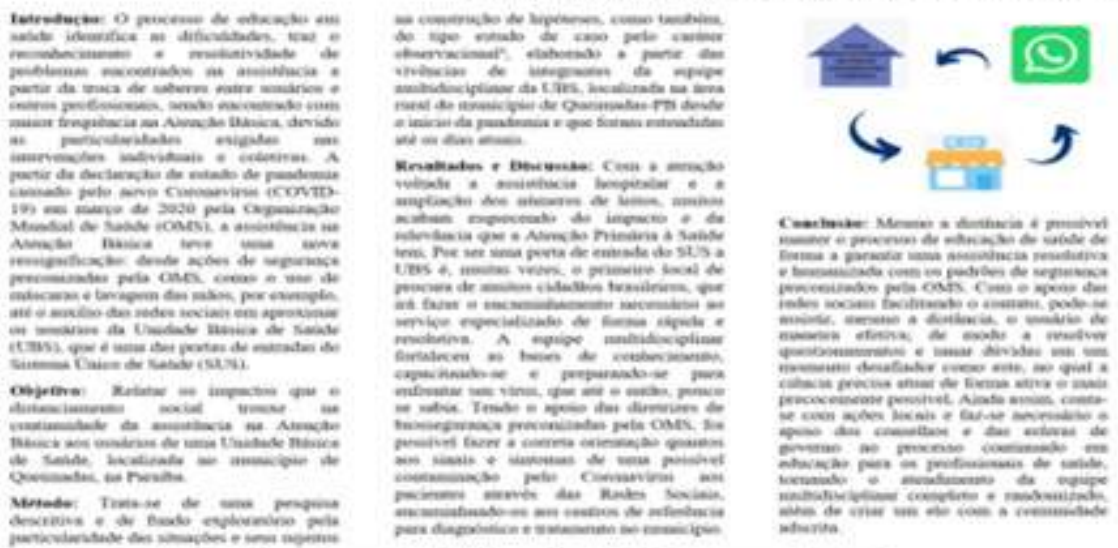

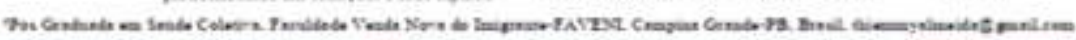

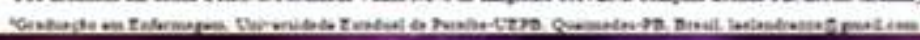




\section{O ACOLHIMENTO COM CLASSIFICAÇÃO DE RISCO NA ATENÇÃO BÁSICA: A EXPERIÊNCIA DE UMA CAPITAL DA AMAZÔNIA LEGAL, PORTO VELHO, RONDÔNIA, BRASIL.}

\section{PORTO VELHO-RO}

2021

\section{II DE CESTAO DE TRABAIIO EMUCAC}

EXPERIFNCIA DE MATRICIAMIETO NA SAOUDE DOTRABALHADOR

VITIMA DE. ACIDENTE DE. TRABAL.HO

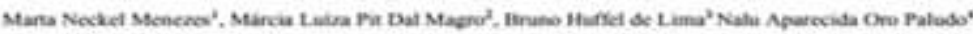

Objete da Pesquisa: Análise da experiếncia de apoio matricial desenvolvida pelo CERFST de Chapecó no projeto de acompanhamento socioassistencial de trabalhadores vitimas de acidentes de trabalho grave.

Métedo: Pesquisa mista, com a utilizaçào de observaçâ-participante, entrevista semiestruturada e pesquisa documental. Resultades obtides/Conclusàe

- A experiéncia possibilita o suporte ténico-pedagógico, institucional e de retaguarda especializada para os profissionaís da rede de saóde pública, đe modo a integrar saúde do trabalhador e atenç̃o primária, possibilitando o reconhecimento dos usuários na sua condiçlo de trabalhadores, a maior qualificacllo e resolutividade do cuidado e o avanço na produçlo do cuidado integral à saúde do trabalhador.

- Os resultados da pesquisa documental permitiram maior compreensio acerca das repercussôes do acidente de trabalho na vida do trabalhador e de sua familia $\mathrm{cm}$ funcão das vulnerabilidades fisicas, psiquicas esociais por ele produridas ou reforçadas.

- A experitencia de apoio matricial representa uma estratégia potente para a qualificaçlo e incorporaçlo do cuidado integral à saúde do trabalhador na rede de saúde pública.

:Conton-

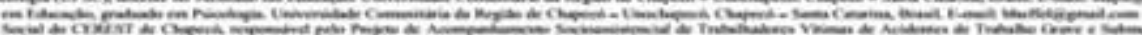

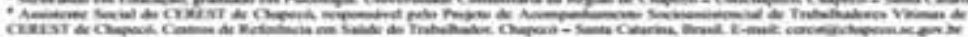




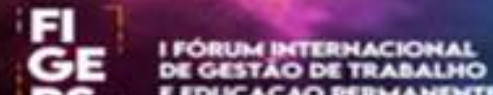

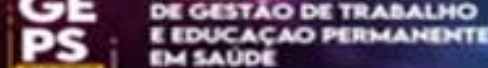

RODA DE CONTERSA: PLAVEANDO O STPORTE BASICO DE ITAA EM PEDLTRIA NO DOSHCHIO

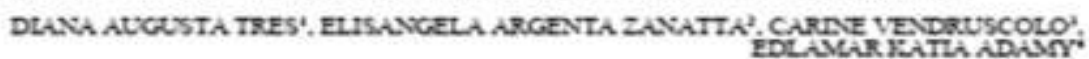

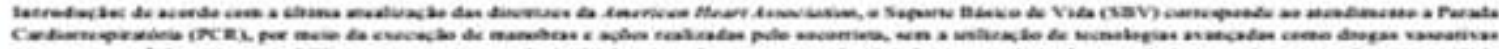

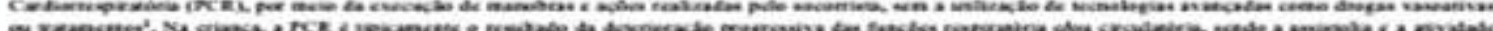

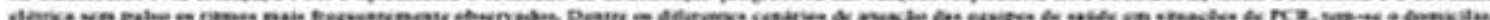

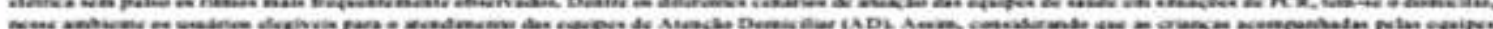

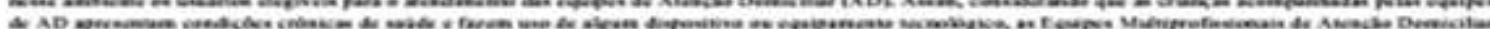

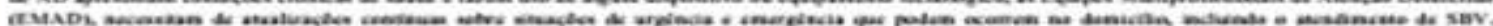

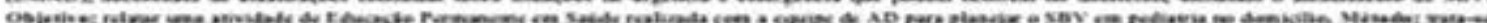

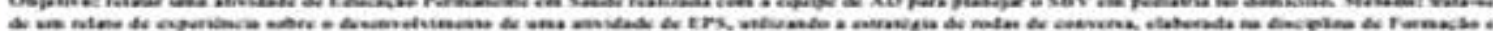

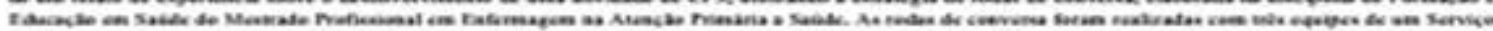

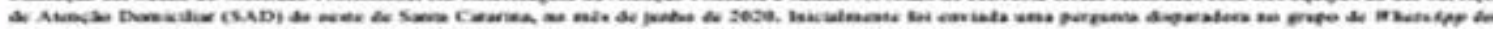

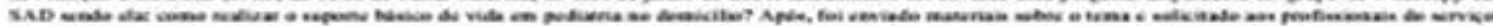

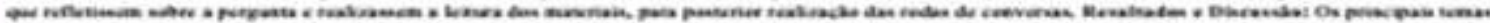

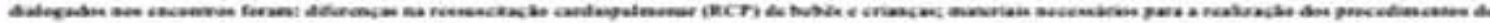

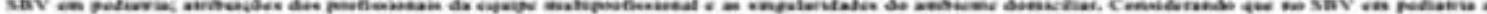

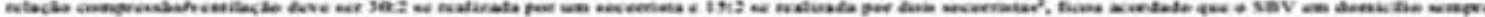

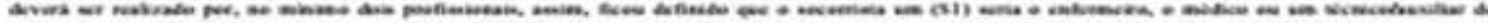

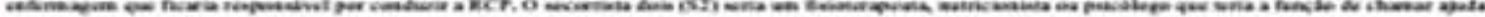

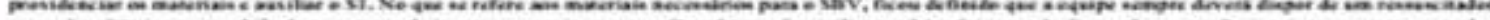

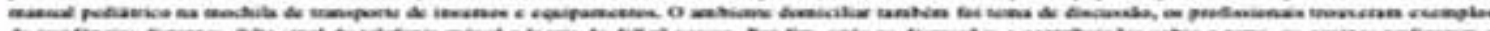

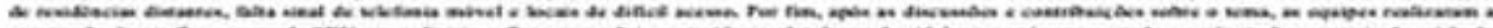

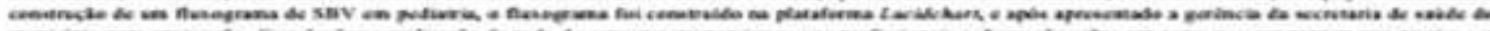

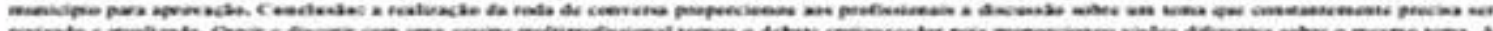

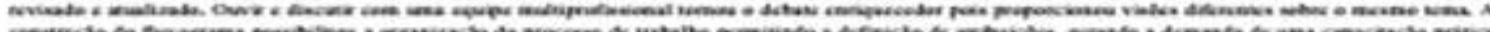
кед

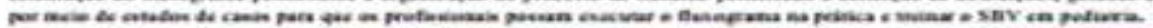

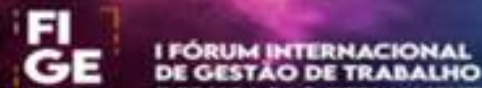

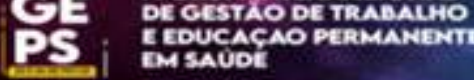

\section{EDUCACÃO PERMANENTE EM SAÚdE NA FORMACIO}

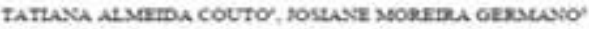

\section{ETRODUCio}

Estusar "no" c para o" trathatho, como

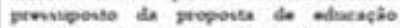

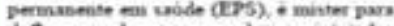

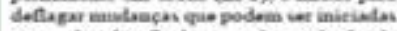

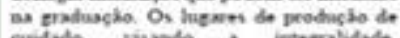

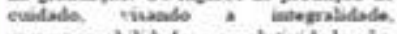

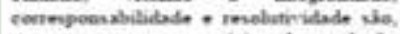
20 merimo teapes, enairios de peoduclo

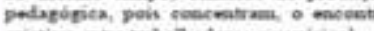
criatio entre trahalhaderes e vividries'

\section{ORTETTO}

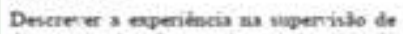
divceetev de Cutve de praduasto de

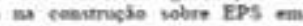
USP.

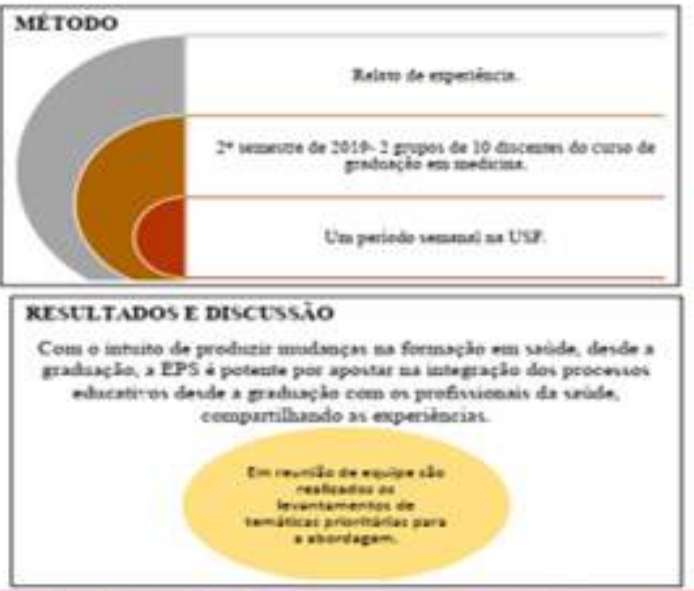

\begin{tabular}{|c|}
\hline CONCLUSATo \\
\hline 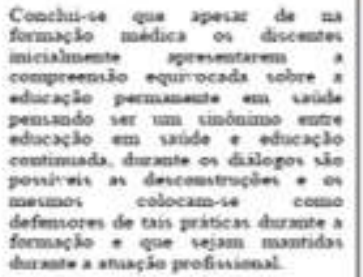 \\
\hline Kofortateds \\
\hline 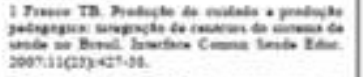 \\
\hline 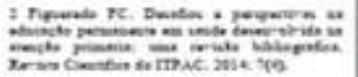 \\
\hline
\end{tabular}




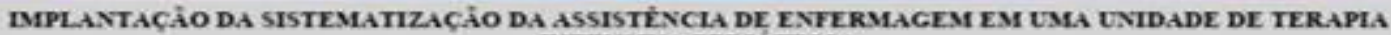
INTENSTA PEDLATRICA

Intredurito

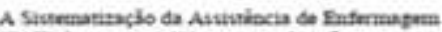

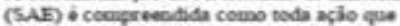

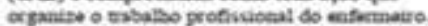

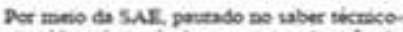
cimoribce, ¿ possitivel a operacienalinaçio do Drockio de Enfermigatin (PD).

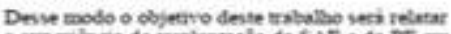
AE C do DE ex

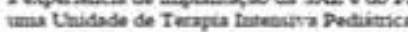
(UTD)

\section{Mtetedologin}

Ralano de expenekocia, renhirado por entemwers:

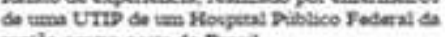
repilo ceneo orsta do Brasil.

Quanao a implantacio da SAE e do PE, por meno 6o ACARU. apticativo patrio dos boppitas

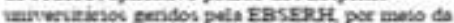
fincionatidade "Dencriplio de Enstrmagner"

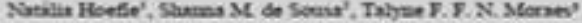

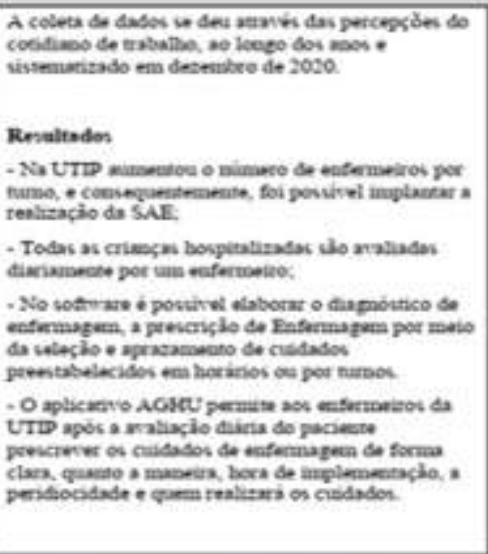

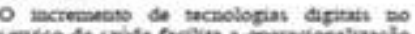

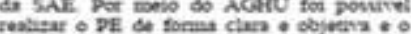

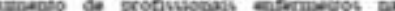

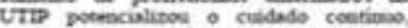

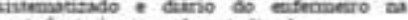

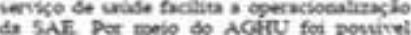

\section{[1] E EDUCACAO PERMANENTE LS i Emsavor}

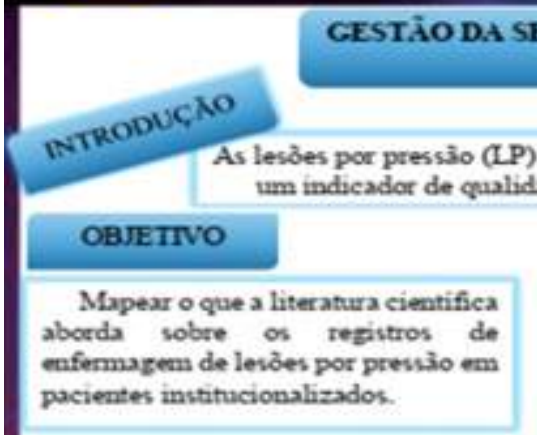

pacientes institucionalizados.

RESULTADOSI
DISCUSSIO
CONSIDERACOES
FTNALS

\section{RAVCA E O REC}

\section{POR PRESSÃ}

CRISTLANE BARETTA, "ROSAVA AMORA ASCARI" 


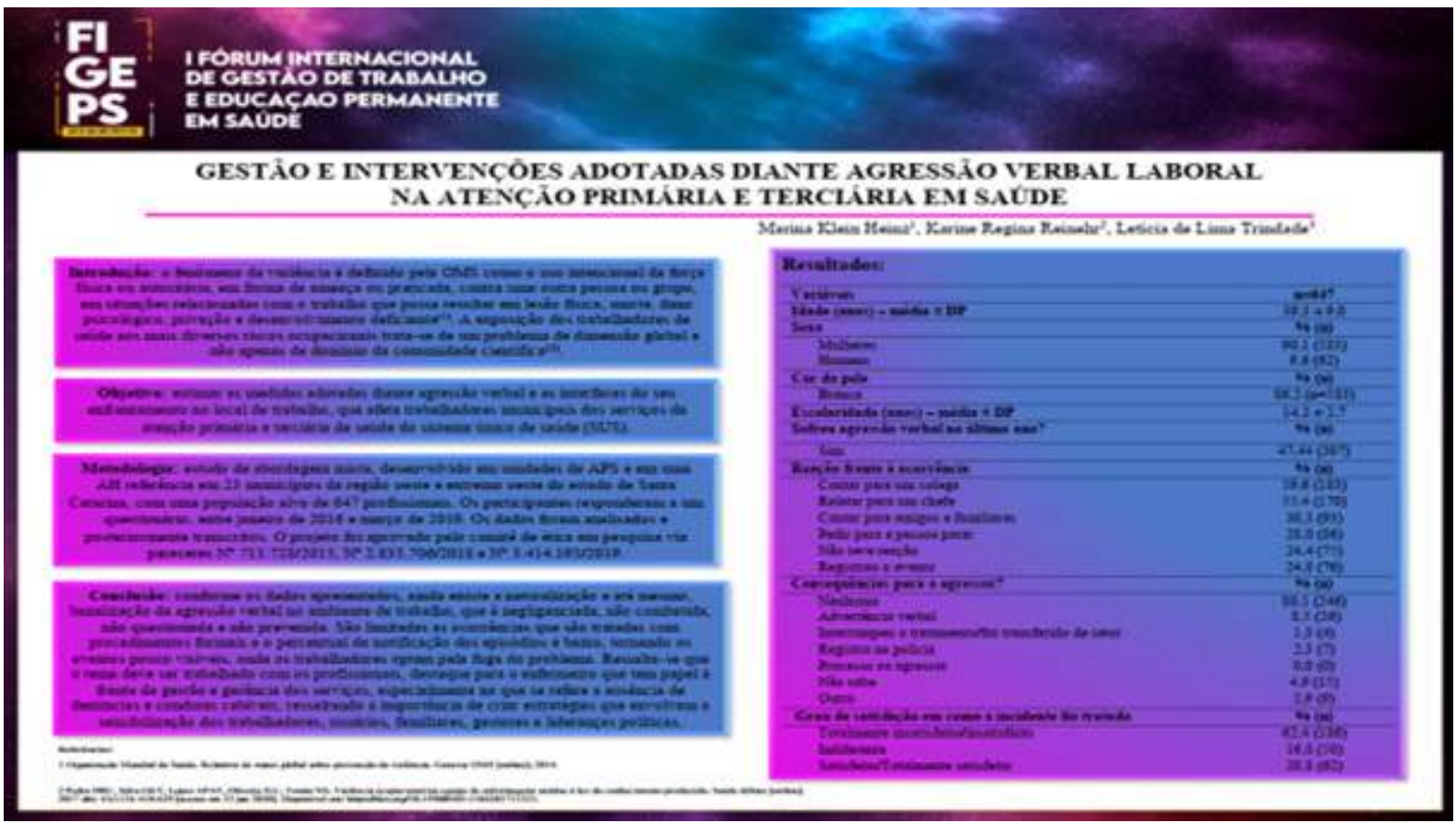

\section{If

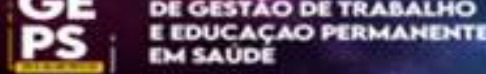

INSTRUMENTOS GERENCIAIS NA ENFERMAGEMI UM RELATO DA

PRATICA ASSISTENCIAL

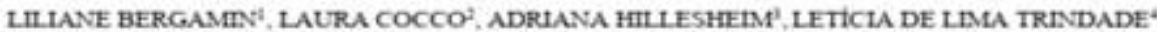

INTRODUcio

A Eufmagras vear he destacando cada vez mais na area da sabide. e isso ye

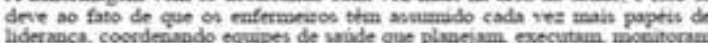

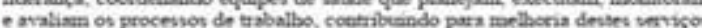

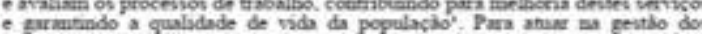

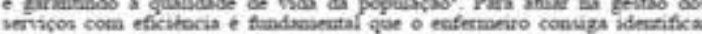
problema(a), beta como de inplementar acbes que contribuna com a unlizados purn qualificat a muistencia on gentio dos servicen de sabde ed os Procedieneation

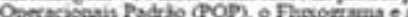

\section{MÉTODo}

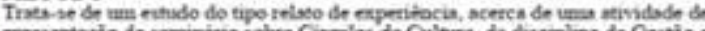
mpresentacilo de seminaino iobte Circulos de Culhura, de disciplina de Cestio e

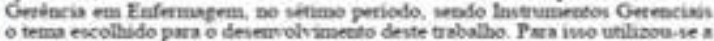

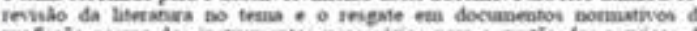

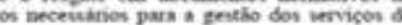

furrekfeys

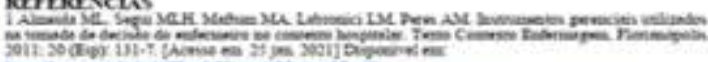

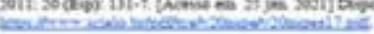

\section{OBNErrvo}

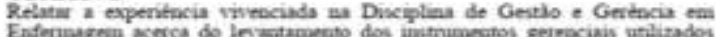
pelos entrumetios.

RESULTADOS E DISCUSSí

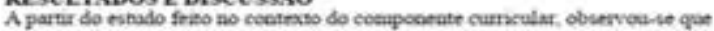

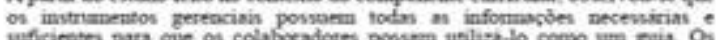

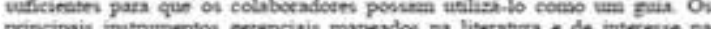

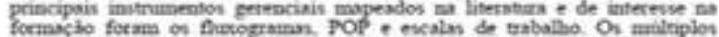

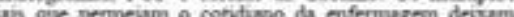

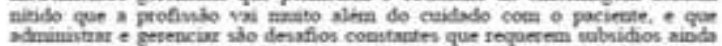

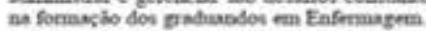

covcuesio

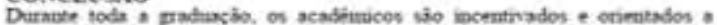

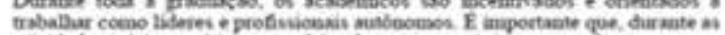

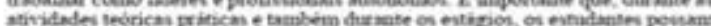

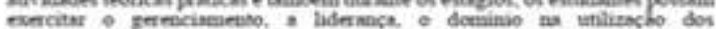

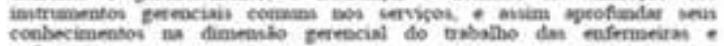
etefremarives. 


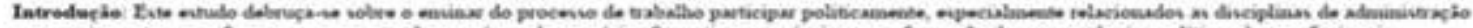

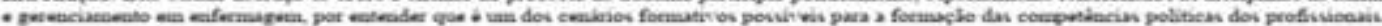

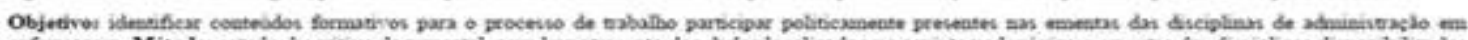

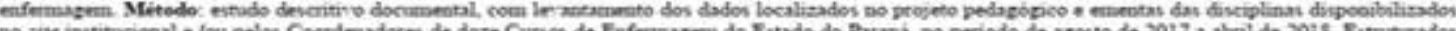

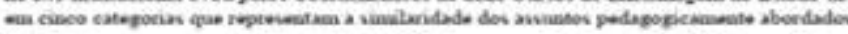

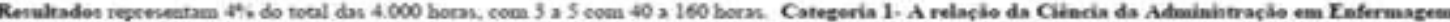

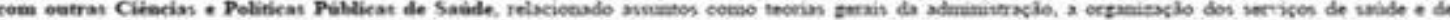

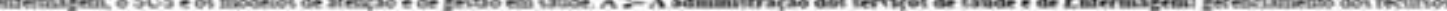

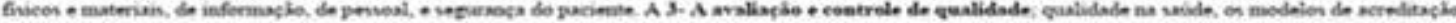

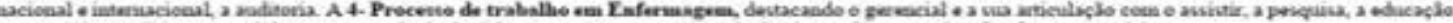

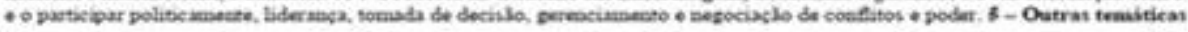

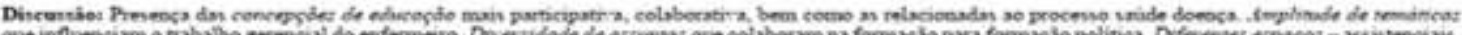

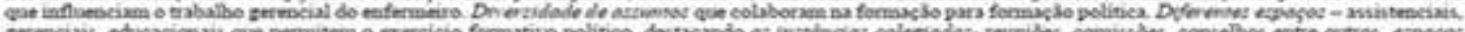

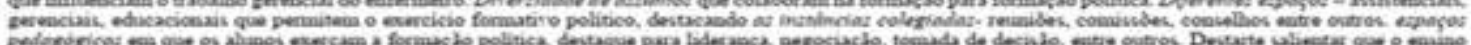

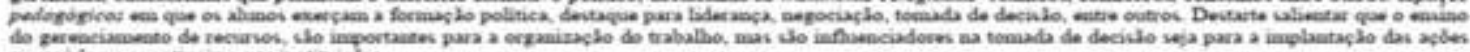

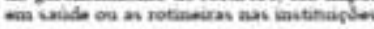

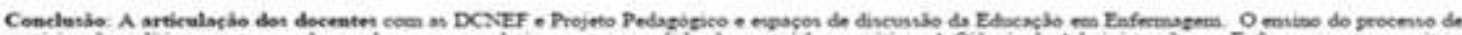

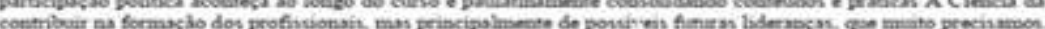

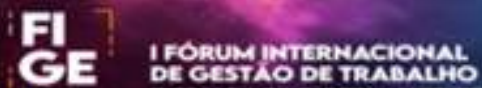 LS; EMUCACAO PERMANEATIE}

PARTICIPACX̃O DE DISCENTES NA EDUCACÃO PERMANENTE ACERCA DA

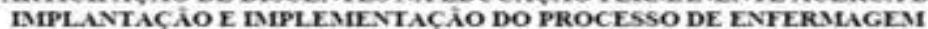

Débora Althaus Bonet ${ }^{2}$, Laura Cocco? , Carla Argenta?, Edlamar Kata Adamy

Introđuçăo: O Processo de Enfermagem (PE) e um instnimento metodológęco que permite organizar a gestao do cuidado, dando autononia 30 profistional de enfermagem ${ }^{1}$ Para que o PE seja efetivamente utilizado se toma imprescindivel que o servico de educacso permanente anue a fim de interagir conteodos teóricos com conteudo que se concretizem em sitwaçes reais mas quais on profissionais necessitam aleançar solaçoes efetivas, com base em respaldo teórico-pratico?

Metodo: trata-se de tum relato de expervéncia elaborado a partir das experiencias de dascentes mediante a educaşo permanente acetca da implantaça do PE em um bospital escola de alta coraplexadade ma Regaio Oeste de Santa Catarina

Conclusao: Nota-se a muportincia da contribucsto da educaça permanente na pratica profissional evidenciada por meio das atitudes que o profivional assume enquixnto cuidx, ja para os discentes eavolvidos neste processo tem a oportunidade de aliar a teoria aprendida em sala de anla com a pratica destro de um ambiente horputalar desemvolvendo babalidades gerencias e awistenciais

\section{Objetivo: Relatar a expenéncia de diverutes a participas do da educas lo permanente acerca da $\mathrm{PE}$}

Resultados - discussées: A educacto permanente permesa todas as atriviades de implantac to e implementaça do PE desde a construs to das matrizes assinterias ate as discussoles acerca de estudos de cavos levantados, aosd

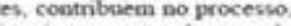
So analisados minuciosamente cads etapa do PE. levantando potencialidades e fragihdades pela equipe. 

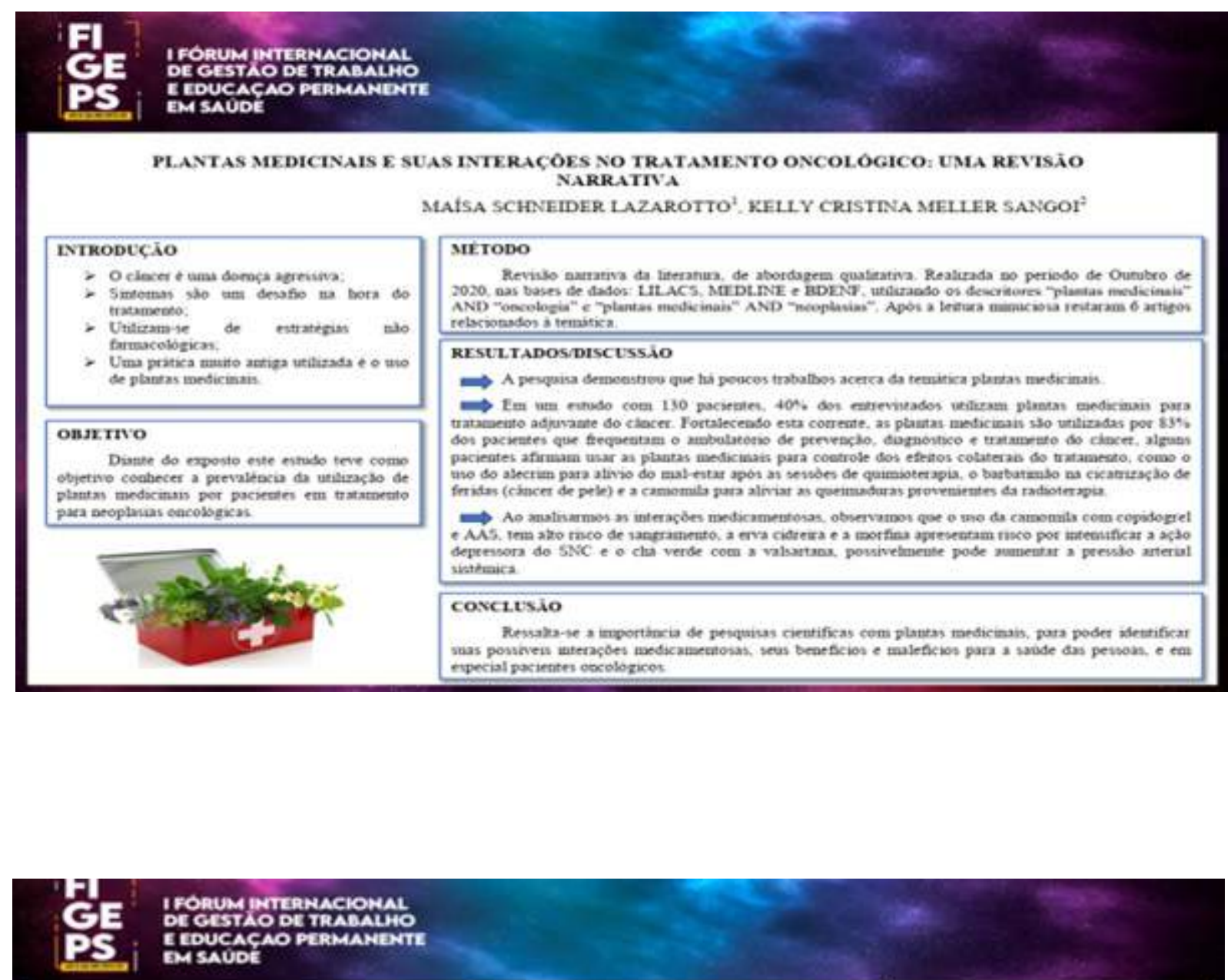

PROCESSO DE EDUCACÃO PERMANENTE EM SAÚDE HOSPITALAR NO OESTE CATARINENSE: UM RELATO DE EXPERIÊNCIA

Daniel J. J. F. Cassemiro', Jussara dos S. Valenti2, Jacira B. de Oliveira? Gleica Pressi4, Vânia Maria Lovera'. Rosana Amora Ascarí

\section{INTRODUÇÃo}

Educação Permancnte em saude, constitui-se $\mathrm{em}$ estratégia fundamental para promover transformaçóes das.

L praticas de trabalho.

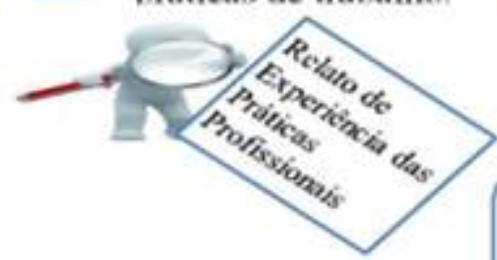

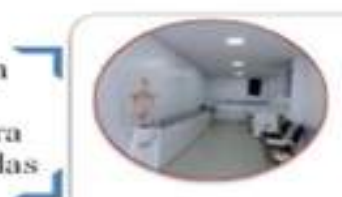

Compartilhar Conhecimentos

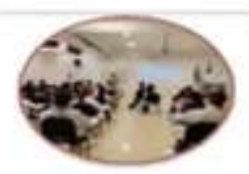

Integraçato Ensino Serviço

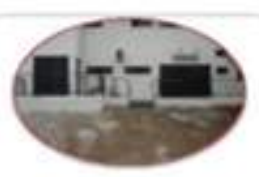

Qualificaçî́o das Práticas Assistências

\section{Resultados}

\section{CONCLUSÃO}

A Educação Permanente em Saúde, enfrenta diversos desafios e necessita do engajamento dos diversos niveis hierárquicos no cotidiano do serviço. 


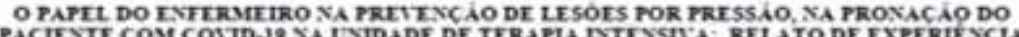
PACENTE COM CONTD-10 NA ENIDADE DE TERAPA RTENSTA: RELATO DE EXPERENCL

Cibele C. de Souza², Aline Cristina A. Furni2, Adriana de Fàtima Manoel², Eliseu C, Campos ${ }^{4}$

\section{Eixo temático}

Pràtica/produtos inovadores na atençào à saúde

\section{Objetivo}

Relatar as principais medidas implantadas na prevenç̄o de lesठ̄es pot pressăo, durante o posicionamento em prona do paciente com Covid-19, em unidade de terapta intensiva de um hospital particular do interiot do estado de Sào Panlo.

\section{Métodos}

Trata-se de um relato de experiência do enfermeiro na prevençăo da lesào por pressào na pronaçäo de pacientes diagnosticados com Covid-19.

Descritores: Infeçàes por Coronavirus; Sindrome do Desconforto Respiratório do Adulto: Decubito Ventral: Enfermagem: Terapia Intensiva.

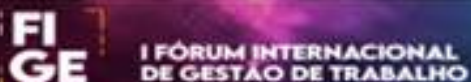

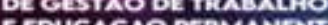 Emsucte}

\section{QUALIDADE DE VIDA DE PROFISSIONAIS DA ENFERMAGEM ATUANTES NAATENCC̄O PRIMÁRIA}

\section{EMTEMPOS DE COVID-19}

Endria Mendes Fabrizrio', Raquel Tatielli Daneluz Rintret', Lisiane da Rosa', Crtais Netto de Brum?' Jülia Graset', Samuel

\section{INTRODUCÃO}

O profisionat enfermeiro na APS acaba vivenciando situacies que podem interferir diretamente na sua condiçâo de saúde e qualidade de vida. Com a pandemia da COVID-19 estas situacoles tén intensificado o processo de trabalho do profissional enfermeito dis Aps.

\section{OBUETIVO}

Avaliar os dominios da qualidade de vida de enfermeiros da APS em tempos de COVID-19.

\section{Mírono}

Colcta de dados de forma remota, de outubro a derembro de 2020 Com questionabrio sociodemogerifice e taboral eo Morlat Heafle

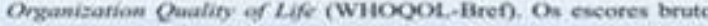
de cada dominio variam de quatro a 20 pontos. Analiser descritivas pelo sufferare Stativeical Package for the Sixcial Scienovi (SPSS), writue 20.0 RESULTADOS Spicgelberg Zage

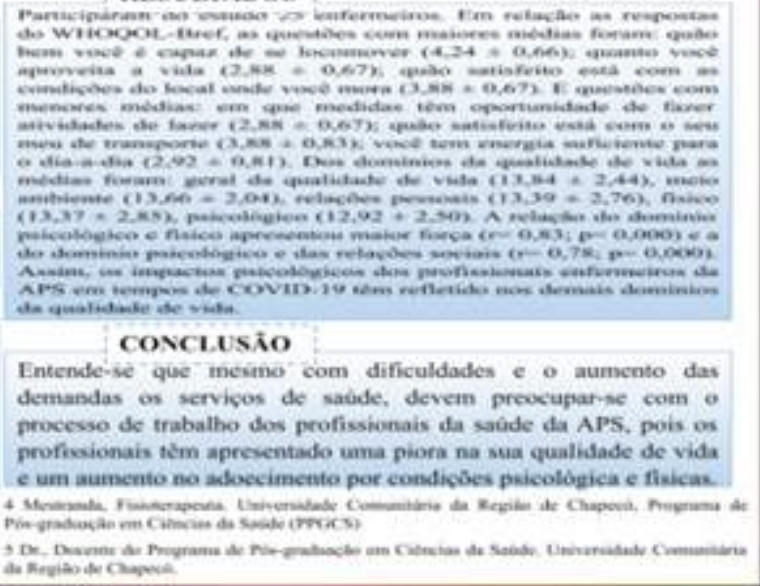



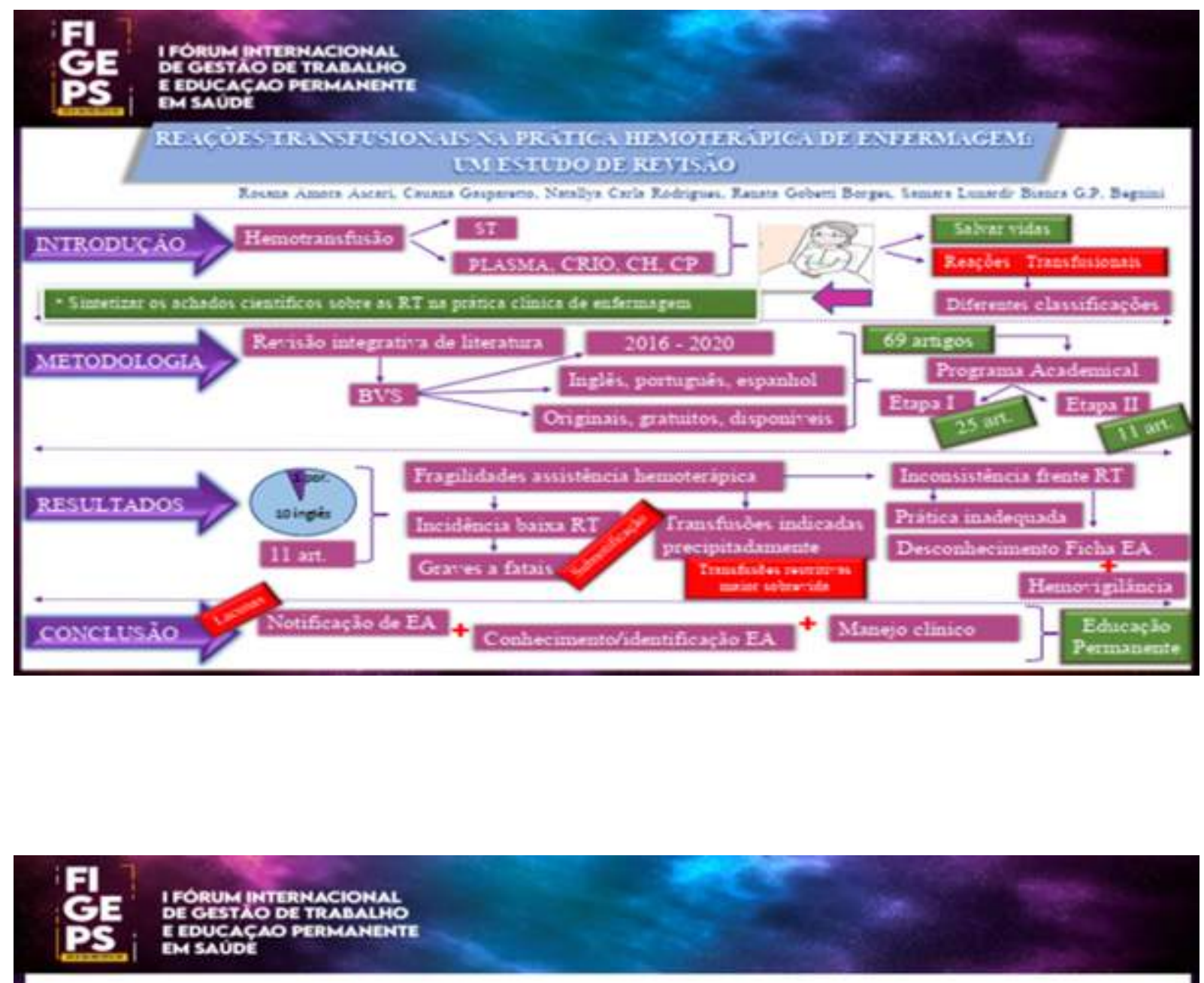

REL ATO DE EXPERIÊNCIA DA ARTICULAÇÃo DA COMISSĀO DE INTEGRAÇÃo ENSINO-SERVTÇO DA REGLÃO OESTESSC DE 2016-2020

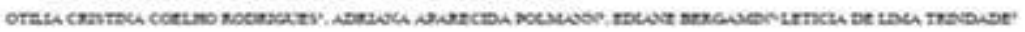

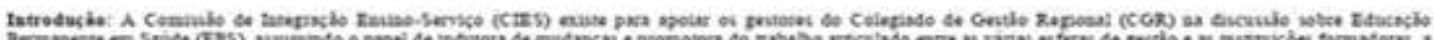

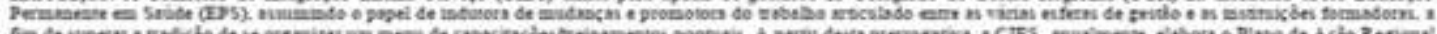

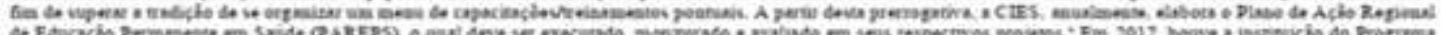

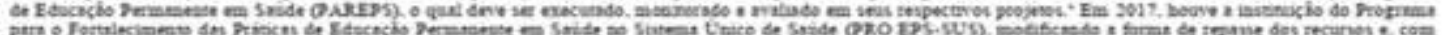

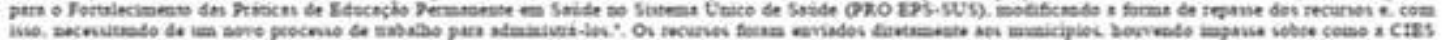

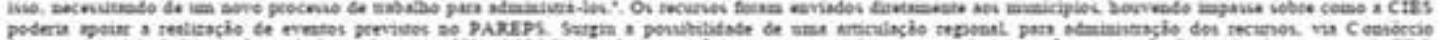

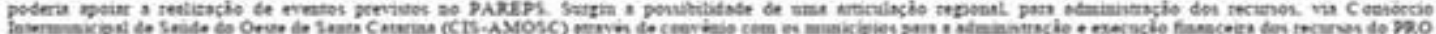

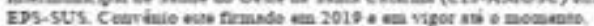

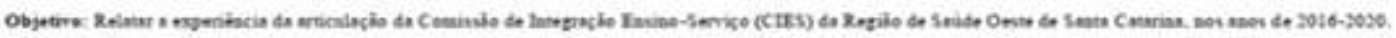

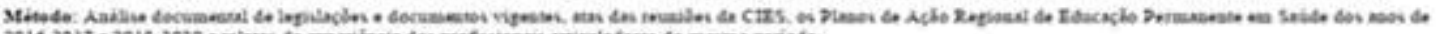

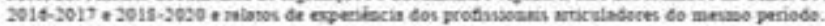

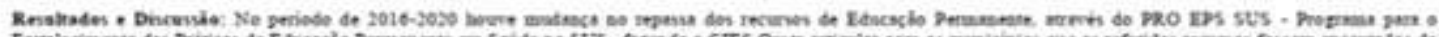

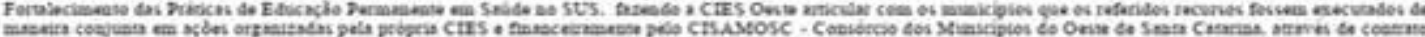

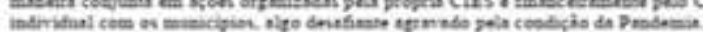

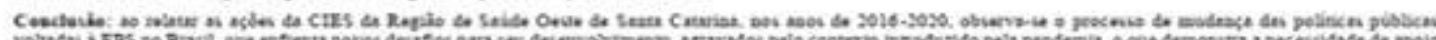

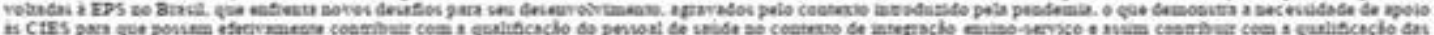
proten the inde otertaden po sus

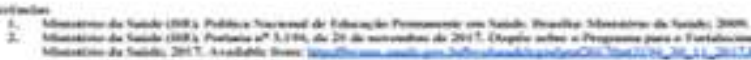




\section{A VTOLENCIA NATURAIZADA NO TRABALHO DA ENFERMAGEM NA ATENCÁ} PRTMARLA A SACDE

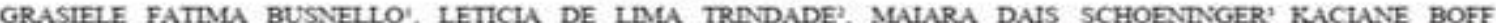
BAUERMANN

\section{INTRODUCX̃o}

Volkecia ne trabalhe - Imvestigaçes Nacionais e Intemacionais: demonstram que a violéncia no local Se trabatho e um problema de saikfe publica em todo o mundo.

\section{RESULTADOS}

Traballadores expostos a violéncia $(83,4 \%$ ). Major prevaliencia da violfacia pucolo pica, divtribuida em $(75,7 \%$ ) a greudes verbais, $(39.1 \%)$ intimidacio/asuedio moral. $(8.9 \%)$ asuedio setual e $(4.1 \%)$ discriminaclo racial $\left(3,0^{\circ}\right.$ ) dos trabalhadores softeram violetecia fisica O unuirio foi o principal agressor. A subcategoria "naturalizacto da violencia" a qual demonstra por meio dos relatos dos trabalhaderes como

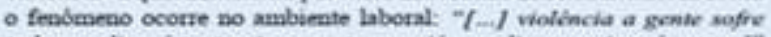

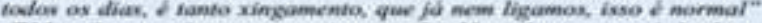

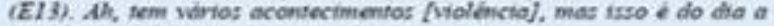

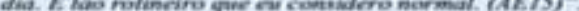

MTOPo

Evtado misto explanatörio. Cenário - 53 ESF/APS; Oeste de Santa Catarina. 169 protissionais da categoria de Fnfermagem (enfenneitos, themicos de enfermagem awoilares de enferma rem):

Etapa QUAN - Survp Questtomatre Workplace Nolence in the Health Sector, $d$ anditue contow com o sothere Stantistical Pockage for the Soctal Sctences (SPSS), versdo 21.0. considentias significarnas as assaciopdes com retrilmado de $p=0,05$

Eropa Qtil. - Entrertsta (1S participantes) Obsenvacio ndo parnicipante + Regartros $\mathrm{em}$ Didino de

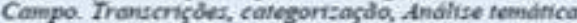

\section{CONSIDERACOFS FINAIS}

A violëncis contra os traballhadores de enfermagem. seflete diretamente no labor, com iniplicacodes of consegrentemente na ausisténcia prestada aos usuinios Relevante institinir a Culhura de Paz

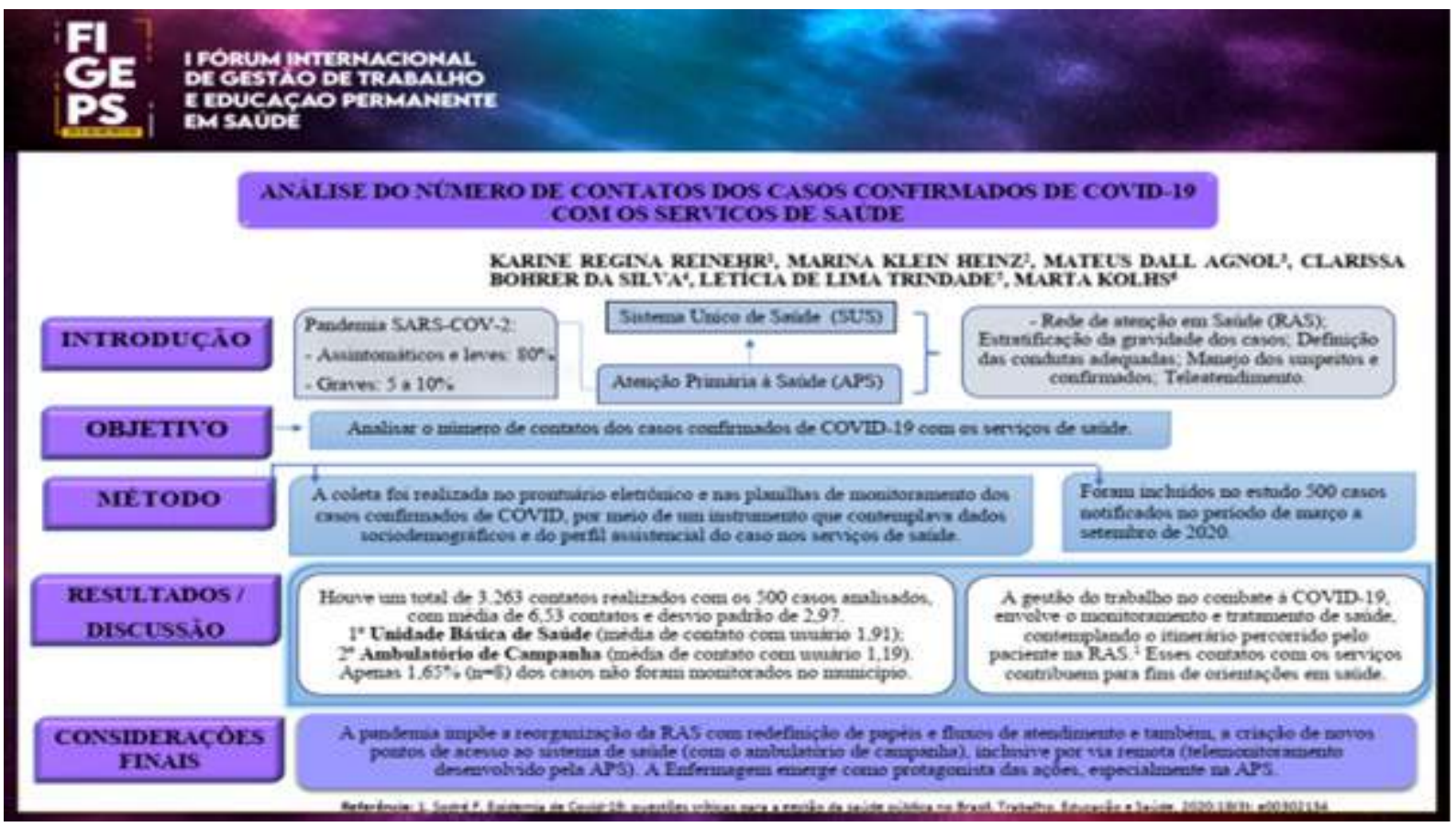




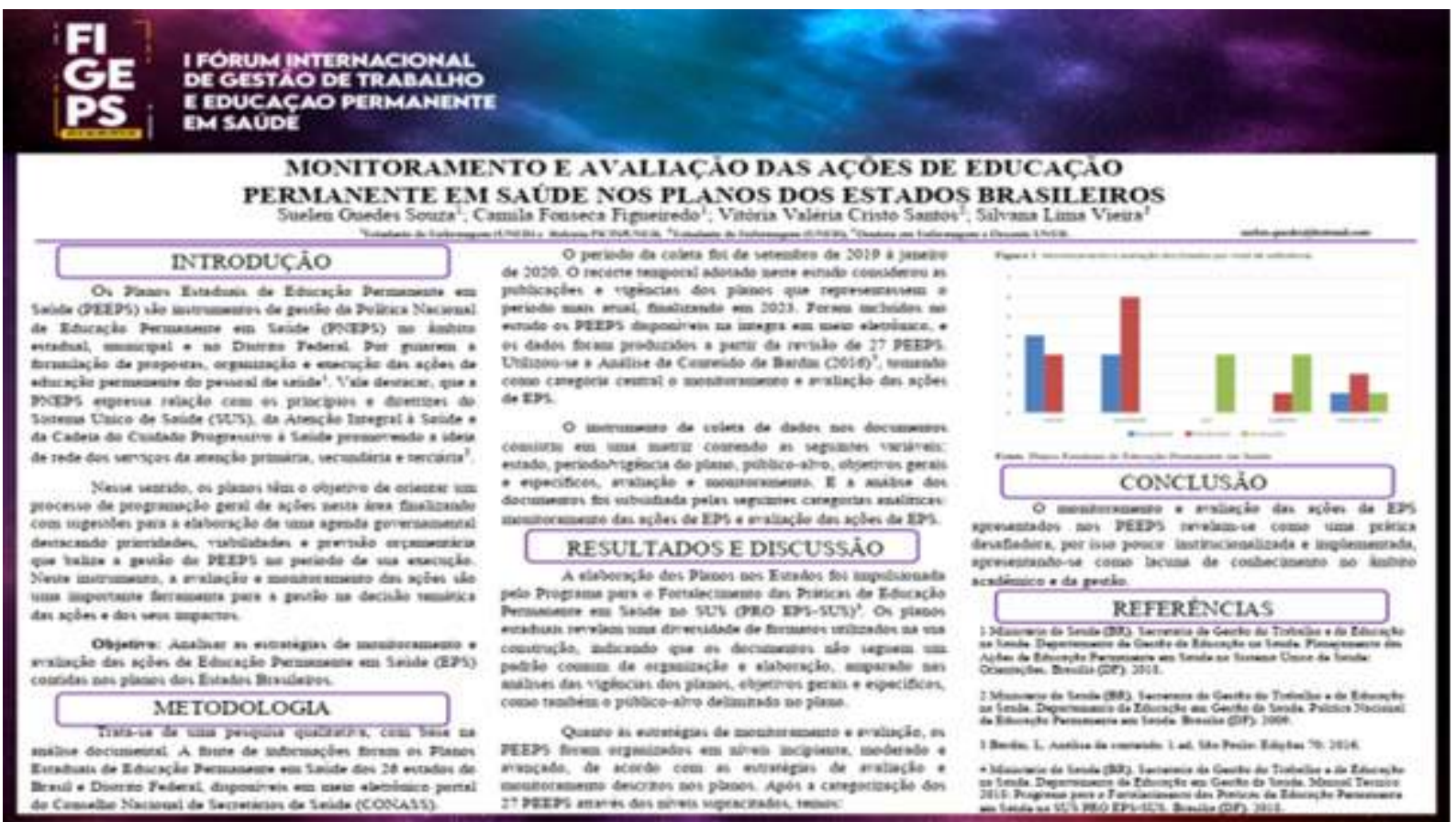

\section{If \\ PS}

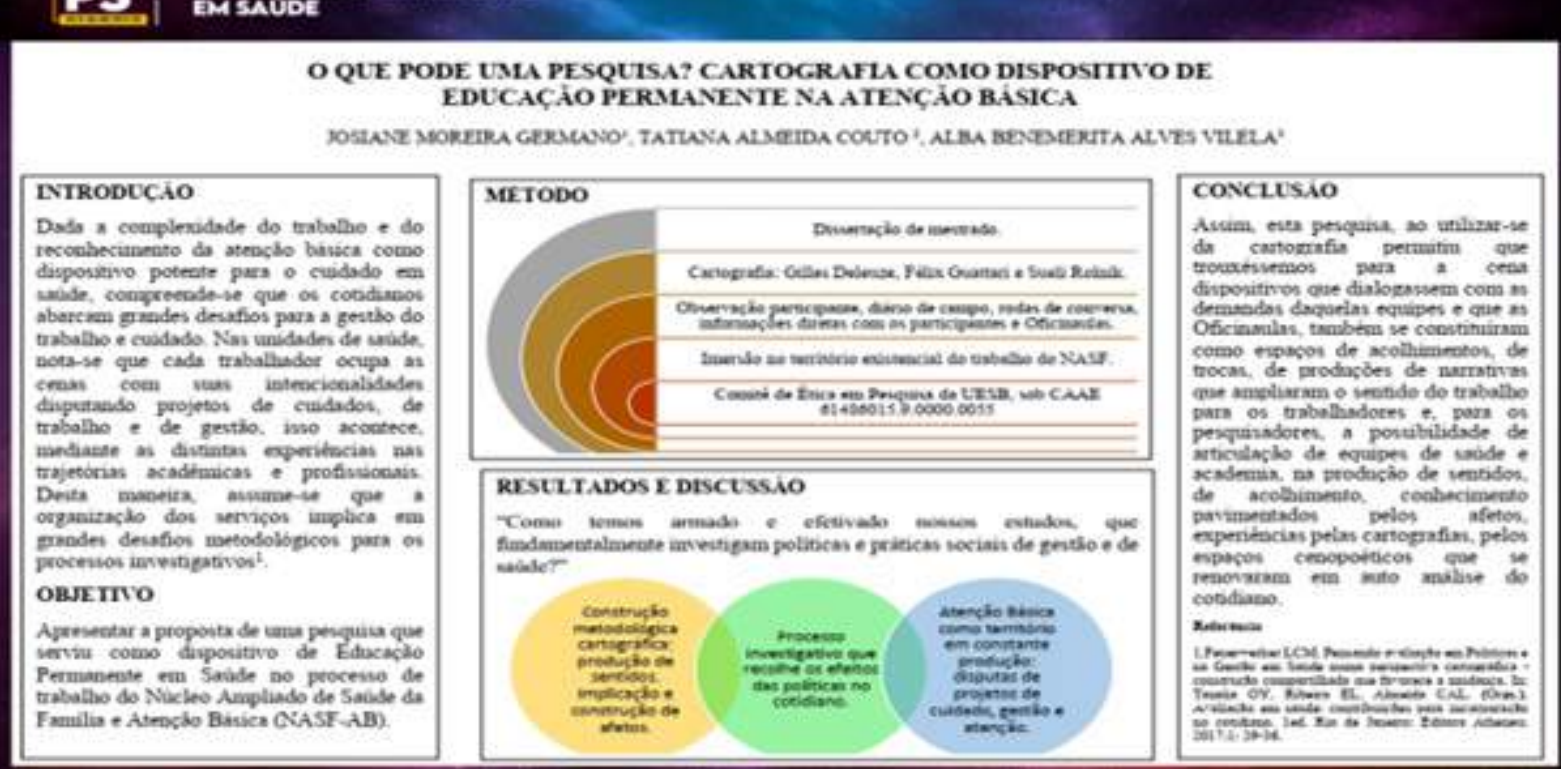


EDCCACAO PERMANENTE NO PROCESSO DE TRABALHO DAS EQUIPES DE SAĆDE/ATENCAO RÁSICA: USOS E SENTIDOS

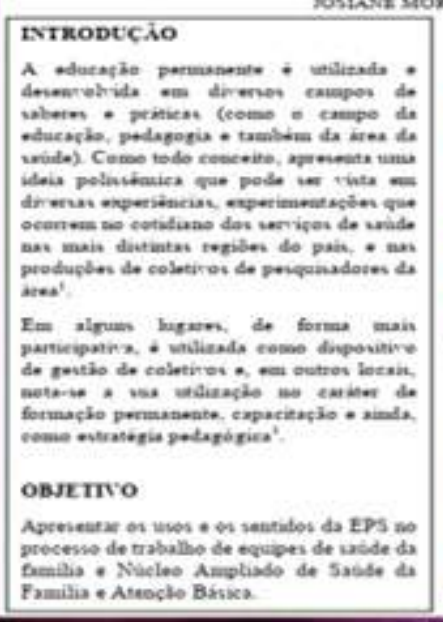

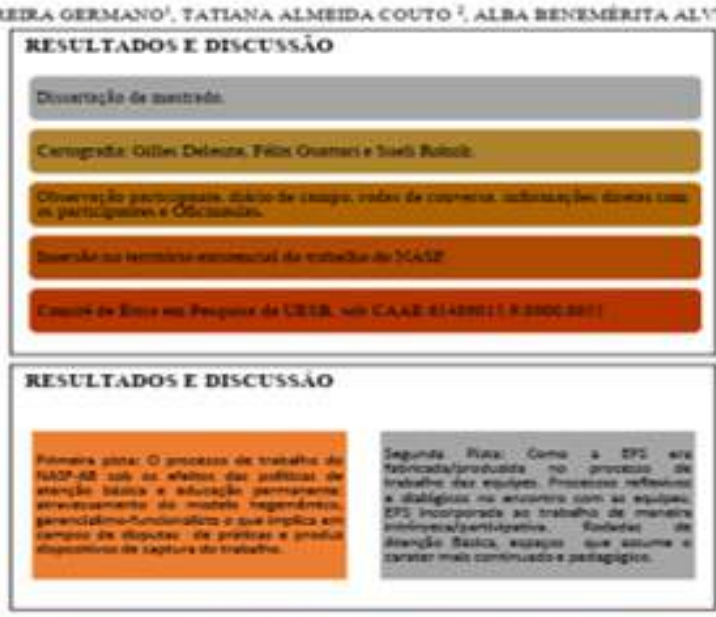

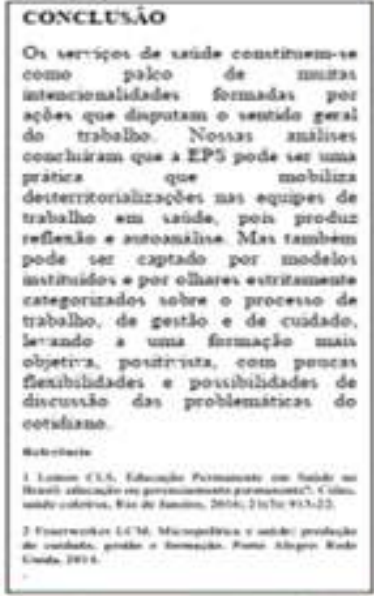

\section{. PS.}

\section{CONSTRUCĀO DE UM CURSO DE CATETER VENOSO CENTRAL EM CRIAVCAS NO DOMICILIO: RELATO DE EXPERIÊNCIA}

GABRIELA BEATRIZ LEONHARDT, SMONE BOETTCHER ELISANGELA VIDAI,

Introdecìo

MARCELO MACHADO, MII ENA MAILON; ADRLANA APARECIDA PAZ

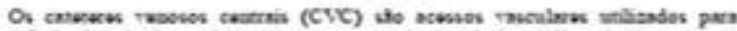

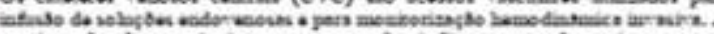

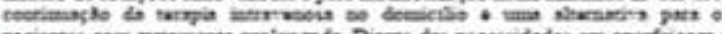

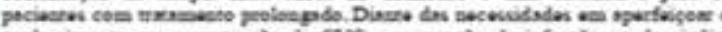

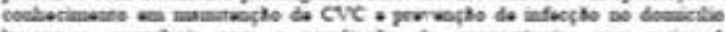

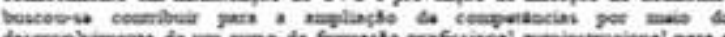

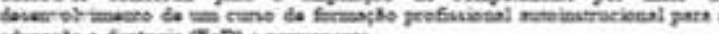

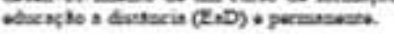

\section{Objetire}

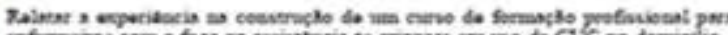

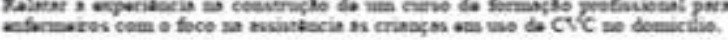

\section{Mätodo}

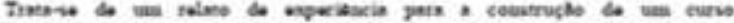

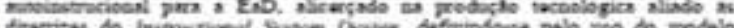

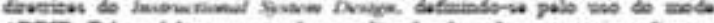

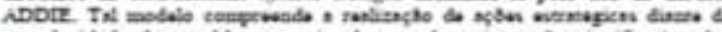

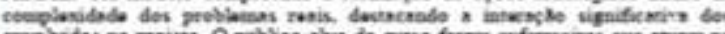

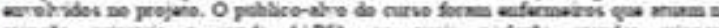

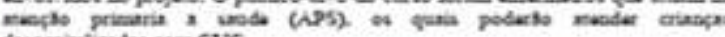

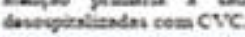

\section{Resultados + Discussib}

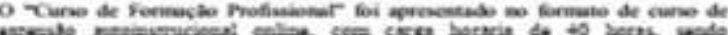

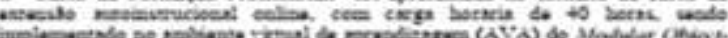

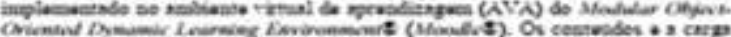

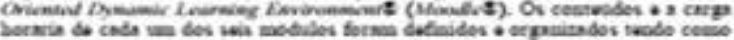

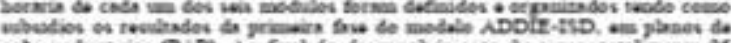

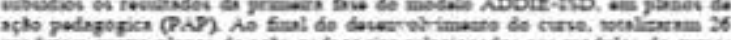

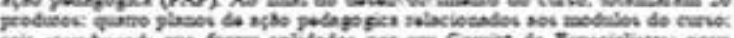

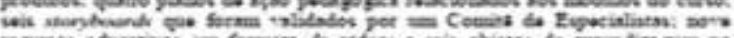

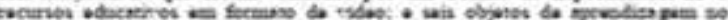

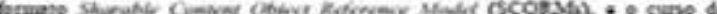

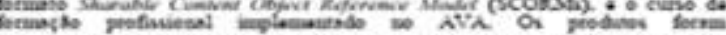

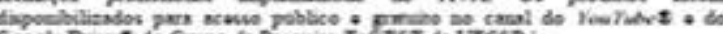
Conclusiáo

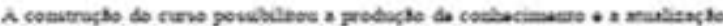

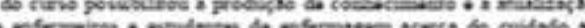

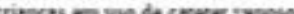

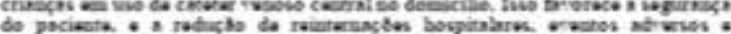

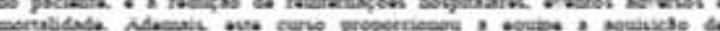

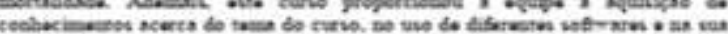

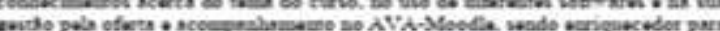

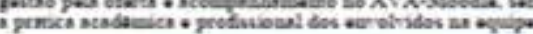

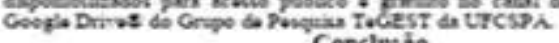


O MANEJO DA DOR ONCOLOGICA EM CUIDADOS PALLATIVOS, NA

PRAXIS LABORAL DA ENFERMAGEM

ROBSON LOVTSON" ERICA C, DALABONA?, DEBORA MARCHETT1', TANIA M. ASCART', SANDRA M. VANINT!

ETRODUCAO

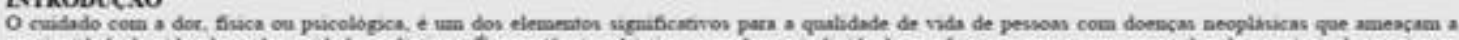

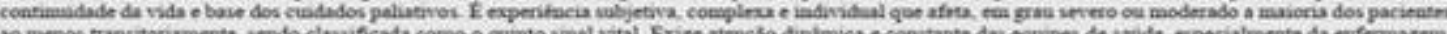

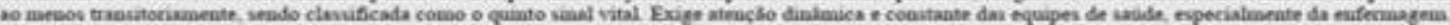

OBETTO

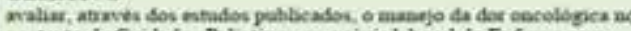

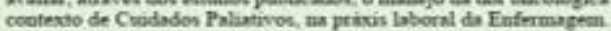

\section{RESULTADO E DISCESSiO}

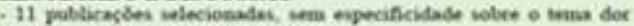
oncolónica eo traballio de enfermatrm

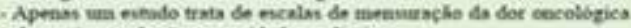
- de wer importincis nos ctuidados poliatives

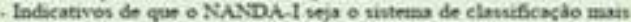
empregado para a formulacba do da provtico de enfensagente da der enc cuadados palatives

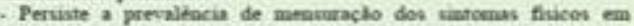

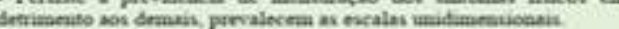

mrraxickas

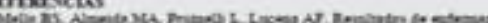

MTODOLOCL

Rernis afogentiva -SCHLO BVS

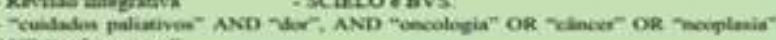
AND Fenfermagem"

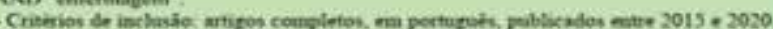

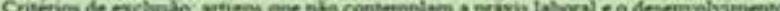

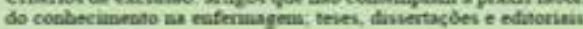

conclesio

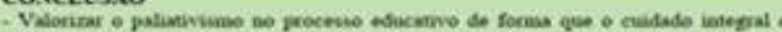

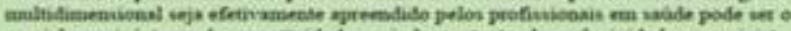

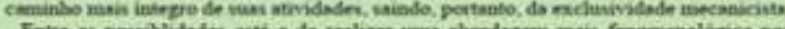

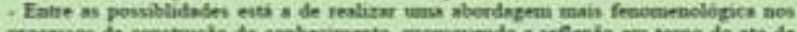

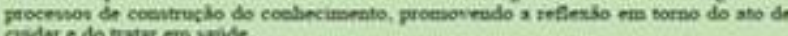

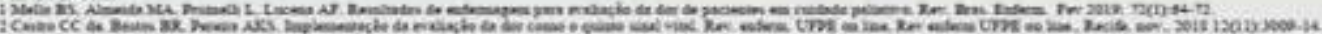

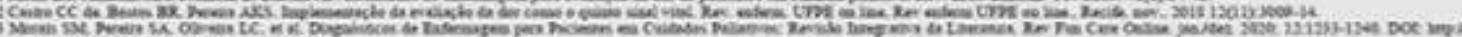

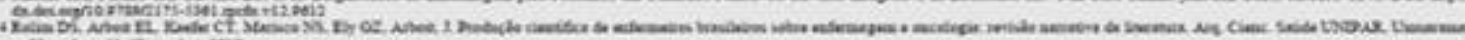

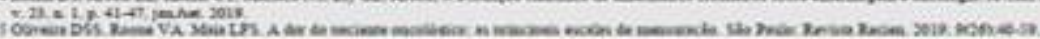

\section{[E] if: EDUCACAO PERMAMERT:}

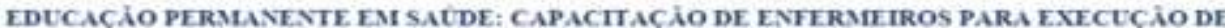
ELETROCARDIOGRAMA DE REPOESO

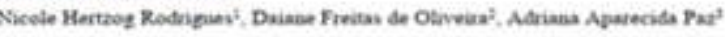

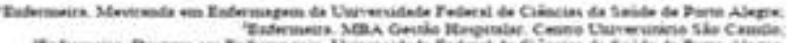

\section{ISTBODUCĀO}

O eletrocardiograma (ECO) e a reproducjo monifica da stividad cietrica do coracho durabite o seu fibciobarmeato, resistradn s partik

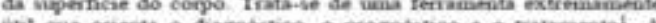

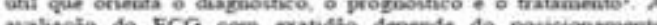

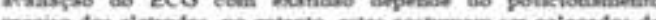
Mena and eletradon.

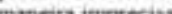

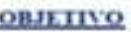

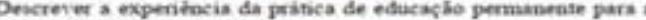
execuciso de ECG de repouso

\section{Mirtopotogra}

Relane de expeneneia weter a pritica de eduescio permanente realirada on um henpitat da rendo metrepolitans de Porte Aleare.

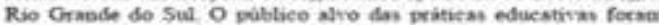
moformerisen de diversos setotes ds institusic to

\section{REStLTADOS X DISCESSio}

A gratica educativa foi aplicada em doin motmeaton, seodo un teoticico e cutro pritico.

Verificos

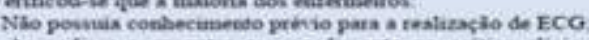

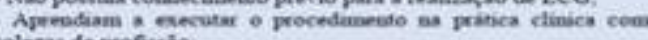
Metepas de grofivió,

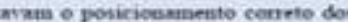

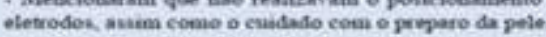

\section{concuesto}

A pritica nducariva for zauiso satishtona petos relatos don

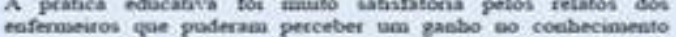

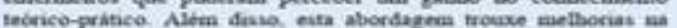

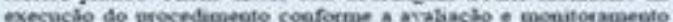
da quatida de dos ECG pelo chefe da equipe de cardiologia.

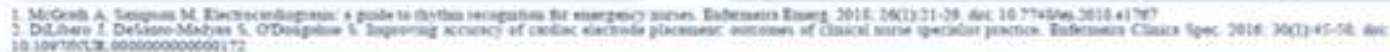




\section{REESTRUTURACAOO DO SERVTCO DA CONIISS AOO HOSPITALAR DE TRANSPLANTE (CHT) DE UM HOSPITAL PÚBLICO NO OESTE}

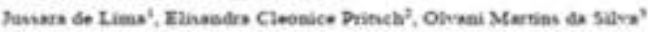

Introduchlo: O papel do eufermeiro freate a doaclo de érglios a e que ao mesmo tempo existe a posvibilidade de salvar vidav

Objetivo: relatar as aç̄es zerenciais de enfermagem deveavolvidas para semodelar o servace da Comisslo Hospitaler de Transplunte (CHT) de um hospital publice no oeste de santa Catarina, com vistas ao sumeato da efetivaçio de copptaclo de orglos e tecidos humanos Metodo: relato de experiencia que retrata aços realizadas no periodo de 2019 a 2020 pela cootdenaçio do serviço de captaçăo e tansplante de um hospinal publico do Oeste de Santa Catarina, com vistas ao aumento da efetivaço de captacio de orgios ems que form remodeladas as rotinas do setor no que se refere aos procestos administrativos gerenciais, assistenciais e educaclo permanente.

Conclusào: para obeenclo de melhoria nos resulados a equipe da CHT. traballhou ex tris frentes a saber zetescixmento o reentrunuraçlo das acdes; educaçlo permanente e implementaçà da avistetacia. Resultado que culminou em bomenagems ao servico de "methores resultados do ano" e de "enfermeira que mais implementou acoles no ano, no estado de Santa Catarina.

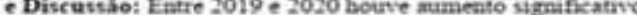
numero de potiffcaçes, entrevistas e doacdes eferivadas, com queda ans recusas. Para obert esses indices no que se reffre so Gerenciamento e reentruturachio das acbét: novos profissionais foram aloxados ao setot: ajustes nas escalas de trabalho, envolvimesto de todos os enfermeiros nas entrevistas e procedimestos cirurgicos, reunides mensais, balanco dos resultados, estabelecimento de metas, busca ativa e maditoria mensal Educacilo permanente: capacitacdes dos colaboradores mensalmente, dos recém admitidos durante a interraça dor funcionirios. Companhas educativas e palestras em eventos. Implemeataçio da Assistécia. acolhimento dos familiares, melhora da communicachlo, acesso e facilitacio das visitas a UTI, informativo a todos os eavolvidos com o protocolo de morte encefalica do pacieate. Acreticimo da realizachio do teste pasa a corid $19 \mathrm{em}$ todos os pacientes que abem protocolo.

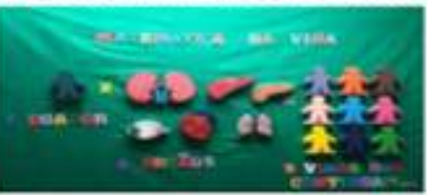

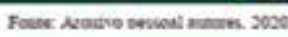

\section{GE togum

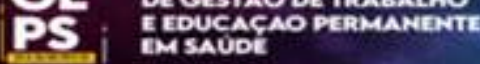

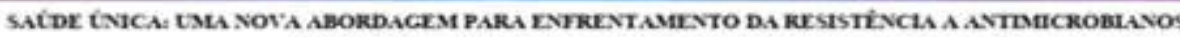

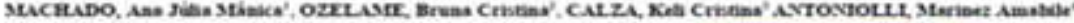

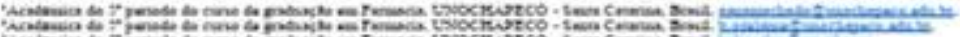

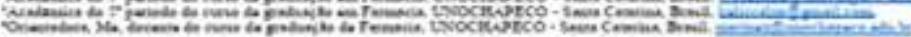

Brmaocelo

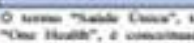

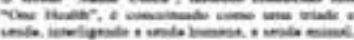

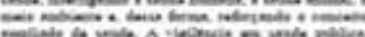

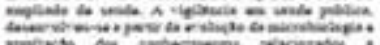

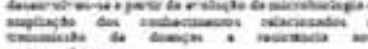
Cosirmo

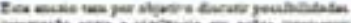

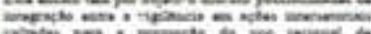

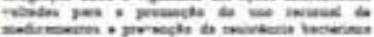
sertocos

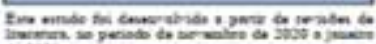

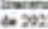
Nunbichs

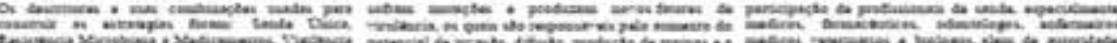

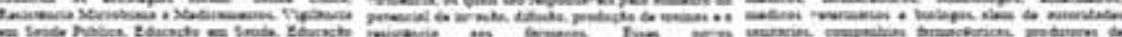

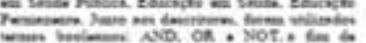

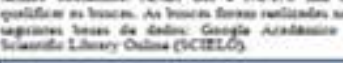

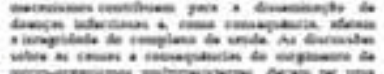

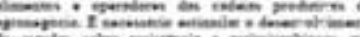
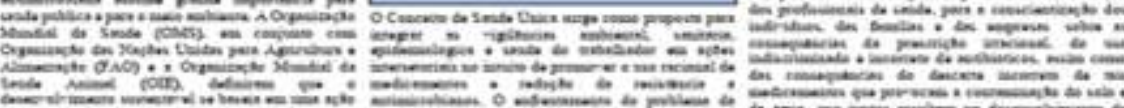


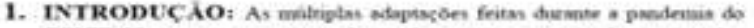

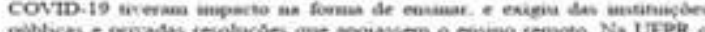

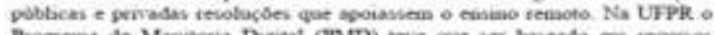

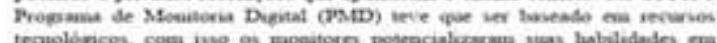

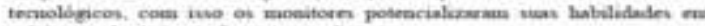

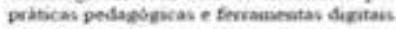

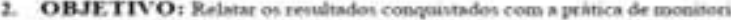

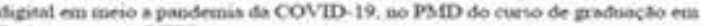
Eafecuagena de UFPR.

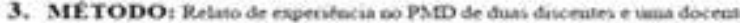

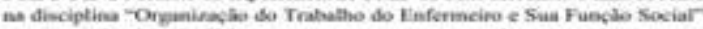

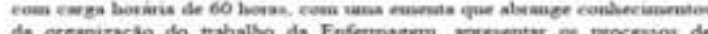

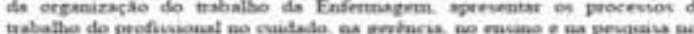

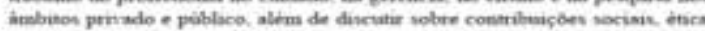

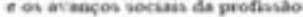

6. REFERENCLAS

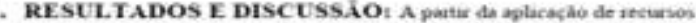
C tm verectu nso to e desentohimatesto de

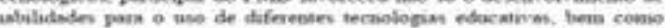

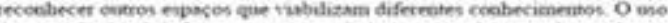

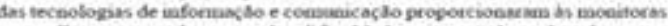

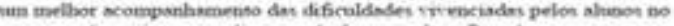

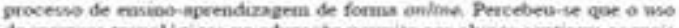

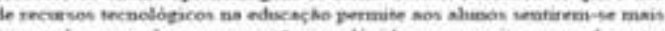

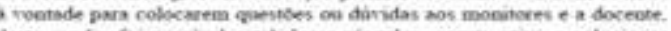

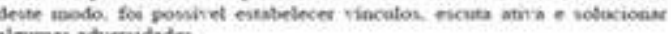
algumas adversidade

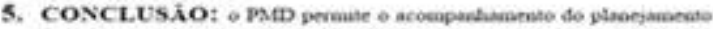
pedagópico juato no docente respomancel pels dinciplins despertando A

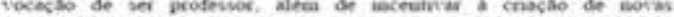

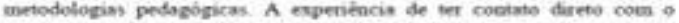

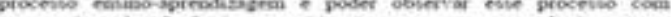

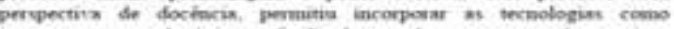

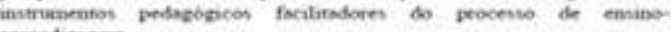
mereaduagem

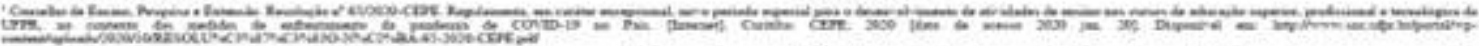

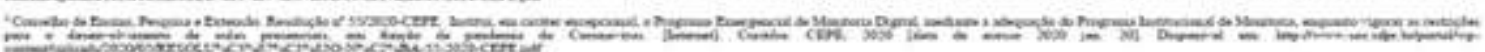

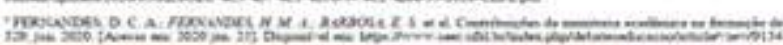

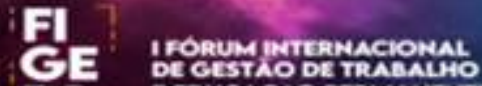 EDOCACAO PREMANEMTI PS i EMsuofe}

\section{EDUCAÇÃO EM TEMPOS DE PANDEMIIA: RELATO DE EXPERIÊNCLA}

ANA BEATRIZ MATTOZO AMORIM', INGRID MANOELLA BORGES?, SARAH DANY ZEIDAN

\section{ESTOOECTO}

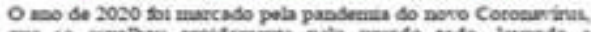

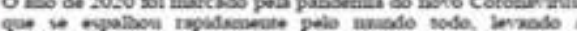

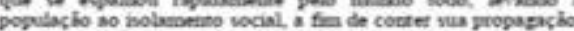

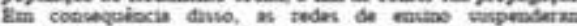

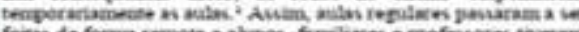

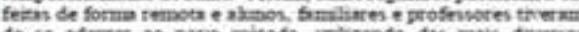

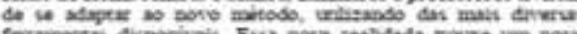

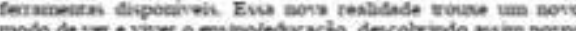

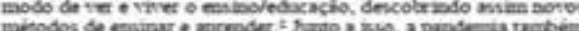

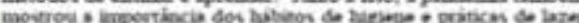

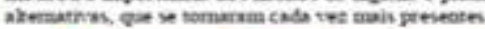

\section{OAn:mरo}

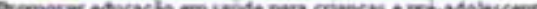

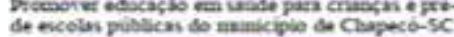

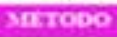

A seinidade foi realiasda no segundo semestre de 2030 ma

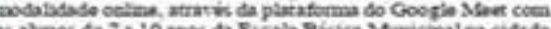

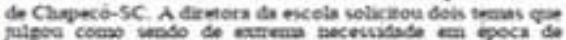

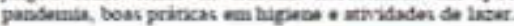

YASSRE', THAIS MARAFON" VICTORIA YTERA HERTZ" MARTA KOLHS*

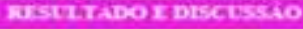

- 70 participantes as sals enline.

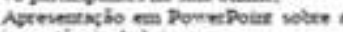
Miportincia de trincar

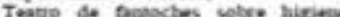
corporal

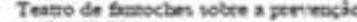
a corsit 19

Video da lavapean corrva das malos.
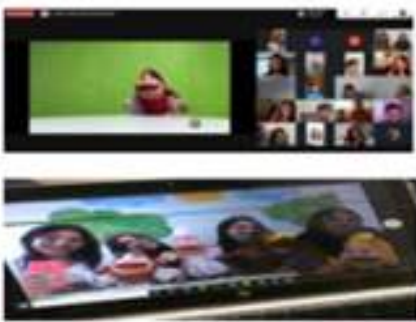

\section{coscrusto}

- Derceplo as grade relenincia do

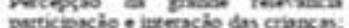

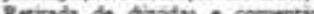

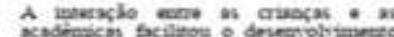
dis monidader.

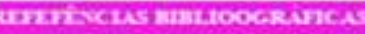

CORDIIRO. Ferolma Maris de Araíso. O

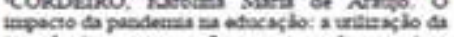

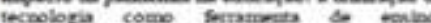
Faculdason IDWN $3030,2.3$.

QQCERROZ, Norma Lacia Ners et al Briacadein

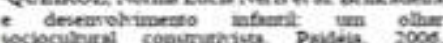
$100-9), 160-179$.

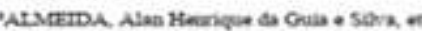
a1 Camificacio na ndicaglo fivica ncolk: of

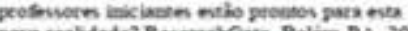

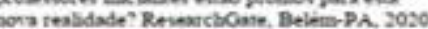




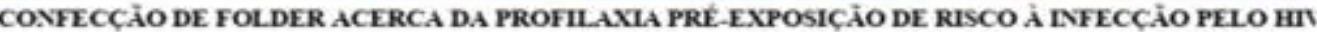

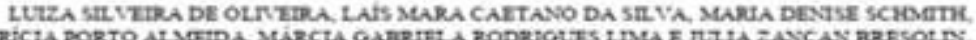

\section{Thedere}

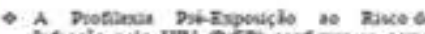

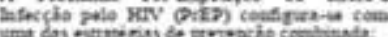

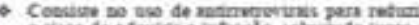

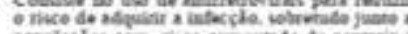

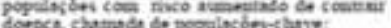

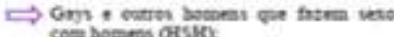

$\Rightarrow$ Proses manomik

$\Rightarrow$ Prebuvenis do smo

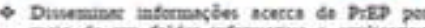

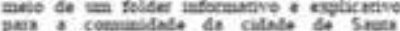

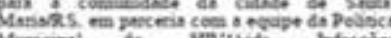

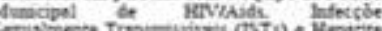

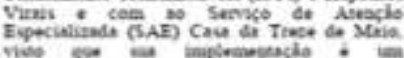

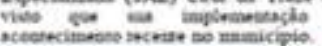

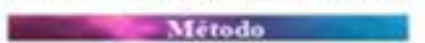

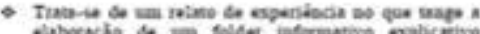

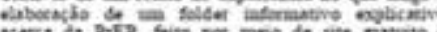

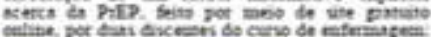
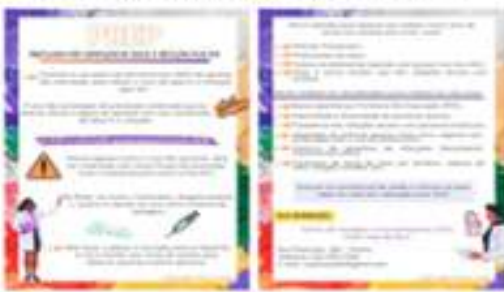

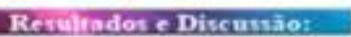

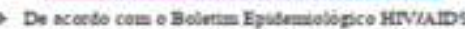

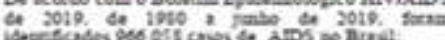

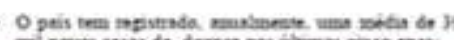

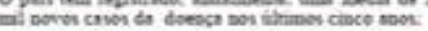

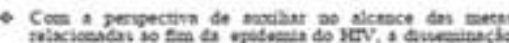

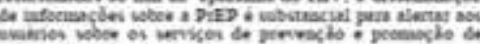

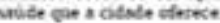

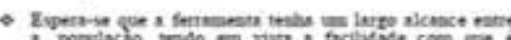

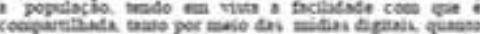

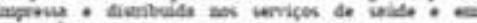
cangritar

\section{Enonctusa}

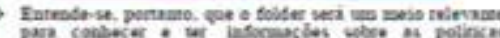

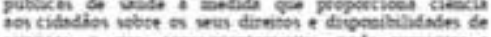

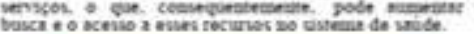
Refaribcian:

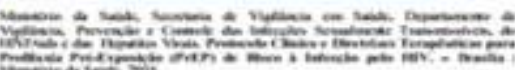

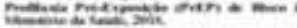

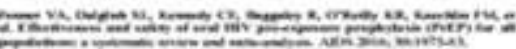

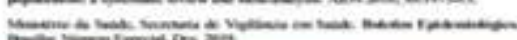

\section{Fe \\ PS}

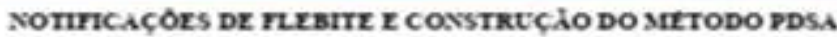

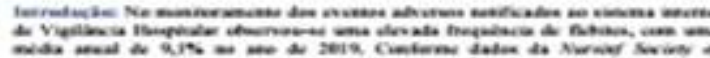

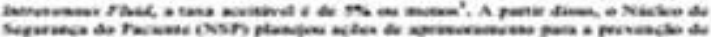

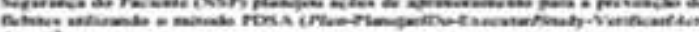

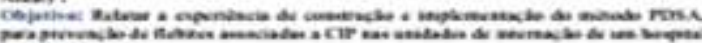

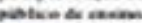

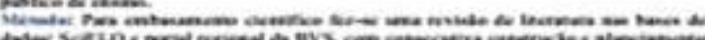

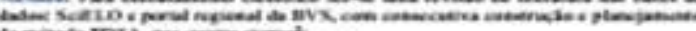

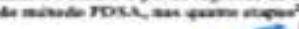

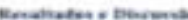

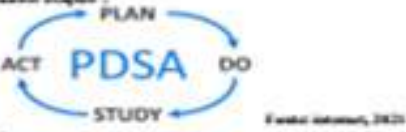

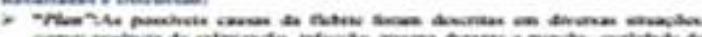

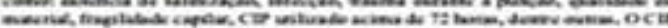

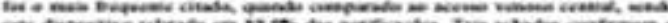

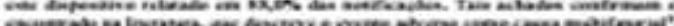

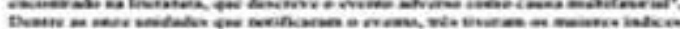

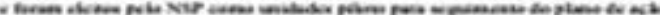

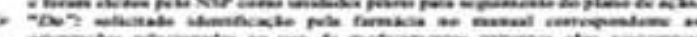

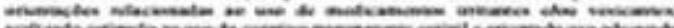

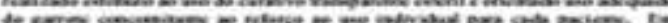
2.

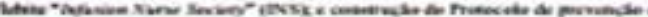

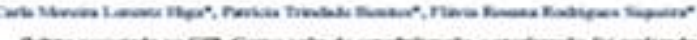

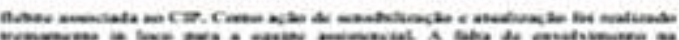

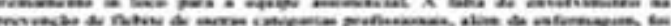

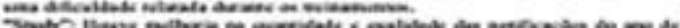

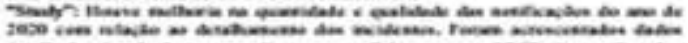

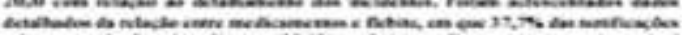

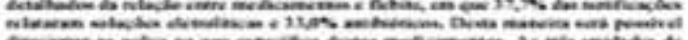

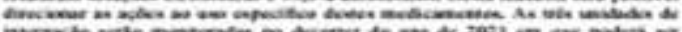

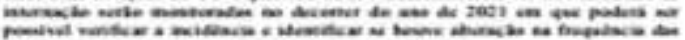

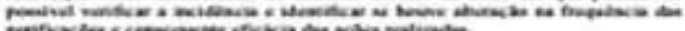

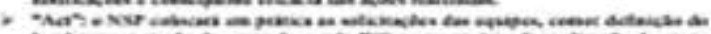

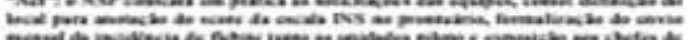

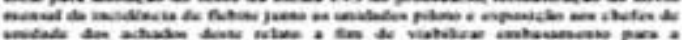

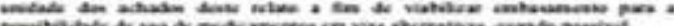

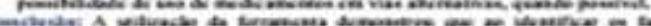

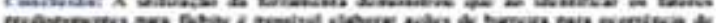

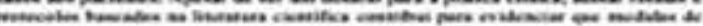

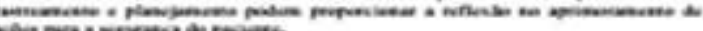

Mutertaris

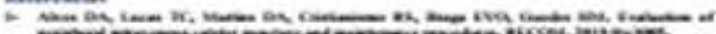
tow

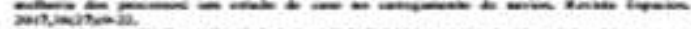
10nk (1) 


\section{'FE? Hopumpiennacionat \\ PSi EmSAUDE}

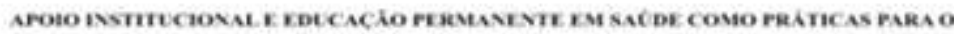

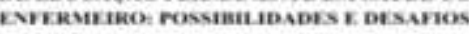

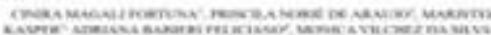

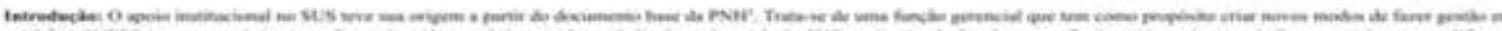

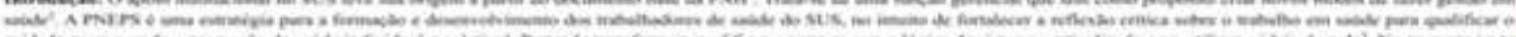

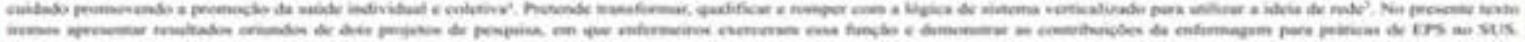

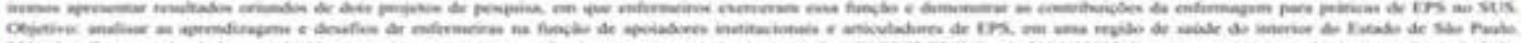

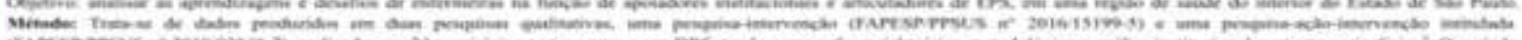

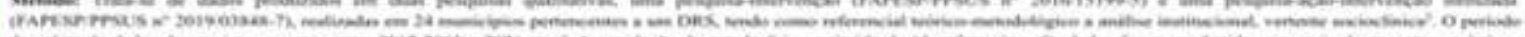

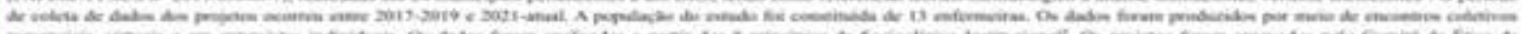

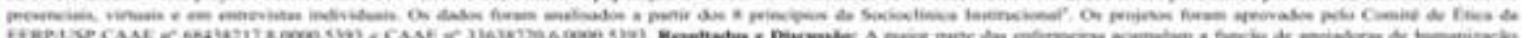

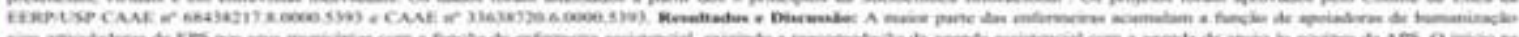

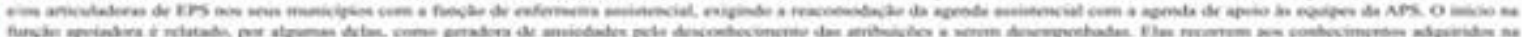

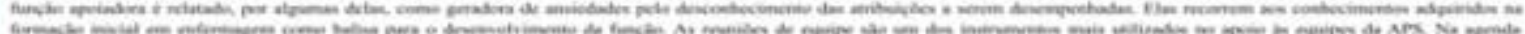

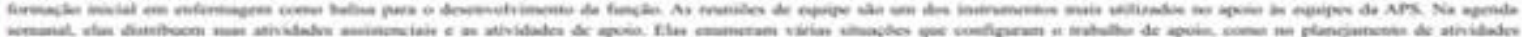

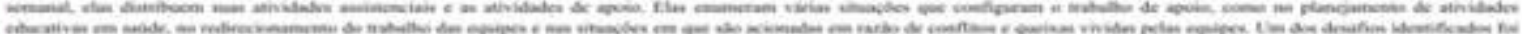

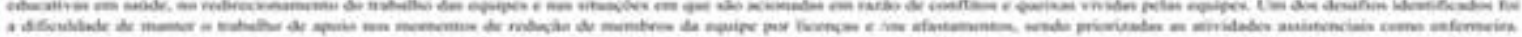

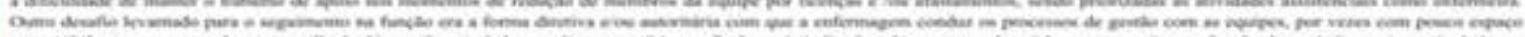

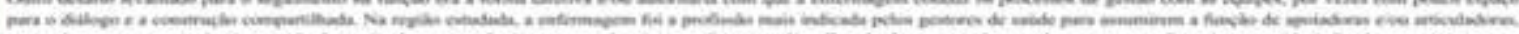

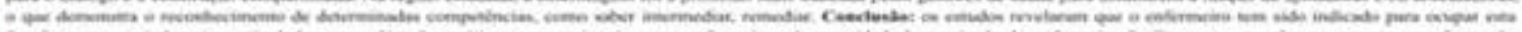

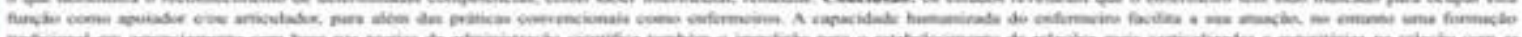

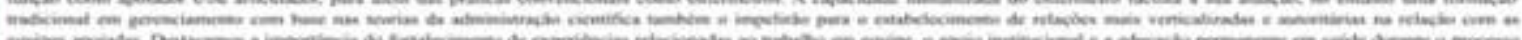

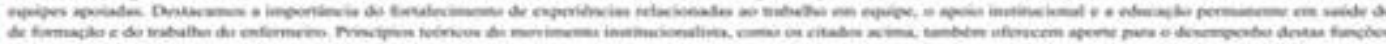

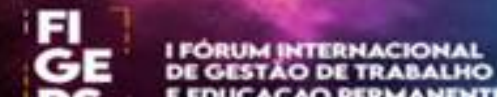 PS i tevecacion}

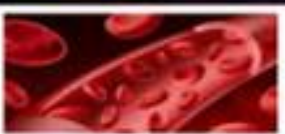

INTRODECÃO

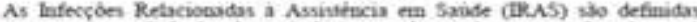

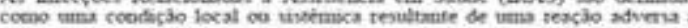

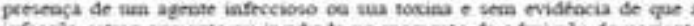

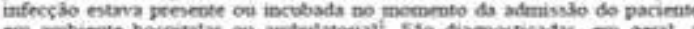

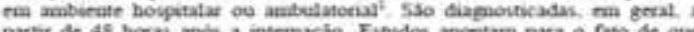

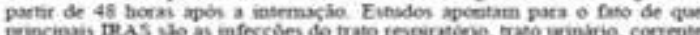

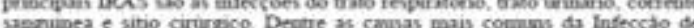

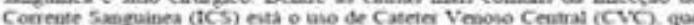

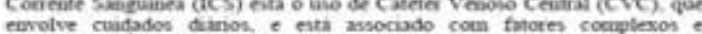
amithbiterian?

\section{OBนTIV}

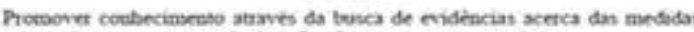
pereventivas pura o coetrole de infecclio ma conteate sapguinea

\section{METrodo}

Eitudo de revisio miegrava, sas bases de dados LIIACS, MEDLDE o Srielo, sorm os descritores: ceceitrole de infeceles, infesclo bosputalar

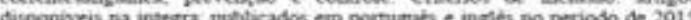
a 2020

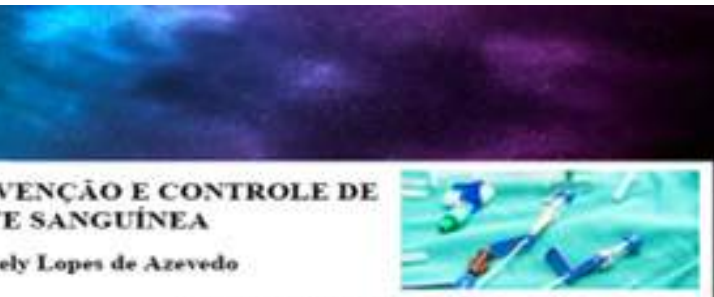

RESETTADOS E DTSCESลัo

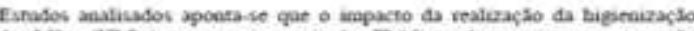

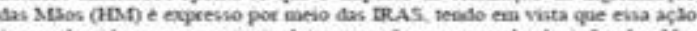

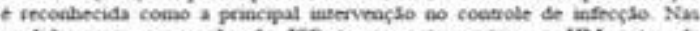

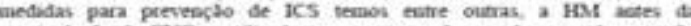

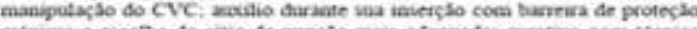

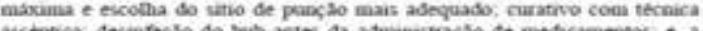

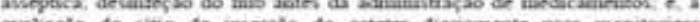

\section{covicusio}

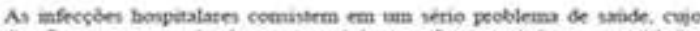
dessfo pura prevenir danos e prejuizos entbo amociados sos cridados decoctenters de procenion eu das estrututas de ansitetacis. Afualizacho de protocolos equecificos de criterion divenosticon e medidas de prevenclo pura

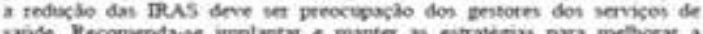

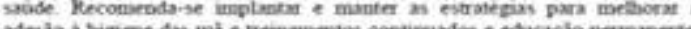

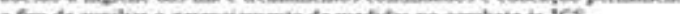

netivimint

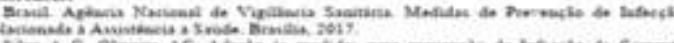
2.0.

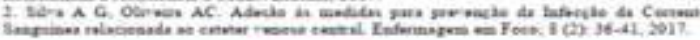




\section{'FE? Lopumpitanacionat \\ PS. EEUCACAO PERMANERTE \\ EMSAUDE}

BUNDLES E EDUCACÃO PERMANENTE COMO ESTRATÉGLAS PARA PREVENCAO DE MNEUMONIA ASSOCLADA VENTILCCAO MECANICA

\section{Raquel de Oliveira Laudiosa da Motta, Suely Lopes de Arevedo}

INTRODUCÃo

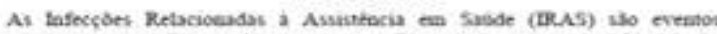

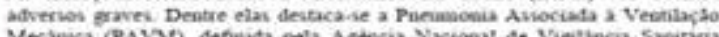

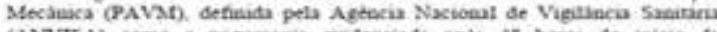

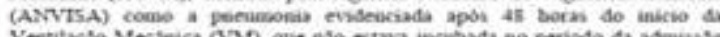

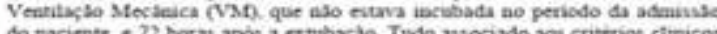
do paciente, e 72 borat apos a extubasalo. Tudo asseciado aos criterios climicon obiervidos an anilise des resultados de exames radiologicos o taboritorias?

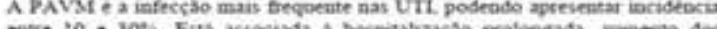

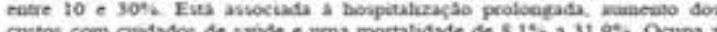

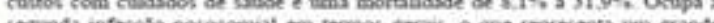

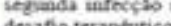

\section{OBNETIO}

Identificat ax lineratura ciratifica as imtervencoen unifiradas sa peanca ctimica

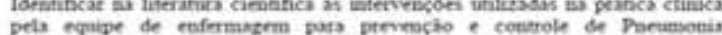
Asuocisda a Ventabiso Mecinica

\section{str. ToDo}

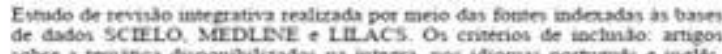

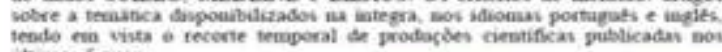
atrinos 5 amos.

\section{kESTLYADOS E DISCUSSío}

Des einudos selecionsdos for possivel definir gue a ideunfeacto dos priacipais

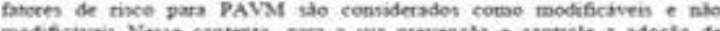

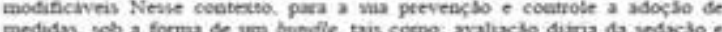

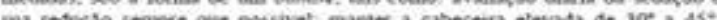

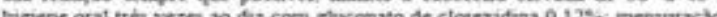

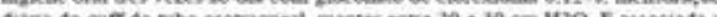

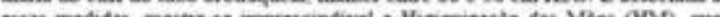

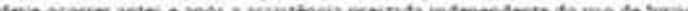

\section{concretsio}

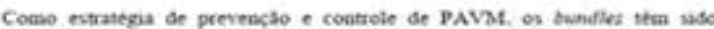

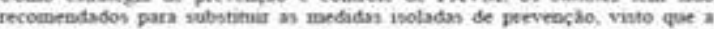

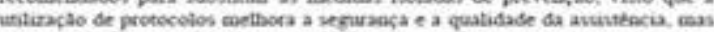

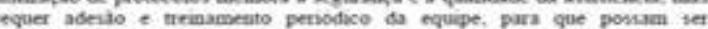
conuderados iaficadores de cualidace Dene modo, a separasas do paciestr

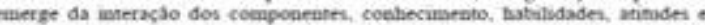

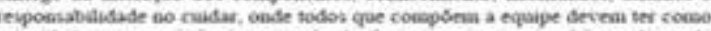

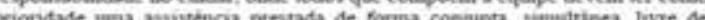

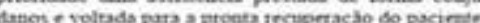

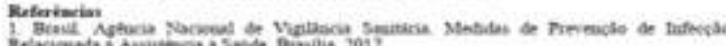

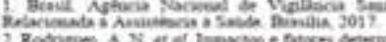

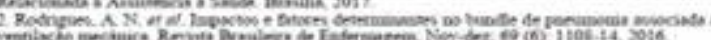

\section{Fie -G i E EDUCACAO PERMANENTE}

AGE DDAMENTO DA VACINA INFLENZA COMO ESTRATEGLA PARA ALMENTAR COBERTLRA VACINA.

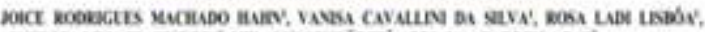

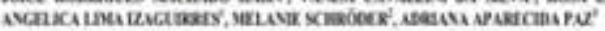

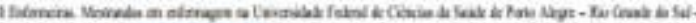

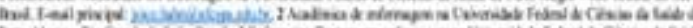

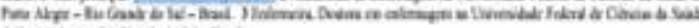

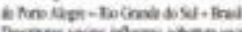

srnesecio

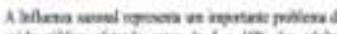

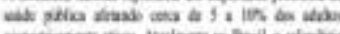

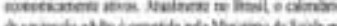

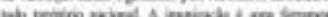

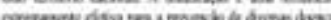

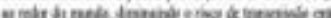

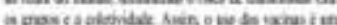

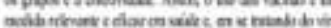

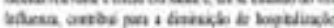

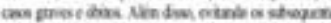

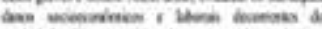

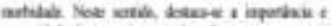

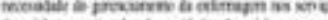

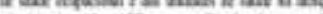

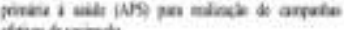

oอบrmo

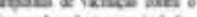
van an corta

vertoeotocat

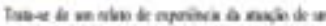

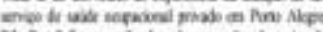

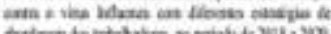

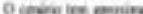
200 noldias on

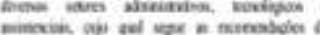

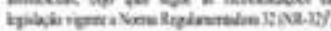

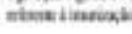

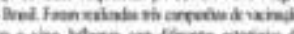

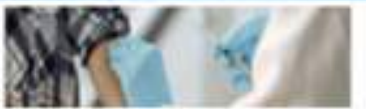

ascurabex r texcustio

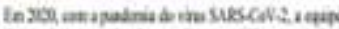

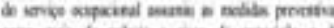

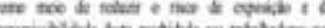

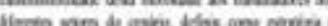

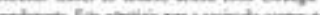

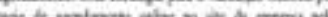

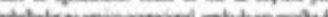

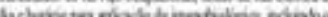

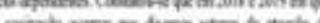

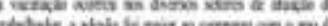

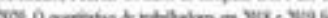
ion

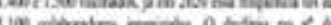

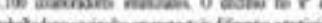

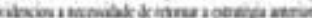
(1)

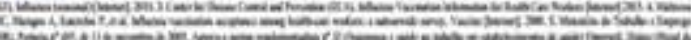

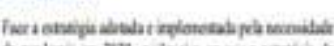

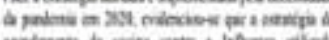

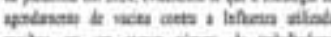

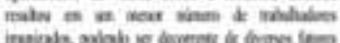

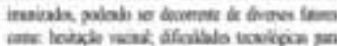

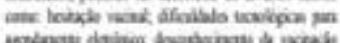

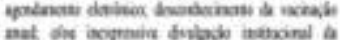

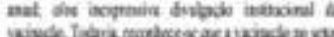

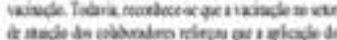

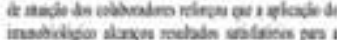

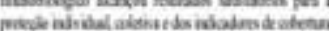

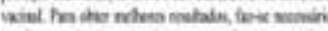

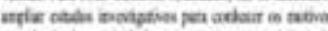

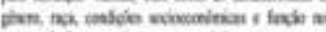

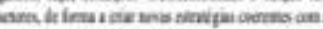

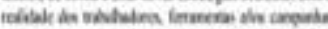

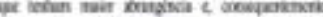

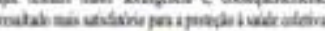
Eakndpa miren

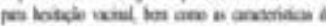




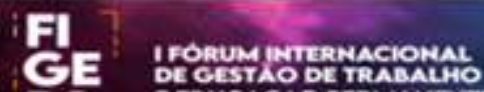 \\ PS, EmSACACAO PERManemite}

\section{MIPACTO E RELEVÂNCLA: INTERFACE NO PROCESSO DE AVALIACÃO DOS PROGRAMAS DE POS-}

GRADUACAO

ALANA CAMILA SCHNEIDER', PATRICLA POLTRONIER1'2, DENISE ANTUNES DE

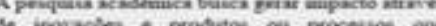

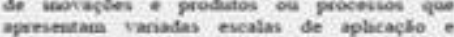

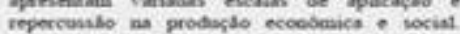
Peute senabo, reconthecendo on Propramas de Pós.

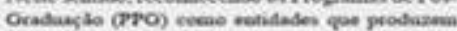

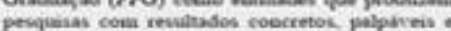

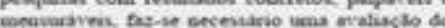
empacto serado pelo produto produnido durater

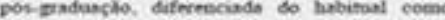
propouto no modele de maliasto da Coondenachà

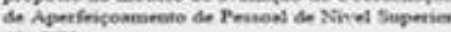
(CAures)

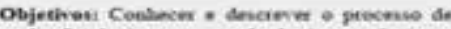

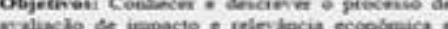
vecial gotse os produsos. procensos at

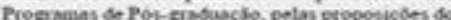
Propes de Trabathe CAPIS
Metodologia: Retaso de repecitaris de uma

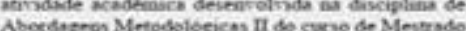
Arocintron Mrtodolegies 11 de curno de Mentrado

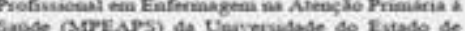

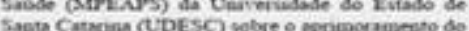

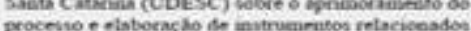

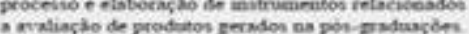

Kevulivdosi Hi atruas poinos selevautes pars veree

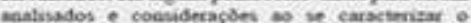

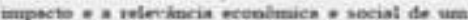

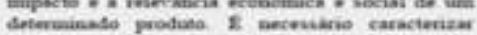
quem vai unufivir de au dade prodico proverieste da pis-eratuarto. - geval a vis percegrto do importincis da stikizacio do menise e guat a

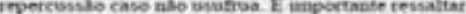

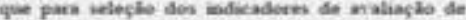

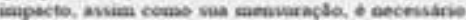
coenuderar o tipo de produno serado, bem como uns

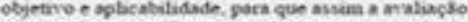

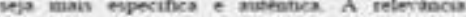

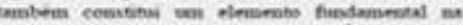
wabisa, seristo n wa importincis $\hat{E}$ muportasie Sentacar que nae prodveo dervinade da pon-eraduaçlo para s solucto de alguens AZAMBUJA ZOCCHE'

griecia dos protiems so vio promorer inupacto

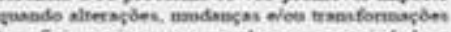

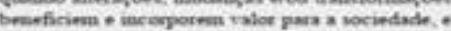

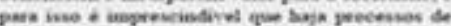
palidacto e suditoria dos dades gerados, risunde

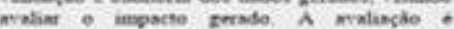

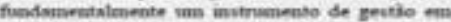

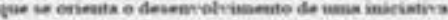

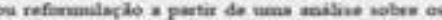

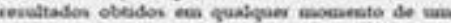

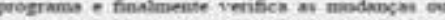

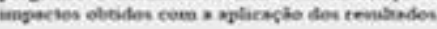

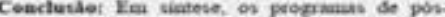

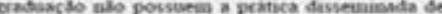

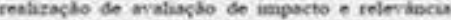

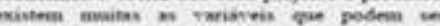

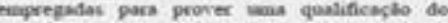

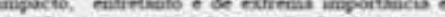

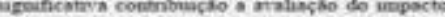

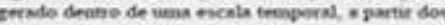

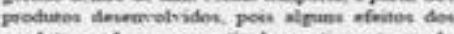
beoeficios apos nento teiapo ds apticabilidade

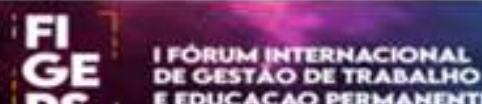 EMsudit

DHPACTO E RELEVÂNCLA: INTERFACE NO PROCESSO DE AVALIACÃO DOS PROGRAMAS DE POSGRADUACÃo

ALANA CAMILA SCHNEIDER', PATRICLA POLTRONIER1'2, DENISE ANTUNES DE

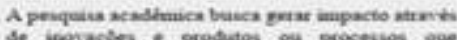

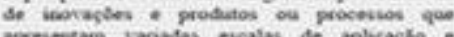

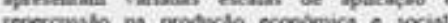

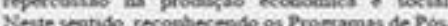

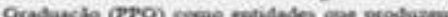

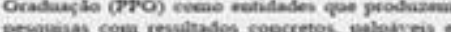

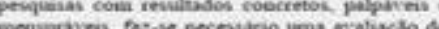

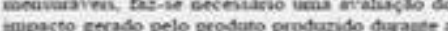

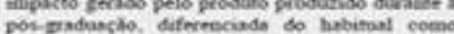

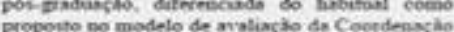
propeuto no modelo de malias ko da Coet densia (CANes)

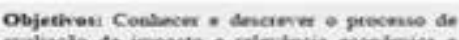

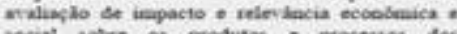

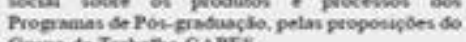
Cropo de Trabathe CAIPES
Metodologia: Rotaso de roperituris de uma atividade academica desenrotrida na disciphina de Aberduenos Mrtodologiens II de curno de Meutrade

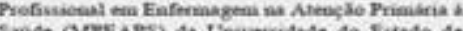

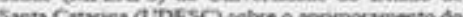

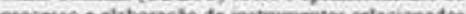

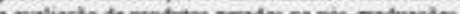

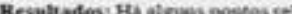

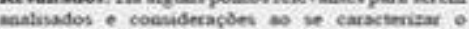

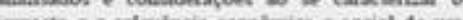

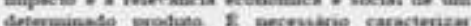

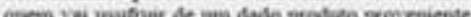

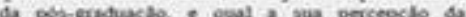
da pos gratuzaso, a gal a sia percepis da

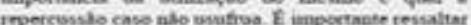

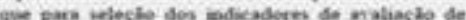

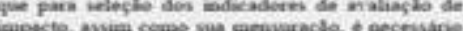
coenderar o tipo de produno serabo, bem coms ves

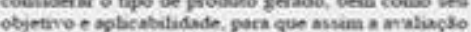

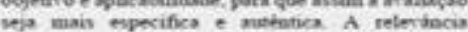

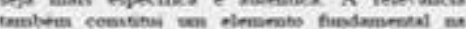

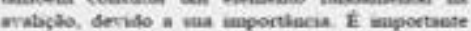
dentacar que nae prodice denvide da pen-eraduacto para s solucso de alpums AZAMBUJA ZOCCHE

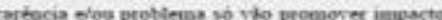

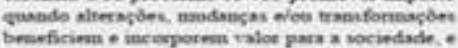

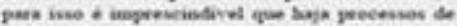
alidaço e miditoria dos dados gerados, rismode

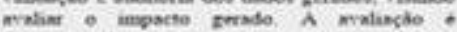

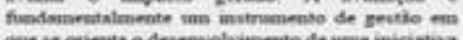

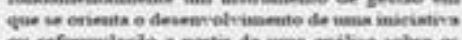

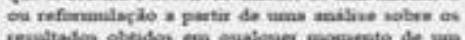

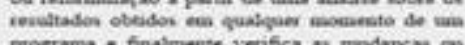

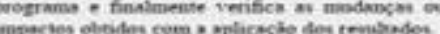

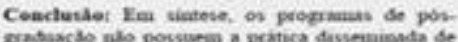

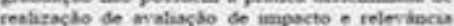

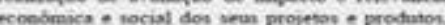

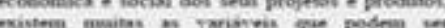
encregudas pass prover mana qualificacto de

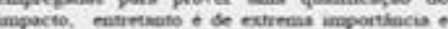

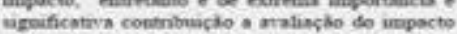

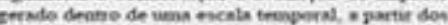

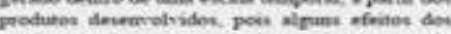

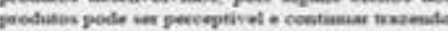

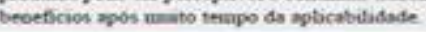




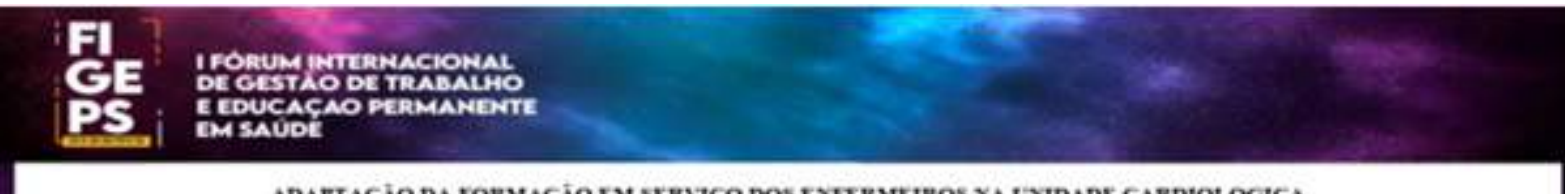

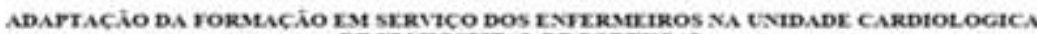

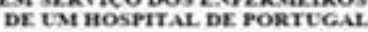

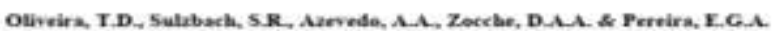

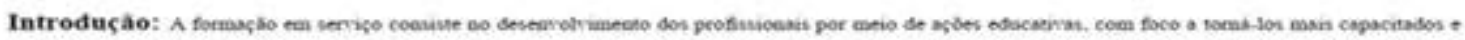

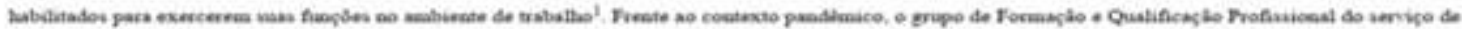

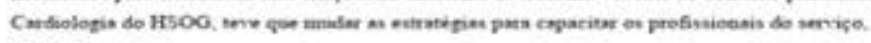

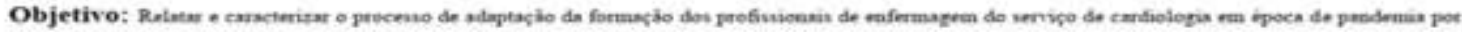

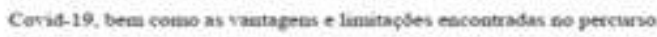

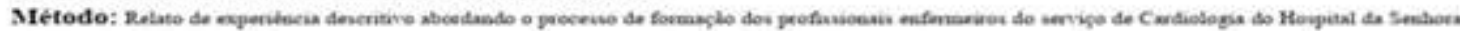

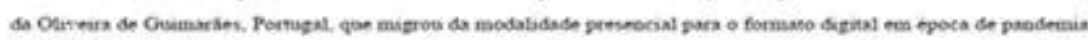

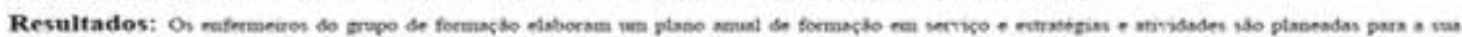

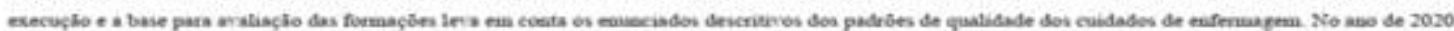

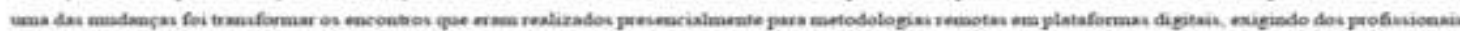

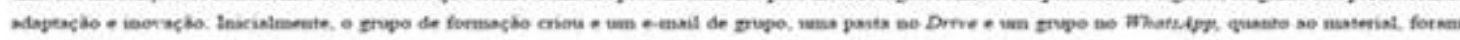

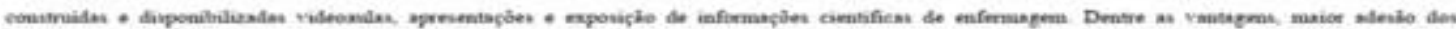

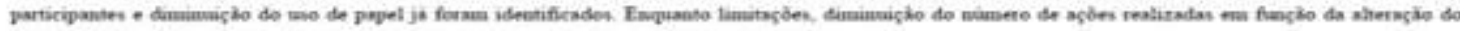

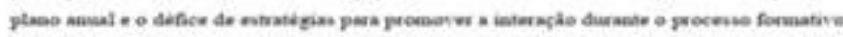

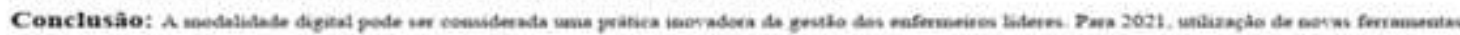

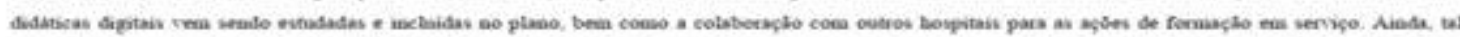

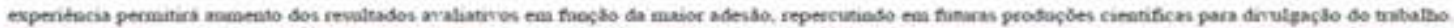

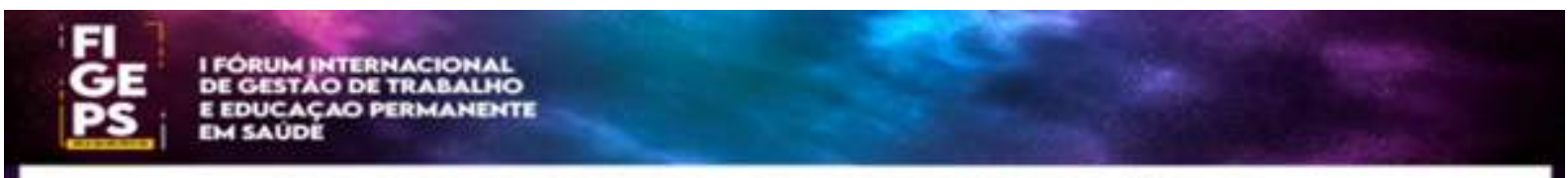

APLICACÃO DA METODOLOGL ON THE JOB COMO ESTRATEGL DE

EDUCACÁO PERNLANENTE NO CONTEXTO HOSPITALAR

LUCAS CORMÉA PREIS', OUU LANA COSENTINO FREITAS SANTOS', MQUELINE CAETANO'

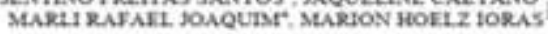

Objetivo: Relatar a experiència de uma instituiçio hospitalar de grande porte com a utilizaço da metodologia on the job para a capacitaçâ de profissionais de enfermagem.

Mretodo: Estudo do tipo relato de experiência visando apresentar estratégias de capacitaçăo da equipe de enfermagem de um hospital de grande porte localizado no sul do Estado de Santa Catarina com utilizaclo da metodologia on the job.

Resuitados: A complexidade do trabaltho em saúde em ambiente hospitalar aponta para a definiçăo de estratégias mais efetivas de manutenço constante de um programa de atualizaço da equipe de enfermagem. A metodologia on the job mostra-se eficiente, haja vista que ela acontece diretamente no local de trabalho de cada profissional. Na instituiçlo, estes treinamentos sało realizados pelos profissionais atuantes no serviço de educaçăo continuada e possuem duraçăo média de 30 minutos. A equipe de enfermagem é reunida em um espaço anplo e em circulo e iniciam-se as discussठ̋s acerca do tema do treinamento. Após as discussóes teóricas do conteúdo, sempre se disponibiliza um espaço para troca de ideias e realizaçio de questionamentos acerca dos temas apresentados Materiais utilizados: cartazes, flyers institucionais, fipp chart, entre outras

Conclusào: A enfermagem é uma profissalo com papel primordial no atendimeato ao paciente e possuir babilidades e capacidade ampla de conhecimentos, exige dedicaça e atualizaçało constante. Estabelecer estratégias como a metodologia on the job para a atualizaçâo dos profissionais de enfermagem mostra-se positivamente frente aos desafios enfrentados diariamente durante as atividades laborais. 


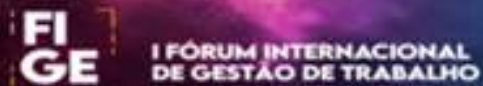 \\ PS, Em EAUADE}

EDUCAÇC̄O PERMLANENTE ON LINE NA REDE A ATENCÃO A SAÚdE DO

MUNICIPIO DE CHIPECO: RELATO DE EXPERIENCL

INTrODUCAC

A Rede de Atencilo s Smide (RAS) do mumicipie de Chapecó recele tam nimiero

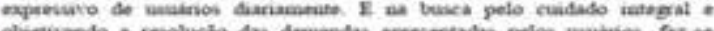

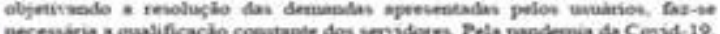

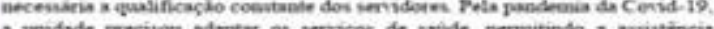

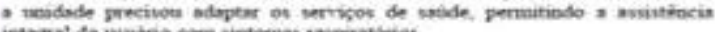

\section{MIITODOLOGL}

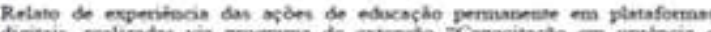
camerplecia nat

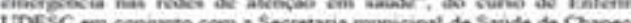

\section{orstz. TADOS z DISCESsio}

Fechm malizadas 36 encentros oe liar cem ms semalticas

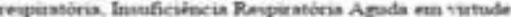

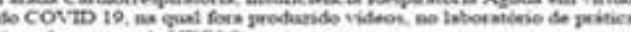
de enferma pria da UDESC.

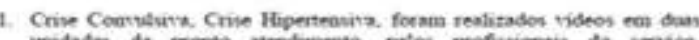

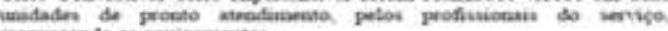

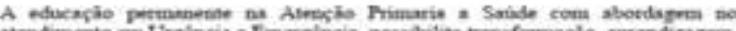

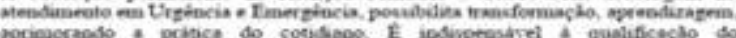

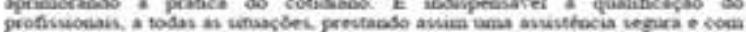
quaslitade

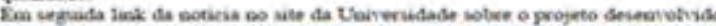

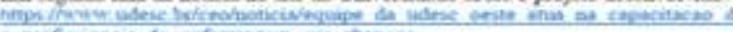

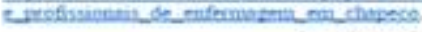

\section{covcrusio}

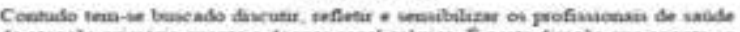

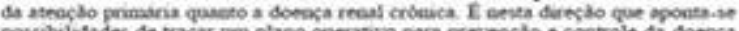

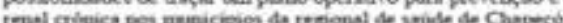

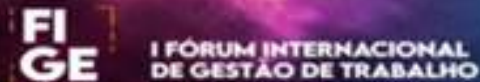 PS i ERUCACAO PERMANENTE}

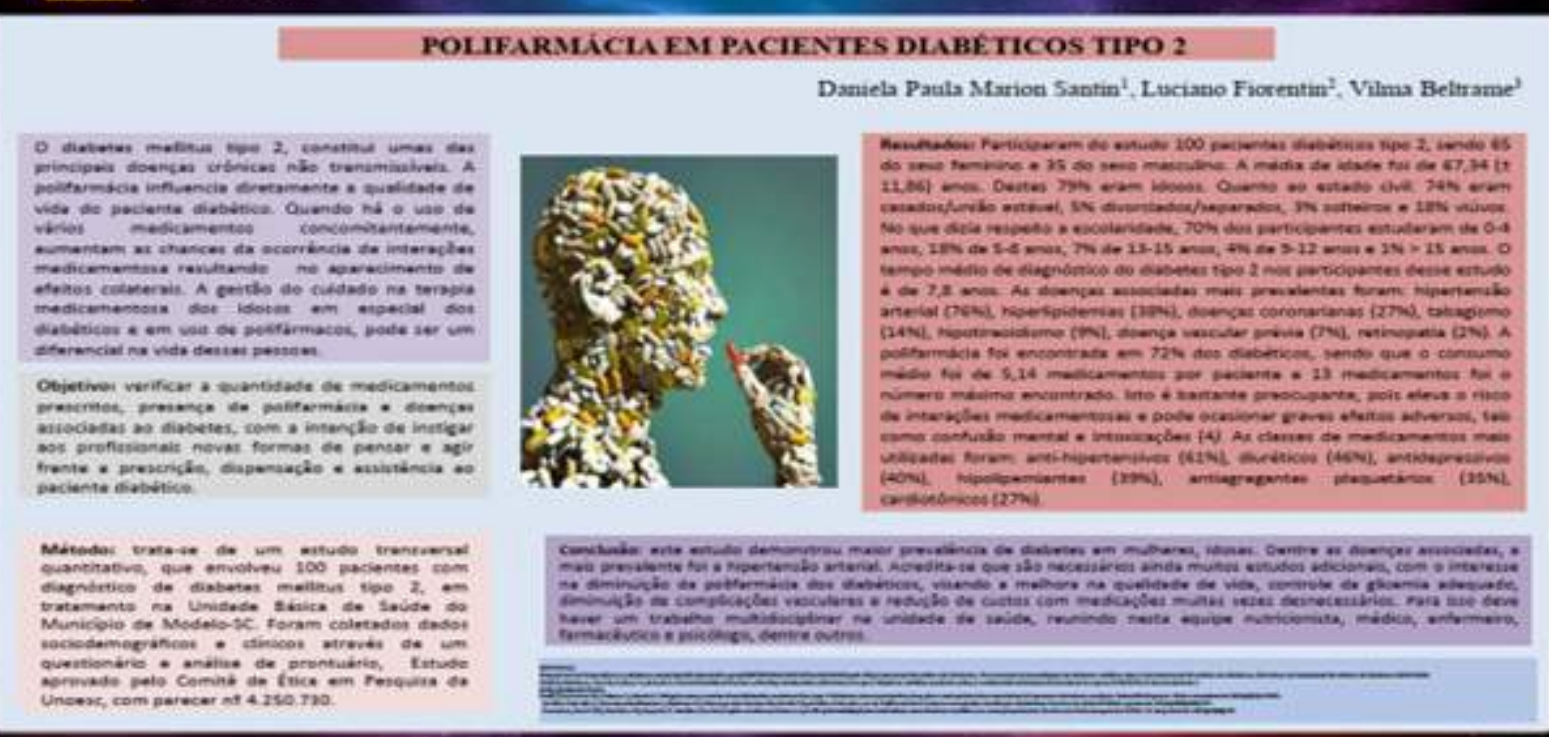




\title{
'FE? Lopumpreamacionat

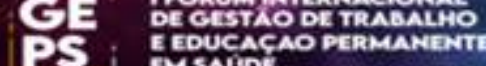 EMsiude
}

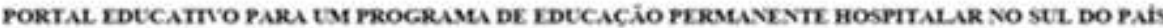

\author{
Cicoset RM, Fontana EJ, Zocche D,M Micherieti VCD.
}

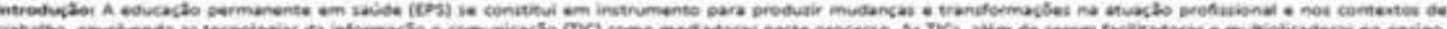

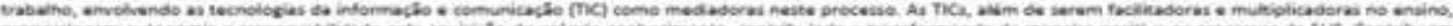

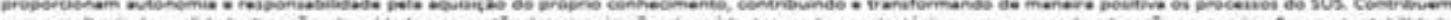
mar.

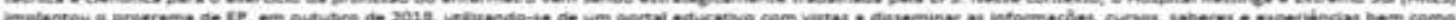

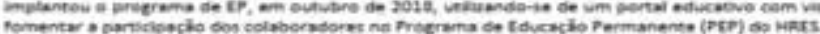

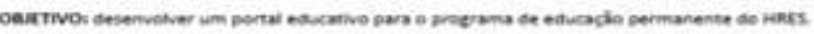

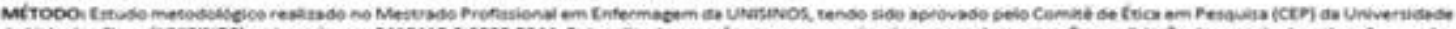

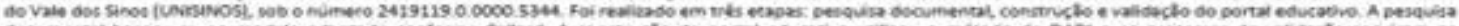

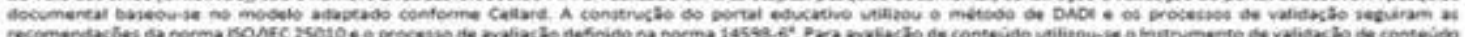

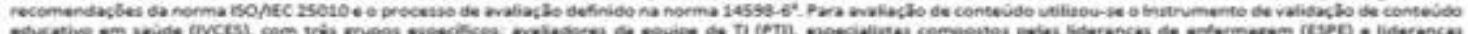

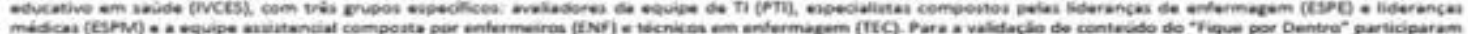

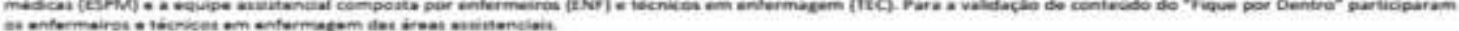

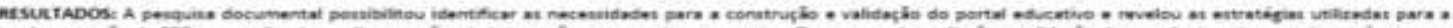

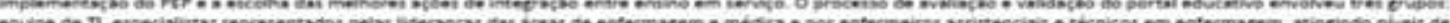

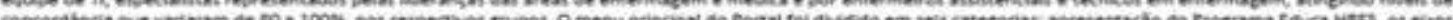

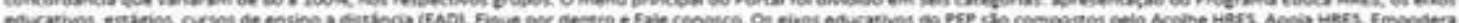

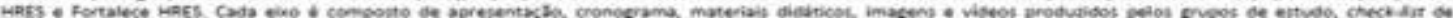

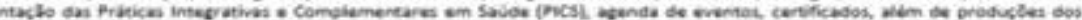

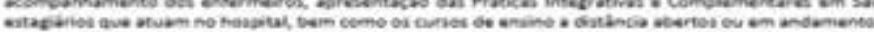

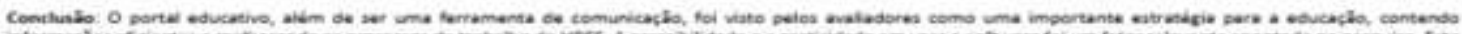

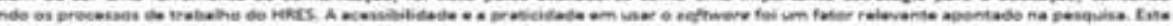

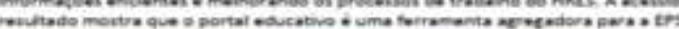

\section{[1]

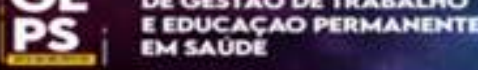

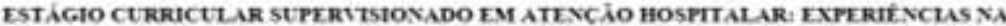
PANDEMALCOND

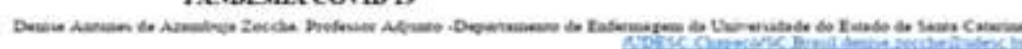

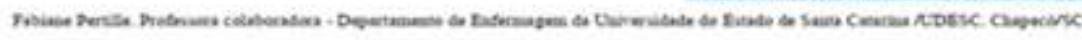

Introducia:

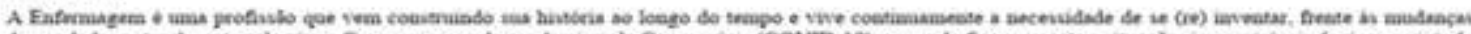

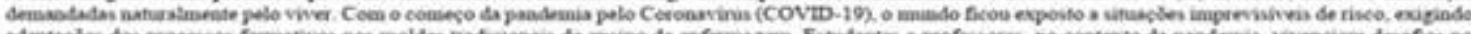

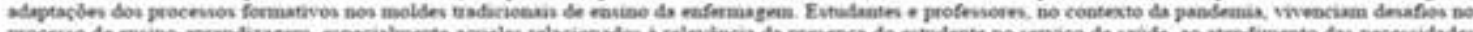

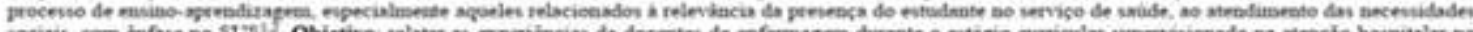

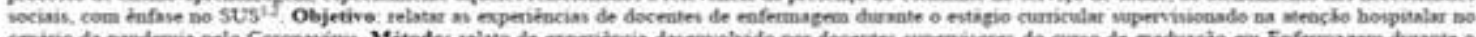

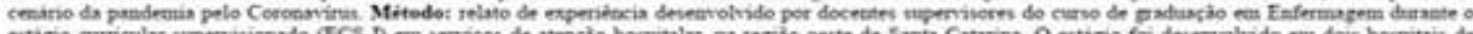

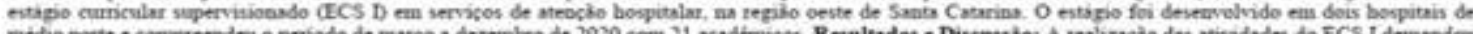

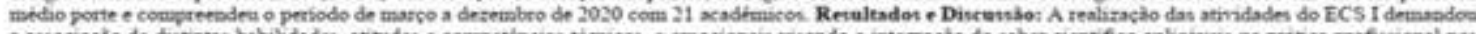

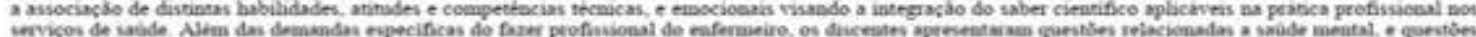

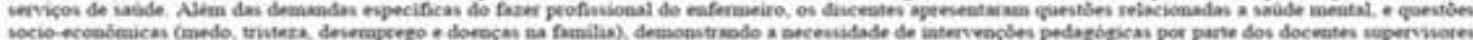

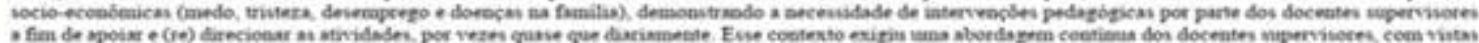

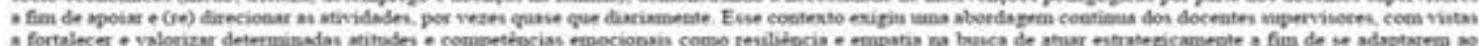

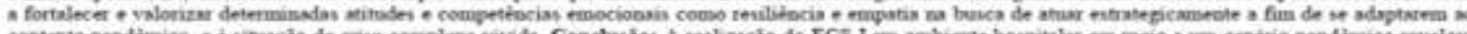

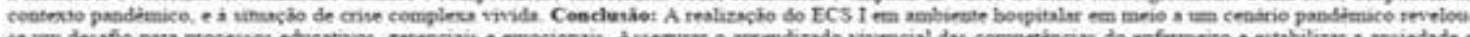

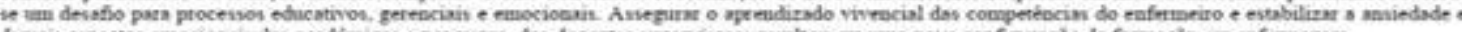

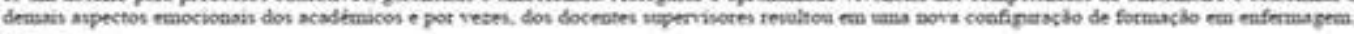
Roferinecian

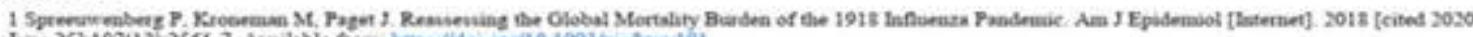

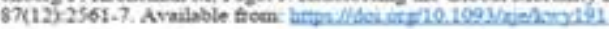

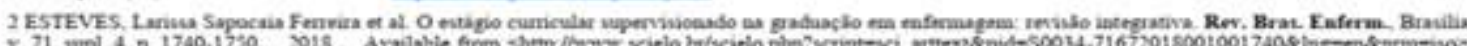

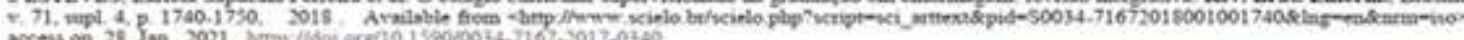

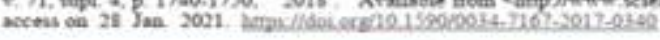




\section{GERENCLANDO O CUIDADOE A SEGURANCA DO PACTENTE COMO} SAFETY HUDDLE

LUCAS CORREA PREIS', OTUULANA COSENTINO TRETAS SANTOS? IAQUEUNE CAETANO

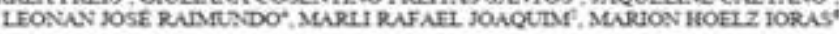

Objetivo: Relatas a experiência de um hospital de grande porte com a implementaçầ da metodologia Safety Huddle.

Método: Estudo do tipo relato de experiéncia, abordando a utilizaçà da metodologia Safety Huddle em um hospital de grande porte localizado no sul do Fistado de Santa Catarina

Resultados: $O$ Safety Huddle na instituiçăo baseia-se em quatro principios: melhorar a gestho do cuadado, potencializas a segurança do paciente. maximizar a qualidade do cuidado e qualifieas as estratégias de cornumicaçầo. Acontece diariamente sempre às $0 \$ \mathrm{~h} 15 \mathrm{~min}$ da manhă, em um auditório amplo, em formato de circulo, de pé e com duraçăo de 15 minutos, comparecendo em média 20 profissionais de diferentes àreas da instituiçào

Conclusào: Com a proposta de ser uma reuniào rápida e resolutiva, a metodologia permute que a equipe seja rápida no desenvolvimento de planos de remediaça de problemas, dinos ou riscos para pacientes, familiares e trabalhadores. Permite que os lideres tomem decisdes baseando-se em experiencias qualitativas e assertivas anteriores, de forma participativa e descentralizada.

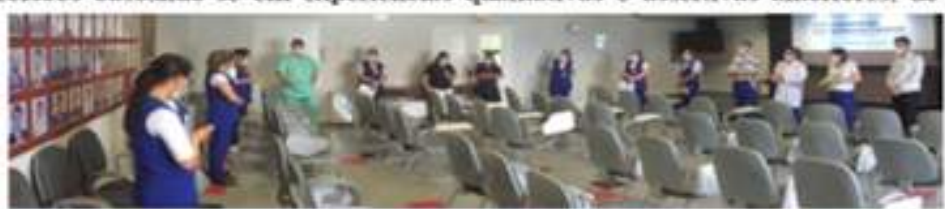

\begin{tabular}{|c|c|}
\hline \multirow{2}{*}{\multicolumn{2}{|c|}{ 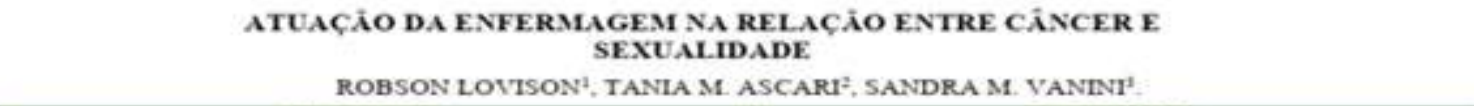 }} \\
\hline & \\
\hline 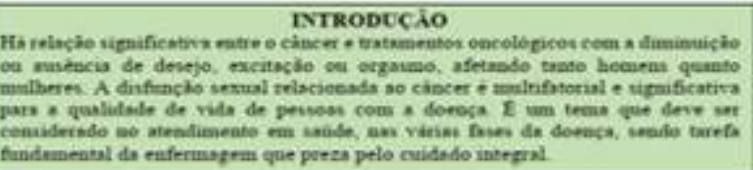 & 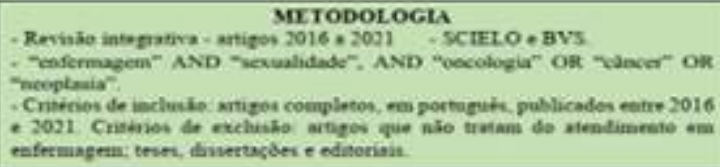 \\
\hline \multicolumn{2}{|c|}{ 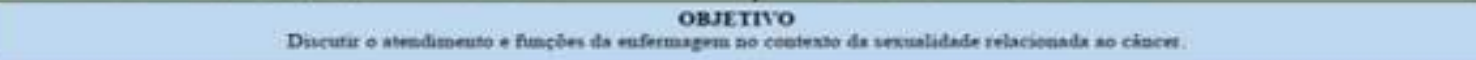 } \\
\hline 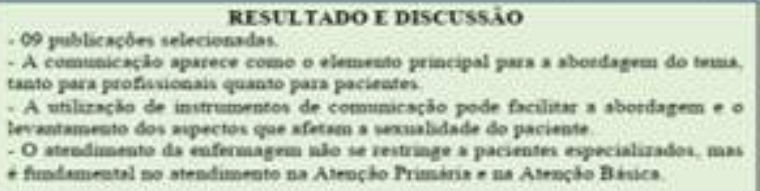 & 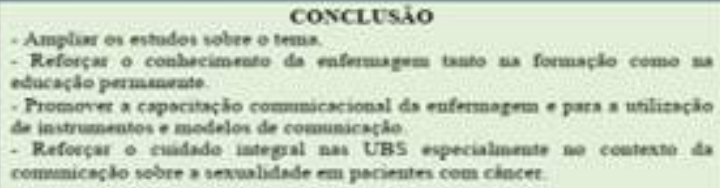 \\
\hline \multicolumn{2}{|c|}{ 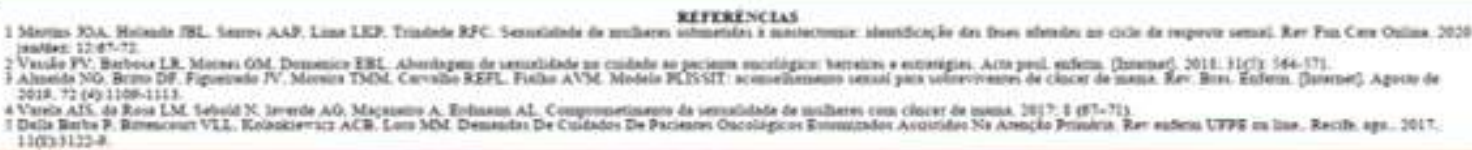 } \\
\hline
\end{tabular}




\section{A TEORIA DE PAULO FREIRE E SUAS INTERFACES COM A PROFESSORALIDADE: UMA REFLEXAO} TEORICO-EPISTEMOLOGICA

BLANCA JOANA MATTA, CARLA BOSANE PAZ ARRUDA THO

INTRODUCÃO: A profissito docente pode ser considerada um proeesso que vai se construindo ao longo da trajetória formativa dos sujeitos. Formaça e deseuvolvimento profissional se complementam em um processo no qual a profestoralidade vai se construindo

OBJETTVO: refletir teorienmente sobre as contribaiçôes do pensamento de Hegel, enquanto epistemologia da teoria de Paulo Freire, para a professoralidade na area da saude.

METODOt este ensaio eonsiste em uma reflexlo teóriea originada do eurso de dontorado do Programa de Pósgraduaçào em Cièncias da Saude, da Universidade Comunitária da Regiào de Chapecó - Unochapeé.

\section{HEGEL.}

SENHOR X ESCRAVO Relą̧a dialetie:

\section{RESULTADOS E DISCUSSAO:}

PAULO FREIRE

OPRESSOR X OPRIMIDO

Relaçito dialetic:
PROFESSORAIIDADE

DOCENTE $X$ DISCENTE Relaçso dialetiea

CONCLUSíOt a principal contribuiçào do pensamento de Hegel, na teoria de Paulo Freire para a professoralidade na frea da sabde e a dialética da atividade doeente. Nense processo, educador e edueando encontram-se, transformam-se, $e$ eressern juntos, por meio da dialétiea, sendo ambos sujeitos do prosesso ensino-aprendizagem e saem transformados.

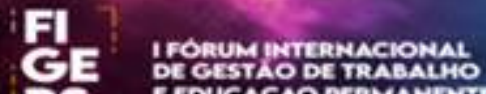 EM SAUDC

ELABORACÃO DE UMA TECNOLOGIA EDUCACIONAL PELA

ENFERMAGEM: SERIOUS GAME SOBRE CIRURGIA SEGURA

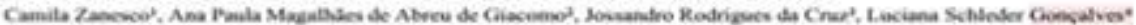

Pesquisa original Prática/produtes inevaderes na attençàs à saùde

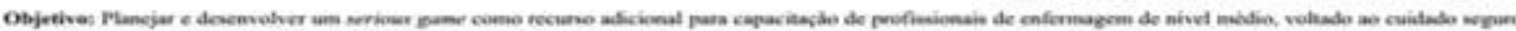

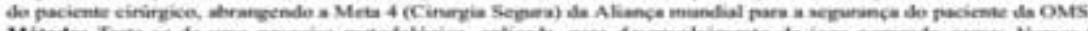

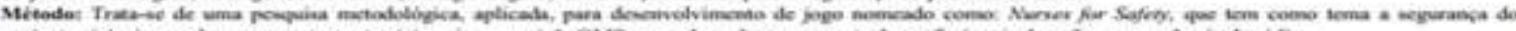

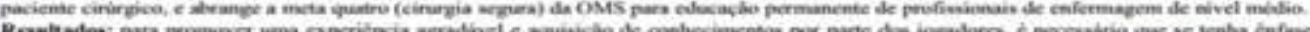

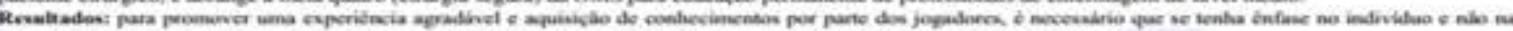

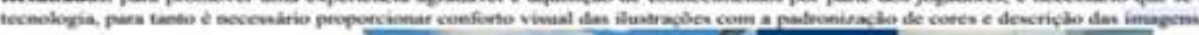
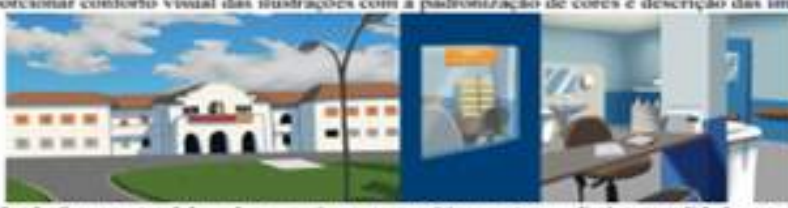

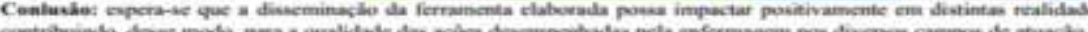

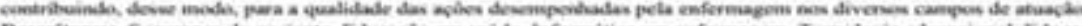

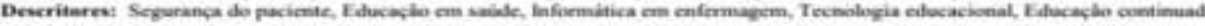

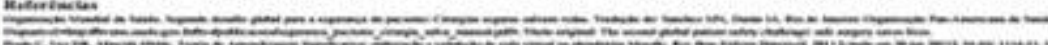

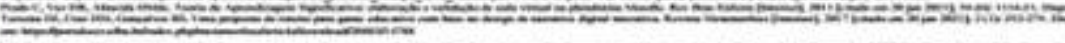

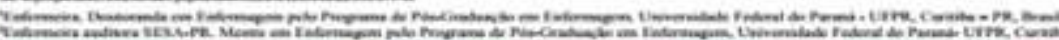




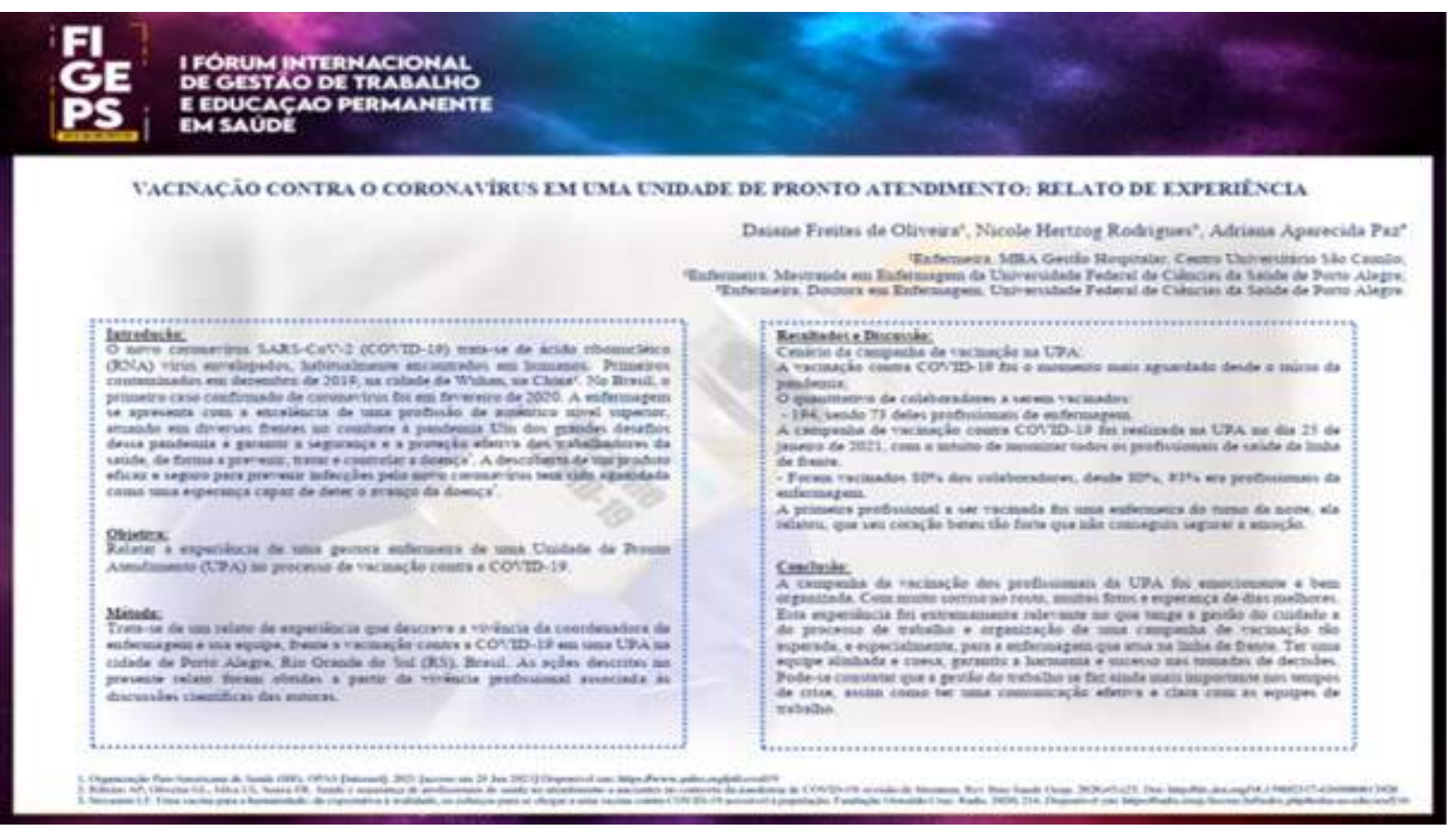

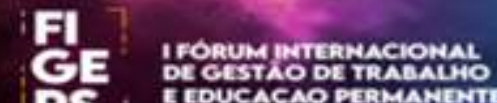 PS i troucacion}

\section{ORGANIZACÃO DA GESTẢO DO TRABALHO NA ESTRATĖGLA SAÚDE DA FAMILLA}

DANIELA SAVI GEREMHA? MENNIFER SOUZA DE OLTVERA?

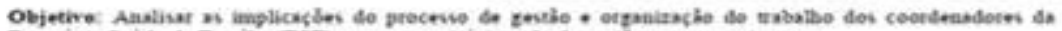

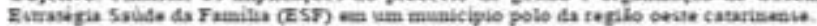

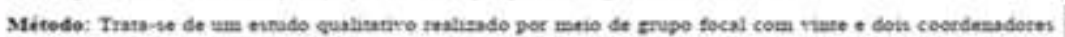

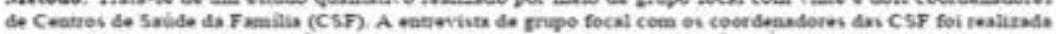

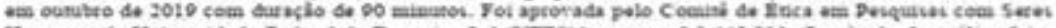

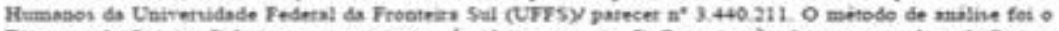

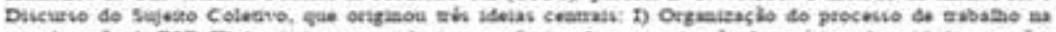

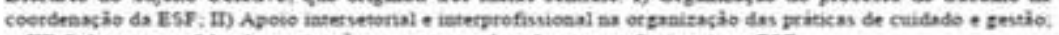

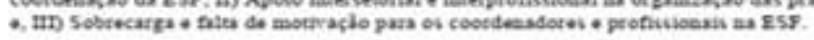

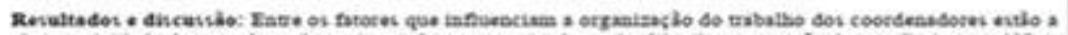

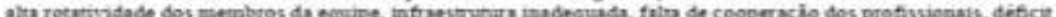

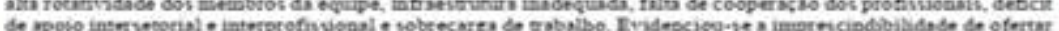

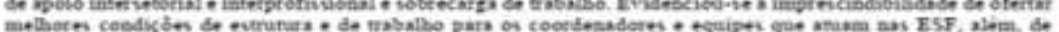

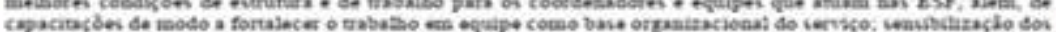

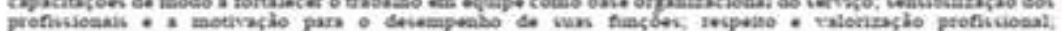

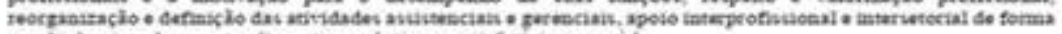

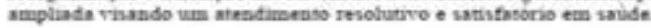

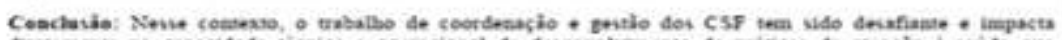

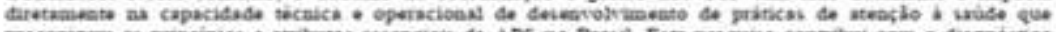

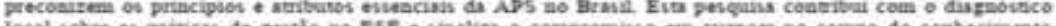

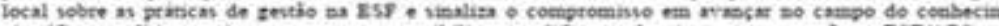

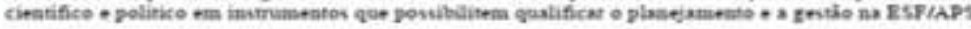

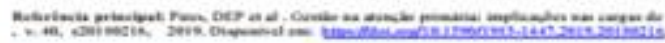

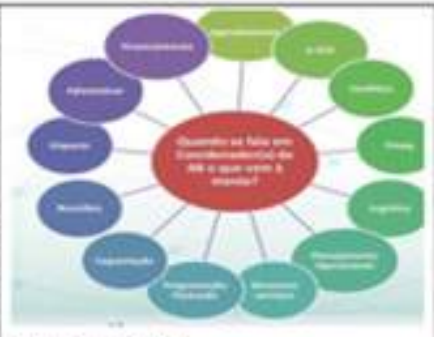

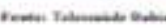

Tisanciamente.

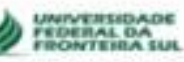




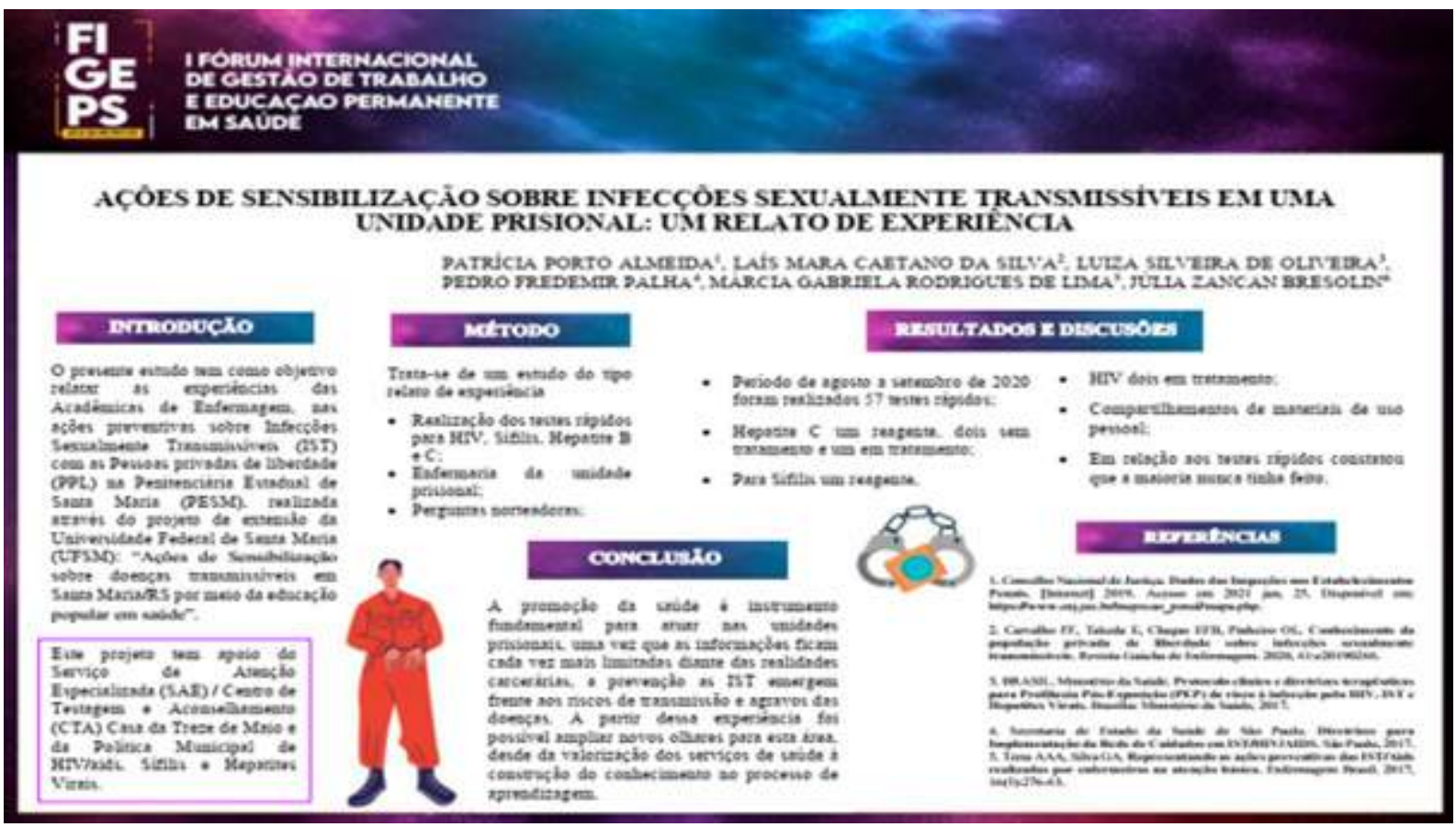

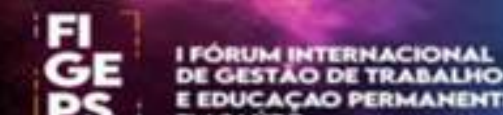 \\ PS, Emsaced}

RELATO DE EXPERIÊNCLA: RODA DE CONVERSA EM UMLA UNIDADE PRISIONAL DURANTE A CAMPANHA NOVEMBRO AZUL

\section{Drmobucko}

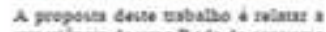

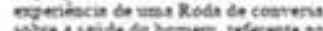

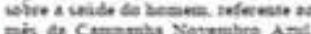

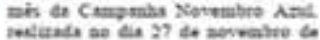

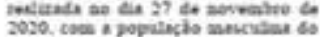

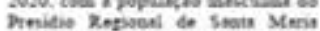

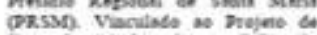

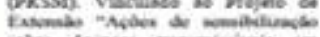
ielec demsen trasumivisteis of

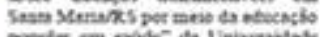

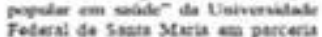

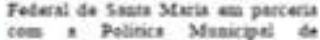

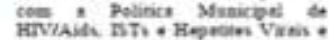
Service de Aneclo Evecinarade (SAF) I Ceans is Trustom. Cembir

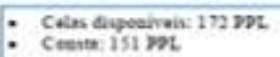

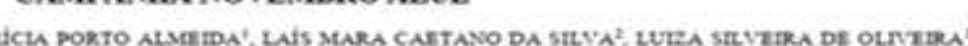

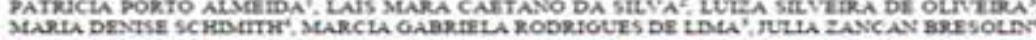

\section{Mitrodo}

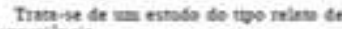

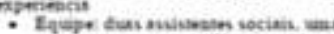

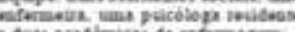

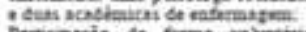

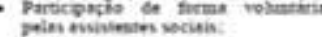
Than noontadoc Ciack to ist:

int

20 particiganses wowados en dais

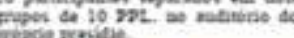

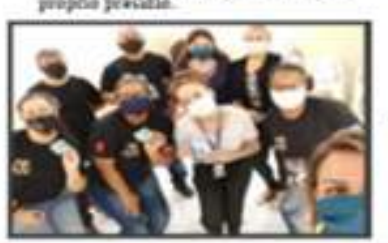

\section{WESULTADOS $x$ DISCUSOES}

- O primeno mpo moveoset

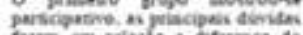

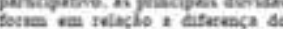

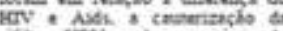

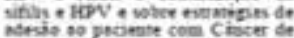
Divian.

- O ugindo gripe intengiv maser

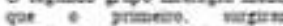

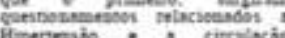

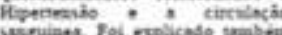

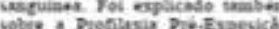

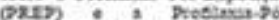

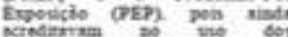
crintiring of who sol inv

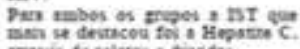

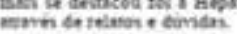

\section{Concrusto}

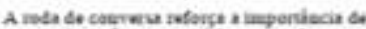

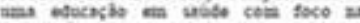
prenterio ot doesch an midadei pritionatic os evisas of os relatod

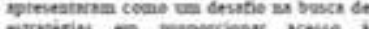

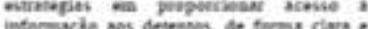

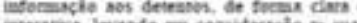

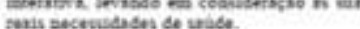

\section{meratocus}

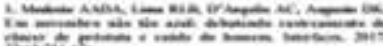
Atrith

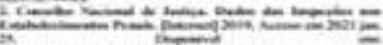

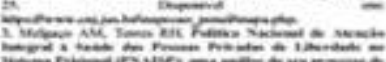
-

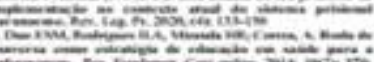



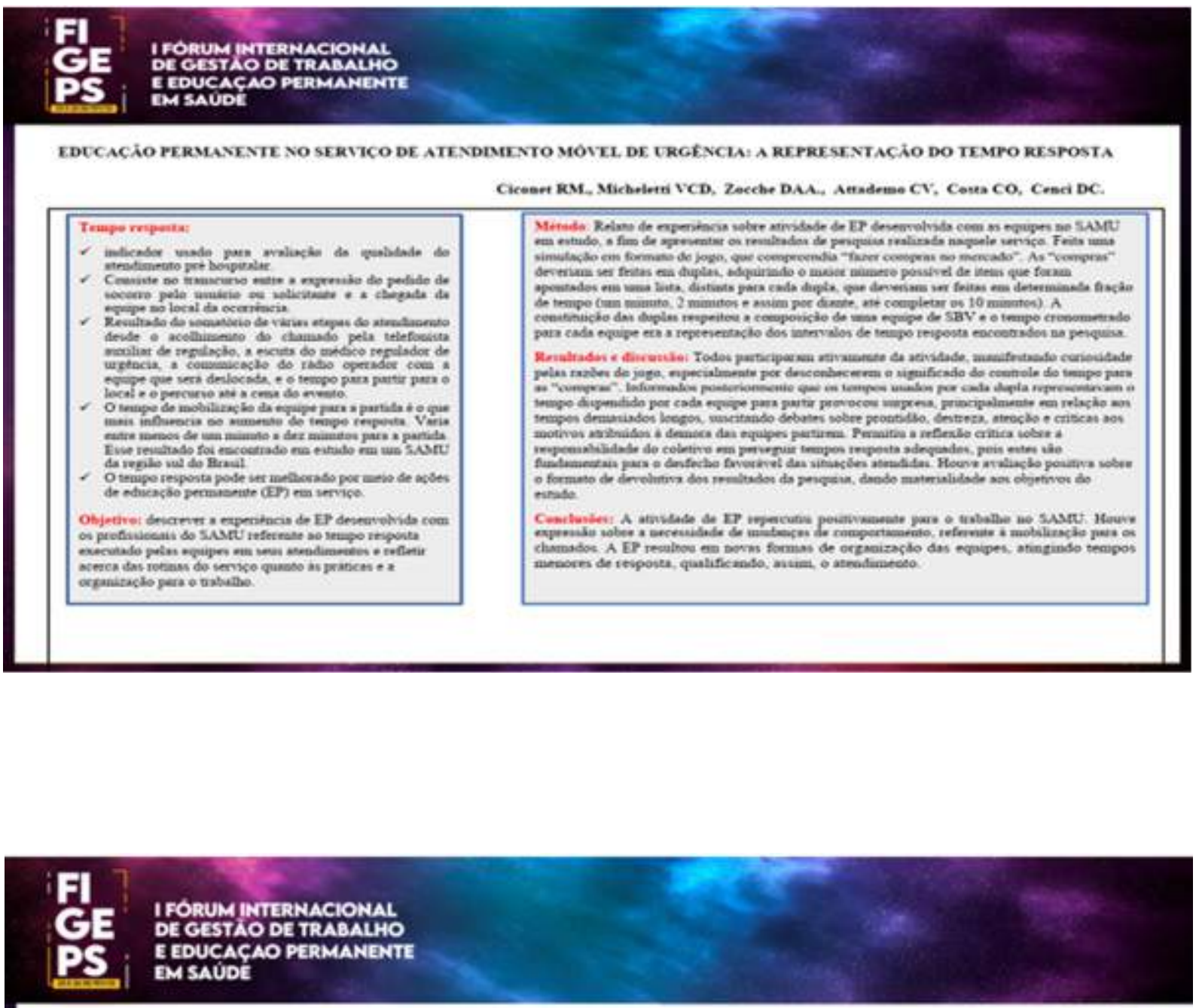

O ENTERMEIRO PRETENINDO ACIDEYTES DE TRABALHO EM TFMPOS DE PANDEMA: RELATO DE EXPERIEXCLA

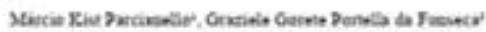

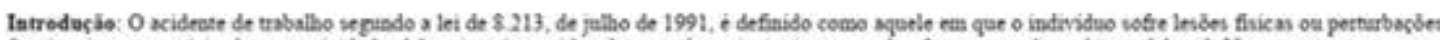

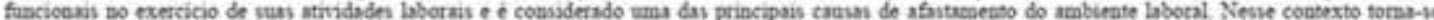

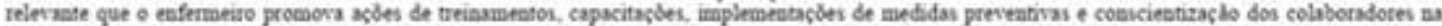

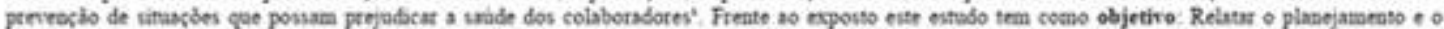

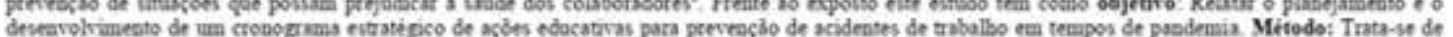

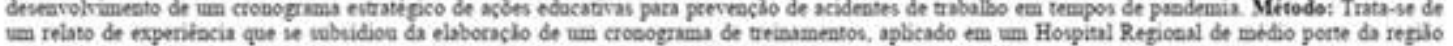

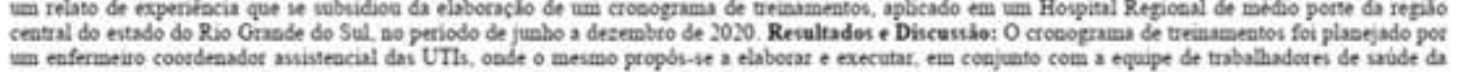

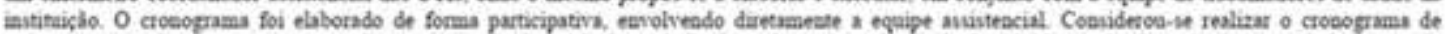

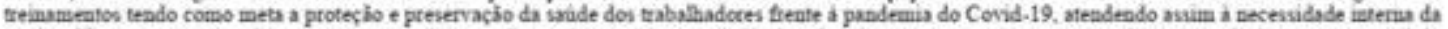

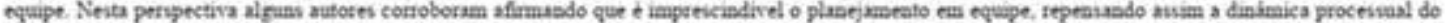

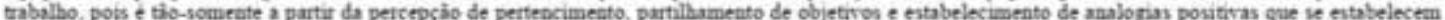

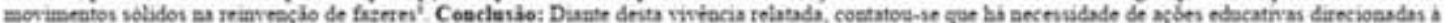

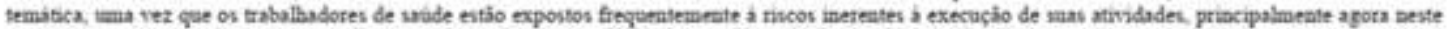

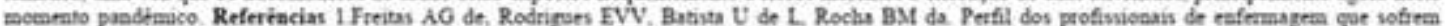

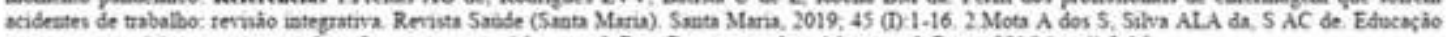

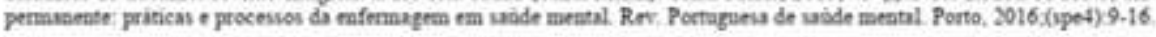

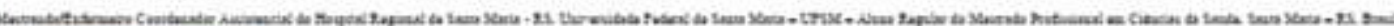

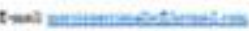

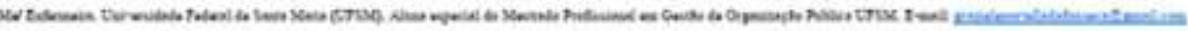




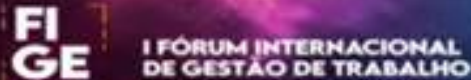 PS, ERUCACAO PERMANENTI}

\section{MOMENTOS DE EDUCACC̄̃ PERMANENTE EM SAÚDE PARA UM PROJETO DE INTERVENÇẢO: UM RELATO DE EXPERIENCIA}

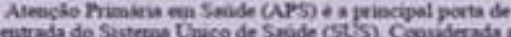

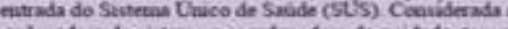
erdmadora do aistmis r cocrdenaber do cuibado, lew

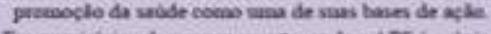

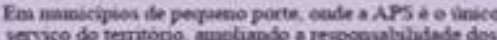

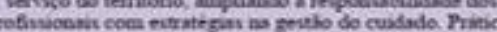
de Ethocaclo Penanente mu sabile (EPS) pode ser o

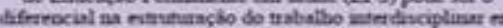

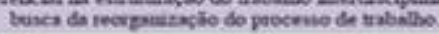

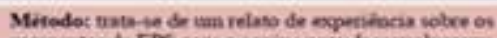
momputvi de EPS com a everpe para deinovolver um

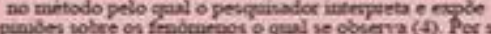

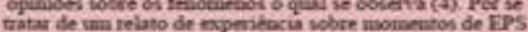
pars o deicavolvimento de um grojeto de intrivexclo, sto bouve aecevidade de elb coracio de terumo de

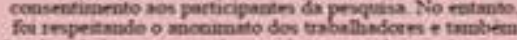

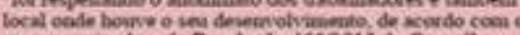

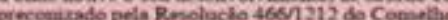

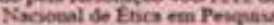

Luciano Frotentin', Karina Schopte, Carine Vendruscolo', Vima Beltrame *

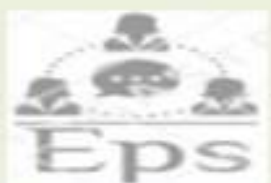

Objetivare objetwo desie inlate de

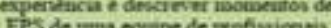
IPS do uma equipe de jretiviecasis de APS, jara elabors una plaso de
Reishader.

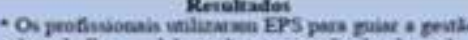
do rabulbo na elaboracko e excecuclo do plino de - A base de purtila para memantos de EPS se dea 2

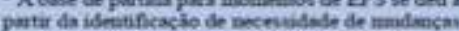

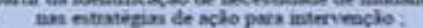

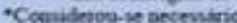

1 - reevtruturaclo en coosoldeclo de npaçon.

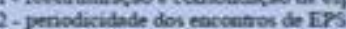
cenipoutos por nouipes mailtiptótuionast esem

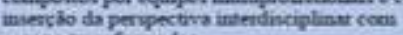
evegpe trwatominder.

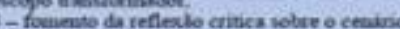
que pencisat ue troblecrado

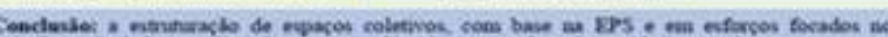

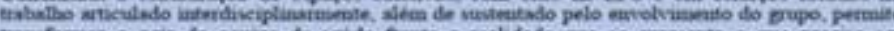

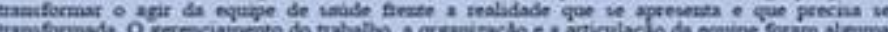

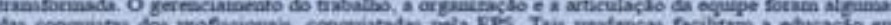
(a)

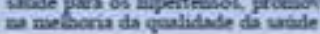

\section{'E] ifonmpirenacionat PSi EMSAUDE}

\section{CARUCTERIZACIOO DA ATEXCEOO DOMICILAR NO ATENDIMENTO AS CRUNCAS CON NECESSIDADES}

ESPECLIS EM SANTA CATARINA

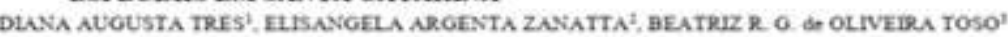

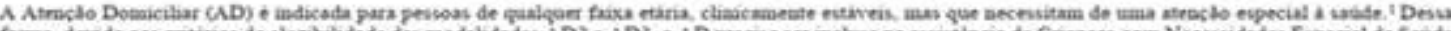

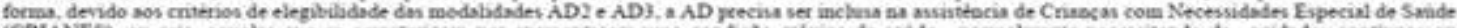

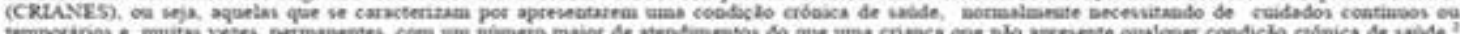

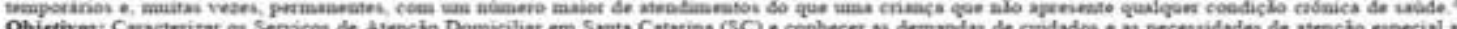

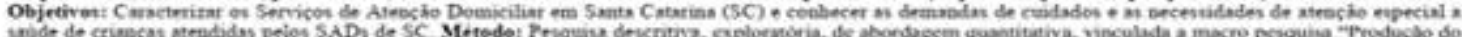

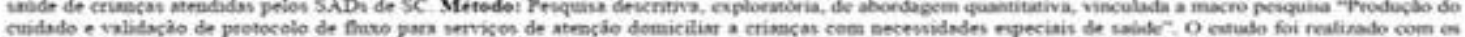

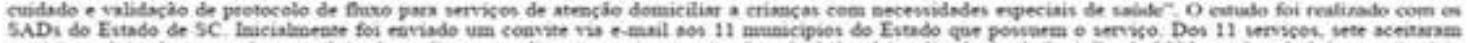

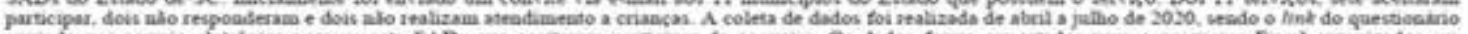

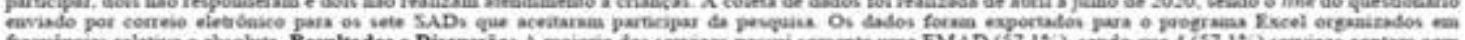

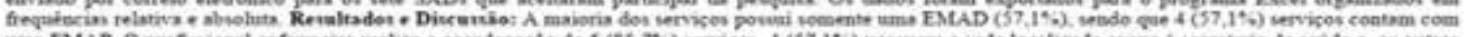

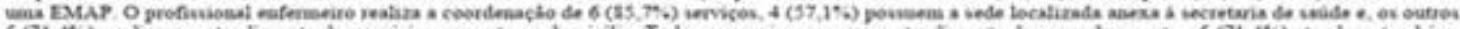

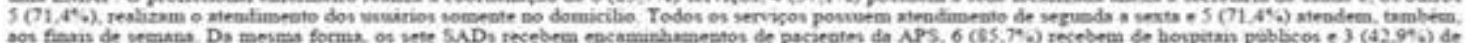

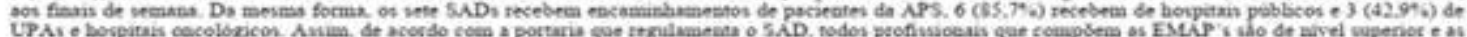

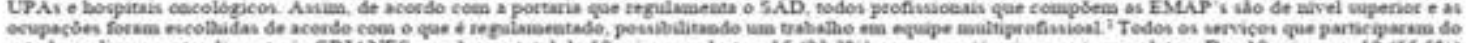

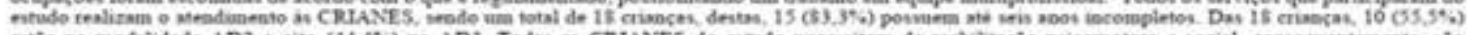

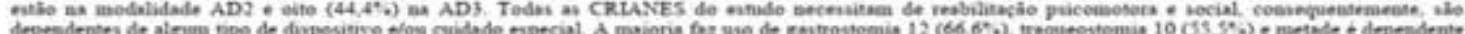

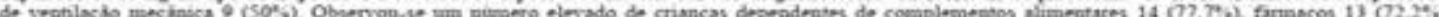

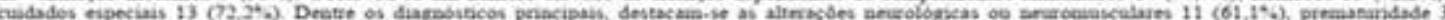
$16.6 \%$. maif

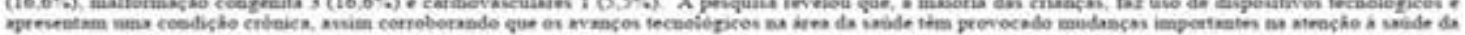

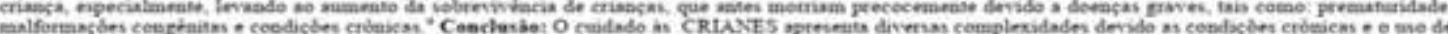

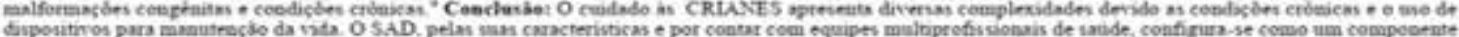

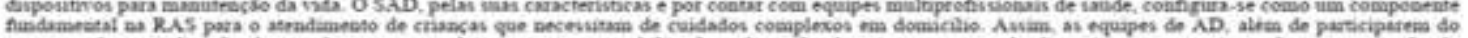

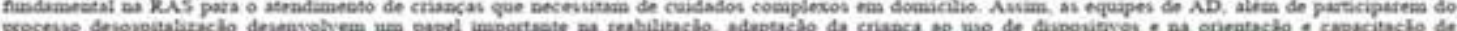

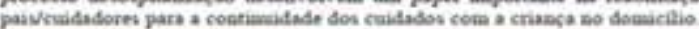




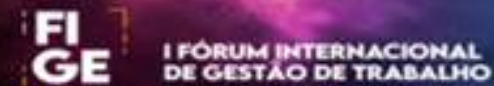 \\ PS. ERUCACAO PERMANEMTE \\ EMSAUDE}

PROCEDIIENTO OPERACIONAL PADRAO (POF): Relato de Experiencia de Qualificaçion na Rede de Atençào ì Sande

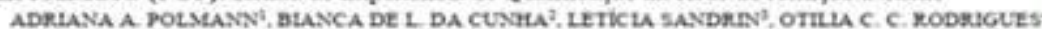

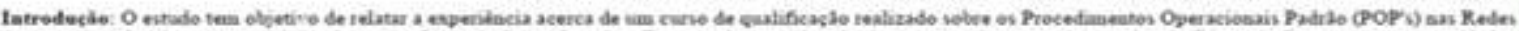

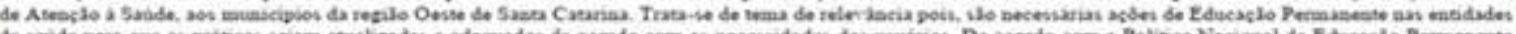
(B)

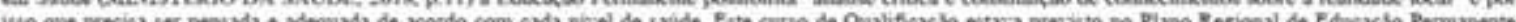

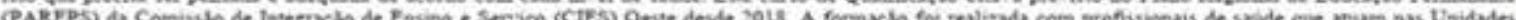

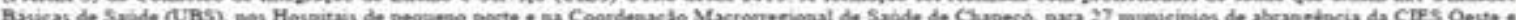

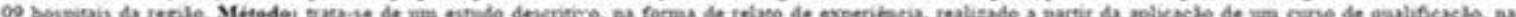

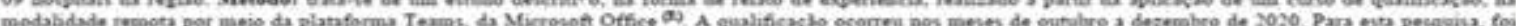

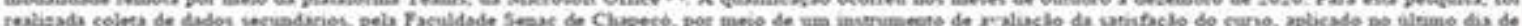

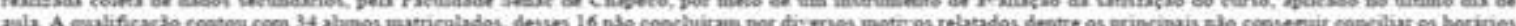

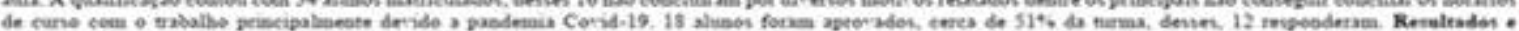

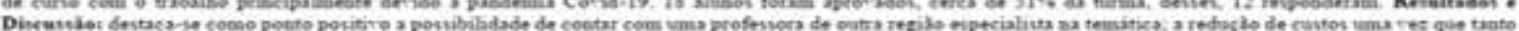

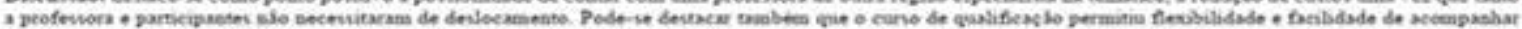

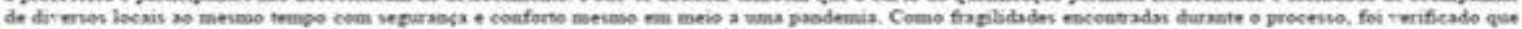

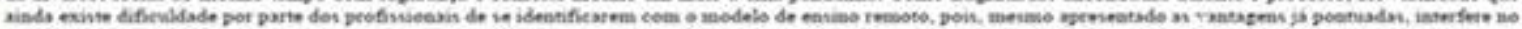

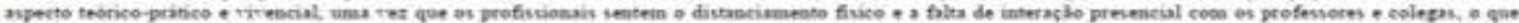

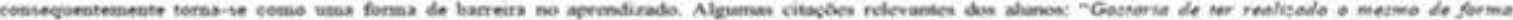

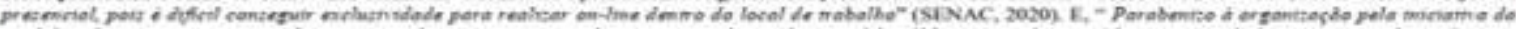

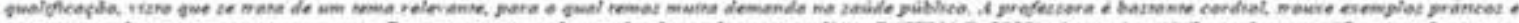

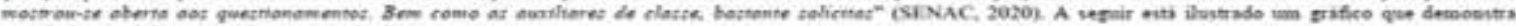

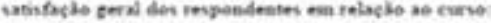

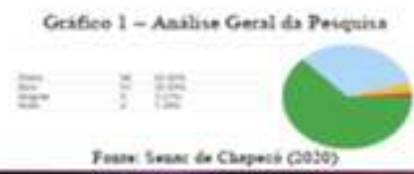

\section{[1] PS} DESENVOLVTMENTO DE DISPOSTTYO DE COMUNICACĀO AUMENTATTVA, PRODUZIDO A BAIXO CUSTO, PARA PACTENTES COM DISFUNCOES MOTORAS

\section{INTRODUCĀO}

A tecnologia assistiva em Comunicaçä Aumentativa Alternativa (CAA) \& voltada par solucionar ou ampliar qualquer perda de habilidade comunicativa, a fim de proporcionar uma comunicaç̃o eficaz. promover a participaşlo social e a methora da qualidade de vida. Casos de pacientes hospitalizados mostram que ate $38 \%$ das crianças em tratamento hospitalar apresentaram alguma dificuldade em comunicar (Moraes, 2019).

\section{OBJETTVO}

Desenvolver dispositivo portátil de comunicaç̧o alternativa para pacientes com capacidade cognitiva reduzida, supressło de fala e perda de movimentos de membros superiores.

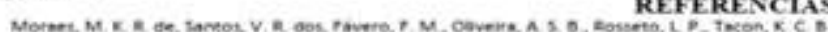

METODO
CONCRICÃO MORAES', SILVA ${ }^{2}$, LETE *

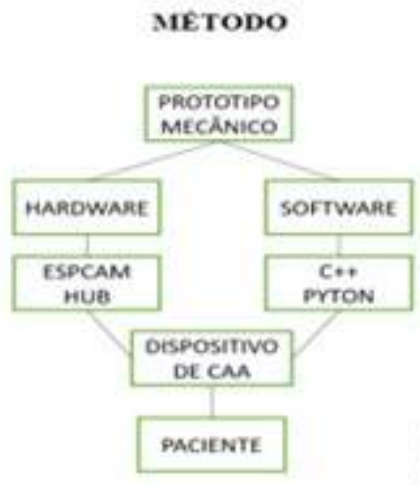

- protótipo inicial fol desenvolvido e configurado inicialmente parar fazer o reconhecimento facial paciente, e posteriormente emitir sinais luminosos em dois LEDS a partir do movimento de abertura e fechamento das palpebras.

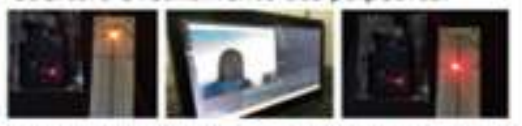

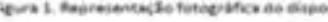

\section{CONCLUSTO}

O dispositivo desenvolvido apresentou proposiçāo de uma estratégia eficaz para viabilizar a 'comunicação alternativa aumentativa" a baixo custo e de fácil aplicabilidade.

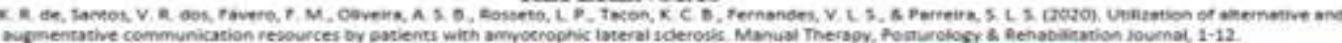

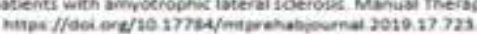




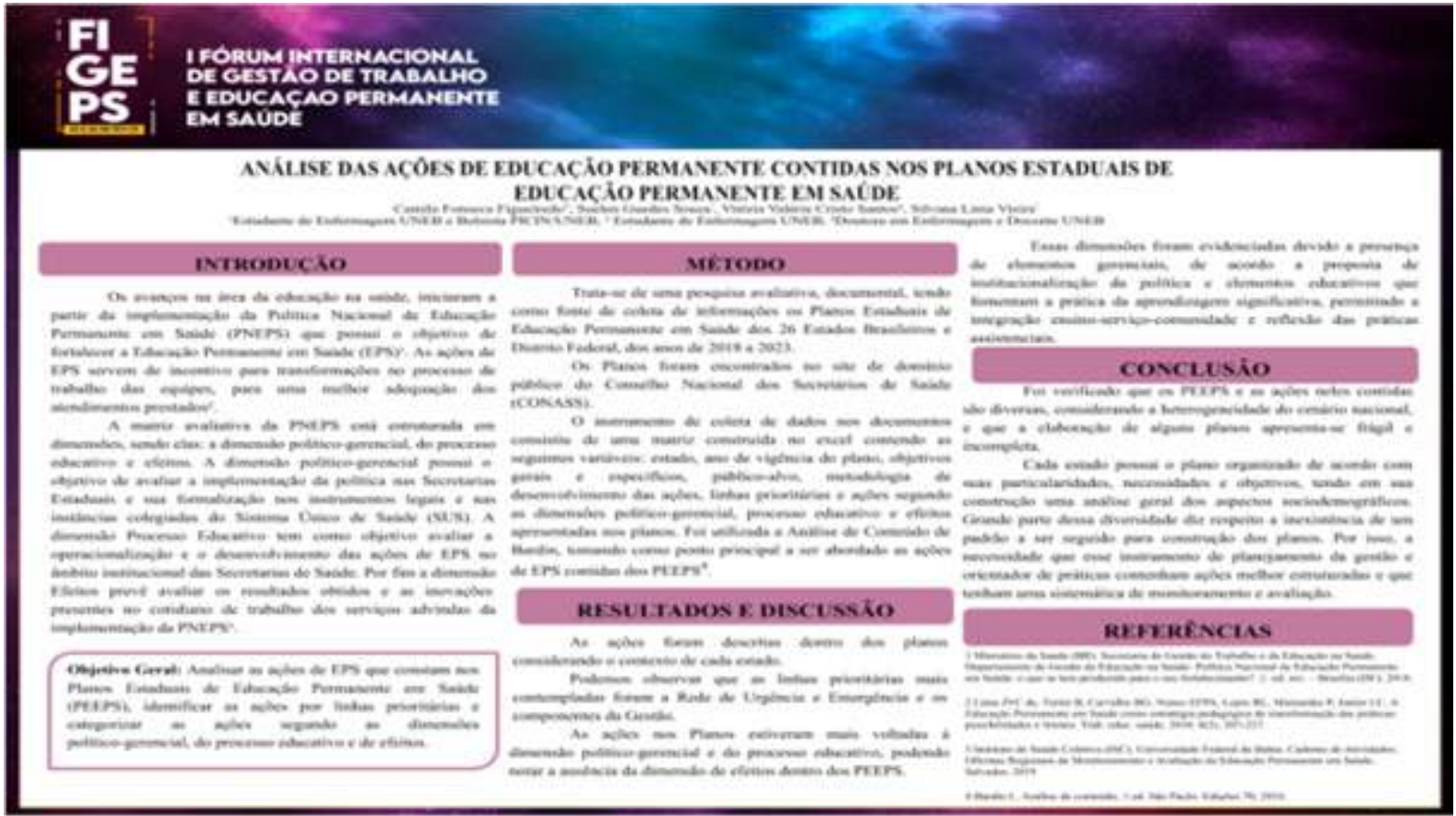

\section{[E] \\ PS.}

ROTATTVIDADE MEDICA E SEUS DESAFIOS NA ATENĊ̃O BASICA: ANÄLISE EM UM MUNICIPIO DOSUL CATARINESE

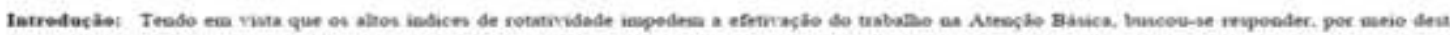

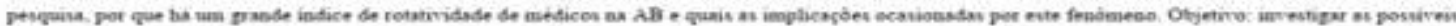

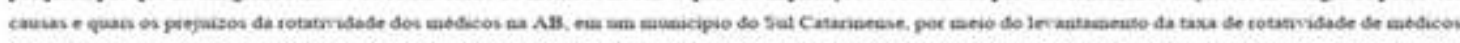

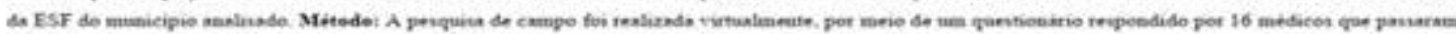

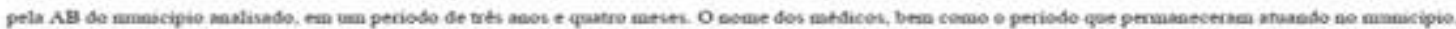

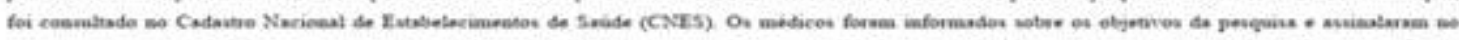

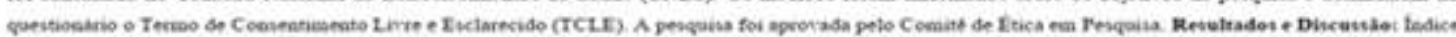

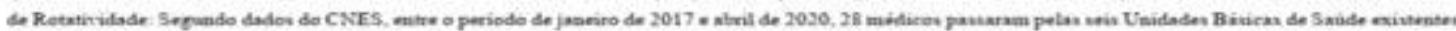

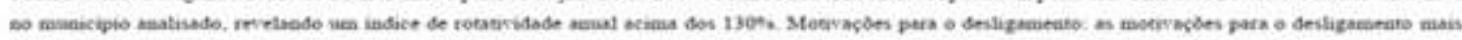

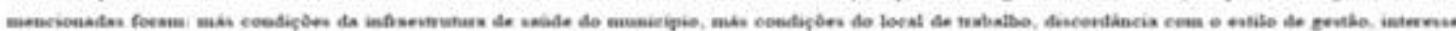

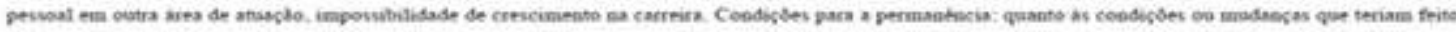

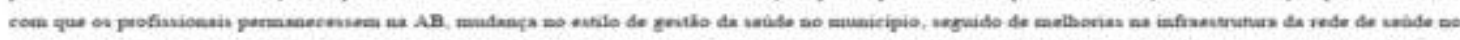

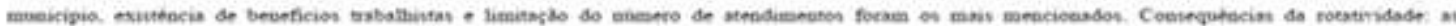

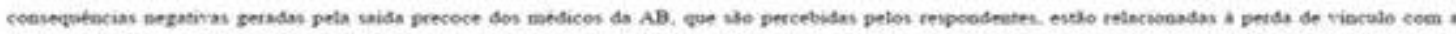

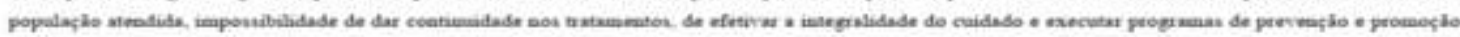

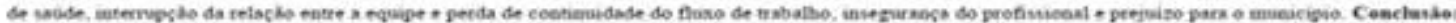

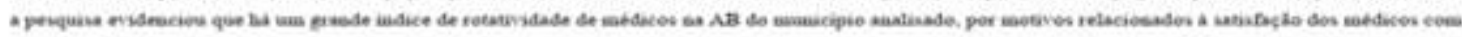

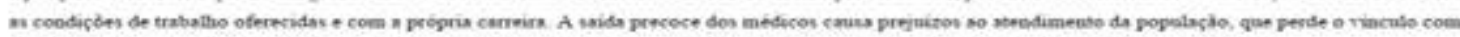

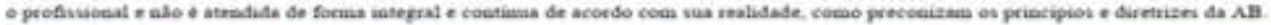




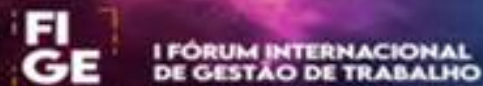

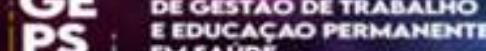 \\ EMSAUDE}

\section{TECNOLOGLA DA INFORMACÃO: FERRAMENTA PARA AUXIILAR}

O PROCESSO DE TOMADA DE DECISOES NA ENFERMAGEM

Andre Luiz S. Braga, Rosangela C. M. Tavares, Suely L Azevedo, Maritza C. O. Sanchez, Maria Lucia C. Moura.

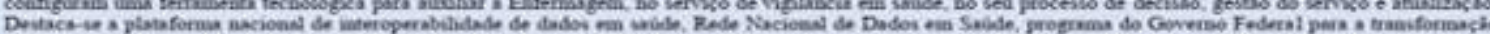

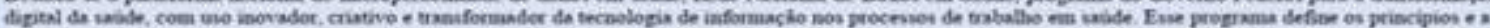

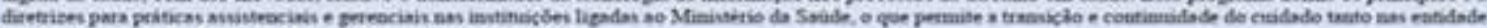
publicas de sobile do 545 enemo nes setores privades de saude.

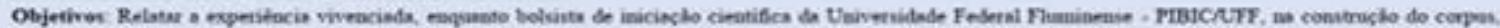

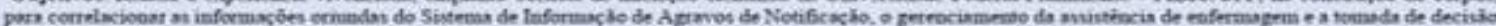

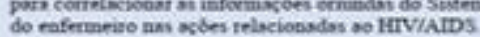

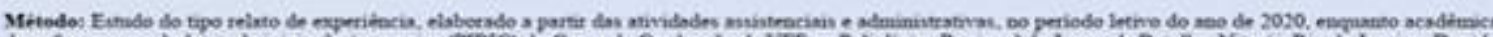

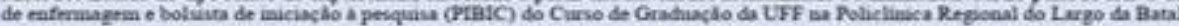

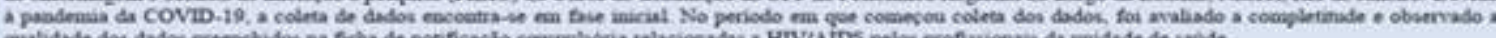

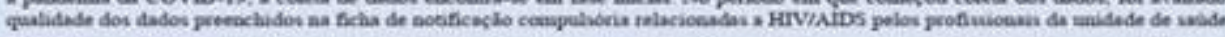

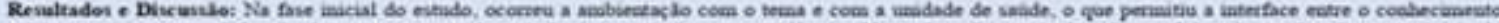

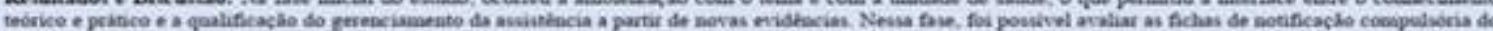

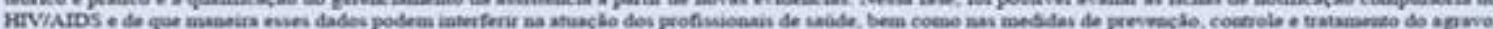

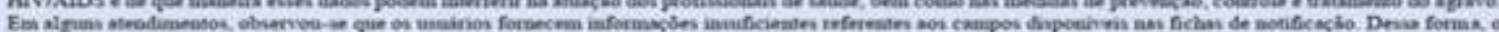

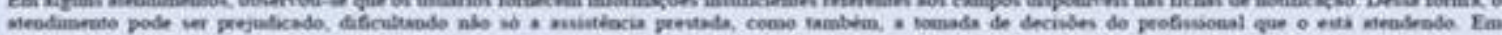

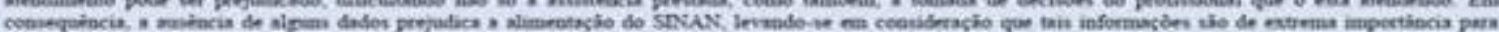

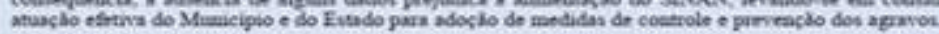

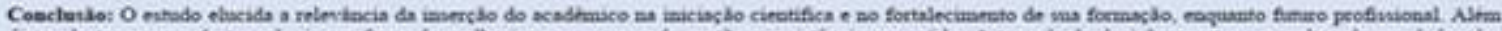

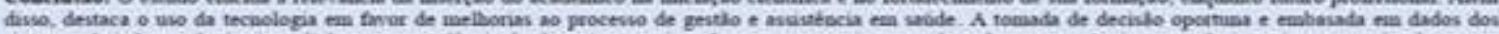

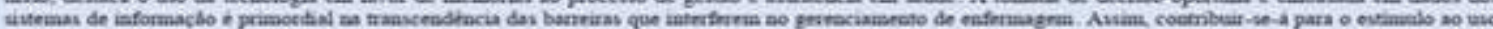

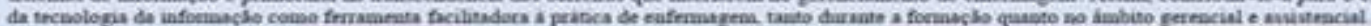

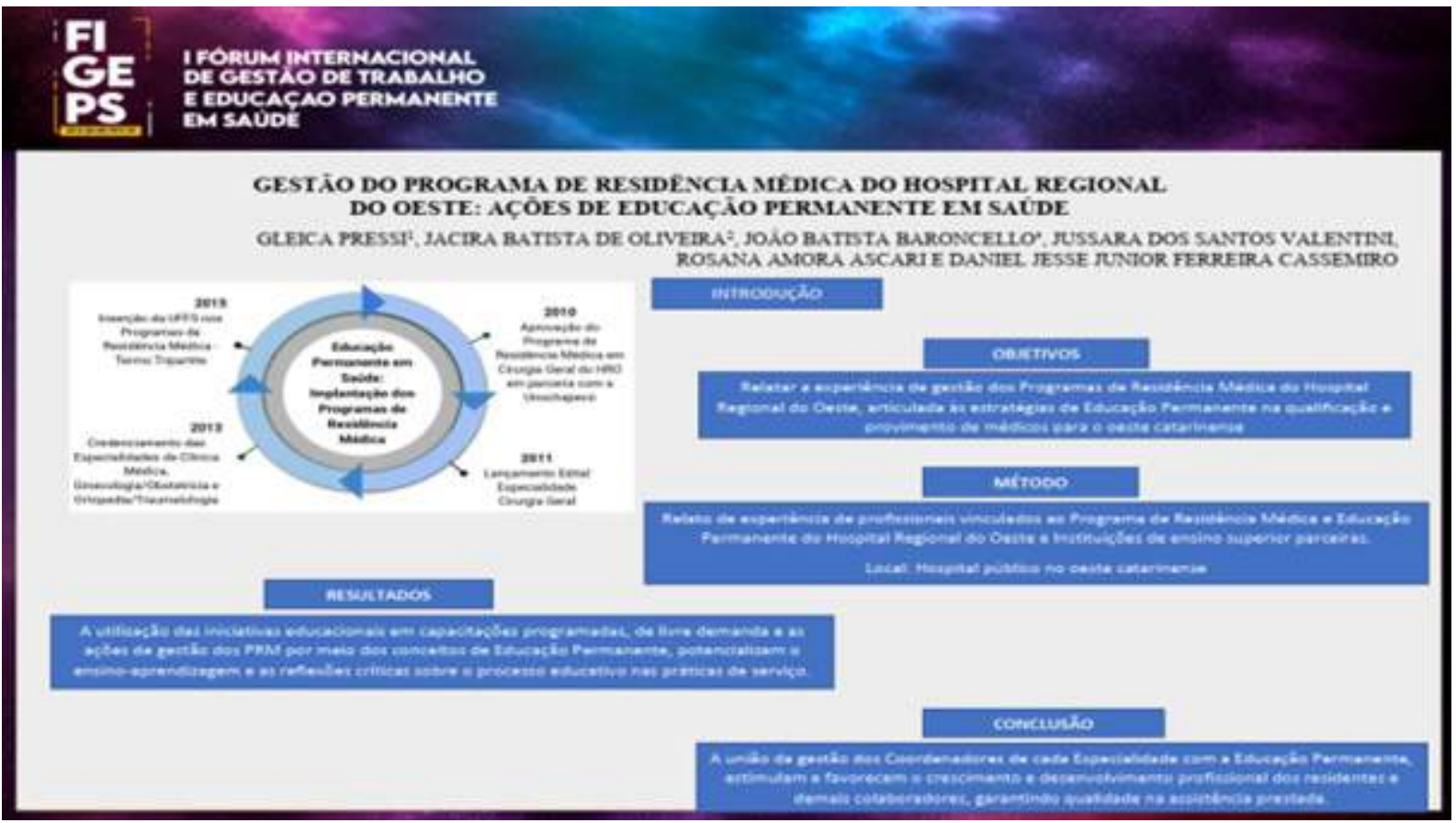




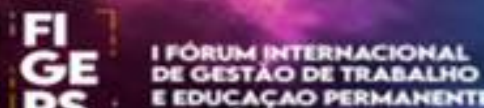 Emsuode}

CONCEPCÓES DE EDUCACÄO PERULANENTE EM PLANOS ESTADUAIS DE EDUCACÁo PERMANETE EMSAUDE

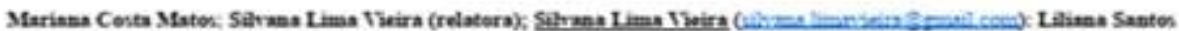

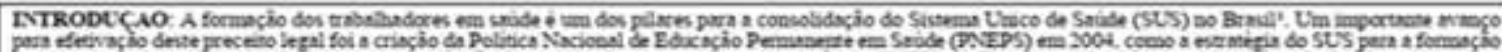

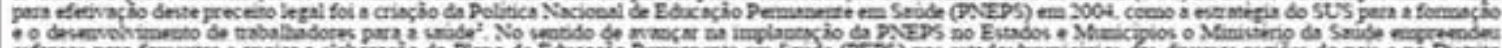

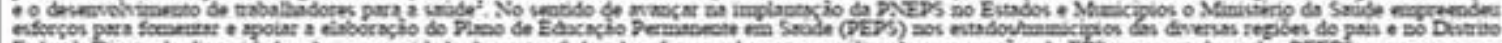

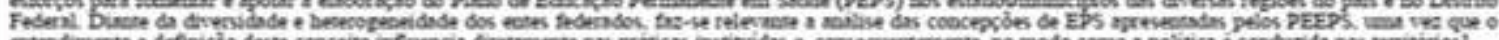

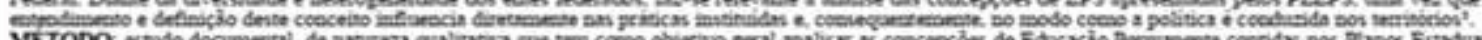

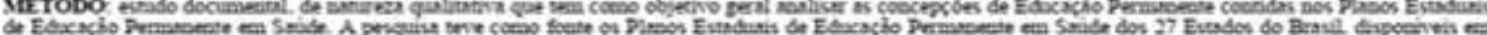

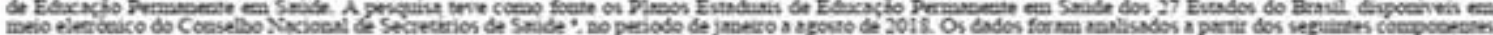

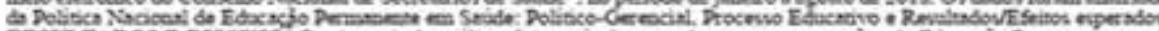

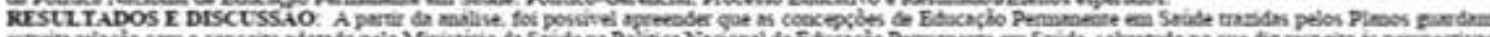

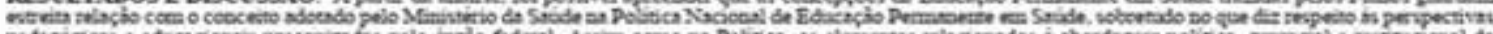

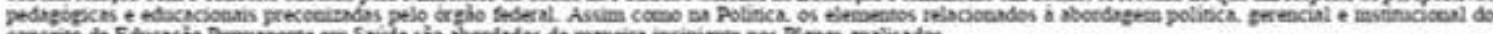

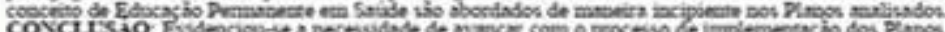

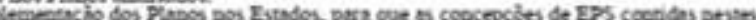

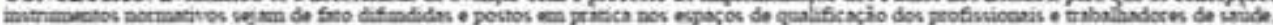

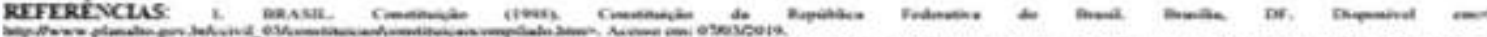

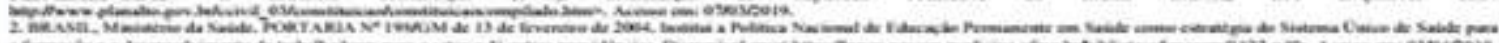

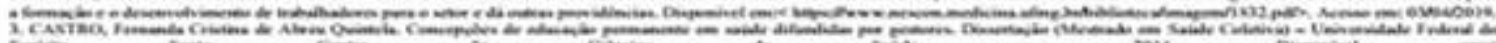

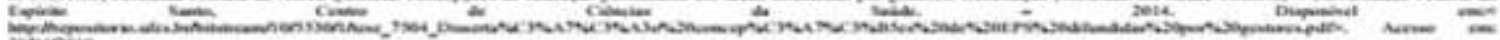

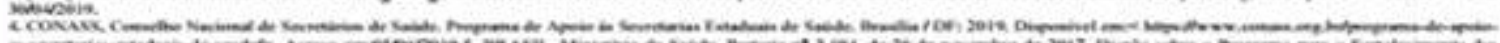

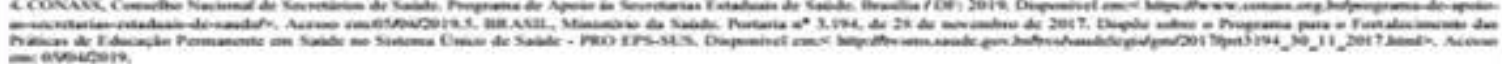

-

\section{[E.}

EDUCACAO PERMINENTE PARA PROFISSIONAIS DE ENFERMAGEI SOBRE CUDADOS COMT

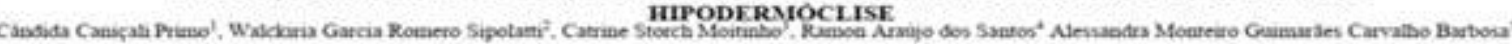

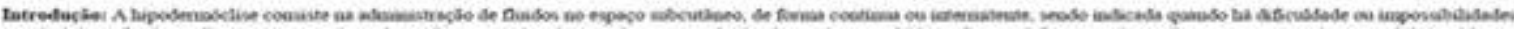

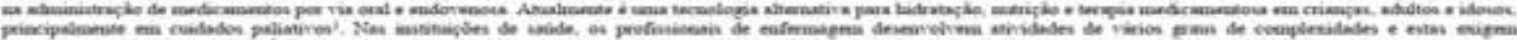

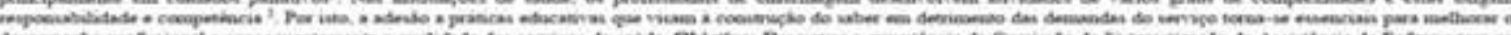

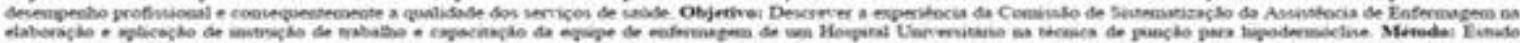

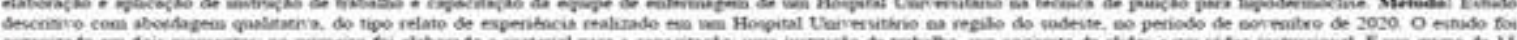

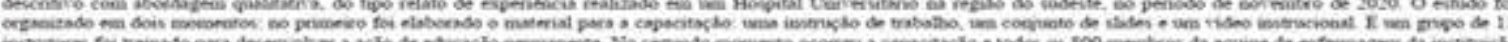

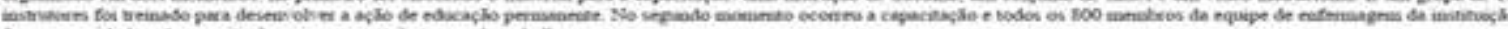

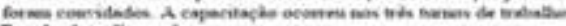

Rerivitadoe ditrentios

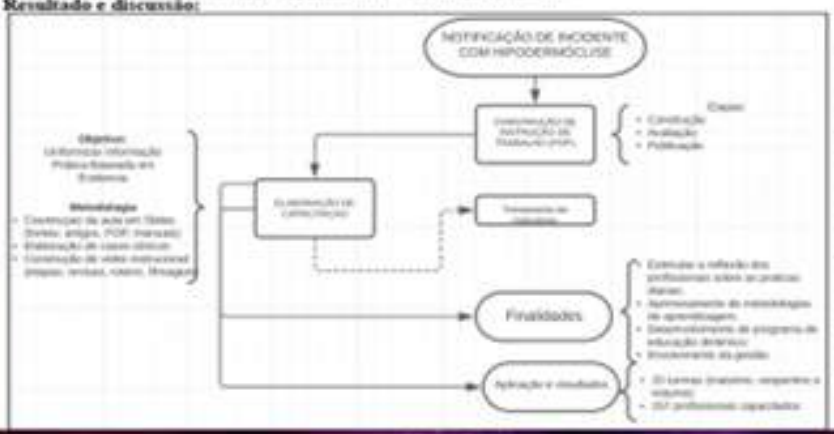

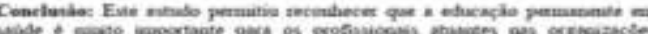

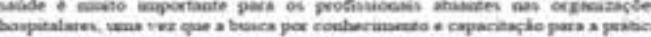

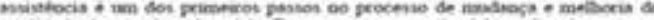

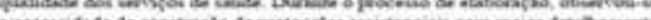

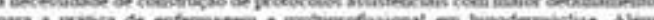

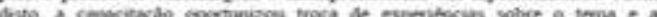

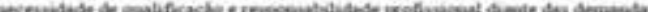

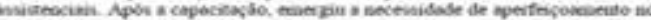

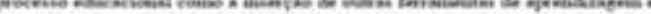

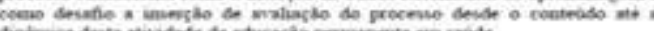




\section{If \\ PS : E EDUCACNO PERMANTENTE \\ EM ENCACE}

TEORL DE NOLA PENDER, USO NO TRABAL HO FM HOME OFFTCE, DER.NTE A PANDEMIA

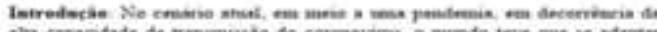

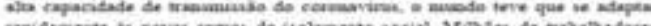

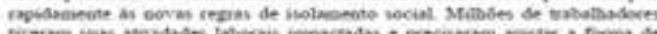

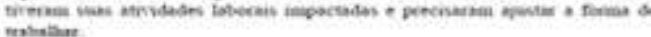

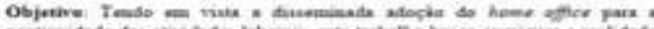

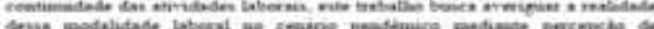

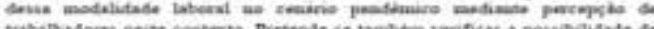

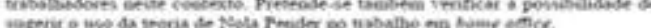

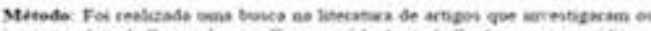

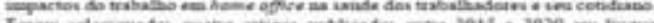

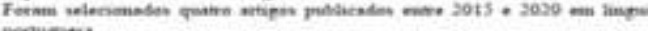

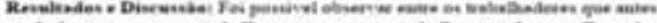

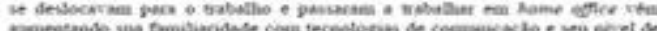

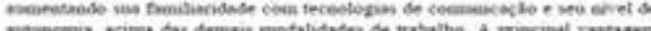

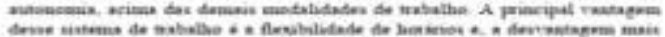

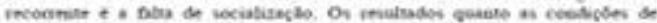

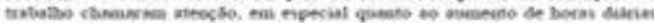

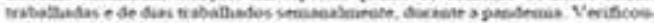

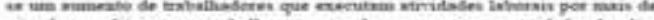

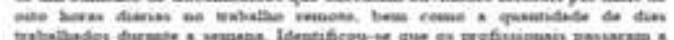

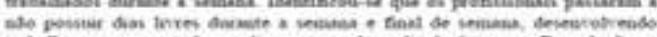

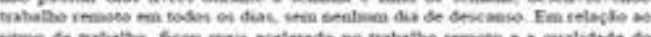

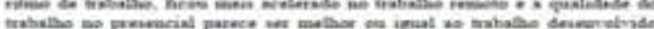

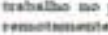

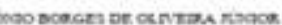

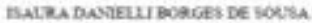

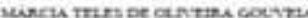

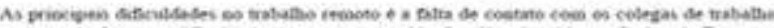

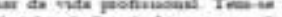
thes whatases.

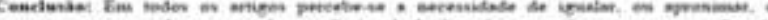

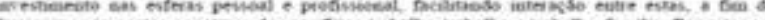

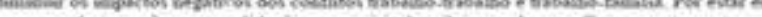

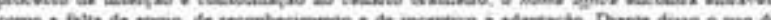

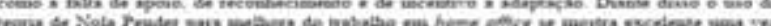

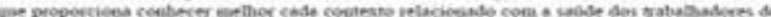

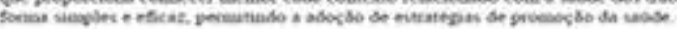

\section{Reterincias.}

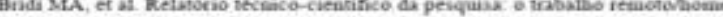

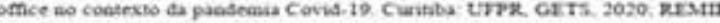

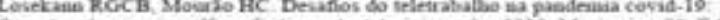

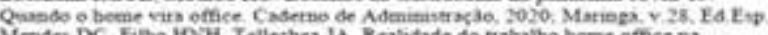

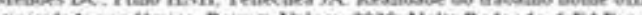

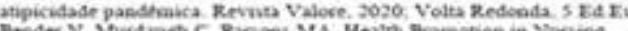

Practice New Jesser Pearvet. 2014

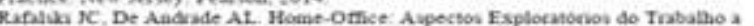

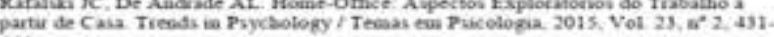
$p_{4+1}$

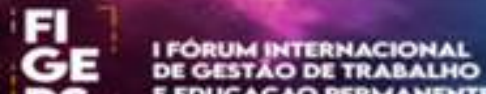 PS. EMSAude}

\section{METODOLOGLAS UTILIZADAS NA AVALLACÃO DE CUSTO-EFETTVIDADE:} TENDÉNCTA DA PRODUCĀO CTENTIFICA

ORAZIELE GORETE PORTELLA DA FONSECA', MÄRCDO KIST PARCLNEL LO'

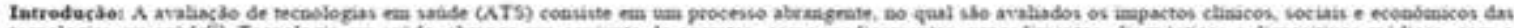

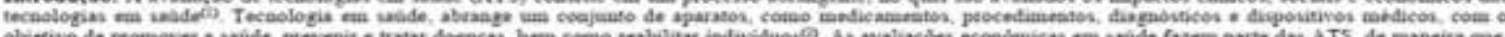

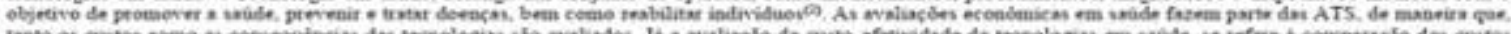

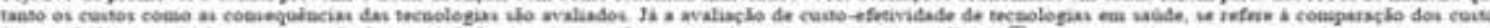

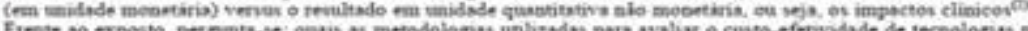

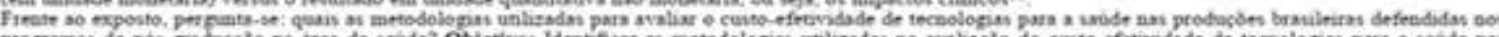

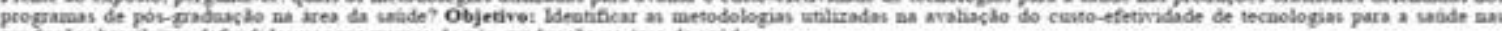

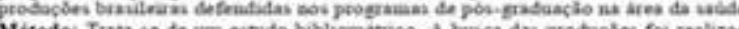

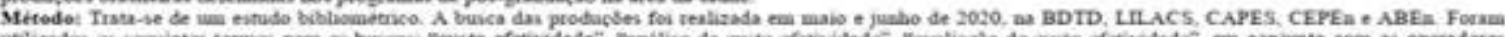

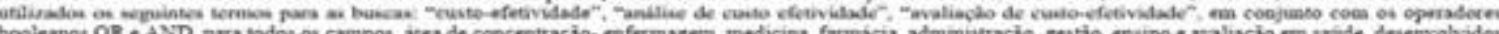
no Bentel

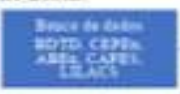

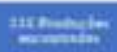
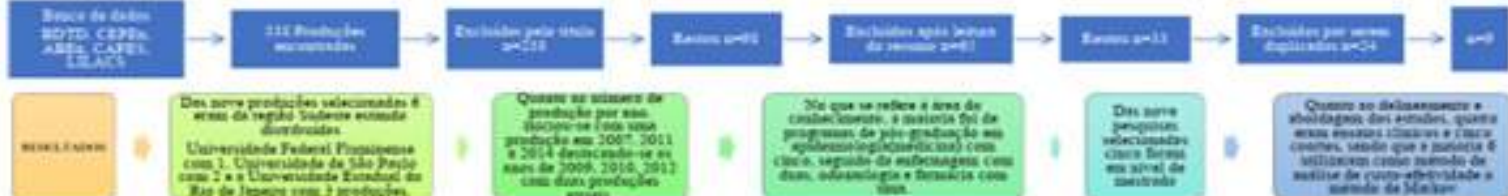

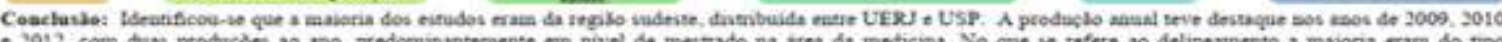

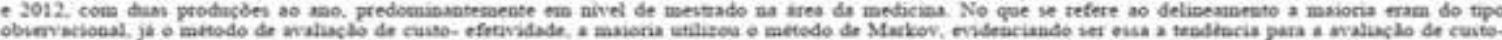

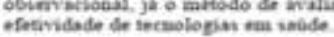

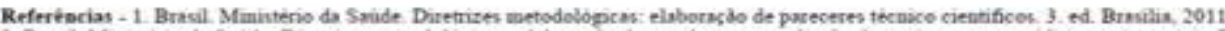




\section{IFonumigrenacionat

PROCESSO DE TRABALHO E GERENCLAMENTO DO CUIDADO: REFLEXOES SOBRE O PAPEL DO ENFERMEIRO

GEAZTELE GORETE PORTELLA DA FONSECA', MARCIO KIST PARCLANEILO

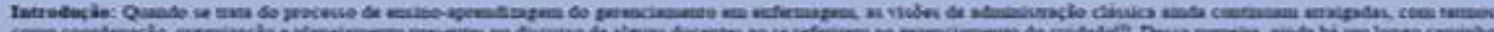

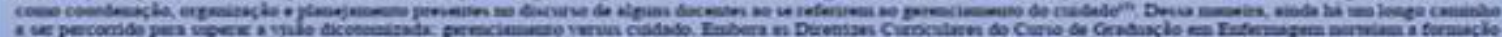

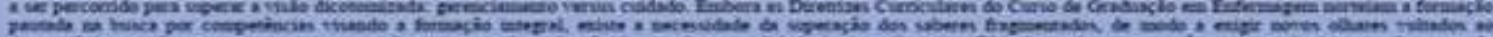

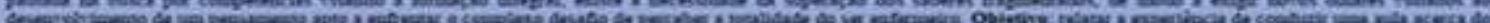

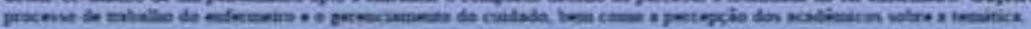

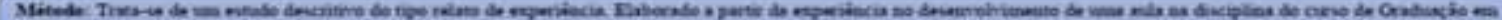
(j)

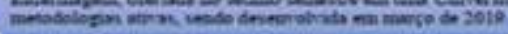

Minated

Minestot

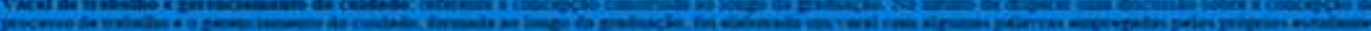

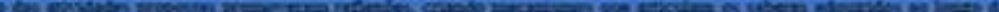

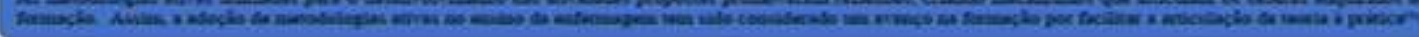

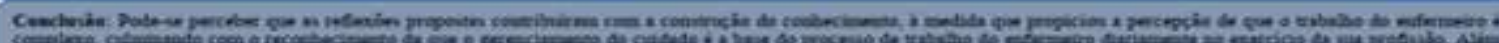

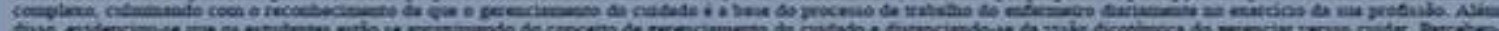

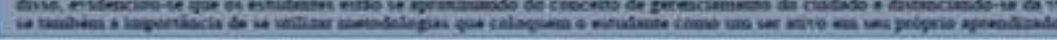

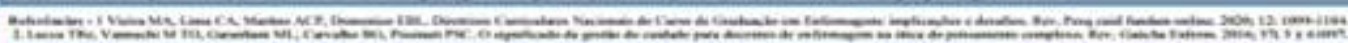

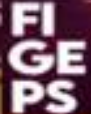 \\ tropum rompincionat E EDUCACNO PERMANIENTI \\ Lin SAUD:}

AVALIACAO DA CAPACIDADE PARA O TRABAL HO DOS PROFISSIONAIS DA ATENCAO PRIMARA A SAÚDE: ESTUDO TRANSVERSA.

SILVEIRA COS S $^{2}$ CHRISTOVAM B P

Introduçao: A avaliaçto da saude do trabalhador quanto a sua capacidade para o traballho mostra-se relevante, pois o profissional necesut: ver avaliado e acompanhado quanto à prevençlo de doencas ocupacionaib, que podem aparecer ao longo de aua funçto laboral, se acentuar cota o processo de exvellhecimento e com o aparecumento de doencas crónicas

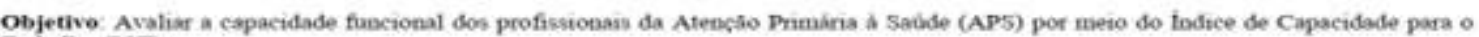
Traballo (ICT)

Metodo Trata-se de estudo transvernal. de sbortagem quantitativa. Para coleta de dados o instrumerato ubilazado for o tCT Resultados e Discussalo:

Media de 43 anos, apenas um emprego $(85.2 \%)$.

40 horas semanais trabalhadas $(87,5 \% 6)$ com apenas un ano traballhado $(30,746)$

Os agentes corumintainos de satide (ACS) com 33,046 .

- As comorbidades mais predominantes: depressto e lesdes nas costas.

$100 t 6$ os participantes apresentaram ao menos um tipo de comorbidado, nato recebiam adicional de ansalubridade ou periculonadade,

nato possuiam vinculos empregaticios, canteina de trabalho assinada e seguridade social:

O impacto da depreusao o maior e mais signaficativo ainda que o impucto da lesto nas costas Sendo avsim, respobdendo à questso norteadora da pesquisa baseado no ICT, a depressato e lesdes nas costas despontam como fatores que mass impactam na dumimaicho da capacidade funcioesal dos profissionass de saode da APS

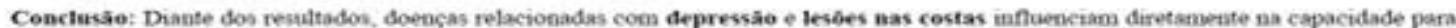
o traballo, repercutindo assim, em escore mas baicos, sendo que o impacto da depressao ainda é maior e mais sigmificativo que o mipacto das lesces nas costas Referencias:

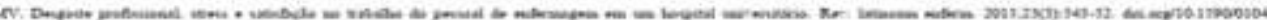

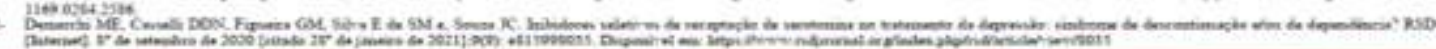




\section{If \\ CE, DEGESTAO DE TRABAHO
ES: EDUCACAO PERMAMENTE}

EDUCACIO PERMANENTE NA PANDEMTA DA CONTD-19 - REL TTO DE EXPERIENCIA

Eliete Aparecida Teodoro Amarat', Eliane Ramos Pereira2. Janaina Mengal Gomes
Fabn, Raquel Dias dos Santos Dantas"

Intretucto:

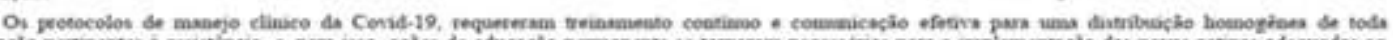

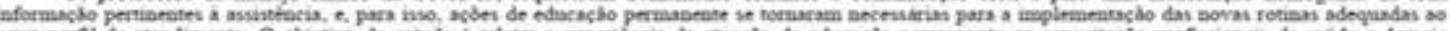

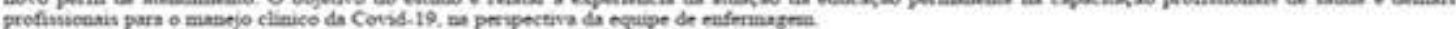
Metode:

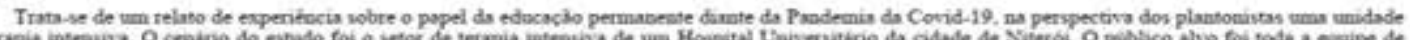

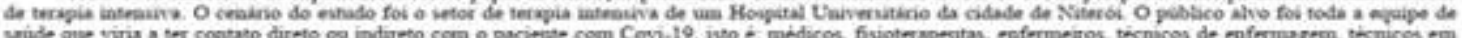

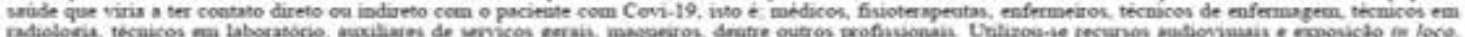

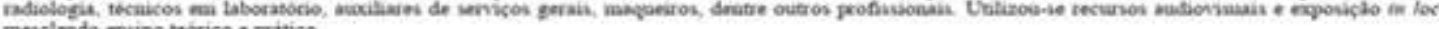
mesclasdo envino teórico e juitico

Rersaltades e Discussie:

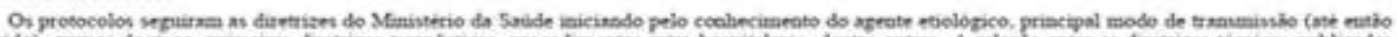

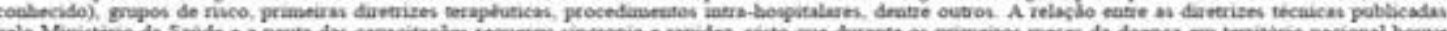

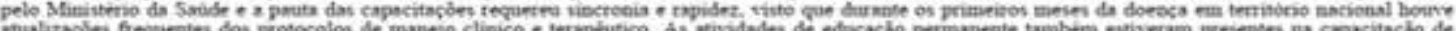

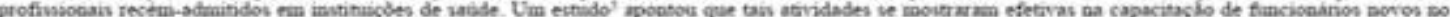
contende da paselemis

Conclutio:

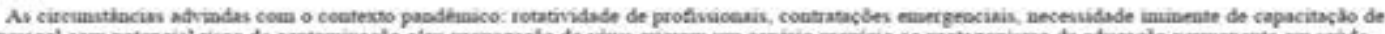

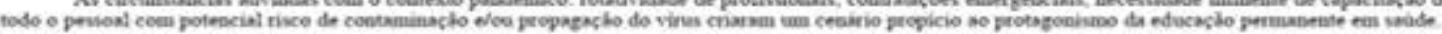

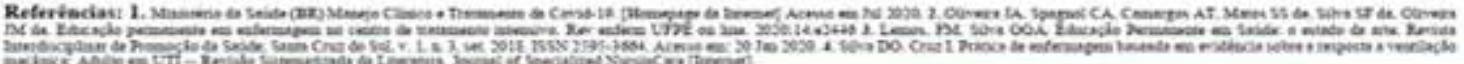

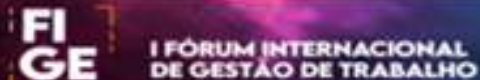

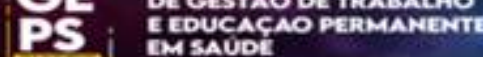 \\ EMsaudi}

TECNOLOGIA EDUCACIONAL UM CAMINHO PARA EDUCACAO EM SAUDE NA

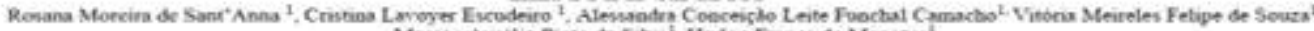

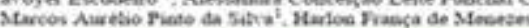

DTroptceto

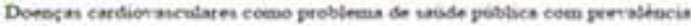
minatat.

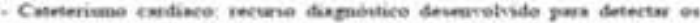
sermos que acometena o ceracklo:

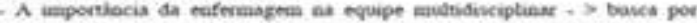

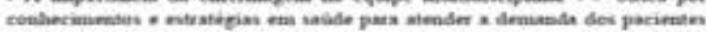

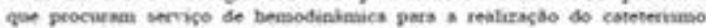

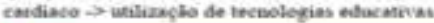

\section{ORIET⿱宀⿻三丨口}

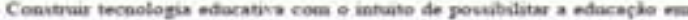

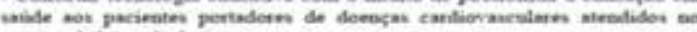

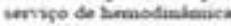

\section{STIODC}

Tipo de eitublo: descritivio, gastitative

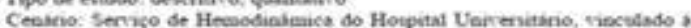

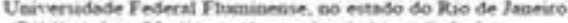

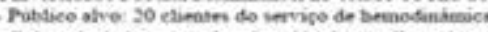

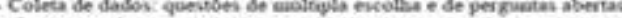

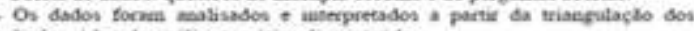

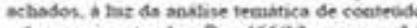

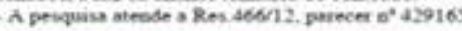

\section{RESELIADOS E. DISCESSTO}

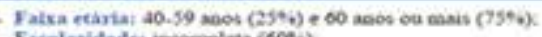

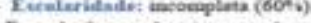

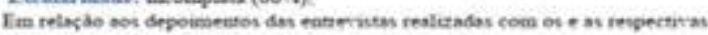

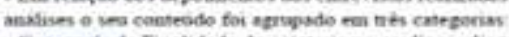

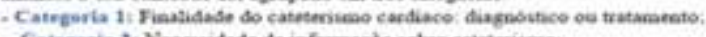

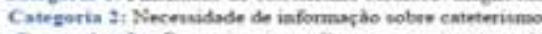

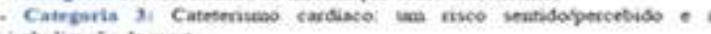

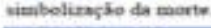

\section{COSCLEST}

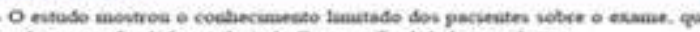

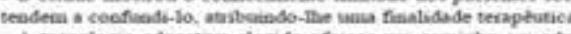

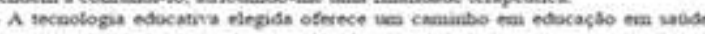

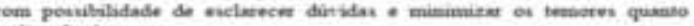

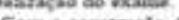

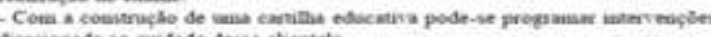

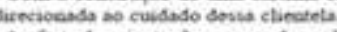

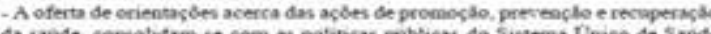

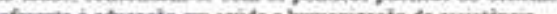

Rerinesciss

की 


\section{PRIMIEIROS SOCORROS NA GRADUACÃO DE CIENCIAS BIOLOGICAS: UMLA} DISCUSSAO NECESSIRIA

Me, Enf Karen Cristiane Pereira de Morais's Mda Enf Aline Gomes Iha?

\begin{abstract}
Objetivo: relatar a experiebcia de enfermeiras ao ministrar conteido de primeiros socorros a graduandos do curso de ciéncias biologicas
\end{abstract}

Retultados e Discussdo: destaca-se que durante o periodo de isolamento social, o ensino superior teve que se readaptar e realizar as atividades de maneira remota, desta forma a Universidade Federal de Santa Maria organizou o Regime de Exercicios Doraiciliares Especiais (RIDE), portanto pensando po atual contexto. fot orpanizada uma atividade com foco na Lea Lucas e nocóes básicas de primeiros sococros para académicos A inclunlo da tembitica de primeiros vocorros constitu-se cotno demanda iminente no campo da educaço em àmbito amindial. considerando os diversos niveis de ensino bern como a disponibilizacto de recurios nos mais divernos atubsentes, who ha necessadude de espera dos academicos para realizar este treinamento posterior a formatura. a tei Lucas garante aos alunos de educaçăo bastica um atendimento imediato e quando os acadtmicos possuem essa capacitacto ha mais chances de vidas serem salvas e o conhecimento de primeiros socotros nid deve se restringir acos cuissos da area da soude
Métode: Relato de expentncia da oficina -Primeiras Secorros. - que facer?", ministrada na dinciplina "Temiticas Conteniporineas" do curso de Cietucias Biologicas da Universidade Federal de Santa Maria, campus Palmeira das Missoes, e fos realizado de mineira virtual com metodologia exposativa dialogada com apresentaçjo de imagens e videos para ilustrar as falas das enfermeiras. A oficina foi realizada no més de dezembeo de 2020 , teve duracio de duas horas

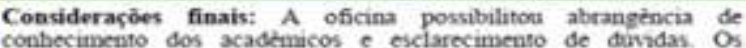
graduandos avaliaram de maneira positiva os contejolos ministrados e pertinentes para sua formacto acadenica. pois eles irlo realizar esta gios pertunentes para sua formacto acadennica, pois eles irto realizar estagos emergencia. Entende-se que é de suma importancia e relevincia debater emergencia. Entende-se que e de suma importincia e relevincia debates sobre eute tema na academia, poss e uma forma de preencher uma lacuma
no conhecimento. Ministrar esta oficina de maneira online foi um no conhecimento, Ministrar esta oficina de maneira onlime foi um desafio inicial para as autoras e cada oficina ministrada e adaptada
conforme os participantes e evento, apesar disso, as autoras avaliam positivamente a realizaçio de oficina neste formato, pois o objetrvo principal é de que os participantes conhecam a Lei Lucas e consigam identificar e agir corretamente em situaçes emergtncia.

\section{GE tersacute}

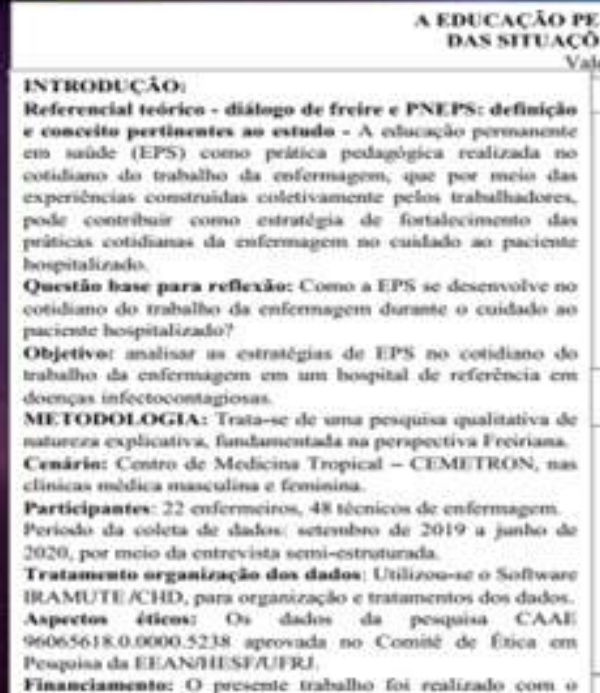

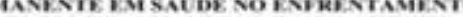

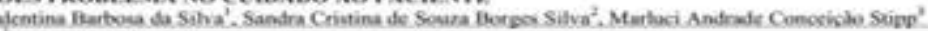

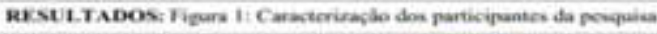

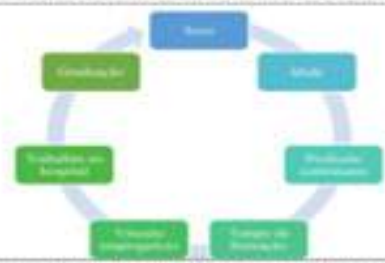

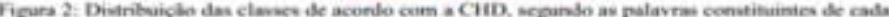
clawe, pvit. 2018

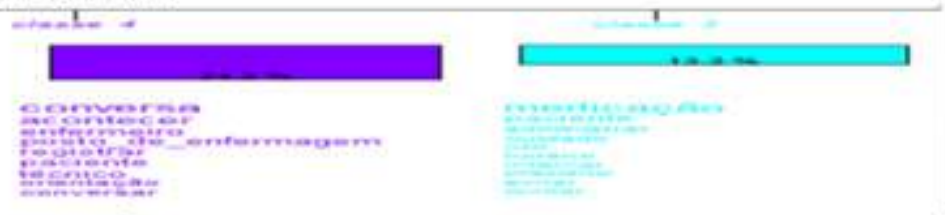

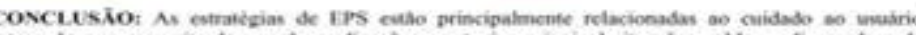

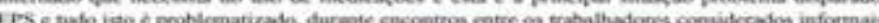




\section{TRANSTORNO MENTAL COMUM EM PROFISSIONAIS DA ATENCÃO PRIMÁRIA EM}

TENIPO DE COVID-19

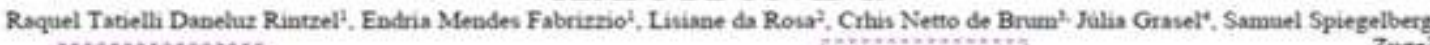

INTRODUCÁO

No trabilitho dà enfermagen hs frequente exponişào a elementos e fatotes que favotecem o deseavolvamento de Iranstomos Mentais Comuns (TMC), cujo acometimento pode ter mumentado em decorrència das condiçes de satude agravadas pela Coronavinu Decorte 2019 (COVTD.19), sendo or enfermeitos da Atencho Primiria en Sabde (APS) um dos grupos afetados.

\section{OBJETIVO}

Identificar a prevenca de transtorno mental comam em enfermeirot As ateaclo ptimbria a saude ema temios de COVID.19.

\section{METóo}

Colets de dados online de outubro a dezembro de 2020 a partix de e-mati aos enfermeitos da APS do municipio de Chapeco, contendo um quevtionino sociodemogrifico, econb́mico e laboral - o Self-Reporting Qvertionnaire (SRQ-20). Analises descritivas pelo sofware Sranisical Pachage for the Social Setences (SPSS). vertion 20.0 .

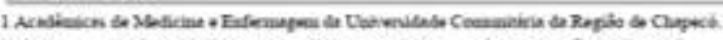

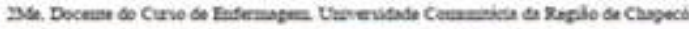

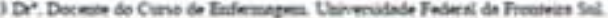

RESULTADOS Participaram do esthido 25 enfermeiros, $24 \%$ relatam sentis sintomas em relaçlo a TMC e $28 \%$ utilizam alpum medicamento para TMC. A avaliaçlo do TMC pelo SRQ-20 identificou uma media de pontos de $9.2=5,8$, conviderada elevada e indicando a presenga de TMC em $65 \%$ des enfermeitos. Os enfermetros da APS. apesar de nilo atuarem na treate de eafrestameato da COVID-19, estilo ema constante contato com essa e cutras dorpças e tho afetados pelo a gravamento das condaches de traballo com a chegada do novo coronavirus, alem de toda a pressio e impacto eanocional sofrida tambera pelo restante da populaçlo, o que eleva a incidhocia de TMC

\section{CONCLUSÄ́}

As dificuldades enfreatadas pelos enfermeiros da APS on afeta de modo cognitivo e puiconsocial, levando ao desmulvimento de TMC. Touma-se necessirio o desenvolvimento de acles que visem minimizar os danos na saude desses

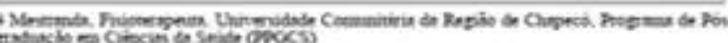

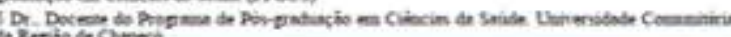

\section{[E] - 5 : EDUCACAO PERMANENTE EM SAODE}

\section{A MIPORTÁNCIA DA EDUCACÃO PERMANENTE PARA A EQUIPE DE ENFERMAGEM NA PANDEMIA DA COVTD 19}

AINE DE OLIVEIRA', SUELY AZEVEDO'2, THAIS GUERRA ', ROSANE AGULAR', HERICA DE OLIVEIRA'. NATALIA MARQUES"

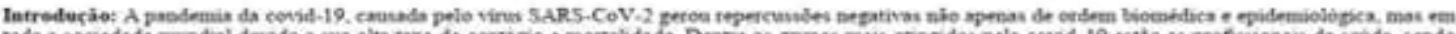

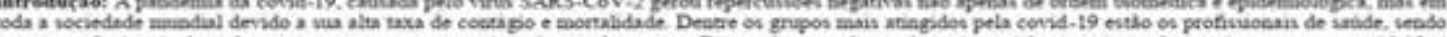

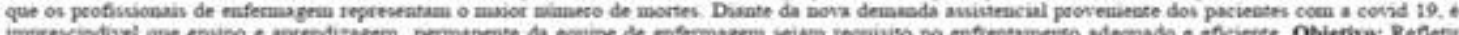

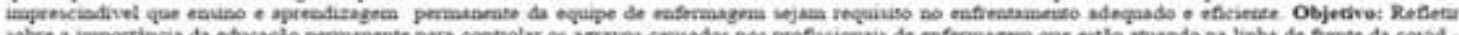

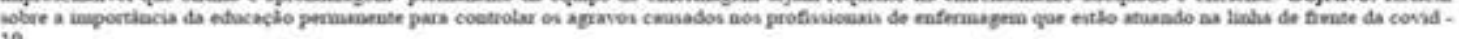
19

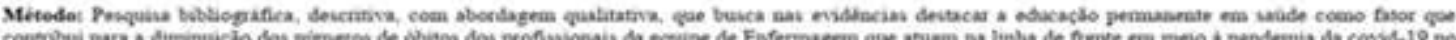

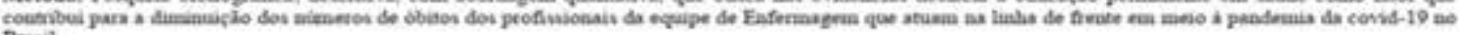
Brmil

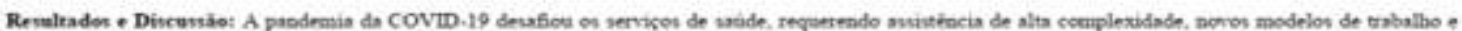

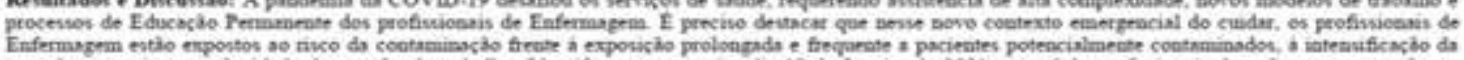

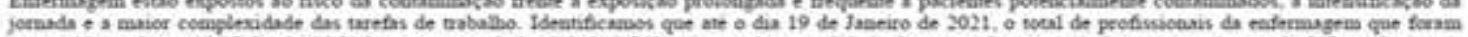

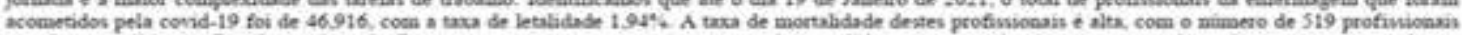

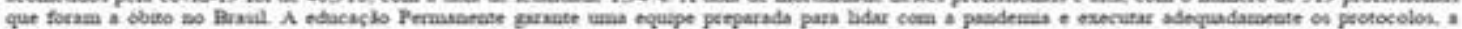

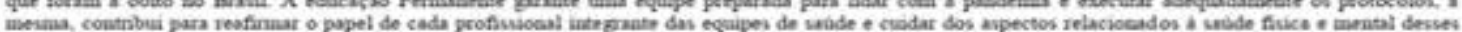

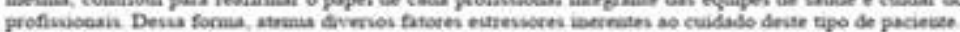

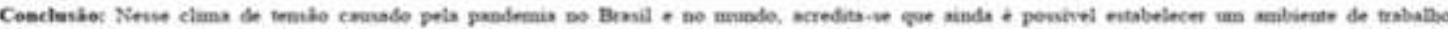

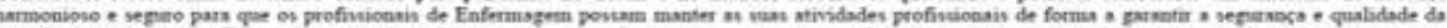

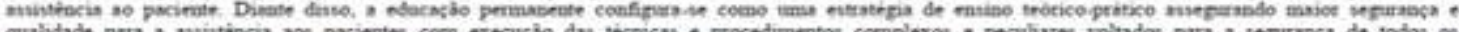

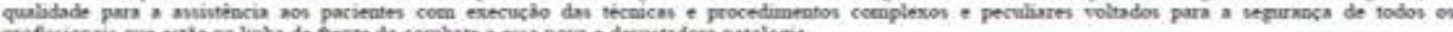

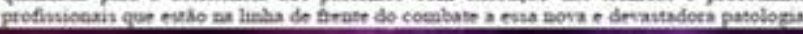




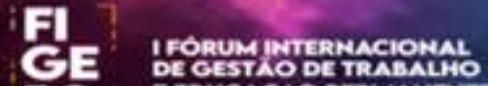 \\ PSi EmSAUACAO PERMANEMTE}

UTILIZACAO DO SHORT FORM HEALTH SURVEY PARA AVALIAR A

QUALIDADE DE VTDA DE PESSOAS DESEMIPREGADAS

FRANCISCO ANTONDO BORGES DE OUTEIRA TCNDOR', IZALANE PAES RIBEIRO DE SOUSA

NTRODECiO

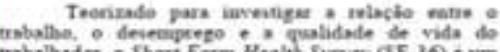

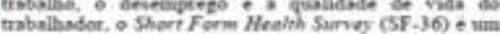

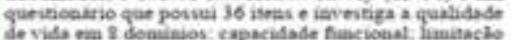
por aspectos tivices: dor: matado geral de saide.

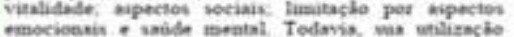

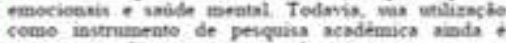

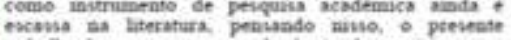

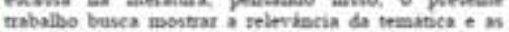

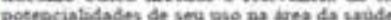

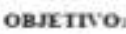

- objervo desse trabathe foi maniture qualidade de vide eatre on traballindores deventprepadion

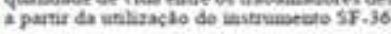

\section{Mr TODO}

A perguis fin reslizads por mevo on

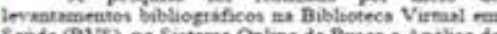

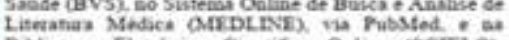

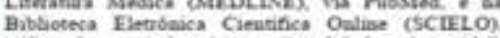

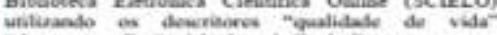

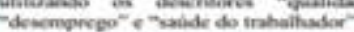

\section{RESTLTADOS:}

Oburvos-us gue indiviluos pertadoes of plo denemprego coom on dominion fivico igravad.

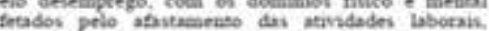
Frecipalinente so que taine* dor avpectos mestas. Eis olaclo a populaclo de audherw sor twerain perte

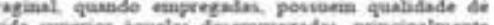

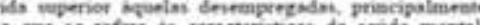

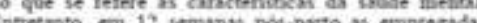
itan

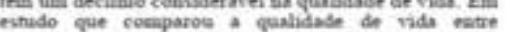

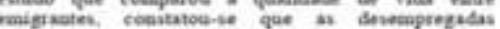

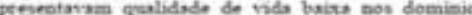

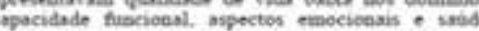
mestal Coetudo, on emingrates com carp botira

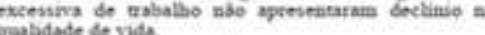

Discessio:

O SF-36 drmenatroe crabies nirsagretrs pws

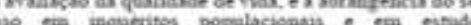

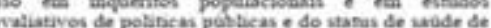

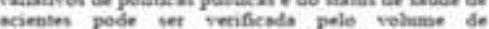

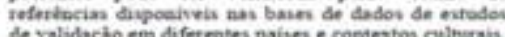

O peoposito devse mutrumento et detectur difenacai

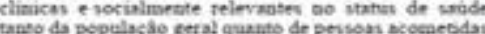

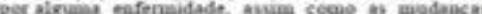

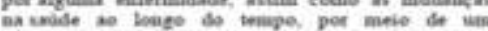
nimerto reciurido de dimentedes entatinticumente ofiesente

\section{coxcuesio:}

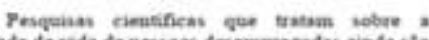
quatulade de vida de pervoas devempregadas aisda ua

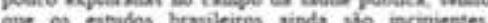

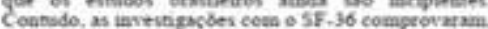

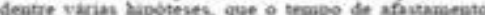

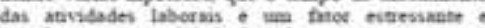
manfare na va qualidade de vila.

\section{REFERE NCOS}

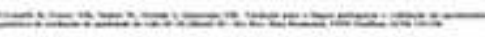

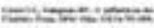

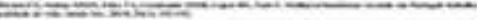

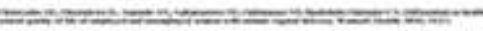

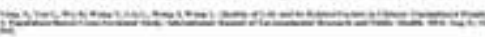

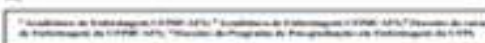

\section{If PS

ORIENTACÖES DO MINISTERIO DA SAÚDE PARA A ATUACÃO E

GEST X̃O DE ENFERMLAEM NA SAÚDE DA MULHER NO PUERPÉRIO

MIRIAN GLACOMEL ". SILVANA DOS SANTOS ZANOTELLI², DENISE ANTUNES DE AZAMBUJA ZOCCHE

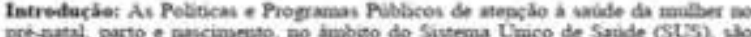

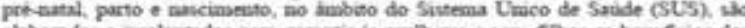

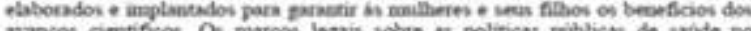

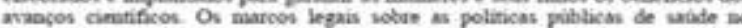

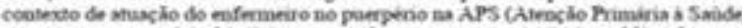

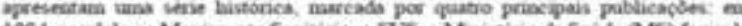

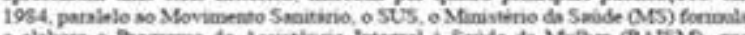

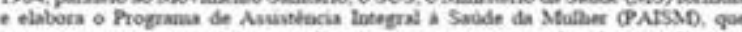

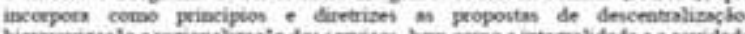

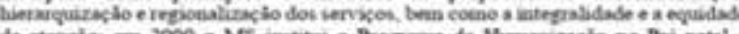

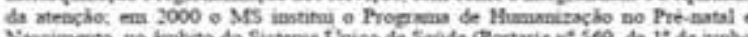

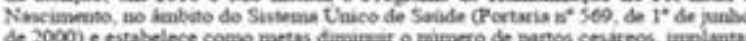

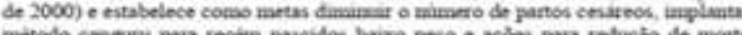

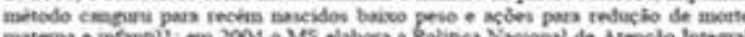
o Satian

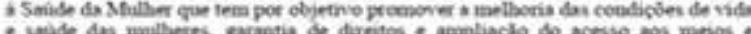

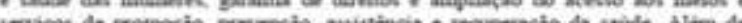

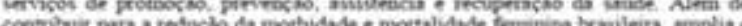

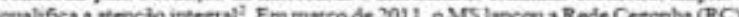

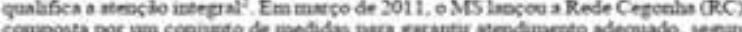

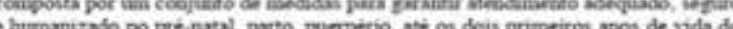

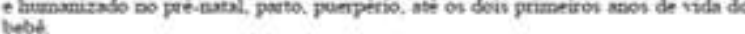

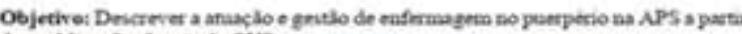
das poblicackes legesis do SUS

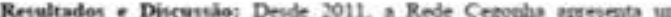

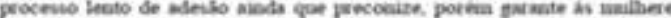
gevtruter e poerperss atencicio e cuidodo minplisdos. A RC couta cont recunes

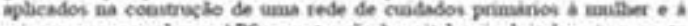
crinsck, gur eavolve a APS e I stencio bouputalar, inchuindo o trasuponte

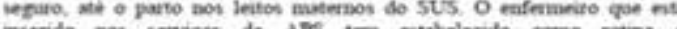

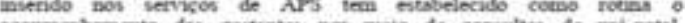

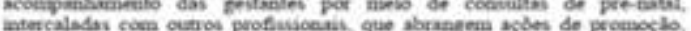

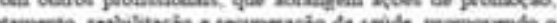

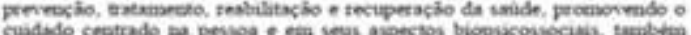

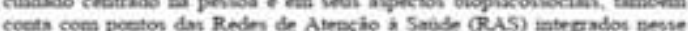

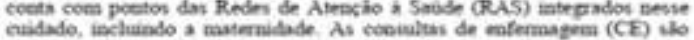

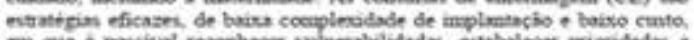

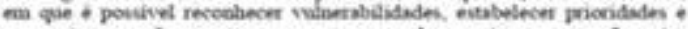

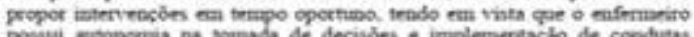

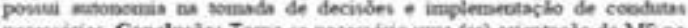

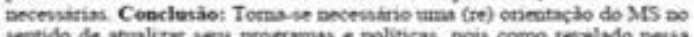

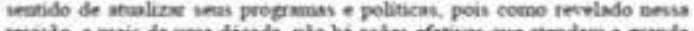

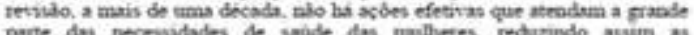

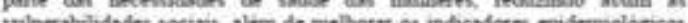

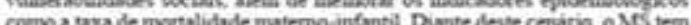

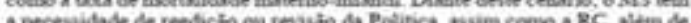

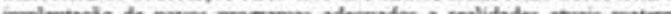
infortis de pais 

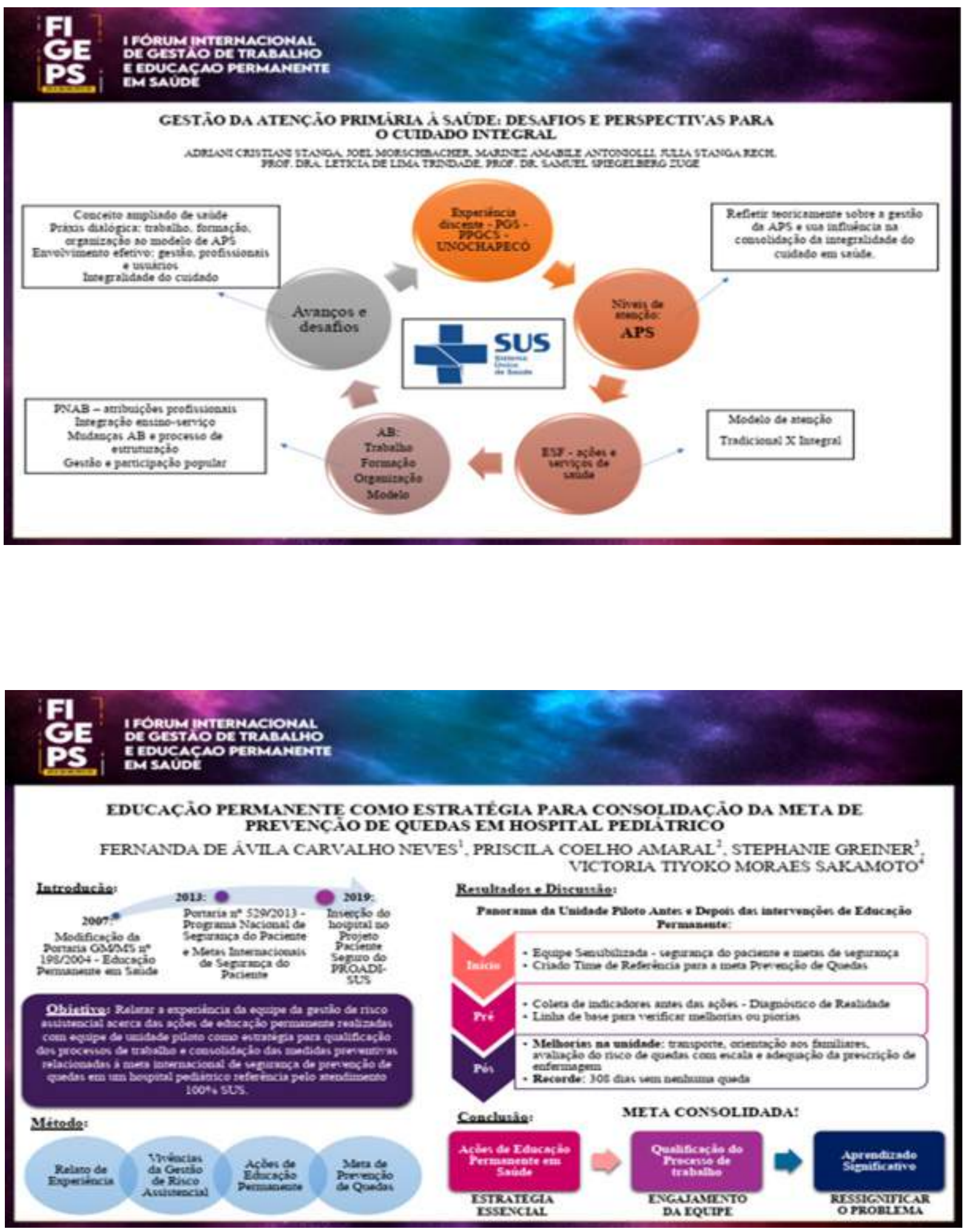


\section{MENSAGEM FINAL}

O I FIGESPS nasceu com a expectativa de que fosse o primeiro, dentre muitos eventos com essa temática, organizados pelo Mestrado Profissional em Enfermagem na Atenção Primária à Saúde da UDESC. Não por acaso, as primeiras conversas sobre a necessidade de um evento com essa perspectiva aconteceram ainda no ano de 2020; um ano singular, que despontou com importante significado para a Enfermagem. Além da celebração do bicentenário de nascimento de Florence Nightingale, precursora da Enfermagem e as iniciativas da Campanha Nursing Now, reconhecendo o protagonismo da profissão, o mundo foi surpreendido pela maior crise de saúde pública dos últimos tempos, pela emergência da Coronavírus Disease (COVID-19). A falta de uma estratégia de enfrentamento sólida, defendida uniformemente pelas autoridades do Brasil, a restrita disponibilidade de Equipamentos de Proteção individual (EPI), a baixa testagem e a inadequabilidade das políticas de proteção dos trabalhadores da área da saúde resultou em milhares de mortes, inclusive de profissionais de saúde e de Enfermagem.

Foram esses elementos que nos provocaram a refletir sobre a necessidade de insistir no diálogo sobre a dimensão da gestão, no trabalho da Enfermagem. Percebemos afinal, mais do que nunca, os impactos da contribuição de Florence Nightingale, pois, de certa forma, as condutas de gestão (e também de cuidado), necessárias para o controle da pandemia, foram muito semelhantes aquelas do século XIX, por ela determinadas. Por outro lado, isso nos sinalizou para a fragi- lidade da evolução da ciência e para a (pouca) participação da Enfermagem nesse âmbito. A educação permanente, como parte importante dessa dimensão da gestão, se evidencia nas iniciativas da Enfermagem para o enfrentamento da COVID-19, o que reforça que a profissão, também nessa direção, exerce protagonismo.

As mesas e os trabalhos compartilhados, não por acaso, de forma virtual, neste evento, nos provocaram

A Atenção Primária à Saúde, mais do que nunca, ganha evidência como Política fundamental ao controle de situações pandêmicas e mesmo, para a prevenção de doenças e promoção da saúde das pessoas e das coletividades. Assistimos às dificuldades de países como os EUA, que, apesar ........ se mostrou mais vulnerável.... Isso nos sinaliza para a importância de valorizarmos e fortalecermos nossa APS e o SUS no Brasil!

Como parte $d a$ equipe interdisciplinar, na atualidade, conforme discutido nas mesas, a importância para avançarmos para a interprofissionalidade nos faz perceber que nosso saber é fundamental para aquilo que desempenhamos sozinhos ou com a equipe, principalmente porque estamos presentes e participativos em quase todos os cenários de produção da saúde. As trocas nos estimulam. Somos criativos, para além da nossa expertise e cientificidade.

Dra - CARINe Vendruscolo

Dra LeTÍCIA DE LimA TRINDADE

Dra ${ }^{\text {a }}$ ROSANA AMORA ASCARI

COMISSÃo OrgaNizAdorA do I FIGEPS 


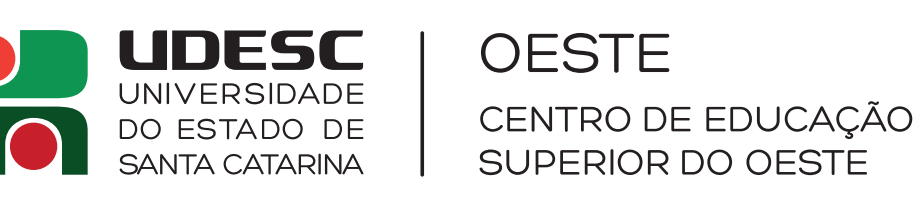

